Scheila Roberta Janke

Die Religiosität der Pommern in Brasilien

Eine Studie zu den pommerschen Einwanderern und deren Nachkommen im 19. und 20. Jahrhundert

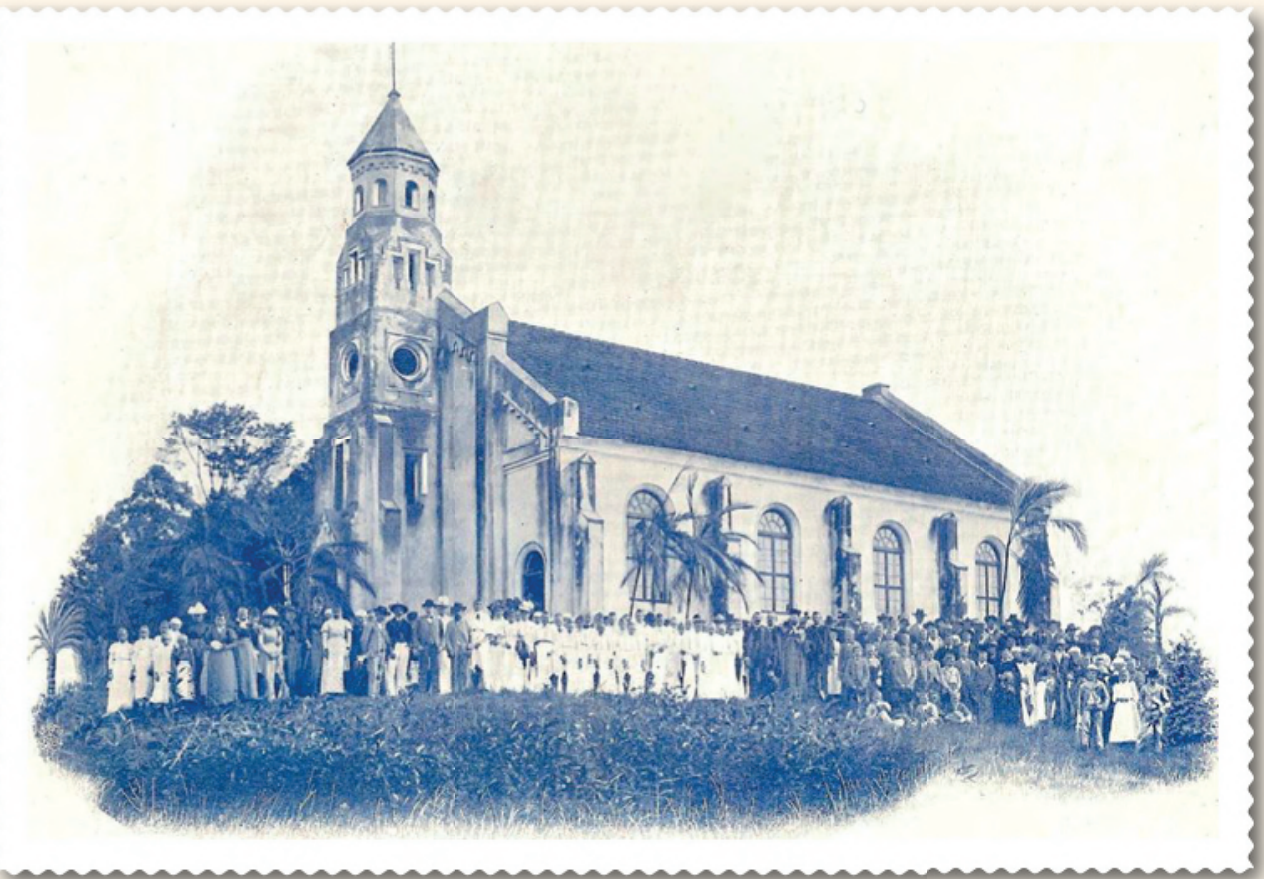

Universitätsdrucke Göttingen 

Scheila Roberta Janke

Die Religiosität der Pommern in Brasilien

Dieses Werk ist lizenziert unter einer

Creative Commons

Namensnennung - Weitergabe unter gleichen Bedingungen

4.0 International Lizenz.

(c) $\underset{\mathrm{BY}}{(1)}$ (2) 
erschienen in der Reihe der Universitätsdrucke im Universitätsverlag Göttingen 2019 
Scheila Roberta Janke

\section{Die Religiosität der Pommern in Brasilien}

Eine Studie zu den pommerschen Einwanderern und deren Nachkommen im 19. und 20. Jahrhundert

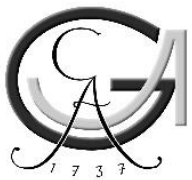

Universitätsverlag Göttingen 2019 


\section{Bibliographische Information der Deutschen Nationalbibliothek}

Die Deutsche Nationalbibliothek verzeichnet diese Publikation in der Deutschen Nationalbibliographie; detaillierte bibliographische Daten sind im Internet über $<$ http://dnb.dnb.de $>$ abrufbar.

Finanzielle Unterstützung für die Publikation: Evangelische Kirche in Deutschland (EKD) und die Kulturabteilung des Auswärtigen Amtes

\section{Autorenkontakt}

Scheila Roberta Janke

E-Mail: scheilajanke@gmail.com

Dieses Buch ist auch als freie Onlineversion über die Homepage des Verlags sowie über den Göttinger Universitätskatalog (GUK) bei der Niedersächsischen Staats- und Universitätsbibliothek Göttingen (http://www.sub.uni-goettingen.de) erreichbar. Es gelten die Lizenzbestimmungen der Onlineversion.

Satz und Layout: Scheila Roberta Janke

Titelabbildung: Erste Stadtkirche in Timbó (SC), Brasilien (s. Abb. 19, S. 261 in diesem Band). Mit freundlicher Genehmigung von Nelso Weingärtner (Foto: Fotograf Schmidt aus Salto Weissbach (SC), Brasilien).

(C) 2019 Universitätsverlag Göttingen

https://univerlag.uni-goettingen.de

ISBN: 978-3-86395-394-2

DOI: https://doi.org/10.17875/gup2019-1139 


\section{Inhaltsverzeichnis}

Vorwort 9

I - Einleitung $\quad 11$

II - Die Pommern und ihre Auswanderung nach Brasilien 19

1. Überblick über die Geschichte Pommerns 20

2. Hauptmotive der Auswanderung $\quad 26$

2.1. Soziale, politische und ökonomische Hintergründe 27

2.2. Religiöse Motivation $\quad 33$

2.3. Einwanderungspropaganda $\quad 39$

3. Pommersche Einwanderung nach Brasilien 47

4. Befürworter und Gegner der Auswanderung und ihre Interessen $\quad 54$

4.1. Auswanderung als Mittel zur Entspannung sozialer und wirtschaftlicher Probleme $\quad 54$

4.2. Die zurückhaltende Haltung Preußens zur Auswanderung nach Brasilien 56

4.3. Wirtschaftliche, ideologische und expansionistische Interessen bei den Einwanderern in Brasilien $\quad \mathbf{6 0}$ 
5. Stellungnahme Brasiliens gegenüber den Einwanderern von der Monarchie bis zum Zweiten Weltkrieg

5.1. Verlegung des portugiesischen Königshauses nach Brasilien (1808-1822)

5.2. Kaiserzeit (1822-1889)

5.3. Von der Ausrufung der Republik bis zur Entstehung des

Neuen Staates (1889-1937)

5.4. Von der Entstehung des Neuen Staates bis zum Ende des

Zweiten Weltkrieges (1937-1945)

94

6. Zwischenfazit

102

III - Ausgangslage, Anfänge und Entwicklung

105

1. Die Reise nach Brasilien

106

2. Die Ankunft in den Kolonien

115

2.1. Die Waldrodung und der Anfang in den Siedlungen

120

2.2. Schwierigkeiten mit Beamten, Kolonieverwaltung,

Gerichtsverfahren und Geschäftspersonen

126

2.3. Der Konflikt mit den indigenen Völkern

141

2.4. Die Schwierigkeiten der Protestanten in einer römisch-katholischen Umwelt

145

3. Evangelisch-lutherische Religiosität im brasilianischen Urwald

3.1. Die Waldärzte, „Gesundbeter" und Himmelsbriefe: die

Religiosität der Pommern und ihre Bedeutung in Notsituationen

3.2. Die Errichtung kirchlicher Gemeinden - eine konkrete

Umsetzung der lutherischen Doktrin des Priestertums aller

Gläubigen

3.2.1. Mitgebrachte Glaubensquellen: ihre Bedeutung für die

Erhaltung des Glaubens

3.2.2. Die Verwendung von Glaubensquellen bei der häuslichen Andacht

3.2.3. Die Tätigkeit der Laien und Kolonistenpastoren

3.2.4. Die Bedeutung von kirchlichen Amtshandlungen,

Gebeten und Liedern

3.2.4.1. Geburt und Taufe

3.2.4.2. Konfirmation und Trauung

205

3.2.4.3. Die Feier des Heiligen Abendmahls

208

3.2.4.4. Beerdigung

216

4. Die Entwicklung der Pommern in Brasilien

221

4.1. Die Organisation eines familiären Subsistenzbetriebes

und ihre Herausforderungen

4.2. Der Industrialisierungsprozess in den Siedlungsgebieten 
IV - Institutionelle Formierung und Konflikte

1. Die Ankunft der Geistlichen und die Strukturierungsphase der Gemeinden

2. Errichtung von Orten für den Gottesdienst

2.1. Erste Phase: Hausgemeinden, provisorische Gottesdienstorte und Errichtung von Kirchen-Schulen, Bethäusern und Kapellen

2.2. Zweite Phase: Errichtung von massiven Kirchen und Anschaffung von Glocken

2.3. Dritte Phase: Der Aufbau einer ,würdigen Kirche" nach der Ausrufung der Republik

3. Die Errichtung anderer Institutionen in den Siedlungsgebieten 3.1. Schul- und Bildungswesen

3.1.1. Kolonie- und Gemeindeschulen

3.1.2. Deutsche Schulen

3.1.3. Volks- und Mittelschulen und die Ausbildung von Lehrern

3.2. Die Errichtung von Kranken-, Entbindungshäusern und sozialen Anstalten

3.3. Errichtung kultureller und landwirtschaftlicher Vereine

4. Die Entstehung kirchlicher Synoden in Brasilien und die

Entwicklung von Konflikten aufgrund unterschiedlicher Interessen

4.1. Konflikte zwischen Gemeinden, Geistlichen, Missionaren und Kolonistenpastoren

4.2. Konfessionelle Streitigkeiten

\section{V - Im Zeichen des Nationalismus}

1. Ethnische und Deutschtumsproblematik

2. Der Erste Weltkrieg und die Reaktion der brasilianischen Bevölkerung

3. Die Position der Deutschen und Deutschbrasilianer im Verhältnis zum brasilianischen Integralismus und zum Nationalsozialismus

3.1. Der brasilianische Integralismus

3.2. Der Nationalsozialismus

4. Das Nationalisierungsprogramm und seine Auswirkungen auf die kirchlichen Gemeinden

5. Der Zweite Weltkrieg: Verbote, Verfolgung, Folter und Inhaftierungen 
IX - Exkurs: Himmelsbriefe

405

(1-A) Exemplar des Himmelsbriefes genannt Gredoria aus Espírito Santo

(1-B) Exemplar des Himmelsbriefes Gredoria aus Rio Grande do Sul

(2) Exemplar des Himmelsbriefes aus Santa Catarina

(3) Haus- und Schutzbrief aus Espírito Santo

(4) Exemplar des Schutzbriefes aus Santa Catarina 


\section{Vorwort}

An dieser Stelle danke ich meinem Doktorvater Prof. Dr. Thomas Kaufmann für seine kompetente und aufmerksame Betreuung im Laufe meiner Promotion. Im Rückblick auf die Jahre, in denen ich mich dem Promotionsprojekt gewidmet habe, bin ich besonders dankbar für den reichen Lernprozess. Die Vorschläge und Anmerkungen und die fruchtbaren inhaltlichen Diskussionen haben nicht nur zum Gelingen dieses Projektes beigetragen, sondern werden mich auch auf meinem weiteren akademischen Weg prägen. Ein besonderer Dank geht auch an Herrn Dr. Alejandro Zorzin, meinen dritten Betreuer, der mir besonders bei der Recherche und Auswertung der Himmelsbriefen geholfen hat, und an Herrn Prof. Dr. Martin Tamcke, meinen zweiten Betreuer, für wichtige Anmerkungen und Literaturvorschläge.

Herzlich danke ich auch meinen Professoren in Brasilien, die mich bereits während meines Studiums mit ihrem Wissen und ihrer Hingabe inspiriert haben: Herr Prof. Dr. Rudolf von Sinner, der mir auf die Bedeutung der pommerschen Religiosität und deren Untersuchung anhand von primären Quellen nahegelegt hat; Herr Prof. Ms. Osmar Luiz Witt, der mir den Zugang zu wichtigen Quellen aus dem historischen Archiv in São Leopoldo/RS ermöglicht hat; Herr Prof. Dr. Wilhelm Wachholz, mit dem ich als wissenschaftliche Mitarbeiterin zu dem Thema „Historische Untersucbung der materiellen Kultur [in Bezug auf kircbliche Gebäude] als Ausdruck von Konfessionalität und Spiritualität in Gemeinden der Evangelischen Kirche Lu- 
therischen Bekenntnisses in Brasilien "forschen durfte, das auch in dieser Dissertation einen prominenten Platz hat.

Ich bedanke mich auch bei der Evangelischen Kirche Lutherischen Bekenntnisses in Brasilien, die mich für eine Promotion in Deutschland ernannt, mein Projekt entsprechend genehmigt und mich für diese Studienzeit vom Pfarramt freigestellt hat. Ein ganz lieber Dank auch an die Evangelische Kirche Deutschlands - EKD und die Kulturabteilung des Auswärtigen Amtes für die finanzielle Unterstützung durch ein Stipendium, ohne welches diese Arbeit nicht hätte abgeschlossen werden können. Herrn Dr. Martin Illert und Frau Helga Meyer danke ich besonders für die aufmerksame Beratung in den vergangenen Jahren.

Für dieses Projekt waren archivalische Recherchen sehr wichtig. An dieser Stelle will ich mich auch bei den vielen Mitarbeiterinnen und Mitarbeitern der verschiedenen Archive - des Evangelischen Zentralarchivs in Berlin, des Pommerschen Landesarchiv Greifswald, des Landeskirchlichen Archivs der Evangelisch-Lutherischen Kirche Bayerns in Nürnberg, des Archivs der Basler Mission in der Schweiz und des Historischen Archivs der Evangelischen Kirche Lutherischen Bekenntnisses in Brasilien in São Leopoldo - für ihre Begleitung bedanken. Ohne ihre Hilfe hätte ich den Berg von Akten nicht bewältigen können. Ein herzlicher Dank auch an Pastor Nelso Weingärtner und Pastor Aldo Beskow, die mir ihre privaten Archive zur Verfügung gestellt haben, sowie an Pastor Inácio Lemke, der mich zu einem Besuch bei pommerschen Familien begleitet hat. Auch an Prof. Dr. Claudete Beise Ulrich, Prof. Dr. Martin Dreher, Judith Pitter, Pastorin Mariane Beyer Ehrat, Diakonin Angela Lemke, Pastor Edson Pils, Claudio Böhning und Renato Raasch, die mich auf wichtige Quellen hingewiesen haben. Der Graduirtenschule für Geisteswissenschaften der Universität Göttingen danke ich für die finanzielle Unterstützung bei Recherchereisen und für die Möglichkeit, an verschiedenen Fortbildungskursen teilzunehmen. Ein besonderer Dank geht auch an Yatiker Yildiz, Delphine Conzelmann und Judith Pitter, die mich bei der Korrektur meiner Arbeit unterstützt haben.

Meiner Familie und den vielen Freunden, die ich während meines Aufenthalts in Göttingen kennenlernen durfte, und auch denen, die nicht da sein konnten, aber mich durch Nachrichten im Laufe dieser Jahre begleitet haben, danke ich für die Unterstützung an guten und schlechten Tagen. Ein ganz besonderer Dank an meinen Mann, der mir in schwierigen Momenten beigestanden hat. Ich danke alle, die den schönen Zug zur Gänseliesel vorbereitet und mir dabei begleitet haben. Das war ein unvergesslicher Moment!

Ich widme diese Arbeit meinen Eltern, Dirce Hoeltgebaum Janke und Nilton Janke, meinem Mann, Daniel Kreidlow, Alfons und Erica Hoeltgebaum, geb. Krieser und Ernesto und Waltraudt Kertzendorf, geb. Janke, (die vier in memoriam).

Göttingen, im November 2018.

Scheila Roberta Janke 


\section{I - Einleitung}

Die Immigrationsforschung, die sich mit der deutschen Einwanderung nach Brasilien im Laufe des 19. und 20. Jahrhunderts und mit dem Leben der Einwanderer in den Siedlungsgebieten beschäftigte, ist umfangreich. Ideologisch geprägte Darstellungen durchziehen die verschiedenen Zeitperioden, manche Autorinnen und Autoren schrieben ihre Werke mit der persönlichen Unterstützung des brasilianischen Kaisers ${ }^{1}$, im offiziellen Auftrag ihrer Länder ${ }^{2}$, im Zuge expansionistischer Bestrebungen ${ }^{3}$ oder unter dem Einfluss einer volkstümlichen Ideologie. ${ }^{4}$ Die Figur

\footnotetext{
${ }^{1}$ Avé-Lallemant, Robert. Reise durch Südbrasilien im Jabre 1858. 1. Teil. Leipzig: F. A. Brockhaus, 1859; Avé-Lallemant, Robert. Reise durch Südbrasilien im Jahre 1858. 2. Teil. Leipzig: F. A. Brockhaus, 1859.

2 Wie der Schweizer Bevollmächtigte Johann Jakob von Tschudi (Von Tschudi, Johann Jakob. Bericht des Herrn von Tschudi, außerordentlichen schweizerischen Gesandten in Brasilien an den Bundesrath über den Zustand der Kolonien der brasilianischen Provinzen Santa Catharina und San Pedro do Rio Grande do Sul vom 18.6.1861; Von Tschudi, Johann Jakob. Bericht des Herrn von Tschudi, außerordentlichen Gesandten in Brasilien über die Kolonien Santa Isabel, Santa Leopoldina und Rio Novo usw. vom 20.12.1860. Beides In: Hörmeyer, J. (Hrsg.) Actenstücke Brasilianischer Seite betreffend die Kolonisation des Kaiserreiches. 3. Jahrgang, Heft 3, Rudolfstadt/Berlin: Verlag des F. priv. Hofbuchdruckerei/Franz Wagner, 1861. S. 209-259 und 260-286).

${ }^{3}$ Dedekind, Max. 75 Jabre deutsch-evangelischer Diasporaarbeit in Nord- und Südbrasilien. Barmen: Wiemann, 1912; Dedekind, Max. Brasilien, das Ziel deutscher Auswanderer und die Deutsche Evangelische Kirche in Brasilien. Elberfeld: Evangelischen Gesellschaft für die protestantischen Deutschen in Südamerika, 1924; Bürger, Otto. Brasilien. Eines Landes- und Wirtschaftskunde für Handel, Industrie und Ein-
} 
des deutschen Pioniers, der den brasilianischen Urwald gerodet und bewältigt hat sowie durch fleißige Arbeit zur Entwicklung des Landes beitrug, wird teilweise idyllisch dargestellt, wobei diese Darstellungen im Grunde mit der Absicht der brasilianischen Regierung bezüglich der Einwanderung übereinstimmten und die grausamen Maßnahmen der Einwanderer gegen die brasilianischen Ureinwohner unerwähnt lassen. Sie verschweigen weiterhin, dass europäische Einwanderer erheblich leichteren Zugang zum Erwerb billigerer Ländereien hatten als Afrobrasilianer, „Mulatos", „Caboclos" oder Brasilianer der unteren Schichten, denen ein solcher Besitz teilweise verboten war. Demgegenüber stellen viele Studien die Einwanderer und deren Nachkommen auch als Opfer dar, insofern sie von der brasilianischen Regierung mangelhaft unterstützt wurden und unzähligen Schwierigkeiten ausgesetzt waren. Doch entsprechen solche Darstellungen nur begrenzt der vorherrschenden Selbstwahrnehmung vieler Immigranten, da die Mehrheit der Einwanderer Kaiser Pedro II. in erster Linie dankbar war und den Verlust seiner Unterstützung durch den Ausruf der Republik bedauerten. Außerdem erwiesen sich die Einwanderer und deren Nachkommen bei der Bewältigung von Herausforderungen und Schwierigkeiten in den Siedlungsgebieten keineswegs als Opfer, sondern sie übernahmen selbst die Verantwortung für die Lösung ihrer Probleme. Von Zeit zu Zeit kam es in diesem Sinne sogar zu Protesten gegen ungerechte und korrupte Koloniedirektoren und fortwährend kämpften die Immigranten und deren Nachkommen um die Anerkennung ihrer Rechte seitens des brasilianischen Staates.

Unglücklicherweise kommen die Einwanderer und deren Nachkommen in dem hier betrachteten Zeitraum selten selbst zur Sprache, was die Narration der Geschichte aus ihrer Perspektive erschwert. Die klassischen und ältesten Studien über die deutsche und pommersche Einwanderung nach Brasilien konzentrierten sich auf den Kolonisationsprozess und auf die harten, verschiedenen und teilweise aus europäischer Sichtweise exotischen Lebensbedingungen innerhalb der brasilianischen Siedlungsgebiete. Das religiöse Leben wurde als ein Bereich neben anderen betrachtet und vor allem aus der Perspektive der Geistlichen, die in die deutschen Siedlungsgebiete entsandt wurden, der europäischen Reisenden und der kirchlichen und staatlichen Repräsentanten, also einer intellektuellen Elite, geschildert. ${ }^{5}$ Eine zweite Studienwelle befasste sich mit der Institutionalisierung der

wanderung. Leipzig: Dieterich, 1926; Aldinger, Paul. Kirchlich-kolonisatorisches Merkblatt für Brasilien. Witzenhausen: Chr. Trautvetter, um 1922.

${ }^{4}$ Kahle, Maria. Deutsche Heimat in Brasilien. Berlin: Grenze und Ausland, 1937.

5 Wagemann, Ernst Friedrich: Die Deutschen Kolonisten im brasilianischen Staate Espirito Santo. München/Leipzig: Duncker \& Humbolt, 1915; Wernicke, Hugo. Viagem pelas colônias alemãs do Espirito Santo. A população evangélico-alemã no Espírito Santo: uma viagem até os cafeicultores alemães em um estado tropical do Brasil. Vitória: Arquivo Público do Estado do Espírito Santo, 2013. Übersetzt aus dem Original Deutsch-evangelisches Volkstum in Espirito Santo: Reise zu deutschen Kaffeebauern in einem tropischen Staate Brasiliens. Potsdam: Stiftungsverlag, 1910; Von Tschudi, Johann Jakob. 
Gemeinden in kirchlichen Synoden und der Entstehung der Evangelischen Kirche Lutherischen Bekenntnisses in Brasilien. ${ }^{6}$ Eine dritte Studienwelle stellt die Einwanderer selbst und deren Nachkommen in den Mittelpunkt der Untersuchung. Diese Perspektive erfreute sich vor allem in den letzten Jahren vermehrter Aufmerksamkeit. Die Erfahrungen der Vorfahren zu Beginn der Kolonisation, aber auch während der Kriegs- und Nationalisierungszeit, sowie die Pflege kultureller und religiöser Traditionen wurden durch empirische Forschungen erhoben und bewertet, um die noch erschließbaren Informationen zu systematisieren. ${ }^{7}$

Diese Arbeit kann nicht, wie zunächst angedacht, die Bedeutung der evangelisch-lutherischen Religiosität der Pommern und deren Nachkommen auf Grundlage von Kolonistenberichten untersuchen, da diese aufgrund schwieriger Verhältnisse, mangelnder Schulbildung, strengem Arbeitsrhythmus und schlechter Kommunikationsmöglichkeiten kaum Berichte über ihr Leben hinterließen, ganz zu schweigen von Berichten über die Bedeutung ihres Glaubens. Hinzu kommt außerdem, dass viele deutschsprachige Dokumente, möglicherweise auch Briefe und Berichte, in der Nationalisierungs- und Kriegszeit beschlagnahmt oder vernichtet wurden. Mündliche Überlieferungen von späteren Nachkommen mangeln ihrerseits oft an historischer Genauigkeit, vermischen verschiedene Ereignisse oder versuchen negative Aspekte, beispielsweise eine Sympathie oder Anhängerschaft ihrer Vorfahren zum deutschen Nationalsozialismus, zu verbergen. Diese Tendenz konnte in verschiedenen Feldstudien, die in den letzten Jahren unter pommerschen Nachkommen durchgeführt und für diese Arbeit verwendet wurden, festgestellt werden.

Deswegen bevorzugt diese Studie die Auswertung primärer und zeitgenössischer Quellen aus verschiedenen Archiven, sowie die Analyse erstens der mitgebrachten Glaubensquellen der Einwanderer und deren Nachkommen und zweitens derjenigen Glaubensquellen, die im Laufe der Zeit in den Gemeinden einge-

Reise durch Süd-Amerika. 3. Band. Leipzig: F. A. Brockhaus, 1867; Von Tschudi, Johann Jakob. Reisen durch Süd-Amerika. 4. Band. Leipzig: F. A. Brockhaus, 1868.

${ }^{6}$ Schröder, Ferdinand. Brasilien und Wittenberg. Ursprung und Gestaltung deutschen evangelischen Kirchentums in Brasilien. Berlin/Leipzig: De Gruyter, 1936; Prien, Hans-Jürgen. Formação da Igreja Evangélica no Brasil. Das comunidades teuto-evangélicas de imigrantes até a Igreja Evangélica de Confissão Luterana no Brasil. São Leopoldo/Petrópolis: Sinodal/Vozes, 2001; Wirth, Lauri Emilio. Protestantismus und Kolonisation in Brasilien. Der evangelische Gemeindeverband in Brasilien: Kontextualität, Ekklesiologie und Institutionalisierung einer deutschen Einwandererkirche in Santa Catarina. Erlangen: Verlag der Ev- Luth. Mission, 1992; Krause, Henrique. Lutherische Synode in Brasilien. Geschichte und Bekenntnis der Evangelisch-Lutherischen Synode von Santa Catarina, Paraná und anderen Staaten Brasiliens. Erlangen: Verlag der Ev- Luth. Mission, 1993.

${ }^{7}$ Rölke, Helmar. Raízes da Imigração alemã: história e cultura alemã no estado do Espirito Santo. Vitória: Arquivo Público do Estado do Espírito Santo, 2016; Martinuzzo, José Antonio. Germânicos nas Terras do Espirito Santo - Deutschsprachige im Bundesstaat Espirito-Santo. Vitória: Governo do Estado do Espírito Santo, 2009; Granzow, Klaus: Grün ist das Tal am Rio Itajai. Pommeranos in Brasilien. Hamburg: Pommerscher Buchversand, 1972; Granzow, Klaus: Pommeranos unter dem Kreuz des Südens. Deutsche Siedler in Brasilien. Słupsk: Grawipol, 2000. 
führt wurden. Als Hauptquellen dienen die Akten über die Auswanderung der Pommern nach Brasilien im Pommerschen Landesarchiv Greifswald, die Gemeindeakten über die Diasporaarbeit in Brasilien, die sich im Evangelischen Zentralarchiv in Berlin, im Landeskirchlichen Archiv der Evangelisch-Lutherischen Kirche Bayerns in Nürnberg, im Archiv der Basler Mission in der Schweiz und im Historischen Archiv der Evangelischen Kirche Lutherischen Bekenntnisses in Brasilien in São Leopoldo (RS) befinden. Hinzu kommen pommersche Gesangbücher (Heiliges Lippen- und Herzens-Opfer einer gläubigen Seele oder Vollständiges Gesangbuch; Vermebrtes Kirchen- und Haus-GesangBuch für das Königl. Schwedische Herzogthum Pommern und Fürstenthum Rügen), Andachtsbücher (Handbuch in guten und bösen Tagen von Johann Friedrich Stark; Evangelisches Hausbuch für die Deutschen im Ausland; auch Gebetsbücher als Anhang der erwähnten Gesangbücher) und Predigtbücher (mehrere Predigtbücher von Louis Harms, das Predigtbuch Evangelische Zeugnisse der Wabrheit zur Aufmunterung im wahren Christentum von Immanuel Gottlob Brastberger). Neben diesen Zeugnissen werden auch Quellen magischen Inhalts, wie das sogenannte 6. und 7. Buch Mosis und verschiedene Exemplare von Himmels- und Schutzbriefen in die Betrachtung mit einbezogen. Auf Zeitungsartikel wird nur punktuell zurückgegriffen, soweit sie relevante Erwägungen in Bezug zum Thema beinhalten, da sich in ihnen in der Regel auch die Sichtweise einer intellektuellen Elite widerspiegelt.

Ein großer Teil der primären und zeitgenössischen Quellen umfasst die kirchliche Korrespondenz zwischen Pastoren und Missionaren sowie zwischen kirchlichen Repräsentanten in Brasilien und der Kirche oder verschiedenen Bildungsanstalten (besonders Archivquellen), gesammelte Kolonistenberichte, Tagebücher, Gemeindechroniken und Geschichtsdarstellungen von Pastoren und Missionaren. Diese waren auch die ersten, die die Geschichte der pauschal benannt „deutschen " Einwanderung sowie die Geschichte der kirchlichen Gemeinden in Brasilien schriftlich überliefert haben. Solche Überlieferungen aber orientierten sich vornehmlich an der Erfahrung der ,deutschen "Einwanderer und ihrer Nachkommen in Brasilien, und verfolgten bestimmte Interessen, wie die Wahrung des evangelischen Glaubens, oft in Verbindung mit der ideologischen Wahrung des Deutschtums in der Diaspora. Quellen über die europäische Einwanderung und den Ansiedlungsprozess der Einwanderer in Brasilien aus der Perspektive der Einheimischen sind kaum vorhanden. Dies kann unter anderem auf mangelhafte Bildung in unteren Gesellschaftsschichten sowie die Verdrängung indigener Völker und auf die organisierte Sklaverei in Brasilien zurückgeführt werden. Aus diesem Grund ist es auch kaum möglich Konflikte und Integrationsschwierigkeiten zwischen Einwanderern und einheimischer Bevölkerung aus der Sicht der Afrobrasilianer, der indigenen Völker und der Lusobrasilianer zu rekonstruieren. Die lusobrasilianische Elite in Brasilien interessierte sich lange Zeit wenig für diese Problematik und fühlte sich erst dann gezwungen, zum Thema „Einwanderer" Position zu beziehen, als sie sich in ihren politischen und ökonomischen Interessen bedroht fühlte oder, wie im zweiten Kapitel ausgeführt wird, im Zuge des brasilianischen Nationalis- 
mus gestärkt. Aus diesem Kontext stammen auch die Polizeidossiers von Polizeikommissar Py und der Polizeiabteilung für politische und soziale Ordnung. ${ }^{8}$ Die Lebensbedingungen der Einwanderer und deren Nachkommen in den ersten Jahrzehnten nach der Einwanderung der ersten Immigranten wurden aus einer meist eurozentrischen Perspektive erfasst. Diese Darstellung tendiert dazu, die Entwicklung und den Fortschritt in den Siedlungsgebieten den europäischen Einwanderern zuzuschreiben und ihr Verhalten sowie die Diskriminierung anderer Brasilianer zu rechtfertigen. Eine solche Haltung vertraten wiederum viele Nachkommen der Einwanderer beziehungsweise Deutschbrasilianer in ihren Darstellungen und Berichte, was diese Arbeit zeigen wird.

Erst in den letzten Jahrzehnten haben Kirchenhistoriker wie Dreher ${ }^{9}$ und Historikerinnen wie Seyferth ${ }^{10}$ und Magalhães ${ }^{11}$ die enge Verbindung zwischen Ethnie und evangelisch-lutherischem Glauben unter Einwanderer und deren Nachkommen hinterfragt und die ethnische Problematik zwischen Deutschbrasilianern und einheimischer Bevölkerung behandelt. Aus der Sekundärliteratur, besonders aus den Werken von Perazzo ${ }^{12}$, Cancelli ${ }^{13}$, Gertz, ${ }^{14}$ Fáveri $^{15}$ und Ackermann ${ }^{16}$, konnten Informationen über die Zeit des Nationalismus in Brasilien entnommen werden. Cancelli, Perazzo und Ackermann haben eine durchgehende Archivrecherche in brasilianischen Staatsarchiven durchgeführt. Somit schließen sie eine Lücke in der Forschung, da kirchliche Quellen, besonders aufgrund der Repression zu dieser Thematik meist schweigen oder nur unvollständige oder mangelnde Informationen enthalten. Zudem gibt Cancelli Auskunft über die Repressionen gegen „,deutsche“ Einwanderer und ihre Nachkommen, aber auch gegen Italiener und

\footnotetext{
8 Py, Aurélio da Silva. A $5^{a}$ Coluna no Brasil. A conspiração Nazi no Rio Grande do Sul. Porto Alegre: Globo, 1942; Delegacia de ordem política e social de Santa Catarina, O punbal nazista no coração do Brasil. Florianópolis: Imprensa Oficial do Estado, 1944.

${ }^{9}$ Dreher, Martin Norberto. Igreja e Germanidade. Estudo crítico da história da Igreja Evangélica de Confissão Luterana no Brasil. São Leopoldo/Porto Alegre/Caxias do Sul: Sinodal/Escola Superior de Teologia São Lourenço de Brindes/Universidade de Caxias do Sul, 1984.

10 Seyferth, Giralda. Nacionalismo e identidade étnica. A ideologia germanista e o grupo étnico teutobrasileiro numa comunidade do Vale do Itajaí. Florianópolis: Fundação Catarinense de Cultura, 1981.

${ }^{11}$ Magalhães, Marionilde Brepohl de. Pangermanismo e nazismo. A trajetória alemã no Brasil. Campinas: UNICAP/FAPESP, 1998.

${ }^{12}$ Perazzo, Priscila Ferreira. O Perigo Alemão e a Repressão Policial no Estado Novo. São Paulo: Divisão de Arquivo do Estado, 1999.

${ }^{13}$ Cancelli, Elizabeht. O mundo da violência: repressão e estado policial na era Vargas (1930-1945). Campinas: Universidade Estadual de Campinas, 1991.

${ }^{14}$ Gertz, René. O fascismo no sul do Brasil. Germanismo, nazismo, integralismo. Porto Alegre: Mercado Aberto, 1987.

${ }^{15}$ Fáveri, Marlene. Memórias de uma (outra) guerra. Cotidiano e medo durante a Segunda Guerra em Santa Catarina. Florianópolis: Universidade Federal de Santa Catarina, 2002.

${ }^{16}$ Ackermann, Silvia Regina. Quando preferir um samba ao bino nacional é crime: integralismo, etnicidade e os crimes contra o Estado e a Ordem Social (Espírito Santo - 1934-1945). São Carlos: Universidade Federal de São Carlos, 2009.
} 
Japaner und deren Nachkommen. Dadurch wird deutlich, dass alle Bevölkerungsteile, die irgendeine ethnische oder ökonomische Verbindung mit den Achsenländern hatten, solchen Maßnahmen ausgesetzt werden konnten, wobei die Italiener und deren Nachkommen wenigstens sprachlich und religiös schneller assimiliert waren. Seibel ${ }^{17}$ sowie Fáveri und Ackermann sammelten außerdem Informationen über verschiedenen Befragungen oder führten selbst eine Feldforschung mit pommerschen Nachkommen durch, so dass sie viele Informationen, die sonst meist nur mündlich überliefert wurden, erfassen konnten. Ein größeres Problem, das sich dabei jedoch stellt, ist die Tendenz vieler Einwanderernachkommen, bestimmte Informationen über ihre Vorfahren zu verweigern oder eine allgemein akzeptierte Version der Ereignisse zu reproduzieren, was die Autorinnen und Autoren nicht immer erkennen oder zumindest nicht thematisieren. Der Fokus richtet sich in der Regel auf die Darstellung schlüssiger Fakten. Auf diese Weise kann schnell der Eindruck entstehen, dass die Pommern in Brasilien nichts über den Nationalsozialismus wussten, keine Sympathie für den Nationalsozialismus und den brasilianischen Integralismus hatten und als „Pommern “ - plötzlich nicht mehr als „Deutsche“ - überhaupt keine Art von Deutschtum pflegten.

Weil kirchliche und kirchenhistorische Quellen wenig Informationen über die magischen Praktiken der Pommern und deren Nachkommen geben, oder sie von vornherein als "Aberglaube" bezeichnen, sind die Arbeiten der Anthropologin Bahia ${ }^{18}$, des Pastors Weingärtner ${ }^{19}$ und der Historikerin und Sozialwissenschaftlerin Maltzahn ${ }^{20}$ von entscheidender Bedeutung. Obwohl Pastor Weingärtner solche Praktiken zum Aberglauben zählt, sammelte er im Laufe seiner Pfarrtätigkeit eine Reihe von Quellen magischen Inhaltes unter pommerschen Einwanderer und deren Nachkommen und war einer der ersten, die mit solchen Quellen inhaltlich, nicht nur deskriptiv, umgegangen ist. Maltzahn und Bahia führten ihrerseits Feldforschungen durch und interpretierten diese Quellen aus einer religiösen, anthropologischen, ethnischen und kulturellen Perspektive. Ihre Untersuchungen leiden aber darunter, dass sie keinen Zugang zu Informationen über die Überlieferungsgeschichte dieser Quellen hatten. Solche Informationen, die meist von Stübe zusammengefasst wurden, erklären jedoch den Kontext, in dem diese Quellen entstanden sind, wie sie in bestimmten Situationen und im Hinblick auf unterschiedliche Motivationen erarbeitet und erweitert wurden. In diesem Sinne konnten die Studien von Stübe ${ }^{21}$, Dieterich ${ }^{22}$, Schlegel23, Röhrich ${ }^{24}$, Jacoby ${ }^{25}$, Bauer ${ }^{26}$ und

\footnotetext{
${ }^{17}$ Seibel, Ivan. Imigrante no século do isolamento/1870-1970. São Leopoldo: Traço, 2010.

18 Bahia, Joana. O tiro da bruxa. Identidade, magia e religião na imigração alemã. Rio de Janeiro: Garamond, 2011.

${ }_{19}$ Weingärtner, Nelso. Mundo da Superstição. Orientação para a vida de fé. São Leopoldo: Sinodal, 2014.

${ }^{20}$ Maltzahn, Gislaine Maria. Família, ritual e ciclos de vida. Estudo Etnográfico sobre narrativas pomeranas em Pelotas (RS). Pelotas: Universidade Federal de Pelotas, 2011.

${ }^{21}$ Stübe. Sonntagsbrief. In: Hoffman-Krayer, E.; Bächtold-Stäubli, Hanns (Hrsg.) Handwörterbuch des Deutschen Aberglaubens. Band VIII. Berlin/Leipzig: Walter de Gruyter, 1936/1937. S. 99-104; Stübe,
} 
Becker \& Nail27 sowie besonders die Himmelsbriefe und magische Formeln selbst diese Lücke in der brasilianischen Forschung schließen.

Für die Studie wurde ein qualitativer Ansatz grundlegender Natur mit einem explorativen Ziel gewählt. Mithilfe eines historischen Vorgehens soll die Religiosität der Pommern und deren Nachkommen und die Einbindung in eine Glaubensgemeinschaft im konkreten Umgang mit Krisen, Verlusten und Schwierigkeiten analysiert werden.

In einem ersten Kapitel werden das Phänomen der Emigration, die Motive der Auswanderer, die Stellungnahme der preußischen Regierung sowie die ökonomischen und ideologischen Interessen deutscher Unternehmer und intellektueller Eliten bezüglich der Auswanderung und in Hinblick auf die Einwanderer in Brasilien behandelt. Danach soll weiterhin die politische, soziale und religiöse Situation innerhalb Brasiliens betrachtet werden, beginnend bei der Verlegung des portugiesischen Königshauses nach Brasilien bis zu den Folgejahren des Zweiten Weltkriegs, da diese durchgehend direkten Einfluss auf die Lebensbedingungen in den Siedlungsgebieten hatten. Politische Veränderungen, die sich im Laufe der Zeit ereigneten, hatten zeitweise positive, aber auch negative Auswirkungen auf die Situation der Einwanderer und deren Nachkommen.

Hieran schließt sich das nächste Kapitel an. Darin werden die Probleme bei der Reise, der Ankunft und der Ansiedlung, die Herausforderungen im Umgang mit dem Urwald und der Akklimatisierung, die Konflikte mit indigenen Völkern sowie die Schwierigkeiten der Protestanten in einer römisch-katholischen Umwelt dargestellt. Dabei soll zugleich die Bedeutung des individuellen und kollektiven Glaubens und der gegenseitigen Unterstützung der Nachbarn und Gemeindemitglieder bei der Bewältigung von Schwierigkeiten, Krisen, Krankheiten und Verlusten untersucht werden. Die aus der Heimat mitgeführten Glaubensquellen und Quellen magischen Inhaltes trugen angesichts des Arzt- und Pfarrermangels zur

R. Der Himmelsbrief. Ein Beitrag zur allgemeinen Religionsgeschichte. Tübingen: Mohr (Paul Siebeck), 1918.

22 Dieterich, Albrecht. Himmelsbrief. In: Blätter für Hessische Volkskeunde. Hrsg. im Auftrag der Vereinigung für Hessische Volkskunde, Nr. 3, III. Jahrgang, 1901. S. 9-12.

${ }^{23}$ Schlegel, Birgit. Glaube und Magie gegen die Gefahren des Krieges in Schutzbriefen. In: Zeitschrift für Regionale Forschung und Heimatpflege - Südniedersachsen, 34. Jahrgang, 3/September 2006, S. 65-70.

${ }^{24}$ Röhrich, L. Himmelsbriefe. In: Galling, Kurt; Von Campenhausen, Hans Frhr; Dinkler, Erich; Gloege, Gerhard; Løgstrup, Knud E. (Hrsg.) Die Religion in Geschichte und Gegenwart. Handwörterbuch für Theologie und Religionswissenschaft. 3. Auflage, 3. Band. Tübingen: Mohr (Paul Siebeck), 1959. S. 338-339.

25 Jacoby. Mosis, das sechste und siebente Buch. In: Hoffman-Krayer, E.; Bächtold-Stäubli, Hanns (Hrsg.) Handwörterbuch des Deutschen Aberglaubens. Band VI. Berlin/Leipzig: Walter de Gruyter, 1934/1935. S. 584-593.

${ }^{26}$ 6./7. Buch Moses. Einleitung und Bildkommentare von Wolfgang Bauer. Berlin: Karin Kramer, 1979.

27 Beckert, Hans Günther; Nail, Norbert. Der alte Gasthof zum Scbützenpfubl in Marburg. Mit einem Beitrag über „Himmelsbrief“. Marburg: Magistrat der Stadt Marburg, 2008. 
Erhaltung des Glaubens und zur Bewältigung von Krisen, Schwierigkeiten und Trauer bei und wurden darüber hinaus bei der Behandlung von Krankheiten und als greifbare Schutzmaßnahmen gegen Gefahren verwendet. Laien übernahmen zudem die Funktionen von Ärzte und Hebammen sowie von Geistlichen in Notsituationen. Zum Schluss soll noch die industrielle Entwicklung in manchen Siedlungsgebieten analysiert werden, die den Einwanderern und deren Nachkommen bessere Aufstiegsmöglichkeiten bot und ihre definitive Etablierung sicherstellte.

Das vierte Kapitel beginnt mit der Darstellung der Ankunft der Geistlichen und der Strukturierung von kirchlichen Gemeinden in Brasilien. Es handelt sich um den Beginn des kirchlichen Institutionalisierungsprozesses, der in der Entstehung der kirchlichen Synoden mündet. Ihren ökonomischen Verhältnissen entsprechend, setzten sich die Einwanderer und deren Nachkommen für den Aufbau und die Organisation kirchlicher Gemeinden, Schulen, Kranken- und Entbindungshäuser und anderer Anstalten ein. Die Betrachtung ihres Engagements bezüglich der Errichtung einer ,würdigen Kirche" und eines Sozialwesens im Umfeld der kirchlichen Gemeinde gibt damit auch Auskunft über die soziale Funktion des Glaubens. Hieran schließt sich auch die Betrachtung der Konflikte zwischen Gemeinden, Geistlichen und Laienpastoren sowie die konfessionellen Streitigkeiten. Die Betrachtung dieser Konflikte gibt Auskunft über unterschiedliche Auffassungen von Kirche, Gemeinde und Konfession, aber auch über Interessenkonflikte zwischen verschiedenen Gruppen.

Im Zuge der Nationalisierungs- und Kriegszeit kam die fehlende Integration und der ethnische Konflikt zwischen Einwanderern und der einheimischen Bevölkerung deutlich zum Ausdruck. Die Propaganda gegen die „deutsche Gefahr" hetzte besonders während des Ersten Weltkrieges die brasilianische Bevölkerung gegen die Einwanderer und deren Nachkommen auf. Im Zweiten Weltkrieg wurde diese Propaganda von der brasilianischen Regierung genutzt, um ihre Unterdrückungsmaßnahmen gegen „Fremde“ zu legitimieren. Als ihre Institutionen Schulen, Krankenhäuser, Vereine und in manchen Fällen auch Kirchen - geschlossen werden mussten, hielten die Einwanderer und deren Nachkommen durch ihren Glauben gestärkt zusammen. Sie übernahmen nach der Inhaftierung von Pastoren wieder pfarramtliche Funktionen und setzten das kirchliche Leben trotz zahlreicher Einschränkungen fort. Das wird im sechsten Kapitel thematisiert.

Die Bewältigung verschiedenster Herausforderungen führte zu einem Wachstumsprozess, der letztlich in die Entstehung einer in Brasilien verwurzelten Kirche evangelisch-lutherischen Glaubens mündete. Eine kurze Darstellung dieses Entstehungsprozesses folgt im letzten Kapitel dieser Arbeit. 


\section{II - Die Pommern und ihre Einwanderung nach Brasilien}

Dieses Kapitel beginnt mit einer kurzen Darstellung der Geschichte Pommerns, der Motive für die Auswanderung und mit den politischen, wirtschaftlichen, sozialen und ideologischen Interessen der Emigration. Danach richtet sich der Blick auf Brasilien in Zusammenhang mit den wichtigsten Zielen pommerscher Einwanderung, wie auch auf die Einwanderungspolitik und auf den Umgang mit den Immigranten und deren Nachkommen nach ihrer Ankunft 1824 bis zur Zeit des Zweiten Weltkrieges.

Zunächst sollte betont werden, dass die Einwanderungsgeschichte der Pommern in Brasilien unmittelbar in Verbindung mit der von verschiedenen anderen deutschsprachigen und europäischen Einwanderern steht. Sie wurden in denselben Kolonisationsgebieten angesiedelt und erlebten auf diese Weise einen gemeinsamen, aber je nach Kontext nicht homogenen Akkulturations- und Assimilationsprozess, der neben und vor der Akkulturation mit den Brasilianern stattfand. Als europäische Einwanderer standen sie denselben Herausforderungen gegenüber und wurden seitens der brasilianischen Regierung in Bezug auf das Gesetz auf dieselbe Weise behandelt. Die regionalen Unterschiede zwischen ihnen verloren nach der Entstehung des Deutschen Kaiserreiches 1871, besonders nach dem Rücktritt Bismarcks 1890 und durch die aggressive Verbreitung nationalistischer und volkstümlicher Ideologie an Bedeutung und trugen je nach lokalen Verhält- 
II - Die Pommern und ihre Einwanderung nach Brasilien

nissen zur Entwicklung eines bewussten oder unbewussten deutschen Nationalgefühls unter ihnen bei. Die allgemeine Bezeichnung deutsche Einwanderer galt für die verschiedenen Einwanderergruppen und wurde in der alten Heimat ebenso wie von der brasilianischen Gesellschaft verwendet.

Der Fokus der Analyse liegt auf der Religiosität der Pommern in ihrer alten Heimat und den gesetzlichen Bedingungen ihrer Ausübung im römisch-katholisch geprägten Brasilien. Diese Betrachtungen dienen als Grundlage für die anderen Kapitel.

\section{1. Überblick über die Geschichte Pommerns}

Im Folgenden soll ein Überblick über die Geschichte Pommerns Auskunft über die Religiosität, den Christianisierungsprozess, die Einführung der Reformation und ihren Einfluss auf die Entwicklung des Landes, aber auch über die Vorbedingungen zur Entwicklung von Leibeigenschaft, die die Pommern für Jahrhunderte unterdrückten, geben. Die ersten Aspekte sind besonders für die Analyse der Religiosität der Pommern im dritten Kapitel wichtig, die Unterdrückung unterer sozialer Schichten trug wiederum wesentlich zur Auswanderung der Pommern bei.

Pommern wurde zunächst von ostgermanischen Völkern (Rugier, Burgender und Goten) bewohnt, die das Land zwischen dem 3. und 6. Jahrhundert im Kontext der Völkerwanderung verließen. Zwischen dem 6. und 7. Jahrhundert ließen sich dort Slawen nieder, unter ihnen Wenden und Kaschuben, die sich mit der verbliebenen Bevölkerung vermischten. ${ }^{28}$ Die Wenden verehrten verschiedene Naturgottheiten, der wichtigste unter ihnen war Triglaw, für den ein Tempel in Stettin errichtet wurde. Sie erkannten in den Naturgottheiten dämonische Mächte und befragten sie zu Kriegs- und Erntezeiten. Mithilfe von Opfern und Ritualen versuchten sie den Zorn der Götter zu besänftigen, unter anderem durch Menschenopfer und die Darbietung der ersten Erntefrüchte. Zu ihrer Religiosität gehörten auch Hexerei-, Wahrsagungs- und Verschwörungspraktiken und der Totenkult. Auch nach der Christianisierung wurden diese Gottheiten durch Anbetung der Naturgeister weiterhin verehrt. ${ }^{29}$

Jahrhunderte lang hatten sich die Pommern den Christianisierungsversuchen widersetzt und waren nach Weingärtner eines der letzten europäischen Völker, die

\footnotetext{
${ }^{28}$ Csallner, Heinz. Bilder aus Hinterpommern. Dörfler, 2002, S. 6. Über die slawischen Stämme und Burgen siehe Schmidt, Roderich. Das historische Pommern. Köln/Weimar/Wien: Böhlau, 2009, S. $62-72$.

${ }^{29}$ Rölke, Helmar. Descobrindo Raízes. Vitória: UFES, 2016, S. 11f. Es ist im dritten Kapitel zu beobachten, wie die Pommern bestimmte Praktiken in Anlehnung an diese Religiosität in Zusammenhang mit ihrem christlichen Glauben folgten. Den Toten wurde nach ihrer ursprünglichen Religion Kleidung und Gegenstände mit ins Grab gegeben, die ihnen während ihres Lebens lieb waren. So wünschten sich die christianisierten Pommern, mit Bibel, Gesangbuch und Andachtsbuch neben anderen Gegenständen beerdigt zu werden.
} 
sich christianisieren ließen. ${ }^{30}$ Weil sie aber eine Allianz mit den deutschen Staaten, die ihnen Wirtschaftskraft und Verteidigung gegen die Polen anbieten konnten, bevorzugten, gaben sie diesen Widerstand allmählich auf. Auch der pommersche Herzog Wartislaw I. (um 1100-1148) war bereit, das Christentum als Gegenleistung für den Schutz durch die Germanen gegen die Polen zu akzeptieren.

Bereits im Jahre 1000 wurde nach dem Kriegszug der Polen, der bis an die Ostseeküste reichte, das Bistum Kolberg gegründet, das aber mit dem Tod des Bischofs Reinbern 1017 in Vergessenheit geriet. ${ }^{31}$ Größere Bedeutung hatte die Christianisierung durch den deutschen Bischof Otto von Bamberg. 1124 begann er sein Bekehrungswerk in Pyritz und setzte es in Cammin, Wollin, Stettin, Lebbin, Garz, beziehungsweise im Odergebiet, und dann in Kolberg und Belgard bis an die Persante fort. ${ }^{32}$ Unterwegs soll er elf Kirchen gegründet und 22.165 Pommern getauft haben. In Stettin wurde der Triglaw-Tempel zerstört. Laut Rölke kehrten die Pommern aber sofort zu ihrem alten Glauben zurück, sobald Otto von Bamberg ihr Land verließ. ${ }^{33} 1128$ unternahm Otto von Bamberg eine zweite Missionsreise mit Unterstützung des deutschen Königs und späteren Kaisers des Römisch-Deutschen Reiches Lothar III. (1125-1137) und bereiste diesmal das vorpommersche Territorium. Er zog von Usedom nach Wolgast und Gützkow, wo auch heidnische Tempel zerstört wurden. ${ }^{34} 1140$ wurde das Bistum Pommern errichtet und die Adalbertskirche in Wollin zum Bischofssitz bestimmt. 1147 fand ein vom Zisterzienser-Abt Bernhard von Clairvaux ausgerufener Kreuzzug gegen die Wenden statt, der jedoch von den sich zum Christentum bekennenden Pomeranen ${ }^{35}$ zurückgedrängt wurde. 1153 wurde mit Unterstützung des pommerschen Herzogs Ratibor I. († 1156) das erste Kloster in Stolpe gegründet, in das Benediktinermönche einzogen. ${ }^{36}$ Er und seine Gemahlin stifteten auch das Kloster Grobe auf der Insel Rügen, wo sich Prämonstratenser-Mönche aus

\footnotetext{
${ }^{30}$ Den Pommern wurden zwei Optionen gegeben: Entweder ließen sie sich christianisieren oder sie würden enthauptet werden. Viele ließen sich nicht taufen und wurden deswegen enthauptet. Aus diesem Grund wurden die Pommern als "pommerscher Dickkoop" bezeichnet. Weingärtner, Nelso. História da Comunidade Evangélica de Timbó. Blumenau: Otto Kuhr, 2008, S. 72. Der pommersche Herzog Wartislaw I. soll nach Überlieferungen im Jahre 1136 von einem Heiden erschlagen worden sein, denn das Volk lehnte sich aufgrund seiner unterstützenden und fördernden Position gegenüber der Christianisierung gegen ihn auf. Damitz, Hans. Stellenwert der Christianisierung Pommerns und die Bedeutung für die pommersche Kirche, Januar 1989, S. 4. Manuskript im Privatarchiv von Pastor Nelso Weingärtner.

31 Schmidt, Das historische Pommern, S. 101f; vgl. Damitz, Hans. Das alte Pommern. Manuskript von 24.9.1994, S. 2. Privatarchiv von Pastor Nelso Weingärtner.

32 Schmidt, Das historische Pommern, S. 104.

33 Rölke, Descobrindo Raízes, S. $11 \mathrm{f}$.

${ }^{34}$ Schmidt, Das historische Pommern, S. $106 \mathrm{f}$.

35 Pomeranen und Wilzen waren Wendenvölker, die jenseits und diesseits der Oder wohnten, obwohl eine genaue Abgrenzung zwischen einzelnen Völkerschaften unmöglich ist. Schmidt, Das bistorische Pommern, S. 64.

${ }^{36}$ Damitz, Stellenwert der Christianisierung Pommerns, S. 6.
} 
Magdeburg niederließen. ${ }^{37}$ Als der dänische König Waldemar I. (1157-1182) die Insel Rügen eroberte, führte er dort 1168 das Christentum für die Restbevölkerung gewaltsam ein. Auf diese Weise wurde ganz Pommern zu einem christlichen Land. 1175 wurde das Bistum von Wollin nach Cammin verlegt. ${ }^{38}$ Bald kamen auch Predigerorden nach Pommern, so dass bis 1300, als die Phase der Klostergründungen in Pommern im Wesentlichen beendet war, mehr als dreißig Klöster für Mönche und Nonnen der Prämontenser, Zisterzienser, Benediktiner, Augustinianer, Franziskaner und Dominikaner gegründet worden waren. ${ }^{39}$

Um 1500 wies das religiöse Leben in Pommern ein zwiespältiges Verhältnis auf. Einerseits herrschte eine Volksfrömmigkeit und gesteigerte Kirchentreue, die sich in einer Vielfalt von frommen Stiftungen, Wallfahrten und Heiligenkulten äußerte, andererseits wurden die Kritik an den herrschenden kirchlichen Zuständen und der Wunsch nach kirchlichen Reformen laut. ${ }^{40}$ In diesem Kontext predigte Johann Knipstro 1521 die Lehre Luthers in Pyritz. 1523 sandte Luther auf Bitte der Stettiner Ratsherren den Magister Paul von Rode als Prediger nach Stettin. 1523 begann die Reformation in Stolp durch die Tätigkeit von Christian Ketelhut und Johannes Amandus, mit dem die reformatorische Bewegung einen revolutionären Zug annahm. Um die Ordnung wieder herzustellen kam 1525 Herzog Georg I. (1493-1531) in die Stadt und erlaubte den Bürgern einen Prediger zu wählen. Sie wählten den Magister Jakob Hogensee, der nach seinem Studium in Wittenberg 1520 in Danzig predigte und dem Reformator Melanchthon nahestand. In Schwerin weilten ihrerseits seit 1522 Johann Kureke und seit 1523 Christian Ketelhut. Am Karfreitag 1525 drang eine tobende Volksmenge in die St. Nikolaikirche ein und plünderte diese. Der Mob richtete auch in den Klöstern große Verwüstungen an. Der Stadtrat gab den Ketzern die Schuld, aber da die Mehrheit der Bevölkerung sich der evangelischen Partei zugehörig erklärte, wurden ihre Repräsentanten in den Rat aufgenommen. Durch ihren Einfluss wurde die lutherische Lehre in die Stadt eingeführt. In Greifswald hielt man zunächst an der alten Lehre fest, unter anderem aufgrund des Einflusses der Universität, bis 1531 Johann Knipstro in der Nikolaikirche die erste evangelische Predigt hielt. In November wurde die letzte Messe nach katholischem Ritus vollzogen und auch in anderen Kirchen der Stadt waren evangelische Prediger tätig. Trotz aller Gegenmaßnahmen des Bischofs Erasmus von Manteuffel (1475-1544) breitete sich die

\footnotetext{
${ }^{37}$ Damitz, Das alte Pommern, S. 3.

${ }^{38}$ Schmidt, Das historische Pommern, S. 5.

39 Damitz, Stellenwert der Christianisierung Pommerns, S. Gff. Mönche ließen deutsche Ackerbauern, Handwerker und Kaufleute holen, die das Land im Umkreis der Klöster kultivierten und Städten gründeten. Aus diesem Grund trugen die pommerschen Herzöge aktiv und zielstrebig dazu bei, mehrere Klöster zu gründen und weitere deutschen Siedler ins Land zu holen. Ebd., S. 13; Damitz, Das alte Pommern, S. 4. Die planmäßige Besiedlung mit Deutschen geschah aber hauptsächlich im 13. und 14. Jahrhundert. Marzahn, Wolfgang. Erinnerungen an Hinterpommern. Leer (Ostfriesland): Gerhard Rautenberg, 1971, S. 5; auch Csallner, S. 6.

${ }^{40}$ Schmidt, Das bistorische Pommern, S. $290 \mathrm{f}$.
} 
evangelische Bewegung auch im Stiftsgebiet von Cammin aus. In Kolberg ging die Hinwendung zum neuen Glauben stärker vom Rat als vom Volk aus, so dass er sich dort zu Beginn des Jahres 1531 auch in der größten Stadt des Stiftsgebiets durchsetzte. ${ }^{41}$

Wenige Tage nach dem Tod Herzogs Georg I. beschloss der Landtag zu Stettin im Mai 1531, die evangelische Predigt frei zu geben. 1534 wurde ein Landtag in Treptow an der Rega einberufen, um über die „Unstimmigkeiten in der Erkenntnis des göttlichen Wortes ${ }^{642} \mathrm{zu}$ beraten. Zu den Vorverhandlungen wurden die evangelischen Prediger aus Stralsund, Stettin, Greifswald, Stargard und Stolp sowie Johannes Bugenhagen, ${ }^{43}$ der sogenannte „Dr. Pommeranus“, eingeladen. Ein theologisches Gutachten mit vierzehn Artikeln wurde erarbeitet, was für die Gestaltung der kirchlichen Verhältnisse in Pommern bestimmend wurde. Von Januar bis Juni 1535 führte Bugenhagen unter Beteiligung herzoglicher Räte und Hauptleuten Visitationen durch. 1535 gab er auch eine neue Kirchenordnung heraus. ${ }^{44}$ Zunächst schloss sich das Bürgertum in den Städten, dann die pommerschen Herzöge und letztlich die unteren Schichten der Reformation an. 1535 trat Pommern dem Schmalkaldischen Bund (1531-1546) bei ${ }^{45}$, obwohl es sich beim Kriegsausbruch zwischen Kaiser Karl V. (1500-1558) und den Schmalkadenern 1546 unzureichend beteiligte. ${ }^{46}$ Das auf dem Augsburger Reichstag von 1548 erlassene Interim wurde von den pommerschen Herzögen förmlich anerkannt, gleichzeitig jedoch erklärten sie sich für theologische und kirchliche Angelegenhei-

\footnotetext{
${ }^{41}$ Schmidt, Das historische Pommern, S. 292-297.

${ }^{42}$ Schmidt, Das historische Pommern, S. 298.

43 Johannes Bugenhagen wurde 24.6.1485 in Wollin geboren. Er wurde 1509 zum Priester ordiniert und wirkte an der Marienkirche in Treptow. 1517 übernahm er das biblische Lektorat im Kloster Belbuck und erhielt vom Herzog Bogislaw X. (1474-1523) den Auftrag, Materialien für eine Geschichte Pommerns zu sammeln. So entstand innerhalb eines Jahres sein Werk „Pomerania“. 1520 las Bugenhagen die Schrift Luthers „Von der babylonischen Gefangenschaft der Kirche" und wandte sich dem Wittenberger Theologen zu. 1521 siedelte er nach Wittenberg über, wurde einer der engsten Vertrauten und der Beichtvater Luthers und 1523 Stadtpfarrer und Universitätsprofessor. Bugenhagen wirkte auch im Mitarbeiterkreis Luthers an der Bibelübersetzung mit. Er starb am 20.4.1558 in Wittenberg. Kaufmann, Thomas. Reformatoren. Göttingen: Vandenhoeck \& Ruprecht, 1998, S. 57f; Schmidt, Das historische Pommern, S. 292.

${ }^{44}$ Die „Kercken ordeninge des gantzen Pamerlandes, dorch de Hochgebaren Försten und Heren, Heren Barnym und Philips, beyde gevedderen, up dem landdage tho Treptow tho eeren dem billigen Evangeho beslaten". Schmidt, Das bistorische Pommern, S. 299-301. Es wird Bugenhagen zugeschrieben, er habe die erste Übersetzung der Lutherbibel ins Plattdeutsche im Jahre 1533/1534 durchgeführt. Es handelt sich um die Lübecker Bibel: De Biblie vth der vthlegginge Doctoris Martini Luthers yn dyth düdesche vlitich vthgesettet mit sundergen underrichtingen alse men seen mach. Lübeck, 1533. Nach Goeze waren hier aber andere Übersetzer am Werk, die von Bugenhagen lediglich bei schwierigen Passagen unterstützt wurden. Die Barther Bibel, die 1588 herausgegeben wurde, ist eine überarbeitete Ausgabe der Lübecker Bibel und wurde in Pommern sehr bekannt. Goeze, Johann Melchior. Versuch einer Historie der gedrucktenniedersächsischen Bibeln vom Jabr 1470 bis 1621. Halle: Gebauer, 1775, S. 152ff, 204ff. Spätere Ausgaben der Barther Bibel wurden von pommerschen Einwanderern nach Brasilien gebracht.

${ }^{45}$ Kaufmann, Thomas. Geschicbte der Reformation in Deutschland. Berlin: Suhrkamp, 2016, S. $615 \mathrm{f}$.

${ }^{46}$ Schmidt, Das historische Pommern, S. 11.
} 
ten nicht zuständig. Als 1555 der Augsburger Religionsfriede die Gleichberechtigung des lutherischen Bekenntnis im Reich garantierte, war die Reformation in Pommern entsprechend der Formel „cuius regius, eius religio “ (wem das Land gehört, der bestimmt die Religion) gesichert. ${ }^{47}$ Die Konkordienformel von 1577 mit ihrer integrativen Lehre wurde aber in Pommern nie angenommen. ${ }^{48}$ Am Ende des 16. Jahrhunderts war Pommern ein „evangelisches, vom Luthertum geprägtes Land“, dessen Landeskirche aber nicht auf die lutherische Orthodoxie der Konkordienformel festgelegt war. ${ }^{49}$

Die Reformation trug erneut zur Annäherung der Pommern an die deutsche Kultur bei ${ }^{50}$ und mit der Gegenreformationsbewegung in Polen ab 1587 entstand eine konfessionelle Abgrenzung zwischen den Bewohnern Pommerns und Polens. Trotz des Herrschaftswechsels in den östlichen Landteilen blieb Pommern überwiegend evangelisch-lutherisch (90\%). ${ }^{51}$

Bereits vor dem Christianisierungsprozess fand der Prozess des Bauernlegens beziehungsweise die Einziehung und Besetzung kleinerer Besitze durch den Adel statt. Als Gegenleistung beschützten die Adligen die Kleinbauern, Tagelöhner und Handwerker in Kriegszeiten. Mit dem allmählichen Verlust ihrer Ländereien mussten die unteren Schichten jedoch immer mehr für den adeligen Schutz arbeiten. Die schwache Regierung, die vom Adel bei der Finanzierung ihrer Kriege abhängig war, behinderte die Entwicklung dieses Feudalsystems nicht ${ }^{52}$ und so bestand in Pommern ab der zweiten Hälfte des 16. Jahrhunderts ein Untertänigkeitsverhältnis ${ }^{53}$ durch den unteren Besitzadel. Bei der Gründung deutscher Dörfer beauftragte der Grundherr einen Unternehmer und überließ ihm dafür eine bestimmte Fläche Land, wo dieser hauptsächlich Bauern ansiedeln sollte. Die Bauern bekamen einen Hof mit etwa einer Hufe Land (eine pommersche Hu$\mathrm{fe}=19 \mathrm{ha})$ als Erbrecht zugewiesen. Die ersten Jahre waren abgabenfrei, aber sie

\footnotetext{
47 Kaufmann, Thomas. Erlöste und Verdammte. München: Beck, 2016, S. 187.

${ }^{48}$ Kaufmann, Erlöste und Verdammte, S. 306.

${ }^{49}$ Schmidt, Das historische Pommern, S. 302-306.

${ }^{50}$ Krockow, Christian Graf von. Die Reise nach Pommern. Deutsche Verlags-Anstalt, 1985, S. 200-206.

51 Pommersche Landmannschaft. Pommern, gestern, heute und morgen. Lübeck: Pommerscher Zentralverband, 1985. Traditionelle pommersche Familien mit katholischen Verzweigungen wurden am Ende „polonisiert" und andere "germanisiert". Krockow, S. 200-206. In Brasilien entstand eine ähnliche konfessionelle Abgrenzung zwischen den römisch-katholischen Brasilianern und den evangelischlutherischen Einwanderern. Ein pommerscher Nachkomme berichtet, dass er nie einen katholischen Pommern gekannt hat, alle seien lutherisch. Katholisch sei für Pommern ein Synonym für Brasilianer. Seibel, Ivan. Imigrante no século do isolamento/1870-1970. São Leopoldo: Traço, 2010, S. 249.

${ }^{52}$ Rölke, Descobrindo Raíres, S. 19; Rölke, Helmar. Raíres da Imigração alemã. Vitória: Arquivo Público do Estado do Espírito Santo, 2016, S. 59f.

${ }^{53}$ Dazu Goldschmidt, Hans. Die Grundbesitzverteilung in der Mark Brandenburg und in Hinterpommern vom Beginn des dreißigiäbrigen Krieges bis zur Gegenwart. Berlin: Carl Heymanns Verlag, 1910; Goehrtz, Emil. Das Bauernhaus im Regierungsbezirk Köslin. In: Metz, Friedrich (Hrsg.) Forschungen zur deutschen Landes- und Volkskunde. 28. Band, Heft 3. Stuttgart: J. Engelhorns, 1931, S. 244-269.
} 
mussten der Kirche den Zehnten ${ }^{54}$ und dem Grundherrn einen Zins bezahlen und Schutz- und Verteidigungsdienste leisten. Die Bewirtschaftung des Landes folgte einem genossenschaftlichen Prinzip. In Bezug auf Rechtspflege und Verwaltung besaß die Dorfgemeinschaft eine bestimmte Selbständigkeit, aber da die Bauern in immer größerer Abhängigkeit von den Grundherren gerieten, verschoben sich diese Verhältnisse im Laufe der Zeit zu Ungunsten der Bauern. ${ }^{55}$

Nach dem Dreißigjährigen Krieg (1618-1648) kam es nicht mehr zu einer Bildung des Bauernstandes. Viele Familien waren umgekommen, andere verloren mehr als die Hälfte ihres Besitzes oder wurden vertrieben. ${ }^{56}$ Der Adel nutzte diese Gelegenheit und zog viele Höfe unter eigener Verwaltung ein. ${ }^{57}$ Laut Motsch ging die Verbreitung der Leibeigenschaft ${ }^{58}$ im 16. Jahrhundert in ostelbischen Gebieten, insbesondere in Pommern, zu Lasten der bäuerlichen Besitzstellen und ihrer Rechte. Die Ausdehnung grundherrlichen Besitzes durch den Ausbau von Rittergütern beziehungsweise Vorwerkswirtschaften und in Zusammenhang damit die Einziehung von Bauernland und die Erhöhung der Frondienste und Abgaben verursachten eine Flucht oder Abwanderung der Bauern. Viele Pommern flohen

${ }^{54}$ Der Begriff bezeichnet die zehnprozentige Steuer in Form von Geld oder Naturalien an die Kir-
che.
55 Goehrtz, S. 245. Über die verschiedenen Schichten der Dorfbevölkerung siehe Münch, Ernst. 55 Goehrtz, S. 245. Über die verschiedenen Schichten der Dorfbevölkerung siehe Münch, Ernst. Mecklenburg und Vorpommern. Rostock: Hinstorff, 1995, S. 125f; Heck, Uwe; Heitz, Gerhard. Die Union der Stände von 1523. Ereignis und Folgen. In: Karge; Rakow; Wendt (Hrsg.) Ein Jabrtausend Mecklenburg und Vorpommern. Rostock: Hinstorff, 1995, S. 134; Rölke, Raizes da Imigração alemã, S. 21f, 53-57; Thiel, Uwe; Neumann, Harry. Priebkow - ein Rittergut in Hinterpommern. Witten: DIP-DigitalPrint, 2011, S. 166f. Über die Gutsherrschaften siehe Goldschmidt, S. 29-33.

${ }^{56}$ Damitz, Das alte Pommern, S. 6.

${ }^{57}$ Die Gutsherrschaften setzten bei der Wiederbesetzung der verödeten Höfe an die Stelle der früheren Erbbauern Lassiten ein, Untertanen mit gewissen Nutzungsrechten, die vom Gutsherrn gekündigt werden konnten. So setzte sich die Unterbrechung der Erblinie in Bezug auf die Nutzungsrechte in Hinterpommern fast völlig durch. Die Gutsherren vergrößerten ihren Besitz, indem sie die Arbeitskraft der Bauern weiterhin nutzten, sie jedoch zur untersten bäuerlichen Schicht herabdrückten. Gutsherren konnten auch das Land verpachten: Entweder an Pächter, die gutsuntertänige Bauern engagierten oder an Personen, die eine bauernähnliche Stellung erhielten, aber kein Recht auf die Dienste anderer Bauern hatten. In anderen Fällen entstanden Pächter aus Lassiten, deren Nutzungsbesitz zeitlich begrenzt war. Diese Pachtbauern waren in Ückermark und Pommern besonders präsent. In Hinterpommern, vor allem in den Kreisen Lauenburg und Bütow, waren ganze Dörfer von Edelleuten bewohnt, die in Vorwerken oder Bauerhöfen nach Sitte und Lebensart fast wie Bauern lebten. Goldschmidt, S. 61-63.

${ }^{58}$ Der Begriff Leibeigenschaft bezeichnet die persönliche und wirtschaftliche Abhängigkeit von einem Gutsherrn. Leibeigene waren zu Frondienste verpflichtet und standen unter der Gerichtsbarkeit ihrer Herren. Sie durften den Gutshof ohne Erlaubnis nicht verlassen und nicht ohne Genehmigung des Leibherrn heiraten. In der Regel waren sie auch Grundhörige und der Grundherr gleichzeitig Leibherr des Bauern. Grundhörige bewirtschafteten den Grund und Boden ihres Grundherrn und schuldeten ihm als Gegenleistung Naturalabgaben und Hand- und Spanndienste. Leibeigene hatten aber größere Pflichten und waren von dem Leibherrn doppelt abhängig. Ullmann, Ingo. Die rechtliche Behandlung holsteinischer Leibeigener um die Mitte des 18. Jabrbunderts. Frankfurt a.M.: Peter Lang, 2007, S. 32-35, 125, 139. 
nach Polen, besonders in der zweiten Hälfte des 16. und im ersten Drittel des 17. Jahrhunderts. ${ }^{59}$

Aufgrund seiner strategischen Position erlebte Pommern unzählige Kriege und Konflikte, die das Land mehrmals zerteilten, zerstörten, verwüsteten und neu anordneten und dabei Verarmung und Elend unter der Bevölkerung auslösten. Besonders der Dreißigjährige Krieg führte zur Verschlechterung der landwirtschaftlichen Bedingungen und einer extremen allgemeinen Not. Preußische Truppen beschlagnahmten Ernten und Zuchttiere der Bauern und die Schweden zogen bei ihnen Steuern für ihren Unterhalt ein. ${ }^{60}$ Ein großer Teil der pommerschen Bevölkerung kam ums Leben. Am Ende des Krieges dehnte Schweden seinen Besitz über ganz Vorpommern aus und Hinterpommern wurde, nach dem Aussterben des pommerschen Herzogshauses, an Brandenburg angeschlossen. 1720 trat Schweden aber Stettin und Vorpommern gegen eine hohe Entschädigung an Preußen ab. 1806 kamen napoleonische Truppen ins Land und übernahmen Stettin. Hinterpommern wurde zum Durchgangskorridor französischer Truppen und durchlitt eine neue Zerstörungswelle, während Vorpommern sich unter russischer Herrschaft befand. In den Befreiungskriegen (1813-1815) wurde Pommern von der französischen Besatzung erlöst. 1815 entstand auf dem Wiener Kongress die freie und einheitliche Provinz Pommern mit drei Regierungsbezirken: Stettin, Stralsund und Köslin. ${ }^{61}$ 1817/1818 erlangte sie den Status einer preußischen Provinz. ${ }^{62}$ Am Ende des Zweiten Weltkrieges (1945) kamen die Russen und zerstörten viele hinterpommerschen Städte und Dörfer, die überlebende Bevölkerung musste fliehen. Hinterpommern wurde an Polen angeschlossen und Vorpommern vereinigte sich mit dem Land Mecklenburg.

\section{Motive der Auswanderung}

Verschiedene Motive trieben die Pommern zusammen mit anderen deutschen Einwanderern zu einer Auswanderung nach Brasilien. Diese beinhalteten politische, soziale, ökonomische und religiöse Faktoren. Die drei ersten sind miteinander verwoben und werden aus diesem Grund zusammen betrachtet. Dafür ist kurz auf die Aufhebung der Untertänigkeitsverhältnisse einzugehen, um die ökonomischen und sozialen Folgen für das Leben der Bauern, Tagelöhner und Handwerker zu betrachten. Danach wird auch der religiöse Aspekt berücksichtigt, denn angesichts der Verfolgung einiger religiöser Gruppen bedeutete die Emigration auch die Möglichkeit, den Glauben frei auszuüben. Letztlich spielte die Auswan-

\footnotetext{
59 Motsch, Christoph. Grenzgesellschaft und frühmoderner Staat. Göttingen: Vandenhoeck \& Ruprecht, 2001, S. 40-42.

${ }^{60}$ Rölke, Descobrindo Raízes, S. 17.

61 Csallner, S. 7.

${ }^{62}$ Schmidt, Das historische Pommern, S. 17.
} 
derungsliteratur und -propaganda, besonders Auswandererbriefe mit positiven Darstellungen, eine wichtige Rolle bei der pommerschen Emigration.

Last spricht über zwei Motivationsrichtungen zur Auswanderung. ${ }^{63}$ Es gab einerseits abstoßende Motive, wie Missernten, Hungersnot, Arbeitslosigkeit, Kriege, gescheiterte Revolutionen und Perspektivlosigkeit. Andererseits lagen anziehende Motive der Emigration zugrunde, nach welcher die Emigranten eine Verbesserung ihrer bisherigen Lebenslage im Übersee erhofften. Sie wurden durch positive Berichte über das Einwanderungsland und über gute Aufstiegsmöglichkeiten begünstigt. Diese Motivationsrichtungen stehen im Hintergrund der folgenden Analyse.

\subsection{Soziale, politische und ökonomische Hintergründe}

Bereits 1719 ordnete König Friedrich Wilhelm I. (1713-1740) die Aufhebung der Leibeigenschaft auf den Domänen an und verbat das Bauernlegen, konnte sich jedoch nicht gegen den Adel durchsetzen. Auch die neue Bauernordnung von 30. Dezember 1764 versuchte die bedrückende Lage der Bauern durch die Regelung der Verhältnisse zwischen Gutsuntertanen und Herrschaft zu erleichtern. Doch die Lage der Bauern verbesserte sich nich ${ }^{64}$ und die Gutsherren besaßen zudem die Patrimonialgerichtsbarkeit über alle Gutseinwohner und übten somit eine große Machtstellung aus. Auch für die geringe Polizeigewalt waren sie verantwortlich.

Nach der Kabinettsorder von 26. Februar 1777 wurden die Bauernhöfe in den Amtsdörfern erblich. ${ }^{65}$ Doch durch die zahlreichen Landteilungen zwischen den Erben wurden die Grundstücke für den Unterhalt vieler Familien zu klein. So verpachteten sie ihr Land oder mussten für Großgrundbesitzer arbeiten. 1794 wurde das Allgemeine Preußische Landrecht in Pommern eingeführt und 1799 ordnete König Friedrich Wilhelm III. (1797-1840) für alle königlichen Domänen die Umwandlung der Bauerngüter in freies Eigentum und die Aufhebung der Leibeigenschaft an. Die Bauern konnten nun ihre bewirtschafteten Höfe gegen ein Erbstandsgeld ${ }^{60}$ erwerben und ihre Freiheit durch Geld oder Abtretung unkulti-

\footnotetext{
${ }^{63}$ Last, Arne. Die Auswanderung von Pommern nach Brasilien im 19. Jabrbundert. Greifswald: Ernst-MoritzArndt-Universität, 2011, S. 17 f.

${ }^{64}$ Über die Lebens- und Arbeitsbedingungen der Untertanen siehe Goehrtz, S. 245f; Clemens, Lieselotte. Die Auswanderung der pommerschen Alththeraner in die USA. Hamburg: Pommerscher Zentralverband, 1976, S. 99-101; Thiel; Neumann, S. 175, 229-232, 258-260, 270.

${ }^{65}$ Goehrtz, S. 246f.

${ }^{66}$ Bei der Erbpacht wurde zwischen Eigentums- von Nutzungsrecht getrennt. Das Nutzungsrecht umfasste ein veräußerliches und vererbliches absolutes Recht gegen Verpflichtung zu bestimmten Leistungen. Bei Antritt der Erbpacht zahlte der Erbpächter an den Grundeigentümer ein Erbstandsgeld, beziehungsweise eine Art Kaufgeld für das ihm überlassene Inventar. Reinicke, Christian. Pacht. In: Lexikon des Mittelalters. Band 6. München/Zürich: Artemis \& Winkler, 1993, S. 1607-1609.
} 
II - Die Pommern und ihre Einwanderung nach Brasilien

vierten Landes erkaufen. 1807 wurde diese Reform für ganz Preußen verkündet. ${ }^{67}$ 1806 wurde die Leibeigenschaft auch in Vorpommern durch den schwedischen König Gustav IV. (1792-1809) aufgehoben, aber die Umsetzung des Gesetzes verzögerte sich aufgrund der napoleonischen Kriege. Die Bauern sollen hier, nach Angaben von Damitz, zu noch weniger Landbesitz als in Hinterpommern gekommen sein. ${ }^{68}$ 1810/1811 wurden die Zünfte, die die Berufstätigkeit einschränkte, aufgehoben. Das Untertänigkeitsverhältnis wurde jedoch erst durch das Regulierungsedikt vom 14. September 1811 komplett aufgelöst. ${ }^{69}$

Die Gutsherren fürchteten sich vor finanziellen Verlusten und protestierten, dass zu viel ihres Landes den Bauern überlassen wurde. Sie forderten eine Änderung des Gesetzes, so dass 1811 ein Edikt erlassen wurde, nach welchem die Frondienste der Bauern nur gegen Abgabe von einem Drittel für erbliche und bis zur Hälfte des Bauernlandes für unerbliche Bauern mit Nutzungsrechten an den Grundherren abgelöst werden konnten. ${ }^{70}$ Die Ablösung konnte in Kapital oder Getreide geleistet werden. ${ }^{71}$ So mussten die Untertanen ihr Eigentum und die Befreiung von Diensten durch Landabtretung und Zahlung erkaufen. Die zahlreichen Konzessionen für die Großgrundbesitzer verursachten den Verlust der Hälfte oder der gesamten bebauten Ländereien der Bauern. Es gelangt nur den Mittelund Großbauern ein Grundstück als Eigentum zu erwerben und ihre Dienste durch intensive Arbeit abzulösen. Viele verschuldeten sich, weil sie die nötigen Leistungen zur Deckung ihrer Schulden nicht aufbringen konnten und wurden aufgrund hoher Steuern oder Nicht-Tilgung ihrer Schulden zur Auswanderung gezwungen. Es war üblich, dass eine Reihe von Familien derselben Gemeinde ihren Besitz verließ, um der Verfolgung durch polizeiliche Autoritäten und der Steuerbeamten $\mathrm{zu}$ entkommen. ${ }^{72}$ Die erdrückende Lage führte letztlich so zu Straftaten. ${ }^{73}$

\footnotetext{
${ }^{67}$ Damitz, Hans. Die Wirtschaftliche und gesellschaftliche Entwicklung Pommerns zwischen 1800 und 1860. In: Greifenberg-Treptower Geschichtsverein e.V. (Hrsg.) Beiträge zur Greifenberg-Treptower Geschichte. Eichstätt: Franz-Sales-Verlag, 1987, S. 47f.

${ }_{68}$ Damitz. Die wirtschaftliche und gesellschaftliche Entwicklung Pommerns, S. 51.

${ }^{69}$ Thiel; Neumann, S. 232.

${ }^{70}$ Damitz. Die wirtschaftliche und gesellschaftliche Entwicklung Pommerns, S. 49.

${ }^{71}$ Gesetzsammlung für die Königlichen Preußischen Staaten, 1811, 1816, 1829. Ausgegeben zu Berlin, S. 284, 287, 292f, 299, Regulierungsedikt \20, 40 und 58. Zitiert nach Clemens, S. 102.

72 Willems, Emílio. A Aculturação dos alemães no Brasil. São Paulo: Companhia Editora Nacional, 1980, S. 34,36 .

73 Granzow berichtet über die Familie Guse, die auf dem Rittergut Grünewald gedient hatte und nach Domingos Martins (ES) auswanderte, weil sie die Abhängigkeit von den strengen Gutsherrn und die schwere überlastende Arbeit nicht mehr ertragen konnte. Nachdem der Schwager namens Wruck erneut vom Gutsherrn ungerechtfertigt angeschrien wurde, schlug er seinen Herrn mit einem Traghebel für Wassereimer und musste fliehen. Granzow, Klaus. Pommeranos unter dem Kreuz des Südens. Słupsk: Grawipol, 2000, S. 177. Ein weiterer Tagelöhner stahl Brennholz aus dem Gutshof und suchte die Auswanderung als Fluchtweg. Rölke. Raizes da Imigração alemã, S. 285.
} 
Die Regulierung von 1816 schränkte zudem die Zahl der zugelassenen Bauernstellen durch eine Reihe von Restriktionen ein. Das Land konnte nur dann Bauern übergeben werden, wenn es seit 1763 katastermäßig erfasst und mit bäuerlichen Pächtern besetzt war. ${ }^{74}$ Nicht spannfähigen Bauern beziehungsweise kleinere bäuerliche Wirtschaften wurden von dieser Regulierung ausgeschlossen. ${ }^{75} \mathrm{Ab}$ gaben von bis zu 50\% der Ländereien an die Gutsbesitzer wurden für zulässig erklärt und Hofstellen, welche diese Auflagen nicht erfüllten, wurden zu Dienstbetrieben umstrukturiert: Wenn sie erblich waren, mussten sich Gutsherr und Bauer darüber einigen, sonst wurden diese Hofstellen den nicht-erblichen Stellen gleichgesetzt, über welche die Gutsherren frei verfügen konnten. In diesem Fall hatten sie das Recht, ihre Hofstellen nach Erlöschen des Vertragsverhältnisses Dienstfamilien aus der klein- oder unterbäuerlichen Schicht zur Verfügung zu stellen oder sie dem Gutsland hinzuzufügen. ${ }^{76}$ So verblieb ein Teil der nicht spannfähigen Bauern auf den Gutshöfen, ein weiterer Teil wurde auf dem Gut als Dienstfamilie angesiedelt und alle anderen nicht spannfähigen Bauern wanderten ins Gewerbe ab oder arbeiteten als freie Tagelöhner ${ }^{77}$, ohne sicheres Einkommen und waren somit besonders in Krisenzeiten Schwierigkeiten ausgesetzt. Die Einführung dieser Agrargesetzgebung kurz nach dem Ende der Befreiungskriege (1813-1815) in Verbindung mit Missernten trug laut Damitz zu der Hungersnot 1816/1817 bei. ${ }^{78}$ Davon waren aber eher die westdeutschen Länder betroffen und weniger die Pommern. ${ }^{79}$ Durch das Gesetz über Gemeinheitsteilungen von 1821 wurden in Preußen der unterbäuerlichen Schicht das Forst- und Weiderecht genommen. Mit der Abschaffung der kommunalen Ländereien und dem Verlust ihres kultivierten Landes wurde die Mehrheit der Bauern in die unterbäuerliche Schicht herabgesetzt, aus der Fürsorgepflicht des Gutsherrn entlassen und unzureichend ausgebildet auf den freien Arbeitsmarkt abgeschoben. ${ }^{80}$ Andere Enterbte suchten Arbeit in den industriellen Zentren im deutschen Westen.

\footnotetext{
${ }^{74}$ Damitz, Die wirtschaftliche und gesellschaftliche Entwicklung Pommerns, S. 60.

75 Thiel; Neumann, S. 233.

76 Durch die Regulierung der gutsherrlich-bäuerlichen Verhältnisse verlor der Bauernstand mit der Agrargesetzgebung etwa 4 Millionen Landmorgen an den Großgrundbesitz, Thiel; Neumann, S. 374. Über die Grundbesitzverteilung in den verschiedenen Kreisen Pommerns siehe Meißner-Zuckers. Die Landwirtschaft. In: Cronau, Curt (Hrsg.) Hinterpommern. Stettin: M. Bauchwitz, 1929, S. 24-80.

77 Die Lebens- und Arbeitsbedingungen der Tagelöhner entsprachen nach Clemens teilweise den vorherigen Untertanenschaftsverhältnissen. Der Unterschied war, dass sie nach dem Vertragsablauf eine neue Arbeit suchen mussten, was angesichts der wachsenden Arbeitslosigkeit schwieriger wurde. Clemens, S. 104, vgl. mit Lubinski, Axel. Entlassen aus dem Untertanenverband. Osnabrück: Universitätsverlag Rasch, 1997, S. 234f; Zaddach, Carl. Lothar Bucher und die Verhältnisse in Hinterpommern von 1843-1848. Heidelberg: Carl Winters Universitätsbuchhandlung, 1913, S. 23f.

78 Damitz, Hans. Pommern im 19. Jabrhundert. Manuskript, 26.9.1994, S. 2. Privatarchiv von Pastor Nelso Weingärtner. Nach dem Bericht von Wilhelm Ehlert, aus Belgard, mussten einige Familien das Essen rationieren. Altmann, Luciana. 500 Anos de Pomerode. Santa Maria: Pallotti, 2002, S. $18 \mathrm{f}$.

${ }^{79}$ Damitz, Die wirtschaftliche und gesellschaftliche Entwicklung Pommerns, S. 64.

${ }^{80}$ Clemens, S. 103.
} 
Mit der Aufhebung der Untertänigkeitsverhältnisse erlangten die Menschen die Freiheit, ohne die Erlaubnis der Gutsherren umzusiedeln. Nach dem Gewerbesteueredikt von 1810 konnte durch Einlösung eines Gewerbescheines jede Person, auch ohne einen Befähigungsnachweis, ein Gewerbe betreiben. ${ }^{81}$ So wurden viele ehemaligen Bauern zu selbständigen Arbeitern und wanderten aus ihren ursprünglichen Siedlungsgebieten ab. Handwerker arbeiteten in gewerblichen oder industriellen Unternehmen in Städten oder als Landarbeiter in umliegenden Dörfern, manchmal kam es auch zu einer Mischung beider Tätigkeiten. ${ }^{82}$ Der negative Aspekt der neu gewonnenen Freiheit war ein Überangebot an Handwerkern und Gewerblichen, die sich nicht konkurrenz- und leistungsfähig im freien Wettbewerb und in der wachsenden industriellen Massenproduktion etablieren konnten. Auch die Städte konnten das Überangebot an Arbeitssuchenden nicht absorbieren. Das führte letztendlich zu Landabtretung, Verkleinerung der Höfe, Verschuldung, niedrigen Löhnen, Arbeitslosigkeit und Verarmung. Ab den zweiten Drittel des 19. Jahrhunderts, mit dem Aufschwung der industriellen Produktion, war Handarbeit in gewerblichen Produktionen weniger gefragt, was letztlich zu einer Verbilligung gewerblicher Produkte führte. ${ }^{83}$ Viele solcher Arbeiter und Handwerker wanderten in den 1850er Jahren nach Brasilien aus, um dort ihren Beruf konkurrenzlos auszuüben und eine autonome industrielle Existenz zu gründen oder billig Land zu erwerben. ${ }^{84}$

Die Einführung neuer und intensiverer Anbau- und Erntemethoden durch die Entdeckung des Mineraldüngers, landwirtschaftliche Meliorationen, Deichbauten und den Ausbau der bis dahin ungenutzten Nutzflächen benötigte zunächst eine steigende Anzahl an Arbeitskräften. Die Landwirtschaft erlebte zudem einen Prozess der Mechanisierung und höherer Produktivität. Aber auch wenn es dadurch zu einer kurzfristigen Entspannung auf dem Arbeitsmarkt kam, konnten bald nicht mehr alle Lohnarbeiter eine Arbeit finden, denn die Verwendung der Dampfmaschinen im Gelände hob das landwirtschaftliche Dreifachsystem ${ }^{85}$ auf und ersetzte somit die Handarbeit. ${ }^{86}$ Erneut setzte Arbeitslosigkeit und dadurch bedingte Migration ein. ${ }^{87}$ Der Staat versuchte durch neue Gesetze die hohe Arbeitslosigkeit und deren Folgen zu bekämpfen, wie beispielsweise durch das Ver-

\footnotetext{
${ }^{81}$ Clemens, S. 105.

82 Lebender, Eberhard. Ein Dorf und Rittergut in Hinterpommern. Wentdorf: Selbstverlag, 2013, S. 139. Über das Leben der Bauern, Tagelöhner und Handwerker: Rölke. Descobrindo Raízes, S. 40-46; Schleinert, Dirk; Wartenberg, Heiko: Das alte Pommern, Leben und Arbeiten auf dem platten Land. Rostock: Hinstorff, 2010.

${ }^{83}$ Last, S. 21.

84 Willems, S. 33.

${ }^{85}$ Beim landwirtschaftlichen Dreifachsystem wurden die Ländereien in drei Teilen geteilt: Für die Kultivierung von Sommergetreide, von Wintergetreide und ein Stück blieb als Brachland liegen. Schleinert; Wartenberg, S. 21f; vgl. Weimar, Günter. Arquitetura Popular da Imigraşão Alemã. Porto Alegre: UFRGS, 2005, S. 37, $41 \mathrm{f}$.

${ }^{86}$ Rölke, Raíres da Imigração alemã, S. 66.

${ }^{87}$ Last, S. 50.
} 
bot der Kinderarbeit und die Beschränkung der Arbeitszeit der Kinder von über zwölf Jahren auf zehn Stunden. Zudem reorganisierte er auch das Schulwesen, das bis dahin ein Privileg des Adels und der oberen Schichten gewesen war. ${ }^{88}$ Dies alles konnte aber die Arbeitslosigkeit nicht nachhaltig eindämmen. Außerdem hatte das Bürgertum Zugang zum verhandelbaren Landbesitz und der Adel begann daraufhin bürgerliche Arbeiter zu engagieren. Frühere Landwirtschaften verwandelten sich in moderne kapitalistische Unternehmen. Im Kontext der Industrialisierung wurden tausende Kleinbauern von den Ländereien verjagt, die sie bis dahin als eine familiäre und vielfältige Landwirtschaft bebaut hatten. Als qualifizierte Arbeitskraft in einem Leistungsbetrieb taugten sie aber nicht.

Mit der Umsiedlungs- und Heiratsfreiheit in Zusammenhang mit der Entstehung eines Handels- und Agrarkapitalismus, dem Rückgang der Kindersterblichkeit und der Verbesserung der hygienischen und medizinischen Umstände, kam es ab 1800, besonders in den 1840er Jahren, zu einem enormen Bevölkerungswachstum in Pommern. Viele ehemalige Untertanen heirateten und verließen den Gutshof, zogen in die Industriezentren und größere Städte und bildeten neben dem Bürgertum ein abhängiges Industrieproletariat. Die Auswanderungswelle der ländlichen Bevölkerung in die Städte in der ersten Hälfte des 19. Jahrhunderts wird von manchen als „Landflucbt" bezeichnet. ${ }^{89}$ Der große Überfluss an Arbeitskräften konnte aber auch nicht von der Industrie kompensiert werden und Bauern galten gemeinhin als unqualifizierte Arbeitskraft. Der Überbevölkerungsfaktor, in Zusammenhang mit sozialer Desintegration, der Mobilitätsbereitschaft und -möglichkeit, der niedrigen und stagnierenden Löhne bei steigenden Preisen und Steuern und den unsicheren Lebensbedingungen, führte zu sozialen Spannungen. ${ }^{90}$ Wer nicht als Tagelöhner bei einem ehemaligen Grundherrn arbeiten oder sich als Arbeitsloser im Industrieproletariat in den Städten enden wollte, wählte die Binnenwanderung in und zwischen deutschen Staaten oder in andere europäische Länder, bis die Auswanderung einsetzte. Sie bedeutete nach Lubinski eine „Flucht vor sozialem Abstieg oder gar Elend".91 Angesichts des sozialen und wirtschaftlichen Elends und der Ausbeutung der unteren Schichten spielte den Wunsch, sein „eige-

\footnotetext{
${ }^{88}$ Rölke, Descobrindo Raízes, S. 25; Rölke, Raizes da Imigração alemã, S. 65.

89 Thiel; Neumann, S. 374; Schleinert; Wartenberg, S. 16. Die Mobilität wurde auch durch die zollpolitische Einigung aller Regionen und den Ausbau des Eisenbahnnetzes begünstigt. Es unterstützte letztendlich auch die Beförderung der Auswanderer zu den Hafenstädten. Sievers. Handel und Industrie mit besonderer Berücksichtigung des Verkehrswesens. In: Cronau, Curt (Hrsg.) Hinterpommern. Stettin: Bauchwitz, 1929, S. 81-119; Leidig. Die preußische Auswanderungspolitik. In: Philippovich, E. von (Hrsg.) Auswanderung und Auswanderungspolitik in Deutschland. Leipzig: Duncker \& Humboldt, 1982, S. 462.

${ }^{90}$ Krause, Henrique. Lutherische Synode in Brasilien. Erlangen: Verlag der Ev- Luth. Mission, 1993, S. 17.

${ }^{91}$ Lubinski, S. 247.
} 
ner Herr auf eigenem Boden zu sein",92 eine wesentliche Rolle bei der pommerschen Auswanderung. Nach Greverus:
„Das Wort Freibeit hatte hier einen weiten und für Europa unerfüllbaren Spielraum: Freiheit war nicht nur die Freiheit des politischen und religiösen Denkens, sondern es war auch die Freibeit für den ,kleinen Mann', sein erworbenes Land zu bewirtschaften, frei von Abgaben und Steuern, sein Vorwärtskommen nur abhängig von der eigenen Tüchtigkeit".93

Mit der Entstehung des Deutschen Bundes (1815-1866) wurde die deutsche adelig-bürgerliche Amtsaristokratie deutscher Staaten erhalten. Die Staatsmitglieder waren nach innen souverän, jedoch gebunden an die Mehrheitsbeschlüsse des Deutschen Bundes. Gegen dieses monarchisch-reaktionäre System forderte der bürgerliche Liberalismus einen nationalen Verfassungsstaat, der die politische Mitwirkung des Bürgertums garantieren sollte. ${ }^{94}$ Liberale Kreise strebten nach Selbstständigkeit und Unabhängigkeit gegen die absolutistische Herrschaft der Landesherren und der Staatsbürokratie und plädierten für die Festigung der säkularen Staaten mit demokratischen und republikanischen Regierungen und einer ökonomischen Autonomie. Die Nationalisten strebten ihrerseits die Herstellung der Nationalstaaten auf Basis ethnischer, kultureller, sprachlicher und moralischer Beziehungen an. Diese beiden Bewegungen fassten die damalige Unzufriedenheit der Bevölkerung zusammen. ${ }^{95}$ Außerdem überlastete die Erhaltung der Beamtenstaaten und die Kriegsfinanzierung den Staatshaushalt und die Bevölkerung konnte die Kriege ${ }^{96}$, den Wehrdienst und den Obrigkeitsdruck nicht mehr ertragen. Angesichts der Perspektivlosigkeit, Arbeitslosigkeit und Verarmung entstanden überall in den Städten Konflikte und Rebellionen. ${ }^{97}$ Die Regierungen begannen diese Bewegungen brutal zu unterdrücken und Menschen mit differenten politischen Ansichten zu verfolgen. Aus diesem Grund sahen viele Burschenschaftler,

\footnotetext{
92 Grothe, Hugo. Im Kamp und Urwald Südbrasiliens. Berlin/Halle: Buchhandlung des Waisenhauses, 1936, S. 25; vgl. Giurus, Friedrich. Meinrad Piske. Blumenau: Otto Kuhr, 1998, S. 7.

${ }^{93}$ Greverus, Ina-Maria. Der territoriale Mensch. Frankfurt, 1972, S. 137. Zitiert nach Clemens, S. 64.

${ }^{94}$ Krause, Lutherische Synode in Brasilien, S. 16.

${ }^{95}$ Martinuzzo, José Antonio. Germânicos nas Terras do Espirito Santo. Vitória: Governo do Estado do Espírito Santo, 2009, S. 30f.

${ }^{96}$ Hier sei auf die letzten Kriege hinzuweisen, die in einigen Einwandererberichten erwähnt wurden und wofür ausgewanderte Soldaten in Brasilien ausgezeichnet wurden: Die Befreiungskriege (18131815), der Deutsch-Dänische Krieg (1864), der Preußisch-Österreichischen Krieg (1866) und der Deutsch-Französischen Krieg (1870-1871). Siehe den Bericht des pommerschen Siedlers Carl Butzke aus Blumenau (SC) über seinen Dienst in der russischen Revolution und im PreußischÖsterreichischen Krieg vor seiner Auswanderung, Mein Lebenslauf und Lebenskampf. Zitiert nach Evangelische Synode von Santa Catarina und Paraná. Unsere Väter. São Leopoldo: Rotermund, 1961, S. $96,98$.

${ }^{97}$ Wie die Demagogenverfolgungen nach dem Wartburgfest 1817, die Karlsbaden Beschlüsse 1819, das Hambachfestival 1832, die Aufstände in Köln 1837 und Schlesien 1844 und besonders die Revolution von 1848-1849. Last, S. $18 f$.
} 
Akademiker, Handwerker und Arbeiter sich gezwungen, ihr Land zu verlassen ${ }^{98}$, vor allem nach dem Scheitern der Revolution von 1848. Unter ihnen befanden sich die sogenannten Brummer, Soldaten und Mitglieder der mittleren Schichten, die an der Revolution beteiligt waren und teilweise im Schleswig-Holsteinischen Krieg (1848-1851) mitgekämpft hatten. ${ }^{99}$

Vor 1871 mangelte es dem Deutschen Bund an politischer Strahlkraft, da es sich hierbei lediglich um ein Konglomerat verschiedener Staaten handelte. Brasilien repräsentierte in diesem Sinne ein weites Reich, das sich ökonomisch entwickeln konnte und einen leichten Landerwerb ermöglichte. Das bot auch Spekulanten eine Gelegenheit, da sie aufgrund des Verlustes ihrer Unternehmen nach einem neuen ökonomischen Aufstieg strebten. Aus Abenteuerlust wanderten besonders Kaufleute und Grundbesitzer aus, die von Gewinnerwartung getrieben wurden. ${ }^{100}$

Nach dem Ersten Weltkrieg emigrierten aufgrund der Kriegsfolgen andere Deutsche nach Brasilien, besonders zwischen 1920 und 1925.101 Mit der Entstehung der Weimarer Republik (1918-1933), bei welcher die Sozialdemokraten die Macht übernahmen, wanderten Anhänger der Rechtsparteien aus, die mit einem Regime mit sozialistischen Tendenzen unzufrieden waren, und ebenso Mitglieder des Spartakus Bundes, kommunistische Aktivisten, die gegen die republikanische Partei gekämpft hatten. ${ }^{102}$ Aufgrund der wirtschaftlichen und kommerziellen Beziehungen zwischen Deutschland und Brasilien in den 1920er bis 1940er Jahren wanderten besonders bürgerliche Deutsche aus. Sie erlebten in der Heimat einen starken Industrialisierungsprozess und verfügten über Kapital für die Gründung industrieller Unternehmen in Brasilien, weswegen sie auch urbane Gebiete bevorzugten. ${ }^{103}$

\subsection{Religiöse Motivation}

Viele Pommern emigrierten aufgrund ihres Glaubens, besonders in die USA. Das steht in Zusammenhang mit der Einführung der „Union“ in Preußen und mit der Entwicklung altlutherischer Gemeinden und Erweckungsbewegungen, worauf kurz einzugehen ist. Aus der Tätigkeit mancher Pommern bei der Vollziehung von Lesegottesdiensten und kirchlichen Amtshandlungen angesichts des Pfarrmangels

\footnotetext{
${ }^{98}$ Last, S. 14, 18f. Einige siedelten sich in Santa Cruz do Sul (RS) und Dona Francisca-Joinville (SC). Willems, S. 36f.

99 Schulze, Frederik. Auswanderung als nationalistisches Projekt. Köln/Weimar/Wien: Böhlau, 2016, S. 93.

100 Last, S. 19.

101 Verband für Evangelische Auswandererfürsorge 1926, S. 13. In: MLV 51/17 60.

102 Willems, S. 37; Dreher, Martin Norberto. Igreja e Germanidade. São Leopoldo/Porto Alegre/Caxias do Sul: Sinodal/Escola Superior de Teologia São Lourenço de Brindes/Universidade de Caxias do Sul, 1984, S. 36.

103 Perazzo, Priscila Ferreira. O Perigo Alemão e a Repressão Policial no Estado Novo. São Paulo: Divisão de Arquivo do Estado, 1999, S. 58.
} 
und der Entwicklung von Freigemeinden, die sich nicht einer kirchlichen Institution unterordnen wollten, lässt sich aber feststellen, dass Altlutheraner, neben den USA, auch nach Brasilien auswanderten.

Durch den Einfluss des Rationalismus entwickelte sich die Kirche im schwedischen Pommern (Vorpommern) zu einer staatlich reglementierten Kirche. Im preußischem Pommern (Hinterpommern) vertraten die Könige eine tolerante Position unter Lutheranern und Reformierten. ${ }^{104} 1701$ wurde Preußen Königreich und der preußische König Friedrich I. (1701-1713) gleichzeitig Oberhaupt der Landeskirche. ${ }^{105}$ Weil der Streit der lutherischen Orthodoxie gegen die Reformierten im 16. und 17. Jahrhundert beendet war, der Pietismus sich kaum mit konfessionellen Unterschieden befasste und der Indifferentismus der Aufklärung und des Rationalismus die konfessionellen Unstimmigkeiten nivellieren ließ, fand der preußische König Friedrich Wilhelm III. (1797-1840) günstige Vorbedingungen für die Einführung der kirchlichen Union anlässlich der 300. Reformationsfeier im Jahre 1817. 1822 wurde die „Agenda für die Evangelische Kirche in den Kgl. Preuß. Landen" herausgegeben. 106 Fast alle pommerschen Gemeinden führten die unierte Agenda 1827 ein und traten 1830 der Union bei. ${ }^{107}$ Nüssel weist aber darauf hin, dass die Union in bestimmten Staaten rein institutionell und organisatorisch funk-

\footnotetext{
${ }^{104}$ Damitz, Die Kirche im Land, S. 4. Manuskript im Privatarchiv von Pastor Nelso Weingärtner. ${ }^{105}$ Schulz, Petra Karin Ursula. Tribsow. Ein Dorf in Hinterpommern. Husum: Husum Druck- und Verlagsgesellschaft, 2010, S. 15.

106 In Anlehnung an die Bemühungen seines Vorgängers, der am Anfang des 18. Jahrhunderts die altkirchliche und für alle Konfessionen akzeptierbare anglikanische Liturgie und Kirchenverfassung in Preußen einzuführen versuchte, entwarf Friedrich Wilhelm III. seit 1815 verschiedene Modelle einer altkirchlichen Liturgie. Eine erste Fassung wurde an Hof- und Domkirchen seit 1815 erprobt und Ende 1816 als Militärliturgie verbindlich gemacht. Mit der Einführung der Union 1817 schien kein Hindernis mehr für die Neubearbeitung einer Agenda im Weg zu stehen. Seit 1819 arbeitete der König an der Rekonstruktion des altkirchlichen Gottesdienstes auf Grundlage der Messformulare Luthers. So erstellte er 1821 eine Einheitsliturgie, die hauptsächlich dem Aufbau der reformatorischen Messe folgte und darüber hinaus Elemente der katholischen, reformierten und russischorthodoxen Messe vereinigte. Diese Liturgie sollte die Einheit der protestantischen Konfessionen vollenden und die Idee eines überkonfessionellen Christentums als Grundlage der Heiligen Allianz zwischen Preußen, Österreich und Russland verkörpern. Auch der Plan einer staatlichen Normalkirche für die Errichtung des Berliner Doms und von mittleren und kleinen Kirchen im Jahre 1827 diente zur Durchsetzung einer überkonfessionellen und staatlichen Einheitskirche in Preußen und zur Fortsetzung der königlichen Religionspolitik. 1827 veröffentlichte der König auch seine Denkschrift „Luther in Beriebung auf die preussische Kirchenagenda". Damit wollte er nachweisen, dass die neue Agenda mit den von Luther gereinigten Anfängen des christlichen Kultes übereinstimmte. Schubert, Anselm. Religiöse Restauration und technische Rationalisierung. In: Historische Zeitschrift. Bd. 297, Nr. 1. Berlin: de Gruyter Oldenbourg, 2013, S. 73, 79f.

107 Heyden, Hellmuth. Zur Geschichte der Kämpfe um Union und Agende in Pommern. In: Büttner, Heinrich; Von Campenhausen, Hans Frhr; Fink, Karl August; Schneemelcher, Wilhelm; Wolf, Ernst (Hrsg.) Zeitschrift für Kirchengeschichte. 4. Folge IX, LXXI. Band, 1960. Stuttgart/Berlin/ Köln/Mainz: Kohlhammer Verlag, S. 288f. Clemens, S. 15-17, 24f.
} 
tionierte und konfessionelle Besonderheiten in Gemeinden weiterhin Bestand hatten. ${ }^{108}$

In Schlesien und Pommern erhob sich jedoch Widerstand gegen die Entstehung einer Unierten Kirche und gegen den Antrag der Berliner Geistlichkeit beider Konfessionen zur Aufnahme des Namens evangelische statt reformierte oder lutherische Kirche. ${ }^{109}$ Die separierten Lutheraner fühlten sich in ihrer Glaubens- und Gewissensfreiheit beschränkt, wollten ihre Glaubensansätze und Liturgie behalten und lehnten andere Glaubensrichtungen oder Zugeständnisse ab. ${ }^{110}$ Dieses strenge Luthertum zeigte besondere Aufgeschlossenheit für den Konfessionalismus und fand in der Erweckungsbewegung seinen Ursprung. ${ }^{111}$ Im Juni 1830, als die Union definitiv anlässlich der 300. Jubiläumsfeier der Augsburgischen Konfession eingeführt wurde, entstand in Breslau die erste Gemeinde der unionsfreien lutherischen Kirche, die ab 1845 als Altlutheraner und altlutherische Kirche bezeichnet wurde. Sie sahen in einem Anschluss an die Evangelische Landeskirche eine Abweichung vom wahren lutherischen Glauben und bestanden auf eigenen Geistlichen, Lehrern und ihrer eigenen Liturgie. ${ }^{112}$

Die Regierung verfolgte die Altlutheraner mit dem Verbot ihrer Gottesdienste, Suspendierung, Aufhebung oder Inhaftierung altlutherischer Pastoren und Beschlagnahmung oder gewaltsamer Enteignung von Kirchen oder kirchlichen Gebäuden. Notgottesdienste in Privathäusern, Scheunen, Wäldern, Steinbrüchen, Sandgruben etc. standen unter Geldstrafe und mittellose Mitglieder wurden gepfändet. Weitere ökonomische Sanktionen wurden ihnen auferlegt und ihre Schulen geschlossen. ${ }^{113}$ Alle Bemühungen um die Anerkennung ihres Glaubens wurden abgewiesen, was den Widerstand der Altlutheraner noch stärkte. Seit 1834 bildeten sich altlutherischen Gemeinden außerhalb Schlesiens und 1835 verbreitete sich die Bewegung in Pommern. ${ }^{114}$ Erst 1845 erkannte die preußische Regierung die Altlutheraner an, jedoch nicht als Kirche. Es wurde ihnen lediglich die freie Ausübung ihres Gottesdienstes gestattet. ${ }^{115}$

Die Notzeit nach den Befreiungskriegen in Verbindung mit der Reaktion antirationalistischer Kreise gegen ein oberflächliches Christentum und die Einführung der Union erweckte in den Menschen ein bewussteres Glaubensleben. So sammelten sich kleine Gruppen von Handwerkern und Gutsleuten, die sich die „Stillen im

\footnotetext{
108 Nüssel, Friederike. Unionen, kirchliche. In: Betz, Hans Dieter; Browning, Don S.; Janowski, Bernd; Jüngel, Ebenhard (Hrsg.) Religion in Geschichte und Gegenwart. 4. Auflage, Bd. 8 Tübingen: Mohr Siebeck, 2005, S. 750f.

${ }_{109}$ Clemens, S. 16.

${ }^{110}$ Damitz, Die wirtschaftliche und gesellschaftliche Entwicklung Pommerns, S. 64f.

111 Clemens, S. 17, 20 f.

112 Clemens, S. 21; Mühle, S. 266.

113 Clemens, S. 21f; Schulz, S. 85.

114 Clemens, S. 22f.

115 Wachholz, Wilhelm. Luterano? Reformado? Unido? Evangélico! In: Evangelho, Bíblia e Escritos Confessionais. São Leopoldo: Escola Superior de Teologia, 2004, S. 107.
} 
Lande" nannten, zur Andacht und seelischer Stärkung. ${ }^{116}$ In Stettin bildete sich bereits 1816 eine Bibelgesellschaft, die als "Freunde der reinen Lehre" bezeichnet wurde. ${ }^{117}$ In Berlin versammelte sich eine Gruppe ehemaliger Freiheitskämpfer unter dem Namen „Laien in der Kirche“, um über Politik und Religion zu diskutieren. ${ }^{118}$ Ernst Moritz Arndt war wiederum auf der Insel Rügen tätig. Die Erweckung durch das Evangelium entwickelte sich zu einer Bewegung, die sich vor allem im östlichen Pommern und anderen Gebieten ausbreitete. Hauptorte der Erweckungsbewegung in Pommern, wo sich Konventikel gebildet hatten, waren Cammin (Dörfer Fritzow, Jassow, Polchow und Königsmühl), Stolp und Greifenberg. Sie lehnten den rationalistischen Geist ab und öffneten sich dem Konfessionalismus der Altlutheraner. Obwohl sie zur Landeskirche gehörten, hielten sie ihre Gottesdienste im Sinne der Erweckung, weswegen sie auch unter Beobachtung staatlicher und kirchlicher Behörden standen.

Die Güter der Brüder Gustav, Heinrich und Carl von Below bei Stolp waren um 1820 Mittelpunkt einer Erweckungsgruppe in den Kreisen Schlawe (Gut Seehof in Pennekow), Wollin und Naugard in Pommern. Zunächst hielten sie Gottesdienste und Andachten in ihren Gutshäusern an Sonn- und Feiertagen ab. Bei diesen Anlässen interpretierten sie die Bibel und andere Predigten und beteten frei. Die Anzahl der Teilnehmer, besonders Gutsarbeiter, Schäfer und Handwerker, vermehrte sich im Laufe der Zeit so stark, dass sie sich im Hof oder Garten versammeln mussten. ${ }^{119}$ Das war ein Novum, denn bis dahin war eine Gemeinschaft mit Menschen aus verschiedenen Gesellschaftsschichten eher ungewöhnlich. Auch Mitglieder der unteren Schichten entwickelten sich zu Predigern und Wortführern. ${ }^{120}$ Zunächst wehrten sie sich nicht gegen die Union und ihre Agenda, aber als sie die rationalistischen Pastoren nicht für ihre Erweckung gewinnen konnten, spalteten sie sich von der Kirche ab. Ihre Versammlungen standen unter polizeilicher und kirchlicher Beobachtung, sie mussten Geldstrafen zahlen, ihr Besitz wurde gepfändet oder sie wurden eingesperrt. ${ }^{121}$ Bis zur Mitte des 19. Jahrhunderts erstreckte sich die Erweckungsbewegung auf Dörfer zwischen Stolp, Bütow und der Ostsee, zwischen Rügenwalde und Stolpmünde. Bald danach trat sie auch in anderen Gegenden Pommerns auf.

\footnotetext{
${ }_{116}$ Marzahn, S. 9.

117 Damitz, Pommern im 19. Jabrbundert. 10.3.1991, S. 9; Damitz, Die Kirche im Land, S. 5.

118 Marzahn, S. 9.

119 Marzahn, S. 11.

120 Damitz, Die Kirche im Land, S. 6.

${ }^{121}$ Clemens, S. 27f. Nach Angaben von Clemens entstand unter den Brüdern von Below ein gewisser Fanatismus schwärmerischen Charakters. In ihren Versammlungen geschahen Visionen, Verzückungen, Weissagungen, Krankenheilungen und Exorzismen und es wurde sogar in Zungen geredet. Sie bildeten eine in sich selbst geschlossene Gemeinde und trennten sich von der Landeskirche, bevor sie unter den Einfluss der Altlutheraner gerieten.
} 
Unter dem Tischler Zühlsdorf, der seit 1835 Konventikelprediger in Cammin war und sich mit seinen Anhängern vom Armenschullehrer Bagans trennte ${ }^{122}$, begann die erste Hinwendung zum Altuthertum in Pommern. Zusammen mit dem Lehrer Luck aus Bünnewitz trat er für die altlutherische Kirche ein. Im August 1835 unterstellten sich seine Anhänger der Breslauer Synode. Bald drang die altlutherische Bewegung in andere Orte des Camminer Kreises und umfasste die Nachbarkreise Wollin und Naugard. ${ }^{123} 1836$ schlossen sich Heinrich von Below und seine Anhänger ebenfalls der Breslauer Synode an. Weil sie sich aber nicht der strengen Ordnung der Altlutheraner unterordnen konnten, trennten sie sich 1841 von Breslau und konstituierten eine separate lutherische Gemeinde mit eigener Verfassung und etwa 1.500 Mitgliedern. ${ }^{24}$

Im Kreis Greifenberg an der Rega begann die Erweckungsbewegung durch den Gutsbesitzer Adolf von Thadden in Triglaff und durch seinen Schwager Ernst von Senfft-Pilsach, den sogenannten "Scheunenprediger" in Rottnow. Dieser hielt neben Hausandachten auch Erbauungsstunden. Beide wandten sich gegen die preußische Agenda und gegen den aufklärerischen Zeitgeist der Pastoren. Adolf von Thadden holte Erweckungsprediger für Hausandachten auf sein Gut und seine Versammlungen wurden von adligen Freunden, gleichgesinnten Pastoren, Menschen verschiedener Berufe, Gutsarbeitern und Dorfbewohnern besucht. Seit 1829 fanden regelmäßige Konferenzen in Triglaff statt, zu denen Pastoren aus dem gesamten norddeutschen Raum anreisten und sich zur Bibelarbeit und Besprechung der kirchlichen Lage und des Gemeindelebens trafen. ${ }^{125} 1848$ schloss sich von Thadden den Altlutheranern an. Zunächst durften beide Parteien, die landeskirchlich orientierten und die Altlutheraner, die Dorfkirche zu verschiedenen Tagesstunden nutzen. Weil erstere aber den Altlutheranern das Nutzungsrecht für die Kirchengebäude entziehen wollten und weil die altlutherische Gemeinde anhaltend wuchs wurde 1855 eine neue Kirche mit Hilfe von Thaddens gebaut. ${ }^{126}$ Um Pastor Görcke bildete sich eine große Gemeinde in Pyritz, die sich intensiv mit Bibelauslegung befasste und sich als besonderer Kreis innerhalb der lutherischen Kirche verstand. Weil Görcke als Pastor nach Zarben versetzt wurde, breitete sich die Gruppe nach Treptow, Kreis Greifenberg und in Wusterwitz, Kreis Dramburg aus, wohin sein Schwager Pastor Gustav Knack berufen wurde. ${ }^{127}$ In beiden Stellen hielten Familien unter dem Einfluss dieser Pastoren Hausandachten, lasen die Bibel und sangen christliche Lieder. Zahlreiche Menschen kamen in diesen Bibelstunden zusammen und ließen sich im Glauben stärken. Nach Damitz

\footnotetext{
122 Heyden, S. 300f.

123 Clemens, S. 26f

${ }^{124}$ Heyden, S. 315-317; Clemens, S. 32.

125 Clemens, S. 28-30; Damitz, Pommern im 19. Jabrbundert und die Auswanderung der Pommern, S. 5. Manuskript von 29.9.1994. Privatarchiv von Pastor Nelso Weingärtner; Damitz, Die Kirche im Land, S. 6f; Von Thadden, Rudolf. Trieglaff. Göttingen: Wallstein, 2010, S. 27-42, 63-69.

126 Von Thadden, S. 64f.

${ }^{127}$ Damitz, Pommern im 19. Jabrbundert, 10.3.1991, S. 10.
} 
wurden Gustav Knack und Moritz Görcke Wegbereiter für die „Landeskirchliche Gemeinschaft". 128

Laut Krause bemühten sich diese Erweckungsbewegungen um die Wiederherstellung der Einheit zwischen christlicher Lehre und Leben und der lutherischen Reformation. Sie versuchten durch eine neue Bibelfrömmigkeit und den Widerstand gegen den rationalistischen Vernunftglauben die Einseitigkeit der Orthodoxie und des Pietismus zu überwinden und betonten gegenüber dem Aufklärungschristentum eine persönliche Frömmigkeit und Rückbesinnung auf das ursprüngliche biblische Christentum. Weil sie sich an keine feste Kirchenordnung oder äußeren Formen hielten, überschritten sie politische, konfessionelle und territoriale Grenzen. Konfessionelle Grenzen innerhalb der Bewegung traten jedoch bald hervor, so dass in einigen Gebieten Deutschlands doch ein Übergang von der Erweckungsbewegung zum konfessionellen Luthertum in kirchlichen Kreisen um Wilhelm Löhe, Adolf Petri, Ludwig Harms und anderen stattfand. ${ }^{129}$

Das religiöse Motiv betraf vor allem die pommersche Emigration in die USA. Aufgrund der staatlichen Verfolgung und Unterdrückung gegen Altlutheraner und Erweckungsgruppen wanderten ganze Gemeinden dorthin aus. ${ }^{130}$ Dies spielte aber sicherlich auch eine Rolle bei der Auswanderung nach Brasilien, wie aus dem Beispiel der Hausgemeinden, wo Elemente der Erweckungsbewegung und des konfessionellen Luthertums erkennbar sind, und der Freigemeinden noch zu sehen sein wird. Als der Gotteskastenverein Missionare nach Brasilien sandte, identifizierten sich viele Pommern mit dem lutherischen Konfessionalismus - ein weiterer An-

\footnotetext{
${ }_{128}$ Damitz, Die Kirche im Land, S. 7f; Marzahn, S. 11-13, 29.

${ }^{129}$ Krause, Lutherische Synode in Brasilien, S. 21f. In der Mitte des 19. Jahrhunderts wurde die Erlanger Universität der Ausgangs- und Kristallisationspunkt der strenglutherischen Erneuerung neben Rostock, Leipzig, Dorpat (Estland) und die Erweckungszentren Neuendettelsau und Hermannsburg. Die Gotteskastenvereine standen in Zusammenhang mit dem konfessionellen Luthertum und seiner Diasporapflege. Sie sträubten sich gegen die preußische Kirchenunion und sendeten später viele Missionare zu den pommerschen Gemeinden in Brasilien. Ebd., S. 25.

${ }_{130}$ Schulz, S. 85. Nach Heyden verließen zwischen 1831 und 18431.791 Menschen ihre pommersche Heimat aus religiösen Gründen. Heyden, S. 306. Von 1837 bis 1845 gingen etwa 1.881 Altlutheraner nach Nordamerika, vor allem aus den Kreisen Kammin und Randow. Mühle, Rainer. Zur Geschichte der Auswanderung aus Pommern im 19. Jahrhundert. In: Karge, Wolf; Rakow, PeterJoachim; Wendt, Ralf. (Hrsg.) Ein Jabrtausend Mecklenburg und Vorpommern. Rostock: Hinstorff, 1995, S. 265. Allein im Juli 1839 waren es etwa 570. Rölke, Descobrindo Raizes, S. 33. Zwischen 1831 und 1840 gaben 564 Personen aus dem Regierungsbezirk Stettin ihren Glauben als Auswanderungsgrund an, im Vergleich zu 153, die wirtschaftliche Motive angaben. In den beiden folgenden Jahren waren es 1.225 Personen, die des Glaubens wegen emigrierten. Auffällig ist, dass religiöse Beweggründe fast ausschließlich aus dem Regierungsbezirk Stettin, vor allem aus den Kreisen Cammin und Greifenberg angegeben wurden. Zwischen 1835 und 1843 gaben nur 78 Personen aus dem Bezirk Köslin ihren Glauben als Auswanderungsgrund an, während zwischen 1840 und 1843 niemand aus dem Bezirk Stralsund Glaubensgründe für die Emigration angab. Diese Zahlen umfassen aber nur Menschen, die mit Entlassungspapieren auswanderten. Stock, Otto. Die Auswanderung aus Pommern bis zum Jahre 1871. In: Monatsblätter der Gesellschaft für pommersche Geschichte und Altertumskunde, Bd. 5, 1934, S. 68, 72. Zitiert nach Last, S. 52f.
} 
haltspunkt für frühere Erweckungserfahrungen oder Partizipation in altlutherischen Gemeinden.

\subsection{Einwanderungspropaganda}

Nach der Analyse sozialer, wirtschaftlicher, politischer und religiöser Faktoren, die zur Auswanderung beitrugen, soll nun auf die Berichte und Darstellungen über die Perspektiven und Lebensbedingungen in Brasilien eingegangen werden, die besonderen Einfluss auf die Auswanderung hatten. Angesichts der wachsenden Suche nach Auswanderungsmöglichkeiten entwickelte sich eine Emigrationsindustrie, zu welcher Schriften, Auswanderungsvereine, Agenturen, Reedereien, die Wahl der Reiserouten, die Ein- und Auswanderungspolitik der jeweiligen Länder, verkehrslogistische Gegebenheiten ${ }^{131}$, Werbezettel und Auswandererbriefe gehörten.

Brasilien begann erst ab 1818 und 1824 als Auswanderungsziel attraktiv zu werden. ${ }^{132}$ Zunächst kamen nur einige wenige Personen, unter ihnen nur vereinzelte Pommern dorthin. Bald setzten sich die Zentral- und später auch die Provinzialregierungen Brasiliens durch eine Reihe von Verordnungen und Gesetze für die Immigration ein. ${ }^{133}$ Die Zentralregierung bezahlte Agenten für die Rekrutierung von Einwanderern, wie der prominente Major von Schäffer ${ }^{134}$ oder später der Redakteur der Hamburgischen Zeitung für Auswanderungs- und Kolonisationsangelegenbeiten Wilhelm Hühn ${ }^{135}$, und versprach den Auswanderern freies und teils unbe-

\footnotetext{
${ }^{131}$ Last, S. 24.

132 Krause, Lutherische Synode in Brasilien, S. $17 \mathrm{f}$.

133 Avé-Lallemant, Robert. Reise durch Südbrasilien im Jahre 1858. 1. Teil. Leipzig: F. A. Brockhaus, 1859, S. 465f. Eine Auflistung mit Verträge zwischen der kaiserlichen Regierung und den verschiedenen Kolonisationsgesellschaften befindet sich in Carvalho, Augusto de. O Brazil. Colonisação e Emigração. Porto: Imprensa Portuguesa, 1876, S. 511.

134 Georg Anton von Schäffer, geboren am 7.1.1779 in Münnerstadt, gestorben in Jacarandá, Provinz Bahia (BA) - Brasilien, lebte nach einer Reise nach Alaska und Asien in Rio de Janeiro (RJ) und genoss seitdem das Vertrauen der Prinzessin Leopoldina und des Ministers José Bonifácio. Der Prinz-Regent nahm ihn als Major in seiner Ehrengarde auf. Er reiste nach Deutschland mit dem Auftrag, deutsche Soldaten, Bauern und Handwerker für Brasilien anzuwerben. Dreher, Martin Norberto. Sträflinge aus Mecklenburg-Schwerin und die Anfänge deutscher Einwanderung in Brasilien. São Leopoldo: Oikos, 2010, S. 9f.

${ }^{135}$ Wilhelm Hühn rekrutierte Einwanderer für die privaten Kolonien São Lourenço do Sul (RS) und Blumenau (SC). 1857 reiste der Kolonisator Jakob Rheingantz nach Europa und verhandelte persönlich mit seiner Firma, um Einwanderer für seine Kolonie zu gewinnen. Bosenbecker, Patricia. Uma colônia cercada de estâncias: Porto Alegre: Universidade Federal do Rio Grande do Sul, 2011, S. 44. Kolonisten aus Blumenau (SC) empfahlen ihn durch Briefe an Freunde in Deutschland und bezeichneten ihn als zuverlässigen Vermittler. Hamb. Zeit. für Auswanderer 1857, Nr. 20. Brief aus Blumenau vom 19.12.1857. Zitiert nach Schröder, Ferdinand. Die deutsche Einwanderung nach Südbrasilien bis zum Jahre 1859. Berlin: Ev. Hauptverein für Deutsche Ansiedler und Auswanderer, 1930, S. 94f. Köbling berichtet, dass eine Agentur in Hamburg für die Anwerbung von Einwanderern, besonders Pommern und Rheinländer, für die private Kolonie São Lourenço do Sul (RS) gegründet wurde.
} 
waldetes Land mit einem vorläufigen Haus, freie Überfahrt, Zuchttiere, Saatgut und zweijährige finanzielle Beihilfen. ${ }^{136}$ Die Pommern wählten besonders ab 1859 Brasilien neben Russland, Australien, Kanada oder Südafrika als Einwanderungsland statt der USA aufgrund der nordamerikanischen Wirtschaftskrise 1859 oder des Bürgerkriegs (1861-1865). ${ }^{137}$ Nach der Gründung des Deutschen Reichs 1871 gefiel die Auswanderung in den Vereinigten Staaten auch nicht mehr, weil die Emigranten sich dort bald assimilieren ließen. ${ }^{138}$

Last erwähnt ein dreistufiges Auswanderungsgeschäft in den 1830er Jahren. Zunächst schlossen die Agenten Verträge mit den Reedereien zur Beförderung von Auswanderern ab. Die Agenten verfügten über Agentur-Niederlassungen in den Hafenstädten und ernannten Hauptagenten für die Eröffnung von Filialen in den wichtigsten Städten. Die Hauptagenten stellten Unter- oder Mittelagenten in kleineren Städten und Dörfern ein, oft ehemalige Auswanderer, um die Zielorte glaubwürdig darstellen zu können. Die Agenten erhielten bei der Vermittlung von Auswanderungswilligen eine Pauschale für jeden Einwanderer, weswegen sie möglichst viele anwerben wollten, wenn auch teilweise durch skrupellose Werbemethoden und mit Hilfe unhaltbarer Versprechungen. ${ }^{139}$ Ein pommerscher Nachkomme berichtet zum Beispiel, dass 1872, als er als Kind gemeinsam mit seiner Familie nach Brasilien auswanderte, ein Agent namens Knorr aus Hamburg seinen Vater gebeten hatte, möglichst viele Menschen zur Auswanderung zu bewegen, denn Brasilien wäre das ,beste Land für die Armen“."140

Die Tätigkeit verschiedener Einwanderungsagenten in Pommern konnte besonders in der zweiten Hälfte des 19. Jahrhunderts nachgewiesen werden. ${ }^{141}$ Der Gärtner August Klein aus Mersin, Regierungskreis Köslin wurde von einem Mittelagenten überredet, nach Blumenau (SC) auszuwandern. ${ }^{142}$ Für weitere 22 Auswanderer aus den Kreisen Rügen und Greifswald vermittelte ein gewisser Kaufmann Lobeck aus Demmin die Reise nach Brasilien. ${ }^{143}$ Ein Schreiben des preußi-

Köbling, Fritz. Die Kolonie São Lourenço im Staate Rio Grande do Sul. In: Deutsche Post, São Leopoldo, 18.11.1908, Nr. 3355, EZA 121/19.

136 Seidler, Carl. Zehn Jahre in Brasilien während der Regierung Dom Pedro's und nach dessen Entthronung. Quedlinburg/Leipzig: Gottfr. Basse, 1835, S. 168; Schröder, Ferdinand. Brasilien und Wittenberg. Berlin/Leipzig: De Gruyter, 1936, S. 13f, 28f; Bericht des Koloniedirektors Dr. Hillebrandt über die Gründung der Kolonie São Leopoldo. Rev d. Arch. Publ. do Porto Alegre, 1924, S. 346ff. Zitiert nach Schröder, Die deutsche Einwanderung nach Südbrasilien, S. 46; Josenhaus (Hrsg.) Der Evangelische Heidenbote, Nr. 4, April 1864. Basel: Felix Schneider, S. 37.

${ }^{137}$ Mühle, S. 269-271; vgl. Kahle, S. 33.

138 Sudhaus, Fritz. Deutschland und die Auswanderung nach Brasilien im 19. Jabrbundert. Hamburg: Hans Christians, 1940, S. 150.

139 Last, S. 26.

140 Zummach, Marta. O que minha vovó me contava. In: Der Junge Kämpfer, ano 2, Nr. 8, 1936. Zitiert nach Rölke, Raíres da Imigração alemã, S. 254.

141 Last, S. 8.

142 PLAG Rep. 65c Nr. 169.

143 PLAG Rep 65c Nr. 162. 
schen Innenministeriums an die Bezirksregierung Köslin 1876 machte auf einen gewissen Wilhelm Hasemann aufmerksam, der zuvor zwei Jahren in Brasilien gewesen war und nach seiner Rückkehr Auswanderungswillige für Brasilien in Dramburg, Falkenburg und Tempelburg anwarb. Von der Polizei entdeckt, musste er eine Haftstrafe verbüßen, warb nach seiner Entlassung aber weitere Emigranten an. ${ }^{144}$ Über den Regierungsbezirk Stettin sind keine Informationen vorhanden. Weil Agenten in Pommern nur geringe Aktivitäten nachgewiesen werden konnten, ist anzunehmen, dass die Auswanderer bis zu den Hafenstädten reisten und dort ihre Passageverträge bei Expedienten, wie beispielsweise Lobedanz, Louis Knorr und Comp. etc., aushandelten. ${ }^{145}$ Viele Emigranten ließen sich nach Gaebler erst von den Auswandererbüros in den Hafenstädten über mögliche Einwanderungsziele beraten. ${ }^{146}$ Andere wurden heimlich oder mithilfe von Unteragenten der Nachbarstaaten angeworben. ${ }^{147}$

Auswanderungsvereine, die vielerorts seit Anfang der 1840er Jahren entstanden, übten eine beratende und belehrende Funktion aus und vermittelten Informationen über Emigrationsmöglichkeiten, Gesetzesbestimmungen und Transport. Sie warnten teilweise vor der Anwerbung von Agenten und vor Auswanderungsverträgen, versuchten jedoch die Emigration nach ihren eigenen Interessen und Gewinnen in bestimmte Gebiete zu lenken. Sie arbeiteten manchmal mit Kolonisationsvereinen oder Abgesandten der Regierungen zusammen. ${ }^{148}$ Laut Daemon ermöglichte das Landwirtschaftsministerium den Auswanderern erst ab 1871 durch Rundschreiben an die brasilianischen Konsule in Europa, dass Niederlassungsorten in Brasilien ausgewählt werden konnten. ${ }^{149}$

Seit Beginn des 19. Jahrhunderts kann eine Auswanderungsliteratur nachgewiesen werden, die sich aufgrund der Massenauswanderung ab der zweiten Hälfte des 19. Jahrhunderts umso stärker verbreitete und über Chancen und Gefahren informierte. ${ }^{150}$ Kolonisationsgesellschaften, Staaten, Koloniedirektoren, Agenten,

\footnotetext{
${ }^{144}$ SAS: Starostwo Powiotowe Bialogard Nr. 125, Blatt 26. Zitiert nach Last, S. 66.

145 Last, S. 72. Über die Kritik an Händler, Reeder, Vermittler und Expedienten siehe: Stenographische Berichte des Hauses der Abgeordneten, 1859, Bd. 2, S. 888. Zitiert nach Sudhaus, S. 113; Last, S. 56; Rölke, Raizes da Imigração alemã, S. 101f, 271.

146 Gaebler, Deutsche Auswanderung und Kolonisation. Erster Rechenschaftsbericht des Berliner Vereins zur Centralisation deutscher Auswanderung und Kolonisation. Berlin: F. L. Schneider, 1850, S. 52, PLAG Rep. 65c Nr. 163.

147 Sudhaus, S. 32.

${ }^{148}$ Es gab zwei Arten von Auswanderungsvereinen: Die, die sich auf die allgemeine Auswanderung, und andere, die sich auf ganz bestimmte Emigrationsgebiete spezialisierten. Last, S. 26, 44. Mit dem Ausbau des Hamburger Schiffsverkehrs und mit regelmäßigeren Dampfverbindungen wurde das Interesse des Hamburger Handels für die Anlegung deutscher Siedlungen erweckt. Sudhaus, S. 68.

149 Daemon, Basílio Carvalho. Provincia do Espirito Santo. Vitória: Secretaria do Estado da Cultura/Arquivo Público do Estado do Espírito Santo, 2010, S. 452.

150 Schröder, Die deutsche Einwanderung nach Südbrasilien, S. 75. 1824 erschien das erste Propagandabuch, das nach der Unabhängigkeit Brasiliens 1822 von Major von Schäffer veröffentlicht wurde: Schäffer, Georg Anton von. Brasilien als unabhängiges Reich in historischer, mercantilistischer und politischer Beziehung gescbildert. Altona: Hammerich, 1824. Nach Dreher versprach von Schäffer in diesem Buch
} 
Emigrationsbehörden, Reedereien und ausländische Wirtschaftsunternehmen veröffentlichten Artikel und Bücher, um neue Siedler anzuwerben. Oft wiesen sie aber nicht auf Menschenhändler, auf die wahren Lebensbedingungen und Preisverhältnisse im neuen Land und auf falsche Versprechungen über schnelle Aufstiegsmöglichkeiten, große landwirtschaftliche Produktivität usw. hin. ${ }^{151}$ Besonders die Allgemeine Auswanderungs-Zeitung in Rudolfstadt veröffentlichte Artikel zur Förderung der Auswanderung nach Brasilien. ${ }^{152}$ Sie gab unter anderem die Schriften von Dr. Blumenau über seine Kolonie und das Buch des Hamburger Agenten F. Schmidt heraus. Über die Kolonie Dona Francisca (SC) gab die Direktion des Hamburger Kolonisationsvereins Auskunft, beispielsweise durch die monatlichen Mitteilungen betreffend die deutsche Kolonie Dona Francisca. Neben Berichten über die Arbeit des Vereins, über die Kolonie und die Landbau- und Gewerbemöglichkeiten wurden Berichte von Kolonisten mit Meldungen über die günstige Entwicklung der Siedlung wiedergegeben. ${ }^{153}$

Deutsche Soldaten, die 1824 nach Brasilien auswanderten und dem Fremdenbataillon des Kaisers Pedro I. beitraten, trugen wesentlich zu dem schlechten Ruf Brasiliens als Einwanderungsland bei ${ }^{154}$, obwohl einige von ihnen auch positive Schilderungen vermittelten. ${ }^{155}$ 1849, als der Kolonisationsverein in Hamburg gegründet wurde, entstand der Verein zur Zentralisation deutscher Auswanderung und Kolonisation in Berlin. Er war ein Ausgangspunkt der Angriffe gegen die Auswanderung nach Brasilien. ${ }^{156}$ Die Kritik an den Werbe- und Kolonisationsmethoden für die Parceriakolonien in den brasilianischen Provinzen Rio de Janeiro, São Paulo und Minas Gerais hatte auch eine sehr schädliche Wirkung auf die Beurteilung der südbrasilianischen Siedlungen ${ }^{157}$ und auf Espírito Santo. Überall entstanden Mahnungen und Warnbriefe, um über die Gefahren der Auswanderung nach

nichts, was nicht in den Dekreten und in seinen Instruktionen enthalten war und mahnte vor den Schwierigkeiten der Reise und des neuen Landes. Dreher, Sträflinge aus Mecklenburg-Schwerin, S. 9, 18f. ${ }^{151}$ Von Tschudi erwähnt den Zeitungsartikel der Hansa von 23.8.1856, in dem angegeben wird, dass 1.000 Kaffeebäume etwa 600 Arrobas produzierten. Er stellte aber fest, dass etwa 65 bis 70, höchstens 100 Arrobas von 1.000 Kaffeebäume produziert werden konnten. Von Tschudi, Johann Jakob. Bericht des Herrn von Tschudi, außerordentlichen Gesandten in Brasilien über die Kolonien Santa Isabel, Santa Leopoldina und Rio Novo usw. vom 20. December 1860. In: Hörmeyer, J. (Hrsg.) Actenstücke Brasilianischer Seite, betreffend die Kolonisation des Kaiserreiches. 3. Jahrgang, Heft 3, Rudolfstadt/Berlin: Verlag des F. priv. Hofbuchdruckerei/Franz Wagner, 1861, S. 282.

152 Zur Auflistung der Zeitungen und Schriften, die als Auswanderungspropaganda dienten, siehe Schentke, H. Mabnruf gegen die Auswanderung nach Brasilien, Berlin, S. 9-11, PLAG Rep 65c Nr. 167; Sudhaus, S. $77 f$.

153 Sudhaus, S. 79.

${ }^{154}$ Lienau, J. F. v. (Hrsg.) Darstellung meines Schicksals in Brasilien und der von mir gemachten Erfahrungen über die Behandlung der durch Major Schäffer dabin beförderten europäischen Auswanderer. Schleswig: Taubstummen-Institut, 1826; Sudhaus, Fußnote 65, S. 34.

155 Last, S. 39.

156 Gaebler, Deutsche Auswanderung und Kolonisation. Berlin: F. L. Schneider, 1850, PLAG Rep. 65c Nr. 163.

157 Sudhaus, S. 80-84. 
Brasilien aufzuklären und davon abzuraten. ${ }^{158}$ Hier ist besonders auf den Mahnruf gegen die Auswanderung nach Brasilien von Schentke hinzuweisen, dessen Kritik sich auf die politische Randposition der Einwanderer, die mangelhafte Kolonisationsstruktur Brasiliens, die Unzulänglichkeit der Gesetzgebung und Verwaltung, gegen Privatspekulationen und falsche Versprechungen richtete. ${ }^{159}$ Diese negative Stellungnahme beeinflusste letztlich die deutsche öffentliche Meinung und damit die Einstellung zu Brasilien und beeinträchtigte somit die Einwanderung in allen Kolonien. ${ }^{160}$

Der schweizerischen Bevollmächtigte von Tschudi ${ }^{161}$, der zwischen 1857 bis 1861 die Siedlungsgebiete bereiste und kritische Anmerkungen über die Lebensbedingungen der Kolonisten veröffentlichte, hielt ein Abraten zur Auswanderung nach Brasilien aber für ungerechtfertigt:

„Nachdem ich nun Tausende von deutschen Colonisten in Brasilien gesehen habe, die mit ibrem Lose zufrieden sind und sich in ibren dortigen Verhältnissen wirklich glücklich füblen, so finde ich, dass ein so entschiedenes Abrathen gegen die Auswanderung nach Brasilien, selbst wenn es in den reinsten Absichten geschieht, durchaus nicht gerechtfertigt ist" 162

Beweise für die gute Entwicklung der Kolonien ${ }^{163}$ und den Beitrag der Einwanderer zur landwirtschaftlichen und industriellen Entwicklung des Landes lieferten die Auszeichnung der Siedlung Blumenau (SC) auf der Pariser Weltausstellung 1867 und die Industrieausstellungen in den Provinzen Rio de Janeiro, Santa Catarina und Rio Grande do Sul. ${ }^{164}$ Schentke kritisierte allerdings die Auszeichnung von

\footnotetext{
158 Gaebler, Deutsche Auswanderung und Kolonisation. Berlin: F. L. Schneider, 1850, PLAG Rep. 65c Nr. 163; Ulrich, Wilhelm. Ein Wort an alle Auswanderungslustige. Stettin: Friedrich Nagel, 1852, S. 15, PLAG Rep. 65c Nr. 163; Jäger, Hermann: Offener Brief an die Bauern und an Bauernfreunde, PLAG Rep 65c, Nr. 163.

${ }^{159}$ Schentke, H. Mabnruf gegen die Auswanderung nach Brasilien, S. 25f, 35-59, PLAG Rep 65c Nr. 167.

160 Über den sogenannten ,offene Federkrieg " zwischen Gegner und Verteidiger der brasilianischen Kolonisation siehe Sudhaus, S. 88-98, 116.

${ }^{161}$ Johann Jakob von Tschudi, geboren am 25.7.1818 in Glarus und gestorben am 8.10.1889 in Lichtenegg, war ein Naturforscher, Forschungsreisender, Zoologe, Linguist und Diplomat. Von 1857 bis 1859 bereiste er Brasilien, die La-Plata-Staaten, Chile, Bolivien und Peru. 1859 war er als Gesandter der Schweiz in Brasilien und bereiste die mittleren und südlichen Provinzen und Kolonisationsgebiete. 1861 kehrte er zurück und veröffentlichte von 1866 bis 1869 fünf Bände über seine Reisen nach Südamerika.

162 Von Tschudi, Johann Jakob. Reisen durch Süd-Amerika. 4. Band, Leipzig: F. A. Brockhaus, 1868, S. 78.

${ }^{163}$ In Brasilien bedeutet Kolonie ein Gebiet im Binnenland im Gegensatz zu einer Stadt. Der Begriff bezeichnet auch einen Bauernhof, beziehungsweise die Ländereien, das Haus, die Pflanzungen und Zuchttiere einer Familie auf ihre Kolonie. Bahia, Joana. O tiro da bruxa. Rio de Janeiro: Garamond, 2011, Fußnote 8, S. 350.

164 Sudhaus, S. 142, 145.
} 
Blumenau (SC), weil sie als Privatkolonie von der Regierung übernommen werden musste. ${ }^{165}$

Laut Sudhaus beruhten die schlechten Urteile über die Kolonisation Brasiliens nicht auf eigener Kenntnis des Landes, sondern auf subjektivem Empfinden und auf Aussagen Dritter. Viele solcher Berichte stammten von Reisenden, die in wenigen Wochen die verschiedenen Siedlungsgebiete besucht, aber die Perspektive der Einwanderer und deren Nachkommen nicht berücksichtigt hatten. Dieses beschränkte Wissen wurde aber auf alle Kolonisationsgebiete angewandt und somit verallgemeinert, obwohl viele Siedler zufrieden waren und sich in einer besseren Situation als vormals in der Heimat befanden. ${ }^{166}$

Die brasilianische Regierung versuchte sich durch Veröffentlichung verschiedener Schriften gegen die Vorwürfe zu verteidigen. Kaiser Pedro II. beauftragte auch den Fotografen Viktor Frond, die Kolonisationsgebiete der Provinz Espírito Santo zu fotografieren. Die Bilder sollten in Europa gezeigt werden und Immigranten für die Ansiedlung anwerben. Ob diese Idee in die Tat umgesetzt wurde, ist nicht bekannt. ${ }^{167}$

Die Diskussion um die Kolonisation erweckte in den 1860er Jahren ein allgemeines Interesse an Brasilien. In Zusammenhang mit den deutschen wirtschaftlichen Interessen im Land wurden Reisende und Wissenschaftler beauftragt, sich vor Ort über die genauen Bedingungen ein Bild zu machen. ${ }^{168}$ Inwieweit die städtischen Unterschichten und vor allem die ländliche Bevölkerung Zugang zu der daraus entstandenen Literatur hatte, ist unklar. Nach Last war es ihnen aber nun möglich, ihre Lebensverhältnisse mit den Lebensperspektiven anderer Länder zu vergleichen. ${ }^{169}$ Handzettel und kleine Werbebroschüren von Emigrationsagenten, Reedereien und Kolonisationsunternehmen waren wiederum leicht zu verbreiten und schilderten in attraktiver Weise die Aufstiegsmöglichkeiten in Übersee. ${ }^{170}$ Ein

\footnotetext{
165 Schentke, H. Mabnruf gegen die Auswanderung nach Brasilien, S. 34, PLAG Rep 65c Nr. 167.

166 Sudhaus, S. 108, 141. Vgl. Gerstäcker, Friedrich. Achtzehn Monate in Südamerika. Gesammelte Schriften Bd. 15, Jena 1862/1863, S. 86. Zitiert nach Sudhaus, S. 135-138.

167 Franceschetto, Cilmar. Victor Frond: o pioneiro da fotografia no Espírito Santo - Dados sociológicos da imigração suíça no Espírito Santo. In: Von Tschudi, Johann Jakob. Viagem à provincia do Espirito Santo. Vitória: Arquivo Público do Estado do Espírito Santo, 2004, S. 123-152. Über die Kritik von Tschudis an diesem Unternehmen siehe Von Tschudi, Johann Jakob. Reisen durch Südamerika. 3. Band. Leipzig: F. A. Brockhaus, 1867, S. 34.

168 Sudhaus, S. 150 f.

${ }^{169}$ Last, S. 25.

${ }^{170}$ Ein Beispiel einer Werbungsbroschüre für die Kolonie Rio Novo (ES) siehe Roos, Ton; Eshuis, Margje. Os Capixabas Holandeses. Vitória: Arquivo Público do Estado do Espírito Santo, 2008, S. 145149. Der Hauptagent A. von Jasmund veröffentlichte Informationsschriften über die von ihm angebotenen Überseefahrten nach Kanada, Amerika, Chile, Australien und Brasilien auf attraktivem farbigem Papier. Informationen über Verpflegung und Überfahrtpreise wurden am Beispiel von Nordamerika dargestellt, ohne dabei die Bedingungen für Brasilien direkt zu erwähnen. SAS: Starostwo Powiotowe Gryfice, Nr. 58, Blatt 240f, vgl. mit SAS: Starostwo Powiotowe Bialogard, Nr. 125, Blatt 38f. Beide zitiert nach Last, S. 66f. Auf diese Weise bot er Reisen nach Brasilien an, schützte sich aber gleichzeitig vor dem Vorwurf, explizite Auswanderungswerbung dafür zu machen.
} 
gutes Beispiel für die enge Verzahnung von Agentenwerbung und Informationsverbreitung durch Verwandte und Bekannte wird von zwei Tagelöhnern und einem Stellmachergesellen in Groß Vorbeck im Jahre 1873 geliefert. Sie erhielten durch den Bruder des Stellmachers einen Prospekt von der Firma Louis Hermes aus Antwerpen, Belgien, und entschieden sich für eine Auswanderung nach Brasilien. Nachdem sie aber von einem Baron, der schon einmal in Brasilien war, erfuhren, dass die in dem Prospekt geschilderten Bedingungen nicht zuträfen, verzichteten sie darauf. Später entschlossen sich die drei doch nach Brasilien auszuwandern, jedoch nicht mehr über die Firma Louis Hermes, sondern über die Firma Lobedanz aus Hamburg, die Handzettel über die Auswanderung in ihrem Ort verbreitet hatte. ${ }^{171}$

Aber kein Mittel war effektiver als Auswandererbriefe. Der Agent José dos Santos sandte Briefe aus Lissabon über Hamburg an Bewohner des pommerschen Regierungsbezirks Köslin. Darin wurden die Vorteile der Kolonien idyllisch dargestellt. Zur gleichen Zeit verbreitete sich unter den Bewohnern dieses Regierungsbezirkes das falsche Gerücht, der Kaiser befürworte die Auswanderung nach Brasilien. ${ }^{172}$ Berichte und Briefe der Ausgewanderten wurden manchmal öffentlich vorgelesen. ${ }^{173}$ Großen Einfluss gewann der sogenannte Buffallosbrief eines pommerschen Einwanderers, eines Schusters namens Züngler, datiert vom 6. Oktober 1835. Er beschrieb Amerika als ein idyllisches Land, mit fruchtbarem Boden, reichlich Nahrung, wo ein Tagelöhner besser als ein Gutsbesitzer lebe. Abschriften dieses Briefes wurden ab 1836 derart unter den Gemeinden in Brandenburg und Pommern verbreitet, so dass in kurzer Zeit die „Fleischtöpfe Amerikas" in ganz Preußen bekannt waren. ${ }^{174}$

Die Informationen über die wahren Bedingungen in den Siedlungsgebieten waren in diesen Briefen widersprüchlich dargestellt, je nach eigener Einschätzung und Erfahrung der Betroffenen. Einige waren zufrieden und berichteten über ihren Erfolg. Aus Brasilien kamen zum Beispiel Nachrichten von Menschen, die in wenigen Jahren reich geworden waren ${ }^{175}$ und sogar eine bestimmte Machtposition erreicht hatten. Niemand vermisste das Heimatland und alle lebten in Brasilien wie Prinzen und Grafen. ${ }^{176}$ Die Kolonien seien voller Menschen, die nur mit dem Nötigsten ankamen und nach kurzer Zeit ein gemütliches Haus, Möbel, Pferde, Rinder kauften und sogar Ersparnisse besaßen. Der brasilianische Kaiser empfand Sympathien für die Deutschen und schenkte ihnen Land, Arbeitswerk-

\footnotetext{
171 SAS: Starostwo Powiotowe Kolobrzeg, Nr. 62, ohne Seitenangaben. Zitiert nach Last, S. $68 f$.

172 SAS: Starostwo Powiotowe Bialogard, Nr. 125, Blatt 392f. Zitiert nach Last, S. 67.

173 Last, S. 25.

174 Clemens, S. 34-36; Damitz, Die wirtschaftliche und gesellschaftliche Entwicklung Pommerns, S. $68 \mathrm{f}$.

175 Gaebler, Deutsche Auswanderung und Kolonisation, S. 41, 52, PLAG Rep 65c Nr. 163.

176 Brief von Peter Paul Müller, 16.7.1826. In: Von Freeden, H.; Smolka, G. Auswanderer. Leipzig 1937, S. 84f. Zitiert nach Willems, S. 35.
} 
zeuge, Zuchttiere und gebe ihnen staatliche Subventionen. ${ }^{177}$ Der Boden sei überall fruchtbar, das Vieh könne frei weiden und es gebe keinen langen Winter. Überall wurden verführerische Versprechungen gemacht: „komme nach Amerika und werde reich!" 178 Die Aussichten konnten also nicht besser sein. Willems berichtet, dass sich aufgrund solcher Berichte eine Auswanderungstradition in einigen Gebieten entwickelte. ${ }^{179}$ Aufgrund der geographischen Nähe mancher Orte, aus denen Auswanderer stammten, erhielten die Bewohner direkte Informationen über die Lebensbedingungen in Siedlungsgebieten und wurden dadurch zur Emigration angeregt. So berichtete Carl Butzke aus Timbó (SC):

„Es waren aus unserem Dorf schon Bekannte in Blumenau. Die hatten geschrieben, dass man in Blumenau 100 Morgen Umvaldland für billiges Geld erhalten könnte. Das Schreiben hat mich gelockt. Am 6. April habe ich mit noch 6 Familien Deutschland verlassen. Es war im Jahr 1869":180

Und Joachim Holz, aus Espírito Santo:

„Mit einemmal hieß es, da wandern welche aus nach Brasilien. Meine Eltern bekamen auch gleich Lust. Da wurde alles verkauft und mit nach Brasilien".181

Die Auswanderer bevorzugten in der Regel Informationen, die sie über Angehörige und Bekannte bezogen. Die Familien Mähl und Lüthke aus Hohendorf unterschrieben 1857 beim Expedienten Louis Knorr \& Comp. ihre Reiseverträge, so wie die Familie Brümer, die zwei Jahre später aus demselben Ort nach Brasilien auswanderte. Alle reisten über dieselbe Route von Hamburg aus. ${ }^{182}$ Nach Bosenbecker ließen viele Einwandererfamilien ihre Angehörigen nach einigen Monaten oder Jahren nachkommen. In anderen Fällen wanderte zunächst ein Familienglied aus, das dann Auskunft über die Bedingungen im Land gab und teilweise nach Entsendung des Reisegeldes seine Familie nachkommen ließ. ${ }^{183}$ So reiste 1866 ein weiterer Teil der pommerschen Familie Eggert nach Joinville (SC), nachdem die ersten schon 1865 ausgewandert waren. ${ }^{184}$ Die Familie Piske emi-

\footnotetext{
177 Kahle, Maria. Deutsche Heimat in Brasilien. Berlin: Grenze und Ausland, 1937, S. 19.

178 Costa, Jairo Scholl. O Pescador de Arenques. Pelotas: EDUCAT, 2007, S. 29, $130 \mathrm{f}$.

179 Willems, S. 35.

180 Butzke, Carl Friedrich Wilhelm. Mein Lebenslauf und Lebenskampf. In: Evangelische Synode von Santa Catarina und Paraná, S. 96, 98.

${ }^{181}$ Holz, Joachim. Die ersten sechs Jahren in Espírito Santo, Brasilien. In: Heimatbote für die Gemeinden der Deutschen Lutherischen Kirche in Espirito Santo. Nr. 4, April 1936, S. 2-4, MEW 4.194.

182 Arquivo histórico de Joinville. Listagem informatizada dos imigrantes 1851-1891, 1897-1902. Vgl. Listen 26 und 38. In: http://www.arquivohistoricojoinville.com.br/ListaImigrantes/lista/tudo.htm Zugang am 14.3.2016.

${ }^{183}$ Bosenbecker, S. 57.

184 Boehs, Astrid. Uma Familia, tempos, movimentos e espaços. Verfügbar in: http:/ /astrideboehs.blogspot.de/ 2008/11/uma-familia-tempos-movimentos-e-espaos.html Zugang am 29.3.2016. Keine Seitennummerierung.
} 
grierte 1872 aus Kloetzin, nachdem Verwandte sich bereits in der Provinz Santa Catarina niedergelassen hatten. ${ }^{185}$

Andere wiederum waren frustriert und rieten von einer Auswanderung ab. 186 Diese negativen Berichte wurden auch vom Regierungsministerium verwendet, um die Auswanderung einzudämmen. ${ }^{187}$ In ihnen wird Auskunft über die schlechten Verhältnisse und die Isolierung im brasilianischen Urwald gegeben. Eine pommersche Familie, die brieflich durch ihre Verwandten zur Auswanderung nach Teutônia (RS) ermuntert wurde, verzichtete 1866 auf eine Auswanderungserlaubnis. Laut der Behörden konnte in den Briefen aus Brasilien nicht festgestellt werden, ob ihre Verwandten nicht eventuell in Sklaverei geraten waren. ${ }^{188}$ Nach Last strichen manche Agenten negative Darstellungen aus Auswandererbriefen oder korrigierten den Inhalt ins Positive. ${ }^{189}$ Dass einige Versprechen nicht der Wahrheit entsprachen oder dass neben den schönen Vorstellungen auch Schwierigkeiten zu bewältigen waren, erfuhren die Einwanderer erst in Brasilien.

\section{Pommersche Einwanderung nach Brasilien}

Im oberen Abschnitt gaben die Hauptmotive der Auswanderung bereits Hinweise auf die verschiedenen Gruppen der Pommern, die nach Brasilien emigrierten. Diese sollen nun kurz mit den Herkunfts- und Ansiedlungsorten in brasilianischen Kolonisationsgebieten erörtert werden, soweit die Informationen erhalten geblieben sind.

Die genaue Anzahl pommerscher Einwanderer nach Brasilien ist schwer zu bestimmen. Das liegt zum einen daran, dass Auswanderungs- und Einwanderungslisten von Zollbehörden und Schiffen den Herkunftsort der Immigranten nicht spezifisch angaben. ${ }^{190}$ Ein Vergleich der Daten zwischen den Listen aus Europa und Brasilien weist große Unterschiede auf. Oft wurden die Auswanderer dort allgemein als „Preußen" bezeichnet. ${ }^{191}$ Manche waren weder in Einwanderungslisten gelistet noch in staatliche Archive und kirchliche Register eingetra-

\footnotetext{
185 Giurus, Meinrad Piske, S. 7.

186 Roscoe-Brief vom Schuhmacher Schwarz aus Cammin, 11.7.1838. Zitiert nach Clemens, S. 48; Auswandererbrief in den Landratsakten. Zitiert bei Heyden, S. 306.

${ }^{187}$ Dazu siehe Clemens, S. 38-44.

${ }^{188}$ Hensel, Beiträge zu näheren Kenntnis der brasilianischen Provinz Rio Grande do Sul. Zeitschrift für Erdkunde. Berlin, 1867, Anm., S. 254. Zitiert nach Sudhaus, S. 124.

${ }^{189}$ Last, S. 26f.

190 Rölke, Raízes da Imigração alemã, S. 290. Eine Auflistung deutscher Einwanderer (dabei wurden Einwanderer aus Deutschland, Österreich, Holand, Belgien, Luxemburg und aus der Schweiz einbezogen) die zwischen 1846 und 1957 nach Espírito Santo emigrierten, unter ihnen Pommern, befindet sich in Franceschetto, Cilmar. Imigrantes Espirito Santo. Vitória: Arquivo Público do Estado do Espírito Santo, 2014, S. 949-1068. Die genaue Herkunft von vielen ist aber unbekannt.

191 Siehe Liste der ersten Einwanderer in Blumenau (SC). Weingärtner, Nelso. Martin Luther e Santa Catarina. Timbó: Tipotil, 2012, S. 89; auch Rölke, Raǐzes da Imigração alemã, S. 82.
} 
gen. ${ }^{192}$ Nach der Vereinigung 1871 wurden die Pommern in der Regel nicht mehr als solche benannt, was aber nicht bedeutet, dass keine Pommern mehr emigrierten, denn viele kamen erst in den 1870er Jahren nach Brasilien. Sie galten aber nun als Reichsdeutsche. Zum anderen durften nach dem Allgemeinen Landrecht Preußens ausschließlich Untertanen mit Besitz einer Erlaubnis auswandern, so dass zwischen 1844 und 1851 nur preußische Auswanderer mit einer Entlassungsurkunde aufgelistet wurden. Viele Pommern emigrierten aber ohne Entlassungspapiere. Erst nach 1855 wurden auch diejenigen registriert, die auch ohne Papiere auswanderten. Mit Hilfe statistischer Erhebungen der Überseehäfen konnte aber bewiesen werden, dass die reale Anzahl der Emigranten größer war als die Registrierungen hergaben. ${ }^{193}$ Letztlich wurden erst mit dem Reichstagsbeschluss 1871 damit begonnen, die Vor- und Nachnamen, den Herkunftsort und das Zielland der Auswanderer aus dem Deutschen Reich zu registrieren. ${ }^{194}$ In Bremen erfolgten ab 1832 und in Hamburg ab 1846 die ersten Aufzeichnungen über Auswanderer, jedoch wurde erst ab 1866 in Bremen und seit 1851 in Hamburg zwischen deutschen und nicht-deutschen Auswanderern unterschieden. ${ }^{195}$ Aus diesem Grund wurde die Einwanderung nach Brasilien allgemein als "deutscbe " Einwanderung bezeichnet, trotz der verschiedenen Herkunftsorte der Emigranten. Vom Kolonialdiskurs beeinflusst ging man statt von heterogenen und regionaler Identitäten von einer ,deutschen "Gemeinschaft aus. ${ }^{196}$

Durch neue Datensammlungen wurden präzisere Auswandererzahlen für Pommern ermittelt, obwohl die regionale Herkunftsbestimmung aufgrund der summarischen Aufstellung für die einzelnen Provinzen entfiel. Die Preußische Statistik gab die Herkunftsregionen bis 1886 an, es zeigten sich aber große Differenzen zwischen den Angaben der Preußischen Statistik und der Statistik des Deutschen Reichs, vor allem für das Jahr $1873 .{ }^{197}$

Nach Auswertung der Angaben der namentlichen Nachweise der aus dem Regierungsbezirk Stralsund Ausgewanderten zwischen 1830 und 1869198, der Preußischen Statistik und der Statistik des Deutschen Reiches wurden die ersten sechs pommerschen Einwanderer nach Brasilien auf das Jahr 1842 datiert. Sie stammten

\footnotetext{
192 Bosenbecker, S. 12f; vgl. Rölke, Raízes da Imigração alemã, S. 290, mit dem Beispiel von Friedrich August Höhne, dessen Ankunft nirgendwo in Espírito Santo registriert wurde.

193 Preußische Statistik, Hrsg. in zwanglosen Heften vom Königlichen Statistischen Bureau in Berlin, Bd. XXVI, Berlin 1874, S. III-VI. Zitiert nach Last, S. 22.

${ }^{194}$ Vierteljahreshefte zur Statistik des Deutschen Reichs für das Jahr 1873, Hrsg. vom Kaiserlichen Statistischen Amt (Statistik des Deutschen Reichs Bd. II), Berlin 1874, S. II.129. Zitiert nach Last, S. 61.

195 Last, S. 61.

196 Schulze, S. 133.

197 So ermittelte die Preußische Statistik eine Anzahl von 126 Personen, die aus Pommern nach Mittel- und Südamerika und Mexiko emigrierten, während die Statistik des Deutschen Reichs 2.446 pommersche Emigranten, die über Hamburg, Bremen und Antwerpen nach Brasilien auswanderten, angab, Last, S. 93-96.

198 PLAG Rep 65c, Nr. 159.
} 
aus den Kreisen Greifswald und Groß Kiesow. Die nächsten folgten 1845 aus Frauendorf, Greifswald und Stralsund. ${ }^{199}$ Der Kreis Greifswald bildete die wichtigste Kernregion der Auswanderer des Regierungsbezirkes Stralsund. Aus Greifswald und dessen Umgebung, Stralsund, Grimmen, Bremenhagen, dem Kreis Rügen, sowie aus Barth und Frauendorf wanderten zwischen 1857 und 1869 der Großteil der Brasilienauswanderer aus dem Regierungskreis Stralsund aus. ${ }^{200}$ In den Jahren 1857 bis 1859 gab es einen steilen Anstieg der Auswandererzahlen nach Brasilien. ${ }^{201}$

Ab 1862 geben die Veröffentlichungen der Preußischen Statistik weitere Daten über pommersche Auswanderer nach Brasilien preis. Obwohl als Bestimmungsziel allgemein Mexiko, Mittel- und Südamerika angegeben wird, ist aus dem Beispiel der Statistiken für den Regierungsbezirk Stralsund eine Mehrheit pommerscher Emigranten nach Brasilien zu entnehmen, dem eine ähnliche Verteilung der Auswanderungsziele für die Bezirke Köslin und Stettin folgt. ${ }^{202}$ Die Preußischen Statistiken zwischen 1862 und 1872 erwähnen folgende Herkunftsorte der Pommern, die nach Süd- und Mittelamerika emigrierten: Aus dem Regierungsbezirk Stettin die Kreise Naugard, Pyritz, Kammin und Regenwalde; aus dem Regierungsbezirk Köslin der Kreis Belgard; aus dem Regierungsbezirk Stralsund der Kreis Greifswald. ${ }^{203}$ Bis 1871 verzeichneten die Jahre 1862, 1868 und 1869 größere Höhepunkte an Auswanderern nach Mittel- und Südamerika. Die preußischen Statistiken weisen eine weitere größere Emigrantenzahl zwischen 1868 und 1869 auf, innerhalb dessen 1.222 Personen das Land verließen. ${ }^{204}$

Laut offiziellen Angaben der Statistik des Deutschen Reichs wanderten zwischen 1871 und 1900 12.230 Pommern nach Brasilien aus. Die Höhenpunkte der Auswanderung umfassen die Jahre 1872 mit 1.315 pommerschen Emigranten und 1873 mit 2.335. ${ }^{205}$ Danach sanken die Zahlen der Auswanderer bis zu einem letzten Gipfel in den Jahren 1889 und 1890.206 Zwischen 1871 und 1900 stellte Pommern den größten Teil der Brasilienauswanderer aus ganz Deutschland. ${ }^{207}$ Ende

\footnotetext{
199 Auflistungen von Auswanderern, die vor 1862 aus den Regierungskreisen Köslin und Stettin emigrierten, aus denen die meisten pommerschen Einwanderer in Brasilien stammten, konnten nach Last nicht gefunden werden.

200 PLAG Rep. 65c Nr. 159; Last, S. 58, 64.

${ }^{201}$ Last, S. 45.

${ }^{202}$ Last, S. 59.

${ }^{203}$ Last, S. 59. Last erwähnt fälschlicherweise Kammin als ein dem Regierungsbezirk Köslin zugehörender Kreis.

${ }^{204}$ Preußische Statistik, Hrsg. in zwanglosen Heften vom Königlichen Statistischen Bureau in Berlin, Bd. XXVI, 1874, S. 221-229. Zitiert nach Last, S. 59 f.

${ }^{205}$ Last, S. 93; vgl. Grosselli, Renzo M. Colônias Imperiais na Terra do Café. Vitória: Arquivo Público do Estado do Espírito Santo, 2008, S. 205.

${ }^{206}$ Last, S. 61f, auch Tabelle 4, S. 93.

${ }^{207}$ Last, S. 62, auch Tabelle 3 und Diagram 3, S. 91 f.
} 
des 19. Jahrhunderts, nach dem Ersten und kurz vor dem Zweiten Weltkrieg emigrierten weitere Pommern nach Brasilien, besonders in größere Industriestädte. ${ }^{208}$

Dabei sollte nicht vergessen werden, dass die Zahlen der Statistik des Deutschen Reichs nur die genehmigten Auswanderer oder die, die durch ihre Herkunftsangabe in Einschiffungshäfen registriert wurden, enthalten. Eine nicht unbeträchtliche Anzahl pommerscher Auswanderer emigrierte nach Brasilien, ohne erfasst worden $\mathrm{zu}$ sein. ${ }^{209}$ Außerdem wurde die ursprüngliche Herkunft vieler Pommern, die durch Migration in anderen deutschen Staaten sesshaft waren, oft nicht in Betracht gezogen. Einige davon kamen bereits 1824 nach Brasilien. ${ }^{210}$ Ebenso ist die Anzahl der Pommern, die Anfang des 19. Jahrhunderts in den deutschen Westen im Kontext des Industrialisierungsprozesses migrierten und von dort aus nach Brasilien gingen, nicht erfasst worden.

Es ist in dieser Arbeit nicht möglich, die Namen aller bekannten Dörfer, Kreise, Städte und Herkunftsorte aller nach Brasilien ausgewanderten Pommern aufzulisten. Die Herkunftsangaben sind zudem in den meisten Fällen ungenau oder werden gar nicht erwähnt. ${ }^{211}$ Nach Damitz sollen insgesamt etwa 30.000 Pommern nach Brasilien ausgewandert sein, zwei Drittel von ihnen landeten in den südlichen Provinzen Rio Grande do Sul, Santa Catarina und Paraná und ein Drit-

208 Siller, Rosali Rauta. Infância, Educação Infantil, Migrações. Campinas: Universidade Estadual de Campinas, 2011, S. 27.

209 Preußische Statistik. Hrsg. in zwanglosen Heften vom Königlichen Statistischen Bureau in Berlin, Bd. XXVI, 1874, S. V. Zitiert nach Last, S. 62.

210 Dreher. Sträflinge aus Mecklenburg-Schwerin, S. 132, 165, 185. Vermutlich, weil sie sich in Korrekturhäusern und Gefängnissen in Mecklenburg befanden und als mecklenburgische Bürger galten, wurden sie in den oben genannten Statistiken als Pommern nicht erfasst.

211 Nach Forschungsreisen oder Recherchen in Archiven und kirchlichen Registern präsentieren einige Autoren eine Auflistung der wichtigsten Herkunftskreise und -orte pommerscher Einwanderer in Brasilien. Granzow, Pommeranos unter dem Kreuz des Südens, S. 204 gibt eine Liste mit Herkunftsorten pommerscher Einwanderer aus Espírito Santo, Santa Catarina und Rio Grande do Sul; Weingärtner. História da Comunidade Evangélica de Timbó, S. 100-107 erwähnt die Herkunftsorte, die in den Sterberegistern der Gemeinde Timbó (SC) angegeben wurden; Ramlow, Udo; Resende, João M. O. A colonização de Pomerode. In: Prefeitura Municipal de Pomerode. Pomerode, sua história, sua cultura, suas tradições. V. 2. Pomerode: Mayer, 1985, S. 14-16 zitiert die Herkunftsorte der Pommern aus Pomerode (SC); die Einwanderungslisten aus dem Archiv von Joinville (SC) geben manchmal auch den Herkunftsort der Pommern an, siehe Arquivo histórico de Joinville; Rölke. Descobrindo Raizes, S. 93-102 listet die Herkunftsorte pommerscher Einwanderer auf, die in den Tauf-, Trauungsund Sterberegistern der Gemeinden Santa Leopoldina I-Luxemburg, Santa Leopoldina II-Jequitibá, Santa Maria de Jetibá, Califórnia (Domingos Martins) und Santa Joana (ES) auftauchen; bei Rheingantz, Karl Wilhelm. Die Gründung der Kolonie São Lourenço und ibr Gründer Jakob Rheingantz [1907?], S. 23f, EZA 5/2304 befindet sich im Anhang 1 ein Verzeichnis mit den Auswanderern, die mit dem holländischen Schiff Twee V rieden nach São Lourenço do Sul bestimmt waren; Last, S. 71 listet die Herkunftsorte von 128 Pommern, die 1875 nach Santa Catarina und Rio Grande do Sul befördert wurden. Über Auswandererlisten des Staatsarchivs Hamburg mit Hamburger Passagierlisten von 1850 bis 1934 siehe http://www.hamburger-passagierlisten.de/; auch Familienforschungsportal https://www.ancestry.de/ Zugang am 22.3.2017. Mithilfe dieser Homepage können Einwanderernachkommen die Herkunft ihrer Vorfahren erforschen. 
tel in Espírito Santo.212 In dieser Arbeit werden die Pommern in drei Provinzen, bei denen eine stärkere pommersche Kolonisation bekannt ist, nämlich Rio Grande do Sul (= RS), Santa Catarina (= SC) und Espírito Santo (= ES) betrachtet. Mit der Entwicklung und Emanzipation der Kolonien entstanden neben den Hauptsiedlungen mehrere Siedlungsorte mit pommerschen Einwanderern und deren Nachkommen und durch Migrationsbewegungen zerstreuten sie sich auch in neue Siedlungsgebiete und Provinzen.

Weil die Pommern in unterschiedlichen Perioden nach Brasilien auswanderten, repräsentierten sie verschiedene Phasen kultureller Veränderungen. Die Weltanschauung der Bauern und Tagelöhner sah anders aus als die der Handwerker und industriellen Arbeiter, die in den deutschen Westen umgesiedelt waren, der Liberalen und Nationalisten - besonders nach 1890 - und der, die nach dem Ersten oder kurz vor dem Zweiten Weltkrieg emigrierten. Deswegen ist die Analyse der Pommern in Brasilien alles andere als uniform. Obwohl die Mehrheit der ausgewanderten Pommern in ihrer Heimat zweifellos Bauern oder Tagelöhner waren ${ }^{213}$ ist darauf hinzuweisen, dass viele Mitglieder unterschiedlicher Berufe sich bei der Einwanderung als Bauern ausgaben ${ }^{214}$, da die brasilianische Regierung Bauernfamilien für die Kolonisation bevorzugte. Sie genossen im Vergleich zu den wirklichen Bauern einen höheren Status und einen besseren Zugang zum städtischen Leben in den Kolonisationsgebieten, obwohl sie zunächst auch ausschließlich als Bauern arbeiten mussten, bis sie in den Kolonien einen Markt für ihre Produkte bilden konnten. Bald suchten sie nach einem urbanen Gebiet oder siedelten um. Wenn dies nicht möglich war, übten sie ihre Berufe neben ihrer landwirtschaftlichen Arbeit aus und trugen somit zur Entstehung kleinerer Städte bei. Unter ihnen befanden sich Arbeiter, Handwerker, aber auch Ärzte, Akademiker, Offiziere, Kaufleute, Juristen, Architekten, Staatsbeamte, Lehrer und Apotheker215, die von den primitiven Lebensverhältnissen in den Siedlungsgebieten teilweise enttäuscht waren. Einige wurden später Journalisten, Politiker, Lehrer und Unternehmer.

Es soll nun kurz auf die Siedlungsorte eingegangen werden, die namentlich pommersche Einwanderer zugewiesen bekamen. Einige Pommern kamen 1824 in die Kolonie São Leopoldo (RS). ${ }^{216}$ Nach Angaben eines Regierungsvertrags vom 12. November 1829 kamen etwa 400 Einwanderer, nach Schmidt zwischen 1829

\footnotetext{
${ }^{212}$ Damitz, Hans. Die ausgewanderten Pommern und die Stellung von Scbule und Kirche im ländlichen Brasilien. Mai/Juni 1991, S. 1. Manuskript im Privatarchiv von Pastor Nelso Weingärtner.

213 Dreher, Igreja e Germanidade, S. 15.

${ }^{214}$ Magalhães, Marionilde Brepohl de. Pangermanismo e nazismo. Campinas: UNICAP/FAPESP, 1998, S. 26.

${ }^{215}$ Schröder, Brasilien und Wittenberg, S. 14f; Fischer, Joachim. Geschichte der Evangelischen Kirche Lutherischen Bekenntnisses in Brasilien. In: Fischer, Joachim; Jahn, Christoph (Hrsg.) Es begann am Rio dos Sinos. Erlangen: Verlag der Ev. Lutherischen Mission, 1970, S. 92.

${ }^{216}$ Dreher. Sträflinge aus Mecklenburg-Schwerin, S. 132, 165, 185.
} 
und 1833 in ihrer Mehrheit Pommern, in die Provinz Espírito Santo. ${ }^{217} 1831 \mathrm{ka}-$ men weitere 105, aber einige siedelten bald nach Porto Alegre (RS) um. ${ }^{218}$ Durch Angaben in Kirchenregistern, Briefen und Berichten über die Gemeinde Santa Isabel (SC) in den Jahren 1847 bis 1867 werden sechs pommersche Familien namentlich erwähnt. ${ }^{219}$ Stoer berichtet aber, dass sie erst zwischen 1862 und 1863 kamen. ${ }^{220}$ In Rio Grande do Sul waren die Kolonien São Lourenço do Sul $(1858)^{221}$, Santa Cruz do Sul (1849) 222 , Nova Petrópolis (1858) 223 und Santo Ângelo-Agudo (1857) 224 diejenigen, die eine größere Anzahl von Pommern aufwiesen. In Santa Catarina wurden sie besonders in den Kolonien Blumenau (1850) 225 , Brusque (1860) 226 und Dona Francisca-Joinville (1851)227, später auch in São Bento do Sul ${ }^{228}$ und Jaraguá do Sul229 angesiedelt. In Paraná siedelten einige Pommern aus Dona Francisca-Joinville nach Curitiba ${ }^{230}$, Rio Negro, Ponta Grossa und Lapa um. ${ }^{231}$ Und in Espírito Santo waren sie vor allem in der Kolonie Santa Leopoldina $(1857)^{232}$ repräsentativ, von dort aber zerstreuten sie in die ganze Provinz. Manche Pommern wurden auch in Parceriakolonien von São Paulo ${ }^{233}$, Minas Gerais ${ }^{234}$ und Rio de Janeiro ${ }^{235}$ angesiedelt, diese werden aber im Rahmen dieser Arbeit nicht

217 Daemon, S. 328; Schmidt, Artur. Die Anfänge der Diakonie in Espirito Santo. Augsburg: FDL Verlag, 1984, S. 176.

${ }^{218}$ Daemon, S. 332.

${ }^{219}$ Weingärtner, Martin Luther e Santa Catarina, S. 60-66.

220 Stoer, S. 3.

221 Rheingantz, Die Gründung der Kolonie São Lourenço und ibr Gründer Jakob Rheingantr. [1907?], EZA 5/2304; Schröder, Brasilien und Wittenberg, S. 17.

222 Schröder, Brasilien und Wittenberg, S. 130-144.

223 Schröder, Brasilien und Wittenberg, S. 87f.

224 Schröder, Brasilien und Wittenberg, S. 148-154.

225 Schröder, Brasilien und Wittenberg, S. 275-278; Hornburg, Rudolf. Jabrbundertfeier der evangelischen Kirche von Testo Alto. In: Prefeitura Municipal de Pomerode. Pomerode, sua história, sua cultura, suas tradições. V. 3. Pomerode: Prefeitura Municipal, 1986, S. $31 \mathrm{f}$.

226 Schröder, Brasilien und Wittenberg, S. 273-275.

227 Schröder, Brasilien und Wittenberg, S. 278-280.

228 Kahle, S. 91f.

229 Schröder, Brasilien und Wittenberg, S. 289.

${ }^{230}$ Schröder, Brasilien und Wittenberg, S. 295; Krause, Lutherische Synode in Brasilien, S. $61 \mathrm{f}$.

${ }^{231}$ Comité für die protestantischen Deutschen in Brasilien. Die Arbeit unter den Evangelischen Deutschen in Brasilien. Barmen: D. B. \& T. G. Wiemann, 1878, S. 82f.

232 Schröder, Brasilien und Wittenberg, S. 19; Wagemann, Ernst Friedrich. Die Deutschen Kolonisten im brasilianischen Staate Espirito Santo. München/Leipzig: Duncker \& Humbolt, 1915, S. 21f; Daemon, S. 98; Kahle, S. 33, 52; Franceschetto, Imigrantes, S. 949-1031.

233 Wie in Ubatuba (SP), Von Tschudi, Bericht über die Kolonien Santa Isabel, Santa Leopoldina und Rio Novo, S. 265f; Campinas (SP) und Cosmópolis (SP), Kahle, S. 60f.

${ }_{234}$ Rothe, Max. 100 Jahre deutsche Einwanderung in Teófilo Otoni, Minas Gerais. 1856-1956. Kopien von Maria Jordan-Marx, einer Enkelin von Pastor Hollerbach, S. 33, BMA PABV 545 Johann Leonhard Hollerbach.

235 Aus der Festschrift der Mittelbrasilianischen Synode zu ihrem 50. Gründungstag am 28./30. Juni 1912/1962, BMA PABV 703, Johann Jakob Zink; Von Tschudi, Johann Jakob. Bericht des Herrn von Tschudi, außerordentlichen schweizerischen Gesandten in Brasilien an den Bundesrath über den 
behandelt. Andere befanden sich unter den Wolga- oder Russlanddeutschen, die in den 1870er und 1890er Jahren hauptsächlich in der Provinz Paraná angesiedelt wurden. Einige von ihnen kamen aber auch nach Santa Isabel (SC) ${ }^{236}$, Dona Francisca-Joinville (SC) ${ }^{237}$, Blumenau (SC) ${ }^{238}$, Ijuí (RS) und São Sebastião do Caí (RS). ${ }^{239}$ Sie waren Anfang des 19. Jahrhunderts nach Russland ${ }^{240}$ oder nach Polen ausgewandert ${ }^{241}$ und von dort emigrierten sie nach Brasilien, manche erst nach dem Ersten Weltkrieg. ${ }^{242}$ Ein Hinweis, dass Pommern in den 1890er Jahren durch die Hanseatische Kolonisationsgesellschaft an dem Itapocu-Tal Richtung Hochebene des Staates Santa Catarina nach Hansa-Humboldt (SC) und São Bento do Sul (SC) und gleichzeitig in den Gebieten der Nebenflüsse des Itajaís im Bergland bis Hansa-Hamônia (SC) und Trombudo-Tal angesiedelt wurden, kann bestimmter Ortsbenennung entnommen werden, wie es beispielsweise mit Neu Stettin der Fall ist. Unter den pommerschen Einwanderern war es üblich, Flüsse, Straßen, Orte und Kirchen in den Kolonien nach ihren Herkunftsorten zu benennen. ${ }^{243}$

Zusammenfassend lässt sich feststellen, dass die Pommern zusammen mit anderen Auswanderern in verschiedenen Epochen emigrierten und kein eindeutiges Profil aufweisen. In dieser Arbeit wird auf die allgemeine Tendenz ausgewichen, die Pommern unter dem Klischee der „armen“244 und „ungebildeten Bauern“ zu be-

Zustand der Kolonien der brasilianischen Provinzen Santa Catharina und San Pedro do Rio Grande do Sul vom 18. Juni 1861. In: Hörmeyer, J. (Hrsg.) Actenstücke Brasilianischer Seite, betreffend die Kolonisation des Kaiserreiches. 3. Jahrgang, Heft 3, Rudolfstadt/Berlin: Verlag des F. priv. Hofbuchdruckerei/ Franz Wagner 1861, S. 236.

236 Weingärtner, Martin Luther e Santa Catarina, S. 60-66.

237 Weingärtner, Martin Luther e Santa Catarina, S. 124.

238 Willems, S. 39.

239 Witt, Osmar Luiz. Igreja na Migração e Colonização. São Leopoldo: Sinodal/IEPG, 1996, S. $51,58$.

240 Verband für Evangelische Auswandererfürsorge 1926, S. 10, MLV 51/17 60.

241 Motsch, S. 40-42, 412-417. Von 1816-1820 gab es eine bedeutende pommersche Auswanderung aus den Regierungsbezirken Köslin und Stettin nach Russland und Polen. Am Ende der 1820er Jahren neigten hinterpommersche Familien vor allem aus den Kreisen Rummelsburg, Neustettin, Schlawe, Belgard und Cammin dazu, nach Polen auszuwandern. In noch größerem Umfang emigrierten sie in der Mitte der 1840er Jahre. Aus dem Regierungskreis Stettin wanderten 1844/1845 etwa 665 Pommern aus den Kreisen Kammin und Naugard, einige Hunderte aus Regenwalde, Greifenberg und Usedom-Wollin nach Polen und 107 Personen aus dem Regierungskreis Köslin, Kreis Fürstentum nach Russisch-Polen aus. In den Jahren nach dem Wiener Kongress und verbunden mit der Inkorporation Schwedisch-Pommerns im preußischen Staat emigrierten viele Pommern aus dem neuen Regierungsbezirk Stralsund nach Schweden. Mühle, S. 263-271.

242 Schulze, S. 154.

243 Im Siedlungsgebiet Pomerode (SC), das damals zur Kolonie Blumenau (SC) gehörte, stammten die meisten Einwanderer aus dem Regatal in Hinterpommern. Sie nannten den Siedlungsort, den Fluss und sogar die Kirche Rega. Die Straße, die von Timbó (SC) nach Pomerode (SC) führte, wurde Pommernstraße genannt. Die Zweiggemeinden wurden Rega I, Rega II, Rega III und Obere Rega genannt. In Paraíso (RS) hieß eine Zweiggemeinde Pommernserra, in Santa Cruz do Sul (RS) gab es die Gemeinde Linha Schwerin und in São Lourenço do Sul (RS) wurde eine weitere Zweiggemeinde Pommerstraße benannt. Schröder, Brasilien und Wittenberg, S. 144, 154,161, 275; vgl. Kahle, S. 35.

244 Die Pommern waren nicht unter den ärmsten Auswanderern, wie oft vermutet wird, siehe Damitz, Die wirtschaftliche und gesellschaftliche Entwicklung Pommerns, S. 70, obwohl damit nicht 
II - Die Pommern und ihre Einwanderung nach Brasilien

trachten. Diese Darstellung überträgt ihnen eine Opferrolle, die ihrem Verhalten jedoch in keinen Fall entspricht. Zur Zeit ihrer Emigration hatten viele Pommern Erfahrungen mit dem Industrialisierungsprozess und entwickelten dabei Kenntnisse, die ihnen bei der Gründung von kleineren Unternehmen in den Siedlungsgebieten Brasiliens zu Gute kamen. Viele konnten aufgrund ihrer mitgebrachten Ersparnisse nach wenigen Jahren ihre Landschuld tilgen und sich schneller emporarbeiten, was im Vergleich zu Mittellosen bei gleichen Bedingungen nicht der Fall war. Die jüngeren Bestrebungen, durch regionale Ethnizität die Pommern von den restlichen Deutschen abzugrenzen, kann als Versuch verstanden werden, ihnen eine mögliche Sympathie oder Beteiligung an der Deutschtumspflege und später am Nationalsozialismus abzusprechen. Es handelt sich hierbei um eine Korrektur aufgrund der negativen Bewertung dieser Ideologien, die dann einfach auf frühere Zeiten übertragen wurde. Sie lässt jedoch den Assimilationsprozess der Pommern mit anderen deutschen Einwanderern, unter anderem durch Heirat, sowie die Tatsache, dass eine große Anzahl von Pommern nach 1871 als Reichsdeutsche emigrierte, außer Betracht.

\section{Befürworter und Gegner der Auswanderung und ihre Interessen}

Die Emigrationsbewegung hatte von Anfang an ihre Unterstützer und Gegner, die aus politischen, wirtschaftlichen und sozialen Interessen die Auswanderung befürworteten oder dagegen waren. Die unterschiedlichen Stellungnahmen verschiedener Gruppen förderten und erschwerten gleichzeitig die Auswanderung und beeinflussten das Schicksal vieler Emigranten.

\subsection{Auswanderung als Mittel zur Entspannung sozialer und wirtschaftlicher Probleme}

Bereits in den ersten Jahren erwies sich die Auswanderung als ein effizientes Ventil sozialer und ökonomischer Probleme. So wurden Insassen von Korrektur-, Landarbeits- und Zuchthäusern und Inhaftierte als Arbeiter nach Brasilien ab-

\footnotetext{
gesagt ist, dass sie von wirtschaftlichen Krisen verschont blieben und sehr sparsam leben mussten. Besonders Schweizer und Hunsrücker, die zwischen 1818 bis 1838 aufgrund der Folgen des sogenannten Hungerwinters 1816 und 1817 emigrierten, lebten unter erheblichem wirtschaftlichen Druck in ihrer Heimat. Grothe, S. 40; Sudhaus, S. 27. Die Pommern mussten über ein gewisses Vermögen verfügen, das sie verkaufen konnten, um Geld für Transport, Unterkunft in Hafenstädten und die Reise zu sammeln. Nach Willems emigrierten viele Auswanderer nachdem die Lebensbedingungen in der Heimat sich verbessert hatten. Sie hatten kein soziales oder ökonomisches Bedürfnis auszuwandern, wählten aber die Emigration aufgrund der anziehenden Versprechen von billigen Ländereien und guten Aufstiegsmöglichkeiten. Willems, S. 34f, vgl. Von Tschudi, Reise durch Südamerika. 3. Band, S. 41; Zummach, Marta. O que minha vovó me contava. In: Der Junge Kämpfer, Nr. 8, 1936. Zitiert nach Rölke, Raízes da Imigração alemã, S. 254.
} 
transportiert, damit sich die erdrückende Lage im eigenen Land stabilisieren konnte.

Aufgrund des Industrialisierungs- und Urbanisierungsprozesses in Zusammenhang mit der Migration der Menschen in Industriezentren und dem Bevölkerungswachstum verschlimmerte sich die soziale Lage besonders in großen Städten. Durch Arbeitslosigkeit und Verarmung hatten sich Obdachlosenkontingente gebildet, die zu einer erhöhten Kriminalität, Bettelei und zu einem, in abwertenderer Weise bezeichneten, „Vagabundieren“ 245 oder ,müßigen Volkes'246 führten. Überall wurden Heime und Korrekturhäuser für die Beherbergung von Bettlern, Heimat-, Arbeits- und Obdachlosen errichtet. ${ }^{247}$

Allerdings reichten diese Anstalten bald nicht mehr aus. So beschloss der Regierungskreis Mecklenburg einen von Major Anton von Schäffer und Graf von der Osten-Sacken ausgehandelten Vertrag mit der brasilianischen Regierung: Der Menschenüberschuss beziehungsweise die emigrationswilligen Landarbeitshäusler sollten auf Landeskosten zu den Auswanderungsschiffen in Hamburg gebracht und nach Brasilien transportiert werden. Gleichzeitig sollten diese unerwünschten Bürger und „Halbmenschen'248, unter ihnen politische Gefangene, Obdachlose, Arbeitslose und arme Familien, die brasilianische Staatsbürgerschaft bekommen. Die Kosten für die Überfahrt und die notwendige Verpflegung übernahm das Einwanderungsland. Unter den Sträflingen und Insassen dieser mecklenburgischen Landarbeits- und Zuchthäusler, die seit 1824 nach Brasilien abtransportiert wurden, befanden sich einige Pommern, wie dem Verzeichnis der Inhaftierten im Kriminalgefängnis zu Bützow, des Landarbeitshauses zu Güstrow und des Zuchtund Stockhauses zu Dömitz zu entnehmen ist. ${ }^{249}$ Auch andere Regierungen wie

\footnotetext{
245 Der Kommandant des Schiffes P. H. Schumacher, mit dem die ersten Landarbeitshäusler nach Brasilien reisten, schrieb über sie: „Es befand sich durchaus kein Verbrecher unter diesen Menschen, denn in Mecklenburg ist Geschäftslosigkeit und Trunkenheit der ärmern Klasse schon binreichend, um im Arbeitshause eingesperrt zu werden". Schumacher, P. H. Beschreibung meiner Reise von Hamburg nach Brasilien im Juni 1824 nebst Nacbrichten über Brasilien bis zum Sommer 1825 und über die Auswanderer dabin. Braunschweig 1826, S. 10f. Zitiert nach Manke, Matthias. "Denn es waren zum Theil nur Halbmenschen". In: Röpke, Andreas (Hrsg.) Mecklenburgische Jabrbücher. 122. Jahrgang, 2007, S. 220. Vgl. Grothe, S. 42

246 Sudhaus, S. 37.

247 Dreher. Sträflinge aus Mecklenburg-Schwerin, S. 22.

248 Manke; vgl, Acta, die erste Abführung von Landarbeitshäusern nach Brasilien betreffend, Blatt 33. In: Mecklenburg Geheimes und Haupt-Archiv Schwerin MLHA Schwerin Kabinett I, Vol. 3. Zitiert nach Dreher. Sträflinge aus Mecklenburg-Schwerin, S. 45.

${ }^{249}$ Es waren: a) Nr. 16: Johannes Christ Jantzen, 28 Jahre aus Kunzow in Steukow, Pommern, inhaftiert wegen Raubmord, vorher Soldat und Schustergeselle; b) Nr. 23: Cath. Dor. Classen verehl. Sellmann, 44 Jahre aus Groewzow in Pommern, inhaftiert wegen Vagabundierens; c) Nr. 13: Daniel Grüder, 34 Jahre aus Abtshagen in Pommern, inhaftiert wegen Mord. Acta, Abführung von Sträflinge und Vagabunden aus Dömitz, Bützow und Güstrow nach Brasilien durch Rittmeister Hanfft, betreffend, (1825), Blätter 15-16, 77-82 und 107-112, In: Mecklb. Geheimes und Haupt-Archiv Schwerin - MLHA Schwerin Kabinnet I. Zitiert nach Dreher. Sträflinge aus Mecklenburg-Scbwerin, S. $132,165,185$.
} 
Hannover, Hamburg 250 und Potsdam ${ }^{251}$ sorgten für den Abtransport ihrer Gefangenen, Sträflinge, Obdach- und Arbeitslosen nach Brasilien. Die preußische Regierung soll über einen möglichen Transport von Sträflingen aus preußischen Gefängnisse verhandelt haben, dieser fand jedoch nicht statt.252 Auch Pommern überlegte sich, einen Vertrag mit Major von Schäffer zu schließen. Das Projekt scheiterte jedoch nach einer Rücksprache mit dem Oberpräsidenten und dem preußischen Innenministerium. ${ }^{253}$ Auf diese Weise sorgte die Verlagerung europäischer Auswanderungskontigente für einen Ausgleich und zur Entspannung der ökonomischen, sozialen und hygienischen Situation in Europa ${ }^{254}$, dem aus diesen Gründen ständig die Entstehung von Rebellion drohte. Der Badenser Konsul Ackermann äußerte sich wie folgend:

„Nur Auswanderung kann die unnatürliche Lage, in die die Staaten geraten sind, ändern. Die überschüssige Massen müssen fort, um den Zurückbleibenden die frühere Rube und das verlorene Glück wiederzugeben". 255

Laut von Tschudi wurde eine Menge „zusammengerafftes Gesindel" als Kolonisten nach Brasilien transportiert. Sie leisteten damit Europa einen sozialen Dienst, das sie los wurde, richteten hingegen in Brasilien eher Schaden an, das viele nicht arbeitswillige und kriminelle Menschen aufnahm. ${ }^{256}$ Während der Transport von Sträflingen als Staatsangelegenheit behandelt und organisiert wurde, blieb die Auswanderung der freien Untertanen völlig ungeleitet. ${ }^{257}$

\subsection{Die zurückhaltende Haltung Preußens zur Auswanderung nach Brasilien}

Anders als beim Transport von Insassen aus Korrekturhäusern und Gefängnissen, über welche Preußen selbst verhandelte, wünschte es sich hingegen keine Auswanderung ihrer unbescholtenen Untertanen nach Brasilien. Preußen setzte sich bis 1890 mit Gesetzen und Abmahnungen dagegen ein, obwohl dadurch die Auswanderungstendenz nicht gestoppt werden konnte. Auf die Interessen und Motive des preußischen Staates soll nun eingegangen werden.

\footnotetext{
${ }^{250}$ Sudhaus, S. 35-37; vgl. Dreher, Sträflinge aus Mecklenburg-Schwerin, S. 21.

251 Josenhaus (Hrsg.) Der Evangelische Heidenbote, Nr. 4, April 1864, S. 39.

252 Hunsche, K. H. Früheste Berichte über Schicksale deutscher Auswanderer nach Brasilien. In: Kalender für die Deutschen in Brasilien, São Leopoldo, 1937. Zitiert nach Sudhaus, S. 33.

253 PLAG Rep. 65c, Nr. 158, S. 1-7. Warnungen von der preußischen Regierung in Berlin vor von Schäffer und seinen Agenten haben darin Einfluss ausgeübt. SAS: Starostwo Powiotowe Gryfice, Nr. 57, S. 16. Zitiert nach Last, S. 65.

254 Prien, Hans-Jürgen. Formaşão da Igreja Evangélica no Brasil. São Leopoldo/Petrópolis: Sinodal/ Vozes, 2001, S. 26; Krause, Lutherische Synode in Brasilien, S. 15.

255 Ackermann, Franz Xaver. Das Kaiserreich Brasilien. Heidelberg: Groos, 1834. Zitiert nach Sudhaus, S. 23.

256 Von Tschudi, Bericht über den Zustand der Kolonien der brasilianischen Provinzen Santa Catharina und San Pedro do Rio Grande do Sul, S. 255.

257 Sudhaus, S. 37.
} 
Die für alle Territorien des Deutschen Bundes geltenden Auswanderungsbestimmungen von 8. Mai 1815 wurden im Laufe des 19. Jahrhunderts wiederholt geändert, entweder um die Auswanderung zu reduzieren oder ihre Bedingungen zu verbessern. ${ }^{258}$ Die preußische Regierung verbat die Anwerbung durch Major von Schäffer, lehnte die Gesuche brasilianischer Gesandter in den 1840er Jahren ab und wollte die großen Emigrationskontingente so weit wie möglich halten, um die militärische und politische Position Preußens aufrechtzuerhalten und die landwirtschaftlichen Regionen in den Grenzgebieten gegen Russland und Polen zu schützen. ${ }^{259}$ Sie wollte die Auswanderung nach Brasilien aber auch aufgrund der negativen Berichte über die schlechten Lebensbedingungen in den Kolonien nicht zulassen, unter anderem um die Rückkehr verarmter Emigranten ${ }^{260}$ und damit mögliche Unkosten ${ }^{261} \mathrm{zu}$ verhindern. Obwohl Preußen die Auswanderung zu verhindern suchte, stellte es keine Anstrengungen an, die Emigrationsursachen zu beheben. 262

Preußische Untertanen durften das Land ohne einen Erlaubnisschein, eine Aufnahmeerklärung Brasiliens mit der „Vergabe des Bürgerrecbtes" und eine Verzichtserklärung auf die preußische Staatsangehörigkeit vorzulegen, nicht verlassen. ${ }^{263}$ Auswanderer, die ohne Pass ausreisen wollten, wurden zurückgewiesen. Sie

${ }^{258}$ Last, S. $6 \mathrm{f}$.

259 Sudhaus, S. 58f. Preußische Auswanderer wurden sogar von den Schiffen geholt, um ihrer Wehrpflicht nicht zu entgehen. Hunsche, Carlos. Pastor Heinrich Wilhelm Hunsche e os comegos da Igreja Evangélica no sul do Brasil. Porto Alegre: Metrópole, 1977, S. 44. Zitiert nach Rölke, Raízes da imigração alemã, S. 99.

${ }^{260}$ Sudhaus, S. 32.

${ }^{261}$ Dreher, Sträflinge aus Mecklenburg-Schwerin, S. 20.

262 Last, S. 55.

263 Dreher, Sträflinge aus Mecklenburg-Schwerin, S. 20; vgl. Gesetz über die Erwerbung und den Verlust der Eigenschaft als Preußischer Unterthan "von 1842 und Eintritt in fremde Staatsdienste von 31.12.1842 \ 15 und 22, PLAG Rep. 65c Nr. 154. Ein Exemplar einer Entlassungsurkunde aus 1873 enthält folgenden Inhalt: "Coeslin, den 17. März 1873. Die unterzeichnete Königliche Regierung bescheinigt biedurch, dass dem Tagelöhner Carl Friedrich Wilhelm Butzke aus Arnhausen im Kreise Belgard, geb. 19. Mai 1845, auf sein Ersuchen und behufs seiner Auswanderung nach Blumenau in Süd-Amerika nebst seiner Ehefrau Emilia Friederike Caroline Erdmann geboren am 9. Dezember 1848 und folgende minderjährigen, unter väterlicher Gewalt stehenden Kindern: 1) Fritz Carl Wilhelm, geboren am 20. Juli 1869, 2) Wilhelm Albert Julius, geboren am 8. August 1872, die Entlassung aus der Preußischen Staatsangebörigkeit erteilt worden ist. Diese EntlassungsUrkunde bewirkt für die ausdrücklich darin genannten Personen mit dem Zeitpunkte der Aushändigung den Verlust der Preußischen Staatsangehörigkeit, sie wird jedoch unwirksam, wenn der Entlassene nicht binnen sechs Monaten vom Tage der Aushändigung der Entlassungs-Urkunde seinen Wohnsitz außerhalb des Bundesgebiets verlegt oder die Staatsangebörigkeit in einem anderen Bundesstaate ervirb (\$) 18 des Gesetzes über die Erwerbung und den Verlust der Bundes[-] und Staatsangehörigkeit vom 1. Juni 1870 B.G.Bl.S. 355. Königliche Preußische Regierung. Abteilung des Innern. Entlassungs-Urkunde 1 A.276.3.73“. Weingärtner, Nelso. Crônica da Comunidade Evangélica de Timbó. Blumenau: Gráfica 43, 1969, S. 10. Der Konsens zur Auswanderung musste schriftlich bei der Provinzialregierung beantragt werden. In den Akten des Stettiner Archivs konnten diktierte Anträge über lose Anschreiben bis hin zu von den Lokalbehörden angefertigten Vordrucken gefunden werden. Für die Erhaltung eines Konsenses mussten die Taufscheine des Familienoberhaupts und der Familienmitglieder, die Entlassungsurkunde aus dem Militärdienst, eine Bescheinigung der Kreisgerichtskommission, dass keine Verhandlungen oder Verfahren gegen sie vorlagen, ein polizei- 
II - Die Pommern und ihre Einwanderung nach Brasilien

mussten zudem beweisen, dass sie keine Schulden hinterließen, die Steuer bezahlt und eine Gebühr von 10\% für das eigene Eigentum entrichtet hatten und dazu noch die Mittel zur Reise (4.000 Gulden oder 226 Taler pro Person) selbst aufbringen. ${ }^{264}$ Nach Leidig nahm die preußische Regierung eine strenge juristische Einstellung gegenüber den Auswanderern ein. Mit der Emigration, die mit dem Entzug der preußischen Staatsangehörigkeit einher ging, spielten sie für die Regierung keine Rolle mehr. ${ }^{265} \mathrm{Ob}$ diese Entlassungsurkunde ihnen bei einer möglichen Rückkehr dabei hinderte, ihre Staatsbürgerschaft zurück zu erwerben, ist durch die Quellen nicht festzustellen.

Der Transport und deren Vermittlung durch Agenten und Auswanderungsunternehmen, wie auch die Konzessionierung der Agenten wurde im Gesetz über die Beförderung von Auswanderern vom 7. Mai 1853 geregelt. ${ }^{266}$ Demzufolge drohte demjenigen Geld- oder Gefängnisstrafe, der ohne Zulassung zum Geschäftsbetrieb Verträge mit Auswanderern zum Zwecke der Beförderung in außerdeutsche Länder abschloss oder vermittelte. ${ }^{267}$ Zur selben Zeit verhandelte Preußen mit Brasilien über die Verbesserung der gesetzlichen Situation der Einwanderer, beispielsweise in Bezug auf die staatliche Anerkennung protestantischer Ehen und der Zusicherung eines Landerwerbs. Aber alle Versuche scheiterten an dem Widerstand der konservativen Partei Brasiliens. Das führte, in Zusammenhang mit dem Druck preußischer Gutsbesitzer gegen die Auswanderung und anderen politischen Interessen, zur Erlassung des Heydtischen Edikts vom 3. November 1859. Dieses verbat unter anderem die Mittel zur Förderung und Werbung für eine Auswanderung nach Brasilien ${ }^{268}$ und die Emigration mit Hilfe eines Darlehens für die Überseefahrt und den Landerwerb ${ }^{269}$ und stellte einen Verstoß unter Geldstrafe. ${ }^{270}$ Das

\footnotetext{
liches Führungszeugnis und der Nachweis über vorhandene Reisemittel ausgehändigt werden. Bei einem positiven Bescheid bekamen sie die Entlassungsurkunde gegen eine Stempelgebühr ausgehändigt. SAS: Starostwo Powiotowe Kolobrzeg, Nr. 63, Blätter 79-327. Zitiert nach Last, S. 69f. Karl Gotthilf Schulz und seine Familie aus Glietzig, Regenwalde, die 1859 nach Espírito Santo auswanderte, reiste bis Stettin, um eine Auswanderungserlaubnis von der Provinzialregierung Pommerns zu erhalten. Später beantragte er noch ein Führungszeugnis, um ihre Unbescholtenheit zu beweisen. Siehe Auswanderungserlaubnis für Karl Gotthilf Schulz, seine Frau Caroline Friederike Ernestina geb. Brandt und Kinder Friedrich August Wilhelm, Wilhermine Caroline Justine, Emilie Ottilie Auguste und Albertine Henriette Wilhermine. Stettin, 12.3.1859; auch das Führungszeugnis. Glietzig, 16.4.1859. Zitiert nach Rölke. Raizes da Imigração alemã, S. $264 f$.

${ }^{264}$ Dreher, Sträflinge aus Mecklenburg-Schwerin, S. 20; Sudhaus, S. $32 \mathrm{f}$.

265 Leidig, S. 438.

266 Sudhaus, S. 107; Last, S. 27.

${ }^{267}$ Leidig, S. 446f.

268 Prien, S. 41. Über Unternehmen, die ihre Konzessionierung verloren, siehe Sudhaus, S. 116.

${ }^{269}$ Rölke, Raíres da imigração alemã, S. 107.

${ }^{270}$ Fischer, Geschichte der Evangelischen Kirche, S. 89. Das Auswanderungsverbot sollte die brasilianische Regierung dazu bringen, folgende Aspekte zu regeln: Anerkennung protestantischer Eheschließungen, Auflösung der Gesellschaft für Kolonisation und Verbot der Parceriaverträge. Die Jurisdiktion in Nachlasssachen sollte an den preußischen Konsul übergeben werden und Protestan-
} 
Edikt machte keinen Unterschied zwischen den verschiedenen Kolonisationstypen und -gebieten Brasiliens. 1871 galt das Emigrationsverbot bereits für das ganze Deutsche Reich. Für die Ansiedlungen in Südbrasilien wurde es erst 1896 aufgehoben. ${ }^{271}$

Mit der Entstehung des Deutschen Reiches 1871 wurden Hoffnungen auf die Aufhebung des Heydtischen Edikts geknüpft. Aber alle Bittschriften und Petitionen der Repräsentanten der Einwanderer und des Deutschtums zur Aufhebung des Edikts und für eine Gleichstellung mit dem Auswanderungsgesetz für Nordamerika wurden abgelehnt. ${ }^{272}$ Der Reichskanzler Bismarck ${ }^{273}$ (1871-1890) entzog der Emigration jede Unterstützung und Förderung, um billigere Arbeitskräfte für die Industrialisierungspläne des Reiches zu sichern. ${ }^{274}$ Er bekam Rückhalt von der Gutsbesitzerpartei, vor allem aus den ostelbischen Gebieten, die bereits in der zweiten Hälfte der 1850er Jahre die Auswanderung aufgrund des Mangels an Arbeitskräften ${ }^{275} \mathrm{zu}$ erschweren und zu bekämpfen versuchte. In diesem Sinne kam die preußische Regierung mit dem Heydtischen Edikt den Interessen der deutschen Großgrundbesitzer entgegen, die für seine Nicht-Aufhebung sorgten. ${ }^{276}$ Eine Aufhebung könnte als Auswanderungsförderung verstanden werden, was gegen die bisher verfolgte Politik Bismarks stand. Außerdem ließen sich die Einwanderer in Brasilien einbürgern und das Reich hatte kein Interesse, die bereits brasilianisch eingebürgerten Deutschen durch den Zuzug weiterer Einwanderer zu mehren. ${ }^{277}$

Das Heydtische Edikt verhinderte aber nicht, dass viele Hunderte auf inoffiziellem Wege nach Brasilien auswanderten, zum Beispiel über andere Häfen oder ohne behördliche Genehmigung und Entlassungspapiere. ${ }^{278}$ Illegale Agenten warben weitere Auswanderungswillige mit Hilfe von Handzetteln an ${ }^{279}$ und der Informationsfluss über die erfolgreichen Lebensläufe der Ausgewanderten war nicht

ten sollten die gleichen Unterstützungen bei Kirchbauten erhalten wie Katholiken. Schröder, Brasilien und Wittenberg, S. 47f.

271 Willems, S. 47.

${ }^{272}$ Schulze, S. 94, 155f, 171.

${ }^{273}$ Laut Bismarck war ein Deutscher, der seine Heimat verlassen hatte, kein Deutscher mehr und verdiente keine Solidarität seitens seiner ehemaligen Landsleute. Dreher, Igreja e Germanidade, S. 43. Er bezeichnete die Auswanderer als „Verräter des Vaterlandes“. Sudhaus, S. 158. 1868 intervenierte Bismarck auch gegen die Angliederung der ersten evangelischen Synode in Rio Grande do Sul an den Evangelischen Oberkirchenrat. Dreher, Igreja e Germanidade, S. 44, Fußnote 23.

${ }^{274}$ Martinuzzo, S. 55; Siller, S. 23.

${ }^{275} \mathrm{Um}$ die Arbeitskraft zu ersetzen mussten Landbesitzer ausländische Arbeiter, besonders aus Polen, einstellen. Thiel; Neumann, S. 374.

276 Sudhaus, S. 159.

277 Promemoria betreffend die Auswanderung nach Brasilien und die Frage der eventuellen Aufhebung der in Preussen und einigen anderen deutschen Staaten in Geltung stehenden RepressivVorschriften, 18.11.1885, DZA Potsdam, AA Nr. 30252, Bl. 107-114. Zitiert nach Prien, S. 43.

278 Sudhaus, S. 29. Einzelne Passagiere sollten heimlich oder mit falschen Namen gereist haben. Roos; Eshuis, S. 20.

279 SAS: Starostwo Powiotowe Gryfice, Nr. 58, Blatt 240f; SAS: Starostwo Powiotowe Kolobrzeg, Nr. 62. In der Akte sind keine Blattangaben vorhanden. Zitiert nach Last, S. 57. 
zu kontrollieren. Wer die nötigen Papiere nicht schon vor der Einschiffung besaß, erhielt ein ähnlich aussagekräftiges Dokument vom Generalagenten des Zentralen Kolonisationsverbands von Rio de Janeiro (RJ) in Hamburg, Dr. F. Schmidt. ${ }^{280}$ Es erfolgte keine nennenswerte Abnahme der Auswanderung durch das Edikt. ${ }^{281}$

Als Leo von Caprivi (1890-1894) auf Bismarck als Reichskanzler folgte, wurde die ablehnende Haltung gegenüber der Auswanderung revidiert. Eine gesamtdeutsche Regelung zur Auswanderung erfolgte aber erst durch das Reichsgesetz von 1897282 , das ein freies Auswanderungsrecht für Reichsangehörige verkündete. Das Gesetz legte eine Konzessionspflicht für Emigrationsunternehmer und Kolonisationsgesellschaften fest und organisierte die Auswanderungsberatung unter der Leitung des Außenministeriums. Dieses erteilte für bestimmte Länder oder Landesteile und für bestimmte Einschiffungshäfen eine Auswanderungserlaubnis und lenkte auf dieser Weise die Emigration in geeignete Gebiete. ${ }^{283}$ Aber der Plan einer gesteuerten Auswanderung scheiterte, zum einen wegen der aufsteigenden Wirtschaftskonjunktur Deutschlands im Jahr 1896, wodurch sich die Anzahl der Auswanderungswilligen verringerte. Zum anderen aufgrund der US-amerikanischen Absichten in Brasilien im Sinne der Monroe-Doktrin eine Unabhängigkeit amerikanischer Länder von europäischen Märkten zu erzielen. Weitere Gründe waren außerdem die gleichgültige und manchmal ablehnende Haltung vieler Deutschbrasilianer gegenüber deutschen Expansionsbestrebungen und letztendlich der Ausbruch des Ersten Weltkriegs. ${ }^{284}$

\subsection{Wirtschaftliche, expansionistische und ideologische Interessen bei den Einwanderern in Brasilien}

Obwohl die preußische Regierung bis 1890 eine zurückhaltende Position in Bezug zur Auswanderung nach Brasilien vertrat, setzten sich verschiedene Kräfte von Anfang an für ihre Förderung entsprechend ihrer kommerziellen, expansionistischen und ideologischen Ziele ein. Deutsche Einwanderer in Brasilien sollten ein „neues Deutschland“ bilden und zur Entstehung eines ,großen Deutschlands" weltweit beitragen.

Bereits in den 1820er Jahren erkannten die Hafenstädte Hamburg und Bremen die Bedeutung der Auswanderung nach Brasilien für den deutschen Handel, denn deutsche Siedlungen könnten sich zu wichtigen Handelsgebieten und Konsumen-

\footnotetext{
${ }^{280}$ Gesundheitsgutachten von 26.4.1859 und Gutachten von Dr. Carl Er. Cordes an die Auswanderer, Hamburg, 27.4.1859. In: APEES, Livro de Contratos 1859-1860. Zitiert nach Rölke, Raízes da Imigração alemã, S. 267-270.

281 Last, S. 45.

282 Last, S. 27, 29.

283 Wirth, Lauri Emilio. Protestantismus und Kolonisation in Brasilien. Erlangen: Verlag der Ev- Luth. Mission, 1992, S. 39. Vgl. Braunschweig. Die Evangelische Diaspora deutscher Zunge in Brasilien, vornehmlich in Rio Grande do Sul, 24.9.1908, S. 114, EZA 200/1/2152.

284 Wirth, S. 39.
} 
ten deutscher Industrieerzeugnisse entwickeln. ${ }^{285}$ Im Juli 1827 unterschrieb PreuBen einen hanseatisch-brasilianischen Freundschafts-, Schifffahrts- und Handelsvertrag mit Brasilien. 286 War die Auswanderung zunächst eine innenpolitische und soziale Frage, wurde sie in den 1830er und 1840er Jahren auf diese Weise zu einer staatlich-nationalen und ökonomisch wichtigen Angelegenheit.

Weil Brasilien in Bezug auf den internationalen Handel von England abhängig war und Hamburg seine führende Stellung hinsichtlich des Auswanderertransports gegenüber Bremen nicht verlieren wollte ${ }^{287}$, setzten sich Vertreter des Hamburger Großhandels und Schiffsgesellschaften für die Anlegung von brasilianischen Landwirtschaftskolonien ein. Ihre handelspolitischen Interessen führten zur Gründung von Auswanderungs- und Kolonisationsgesellschaften, unter ihnen der Verein zum Schutze der deutschen Auswanderer 1845/1846 und der Kolonisationsverein von 1849, beides in Hamburg gegründete kaufmännischen Aktionärvereine. Der erste sandte 1846 Dr. Hermann Blumenau nach Brasilien, wo er 1850 die Kolonie Blumenau (SC) gründete. Der Kolonisationsverein legte 1851 auf dem Erbgut der Prinzessin Francisca und ihres Ehegatte Prinz von Joinville die Kolonie Dona Francisca-Joinville (SC) an. ${ }^{288}$

Die deutschen Staaten wollten auch nicht zusehen, wie ihre Untertanen für das deutsche Volk verloren gingen. ${ }^{289}$ So stellte der Bremer Syndikus Gildemeister den Plan vor, „in Südamerika für Deutschland das erstehen zu lassen, was Nordamerika für England bedeutete "290 Die Auswanderung sollte von Nordamerika nach Südbrasilien umgeleitet werden, um ein „Neudeutschland über See“ zu schaffen. ${ }^{291}$ Dies stand im Zusammenhang mit Einigungsbestrebungen, die 1848 zum Ausdruck kamen, und mit einem Mangel an deutschen Kolonien in Übersee. Preußen erlangte aufgrund des wachsenden Industrialisierungsprozesses und der militärischen Siege gegen Dänemark (1864), Österreich (1866) und Frankreich (1871) eine ökonomische und politische Hegemonie, die das patriotische Gefühl der Bevölkerung förderte und zur Entstehung des Deutschen Reiches 1871 führte. ${ }^{292}$ Durch diesen Geist beeinflusst, hatten die Auswanderungsförderer die Ausdehnung des Kapitalismus durch Gewinnung neuer Märkte in Übersee, in enger Verbindung mit der Pflege deutscher Sprache und Sitte unter Einwanderern und deren Nachkommen, zum

\footnotetext{
285 Sudhaus, S. 38.

286 Prien, S. 32.

${ }^{287}$ Last, S. 44.

288 Wirth, S. 35.

289 Die Emigranten, die nach den USA, Kanada, Russland und Australien ausgewandert waren, galten als assimiliert und für die Heimat verloren. Sie entwickelten sich zu Herstellern und Konsumenten von Industrieprodukten konkurrierender Nationen. Statt nach Nordamerika, das einen Konkurrenzmarkt für Deutschland darstellte, sollten Länder in Zentral- und Südamerika, vor allem Südchile, Brasilien und Uruguay als Auswanderungsalternative dienen. Gaebler. Deutsche Auswanderung und Kolonisation, S. 3f, 7, 21, PLAG Rep. 65c Nr. 163.

${ }^{290}$ Schröder, Brasilien und Wittenberg, S. 14.

291 Sudhaus, S. 47, 49; Wirth, S. 35.

292 Rölke, S. 57 f.
} 
Ziel. ${ }^{293}$ Nach Gaebler bildete die Kolonisation eine Industrie, für welche das Deutsche Reich im reichen Maße über das „(Kolonisten)-Material“ verfügte und gegenüber Zentralamerika, Südbrasilien, Südchile und Uruguay hinreichendes Kapital zu Gebote stand, „um zu den dort üblichen hohen Zinsen jene Industrie auch auszubeuten" 294 Diese Bestrebungen sollen nach Sudhaus zunächst eines staatlichpolitischen Charakter entbehrt haben und verfolgten rein handelswirtschaftliche Ziele. Eine staatsrechtliche Erwerbung von Gebieten kam nicht in Frage, weil die Zeit kolonialer Abhängigkeit als beendet angesehen wurde. ${ }^{295}$

1883 unterstützte die Kolonisationsgesellschaft und 1885 der Landwirtschaftsrat eine Lenkung der Auswanderung in Richtung der südlichen Provinzen Brasiliens. Dort waren die deutschen Siedlungsgebiete dem kulturellen Einfluss der Brasilianer angeblich weniger ausgesetzt und es existierten auch keine Halbpachtkolonien. Die Südamerikanische Kolonisationsgesellschaft, die 1882 durch den Verein für Handelsgeographie gegründet wurde, und die 1886 von der Deutschen Koloniegesellschaft ins Leben gerufene Gesellschaft für die deutsche Ansiedlung in Südamerika „Hermann" zielten auf den Erwerb großer Landstriche für die Ansiedlung von Kolonisten ab. ${ }^{296}$

In diesem Kontext begann auch das Deutsche Reich, durch den Erwerb deutscher Schutzgebiete ${ }^{297}$, die frei verfügbar und von keinem anderen Land beansprucht wurden, verstärkt territoriale Expansionsbestrebungen in Übersee zu entwickeln. Zu diesem Zweck instrumentalisierte es die deutschen Schulen und die Presse im Ausland und den Besuch der deutschen Kriegsmarine in deutschen Kolonisationsgebieten als ideologisches Propagandamittel.298 Die deutschnationalistischen Gefühle der Einwanderer und deren Nachkommen sollten gefördert werden, damit sie sich mit der alten Heimat verbunden fühlten. In diesem Geist wurde bereits 1881 der Allgemeine Deutsche Schulverein zur Erhaltung des Deutschtums im Ausland gegründet. ${ }^{299}$ Er setzte sich für die Errichtung deutscher Schulen

293 Wernicke, Hugo. Viagem pelas colônias alemãs do Espirito Santo. Vitória: Arquivo Público do Estado do Espírito Santo, 2013, S. 16. Über den Kolonialdiskurs für Rio Grande do Sul siehe Schulze, S. 105-181.

${ }^{294}$ Gaebler. Deutsche Auswanderung und Kolonisation, Berlin, 1850, S. 22, PLAG Rep. 65c Nr. 163.

295 Sudhaus, S. 48.

296 Prien, S. 42. In der Provinz Rio Grande do Sul sollten Ländereien für die Siedlung deutscher Immigranten angekauft werden. Ein ähnliches Projekt wurde für Santa Catarina und Paraná geplant, mit Genehmigungen für Eisenbahnbau und industriellen Einrichtungen. Sudhaus, S. 164.

297 Wellnitz, Britta. Deutsche evangelische Gemeinden im Ausland. Tübingen: Mohr Siebeck, 2003, S. 18, 20-22; vgl. Sudhaus, S. 54; Py, Aurélio da Silva. A $5^{a}$ Coluna no Brasil. Porto Alegre: Globo, 1942, S. 12-17. Tannenberg stellte 1911 den brasilianischen Staat Rio Grande do Sul und lateinamerikanische Länder, wie Paraguay, Uruguay und Chile als Teil eines „deutschen Protektorats in Südamerika" dar. Tannenberg, Otto Richard. Groß-Deutschland. Die Arbeit des 20. Jahrbunderts. Leipzig/Gohlis: Volger, 1911. Zitiert nach Py, S. 12-14.

298 Dreher, Martin Norberto. História do Povo Luterano. São Leopoldo: Sinodal, 2005, S. 55.

${ }^{299}$ Er wurde 1908 als Verein für das Deutschtum im Ausland rekonstituiert. Prien, S. 351; Wirth, S. 40. Über die Deutschtumspolitik in Rio Grande do Sul siehe Schulze, S. 46-104. 
im Ausland, die Anstellung deutscher Lehrkräfte, die Verbreitung deutscher Literatur und die Finanzierung deutschbrasilianischer Studenten im Deutschen Reich ein. ${ }^{300}$ Die Zentralstelle für die Forscbung des Deutschtums im Ausland finanzierte Forschungsprojekte zur Unterstützung der Auswanderung und Förderung des Deutschtums im Ausland. Dadurch wurde versucht, eine Elite von Deutschbrasilianern zur Bewahrung des Deutschtums zu bilden. ${ }^{301}$ Die Herausgabe von Büchern und Artikel über die Auslandsdeutschen und über Brasilien diente teilweise unbewusst kolonisatorischen Zielen. ${ }^{302}$ Seit 1889 unterstützte das Auswärtige Amt finanziell deutschsprachige Schulen, die Förderung kultureller Belange und die deutsche Presse in Brasilien. Die 1903 gegründete Ortsgruppe Hamburg des Allgemeinen deutschen Schulvereins zur Erbaltung des Deutschtums im Ausland, die ,im engen Einvernehmen" mit der Hamburgischen Handelskammer, der Hanseatischen Kolonisationsgesellschaft und den Oberschulbebörden entstand, arbeitete wiederum in Verbindung mit den in Brasilien tätigen deutschen kirchlichen Organisationen auf die Verbreitung der Deutschtumspolitik hin. .03

1890 wurde der Alldeutsche Verband ins Leben gerufen. Für die Gründung neuer und differenzierter Märkte im Ausland ersetzte er territoriale Eroberungspläne durch eine intra-kapitalistische Konkurrenz und politische und ideologische Propaganda. Eine intellektuelle Elite von Journalisten, Unternehmern, Händlern und Geistlichen engagierte sich für eine technische, wissenschaftliche und militärische Kooperation mit diplomatischen Ansätzen, um die Aufmerksamkeit lateinamerikanischer Eliten für den deutschen Markt zu gewinnen. Diese Elite investierte in Propaganda über die Überlegenheit des deutschen Volkes, seiner Kultur und Wirtschaft. Eine Unterstützung ihrer Ideen fanden sie jedoch nicht im Reichskanzler Bismarck (1871-1890). Dieser interessierte sich nicht für derartige Strategien, die die guten Beziehungen zu den Vereinigten Staaten gefährden könnten. Er billigte keinen militärischen Einsatz in Übersee oder die Bildung eines bürokratischen Apparates, was zwangsläufig im Falle einer derartigen Expansion nötig gewesen wäre. Stattdessen förderte er den freien Handel per Gesetzgebung. ${ }^{304}$

Unabhängig davon strebte der Alldeutscher Verband die Entwicklung des deutschen Nationalcharakters unter den Deutschen weltweit, die Bewahrung der deutschen Sitten und eine Vereinigung des Deutschtums an. Um diese Ziele zu erreichen, arbeitete er an einer Erweckung des nationalen Bewusstseins in der Heimat, an der Orientierung der Erziehung und Schule im deutschen Nationalgeist, an der Bewahrung deutscher Eigenart in allen Ländern mit deutschen Einwanderern und

\footnotetext{
300 Schulze, S. 289-305.

301 Magalhães, Pangermanismo e nazismo, S. 105-107.

302 Schulze, S. 286-289.

303 Wirth, S. 40, 93.

304 Magalhães, Marionilde Brepohl de. Racismo no sul do Brasil: heranças de um mito. In: Revista História. São Paulo, Nr. 129-131, ago-dez 1993, ago-dez 1994, S. $166 f$.
} 
an der Forderung einer energischen expansionistischen Politik. ${ }^{305}$ Zusammen mit der Deutschen Koloniegesellschaft und der Hanseatischen Kolonisationsgesellschaft unterstützte er den deutschen Kolonialismus und förderte durch deutsche Schulen, Presse, Kirchen und Vereine in Brasilien die Verbreitung der Ideologie eines „großen Deutschlands" und die Bewahrung des Deutschtums. ${ }^{306}$

Mit der Erklärung Brasiliens zur Republik 1889 hofften einige Kolonialexpansionisten, dass sich nach dem Sturz der Monarchie und dem Interessenskonflikt zwischen den nördlichen und südlichen Provinzen, eine deutsch-südbrasilianische Republik in Brasilien entwickeln würde. Grund für diese Hoffnungen gaben ihnen zum Teil die Bürgerkriege, die in den ersten fünf Jahren der Republik in verschiedenen brasilianischen Provinzen ausbrachen und vornehmlich Auskunft über die Unzufriedenheit des Volkes mit der Regierung gab. Auf diese Weise dachten die Kolonialexpansionisten, dass die deutschen Einwanderer und deren Nachkommen sich aktiv an einer Revolution zur Unabhängigkeit der südlichen Provinzen beteiligen würden. ${ }^{307}$ Vor allem aufgrund der Dauer und Wildheit der Föderalistischen Revolution (1893-1895) im Süden und angesichts der dortigen großen Anzahl deutscher Einwanderer und deren Nachkommen und ihres wirtschaftlichen Einflusses, wuchs ihre Zuversicht auf eine Abtrennung von Brasilien. In der Zeitung Der Deutsche Ansiedler schrieb der Leiter der Rheinischen Mission und des Comités für die protestantischen Deutschen in Brasilien, Friedrich Fabri:

„Für die Entwicklung des Deutschtums überhaupt wird die Ausrufung der Republik eher günstige als nachteilige Folgen bringen. Es ist keinerlei Aussicht, daß Brasilien sich als einheitlicher Freistaat auf längere Dauer halten werde. Das Land ist zu ausgedehnt... und die wirtschaftlichen und sozialen Interessen von Nord-, Mittel- und Südbrasilien sind zu entgegengesetzt... Die Bildung mehrerer, vielleicht vieler Republiken wird aber auch die Stellung der Deutschen in Südbrasilien stärken und ibren Einfluß in den betreffenden Provinzen heben "308

Nach Fabri könnten die südlichen Provinzen Brasiliens eine landwirtschaftliche Kolonie Deutschlands bilden und sich zum Handelsplatz deutscher Produkte entwickeln. Dafür müsse der deutsche Kaiser mit der brasilianischen Regierung über eine größere Einwanderung nach Südbrasilien verhandeln. ${ }^{309}$ Südbrasilien würde unabhängig bleiben, aber mit Deutschland durch finanzielle, kommerzielle und kulturelle Beziehungen verbunden sein oder ein deutsches militärisches Protektorat bilden. 310

\footnotetext{
305 Der Urwaldsbote Kalender, 1900, Blumenau, S. 101. Zitiert nach Seyferth, Giralda. Nacionalismo e identidade étnica. Florianópolis: Fundação Catarinense de Cultura, 1981, S. $35 \mathrm{f}$.

306 Magalhães, Pangermanismo e nazismo, S. $41 \mathrm{f}$.

307 Dreher, Igreja e Germanidade, S. 44; Wernicke, S. 15.

308 Der Deutsche Ansiedler 1, 1890, S. 4f. Zitiert nach Wirth, S. 53, Anmerkung 32.

309 Dreher, Igreja e Germanidade, S. 83f.

310 Sievers, Wilhelm. Südamerika und die deutschen Interessen, 1903. Zitiert nach Py, S. 14f.
} 
Als sich die Bestrebung einer politischen Einverleibung der südlichen Provinzen Brasiliens als undurchführbar erwies, setzten sich die Verteidiger des deutschen Expansionismus nun für die Bewahrung des Deutschtums und des deutschen Volkstums unter den Einwanderern und deren Nachkommen ein. Seit dem Rücktritt Bismarcks 1890 beteiligten sich zunehmend deutsche Unternehmer, nicht nur aufgrund missionarischer, expansionistischer und nationalistischer Ziele, sondern auch beseelt von einem pragmatischen Geist, verstärkt an der wirtschaftlichen Erschließung und Besiedlung Südbrasiliens. Bahnbau- und Siedlungsgesellschaften brachten die enge Verflechtung wirtschaftlicher Interessen mit dem Bestreben, die deutsche Auswanderung zu fördern, zum Ausdruck. ${ }^{311}$

Die Deutschtumspolitik entwickelte sich, besonders nach der Aufhebung des Heydtischen Edikts von 1896, auf aggressive Weise. Deutsche Presse, Schulen, Kirchen und Vereine wurden stärker als zuvor gefördert und unterstützt ${ }^{312}$, deutsche Konsule und Diplomaten bereisten die Kolonisationsgebiete, die deutsche Marine landete in brasilianischen Häfen und Matrosen besuchten die Siedlungen, um in den Siedlern patriotische Gefühle für die alte Heimat zu erzeugen. ${ }^{313}$ Das deutsche Konsulat in Rio de Janeiro (RJ) zum Beispiel dekorierte ehemalige Soldaten in Santa Leopoldina (ES), die in den deutschen Einigungskriegen gekämpft hatten. ${ }^{314}$ Zwischen 1893 bis 1913 gewährte das Deutsche Reich den Deutschbrasilianern das Recht, die deutsche Staatsangehörigkeit zu erlangen. ${ }^{315} 1913$ ermöglichte das Delbrückgesetz eine doppelte Nationalangehörigkeit für Auslandsdeutsche. ${ }^{316}$

Zur Beförderung kultureller, staatspolitischer und wirtschaftlicher Interessen dienten auch kirchliche Missionsvereine und Bibelgesellschaften. ${ }^{317} 1896$ wurde in Witzenhausen a.d. Werra der Evangelische Hauptverein für deutsche Ansiedler und Auswanderer gegründet, ein Kolonialamt oder Auswärtiges Amt für das evangelische Deutschtum im Ausland. ${ }^{118}$ Die Evangelische Gesellschaft für die protestantischen Deutschen in Amerika bekam finanzielle Unterstützung vom Evangelischen Oberkirchenrat, vom Evangelischen Verein der Gustav-Adolf-Stiftung und vom 1901 gegründeten Verein zur Pflege evangelischen Deutschtums in außeneuropäischen Ländern (seit 1905 Verein

\footnotetext{
311 Hier ist auf die Rio-Grande Nordwestbahn- und Siedlungsgesellschaft, die 1898 eine Konzession für den Bau einer Bahnstrecke und für die Kolonisation im Gebiet der Sieben Missionen (RS), und auf die Santa Catharina-Eisenbahn-Aktiengesellschaft beim Bau der Eisenbahnlinie Blumenau über Hansa bis Rio Grande-São Paulo hinzuweisen. Diese waren Unternehmen der Deutschen Bank, der Disconto-Gesellschaft mit dem Schaffhausenschen Bankverein, der Bank für Handel und Industrie und des D. Bleichröder. Sudhaus, S. 180f. Nach Schulze waren sie aber Verlustgeschäfte. Schulze, S. 58.

312 Dreher, Igreja e Germanidade, S. 45; Fonseca, Maria Angela Peter da. Estratégias para a Preservação do Germanismo (Deutschtum). Pelotas: Universidade Federal de Pelotas, 2007, S. 30.

313 Dreher, Igreja e Germanidade, S. 45f; Schulze, S. 62.

314 Wernicke, S. $93 \mathrm{f}$.

315 Magalhães, Pangermanismo e nazismo, S. 111f.

${ }^{316}$ Es wurde auch als Reichs- oder Staatsangehörigkeitsgesetz bezeichnet. Seyferth, S. 125.

317 Krause, Lutherische Synode in Brasilien, S. 19f.

318 Prien, S. 348f.
} 
Diaspora) ${ }^{319}$ und sorgte für die Finanzierung von Kirchen und Schulen in deutscher Sprache im Ausland. Auch wenn diese Institutionen einerseits expansionistische Interessen unterstützten, setzten sie sich andererseits auch für die geistliche und schulische Betreuung ihrer pfarrerlosen Glaubensbrüder in der Diaspora ein. 320

Seit 1900 konnten sich kirchliche Gemeinden im Ausland dem Berliner Oberkirchenrat anschließen, um personelle und finanzielle Unterstützung zu bekommen. ${ }^{321}$ So verwandelten sich die Gemeinden in Brasilien zu „Auslandsgemeinden". Durch das Gesetz vom 7. Mai 1907 konnten sie sich auch an die Preußische Landeskirche angliedern. Der Oberkirchenrat bekam dadurch die Macht, Einwanderergemeinden $\mathrm{zu}$ institutionalisieren und sich in kirchliche Fragen einzumischen. Letztendlich beeinflusste er somit das Profil evangelischer Gemeinden in Brasilien. ${ }^{322}$ Das Deutsche Reich subventionierte jährlich über den Schulfond des Außenministeriums die Erhaltung des deutschen Schulwesens in Brasilien, die Besoldung von Lehrkräften, Ausbildungsseminare und Ausgaben für didaktische Bücher und Materialien. ${ }^{323}$

1913 schlossen sich Unternehmen in Hamburg zur Vereinigung zur Förderung deutsch-brasilianischer Handelsinteressen zusammen. Schulze stellt aber fest, dass das Hauptinteresse deutscher Firmen nicht auf deutschen Emigranten lag, denn diese gründeten ihre Unternehmen vielmehr in den brasilianischen Staaten Rio de Janeiro und São Paulo. Projekte im Süden verzeichneten eher Verluste, so dass Vertreter deutscher Firmen nach Schulze keine wichtige Rolle für die Deutschtumspolitik gespielt haben können. ${ }^{324}$

Mit dem Ausbruch des Ersten Weltkrieges (1914-1918) bekamen die Deutschtumsideologie und die Aktivität des Alldentschen Verbandes neue Impulse. Ein patriotisches und nationales deutsches Bewusstsein und ein sehnsüchtiges Heimatgefühl ${ }^{325}$ mit einer stärkeren Bewertung von Ethnie, Kultur und Sprache wurden unter den Einwanderern und deren Nachkommen in Brasilien erzeugt, begünstigt unter anderem durch die Spannungen mit der brasilianischen Gesellschaft und die Anhängerschaft des Panamerikanismus seitens einer brasilianischen Elite. Deutsche Kaisertruppen landeten wieder in brasilianischen Häfen und besuchten Koloniegebieten, wo sie überall feierlich empfangen wurden. ${ }^{326}$

\footnotetext{
319 Schulze, S. 76.

320 Magalhães, Racismo no sul do Brasil, S. $23 \mathrm{f}$.

321 Dreher, História do Povo Luterano, S. 55; Schulze, S. 77.

322 Dreher, História do Povo Luterano, S. 56; Dreher, Igreja e Germanidade, S. 125-164.

323 Dreher, Igreja e Germanidade, S. 45; Wernicke, S. 93.

324 Schulze, S. $57 \mathrm{f}$.

325 Perazzo, S. 50.

326 Grube, Karl. Bei deutschen Brüdern im Urwald Brasiliens. Leipzig: Dieterich, 1916, S. 100-103.
} 
Die Weimarer Republik (1918-1933) versuchte bald nach dem Ersten Weltkrieg eine freundschaftliche Beziehung zu Brasilien aufzubauen. ${ }^{327}$ Aufgrund der deutschen Kriegsniederlage und der dem Deutschen Reich international aufgezwungenen Sanktionen und Demütigungen entstand ein fruchtbarer Boden für den aufkommenden Nationalsozialismus und den damit verbundenen expansionistischen Gedanken. Der Verein für das Deutschtum im Ausland nahm seine Arbeit in Brasilien 1919 wieder auf, um Führungsinstanzen für deutschsprachige Schulen in Brasilien zu stellen. ${ }^{328} 1919$ gründete er den Deutschen Schutzbund für Grenz- und Auslandsdeutsche. 1922 wurde der Deutsche Evangelische Kirchenbund gegründet, der ab 1924 den Anschluss ausländischer Gemeinden ermöglichte. ${ }^{329}$ Ab 1925 fanden in Deutschland jährlich die sogenannten Tagungen des Auslandsdeutschtums statt, die durch nationalsozialistische Organisationen unterstützt wurden und auf die Integration der Auslandsdeutschen zugunsten der Interessen des Deutschen Reiches abzielten. ${ }^{330}$ Die deutsche Kulturpolitik arbeitete seit den 1930er Jahren systematisch an der Verbreitung von Informations- und Propagandamaterial über das Deutsche Reich für Deutsche und Deutschstämmige. ${ }^{331}$ Reisende, unter ihnen der Reichskanzler Hans Luther, besuchten Siedlungsgebiete, um die Beziehungen zwischen Deutschland und Auslandsdeutschen zu pflegen. ${ }^{332}$

Die Ziele des Alldeutschen Verbandes wurden von der Nationalsozialistischen Deutschen Arbeiterpartei (NSDAP) kompromisslos für die Entstehung eines „Großen Deutschlands" übernommen. ${ }^{333}$ Die Einrichtungen, durch welche das Deutschtum im Ausland gepflegt wurde, nämlich Kirche, Schule und Vereine, wurden mehr oder weniger von der nationalsozialistischen Ideologie beeinflusst. Die nationalsozialistische Ideologie wurde auch durch das Deutsche Auslandsinstitut und die Auslandsorganisation der NSDAP unterstützt und deutschbrasilianische Sympathisanten des Nationalsozialismus ohne deutsche Staatsangehörigkeit konnten sich dem Bund der Freunde der Hitlerbewegung anschließen. ${ }^{334}$ Der Verein für das Deutschtum im Ausland entwickelte sich 1933 wiederum zum Instrument der nationalsozialistischen Aktivität im Ausland. ${ }^{335}$ Vielerorts koordinierten Nationalsozialisten Deutschtumsverbände und verbanden diese mit Antisemitismus und Rassismus. 336 Neue Propagandastrategien hatten die Formation nationalsozialistischer Orts-

\footnotetext{
327 Der Minister Plehn besuchte 1921 den Staatsgouverneur in Florianópolis (SC) und die deutschen Kolonien Brusque (SC), Blumenau (SC), Jaraguá do Sul (SC) und Joinville (SC), um Sympathien für Deutschland und Unterstützung für einen deutschen Wiederaufstieg zu gewinnen. Krause, Lutherische Synode in Brasilien, S. 164f.

328 Wirth, S. 124.

${ }^{329}$ Dreher, Igreja e Germanidade, S. 17.

330 Seyferth, S. 89.

331 Schulze, S. 67; Magalhães, Pangermanismo e Nazismo, S. 129.

332 Schulze, S. 67.

${ }^{333}$ Seyferth, S. 41.

334 Magalhães, Pangermanismo e nazismo, S. 135f.

335 Prien, S. 351.

336 Schulze, S. 68.
} 
gruppen in Brasilien zum Ziel. Deutsche Schauspielergruppen, Spielscharen, Künstler und Zirkusse und die Fahrten der Zeppeline zwischen 1930 bis 1937 in Curitiba (PR), Joinville (SC), Pelotas (RS) und Porto Alegre (RS) sollten die Begeisterung für Deutschland erneut wecken. ${ }^{337}$ Deutschbrasilianische Studenten und Lehrer ließen sich in Deutschland mit finanzieller Unterstützung des Deutschen Bundes im Ausland und der deutschen Kirche ausbilden ${ }^{338}$ und Jugendliche bekamen die finanziellen Mittel für eine Reise in die Heimat ihrer Vorfahren. 339 Manche Gymnasien und Schulen erhielten Prämien und Richtlinien für den deutschen Unterricht im Ausland ${ }^{340}$ und bekamen ihre Bücher durch die Mittelstelle für deutsche Auslandsbüchereien zum Geschenk. ${ }^{341}$

Der Nationalsozialismus beabsichtigte die Bildung einer weltumspannenden deutschen Volksgemeinschaft und die Einbeziehung der von ihnen sogenannten „Auslandsdeutschen“ oder „Volkesgenossen"342 in völkisch-ideologischer, kultureller, teilweise auch in politischer und wirtschaftlicher Hinsicht. Das wurde wieder durch kirchliche und staatlich gebundene Organisationen gefördert. ${ }^{343}$ Die Deutschen im Ausland dienten ideologisch für die Bestrebungen einer deutschen Welthegemonie, obwohl Schulze davon ausgeht, das Deutschtum im Übersee habe zu dieser Zeit an Bedeutung verloren und die deutsche Außenpolitik habe sich in Lateinamerika auf die Förderung des Außenhandels beschränkt. ${ }^{344}$ Laut Magalhães sollten aber Auslandsdeutsche Repräsentanten des Deutschen Reiches im Ausland sein und möglicherweise eine militärische Reserve bilden. ${ }^{345}$

\footnotetext{
337 Schulze, S. 68; Arbeitsgemeinschaft 25. Juli in Rio Grande do Sul (Hrsg.) Kurze Geschichte der deutschen Einwanderung in Rio Grande do Sul. São Leopoldo: Rotermund, 1936, S. 88. Die Arbeitsgemeinschaft 25. Juli wurde 1936 unter Vorsitz von Fritz Rotermund, Sohn des Pastors Dr. Wilhelm Rotermund, konstituiert. Der Name leitet sich vom Tag, als die ersten Einwanderer in São Leopoldo (RS), am 25.7.1824, ankamen ab. 1927 wurde dieser Tag zu einem lokalen Feiertag, 1934 als Feiertag für ganz Rio Grande do Sul erklärt. Schulze, S. 101.

338 Bericht des Inspektorchefs Armin Walter Bernhardt an den Polizeichef, Porto Alegre, 14.7.1938. Zitiert nach Py, S. 195, siehe auch S. 223. 1937 beantragte Pastor Knäpper ein Stipendium für zwei oder drei Lehrer, damit sie sich mit der Hitlerjugend und der volksdeutschen Arbeit in Deutschland bekannt machen konnten. Prien, S. 393.

339 Grothe, S. 96-99.

${ }^{340}$ Bericht des Inspektorchefs Armin Walter Bernhard an den Polizeichef Aurélio da Silva Py. Zitiert nach Py, S. $195 f$.

341 Prien, S. 387; auch Fußnote 311 mit einer Auflistung von Büchern, die der Riograndenser Synode geschenkt wurden. Schinke erwähnt den Kontakt zwischen einem deutschen Lehrer in Brasilien, Erich Schulz, mit einer deutschen Lehrerin in Deutschland, Hedwig Pfleiderer, die ihm Zeitschriften und Indoktrinationsbriefe schickte. Auch der Korrespondent des Instituts für Auslandskunde, Friedrich Esser, verspricht ihm regelmäßig Zeitungen und Zeitschriften zu senden. Kaethe Kaiser schickte ihm letztendlich auch Bilderbogen deutscher Soldaten und einen Flottenkalender. Schinke, Werner H. E. Erich Schulr, 1898-1974. Lageado: UNIVATES, 2013, S. 68-71.

342 Py, S. 308f.

${ }^{343}$ Krause, Lutherische Synode in Brasilien, S. 258; Dreher, Igreja e Germanidade, S. 83-87.

${ }^{344}$ Schulze, S. 68.

345 Vertrauliche Korrespondenz von Bohle an die Auslandsorganisation der NSDAP, 1937. In: Archiv für Zeitgeschichte München. Zitiert nach Magalhães, Racismo no sul do Brasil, S. 174.
} 
Wenn auch die preußischen Einwanderer zunächst ihre Staatsangehörigkeit mit ihrer Auswanderung verloren, blieben sie entsprechend der nationalistischen Weltanschauung aufgrund ihrer Abstammung immer „Deutsche“, auch wenn sie in einem anderen Land geboren waren. Nach einem Brief des Deutschen Konsulat in Porto Alegre (RS) galt:
„Die brasilianische Staatsangehörigkeit wird nach brasilianischem Recht durch die Tat- sache der Geburt in Brasilien wirksam und ist von der Eintragung in Geburtsregister an sich unabbängig. Das Register dient nur den Nachweis dieser Tatsache. Die Deutsche Reichsangebörigkeit wird durch Abstammung von einem Deutschen erworben, obne Rücksicht auf die Zugehörigkeit des Landes, in dem die Geburt erfolgt. Infolgedessen be- sitzen die Kinder eines deutschen Reichsangehörigen, die in Brasilien geboren werden, die Deutsche Reichsangehörigkeit und die brasilianische Staatsangehörigkeit" "346

Als 1933 die Nationalsozialisten die Deutsche Evangelische Kirche als Nachfolgerin des Deutschen Evangelischen Kirchenbundes gründeten, übernahm das 1934 gegründete Kirchliche Außenamt die Auslandsarbeit im Sinne einer "volksdeutschen Arbeit".347 Die neuen Pfarrer, die in den 1920er Jahren nach Brasilien kamen, repräsentierten in ihrer Mehrheit eine nationalsozialistische Position. Zusammen mit gleichgesinnten Lehrern trugen sie wesentlich zur Verbreitung von Deutschtumsdiskursen bei. ${ }^{348}$ 1934 präsentierte das Kirchliche Außenamt der Deutschen Evangelischen Kirche Richtlinien für Pastoren und Gemeinden im Ausland, um die Zusammenarbeit mit den Auslandsorganisationen der NSDAP zu fördern. ${ }^{349}$ Die vier Synoden in Brasilien schlossen sie ihm an und so stellte die ethnische Zugehörigkeit zum deutschen Volk ein Kriterium für die Zugehörigkeit zur ,deutschen Kirche in Brasilien "dar. ${ }^{350}$

Die protestantische Kirche war in diesem Sinne ein wichtiger Akteur der Deutschtumspolitik in den Siedlungsgebieten. Die kirchlichen Gemeinden galten als Diasporagebiete, in welchen der Glauben und das Deutschtum bewahrt werden sollten. ${ }^{351}$ Deutsche Schulen dienten nicht nur als Pflegeort für die Bewahrung des Deutschtums, sondern auch als Mittel für die Einführung nationalsozialistischer Ideologie durch didaktisches Propagandamaterial. ${ }^{352}$ Filme über das Dritte Reich ${ }^{353}$ wurden in kirchlichen Gemeinden und Schulen gezeigt. Bestimmte Gruppen widmeten sich Printinformationen oder Rundfunkübertragungen deut-

\footnotetext{
346 Schreiben des Deutschen Konsulats an Herrn Paul Koplin, Porto Alegre, 22.6.1931. Zitiert nach Py, S. 89.

347 Schulze, S. 80.

348 Schulze, S. 80 f.

349 Wirth, S. 150.

350 Wirth, S. 179.

351 Schulze, S. 71.

352 Altmann, S. 44.

353 Schreiben Nr. 1 (Kopie) von E. Dorsch an die Oberhäupter des Kreises V, Porto Alegre 7.2.1938. Zitiert nach Py, S. 72f; Ribas, O Nazismo em Santa Catarina. In: Delegacia de ordem política e social de Santa Catarina, O Perigo nazista no coraşão do Brasil. Florianópolis: Imprensa Oficial do Estado, 1944, S. 40.
} 
II - Die Pommern und ihre Einwanderung nach Brasilien

scher Radiosender.354 Deutsche Konsule, Landesgruppenleiter der NSDAP in Brasilien, Schulvereinigungsvertreter, Schullehrer und Geistliche ${ }^{355}$ hielten Ansprachen und Referate über das Deutsche Reich. ${ }^{356}$

Unterstützer des deutschen Nationalismus und Mitglieder der Mittelschicht in Deutschland wanderten nach Brasilien aus, um dort Firmen und Unternehmen zu gründen und Kontakt mit höheren deutschbrasilianischen Schichten zu schließen und wirtschaftliche Verträge zu festigen. ${ }^{357}$ Sie übernahmen angesehene Posten in Banken und Geschäften und dienten als Informationsquellen über die ökonomische Situation Brasiliens. ${ }^{358}$ Leitende Sektoren der Nationalsozialisten erweckten wieder die Hoffnung auf eine mögliche Annexion der südlichen Staaten Brasiliens. Autoren wie Rauschning ${ }^{359}$ berichteten über die Pläne des Führers für die Eroberung dieses Gebietes, was aber nach Gertz nie konkret bewiesen werden konnte. 360

Der Nationalsozialismus besaß eine Kernpartei in Südbrasilien, die von Berlin kontrolliert wurde und die NSDAP verfügte über ein organisiertes Infiltrationssystem in Brasilien. Die Nazis strebten laut Prien die Installation einer integralistischen Diktatur in Brasilien und die Rechtsanerkennung ethnischer Gruppen an, die den Deutschbrasilianern politische Autonomie gewähren sollte. Diese Pläne scheiterten jedoch nachdem der brasilianische Präsident Getúlio Vargas die Existenz aller Parteien 1938 verbat und alle oppositionellen Aufstände unterdrückte. Damit scheiterte die Utopie eines Neuen Deutschlands in Brasilien. ${ }^{361}$ Auf die Sympathien und Anhängerschaft von Deutschen und Deutschbrasilianern in Bezug zum Nationalsozialismus wird noch eingegangen werden.

\footnotetext{
354 Ribas, O Nazismo em Santa Catarina, S. 42.

355 Wie in der Gemeinde 25 de Julho (ES), Krause, Lutherische Synode in Brasilien, S. 275. Sie sollen nach Py biblische Texte mit der Doktrin des Nationalsozialismus verbunden haben. Py, S. 59.

356 Der Vorsitzende des Deutschen Schulvereins, Herr Möller, und der Landesgruppenleiter der NSDAP in Brasilien, Herr von Cossel, besuchten beispielsweise die Gemeinde Laranja da Terra (ES) und hielten Vorträge über das „Neue Deutschland“, bei welchen sie besonders auf die Verbundenheit der Deutschbrasilianer mit der alten Heimat hinwiesen. Aus unseren Gemeinden. In: Heimatbote für die Gemeinden der Deutschen Lutherischen Kirche in Espirito Santo. Nr. 4, April 1936, S. 4, MEW 4.194.

357 Magalhães, Pangermanismo e nazismo, S. $42 \mathrm{f}$.

358 Ribas, O Nazismo em Santa Catarina, S. 48.

359 Rauschning, Gespräche mit Hitler, S. 78. Zitiert nach Py, S. $17 \mathrm{f}$.

${ }^{360}$ Gertz, René. O fascismo no sul do Brasil. Porto Alegre: Mercado Aberto, 1987, S. 75. Nach Py, der dafür keine Quellen erwähnt, wird Rio Grande do Sul als Teil des deutschen Lebensraumes in Dokumenten der nationalsozialistischen Partei erwähnt. Py, S. 57.

361 Prien, S. $285 f$.
} 


\section{Stellungnahme Brasiliens gegenüber den Einwanderern von der Monarchie bis zum Zweiten Weltkrieg}

Bis jetzt wurde die Auswanderungskonjuktur mit ihren verschiedenen Aspekten analysiert. Nun soll sich der Fokus auf das Aufnahmeland richten. Für die ersten Einwanderer galten bestimmte Gesetze und Vergünstigungen, die später aufgrund der Opposition und der politischen, wirtschaftlichen, kulturellen und sozialen Ereignisse geändert oder aufgehoben werden mussten. Die Siedler wurden durch die Einwanderungspolitik unterstützt, gleichzeitig aber kirchlich, schulisch, politisch und sozial vernachlässigt, was einen fruchtbaren Boden für ihre ethnische Absonderung und die Entwicklung einer deutsch-nationalistischen Ideologie unter ihnen bereitete und sie damit in Konflikt mit dem brasilianischen Nationalismus brachte. Wie Brasilien die Einwanderer aufnahm und wie sie im Laufe der Geschichte behandelt wurden, soll nun untersucht werden.

5.1. Von der Verlegung des portugiesischen Königshauses nach Brasilien bis zur Unabhängigkeit Brasiliens (1808-1822)

Mit Ausnahme schweizerischer Einwanderer, die bereits ab 1818 nach Brasilien auswanderten, immigrierten Deutsche hauptsächlich nach der Unabhängigkeit Brasiliens von Portugal ins Land. Aber die Vorbedingungen für ihre Ankunft wurden bereits vor der Kaiserzeit beschlossen.

Bis 1808 galt Brasilien als Ausbeutungskolonie Portugals. Es war von der Außenwelt abgeriegelt und bis auf eine kleine Elite, die den portugiesischen Hof neben erfolgreichen Unternehmern und Landbesitzern einschloss, lebte der größte Teil der brasilianischen Bevölkerung unter prekären Bedingungen, ohne Zugang $\mathrm{zu}$ Kultur und Bildung. Schulen, Kirchen und Presse waren nur unzureichend verfügbar. ${ }^{362}$ Als Napoleon 1808 Portugal besetzen wollte, floh João VI. (seit 1872 als Regent aufgrund der Krankheit seiner Mutter, die als regierungsunfähig erklärt worden war, von 1816-1822 König des Vereinigten Königreichs von Portugal, Brasilien und Algarve) und verlegte seine Residenz nach Rio de Janeiro (RJ). Erst damit begann ein Entwicklungsprozess mit der Gründung von Grund- und Oberschulen, einer Kunstakademie, Bibliotheken, Museen, einer brasilianischen Bank und einer königlichen Presse. Unter dem Druck Englands wurden 1808 die Häfen für befreundete Schiffe und fremde Importgüter geöffnet und die Einschränkungen für gewerbliche Tätigkeiten zwischen Untertanen und Ausländern aufgehoben. 363

\footnotetext{
362 Schröder, Brasilien und Wittenberg, S. 13, 15.

363 Die Öffnung der Häfen für ausländische Schiffe begünstigte durch die von Frankreich verfügte Kontinentalsperre 1806 allein England. Wirth, S. 18, 42.
} 
Portugal gewährte den englischen Anglikanern in Brasilien Religionsfreiheit, jedoch nur mit Einschränkungen. ${ }^{364}$ Brasilien war verfassungsmäßig römischkatholisch, der König jedoch ein Liberaler. Da sich die liberale Politik oft gegen die römisch-katholische Kirche durchsetzte, konnte in diesem Kontext der Protestantismus mit den Einwanderern ins Land gelangen.

Seit 1808 gewährte João VI. Landschenkungen für Einwanderer, um die Immigration voranzutreiben und mit dem Erlass von 1814 wurden weitere europäische Einwanderer nach Brasilien eingeladen. ${ }^{365}$ Die Konfessionszugehörigkeit solle dabei kein Hindernis darstellen und weil bis dahin nur wenige katholische Einwanderer ins Land kamen ${ }^{366}$, beschloss die Auswanderungskommission 1819 die Immigration nach Brasilien auch Nicht-Katholiken zu ermöglichen. 367 Aber nach der Verordnung von 1820 bewilligte der König Ländereien und die portugiesische Staatsangehörigkeit ausschließlich für römisch-katholische Einwanderer. ${ }^{368}$ Gleichzeitig stiftete er einen Fonds zur Unterstützung der Einwanderung, um den südlichsten Teil des Landes zu besiedeln. ${ }^{369}$

1815 wurde Brasilien zum Königreich erhoben und bekam eine zentrale Verwaltung. Die Regionalismen wurden abgeschafft und es begann ein Prozess der Entstehung einer brasilianischen Nation, an deren Bildung und Entwicklung die Einwanderer und deren Nachkommen teilnahmen. ${ }^{370}$ Die Brasilianer strebten aber nach einer völligen Unabhängigkeit von Portugal. Auf Aufforderung des portugiesischen Parlaments und aufgrund der portugiesischen Revolution kehrte der König 1821 nach Portugal zurück und hinterließ seinen Sohn Pedro I. (1822-1831) als Regenten. Diese Rückkehr und die stärker werdenden internen Differenzen mit Portugal lösten einen Umbruch aus. Gegen den Unterdrückungsversuch des portugiesischen Hofes erhob sich eine Bewegung, die sich für eine Loslösung von Portugal einsetzte. Der Prinzregent erklärte sich zum „ewige [n] Verteidiger“ Brasili-

\footnotetext{
364 Über Protestanten in Brasilien vor der Einwanderung im 19. Jahrhundert siehe Schröder, Brasilien und Wittenberg, S. 15; Wellnitz, S. 285.

365 Last, S. 36.

366 Schröder, Brasilien und Wittenberg, S. 16.

${ }^{367}$ Fluck, Marlon Ronald. Basler Missionare in Brasilien. Bern: Peter Lang, 2004, S. 70. Die Bewilligung von Ländereien beschränkte sich laut Last auf die schweizerische Kolonie Nova Friburgo (RJ) und die Kolonie Leopoldina (BA), beide gegründet im Jahre 1818. Last, S. 36.

368 Damitz, Hans. Die deutsch-pommerschen Siedlungen in den drei Südstaaten Brasiliens und ibr kulturelles Leben. Vortrag am Seminar der Ostsee-Akademie, 25-27. April 1997, S. 1. Manuskript im Privatarchiv von Pastor Nelso Weingärtner. Nach Fluck erhielten die schweizerischen Einwanderer 1818 die portugiesische Staatsangehörigkeit bald nach ihrer Ankunft. Fluck, S. 71. Als von Schäffer Einwanderer in Europa anwarb, wies er auf das obengenannte Dekret hin und versprach den Einwanderern die brasilianische Bürgerschaft. Dekret über die Zulassung ausländischer Kolonien in Brasilien. Archiv des Ministeriums für Auswärtige Angelegenheiten, Kopie, 16. März 1820. Zitiert nach Dreher, Sträflinge aus Mecklenburg-Schwerin, S. 10, 15-18. Von Schäffer betrachtete aber nicht den 8. Artikel des Dekrets, nach welchem dies nur für römisch-katholische Einwanderer garantiert wurde. Außerdem trat 1824, als die deutschen Einwanderer ankamen, die neue Bundesverfassung in Kraft.

${ }^{369}$ Sudhaus, S. 21.

${ }^{370}$ Dreher, Igreja e Germanidade, S. 23.
} 
ens, vertrieb die portugiesischen Truppen und erklärte mit dem Ruf „Unabbängigkeit oder Tod" am 7. September 1822 die Unabhängigkeit Brasiliens. Er wurde am 12. Oktober 1822 zum Kaiser ernannt. ${ }^{371}$

\subsection{Kaiserzeit (1822-1889)}

Mit der Unabhängigkeit Brasiliens wurde die Einwanderungspolitik verstärkt vorangetrieben. Der Kaiser versprach den Einwanderern zahlreiche Begünstigungen, die aber den Widerstand seitens nativistischer und konservativer Kreise hervorrief. Je nach politischen, ökonomischen und religiösen Interessen sorgten diese dafür, dass die finanziellen Ausgaben zur Unterstützung der Einwanderung reduziert oder eingestellt und die gesetzlichen Regelungen für Einbürgerung, Regulierung der Landkonzession und Anerkennung protestantischer Ehen nicht genehmigt wurden. Hinzu leerten Kriege und Revolutionen die öffentlichen Kassen und Einwanderungsagenten, Beamte und Koloniedirektoren missachteten die Gesetze. Auch der schlechte Ruf Brasiliens in Europa und die preußischen Maßnahmen gegen die Auswanderung nach Brasilien beeinträchtigten die Emigration.

Der brasilianische Kaiser Pedro I. war mit der Tochter des letzten Kaisers des Heiligen Reiches deutscher Nation und österreichischer Prinzessin Maria Leopoldina verheiratet, was die Einwanderung deutscher Immigranten beeinflusst haben könnte. 372 Aber politisch betrachtet bildeten Immigranten aus Kolonialstaaten wie Frankreich, Holland, Spanien und England ein Risiko für das junge Kaiserreich. Aus diesem Grund wurden eher deutsche, schweizerische, österreichische und italienische Einwanderer für die Einwanderung angeworben. ${ }^{373}$ Daneben verfolgte das Kaiserreich mit der Einwanderung verschiedene Interessen:

a) Das Land benötigte Soldaten für den Schutz von Grenzgebieten im unbebauten Süden, die noch nicht gefestigt waren und wo Gefahr bestand, Teile dieser Gebiete durch Invasionen und Kriege zu verlieren. ${ }^{374}$ So wurden Einwanderer

\footnotetext{
371 Bürger, Otto. Brasilien. Leipzig: Dieterich, 1926, S. 30; Wirth, S. 19.

372 Fischer, Geschichte der Evangelischen Kirche, S. 90; Schröder, Brasilien und Wittenberg, S. 14.

373 Martinuzzo, S. 21; Dreher, Igreja e Germanidade, S. 29. Die Verbindung zwischen Einwanderung deutschsprachiger Siedler und des königlichen Hauses ist bei den Namen der Kolonien zu erkennen. Die Kolonien São Leopoldo (RS) 1824 und Santa Leopoldina (ES) 1857 wurden zur Ehre der Kaiserin Leopoldina und ihre Tochter benannt. Die Kolonien Nova Petrópolis (RS) 1858 und Petrópolis (RJ) 1845 weisen auf den Kaiser Pedro II., Sohn von Kaiser Pedro I. und Kaiserin Leopoldina, hin. Mit dem Namen der ältesten Tochter vom Kaiser Pedro II. wurden zwei Kolonien benannt, nämlich Santa Isabel (SC) 1847 und Santa Isabel (ES) 1847. Und die Kolonie Dona Francisca-Joinville (SC) 1851 wird nach der Schwester vom Kaiser Pedro II. und ihrem Mann (Prinz von Joinville) benannt. Bahia, S. 10.

374 Besonders zu diesem Zweck sandte der Kaiser den Major Georg Anton von Schäffer nach Deutschland. José Bonifácio de Andrade e Silva, Instrucções particulares para servirem de regulamento ao Senhor Jorge Antonio Schaeffer na Missão com que parte desta corte para a de Vienna d'Austria, e outras, Rio de Janeiro, 21.8.1822, AHI 271/1/1 - Parte I. Zitiert nach Fluck, S. 83; vgl. Dreher, Sträflinge aus Mecklenburg-Schwerin, S. 11-15.
} 
dort in einer Art „Agro-militärische Kolonisation“375 angesiedelt, um diese Ländereien gleichzeitig zu schützen und zu bebauen. In der Provinz Rio Grande do Sul fand die Immigration gerade im Kontext der Grenzstellung und Besitzkonsolidierung statt. ${ }^{376}$ Nach Christillino bekam aber die Grenzstellungsfrage eine sekundäre Rolle beim Verständnis des Immigrationsprozesses in diesem Staat, denn die Kolonisation richtete sich im Laufe der kaiserlichen Periode nicht nach den Grenzgebieten zu Uruguay und Argentinien ${ }^{377}$;

b) Angesichts der großen Anzahl afrikanischer Sklaven und „Mulatos' ${ }^{678}$, die als minderwertige Rassen diskriminiert wurden, wollte die Regierung das Land mit „weißen“ Einwanderern bevölkern, um einen Ausgleich zur „schwarzen“ Bevölkerung zu bieten. ${ }^{379}$ Dirigenten fürchteten sich auch vor Sklavenrebellionen und im Unterschied zu ihnen galten die Einwanderer als gefügig und unterwürfig. ${ }^{380}$ Als „,besseres Menschenmaterial“ sollten Einwanderer die „Weißelung der Rasse“381 durchführen und zur Entstehung einer zivilisierten und christlich geprägten Gesellschaft beitragen $^{382}$;

c) Aufgrund des Drucks aus England in Bezug auf die Aufhebung der Sklaverei sah sich der Kaiser gezwungen, die Arbeitskraft der Sklaven in den Großlandwirtschaften durch Immigranten zu ersetzen ${ }^{383}$;

d) Einwanderer sollten durch die Gründung eines freien Familienbesitzsystems $^{384}$ oder Kleinbauerntums ${ }^{385}$ eine mittlere Schicht zwischen der Unterschicht (Sklaven) und der Oberschicht (Großlandbesitzer) bilden. Auf diese Weise sollten sie die im Lande hergestellten Produkte konsumieren, aber keine Konkurrenz für die Großgrundbesitzer darstellen. Sie sollten auch gleichzeitig die politische Hegemonie der Landwirte aufheben und eine zusätzliche Unterstützungsbasis für die Zentralregierung bilden. ${ }^{386}$ Außerdem sollten sie die Produktion für den internen

\footnotetext{
375 Lazzaroto, Danilo. História do Rio Grande do Sul. Porto Alegre: Sulina, 1982, S. 49. Zitiert nach Witt, S. 18.

376 Die Einwanderer waren hier nicht willkommen, denn sie bekamen das Land, für das die Lusobrasilianer (Nachkommen der Portugiesen) jahrhundertelang gekämpft hatten. Dreher, Igreja e Germanidade, S. $27 \mathrm{f}$.

377 Christillino, Cristiano Luis. A Colonização e a grilagen no Rio Grande do Sul no século XIX. In: MNEME Revista de Humanidades, V. 08. Nr. 22, jun./jul. de 2006, S. $106 f$.

378 „Mulato" bezeichnet das Individuum, das aus der Rassenmischung eines Schwarzen und eines Weißen entsteht.

${ }^{379}$ Schröder, Brasilien und Wittenberg, S. 13; Wirth, S. 21.

380 Christillino, S. $104 f$.

381 Dreher, Martin Norberto. Kontexte und Kirche, Werden und Gegenwart der IECLB. In: GustavAdolf-Werk (Hrsg.) Evangelium - Markt-Kreur. Leipzig: Gustav-Adolf-Werks, 2011, S. 15.

382 Schröder, Brasilien und Wittenberg, S. 13; Krause, Lutherische Synode in Brasilien, S. 16; Grosselli, S. 140 .

383 Dreher, Igreja e Germanidade, S. 26; Grosselli, S. 138; Schröder, Brasilien und Wittenberg, S. $32 \mathrm{f}$.

384 Martinuzzo, S. 46.

385 Martinuzzo, S. 43; Witt, S. 15f.

386 Christillino, S. 107; Witt, S. 20.
} 
und externen Markt stärken und als Folge daraus Importkosten reduzieren ${ }^{387}$ und die staatliche Finanzlage mit Exportprodukten verbessern ${ }^{388}$;

e) Einwanderer sollten mit den ihnen zugesprochenen besseren Eigenschaften (Arbeitsamkeit, Fleiß, Disziplin, Intelligenz, Ordnung, Ehrlichkeit und Wirtschaftlichkeit) ${ }^{389}$ das Land aus seiner „ökonomischen Schläfrigkeit" und kolonialen Rückständigkeit befreien ${ }^{390}$, zum wirtschaftlichen, industriellen, kulturellen und gesellschaftlichen Aufschwung beitragen und die nationale Infrastruktur durch Waldrodung, Landbebauung, Errichtung von Straßen und Eisenbahnstrecken ${ }^{391}$ aufbauen;

f) Die kaiserliche Regierung beabsichtigte mit der Ansiedlung von Einwanderern indigene Völker zum Rückzug aus bestimmten Gebieten zu zwingen ${ }^{392}$, so dass sie auf diese Weise, nur durch andere Methoden, den Vernichtungsprozess der indigenen Völker vollenden konnten. ${ }^{393}$ Die Siedler sollten entlang der gebauten oder geplanten Straßen angesiedelt werden, die gerade Gebiete der indigenen Völker durchliefen, und somit Soldatentruppen vor Angriffen schützen. ${ }^{394}$

An dieser Stelle sei auch kurz auf die verschiedenen Kolonisationstypen ${ }^{395}$ Brasiliens eingegangen: a) imperiale oder kaiserliche Kolonien: Wurden von der Zentralregierung angelegt und bekamen staatliche Subventionen und vor 1830 unentgeltliches Land. Beispiele für diese Gebiete, in denen Pommern angesiedelt wurden, sind: São Leopoldo (RS), gegründet 1824 und Santa Leopoldina (ES) 1856; b) provinzielle Kolonien: Kolonisationsunternehmen der provinzialen Regierungen, die einen Direktor für ihre Verwaltung stellten. Beispiele: Santa Cruz do Sul (RS) 1849, Santo Ângelo (RS) 1857, Nova Petrópolis (RS) 1858, Santa Isabel (ES) 1847, Brusque (SC) 1860; c) Privatkolonien durch Kolonisationsgesellschaften: Dona FranciscaJoinville (SC) 1851, gegründet durch die Hamburger Kolonisationsgesellschaft und die Hansakolonien, wie Hansa Hammonia (SC) 1897 durch die Hanseatische Kolonisationsgesellschaft; d) private Kolonisierung von Unternehmen: Kolonien, die von privaten Unternehmen gegründet und verwaltet wurden. Beispiele: Blumenau (SC) 1850 und São Lourenço do Sul (RS) 1858; e) Parceria- oder Halbpachtkolonien:

\footnotetext{
387 Weingärtner, Nelso. 150 Anos de Presença Luterana no Vale do Itajaí 1850-2000. Blumenau: Otto Kuhr, 2000, S. 6.

388 Nagar, Carlo. O Estado do Espírito Santo e a Imigração Italiana. Vitória: Arquivo Público do Estado do Espírito Santo 1895, S. $11 \mathrm{f}$.

${ }^{389}$ Schulze, S. 189-191.

390 Grosselli, S. 137, 150.

${ }^{391}$ Martinuzzo, S. 26; Grosselli, S. 143; Gertz, O fascismo no sul do Brasil, S. 21; Witt, S. 19.

392 Rieth, Ricardo Willy. Raízes históricas e identidade da Igreja Evangélica Luterana do Brasil (IELB). In: Estudos Teológicos V. 49, Nr. 2: Jul./dez. 2009, São Leopoldo, S. 208.

393 Wirth, S. 48. Über die Vernichtungsphasen der indigenen Völker am Beispiel von Santa Catarina, Ebd., S. $49 f$.

${ }^{394}$ Prien, S. 48. Das war der Fall bei der Anlegung der Kolonie Teresópolis-Santa Isabel (SC) als „Militärkolonie" zum Schutze gegen indigene Völker. Dedekind, Max. 75 Jahre deutsch-evangelischer Diasporaarbeit in Nord- und Südbrasilien. Barmen: Wiemann, 1912, S. 77.

395 Von Tschudi, Reisen durch Südamerika, 4. Band, S. 68f; Prien, S. 35-39.
} 
Die Einwanderer bekamen als Halbpächter ein Stück Land, waren aber verpflichtet, zusätzlich auf den Plantagen der Grundbesitzer zu arbeiten. Sie mussten zudem die Hälfte ihres Nettoertrags den Großgrundbesitzern abtreten. ${ }^{396}$ Beispiele: Teófilo Ottoni (MG) ${ }^{397}$ und Ybicaba (SP). 398 Während alle anderen Kolonientypen auf die Gründung eines familiären Kleinbauerntums abzielten, sollte die Kolonisation in Halbpachtkolonien ein Ersatz für Sklavenarbeit in den Großlandwirtschaften darstellen. Diese Kolonien werden in dieser Arbeit nicht behandelt.

Nach der Unabhängigkeitserklärung 1822 befanden sich die Einrichtungen für Verwaltung und Rechtspflege im Kaiserreich in einem mangelhaften Zustand. Angesichts der Konfrontationspolitik ${ }^{399}$ zwischen Gemäßigten und Radikalen, des Kriegs mit den argentinischen Provinzen (1825-1828) und den inneren separatistischen und republikanischen Bewegungen, konnte sich der Kaiser zunächst dieser Bedürfnisse nicht besonders widmen. ${ }^{400}$ Das Verbot des Sklavenhandels 1831401, zusammen mit der Eröffnung der Häfen für den internationalen Handel und der Unabhängigkeitserklärung bereiteten jedoch die optimalen Bedingungen für das Immigrationsunternehmen. ${ }^{402}$ Brasilien war ein attraktives Land für Einwanderer, die sozial aufsteigen wollten, denn es benötigte Arbeitskräfte und befand sich in einem anfänglichen aber sich entwickelnden Industrialisierungsprozess.

Kaiser Pedro I. unterstützte die Einwanderung verschiedener Ethnien und verfolgte eine siedlungsfreundliche Politik. Die Zentralregierung regelte die Voraussetzungen der Kolonisation und deren Einzelheiten in einer Reihe von Gesetzen und Verordnungen und hob 1824 die Beschränkung der Einwanderung für ausschließlich römisch-katholische Immigranten auf. ${ }^{403}$ Sie gewährte in der Ver-

\footnotetext{
396 Die schwierigen Lebensbedingungen der Einwanderer in diesen Kolonien waren für den schlechten Ruf Brasiliens als Einwanderungsland besonders verantwortlich. Schentke, H. Mabnruf gegen die Auswanderung nach Brasilien, Berlin, S. 20-25, PLAG Rep. 65c Nr. 167; Verwaltungs-Rath des Vereins zur Centralisation deutscher Auswanderung und Colonisation. „Oeffentliche Warnung! Vor der Auswanderung nach den Besitzungen der ,fünf der angesehensten Landgut-Besitzer des Kaiserreichs Brasilien' in der Provinz Rio de Janeiro", 17.1.1852, S. 93f, PLAG Rep. 65c Nr. 163; vgl. Fluck, S. 11-117. Ein Arbeitsvertrag befindet sich in Avé-Lallemant, Robert. Reise durch Südbrasilien im Jabre 1858. 2. Teil. Leipzig: F. A. Brockhaus, 1859, S. 427ff.

397 Rothe berichtet, dass im Tal São Benedicto meistens Pommern angesiedelt wurden. Rothe, Max. 100 Jahre deutsche Einwanderung in Teófilo Otoni, Minas Gerais. 1856-1956. Kopie von Maria JordanMarx, einer Enkelin von Pastor Hollerbach, BMA PAVB 545, Johann Leonhard Hollerbach.

398 Zwischen 1827 und 1860 wurden hier deutsche und schweizerische Einwanderer angesiedelt. 1857 rebellierten sie sich gegen die Arbeitsausbeutung des Senators Vergueiro. Fluck, S. 113-190.

${ }^{399}$ Der Kaiser übte eine Moderationsfunktion zwischen der konservativen Partei der Landaristokraten und Viehzüchter und der liberalen Partei einer kleinen Elite von Rechtsanwälten, Geschäftspersonen, Ärzten, Ingenieuren, Beamten und Geistlichen. Die politische Präsenz der brasilianischen Bevölkerung war fast inexistent, denn bis 1880 beschränkte sich das Wahlrecht auf 1\% der gesamten Bevölkerung. Prien, S. 100.

${ }^{400}$ Bürger, S. 30.

${ }^{401}$ Schröder, Brasilien und Wittenberg, S. 27f. Das Sklavenhandelsverbot wurde aber erst ab 1850 praktisch umgesetzt, erst um 1888 komplett aufgehoben.

402 Martinuzzo, S. 23.

${ }^{403}$ Last, S. 36f.
} 
fassung von 25. März 1824 Religionsfreiheit für alle Nicht-Katholiken, allerdings mit einigen Einschränkungen:
„Die Römisch-katholisch apostolische Religion bleibt weiterhin die Religion des Kaiser- reiches. Alle andere Religionen werden erlaubt mit ibrem häuslichen oder privaten Got- tesdienst, der in hierzu bestimmten Häusern gehalten wird, die nicht die äußere Form ei- ner Kirche haben dürfen" 404

Die Protestanten wurden demnach nur toleriert. In Kolonisationsverträgen wurden die Anstellung von Geistlichen ${ }^{405}$ und sogar der „Bau und Ausstattung einer Hauptkapelle am Stadtplatz" ${ }^{406}$ versprochen, aber das geschah nur in vereinzelten Fällen. Gesetzlich war es ihnen nicht erlaubt, Kirchen mit Türmen zu errichten oder diese mit Glocken und Kreuzen zu schmücken. Wer sich nicht daran hielt, musste eine Geldstrafe von 2 bis 12 Milréis zahlen. ${ }^{407}$ Die Einwanderer hielten sich jedoch nicht daran, wie später zu sehen ist. ${ }^{408}$ Der Kaiser war ein Liberaler und dass die römisch-katholische Kirche weiterhin Staatsreligion war, lag eher an dem großen politischen Einfluss der konservativen Partei als an seinen religiösen Überzeugungen. So bewiesen auch die Behörden meistens in Bezug zum äußeren Aspekt protestantischer Kirchen Toleranz auf. Ein Pastor aus Rio Grande do Sul berichtet:
„Wir leben ja in einem stockkatholischen Land, und wenn wir uns einer sebr freien Ausübung unseres Kultus erfreuen, so liegt das hauptsächlich daran, daß die Gesetze wenig streng gehandhabt werden. Erwacht einmal das Gesetz, wie wir's kürzlich erleb- ten, so stehen wir obne Schutz da".409

Bis 1830 hatte die Regierung den Einwanderern Land und Vieh aus dem kaiserlichen Besitz zur Verfügung gestellt, zahlte ihnen aus der Staatskasse eine finanzielle Beihilfe für die Anfangszeit und bot ihnen noch mehrere andere Unterstützun-

\footnotetext{
${ }^{404}$ Evangelische Synode von Santa Catarina und Paraná, S. 202; Dreher, Igreja e Germanidade, S. $23 f$.

405 Römisch-katholische Priester wurden von der kaiserlichen Regierung besoldet, Weingärtner, 150 Anos de Presença Luterana no Vale do Itajaí, S. 12. Aber protestantische Gemeinden bekamen einen besoldeten Geistlichen von der Regierung erst dann, wenn sie mehr als 600 Mitglieder umfassten. Schlatter, Wilhelm. Gescbichte der Basler Mission 1815-1915. Basler: Basler Missionsbuchhandlung, 1916, S. 88f; Fluck, S. 192.

406 Schröder, Brasilien und Wittenberg, S. $28 \mathrm{f}$.

${ }^{407}$ Prien, S. 41; Dreher, Igreja e Germanidade, S. 23f.

408 Wachholz, Wilhelm. Luteranismo no Brasil: trajetórias e desafios. In: Estudos Teológicos V. 49, Nr. 2: Jul./dez. 2009, São Leopoldo, S. 182; vgl. Prien, S. 124. Der liberale Geist eines in Brasilien anwachsenden Bürgertums wollte nach Wachholz die koloniale Mentalität der konservativen Gesellschaft durch eine moderne und progressive ersetzen. Laut Prien befand sich die kirchliche Institution im Dekadenzzustand, so dass eine Elite die Existenz protestantischer Gemeinden als Gegengewicht zur Macht der Staatsreligion tolerierte und sogar förderte, obwohl sie dieser treu blieb. Ebd., S. $83 \mathrm{f}$.

409 Römer, Ch. (Hrsg.) Der Evangelische Heidenbote, Nr. 1, Januar 1888, Basel: Missionsbuchhandlung, S. 46. Vgl. Evangelische Gesellschaft für die Protestanten in Amerika. Der Deutsche Ansiedler. Nr. 5, 1886, Berlin, S. 34.
} 
gen. ${ }^{410}$ Außerdem garantierte sie ihnen die Erlangung der brasilianischen Staatsbürgerschaft gleich nach der Ankunft und eine zehnjährige Befreiung von Steuerabgaben und dem Militärdienst. ${ }^{411}$ Ribeyrolles weist darauf hin, dass sie über gute Verordnungen für das Kolonisationsunternehmen verfügte, die von der Einschiffung der Einwanderer bis zu ihrer Niederlassung in den bestimmten Kolonisationsgebieten alles regelte. ${ }^{412}$ Aber diese wurden häufig von Agenten, Kolonisationsgesellschaften, Vermittlern und Koloniedirektoren nicht beachtet. Die ersten warben teilweise ungeeignete Menschen für den Ackerbau an und umgingen die Auswanderungsgesetze Preußens durch den Schmuggel illegaler Auswanderer. Koloniedirektoren vernachlässigten die Vermessung der Grundstücke und boten den Einwanderern keine angemessene Unterkunft und Niederlassung. Beamte verteilten die Subventionen auch nicht ordnungsgemäß. Nach von Tschudi verfügte die Regierung aber über keinen durchdachten Kolonisationsplan, was zur

410 Nach Angaben von Avé-Lallemant sollten diese Vergünstigungen nur den ersten 2.000 Einwanderern bewilligt werden. Für die Spätkommenden wurde unter bestimmten Bedingungen nur ein Teil davon ausgeteilt. Avé-Lallemant, Reise durch Südbrasilien im Jabre 1858. 1. Teil, S. 210. Um 1859 gewährte die Regierung einen Vorschuss eines Teils oder der ganzen Reise für Immigranten. Subsidien, Ackerbauwerkzeuge, Sämereien, bekamen nur diejenige als Vorschuss, die über keine eigenen Subsistenzmittel verfügten oder sie durch eigene Arbeit nicht anzuschaffen imstande waren. Andere mussten gegen Lohn arbeiten, wobei ihnen die Tagesbeiträge gestrichen wurden. Sie mussten auch 11/2 Réis pro Quadratklaftern (1 Quadratklafter = etwa 1,80m) für die gemachten Rodungen und Vorarbeiten an ihren Grundstücken zahlen. Erst nach fünf Jahren begann die Rückzahlung der gesamten Ländereien und Vorschüsse. Bericht des General-Landamtes für 1859. In: Hörmeyer, J. (Hrsg.) Actenstücke Brasilianischer Seite, betreffend die Kolonisation des Kaiserreiches. 1. Jahrgang, Heft 6, Rudolfstadt/Berlin: Verlag des F. priv. Hofbuchdruckerei/Franz Wagner, 1859, S. 45f.

${ }^{411}$ Bericht des Koloniedirektors Dr. Hillebrandt über die Gründung der Kolonie São Leopoldo. Rev d. Arch. Publ. do Porto Alegre, 1924, S. 346ff. Zitiert nach Schröder, Die deutsche Einwanderung nach Südbrasilien, S. 46. Vgl. Vertrag vom 2.6.1824 zwischen von Schäffer und dem Großherzog Mecklenburg-Schwerin für die Auswanderung von Insassen des Arbeitshauses von Güstrow; Acta, die zweite Abführung von Stock- und Zuchthausgefangenen nach Brasilien betreffend. In: Mecklenburg Geheimes und Haupt-Archiv Schwerin, MLHA Schwerin Kabinett I - Sig 54; Acta Abführung von Sträflinge und Vagabunden aus Dömitz, Bützow und Güstrow nach Brasilien durch Rittmeister Hanfft, betreffend. In: Mecklb. Geheimes und Haupt-Archiv Schwerin - MLHA Schwerin. Kabinett I. Alles zitiert nach Dreher, Sträflinge aus Mecklenburg-Schwerin, S. 24f, 100-102, 160-163, 170-173, 180183. Nach Angaben von Seidler ,sie sollten als brasilianischer Landeskinder adoptiert [eingebürgert] werden und alle Rechte und Verpflichtungen eines brasilianischen Bürgers baben". Seidler, S. 167f. Durch das Dekret von 14.8.1827 wurden alle Einwanderer, die vor der Abhängigkeitserklärung 1822 die portugiesische Staatsbürgerschaft erhielten, auch brasilianisch eingebürgert. Martínez, Elda González. La Immigración esperada. Madrid: Consejo Superior de Investigaciones Científicas, 2003, S. 26f.

412 Ribeyrolles erwähnt die Verordnungen von 2.4.1855 (Statut des Zentralvereins für Kolonisation in Rio de Janeiro); 15.9.1855; 1.5.1858; 18.11.1858. Ribeyrolles, Carlos. Estudo sobre a colonisação brasileira. Rio de Janeiro: Typografhia Nacional, 1860, S. 156-158, 189-201, 207-228; vgl. Von Tschudi, Bericht über die Kolonien Santa Isabel, Santa Leopoldina und Rio Novo usw., S. 260. Vgl. Kurze Übersicht der Maßregeln der Kaiserl. brasilianischen Regierung zu Gunsten der Kolonisation. In: Hörmeyer, J. (Hrsg.) Actenstücke Brasilianischer Seite, betreffend die Kolonisation des Kaiserreiches. 3. Jahrgang, Heft 1, Rudolfstadt/Berlin: Verlag des F. priv. Hofbuchdruckerei/Franz Wagner, S. 26-32. 
Verschwendung enormer Summen führte. ${ }^{413}$ Nicht zuletzt führte das Wechselspiel zwischen staatlichen und privaten Interessen der Großgrundbesitzer im Laufe der Zeit zu mehreren Modifikationen und Anpassungen im Einwanderungsgesetz und zur Entwicklung unterschiedlicher Kolonisations- und Arbeitsmodelle. ${ }^{414}$

Das Entgegenkommen des Kaisers und die positive Entwicklung der Kolonien riefen bald Widerstände hervor. ${ }^{415}$ Bereits in den 1820er und 1830er Jahren bildete sich ein Nationalgefühl oder „Nativismus' ${ }^{416}$, das die Zuwanderung von Einwanderern ins Land nicht dulden wollte. Nationalistische Kreise waren der Meinung, die Regierung fördere eine Überfremdung im Land und warnten von einer ,deutschen Gefahr" ${ }^{417}$ Die lusobrasilianische Gesellschaft merkte auch, dass sich die Einwanderer und deren Nachkommen durch Ausübung ihrer Aktivitäten emporarbeiteten und dadurch sozial aufstiegen. Daraufhin begannen sie diese als Bedrohung für das politische Monopol der Oligarchien, besonders im Süden, und der brasilianischen Nationalität zu sehen. ${ }^{418}$ Den Einwanderern wurden Restriktionen auferlegt und die Kolonisation nicht mehr gefördert wie zuvor. Auf der einen Seite wehrten sich Großgrundbesitzer aufgrund ökonomischer Motive gegen das Kolonisationsunternehmen, auf der anderen Seite die republikanische Partei aufgrund ihrer politischen Interessen. Dafür verwendeten sie manchmal moralische Argumente und stellten beispielsweise die Arbeitsethik und den Charakter der Einwanderer in Frage. ${ }^{419}$ Auch die römisch-katholische Kirche als Staatsreligion war gegen eine Einwanderung von Protestanten. 1830 versammelten sich die oppositionellen Mächte zu einem Reichstag und stimmten dem Verbot von staatlichen Ausgaben für Einwanderung, Siedlung und fremder Kolonisation zu. ${ }^{420}$ Beim Haushaltsgesetz von 1831 wurden die Kredite und Subventionen für die Einwanderung gestrichen und die Grundstücke für neue Einwanderer wurden nicht mehr so großzügig berechnet wie zuvor.

In der Regentschaftsperiode (1831-1840) wurden genaue Bedingungen für die Einbürgerung der Einwanderer festgesetzt. Die Bürgerschaft wurde ihnen ab 1832 nicht wie zuvor einfach verliehen, sie mussten sich einem detaillierten Einbürgerungsprozess unterwerfen. ${ }^{421}$ Weil die Mehrheit der Siedler keinen Zugang zu

\footnotetext{
413 Von Tschudi, Bericht über den Zustand der Kolonien der brasilianischen Provinzen Santa Catharina und San Pedro do Rio Grande do Sul, S. 255f.

${ }^{414}$ Last, S. 7.

415 Breitenbach, Wilhelm. Die Provinz Rio Grande do Sul, Brasilien und die deutsche Auswanderung dabin. Heidelberg: Carl Winter's Universitätsbuchhandlung, 1885, S. 21 (125).

${ }^{416}$ Dreher, Igreja e Germanidade, S. 23.

${ }^{417}$ Schröder, Brasilien und Wittenberg, S. $14 f$.

418 Willems, S. 117, vgl. Von Tschudi, Reisen durch Südamerika. 4. Band, S. $13 f$.

419 Witt, S. $16 f$.

${ }^{420}$ Kahle, S. 15; Wirth, S. 43.

${ }^{421}$ Einwanderer im Alter von 21 Jahren mussten bürgerliche Ehrenrechte besitzen, einen Aufenthalt von vier Jahren vorweisen und die Absicht erklären, in Brasilien sesshaft zu werden. Außerdem mussten sie Vermögen besitzen und beweisen, dass sie eine ehrliche und nützliche Arbeit durchführten. Für die ansässigen Einwanderer in São Leopoldo (RS) und Três Forquilhas (RS) wurde per
} 
diesen Informationen hatte, beantragten nach Martínez nur wenige ihre brasilianische Staatsbürgerschaft. ${ }^{422}$ Sie hatten die Staatsangehörigkeit ihres Herkunftslandes inzwischen verloren ${ }^{423}$, ließen sich aber nicht in den brasilianischen Staatsverband aufnehmen, so dass sie ,vaterlandslos"waren. ${ }^{424}$ Diejenigen, die sich dem Einbürgerungsprozess unterwarfen, bekamen jedoch trotzdem nicht alle staatsbürgerlichen Rechte zugestanden. Nach der Bundesverfassung durften beispielsweise Nicht-Katholiken kein Abgeordnetenamt übernehmen. ${ }^{425}$ Die Regierung wollte damit die obersten Staatsämter vor Überfremdung schützen. Die Einwanderer lebten politisch, sozial und religiös am Rande der Gesellschaft.

1834 bekamen die Provinzen, durch einen Zusatz in der Verfassung, eine gröBere Selbstständigkeit und den Auftrag, die Kolonisationsangelegenheiten selbst zu verwalten. ${ }^{426}$ Ein Kolonisationsgesetz wurde 1836 für Santa Catarina und 1845 für Rio Grande do Sul erlassen, aber es gab kein einheitliches Gesetz in Bezug auf Landverteilung, Landbesitz und bürgerliche Rechte. ${ }^{427}$ Aufgrund dieser Gesetze erfolgte die Kolonisation entweder in provinzieller Verwaltung (vor allem in Rio Grande do Sul) oder durch Kolonisationsgesellschaften und -unternehmer (besonders in Santa Catarina). ${ }^{428}$ Das endgültige Kolonisationsgesetz stammt aus dem

Dekret vom 3.9.1846 die Einbürgerung durch einfache Meldung bei den Behörden durchgeführt. Dieses Recht wurde am 31.5.1851 auch auf Kolonisten aus São Pedro de Alcântara (SC) und Petrópolis (RJ) ausgedehnt. Die seit zwei Jahren ansässigen Kolonisten von Santa Cruz do Sul (RS) bekamen nach dem Generalgesetz von 5.9.1846 das Recht, sich als brasilianische Bürger ohne Kosten und Schwierigkeiten einbürgern zu lassen oder auch nicht. Carvalho, S. 409ff; Schröder, Die deutsche Einwanderung nach Südbrasilien, S. 56, 85; Schröder, Brasilien und Wittenberg, S. 33. Nach Martínez sollte schon das Dekret von 3.9.1843 die Einbürgerungsfrist auf zwei Jahren verringern und seitdem wurden die ansässigen Kolonisten in São Leopoldo (RS) und São Pedro de Alcântara (SC) als Eingebürgerte anerkannt. Martínez, S. 26f. Entsprechend der Anweisungen von 23.11.1861 wurden den freiwilligen Einwanderern weiterhin die brasilianische Staatsbürgerschaft nach zwei Jahren und eine Befreiung vom Militärdienst versprochen. Carvalho, S. 486f.

422 Martínez, S. 26f. Dr. Blumenau forderte seine Einwanderer auf, sich brasilianisch einbürgern zu lassen, sobald sie ihr Landlos bekamen. Dreher, Igreja e Germanidade, S. 40. In Espírito Santo zeigten die Einwanderer aber wenig Interesse für die Legalisierung ihrer politischen Situation im Land. Rölke, Raǐes da Imigração alemã, S. 401.

${ }^{423}$ Bürger, S. 378; vgl. Gesetz über die Erwerbung und den Verlust der Eigenschaft als Preußischer Unterthan von 1842 und Eintritt in fremde Staatsdienste von 31.12.1842, \$ 15 und 22, PLAG Rep. 65c Nr. 154; vgl. Entlassungsurkunde in Weingärtner, Crônica da Comunidade Evangélica de Timbó, S. 10.

${ }_{424}$ Breitenbach, S. 21 (125); Weingärtner. História da Comunidade Evangélica de Timbó, S. 67.

${ }^{425}$ Wirth, S. 20; Dreher, Igreja e Germanidade, S. 24. Laut Borchard wies aber diese Verfassung viele Lücken auf, denn sie besagte, dass Nicht-Katholiken nicht in die Abgeordnetenkammer gewählt werden durften, schwieg aber bezüglich der Beteiligung an Stadt- oder Provinzräte. Borchard, Hermann. Die Deutschen und die deutsch-evangelische Kirche in Brasilien. In: Der Dentsche Ansiedler Nr. 4, 1866, S. 32. Zitiert nach Dreher, Igreja e Germanidade, S. 24; vgl. Dedekind, Brasilien, S. 9.

426 Breitenbach, S. 34 (138).

427 Prien, S. 35.

${ }^{428}$ Fischer, Geschichte der Evangelischen Kirche, S. 87f. Unternehmer und Kolonisationsgesellschaften schlossen einen Vertrag mit den Emigranten, streckten ihnen die Reisekosten vor und ließen sich die Summe für Reise, Land und Vorschüsse in bestimmten Raten zurückzahlen. Schröder, Die deutsche Einwanderung nach Südbrasilien, S. 62, 64; Wüstner, S. 6f. 
Jahre 1854, als sich die provinzielle Kolonisation in Rio Grande do Sul durchsetzte. ${ }^{429}$ Weil die Provinzen aber nicht über finanzielle Ressourcen zur Unterstützung von Einwanderern verfügten, führte die Bestimmung zu erheblicher Einschränkung der Einwanderungsförderung.

Als Pedro II. (1840-1889) 1840 die Regierung inmitten von Putschen und Revolutionen ${ }^{430}$ übernahm, gewann die Einwanderungspolitik wieder an Aufmerksamkeit. Ab 1842 setzte sich eine größere Einwanderungspropaganda in Deutschland durch, um Siedler nach Brasilien zu locken. ${ }^{431}$ Ein kaiserliches Dekret von 26. April 1844 rief Auswanderer auf: „Handwerker und Landleute unbescholtenen Rufes, kräftiger und gesunder Leibesbeschaffenheit und jugendlichen Alters, welche die Überfabrt nicht bezablen können "4332 1843 brachte der Abgeordnete und spätere Minister Joaquim Jose Rodriguez im Reichstag einen Gesetzentwurf, betreffend die Aussonderung der Staatsdomäne von dem in Privatbesitz befindlichen Grund und Boden, ein. Dieser stieß auf heftigen Widerstand von Seiten der Landaristokratie, da diese die Abgabe eines Teils ihres Besitzes, soweit sie es nicht rechtmäßig erworben hatten, und die Entstehung einer Schicht von Kleinbauern, die ihnen Konkurrenz beim Kaffeeanbau bereiten könnte, fürchtete. Ihr Widerstand führte 1844 erneut zu der Erlassung eines kaiserlichen Gesetzes mit Beschränkungen der Subventionen für die Einwanderung. ${ }^{433}$ Trotzdem schloss die Zentralregierung Verträge mit privaten Unternehmen über den Import von Einwanderern ab. ${ }^{434}$

Erst 1850 wurde die Landkonzession unbebauter Staatsländereien in Brasilien gesetzlich geregelt. ${ }^{435}$ Herrenlose Ländereien, die als Staatseigentum galten, konnten nach dem neuen Agrargesetz nur durch Kauf erworben werden, der innerhalb von fünf Jahren zu bezahlen war oder bei Verzögerungen mit 1\% pro Monat verzinst werden sollte. ${ }^{436}$ Außerdem sollten ausländische Landkäufer nach zwei Jah-

\footnotetext{
${ }^{429}$ Schröder, Die deutsche Einwanderung nach Südbrasilien, S. 87.

${ }^{430}$ Unter ihnen der Farrapenkrieg in Rio Grande do Sul (1835-1845), der auf eine Lostrennung vom Reich abzielte. Bürger, Brasilien, S. 31. Die Farrapenrevolutionäre versprachen zunächst die Befreiung von Sklaven und Religionsfreiheit, weswegen sie die Sympathien vieler Einwanderer gewannen. Selbst Geistliche kämpften in diesem Krieg und kamen im Kampf ums Leben. Prien, S. 54f

${ }^{431}$ In diesem Jahr kamen, wie beschrieben, Pommern nach Brasilien. PLAG Rep. 65c Nr. 159; Last, S. 58,64 .

432 Allgemeine Zeitung von 10.2.1845. Zitiert nach Sudhaus, S. 55.

433 Schröder, Brasilien und Wittenberg, S. 36-39.

434 Siehe den Vertrag zwischen Regierung und Caetano Pinto für die Anwerbung von Kolonisten nach Rio Grande do Sul, PLAG Rep 65c, Nr. 167; vgl. Last, S. 38.

435 Wirth, S. 21. Ein Dekret von 17.12.1548 hatte bereits verordnet, dass Landverleihungen ordnungsgemäß registriert, bestätigt und vermessen werden sollten und spätere Gesetze versuchten, Ordnung in die Landbesitzfrage zu bringen, aber die "Besitzergreifung" wurde weiter praktiziert. Schröder, Die deutsche Einwanderung nach Südbrasilien, S. 66f. Bis 1850 wurden die Rechte über unbebaute Ländereien durch drei verschiedenen Arten von Landbesitztiteln gewährt: durch Schenkung, „Sesmaria“, beziehungsweise Konzession unbebautes Land für Kolonisierung, und Erwerb. Witt, S. 20.

436 Der Unterhalt in den Häfen und der Transport bis zu den Kolonien blieben weiterhin kostenlos. Last, S. 38. Roos und Eshuis weisen darauf hin, dass mit diesem neuen Agrargesetz die Anschaffung
} 
ren eingebürgert werden. Obwohl die Ausführung des Gesetzes sich an den bestehenden Verhältnissen, an Besitzstreitigkeiten und der Besorgnis vor negativen Auswirkungen auf das innere Staatsleben stieß, bedeutete es einen Fortschritt zur Sicherung des Grundeigentums, denn nun konnten ,herrenlose Ländereien“ nur „durch Kauf in Besitz, genommen werden “437 Die mit dem Verkauf dieser Ländereien erwirtschafteten Einnahmen sollten in die Einwanderung investiert werden. 438 Trotzdem wurden diese Grundstücke später von ehemaligen Besitzern beansprucht ${ }^{439}$ und weitere Landkonzessionen einer Elite und Mitgliedern höherer Amtsposten in Rio Grande do Sul gewährt. ${ }^{440}$

Im Jahr 1855 wurde die Zentralgesellschaft für die Kolonisation gegründet, die sich vertraglich verpflichtete, binnen fünf Jahren 50.000 Einwanderer anzusiedeln. Sie versprach, Transport bis zum Zielort und die Siedlungs- und Unterkunftskosten der Auswanderer zu übernehmen. ${ }^{441}$ Als sie aber 1864 aufgelöst wurde, hatte sie nur 6.000 Einwanderer befördern können. ${ }^{442}$ Nach Angaben von Ribeyrolles garantierte die brasilianische Regierung 1858 ausschließlich den ersten 150 Einwandererfamilien, die sich in kaiserlichen Kolonien niederließen, die Errichtung eines provisorischen Hauses, Waldrodung in einer Fläche von 100 Klaftern und die Bereitstellung von Saatgut und Vieh. ${ }^{443}$ Diese Aussage wurde aber als Garant für alle Einwanderer verstanden, was zu bitteren Enttäuschungen, Reklamationen und Vorwürfen geführt hat. 1859 stiegen die Summen und Konzessionen für die Kolonisation erneut an, aber Missverständnisse, die Gegenpropaganda Deutschlands und das Heydtische Edikt beeinträchtigten das Einwanderungsprojekt. ${ }^{444}$

von Ländereien für viele Einwanderer fast unmöglich wurde, denn am Ende ihres zweiten Ansiedlungsjahres mussten sie die ersten Landesraten zahlen und sie in sechs Jahren abgezahlt haben, was aber angesichts der mangelnden finanziellen Ressourcen der Siedler in den ersten Jahren sehr schwierig war. Roos; Eshuis, S. 50.

${ }^{437}$ Schröder, Die deutsche Einwanderung nach Südbrasilien, S. 66-68.

438 Schröder, Brasilien und Wittenberg, S. 38f; Christillino, S. 103.

439 Kolonisten aus São Pedro de Alcântara (SC) mussten zum Beispiel das Land, das ihnen vom Kaiser geschenkt wurde, erneut kaufen. Prien, S. 35. Ähnliches geschah in São Leopoldo (RS), wo die Situation erst 1863 geregelt wurde. Schröder, Brasilien und Wittenberg, S. 38; Wernicke, S. 174.

440 Eine Elite ermöglichte die Ausdehnung der Immigration, indem sie Ressourcen in provinziellen und städtischen Versammlungen garantierte. Sie sahen große Vorteile in der Einwanderung, denn durch Waldrodung, Ausbau von Straßen und Errichtung von Stadtplätzen stiegen auch die Preise für ihre Grundstücke. Die Möglichkeit, Ländereien für höhere Preise zu verkaufen förderte aber den illegalen Landbesitz, was mit der privaten Kolonisation umso mehr in Gang gesetzt wurde. So fielen tausende Hektar Land durch Betrug in die Hände von Kolonisationsagenten. Landkonzessionen wurden vom Provinzpräsident und vom Vorstand des Ministeriums für öffentliche Ländereien und Kolonisation vergeben, weil diese einen politischen Platz im Senat oder im Provinzlandtag anstrebten. Christillino, S. 113-125.

441 Roos; Eshuis, S. 15, vgl. Josenhaus (Hrsg.) Der Evangelische Heidenbote, Nr. 4, April 1864, S. 37.

442 Sudhaus, S. 88.

443 Verordnung von 18.11.1858. Zitiert nach Ribeyrolles, S. 221-228.

444 Schröder, Brasilien und Wittenberg, S. 44. Die Kolonie Blumenau (SC) musste deswegen später der Regierung übergeben werden. Von 96 Privatkolonien, die zwischen 1846 und 1860 gegründet wurden, wurden 66 aufgelöst. Von 33 Staatskolonien wurden 29 aufgelöst. Last, S. 40. 
Obwohl die Regierung den Protestanten freie Ausübung ihrer Religion gewährte, befanden diese sich vor allem in Bezug zur gesetzlichen Anerkennung ihrer protestantischen Ehen in einer schwierigen Lage. Für die Eheschließung protestantischer Paare gab es keine Regelungen und ihre eingesegneten Ehen besaßen keine Rechtsgültigkeit, auch nicht solche, die vor der Einwanderung geschlossen waren. Die Regierung versuchte die Zivilehe einzusetzen, stieß damit aber lange Zeit auf die Opposition des katholischen Klerus. So wurden protestantische Ehen als Konkubinat angesehen. ${ }^{445}$ Ausschließlich römisch-katholische Priester waren für die Geburts-, Trauungs- und Sterberegister verantwortlich, so dass protestantische Ehen gesetzlich durch sie für gültig erklärt werden mussten. ${ }^{446}$ Manchmal wurden die Protestanten als "Ketzer" in kirchlichen Registern eingetragen. ${ }^{447}$ Nach Sudhaus besaß aber die Nicht-Anerkennung protestantischer Ehen, bei der in der Regel toleranten Haltung des brasilianischen Katholizismus, im Leben der Einwanderer und deren Nachkommen bis um die Jahrhundertmitte wenig Bedeutung. ${ }^{448}$ Nur da, wo die Regierungsbeamten oder eine große Anzahl von Katholiken sich gegen die Vollziehung protestantischer Ehen aussprachen, kam es zu Streitigkeiten. ${ }^{449}$ Ein gravierender Negativaspekt der NichtAnerkennung der Ehen bezog sich auf das Erbrecht ${ }^{450}$, was vielen Nachkommen besondere Schwierigkeiten bereitete.

Nach Prien zeichnete sich der Katholizismus in Brasilien durch einen tridentinischen Charakter und ultramontanen Klerus aus, der protestantische Gemeinden nicht akzeptieren konnte. ${ }^{451}$ Die Jesuiten stützten sich bei ihrer Ablehnung auf die brasilianische Bundesverfassung und betonten, Mischehen seien nur von der römisch-katholischen Staatsreligion zu schließen. Gemäß dem Dekret vom 3. November 1827 war die Eheschließung eine religiöse Angelegenheit, was bedeutete, dass nicht-katholische Ehen für gesetzwidrig und die daraus entstandenen Kinder für unehelich erklärt wurden. Mischehen bedurften außerdem einen Dispenses seitens des katholischen Bischofs und der protestantische Ehepartner musste, ebenso wie der protestantische Geistliche, sich unter Eid verpflichten, die Kinder im Sinne der römisch-katholischen Kirche zu erziehen. ${ }^{452} \mathrm{Oft}$ wollte der katholische Priester den bischöflichen Dispens nicht einholen, während der protestanti-

\footnotetext{
${ }^{445}$ Fischer, Geschichte der Evangelischen Kirche, S. 89; Schröder, Brasilien und Wittenberg, S. 16.

446 Bühler, Fritz. Ein Beitrag zur Kirchenkunde Südamerikas. Deutsche evangelisch lutherische Pionierarbeit in Brasilien. [1917/1918], S. 7, MLV 51/17 108.

447 Seibel, Imigrantes no século do isolamento, S. 131; Seibel, Ivan. Imigrante a duras penas. Nova Petrópolis: Amstad, 2007, S. 231.

448 Sudhaus, S. 113.

449 Rölke, Raízes da Imigração alemã, S. 106.

${ }^{450}$ Prien, S. 40f; Fluck, Fußnote 350, S. 178.

451 Prien, S. $105 f$.

452 Siehe Zeitungsabschnitt eines Artikels über Brasilien im Gustav-Adolf-Blatt, EZA 200/1/2151, ohne Jahresangabe; vgl. Schröder, Brasilien und Wittenberg, S. 48.
} 
sche Geistliche sich weigerte, einen derartigen Schwur zu leisten.453 Katholische Geistliche wollten wiederum Kinder mit protestantischen Paten nicht taufen. ${ }^{454}$ Eine Gesetzesübertretung seitens protestantischer Geistlicher konnte mit einem Jahr Haft bestraft werden. ${ }^{455}$ Zudem wurden sie in ihrer Amtsausübung eingeschränkt. 1857 wurde beispielsweise Pastor Klenze in São Leopoldo (RS) die Befugnis für kirchliche Amtshandlungen entzogen, weil er eine Mischehe gesegnet hatte ${ }^{456}$ und Pastor Hermann Borchard wurde 1864 verhaftet, weil er einen Leichenzug im Ornat begleitete. ${ }^{457}$ Wenn auch die Einwanderer zunächst die staatliche Unterstützung von Geistlichen zugesichert bekamen, fiel die Besoldung von Pastoren bald weg. Eine Ausnahme bildete die Kolonie Dona Francisca-Joinville (SC), wo der Hamburger Kolonisationsverein dieselben Rechte für die Vollziehung von Trauungen seitens der kaiserlichen Regierung bekam. ${ }^{458}$ Es handelte sich vermutlich hierbei um eine Begünstigung für eine Privatkolonie, die auf dem Landbesitz des Prinzen von Joinville, François de Orleans, angelegt wurde. Er war mit der Schwester des Kaisers Pedro II., Dona Francisca, verheiratet. Als Pastor Hoelzel 1858 die Gemeinde verließ, empfahl er seinen Mitgliedern ihre Ehe vor dem Notar abzuschließen. ${ }^{459}$ Weitere Informationen über die Anerkennung dieser Ehen stehen nicht zur Verfügung.

Bereits 1855 begannen die Verhandlungen zwischen dem preußischen Gesandten Levenhagen und dem brasilianischen Innenminister Nascentes d'Azambuja über die Einführung der Zivilehe und die Regelung protestantischer Ehen. Aber die Verhandlungen blieben bis 1859 erfolglos angesichts der Opposition der Katholiken. ${ }^{460}$ Erst am 11. September 1861 wurde über ein Gesetz mit toleranteren Bestimmungen entschieden und mit der Vorschrift vom 17. April 1863 veröffentlicht. ${ }^{461}$ Die im Ausland geschlossenen Ehen wurden danach als

\footnotetext{
453 Siehe Schreiben Blumenaus vom 16.2.1863 an die Provinzialregierung. In: Niedersächsisches Staatsarchiv in Wolfenbüttel 192 N XXII 71 und Reily, Duncan. A História documental do protestantismo no Brasil. São Paulo, 1984, S. 49. Beide zitiert nach Wirth, Anmerkung 91, S. 86.

454 Avé-Lallemant, Reise durch Südbrasilien im Jahre 1858. 1. Teil, S. 162.

455 Josenhaus (Hrsg.) Der Evangelische Heidenbote, Nr. 4, April 1864, S. 45.

456 Schröder, Brasilien und Wittenberg, S. 47.

${ }^{457}$ Dreher, Kontexte und Kirche, Werden und Gegenwart der IECLB, S. 16.

${ }_{458}$ Bühler, Fritz. Ein Beitrag zur Kirchenkunde Südamerikas. [1917/1918], S. 7, MLV 51/17 108.

${ }^{459}$ Wüstner, S. 16.

${ }^{460}$ Der Gesetzentwurf in Bezug auf protestantische Ehen. Zweite Lesung. In: Hörmeyer, J. (Hrsg.) Actenstücke Brasilianischer Seite, betreffend die Kolonisation des Kaiserreiches. 2. Jahrgang, Heft 4, Rudolfstadt/Berlin: Verlag des F. priv. Hofbuchdruckerei/Franz Wagner, 1860, S. 165-226. Vgl. Sudhaus, S. 114; Schröder, Brasilien und Wittenberg, S. 46f.

461 Dekret Nr. 1.141 von 11.9.1861 welches die bürgerlichen Rechtswirkungen der den Reichsgesetzen gemäß geschlossenen Ehen auf die Personen ausdehnt, welche eine von der Staatsreligion abweichende Lebre bekennen, und anordnet, dass die Heirats-, Geburts- und Totenregister der gedacbten Personen sowie die notwendigen Bedingungen geregelt werden, damit die Pastoren der tolerierten Religionen Handlungen vornehmen können, die bürgerliche Rechtswirkungen erzengen. In: Hörmeyer, J. Actenstücke Brasilianischer Seite, 3. Jahrgang, Heft 3, Rudolfstadt/ Berlin: Verlag des F. priv. Hofbuchdruckerei/Franz Wagner, 1861, S. 343f; vgl. Das Gesetz über die Ehen zwischen Nichtkatholiken und das Reglement zur Ausfübrung derselben. In: Hörmeyer, J. (Hrsg.) Acten-
} 
bürgerlich anerkannt, sobald ein Trauschein vorgelegt wurde. Die fortan vollzogenen evangelischen Ehen hatten Gültigkeit, wenn der vollziehende Geistliche bei den Behörden registriert war und der Trauschein beim Standesamt der Stadt in das betreffende Buch eingetragen wurde. ${ }^{462}$ Protestantische Ehen, die vor 1863 geschlossen wurden, im Auslande getraute Paare und gemischte Ehen, die nach dem protestantischen Ritus oder durch einen unregistrierten Pfarrer vollzogen wurden, hatten weiterhin keine Gültigkeit. ${ }^{463}$

Um wieder Anreize für die Einwanderung zu bieten sicherte die brasilianische Regierung den Einwanderern 1867 Ressourcen für die Überfahrt, Unterkunft für die ersten Monate, Landerwerb ${ }^{464}$ und zudem fünfzehn Tage Lohnarbeit in den ersten sechs Monaten ${ }^{465}$ zu. Aber nach der Zustimmung des Freischoßgesetzes 466 1871 begannen die Repräsentanten der Großgrundbesitzer wieder gegen das Kolonisationsunternehmen vorzugehen. Die Kolonisation sei die schlechteste „Art des Sozialismus", denn damit gelangt das ausländische und elende Proletariat ins Land, um den armen und landlosen Brasilianern das Brot weg zu nehmen. ${ }^{467}$ AuBerdem wuchs mit der Entstehung des Deutschen Reiches 1871 und angesichts der fehlenden Integration der Einwanderer und deren gesellschaftlicher Partizipation die Angst vor der Deutschen Gefahr. ${ }^{468}$ Diese Theorie wurde vor allem durch US-amerikanische, englische und französische Zeitungen mit Bezug zum imperialistischen Wettlaufs verbreitet. Sie berichteten über Bestrebungen Deutschlands hinsichtlich eines territorialen Anspruchs in Südbrasilien. In diesem Kontext gefährdete die Bewahrung einer fremden Nationalität die politische Loyalität deutscher Einwanderer und deren Nachkommen zu Brasilien. ${ }^{469}$

\footnotetext{
stïcke Brasilianischer Seite, 4. Band, Rudolfstadt/Berlin: Verlag des F. priv. Hofbuchdruckerei/Franz Wagner, 1863, S. 134-136 und Dekret Nr. 3.069 über das Heirats-, Geburts- und Totenregister von NichtKatholiken. In: Carvalho, S. 477-486.

462 Schröder, Die deutsche Einwanderung nach Südbrasilien, S. 80; Fischer, Geschichte der Evangelischen Kirche, S. 89f. Dieses Gesetz ermöglichte, dass auch nicht-ordinierte Pastoren sich als Geistliche registrieren lassen konnten, weswegen die Riograndenser Synode die Regierung bat, die Kandidaten durch eine kirchliche Kommission auf ihre theologische Bildung hin überprüfen zu lassen. Dieser Vorschlag zielte auf die Registrierung von Kandidaten, die von ihr vorgeschlagen wurden oder denen sie zugestimmt hat, ab, um das Phänomen des „Kolonistenpfarrertums", worauf noch einzugehen ist, kontrollieren zu können. Brief an die würdigen Herren, Vertreter der Nation, 30.5.1885, EZA 5/2157, Beilage 108, auch AHI SR 8/4, Beilage 004; Brief des Verwaltungsrates der Riograndenser Synode an die Vertreter der Nation, São Leopoldo, 1.7.1886, AHI SR 1/3, Beilage 072.

${ }^{463}$ Schröder, Brasilien und Wittenberg, S. 46; Dreher, Igreja e Germanidade, S. 25.

${ }^{464}$ Franceschetto, Imigrantes, S. 945.

465 Grosselli, S. 213, 215.

${ }^{466}$ Lei do Ventre Livre. Mit diesem Gesetz wurden die Sklavenkinder ab der Geburt als freie Menschen erklärt.

467 Lazzari, B. M. Imigração e ideologia: a reação do Parlamento brasileiro à política de colonizaçãa e emigracãa (1850-1875). Ed EST/UCS, 1980, S. 63. Zitiert nach Grosselli, S. 144.

468 Willems, S. 46.

${ }^{469}$ Schulze, S. 194.
} 
1880 konnten Nicht-Katholiken in das Reichsparlament und die Provinzialversammlungen gewählt werden. Auch der Einbürgerungsprozess wurde erleichtert. ${ }^{470}$ Gleichzeitig begann die Regierung die Kolonien zu emanzipieren, auch wenn diese sich in einem noch unfertigen Zustand befanden. ${ }^{471}$ Ein Kredit von etwa 1 1 $\frac{1}{3}$ Millionen Milréis wurde für die Unabhängigkeit der Staatskolonien bereitgestellt ${ }^{472}$, wofür Kolonisten ihre gesamte Landschuld bezahlen mussten, obwohl viele von ihnen dazu nicht in der Lage waren. In Nova Petrópolis (RS) soll einigen Siedlern mit Exekution gedroht worden sein. ${ }^{473}$ Keine Kolonie durfte mehr auf staatliche Kosten gegründet werden und Ausgaben für die Immigrationsförderung wurden eingestellt. ${ }^{474}$ So setzten sich vor allem Privatunternehmen für die Gründung von Kolonien in Brasilien ein. Diese warben zwischen 1871 und 1880 größere Mengen von Immigranten an, vor allem Italiener. ${ }^{475}$ In den 1880er setzten sich auch mehrere Gesellschaften für die Einwanderung ein. ${ }^{476}$

Die kaiserliche Regierung förderte die Einwanderung und Kolonisation bis zur Entstehung der Republik. Aber die Herausforderungen des seit kurzem unabhängigen Kaiserreiches, die Opposition verschiedener Gruppen samt der Propaganda gegen die Einwanderung nach Brasilien und die hohen Kriegsausgaben beeinträchtigten das Immigrationsprojekt. Im Großen und Ganzen wurden die Einwanderer aber gut behandelt. Sicher verfolgte die Regierung dabei ihre eigenen Interessen, aber bei Bedarf setzte sie sich für die Siedler ein, wie beispielsweise durch Verlegung von Immigranten aus der Parceriakolonien nach Espírito Santo oder Südbrasilien ${ }^{477}$, Besoldung von Geistlichen und Errichtung von Kirchen, wie im dritten Kapitel ausführlicher beschrieben wird.

\footnotetext{
${ }^{470}$ Sudhaus, S. 161.

471 Breitenbach, S. 32 (136) und 34 (138). „Colonieen [sic!] obne Straßen, Wege und folglich obne Markt für ibre Erzeugnisse, ibren eigenen geringen Hilfsmitteln überlassen, ist, was die Regierung „emancipieren" nennt". Schentke, H. Mahnruf gegen die Auswanderung nach Brasilien, S. 39, PLAG Rep 65c Nr. 167.

472 Schröder, Brasilien und Wittenberg, S. 44.

473 Breitenbach, S. 32 (136).

${ }^{474}$ Schröder, Brasilien und Wittenberg, S. 44.

475 Martinuzzo, S. 36f.

476 Unter ihnen standen der Zentralverein für Einwanderung (1883), der von drei wichtigen Repräsentanten der Deutschen in Brasilien, Carl von Koseritz, Hermann Blumenau und Hugo Gruber, gegründet wurde, und die von Großgrundbesitzern ins Leben gerufene Gesellschaft für Immigrationsforderung (1886). Last, S. 41.

477 Einwanderer von Parceriakolonien der Provinz Rio de Janeiro wurden in die Kolonie Santa Isabel (SC) umgesiedelt, siehe Von Tschudi, Bericht über den Zustand der Kolonien der brasilianischen Provinzen Santa Catharina und San Pedro do Rio Grande do Sul, S. 236; Weingärtner, Martin Luther e Santa Catarina, S. 56. Andere wurden aus der Pachtkolonie in Ubatuba (SP) nach Santa Leopoldina (ES) umgesiedelt, Von Tschudi, Bericht über die Kolonien Santa Isabel, Santa Leopoldina und Rio Novo, S. 265f; Rölke, Raižes da Imigração alemã, S. 288.
} 
5.3. Von der Ausrufung der Republik bis zur Entstehung des Neuen Staates (1889-1937)

Mit der Ausrufung der Republik und dem Erlass einer neuen Bundesverfassung gewannen die Einwanderer und deren Nachkommen religiöse und politische Gleichberechtigung. Trotz der reservierten Einstellung der Republikaner ihnen gegenüber durften sie ihre Institutionen frei entwickeln. Die tolerante Haltung würde sich jedoch angesichts der sprachlichen, ethnischen und kulturellen Absonderung, der Tätigkeit deutscher Deutschtumsagenten und des Ersten Weltkrieges bald ändern. Die Hervorhebung einer bodenständigen Kultur in Zusammenhang mit der Propaganda über die Deutsche Gefabr bereitete dem brasilianischen Nationalismus seinen Weg.

Seit den 1870er Jahren wurden diejenigen Stimmen lauter, die eine Ausrufung der Republik in Brasilien einforderten. ${ }^{478}$ Als Kaiser Pedro II. 1887 in Europa weilte, führte die Thronfolgerin, Prinzessin Isabel, die Regentschaft in Brasilien in seiner Abwesenheit. Am 13. Mai 1888 erließ sie das Gesetz zur vollständigen Abschaffung der Sklaverei, das sogenannte „Goldene Gesetž, bot aber den Großgrundbesitzern keine Entschädigung für das entstandene Arbeitsvakuum. Einige Landwirte, unzufriedene Offizierskreise und Republikaner verhafteten daraufhin am 15. November 1889 die Minister und den kurz zuvor zurückgekehrten Kaiser und forderten ihn auf, das Land zu verlassen. Am selben Tag wurde die Republik der Vereinigten Staaten Brasiliens proklamiert. ${ }^{479}$ Der größte Teil der Bevölkerung aber, auch die Einwanderer und deren Nachkommen, blieben weiterhin vom politischen Leben ausgeschlossen, wo ausschließlich Alphabetisierte wählen durften. Für viele Einwanderer und deren Nachkommen bedeutete der Sturz des Kaisers den Verlust ihres stärksten Verteidigers. 480

Die neue Bundesverfassung von 1890 führte die Trennung von Kirche und Staat, die allgemeine Aufnahme in den Staatsverband und die Gleichberechtigung aller brasilianischen Bürger in Bezug auf Konfession und die Zivilehe ein. ${ }^{481}$ Alle Religionen durften ihren Kultus frei ausüben und der Staat durfte keine Religion durch staatliche Subventionen privilegieren. ${ }^{482}$ So bekamen die Protestanten die gesetzliche Erlaubnis, ihre Kirchen mit Türmen und Glocken zu schmücken. Alle Kinder, die in Brasilien geboren wurden und alle am 15. November 1889 in Brasi-

\footnotetext{
${ }^{478}$ Bürger, S. 32.

${ }^{479}$ Dedekind, Max. Brasilien, das Ziel deutscher Auswanderer und die Deutsche Evangelische Kirche in Brasilien. Elberfeld: Evangelische Gesellschaft für die protestantischen Deutschen in Südamerika, 1924, S. 5; Bürger, S. 32.

480 Magalhães, Pangermanismo e nazusmo, S. 108.

${ }^{481}$ Dedekind, Brasilien, das Ziel deutscher Auswanderer, S. 6; Dreher, Igreja e Germanidade, S. 26.

482 Schröder, Brasilien und Wittenberg, S. 49f; Rechtsform der Missionsarbeit in Brasilien, EZA 5/2453, Beilage 208. Der Protest des Vorstandes der Riograndenser Synode gegen bestimmte Privilegien der katholischen Kirche hatte darauf Einfluss. Brief des Direktionsrates der Riograndenser Synode an den Polizeichef des Staates Rio Grande do Sul, João de Barros Cassal, 13.12.1889, AHI, SR 8/4, Beilage 010.
} 
liens ansässigen Ausländer bekamen automatisch die brasilianische Staatsbürgerschaft. Ausnahme bildeten diejenigen, die bis zum 24. August 1891 den Wunsch nach Beibehaltung ihrer ursprünglichen Nationalität erklärten. 483 Als brasilianische Bürger durften Einwanderer nun auch politische Ämter bekleiden. Nach Martínez bekamen die Ausländer per Dekret vom 3. November 1911 dieselben Zivilrechte wie die Einheimischen zugeschrieben. ${ }^{484}$

Die Mehrheit der konservativen Mitglieder hatte sich den Republikanern zugewandt, um damit ihre Abneigung gegen die Liberalen zu demonstrieren. Den Liberalen war es übrigens gelungen, die letzten Minister in der kaiserlichen Regierung einzubringen. Weil jedoch Einwanderer und deren Nachkommen in ihrer Mehrheit Monarchisten und Mitglieder der liberalen Partei waren, nahmen die Republikaner eine negative Haltung ihnen gegenüber ein. 485 Jedoch ermöglichten ihnen die Republikaner, entsprechend einer positivistischen Verfassung, die Entwicklung eines deutschen Schulwesens und die Bewahrung ihrer Kultur durch Literatur, Presse und Vereine. ${ }^{486}$

Mit der Republik bekam die Einwanderungs- und Kolonisationspolitik neue Antriebe. Verschiedene Konzessionen wurden abgegeben, die Einwanderungspropaganda gestärkt und viele Beförderungsverträge abgeschlossen. Diese Maßnahmen beeinträchtigten aber den Haushalt derart, dass die Vergünstigungen wieder verringert werden mussten. Die Regierung übernahm nun nur noch den Aufenthalt auf der Blumeninsel in Rio de Janeiro (RJ) und die Fahrt von dort bis in die gewünschte Kolonie. ${ }^{487}$ Die deutsche Einwanderung behielt ihren Kurs in Santa Catarina und Rio Grande do Sul bei, besonders nach der Aufhebung des Heydtischen Edikts $1896^{488}$ und der Verkündung des neuen Reichsgesetzes über das Auswanderungswesen 1898.489 Nach Espírito Santo kamen nur noch vereinzelt Einwanderer. ${ }^{490}$ Hier war das Heydtische Edikt noch gültig, obwohl die brasiliani-

\footnotetext{
483 Bürger, S. 37f; Baviera, Princesa Teresa da. Viagem ao Espirito Santo 1888. Vitória: Arquivo Público do Estado do Espírito Santo, 2013, Anmerkung 55, S. 62. Nach dem Bericht von Pastor Treptau verloren viele Einwanderer dadurch ihre deutsche Staatsbürgerschaft, weil sie sich nicht in die deutsche Konsulatmatrikel eintragen ließen. Bericht von Pastor Gustav Treptau von 4.12.1893. In: Schmidt, Die Anfänge der Diakonie, S. 32. Manche Geistliche und besonders Verteidiger des Deutschtums kritisierten die Gemeindemitglieder für die Annahme der brasilianischen Staatsangehörigkeit und bedauerten, dass bei ihnen der deutsche Nationalstolz abging. Köbling, Fritz. Die Kolonie São Lourenço im Staate Rio Grande do Sul. In: Deutsche Post, Nr. 3355, São Leopoldo, 18.11.1908, EZA $121 / 19$.

484 Martínez, S. 31.

485 Dreher, Igreja e Germanidade, S. 41; Prien, S. 103; Magalhães, Pangermanismo e nazismo, S. 108.

486 Dreher, Igreja e Germanidade, S. 42f; Magalhães, Pangermanimo e nazismo, S. 109.

${ }^{487}$ Schröder, Brasilien und Wittenberg, S. 44f; Fischer, Geschichte der Evangelischen Kirche, S. 90.

${ }^{488}$ Mit der neuen Bundesverfassung von 1890 wurden die Provinzen zu autonomen Staaten erhoben.

489 Prien, S. 133.

${ }^{490}$ Grosselli, S. $443 f$.
} 
sche Regierung 1892 durch Dekret spezielle Begünstigungen für Einwanderer, die sich in diesem Staat niederlassen wollten, zusicherte. ${ }^{491}$

Die Aufhebung des Heydtischen Edikts für die südlichen Staaten Brasiliens in Zusammenhang mit der Stärkung des Deutschen Reiches und der Ausbreitung der deutschen Weltwirtschaft erweckte Misstrauen in nativistischen Kreisen. ${ }^{492}$ Dies steigerte sich, als man zu erkennen begann, dass die Regierung Einwanderer im Süden und in Espírito Santo in fast geschlossenen Kolonisationsgebieten ansiedelte und sie bezüglich der Erlernung der Landessprache und der gesellschaftlichen Integration vernachlässigte. Deutsche Institutionen hatten Hand bei der Verbreitung des Deutschtums und der Entwicklung expansionistischer Ziele unter den Einwanderern und deren Nachkommen. Dass in Brasilien geborene Kinder in einer Fremdsprache sozialisiert wurden, konnten die nativistischen Kreise nicht akzeptieren. Neue Dekrete und Gesetze versuchten den Handlungsspielraum neuer Einwanderer einzuschränken. Seit 1907 wurde die Einbürgerung schwieriger und Dekrete von 1907 und 1924 reglementierten die Ausweisung von Ausländern. 493

Bereits 1904 wurde eine Schulpolitik für die Vereinheitlichung und Nationalisierung des Schulwesens in Santa Catarina (SC) eingesetzt. ${ }^{494}$ Weil der Staat aber nicht über genügend Mittel für die Gründung staatlicher Schulen und nur über wenige Lehrkräfte verfügte, konnte das deutsche Schulwesen sich weiter entwickeln. In Rio Grande do Sul investierte der Staat etwa ein Viertel seines Staatshaushalts in das Bildungswesen, zahlte Lehrergehälter und Miete für frühere Vereinsschulhäuser oder Lehrerwohnungen und viele Privatschulen wurden in Staatsschulen umgewandelt. Strengere Examen für Lehrkräfte wurden besonders in Santa Catarina eingeführt.495 1909 implementierte der Innensekretär Protásio Alves ein Schulprogramm für die nationale, politische und moralische Vereinheitlichung ganz Brasiliens und Portugiesisch wurde als Sprache in Privatschulen obligatorisch. Kostenlose Portugiesisch-Abendkurse wurden gefordert und junge Lehrer ins Hinterland gesandt. ${ }^{496} 1913$ waren Privatschulen in Santa Catarina verpflichtet, den Besuch staatlicher Schulbehörden zu gestatten und Auskünfte über ihren Unterricht zu erteilen. Privatschulen mussten jährlich eine Schulstatistik, einen Stundenplan und ein Programm für die Gestaltung von Nationalfeiertagen vorstellen. ${ }^{497}$

\footnotetext{
${ }^{491}$ Nagar, S. 20-27.

492 Sudhaus, S. $177 f$.

${ }^{493}$ Cancelli, Elizabeht. O mundo da violência. Campinas: Universidade Estadual de Campinas, 1991, S. $248,250$.

${ }^{494}$ Fischer, Geschichte der Evangelischen Kirche, S. 138; Schröder, Brasilien und Wittenberg, S. 354.

495 Von 45 Kandidaten bestanden nur 16 ihr Examen. Aldinger, Paul. Die Gestaltung unsres Schulwesens in Santa Catharina. In: Deutsche Ansiedler, Januar 1907, EZA 5/2455.

496 Schulze, S. 204f.

${ }^{497}$ Schröder, Brasilien und Wittenberg, S. 356. 1916 existierten in Blumenau (SC) 127 Unterrichtsanstalten, 117 Privat- und 10 Regierungsschulen. 107 von ihnen unterrichteten auf Deutsch. Ebd., S. 272.
} 
Zunächst verhielt sich Brasilien im Ersten Weltkrieg (1914-1918) neutral.498 Weil es aber wirtschaftlich und politisch besonders von den USA abhängig war, wurde es nach der Zerstörung brasilianischer Schiffe veranlasst, Deutschland im Oktober 1917 den Krieg zu erklären. ${ }^{499}$ Dies nahmen die nationalistischen Gruppen in Brasilien zum Anlass, ihre Maßnahmen gegen eine Überfremdung des Landes durchzusetzen. Das Innenministerium sandte einen Brief an die brasilianischen Staaten mit deutschen Siedlungsgebieten und verbot die Veröffentlichung deutscher Zeitungen, was auch Gemeindeblätter und -zeitungen betraf ${ }^{500}$ und ordnete die Schließung deutscher Schulen an, an denen die Landessprache Portugiesisch nicht gelehrt wurde.501 Bereits Ende 1914 wurde der Briefverkehr mit Deutschland eingeschränkt und erst 1919 wieder vollkommen erlaubt. Die beschlagnahmte Korrespondenz ging nach Rio de Janeiro (RJ) in die Zensur. ${ }^{502}$ Der deutsch-brasilianische In- und Exporthandel stagnierte, was eine Wirtschaftskrise auslöste..$^{503}$ Die Nationalistische Liga plädierte für eine Nationalisierung der Eingewanderten und deren Nachkommen und eine Stärkung der Staatsautorität durch Zentralisierung, Uniformierung und Militarisierung. 504

Die Verbreitung des Mythos einer „Deutschen Gefabr" und die Angst vor einer möglichen Annektion der südlichen Staaten im Falle einer Niederlage der Alliierten erregte unter der brasilianischen Gesellschaft Empörung, die sich gegen Einwanderer und deren Nachkommen richtete. ${ }^{505}$ Die deutschfeindlichen Angriffe und Demonstrationen, die noch ausführlicher zu behandelt sind, brachten die Spannung zwischen brasilianischer Gesellschaft und Einwanderergesellschaft zum Ausdruck. ${ }^{506}$

Während des Krieges wurden viele Privatschulen, besonders in Städten, geschlossen. Das deutsche Schulwesen wurde dadurch zwar nicht aufgehoben, aber erheblich eingeschränkt. Wo Privatschulen geschlossen wurden, sollten diese theoretisch durch staatliche ersetzt werden, aber ihre Anzahl entsprach bei weitem

\footnotetext{
498 Bürger berichtet, dass der Kriegsausbruch die Politik Brasiliens in zwei Gruppen teilte, die Deutschfreundlichen, unter ihnen Katholiken und ihr Klerus, die zunächst Neutralität bewahren wollten, und die Radikalen, die später die Kriegserklärung gegenüber Deutschland erzwangen. Bürger, Brasilien, S. 33f.

499 Der Belagerungszustand wurde November 1917 aber nur für die Staaten Rio de Janeiro, Distrito Federal, São Paulo, Paraná, Santa Catarina und Rio Grande do Sul ausgerufen, Espírito Santo blieb ausgeschlossen. Dreher, Igreja e Germanidade, S. 47.

500 Das geschah, weil sie oft Artikel über die Kriegslage aus einer deutschen Perspektive veröffentlichten und Spenden für das Rote Kreuz, für die Nationalstiftung für Hinterbliebene und für die Volksversammlung der Deutschen im Ausland sammelten. Wirth, S. 114f.

${ }^{501}$ Dreher, Igreja e Germanidade, S. 47; Wirth, S. 115.

502 Brief des Ständigen Vertreters des Evangelischen Oberkirchenrats für Brasilien von 15.11.1917, S. 7f, EZA 5/2158, Beilage 461.

${ }^{503}$ Krause, Lutherische Synode in Brasilien, S. 143.

504 Prien, S. 276.

505 Magalhães, Pangermanismo e nazismo, S. $115 f$.

${ }^{506}$ Magalhães, Racismo no sul do Brasil, S. 170.
} 
nicht den schulischen Bedürfnissen in den Siedlungsgebieten. Staatliche Dekreten und das neue Schulgesetz änderten den Schulplan und erzwangen die Einführung neuer Fächer, die Anwendung von brasilianisch didaktischem Material und die Ablegung eines Examens in portugiesischer Sprache.507 Die Durchführung dieser Maßnahmen stand unter staatlicher Aufsicht. ${ }^{508}$ Die staatlich geprüften und vom Staat neu angestellten Lehrkräfte wurden nun auch von ihm besoldet. ${ }^{509}$ Nach Verordnung des Nationalen Kongresses 1918 durfte keine fremdsprachige Grundschule mehr eröffnet werden. Fremdsprachige Namen für Schulen ${ }^{510}$, Läden, Geschäfte, Straßen, Städte, Gebiete, wie auch die Registrierung fremder Namen waren verboten und wurden mit einer Geldstrafe geahndet. Gewährte Einbürgerungen und Amtsnominierungen für Personen, die die Landessprache nicht beherrschten, konnten aufgehoben werden. ${ }^{511}$

Aufgrund des Mangels an staatlichen Schulen durften deutsche Schulen nach dem Krieg ihren Betrieb wieder aufnehmen, wobei bestimmte Regelungen ortsabhängig strenger oder milder ausgelegt wurden. Nach dem Gesetz sollten die Hauptfächer auf Portugiesisch unterrichtet werden, aber eine große Anzahl Schulen folgte dieser Vorschrift nicht, teilweise aus Mangel an Lehrkräften, die die Landessprache beherrschten, teilweise, um das Deutschtum zu pflegen. In Blumenau (SC) hatten es die Einwanderer und Nachkommen geschafft, dass der Schulinspektor Orestes Guimarães diese Forderungen milder durchführte. Durch ihren politischen Einfluss wurden auch nach und nach deutschbrasilianische Lehrer an Regierungsschulen angestellt. ${ }^{512}$ Aber in vielen Siedlungsgebieten galt noch das Verbot der deutschen Sprache und das intellektuelle Niveau der Einwandererkinder sank aufgrund dieser mangelhaften Bedingungen und der schlechten Qualifizierung der Lehrkräfte. 513

\footnotetext{
507 Dedekind, Brasilien, S. 24; Schröder, Brasilien und Wittenberg, S. 356f; Krause, Lutherische Synode in Brasilien, S. 154; Bestimmung des staatlichen Innensekretärs, L. Petry, São Leopoldo, 18.1.1918, AHI, SR 13/5, Beilage 040 .

508 Anordnungen des Innensekretärs, Dr. Protasio Alves zu den Präsidenten der Schulkonferenzen von 11.5.1918. In: Zeitung Correio do Povo. Porto Alegre, Ano XXIV, Nr. 111, 12.5.1918, AHI, SR 13/5 Beilage 021 .

509 Pastor Bühler berichtet, dass der Staat den Lehrern in Privatschulen, die sich um die Landessprache bemühten, eine monatliche Beihilfe von 15 bis 30 Milréis gewährte. Bühler, Fritz. Ein Beitrag zur Kirchenkunde Südamerikas. [1917/1918], S. 90, MLV 51/17 108.

${ }^{510}$ Das Gesetz wurde nicht überall streng ausgeführt, wie am Beispiel des deutschen Gymnasiums in Pelotas (RS) zu erkennen ist. Es wechselte seinen Namen erst 1924 zu Collegio Internacional. 1925 wurde es Collegio Allemão benannt. Später hieß es wieder Deutsches Gymnasium in Pelotas, musste 1941 einen neuen portugiesischen Namen bekommen, so dass es in Collegio Carlos Ritter benannt wurde. Fonseca, S. 139.

511 Zeitung O Independente. Anno XVIII Nr. 1994, Porto Alegre, 6.2.1918, AHI, SR 13/5 Beilage 038; Prien, S. 201.

512 Bericht Hübbes über die Schulgesetzgebung in Santa Cazharina [sic!], 16.6.1924, EZA 5/2455, Beilage 242.

513 Prien, S. 217-219.
} 
Der Sieg der Entente und damit die Niederlage Deutschlands stärkte das patriotische Gefühl und den Nationalismus der Brasilianer. ${ }^{514}$ Eine örtlich verwurzelte Kulturbewegung bildete sich und hob die einheimischen Elemente der brasilianischen Kultur hervor. Sie plädierte in Zusammenhang mit der Ideologie der Rassenmischung für die Assimilierung verschiedener Kulturen in einer normativen brasilianischen Kultur und fand ihren Ausdruck in der Woche für moderne Kunst 1922, die als Ausgangspunkt für den brasilianischen Nationalismus gilt. ${ }^{515}$

Seit den 1930er Jahren engagierten sich intellektuelle Kreise für die Einrichtung eines kulturellen Nationalprojekts, um das Land zu "verbrasilianisieren".516 Portugiesisch sollte als nationale Sprache eingeführt und alle Einwanderergruppen in einer brasilianischen Rasse integriert werden. Die ethnische Heterogenität, der hohe Anteil der Einwanderer, das Erbe der Sklaverei, die Oligarchien, die Modernisierung Brasiliens und der historische Einfluss ausländischer Nationen wurden hinterfragt. Einwanderer galten noch als positives Element für die brasilianische Gesellschaft ${ }^{517}$, wurden aber aufgrund ihrer Isolierung, ihrer industriellen Entwicklung und damit ihre Mitgliedschaft in einer bedrohlich wirkenden Arbeiterklasse und letztendlich aufgrund ihrer ausländischen Ideologien (des Anarchismus, Kommunismus, bald auch Faschismus und Nationalsozialismus) als eine Gefahr für die Bildung einer brasilianischen Nation angesehen. ${ }^{518}$ Die Angst vor einer „Deutschen Gefabr" und einer deutschen Invasion in Südamerika wurde vor allem durch die politisch-ideologische Propaganda aus Frankreich, England und der USA in den 1930er und 1940er Jahren, besonders nach dem Machtaufstieg Hitlers und seiner Pläne über die Gründung eines Großen Deutschlands, neu artikuliert. ${ }^{519}$ Selbst in Espírito Santo gingen Gerüchte über eine Infiltration von Agenten Hitlers in Form von deutschen Pastoren und Lehrer und über eine mögliche Angliederung des Staats in eine deutsche Provinz, um. ${ }^{520}$

Der brasilianische Nationalismus fand seinen Ausdruck zunächst in der Integralistischen Bewegung. Sie wurde 1932 gegründet und stammte vom rechten Rand des brasilianischen Nationalismus, der sich der 1922 gegründeten kommunistischen Partei mit ihren populistischen Idealen widersetzte. Aufgrund ihrer Kleidung, Symbolik, Begrüßung mit ausgestreckter Hand ${ }^{521}$, Rituale, Ideologie und der Mys-

\footnotetext{
514 Magalhães, Pangermanismo e nazismo, S. 117.

515 Wirth, S. 23f.

516 Dreher, Igreja e Germanidade, S. 49, vgl. Schulze, S. 204f.

517 Die Theorie der „Weißelung der Rasse“ spielte wieder eine Rolle als Ideal für die Konstruktion des Brasilianismus. Perazzo, S. 35.

518 Perazzo, S. 40, 42.

519 Perazzo, S. 28; Fáveri, Marlene. Memórias de uma (outra) guerra. Florianópolis: Universidade Federal de Santa Catarina, 2002, S. 33; Gertz, O fascismo no sul do Brasil, S. 74f.

${ }^{520}$ Rölke, Raízes da Imigração alemã, S. 391.

${ }^{521}$ Die Integralisten wurden aufgrund ihrer Bekleidung als ,grïne Hemden" bezeichnet. Als Symbol fungierte der griechische Buchstabe $\Sigma$, der auf ihrer Fahne prangte. Sie begrüßten sich mit dem Wort „Anauê", eine Mischung aus verschiedener Begrüßungen des indigenen Volkes Tupi. Ackermann,
} 
tik um den Führer wurden ihre Anhänger, unter ihnen viele Einwanderer und deren Nachkommen, mit dem deutschen Naziregime oder dem italienischen Faschismus $^{522}$ in Verbindung gebracht. Präsident Getúlio Vargas gehörte zunächst dem Integralismus an. 1934 erließ er eine neue Bundesverfassung mit nationalistischen Maßnahmen, nach welcher vor allem das deutsche Schulwesen durch Errichtung von Grundschulen mit nationalistischem Charakter und Einführung brasilianischer Lehrkräfte in Einwanderungsgebieten beeinträchtigt wurde. ${ }^{523}$ Ein Eintrittsquotensystem von $2 \%$ für jede in den letzten 50 Jahren ausgewanderten Ethnien wurde eingeführt. ${ }^{224}$ In Zusammenhang mit der Bundesverfassung von 1937 wurden die vormals erlangten Rechte der Ausländer erneut eingeschränkt. Eingebürgerte durften beispielsweise eine Reihe von Berufen nicht mehr ausüben und auch nicht in bestimmte Ämter gewählt werden. 525

Bis 1937 zeigten die Nationalisierungsmaßnahmen, aufgrund der innenpolitischen Wirrungen im Lande, keinen bedeutenden Effekt. Ihre Durchführung stand in Zusammenhang mit der regionalpolitischen Machtkonstellation der Kolonisationsgebiete und wurde je nach Ort mal strenger, mal milder durchgesetzt. In Santa Catarina wurde zum Beispiel die Teilung der Stadt Blumenau (SC) Anfang 1934 in fünf verschiedenen Städte ${ }^{526}$ als Vergeltung für die Wahlniederlage ${ }^{527}$ der Landes-

Silvia Regina. Quando preferir um samba ao bino nacional é crime. São Carlos: Universidade Federal de São Carlos, 2009, S. 28.

522 Der integralistische Führer Plínio Salgado reiste 1930 nach Italien, wo er den Faschismus von Benito Mussolini kennenlernte und sich von ihm beeinflussen ließ. Ackermann, S. 28.

523 Bereits im Jahre 1931 hatte ein Schulgesetz die Einführung sprachlich und fachlich und vor allem staatlich geprüfter Lehrkräfte und einen festen Lehrplan in den Privatschulen festgelegt. Dekret in deutscher Übersetzung, EZA 5/2453, Beilage 135; vgl. Das neue Schulgesetz für Santa Catharina. In: Scbulbuch, Organ zum Ausbau der Schulbuchliteratur in Brasilien, Nr. 34, São Leopoldo, Mai 1931 EZA 5/2453 Beilagen 167f. Mit den Maßnahmen der neuen Bundesverfassung 1934 erhöhte sich die Anzahl städtischer Schulen in Santa Catarina, die in der Landessprache unterrichteten, von 130 in 1830 zu 522. Deutsches Pfarrerblatt, v. 42, Nr. 35, 1938, S. 566. Zitiert nach Prien, S. 282. Die deutschen Geistlichen kritisierten die Errichtung vieler staatlicher Schulen, die aus ihrer Sicht die Schwächung und Nationalisierung des deutschen Schulwesens zum Ziel hatten. Dedekind, Brasilien, das Ziel deutscher Auswanderer, S. 45. Sudhaus argumentiert, dass deutschbrasilianische Schulen deutscher Sprache so brasilianisch wie die lusobrasilianischen portugiesischer Sprache seien, weswegen der brasilianische Staat beide unterstützen müsse. Sudhaus, Fritz. Os trabalhos de ensino teuto-brasileiros e a questão de sua existência. Zitiert nach Py, S. 25.

524 Magalhães, Pangermanismo e nazismo, S. 43; Siller, S. 26.

525 Willems, S. 386f.

526 Die Distrikte von Dalbérgia (Ibirama), Gaspar, Indaial und Timbó wurden von Blumenau (SC) abgetrennt. Die Teilung der Stadt löste große Proteste unter der Bevölkerung aus, worauf die Polizei in Timbó (SC) und Indaial (SC) mit Gewalt und Inhaftierungen reagierte. Associação dos Amigos do Arquivo Histórico de Indaial. Indaial. Conhecendo sua história. Indaial: AMARHIN, t. 2, n. 1, mar./maio 2016, S. 27.

${ }_{527}$ Blumenau (SC) verfügte über die größte Wahlquote von Integralisten im Staat. Im Plebiszit von 1937 wurde der integralistische Führer Plínio Salgado in vielen Städten mit deutscher Kolonisation gewählt, Vargas hingegen bekam in einigen Orten gar keine Stimmen. Kuehne, João. O Integralismo nazi-fascista em Santa Catarina. In: Delegacia de ordem política e social de Santa Catarina, O Perigo nazista no coração do Brasil. Florianópolis: Imprensa Oficial do Estado, 1944, S. 142f, 170. 
regierung in deutschen Siedlungsgebieten angesehen. Gleichzeitig wurde die Verstaatlichung der Schulen beschlossen. ${ }^{528}$

Nach Gertz pflegten Brasilien und Deutschland zwischen 1930 und 1938 gute politische und wirtschaftliche Beziehungen und hielten eine ausgeglichene Handelsbilanz aufrecht.529 Auf die guten Wirtschaftsbeziehungen folgte eine freundschaftliche politische Annäherung und Präsident Vargas entwickelte eine immer größere Sympathie für den deutschen Nationalsozialismus.530 Beide Länder kämpften zusammen gegen den Kommunismus und verhandelten über einen gegenseitigen Informationsaustausch und Auslieferung von Kommunisten. 531 Vargas empfahl auch Mitgliedern der Staatsregierung an deutschbrasilianischen Feierlichkeiten in Kolonisationsgebieten teilzunehmen ${ }^{532}$ und förderte sogar die öffentliche Darstellung des deutschen Nationalismus. ${ }^{533}$ Auf diese Weise konnte die Nazipartei (NSDAP) sorgenlos ihre politische Parteipropaganda ${ }^{534}$ in Brasilien betreiben und (NSDAP-)Zellen gründen. ${ }^{535}$

\subsection{Von der Entstehung des Neuen Staates bis zum Ende des Zweiten Weltkrieges (1937-1945)}

Die innenpolitischen Wirren in Brasilien führten zu einem staatlichen Putsch, bei dem Präsident Vargas alle oppositionellen Kräfte beseitigte und ein nationalistisches Regime in Brasilien einführte. Er strebte nach einer nationalen Integration aller Ethnien und griff in diesem Sinne die wichtigsten Institutionen der Einwanderer und deren Nachkommen, nämlich deutsche Schulen, Presse, Vereine, Kirchen und Familien an. Ihre Sprache wurde verboten und ihre ehemalige Beteiligung oder Sympathie für den Integralismus oder Nationalsozialismus, wie auch

\footnotetext{
528 Wirth, S. 155; Gertz, O fascismo no sul do Brasil, S. 66-68.

${ }^{529}$ Perazzo, S. 38f; Gertz, O fascismo no sul do Brasil, S. $61 \mathrm{f}$.

530 Gertz, O fascismo no sul do Brasil, S. 107.

531 Hier ist die Geschichte von Olga Benário Prestes zu erwähnen. Geboren am 12.2.1908 in München, engagierte sie sich seit ihrer Jugend für die Kommunistische Partei in Deutschland, wurde verhaftet und floh in die Sowjetunion. Von dort wurde sie nach Brasilien gesandt, um die lokale Kommunistische Partei zu unterstützen. Sie heiratete den Brasilianer João Carlos Prestes, der einen Aufstand gegen die Regierung Vargas organisierte. Das Ehepaar wurde 1936 verhaftet und Olga Benário Prestes von der Polizei von Distrito Federal (DF) dem deutschen Geheimdienst ausgeliefert und deportiert. Sie starb im Konzentrationslager Bernburg in der Gaskammer am 23.4.1942. Cancelli, S. 180, $186 f$.

532 Gertz, O fascismo no sul do Brasil, S. 65; Perazzo, S. 35.

533 Gertz, O fascismo no sul do Brasil, S. 87.

534 Der Deutsche Ausländerdienst war zum Beispiel für die Verbreitung von Propaganda und für Berichte über die Tätigkeit der deutschen Regierung weltweit verantwortlich. Plakate mit Hitlerbildern, Abzeichen und Uniformen wurden kostenlos als Geschenk Deutschlands überall verteilt. Py, S. 168190 und Beilagen.

535 Über die Tätigkeit der NSDAP im Staat Rio Grande do Sul siehe Py, S. 60-142; über seine Tätigkeit in Santa Catarina siehe Ribas, O Nazismo em Santa Catarina, S. 24f. Über die Entstehung und Organisation der NSDAP in Südamerika siehe Py, S. 368-398.
} 
die Verwendung ihrer Sprache in der Öffentlichkeit wurde mit Folter und Inhaftierung bestraft.

Im Jahre 1937 trennte sich Präsident Vargas, der bereits seit 1930 Brasilien regierte, von der Integralistischen Partei, organisierte einen Staatsputsch, entmachtete die Staatsgouverneure, das Parlament, den Senat, die städtischen Kammern und die Magistrate und hob die Bundesverfassung von 1934 auf. Alle politischen Parteien wurden aufgelöst, um die ,nationale Einheit" zu sichern. ${ }^{536}$ So entstand der Neue Staat (1937-1945). Die Integralisten organisierten 1938 zwei Aufstände ${ }^{537}$, scheiterten aber und wurden danach verfolgt. Die Teilnahme der Deutschen und ihrer Nachkommen am Integralismus oder an der Politik der NSDAP war nach Wirth nicht der Auslöser für das Nationalisierungsprogramm, beschleunigte und legitimierte es jedoch angesichts des internationalen Drucks gegen die Expansion des Faschismus. ${ }^{538}$ Durch ihn erlangte Vargas die Auflösung der Pro-Deutschtumund Pro-Nationalsozialismuspropaganda. ${ }^{539}$

Mit der Expansion des Pangermanismus repräsentierte die Tätigkeit einer deutschen Partei mit einem deutschen Nationalismusprogramm wie die NSDAP in Brasilien eine nationale und internationale Bedrohung nicht nur aufgrund des Zweiten Weltkrieges, sondern auch für die Entwicklung einer brasilianischen $\mathrm{Na}$ tionalidentität ${ }^{540}$, für die politische Souveränität des brasilianischen Staates und für deutschfeindliche Regime in Südamerika, die durch pro-deutsche Regime gestürzt werden konnten. ${ }^{541}$ Die Handlungsfreiheit der Ausländer und die Toleranz der Regierung angesichts der Infiltration des Nationalsozialismus, mithilfe der zwischen 1930 und 1938 eingewanderten Deutschen, wurde kritisiert. ${ }^{542}$ Laut Perazzo verfügte Vargas bis dahin über keinen festen politischen und ideologischen Plan für Brasilien. Er wollte aber das Bild eines zurückgebliebenen Landes revidieren und Deutschland galt ihm als Muster für wirtschaftliche Modernität und eines

\footnotetext{
536 Prien, S. 286; Ackermann, S. 50-59.

537 Die Vermutung, die Nazis haben zusammen mit den Integralisten diese Aufstände organisiert war laut Prien ein Propagandamanöver der brasilianischen Nationalisten gegen die Aktivität der nationalsozialistischen Partei in Brasilien. Es wurden nie Indizien über eine mögliche Partizipation der Nazis gefunden. Prien, S. 285 f.

538 Wirth, S. 143.

539 Droogers, André. Religião, Identidade e Segurança entre Imigrantes Luteranos da Pomerânia no Espírito Santo (1880-2005). In: Religião e Sociedade, Rio de Janeiro, 28 (1), 2008, S. 28f.

${ }_{540}$ Nationalsozialistische Reichsdeutsche führten eine Denationalisierungspropaganda durch, indem sie Deutsche in Brasilien von einer Einbürgerung abrieten und Deutschbrasilianer von ihrer deutschen Zugehörigkeit überzeugten. Einige Deutsche, die sich in Brasilien einbürgern lassen wollten, wurden in Santa Cruz do Sul (RS) verfolgt und gedemütigt. Brief von Luiz Beck da Silva an den Polizeichef Paulo Acosta Rodrigues, Santa Cruz, 25.2.1938. Zitiert nach Py, S. 112.

541 Gertz, O fascismo no sul do Brasil, S. 74-80.

542 Reserviertes Schreiben von José Meira de Vasconcelos, Kommandant des 1. Militärgebietes und der 1. Infanteriedivision an den Kriegsminister, Rio de Janeiro, 10.3.1939, Justizministerium, Abteilung für nationale Sicherheit, IJ1 1422 (Past 1, cad 6, 1939), ANRJ (A97, PEP). Zitiert nach Perazzo, S. 33 .
} 
erfolgreichen Politikprogramms, trotz wiederholter Rückschläge. ${ }^{543}$ Mit dem Aufstieg Hitlers erlange es seinen politischen Höhepunkt, so dass der Nationalsozialismus die Inspiration für die Einrichtung eines nationalistischen Staates in Brasilien wurde ${ }^{544}$ und die brasilianischen Nationalisierungsmaßnahmen wiesen große Ähnlichkeiten mit dem deutschen Programm auf. ${ }^{545}$

Die brasilianische Polizei stellte fest, dass einige nationalsozialistische Deutsche Beziehungen mit Integralisten pflegten. So wurden die 1936 gewählten Integralisten ihren Ämtern enthoben ${ }^{546}$, Mitglieder oder Sympathisanten des Integralismus und des Nationalsozialismus angezeigt und verfolgt. Vor allem in Santa Catarina repräsentierten deutsche Siedler eine einflussreiche industrielle Schicht, die aus der Sicht des brasilianischen Nationalstaates dringend nationalisiert werden musste. Aus diesem Grund wurden die Nationalisierungsmaßnahmen hier strenger als in anderen Staaten umgesetzt. Sie zielten besonders auf unabhängige Institutionen ab, unter ihnen Schulen und Kirchen, die aufgrund ihrer Selbstständigkeit gegenüber dem Staat außer Kontrolle geraten zu sein schienen. Außerdem wiesen die Kolonisationsgebiete eine schwierige Integration auf. Ihre Bevölkerung widersetzte sich jedwedem Einfluss gegen ihre eigene ideologische Gesinnung und frühere Nationalisierungsgesetze wurden ignoriert. Sie sonderten sich sprachlich, ethnisch und kulturell von der brasilianischen Gesellschaft ab und übten eine methodische und organisierte Propaganda mit Hilfe von eigenen Zeitungen, Zeitschriften, Büchern und Kalender aus, bekamen finanzielle und materielle Unterstützung vom deutschen Staat und von Organisationen für die Aufrechterhaltung ihrer Institutionen und veranstalteten religiöse Versammlungen und Aktivitäten in deutscher Sprache. ${ }^{547}$

In der ersten Phase des Nationalisierungsprogramms bis 1938 rückte zunächst wieder das Bildungssystem in den Fokus: Schulen mussten auf Portugiesisch unterrichten, ausschließlich brasilianische Bürger durften Direktionsstellen übernehmen, die ganze Lehrerschaft musste in Brasilien geboren oder eingebürgert und ausgebildet sein, Kinder bis vierzehn Jahren durften keine Fremdsprache lernen, Subventionen aus fremden Staaten, von Institutionen und Kirchen waren verboten und es wurden neue Fächer eingeführt. Ab 1939 durfte keine Fremdsprache mehr öffentlich gesprochen werden, auch nicht bei religiösen Zeremonien und Veranstaltungen, die Armee und die Behörden sollten Gebiete mit fremder Kolonisierung kontrollieren und kulturelle Vereine, ${ }^{548}$ die in Verbindung mit dem Ausland standen, schließen. Kommunikationsmedien in fremder Sprache wurden

\footnotetext{
543 Perazzo, S. 33 f.

544 Perazzo, S. 35.

545 Seyferth, S. 186f; Perazzo, S. 36; Fáveri, S. 52, 58 und 64 Fußnote 211.

${ }^{546}$ Fáveri, Fußnote 768, S. 228.

547 Seyferth, S. 181; Perazzo, S. 56.

548 Weil die Existenz von kulturellen und wohltätigen Vereinen zunächst erlaubt war, nutzten Mitglieder der NSDAP-Partei die Gelegenheit, sich diesen Vereinen anzuschließen oder ihre Institutionen einen wohltätigen Charakter zu geben, um ihre politische Tätigkeit zu verbergen. Perazzo, S. 45.
} 
zensiert, dann eingeschränkt und später ganz verboten. ${ }^{549}$ Um einer NichtTeilnahme am staatlichen Schulbesuch entgegenzuwirken, forderten die Behörden Geldstrafen von Eltern, die ihre Kinder nicht an brasilianischen Schulen unterrichten ließen. ${ }^{550}$ Jugendliche mussten sich nach einem Dekret vom 2. März 1940 an die Brasilianische Jugend angliedern, um sich zu integrieren und patriotisch geprägt zu werden. ${ }^{551}$ Deutsche Anstalten, Kindergärten, sportliche und kulturelle Vereine und Bibliotheken wurden geschlossen, ihre Unterlagen und Sachgegenstände, besonders Waffen aus Schützenvereinen, beschlagnahmt und teilweise zerstört. Ihre Direktoren oder Präsidenten wurden durch brasilianische Offiziere ersetzt. 552

Nach den Schulen und Vereinen sollten die Kirche und letztendlich die Familien eine patriotische Identität und ein nationales Bewusstsein entwickeln. Die brasilianische Regierung beabsichtigte jedoch keine Beschränkung der Religionsfreiheit kirchlicher Gemeinden und wollte die deutschen Schulen nicht schließen, verlangte aber das Unterrichten der Hauptfächer in der Landessprache Portugiesisch ${ }^{53}$ und die Zwangsassimilierung ethnischer, sprachlicher und kultureller Bevölkerungen. ${ }^{554}$ Aber sie konnte nicht genügend Ressourcen aufbringen für die Ausbildung von Lehrkräften und die Errichtung staatlicher Schulen und bot auch sonst keine kulturellen und sozialen Anpassungsbedingungen.

Ausländer mussten nach dem Dekret 341 von 17. März 1938 ein von Polizeibeamten erstelltes „Zeugnis gutes Verfabren im Ausland" für zivile Unternehmen, Vertragsschließungen und Gründung von Firmen vorlegen. Das Dekret 383 vom 18. April 1938 verbot die politische Tätigkeit von Ausländern, die Organisation fremder Vereine und die Zurschaustellung fremder Flaggen oder Gegenstände. 1938 verbat Brasilien die Existenz der deutschen NSDAP und rief den deutschen Botschafter ab. ${ }^{555}$ Nach dem Dekret 392 vom 27. April 1938 konnte jeder Anklage gegen einen Ausländer zu seiner Deportierung führen. In Gegenden mit überwiegend fremdstämmigen Ansiedlungen etablierte die Regierung brasilianische Fami-

\footnotetext{
${ }^{549}$ Krause, Lutherische Synode in Brasilien, S. 289; Wirth, S. 143; vgl. Der Christenbote, Nr. 6, 1941, S. 1f; Der Urwaldsbote Nr. 9, 29.7.1941; Kolonie Zeitung Nr. 61, 31.7.1941. Alle In: EZA 5/2165. Das geschah, weil die deutsche Presse in Brasilien als Organ zur Bewahrung des Deutschtums in deutschen Gebieten, vor allem in Südbrasilien, fungierte. Fonseca, S. 71-73. Durch eine Erlaubnis des Justizministers konnten aber einigen Zeitungen, wie der Urwaldsbote, die Kolonie Zeitung, die Volkszeitung und die Blumenauer Zeitung wieder gedruckt werden. Py, S. 213. Der Polizeichef Py kritisiert die Tatsache, dass in den protestantischen Gemeindezeitungen mehr Nachrichten über Politik und Krieg als über Religion gab. Aus diesem Grund wurden sie als Deutschtums- beziehungsweise nationalsozialistische Propaganda verstanden. Ebd., S. 210.

${ }^{550}$ Fáveri, S. 78.

551 Fáveri, S. 66; Cancelli, S. 272.

552 Siehe Der Deutsche Ansiedler. Ano 77, Nr. 36, Januar, März 1939. Zitiert nach Py, S. 218.

${ }_{553}$ Zeitungsartikel Die Catharinenser Privatschulen. EZA 5/2453, Beilage 180, ohne Angabe von Autor und Datum.

554 Ackermann, S. $97 \mathrm{f}$

555 Wirth, S. 156.
} 
lien, um eine Assimilation zu forcieren ${ }^{556}$, während neue Einwanderer planmäßig in gemischten Kolonien untergebracht wurden. ${ }^{557}$ Das Dekret vom 4. Mai 1938 reglementierte erneut die Einreise von Ausländern ins Land und legte Quoten von 2\% für das Ansiedeln von Einwanderern gleicher Herkunft in einem Gebiet fest und verbot homogene Siedlungen von Immigranten derselben Nationalität, um die örtliche Anhäufung von Einwanderern gleicher Abstammung zu verhindern. Die Verordnung vom 18. Mai 1938 setzte die Todesstrafe durch Erschießung für Übertretungen gegen die Staatssouveränität und nationale Sicherheit fest. ${ }^{558}$ Das Dekret Nr. 1.545 vom 25. August 1939 ordnete die Überwachung ausländischer Kolonialzonen an, wenn nötig durch geheime Besichtigungen. ${ }^{55}$ Deutsche, italienische und japanische Einwanderer mussten binnen fünfzehn Tagen ihre Adresse den polizeilichen Beamten mitteilen. Häusliche Versammlungen waren ihnen verboten und sie durften nicht ohne Erlaubnis oder Geleitbrief reisen. ${ }^{560}$

Die USA, die im Juli 1941 einen gegenseitigen Nicht-Angriffs-Paket mit Brasilien, den sogenannten Parnamirim Field unterschrieben ${ }^{561}$, wollten die „drei Amerikas" miteinander verbinden. Dafür verbreiteten sie eine „Panamerikanische Ideologie“, entsprechend welcher nicht die Erhöhung einer Rasse und eines Volkes, sondern die Solidarität zwischen verschiedenen Nationen und der Respekt gegenüber ihrer nationalen Souveränität akzentuiert wurde. Diese Ideologie, zusammen mit der Politik der , ,guten Nachbarschaft" "zwischen den amerikanischen Ländern, bestimmte angesichts der Angst einer Deutschen Gefahr letztendlich die Position Brasiliens, das sich bis dahin im Zweiten Weltkrieg neutral verhalten hatte und die ökonomische Rivalität zwischen Deutschland und den USA um lateinamerikanische Märkte bis 1942 für seine eigenen Zwecke zu nutzten wusste. ${ }^{562}$ Die US-amerikanische Zeitung New York Times ${ }^{563}$ schrieb, dass die deutsche Regierung in Kooperation mit Unternehmern und Mitarbeitern deutscher Firmen in Brasilien einen Spionage-

\footnotetext{
556 Perazzo, S. 44f; Wirth, S. 155.

557 Kahle, S. 65; Siller, S. 26.

558 Perazzo, S. 46.

559 Krause, Lutherische Synode in Brasilien, S. 289

${ }^{560}$ Fáveri, S. 294-298. Ein Exemplar eines Geleitbriefes aus Rio do Testo-Pomerode (SC) befindet sich bei Altmann, S. 54; vgl. Schreiben des Polizeichefs an das Innen- und Justizsekretariat. Ano 1942, Akte Nr. 39, Zweites Trimester, 16.3.1942 und 28.4.1942. Zitiert nach Ackermann, S. 142. Das Dekret erklärte nichts über die Bedingungen zur Durchführung des Gesetzes, so dass jeder Staat diesbezüglich seine eigenen Regeln aufstellen konnte. Perazzo, S. 207f. Cancelli weist darauf hin, dass der Geleitbrief die Kontrolle über die Bevölkerung angesichts einer möglichen Bedrohung ermöglichte, weswegen auch Brasilianer dieses Dokument benötigten. Cancelli, S. 278f.

561 Seibel, Imigrante no século do isolamento, S. $256 \mathrm{f}$.

562 Perazzo, S. 38.

563 Dossier - Zeitungsartikel. Ein Kommentar des New York Times: desmantelada a máquina da Gestapo pela liquidação das firmas alemãs no Brasil (die Gestapo-Maschine wurde durch die Liquidation deutscher Firmen in Brasilien zerschlagen). In: Diário da Noite, Thema: Gestapo, Rio de Janeiro, 5.10.1943. “Alemão”, S. 16, doc Nr. 00023, DOPS-RJ, APERJ, (Cc120, PFP). Zitiert nach Perazzo, S. 161.
} 
dienst aufgebaut hatte. Aus diesem Grund ordnete die brasilianische Regierung die Auflösung deutscher Unternehmen im Land an. ${ }^{564}$

Nach dem deutschen Angriff auf brasilianische Handelsschiffe wurde Brasilien im August 1942 wieder von den USA gedrängt, Deutschland den Krieg zu erklären. ${ }^{565}$ Die Nationalisierungsmaßnahmen wurden nun umso strenger durchgesetzt und aufgrund des Krieges für berechtigt gehalten. Deutsche und Deutschbrasilianer wurden als „Deutsche Gefahr“, „Fünfte Kolonne“566, „Hitlersfreunde“ und „Feinde der Nation" bezeichnet und als Spione im Dienst Deutschlands verfolgt. Ihre Häuser standen unter Beobachtung und wurden geplündert, deutsche Bücher und Schriften wurden beschlagnahmt oder verbrannt, Menschen gefoltert und inhaftiert. ${ }^{567}$ Versammlungen, politische Diskussionen, Sympathieäußerungen gegenüber den Achsenländern, das Tragen und der Handel mit Waffen, die Verbreitung von Drucksachen, die Verwendung fremder Sprachen in der Öffentlichkeit waren verboten. ${ }^{568}$ Bereits nach der Verordnung Nr. 4.166 vom 11. März 1942 konnte das Vermögen deutscher, italienischer und japanischer Einwanderer für Kriegsverluste oder Kriegsfinanzierung konfisziert werden ${ }^{569}$ und der Eintritt neuer Einwanderer wurde durch strenge Regelungen kontrolliert. ${ }^{570}$ Zwei Tage später waren Verkauf und Belastung unbeweglicher Sachen aus ihrem Eigentum nur mit besonderer Genehmigung möglich und von den Guthaben der Reichsdeutschen zog die brasilianische Regierung 10\% bis 30\% für die Bildung eines Kriegsfonds ein. ${ }^{571}$ Fremde Benennungen für Straßen, Flüsse, Schneisen, Orte, Vereine, Geschäfte

\footnotetext{
564 Perazzo, S. $160 f$.

565 Wirth, S. 157; vgl. Camões Filho, Ribeiro do Couto. O Canto do Vento. São Paulo, 2003, S. 47.

566 Der Begriff Fünfte Kolonne entstand im Kontext des Spanischen Bürgerkerieges. Der geplante Staatsstreich des General Franco gegen die Volksfront-Regierung wurde 1939 mit militärischer Hilfe aus Italien und Deutschland durchgeführt. Mit dem Vorrücken vier Truppen-Kolonnen gegen Madrid erwähnte Franco das Vorhandensein einer fünften Kolonne von Sympathisanten der Revolutionäre beziehungsweise Spione. Der Begriff wurde im Zweiten Weltkrieg von der brasilianischen Regierung übernommen, um die Tätigkeit deutscher Spione zu bezeichnen. Ribas, Antônio de Lara. Que é a „quinta-coluna“? In: Delegacia de ordem política e social de Santa Catarina, Perigo nazista no coração do Brasil. Florianópolis: Imprensa Oficial do Estado, 1944, S. 187-205.

${ }^{567}$ Fischer, Geschichte der Evangelischen Kirche, S. 165.

568 Merkblatt über die Lage der Deutschen in Brasilien. Zusammengestellt auf Grund der bis Juli 1943 vorliegenden amtlichen und privaten Nachrichten, 31.7.1943, S. 2, MEW 3.20.

569 Junges, Leandro S. Campos de Concentração em Santa Catarina. In: A Notícia. Privatarchiv von Pastor Nelso Weingärtner. Das Haus der Familie Richter (ausgewandert im Jahre 1905) in Ibirama (SC) wurde am 1.10.1944 von der Polizei gestürmt. Sie beschlagnahmten Dokumente, Schuldscheine und die gesamten Ersparnisse der Familie. Weil viele Deutschbrasilianer ihr Vermögen nicht bekannt gegeben hatten, verloren sie das, was die Polizei bei den Hausdurchsuchungen beschlagnahmte. Fáveri, S. 246-248, 300. Über konfisziertes Geld in Espírito Santo siehe Schreiben Nr. 170, 20.8.1942 und Nr. 177, 24.8.1942 an das Innen- und Justizsekretariat des DOPSs, Fundo Interior e Justiça, Pasta 50, ano 1942, APEES. Zitiert nach Ackermann, S. 128.

570 Cancelli, S. $277 f$.

571 Merkblatt über die Lage der Deutschen in Brasilien, 31.7.1943, S. 1, MEW 3.20.
} 
etc. wie auch fremde Namen mussten ,verbrasilianisiert" werden. ${ }^{572}$ Das Dekret Nr. 4.766 vom 1. Oktober 1942 bestimmte den Spionagedienst ${ }^{573}$, den Besitz von Telegrafie- und Radiogeräten für Distanzkommunikation ${ }^{574}$, die Verbreitung von Informationen für ausländische Autoritäten und die öffentliche Schmähung gegen den Staat und das Regime als Militärverbrechen und Verstoß gegen die nationale Sicherheit. ${ }^{575}$

Die brasilianische Bevölkerung wurde besonders durch englische und nordamerikanische Kriegspropaganda ${ }^{576}$, aber auch durch Gerüchte ${ }^{577}$ aufgehetzt, Deutsche und Deutschbrasilianer anzuzeigen, sie zu beobachten und zu diskreditieren. Denunziationen wurden befürwortet und die brasilianische Bevölkerung aufgefordert, mit der Polizei zu kooperieren. Viele Briefe und Telegramme wurden direkt an Präsident Vargas geschickt, was jedoch die Arbeit der Polizei enorm überlastete. ${ }^{578}$ Besonders im lokalen Bereich waren Prozesse und Streitigkeiten angespannter und persönlich oder durch Rache motiviert. ${ }^{579}$ Unter den Anklägern befanden sich auch Deutsche oder Deutschbrasilianer, die ihre Nachbarn oder Bekannten aus allen möglichen Motiven heraus denunzierten. ${ }^{580}$ Einige Ankläger meldeten sich bei der Polizei, andere gaben falsche Namen an oder blieben ano-

572 In Pomerode (SC) musste die Familie Siewert ihre Tochter als Sievert registrieren. Roland wurde als Rolando registriert usw. Altmann, S. 50. Der ehemalige Präfekt von Indaial (SC) war als Johann Friedrich Hennings registriert. Wegen der Nationalisierung wurde sein Name zu João Frederico Hennings geändert, aber in seinem Führerschein stand João Hennings Filho. Mit diesem Namen wurde er am 13.8.1943 im Gerichtsbezirk Indaial registriert. Associação dos Amigos do Arquivo Histórico de Indaial, t. 2, n. 1 mar./maio 2016, S. 40f. Die Namensänderung brachte später viele Schwierigkeiten bei der Aufteilung des Erbes, weil die verbrasilianisierten Namen nicht mit den Registern übereinstimmten. Zeugen mussten bestätigen, dass es sich um dieselbe Person handelte. Fáveri, S. 316.

5731942 entdeckte die Polizei in verschiedenen südamerikanischen Ländern ein deutsches Spionagenetz. Über die Tätigkeit deutscher Spione in Brasilien siehe Perazzo, S. 100-142; Py, S. 95-111, 284303, 327-334. Die USA und England forderten die brasilianische Regierung auf, dieses Netzt aufzudecken, abzuhören und zu zerstören, denn sie selbst sahen sich dadurch in ihrer Kriegstaktik geschwächt und orientierten, beziehungsweise kontrollierten den Kontraspionagedienst der Brasilianer. Perazzo, S. 167-192.

574 Seit 1940 waren Kriegsnachrichten in Rundfunktransmissionen verboten, vor allem wenn das Rundfunkprogramm aus Deutschland gesendet wurde. Schulze, S. 148.

575 Perazzo, S. 49.

576 Merkblatt über die Lage der Deutschen in Brasilien, 31.7.1943, S. 3, MEW 3.20; vgl. Zeitung $A$ Nação Ano I, Nr. 27, 18.4.1939, Nr. 28, 19.4.1939 und Nr. 35, 27.4.1939. In: AHI, SR 18/3, Beilagen 006, 007, 013; auch die anonymen Broschüren, die vor der Deutschen Gefahr warnten. Bereich ,Alemão', Akte 09, Dokument Nr. 00003, DOPS-RJ, APERJ, (ca18, PFP). Zitiert nach Perazzo, S. 55 .

577 Fáveri, S. 41-50; vgl. Der Deutsche Ansiedler. Ano 77, Nr. 36, Januar, März 1939. Zitiert nach Py, S. 217.

${ }^{578}$ Cancelli, S. 35, 77f, 191, 283.

${ }^{579}$ Die Lage der Deutschen in Brasilien bis Oktober 1942, Berlin: Auswärtiges Amt, 15.1.1943, S. 2, MEW 3.20; Fáveri, S. 71; Cancelli, S. 286-296.

580 Merkblatt über die Lage der Deutschen in Brasilien, 31.7.1943, S. 6, MEW 3.20; Perazzo, S. 156158; Ludwig, Sabine. In Blumenau und Pomerode. Würzburg: Bergstadtverlag Korn, 1997, S. 98. 
nym. Eine einfache Anzeige oder ein leichter Verdacht, begründet oder nicht, führte zur polizeilichen Ermittlungen, Aufsicht, Folter und der Eröffnung eines Strafprozesses. In vielen Fällen blieben die Verdächtigen inhaftiert, bis die Ermittlungen beendet waren. Die Polizei genoss Autonomie und Autorität und konnte selbst bestimmen, wer, wie lange und mit welchen Methoden befragt und festgehalten werden sollte, ohne auf die Entscheidung des Nationalen Gerichts ${ }^{581}$ warten zu müssen. Viele wurden bald freigelassen, aber aufgrund der von ihnen ausgehenden angeblichen Gefahr für die nationale Sicherheit, obwohl ihnen nichts nachgewiesen werden konnte, blieben einige bis $\mathrm{zu}$ einem Jahr inhaftiert. ${ }^{582}$ In abgelegenen Orten im Binnenland wurden zahlreiche Inhaftierungen nie registriert. $^{583}$

Die Inhaftierten wurden in Hafteinrichtungen, Gefängnissen oder Konzentrationslager gebracht. ${ }^{584}$ Letztere sind nicht mit den Konzentrationslagern in Europa vergleichbar. Dort wurden deutsche Pastoren, politische Gegner und Ausländer, unter ihnen Deutsche und Deutschbrasilianer, inhaftiert ${ }^{585}$, wodurch sie eher Inhaftierungslager darstellten. Inhaftierungslager gab es in den brasilianischen Staaten Rio Grande do Sul (Daltro Filho), Santa Catarina (Florianópolis und Joinville) ${ }^{586}$, Paraná, São Paulo, Rio de Janeiro, Espírito Santo (Vitória und Maruípe ${ }^{587}$, Minas Gerais, Pará und Pernambuco. Es gibt zwar kein Verzeichnis über Mord oder andere Todesursachen, aber die Gefangenen mussten in einigen Lagern Zwangsarbeit leisten oder in vereinzelten Fällen Folter erdulden. ${ }^{588}$

5811936 wurde das Nationale Sicherheitsgericht gegründet, um Subversionsversuche und Revolutionen gegen den Staat zu verhindern. Es entstand als ein Organ der Militärjustiz, verselbstständigte sich 1937 mit der neuen Bundesverfassung des Neuen Staates. Weil es sich letztendlich erlaubte, auf die Präsenz des Angeklagten zu verzichten, wurde ein Spielraum für Folter ermöglicht. Das Nationale Sicherheitsgericht arbeitete in enger Verbindung mit der Polizei, denn die Richter betrachteten die Anklagen als bewiesene Straftaten. In Bezug auf ideologische Anklagen wurde beispielsweise nicht die Tat der Person, sondern ihre politische Überzeugung als Strafe betrachtet. So fungierte dies zum staatlichen Repressionsmittel. Durch das Dekret von 1938 verurteilte das Gericht auch Verbrechen gegen die soziale Ordnung. Ackermann, S. 153f.

582 Perazzo, S. 148f, 197, 205.

583 Merkblatt über die Lage der Deutschen in Brasilien, 31.7.1943, S. 6, MEW 3.20.

${ }^{584}$ Im Jahre 1942 sollen etwa 2.000 bis 3.000 von 100.000 Reichsdeutschen in Brasilien inhaftiert gewesen sein. Die Lage der Deutschen in Brasilien bis Oktober 1942, Berlin: Auswärtiges Amt, 15.1.1943, S. 3, MEW 3.20.

585 Perazzo, S. 30.

${ }^{586}$ Junges, Leandro S. Os presos em Santa Catarina. In: A Noticia. Privatarchiv von Pastor Nelso Weingärtner.

587 Ackermann, S. 132.

${ }^{588}$ Kurze Zusammenfassung aus Berichten Zurückgekehrter über die Internierungslager in Brasilien, 3.7.1944, EZA 5/2168; Junges, Leandro S. Campos de Concentração em Santa Catarina; Perazzo, S. 30. Briefe der Internierten wurden von der Polizei kontrolliert, zensiert oder die, die Auskunft über die schlechten Bedingungen in den Lagern gaben, beschlagnahmt. Siehe Carta (Übersetzung) de „paisinho" para meus queridos três tratantes“, ohne Angaben von Ort und Datum. Estação Experimental de Produção Animal ou Campo de Concentração de Pindamonhangaba, Pront. Nr. 15.591, DEOPS-SP, DAESP. Zitiert nach Perazzo, S. 223; vgl. Camões Filho, S. 51, 53, 84; Abschrift des 
Weil Vargas die Inspiration für seinen nationalistischen Staat im nazifaschistischen Regime fand, verursachte der Absturz dieses Regimes auch den Absturz seiner Machtstellung. Er verlor die Unterstützung des Militärs und wurde am 29. Oktober 1945 letztlich abgesetzt. Die strengen Maßnahmen gegen die Einwanderer und deren Nachkommen wurden danach allmählich aufgehoben.

\section{Zwischenfazit}

Zusammenfassend lässt sich feststellen, dass verschiedene ökonomische, soziale, politische und religiöse Motive, wie auch eine organisierte und gut vernetzte Einwanderungspropaganda die Pommern zur Emigration trieben. Weil sie in unterschiedlichen Perioden auswanderten, bildeten sie keine homogene Gruppe, sondern umfassten mehrere sozialen Schichten und wurden von den jeweiligen politischen, sozialen, wirtschaftlichen und ideologischen Ereignissen eines breiten Zeitraums beeinflusst. In Brasilien ließen sie sich besonders in Koloniegebieten in den Provinzen Rio Grande do Sul, Santa Catarina und Espírito Santo nieder.

Die alte Heimat sah in der Auswanderung ihrer Untertanen zunächst eine Lösung für ihre sozialen und wirtschaftlichen Probleme, aber unter dem Druck der Großgrundbesitzer und Industriellen und entsprechend militärischer, politischer und ökonomischer Interessen riet sie den Emigrationswilligen von der Auswanderung ab und erließ mehrere Gesetze, um den Emigrationsstrom zu stoppen. Das wichtigste war das Heydtische Edikt 1859. Deutsche Kaufleute sahen ihrerseits in den Emigranten zukünftige potentielle Konsumenten ihrer Industrieprodukte im Ausland. Bereits ab den 1820er und verstärkt in den 1840er Jahren, besonders aber nach der Entstehung des Deutschen Reiches 1871, beeinflusst durch nationalistische, wirtschaftliche und ideologische Interessen, setzten sie sich zusammen mit Kolonisations- und Missionsgesellschaften für die Entwicklung eines „neuen Deutschlands" im Ausland ein. Die zurückhaltende Position des deutschen Reiches änderte sich 1890, denn nun engagierte sich auch der Staat für die Deutschtumspflege der Auslandsdeutschen und für die Lenkung des Auswanderungsstroms in bestimmte Gebieten. Der Nationalsozialismus führte diese Pläne auf aggressive

Briefes von Major Hansotto Vorberg, 22.5.1944, EZA 5/2168. Über die Bedingungen in den Inhaftierungslagern in den Staaten Paraná, Santa Catarina, Rio Grande do Sul und in Niterói (RJ) siehe Berichte des Delegierten des internationalen Roten Kreuzes, Eric Haegler. Zitiert nach Perazzo, S. 217-232. Über die Bedingungen der Inhaftierungslager im Staat São Paulo siehe Camões Filho, S. 55-67, 87-100. Die Zeitung Der Urwaldsbote von 29.7.1941 Nr. 9 berichtet über die Situation in Inhaftierungslager Brasiliens im Artikel Merkmale über die deutschen in Brasilien, S. 155, EZA 5/2165. Auch Berichte von freigelassenen Pastoren geben Auskunft über die Lebensbedingungen und Anzahl der Inhaftierten: Brief von Bischof Dr. Heckel an die deutschen evang. Pfarramt aus Südamerika, Berlin, 11.9.1944, S. 5; Merkblatt über die Lage der Deutschen in Brasilien, 31.7.1943, S. 6-16; Die Lage der Deutschen in Brasilien bis Oktober 1942, Berlin: Auswärtiges Amt, 15.1.1943, S. 3. Alle drei In: MEW 3.20. Über andere Inhaftierungsorte siehe Fáveri, S. 190-209; Cancelli, S. 440f. 
Weise fort und forderte alle Deutschen weltweit auf, sich an der Entwicklung eines ,großen Deutschlands "zu beteiligen.

In Brasilien bereitete die Monarchie die Grundlagen für die Ankunft der Einwanderer. Aber die Immigrationspolitik wurde erst nach der Unabhängigkeit Brasiliens 1822 im vollen Maß umgesetzt. Die kaiserliche Regierung unterstützte die Einwanderer mit staatlichen Subventionen und durch leichtem Landerwerb, stieß damit aber auf die Opposition nationalistischer, oligarchischer, konservativer, republikanischer und katholischer Kreise. Diese sorgten immer wieder für die Verringerung oder Aufhebung staatlicher Ausgaben für die Immigration und setzten sich gegen eine bessere Regelung für protestantische Ehen, Einbürgerungen und vergünstigte Landkonzessionen ein. Obwohl Brasilien ein römischkatholisches Land war, konnten die Einwanderer ihren Kultus mit gewissen Einschränkungen, die aber nicht streng ausgelegt wurden, ausüben. Problematisch war auch ihre politische Ausgrenzung, denn Nicht-Katholiken durften bestimmte Ämter nicht übernehmen. Mit Ausrufung der Republik 1889 erlangten die Einwanderer und deren Nachkommen politische und religiöse Gleichberechtigung. Weil sie aber bis dahin hauptsächlich Monarchisten gewesen waren, standen die Republikaner ihnen kritisch gegenüber. Trotzdem wurde ihnen die Organisation und Gründung eigener Institutionen ermöglicht. Nativistische Kreise wandten sich verstärkt gegen sie und ihren Mangel an Integration im kulturellen, sprachlichen und ethnischen Bereich. Mit der Kriegserklärung gegen Deutschland 1917 wurden die ersten Nationalisierungsmaßnahmen durchgesetzt, jedoch bald wieder aufgehoben. Mit der Entstehung des Neuen Staates 1937 wollte die brasilianische Regierung die Siedler und ihre Institutionen zwangsmäßig nationalisieren, was aber den Konflikt zwischen Einwanderer- und Aufnahmegesellschaft verstärkte. Besonders nach der Kriegserklärung gegen Deutschland 1942 und beeinflusst durch die US-amerikanische Propaganda der Deutschen Gefahr, wurden Deutsche und Deutschbrasilianer wegen der Verwendung ihrer Sprache, ehemaliger Sympathien für oder Beteiligung an der integralistischen Partei oder dem Nationalsozialismus oft zu ungerecht verfolgt, drangsaliert, gefoltert und inhaftiert.

Nach der Analyse dieser historischen Hintergründe wird in den folgenden Kapiteln auf die Widerstandskraft des Glaubens eingegangen. Angesichts der verschiedenen Schwierigkeiten, denen die Pommern im Laufe ihrer Geschichte in Brasilien ausgesetzt waren, erwiesen sie sich in verschiedenen Aspekten als widerstandsfähig, indem sie flexibel auf unterschiedliche Belastungssituationen reagierten, nach aktiven Strategien für die Bewältigung ihrer Probleme suchten, soziale Netzwerke bildeten und handlungs- und anpassungsfähig blieben. Obwohl diese Fähigkeiten mehr oder weniger mitbetrachtet werden, wird die folgende Analyse sich besonders auf die Bedeutung des Glaubens, der Religiosität und Spiritualität der Pommern konzentrieren. 



\section{III - Ausgangslage, Anfänge und Entwicklung}

Im vorigen Kapitel wurde die Auswanderungs- und Einwanderungsgeschichte der Pommern mit ihren unterschiedlichen Facetten und politischen, wirtschaftlichen, sozialen, kulturellen, religiösen und ideologischen Ursachen analysiert. Diese Aspekte waren wichtig, da sie direkten Einfluss auf die Lebensverhältnisse der Pommern in den Kolonisationsgebieten hatten. Im Folgenden soll die Widerstandskraft der Pommern bei der Bewältigung ihrer täglichen Herausforderungen und Schwierigkeiten und hierbei insbesondere auf die Bedeutung ihrer evangelisch-lutherischen Religiosität eingegangen werden. An dieser Stelle ist wichtig zu erwähnen, dass bei den Pommern neben dem Christianisierungsprozess und ihrer späteren Hinwendung zum lutherischen Glauben ein magischer Traditionalismus praktiziert wurde. Sie sahen keinen Widerspruch zwischen dem kirchlichen Glauben und diesen magischen Praktiken, die von Außenstehenden in abwertender Weise als Aberglaube bezeichnet wurden. Aus diesem Grund ist hier von einer evangelisch-lutherischen Religiosität der Pommern die Rede.

Diese Arbeit bricht mit dem Paradigma, die Pommern als passive Opfer ihrer Situation in Brasilien darzustellen. Ohne ihre Schwierigkeiten zu unterschätzen liegt die Betonung auf ihren Bewältigungs- und Anpassungsstrategien, auf ihrer Kreativität, ihrem Optimismus und Lösungsorientierung bei Problemen, auf der Bildung sozialer Netzwerke rund um die kirchliche Gemeinde und besonders auf der Rolle ihrer Religiosität. 


\section{Die Reise nach Brasilien}

„Wir treten jetzt die Reise zum Land Brasilien an. Sei bey uns, Herr, und weise, ja mache selbst die Bahn. Sei bey uns auf dem Meere mit Deiner Vaterhand, so kommen wir ganz sicher in das Brasilienland ... ".589

Die optimistische Einstellung und hoffnungsvolle Zukunftsperspektive trieben Tausende pommerscher Einwanderer nach Brasilien, um ihren Kindern eine bessere Zukunft zu ermöglichen. In diesem ersten Abschnitt sollen kurz die Reisebedingungen und die Bedeutung des Glaubens für die Bewältigung der Widrigkeiten und Verluste bereits während der Fahrt betrachtet werden.

Angesichts der erdrückenden Lage in der Heimat und des offensichtlichen Mangels an Perspektiven für die jüngeren Generationen verkauften diejenigen, die über Besitz und Ländereien verfügten, ihr Vermögen, um die Reise nach Brasilien zu bezahlen. ${ }^{590}$ Andere liehen sich das Reisegeld bei Bekann-

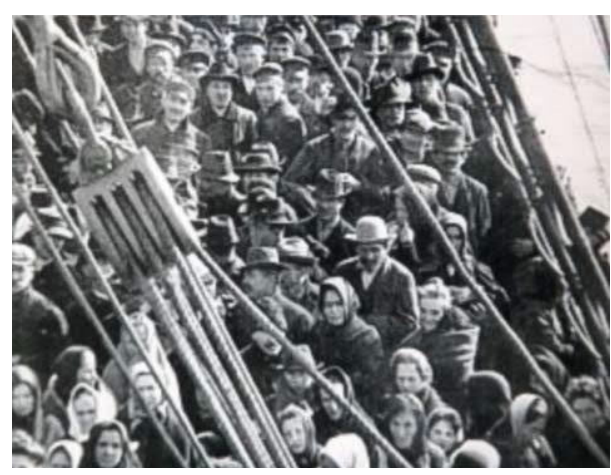

Abb. 1: Einschiffung im Hamburger Hafen. Bild im Pommerschen Immigrationsmuseum - Santa Maria de Jetibá (ES). Quelle: Siller, S. 36. ten ${ }^{591}$, waren auf die Hilfe kirchlicher Gemeinden angewiesen ${ }^{592}$ oder bekamen ihre Reise von der brasilianischen Regierung oder von Kolonisationsgesellschaften als Vorschuss ${ }^{593}$ finanziert. Viele Familien verschuldeten sich auf diese Weise schon vor der Überfahrt. Die Pommern emigrierten über die Hafenstädte Hamburg und Bremen (Deutschland) ${ }^{594}$, Antwerpen (Belgien) 595 oder Dünkirchen und Le Havre (Frankreich) ${ }^{596}$ nach Brasilien.

589 Abschnitt eines Flugblättertextes, der in Hamburg verteilt wurde. Evangelische Synode von Santa Catarina und Paraná. Unsere Väter. São Leopoldo: Rotermund, 1961, S. 14.

590 Altmann, Luciana. 500 Anos de Pomerode. Santa Maria: Pallotti, 2002, S. 20.

591 Dreher, Martin Norberto. História do Povo Luterano. São Leopoldo: Sinodal, 2005, S. 49.

592 Seibel, Ivan. Imigrante a duras penas. Nova Petrópolis: Amstad, 2007, S. 54.

593 Ferraz, Luiz Pedreira do Coutto. Die deutschen Ackerbau-Colonien in Santa Catharina (Brasilien). Hamburg: G. W. Niemeyer, 1859, S. 48; Last, Arne. Die Auswanderung von Pommern nach Brasilien im 19. Jahrbundert. Greifswald: Ernst-Moritz-Arndt- Universität, 2011, S. 74.

594 Die Mehrheit der Auswanderer reiste über Hamburg, etwa 30\% über Antwerpen, vor allem in den Jahren 1875 bis 1886 und 1891. Bremen konzentrierte sich auf die Auswanderung nach Nordamerika, während Hamburg als führender deutscher Auswanderungshafen für südamerikanische Länder galt. Von Bremen aus fuhren auch Schiffe nach Südamerika, jedoch bevorzugten die Auswanderer eher den Hamburger Hafen. Last, S. 70f.

595 Rheingantz, Karl Wilhelm. Die Gründung der Kolonie São Lourenço und ibr Gründer Jakob Rheingantz. [1907?], S. 15, EZA 5/2304; Schröder, Ferdinand. Brasilien und Wittenberg. Berlin/Leipzig: Walter de Gruyter, 1936, S. 132; Rocha, Levy. Viagem de Pedro II ao Espírito Santo. Vitória: Arquivo Público do Estado do Espírito, 2008, S. 122; Last, S. 71. Einschiffungen über Antwerpen geschahen vor allem 
Willems zufolge reisten viele Familien aufgrund ihrer hohen Verschuldung oder um polizeilichen Autoritäten zu entkommen bevorzugt über niederländische Häfen. ${ }^{597}$ Für Major von Schäffer ${ }^{598}$ war die Verschiffung seiner angeworbenen Soldaten über Hamburg verboten, so dass er sie beispielsweise über den Hafen von Altona, das damals zu Dänemark gehörte, verschiffen ließ. ${ }^{599}$

Einige Schiffe sollen während der Reise zu anderen Ziele umgeleitet worden sein. Ein solches Vorgehen kann jedoch durch die vorhandenen Quellen nicht nachgewiesen werden und es gibt kein Hafen- oder Schiffsregister mit Informationen über mögliche Schiffsumleitungen. Jedoch stimmt die Liste der Ausgewanderten in manchen Fällen nicht mit dem Ankunftsort überein. Seibel belegt dies mit dem Hinweis auf die Passagiere des Schiffes Borsing, die 1859 von Antwerpen in die USA unterwegs waren. Diese bemerkten erst auf der Reise, dass das Schiff einer anderen Reiseroute Richtung Süden folgte und letztendlich in Vitória (ES) anlangte. Vor der Abreise erfuhren einige Passagiere, dass aufgrund des Heydtischen Edikts keine Auswandererschiffe nach Lateinamerika fahren durften. Weil die Unterlagen der Auswanderer im Schiff oft konfisziert wurden, konnten diese nichts dagegen unternehmen. ${ }^{600}$ Bereits 1837 sollen 238 deutsche Einwanderer auf dem Schiff Justine nach Australien befördert werden, kamen aber in Petrópolis $(\mathrm{RJ})^{601}$ an und holländische Auswanderer aus Zeeland, die in die USA emigrieren

wegen des Heydtischen Edikts von 1859. So ließen sich Auswanderer in anderen als den preußischen Häfen einschiffen. Wernicke, Hugo. Viagem pelas colônias alemãs do Espirito Santo. Vitória: Arquivo Público do Estado do Espírito Santo, 2013, S. 18; vgl. Einzelblätter mit Listen von Einwanderern, die in Antwerpen eingeschifft wurden, AHRS. Colonização. Agente de Colonização em Anvers. Steinmann \& Cia, 1858-1864, Bündel Nr. 33, Archivbox Nr. 19. Zitiert nach Bosenbecker, Patricia. Uma colônia cercada de estâncias. Porto Alegre: Universidade Federal do Rio Grande do Sul, 2011, S. 58. 596 Rölke, Helmar. Raízes da Imigração alemã. Vitória: Arquivo Público do Estado do Espírito Santo, 2016, S. 271.

597 Willems, Emílio. A Aculturação dos alemães no Brasil. São Paulo: Companhia Editora Nacional, 1980, S. 34, 36.

598 Siehe Kapitel II, Abschnitt 2.3, Fußnote 134.

${ }^{599}$ Dreher, Martin Norberto. Sträflinge aus Mecklenburg-Schwerin und die Anfänge deutscher Einwanderung in Brasilien. São Leopoldo: Oikos, 2010, S. 9. Die von Major von Schäffer angeworbenen Soldaten beteiligten sich an der Revolution von 1848 und hatten teilweise im Schleswig-Holsteinischen Krieg (1848-1851) mitgekämpft. Sie wurden von der brasilianischen Armee gegen den argentinischen Diktator Rosas um 1852 rekrutiert und ließen sich in Rio Grande do Sul nieder. Fonseca, Maria Angela Peter da. Estratégias para a Preservação do Germanismo. Pelotas: Universidade Federal de Pelotas, 2007, S. 14f, vgl. Von Tschudi, Johann Jakob. Bericht des Herrn von Tschudi außerordentlichen schweizerischen Gesandten in Brasilien an den Bundesrath über den Zustand der Kolonien der brasilianischen Provinzen Santa Catharina und San Pedro do Rio Grande do Sul vom 18. Juni 1861. In: Hörmeyer, J. (Hrsg.) Actenstücke Brasilianischer Seite betreffend die Kolonisation des Kaiserreiches. 3. Jahrgang, Heft 3, Rudolfstadt, 1861, S. 250.

600 Seibel, Imigrante a duras penas, S. 91-93.

$6011^{\circ}$ Centenário da Inauguraşão da Igreja Evangélica de Petrópolis, Estado do Rio de Janeiro. 24 de maio de 1863 - 24 de maio de 1963. In: BMA S VI A.1-T.I. 11, S VII F 2. 
wollten, landeten stattdessen in Brasilien. ${ }^{602}$ Einwanderungsagenten und Schiffsgesellschaften nutzten diese Unzulänglichkeiten zu ihren Gunsten, da die brasilianische Regierung ihnen Zuschüsse gab, um mehr Siedler ins Land zu bringen. ${ }^{603}$ Zudem bekamen mittellose Einwanderer keine Auswanderungserlaubnis in die Vereinigten Staaten. ${ }^{604}$ Dies war der Grund, weswegen einige Auswanderer sich als Soldaten in der brasilianischen Armee verpflichten mussten, um ihre Überfahrt zu finanzieren. ${ }^{605}$

Nur in Ausnahmefällen konnten die Auswanderer nach einem nur kurzen Aufenthalt in den Häfen die gebuchte Reise antreten. Im Normalfall jedoch, besonders wenn sie noch keine Reise gebucht hatten, mussten sie zunächst ein Auswanderungsbüro suchen und mehrere Wochen oder gar Monate auf ihr Schiff warten. In den Hafenstädten wurden viele potentielle Auswanderer mit dem Vorgaukeln angeblich hoher Kosten für Unterkunft, Lebensmittel, Hafengebühren und andere Dinge, die angeblich für das Leben in der Fremde notwendig sein sollten, von Betrügern und teilweise auch von den Agenturen ausgebeutet. ${ }^{606}$ Laut Rölke wurden erst 1892 Auswandererschuppen als Unterkunft für Auswanderer in Hamburg errichtet, um sie von der lokalen Bevölkerung zu trennen. Es wurde auch eine katholische und protestantische Kirche und eine Synagoge erbaut. ${ }^{607}$ Nach Angaben des Auswanderers Pospissil stand jedoch bereits im Jahr 1863 ein Einwanderungshaus in Hamburg. ${ }^{608}$ Die Evangelisch-lutherische Auswanderermission organisierte wiederum Gottesdienste in der Kirche, im Hospiz, im Tropeninstitut, am Hafen oder im Haus des Pastors Hardeland. Sie bot den Auswanderern auch tägliche Andachten und Abschiedsgottesdienste. ${ }^{609}$ In Einzelfällen wurden Konfirmationen und Trauungen vollzogen. Fast alle Russlanddeutschen, unter ihnen auch einige Pommern, nahmen an Abendmahlsfeiern vor der Reise teil. ${ }^{610}$ Auswanderer bekamen auch Bibeln, Gesangbücher und den Kleinen Kate-

602 Roos, Ton; Eshuis, Margje. Os Capixabas Holandeses. Vitória: Arquivo Público do Estado do Espírito Santo, 2008, S. 88.

603 Grosselli, Renzo M. Colônias Imperiais na Terra do Café. Vitória: Arquivo Público do Estado do Espírito Santo, 2008, S. 204.

604 Seibel, Ivan. Imigrante no século do isolamento/1870-1970. São Leopoldo: Traço, 2010, S. 82.

605 Last, S. 73 f.

606 Wilhelm Ulrich: Ein Wort an alle Auswanderungslustige. Verlag von Friedrich Nagel, Stettin, 1852, S. 15, PLAG Rep 65c Nr. 163; Last, S. 72.

607 Rölke, Raízes da Imigração alemã, S. 272, 277-280.

608 Evangelische Synode von Santa Catarina und Paraná, S. 16.

${ }^{609}$ Verband für Evangelische Auswandererfürsorge 1926, S. 10, MLV 51/17 60. Der Verband für Evangelische Auswandererfürsorge berichtet weiter, dass vor der Abfahrt oft das Lied „So nimm denn meine Hände" (Deutscher Evangelischer Kichenausschuß. Deutsches Evangelisches Gesangbuch, Berlin: Mittler \& Sohn, 1926, Lied 369) gesungen wurde. Dieses Lied sangen die Pommern und deren Nachkommen auch gern bei Beerdigungen.

${ }^{610}$ Die Evangelisch-lutherische Auswanderermission zu Hamburg (E.V.) im Jabre 1920, S. 1; Verband für Evangelische Auswandererfürsorge 1926, S. 10, 16. Beides In: MLV 51/17 60. 
chismus als Abschiedsgeschenk von der Hamburger Bibelgesellschaft ${ }^{611}$, der Seemannsmission oder anderen Auswanderervereinen ${ }^{612}$ mit auf den Weg. Die Auswanderermission übte auch eine wichtige soziale Funktion aus, indem sie die Auswanderer bei Reiseangelegenheiten, Besorgung von Fahrkarten und Gepäck, Geldwechsel, Transferleistungen vom Bahnhof, Unterkunft und mit Beratung unterstützte. Außerdem gab sie Geleitbriefe für Einwanderermissionen in Übersee aus, um sie vor etwaigen Ausbeutungen Fremder zu schützen und einen kirchlichen Anschluss zu vermitteln. ${ }^{613}$ Aber die Mehrheit der Pommern, die bereits im 19. Jahrhundert ausgewandert waren, war sich selbst überlassen.

Die lange Überseereise auf engstem Raum mit Stürmen, Seuchen, Schmutz und Hunger ${ }^{614}$ verlangte von den Reisenden ein großes Durchhaltevermögen. Ein Segelschiff wurde von den Einwanderern von Humboldt auf „Hungerboldt" umbenannt ${ }^{615}$, weil viele während der Reise, die sich über die Maßen hinaus verzögerte, hungern mussten. ${ }^{616}$ Andere zogen sich Krankheiten zu, die sich aufgrund der mangelnden hygienischen Bedingungen und der Hitze leicht und schnell zu Epidemien ausweiteten. Seekrankheit, Lebensmittelvergiftungen, Cholera, Gelbsucht, Lungeninfektionen und Fieber waren keine Seltenheit. Außerdem reisten die ersten Einwanderer in Ladenräumen von Frachtsegelschiffen als Zwischendeck-

${ }^{611}$ Kahle, Maria. Deutsche Heimat in Brasilien. Berlin: Grenze und Ausland, 1937, S. 55. Nach Krause wurde am 21.6.1821 der Verein zur Verbreitung kleiner christlicher Schriften gegründet, der mit der seit 1815 vorhandenen Bibelgesellschaft arbeitete. Krause, Henrique. Lutherische Synode in Brasilien. Erlangen: Verlag der Ev- Luth. Mission, 1993, S. 19.

${ }^{612}$ Fischer, Joachim. Geschichte der Evangelischen Kirche Lutherischen Bekenntnisses in Brasilien. In: Fischer, Joachim; Jahn, Christoph (Hrsg.) Es begann am Rio dos Sinos. Erlangen: Verlag der Ev. Lutherischen Mission, 1970, S. 100; Verband für Evangelische Auswandererfürsorge 1926, S. 7, MLV 51/17 60; Hennig, Martin. Os auxílios de entidades evangélicas na Alemanha em prol dos evangélicos no Brasil, dos seus primórdios até o ano de 1900. In: Fischer, Joachim (Hrsg.) Ensaios Luteranos. São Leopoldo: Sinodal, 1986, S. 88; Wirth, Lauri Emilio. Protestantismus und Kolonisation in Brasilien. Erlangen: Verlag der Ev- Luth. Mission, 1992, S. 35, Anmerkung 5.

${ }^{613}$ Die Evang. lutherische Auswanderermission zu Hamburg (E.V.), MLV 51/17 60; vgl. Evang. Hauptverein für deutsche Ansiedler und Auswanderer. Was will der Evang. Hauptverein für deutsche Ansiedler und Auswanderer (E.V.) zu Witzenhausen a.d. Werra?. Witzenhausen a.d. Werra: August 1909, MLV 51/17 60. In Pölitz, Pommern, war Pastor Mummelthey Leiter einer Zweigstelle des Evangelischen Hauptvereins für Deutsche Ansiedler und Auswanderer. Verband für Evangelische Auswandererfürsorge 1926, S. 20, MLV 51/17 60.

${ }^{614}$ Grothe, Hugo. Im Kamp und Urvald Südbrasiliens. Berlin/Halle: Buchhandlung des Waisenhauses, 1936, S. 25.

615 Granzow, Klaus. Pommeranos unter dem Kreuz des Südens. Słupsk: Grawipol, 2000, S. 180.

${ }^{616}$ Zahlreiche Kolonisten beschwerten sich, ,über die scblechte Beförderung an Bord der von Steinmann u. Co. in Antwerpen expedierten Schiffe“. Die Klagen bezogen sich vorzüglich „,auf Mangel und scblechte Qualität von Lebensmitteln und Trinkwasser, Wegnabme der abgeschlossenen Contracte [Verträge] und auf zuweilen vorkommende rohe Behandlung von Seiten der Schiffscapitäne und Steuerleute". Von Tschudi, Bericht über den Zustand der Kolonien der brasilianischen Provinzen Santa Catharina und San Pedro do Rio Grande do Sul, S. 252. Einige Schiffe segelten mit mehr Menschen als erlaubt. Rölke, Raízes da Imigracão alemã, S. 272. 
spassagiere ${ }^{617}$ und die Kranken schliefen unter den Gesunden. Nur auf größeren Schiffen stand ein Arzt zur Verfügung. ${ }^{618}$ Während einerseits die Stürme während der Überfahrt die Reisenden besonders ängstigten ${ }^{619}$, konnten andererseits die Segelschiffe ohne Wind ihrem Kurs nicht folgen und blieben tagelang bewegungslos mitten im Meer liegen. ${ }^{620}$ Einige Berichte geben Auskunft über die Reisebedingungen der damaligen Zeit. Auch wenn sie nicht immer von pommerschen Einwanderern stammen, gelten sie als Muster für die Erfahrungen aller Passagiere. Joachim Holz aus Espírito Santo berichtet:
„Es war das Jahr 1858 als meine Eltern nach Brasilien auswanderten. (...) Da sind wir auf der Elbe nach Hamburg runter gefahren (...) In Hamburg mußten wir noch vier Tage warten, das Schiff war noch nicht eingerichtet. Da sind wir noch umber gegangen und haben uns was angesehen. (...) Die Fahrt dauerte sechs Wochen; es ging von Ham- burg gleich nach Vitória". ${ }^{621}$

Ein detaillierter Reisebericht ist aus dem Jahre 1863 überliefert. Es stammt von einem österreichischen Einwanderer namens Antonio Pospissil:
„Es war am 8. Mai 1863. (...) In Hamburg mußten wir in das neue Auswandererhaus und uns drei Tage behelfen. (...) ein Schleppdampfer [nahm uns] aus dem Hamburger Hafen nach Cuxhaven. Hier verblieben wir drei Tage, fubren dann in den englischen Kanal, erbielten aber daselbst so starken Gegenwind, daß wir über 100 Meilen in die Nordsee getrieben wurden. (...) Und erst die Seekrankheit! Einer liegt da, der andere dort, und da muß man sich vorstellen, wie wir gelegen haben. Wir fuhren Zwischendeck und waren zusammengesperrt wie in einem Hühnerstall; denn wir waren mebr als 250 Personen obne Schiffspersonal. Oben waren Betten eingerichtet, für vier oder fünf Perso- nen, unten ebenfalls, aber bei der Seekrankheit - so etwas muß man erleben! Es ekelte

617 Damitz, Hans. Pommerland in Brasilien, S. 1, Manuskript im Privatarchiv von Pastor Nelso Weingärtner, ohne Jahresangabe.

618 Seibel, Imigrante a duras penas, S. 84f, 87, 91, 98, 106; Roos; Eshuis, S. $21 \mathrm{f}$.

619 Das Schiff Argus verlor seinen Hauptmast aufgrund eines Sturmes und musste zurückkehren. Wieder auf See führten starke Winde dazu, dass das Schiff die Wightsinsel in England anlaufen musste. Erst fünfzehn Tagen später konnte es nach Rio de Janeiro (RJ) segeln. Woortmann, Ellen Fensterseifer. Identidades e Memória entre teuto-brasileiros: os dois lados do Atlântico. In: Horizontes Antropológicos, Porto Alegre, Ano 6, Nr. 14, 2000, S. 224f. Das holländische Schiff Calcilia wurde 1826 von einem Sturm an der englischen Küste überrascht. Der Kapitän verließ mit der Schiffsmannschaft das Schiff auf Rettungsbooten und überließ die Einwanderer ihrem Schicksal. Nach drei Wochen umhertreiben auf hoher See fand eine englische Brigg das Schiff und brachte es in den Hafen von Plymouth. Die Passagiere wurden erst 1828 nach Brasilien befördert. Arbeitsgemeinschaft 25. Juli in Rio Grande do Sul. Kurze Geschichte der deutschen Einwanderung in Rio Grande do Sul. São Leopoldo: Rotermund, 1936, S. 17. Das Schiff Emma und Emilie erlitt einen Schiffbruch, bei welchem viele Einwanderer ums Leben gekommen sind. Schröder, Ferdinand. Die deutsche Einwanderung nach Südbrasilien bis zum Jahre 1859. Berlin: Ev. Hauptverein für Deutsche Ansiedler und Auswanderer E. V., 1930, S. 86f.

${ }^{620}$ Seibel, Imigrante a duras penas, S. 89, 104, 106.

${ }^{621}$ Holz, Joachim. Die ersten sechs Jahren in Espírito Santo, Brasilien. In: Heimatbote für die Gemeinden der Deutschen Lutherischen Kirche in Espirito Santo. Nr. 4, April 1936, S. 2f, MEW 4.194. 
uns vor allem und wenn es die besten Speisen waren, und hatte man wirklich Lust, etwas zu essen, dann bebielt der Magen nicht. Acht Tage später kamen wir an dieselbe Stelle zurück, von der wir ausgefahren waren. (...) Die Fabrt wäre wobl schön gewesen, aber Pfingstagmontag, Dienstag und Mittwoch hatten wir so fürchterlichen Sturm, daß wir armen Seekranken nicht einmal auf Deck gehen durften, um Luft zu schöpfen. Wir wurden eingesperrt und wußten nicht mehr, was um uns und über uns vorging. Ein Glück, daß unser Schiff so schwer beladen war; denn bätte es der Sturm auf die Seite geworfen, wären wir Eingesperten elendig ertrunken. (...) Hunger litten wir wobl nicht während der Fahrt, aber was es zu essen gab, waren wir nicht gewohnt, und das Wasser konnten wir nicht trinken. Das Fleisch war gut, aber so stark gesalzen, daß man furchtbar durstig wurde. Das W asser in Fässern war dick wie Jauche, voll Gestank und Würmern, so daß man es nicht einmal sehen mochte. (...) Der Zwieback, der auf dem Schiffe anstatt Brot benutzt wurde, mußte vor vielen Jahren gebacken worden sein; es war hart wie Stein. (...) Ob es uns schmeckte, darum kümmerte sich niemand, aber der Hunger war doch gestillt. Dann sahen wir Wal- und Haifische, und den größten Spaß machten uns die fliegenden Fische. Sie fielen an Deck, wurden gesammelt und in der Küche gebraten. Drei Monate waren wir nun schon zwischen Himmel und $W$ asser, und noch immer ließ sich kein Land sehen. (...) Da, eines Morgens (...) entdeckte einer der Unseren am Horizont einen dunklen Fleck. (...) Endlich Land! Das war ein Jubel! (...) Am anderen Morgen konnten wir weiterfahren und erreichten noch am selben Tage Santa Catharina. (...) Der Anker wurde emporgezogen, und unter Führung des Lotsen fuhren wir weiter. Da fubr unser Schiff einen Felsen an, derart, dass wir alle zusammenzuckten und vermeinten, wie würden im Leben den Fuss nie auf brasilianischen Boden setzen, und es würde uns wohl so gehen wie unserem Kameraden Manoel Schaffer, der acht Tage zuvor gestorben war; sein Körper war in Segeltuch eingenäht und in's Meer versenk.t worden. (...) Den dritten Tag wurden unsere Sachen ausgeladen, wir durften alle an's Land".622

Bereits während der Reise spielte der Glaube eine wichtige Rolle, besonders, wenn die Reisenden Abschied von Angehörigen oder Bekannten, die während der Reise ums Leben gekommen waren, nehmen mussten. Laut Roos und Eshuis begingen die Passagiere an Sonntagen den Gottesdienst auf dem Schiff. ${ }^{623}$ Sie lasen und sangen auch Psalmen und Lieder während der Stürme oder in bedrückenden Momenten ${ }^{624}$, denn Pastoren waren selten am Bord. Die Pastoren Ehlers ${ }^{625}$ und Lange bildeten hierbei eine Ausnahme. Ehlers reiste 1824 auf dem Schiff Germania

\footnotetext{
${ }^{622}$ Evangelische Synode von Santa Catarina und Paraná, S. 16, 18, 20.

${ }^{623}$ Roos; Eshuis, S. 22; Vgl. „Der Gottesdienst an Bord war der letəte seit Wochen gewesen“. Gustav AdolfVerein in Rio Grande do Sul (Hrsg.) Gesegnete Kindergabe, S. 6. In: EZA 5/2222; Die Evangelischlutherische Auswanderermission ₹u Hamburg (E.V.) im Jabre 1920, S. 2, MLV 51/17 60.

${ }^{624}$ Roos; Eshuis, S. 21.

625 Die Pastoren Ehlers und Voges wurden vom Major von Schäffer als Bordpfarrer für die Begleitung der Passagieren engagiert. Prien, Hans-Jürgen. Formação da Igreja Evangélica no Brasil. São Leopoldo/Petrópolis: Sinodal/Vozes, 2001, S. 51f, 59, Fußnoten 102 und 106.
} 
nach São Leopoldo (RS), während Lange die Einwanderer aus Chatura, ein russisches Wolgagebiet, zu der Kolonie Brüdertal (SC) begleitete. ${ }^{626}$ Bald erfuhren Auswanderermissionen im Voraus, ob ein Pastor nach Übersee mitreisen würde und verabredeten die Abhaltung von Gottesdiensten während der Fahrt mit ihm. Die Gottesdienste entsprachen einem Bedürfnis der Menschen an Bord ${ }^{627}$ und fanden rege Teilnahme. ${ }^{628}$

Während der Fahrt wurden auch Taufen, Trauungen und Bestattungen vollzogen $^{629}$, die Pastor Ehlers beispielsweise später im Gemeinderegister von São Leopoldo (RS) eintrug. ${ }^{.30}$ Viele Witwen und Junggesellen heirateten an Bord, um die Vergünstigungen der brasilianischen Regierung für Familien zu erlangen. Diese zahlte Prämien für Familien und bevorzugte diese bei der Kolonisation. ${ }^{631} \mathrm{Um}$ diese Vorteile zu genießen und damit die Existenz in Brasilien zu sichern, heirateten Verwitwete, die während der Reise ihren Ehegatten oder ihre Ehegattin verloren hatten, eine alleinstehende oder eine verwitwete Person. Solche Ehen wurden „Vernunftheirat" genannt. ${ }^{632}$

Die mitgebrachten oder auf die Reise mitgegebenen Bibeln, Gesangbücher und Andachtsbücher halfen den Reisenden, die schwierigen Momente der Trauer, der Verzweiflung, Erkrankung und Entmutigung erträglicher zu machen. Viele Menschen, besonders Kinder, starben während der Fahrt. ${ }^{633}$ Das Ehepaar Piske,

${ }^{626}$ Viele dieser Einwanderer waren Pommern, die Jahre zuvor nach Russland ausgewandert waren. Weingärtner, Nelso. Martin Luther e Santa Catarina. Timbó: Tipotil, 2012, S. 124f.

627 Verband für Evangelische Auswandererfürsorge 1926, S. 16, MLV 51/17 60.

${ }^{628}$ Brief von Pastor Grau an den Basler Missionsdirektor, Rio do Sul, 10.6.1926, BMA, PABV 1981; Roos; Eshuis, S. 22.

${ }^{629}$ Avé-Lallemant, Robert. Reise durch Südbrasilien im Jahre 1858. 2. Teil. Leipzig: F. A. Brockhaus, 1859, S. 203.

${ }^{630}$ Über eine Liste mit den in einem Schiff Getauften, Getrauten und Bestatteten siehe Müller, Telmo Lauro. Herança de geração em geração. São Leopoldo: Rotermund, 1988, S. 11-13.

631 Ältere Menschen sollen manchmal keine Subventionen bekommen haben, da sie sich zu der harten Koloniearbeit nicht mehr eigneten. Bosenbecker, S. 44.

${ }_{632}$ Der Familienvater Springer starb zusammen mit einem Sohn im Schiff. Er hinterließ seine Frau mit einem Säugling und fünf Kinder, die dann den Schweizer João Sänger heiratete. Frau Werlang heiratete den Bruder ihres verstorbenen Mannes. Die Witwe Mentz reiste mit ihren beiden Kindern, ihren Eltern und Geschwistern nach Brasilien. Am 2.6.1824 heiratete sie Hubertous Stock, der noch vor der Ankunft in São Leopoldo (SC) starb. Gleich danach heiratete sie den Witwer Pedro Wingert, der auch seine Frau während der Schiffsreise verloren hatte. Der Witwer Loré verlor seine Frau an Bord und heiratete drei Wochen nach der Ankunft in Brasilien Maria Catarina Cassel. João Frederico Bohrer, dessen Frau auf dem Schiff starb und ihm drei Kinder hinterließ, nahm Frau Engers zur Frau. Woortmann, S. 212f.

${ }^{633}$ Bei der Reise mit dem Schiff Gutenberg Juni 1872 starben acht Kinder von 0 bis 2 Jahren. Franceschetto, Cilmar. Imigrantes Espirito Santo. Vitória: Arquivo Público do Estado do Espírito Santo, 2014, S. 948. Marta Zummach berichtet, dass elf Kinder auf ihrem Schiff ums Leben gekommen waren. Zummach, Marta. O que minha vovó me contava. In: Der Junge Kämpfer, ano 2, Nr. 8, 1936. Zitiert nach Rölke, Raízes da Imigração alemã, S. 254. Laut Mathias Franzen starben 47 von 874 Passagiere des Schiffes Albess 1828 bei der Fahrt, was für die damaligen Verhältnisse normal war. Arbeitsgemeinschaft 25. Juli in Rio Grande do Sul, S. 17. Auf dem Schiff Caroline nach São Francisco do Sul (SC) starben 14 von 77 Passagiere. Correia, Wilson. Eng. Carl August Wunderwald. O 
das nach Timbó (SC) auswanderte, verlor bereits an dem Anreisetag eine Tochter. Während der Reise starben zwei weitere Söhne, die dem Meer, unter dem Verlesen eines Bibeltextes und Gebet ${ }^{634}$, übergeben werden mussten. ${ }^{635}$ Das Wort Gottes war der einzige Trost beim Verlust eines Angehörigen auf dem Weg zu einem besseren Leben. Einzelne Erwachsene sollen sich in ihrer Verzweiflung oder aus Hungersnot das Leben genommen haben. ${ }^{636}$

Die Emigranten reisten mit Segel- oder Dampfschiffen nach Brasilien. Obwohl sich die Fahrtdauer mit den Dampfschiffen wesentlich verringerte, wurden bis Ende der 1870er Jahre regelmäßig Segelschiffe eingesetzt, um Kosten zu reduzieren. ${ }^{637}$ Erst ab 1875 wurden Dampffahrten bevorzugt. ${ }^{638}$ Die brasilianischen Zielhäfen waren auch durch wirtschaftliche Handelswege bestimmt. Größere Transatlantikschiffe landeten ausschließlich in den Häfen von Santos (SP) und Rio de Janeiro (RJ). Andere segelten bis zu kleineren Häfen in den Provinzen, wie Rio Grande (RS), São Francisco do Sul (SC) und Vitória (ES). Tausende Einwanderer mussten zunächst im Hafen von Rio de Janeiro (RJ) Halt machen bevor sie weiter zu ihrem eigentlichen Ziel befördert werden konnten. Sie lebten während dieser Zeit in der Regel auf der vor Rio de Janeiro (RJ) gelegenen Blumeninsel. Einige Einwanderer berichten über einen monatelangen Aufenthalt und endloses Warten auf Weiterbeförderung zu den Koloniegebieten. ${ }^{639}$ Viele verschuldeten sich aufgrund der Aufenthaltskosten, andere starben an Gelbfieber. ${ }^{640} \mathrm{Nach}$ Anweisungen vom November 1861 sicherte die Regierung den Einwanderern, die in Regierungskolonien angesiedelt werden sollten, eine Unterkunft auf der Insel Bom Jesus in Rio de Janeiro (RJ) zu. ${ }^{641}$ Laut Angaben eines Einwanderers namens Höhne aus dem Jahre 1869 bekamen sie dort kostenfreie Logis und Essen. Ein Siedler aus Santa Isabel (ES) berichtet:

bandeirante alemão no sertão catarinense. In: Prefeitura Municipal de Pomerode. Pomerode, sua história, sua cultura, suas tradições. V. 4. Pomerode: Prefeitura Municipal, 1987, S. 12.

634 Roos; Eshuis, S. 22.

635 Gierus, Friedrich. Meinrad Piske. Blumenau: Otto Kuhr, 1998, S. 7. Um Krankheiten zu vermeiden, mussten die Leichen in einem Sarg aus Bretterkästen oder in alten Säcke genäht dem Meer übergeben werden. Vgl. August Baecker "Zum Auswandererwesen", Separat-Abdruck aus der „Hamb. Börsen-Halle“ vom 29. Juli 1873. In: Acta Gen. Regierung zu Stralsund 1856-1912, PLAG Rep 65c, Nr. 166; Granzow, Pommeranos unter dem Kreuz des Südens, S. 34, 180; Granzow, Klaus. Grün ist das Tal am Rio Itajai. Hamburg: Pommerscher Buchversand, 1972, S. 70; Seibel, Imigrante a duras penas, S. 99; Interview mit Janeta Tressmann Jacob am 20.5.2009. Zitiert nach Siller, Rosali Rauta. Infância, Educação Infantil, Migrações. Campinas: Universidade Estadual de Campinas, 2011, S. $37 \mathrm{f}$.

636 Woortmann, S. 225.

${ }^{637}$ Last, S. 74.

638 Rölke, Raízes da Imigração alemã, S. 294.

${ }^{639}$ Last zufolge war es mit einer Wartezeit von etwa drei Monaten zu rechnen, denn aufgrund der großen Anzahl von Menschen konnten nicht alle schnell abtransportiert werden. Last, S. 76.

${ }^{640}$ Von Tschudi, Bericht über den Zustand der Kolonien der brasilianischen Provinzen Santa Catharina und San Pedro do Rio Grande do Sul, S. 230.

${ }^{641}$ Carvalho, Augusto de. O Bražil, colonização e imigração. Porto: Imprensa Portuguesa, 1876, S. $486 f$. 
„Am 13. Oktober 1847 langten wir in Rio de Janeiro an, wo wir liebreich aufgenommen wurden. Am 21. wurden wir ausgeschifft und kamen auf eine Festung, wo wir vom Kaiser unterstützt wurden. Wir bekamen gute Lebensnabrung und konnten auch ein wenig Geld verdienen. Wir blieben da bis zum 17. Dezember; dann wurden wir wieder eingeschifft und kamen nach der Provinz. Espirito Santo, wo wir am 21. vor der Stadt Victoria anlangten und vom Präsidenten empfangen wurden". ${ }^{642}$

Ausnahmen galten für diejenigen, die nach Südbrasilien befördert werden würden. Diese mussten 800 Réis pro Person zahlen, weil die Zentralregierung ihnen aufgrund der neuen Erlasse keine Subventionen mehr zahlte. ${ }^{643}$

Wer für eine Kolonie in Espírito Santo bestimmt war, reiste dann bis Vitória $(E S)^{644}$ und nach einen kurzen oder langen Aufenthalt weiter zu den Kolonien Santa Isabel (ES) oder Santa Leopoldina (ES). ${ }^{645}$ Einige Schiffe brachten die Einwanderer auch direkt nach Vitória (ES). ${ }^{646}$ Die Einwanderer, die für die Provinz Rio Grande do Sul bestimmt waren, segelten zunächst auch bis Rio de Janeiro $(\mathrm{RJ})$ und von dort nach Porto Alegre (RS), von wo sie einige Wochen später mit Kanus durch den Rio dos Sinos-Fluß bis São Leopoldo (RS) ${ }^{647}$ oder durch den Jacuí-Fluß nach Santa Cruz do Sul (RS) gebracht wurden. ${ }^{648}$ Die Immigranten der Kolonie São Lourenço do Sul (RS) landeten im Hafen von Rio Grande (RS). Von dort wurden sie zunächst auf Kanus umgeladen und dann mithilfe von Ochsen gezogenen Wagen zur Kolonie gebracht. ${ }^{649}$ In Santa Catarina landeten die Immigranten für die Kolonie Blumenau (SC) im Hafen von São Francisco do Sul (SC) oder Itajaí (SC). Sie wurden mit Kanus durch den Itajaí-Açu-Fluß nach Itajaí (SC) ${ }^{650}$ und von da nach Blumenau (SC) gebracht. ${ }^{651}$ Auch Einwanderer, die für

\footnotetext{
${ }^{642}$ Allgemeine Auswanderungszeitung, Rudolfstadt, 1852, S. 321. Zitiert nach Schröder, Brasilien und Wittenberg, S. $327 \mathrm{f}$.

${ }^{643}$ Brief von Böhne, Rio de Janeiro, 4.10.1869. Zitiert nach Rölke, Raízes da Imigração alemã, S. 608.

${ }^{644}$ Franceschetto, Imigrantes Espirito Santo, S. 944.

${ }^{645}$ Wernicke, S. 36-41; Rölke, Raižes da Imigraşão alemã, S. 297; Nagar, Carlo. Relato do Cavalheiro Carlo Nagar, Cônsul Real em Vitória: Vitória: Arquivo Público do Estado do Espírito Santo, 1895, S. 46f; Gaede, Valdemar. Presença Luterana no Espirito Santo. São Leopoldo: Oikos, 2012, S. 18.

${ }^{646} \mathrm{Holz}$, Joachim. Die ersten sechs Jahren in Espírito Santo, Brasilien. In: Heimatbote für die Gemeinden der Deutschen Lutherischen Kirche in Espirito Santo. Nr. 4, April 1936, S. 2-4, MEW 4.194; Rocha, S. 122; Franceschetto, Imigrantes Espirito Santo, S. 946; Damitz, Hans. Entwicklungsaspekte zur Situation der Brasilianer deutscher Abstammung im Staat Espirito Santo, S. 5. Privatarchiv von Pastor Nelso Weingärtner, ohne Jahresangabe. Über eine Auflistung mit Schiffen, die pommersche Einwanderer nach Espírito Santo gebracht haben, siehe Franceschetto, Imigrantes Espirito Santo, S. 946; Daemon, Basílio Carvalho. Provincia do Espirito Santo sua descoberta, história cronológica, sinopse e estatística. Vitória: Arquivo Público do Estado do Espírito Santo, 2010, S. 462f.

${ }^{647}$ Müller, Herança de geração em geração, S. 9f.

648 Über Schiffe, die Immigranten nach Santa Cruz do Sul (RS) befördert haben, siehe Schröder, Die deutsche Einwanderung nach Südbrasilien, S. 86f; Schröder, Brasilien und Wittenberg, S. 132.

${ }^{649}$ Rheingantz, Karl Wilhelm. Die Gründung der Kolonie São Lourenço und ibr Gründer Jakob Rheingantz. [1907?], S. 15f, EZA 5/2304; Köbling, Fritz. Die Kolonie São Lourenço im Staate Rio Grande do Sul. In: Deutsche Post, São Leopoldo, Nr. 3355, 18.11.1908, EZA 121/19.

${ }^{650}$ Weingärtner, Nelso. História da Comunidade Evangélica de Timbó. Blumenau: Otto Kuhr, 2008, S. 27.
} 
die Kolonie Dona Francisca-Joinville (SC) bestimmt waren oder später um 1885 im Itapocu-Tal (SC) ${ }^{652}$ angesiedelt wurden, landeten in São Francisco do Sul (SC). ${ }^{653}$ Manche Familien landeten zunächst in der Hauptstadt Florianópolis (SC) und fuhren mit Karren nach Blumenau (SC). 654

\section{Die Ankunft in den Kolonien}

In Brasilien gelandet mussten die Einwanderer zu den Kolonien befördert werden. Diese waren aber oft nicht vorbereitet für die Ankunft dieser vielen Menschen, so dass die Einwanderer zunächst in provisorischen Unterkünften untergebracht wurden, bis sie die ihnen zugewiesenen Landstücke betreten konnten. Nun standen sie vor der Herausforderung, den Urwald auf ihren Grundstücken zu roden, sich vor Angriffen der wilden Tiere im Urwald zu schützen und Krankheiten ohne Arzt und Krankenhaus zu meistern. Weil in vielen Siedlungsgebieten bereits indigene Völker lebten ohne sesshaft zu sein, kam es zu Konflikten zwischen ihnen und den Einwanderern. Dazu kamen die Probleme mit korrupten Beamten, schlechter Kolonieverwaltung, die hohen Kosten bei Gerichtsverfahren und Ausbeutung durch Geschäftsleute und letztendlich die schwierige Situation der Protestanten im römisch-katholischen Brasilien in Bezug auf die Anerkennung ihrer Ehen und Ausübung ihrer Religion. Wie die Einwanderer und deren Nachkommen diese Schwierigkeiten bewältigten, soll nun dargestellt werden.

An dieser Stelle soll zunächst hervorgehoben werden, dass die folgende Darstellung aufgrund der vorherrschenden Quellenüberlieferung meist auf der Wahrnehmung der Einwanderer und deren Nachkommen beruht. Sie könnte den Eindruck entstehen lassen, dass die Siedler Opfer der Umstände waren. Aber hier berichten europäische Siedler über eine neue Umgebung, die in ihren Augen, selbst wenn sie aus unteren Schichten kamen, exotisch, chaotisch und extrem herausfordernd erschien. Die brasilianischen „Caboclos" 655 hatten die gleiche Um-

${ }_{651}$ Bürger, Alexander. Colonie Blumenau, 19.1.1857. In: Blumenau, Hermann. Jabresbericht über die Ereignisse und Fortscbritte der deutschen Kolonie Blumenau 1856. Hamburg: Robert Kittler, 1857, S. 13; Blumenauer Gedenktage. Ausschnitt einer Zeitung vom Jahre 1932, S. 49, EZA 5/2486; Evangelische Synode von Santa Catarina und Paraná, S. 98; Buzzarello, Silvinha. O menino emigrante: Albert Paul Ramlow. In: Prefeitura Municipal de Pomerode, Pomerode, sua história, sua cultura, suas tradições. V. 6. Pomerode: Prefeitura Municipal, 1996, S. 31.

${ }^{652}$ Weingärtner, Martin Luther e Santa Catarina, S. $124 f$.

653 Wüstner, Fr. Kirchengemeinde Joinville. São Leopoldo: Rotermund, 1951, S. 7; vgl. Schröder, Brasilien und Wittenberg, S. 279f. Eine Auflistung mit 119 Einwanderungsschiffen, die Immigranten zu den Kolonien Dona Francisca (SC) und Blumenau (SC) brachte, befindet sich in Arquivo histórico de Joinville. Listagem informatizada dos imigrantes 1851-1891, 1897-1902, Verfügbar in: http://www.arquivohistoricojoinville.com.br/ListaImigrantes/lista/tudo.htm Zugang am 15.3.2016. 654 Altmann, S. 21f.

655 „Caboclo" bezeichnet in Brasilien das Individuum, das aus der Rassenmischung eines Mitglieds eines indigenen Volkes und eines Weißen entsteht. In einem abwertenden Sinne wird er verwendet, 
gebung ganz anders wahrgenommen. Sie konnten die widrigen Lebensbedingungen im Urwald gut meistern und waren die korrupte und mangelhafte Verwaltung der Beamten gewohnt: Dies war die einzige Umwelt, die sie je gekannt haben. Weil ihre Umwelt für sie alltäglich war, sahen sie auch keine Notwendigkeit, darüber zu berichten. Die Siedler hingegen geben Auskunft über jedes Detail ihrer Anpassung in der neuen Umwelt, weil sie trotz allen Herausforderungen im Grunde auch zufrieden waren mit ihrer Leistung, den tropischen Urwald gerodet, die Wildnis bewältigt und einen Lebensunterhalt für sie und ihre Familie geschaffen zu haben.

Bei der Reise zu den Kolonien mussten die Einwanderer in kleinen Segelschiffen reisen, waren dem Unwetter ausgesetzt und für die eigene Verpflegung verantwortlich. ${ }^{656}$ Die Kanus transportierten in der Regel nur vier Familien mit ihrem Gepäck ${ }^{657}$, einige verloren deswegen ihre Besitztümer oder Teile davon ${ }^{658}$, während anderen das Gepäck an falsche Adressen geliefert wurden. ${ }^{659}$ Einige Einwanderer wurden betrogen, weil sie überteuerte Summen für ihre Weiterreise zahlen mussten. ${ }^{660}$ Manchmal wurden Immigranten in die falschen Kolonien transportiert $^{661}$, und Einwandererfamilien aus Rio Grande do Sul und Santa Catarina klag-

um die Figur eines Mannes aus dem Binnenland zu adjektivieren, der angeblich eine rohe, verdächtige oder tückische Art besitzt.

656 Auf dem Schiff Carolina, das Einwanderer von Rio de Janeiro (RJ) nach Porto Alegre (RS) beförderte, starben 20 Personen. Sie sandten einen Brief an den Kaiser und protestierten gegen die schlechten Bedingungen, Woortmann, S. 227; vgl. Altmann, S. 21.

${ }^{657}$ Von Tschudi. Bericht über den Zustand der Kolonien der brasilianischen Provinzen Santa Catharina und San Pedro do Rio Grande do Sul, S. 253; Damitz, Entwicklungsaspekte zur Situation der Brasilianer, S. 5.

658 Witt, Osmar Luiz. Igreja na Migração e Colonização. São Leopoldo: Sinodal/IEPG, 1996, S. 57.

${ }^{659}$ Im Jahre 1874 befand sich das Gepäck eines Einwanderers, der nach Blumenau (SC) befördert wurde, in Santa Leopoldina (ES). Grosselli, S. 156; Rölke, Raǐes da Imigração alemã, S. 480.

660 Avé-Lallemant, Reise durch Südbrasilien. 2. Teil, S. 207. Um die Einwanderer vor Betrügereien zu schützen, gab der Deutsche Hilfsverein 1929 ein Merkblatt für Einwanderer nach Rio de Janeiro. EZA 5/2201. Später versuchten die kirchlichen Synoden in Brasilien den Einwanderern beizustehen und diese zu beraten. In Porto Alegre (RS) empfing ein Pastor die Neuankömmlinge im Hafen. 1921 ernannte die Riograndenser Synode einen Siedlungspfarrer zu diesem Zweck, 1927 richtete der Evangelische Gemeindeverband von Santa Catarina und Paraná eine Ansiedlungsberatungsstelle ein. In Blumenau (SC), Joinville (SC), Florianópolis (SC) und Itajaí (SC) wurden Einwanderungsberatungsstellen gebildet. Fischer, Geschichte der Evangelischen Kirche, S. 127; Dedekind, Max. Brasilien, das Ziel deutscher Auswanderer und die Deutsche Evangelische Kirche in Brasilien. Elberfeld: Evangelischen Gesellschaft für die protestantischen Deutschen in Südamerika, 1924, S. 22. Nach Breitenbach hat diese Hilfe aber nicht immer gut funktioniert. Breitenbach, Wilhelm. Die Provinz Rio Grande do Sul, Brasilien und die deutsche Auswanderung dabin. Heidelberg: Carl Winter's Universitätsbuchhandlung, 1885, S. 24 (128). ${ }^{661} \mathrm{Im}$ Jahre 1846 kamen 163 Personen, die für Südbrasilien bestimmt waren, in Santa Isabel (ES) an, 1874 landeten die Verwandten von Carlos Schuhmacher und der Einwanderer Carlos Strey, die für Santa Leopoldina (ES) bestimmt waren, in Blumenau (SC). Rölke, Raízes da Imigração alemã, S. 283, 488. Einwanderer aus Santo Ângelo (RS) beschwerten sich 1857, dass sie für die Kolonie Santa Cruz do Sul (RS) bestimmt waren. Sie weigerten sich, das Schiff zu verlassen, wurden aber dazu gezwungen. Unbekannter Autor. Ausdehnung der Kolonisation. In: Neue deutsche Zeitung Nr. 171, Porto Alegre, 24.7.1934, S. 1. Zitiert nach Willems, S. 63. 
ten über die Willkür einiger Behörden, Verwandte oder Bekannte einfach nach Espírito Santo zu versetzen und ihnen zu untersagen, schriftlich oder mündlich mit Vertretern ihrer Länder Kontakt aufzunehmen. ${ }^{662}$

Die ersten Einwandererfamilien wurden vom Landvermesser zu den Kolonien begleitet und mussten manchmal in manchen Orten bei der Errichtung eines Einwandererschuppens helfen. Dabei lernten sie gleich, Schneisen in den Urwald zu schlagen und ihre eigenen Hütten zu bauen. Pastor Soboll berichtet:

„Ein „Landmesser“ ordnete eine Gruppe von etwa zehn Familien. So fubr er dann mit allen auf flachen Kähnen den Fluss aufwärts bis zu der Stelle, da die Gewässer aus den Bergen herunterkamen und nicht mehr per Kahn zu befahren waren. Jeder bekam nun einen kleinen Sack zu tragen mit einer Ration von Lebensmitteln und Saatkorn. Die Männer bekamen Buschmesser und Stieläxte in die Hand, und dann gings gleich ab in den Urwald hinein, binauf in die Berge. Eine Gruppe von jungen Männern musste mit Buschmesser und Stielaxt einen Weg durch das dichte Waldgestrüpp schlagen, dessen Richtung vom Landmesser per Kompass bestimmt wurde. Die Familien, viele mit kleinen Kindern, krochen hinterdrein. (...) Als es jedoch Abend wurde, zeigte der Landmesser, wie man die vielen grossen Blätter bündelte und sich mit ibnen einen notdürftigen Schutz gegen Regen verschaffen konnte. Aber das schwere, tropische Gewitter der Nacht war so stark, dass niemand trocken blieb. Die Kinder weinten, die Mütter ebenfalls, die Väter knirschten mit den Zähnen in dem verbissenen Willen, diese Anfangstage zu überstehen. Jedes unbekannte Geräusch in dem endlosen Urwald ängstigte das obnehin verängstigte Völkchen. Aber trotzdem wurde es endlich Morgen, und mit neuem Mut wurden die Bündel geschnürt und wurde die Reise fortgesetzt, noch ein Tag und noch ein Tag und noch ein Tag, bis ein bergiges Hochland von etwa 500 Meter über dem Meere erreicht war. Hier wurde in Gemeinschaftsarbeit von allen eine kleine Lichtung geschlagen und der erste Rancho wurde errichtet, ein Schuppen, der von schweren Regenfällen allen den so nötigen Schutz bieten konnte. Der Landmesser zeigte genau, wie es gemacht wurde: Vier Pfähle in die Erde gerammt, die Wände ausgekleidet mit geflochtenem Gestrüpp und Laubwerk und das Dach wurde gedeckt mit Blättern, die an langen Stangen befestigt waren, die dann über den Schuppen gelegt wurden, eine immer höher als die andere, so dass sie alles Wasser ableiten konnten. So lernte nun jeder, wie er es machen musste, wenn er sein erstes Haus bauen wollte. Der Landmesser gab in den nächsten Tagen an wo jede Familie sich ansiedeln sollte, und dann verschwand er". 663

Landvermessung und anschließende Zuweisung an die Siedlerfamilien konnte sich monate- oder jahrelang hinauszögern. ${ }^{664}$ Übergangsweise mussten die Einwande-

\footnotetext{
662 Von Tschudi. Bericht über den Zustand der Kolonien der brasilianischen Provinzen Santa Catharina und San Pedro do Rio Grande do Sul, S. 253; Von Tschudi, Johann Jakob. Reisen durch SüdAmerika. 3. Band. Leipzig: F. A. Brockhaus, 1867, S. 412.

${ }^{663}$ Soboll, Heinz Friedrich. Esel und Pastoren. São Paulo: Artebr, 2011, S. 11-13.

${ }^{664}$ Von Tschudi, Johann Jakob. Reisen durch Süd-Amerika. 4. Band. Leipzig: F. A. Brockhaus, 1868, S. 22; Von Tschudi, Reisen durch Süd-Amerika. 3. Band, S. 412.
} 
rer in provisorischen Gebäuden oder bei älteren Kolonistenfamilien einquartiert werden. ${ }^{665}$ Schlimmstenfalls kampierten sie in Stroh- und Palmitenschuppen. ${ }^{666}$ Selbst wenn die Einwanderer endlich Grundstücke zugewiesen bekamen, hieß das noch nicht, dass sie sich endgültig niederlassen konnten. Als Beispiel hierfür kann die Situation der Siedler in Santa Isabel (ES) genannt werden. Hier erfuhren die Siedler bei ihrer Ankunft in den Jahren 1846 und 1847, dass nur die Hälfte der Grundstücke abgemessen waren. Sie mussten die Schneisen selbst schlagen und eine Verbindung zwischen den einzelnen Grundstücken herstellen. Als sie sich endlich niedergelassen hatten, bekamen sie einen Befehl aus Vitória (ES) und mussten nach Viana (ES) zurückkehren, weil indigene Völker in diesem Gebiet herumliefen und es zu Konflikte kommen könnte. ${ }^{667}$ Hier kann man deutlich sehen, wie die Staatsverwaltung sich um die Siedler kümmerte. Diese sollten zunächst in Sicherheit gebracht werden, bis die Regierung Maßnahmen für den Rückzug der indigenen Völker ergreifen konnte.

Wo der Zuzug neuer Einwanderer groß war und die ersten Siedler noch auf die Vermessung ihrer Ländereien warteten, reichten die errichteten Einwandererschuppen nicht mehr aus. Im Jahre $1873 \mathrm{kam}$ es in Santa Leopoldina (ES) zu solch einer Situation. Als die Hütten nicht mehr ausreichten, um die Ankömmlinge aufzunehmen, wurde ein weiterer improvisierter Einwandererschuppen für sie errichtet. Trotz der schon knappen Wohngelegenheiten, kamen immer mehr Einwanderer nach Santa Leopoldina (ES). Letztlich wurden ca. 500 Personen in vier Gruppen eingeteilt. Eine kam in einem Schuppen im Hafen, eine andere in einem Haus unter, die dritte wurde auf vier Häuser, die ein Brasilianer zur Verfügung stellte, aufgeteilt und die vierte Gruppe ging ins Binnenland. ${ }^{668}$ Der Einwanderer Joachim Holz berichtet hierzu:

„Da [in Porto do Cachoeiro] standen paar Strobbütten (...). Von da ging es zu Fuß zwei Stunden aufwärts am Santa Maria. Da war eine lange Strohbütte, in der haben wir eine Zeitlang gewohnt (...) Von da gings weiter nach der Brigança [sic! Bragança, Kolonie Santa Leopoldina (ES)](...) Wie lange wir gelegen haben, weiß ich nicht mehr". ${ }^{669}$

In Blumenau (SC) konnten sich die Einwanderer ihr Grundstück nach einem kurzen Aufenthalt im Einwandererschuppen selbst aussuchen und auf Wunsch später

\footnotetext{
665 Arbeitsgemeinschaft 25. Juli in Rio Grande do Sul, S. 19; Rheingantz, Karl Wilhelm. Die Gründung der Kolonie São Lourenço und ihr Gründer Jakob Rheingantz. [1907?], S. 16, EZA 5/2304.

666 Willems, S. 112.

667 Wagemann, Ernst Friedrich: Die Deutschen Kolonisten im brasilianischen Staate Espirito Santo. München/Leipzig: Duncker \& Humbolt, 1915, S. $28 f$.

668 Grosselli, S. 213. Rölke berichtet, dass erst 1889 ein Gasthaus namens Pedra d'Agua für die Einwanderer in Espírito Santo errichtet wurde. Rölke, Raízes da Imigração alemã, S. 305.

${ }^{669}$ Holz, Joachim. Die ersten sechs Jahren in Espírito Santo, Brasilien. In: Heimatbote für die Gemeinden der Deutschen Lutherischen Kirche in Espirito Santo. Nr. 4, April 1936, S. 3, MEW 4.194.
} 
auch wechseln, wie den Berichten von Carl Butzke und Emil Manke ${ }^{670}$ zu entnehmen ist. Der Bergmann Brotmann berichtet jedoch, dass er einen Zettel erhielt, auf dem die Nummer einer Landparzelle stand, was darauf hindeutete, dass auch hier, wie anderswo ${ }^{671}$ die Grundstücke verlost wurden. Als er sich zusammen mit einem gewissen Hersig auf dem Weg zu seinem Grundstück machte, konnte er dieses aber nicht finden. ${ }^{672}$

Die Einrichtungen der Einwandererschuppen gestalteten sich spartanisch. In Espírito Santo wurden sie auf Pfählen gebaut, Palmenblätter dienten als Dach und Wände und sie waren mit Etagenbetten ausgestattet. ${ }^{673}$ Ein Blumenauer Kolonist berichtet über die Verhältnisse im Einwandererschuppen und über die Art und Weise der Einwanderer, sich mit dieser Situation abzufinden:

„Nicht weit von der Mündung der Garcia in den Itajaby stand das für uns Ankömmlinge wichtigste Gebäude: der Empfangsschuppen. Sehr einladend sah er gerade nicht aus; von außen wie von innen bot er einen trostlosen Anblick, lang und schmal gebaut, einem verfallenen Schafstall veraweifelt ähnlich. (...) Natürlich waren zum Bau nur Palmiten und Dachblätter verwendet worden, die Wände bestanden aus Fachwerk und waren einmal mit Lehm beschmiert gewesen. Da aber der ganze Schuppen von Zeit zu Zeit durch das Hochwasser der Garcia überschwemmt wurde, so hatte der Lehm längst losgelassen und lag nun, reichlich mit Schlamm vermischt, vor und in dem Schuppen. Fenster und Luken waren überflüssig erachtet worden, die Tür war noch nicht eingesetrt, sondern durch eine große Öfnung in der Wand nur angedeutet, für Ventilation war somit reichlich gesorgt. Die Dielen bestanden aus Gottes blankem Erdboden, den man zu ebnen vergessen hatte. (...) Das traurige Gebäude war auf den Namen ,Empfangshaus' getauft, die einzelnen Koben nannte man Zimmer. Die neuen Ankömmlinge hatten glücklicherweise noch nicht die Annehmlichkeiten und Freuden des Zwischendecks vergessen, und so bielten sie obne Murren ibren Einzug. Nur einige wenige, die drüben bessere Tage gesehen hatten, murmelten etwas in den Bart, was nicht gerade schmeichelhaft klang. Aber was half's? Mitgefangen, mitgehangen, hiess es hier. Eine andere Unterkunft war um keinen Preis zu beschaffen, also immer rein ins Vergnügen, es wird schon gehen. Und es ging wirklich, besser als mancher gedacht hatte. Einer half dem andern, sich in dem neuen Heim einzurichten, und nach kurzer Zeit sab es schon leidlich wohnlich aus. Doch die Zeit, die wir im Schuppen zubringen mußten, war für uns die Zeit der schlimmsten Leiden. Unterstützung gab es nicht, die meisten waren blutarm, einige hatten sogar Schulden, als sie hier ankamen, Verdienst gab es nur wenig. Dazu kam die ungewohnte, langandauernde Hitze, das Ungeziefer, vor dem man sich nicht retten konnte, die veränderte Kost, Akeklimatisationsbeschwerden usw. Viele hatten Heimweh. Kurv, es erging uns, wie es allen Neulingen ergebt: wir mußten uns erst bineinfinden und bineinleben in

\footnotetext{
${ }^{670}$ Evangelische Synode von Santa Catarina und Paraná, S. 68, 98.

671 Wie in Santa Isabel (ES). Allgemeine Auswanderungszeitung, Rudolfstadt, 1852, S. 321. Zitiert nach Schröder, Brasilien und Wittenberg, S. $327 f$.

672 PLAG Rep 65c, Nr. 169, Blatt 35f.

${ }^{673}$ Nagar, S. 47.
} 
die uns gän₹lich fremden Verbältnisse. Bei manchen ging es schnell damit, andere wieder konnten ibr Vaterland lange nicht vergessen. Ja, ich kenne noch etliche von unseren Schiffsgenossen, denen noch beute die Tränen in die Augen treten, wenn sie der alten Heimat gedenken. Und doch liegen so viele Jahre dazpischen! Aber es ist halt ein eigenes Ding mit dem Lande, wo man geboren und gross geworden ist. Vergessen hat es wobl keiner! Doch zurück wären die Wenigsten gegangen, auch wenn sie gekonnt bätten, denn bier fanden wir, was für den Armen drüben unerreicbbar ist, Freibeit und Eigentum".674

Wo es kein Einwandererhaus gab oder wo sie angesichts der großen Anzahl von Neuankömmlingen überfüllt waren, mussten die Einwanderer unter freiem Himmel, im Schutz eines Urwaldbaums oder hinter Felsen übernachten, so wie in mehreren Orten von Rio Grande do Sul ${ }^{675}$ und Espírito Santo. ${ }^{676}$ Wer Glück hatte kam jedoch zunächst in den Häusern der ansässigen Kolonisten unter. ${ }^{677}$

In der Regel gingen zuerst die Männer zu den ihnen zugewiesenen Ländereien, schlugen Schneisen mit dem Buschmesser durch das Dickicht und legten Wege an. Dann schufen sie einen Platz für eine provisorische Hütte und einen Acker ${ }^{678}$ und holten danach ihre Familien samt Hab und Gut zu Fuß oder mit Kanus zu sich. ${ }^{679}$ In vielen Orten bauten sie ihre provisorischen Bretter- oder Palmitenhütten in Gemeinschaftsarbeit.

\subsection{Die Waldrodung und der Anfang in den Siedlungen}

Die Einwanderer kamen mit dem Versprechen nach Brasilien, ein fertig angelegenes Grundstück, teilweise sogar fertig kultiviertes Land, ein fertig gebautes Haus und Schadensersatz für den Waldschlag zu bekommen. Diese Kolonialisierungspläne der brasilianischen Regierung wurden aber aufgrund unterschiedlichen Fak-

\footnotetext{
${ }^{674}$ Plaudereien eines alten Kolonisten. In: Deeke, José. Das Munizip Blumenau und seine Entwicklungsgeschichte, 1917. Zitiert nach Evangelische Synode von Santa Catarina und Paraná, S. 24, 26; vgl. Blumenauer Gedenktage. Ausschnitt einer Zeitung vom Jahre 1932, S. 50f, EZA 5/2486.

675 Kahle, S. 25; Köbling, Fritz. Die Kolonie São Lourenço im Staate Rio Grande do Sul. In: Deutsche Post, São Leopoldo, 18.11.1908, Nr. 3355, EZA 121/19.

676 Berichte von Frau Dummer und Carl Seibel. Zitiert nach Granzow, Pommeranos unter dem Kreuz des Südens, S. 25, 38; Seibel, Imigrantes no século do isolamento, S. 88; Seibel, Ivan. Imigrante a duras penas, S. 129, 153.

677 Rheingantz, Karl Wilhelm. Die Gründung der Kolonie São Lourenço und ibr Gründer Jakob Rheingantz. [1907?], S. 16, EZA 5/2304.

${ }^{678}$ Holz, Joachim. Die ersten sechs Jahren in Espírito Santo, Brasilien. In: Heimatbote für die Gemeinden der Deutschen Lutherischen Kirche in Espirito Santo. Nr. 4, April 1936, S. 3, MEW 4.194; Allgemeine Auswanderungszeitung, Rudolfstadt, 1852, S. 321. Zitiert nach Schröder, Brasilien und Wittenberg, S. 327f; Evangelische Synode von Santa Catarina und Paraná, S. 68; Granzow, Pommeranos unter dem Krenz des Südens, S. 143. Über die Erbauung von Hütten siehe Soboll, S. 22f; Weingärtner, História da Comunidade Evangélica de Timbó, S. 52; Ramlow, Udo. Desavenças entre Índios e Colonos. In: Prefeitura Municipal de Pomerode. Pomerode, sua história, sua cultura, suas tradições. V. 3. Pomerode: Prefeitura Municipal, 1986, S. 7.

${ }^{679}$ Weingärtner, História da Comunidade Evangélica de Timbó, S. 75f; Granzow, Pommeranos unter dem Kreuz des Südens, S. 143; Weingärtner, Martin Luther e Santa Catarina, S. $126 f$.
} 
toren, auf die später noch ausführlicher eingegangen wird, nicht umgesetzt. Zudem mussten die Einwanderer tropische Krankheiten bewältigen und sich vor Angriffen wilder Tieren schützen.

Als die Einwanderer die ihnen zugewiesenen Grundstücke beziehen durften, begannen sie mit der Waldrodung. Dabei wurden die gewöhnlichen landwirtschaftlichen Techniken Brasiliens für die Anlegung ihrer Plantagen verwendet: Rodung, Waldbrand und Pflanzung. ${ }^{680}$ Laut Willems stellten sich einige Immigranten zunächst gegen diese primitiven Kultivierungsmethoden. ${ }^{61}$ Für die Sicherung ihrer Existenz mussten sie jedoch so schnell wie möglich pflanzen und ernten ${ }^{682}$,

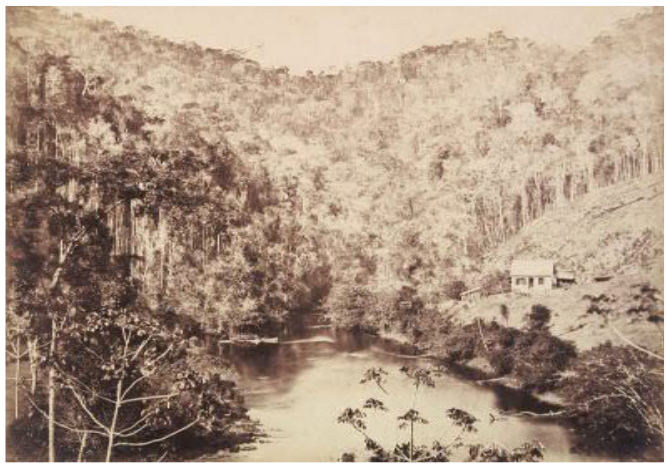

Abb. 2: Haus und Landlos in Santa Isabel (ES). Foto des französischen Fotografen Victor Frond im Auftrag der kaiserlichen Regierung im Jahre 1860. Die erbaltene Sammlung von 16 Fotos, die im Nationalarchiv von Rio de Janeiro (RJ) verfügbar ist, sollte in Europa ausgestellt werden, um europäische Einwanderer für die Kolonien in Espirito Santo, die einen schlechten Ruf genossen, zu engagieren. Frond bereiste und fotografierte die Kolonien in Espirito Santo wenige Monate nach dem Besuch des Kaisers Pedro II. Quelle: Franceschetto, Cilmar. Victor Frond. In: Von Tschudi, Viagem à província do Espirito Santo, S. 144. so dass ihnen keine Alternative blieb, als sich der extensiven Anbaumethoden anzupassen, auch wenn diese dem Boden nachhaltig Schaden zufügten. Sie besaßen zudem keine Maschinen und Düngemittel war zu teuer. Die ihnen bekannten landwirtschaftlichen Methoden ließen sich oft nicht auf den brasilianischen Boden, das hiesige Klima, das Relief und andere Bedingungen vor Ort anwenden. ${ }^{683}$ Je nach Standort, dem Grad der Isolierung und dem Verhältnis zu den Brasilianern, bekamen die ersten Siedler wenig Orientierungshilfe für den Anbau ihrer ersten Kulturen oder für die Verarbeitung von Getreide. Sie verfügten auch nicht über Werkzeuge, die sie später dann selbst herstellen oder den Brasilianern nachahmen mussten.

680 Über Waldrodungsmethoden siehe Wagemann, S. 36f, 55-57, 73; Dedekind, Brasilien, S. 33; Wernicke, S. 122-127.

${ }^{681}$ Aus Angst, das Feuer könne sich verbreiten, verbrannten sie nicht die gerodeten Bäume, sondern trugen sie anderswohin oder verwendeten das Holz für die Umzäunung ihrer Höfe. Dabei vergeudeten sie zu viel Zeit und verpassten den ersten Anbau. Andere entfernten die Baumstümpfe mit der Hacke und schädigten den Boden. Willems, S. 94; Arbeitsgemeinschaft 25. Juli in Rio Grande do Sul, S. $22 \mathrm{f}$.

${ }^{682}$ Nach Grosselli waren etwa 75 Tagen notwendig, um das Land zu roden, ein provisorisches Haus aufzubauen und Schneisen im Wald zu schlagen. Grosselli, S. 357. Dabei hatten die Siedler bereits viel Zeit in Einwandererbaracken verloren, bis ihnen das Land zugewiesen wurde, und das mitgebrachte Bargeld wurde inzwischen ausgegeben.

${ }^{683}$ Grosselli, S. 357-361. 
Die Zeit bis zu ihrer ersten Ernte gestaltete sich demnach auch als die schwierigste. ${ }^{684}$ Ein Siedler aus Alfredo Chaves (RS) berichtete 1892:
„Ich kam mit 8 Jahren nach Brasilien. Zusammen mit Italienern und Polen wurden wir nach Alfredo Chaves in den Wald geschickt. Da ging es uns sehr schlecht, wir mußten Hunger leiden. Hier starb meine Mutter und ein jüngerer Bruder. Auch mein Vater er- krankte. Schon krank machte er sich mit mir zu Fuß auf den $W$ eg in die weit entfernte Kolonie Linha Bonita. Da brachte mein Vater mich bei guten Leuten unter, er selbst ging nach Porto Alegre in die Santa Casa. Nach 3 Monate kam die Nachricht, mein Vater sei daselbst gestorben".685

Das tropische Wetter und die ungewohnte Nahrung ${ }^{686}$ bereiteten den neuen Siedlern ebenfalls große Schwierigkeiten. Als neue Einwanderer nach Dona FranciscaJoinville (SC) kamen, regnete es sechs Wochen lang ,was vom Himmel herunter wollte" ${ }^{687}$ Viele erkrankten, andere kamen ums Leben und aufgrund des sumpfigen Gebietes der Kolonie siedelten viele Siedler nach Curitiba (PR) und in die Umgebung um. ${ }^{688}$ Immigranten litten überall an „Klimawunden“, viele starben an Gelbfieber, Typhus, Malaria, Ruhr, der Wurmkrankheit, Hydrämie ${ }^{689}$ und Bleichsucht. ${ }^{690}$ Was die Situation verschlimmerte war der Mangel an Krankenhäusern und Ärzten. Der 97jährige Carl Butzke aus Rio dos Cedros (SC) berichtet hierüber. Nach dem Verlust seiner ersten Frau im Urwald baute er sich ein Leben mit Hilfe einer neuen Ehe wieder auf. Darüber hinaus freute er sich, dass seine Kinder alle gesund und am Leben geblieben waren, ${ }^{691}$ was angesichts der damaligen Verhältnisse

${ }^{684}$ Holz, Joachim. Die ersten sechs Jahren in Espírito Santo, Brasilien. In: Heimatbote für die Gemeinden der Deutschen Lutherischen Kirche in Espirito Santo. Nr. 4, April 1936, S. 3f, MEW 4.194; Granzow, Pommeranos unter dem Kreuz des Südens, S. 143f; Evangelische Synode von Santa Catarina und Paraná, S. 98.

685 Arbeitsgemeinschaft 25. Juli in Rio Grande do Sul, S. 20.

686 In Santo Ângelo (RS) beschwerten sich die Einwanderer über das schlechte Essen und forderten Geld statt Nahrung von der Regierung. Avé-Lallemant hielt diese Klagen für ungerecht, denn er fand das brasilianische Essen gut. Als er die Siedler fragte, ob sie in der Heimat so gut aßen, schwiegen diese. Avé-Lallemant, Robert. Reise durch Südbrasilien im Jahre 1858. 1. Teil. Leipzig: F. A. Brockhaus, 1859, S. 231. Laut von Tschudi entwickelten viele Einwanderer aber eine Hydrämie aufgrund der ungewohnt ,stärkemeblhaltigen Nabrung und die auf ein Minimum beschränkte Zufubr von Proteïnsubstanzen und Fetten". Von Tschudi, Reisen durch Südamerika. 3. Band, S. 32f.

687 Wüstner, S. 8.

688 Avé-Lallemant, Reise durch Südbrasilien. 2. Teil, S. 348f.

${ }^{689}$ Hierbei handelt es sich um den Mangel an Faserstoff im Blut. Allgemeinde Schwäche, Mattigkeit, Herzklopfen, Brustbeklemmungen, Ödeme, Chlorose, Wassersucht, Geschwüre, Trägheit der Funktionen des Darmkanals und eine starke Anschwellung der Leber waren die Folgen dieser Krankheit. Von Tschudi, Reisen durch Südamerika. 3. Band, S. 32f.

${ }^{600}$ Wagemann, S. 29, 109-111; Josenhaus (Hrsg.) Der Evangelische Heidenbote, Nr. 4, April 1864. Basel: Felix Schneider, S. 38; Avé-Lallemant, Reise durch Südbrasilien. 2. Teil, S. 269f; Avé-Lallemant, Reise durch Südbrasilien. 1. Teil, S. 233; Evangelische Synode von Santa Catarina und Paraná, S. 28; Weingärtner, Nelso. Mundo da Superstição. São Leopoldo: Sinodal, 2014, S. 18-21; Kahle, S. $107 f$.

${ }^{691}$ Aus der Geschichte Frau Hulda Hafermann, geborene Volkmann wird berichtet, dass die Mutter bei der Entbindung starb. Sie hinterließ acht Kinder. Der Vater heiratete wieder und aus der zweiten 
keine Selbstverständlichkeit war. In seinem Bericht kommen auch die Bedeutung seines Glaubens und sein Vertrauen auf Gott trotz widriger Umstände zum Ausdruck:

„In Cedro, am 21. Mär₹ 1875, kam meine liebe Frau ins Wochenbett und ist dann gestorben. Hier im Urwald war damals keine Hilfe. Wagen gab es hier damals noch nicht. Friedrich Donner hat die Leiche per Canoa auf dem Cederfluss bis Timbó gefahren. Sie rubt in Timbó auf dem Friedhof. Sie hat mir drei gesunde Jungens hinterlassen. Sie leben noch und sind verheiratet. Fünf Monate war ich Witwer. Den 29. August 1875 habe ich die zweite Ehe geschlossen mit Auguste geborene Lemke. Zur Traunng sind wir hingeritten nach Badenfurth. In der Kirche in Badenfurth wurden wir durch Pastor Hesse getraut. Meine zweite Ehe war glücklich. Wir haben zusammen die silberne, die goldene und die diamantene Hochzeit gefeiert. Meine zweite Frau ist gestorben den 28. August 1938. Sie wurde 88 Jahre alt. Wir haben in unserer Ehe 7 Kinder aufgezogen, 4 gesunde Jungens und 3 Mädchen. Sie sind alle gesund und sind verbeiratet. Es ist für mich eine grosse Freude, dass ich gesunde Kinder aufgezogen habe, sie sind noch alle am Leben. Auch habe ich wohl 70 Enkel und gegen 100 Urenkel. Unser lieber Herrgott segne sie mit Gesundheit und Zufriedenheit".692

Die Einwanderer mussten sich auch besonders gegen wilde Tiere schützen. Die Jaguare attackierten Menschen, zerstörten Plantagen, fraßen Zuchttiere oder verletzten diese. ${ }^{693}$ Füchse griffen vor allem Geflügel an. Wilhelm Gröner aus Córrego Bley (ES) berichtet über seinen Nachbarn Heinrich Tietz, der fast von einer Wildkatze zerfleischt worden wäre, wenn ihr nicht vorher von einem Pommern in die Kehle geschossen worden wäre. ${ }^{694}$ Die Siedler hingegen versuchten sich dem Leben in der Wildnis anzupassen, wozu auch die Jagd nach Wildtieren gehörte. ${ }^{695}$ Einige freuten sich, dass im Unterschied zu der alten Heimat keine Gesetze die Jagd und das Angeln einschränkten. Das Fleisch diente ihnen als Nahrung und die Felle konnten sie verkaufen oder gegen andere Waren tauschen. ${ }^{696}$ Gustav Rauth aus Pomerode (SC) berichtet hierzu:

„Einmal fingen sie eine Anta, die fast zwei Zentner wog. Meistens aber war die Beute nicht so groß. Sie hatten immer Hunde mit, die das Wild aufspüren mußten. Einmal

Ehe entstanden zehn Kinder, fünf davon starben jedoch in den ersten Jahren. Guenther, Anita. Histórias que a vida conta. In: Prefeitura Municipal de Pomerode, Pomerode, sua história, sua cultura, suas tradições. V. 3. Pomerode: Prefeitura Municipal, 1986, S. 45.

${ }^{692}$ Butzke, Carl Friedrich Wilhelm. Mein Lebenslauf und Lebenskampf. Zitiert nach Evangelische Synode von Santa Catarina und Paraná, S. 98, 100. Carl Wilhelm Butzke starb am 25.8.1941 mit 98 Jahren und hinterließ 10 Kinder, 70 Enkel und 143 Urenkel.

693 Avé-Lallemant, Reise durch Südbrasilien. 1. Teil, S. 216; vgl. Siller, S. 39f; Evangelische Synode von Santa Catarina und Paraná, S. 98.

${ }^{694}$ Granzow, Pommeranos unter dem Kreuz des Südens, S. 20.

${ }^{695}$ Avé-Lallemant, Reise durch Südbrasilien. 1. Teil, S. 215; Siller, S. 39f; Granzow, Pommeranos unter dem Kreuz des Südens, S. 46; Rölke, Raizes da Imigração alemã, S. 461-467, $470 f$.

${ }^{696}$ Granzow, Grün ist das Tal am Rio Itajai, S. 10. 
aber verbielten sich die Hunde merkwürdig: sie jagten nicht weiter, sondern blieben auf der Stelle stehen und bellten und heulten wie verrückt. Als die drei Jäger näher kamen, sahen sie, daß die Hunde alle nach oben auf einen hohen Baum starrten. Die Männer rissen ibre Vorderlader hoch und zielten sogleich, denn ein Tiger 697 bockte sprungbereit auf einem Ast. Sie schossen augenblicklich und trafen den Tiger in die Keble, der mit schrecklichem Gefauche und Gebrüll in eine Astgabel fiel, aus der er sich nicht mehr befreien konnte. (...) Das kostbare Fell verkauften die Jäger an einen Händler für gutes Geld, mit dem sie sich Lebensmittel für die Familie kaufen konnten" 698

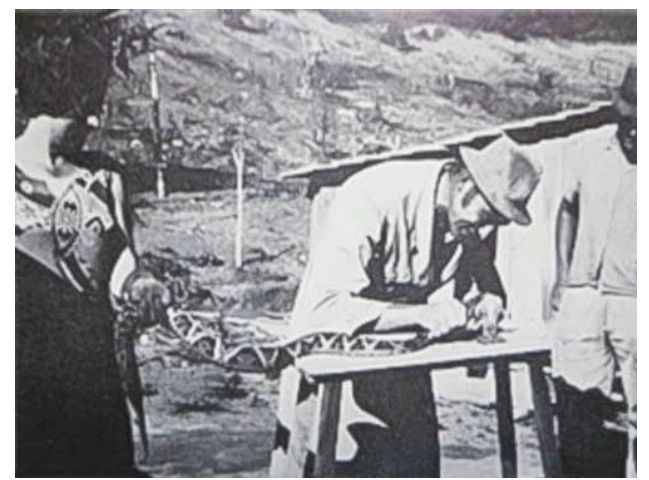

Abb. 3: Mathias Nickel beim Herausziehen des Schlangengiftes in Melgacinho-Califórnia, Domingos Martins (ES). Foto des Schauspielers, Schriftstellers und pommerschen Heimatdichters Klaus Granzow während seiner Studienreise nach Gebieten mit pommerschen Kolonisation in Brasilien im Jahr 1971. Quelle: Granzow, Pommeranos unter dem Kreuz. des Südens. geblichen Heilfähigkeit vermuteten die Kolonisten, diese besäßen magische oder übernatürliche Begabungen ${ }^{701}$, was unter anderem dadurch bekräftigt wurde, dass sie ihre Heilungspraktiken mit Gebeten verbanden. ${ }^{702}$ Nachdem die Landesregierung das Gut Butantan in São Paulo (SP) 1899 gekauft hatte, um ein Labor zur Erzeugung von Schlangenserum zu errichten, begannen einige Kolonisten wie zum Beispiel in California (ES), Schlangen zu fangen, um sie nach São Paulo (SP)

\footnotetext{
${ }^{697}$ Es könnte sich um einen Jaguar oder eine andere Art von Wildkatze gehandelt haben, denn es gibt keinen Hinweis auf die Existenz von Tigern in Brasilien, außer in zoologischen Gärten.

698 Granzow, Pommeranos unter dem Kreuz des Südens, S. 112.

${ }^{699}$ Evangelische Synode von Santa Catarina und Paraná, S. 76.

700 Über Hausmitteln und andere Maßnahmen gegen Schlangengift siehe Avé-Lallemant, Reise durch Südbrasilien. 1. Teil, S. 217; Wernicke, S. 137; Grosselli, S. 399f; Seibel, Imigrante a duras penas, S. 239; Ramlow, Udo; Resende, João M. O. A colonização de Pomerode. In: Prefeitura Municipal de Pomerode. Pomerode, sua bistória, sua cultura, suas tradições. V. 2. Pomerode: Prefeitura Municipal, 1985, S. 12. 701 Wernicke, S. $137 \mathrm{f}$.

702 Rölke, Raízes da Imigração alemã, S. 468.
} 
zu bringen. Wissenschaftler aus dem Butantaninstitut lehrten den Kolonisten, wie sie das Gift den Schlangen entnehmen konnten ${ }^{703}$ (Abb. 3 siehe S. 124). Als Gegenleistung für abgeliefertes Gift bekamen die Kolonisten vom Institut das jeweilige Gegenserum zugesandt, was die Behandlung von Schlangenbissen erheblich verbesserte. Auch Pastor Soboll nahm Kontakt mit dem Butantaninstitut auf und lehrte dem Schlangendoktor seiner Gemeinde, das Serum im Notfall zu verabreichen. ${ }^{704}$ Pastor Langholf, der 1922 in Laranja da Terra (ES) eingesetzt wurde ${ }^{705}$, gründete in seiner Gemeinde eine „Krankenkasse“ für den Kauf von Schlangenserum. ${ }^{706} 1935$ gründete auch Pastor Rölke die „Schlangenkasse“, zu welcher die Mitglieder beitrugen, um mehr Serumspritzen anzukaufen. ${ }^{707}$ Die Kolonisten beauftragten eine geeignete Person aus ihrer Gemeinde, die bei Bedarf den Betroffenen den Wirkstoff spritzte. ${ }^{708}$ Dieses Beispiel offenbart den starken Zusammenhalt der Kolonisten untereinander. Zugleich demonstriert es auch die Kreativität der Siedler mit begrenzten Ressourcen findige Lösungen für ihre Alltagsprobleme zu finden, statt auf die Hilfe des Staates zu warten.

Die Siedler mussten auf jede Art Annehmlichkeit verzichten und sparsam leben, hart arbeiten, sich auf die veränderten Lebensumstände in kurzer Zeit anpassen, Krankheiten ohne medizinische Hilfe bewältigen und sich vor Angriffen der wilden Tiere schützen. Der Lehrer Alwin Lämmel aus Timbó (SC) berichtet, dass trotz aller Entbehrungen und Leiden die Kolonisten glücklich waren, denn sie besaßen nun ihre eigenen Ländereien und konnten daraus machen, was sie wollten. Sie ließen sich angesichts der Schwierigkeiten nicht entmutigen. ${ }^{709}$ Laut dem Siedler Joachim Holz, ,bei all dem, daß es knapp ruging, sind wir nie verzagt gewesen “.710 Zudem trösteten sich die meisten Immigranten mit dem Gedanken, dass es nicht immer so bleiben würde. ${ }^{711}$ Diese Hoffnung und optimistische Einstellung halfen ihnen, die ersten Jahren und widrigen Umstände zu überstehen.

\footnotetext{
703 Granzow, Pommeranos unter dem Kreuz des Südens, S. $70 f$.

704 Soboll, S. 55-58.

${ }^{705}$ Lutherische Kirche in Brasilien (Hrsg.) Lutherische Kirche in Brasilien. São Leopoldo: Rotermund, 1955, S. 179 f.

706 Wann genau die Krankenkasse gegründet wurde wird nicht erwähnt. Langholf, Johan. Dienst an den zerstreuten in Brasilien (und Deutschland-riskiert). Eine [sic] Abschnitt aus der Geschichte lutherisches Diasporafürsorge, S. 15, MEW 4.118. Ohne Jahresangabe.

${ }_{707}$ Gaede, S. 161; vgl. Rölke, Raizes da Imigração alemã, S. 469.

${ }^{708}$ Schmidt, Artur. Die Anfänge der Diakonie in Espirito Santo. Augsburg: FDL Verlag, 1984, S. 177f.

${ }^{709}$ Weingärtner, História da Comunidade Evangélica de Timbó, S. 59.

${ }^{710}$ Holz, Joachim. Die ersten sechs Jahren in Espírito Santo, Brasilien. In: Heimatbote für die Gemeinden der Deutschen Lutherischen Kirche in Espirito Santo. Nr. 4, April 1936, S. 3f, MEW 4.194.

${ }^{711}$ Gustav Adolf-Verein in Rio Grande do Sul (Hrsg.) Gesegnete Kindergabe, S. 8, EZA 5/2222.
} 
2.2. Die Schwierigkeiten mit Beamten, Kolonieverwaltung, Gerichtsverfahren und Geschäftspersonen

Im zweiten Kapitel wurde bereits auf oppositionelle Kräfte hingewiesen, die sich gegen das Immigrationsunternehmen stellten und die Lösung von Landbesitzfragen verzögerten. Das Land litt unter Korruption und Mangel an Staatsressourcen und die Justiz ließ zu wünschen übrig, Beamte vernachlässigten ihre Aufträge und Geschäftsleute beuteten die Siedler finanziell aus. Diese Schwierigkeiten und wie die Immigranten darauf reagierten, soll im Folgenden dargelegt werden.

Viele von der Zentralregierung finanzierten Dienste für die Anlegung von Kolonien wurden nie erfüllt und teilweise kamen Subventionen für Einwanderer nie bei ihnen an. Provinzen und Kolonien bekamen nur wenige Ressourcen vom Landwirtschaftsministerium zugeteilt, staatliche Subventionen kamen mit immer größerer Verspätung an und fielen im Laufe der Jahre immer geringer aus. ${ }^{712} \mathrm{Zu}$ dem fing die Zentralregierung an, den neuen Siedlern das Vieh unter Vorwänden vorzuenthalten. Vor allem in den Provinzialkolonien waren die öffentlichen Mittel beschränkt. ${ }^{713}$ Während die ersten Einwanderer, die in Regierungskolonien angesiedelt wurden, bis 1830 zunächst 75 Hektar Land von der Regierung geschenkt bekamen, erhielten die nachfolgenden Siedler nur noch 50 Hektar und aufgrund des Drucks der Opposition mit dem Landgesetzt von 1850 schließlich nur noch 25 Hektar, die die Siedler in fünf jährlichen Raten zu bezahlen hatten. ${ }^{714}$

Der ständige Parteiwechsel und der Interessenkonflikt zwischen Liberalen und Konservativen innerhalb der Zentralregierung trug wesentlich zur Entwicklung von Korruption in Brasilien bei. Bei jedem Wechsel übernahm die Partei der Zentralregierung auch die Verwaltung fast aller Provinzen und Oppositionsmitglieder und Beamte verloren ihre Ämter. Alle strebten nach höheren Positionen

\footnotetext{
712 Wagemann, S. 30; Grosselli, S. 155f; Rocha, S. 135.

713 Von Tschudi, Bericht über den Zustand der Kolonien der brasilianischen Provinzen Santa Catharina und San Pedro do Rio Grande do Sul, S. 251. Laut Anweisungen von 1861 sollten Einwanderer nur Arbeitsgeräte, Samen und Subventionen für die ersten sechs Monate bekommen, falls ihnen keine andere Arbeit zur Verfügung stand, wie beispielsweise beim Straßenbau. Carvalho, S. 486f. In Blumenau (SC) wurde den neuen Siedlern 4 Milréis (4 Taler) als „kaiserliches Colonisten-Geschenk" bei der Ankunft ausgezahlt. Die Familie Brotman berichtet aber, dass ihnen beim Vertragsabschluss in Hamburg eine Summe von 50 Milréis für Ansiedlung und Errichtung eines Hauses und ein zusätzliches Begrüßungsgeld in Höhe von 6 Milréis zugesichert wurde. Vor Ort erhielt sie aber nur 4 Milréis von der Kolonieverwaltung mit der Begründung, die brasilianische Regierung verfüge über beschränkte Mittel aufgrund des Kriegs gegen Uruguay. PLAG Rep 65c, Nr. 169, S. 35.

${ }^{714}$ Dreher, Martin Norberto. Kontexte und Kirche, Werden und Gegenwart der IECLB. In: GustavAdolf-Werk (Hrsg.) Evangelium - Markt - Kreu₹: evangelisch-lutherisch in Brasilien. Leipzig: Verlag des Gustav-Adolf-Werks, 2011, S. 16; Rölke, Raižes da Imigração alemã, S. 500. Einwanderer in Nova Petrópolis (RS) mussten ihre Landschuld und die gewährten Subsidien nach Angaben von Schröder schon nach fünf Jahren zahlen. Schröder, Die deutsche Einwanderung nach Südbrasilien bis zum Jahre 1859, S. 92. Zum Vergleich benötigten die Siedler in Blumenau (SC) etwa fünfzehn Jahren dafür, Altmann, S. 22. In Santa Leopoldina (ES) konnte Guilherme Raasch erst nach 22 Jahren seine Landschuld tilgen. Rölke, Raízes da imigração alemã, S. 501.
} 
und versuchten sich innerhalb ihrer Amtszeit ökonomisch und politisch abzusichern. Unqualifizierte Menschen kandidierten als Provinzpräsident und erlaubten dabei jede Art von Korruption. ${ }^{715}$ Laut von Tschudi erwarb der Generalinspektor der Provinzialkolonien in Rio Grande do Sul sein Amt durch den herrschenden Nepotismus unter den Provinzialpräsidenten. ${ }^{716}$ Auch die Beamten und Koloniedirektoren waren korrupt. Betrug, Veruntreuung und Erhöhung der Steuern über das gesetzlich vorgeschriebene Maß hinaus waren an der Tagesordnung. ${ }^{717}$ Die Koloniedirektoren von Santa Leopoldina (ES) $)^{718}$ und São Leopoldo (RS) ${ }^{719}$ verteilten Grundstücke nach Lust und Laune und vor allem zu ihrem eigenen Vorteil, unterschlugen Regierungssubventionen für Einwanderer und das Geld, das für öffentliche Arbeiten bestimmt wurde, oder zahlten es nur bestimmten Personen aus. Es gab auch widersprüchliche Angaben über Unterkünfte und Subventionen zwischen Zentral- und Provinzialregierungen. ${ }^{720}$ Wenn die Provinzialregierung ihre Koloniedirektoren wechselte, verschwanden die Dokumente, die das korrupte Verfahren von Beamten und Direktoren hätten beweisen können. ${ }^{721}$

\footnotetext{
715 Brief von Höhne, Rio de Janeiro, 4.10.1869. Zitiert nach Rölke, Raízes da Imigração alemã, S. 610.

716 Von Tschudi, Bericht über den Zustand der Kolonien der brasilianischen Provinzen Santa Catharina und San Pedro do Rio Grande do Sul, S. 251f.

${ }_{717}$ Grosselli, S. 158; Wagemann, S. 29f. „Die Unvollkommenheit der Brasilianischen staatlichen und religiösen Gesetzgebung", die schlechte und mangelhafte Verwaltung der Koloniebeamten und die Korruption waren auch Motive für den Versuch, die Einwanderung nach Brasilien zu hemmen. Dazu siehe Schentke, H. Mabnruf gegen die Auswanderung nach Brasilien, S. 6, PLAG Rep 65c, Nr. 167.

${ }^{718}$ Grosselli, S. 202. Zusätzlich kam es in Santa Leopoldina (ES) innerhalb der Jahren 1857 und 1862 zehnmal zu einem Wechsel im Direktionsamt. Von Tschudi, Reisen durch Süd-Amerika, 3. Band, S. 27f; Wagemann, S. 33f. Die Kolonie Santa Isabel (SC) verfügte ihrerseits zunächst über keinen Direktor und die Siedler wurden sich selbst überlassen. Viele bettelten in São Pedro de Alcântara (SC), weil sie keine Subventionen mehr erhielten. Von Tschudi, Reisen durch Süd-Amerika, 3. Band, S. 404f. Der häufige Direktionswechsel verursachte auch in Nova Petrópolis (RS) eine mangelhafte Verwaltung. Es gab schlechte Verbindungswege und eine unzweckmäßige Verteilung von Lebensmitteln. Von Tschudi, Reisen durch Süd-Amerika, 4. Band, S. 39f. vgl. Schröder, Die deutsche Einwanderung nach Südbrasilien, S. 93.

719 Drei deutsche Polizisten halfen ihm, seine Ungerechtigkeiten auszuüben. Wenn ein Kolonist etwas gegen ihn berichtete, wurde er von ihnen misshandelt oder inhaftiert. Von Tschudi, Reisen durch Süd-Amerika, 4. Band, S. 21f. Nach der Meinung mancher Kolonisten hatten Koloniedirektor und Munizipalrichter ein Bündnis, so dass der Direktor Einfluss auf dem Wahlkampf zugunsten der Partei des Munizipalrichters ausübte, während dieser die Siedler inhaftieren ließ, die den Direktor vor dem Provinzpräsidenten anklagen wollten. Kessel, Oscar von. Administration der ColonisationsDirectoren. Missbräuche. In: Sturz, J. J. Die deutsche Auswanderung und die Verschleppung deutscher Auswanderer. Berlin: Fr. Kortkampf, 1868, S. XLVIII.

720 Rölke, Raízes da Imigração alemã, S. 478, 480f. Unterstützungen, die die kaiserliche Regierung den Kolonisten von Dona Francisca-Joinville (SC) freigab, wurden vom Provinzpräsident nicht verteilt. Von Tschudi, Bericht über den Zustand der Kolonien der brasilianischen Provinzen Santa Catharina und San Pedro do Rio Grande do Sul, S. 219. In Brusque (SC) musste der wohlhabende Polizeikommissar von Itajaí, Joaquim Pereira Liberato, der Provinzregierung mit den Kosten für die Kolonisation zu Hilfe kommen. Von Tschudi, Reisen durch Süd-Amerika, 3. Band, S. 401.

721 Als 1869 José Agostinho Moreira Guimarães die Direktion der Kolonie Santa Leopoldina (ES) übernahm, konnte er kein Inventar und keine Kolonielandurkunden finden, das Einwandererregis-
} 
Die Ungerechtigkeit und Sittenlosigkeit mancher Koloniedirektoren löste hier und dort Protest und Gewalt aus. Einwanderer in Brusque (SC) beklagten sich über Ungerechtigkeit und Brutalität des ansässigen Koloniedirektors ${ }^{722}$, was letztendlich zu Aufruhr und Chaos führte. ${ }^{723}$ Siedler von Rio Novo (ES) bekamen keinen Zugang zu den Akten des Direktors, worin die Landschuld der Kolonisten eingetragen waren, und wussten nicht, wieviel sie ihm schuldig waren. Das löste stillschweigendes Misstrauen und Reklamationen aus, denn nach von Tschudi wollte der Direktor sie durch Schulden von sich abhängig machen. ${ }^{724}$ In Santa Leopoldina (ES) sollen Direktoren Frauen und Töchter der Einwanderer ihren Angehörigen gewaltsam entrissen haben. ${ }^{725}$ Ende 1873 rebellierten hier etwa siebzig Kolonisten, so dass der Provinzpräsident Dr. João Tomé da Silva zu militärischen Maßnahmen greifen musste. ${ }^{726} 1874$ kam es wieder zu Konflikten zwischen Kolonisten und Koloniedirektion. ${ }^{727}$ In Santa Isabel-Campinho (ES) überfielen Kolonisten und Geschäftsleute 1893 das Haus des Kammerpräsidenten von Santa Isabel (ES) und forderten Rechenschaft über das Steuergeld für Straßenausbesserungen und Brückenbauten, die nicht durchgeführt wurden. Sie nahmen die Kassenbücher und Protokolle in Gewahrsam, einige von ihnen misshandelten den Beamten und dessen Frau. Der Präsident rief polizeiliche Hilfe aus Vitória (ES) und die Truppen nahmen die Beteiligten bei ihrer Heimkehr gefangen. Sie mussten zu Fuß bis zur Polizeistation in Vitória (ES) gehen. Derweil wurde in ihre Häuser eingebrochen und geplündert. ${ }^{728}$

Manche Beschwerden gegen die Kolonieverwaltung sollten jedoch mit Vorsicht betrachten werden, vor allem, wenn ein Teil der Einwanderer sich über sie beklagte, während ein anderer sie positiv bewertete. Laut von Tschudi steckte hinter der Weigerung einiger Siedler in Teresópolis (SC), Ländereien in steilen und felsigen Gebieten anzunehmen, die Rivalität des Obersten Gaspar Neves gegenüber dem Koloniedirektor Todeschini. Neves, der selbst Koloniedirektor werden

terbuch enthielt nur Eintragungen bis 1860, neue Einwanderer waren noch nicht in ihren Grundstücken angesiedelt, Gutscheine wurden in Geschäftshäusern in Porto do Cachoeiro (ES) abgegeben und 46 Einwanderer forderten längere Zahlungsfristen für ihre Ländereien. Rölke, Raízes da Imigração alemã, S. 486f.

722 Von Tschudi, Reisen durch Süd-Amerika, 3. Band, S. 39.

${ }^{723}$ Seyferth, Giralda. Colonização e conflito: estudo sobre "motins" e "desordens" numa região colonial de Santa Catarina no século XIX. In: Santos, José Vicente Tavares dos (Org.). Violências no tempo da globalização. São Paulo: Hucitec, 1999, S. 285-330.

${ }^{724}$ Von Tschudi, Reisen durch Süd-Amerika, 3. Band, S. 68; Von Tschudi, Johann Jakob. Bericht des Herrn von Tschudi, außerordentlichen Gesandten in Brasilien über die Kolonien Santa Isabel, Santa Leopoldina und Rio Novo usw. vom 20. December 1860. In: Hörmeyer, J. (Hrsg.) Actenstücke Brasilianischer Seite, betreffend die Kolonisation des Kaiserreiches. 3. Jahrgang, Heft 3, Rudolfstadt/Berlin: Verlag des F. priv. Hofbuchdruckerei/Franz Wagner, 1861, S. 280 f.

${ }^{725}$ Schröder, Brasilien und Wittenberg, S. 330.

${ }^{726}$ Daemon, S. 464; vgl. Grosselli, S. 217-222.

727 Grosselli, S. 222-229; Rölke, Raízes da Imigração alemã, S. 303-305.

728 Bericht von Pastor Gustav Treptau von 4.12.1893. Zitiert nach Schmidt, Die Anfänge der Diakonie, S. 32-36, vgl. Wernicke, S. 102-105. 
wollte, hetzte mit Unterstützung von Geschäftsleuten die Kolonisten gegen die Direktion auf und versprach ihnen höhere Subventionen. ${ }^{729}$ Von Tschudi berichtet, dass in manchen Fällen die Beschwerden der Siedler auch übertrieben waren $^{730}$, besonders, wenn sie sich einfach über alles beklagten. ${ }^{731}$

Nicht überall waren die Verhältnisse schlecht und es gab auch kompetente Direktoren, die sich für die Einwanderer einsetzten. Nach dem Bericht eines Kolonisten aus dem Serragebiet in Rio Grande do Sul bewies der Koloniedirektor viel Geduld mit fleißigen Kolonisten, die ihre Schulden nicht rechtzeitig zurückzahlen konnten. ${ }^{732}$ Der Direktor Rheingantz in São Lourenço do Sul (RS) soll nach Angaben seines Sohnes die Produkte der Kolonisten als Tilgung für ihre Landschulden angenommen und ihnen mit dem Transport von Produkten geholfen haben. ${ }^{733}$ In Blumenau (SC) sorgte Direktor Dr. Hermann Blumenau für die Verteilung von Ländereien, Saatgut, Arbeitsgeräten ${ }^{734}$ und Subventionszahlungen, Aufrechterhaltung der Ordnung und für medizinische und schulische Versorgung. Die Siedler zahlten dafür einen Beitrag für die Vermessung ihrer Ländereien und eine Abgabe an die Koloniekasse und schlossen sich zu einem Kolonieverband zusammen. ${ }^{735}$ Bereits bei der Abgrenzung der Grundstücke wurde ein Ort für die Erbauung von Kirche, Schule und Friedhof und für die Errichtung eines Stadtplatzes festgesetzt. ${ }^{736}$ Carl Butzke, aus Rio dos Cedros-Blumenau (SC) berichtet:

„1869 kam ich in Blumenau an. Da war Brasilien noch Monarchie. Wir wurden gut aufgenommen und unterstütrt. Auch waren die Beamten gut in Blumenau: Dr. Blumenau, H. Wendenburg, Reinhold Freygang. Hoch lebe Brasilien".737

Private Kolonien, wie São Lourenço do Sul (RS), Dona Francisca-Joinville (SC) und Blumenau (SC) litten nach Grothe im allgemeinen nicht wie Regierungs- und Provinzialkolonien an Geldmangel und schlechter Verwaltung. ${ }^{738}$ Aber 1860

\footnotetext{
${ }^{729}$ Von Tschudi, Reisen durch Süd-Amerika, 3. Band, S. 412.

730 Von Tschudi, Johann Jakob. Bericht des schweizerischen außerordentlichen Gesandten in Brasilien, Hrn. v. Tschudi an den Bundesrath über die dortigen Verhältnisse der Kolonisten von 6. October 1860. In: Hörmeyer, J. (Hrsg.) Actenstücke Brasilianischer Seite, betreffend die Kolonisation des Kaiserreiches. Rudolfstadt, 3. Jahrgang, Heft 1, 1861, S. 33 ff.

731 Von Tschudi, Reisen durch Süd-Amerika, 3. Band, S. 400.

732 Briefe aus Südbrasilien (Rio Grande do Sul, Serragebiet) In: Hüben und Drüben, Nr. 1, März 1927, EZA 5/355.

733 Rheingantz, Karl Wilhelm. Die Gründung der Kolonie São Lourenço und ibr Gründer Jakob Rheingantz. [1907?], S. 16f, EZA 5/2304.

734 Altmann, S. 22.

735 Schröder, Die deutsche Einwanderung nach Südbrasilien, S. 109; Schröder, Brasilien und Wittenberg, S. $267 f$.

736 Weingärtner, Nelso. 150 Anos de Presença Luterana no Vale do Itajaí 1850-2000. Blumenau: Otto Kuhr, 2000, S. 16.

737 Butzke, Carl Friedrich Wilhelm. Mein Lebenslauf und Lebenskampf. Zitiert nach Evangelische Synode von Santa Catarina und Paraná, S. 98, 100.

738 Grothe, S. 30; vgl. Von Tschudi, Reisen durch Süd-Amerika, 3. Band, S. 364.
} 
musste die Kolonie Blumenau (SC) an die Regierung übergeben werden ${ }^{739}$ und im August 1870 bestand die Gefahr einer Bauernrebellion, weil der Direktor seine Zusicherung bezüglich der Straßenarbeit nicht einhielt. ${ }^{740} 1873$ ist von einem Anstieg der Anzahl illegaler Landbesetzungen die Rede, woran auch einige Deutsche beteiligt waren. ${ }^{741}$ In São Lourenço do Sul (RS) rebellierten wiederum Einwanderer aufgrund der hohen Zinsen beim Landverkauf ${ }^{742}$, dem Handelsmonopol ${ }^{743}$ und der Sklavenbehandlung ${ }^{74}$ gegen den Kolonisator Rheingantz. Die Situation wurde noch angespannter, als Rheingantz einige Kolonisten anklagte, die ihre Ländereien nicht bezahlt hatten. Eine Gruppe von 150 bis 200 Personen sandte 1865 ein Schreiben an den preußisch diplomatischen Repräsentanten und berichteten über ihre missliche Lage. 1866 sandten sie auch eine Bittschrift an die Provinzialregierung und forderten die Lieferung ihrer Landbesitztitel, die Vermessung der Grundstücke durch einen geeigneten Ingenieur statt durch den Bruder des Kolonisators und die Errichtung einer Schule. ${ }^{745}$ Nur durch polizeiliche Intervention konnte die Situation unter Kontrolle gebracht werden und Baron von Kahlden übernahm provisorisch die Direktion der Kolonie, die 1869 wieder an Rheingantz übergeben wurde. Die Kolonisten bekamen einen Besitztitel, der sie vor späteren Reklamationen wegen Hypothekenschulden bis zur vollständigen Abzahlung der Verkaufssumme für das Grundstück schütze. ${ }^{746}$

${ }^{739}$ Denkschrift im Grundstein der Evangelischen Kirche vom Pastor Oswald Hesse. In: Evangelische Synode von Santa Catarina und Paraná, S. 32; Schröder, Brasilien und Wittenberg, S. 264f, 270.

740 Schreiben Blumenaus vom 21. August 1870 an die Provinzialregierung. In: Niedersächsisches Staatsarchiv in Wolfenbüttel 192 N XXII 136. Zitiert nach Wirth, S. 45.

741 Schreiben Blumenaus vom 31.10.1873 an die Provinzialregierung. In: Niedersächsisches Staatsarchiv in Wolfenbüttel 192 N XXII 162. Zitiert nach Wirth, S. $45 f$.

742 Avé-Lallemant, Reise durch Südbrasilien im Jahre 1858. 1. Teil, S. 497; vgl. Rheingantz, Karl Wilhelm. Die Gründung der Kolonie São Lourenço und ihr Gründer Jakob Rheingantz. [1907?], S. 10-12, 24f, EZA $5 / 2304$.

743 Bosenbecker, S. 73, 96 f.

744 Schentke, H. Mahnruf gegen die Auswanderung nach Brasilien, Berlin, PLAG Pep. 65c Nr. 167.

745 Dazu siehe Kopie des Kriminalprozesses. In: APERS, Nr. 520, Archivbox 006.0311. Der Originalprozess wurde nach Rio de Janeiro (RJ) gebracht, aber es wurde nichts über die Entscheidung des Revisionsverfahren gefunden. Siehe auch die Bittschrift der Kolonisten in São Lourenço von 20.7.1866; vgl. mit Erklärungen von Rheingantz an den Provinzpräsidenten, 12.9.1867. In: AHRS. Alles zitiert nach Bosenbecker, S. 66-69. Über den Angriff auf den Kolonisator Rheingantz und die staatliche Intervention siehe Bosenbecker, S. 67-103; vgl. Schentke, H. Mahnruf gegen die Auswanderung nach Brasilien, Berlin, PLAG Pep. 65c Nr. 167; Rheingantz, Karl Wilhelm. Die Gründung der Kolonie São Lourenço und ibr Gründer Jakob Rheingantz [1907?], S. 13f, EZA 5/2304. Laut Borchard waren ein katholischer Lehrer und einige Intriganten, die die Pommern aufgeregt und zum Aufstand angestiftet hatten. Auszug aus den Akten V. 114. I. E. O. 1931/1868, Brief Borchards an den Oberkirchenrat Berlin, Montevideo, 1.3.1868, EZA 5/2304.

746 Zunächst wurde Rheingantz gezwungen zu unterschreiben, dass Grundstücke für 300 Milréis zu verkaufen waren. Manche nutzten dabei die Gelegenheit, diese Summe den Koloniedirektor in Bargeld für das Land zu zahlen, das sie auf Kredit für 400 Milréis gekauft haben, und verlangten 100 Milréis zurück. Weil jedoch der Polizeileutnant Zeuge der erzwungenen Empfangnahme des Geldes war, wurde das Verfahren rückgängig gemacht. Rheingantz, Karl Wilhelm. Die Gründung der Kolonie São Lourenço und ibr Gründer Jakob Rheingantz. [1907?], S. 13-15, 25f, EZA 5/2304. 
Überall beklagten sich Einwanderer über die Mängel bei der Vermessung ihrer Ländereien, den Verkauf von Grundstücken durch Spekulanten auf überteuerten Preisen ${ }^{747}$ und die Weigerung der Vergabe von Landbesitztiteln. ${ }^{748}$ Die Vermessung der Grundstücke war oft mangelhaft. Unerfahrene und ungebildete Menschen maßen die Grundstücke aus und nutzten Flüsse, Bäume, Steine und Pfähle als Grenzmarkierungen. ${ }^{749}$ Das System der Quadratbrassen ${ }^{750}$ für die Landvermessung berücksichtigte wiederum nicht die natürlichen Verhältnisse und das Relief verschiedener Gebiete. Je nach Beziehung zum Koloniedirektor, in Zusammenhang mit einer mangelhaften Landvermessung, bekamen einige Siedler mehr, andere weniger Land. ${ }^{751}$ Manche Kolonien wurden auch in dafür ungeeigneten Gebieten angelegt, wie Dona Francisca-Joinville (SC) in einem Sumpfgebiet ${ }^{752}$ und Teresópolis (SC) inmitten schmaler Täler. ${ }^{753}$ Viele Siedler erhielten Grundstücke auf steinigem Boden ${ }^{754}$ und in Nova Petrópolis (RS) waren einzelne Landstücke von besonders schlechter Qualität. ${ }^{755}$ In Rio Grande do Sul wurden Schneisen in Nord-Süd-Richtung in den Wald geschlagen und zu beiden Seiten des Weges die Grundstücke in bestimmter Breite und Tiefe abgemessen. Daraus folgte, dass einige Grundstücke mit günstigem Boden und Bewässerung versehen waren, während andere aus felsigem Boden bestanden und wasserarm waren. ${ }^{756}$ In Santa

\footnotetext{
${ }^{747}$ In São Lourenço do Sul (RS) waren Grundstücke um 100\% oder 150\% teurer als in den provinzialen Kolonien, was gesetzlich verboten war. Bericht des Verwalters des 3. Munizipaldistrikts von Pelotas, Herr João de Assunção Tavares, vorgelegt an den Munizipalverwalter Dr. Antero Victoriano Leivas, 31.8.1897. (Handschriften der Stadtsbibliothek von Pelotas). Zitiert nach Grando, Marinês Z. A colonização Européia não portuguesa no Município de Pelotas. In: Ensaios FEE, Porto Alegre 5(2), 1984, S. 51. Die ersten Grundstücke kosteten 1859300 Milréis, 1877 waren sie für 600 Milréis zu erwerben. Aufgrund der hohen Nachfrage nach Ländereien seit 1880 zahlten Siedler 1882800 Milréis und 1886 bereits 1.200 Milréis für ein Grundstück. Nach Bosenbecker verkaufte Rheingantz Grundstücke, die vor der Einwanderung 200 bis 250 Milréis wert waren für 400 bis 800 Milréis. Indem er den Kolonisten Landzahlungsquittungen mit geringeren Werten aushändigte, betrog er auch den Staat durch falsche Steuerangaben. Bosenbecker, S. 73. Laut Willems erstrebten Kolonisationsgesellschaften ihrerseits die Niederlassung möglichst vieler Einwanderer, die dann für möglichst hohe Preise Ländereien erwerben sollten. Die Hamburger Gesellschaft in Hammonia (SC) erwarb zum Beispiel jedes Hektar Land für 1,5 Milréis und verkaufte sie für 36 bis 44 Milréis. Nach dem zweiten Jahr wurden noch Zinsen von 6\% eingezogen. Willems, S. 64.

748 Carvalho, S. 203-206.

${ }^{749}$ Von Tschudi, Reisen durch Süd-Amerika. 4. Band, S. 20 f.

${ }^{750}$ Es handelt sich um ein altes Maß für die Landvermessung. 1 Quadratbrasse umfasste 2,20 Meter.

${ }^{751}$ Rölke, Raižes da Imigração alemãa, S. 242f.

${ }^{752}$ Von Tschudi, Reisen durch Süd-Amerika. 3. Band, S. 351f; Schröder, Die deutsche Einwanderung nach Südbrasilien, S. 99.

${ }^{753}$ Das machte die Absetzung von Produkten extrem schwierig, denn der Fluss war nicht schiffbar und die Kolonisten mussten ihn bis zu 22mal durchwaten. Von Tschudi, Bericht über den Zustand der Kolonien der brasilianischen Provinzen Santa Catharina und San Pedro do Rio Grande do Sul, S. $410 f$.

${ }^{754}$ Comité für die protestantischen Deutschen in Brasilien, Die Arbeit unter den Evangelischen Deutschen in Brasilien. Barmen: Wiemann, 1878, S. 58.

755 Breitenbach, S. $28 \mathrm{f}$ (132f); Schröder, Brasilien und Wittenberg, S. 14.

756 Breitenbach, S. 33 (137).
} 
Leopoldina (ES) hielt sich der Landvermesser nicht an Regierungsverordnungen und teilte die Ländereien einfach nach Augenmaß ab. Sein Nachfolger versuchte diesen Fehler wieder gut zu machen, indem er schon bebautes Land einigen Siedlern ab- und anderen zuteilte. Denjenigen, denen Land weggenommen wurde, wurde stattdessen Urwald zugewiesen, so dass sie die Rodungsarbeit von Neuem beginnen mussten. Ein anderer Beamter begünstigte einige Siedler, während er anderen kleinere Grundstücke mit schlechterem Boden zuteilte. ${ }^{757}$ Im Unterschied zu Kolonien anderer Provinzen wurde in den Kolonien von Espírito Santo kein Stadtplatz geplant. So entwickelten sich keine Dorfgemeinden, was die Isolierung der Siedler zur Folge hatte. ${ }^{758}$

Ein weiteres Problem war, dass niemand sicher sagen konnte, ob an bestimmten Orten der Grund und Boden bereits in Privatbesitz war oder zum öffentlichen Eigentum zählte. Trotz verschiedener Regelungen entzog sich die Besitzergreifung jedweder Kontrolle. ${ }^{759}$ In São Leopoldo (RS ${ }^{760}$ und São Pedro de Alcântara $(\mathrm{SC})^{761}$ erhielten manche Siedler geschenktes Land von der kaiserlichen Regierung, mussten es später jedoch vom rechtmäßigen Besitzer doch noch erwerben. In São Leopoldo (RS) griffen die Siedlungen auf die umliegenden Ländereien über ${ }^{762}$, die teils dem Staat und teils Privatleuten gehörten, was viele Streitigkeiten, Reibungen und Prozesse auslöste und Raum für Landspekulation anbot. Weil viele Siedler über keinen gültigen Besitztitel verfügten, war die Legalisierung ihrer Grundstücke schwierig. 1860 wurde eine Kompagnie gegründet, um die Landstücke erneut zu vermessen. Der Teil der Grundstücke, der die vorgeschriebene Größe von 160.000 Quadratbrassen überschritt, wurde als devolutes ${ }^{763}$ oder Regierungsland zu einem Spottpreis gekauft. ${ }^{764}$ Diejenigen, die durch eine irreguläre Vermessung benachteiligt wurden, erhielten nach der Nachmessung Regierungsländereien als

\footnotetext{
757 Von Tschudi, Reisen durch Süd-Amerika, 3. Band, S. 21-23; vgl. Wagemann, S. 32; Grosselli, S. 200. Die kaiserliche Regierung intervenierte und ordnete die Entschädigung der Beeinträchtigten durch die Zuweisung zusätzlicher oder neuer Ländereien an. Die Kolonisten nahmen diese Vorschläge aber nicht an, weil die Ergänzungsparzellen zu weit von ihrem Wohnsitz entfernt lagen, was deren Bebauung und Überwachung erschwerte. Außerdem wollten sie die drei Jahren Arbeit auf ihrem ursprünglichen Besitz nicht aufgeben, um in einen anderen Teil der Kolonie, wo der Boden ebenso unfruchtbar sein konnte, umzusiedeln.

758 Rölke, Raíres da Imigração alemã, S. 242f, 306; Willems, S. 47.

${ }^{759}$ Selbst Einwanderer in São Leopoldo (RS) haben Ländereien illegal in Besitz genommen, um sie später an neue Siedler zu verkaufen. Porto, Aurélio. O Trabalho alemão no Rio Grande do Sul. Porto Alegre, 1934, S. 161. Zitiert nach Witt, S. 37.

760 Von Tschudi, Reisen durch Süd-Amerika. 4. Band, S. 20.

761 Von Tschudi, Reisen durch Süd-Amerika. 3. Band, S. 416.

762 Avé-Lallemant, Reise durch Südbrasilien im Jahre 1858. 1. Teil, S. 158.

${ }^{763}$ Als devolutes Land wurden alle Länder bezeichnet, die nach der Unabhängigkeit Brasiliens 1822 der privaten Besitznahme für legitime Titel nicht beitraten oder nicht öffentlich zugeteilt wurden. Sie wurden dem Staat zurückgegeben.

${ }^{764}$ Von Tschudi, Reisen durch Süd-Amerika. 4. Band, S. $35 f$.
} 
Entschädigung. ${ }^{765}$ In Espírito Santo mussten die Siedler wiederum ihr Grundstück beim Koloniedirektor beantragen, aber die Landvermessung war teuer, so dass sie ihr Land erst nach Jahren legalisieren lassen konnten. ${ }^{766}$ Dadurch wurde es aber teilweise als devolutes Land angesehen. ${ }^{767}$

Die Vergabe des Landbesitztitels bildete eine weitere Schwierigkeit für viele Siedler. Nach Angaben der Regelungen für Staatskolonien vom 19. Januar 1867 gab es zwei Arten von Landbesitztiteln. Den provisorischen Landbesitztitel768 erhielten Siedler für ihr in Raten gekauftes Land und den definitiven Landbesitztitel wurde jenen ausgestellt, die ihre Landschulden getilgt hatten. Einige Koloniedirektoren weigerten sich allerdings, den Siedlern den definitiven Landbesitztitel zu verleihen. In São Leopoldo (RS) besaßen einige Siedler nach dreißig Jahren noch keinen definitiven Landbesitztitel. ${ }^{769}$ In Santa Catarina wurde laut Willems bis in die 1930er Jahre Betrug bei der Vergabe des Landbesitztitels geübt. ${ }^{770}$ Und als die Siedler in São Lourenço do Sul (RS) ihre Landschuld zahlten, erhielten sie vom Kolonisator keinen Landbesitztitel, sondern nur eine Quittung und in einigen Fällen wurde ein Verkaufszertifikat vor dem Notar abgefasst. Den vollständigen Landbesitztitel für abbezahlte Ländereien gab Rheingantzs Frau erst nach seinem Tod 1877 heraus. ${ }^{771}$ Hingegen wurde in der Kolonie Dona Francisca-Joinville (SC), wo die Grundstücke teurer als in Regierungskolonien verkauft wurden ${ }^{772}$, den Siedler zeitnah der Besitztitel ihrer Grundstücke ausgehändigt. ${ }^{773}$

\footnotetext{
765 Arbeitsgemeinschaft 25. Juli in Rio Grande do Sul, S. 10; Sudhaus, Fritz. Deutschland und die Auswanderung nach Brasilien im 19. Jahrbundert. Hamburg: Hans Christians, 1940, S. $122 \mathrm{f}$.

766 Seibel, Imigrante a duras penas, S. 133, 141.

${ }^{767}$ Die evangelisch-lutherische Kirche bildete in den 1970er Jahren eine Arbeitsgruppe und half den Nachkommen bei der Legalisierung ihrer Ländereien. Rölke, Raízes da Imigraşão alemã, S. 502.

${ }^{768}$ Ein Beispiel eines provisorischen Landbesitztitels befindet sich in Nagar, S. 49-51.

${ }^{769}$ Von Tschudi, Bericht über den Zustand der Kolonien der brasilianischen Provinzen Santa Catharina und San Pedro do Rio Grande do Sul, S. 256. Eine Kopie einer Landesurkunde von Arroio do Padre (RS) befindet sich in einem Büchlein mit Familiengenealogie, Familia Johann Neuscbrank e Helena Neuschrank. Colônia Arroio do Padre I, $10^{\circ}$ Distrito de Pelotas, S. 2f; vgl. Von Tschudi, Reisen durch Süd-Amerika, 3. Band, S. 404f.

770 Willems, S. 112.

771 APERS, Prozess Nr. 460, Inventar von Frederico Carlos Bartz. Standes- und Kriminalamt. Verwaltungsbezirk Pelotas, Archivbox 006.00230, durch Maria Rheingantz unterzeichnet. Zitiert nach Bosenbecker, S. 73.

772 Von Tschudi berichtet, dass die Ländereien in dieser Kolonie vier- bis achtmal teurer als in Regierungskolonien waren. Viele Familien erwarben deswegen kleinere Landparzellen von 50 bis 100 Morgen für 150 bis 300 Milréis. Von Tschudi, Bericht über den Zustand der Kolonien der brasilianischen Provinzen Santa Catharina und San Pedro do Rio Grande do Sul, S. 217. Sie wurden jedoch durch fernere Unterteilungen für die Nachkommen bald zu klein, so dass viele Siedler zu anderen Kolonien umsiedelten. Von Tschudi, Reisen durch Süd-Amerika, 3. Band, S. 350, 360-362, $365 \mathrm{f}$.

${ }^{773}$ Landanweisungsschein der Kolonie Dona Francisca, MEW 3.19; vgl. Von Tschudi, Bericht über den Zustand der Kolonien der brasilianischen Provinzen Santa Catharina und San Pedro do Rio Grande do Sul, S. 218; Von Tschudi, Reisen durch Süd-Amerika, 3. Band, S. 364.
} 
Grube bezeichnete Brasilien als „Advokatenrepublik" 774 und nach Angaben eines Mitglieds der Vermessungskommission, Adalbert Jahn, bildeten die Rechtsanwälte und Prokuratoren in Brasilien ,die größte Landplage ", denn sie taten nichts für die ordentliche Vermessung von Grundstücken und waren dazu noch geneigt, den Siedlern die Schuld für die Nicht-Legalisierung ihrer Ländereien zu geben und sie zu verklagen. Der 1867 erhobene Protest, gegen die mit großer Vergeudung von Staatsgeldern leichtsinnig und feblerbaft gemachten Vermessungen", wurde seitens des Landwirtschaftsministeriums gar nicht untersucht. ${ }^{775}$ Viele Einwanderer verschuldeten sich aufgrund hoher Zinssätze ${ }^{776}$ und Provinzen und Kaiserreich gingen dadurch wertvolle Staatseinnahmen verloren. ${ }^{.77}$ Außerdem wurden Rechtsanwälte und Beamte manchmal von Gutsherren oder anderen einflussreichen Personen bestochen, wodurch sie für sich günstige Entscheidungen bei Kriminalprozessen oder Eigentumstransfers erwirkten. Gerichtsverfahren, Nachlassgerichte ${ }^{778}$ und Landvermessungen und -registrierungen wurden oft zu Gunsten willkürlicher Entscheidungen durchgeführt ${ }^{779}$ und kosteten fast das gesamte Vermögen der Kolonistenfamilien. ${ }^{780}$ Bei Eröffnung eines weiteren Prozesses für die Anfechtung eines Urteils mussten weitere Gebühren gezahlt werden und nicht selten einigten sich Rechtsanwälte beider Seiten auf eine Verlängerung des Prozesses, um so ihre Gewinne zu maximieren. ${ }^{781}$ Aus Sicht der Einwanderer, erzeugte die brasilianische Justiz kein Vertrauen, zudem war sie langsam und teuer. ${ }^{782}$ Geistliche fungierten aus diesem Grund teilweise als Berater in wirtschaftlichen Fragen, indem sie Ko-

\footnotetext{
${ }^{774}$ Grube, Karl. Bei deutschen Brüdern im Urwald Brasiliens. Leipzig: Dieterich, 1916, S. 51f.

775 Jahn, Adalbert. Die Landvermessung und der Landbesitz in Brasilien. In: Sturz, J. J. Die deutsche Auswanderung und die Verschleppung deutscher Auswanderer. Berlin: Fr. Kortkampf, 1868, S. XLVIII.

${ }^{776}$ Ferraz, S. 18.

777 Wernicke, S. 29.

778 Nach Wernicke musste die Familie nach dem Tod des Familienoberhauptes das Stadtgericht benachrichtigen, das eine Kommission zum Hof zur Bewertung des Grundstücks, Herstellung eines Inventars und Verteilung des Besitzes unter den Erben schickte. Für diese Prozedur zogen die brasilianischen Beamten jedoch hohe Gebühren ein, etwa 400 Milréis oder mehr für ein Landlos von 25 bis 32 Hektar, außerdem Honorare für Anwälte und Dolmetscher. Die Erbschaften mancher Familien reichten aber kaum für die Reisekosten bis zur Kolonie, etwa 150 oder 200 Milréis. Wernicke, S. 168f. Graça Aranha, ehemaliger Amtsrichter in Porto do Cachoeiro (ES), schildert ein gerichtliches Verfahren über ein Inventar in seinem Roman Canaã. Zitiert nach Wagemann, S. 131-136.

${ }^{779}$ Seibel, Imigrante no século do isolamento, S. 152, $161 \mathrm{f}$.

${ }^{780}$ Schentke, H. Mabnruf gegen die Auswanderung nach Brasilien, S. 31, PLAG Rep 65c Nr. 167.

${ }^{781}$ Mit Ausnahme der Rechtsanwälte und anderer Beamter genossen die brasilianischen Richter den Ruf, streng unparteiisch zu sein. Wernicke, S. 168f; Kessel, S. XLVII und XLVIII. In Rio Grande do Sul war es aber anders. Der Deputierte des Proviziallandtags in Porto Alegre (RS) sowie der Reichsvertretung Felippe Betbezé d'Oliveira Nery, ein strenger Fremdenfeind, war gleichzeitig Generalinspektor der Provinzialkolonien in Rio Grande do Sul. So wurden Einwanderer in São Leopoldo (RS) von seiner Partei durch die Tätigkeit von Richtern, Polizeibeamten und Koloniedirektoren ungerecht behandelt und teilweise unterdrückt. Siehe Von Tschudi, Reisen durch Süd-Amerika. 4. Band, S. 13f, 34f. Vgl. Porto, Aurélio. Die deutsche Arbeit in Rio Grande do Sul. São Leopoldo, 1934, S. 158, 162ff, 169f. Zitiert nach Willems, S. 118.

782 Willems, S. $367 f$.
} 
lonisten abrieten, Kredite bei brasilianischen Banken aufzunehmen, dienten als Richter, Vermittler oder Übersetzer zwischen ihnen und Staatsbeamten, teilweise um zu vermeiden, dass Konflikte innerhalb der Siedlergemeinschaft durch die brasilianische Justiz zu deren Nachteil gelöst wurden. ${ }^{783}$

Manchmal profitierten die Kolonisten aber selbst von diesen Unregelmäßigkeiten. Die ersten Einwanderer in Santa Isabel (ES) behaupteten, sie müssten die Ländereien und die gewährten Subventionen nicht zurückerstatten. Weil die Regierung darüber keine Vertragsurkunde besaß, erhielten sie beides letztlich kostenlos. Einige erwarben durch „Bitten, Winkelqüge, fingierte Erbschaften“ und dergleichen bis zu drei Grundstücke, die sie gar nicht ganz bebauen konnten. ${ }^{784}$ Ein Einwanderer verließ die Kolonie Santa Leopoldina (ES), ohne sein Grundstück bezahlt zu haben $^{785}$, was sicher kein Einzelfall war. Seidler berichtet, dass die von der Regierung den Einwanderern zugewiesenen Zuchttiere nach vier Jahren zurückgeliefert werden mussten, was aber die Mehrheit nicht tat. ${ }^{786}$ Laut von Tschudi hatte Dr. Blumenau nie einen Kolonisten gerichtlich oder außergerichtlich gepfändet, auch wenn einige von ihnen ihre Ländereien hätten zahlen können. ${ }^{787}$ Karl Bernhard Gessner aus Mulde-Timbó (SC) schreibt am 17. April 1869:

„Als wir hier in Blumenau am 14. September 1868 ankamen, erbielten wir für jedes Familienmitglied, dass älter als 10 Jahren war, 4 Milréis als Geschenk. Bei der Kolonieauswabl erbielt jeder von uns mehr 20 Milréis als Darlehen und für jede Kolonie noch ein Darlehen von 30 Milréis für die Errichtung eines Hauses. Es ist gut möglich, dass diese Darlehen zukünftig rückzuzablen sind, aber wie und wann wissen wir nicht und denken sogar, dass das ursprünglich geliehene Geld eigentlich ein Geschenk ist. Wir beantragten 200 Morgen Land. Jeder Morgen wurde auf 2 Milréis festgelegt. Bis wann dieses Land abbezahlt werden muss, weiß niemand. Es gibt Kolonisten hier, die ihr Land vor mehr als 10 Jahren erhielten und bis jetrt ist noch niemand aufgetaucht, um das Geld zu kassieren. Aber, wenn jemand sein Land verkaufen will, dann muss es abbezahlt werden. Sonst kann man keine neue Kolonie kaufen" "788

Laut Wernicke, wenn Vertragsbestimmungen einerseits nicht vollständig durch die Regierung eingehalten wurden, haben andererseits manche Einwanderer ihre Verpflichtungen auch nicht erfüllt, was nicht geahndet wurde. ${ }^{789}$ Dem Kaiser waren

\footnotetext{
${ }^{783}$ Droogers, André. Religião, Identidade e Segurança entre Imigrantes Luteranos da Pomerânia no Espírito Santo (1880-2005). In: Religião e Sociedade, Rio de Janeiro, Nr. 28 (1), 2008, S. 25.

${ }^{784}$ Von Tschudi, Reisen durch Süd-Amerika, 3. Band, S. 9; G. F. Busch (Hrsg.) Brasilia. 3. Jahrgang, Petrópolis, 6.2.1861, EZA 5/2571.

785 Brief von Höhne, Rio de Janeiro, 4.10.1869. Zitiert nach Rölke, Raízes da Imigração alemã, S. 613.

786 Seidler, S. 168.

${ }^{787}$ Von Tschudi, Reisen durch Süd-Amerika, 3. Band, S. 382f.

788 Original im Brief von Karl Bernhard Gesser. In: Weingärtner, História da Comunidade Evangélica de Timbó, S. 59f. Übersetzung auf Deutsch von S. J.

789 Wernicke, S. 35.
} 
viele Einwanderer dankbar, ihre Kritik bezog sich vielmehr auf Behörden und Koloniedirektoren.

Weil staatliche Subventionen nicht rechtzeitig ausgezahlt wurden, arbeiteten die männlichen Siedler beim Straßenbau, als Gehilfen der Feldmesser, Tagelöhner oder Pächter. ${ }^{790}$ So konnten sie Bargeld verdienen ${ }^{791}$ und etwas sparen. In Dona Francisca-Joinville (SC) setzte sich die Hamburger Kolonisationsgesellschaft für die Eröffnung von Straßen oder die Verteilung von Arbeitsplätzen ein. Jedoch beschwerten sich ca. siebzig Siedler, dass sie für öffentliche Arbeiten mit bis zu zwei Jahren gültigen Schuldscheinen statt Bargeld bezahlt wurden. ${ }^{792}$ Das Gutscheinsystem wurde auch in den Hansakolonien in Santa Catarina eingeführt, wo selbst schuldenfreie Einwanderer für ihre Arbeit an den Straßen mit Gutscheinen bezahlt wurden, die sie in den von der Kolonisationsgesellschaft kontrollierten Geschäften einlösen mussten. ${ }^{793}$ In Santa Isabel (ES) und Santa Leopoldina (ES) wurden Arbeitsverträge der Tagelöhner beim Straßenbau eingestellt, ohne ihnen dafür Lohn oder irgendeine andere Vergütung zu zahlen. ${ }^{794}$

Trotz der guten Einnahmequellen in Kolonien wie São Leopoldo (RS), investierte die Regierung laut von Tschudi zu wenig in den Straßenbau. ${ }^{795}$ In anderen Fällen überließ sie den Straßenbau Privatunternehmen, statt die Strecken unter Aufsicht der Direktoren ausführen zu lassen und Einwanderer dafür zu engagieren. So mussten die Siedler weiterhin mit Subventionen unterstützt werden. ${ }^{796}$ Wo jedoch die Regierung Geld für den Straßenbau bewilligte, wurde dieses oft durch korrupte Beamte unterschlagen oder die Aufträge nicht ausgeführt. Die Arbeiten wurden entweder nur sektionsweise oder ohne Beaufsichtigung eines Sachver-

\footnotetext{
790 Nagar, S. 47f; Von Tschudi, Reisen durch Süd-Amerika, 3. Band, S. 27; Brief eines Kolonisten an seine Verwandten von 14.9.1868. In: Weingärtner, 150 Anos de Presença Luterana no Vale do Itajaí, S. 19; Altmann, S. 25, 154; Mühlinghaus, Friedrich W. Eine Reise zu den neueingewanderten Pommern. In: Sonntagsblatt, Nr. 5, 3. Jahrgang 1890, S. 2. Zitiert nach Witt, S. 50; Holz, Joachim. Die ersten sechs Jahre in Espírito Santo, Brasilien. In: Heimatbote für die Gemeinden der Deutschen Lutherischen Kirche in Espirito Santo. Nr. 4, April 1936, S. 3, MEW 4.194; Regelmäßige Passagier-Beförderung von Hamburg direct nach der deutschen Colonie Dona Francisca, bestehend aus den Districten von Joinville und São Bento, Prov. St. Catharina, Süd-Brasilien, vermittelst der deutschen Post-Dampfschiffe der Hamburg-Südamerikanischen Dampfschiffahrts-Gesellschaft [1910], MLV 51/17 60; Avé-Lallemant, Reise durch Südbrasilien im Jabre 1858. 2. Teil, S. 236; Comité für die protestantischen Deutschen in Brasilien, S. 57

${ }^{791}$ In Santa Isabel (SC) verdienten sie 1 Milréis täglich. Abschrift von Einwandererbriefen der Familie Bauer, die in Enkirch von Heinrich Weingärtner an Pastor Nelso Weingärtner übergeben wurden. Brief Nr. 4, Datum nicht lesbar [1883?], S. 5, AHI, SE 38/6. In Brusque (SC) konnten einige Siedler nur dank der Straßenarbeit ihre Existenz sichern. Willems, S. 112.

${ }^{792}$ Einige verkauften ihre Schuldscheine mit etwa 30 bis $40 \%$ Verlust an Geschäftspersonen in Curitiba (PR), andere bekamen monatelang keinen Lohn und erhielten letztendlich nur einen Teil davon und wiederum andere suchten eine Arbeit als Tagelöhner in der benachbarten Provinz Paraná. Von Tschudi, Reisen durch Süd-Amerika, 3. Band, S. 369.

793 Willems, S. 254.

${ }^{794}$ Grosselli, S. 156; Seibel, Imigrante no século do isolamento, S. 85.

795 Von Tschudi, Reisen durch Süd-Amerika, 4. Band, S. 38.

796 Von Tschudi, Reisen durch Süd-Amerika, 3. Band, S. $413 f$.
} 
ständigen durchgeführt und wiederholt eingestellt. ${ }^{797}$ Grundbesitzer sorgten zudem mit ihrem politischen und finanziellen Einfluss dafür, dass die Straßen ihren eigenen Besitzungen zu Gute kamen. ${ }^{798}$ Inspektoren waren nachsichtig und StraBen wurden manchmal gegen ,alle Prinzipien der Strassenbaukunst und selbst gegen die gesunde Vernunft hergestellt".799 Eine Ausnahme bildete São Lourenço do Sul (RS), wo Landstraßen und Brücken unter Aufsicht der Kommunalverwaltung Pelotas (RS) gebaut und von ihr aufrechterhalten und ausgebessert wurden. ${ }^{800}$

In Santa Cruz do Sul (RS) sagte der Provinzpräsident, diejenigen Siedler, die eine Straße benötigten, sollten diese selbst bauen ${ }^{801}$ und in Santa Isabel (SC) soll die Regierung den Direktor gebeten haben, die Straßenarbeiten zu verzögern ${ }^{802}$, vermutlich wegen aufkommenden Ressourcenmangels. Weil Beschwerden über die mangelhafte Straßenlage kein Gehör bei den zuständigen Beamten fanden, besuchten 1882 zwei deutsche Abgeordneten, Fr. Hänsel und Fr. Bartholomay, einen Provinziallandtag in Porto Alegre (RS) und schlugen einen Gesetzentwurf vor, nach welchem jeder Kolonist 6 Milréis jährlich in die städtische Kasse für Straßenbau und -verbesserung zahlen sollte. Falls ein Kolonist nicht zahlen konnte, sollte er als Ausgleich sechs Tagen beim Straßenbau mitarbeiten. So blieb das Geld innerhalb der Stadt, anstatt in der Hauptkasse verloren zu gehen und zu einem anderen Zweck als dem Straßenbau verwendet zu werden. ${ }^{803}$ In São Lourenço do Sul (RS) sorgte Direktor Rheingantz für die Lieferung von Baumaterial für die Errichtung von Straßen und Brücken, während die Kolonisten die Arbeit durchführten. Später wurde in einer Versammlung beschlossen, dass jeder einen Beitrag von 2 Milréis jährlich für die Erhaltung der Straßen zahlen sollte. ${ }^{804}$ Für Blumenau (SC) gewährte die Regierung keine ausreichenden Subventionen für den Straßenbau, so arbeiteten die Siedler im Auftrag des Kolonisators Dr. Blumenau oder aus eigenem Interesse (Abb. 4 siehe S. 138) an der Errichtung von Straßen, Brücken und Kanälen. ${ }^{805} 1861$ wurde der Pommer Emil Oderbrecht als Feldmesser bei der Koloniedirektion Blumenau (SC) engagiert. 1867 unternahm er

\footnotetext{
797 Von Tschudi, Bericht über den Zustand der Kolonien der brasilianischen Provinzen Santa Catharina und San Pedro do Rio Grande do Sul, S. 223-225.

798 Breitenbach, S. 36 (140); Von Tschudi, Reisen durch Süd-Amerika, 3. Band, S. 351, 358f, 389.

${ }^{799}$ Von Tschudi, Reisen durch Süd-Amerika, 3. Band, S. 404.

800 Rheingantz, Karl Wilhelm. Die Gründung der Kolonie São Lourenço und ibr Gründer Jakob Rheingantz. [1907?], S. 11, EZA 5/2304; Grando, S. 52f.

801 Von Tschudi, Reisen durch Süd-Amerika, 4. Band, S. 49.

802 Abschrift von Einwandererbriefen der Familie Bauer, die in Enkirch von Heinrich Weingärtner an Pastor Nelso Weingärtner übergeben wurden. Brief Nr. 2 von 7.6.1865, S. 2. AHI, SE 38/6.

${ }^{803}$ Breitenbach, S. 37f (141f).

804 Rheingantz, Karl Wilhelm. Die Gründung der Kolonie São Lourenço und ibr Gründer Jakob Rheingantz. [1907?], S. 17, auch Beilage Nr. 7, S. 29f, EZA 5/2304.

805 Evangelische Synode von Santa Catarina und Paraná, S. 98; Von Tschudi, Reisen durch SüdAmerika, 3. Band, S. 386; Volkmann, Waldemar; Volkmann, Elke. Personalidade do nosso passado. In: Prefeitura Municipal de Pomerode, Pomerode, sua bistória, sua cultura, suas tradições. V. 2. Pomerode: Prefeitura Municipal, 1985, S. 19f; Ferraz, S. 5f, 12.
} 


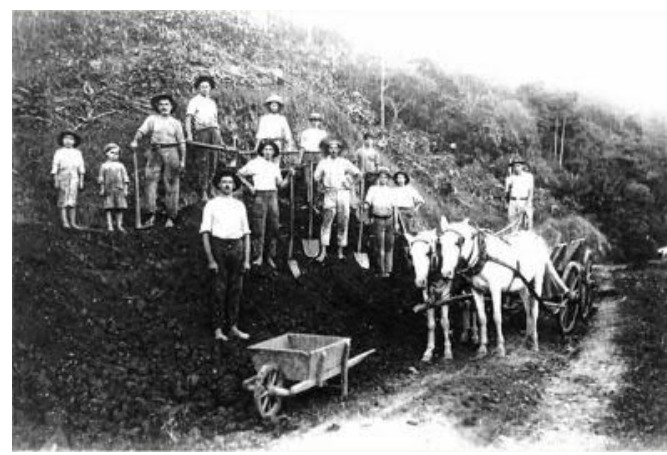

Abb. 4: Erweiterung der Straße zwischen Pomerode und Blumenau (SC), vermutlich aus dem Jabr 1929. Von links nach rechts: Waldemar und Irene (Kinder von Ernesto Volkmann), Carl Klitzkee, Arthur Volkmann, Ernesto Volkmann (neben der Schubkarre), obne Identifikation, Willy Ewald, Alvin Volkmann, Ernesto Prochnow, John Kobls, José Weinfutter, Rudolf Kobls, Julius Ott (oben auf dem Wagen). Quelle: Weege, Heike. Fotos antigas de Pomerode. 2011. eine Expedition zur Erforschung des oberen Itajaí-Gebietes, damit die Regierung Straßen in das Hochland bauen lassen konnte. 806

Von Tschudi machte teilweise die Einwanderer für die ungerechte und chaotische Situation in den Kolonien verantwortlich. Weil sie zumeist Bauern und Tagelöhner waren, interessierten sie sich wenig für die Politik in Brasilien. Mit Ausnahme eines einzigen deutschen Stellvertreters konnten sich die alteingesessenen Kolonisten in São Leopoldo (RS) nicht auf einen gemeinsamen Kandidaten für die Stadtkammer einigen. ${ }^{807}$ Viele von ihnen waren der Meinung, der Staat sei nur da um einem ,die letate Groschen aus der Tasche zu ziehen und dafür zum allgemeinen Besten der Kolonie - nichts zu thun".808 Außerdem waren sie durch den Einfluss der Großbauern im sogenannten „Coronelismo"809-System leicht manipulierbar. ${ }^{810}$ Das Verbot, politische Ämter zu bekleiden, hatte indes viel dazu beigetragen, dass sich protestantische Siedler aus dem politischen Leben zurückzogen. Sie waren oft konservativ eingestellt und standen Veränderungen misstrauisch gegenüber. 811

806 Denkschrift im Grundstein der Evangelischen Kirche vom Pastor Oswald Hesse. In: Evangelische Synode von Santa Catarina und Paraná, S. 36.

807 Von Tschudi, Bericht über den Zustand der Kolonien der brasilianischen Provinzen Santa Catharina und San Pedro do Rio Grande do Sul, S. 247.

808 Breitenbach, S. 21 (125).

${ }^{809}$ Der Coronelismo war ein nationales Politiksystem, worin Politiker und lokale Oligarchen gegenseitig Gefallen austauschten. Die Staatsregierung garantierte die Macht der Oligarchen über die Bevölkerung, indem sie ihnen Kontrolle über öffentliche Stellen gewährte. Die Oligarchen unterstützen die Regierung, indem sie das Volk beeinflussten, die von ihnen gewünschte Partei zu wählen. Nach Gertz entwickelte sich dieses Phänomen vor allem im Binnenland, obwohl einige Oberste (Coronéis), die ihren Dienstgrad durch die Nationalgarde bekommen hatten, ihre Macht auch in kleineren Städten ausübten. Erst mit der Entstehung des Neuen Staates fand der Coronelismus sein Ende. Gertz, René. O fascismo no sul do Brasil. Germanismo, nazismo, integralismo. Porto Alegre: Mercado Aberto, 1987, S. 39; Ackermann, Silvia Regina. Quando preferir um samba ao bino nacional é crime. São Carlos: Universidade Federal de São Carlos, 2009, S. 205f.

${ }^{810}$ Rölke, Raízes da Imigração alemã, S. 494. Nach Gertz überstieg die Partizipation der Bevölkerung in den Wahlen zwischen 1894 und 1930 nie den 5,7\%. Auf diese Weise war es leicht, Wahlen zu kontrollieren, welche in der Regel einen hohen Konsens erlangte. Gertz, O fascismo no sul do Brasil, S. $39 \mathrm{f}$. ${ }^{811}$ Fischer, Geschichte der Evangelischen Kirche, S. 106; Kahle, S. 42. 
Magalhães hingegen bestreitet diese Sichtweise. Auch wenn sich die politische Beteiligung der Einwanderer und deren Nachkommen auf lokale Ebenen beschränkte, sorgten sie für die Errichtung von Straßen, Schulen, Kirchen, Vereinen ${ }^{812}$ und Anstalten und organisierten in einigen Orten Gemeinderäte für die Klärung interner Probleme, deren Vertreter ihre Interessen vor den Beamten verteidigten. ${ }^{813}$ Auch die schon erwähnten Proteste in den Kolonien sind Ausdruck politischer Partizipation der Siedler zur Verbesserung ihrer Lebensverhältnisse. Die Situation änderte sich vor allem mit der Ankunft deutscher Liberaler und Intellektueller nach 1848. Diese setzten sich bald nach ihrer Ankunft für die Rechte deutscher Siedlern ein. Die Forderungen dieser Elite und einer Schicht wohlhabender Industrieller und Händler in den Siedlungsgebieten führte dazu, dass ab 1881 Protestanten und eingebürgerte Brasilianer als Abgeordnete gewählt werden durften. Zunächst bekleideten sie nur niedere Ämter, doch schon bald konnten sie auch höhere Ämter erlangen. ${ }^{814} 1880$ protestierten sie gegen die politische Fremdenfeindlichkeit einiger Brasilianer und in Rio Grande do Sul entwickelten sich 1907 Tendenzen zur Bildung einer kolonialen Partei, die gegen rassistische Angriffe vorgehen sollte. Deutsche Zeitungen positionierten sich gegen die Deutschfeindlichkeit und deutsche Nachkommen gründeten kommerzielle und industrielle Genossenschaften als Versuch, gegen Steuererhöhungen anzugehen. ${ }^{815}$ Die Aktivisten wurden teilweise für ihr exzessives politisches Engagement in Brasilien

\footnotetext{
812 Deutsche Vereine übten auch politische Funktion aus, wie aus den Statuten des Deutschen Verbandes in Porto Alegre (RS) zu entnehmen ist. Diese zielten auf die Verteidigung der Interessen deutscher Einwanderer gegenüber den städtischen und staatlichen Autoritäten ab. Als Vargas bei den Präsidentschaftswahlen konkurrierte riefen verschiedene deutsche Organisationen ihre Mitglieder auf, ihn als Präsident zu wählen. Gertz, O fascismo no sul do Brasil, S. 53 f.

813 Magalhães, Marionilde Brepohl de. Pangermanismo e nazismo. Campinas: UNICAP/FAPESP, 1998, S. 27.

814 Von Tschudi, Bericht über den Zustand der Kolonien der brasilianischen Provinzen Santa Catharina und San Pedro do Rio Grande do Sul, S. 257f. 1886 waren drei der vier Richter in Blumenau (SC) deutsche Siedler, unter den sieben Kammerrepräsentanten waren vier Deutsche. Der Kammervorsitzende in Itajaí (SC) war ein Deutscher und die Verhandlungen des Friedensgerichts wurden von deutschen Richtern durchgeführt. Stutzer, G. Blumenau in Süd-Brasilien als Ziel der dentschen Auswanderung. Goslar: Ludwig Koch, 1886, S. 6. Albert Ramlow aus Pomerode (SC) wurde 1902 Berater im städtischen Verwaltungsbezirk Blumenau (SC). Buzzarello, S. 34.1889 wurde die gesamte Stadtverwaltung von São Leopoldo (RS) durch deutsche Nachkommen gebildet und 1882 wurde Karl von Koseritz als Provinzialabgeordneten in Rio Grande do Sul gewählt. Willems, S. 372. Während in Santa Catarina Einwanderer und Nachkommen allmählich politische Ämter bekleideten (als Gouverneure, Präfekte und Deputierte), sorgte die oligarchische Elite in Rio Grande do Sul für eine zentralisierte Staatsverwaltung, die sich den Siedlern gegenüber ablehnend verhielt und sie unter Kontrolle halten wollte. Die Regierung vermied einerseits die Entwicklung von Oppositionen in den Kolonien dieser Provinz, konnte aber andererseits den politischen Einfluss der Siedler durch ihre Institutionen nicht wirklich ignorieren. Gertz, O fascismo no sul do Brasil, S. 49-51, 54f; Magalhães, Pangermanismo e nazismo, S. 133. Mehr über die Beteiligung der Einwanderer und deren Nachkommen an die brasilianische Politik siehe Gertz, O fascismo no sul do Brasil, S. 27-51.

815 Willems, S. 118f.
} 
kritisiert ${ }^{816}$, obwohl deutsche Siedlungen erst ab den 1930er Jahren eine reale politische Bedeutung erhielten. ${ }^{817}$

Geschäftsleute nutzten wiederum den Mangel an Konkurrenz in den Siedlungsgebieten, um Einwanderer auszubeuten und Preise und Zinsen zu ihren eigenen Gunsten zu bestimmen. In São Leopoldo (RS) zum Beispiel erhielten die Siedler Regierungssubventionen, die sie aber nur in Geschäften ausgeben durften, an denen der Koloniedirektor seinen Anteil hatte. ${ }^{818}$ Manchmal erhielten die Einwanderer ihre Zuschüsse und Fördermittel auch nicht in Form von Bargeld, sondern von Gutscheinen ${ }^{819}$, die sie für Lebensmittel, Arbeitsgeräte und andere Produkte einlösen konnten. Dabei wurden sie oft von Geschäftsleute betrogen ${ }^{820}$, die ihnen Produkte doppelt oder dreifach so teurer verkauften. Den Siedlern waren die Hände gebunden, denn sie waren gezwungen, ihr gesamtes Unterstützungsgeld bei diesen Unternehmen auszugeben. ${ }^{821}$ Falls sie umsiedelten, erhielten sie nur einen Teil ihrer Gutscheine durch Produkte ersetzt. ${ }^{822}$ Geschäftsleute verfügten außerdem über Transport- (Lastwagen oder Frachtschiffe) und Produktionsmittel für die Verarbeitung des Mandiokmehls, des Kaffees und anderer Produkte, vergaben Kredite und beherrschten somit den ansässigen Markt. ${ }^{823}$ In Brusque (SC) verursachte die Abmachung der Händler, Koloniepreise niedrig zu halten, fast den Ruin der Kolonisten. ${ }^{824}$ Die Geschäfte bildeten das Einkaufszentrum der Kolonien, den Treffpunkt der "Tropeiros" (Viehtreiber oder Musterreiter) ${ }^{825}$ oder Wandelhändler ${ }^{826}$, Reisenden und Kolonisten und fungierten so als Informationsund Versammlungsort.

Viele Kolonisten verschuldeten sich bei Geschäftsleuten aufgrund schlechter Ernten oder beklagten sich, dass ihre Rechnungen mit deren Rechnungsbüchern

816 Gertz, O fascismo no sul do Brasil, S. 20; Schulze, Frederik. Auswanderung als nationalistisches Projekt. Köln/Weimar/Wien: Böhlau, 2016, S. 99.

817 Wirth, S. 176.

818 Von Tschudi, Reisen durch Süd-Amerika. 4. Band, S. 22.

${ }^{819}$ Nagar, S. 47f.

820 Mühlinghaus, Friedrich W. Eine Reise zu den neueingewanderten Pommern. In: Sonntagsblatt 3(5), S. 2, 1890. Zitiert nach Witt, S. 50.

821 Seidler, S. 168, 170-172.

822 Grosselli, S. 264f.

823 Wirth, S. 48.

${ }^{824}$ Willems, S. 254.

825 Die Tropeiros besuchten und handelten mit Viehzüchtern, brachten Vieh zu den städtischen Märkten und Schlachthäusern und transportierten Waren durch das Binnenland zu den Kolonien und Kolonialprodukten zu den Märkten. Kahle, S. 129; Baviera, S. 62; Seibel, Imigrante a duras penas, S. 170; Rölke, Raízes da Imigração alemã, S. 505-507; Wernicke, S. 42, 73-76; Soboll, S. 48; Willems, S. 254. Sie suchten Geschäftshäuser in den Kolonien auf, um Aufträge ihrer Kunden einzusammeln und die Bezahlungen für frühere Bestellungen einzukassieren. Arbeitsgemeinschaft 25. Juli in Rio Grande do Sul, S. 33.

826 Wanderhändler bereisten die Koloniegebiete in Rio Grande do Sul mit vierrädrigen Wagen, um Produkte zu verkaufen. Bei der Rückreise beluden sie den Wagen mit Kolonialprodukten für den städtischen Markt. Arbeitsgemeinschaft 25. Juli in Rio Grande do Sul, S. 32. 
nicht übereinstimmten. Weil diese Unternehmer auch Geld als Vorschuss vergaben, Zahlungen vermittelten und das Geld der Kolonisten verwalteten, waren diese abhängig von ihnen. ${ }^{827} \mathrm{Im}$ Laufe der Zeit wurden einige Siedler sogar zu Pächtern auf Ländereien von Geschäftsfamilien ernannt. Diese übten zudem politischen Einfluss auf die Kolonisten aus und bestimmten teilweise durch Einschüchterung, wen sie wählen sollten ${ }^{828}$ und vermittelten den Kontakt zu Beamten. Die Errichtung von Kirchen, Schulen, Straßen und Brücken wurde teilweise durch sie bestimmt. ${ }^{829}$ Sie, ihre Angehörigen und Bekannten wurden oft auch als Vorstandsmitglieder der Kirchengemeinden gewählt und verfügten auf diese Weise auch über eine kirchenpolitische Funktion. Das alles verursachte einen Interessenskonflikt in den Gemeinden. ${ }^{830}$

Die desorganisierte und chaotische Lage bei der Kolonienverwaltung, der Anlegung von Kolonien, der Vermessung und Verteilung von Landstücken, des Landbesitzes und des Straßenbaus sowie das Monopol der Geschäftsleute in einigen Siedlungsgebieten erschwerte und verzögerte den Niederlassungsprozess der Einwanderer, ihre Lebenssicherung und letztendlich das Gedeihen und die Entwicklung ihrer Betriebe. Es waren zum Teil Probleme, mit denen sie zuvor nicht konfrontiert waren und von ihnen neue Bewältigungsstrategien forderten. Die Einwanderer stellten sich jedoch nicht als Opfer dar, sondern übernahmen eine aktive Rolle bei der Lösung ihrer Probleme, manchmal sogar mit Anwendung von Gewalt und „Tricks“, um sich Vorteile zu verschaffen.

\subsection{Konflikte mit den indigenen Völkern}

Die pommerschen Einwanderer wurden gerade in Gebieten angesiedelt, wo verschiedene indigene Völker wohnten und frei herumliefen. Diese waren schon zuvor einem Dezimierungsprozess unter den Portugiesen ausgesetzt gewesen und standen nun erneut vor der Gefahr, ihren Lebensraum zu verlieren. Leider nahmen auch die Einwanderer und deren Nachkommen teil an der Ausrottung der indigenen Völker, indem sie sie erbarmungslos und gewaltsam ,jagten " und ihnen mit „Zivilisierungsversuchen" ihre Kultur und ihren Lebensraum raubten. Dieser Konflikt soll nun betrachtet werden.

Die Einwanderer konnten nicht erahnen, dass sie mit ihrer Niederlassung in den Siedlungsgebieten verschiedene indigene Völker belästigen würden. Diese waren nicht sesshaft, sondern lebten in der Natur, ohne dass sie sich an Grenzen halten mussten, und kehrten von Zeit zu Zeit zu bestimmten Gebieten zurück. Als sie sahen, dass der „weiße Mann"wieder in ihrer Umwelt eindrang und sie besitzen wollte, fühlten sie sich bedroht. Zu ihrer eigenen Verteidigung - sie kannten

\footnotetext{
${ }^{827}$ Kahle, S. 27; Wagemann, S. 83f; Willems, S. 253f; Altmann, S. $148 f$.

828 Roos; Eshuis, S. $92 \mathrm{f}$.

829 Willems, S. $253 \mathrm{f}$.

830 Droogers, S. 23; Roos; Eshuis, S. 92f; Bericht von Pastor Hübbe, 4.1.1926, EZA 5/2185; Vgl. Schreiben des Oberkirchenrats vom 10.6.1925, EZA 5/2484.
} 
bereits den Ausgang der Besetzung von Ländereien durch den „weißen Mann“ attackierten sie die Einwanderer mit ihren Pfeilen, plünderten, raubten oder steckten deren Häuser in Brand, vernichteten deren Plantagen, töteten Zuchttiere, entführten Frauen und Kinder ${ }^{831}$ und ermordeten einige Siedler. ${ }^{832}$ Darauf reagierten die Immigranten mit noch größerer Gewalt durch Waffen, Jagd und anderen Vernichtungsmethoden ${ }^{833}$, denn aus ihrer Sicht waren die indigenen Bevölkerungen nur faulenzende Räuberbanden und „Wilden“. Die Soldaten in Espírito Santo sollen nach Angaben von Roos und Eshuis besonders gewalttätig gegen indigene Völker gewesen sein. Sie nahmen ihnen die Waffen, massakrierten die Männer, vergewaltigten die Frauen und nahmen die Kinder als Sklaven. ${ }^{834}$ In Santa Catarina kam es zur Gründung einer Waldläuferkompagnie 835 und Einstellung von sogenannten „Bugerjäger ‘836, „W Waldkapitäne '837 oder „Indianerjägerbataillone ‘838, bis die brasilianische Regierung 1910 den Indianerschutzdienst gründete und die Mitglieder verschiedener indigener Völker in Reservate gedrängt wurden, wo man sie „„ivilisieren“ oder für die „Zivilisation“ unschädlich zu machen versuchte. 839

831 Granzow, Pommeranos unter dem Kreuz des Südens, S. 102f.

832 Von Tschudi, Reisen durch Süd-Amerika, 4. Band, S. 40; Ramlow, Desavenças entre Índios e Colonos, S. 7-10; Weingärtner, Martin Luther e Santa Catarina, S. 81-85.

833 Baviera, Princesa Teresa da. Viagem ao Espírito Santo 1888. Vitória: Arquivo Público do Estado do Espírito Santo, 2013, S. 108.

834 Roos; Eshuis, S. 36.

835 Laut Wirth wurde sie schon 1836 gegründet, aufgrund schlechter Ausstattung und Nachlässigkeit aber 1879 wieder aufgelöst. Wirth, S. 49; vgl. Von Tschudi, Reisen durch Süd-Amerika, 3. Band, S. 389391. Willems berichtet über ein Sonderkommando, das die Provinzregierung in Santa Catarina erst 1877 organisierte. Willems, S. 83f.

836 „Buger" ist eine abwertende Bezeichnung für indigene Völker. Bugerjäger wurden von Koloniedirektoren oder privat von Kolonisten eingestellt, um Mitglieder indigener Völker zu jagen und in Reservate zu bringen. Wirth, S. 49f; Weingärtner, Martin Luther e Santa Catarina, S. 80f; Ramlow, Udo. Bugres. In: Prefeitura Municipal de Pomerode, Pomerode, sua bistória, sua cultura, suas tradições. V. 4. Pomerode: Prefeitura Municipal, 1987, S. 50; Stange, Erich. Memoraižes: instantâneos históricos de Indaial. Blumenau: E. G. Odorizzi, 2000, S. 14-16. In: Associação dos Amigos do Arquivo Histórico de Indaial. Indaial. Conbecendo sua história. Indaial: AMARHIN, t. 1, n. 2, jun./ago. 2015, S. $14 f$. 837 Associação dos Amigos do Arquivo Histórico de Indaial, t. 1, n. 2, jun./ago. 2015, S. 13-15.

838 Bereits 1850 hatte Dr. Blumenau die kaiserliche Regierung über die „Indianergefahr“ aufmerksam gemacht und um eine Lösung für das Problem gebeten. Er fürchtete einen Vernichtungskrieg gegen die Siedler und das Scheitern seines Unternehmens. Von der Regierung forderte er eine Reform des Schutzdienstes und schlug vor, dass sie den Kolonisten Feuerwaffen zur Selbstverteidigung ausliefern sollte, wie sie sie 1815 bis 1822 den Provinzen Espírito Santo (ES) und Bahia (BA) gegen das Volk der Botokuden zur Verfügung stellte. Schreiben Blumenaus vom 14.2.1856 an die Provinzialregierung. In: Fundação Casa Dr. Blumenau - Arquivo Histórico Prof. José F. da Silva, PO1.02. Zitiert nach Wirth, S. 49; vgl. Schröder, Brasilien und Wittenberg, S. 265. Die Regierung sandte „Indianerjäger", Soldaten oder versah die Kolonisten mit Flinten und Munition. Schentke, Mabnruf gegen die Auswanderung nach Brasilien, Berlin, S. 36, PLAG, Rep 65c Nr. 167; Weingärtner, 150 Anos de Presença Luterana no Vale do Itajaí, S. 24; Fluck, Marlon Ronald. Basler Missionare in Brasilien. Bern: Peter Lang, 2004, S. 222.

839 Wirth, S. 49f. In der Hauptstadt Florianópolis (SC) wurde der Patriotische Bund für Indianerschutz gegründet, denn die brasilianischen Autoritäten versuchten allmählich die indigenen Völker gegen 
Sicher war die Anzahl der Opfer unter den indigenen Völkern viel größer als die der Siedler ${ }^{840}$, obwohl man fast ausschließlich über Informationen aus der Perspektive der Kolonisten verfügt, die über ihre eigenen grausamen Verteidigungsmaßnahmen meist schwiegen. Die Erinnerung der Einwanderer und deren Nachkommen ist sehr vom Diskurs der zivilisierten Einwanderer mit ihrem Pioniergeist geprägt, die den Urwald gerodet und in eine zivilisierte Umwelt umgestalten haben. Diese romantische Darstellung verbirgt jedoch oft die grausamen Methoden, die hinter der sogenannten „Zivilisierung“ steckten. Die Haltung der Einwanderer gegenüber den indigenen Völkern ist keinesfalls zu rechtfertigen, auch wenn sie von der brasilianischen Regierung für den Rückzug der indigenen Völker genutzt und einem gewissen Überlebenskampf ausgesetzt wurden. Wie zu erwarten, gelang es den „Weißen“ zum zweiten Mal die indigenen Völker Brasiliens fast auszurotten.

Die vorherrschende Quellenüberlieferung berichtet über Angriffe vonseiten indigener Völker in São Leopoldo (RS) in den Jahren 1829, 1831, 1832 und $1852^{841}$, in Nova Petrópolis (RS) 1864842, in Caxias do Sul (RS) und Garibalde $(\mathrm{RS})^{843}, 1858$ und 1859 in Santa Maria da Soledade (heute São Vendelino) (RS) ${ }^{844}$ und in Santa Maria (RS) bis 1856. Besonders in Santa Catarina ${ }^{845}$ sollen die indigenen Völker kämpferischer eingestellt gewesen sein. ${ }^{846}$ Seit 1847 wurden Konflikte

das Blutbad der „Bugerjäger“ zu schützen. Willems, S. 83f. In den Reservaten waren die indigenen Völker den Krankheiten der Zivilisation ausgeliefert, wobei viele starben; vgl. Erich. Memoraizes: instantâneos históricos de Indaial. Blumenau: E. G. Odorizzi, 2000, S. 14-16. In: Associação dos Amigos do Arquivo Histórico de Indaial, t. 1, n. 2, jun./ago. 2015, S. 15; Witt, S. 19; Rölke, Raízes da Imigração alemã, S. 255, 314. Vgl. Prien, S. 49.

840 Stange und Deeke berichten über 41 ermordete Siedler und 22 verletzte, die zwischen 1850 und 1915 von den indigenen Völkern angegriffen wurden. Über Opfer unter den indigenen Völkern schwiegen sie ganz. Stange, Erich. Memoraízes: instantâneos históricos de Indaial. Blumenau: E. G. Odorizzi, 2000, S. 14-16. In: Associação dos Amigos do Arquivo Histórico de Indaial, t. 1, n. 2, jun./ago. 2015, S. 15; Deeke, José. Das Munizip Blumenau und seine Entwicklungsgeschicbte. São Leopoldo, ohne Jahresangabe, S. 42. Zitiert nach Willems, S. 83. Nach Schmid sollen etwa 60 Kolonisten in Santa Catarina durch indigene Völker getötet worden sein, während die Immigranten etwa 100 Mitglieder indigener Völker töteten. Schmid, Albert. Indianer und Kolonisten: Aus der Geschichte der deutschen Urwaldssiedlungen Südbrasiliens. Staden-Jabrbuch, V. 5, 1957, S. 247-257. Zitiert nach Prien, S. 49.

841 Avé-Lallemant, Reise durch Südbrasilien. 1. Teil, S. 144f, 160; Von Tschudi, Reisen durch Süd-Amerika, 4. Band, S. 21; Schröder, Die deutsche Einwanderung nach Südbrasilien, S. 51; Arbeitsgemeinschaft 25. Juli in Rio Grande do Sul, S. 19; Willems, S. 82f; Seidler, Carl. Zehn Jabre in Brasilien wäbrend der Regierung Dom Pedro's und nach dessen Entthronung. Quedlinburg/Leipzig: Gottfr. Basse, 1835, S. 202-220; Dedekind, Max. 75 Jahre deutsch-evangelischer Diasporaarbeit in Nord- und Südbrasilien. Barmen: Wiemann, 1912, S. 37.

842 Von Tschudi, Reisen durch Süd-Amerika, 4. Band, S. 40.

843 Prien, S. 48f.

${ }^{844}$ Von Tschudi, Reisen durch Süd-Amerika, 4. Band, S. 42.

${ }^{845}$ Schentke, H. Mahnruf gegen die Auswanderung nach Brasilien, Berlin, S. 17, PLAG Rep 65c Nr. 167; Evangelische Synode von Santa Catarina und Paraná, S. 76.

846 Willems, S. 83. 
zwischen ihnen und Siedlern in Santa Isabel (SC) ${ }^{847}$ registriert. Im Jahre 1877 revanchierten sich die Siedler aus dem Gebiet Rio Bonito in Rancho Queimado (SC) und vernichteten mithilfe eines „Bugerjägers“ eine ganze Gruppe eines indigenen Volkes. ${ }^{848}$ In der Kolonie Blumenau (SC) wurden Angriffe in den Jahren 1852, 1855, 1862, 1866, 1870, 1872, 1883 bis 1895, 1904, 1905 und 1914 registriert $^{849}$, wobei ausführliche Berichte aus den Gebieten Pomerode ${ }^{850}$ und Warnow stammen. ${ }^{851}$ Über einen Angriff in Itoupava Central-Blumenau (SC) berichtete der Pommer Emil Manke seinem Pastor:
„Da aber kam eines Morgens ein schwerer Schlag. Schon lange batte man Anzeichen von lauernden Wilden bemerkt, doch war bisher noch niemand belästigt worden. Nun sass die Familie Manke eines Morgens beim Kaffee. (...) Der Vater hatte gerade die Kaffeekumme zum Trinken angesetzt, da reisst sie ibm ein schwirrender Bugerpfeil vom Munde weg. Entsetzt schauten alle auf den Pfeil, der fest in der Palmitenwand steckte. „Vater, was ist das?", fragt der siebenjährige Emil. „Dat ist en Pietschenstock" beru- bigt die Mutter den Kleinen. Doch bald lässt das einsetzende Gebrüll der Wilden keinen Zweifel mehr: unsere einsame Hütte wird von Bugern überfallen. Der Vater greift die jüngsten Kinder und flüchtet mit ibnen in den Wald. Die Grossen folgen mit der Mutter so schnell sie können. Dreimal stürz̨t die Mutter über die liegenden Bäume, und jedesmal ist der Sturz ibre Bewahrung, weil sie sonst von Pfeilen getroffen worden wäre. Einund- zwanzig Pfeile findet man später auf ihrem Fluchtwege. Als nach Stunden die Nachbarn Mut gefasst haben, sich dem Ort des Überfalls zu nähern, finden sie die Hütte ihres armseligen Hausrates beraubt. Ein letzter Buger flüchtet noch gerade mit einem Topf Schmalz auf der Schulter. Ein Schuss verwundet ihn, und er lässt die Beute fahren. Die Federn der Bettdecken findet man später im Walde. Nun muss man noch armseliger wiederbeginnen als im Vorjabre. Der Vater bringt die jüngsten Kinder mit der Mutter nach Tatutyba, wo sie in Sicherheit sind" .852

In diesem Bericht wird deutlich, dass die Einwanderer mit dem Ausdruck „die lauernden Wilden " die Mitglieder indigener Völker herabsetzten und „wilden Tieren " gleichsetzten. ${ }^{853}$ Ihre Angriffe wurden zudem ideologisch genutzt, um die gewalt-

\footnotetext{
847 Evangelische Confirmanden in Brasilien, ohne Jahresangabe, S. 38, EZA 200/1/2151.

848 Weingärtner, Martin Luther e Santa Catarina, S. 81-85.

849 Associação dos Amigos do Arquivo Histórico de Indaial, t. 1, n. 2, jun./ago. 2015, S. 13-15; Schentke, H. „Mahnruf gegen die Auswanderung nach Brasilien“, Berlin, S. 36, PLAG Rep 65c Nr. 167.

${ }^{850}$ Granzow, Pommeranos unter dem Kreuz des Südens, S. 102-104; Altmann, S. 30; Ramlow, Desavenças entre Índios e Colonos, S. 7-10; Ramlow, Bugres, S. 49f.

851 Giurus, Friedrich. Meinrad Piske. Blumenau: Otto Kuhr, 1998, S. 7; Granzow, Pommeranos unter dem Kreuz des Südens, S. 112f.

852 Evangelische Synode von Santa Catarina und Paraná, S. 68, 70.

853 Vgl. mit den Spaniern, die indigene Völker in Haiti unterjocht und bedrückt haben, weil diese ihrer Ansicht nicht als Menschen bezeichnet werden dürften. Sie hätten unter anderem in ihren Kriegen zu ,wilden Tieren" geworden. Dies gab den Spaniern Anlass dazu, Mitglieder indigener Völker zu töten, ohne dass sie sich dabei als Mörder empfanden. Auch Gelehrte beriefen sich auf Studien der antiken Philosophen, wie Aristoteles, der die „Dienstbarkeit“ einzelner Völker „aus ibrem
} 
same Reaktion ihnen gegenüber zu rechtfertigen und zu demonstrieren, wie europäische Siedler die „,brasilianische Wildnis“ bewältigten und einen wesentlichen Beitrag zum Fortschritt des Landes leisteten. In manchen Fällen adoptierten die Siedler Kinder von indigenen Völkern, die nach einem Angriff zurückgeblieben waren. ${ }^{854}$ Die Frage ist aber, ob diese angeblich gute Tat nicht die Tendenz zu Sklaverei-Verhältnissen birgt, denn die Siedler benötigten Arbeitskräfte in ihren familiären Betrieben, konnten sie aber nicht bezahlen. Die Adoption von solchen Kindern hätte dieses Problem praktisch gelöst.

In Espírito Santo gab es nach Rölke nur gelegentlich Berichte über Konflikte zwischen indigenen Völkern und Siedlern. Bald danach weist er aber auf eine polizeiliche Intervention in Santa Isabel (ES) und auf die Präsenz von indigenen Völkern in Santa Leopoldina (ES) und entlang der Straße Espírito Santo-Minas Gerais hin ${ }^{855}$, was seinen vorherigen Angaben zu widersprechen scheint. Glaubwürdiger sind die Informationen von Theresa von Bayern. Sie berichtet 1888 über Einwanderer in Santa Leopoldina (ES), die sich zwischen 1872 und 1875 auf dem Land des indigenen Volkes der „Botokuden“ niederließen und einen bewussten und aktiven Genozidakt gegen sie verübten: Sie gaben ihnen mit Pocken- und Scharlachvirus infizierte Kleidung. Weil sie keine Immunabwehr gegen diese Krankheiten besaßen, starben sie daran. ${ }^{856}$ Dieses Beispiel, aber auch die Anstellung von „Bugerjägern", verdeutlicht das genozidale, brutale und skrupellose Verhalten der Einwanderer gegenüber den indigenen Völkern. Sobald diese sich nicht dem europäischen Arbeitsethos unterwarfen und sich nicht „zivilisieren" ließen, wurden sie vernichtet.

2.4. Die Schwierigkeiten protestantischer Einwanderer in einer römischkatholischen Umwelt

Protestanten durften ihren Kultus in Brasilien mit Einschränkungen ausüben. Auf die praktischen Konsequenzen dieser Beschränkungen, den Umgang mit Katholiken und die Reaktion der Protestanten angesichts ihrer religiösen Randposition in der römisch-katholischen brasilianischen Gesellschaft soll im Folgenden eingegangen werden.

Die deutschen Einwanderer römisch-katholischen Glaubens, die in den gleichen Siedlungsgebieten mit den Protestanten angesiedelt wurden, waren überrascht, dass gerade im römisch-katholischen Brasilien keinen Priester da war, der

naturgewollten Barbarentum" abgeleitet hatte. Bitterli, Urs. Die ,Wilden“ und die ,Zivilisierten؛ München: C. H. Beck, 2004, S. 136. Bitterli geht davon aus, dass Begriffe wie „Barbar" und „Wilder" Antonyme für das, wofür diejenige, die andere Völker mit solchen Begriffen bezeichnen, sich halten. Idem, S. 367.

${ }^{854}$ Granzow, Grün ist das Tal am Rio Itajai, S. 11, 38f; Granzow, Pommeranos unter dem Kreuz des Südens, S. 103f; Weingärtner, Martin Luther e Santa Catarina, S. 81-85.

855 Rölke, Raizes da Imigração alemã, S. 180, 210.

856 Baviera, S. 108. 
ihnen das Wort Gottes in ihrer Sprache hätte vermitteln könnten. Dies ganz im Unterschied zu den Protestanten von São Leopoldo (RS), mit denen einen deutschen Pastor mitreiste. Der lusobrasilianische Katholizismus mit seinen unzähligen Festen, Novenen und von Raketen begleiteten Prozessionen unterschied sich auch wesentlich vom nüchterneren Katholizismus in der alten Heimat. Viele katholische Einwanderer zogen sich aufgrund dieser Faktoren von ihrem Glauben zurück und drohten in die Gleichgültigkeit zu fallen oder zum Protestantismus zu konvertieren. ${ }^{857}$ Gegenüber dem konfessionell „offeneren“" Katholizismus ${ }^{858}$ der deutschen Siedler in den ersten fünf Jahrzehnten des 19. Jahrhunderts setzten die deutsche Jesuiten, die ab den 1840er Jahren nach Rio Grande do Sul kamen ${ }^{859}$, vor allem in Fragen der Mischehe auf konfessionelle Abgrenzung. Sie zeichneten sich durch religiöse Intoleranz und durch ihren Proselytismus in Brasilien aus. In ihrem Engagement in der Landseelsorge und im Schul- und Bildungswesen konkurrierten sie auch heftig mit den Protestanten. ${ }^{860}$

Vor der Ankunft der deutschen Jesuiten gab es keine Auseinandersetzungen zwischen Katholiken und Protestanten. Mischehen fanden beispielsweise in der Kolonie São Leopoldo (RS) statt. ${ }^{861}$ In Santa Isabel (SC) in den 1830er Jahren aber, wo selbst Einwanderer hauptsächlich römisch-katholisch waren, heirateten die wenigen Protestanten nach dem römisch-katholischen Ritus und ließen auch ihre Kinder römisch-katholisch taufen, nach dem Motto „,die Alten können bleiben, was sie sind, aber eure Kinder müssen katholisch getauft werden". Danach erhielten sie eine Tauf- oder Heiratsurkunde ${ }^{862}$, halfen sogar beim Bau einer katholischen Kirche, so dass die Meinung herrschte, es gäbe dort keine evangelischen Christen mehr. Die Protestanten trafen sich jedoch zu evangelischen Lesegottesdiensten in ihren Häu-

${ }^{857}$ Lutterbeck, Jorge Alfredo. Jesuitas no sul do Brasil. São Leopoldo: Instituto Anchietano de Pesquisas, 1977, S. 76.

858 Schatz, Klaus. Geschichte der deutschen Jesuiten (1814-1983). Band 2. Münster: Aschendorff, 2013, S. 214.

859 Schatz, Klaus. Geschichte der deutschen Jesuiten (1814-1983). Band 1. Münster: Aschendorff, 2013, S. 254f. Die Jesuiten übernahmen 1869 offiziell die Mission in der Provinz Rio Grande do Sul. Erst 1911 kamen die seit der Ausrufung der Republik zu Staaten erhobenen Provinzen Santa Catarina und Paraná dazu. Schatz, Geschichte der deutschen Jesuiten. Band 2, S. 202.

${ }^{860}$ Schatz, Geschicbte der deutschen Jesuiten. Band 2., S. 204; Lutterbeck, S. 65, 83-115. 1909 hatten sie fünf Schulkollegien: in São Leopoldo (RS), Pelotas (RS), Rio Grande (RS), Porto Alegre (RS) und Florianópolis (SC), dazu ein Seminar in Parecy Novo (RS). Ebd., S. 217. Aufgrund der starken Tätigkeit der Jesuiten im Bildungsbereich, der besonders auch die portugiesisch-sprachige Bevölkerung erreichte, musste die erste höhere evangelische Schule in São Leopoldo (RS) zunächst geschlossen werden. Siehe Kapitel IV, Abschnitt 3.1.3.

861 Avé-Lallemant, Reise durch Südbrasilien im Jabre 1858. 1. Teil, S. 162; Lutterbeck, S. 65.

862 Weingärtner, Martin Luther e Santa Catarina. Timbó, S. 52f, 57; Stoer, Hermann. Crônica da Paróquia de Santa Isabel, S. 3. Verfügbar in http://www.aguasmornas.sc.gov.br/noticias3/santa\%20isabel.pdf Zugang 30.5.2016. 
sern und beschlossen bald, eine eigene Kapelle zu bauen. 863 Auch in São Lourenço do Sul (RS) wurden einige Kinder römisch-katholisch getauft und in katholischen Kirchenregistern eingetragen, obwohl ihre Eltern evangelisch blieben. Später wurden diese Kinder evangelisch konfirmiert. 864 In der Regel blieben die Siedler jedoch ihrem Glauben treu und ließen sich nicht überzeugen zum Katholizismus zu konvertieren. Ein Kolonist sagte beispielsweise dem Provinzpräsidenten in Vitória (ES), dass ein rechter Protestant nicht nach Brasilien auswanderte, um katholisch zu werden. ${ }^{865}$ Jedoch angesichts der großen Anzahl protestantischer Einwanderer, wurden sie bald in manchen Gebieten als Bedrohung für den katholischen Glauben angesehen. So wurden Mischehen in São Leopoldo (RS) mit der Ankunft des fanatischen Jesuiten Bonifácio Klüber getrennt. Dem Priester wurde aber von der Provinzialregierung mit Entlassung gedroht, falls er sich nicht mäßige. ${ }^{866}$ Bei der Trauung einer katholischen Witwe mit einem Protestanten protestierte der katholische Priester und sagte, diese Ehe sei gegenüber dem Staat und der Justiz verboten. Die Frau wurde vom Sakrament ausgeschlossen und der Zugang zum katholischen Friedhof wurde ihr verweigert. ${ }^{867}$

Die Nicht-Anerkennung protestantischer Ehen vom brasilianischen Staat spielte in abgeschiedenen Gebieten keine große Rolle für einige Pommern, die eine ähnliche Situation in der alten Heimat erlebt hatten. Vor der Aufhebung der Untertänigkeitsverhältnisse bestimmten dort Gutsherren die Heiratserlaubnis für Eheleute. Viele Paare lebten aus diesem Grund unehelich zusammen, obwohl sie Familien gründeten und einander treu waren. Eine Heiratserlaubnis erhielten sie trotzdem nicht. ${ }^{868}$ Germano Malikoski berichtet, dass er sich nur zivil verheiraten ließ, um das Gesetz zu erfüllen, denn wichtiger war ihm die Eheschließung in der Kirche. ${ }^{869}$ Aus diesem Grund forderten die Einwanderer in Rio de Janeiro (RJ)

\footnotetext{
863 Abschrift der Bittschrift von Pastor Wagner an den Gustav-Adolf-Verein in Württemberg, Sta. Isabel, 15.6.1862, BMA, Q-3-1, 22; vgl. Weingärtner, Martin Luther e Santa Catarina. Timbó, S. 52f, 57; Stoer, S. 3.

${ }^{864}$ Zum Beispiel die Familien Pail. Register der Deutsch-Evangelischen Gemeinde zu São Lourenço 1870-1977, Konfirmationslisten 1872-1876. Die Kinder der Familien Klumb, Krüger, Schäfer, Lautenschlaeger, Hadler und Nebel wurden ohne ihre Eltern in katholischen Registern registriert. Dazu Bistum von Pelotas, Taufbuch III von Boqueirão, S. 2. Zitiert nach Bosenbecker, S. 51.

865 Schreiben von Pastor Bartelmann an Pastor Schmidt, 14.8.1922. Zitiert nach Krause, Lutherische Synode in Brasilien, S. 175.

${ }^{866}$ Von Tschudi, Bericht über den Zustand der Kolonien der brasilianischen Provinzen Santa Catharina und San Pedro do Rio Grande do Sul, S. 245; Von Tschudi, Reisen durch Süd-Amerika. 4. Band, S. $36 \mathrm{f}$.

867 Brief von Pastor Wagner an Josenhans, Sta. Isabel, 22.3.1862; Brief von Pastor Wagner an Josenhans von 10.1.1863, beides in: BMA, FB 1,1.

868 Die Heiratserlaubnis konnte verweigert werden, falls der Gutsherr lediges Gesinde benötigte. Kraus, Antje. „Antizipierter Ehesegen“ im 19. Jabrbundert. Zur Beurteilung der Illegitimität unter sozialgeschichtlichen Aspekten. In: VSWG, 66, 1979, H. 2, S. 174-215, S. 209. Zitiert nach Lubinski, Axel. Entlassen aus dem Untertanenverband. Osnabrück: Universitätsverlag Rasch, 1997, S. $218 f$.

${ }^{869}$ Malikoski, Germano. Interview am 24.12.2014. Quelle, die von der Diakonin Angela Lemke zur Verfügung gestellt wurde.
} 
1858 durch eine Bittschrift mit 274 Unterschriften die Anerkennung der Amtshandlungen evangelischer Pastoren. ${ }^{870}$ Diese Bittschrift wurde auch in Santa Catarina bekannt, denn Pastor Hesse informierte seine Gemeinde in Blumenau (SC) darüber und bat sie, die Bittschrift ebenfalls zu unterschreiben. ${ }^{871}$ Obwohl die Verhandlungen über die Einführung der Zivilehen bereits 1855 begonnen hatten, trug die Bittschrift sicherlich zum Erlass des Gesetzes von 1863 bei, in dem die evangelische Eheschließung in beschränktem Umfang ${ }^{872}$ durch registrierte Geistliche anerkannt werden konnte.

Die Schwierigkeiten waren aber mit dem Gesetz nicht ganz überwunden, vor allem nicht dort, wo keine protestantischen Geistlichen ansässig waren und die Protestanten eine Minderheit gegenüber den Katholiken bildeten. 1873 traute der römisch-katholische Priester Maximiliano Fried ein Ehepaar in Espírito Santo erneut, obwohl es bereits protestantisch getraut worden war. ${ }^{873}$ In Santa Isabel (SC) soll das protestantische Paar, Horst Heinzt und Maria Bauer, am 5. August 1861 während der Trauung vom katholischen Priester nochmals getauft worden sein. Es kann sich aber hierbei auch um eine falsche Anschuldigung gehandelt haben, denn keiner der Anwesenden verstand die lateinischen Worte bei der Zeremonie. Allerdings, als der Priester dem Paar befohlen hatte, die Köpfe zu neigen, eine Formel über sie sprach und sie mit Weihwasser besprengte, gingen selbst die Brasilianer davon aus, sie seien getauft worden. Als die Regierung eine Untersuchung zu diesem Fall durchführte, bestritt der Priester, das Paar getauft zu haben. ${ }^{874}$ Weil derselbe Vorwurf auch gegen andere Priester aus Desterro (SC) und São José (SC) erhoben wurde ${ }^{875}$, konnte der Verdacht nicht ganz getilgt werden, es habe sich doch um eine Taufe gehandelt. Mischehen waren weiterhin nicht geduldet. In diesen Fällen musste der römisch-katholische Teil einen Schein unterschreiben, womit er erklärte, er gehöre nicht mehr der katholischen Kirche an, um sich evangelisch trauen zu lassen. Strenge Katholiken gaben solche Scheine ungern oder gar nicht aus. ${ }^{876}$

In Dona Francisca-Joinville (SC) war die Beziehung zwischen den Geistlichen beider Konfessionen von Anfang an positiv und der katholische Priester Börgershausen unterrichtete katholische wie evangelische Kinder. Ein Grund für

\footnotetext{
870 Brief an den Hohen und Würdigen Vertreter der Brasilianischen Nation im Namen des Vorstandes der Deutsch-Evangelischen Gemeinde zu Rio de Janeiro, 12.8.1858, EZA 5/2157.

871 Evangelische Synode von Santa Catarina und Paraná, S. 64.

872 Arbeitsgemeinschaft 25. Juli in Rio Grande do Sul, S. 81.

873 Brief des Ministeriums für Angelegenheiten der Landwirtschaft, des Handels und der Öffentlichen Arbeiten an den Provinzpräsidenten, 13.1.1873. Zitiert nach Rölke, Raízes da Imigração alemã, S. 528; vgl. Seibel, Imigrante no século do isolamento, S. 146

874 Von Tschudi, Reisen durch Süd-Amerika, 3. Band, S. 409.

875 Arquivo Público do Estado de Sta Catarina. Livro dos Cônsules. Zitiert nach der Anmerkung von Walter F. Piazza. In: Von Tschudi, Johann Jakob. As colônias de Santa Catarina. Blumenau: CNPq/Fundação Casa Dr. Blumenau, 1988, S. 72.

876 Erinnerungen eines deutschen Ansiedlers in Brasilien. In: Sonntagsblatt fïr die evangelischen Gemeinden in Brasilien. 12. Jahrgang 1899, Nr. 38, S. 150, AHI.
} 
diese gute konfessionelle Beziehung könnte sein, dass Dona Francisca-Joinville (SC) eine Privatkolonie war, deren Ländereien von der Kolonisationsgesellschaft ausschließlich an Einwanderer verkauft wurden, so dass hier zunächst fast keine einheimischen Brasilianer lebten. Die Kolonisationsgesellschaft sorgte für die Anstellung von Geistlichen beider Konfessionen, so dass es keinen Grund für Feindseligkeiten aufgrund einseitiger Begünstigungen gab.

Die religiöse Problematik beschränkte sich aber nicht auf Eheschließungen. Verstorbene aus protestantischen Gemeinden wurden nicht auf katholisch geweihten Friedhöfen aufgenommen. Ihnen wurden Gräber in Friedhofsecken ${ }^{877}$, zusammen mit Selbstmördern ${ }^{878}$ oder mit Menschen, die an einer ansteckenden Krankheit gestorben waren ${ }^{879}$, zugeteilt. Sie wurden auch entgegengesetzt zur Sonne begraben. ${ }^{800}$ In einigen Gebieten durfte auf ihren Gräbern kein Kreuz stehen, denn sie galten als „Heiden“ 881 und „Ketzer haben kein Anrecht auf einen Friedhof!" "882 Einige katholische Priester sollen den Segen von einem Teil des Friedhofes genommen haben, damit Protestanten dort ihre Angehörigen bestatten konnten. ${ }^{883}$ Eine Ausnahme bildete wieder die Kolonie Dona Francisca-Joinville (SC), wo die Direktion für die Anlegung eines Friedhofes sorgte, der von beiden Konfessionen genutzt wurde. ${ }^{884}$

In den Kolonien Santa Isabel (ES) und Santa Leopoldina (ES) bereiteten katholische Kapuziner den Protestanten viele Schwierigkeiten bei der Errichtung kirchlicher Gebäude und ließen sie ihre Produkte nicht auf dem Markt verkaufen. Die Feindseligkeiten führten letztendlich zu gegenseitigen Beschuldigungen, wie beispielsweise die Vergiftung an zwei protestantischen Geistlichen in Santa Isabel (ES). ${ }^{885}$ Der Innenminister Marquez de Olinda beauftragte den Provinzpräsidenten 1858, er solle erklären, dass in den Kolonien religiöse Toleranz auszuüben sei, denn die Regierung garantierte allen Einwohnern Religionsfreiheit und die freie Ausübung ihres Kultus. ${ }^{886}$ Angesichts der Bekehrungen von Protestanten unter

\footnotetext{
877 Dedekind, Brasilien, S. 47; Kahle, S. 56.

878 Zeitungsausschnitt eines Artikels über Brasilien im Gustav-Adolf-Blatt, EZA 200/1/2151.

879 Krause, Lutherische Synode in Brasilien, S. 96.

880 Weingärtner, Martin Luther e Santa Catarina, S. 52.

881 Zeitungsausschnitt eines Artikels über Brasilien im Gustav-Adolf-Blatt, EZA 200/1/2151.

${ }^{882}$ Evangelische Synode von Santa Catarina und Paraná, S. 102.

${ }^{883}$ Baade, Joel Haroldo. Da guerra à união. São Leopoldo: Escola Superior de Teologia, 2007, S. 21.

${ }^{884}$ Weil aber die Bevölkerungsanzahl der Evangelischen in Bezug zu den Katholiken dreimal höher war, erlangte der Gemeindevorstand in Abhandlung mit dem katholischen Priester die Abtretung eines Teils der katholischen Friedhofshälfte zugunsten der Evangelischen. Bühler, Fritz. Ein Beitrag zur Kirchenkunde Südamerikas. [1917/1918], S. 12, MLV 51/17 108; Wüstner, S. 16.

885 Pastor Julius König begann seine Tätigkeit am 1.1.1858 und wurde am 9.6.1858 tot aufgefunden. Sein Nachfolger Constantino Hell kam am 11.8.1859 an und starb am 11.12.1859. Schröder, Brasilien und Wittenberg, S. 328. Laut Von Tschudi war einer an Lungentuberkulose und der andere an typhösem Fieber gestorben. Von Tschudi, Reise durch Süd-Amerika. 3. Band, S. 12.

886 Von Tschudi, Reise nach Süd-Amerika. 3. Band, S. 13; Von Tschudi, Bericht über die Kolonien Santa Isabel, Santa Leopoldina und Rio Novo, S. 263.
} 
einer Abschwörungsformel sandte der Provinzpräsident dem katholischen Priester einen Brief folgendem Inhalts:
„Die kaiserliche Regierung habe nicht Colonisten nach Brasilien kommen lassen, um Seelen für den katholischen Glauben zu gewinnen, sondern denselben eine Existen₹ für die Zukunft zu gründen; er verbiete anmit [sic! damit] jede Conversion in der Colonie selbst. Wenn ein Colonist das Bedürfniss füble, seinen Glauben zu ändern, so möge er nach der Hauptstadt kommen und sich bei ibm melden, damit er (der Präsident) sich selbst überžengen könne, ob die Glaubensänderung aus eigenem Antriebe stattfinde, und dann könne der Uebertritt in einer Kirche von Victoria stattinden".887

In São Leopoldo (RS) sollten die Protestanten wiederum den Brief eines jesuitischen Priesters, der 1864 seine Gemeindemitglieder zur Rodung eines Platzes (wörtlich „Baumstämme fallen lassen ") für die Errichtung einer Kirche aufrief, falsch interpretiert haben. Sie meinten, der Priester wolle den Protestanten die „Köpfe schneiden". Diese sammelten sich verzweifelt in Gruppen, kauften Waffen, Schießpulver und Blei für ihre Verteidigung und Frauen und Kinder versteckten sich in den Wäldern. Die kaiserliche Regierung nahm Kenntnis über den Fall und forderte Erklärungen von dem Bischof in Porto Alegre (RS).888 1911 schrieb Pastor Schwab aus Santa Isabel (SC) über die Belästigungen seitens der Jesuiten und Kapuziner, welchen er und seine Gemeinde ausgesetzt waren. Einmal fühlte er sich während eines Gottesdienstes von einem katholischen Priester, der Schießübungen mit einem Karabiner durchführte, provoziert. Derselbe Priester besuchte einige katholische Mitglieder und segnete sie gegen die Protestanten. ${ }^{889}$ Pastor Reuther in Santa Isabel (ES) berichtet, dass er sich ständiger Todesgefahr befände, denn mehrere geschworene Feinde versuchten ihn zu vergiften und zwei von Jesuiten aufgehetzte Holländer hätten Geld bekommen, um ihn umzubringen. ${ }^{890}$ Möglicherweise handelte es sich um eine Reaktion der ansässigen Katholiken auf die Tatsache, dass ortsansässigen katholische Gemeindeglieder an protestantischen Gottesdiensten teilnahmen. ${ }^{891}$ Jesuiten sollten nach Angaben von evangelischen Siedlern den katholischen Frauen, die mit Protestanten verheiratet waren, empfohlen haben, ihre Männer zu vergiften. Ein Jesuit beschuldigte wiederum die Protestanten, auf ihn geschossen zu haben, nachdem er ein evangelisches krankes Mädchen besuchte und taufte. Er behauptete, dass dies wegen dieser und anderer Bekehrungen einiger Protestanten zum Katholizismus geschah. ${ }^{892}$

\footnotetext{
887 Von Tschudi, Reise nach Süd-Amerika. 3. Band, S. 13.

888 Rabuske, Arthur. Antigas paróquias dos jesuítas no Brasil meridional. São João do Montenegro, Santo Antonio de Estrela, Santa Teresinha de Campo Bom. In: Instituto Anchietano de Pesquisas. Pesquisas, São Leopoldo, Nr. 29, 1994/1996, S. 195-198; vgl. Lutterbeck, S. 56, 66.

889 Stoer, S. 13.

890 Brief von Reuther an Von Tschudi, Santa Leopoldina, 25.10.1864, BMA, FB, 1,1.

891 Brief von Pastor Reuther an Weitbrecht, Santa Leopoldina, 2.1.1865, BMA, FB, 1,1.

${ }^{892}$ Lutterbeck, S. $52 \mathrm{f}$.
} 
Die kaiserliche Regierung wollte jeder Art von Proselytismus und den damit verbundenen Feindseligkeiten ein Ende bereiten. Jedoch in der Praxis durften Protestanten katholische Kirchen meistens nicht betreten und Katholiken waren ebenso bei den Protestanten nicht willkommen. Söhne und Töchter durften in der Regel nicht jemand der anderen Religion heiraten und es kam immer wieder zu lokalen Streitigkeiten.

Zusammenfassend lässt sich feststellen, dass die Einwanderer und deren Nachkommen evangelischen Glaubens trotz der erlittenen Restriktionen nicht von ihrem Glauben abwichen. In manchen Fällen, besonders dort, wo sie eine Minderheit unter Katholiken darstellten und keine Aussicht auf die Formierung einer evangelischen Gemeinde hatten, ließen sie sich katholisch trauen und ihre Kinder katholisch taufen. Aber in ihren häuslichen Andachten und Lesegottesdiensten hielten sie an ihrem konfessionellen Glauben fest. Bald setzten sie sich mithilfe ihrer Geistlichen für die staatliche Anerkennung ihrer protestantischen Ehen ein. Damit behaupteten sie sich allmählich als Protestanten in Brasilien.

\section{Evangelisch-lutherische Religiosität im brasilianischen Urwald}

Angesichts des Mangels an medizinischer Versorgung und kirchlicher Dienste in den Siedlungsgebieten übernahm die Religiosität in Verbindung mit dem evangelisch-lutherischen Glauben eine entscheidende Rolle bei der Bewältigung von Krankheiten, als Schutzmaßnahme gegen alle Arten von Gefahren und bei der Organisation von Hausgemeinden ein. Mit den ihnen zur Verfügung stehenden Ressourcen und Fähigkeiten und ihren mitgebrachten Glaubensquellen sorgten die Einwanderer und später ihre Nachkommen für die Entwicklung eines einzigartigen Gesundheitssystems und eines selbstständigen Kirchenwesens, dass ihren Bedürfnissen entsprach. Sie wählten Personen aus ihrer Mitte, die aufgrund ihrer Fähigkeiten oder dem Erwerb bestimmter Kenntnisse die Funktionen eines Arztes, einer Hebamme oder eines Pastors übernehmen konnten. Dieses religiös geprägte System unterstützte sie wesentlich bei der Überwindung von Krankheiten, Verlusten, Trauer, Rückschlägen, Krisen, Entmutigung und Angst, aber auch im Umgang mit Problemen in den Kolonien und in ihrer Umgebung oder mit den Widrigkeiten, die daraus entstanden. 
3.1. Waldärzte, „Gesundbeter“ und Himmelsbriefe: die Religiosität der Pommern und ihre Bedeutung in Notsituationen

„das bißchen Religion ist noch das einzige, was vielen von ihnen bei all den Mühseligkeiten, die sie ausstehen müssen, den Mut erbält" $" 893$

Aufgrund der Isolierung in den Urwaldgebieten, den schlechten Straßenbedingungen und des Mangels an Ärzten verfügten die Siedler in der Regel über keine oder nur eine mangelhafte medizinische Versorgung. Ärzte waren in der Regel in gröBeren Städten ansässig und bis zu ca. 200 Kilometer von den Kolonien entfernt. Eine Ausnahme bildeten die Kolonien São Leopoldo (RS), wo ein Arzt und ein Apotheker mit dem zweiten Einwanderungsschiff angekommen waren ${ }^{894}$, und Dona Francisca-Joinville (SC), wo der Hamburger Kolonisationsverein für die Einstellung eines Arztes, einer Hebamme und eines Apothekers sorgte. ${ }^{895}$ In Blumenau (SC) sollte nach von Tschudi ein allopathischer Arzt und ein Homöopath vorhanden gewesen sein. ${ }^{896}$ In Santa Isabel (ES) zahlte die Regierung einen Arzt und in Santa Leopoldina (ES) soll auch ein Mediziner angestellt gewesen sein. ${ }^{897}$ Trotzdem suchten die Einwandererfamilien das Krankenhaus nur als allerletzte Möglichkeit auf, denn viele besaßen nicht die finanziellen Mittel, teure ärztliche Honorare von 300 bis 500, oder sogar 1.000 Milréis zu bezahlen. ${ }^{898}$ Aufgrund der großen Distanzen mussten sie ihre Kranken auf dem Rücken oder in provisorischen Krankentragen tagelang durch den Urwald zu den Ärzten tragen. ${ }^{899}$ Kahle berichtet über einen Fall in São Bento do Sul (SC), wo der Fuß der Frau eines Siedlers beim Fällen der Bäume durch einen schweren Ast zerschmettert wurde. Die Nachbarshilfe kam hierbei besonders zum Ausdruck, denn zwölf Nachbarn trugen die Frau 90 Kilometer durch den Wald bis nach Joinville (SC). Sie wechselten sich alle zwanzig Minuten ab und brachten drei Nächte im Freien $\mathrm{zu}$, bis sie am vierten Tage im Hospital ankamen. 900

Als Notfallmaßnahme verfügten Pfarrer ${ }^{901}$, Pfarrfrauen ${ }^{902}$, Lehrer ${ }^{903}$, Geschäftsleute oder die Siedler selbst ${ }^{904}$ über Hausmittel oder Medikamente, die sie

\footnotetext{
${ }^{893}$ Nach der Anekdote aus dem Siebenjährigen Krieg. Beckert, Hans Günther; Nail, Norbert. Der alte Gasthof zum Schützzenpfubl in Marburg. Marburg: Magistrat der Stadt Marburg, 2008, S. 138.

${ }^{894}$ Arbeitsgemeinschaft 25. Juli in Rio Grande do Sul, S. 44.

895 Weingärtner, Martin Luther e Santa Catarina, S. 121.

${ }^{896}$ Von Tschudi, Bericht über den Zustand der Kolonien der brasilianischen Provinzen Santa Catharina und San Pedro do Rio Grande do Sul, S. 231. An anderer Stelle erwähnt von Tschudi, dass der Tierarzt als Homöopath praktizierte. Von Tschudi, Reisen durch Süd-Amerika, 3. Band, S. 392.

897 Von Tschudi, Bericht des Herrn von Tschudi, außerordentlichen schweizerischen Gesandten in Brasilien über die Kolonien Santa Isabel, Santa Leopoldina und Rio Novo, S. 262, 268.

898 Reisebericht Braunschweigs über Nord- und Mittelbrasilien vom Jahre 1907, S. 37, EZA 5/2173; vgl. Bericht von Pastor Gustav Treptau von 4.12.1893. Zitiert nach Schmidt, Die Anfänge der Diakonie, S. 22.

${ }^{899}$ Roos; Eshuis, S. 62; Kahle, S. 25.

900 Kahle, S. 92.

901 Soboll, S. 54f, 58f; Stoer, S. 11.
} 
teilweise aus der Heimat mitgebracht hatten. Auch die sogenannten „Walddoktoren “ 905 oder Siedler ${ }^{906}$ stellten Haus- oder Waldheilmittel mit ihrer Kenntnis über Pflanzen ${ }^{907}$, Tees oder Bandagen her. Diese Kenntnis beruhte teils auch auf einem bis jetzt wenig untersuchten frühen Assimilationsprozess zwischen ihnen und indigenen Völkern ${ }^{908}$, Afrobrasilianern, „Mestiços ${ }^{609}$ und Lusobrasilianern. ${ }^{910}$ Andere hatten Erfahrung in homöopathischer Heilkunde oder besaßen homöopathische Bücher. ${ }^{911}$ Mütter gebaren zu Hause, wobei ältere Frauen ihre einzige Hilfe waren, deren Kenntnisse nur auf praktischer Erfahrung beruhte. ${ }^{912}$ Letztendlich fungierten auch ungelernte Menschen als Apotheker und Ärzte. Sie hatten kein Examen absolviert und verfügten nur über eine Zulassung, die sie teilweise durch ihre politischen Kontakte erlangt hatten. ${ }^{913}$ Aber auch Geistliche, die teilweise einen Samariterkurs in der Heimat besucht hatten ${ }^{914}$, dienten als Ärzte ${ }^{915}$, Zahn-

902 Evangelische Synode von Santa Catarina und Paraná, S. 80; Liesenberg, Edgar. Chronik des Evangelischen Pfarrbezirkes Rio do Testo - Pomerode. Pomerode, 1983, S. 13; Brief von Pastor Reuther an Weitbrecht, Santa Leopoldina, 2.1.1865, BMA, FB, 1,1; Krause, Lutherische Synode in Brasilien, S. 195, 197.

903 Chronik von Julius Scheidemantel. Zitiert nach Weingärtner, História da Comunidade Evangélica de Timbó, S. 48, auch S. 51.

904 Altmann, S. 60.

905 Manche Walddoktoren führten auch chirurgische Eingriffe durch. Grosselli, S. 399.

906 Ramlow; Resende, S. 12.

907 Vgl. mit dem Kräutersegen. In: Magisch-sympathetischer Hausschatz oder Die offenbarten Geheimnisse der natürlichen Magie nebst Zauberformeln, Heil-Sprüchen und Schutzsegen wider allerlei Anfechtungen. In: 6./ 7. Buch Moses. Einleitung und Bildkommentare von Wolfgang Bauer. Berlin: Karin Kramer, 1979, S. 187.

908 Schulze, S. 274.

909 „Mestiço" (wörtlich übersetzt Miscbling) ist ein Begriff, der die Individuen, die durch die Mischung der verschiedenen Rassen oder Völkern entstanden sind, bezeichnet. Er umfasst somit die Mischung zwischen Schwarzen und Weißen (Mulatos), zwischen indigenen Völkern und Weißen (caboclos) und zwischen Schwarzen und indigenen Völkern (cafuгo).

910 Costa, Jairo Scholl. O Pescador de Arenques. Pelotas: EDUCAT, 2007, S. 307. Der Begriff Lusobrasilianer beschreibt das Individuum, dass von einem Portugiesen oder einer Portugiesin und von einem Brasilianer oder einer Brasilianerin geboren wurde. Er umfasst auch Individuen portugiesischer Abstammung, die aber in Brasilien geboren wurden.

911 Grimm, H. Deutsche Tätigkeit und Not in Espírito Santo. In: Traeger, P. (Hrg). Süd- u. MittelAmerika, Berlin, Nr. 18, 30.9.1913, S. 278, EZA 5/2563; Altmann, S. 61.

912 In Pomerode (SC) blieb die Hebamme Rosa Borck besonders in Erinnerung. Durch ihre Hände kam ein großer Teil der älteren Bewohner dieses Ortes zur Welt. Altmann, S. 59f. Luise Wilhermine Eggert war wiederum Hebamme in Joinville (SC) und Jaraguá do Sul (SC). Aussage von Hedwig de Souza, Gustav und Luise Wilhermine Eggers Tochter im Jahre 1982. In: Boehs, Astrid. Uma Familia, tempos, movimentos e espaços. Verfügbar in: http://astrideboehs.blogspot.de/2008/11/uma-familiatempos-movimentos-e-espaos.html Zugang am 29.3.2016. Laut Weingärtner wurden sie als „HeckenHebamme" benannt. Weingärtner, Martin Luther e Santa Catarina, S. 101.

913 Wernicke, S. 46. Bis Anfang des 20. Jahrhunderts wurden in Brasilien keine medizinischen Studien von freien Ärzten gefordert. Sie zahlten einen Beitrag von etwa 316 Milréis für eine Zulassung und behandelten Menschen in abgeschiedenen Gebieten. Grosselli, S. 402; vgl. Grube, S. 74.

914 Braunschweig schlägt in seinem Bericht vor, dass Pastoren vor der Aussendung nach Brasilien einen sechs bis acht wöchentlichen Samariterkurs und Pfarrfrauen ebenso einen Hebammenkurs 
ärzte, sogar als Chirurgen. ${ }^{916}$ Zusammenfassend berichtet Pastor Treptau aus California (ES), dass die ärztliche Versorgung unterschiedlicher nicht sein konnte, teilweise homöopathische und allopathische, teilweise unter Anwendung von Heilkunde. ${ }^{917}$

Angesichts dieser Notsituation verließen sich viele Pommern auf die Dienste der „Gesundbeter", „W underheiler" oder „Heilkundigen “918 Sie brachten in Verbindung mit ihrem evangelisch-lutherischen Glauben Heilpraktiken magischen Inhaltes mit

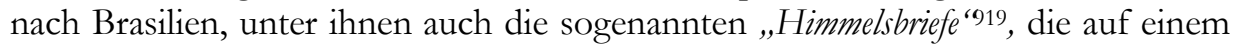
Blatt abgeschrieben als eine Art Amulett oder Schutzmittel gegen alle Art von Gefahren an Leib und Gut, besonders aber gegen Krankheiten, am Körper getragen oder an Türschwellen und Dachböden in Häuser und Schuppen gestellt wurden. Einige von ihnen verfügten über das 6. und 7. Buch Mosis ${ }^{920}$, das sie für Besprechungen und Behandlung verschiedener Krankheiten und Plagen bei Menschen, Tieren und Höfen verwendeten. ${ }^{921}$ Es handelt sich hierbei nicht um ein

besuchen sollten. Auszug aus dem Reisebericht des Pastors Braunschweig, S. 7, EZA 5/2569. Die Gemeinde Santa Maria de Jetibá (ES) bat um die Entsendung eines Geistlichen, der in Krankheitsfällen behilflich sein konnte und einen Samariterkurs besucht hatte. Brief von 3.10.1903 im Archiv der Parochie Santa Maria de Jetibá. Zitiert nach Gaede, S. 117.

915 Aus überseeischen Briefe. In: Der Deutsche Ansiedler, 1884, BMA, PABV 545; Reisebericht von Pastor Braunschweig über Nord- und Mittelbrasilien vom Jahre 1907, S. 37, EZA 5/2173; Schreiben des Pfarrers Christian Zluhan in Sancta Izabel vom 29.11.1878. In: Blätter des Gustav-Adolf-Vereins für das Evangelische Württemberg, Nr. 1, 7. Jahrgang, 1879, S. 6, EZA 200/1/2151; Fluck, S. 362 f.

916 Auszug aus dem Brüderverzeichnis der Basler Mission, BMA, PABV 708; Langholf, Johan. Dienst an den zerstreuten in Brasilien (und Deutschland-riskiert), S. 15, MEW 4.118. Ohne Jahresangabe.

917 Bericht von Pastor Gustav Treptau von 4.12.1893. Zitiert nach Schmidt, Die Anfänge der Diakonie, S. 29.

918 Weingärtner, Mundo da superstição, S. 9. Es waren Menschen, denen eine mystische Fähigkeit nachgesagt wurde, Krankheiten durch das Aufsagen von Besprechungsformeln heilen oder lindern zu können.

919 Siehe Kapitel IX - Exkurs am Ende dieser Arbeit mit Exemplaren, die unter pommerschen Nachkommen in Brasilien gefunden wurden.

${ }_{920}$ Das sechste und siebente Buch Mosis. Sein wahrer Wert und was das Volk darin sucht. Magischsympathetischer Hausschatz. Nach alten Ueberlieferungen aus Geheimschriften und Zauberbüchern für die heutige Zeit erklärt. Dresden: Gutenberg. In: 6./ 7. Buch Moses. Sein wahrer Wert und was das Volk darin sucht. Einleitung und Bildkommentare von Bauer, Wolfgang. Berlin: Karin Kramer, 1979. S. XVII-LXIV. Pommersche Nachkommen in Timbó (SC) besaßen die Ausgabe Philadelphia: Das sechste und siebente Buch Mosis oder der magisch-sympatbische Hausschatz, das ist Mosis magische Geisterkunst, das Geheimniß aller Geheimnisse. Wortgetreu nach einer alten Handschrift mit merkwürdigen Abbildungen. Philadelphia. Privatarchiv von Pastor Nelso Weingärtner; vgl. Sechstes u. siebentes Buch Mosis oder der magisch-sympathetische Hausschatz, das ist Mosis magische Geisterkunst, das Geheimniß aller Geheimnisse. Wortgetreu nach einer alten Handschrift mit staunenerregenden Abbildungen. [Nachdruck der Ausgabe] Philadelphia. Leipzig: Hülsemann, [1980]. Philadelphia wird neben einem anderen Druckort erwähnt und kommt sonst als fiktiver Druckort vor. Jacoby, Mosis, das sechste und siebente Buch. In: Hoffman-Krayer, E.; Bächtold-Stäubli, Hanns (Hrsg.) Handwörterbuch des Deutschen Aberglaubens. Band VI Berlin/Leipzig: Walter de Gruyter, 1934/1935, S. 589f.

${ }_{21}$ Magisch-sympathetischer Hausschatz, S. 31-226; Die Praktika des täglichen Lebens. In: 6./7. Buch Moses. Einleitung und Bildkommentare von Wolfgang Bauer. Berlin: Karin Kramer, 1979, S. $227-$ 
Werk Moses ${ }^{922}$, sondern wurde ihm lediglich nach dem Brauch der Verfasser uralter Zauberbücher zugeschrieben, um ihnen damit eine höhere Weihe und Autorität zu verleihen. ${ }^{923}$ Die ursprüngliche Herkunft einer ersten Handschrift des 6. und 7. Buch Mosis ist nicht erhalten geblieben und das Buch verfügt auch über keine einheitliche Texttradition. ${ }^{924}$ Nach Jacoby erschien 1797 zum ersten Mal eine Version in Deutschland. Weitere Ausgaben Scheibles von 1849, 1851 und 1853 enthalten dazu Charaktere, magische Texte verschiedener Art mit Gebeten, Andachten und Szenen aus dem Geisterreich. ${ }^{925}$ Die bekannteste Version des 6. und 7. Buch Mosis ${ }^{26}$ ist aber eine Sammlung von disparaten Schriften ${ }^{927}$, die zum Teil nichts oder wenig mit Magie und Zauberei zu tun haben. Sie entstand in der Mitte des 19. Jahrhunderts und enthält vor allem Schutzgebete, alte Zaubervorschriften, Beschwörungen, Heil- und Wundermittel und Ähnliches. Der Inhalt variiert von Ausgabe zu Ausgabe ${ }^{928}$ und wird in der volkskundlichen Literatur zur Teufelsbeschwörung, zum „Festmachen“ oder zur Schatzsuche verwendet. Einzelnes weist auf eine uralte Herkunft hin, aber sonst stammt der Inhalt hauptsächlich aus dem

350; Das siebenmal versiegelte Buch der größten Geheimnisse oder magisch-sympathetischer Hausschatz in bewährter Mittel wider viele Krankheiten und Gebrechen des Leibes; nebst wundersamen Geheimnissen zu Erreichung der verschiedenartigsten Zwecke. Leipzig: Hülsemann, [um 1880]; Neunzig Geheimnisse, die ein frommer Einsiedler von seinem Schutzengel bekommen hat, mit Bewilligung einer hohen Geistlichkeit auf's Neue zum Druck befördert für landwirtschaftliche und häusliche Verhältnisse. Gedruckt zu Cöln am Rhein, [um 1880].

922 Neben dem Pentateuch werden Moses verschiedene Pseudepigraphen zugeschrieben, weil er nach allgemeinen Glauben geheime Kenntnis und Zaubermacht besaß (2. Mo. 7,8ff; vgl. 4,2ff). Er galt als ägyptischer Priester und Stifter magischer Schulen und soll die Macht gehabt haben, durch Aussprechen des unbekannten Gottesnamens Menschen töten oder stumm machen zu können. So war er auch in hellenistischen Zauberpapyri bekannt. In der mystischen Literatur galt er als Alchemist aufgrund der Erfindung trinkbaren Goldes (2. Mo. 32,20). Zauberrezepte und magische Schriften aus dem Mittelalter in hebräischer Sprache stehen unter dem Titel „Schwert des Moses“. Es ist zu entnehmen, dass Mose als Schriftsteller magischer Schriften der Alchemie und der Pseudokabbala angesehen wurde und aus dieser Fiktion entstand das 6. und 7. Buch Mosis. Jacoby, Mosis, das sechste und siebente Buch, S. 584f, 587.

923 Bauer, Wolfgang. Vom sechsten und siebenten sowie vom achten und zehnten Buch Mosis. In: 6./7. Buch Moses. Berlin: Karin Kramer, 1979, S. XI.

${ }^{924}$ Jacoby, Mosis, das sechste und siebente Buch, S. 585-591; Bauer, Vom sechsten und siebenten, S. X-XIV.

${ }_{925}$ Bauer, Wolfgang. Einleitung. In: 6./ 7. Buch Moses. Berlin: Karin Kramer, 1979, S. $6 f$.

926 Sechstes u. siebentes Buch Mosis. [Nachdruck der Ausgabe] Philadelphia.

927 Unter ihnen: „Das siebenmal versiegelte Buch"; „Geheime Kunst-Schule magischer Wunder-Kräfte"; „Romanus-Büchlein“", „Engel-Hülfe zu Schutz und Schirm in großen Nöthen“; „Das heilige Sales-Bücblein oder die Glücks-Ruthe" und „Magisch-sympathetischer Hausschatz".

${ }^{928}$ Vgl. Sechstes u. siebentes Buch Mosis. [Nachdruck der Ausgabe] Philadelphia; 6./ 7. Buch Moses. Einleitung und Bildkommentare von Bauer; Das sechste und siebente Buch Moses. Das ist Moses magische Geisterkunst, das Geheimnisse aller Geheimnisse. Wortgetreu nach einer alten Handschrift, mit alten Holzschnitten. Braunschweig: Planet, 1950. 
späten Mittelalter und wurde von der kabbalistischen Lehre geprägt. ${ }^{929}$ Exemplare dieser Versionen wurden aus Pommern nach Brasilien gebracht.

Für die Volkskultur gehört das 6. und 7. Buch Mosis zur sogenannten ,magischen Hausväterliteratur ${ }^{\text {(*30 }}$, die von Generation zu Generation mündlich überliefert wurde. Es mischt profane Bräuche mit kirchlichen Zeremonien, so dass die Behauptung, die Verfasser seien unter dem Volk zu suchen, nicht nachweisbar ist. Seit dem 12. Jahrhundert wurden aber Geistliche aller Stände, sogar Päpste, als Autoren der sogenannten ,schwaržen Bücher" verdächtigt und Ordenskapitel schrieben immer wieder interne Verordnungen gegen den Gebrauch magischer Schriften, ein Beweis für ihre Verbreitung unter ihnen. Außerdem besaßen die Autoren des 6. und 7. Buch Mosis große Kenntnis über Vulgata, Liturgie, Zeremonien und Rituale und Geistliche hatten im Unterschied zum Volk Jahrhunderte früher Zugang zu Bildung und Schreibkunst, so dass es höchstwahrscheinlich sie waren, die für die Anfertigung solcher Bücher verantwortlich waren. ${ }^{931}$ Laut Bauer arbeiteten Mönche die alten Segenstexte um und führten sie in den Klöster ein. Im Mittelalter praktizierten sie trotz des kirchlichen Verbotes das Krankheitsbesprechen zusammen mit Rittern, Soldaten und Mitgliedern aller Stände. ${ }^{932}$

Schon früh wandte sich aber die Geistlichkeit gegen die Anwendung von Segen, Besprechungsformeln und Himmelsbriefen und verdammte diese Formeln als Teufelswerk, obwohl sie selbst für die Entwicklung des Volksglaubens an die Wirksamkeit von Beschwörungen zu religiösen Zwecken durch ihre kirchlichen Segnungen verantwortlich war. Außerdem waren die Heiligen, die in diesem, nun in abwertender Weise benannten, ,abergläubischen Segen “ angerufen wurden, dieselben wie die angebeteten Nothelfer der Kirche. Die Priester bewerteten die von ihnen vollzogenen Segen als gut und heilsam und entwerteten beziehungsweise verurteilten diejenigen der Laien. Sie erlaubten Gebete über Kranken zu sprechen, verbaten aber solche als Amulett bei sich zu tragen, wie auch die Anwendung der Beschwörungen in Himmelsbriefen, die Anrufung unverständlicher Namen und sinnloser Buchstaben. Jedoch gestaltete sich die Linie zwischen Sakralem und Profanen im Laufe der Geschichte mehrmals als recht dünn, denn die Kirche selbst besaß schon früh die Tendenz, vorchristliche und heidnische Zauberformeln mit christlichen Motiven zu verbinden. ${ }^{933}$ Viele Elemente der kirchlichen

\footnotetext{
${ }^{929}$ Jacoby, Mosis, das sechste und siebente Buch, S. 589, 591; Bauer, Vom sechsten und siebenten, S. XII-XIII.

${ }_{930}$ Peukert, Will-Erich. Verborgenes Niedersachsen. Untersuchungen zur Niederländischen Volkssage und zum Volksbuch. Göttingen, 1930, S. 123. Zitiert nach Bauer, Einleitung, S. 6.

931 Bauer, Einleitung, S. 12, 22f.

932 Magisch-sympathetischer Hausschatz, S. 166f.

933 Das geschah zum Beispiel bei der Bekehrung germanischer Völker. Heidnische Bräuche bekamen eine christliche Umdeutung, heidnische Götter wandelten sich zu christlichen Heiligen um, verehrte Kultstätten wurden zu Wallfahrtsorten gemacht und heidnische Beschwörung von Heilmitteln, Pflanzen, Steinen, Nahrungsmitteln, Krankheiten wurden in kirchliche Segnungen umgeformt. Magisch-sympathetischer Hausschatz, S. 173. Auch innerhalb christlicher Konfessionen ist das
} 
Beschwörungsformeln und Segnungen gingen im Mittelalter in die volkstümlichen Beschwörungen über und Anrufungen aus geduldeten Kirchengebeten wurden in Zaubersegen umgeformt. Sie wurden von Geistlichen im Rahmen der Kirche angewendet, verbreiteten sich auch teils mündlich, teils durch Abschriften unter dem Volk. ${ }^{934}$ So unterscheidet sich im Grunde der volkstümliche Glaube an Besprechungsformeln, Heiligungsmitteln und Himmelsbriefe nicht viel von kirchlichen Handlungen.

Die schriftliche Überlieferung von Besprechungsformeln, die teilweise in den verschiedenen Schriften im 6. und 7. Buch Mosis zu finden sind, hielt sich bis ins 17. Jahrhundert, die mündliche Überlieferung teilweise bis heute, beispielsweise unter pommerschen Nachkommen in Brasilien. Handschriftliche Kopien, teilweise mit orthographischen Fehlern, wurden wort- und bildgetreu übernommen und wiedergegeben, wodurch die mündliche Tradition sich oft zu einem fast unverständlichen Hokuspokus entwickelte. ${ }^{935}$ Die Menschen glaubten, mithilfe eines solchen Buches magische Handlungen durch Anwendung der im Buch vorhandenen Praktiken realisieren zu können oder einfach durch seinen Besitz eine Macht mit übernatürlicher Wirkung zu empfangen. Diese Vorstellung wurde umso mehr durch die Tatsache verstärkt, dass das Buch einen Geheimnischarakter besaß und nur wenigen Auserwählten zugänglich war, so dass sein Besitz eine Art Auszeichnung bedeutete und der Besitzer den Ruf als Zauberkundiger genoss. So entwickelte es sich zu einem Heiligtum und Amulett und der Besitz eines solchen Schatzes bedeutete an sich etwas Wunderwirkendes und Zauberkräftiges, auch wenn die Menschen es nicht näher studierten oder in allen Einzelheiten verstanden. ${ }^{936}$

Trotz der Hinwendung zum Christentum pflegten die Pommern ihre ursprünglich heidnischen Traditionen, nach denen sich die Götter durch Naturphänomene (Ernten, Regen, Sonne) und Krankheiten offenbarten. Engel, Geister und Dämonen wohnten ihrer Ansicht nach in Naturelementen, kontrollierten Welter-

Gebet vor einer Heiligenstatue oder einem Gottheitsabbild nicht weit von einem Bildbesprechen entfernt. Menschen glauben fest daran, dass ihre Bitten zu Gott dringen und ihn beeinflussen können und dadurch geistige Handlungen hervorrufen, die ihre persönlichen und sehr irdischen Wünsche erfüllen werden. Kirchenoberste fordern auch ihre Mitglieder auf, nicht an der Wirkungskraft des Anbetens vor dem Kruzifix oder vor einer Heiligenstatue zu zweifeln. Bauer, Wolfgang. Was hat man von dem Volksglauben und der Volksmedizin zu halten? In: 6./7. Buch Moses. Berlin: Karin Kramer, 1979, S. 21.

934 Magisch-sympathetischer Hausschatz, S. 173f.

935 Magisch-sympathetischer Hausschatz, S. 167. In Besprechungsformeln finden sich nicht selten Buchstaben, Silben, Lautkomplexe und teilweise sinnlose Wörter. Es handelt sich um Überreste uralten Buchstaben- und Wortzaubers mit magischer Wirkung, wessen ursprüngliche Bedeutung verloren ging. Diese Buchstabenmystik besaß nach Stübe einen mystischen Ursprung in der Midraschliteratur, entwickelte sich vor allem in der jüdischen Kabbala und von dort gelangte sie in die mittelalterlichen Zauberbücher. Was sie bedeuteten und ob sie überhaupt etwas bedeuteten ist nicht mehr festzustellen. Magisch-sympathetischer Hausschatz, Fußnoten S. 68, 85; Stübe, R. Der Himmelsbrief. Tübingen: Mohr (Paul Siebeck), 1918, S. 44f.

936 Bauer, Vom sechsten und siebenten, S. XIV-XV; Jacoby, Mosis, das sechste und siebente Buch, S. 588 . 
eignisse und konnten Menschen, Tiere und Pflanzen in magischer und mysteriöser Art erreichen und ihnen Krankheiten und Böses zufügen, die mit Hilfe von Ritualen, Zeremonien, Opfern, magischen Formeln, Segensbriefen oder Besprechungen zu beseitigen, zu beherrschen oder zu vertreiben versucht wurden. ${ }^{937}$ Danach fühlten sie sich gesund, befreit und geheilt als hätten sie sich einer ärztlichen Behandlung unterzogen. Für sie war nicht der Weg, sondern die Wirkung das Entscheidende ${ }^{938}$ und eine erfolgreiche Heilung stärkte die Glaubwürdigkeit der „,Gesundbeter" und deren Macht. Auch manche psychotherapeutischen Studien gehen davon aus, dass bei bestimmten seelischen Krankheiten eine rein medizinische Behandlung allein nicht bis in die seelischen Tiefe des Patienten dringen können, weswegen in solchen Fällen eine Sympathie-Behandlung als eine Art volkstümliche Psychotherapie funktionieren kann. ${ }^{939}$ Der Glaube an die Besprechungen und Zaubermittel machte diese erst wirksam: „Das Mittel muß helfen!" 40 , oder "Was einmal geholfen hat, hilft immer wieder".941 Und weil sie daran glaubten, half es ihnen auch. Es handelte sich um die „Macht der seelischen Vorstellungskraft ${ }^{` 942}$, oder „Kraft der Suggestion und Autosuggestion".943 Der Glaube schrieb diesen Mitteln von vornherein eine gewisse Heilkraft zu und die Menschen bildeten hieraus ihre eigenen Glaubensformen. Obwohl manchen mit dieser Methode nicht geholfen werden konnten, wurde der Glaube an die magische Wirkung derselben nicht in Frage gestellt. 944

In der Heilung sahen die Siedler aber die Wirkung Gottes selbst, was besonders in Notsituationen eine wichtige Rolle spielte, weil Besprechungen und Himmelsbriefe ihnen Glauben, Kraft und Kampfeswille verlieh. ${ }^{945}$ In Verbindung mit der christlichen Tradition geschahen diese Praktiken in Form eines Gebets ${ }^{946}$, so dass der „Gesundbeter" die magischen Formeln in Gebetsform und mit biblischen

\footnotetext{
937 Magisch-sympathetischer Hausschatz, S. 166; Borchers, Walter; Kaiser, Karl. Leben und Sterben im pommerschen Volksbrauch. Stettin: Landesbauernschaftsverlag Pommern, 1936, S. 24-26; Weingärtner, Mundo da Superstição, S. 9; Bauer, Was hat man von dem Volksglauben und der Volksmedizin zu halten, S. 23.

${ }_{938}$ Magisch-sympathetischer Hausschatz, S. 170; vgl. Bahia, Joana. O tiro da bruxa. Rio de Janeiro: Garamond, 2011, S. 332f.

${ }^{939}$ Bauer, Was hat man von dem Volksglauben und der Volksmedizin zu halten, S. 23.

${ }_{940}$ Magisch-sympathetischer Hausschatz, S. 72. Hervorhebung nach dem Autor.

${ }^{941}$ Stübe, R. Der Himmelsbrief, S. 4.

942 Magisch-sympathetischer Hausschatz, S. 72.

943 Die Praktika des täglichen Lebens, S. 306.

944 Die Wirkung magischer Mittel umfasst nach Lévi-Strauss zunächst den Glauben des „Gesundbeters" an seine eigene Macht oder Gabe und an seine Methoden, zweitens den Glauben des Kranken an die Macht dieser Person und drittens das Vertrauen und die Anforderungen einer kollektiven Meinung. Lévi-Strauss, C. O feiticeiro e sua magia e a eficácia simbólica. In: Antropologia estrutural. Rio e Janeiro: Tempo Brasileiro, 185, S. 194f. Zitiert nach Bahia, S. 368.

945 Beckert, Nail, S. 131, 138.

946 Rölke, Descobrindo Raizes, S. 54.
} 
Anrufungen ${ }^{947}$ leise aussprach. ${ }^{948}$ Er konnte außerdem Menschen oder Tieren eine häusliche Medizin, Pflanzenheilmittel und sogar Schlangenserum ${ }^{949}$ verabreichen, sie mit einer magischen Formel in Verbindung mit einem Segen oder mit der Trinitätsformel versehen und sie anschließend bekreuzigen. Auf diese Weise wurde der christliche Charakter ihres Handels und das Wirken Gottes hervorgehoben. ${ }^{950}$ Viele Pommern bewahrten Besprechungsformeln und Himmelsbriefe sogar in ihren Bibeln auf ${ }^{951}$, andere kopierten sie in kleinen Heftchen, die sie „Flusterbauck" oder „Flusterbook“"952 nannten. Für den Besprechungsakt wurden Elemente und Objekte verwendet, die im Haus oder Hof leicht verfügbar und Teil ihrer Umwelt waren. ${ }^{953}$ Auf diese Weise umfasste ihr Glaube, in seiner Symbiose von kirchlichen und magischen Inhalten, den Alltag der Menschen.

In manchen Gebieten übten nur bestimmte eingeweihte Männer und Frauen die Besprechung aus, die ihrerseits die Formeln und die Besprechungskunst mit Eifer bewahrten. ${ }^{954}$ Sie mussten bestimmte moralische Kompetenzen aufweisen ${ }^{955}$ und verlangten kein Entgelt für ihren Dienst, empfingen aber, was die Menschen ihnen unaufgefordert und freiwillig anboten.956 Nicht alle „Gesundbeter" besaßen dieselben Fähigkeiten. Einige besprachen einfachere Krankheiten, andere verbanden diese Kenntnisse mit ihrer Erfahrung als Hebamme oder mit dem Wissen über Hausmittel. Für schwere Krankheiten wurden vor allem „Gesundbeter“ außer-

947 Bahia, S. 273. Das pommersche Wort beera bezeichnet die Wörter des „Gesundbeters“ während einer Besprechung, die des Geistlichen während seiner Predigt, die des Hochzeitsbitters, der Frauen beim Polterabend sowie Gebetsworte in verschiedenen Lebenssituationen, wie bei Taufe, Krankheit und Tod. Bahia, S. 225. In diesem Sinne waren die Besprechungsformeln aus etymologischer Sicht auch Gebete.

${ }^{948}$ Nach Rölke, damit der Teufel die Gottesanrufung und dadurch den Heilungsprozess nicht stören konnte. Rölke, Helmar Reinhard. Descobrindo Raízes. Vitória: UFES, 1996, S. 51; vgl. Seibel, Imigrante no século do isolamento, S. 343f, 350. Die ursprünglichen magischen Worte, die teilweise sinnlos sind, wurden nicht gern ausgesprochen oder geschrieben, denn das Mystische, Geheime und Übermächtige war lieber mit Zeichen oder Buchstaben angedeutet. Wenn es bei dieser Andeutung blieb, wurde ihnen Wirksamkeit zugesprochen. Magisch-sympathetischer Hausschatz, Fußnoten S. 85.

949 Roos; Eshuis, S. 63; Seibel, Imigrante no século do isolamento, S. 348, 351-355.

950 Rölke, Raízes da Imigraşão alemã, S. 591; Weingärtner, Mundo da superstição, S. 82.

951 Bahia, S. 272.

952 Rölke, Descobrindo Raízes, S. 52.

953 Bahia, S. 274.

${ }^{954}$ Die magische Wirkung der Besprechungsformeln lag in den Worten, die in einem bestimmten Kontext und in einer bestimmten mythischen Sprache ausgesprochen wurden. In diesem Heilungssystem besaß der „Gesundbeter" die Kommunikationsfunktion, indem er den Übergang zwischen einem kranken Zustand zur Heilung herstellte, während die kranke Person, die an die Macht des „Gesundbeters “über die Krankheit oder über vermutete Geister, die die Krankheit verursachten glaubte, sich heilen ließ. Bahia, S. 280-282.

955 Beispielsweise nicht viel Alkohol trinken, Ausschweifungen vermeiden, ein ordentliches Leben führen und gläubig sein. Bahia, S. 271.

956 Magisch-sympathetischer Hausschatz, S. 166-169; vgl. Maltzahn, Gislaine Maria. Família, ritual e ciclos de vida. Pelotas: Universidade Federal de Pelotas, 2011, S. 85. Siehe auch Interviews mit pommerschen Nachkommen über Besprechungen in Seibel, Imigrante no século do isolamento, S. 343-355. 
halb der Gemeinde gesucht, besonders Brasilianer.957 Laut Willems übernahmen die Einwanderer und deren Nachkommen manche Besprechungsformeln von „Mestiços", weil sie diese für ihre magische Überlegenheit schätzten.958 Aber anders als normalerweise vermutet, gibt es keinen Zusammenhang zwischen Bildungsgrad und der Verwendung von Himmelsbriefen und Besprechungsformel, denn auch in gelehrten Kreisen fanden magische Praktiken treue Anhänger. Besprechungen wurden in Notzeiten sowohl bei Gebildeten als auch Ungebildeten gebraucht und verbreiteten sich unter allen Ständen zu verschiedenen Zeiten und Orten. ${ }^{959}$ Die Einwanderer und ihre Nachkommen schwiegen über die Identität sowohl der "Gesundbeter" als auch derjenigen, die ihre Hilfe in Anspruch nahmen. Deswegen sind Informationen über Akademiker, die Himmelsbriefe besaßen oder "Gesundbeter" aufsuchten, nur mündlich überliefert worden. Einigen Berichten pommerscher Nachkommen in Espírito Santo zu Folge suchten aber auch Geistliche die Hilfe von „Gesundbetern “ für die Heilung von Krankheiten ihrer Kinder auf, denen durch ärztliche Behandlung nicht geholfen werden konnte. .60

Diese Praxis wurde aber von Geistlichen, unabhängig von ihrer akademischen oder seminaristischen Ausbildung, verdammt und als Aberglaube bekämpft. ${ }^{961}$ Trotzdem suchten Gemeindemitglieder diese im Geheimen auf, hauptsächlich wenn eine ärztliche Behandlung erfolglos blieb. Für sie galt eine Besprechung als Mittel gegen Krankheiten und Probleme, für welche die Medizin und Wissenschaft keine befriedigende oder heilende Lösung anbieten konnte. ${ }^{962}$ Sie vermieden darüber zu sprechen, verneinten oder schimpften auf diese Praktiken, obwohl sie sie im Notfall weiterhin heimlich verwendeten. ${ }^{963}$ Als Grund für das kirchliche Verbot der Besprechungen wurde vermutet, dass die Geistlichen eifersüchtig auf die „Gesundbeter" waren, weil auch Pastoren mit Kranken beteten und ihnen teilweise mit ihren medizinischen Kenntnissen halfen. ${ }^{964}$ Aus der Sicht der Siedler waren Geistliche und „Gesundbeter" gleichermaßen mit besonderen Gaben versehen und Bahia weist darauf hin, dass beide für die Entwicklung magischer Narrative verantwortlich waren. Beide evozieren heilige Worte in einer bestimmten heiligen Sprache (Deutsch) und besaßen Autorität über Geheimnisse eines sakralen Universums. ${ }^{965}$ In diesem Sinne stellten der Besitz oder die Verwendung von

957 Oberacker, Karl Heinrich. Brauchtum und Aberglaube bei Kolonisten Pommerscher Abstammung in Brasilien. In: Staden Jabrbuch 9/10, 1961/1962. Zitiert nach Bahia, S. 279; Seibel, Imigrante no século do isolamento, S. 348.

958 Willems, S. 359-361.

${ }^{959}$ Stübe, Der Himmelsbrief, S. 3.

${ }^{960}$ Interviews mit pommerschen Nachkommen. Zitiert nach Seibel, Imigrante no século do isolamento, S. $353 f$.

961 Brief von Pastor Georg Burger an den Missionsdirektor Dr. Fr. Eppelein, Neuendettelsau, 12.11.1942, MEW 4.166.

962 Rölke, Raízes da Imigração alemã, S. 590.

963 Seibel, Imigrante no século do isolamento, S. 339; Altmann, S. 64, $67 \mathrm{f}$.

964 Weingärtner, Mundo da superstição, S. 82.

965 Bahia, S. 282f. 
Himmelsbriefen, magischen und Besprechungsformeln und magischen Quellen auch eine Vollmacht über heilige Inhalte und Gegenstände vonseiten der Siedler dar. Auch „,bibelfeste Leute" und „Säulen der Gemeinde" vollzogen Besprechungen und beriefen sich darauf, dass nach biblischer Überlieferung auch die Apostel Krankheiten heilten.966

Laut Weingärtner verwendeten einige Pommern in Santa Catarina das Gebetsund Andachtsbuch von Johann Friedrich Stark ${ }^{967}$ für das Besprechen, weil es Gebete für kranke und sterbende Menschen enthält, die ihnen vorzusprechen seien, wie es im Titel angedeutet wird. Aus diesem Grund wurde es als „Starkes Buch “ in Anlehnung an „starke Gebete" bezeichnet.968 Aber auch in Gefahrensituationen, beispielsweise bei Gewitter, verwendeten die Siedler Gebete des Stark's Handbuches ${ }^{969}$ in Zusammenhang mit magischen Praktiken. ${ }^{970} \mathrm{Da}$ sich für sie die Inhalte der Gebete aus den kirchlichen Andachtsbüchern und die Besprechungsformeln sehr ähnelten, sahen sie keinen Widerspruch zwischen ihrem kirchlichen Glauben

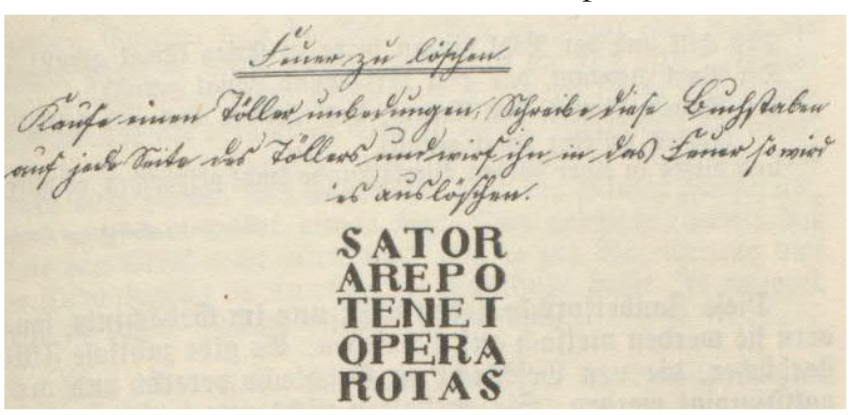

Abb. 5 Sator-Quadrat in einer handschriftlichen Besprechungsformel. Besprechungsbuch aus dem Kreise Kammin im Besitz von Fritz Schul, Stettin. Quelle: Borchers; Kaiser, S. 25. und dem Nachgehen von magischen Praktiken. Wie pommersche Nachkommen berichteten, wurde beides im Namen Gottes getätigt. Besprechungsformel waren für sie "Gebete“ oder ,biblische Zitate". ${ }^{971}$

Die sogenannte $S a$ tor-Arepo-Formel oder das Rotas-Sator-Quadrat (Abb. 5) tauchte bei Besprechungsformeln

oft auf. ${ }^{972}$ Nach Weingärtner war die Sator-Arepo-Formel bereits im 4. Jahrhundert bekannt und wurde angeblich in gnostischen Manuskripten und einem alten kopti-

\footnotetext{
966 Granzow, Pommeranos unter dem Kreuz des Südens, S. 27; Bahia, S. 271, 331; vgl. Seibel, Imigrante no século do isolamento, S. $345 \mathrm{f}$.

967 Stark, Johann Friedrich. Tägliches Handbuch in guten und bösen Tagen. Stuttgart: Steinkopf, 19 Jahrhundert.

968 Weingärtner, Mundo da superstição, S. $37 \mathrm{f}$.

${ }^{969}$ Der gläubige Christ betet bei entstandenem Ungewitter, Seufzer bei einem herannahenden Gewitter. Stark, Tägliches Handbuch, S. 128-133. Dankgebet, nachdem das Gewitter ohne Schaden vorbeigegangen. Ebd., S. 390f.

970 Weingärtner, Mundo da superstição, S. 51.

${ }^{971}$ Seibel, Imigrante no século do isolamento, S. 362.

972 Romanus-Bücblein. Leipzig: Hülsemann, [um 1880], S. 6, 13. Die Formel wurde unter anderem als Feuerlöschmittel in verschiedenen Religionen angewendet, als Amulett gegen Verzauberung und Verhexung und als Heilmittel gegen Tollwut und Epilepsie. Magisch-sympathetischer Hausschatz, S. 164f; Rölke, Descobrindo Raizes, S. 54f.
} 
schen Zauberpapyrus gefunden. Sie zirkulierte über Jahrhunderte in Afrika, Asien und Europa und ist in vielen Zauberbüchern weltweit nachweisbar. ${ }^{973}$ Obwohl sie seit Jahrhunderten zu magischen Zwecken und zur Heilung von Krankheiten benutzt wird, gibt es keine triftige Erklärung für die Bedeutung der ihr innewohnenden Worte. Mit Ausnahme des Wortes „Arepo“ stammen alle andere Wörter der Formel (Sator, Tenet, Opera, Rotas) aus dem Lateinischen. Zudem ist Arepo eine Umkehrung von Opera, wie das Verhältnis zwischen Sator und Rotas. Laut Moeller verfügen die fünf Wörter der Formel über verschiedene Bedeutungen, drei von ihnen gehören zum mithraischen Gedankengut. Die „mithraische Triade “der Mysteriengötter Saturno-Aion, Sol Invictus und Mitbra, kann, so Moeller, in ihr erkannt werden, und sie verfügt außerdem über verschiedene Anagramme, unter ihnen das Pater-Noster-Kren₹. Sie ermöglicht auch die Berechnung verschiedener Zahlen und enthält unterschiedliche Symbole, wie das Kreuz, das Dreieck, das Quadrat und den Kreis. Er sieht diese Formel als eine Verbindung zwischen dem magischen Quadrat und dem Mithraismus einerseits und zwischen der Johannesapokalypse andererseits an. Bei der Formation des Quadrats sollten nicht Worte, sondern Zahlen die Wortauswahl bestimmt haben. Letztendlich erkennt er in dem Quadrat ein Produkt des heidnischen Synkretismus im Römischen Reich an. ${ }^{974}$ Jedenfalls galt das Rotas-Sator-Quadrat als ein starkes Zaubermittel, weil es aus verschiedenen Richtungen gelesen werden konnte. Zauberformeln wirkten, wenn sie von vorn nach hinten gesprochen wurden und konnten umgekehrt aufgehoben werden, indem man sie rückwärts las. Auf diese Weise ermöglichten sie gleichzeitig die Durchführung und Aufhebung von Zaubern. ${ }^{975}$

Obwohl der akademische Religionsdiskurs oft lokale kultische Praktiken von einer seriösen theologischen oder intellektuellen Erwägung ausschließt und sie letztendlich in einer abwertenden Weise als Magie, Aberglaube, Heidentum, Folklore oder Abweichungen des richtigen Glaubens definieren, ergänzten sich für die Siedler beide Glaubenssysteme in ihrem Alltag. Nach Bahia gehörten Himmelsbriefe, Besprechungs- und magische Formeln zur Vorstellungswelt der Pommern und umfassten auch ihre Beziehung zu ihrer Umwelt durch die Reinterpretation religiöser und ethnischer Symbole. ${ }^{976}$ Menschen in großer Not suchen und streben nach einer Instanz, die sie für Glück und Leid verantwortlich machen können. Der christliche Glaube in Verbindung mit einer magischen Religiosität half den Pommern, ihre Angst vor Leid, Krieg, Katastrophen, Krisen, unerklärlichen Vorgängen, gesellschaftlichen Umbrüchen und persönlichen Notsituationen zu überwinden. Die Gestalt magischer Bräuche umfasste nach Stübe außerdem eine Ver-

\footnotetext{
973 Weingärtner, Mundo da superstição, S. 26f; Borchers; Kaiser, S. 24-26.

974 Moeller untersuchte die mithraische Herkunft und die unterschiedlichen Bedeutungen des RotasSator-Quadrats. Mehr dazu siehe Moeller, Walter O. The Mithraic origin and meanings of the Rotas-Sator square. Leiden: E. L. Brill, 1973, S. 1f.

975 Diese Vorstellung ist aus dem Altertum und den klassischen und deutschen Sagen bekannt. Magisch-sympathetischer Hausschatz, S. 165f.

${ }_{976}$ Bahia, S. 132.
} 
bindung mit der Idee des Seelenheils. Menschen lebten in der Regel abseits der großen religiösen und theologischen Diskussionen. Ihre Religiosität fand ihre mächtigen und dauerhaften Wurzeln eher in den Tiefen ihres menschlichen Daseins und war sehr konservativ angelegt, weswegen sie sich nicht von religiösen Veränderungen berühren ließ. Besonders in Notzeiten tauchte dieses Empfinden wieder auf, ${ }^{977}$ wie aus dem Beispiel pommerscher Einwanderer in Brasilien zu entnehmen ist.

Angesichts des Mangels an medizinischer Versorgung und kirchlicher Führung bekamen diese Handlungen große Bedeutung als Heilmittel und Glaubenselement in Notsituationen, wenn Menschen auf konkrete Hilfe angewiesen waren. Laut Schlegel sollten magische Praktiken dabei mitwirken, „da der christliche Glaube allein nicht zu genügen schien ".978 Im Falle einer Krankheit, die das Leben eines Angehörigen bedrohte, nahmen sie jede Hilfe in Anspruch. Dies, und wie die Siedler auch im Leiden ein sinnvolles Wirken Gottes sahen, wird im Folgenden von einem Pommern berichtet:

„[Es] fehlte uns nichts. Wir waren gesund und litten keine Not. Das Schwerste lag nach unserer Meinung hinter uns. Ich glaube heute, es ging uns zu gut, und wäre es so weiter gegangen, wären wir übermütig geworden. Unser Geld und Besitz war uns gewaltig in den Kopf gestiegen. (...) Um uns auf andere Gedanken zu bringen, hat Gott vielleicht die schwere Prüfung über uns kommen lassen. [Der Sohn bekam einen schlimmen Fuß und begann zu hinken]. (...) Als es sich mit unserm Kinde herumsprach, boten verschiedene ihre Hülfe an; der eine wußte dies, der andere jenes. Wir haben alles versucht: Wasserkur, Lebenswecker, Homöopathie, Hausmittel und was sonst noch geraten wurde. Aber nichts wollte anschlagen. Es kam noch eine Frau, welche den kranken Fuß ,besprach". Unserem Pastor durfte ich nichts davon sagen; er nannte das Besprechen sündlichen Aberglauben. Aber meine Frau wollte es; in der Not versuchte man alles. Das Leiden schritt weiter fort. Der Fuß begann abzusterben und ganz. langsam ging es nach oben. Schließlich riet man uns, wir möchten doch lieber mit einem Arz̨te sprechen (...) Beim zweiten Besuch sab er noch bedenklicher drein und erklärte schließlich: „Es hilft nichts anderes mehr, der Fuß muß abgenommen werden“. Zwei Nachbarn erboten sich, uns in dieser schweren Stunde beizustehen. Der Tag kam heran. Am Abend vorher hatten wir mit zitterndem Herzen gebetet, Gott möge die Hand des Arz̨tes lenken und alles zum Besten wenden. (...) Da, wie der Arzt mitten in der Arbeit ist, fängt das Kind an, sich zu bewegen. Es schlägt die Augen auf und erwach aus seiner Betäubung. Es schreit auf, daß es uns durch Mark und Bein geht. - Meine Frau weinte laut u. jammerte: „Ach, du lieber Gott im Himmel, erbarme dich! Mein Kind! Mein armes Kind!" Und auch ich kann meine Thränen nicht halten. (...) - Der Arzt macht ein verlegenes Gesicht. Dann sagte er kur:: „Betäuben dürfen wir das Kind nicht

\footnotetext{
977 Stübe, Der Himmelsbrief, S. 46f.

978 Schlegel, Birgit. Glaube und Magie gegen die Gefahren des Krieges in Schutzbriefen. In: Zeitschrift für Regionale Forschung und Heimatpflege - Südniedersachsen, 34. Jahrgang, 3/September 2006, S. 66.
} 
zum zweitenmale, es könnte darin stecken bleiben. Wir müssen obne dies weiter arbeiten. Haltet das Kind fest; ich werde bald fertig sein". Ich bezwinge mich - es mußja sein - und sage zu den Männern: „Haltet fest! Gott möge belfen“. (...) Thränen laufen mir die Backen herab und mischen sich mit dem Blute meines Kindes. Meine Frau sitzt in einer Ecke und betet und weint vor sich hin. Unser armes Kind windet sich in Qualen. (...) Das Glied ist abgenommen, aber die Blutung ist nicht zu stillen. (...) Der Aræt kann nichts weiter. (...) Der letzte Tropfen Blut scheint aus seinem Körper gewichen zu sein. Es hat das Bewußtsein verloren, aber man merkt noch etwas Leben. Da sagt jemand: „Wollen wir nicht den Engländer holen? Vielleicht kann der noch helfen". (...) Der Mensch giebt die Hoffnung nicht so bald auf. Darum sagte ich Ja. (...) Gegen zwölf Uhr ritt der Nachbar fort; wenn alles gut ging, konnte der Arzt gegen Abend bei uns sein. Es waren furchtbare Stunden, die wir gewartet haben. (...) [Der Arzt] untersuchte die Wunde und sagte: „Da ist wenig zu hoffen; es müßte denn Gott ein Wunder thun“. Er machte sich sogleich ans Werk. (...) Am folgenden Morgen erschien er beizeiten wieder und sah nach. „Euer Kind ist gerettet", sagte er. (...) Ich kann nicht sagen, wie uns dies Wort mit Freude und Dank gegen Gott erfülle. (...) [der Sohn] wurde wieder gesund und kräftig (...) und hat tüchtig arbeiten gelernt. (...) Mit seinem Stelzfuße ist er am Tage der Konfirmation von dem Altar getreten und eingesegnet worden. Wie dankbar schlug unser Herz! Und trotz seines hölzernen Beines hat er ein Mädchen gefunden, welches ibm eine gute, treue Ehefrau geworden ist. Nun hat er schon zwei Kinder (...). Der Tag, welcher uns so Furchtbares brachte, wurde für uns ein heiliger, ernster Gedenktag. Des Nachmittags rubt die Arbeit. Es kommen die Nachbarn, die uns zur Seite gestanden hatten. Wir sitzen zusammen und erzäblen von jener Zeit. Und jedesmal hole ich die Bibel hervor und lese den 118. Psalm und alle danken und beten mit" $" 979$

Wie an diesem Beispiel deutlich wurde, konnte das Besprechen den Menschen in schweren Fällen auch nicht helfen. Jedoch jede Heilung, sei es durch medizinische Versorgung, Besprechen oder Gebet in Zusammenhang mit häuslichen Mitteln, wurde als eine durch Gott gewirkte Heilung interpretiert, in welcher sie die Beihilfe und den Beistand Gottes sahen.

Hier sei zu betonen, dass „Gesundbeter" angesichts der widrigen Umstände in den Kolonien eine nicht zu unterschätzende seelsorgliche Funktion einnahmen. Inmitten der Verzweiflung und Not vieler Familien halfen sie mit ihren Kenntnissen, Ressourcen und standen ihnen bei, besuchten sie und beteten mit ihnen. Auch Himmelsbriefe waren eine wichtige Hilfsquelle bei der Bewältigung von Widrigkeiten, Ängsten und Gefahren, die durch Krankheiten, Naturereignisse, Plagen, Kriege, Revolutionen und Aufstände ${ }^{980}$, wie auch durch vermeintlich unsichtbare

\footnotetext{
${ }^{979}$ Erinnerungen eines deutschen Ansiedlers in Brasilien. In: Sonntagsblatt für die evangelischen Gemeinden in Brasilien. Nr. 37, 12. Jahrgang, 1899, S. 146f. AHI.

980 Die Siedler waren auch dem Schaden der Verfolgung und der Gewalt von Bewegungen und Revolutionen, die in Brasilien ausbrachen, ausgesetzt. Viele der älteren Einwanderer in São Leopoldo (RS) waren Anhänger der fanatischen Muckerbewegung und kamen im Muckeraufstand (1873-1874)
} 
transzendentale Kräfte verursacht werden konnten. Sie gaben den Menschen anhaltende Hoffnung oder gar Zusicherung, von Krankheiten und Gefahren geheilt oder geschützt werden zu können.

Problematisch wurde die Lage, als die Kolonien sich entwickelten und den Siedlern allmählich medizinische Behandlung zugänglich wurde. Einige von ihnen weigerten sich dennoch, ärztliche Behandlungen in Anspruch zu nehmen, und verließen sich weiterhin auf die Dienste der „Gesundbeter" und auf die Macht der Himmelsbriefe. Einige „Gesundbeter" erregten manchmal den Eindruck, sie seien besser für die Behandlung von Krankheiten geeignet als Ärzte. Auf diese Weise starben Menschen, weil sie sich lieber auf Besprechungen, statt auf ärztliche Behandlung verlassen hatten.

\subsection{Die Errichtung kirchlicher Gemeinden- eine konkrete Umsetzung der lutherischen Doktrin des Priestertums aller Gläubigen}

In der Isolation der Urwaldgebiete, angesichts der täglichen Herausforderungen und Schwierigkeiten und besonders nachdem die ersten Siedler gestorben waren, ohne dass man sie würdig bestatten konnte, sehnten sich Einwanderer verschiedener Herkunft nach kirchlichem Leben. Zunächst suchten sie mithilfe ihrer mitgebrachten Glaubensquellen nach Trost und Glaubensstärkung für die Bewältigung widriger Lebenssituationen. Daraus wuchs aber das Interesse, sich mit anderen Familien zu sammeln und evangelisch-lutherische Gottesdienste zu feiern. So organisierten sie sich in Hausgemeinden und wählten jemand aus ihrer Mitte für die Übernahme pastoraler Funktionen. Bei Bedarf vollzog diese Person auch kirchliche Amtshandlungen. Sie waren, wie Droste es bezeichnet, „Überlebensgemeinden“.981

ums Leben. Die Bewegung entstand um die Tochter einer Einwandererfamilie, Jacobina Mentz Maurer. Biehl, João Guilherme. A guerra dos imigrantes: o espírito alemão e o estranho Mucker no sul do Brasil. In: Psicanálise e colonização. Porto Alegre: Artes e Ofícios, 1999, S. 153. Über den Aufstand siehe Petry, Leopoldo. Episódio do Ferrabraz - Os Muckers. São Leopoldo: Rotermund, 1957. Die Kolonien der südlichsten Staaten waren auch Durchgangskorridor von Truppen der Föderalistischen Revolution (1893-1895). Ein pommerscher Kolonist in Forquetinha-Lageado (RS) wurde von den Rebellen als Spion der Regierungstruppen bezeichnet und musste fliehen, um dem Tod zu entkommen. Arbeitsgemeinschaft 25. Juli in Rio Grande do Sul, S. 20f. Auch in Santa Catarina marschierten Truppen durch die Ländereien der Kolonisten und richteten viel Schaden an. Straßen und Eingänge wurden gesperrt. In Santa Isabel (SC) zogen die Regierungssoldaten Männer von neunzehn bis fünfzig Jahren für die Bildung einer Nationalgarde ein, denn Rebellen hatten die Macht in Desterro (SC) übernommen. Zluhan, Christian (Hrsg.) 29. Jahresbericht der Erziebungsanstalt in Sta Isabella, Estado $\mathrm{St}^{\mathrm{a}}$ Katharina, Brasilien vom 1. März 1893 bis 1. März 1894. Basel: M. Werner-Riehm, 1895, S. 4-6, 9, 11f, BMA, PABV 708. In Jaraguá do Sul (SC) wurden einige Frauen vergewaltigt, Männer getötet und das Vieh der Kolonisten gestohlen. Aussage von Matilde Grun, Enkelin des pommerschen Einwanderer Karl Eggert im Jahre 1982. In: Boehs. In solchen Situationen mögen Himmelsbriefe eine besondere Rolle als Schutzmaßnahme gespielt haben.

981 Droste, Rolf. Struktur und Mission der EKLBB. In: Brakemeier, Gottfried (Hrsg.) Glaube im Teilen bewahrt. Erlangen: Verlag der Ev.-Luth. Mission, 1989, S. $206 f$. 


\subsubsection{Mitgebrachte Glaubensquellen: ibre Bedeutung für die Erbaltung des Glaubens}

Für die Erhaltung des Glaubens und für die Bewältigung von Schwierigkeiten spielten die mitgebrachten Glaubensquellen der Pommern eine wichtige Rolle. Im Folgenden wird auf die Herkunft dieser Quellen, ihrem Inhalt und auf die allmähliche Einführung anderer, besonders der Gesangbücher, eingegangen.

Viele Einwanderer brachten die Bibel ${ }^{982}$ (Abb. 6) mit nach Brasilien, das Gesangbuch $^{983}$, den Kleinen Katechismus ${ }^{984}$ und auch Gebets-, Andachts- und Predigtbücher. Mit der Ausdehnung der Kolonien und in Verbindung mit der Migration der Siedler innerhalb Brasiliens, nahmen ihre Nachkommen sie auch mit in die neuen Kolonien. ${ }^{985}$ Die ersten mitgebrachten Gesang- und Andachtsbücher entstanden zur Zeit des Konfessionalismus. Laut Kemper erwuchsen Frömmigkeitslieder und Erbauungsliteratur unter anderem aus dem Ungenügen an einem belehrenden, verkündigenden und vielfach parteilich engagierten Charakter der Katechetik und des Gemeindegesangs im 16. Jahrhundert. Weil die Orthodoxie nicht in die Gesangbücher und die Liedproduktion eingriff, konnten sich Herausgeber und Hersteller an den Bedürfnissen ihres Publikums orientieren und ihre Gesangbücher als Ergänzung, Abwandlung und als funktionalen Ersatz zum damalig gesungenen Kirchenlied konzipieren. Zudem waren wichtige Vertreter der lutherischen Reformationsorthodoxie Liederdichter und schrieben Lieder für das christliche Leben, zum Beispiel für Buße und Beichte, für Hausandachten und Betstunden, für Tageszeiten und Beruf und für Notsituationen aller Art. Es handelte sich

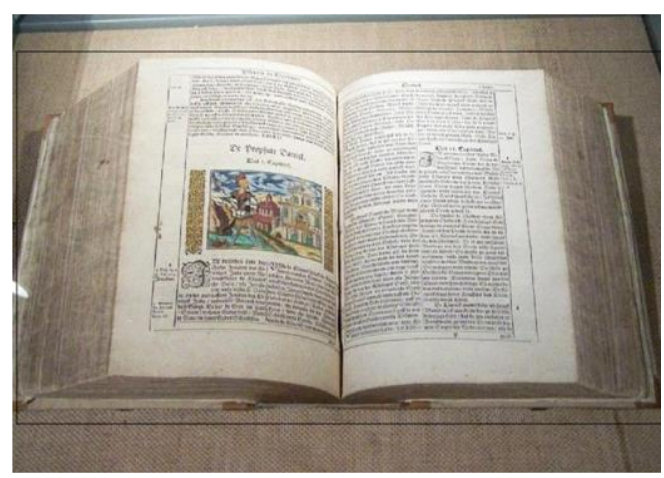

Abb. 6: Exemplar einer Bibel in pommerscher Sprache aus Espirito Santo. Quelle: Seibel Imigrante no século do isolamento, S. 116. um eine Individualisierung und Spezialisierung der Liedproduktion nach Adressaten und bestimmten Umständen. Ihre Funktion fand sie, wie auch die Erbauungsliteratur, in der Privaterbauung, die sich nicht nur auf die Kirche beschränkte. ${ }^{986}$ So ermöglichten die Gesang- und Andachtsbücher auch den Einwanderern die Pflege ihrer Frömmigkeit in der Fremde trotz des Mangels an Geistlichen.

Das bekannteste Gesangbuch, das pommersche Immigranten nach Brasilien mitbrachten, war das Heili-

\footnotetext{
982 Altmann, S. 20.

983 Siller, S. 39f; vgl. Malikoski.

${ }^{984}$ Scheerer. Festschrift der Evangelischen Kirchengemeinde Blumenau aus Anlass ihres 75jährigen Bestehens. Blumenau: Artur Koehler, S. 2, EZA 5/2486; Liesenberg, S. 6; Siller, S. 39 f.

${ }^{985}$ Lutherische Kirche in Brasilien, S. 184.

986 Kemper, Hans-Georg. Deutsche Lyrik der früben Neuzeit. Tübingen: Max Niemeyer, 1987, S. 229.
} 
ges Lippen- und Herzens-Opfer einer gläubigen Seele oder Vollständiges Gesangbuch ${ }^{987}$, das auch als Gesangbuch von Bollhagen ${ }^{988}$ bekannt wurde. Es erhält insgesamt 1313 Lieder, 135 davon wurden später in das Deutsche Evangelische Gesangbuch für Deutsche im Ausland übernommen. Die Lieder unterteilten sich in Morgen-, Abend- und Tischlieder, Sonn- und Festtageslieder, Katechismus-, Buß- und Kommunionslieder, Lieder über die lutherische Lehre, für allerlei Not, Trostlieder, Wetter- und Reiselieder, Lieder vom Tod und Sterben und drei Anhänge mit neuen Liedern. Im Gebetsteil im Anhang des Gesangbuches standen Gebete für verschiedene Anlässe, wie auch der Titel erklärt: Geist-reiches Gebet-Buch, darinnen Morgen- und Abend-Segen auf alle Tage in der Wochen, wie auch Sonn- und Fest-Tags, Buß-, Beicht-, Communion-, Dancksagungs-, Berufs-, Standes-, Creutz-, Anfechtungs-, Krieges-, Hungers-, Pestilenz-, Wetter-, Reise-, Kranckheits- und Sterbens-Gebete. ${ }^{989}$ Dazu kam ein Anhang mit Texten aus den Evangelien und Episteln für Sonn- und Festtage ${ }^{990}$, der sehr nützlich für Gottesdienste und Andachten war. Für den Hausunterricht diente Der Kleine Catechismus mit der Auslegung D. Martin Luthers, der auch die christlichen Fragestücke, die Christliche Haus-Tafel und die Sieben Bußpsalmen enthielt. ${ }^{991}$

987 Heiliges Lippen- und Herzens-Opfer einer gläubigen Seele oder Vollständiges Gesangbuch, enthält in sich die neuesten und alten Lieder des seeligen D. Lutheri und anderer erleucbteten Lebrer unserer Zeit zur Beförderung der Gottseligkeit bey öffentlichen Gottes-Dienst in Pommern und andern Orten zu gebrauchen, eingericbtet auch mit bekannten Melodeyen versehen; nebst einem Geist-reichen Gebets-Buch von den Herrn General-Superintendenten Laurent David Bollhagen, mit vermebrtem Sonn- und Festtags-Register versehen. Alten Stettin: Johann Samuel Leich, 1809. Eine Version aus dem Jahre 1862 wurde unter pommerschen Nachkommen der Familie Klitzke in Timbó (SC) gefunden und befindet sich im Privatarchiv von Pastor Nelso Weingärtner: Heiliges Lippen- und Herzens-Opfer oder Vollständiges Gesang-Buch enthaltend alte und neue Lieder aus Dr. M. Luthers und anderen cbristlichen Gesangbüchern zur Beförderung der Gottseligkeit beim öffentlichen und bäuslichen Gottesdienst in Pommern und an anderen Orten querst eingerichtet von Dr. Laurentius David Bollhagen. Stettin: F. Hessenland, 1862.

988 Sudhaus, Paul. Vergessene deutsche Glaubensbrïder. Hamburg, 1903, S. 5, EZA 200/1/5807. Dr. Theol. Laurentius David Bollhagen wurde am 4.2.1683 in Stargard-Pommern geboren und starb am 7.1.1738 ebenda in Stargard. 1721 wurde er als adjungierter Generalsuperintendent Hinterpommerns ernannt, später auch von Vorpommern. Die erste Version seines Gesangbuches erschien 1726, andere Versionen wurden mit mehreren Liedern ergänzt.

989 Geist-reiches Gebet-Buch, darinnen Morgen- und Abend-Segen auf alle Tage in der Woche, wie auch Sonn- und Fest-Tags, Buß-, Beicht-, Communion-, Dancksagungs-, Berufs-, Standes-, Creutz-, Anfecbtungs-, Krieges-, Hungers-, Pestilenz-, Wetter-, Reise-, Kranckheits- und Sterbens-Gebete enthalten aus Arnds, Gerhards und anderer Evangelischen Lebrer geistreichen Büchern mit allem Fleiß zusammen getragen und in richtiger Ordnung verfasset. Alten Stettin: Johann Samuel Leich, 1809.

990 Evangelia und Episteln auf alle Sonn- und Fest-Tage durchs ganze Jabr wobey auch die in Pommern gebräuchliche besondere Vesper-Texte befindlich, Nebst dem Symbolo Athanasii und der Geschichte vom Leiden, Sterben, Auferstehung und Himmelfahrt unseres Herrn und Heilandes Jesu Christi aus den vier Evangelisten zusammen gezogen. Wie auch die Zerstörung der Stadt Jerusalem mit allem Fleiß nach der Pommerschen Kirchen-Agenda eingerichtet. Anhang von Heiligen Lippen- und Herzens-Opfers.

${ }_{991}$ Der Kleine Catechismus mit der Auslegung D. Martin Luthers. Anhang von Heiligen Lippen- und HerzensOpfers. In São Lourenço do Sul (RS) verwendeten sie den „Katechismus von Jaspis“. Sudhaus, Paul. Vergessene deutsche Glaubensbrüder. Hamburg, 1903, S. 5, EZA 200/1/5807. Dr. Theol. Albert Sigismund Jaspis, geboren am 15.2.1809 in Nossen bei Freiberg a. Mulde und gestorben am 20.12.1885 in Stettin. Er war pastoral-theologischer Schriftsteller und wurde 1855 Generalsuperin- 
Das Vermehrte Kirchen- und Haus-Gesang-Buch für das Königl. Schwedische Herzogthum Pommern und Fürstenthum Rügen ${ }^{992}$ enthielt 652 Lieder, davon kamen 97 ins Deutsche Evangelische Gesangbuch für Deutsche im Ausland. Es enthielt tägliche und Sonn- und Festtagslieder, Lieder über die lutherische Lehre und Sakramente, Lieder für bestimmte Lebenssituationen, wie Klage-, Trost- und Betlieder, Dank- und Sterbelieder. Dieses Gesangbuch verfügte außerdem über eine Anweisung für den Gebrauch der Lieder an besonderen Kirchenfesttagen mit passenden biblischen Texten. Für die private oder familiäre Andacht bot das Christliche Gebet-Büchlein ${ }^{93}$ im Anhang des Gesangbuches Orientierung je nach gewünschtem Anliegen: tägliche Gebete; Gebete beim öffentlichen Gottesdienst; Buß-, Beichte und Abendmahlsgebete; Gebete für allerlei Anliegen, unter anderem für ein seliges Ende.

Je nach ihrem Anliegen oder Bedarf konnten pommersche Einwanderer und deren Nachkommen Lieder, Gebete und biblische Anweisungen in ihren Gesangbüchern für ihre private oder familiäre Andacht verwenden. Viele Siedler machten Gebrauch davon ${ }^{994}$, andere wiederum nicht. Die religiöse Bedeutung der Gesangbücher für die Pommern zeigt sich auch durch den Wunsch, mit dem Gesangbuch neben der Bibel bestattet zu werden. Dieses Verfahren könnte auch der Grund sein, weshalb ältere Exemplare der Gesangbücher unter pommerschen Nachkommen schwer zu finden sind. Die religiöse Glaubensquelle, welche ihnen im Leben wichtig gewesen war, sollte sie nun auch im Tod begleiten.

Stark's Handbuch ${ }^{995}$, das in allen Provinzen mit pommerscher Kolonisation bekannt war' ${ }^{996}$, und die Predigtbücher von Louis Harms ${ }^{997}$ und Immanuel Brastber-

tendent in Pommern. In seinem Amt legte er besonderen Wert auf vorbildliche Predigten und Katechese. 1850 gab er seinen Katechismus heraus, der zur Entwicklung des kirchlichen Unterrichtswesens beitrug: Jaspis, Albert Sigismund. Der kleine Catechismus Luthers aus sich selbst erklärt, wie aus der beiligen Schrift namentlich ibren Geschichten erläutert. Zugleich ein Hülsbü̈blein, durch den Unterricht in der biblischen Geschichte die Unterveisung in der evangelischen Heilslebre vorzubereiten. Elbersfeld/Leipzig: Wilhelm Hassel/J. A. Barth \& Schulze, 1851.

992 Vermehrtes Kirchen- und Haus-Gesang-Buch für das Königl. Schwedische Herzogtbum Pommern und Fürstenthum Rügen. Auf Verordnung der Königl. Hochpreisl. Regierung zum allgemeinen Gebrauch ausgefertiget. Nebst einem erbaulichen Gebet-Buche. Greifswald: Hieronymus Johann Struck, 1750.

${ }_{993}$ Christliches Gebet-Büchlein. Anhang des Vermehrten Kirchen- und Haus-Gesang-Buches.

${ }_{994}$ Schreiben Pastors Langholf über das Gebet, MEW 4.118.

995 Stark, Johann Friedrich. Tägliches-Handbuch in guten und bösen Tagen: enthaltend Aufmunterungen, Gebete und Gesänge für Gesunde, Betrïbte, Kranke und Sterbende, ferner Sprüche, Senfzer und Gebete, den Sterbenden vorzusprechen, mehrere Festandachten, Buß-, Beicht-, Communion- und Wetter-Gebete, Trost- und ErquickungsGebete und Gesänge, wie auch Kriegs-, Theurungs-, Pest- und Friedens-Gebete, nebst einem Gebetbücblein für Schwangere, Gebärende, Wöchnerinnen und für Unfruchtbare. Stuttgart: Steinkopf, 19. Jahrhundert. Joahnn Friedrich Starck, häufig als Stark bekannt, wurde am 10.10.1680 in Hildesheim geboren und starb am 17.7.1756 in Frankfurt. Er studierte Theologie an der Universität Gießen, einem Zentrum des Pietismus. 1709 wurde er als Diakon nach Genf berufen, von 1715 bis 1723 war er Pfarrer in der Dreikönigskirche in Sachsenhausen und ab 1723 in der Barfüßerkirche derselben Stadt. 1742 wurde er zum Konsistorialrat und Sonntagsprediger am Heiliggeisthospital in Frankfurt ernannt. 
gers 998 waren die bekanntesten Predigt- und Andachtsbücher unter Pommern und deren Nachkommen in brasilianischen Siedlungsgebieten. Deutschrussen in Rio Grande do Sul ${ }^{999}$, unter ihnen einige Pommern, verwendeten auch ein Predigtbuch von Adolf Stöcker. ${ }^{1000}$ Stöcker hatte wiederum Vorträge für die Innere Mission und die christlich-soziale Bewegung im selben Saal, der Adolf von Thadden für die Trieglaffer Konferenzen erbaut hatte, gehalten. ${ }^{1001}$ Predigtbücher enthielten Predigten für Sonn- und Festtage des liturgischen Kirchenjahres und spielten auf diese Weise eine wichtige Rolle beim Vollzug von Lesegottesdiensten, denn ihre Struktur ermöglichte die Wahl einer Predigt oder Auslegung nach Bedarf oder bei besonderen Anlässen. Stark's Handbuch enthielt wiederum für jedes Gebet eine Aufmunterung, die sich nach der Art der Unterweisung richtete und wichtige Glaubensthemen der evangelisch-lutherischen Doktrin systematisch behandelte.

Der Inhalt solcher Bücher entsprach den Bedürfnissen und Wünschen der Siedler, denen es in den ersten Siedlungsjahren an medizinischer und geistlicher

${ }_{996}$ Lutherische Kirche in Brasilien, S. 235f; Erinnerungen eines deutschen Ansiedlers in Brasilien. In: Sonntagsblatt für die evangelischen Gemeinden in Brasilien, Nr. 34, 12. Jahrgang, 1899, S. 133, AHI; Schreiben Pastors Langholf über das Gebet, MEW 4.118.

${ }_{997}$ Georg Ludwig Detlef Theodor Harms, bekannt als Louis Harms, wurde am 5.5.1808 in Walsrode geboren, starb am 14.11.1865 in Hermannsburg. Nach seinem Theologiestudium in Göttingen hielt er Bibelstunden und gründete 1834 den Lauenburger Missionsverein. Um seinem Vater zu unterstützen, kehrte er nach Hermannsburg zurück. Mit Bibelstunden, Hausbesuchen und Seelsorge führte er die Erweckung in Hermannsburg ein und gründete 1849 die Hermannsburger Mission. Er gab unter anderem folgende Predigtbücher heraus: Harms, Louis. Sechs Predigten und Dr. Luther's Anweisung zum Gebet. Celle: Schweiger \& Pick, 1851; Harms, Louis. Predigten über die Evangelien des Kirchenjahrs. Hermannsburg: Verlag des Missionshauses, 1868; Harms, Louis. Predigten über die Episteln des Kirchenjabrs. Hermannsburg: Verlag des Missionshauses, 1865 (mit einer Taufhandlung S. 251-256 und eine Trauung, S. 1124-1132).

998 Brastberger, Immanuel Gottlob. Evangelische Zeugnisse der Wabrheit zur Aufmunterung im wabren Christentum. Reutlingen: Enßlich \& Laiblin, 1857. Immanuel Gottlob Brastberger, geboren am 10.4.1716 in Sulz am Necker, gestorben am 13.7.1764 in Nürtingen, gehört zu den Begründern des Württemberger Pietismus.

999 Aus Kirche und Schule. In: Sonntagsblatt Nr. 47, 1891, S. 3. Zitiert nach Witt, S. 59.

1000 Adolf Stöcker, geboren am 11.12.1835 in Halberstadt und gestorben am 2.2.1909 in Gries bei Bozen, Italien, wurde 1863 Pfarrer in Seggerde (Altmarkt) und 1877 Mitglied des Generalsynodalvorstands der altpreußischen Landeskirche. 1877 übernahm er die Leitung der Berliner Stadtmission. 1890 wurde er aufgrund seiner politischen Tätigkeit als Hofprediger abberufen und gründete den Evangelisch-sozialen Kongress. Auf seine Initiative hin wurde auch 1878 die Christlich-Soziale Arbeitspartei gegründet, die 1881 zur Christlich-Sozialen Partei unbenannt wurde. Er veröffentlichte verschiedene Predigtbücher, unter ihnen: Eins ist noth. Ein Jahrgang Volkspredigten über freie Texte. Berlin: Berliner Stadtmission, 1884; Predigten. Berlin, 1886; Den Armen wird das Evangelium gepredigt. Ein Jahrgang Volkspredigten über die Evangelien des Kirchenjahres. Berlin, 1887; Die sonntägliche Predigt. Berlin, 1889; Wandelt im Geist. Ein Jahrgang Volkspredigten über freie Texte. Berlin, 1889; Das Salz der Erde. Ein Jahrgang Zeitpredigten. Berlin, 1892; Verbeißung und Erfüllung. Ein Jahrbundert Volkspredigten über alttestamentliche Texte. Berlin, 1897; Das Evangelium eine Gotteskraft. Ein Jahrgang Volkspredigten über die Evangelien der neuen Perikopen. Berlin, 1900; Beständig in der Apostel Lehre. Ein Jahrgang Volkspredigten über die Episteln der Eisenacher Perikopenreihe. Berlin, 1902. Welches dieser Predigtbücher gemeint war, ist aus den vorhandenen Quellen nicht zu entnehmen.

1001 Von Thadden, Rudolf. Trieglaff. Göttingen: Wallstein, 2010, S. 102. 
Versorgung und Führung mangelte. Viele von ihnen suchten Zuflucht im Gebet neben der Verwendung von magisch-religiösen Mitteln, wie Himmels- und Schutzbriefen und Besprechungsformeln, deren Inhalt manchmal denen der kirchlichen Gebetsbücher ähnelte. Diese geistigen Schriften wurden später auch durch Geistliche oder durch die Kolporteure verteilt oder verkauft. Predigtbücher von Louis Harms ${ }^{1002}$ konnten beispielsweise durch Hermmansburger Missionare in Brasilien und die von Adolf Stöcker durch Pastoren, die vom Oberkirchenrat entsandt wurden, verteilt worden sein, weil sie erst nach dem letzten Viertel des 19. Jahrhunderts herausgegeben wurden. Obwohl die Quellen keine weiteren Predigtbücher erwähnen, ist das Vorhandensein anderen Predigt- und Andachtsbücher nicht auszuschließen.

Angesichts der Bevölkerungszunahme in den Kolonien und des dadurch entstehenden Mangels an religiösen Schriften, ging aus vielen Gemeinden die dringende Bitte in die alte Heimat: „Schicken Sie mir doch eine Bibel, ein Gesangbuch, ein Starcks Gebetsbuch und einen Katechismus".1003 Neben dem Stark's Handbuch wurden auch Brastbergers Andachtsbücher erwünscht. 1004 Aufgrund solcher Bitten sandte der preußische König bereits 1831 und 1863 den Gemeinden São Leopoldo (RS) und Santa Isabel (SC) finanzielle Unterstützung zur Beschaffung von Bibeln und Gesangbüchern. ${ }^{1005}$ Später sorgten die Evangelische Gesellschaft und der Gotteskastenverein für die Beschaffung von Gesangbücher für Gemeinden in Brasilien.

Weil neben Pommern auch Einwanderer anderer Herkunft ihr eigenes Gesangbuch verwenden wollten, wurde bei gemeinsamen Andachten oder Gottesdiensten nicht die Liednummer, sondern der -titel angegeben, so dass jeder es in seinem eigenen Gesangbuch suchen konnte. Dies war nur möglich, weil eine Reihe von Liedern in allen Gesangbücher vorkam. Einige Siedler konnten die Lieder auch auswendig singen ${ }^{1006}$, und so versuchte man sich über das Liedergut in gemischten Kolonien zu einigen. Pastor Hesse aus Blumenau (SC) berichtet:

„Bis zur Einführung eines gemeinschaftlichen Gesangbuches ersuche ich die christliche Gemeinde freundlich, die Gesangbücher, welche man etwa besitzt, zum Gottesdienst mitbringen zu wollen. Ich werde mich bemühen, nur so allgemein bekannte Lieder zu wählen, dass sie in jedem Gesangbuch gefunden werden können".1007

Erst der Evangelische Kirchenausschuß (1903-1922) kümmerte sich um die Herausgabe eines Gesangbuches für Deutsche in der Diaspora und so entstand 1907 das

\footnotetext{
1002 Bühler, Fritz. Deutschtum und Luthertum in Brasilien, 1915, S. 10. Zitiert nach Prien, S. 169; Aus Kirche und Schule. In: Sonntagsblatt Nr. 47, 1891, S. 3. Zitiert nach Witt, S. 59.

1003 Krause, Lutherische Synode in Brasilien, S. 45.

1004 Comité für die protestantischen Deutschen in Südbrasilien. Die Arbeit unter den evangelischen Deutschen in Südbrasilien. Barmen: L. Langewiesche, 1869, S. 23, EZA 200/1/2151.

1005 Dreher, Igreja e Germanidade, S. 77; Damitz, Entwicklungsaspekte zur Situation der Brasilianer, S. 17.

1006 Riegel-Widderhausen, Aus der Arbeit des Lutherischen Gotteskasten in Brasilien. Verlag des Lutherischen Gotteskasten in Bayern, 1926, S. 10, MLV 51/17 108.

1007 Evangelische Synode von Santa Catarina und Paraná, S. 60.
} 
Hausbuch für die Deutschen im Ausland. Es umfasste 240 Lieder, unter ihnen viele Lieder aus den beiden bereits genannten pommerschen Gesangbüchern, aber auch Volkslieder und Lieder aus anderen deutschen Gesangbüchern. Daneben enthielt es Vorschläge für die tägliche Andacht und sonntäglichen Gottesdienst, Tisch-, Morgen-, Abend-, Festgebete, Beicht- und Abendmahlsgebete, Gebete für besondere Tage des häuslichen Lebens, für allerlei Not, für Kranke und Sterbende, ein Verzeichnis biblischer Lesungen für jede Woche und Festtage, den Kleinen Katechismus und die Passions- und Auferstehungsgeschichte Christi. Die zweite Auflage von 1910 fügte eine Zusammenfassung von Luthers Haustafel und den Heidelberger Katechismus hinzu. ${ }^{1008}$ Die Liederauswahl und der Text basiert auf dem Preußischen Militärgesangbuch und obwohl der Evangelische Kirchenausschuß nicht auf die Ersetzung anderer Gesangbücher ${ }^{1009}$ abzielte, bildeten die Lieder des Hausbuches die Grundlage für das Deutsche Evangelische Gesangbuch. 1907 gab der Evangelische Kirchenausschuss auch das Evangelische Liederbuch für Deutsche im Ausland ${ }^{1010}$, einen Sonderdruck des Liederteils des Evangelischen Hausbuches, und ein Choralbuch heraus, die als Ergänzung für das Evangelische Hausbuch und das Evangelische Liederbuch dienen sollten. 10111910 fand eine weitere Kirchenkonferenz in Eisenach statt, die

1008 Brief des Deutschen Evangelischen Kirchenausschußes an den Vorstand der Riograndensen Synode, Berlin, 16.8.1910, AHI, SR 10/1 Beilage 008.

1009 Die ersten evangelischen Geistlichen versuchten nach Dreher sich auf das Westfälische Gesangbuch zu einigen. Nur in der lutherischen Synode einigten sich die Geistlichen des Gotteskastenvereins auf die Einführung des bayrischen Gesangbuchs. Dreher, Kontexte und Kirche, S. 21; vgl. Entwurf einer Gemeindeordnung der deutschen ev. luth. Kirchengemeinde Sta. Maria, Archiv der Parochie Santa Maria de Jetibá. Zitiert nach Gaede, S. 126; Brief vom Lutherischen Gotteskasten in Bayern an den Evang. Luth. Landeskirchenrat in München, Hüßigen, 30.8.1928; Abschrift des Briefes von Pastor Präses Karl Bergold an den Evang. Luth. Landeskirchenrat in München, Castro, 11.2.1929. Beides In: MLV 51/17 119. In verschiedenen evangelischen Gemeinden von Espírito Santo wurde zunächst das Basler Gesangbuch verwendet. Fluck, S. 213; Rölke, Hermann. Beantwortung des „Fragebogens bezueglich der Pflege des deutschen Kirchenliedes im Auslande". MEW 4.194; Gotteskastenwerk, S. 238. In: Evangelisch-lutherischer Friedensbote aus Elsaß-Lotbringen. Nr. 27, 3.7.1904, MLV 51/17 77. In Bibelstunden wurde aus der Kleinen Missionsharfe (Kleine Missionsharfe im Kirchen- und Volkston für festliche und außenfestliche Kreise. 83. Auflage. Gütersloh: C. Bertelsmann [1926?]) gesungen. Kießling, Bruno. Brasilienbericht. In: Schmidt, Artur. Die Anfänge der Diakonie, S. 155; Soboll, S. 33-35. In Dona Francisca-Joinville (SC) wurde auch das Hamburger Gesangbuch, das Württembergische Gesangbuch, Bühler, Fritz. Ein Beitrag zur Kirchenkunde Südamerikas, S. 4f, 22, MLV 51/17 108; Wüstner, S. 12, 17, sowie das Gesangbuch für Christen der Augsburger Konfession benutzt, das auch in manchen Gemeinden von Espírito Santo verwendet wurde. Bericht des Konferenzpräsidenten [Wagner] über seine Tätigkeit, Rio de Janeiro, August 1868, BMA, FB, 1,2; Rölke, Hermann. Beantwortung des „Fragebogens bezueglich der Pflege des deutschen Kirchenliedes im Auslande", MEW 4.194.

${ }_{1010}$ Deutscher Evangelischer Kirchenausschuß (Hrsg.) Evangelisches Liederbuch für Deutsche im Ausland. Berlin: Mittler \& Sohn, 1909.

1011 Brief des Deutschen Evangelischen Kirchenausschußes an die Riograndenser Synode, Berlin, 20.2.1909; vgl. Brief des Deutschen Evangelischen Kirchenausschußes an die Riograndenser Synode, Berlin, 16.8.1910, beides In: AHI, SR 10/1, Beilagen 010 und 008. 1911 wurden 500 Exemplare des Evangelischen Hausbuches für Deutsche im Auslande Ausgabe A, 100 Exemplare des Evangelischen Hausbuches Ausgabe B, 50 Exemplare des Evangelischen Hausbuches Geschenkband, 100 Exemplare des Evan- 
eine Kommission für die Auswahl der etwa 300 bis 400 meist gesungenen Hymnen beauftragte. Das Gesangbuch sollte auch die verschiedenen evangelischen Konfessionen vereinigen. So entstand 1915 das Deutsche Evangelische Gesangbuch für die Schutrgebiete und das Ausland. Aufgrund des Ersten Weltkrieges wurde der Name in Deutsches Evangelisches Gesangbuch. Vom Deutschen Evangelischen Kirchenausschuß den deutschen evangelischen Gemeinden des Auslandes dargeboten geändert.1012 Creutzberg weist aber darauf hin, dass das Deutsche Evangelische Gesangbuch wegen des Kriegs und seiner Folgen erst um 1924 in Brasilien eingeführt wurde. ${ }^{1013}$ Die Riograndenser Synode ${ }^{1014}$ beschloss aber 1918, dass das Gesangbuch des Deutschen Evangelischen Kirchenausschußes in seiner Ausgabe von 1915 mit 387 Lieder, ohne Noten und ohne das Hausbuch in Brasilien reproduziert und in allen Gemeinden eingeführt werden sollte. ${ }^{1015}$ Nach Angaben von Dr. Guilherme Rotermund wurde es in den 1920er Jahren herausgegeben. ${ }^{1016}$ Dieses Gesangbuch wurde nur einmal gedruckt und war seit 1925 in allen vier Synoden bekannt. ${ }^{1017}$ Eine Kommission arbeitete vor dem Zweiten Weltkrieg an der Herausgabe eines neuen Gesangbuches, das erst 1947 als Gesangbuch für die Evangelische Christenheit erschien. Es diente als Grundlage für das spätere Evangelische Kirchengesangbuch von 1950. ${ }^{1018} 1949$ gab die Riograndenser Synode das Evangelische Gesangbuch heraus. Es enthielt 342 Lieder aus dem Deutschen Evangelischen Gesangbuch und 45 Volkslieder zusammen mit dem Hausbuch ${ }^{1019}$, das ausschließlich in seiner ersten Auflage mitgedruckt wurde. ${ }^{1020}$

gelischen Liederbuches für Deutsche im Auslande und 6 Choralbücher zum Liederbuche von der Riograndenser Synode bestellt. Brief des Verlags Mittler an Pastor Rotermund, 16.6.1911, AHI SR 9/1, Beilage 007. 1012 Creutzberg, Leonhard. Estou pronto para cantar. São Leopoldo: Sinodal, 2001, S. 54f.

1013 Creutzberg, S. 60.

1014 Von der Entstehung der kirchlichen Synoden wird im Kapitel IV, Abschnitt 4. die Rede sein.

1015 Brief der Riograndenser Synode Nr. 202 von 6.8.1918 an die Pastoren, AHI, SR 13/1, Beilage 020, auch SR 13/5, Beilage 009.

1016 Creutzberg, S. 62. In den evangelischen Gemeinden Timbó und Massaranduba (SC) wurden Exemplare des Deutschen Evangelischen Gesangbuchs der Ausgabe von 1921 gefunden. Creutzberg, S. 61f. Eine Ausgabe aus dem Jahre 1926 gehörte der Familie Janke aus Timbó (SC), Deutscher Evangelischer Kirchenausschuß. Deutsches Evangelisches Gesangbuch, Berlin: Mittler \& Sohn, 1926.

1017 Creutzberg, S. 62-64. In den folgenden Jahren stieg die Nachfrage an Gesangbüchern. Abschrift des Briefes von Pastor Wilhelm Fugmann, Ponta Grossa 19.10.1931, MEW 4.172; Abschrift des Briefes von Pastor Schliemann [an Pastor Begrich?], Florianópolis, 21.3.1938, AHI, SE 8/6, Beilage 104; vgl. Abschrift des Briefes von Pastor Schliemann an die Riograndenser Synode/Centro de Impressos, 11.6.1938, AHI, SE 11/1, Beilage 208; Abschrift des Briefes von Pastor Schliemann an die Riograndenser Synode/Centro de Impressos, 25.5.1940, AHI, SE 13/1, Beilage 399. 1939 bestellte die Evangelische Synode von Santa Catarina und Paraná einige Gesangbücher bei der EvangelischLutherischen Synode, weil ihr Vorrat bereits erschöpft war. Abschrift des Briefes von Pastor Schliemann an die Lutherische Synode/Missão de Folhetos, 20.4.1939, AHI, SE 11/1, Beilage 095.

1018 Creutzberg, S. 66.

1019 Creutzberg, S. 66f. Als der Verlag in São Leopoldo (RS) 1986 dieses deutsche Gesangbuch nicht mehr veröffentlichte, baten Gemeinden von Espírito Santo und Santa Catarina um eine neue Ausgabe. Die Gemeindemitglieder wurden nach den 100 bekanntesten und 100 beliebtesten Liedern gefragt und so erschien 1995 das Evangelische Gesangbuch. Hrsg. im Auftrag der Evangelischen Kirche Lutherischen Bekenntnisses in Brasilien von der Comunhão Martin Lutero, Blumenau (SC) in Zu- 
An dieser Stelle soll auch auf die Tätigkeit des evangelischen Gemeindebuchhandels und der Wanderbücherei der Evangelischen Diaspora, die vom Evangelischen Oberkirchenrat unterstützt wurde, auf die Kolporteurarbeit der EvangelischLutherischen Synode und auf die Schriftsmission der Riograndenser Synode eingegangen werden. Sie leisteten einen entscheidenden Dienst für die Verbreitung religiöser Bücher. Pastor Lindemann gründete in São Leopoldo (RS) einen evangelischen Volksmissionsverein ${ }^{1021}$ und die Schriftsmission der Riograndenser Synode ließ Bücher und Instrumente aus Hamburg und Sachsen liefern, wofür sie finanzielle Unterstützung aus Barmen und Herrnhut erhielt. Vom Evangelischen Hauptverein für deutsche Auswanderer bekam sie 1898 vier Kisten Bücher, unter ihnen Bibeln für Kirchenaltäre. ${ }^{1022}$ Die evangelische Wanderbücherei bot den Siedlern seit 1914 einen Bestand mit 386 Bänden, Bildern, Wandsprüchen und Konfirmationsscheinen. ${ }^{1023}$ Und der lutherische Kolporteur besuchte Siedlerfamilien, teilweise auch Brasilianer, in einen Turnus von zwei bis drei Jahren ${ }^{1024}$ und verkaufte ihnen christliche Literatur, Bibeln, Gesangbücher, das Liederheft Missionsharfe, Bücher, Andachts-, Predigt- und Gebetsbüchern (besonders Stark's Handbuch), Jugendund Volkserzählungen, religiöse Broschüren und Traktate, theologische und wissenschaftliche Werke, Wandsegenssprüche, biblische Bilder und Karten, sogar Harmonien und Blasinstrumente. ${ }^{1025}$ Hierbei handelte es sich um eine wichtige Missionsarbeit:

sammenarbeit mit der Editora Sinodal, São Leopoldo (RS). Es enthielt 213 der 387 Lieder des alten Gesangbuches. Anstellte der 174 herausgelassenen Lieder wurde eine Beilage mit 11 Liedern und 8 liturgischen Hymnen, unter ihnen Übersetzungen portugiesischer Lieder des brasilianischen Gesangbuches Hinos do Povo de Deus, 33 Lieder des Liederheftes für die Gemeinde - Silberpfeil der Evangelisch-Lutherischen Kirche Bayerns und 5 Lieder von Pastor Lindolfo Weingärtner, hinzugefügt. Ebd., S. 69, 71.

1020 Danach wurden Ausgaben eines separaten Hausbuchs in Brasilien, ohne Gesangbuch, herausgegeben. Hausbuch. São Leopoldo: Sinodal, 1956 und 1959. Die Anweisungen für die tägliche Andacht und sonntägliche Gottesdienste fielen raus und an ihre Stelle kam es eine Liturgie für Lesegottesdienste. Auch Luthers Haustafel und die drei Fragen aus dem Heidelberger Katechismus fielen heraus und die Gebete folgten einer anderen Reihenfolge.

1021 Aldinger, Paul. Kirchlich-kolonisatorisches Merkblatt für Brasilien. Witzenhausen: Chr. Trautvetter, um 1922, S. 27.

1022 Hennig, S. 102. Nur in Ijuí (RS) verkaufte die Schriftmission 191930 Bibeln, 140 neue Gesangbücher, 100 Religionsbücher und 500 kleine Schriften, dazu verbreitete sie 300 Exemplare der Predigt Für eine stille Stunde am Sonntag. Halle, G. Kurze Geschichte der deutsch-evangelisch-lutherischen Gemeinde zu Ijuby zur Feier des 25-jährigen Bestehens der Gemeinde, S. 18f, AHI, SR 83/25.

1023 Geißler, Bruno (Hrg). Die Kulturbedeutung der deutschen evangelischen Kirche in Brasilien. Beihefte der Zeitschrift „Die Evangelische Diaspora“. Leipzig: J. C. Hinrichs’sche Buchhandlung, 1922, S. 22f, EZA 5/2158.

1024 Schmidt, Die Anfänge der Diakonie, S. 108; Lutherische Kirche in Brasilien, S. 18.

1025 Denkschrift über die kirchlichen, schulischen und volksmissionarischen Arbeiten und Anforderungen in Espirito Santo. 1928, S. 3, MLV 51/17 108; Grimm, H. Deutsche Tätigkeit und Not in Espírito Santo. In: Traeger, P. (Hrsg.) Süd- u. Mittel-Amerika. Berlin: Verlag G.m.b.H., 30.9.1913, Nr. 18, S. 278, EZA 5/2563. Auf dem ersten Rundgang des lutherischen Kolporteurs in Gemeinden von Espírito Santo verkaufte er etwa 650 Bibeln, einige in portugiesischer Sprache, 550 Neue Testamente, 550 Pommer- 


\begin{abstract}
„Um das Gotteswort auch in die ärmsten Familien zu bringen, wurde dem einen oder andern mittellosen Familienvater wohl auch eine Bibel oder sonst ein gutes Buch geschenk.t... Trotz mancher Enttäuschungen durfte ich doch immer wieder viel Erfreuliches erleben. Besonders waren viele auch dankbar für Hinweise, wie die Bibel gelesen werden muß, und ich konnte feststellen, daß in der Bibel tatsächlich gelesen wird. Besonders bei bestimmten Gelegenheiten wird sie als Trost und Stärkung gerne gebraucht und beweist immer wieder ibre alte wunderbare Kraft an den Herzen der Menschen ".1026
\end{abstract}

Pastor Soboll berichtet, dass der Besuch des „Büchermannes“ eine Ehre für die Siedler war und alle beeilten sich, seine Schätze anzuschauen und zu kaufen. ${ }^{1027}$ Aufgrund mangelnder Ressourcen teilten sich manche Familien die gekauften Exemplare der Andachtsbüchern oder Schriften ${ }^{1028}$, und in Brusque (SC) spendeten begüterte Mitglieder für das Gemeindeblatt, damit alle Familien in Brusque (SC) und Itajaí (SC) ein Exemplar bekommen konnten. ${ }^{1029}$ Mit der Ankunft der Geistlichen entstanden auch die ersten Gemeindezeitungen, kirchliche Blätter und Kalender, die den Gemeindemitgliedern neben kirchlichen Informationen und Andachten auch allgemeine Auskünfte über Politik, Kirche und Gesellschaft boten. ${ }^{1030}$ Vor

sche Gesangbücher, 500 Stark's Andachts- und Predigtbücher, 600 Kindergebetbücher, 350 Goßners Heræbüchlein, 350 christliche Abreißkalender und kleinere wie größere Geschichtsbücher, Wandsprüche, Bilder, Karten, Traktate, 7 große und 8 kleine Harmonien und andere Musikinstrumente. Die Synode zu Santa Maria (Brasilien) 1928 - Nachtrag zum Besuch bei den deutschen lutherischen Gemeinden im brasilianischem Staats Espírito Santo. Von Dekan Volkert, Windsheim, MLV 51/17 108.

1026 Knoch, Paul. In: Württembergisches Bibelblatt 58, 1932, S. 6ff. Zitiert nach Krause, Lutherische Synode in Brasilien, S. 202.

1027 Soboll, S. 102 f.

1028 Schneider, Albert. Protokoll, aus den Jahren 1938, 1945 und 1951. Zitiert nach Wilbert, Loni Driemeyer; Sell, Simone Falk; Wilbert, Anildo; Jansch, Rolf Karl. História da Paróquia Evangélica Luterana da Barra do Rio Cerro. In: Klug, João; Ulrich, Claudete Beise (Org.) Presença e atuação da Igreja Evangélica de Confissão Luterana de Jaraguá do Sul. Porto Alegre: Metrópole, 2008, S. 115.

1029 Jahresbericht über das Gemeindeleben in Brusque im Jahre 1928. Gemeindeblatt für die evangelischen Gemeinden Brusque und Itajahy, Nr. 12, 1. Jahrgang, März 1929, S. 2f, EZA 5/2525.

10301887 erschien das Sonntagsblatt für die evangelischen Gemeinden in Brasilien von der Riograndenser Synode. Der Deutsche Ansiedler war wiederum eine Zeitung der Evangelischen Gesellschaft für die protestantischen Deutschen in Amerika. Schröder, Brasilien und Wittenberg, S. 247; Witt, S. 7f. Pastor Hermann Faulhaber veröffentlichte ab 1893 den Urwaldsboten und 1900 den Urwaldskalender für die Deutschen in Südbrasilien. Weingärtner, 150 Anos de Presença Luterana no Vale do Itajaí, S. 25. 1895 gab Pastor Wilhelm Gottfried Lange aus Brusque (SC) das Sonntagsblatt für die evangelischen Gemeinden in Santa Catharina heraus, das 1896 als Zeitung der Evangelischen Pastoralkonferenz in Santa Catarina galt. Die EvangelischLutherische Synode gab das Evangelisch-Lutherische Gemeindeblatt heraus. Schröder, Brasilien und Wittenberg, S. 347, 362. 1904 gründete Pastor Dr. Paul Aldinger in Hansa Hammonia (SC) die Zeitung Der Hansa Bote. 1908 veröffentlichte Dr. Braunschweig das monatliche Gemeindeblatt Der Christenbote. Seit 1919 gab Pastor Dohms die Deutschen Evangelischen Blätter für Brasilien heraus. In Espírito Santo erschien 1935 der Heimatbote für die Gemeinden der Deutschen Lutherischen Kirche in Espirito Santo, der 1937 den Namen in Heimatboten für die Gemeinden in Espirito Santo der Deutschen Lutherischen Kirche in Brasilien und des Gemeinde-Verbandes der Mittelbrasilianischen Synode wechselte. Krause, Die lutherische Synode in Brasilien, S. 242f; Rölke, Raizes da Imigração alemã, S. 514. Eine besondere Initiative ergriff Pfarrer 
allem für Siedler, die in sehr isolierten Gebieten wohnten und dadurch fast keinen Zugang zu Informationen hatten, spielten diese Medien als Kommunikationsmittel eine wichtige Rolle. Witt berichtet, dass die Zeitung Sonntagsblatt einen Raum für Bekanntmachungen freiließ, damit Gemeindemitglieder Auskunft über ihre Angehörigen in anderen Kolonien erlangen konnten. ${ }^{1031}$ Diese Arbeit leistete letztendlich einen wichtigen Dienst nicht nur zur Erhaltung des Glaubens, sondern auch zur Entwicklung des geistigen Lebens.

\subsubsection{Die Verwendung von Glaubensquellen bei der bäuslichen Andacht}

Nachdem die wichtigsten Glaubensquellen der Pommern und deren Nachkommen vorgestellt wurden, soll nun auf ihre Verwendung bei der häuslichen Andacht eingegangen werden. Die Art und Weise, wie sie davon Gebrauch machten, war sehr unterschiedlich. Die erwähnten Glaubensquellen boten aber für diejenigen, die sie verwendeten, Glaubenskraft für die Bewältigung ihrer Ängste und Schwierigkeiten und prägten somit ihr religiöses und kirchliches Leben.

Über die Verwendung von Glaubensquellen im alltäglichen Leben, bei besonderen Anlässen und vor allem in Notsituationen gibt die Forschung wenig Auskunft, sie erwähnt in der Regel nur deren Existenz. Es ist jedoch allgemein bekannt, dass viele Siedler die Angewohnheit hatten, an Abenden oder Wochenenden aus der Bibel zu lesen, den Kindern Teile des Kleinen Katechismus oder biblische Geschichten beizubringen und abzufragen und sie das tägliche Beten durch Nachsprechen zu lehren. Ein pommerscher Nachkomme in Pelotas (RS) berichtet, dass besonders an Regentagen die Großmutter ihren Enkeln biblische Geschichten vorlas. Sie brachte ihnen auch die Zehn Gebote bei. ${ }^{1032}$ Auch Mütter übernahmen eine wichtige Rolle bei der Aufrechterhaltung der häuslichen Andacht und des religiösen Unterrichts. Abends unterrichteten sie ihre Kinder, brachten ihnen kirchliche Lieder und die Lehre des Kleinen Katechismus bei, lasen aus der Bibel vor und beteten mit ihnen. ${ }^{1033}$ Der Kleine Katechismus, Kirchenlieder, Gebete und biblische Verse wurden auf diese Weise auswendig gelernt. ${ }^{1034}$ Eines der bekanntesten Gebete, dass Mütter ihrer Kindern beibrachten war Abba, lieber V ater. ${ }^{1035}$ Eines der bekanntesten Kinderlieder war Müde bin ich. ${ }^{1036}$

Andere Familien sammelten sich für eine Andacht, in der sie mit oder ohne Anweisungen eines Gesang- oder Andachtsbuches zusammen sangen, beteten und eine Predigt hörten. Hierfür gab es keine festen Regeln, jede Familie führte ihre

Becker in Santa Maria (RS), der 1928 die erste Zeitung in der Landessprache, die Folhas Evangélicas, herausgab. Schröder, Brasilien und Wittenberg, S. 248.

1031 Witt, S. 64.

1032 Maltzahn, S. 96.

1033 Seibel, Imigrante no século do isolamento, S. 554f; Soboll, S. 14.

1034 Rölke, Raìes da Imigração alemã, S. 520.

1035 Rölke, Raízes da Imigração alemã, S. 571. Gebet von Benjamin Schmolck (1672-1737).

1036 Bahia, S. 148. Im Deutschen Evangelischen Kirchenausschuß. Deutsches Evangelisches Gesangbuch, Lied 375. 
Andacht auf ihre eigene Art durch. Roland Ehlert aus Pomerode (SC) berichtet, dass der Vater den Kindern das Singen und das Tischgebet beibrachte, aus der Bibel und aus einem Predigtbuch las und ihnen das Gelesene erklärte. ${ }^{1037}$ Emil Mankes Vater in Itoupava Central (SC) hielt in den ersten Siedlungsjahren regelmäßige Hausandachten, ,die das Wesen der Kinder stark mitgeprägt haben “.1038 Die Kirche erkannte die Bedeutung der häuslichen Andacht für die Erhaltung des Glaubens in der Diaspora und unterstützte diese Praxis angesichts des Mangels an Geistlichen vor Ort mit der Herausgabe des Hausbuches. Es enthielt unter anderem eine Aufmunterung für die Vollziehung von Hausandachten:

„Kraft des allgemeinen Priestertums aller Gläubigen, (...) suche er [der Hausvater] sich einen kleinen Hausgottesdienst zu schaffen, und wäre es auch nur, indem er an Wochentagen den Morgen- und den Abendsegen und das Tischgebet mit seinem ganzen Hause spräche, um dann Sonntags und an den Tagen, die durch Freud oder Leid aus dem Gleichmaß des Lebens herausgehoben werden, in reicherer Gestaltung für sich und die Seinen aus dem Schacht der heiligen Schrift und den Schätzen der Erbauungsliteratur Trost und Kraft sich darreichen zu lassen, Dank und Gelübde darzubringen. Priesterlich soll er sein Haus regieren, „recht als ein Amtmann Gottes in dieser Welt", wie Luther sagt. Von unseren Vorfahren sagt der Schriftsteller Riebl (...): „W Wenn man nicht in die Kirche gehen konnte, dann las nach alter Sitte der Hausvater am Sonntag Morgen dem ganzen Hause aus der Postille vor. Am Weibnachts- und Neujahrabend versammelte er das Haus um sich und las ein Kapitel aus der Bibel. Dasselbe geschah wohl auch an jedem Sonntag Abend. Ging die Familie zum Abendmahl, dann sprach der Hausvater als Eröffnung des Ganges zur Kirche ein Gebet in der Familienhalle. (...) Wir geben anders in den Tag, wenn wir zuvor mit Gott geredet haben; wir tragen anders die Last, wenn wir zuvor uns Kraft geholt haben; wir stehen anders zu den Menschen, wenn wir zuvor die rechte Stellung zu Gott genommen haben. (...) Obne zu übertreiben, können wir sagen: Hausandachten machen den Menschen glücklich und dankbar, und die ganze Familie durchwehen sie mit dem Hauch des Friedens".1039

Als Muster für Hausandachten, wonach sich viele Einwanderer und deren Nachkommen richteten, galt Folgendes:

„Der Hausvater, der zugleich der Hauspriester ist, oder, wenn der Hausvater fehlt, die Hausmutter, liest den Bibelabschnitt und das Gebet des betreffenden Tages. Darauf spricht der Hausvater oder auch alle Anwesenden gemeinsam das heilige Vaterunser. Der Segen beschließt die kurze Feier. Wenn ein Vers aus dem Gesangbuch zu Anfang und am Ende gesungen werden keann, wird die Andacht an Feierlichkeit gewinnen. An Tagen besonderer Freude oder besonderen Ernstes (Geburtstag, Trauerfall usw.) ist statt

\footnotetext{
1037 Altmann, S. 94.

1038 Evangelische Synode von Santa Catarina und Paraná, S. 72.

1039 Deutscher Evangelischer Kirchenausschuß. Evangelisches Hausbuch für Deutsche im Ausland. Berlin: Mittler und Sohn, 1912, S. 2, 4.
} 
des gewöhnlichen ein sonderliches zu wählen, wie es auf Seiten 63-71 unseres Hausbuches zu finden ist". 1040

Gesangbuchlieder wurden bei Geburtstagen und feierlichen Anlässen gesungen. ${ }^{1041}$ Vor allem ältere Menschen baten um Lieder, die ihr Leben geprägt hatten. Auch in den Bibelstunden wurde viel gesungen ${ }^{1042}$ und Menschen aus den entferntesten Gegenden sammelten sich, um die Auslegung von Bibeltexten zu hören und Lieblingslieder, die sie oft selbst auswählen durften ${ }^{1043}$, zu singen, neue Lieder einzuüben und auswendig zu lernen. ${ }^{1044}$ In der Einsamkeit des Urwaldes bekamen solche Versammlungen eine entscheidende Bedeutung für die Siedler. Sie konnten anders als im Rahmen eines offiziellen Gottesdienstes über wichtige Glaubensfragen diskutieren und sich austauschen, ihre Erfahrungen teilen und Gemeinschaft erleben. Dadurch stärkte sich ihr Glaube und sie schöpften Kraft und Hoffnung für die Bewältigung der alltäglichen Herausforderungen und Schwierigkeiten. Oft zogen sich diese Zusammenkünfte bis Mitternacht hin. ${ }^{1045}$ Das Singen verbesserte die Laune der Siedler, aus ihm schöpften sie Freude am Leben und es half ihnen, ihre Ängste zu überwinden. Pastor Soboll erzählt aus Rio Ponte (ES):

„Am Samstag Abend vor dem Sonntag mit Gottesdienst kamen die Leute zusammen, wo der Pastor zur Nacht blieb, um mit ibrem Pastor die Bibel zu studieren und um zu singen. Das waren Zusammenkünfte, die ich nie im Leben vergessen werde. (...) Hier wurden Fragen erörtert, die in die Einsamkeit der Leute mit ibren Anfangsproblemen passten und bei denen sie sich oft lebhaftig beteiligten, wenn auch zumeist in pommersch Platt. Solche Besprechungen, die wir zwar noch nicht Evangelische Akademie nannten, dauerten etwa eine Stunde lang. Und dann, darauf wartete besonders die Jugend, wurde gesungen. Zunächst die Lieder, die morgen für den Gottesdienst ausgesucht waren, dann aber auch andere, seien es Volkslieder oder geistliche Volkslieder. (...) Von der ersten solcher Samstagsabend-Stunden blieb es feste Gewohnheit, dass stets ein neues Lied eingeübt wurde, von dem wir gleich an Ort und Stelle den Vers auswendig lernten. Aber dann mussten Dabeim weitere etwa vier Verse gelernt werden. (...) $N$ a, wenn wir so eine Stunde geredet und eine weitere Stunde gesungen hatten, gab ich gern das Zeichen zum Schluss der Singerei. Aber da kam ich nicht mit meinem Willen durch. (...) Es musste noch ein halbes Stündchen lang weitergesungen werden, bis das Lied: Ade zur guten Nacht1046, oder: Der Mond ist aufgegangen ${ }^{1047}$, den endgültigen Abschluss des Abends

\footnotetext{
1040 Deutscher Evangelischer Kirchenausschuß. Evangelisches Hausbuch, S. 4.

${ }^{1041}$ Langholf, Johan. Dienst an den zerstreuten in Brasilien (und Deutschland-riskiert), S. 21, MEW 4.118 .

1042 Langholf, Johan. Dienst an den zerstreuten in Brasilien, S. 21, MEW 4.118.

1043 Kießling, Bruno. Brasilienbericht. In: Schmidt, Die Anfänge der Diakonie, S. 155.

1044 Jahresbericht Pastor Fischer, MEW 4.178.

1045 Ergänzungsbericht Pastors Scheerer zum Jahresbericht der Evang. Gemeinde Blumenau für das Jahr 1931, 9.5.1932, EZA 5/2486; Scheerer. Festschrift der Evangelischen Kirchengemeinde Blumenau, S. 7, EZA 5/2486.

1046 Volkslied, um 1850.
} 
klarstellte. Und nun kam für mich das Schönste des ganzen Tages: Da wurden die Bambusfackeln zurecht gemacht, damit sie den Heimweg beleuchteten, also ein Stück Bambusrohr, das etwa einen Meter lang war, in der Mitte aber ein Glied aufwies, also dort einen Verschluss hatte. Oben in die Öffnung wurde Petroleum gegossen und ein alter Lumpen als Abschluss hineingesteckt. Schon formierten sich die Gruppen je nach der Richtung, die sie gehen mussten, die Fackeln wurden angebrannt, und ab gings im Gänsemarsch in den dunklen Urwald binein. Natürlich wurde beim Abmarsch ein Lied angestimmt, das zuerst noch kräftig klang, aber je entfernter die Fackeln durch den Urwald blinkerten, desto entfernter erklang auch der Gesang. Aber gesungen wurde auf dem ganzen Heimweg, denn „dann hat man nicht so viel Angst im dunklen Urwald!" sagte jemand. Ja, so zogen sie nach Hause, einige bis zu zwei Stunden weit, aber am andern Morgen waren alle wieder zum Gottesdienst da. Nach 4 Jahren zählte ich in meinem Büchlein zusammen, wieviel Lieder die Leute bier mit Text und Melodien neu gelernt batten. Es waren 84. Und wenn man durch die Gegend ritt, konnte man oft genug hören wie die Leutchen ibre Lieder sangen, sogar ab und an bei ibrer Arbeit".1048

Stark's Handbuch wurde in vielen Häuser gelesen und besonders in Notsituationen zu Rate gezogen ${ }^{1049}$, wie beispielsweise bei kranken Angehörigen oder heftigem Gewitter. Als Beispiel für den Trost, die diese Gebete spenden konnten, mag folgendes Gebet bei Unwetter dienen:

„(...) O du heilige Dreieinigkeit! erbarme dich über mich und über alle frommen Christen; bedecke mit deiner allmächtigen Hand mein Leib und Leben, Haus und Hof; bewahre die Früchte auf dem Felde; laß den Blitz nicht mein Haus entzünden, und deine Donnerschläge mir nicht schaden; sei du mein Beistand in der Noth, denn Menschenbülfe ist kein Nütze. Ach, du mächtiger Schutzherr deiner Kinder! schaue auf mich, und laß mich unter deinem Schutz und Schirm sicher wohnen. (...). Ach Herr! bewahre mich vor einem bösen schnellen Tod; laß dieses Ungewitter glücklich und obne Schaden vorübergehen. (...) Sei uns gnädig, verschone uns; (...) vor Feuers- und Wassernoth behüte uns; (...) schlage nicht bei uns ein; (...) siehe an des Herren Jesu Tod. Befiehl dem Blitze, daß er nicht / / Ein Unglück hier bei uns anricht'. // Du beilige Dreieinigkeit! / / Nimm Leib und Seel' in deine Hut.// Bewabr' auch Häuser, Hab und Gut. // Verschon' uns, lieber Herre Gott! // Und wende von uns diese Noth;// So wollen wir zu aller Zeit / / Stets rübmen deine Gütigkeit. Amen" "1050

Auch Himmels- und Schutzbriefe $e^{1051}$ wurden als Gebet und Schutzmaßnahme gegen Unwetter verwendet: ${ }^{1052}$ „Wer den Brief in seinem Hause hat oder bei sich trägt, dem wird kein Donnerwetter schaden, und ihr sollt vor Feuer und W asser bebütet werden ".1053

1047 Deutscher Evangelischer Kirchenausschuß. Deutsches Evangelisches Gesangbuch, Lied 373.

1048 Soboll, S. 33-35.

${ }^{1049}$ Schröder, Brasilien und Wittenberg, S. 333.

1050 Der gläubige Christ betet bei entstandenem Ungewitter. Stark, Tägliches Handbuch, S. 130f.

1051 Eine ausführliche Darstellung dieser Briefe befindet sich im Kapitel IX - Exkurs.

1052 Maltzahn, S. 122. 
Vor allem die Weihnachtsgeschichte sprach die Kolonistenfamilien in ihren ersten Siedlungsjahren an, denn sie konnten sich mit den ärmlichen Verhältnissen, in denen Jesus geboren wurde, identifizieren. So wie Jesus in einem Stall zur Welt kam, wohnten auch sie in Hütten und trafen sich in ihren provisorischen Häusern und Baracken zum Gottesdienst. Auf diese Weise erfuhren sie ihn als einen der Ihren. Außerdem brachte die frohe Botschaft ihnen neue Hoffnung, Zuversicht und Lebensfreude mitten in ihr einsames Leben und lenkte sie von ihren Tristessen und den täglichen Schwierigkeiten ab. Nach Angaben eines Siedlers aus Blumenau (SC) in einem Brief, datiert auf den 1. Januar 1867, sammelten sich die Familien um den Weihnachtsbaum, um Gott zu loben und sich nicht entmutigen zu lassen. Sie vertrauten auf die göttliche Güte, die Gott durch den Engel vor Jahrhunderten mit dem Gloria in Excelsis verkündigte. ${ }^{1054}$ Das kommt auch im folgenden Bericht zum Ausdruck:

„An einer langgestreckten Strasse wohnen sie, viele noch in ibren ärmlichen Palmitenhütten, andere in Bretterbäusern, hier und da siebt man auch schon ein gemauertes Haus. (...) Sechs Jahre wohnen die Leute hier. Eine Kirche gibt's nicht. Der nächste Ort, wo Gottes Wort verkündigt wird, ist vier Stunden entfernt (...) Und die Wenigen [die] sich vielleicht in ibrer Hütte ein schnell welkendes Bäumchen mit einigen Lichtern aufgestellt baben und die Weihnachtsgeschichte miteinander lesen, verschwinden unter der Menge. (...) Wie anders gestaltet sich das Weibnachten im Urwalde, wenn es in christlicher Gemeinschaft gefeiert wird. Da hat sich mitten im Urwald eine christliche Gemeinde angesiedelt (...) In der Adventsæeit übten wir fleissig unsere lieben deutschen Weisen. Trat ich dann einmal vor der Tür und fing an: „O du fröbliche" oder „Ihr Kindelein kommet" oder "Stille Nacht", dann fielen von rechts und links die Schulkinder ein, wo sie gerade beschäftigt waren, bei den Häusern oder auf den Feldern; von einem Gehöfte pflanzte sich's fort zum anderen und klang fröhlich in den ernsten Urwald hinein. - Am heiligen Abend (...) als die Weibnachtslieder der Kinder, nebst Chor- und Gemeindegesang mit Harmoniumbegleitung erklangen, als die uralte und doch ewigneue Geschichte von der Geburt des Heilands verkündigt wurde, als dann die Kinder einzeln hervortraten, Lieder und Sprüche aufsagten und jedes ein brennendes Lichtlein empfing, da mochte man vergessen, dass man in einer Wildnis lebte, in der vor knapp fünf Monaten der erste Baum gefällt worden war".1055

Erhaltene Exemplare von Andachts- und Gesangbüchern zeigen Anzeichen häufigen Gebrauchs, wie beispielsweise das Hausbuch der Familie Janke aus Timbó

${ }^{1053}$ Himmelsbrief Gredoria. Gedruckt in der Papelaria Alexandre Ribeiro, Rua do Ouvidor, 72, Rio de Janeiro (RJ); vgl. Maltzahn, S. 141f; Schutzbrief. Handschrift.

1054 Associação dos Amigos do Arquivo Histórico de Indaial. Indaial. Conbecendo sua história. Indaial: AMARHIN, t. 1, n. 4, dez. 2015/fev. 2016, S. 16f.

1055 Aus den Erinnerungen eines alten Pfarrers. Veröffentlicht in Der Christenbote Blumenau, in laufenden Vorsetzungen, Nr. 11 vom November 1921 bis Nr. 8 vom August 1922. In: Evangelische Synode von Santa Catarina und Paraná, S. 108-112. 
(SC). ${ }^{1056}$ Jedoch, unabhängig von der Regelmäßigkeit der Andacht, des Bibellesens oder des Singens erwiesen sich diese Glaubensquellen als wichtiger Faktor für den Erhalt des Glaubens und für die Bewältigung von Ängsten, Gefahren, Verlusten und Schwierigkeiten. Das Beten und Singen spendete den Menschen, die solche Quellen verwendeten, Trost, Stärke, Erquickung und Zuversicht. ${ }^{1057}$ Wüstner berichtet: „Bibel und Gesangbuch waren ibnen vertraut und aus diesen beiden Büchern haben sie in ibrem schweren Existen₹kampf Trost geschöpft".1058 Ein Einwanderer aus Blumenau (SC) schreibt seiner Schwester 1867, dass sie in den ersten Siedlungsjahren neben der fast übermenschlichen körperlichen Anstrengung über einen „,unerschütterlichen Glauben"verfügen mussten, um nicht in den ersten Tagen und Wochen entmutigt zu werden. ${ }^{1059}$ Im Glauben gestärkt, trotzten sie hoffnungsvoller den Herausforderungen und Schwierigkeiten, denn:

„Wenn den Vätern in jenen notvollen Zeiten der Glaube nicht wirklich Halt und Hoffnung gewesen wäre, so bätten sie nicht in ibrer Verlassenheit am Unwaldsrand, wo sie in den ersten Jahren ibren harten Siedlerarbeit die Predigt des göttlichen Wortes völlig entbehren mussten, dem Glauben die Treue bewahren können".1060

\subsubsection{Die Tätigkeit der Laien und Kolonistenpastoren}

Die häusliche Andacht spielte eine entscheidende Rolle für den Erhalt des Glaubens und die Bewältigung von Schwierigkeiten. Aber die Siedler sehnten sich nach einer kirchlichen Gemeinschaft. Aus diesem Grund suchten sie jemand aus ihrer Mitte für den Vollzug von Gottesdiensten und bei Bedarf auch kirchlichen Amtshandlungen. Bewusst oder unbewusst gaben sie dadurch der lutherischen Doktrin des Priestertums aller Gläubiger eine konkrete Gestalt.

Für viele Einwanderer, so wie das oft bei Migrantengruppen der Fall ist, gewann der Glaube und das kirchliche Leben besonders in der Fremde eine zentrale Bedeutung. So entstanden nach Dreher die evangelisch-lutherischen Gemeinden in Brasilien nicht als Resultat der Missionierung kirchlicher und missionarischer Institutionen, sondern aus den religiösen Bedürfnissen der Migranten heraus. Der evangelisch-lutherische Glaube wurde also in einem Immigrationskontext nach Brasilien transportiert. ${ }^{1061}$ Das Gemeindeleben entwickelte sich im Kampf ums Dasein und aus der Sehnsucht nach Glaubenspflege und Kirche. Ein Pommer aus Rio Grande do Sul äußerte sich hierzu wie folgt:

„Es giebt viele Dinge, die man nicht recht achtet, solange man sie besitzt. Sind sie erst nicht mehr da, so erkennt man, was sie wert sind. Mir und vielen anderen ist es in Brasi-

\footnotetext{
1056 Deutscher Evangelischer Kirchenausschuß. Deutsches Evangelisches Gesangbuch; vgl. Soboll, S. $13 \mathrm{f}$.

1057 Dreher, Igreja e Germanidade, S. 203f; Malikoski.

1058 Wüstner, S. 10.

1059 Associação dos Amigos do Arquivo Histórico de Indaial, t. 1, n. 4, dez. 2015/fev. 2016, S. 14-16.

1060 Evangelische Synode von Santa Catarina und Paraná, S. 6.

1061 Dreher, História do Povo Luterano, S. 7.
} 
lien mit Kirche und Schule gegangen. In meinem Heimatdorfe war beides. Gottes Wort hatte ich früher zwar nicht verachtet, aber was geregelter Gottesdienst und kirchliche Ordnung bedeuten, ist mir doch erst in Brasilien zum Bewußtsein gekommen. Gar oft dachte ich an die Heimat und wurde traurig dabei. Aber am traurigsten war doch mein Sinn, wenn der Sonntag kam. Keine Glocke ertönte, kein Gotteshaus öffnete sich. Des Morgens arbeiteten die meisten, des Nachmittags lungerte man, falls nicht auch gearbeitet wurde, herum". 1062

Aus Santa Catarina berichtete ein weiterer Kolonist:

„Ich habe seit sechs Jahren keine Glocken läuten gehört, keinen Gottesdienst mitgemacht, kein Abendmahl genossen und wenn ich sterbe, dann werde ich eingescharrt wie ein Tier, obne Glocke, ohne Pfarrer, obne Gebet. Wie kann ich da selig werden!'"1063

Der Mangel an geregelten Gottesdiensten und kirchlichen Amtshandlungen fiel den Siedlern besonders bei Todesfällen schwer, weil ihnen niemand Trost zusprach oder dem Sterbenden ein Gotteswort sagte. ${ }^{1064}$

Das religiöse Profil der Pommern war aber nicht homogen. Oft werden sie als fromme Christen dargestellt. Dass das kirchliche Leben für sie eine große Bedeutung hatte, ist nicht zu leugnen. In einem oder anderem Sinne waren sie mit ihrer Kirche verbunden ${ }^{1065}$ und sie waren dieser sehr zugetan ${ }^{1066}$, denn ein Leben ohne Kirche entsprach nach ihrer Sicht einem Leben ohne Gott ${ }^{1067}$ und sie konnten sich ein Leben ohne Kirche nicht vorstellen. ${ }^{1068}$ Aber das Verhältnis zur Kirche und die Gestaltung ihres religiösen Lebens war sehr unterschiedlich. Bevor auf die Tätigkeit der Laien eingegangen wird, soll die Unterschiedlichkeit der Gemeindemitglieder betrachtet werden, um die Konfiguration der kirchlichen Gemeinden und später die Konflikte, die aufgrund der verschiedenen Einstellungen bezüglich des kirchlichen Lebens entstanden, zu verstehen.

Nicht alle Siedler waren ernsthafte Christen, aber alle waren absichtsvolle Mitglieder einer evangelischen Gemeinde. ${ }^{1069}$ Und obwohl die Pommern in der Regel einen fundamentalen und traditionellen evangelisch-lutherischen Glauben ${ }^{1070}$

1062 Erinnerungen eines deutschen Ansiedlers in Brasilien. In: Sonntagsblatt für die evangelischen Gemeinden in Brasilien. Nr. 34, 12. Jahrgang, Februar 1899, S. 133, AHI.

1063 Aus dem Brief des Pfarrers Bornfleth, São Bento 11.9.1906, EZA 200/1/6070.

1064 Dedekind, Brasilien, S. 42f.

1065 Dedekind, Brasilien, S. 18.

1066 Sudhaus, Paul. Vergessene deutsche Glaubensbrüder. Hamburg, 1903, S. 2, EZA 200/1/5807.

1067 Rölke, Raízes da Imigração alemã, S. 571.

1068 Granzow, Pommeranos unter dem Kreuz des Südens, S. 85.

1069 Wüstner, S. 17.

1070 Im Unterschied zu Deutschland führt die schlichte Bezeichnung Evangelisch in Brasilien zur Verwechselung mit Pfingst- und Neupfingstkirchen. Der Begriff Lutherisch wird in Brasilien mit Mitgliedern der Missourisynode assoziiert. Diese ist eine Schwester der Evangelischen Kirche Lutherischen Bekenntnisses in Brasilien (EKLBB). Die pommerschen Einwanderer und deren Nachkommen verteilten sich im Laufe der Zeit auf verschiedene Kirchen: die Mehrheit war Mitglied der EKLBB; ein weiterer Teil ging zur Evangelisch-Lutherischen Kirche Brasiliens (Missouri) über; eine dritte Gruppe 
nachgingen, umfasste ihre Religiosität, wie schon beschrieben auch Praktiken magischen Inhaltes. ${ }^{1071}$ Diese Glaubenserfahrung ermöglichte ihnen die Bildung eines inneren und äußeren Ausgangspunktes für ihre anthropologische Existenz und für die Konstruktion von Solidaritäts- und Sinneserfahrungen. ${ }^{1072}$

Gottesdienste, Andachten und kirchliche Amtshandlungen fanden ebenso wie die magischen Praktiken in Privathäusern statt. Erst mit der Errichtung kirchlicher Gebäude, und besonders mit der Ankunft der Geistlichen und der Strukturierungsphase der Gemeinden, änderte sich dieser Zustand. Die Kirche wurde als heiliger Ort für den Vollzug von Gottesdiensten und kirchlichen Amtshandlungen durch einen ordinierten Geistlichen bestimmt, während Häuser weiterhin als Ort für die magischen Praktiken fungierten, die durch Laien praktiziert wurden. Die kirchliche Institution konnte die erlebte und erlernte Glaubenspraxis der Siedler nicht ändern, denn sie hatte sich in den Jahrzehnten der Abwesenheit geistiger Führung etabliert. Nicht alle Pommern jedoch praktizierten die Dualität von magischen Praktiken und kirchlichem Glauben. Eine nicht geringe Zahl der pommerschen Siedler stand den Besprechungen und Himmelsbriefen skeptisch gegenüber oder sie lehnten diese aufgrund ihres lutherischen Konfessionalismus ab. Auf eine Verallgemeinerung in Bezug zu ihrer evangelisch-lutherischen Religiosität sollte daher verzichtet werden.

Auf Grundlage der Informationen von Weingärtner ${ }^{1073}$ in Zusammenhang mit Quellen, die einen differenzierten Blick auf die Religiosität der Pommern ermöglichen, können drei verschiedenen Gruppen genannt werden. Erstens gab es pietistische Kreise, beeinflusst durch einen strengen lutherischen Konfessionalismus, die besonderen Wert auf ihre mitgebrachten Glaubensquellen legten. ${ }^{1074}$ Mit diesen Quellen vollzogen sie regelmäßige Andachten und den Unterricht für die Kinder.

gehörte zum Verband der Lutherischen Freigemeinden und ein vierter Teil der Evangelischen Kongregationalkirche an. Dreher, História do Povo Luterano, S. 49. Um die konfessionelle Spezifität der EKLBB von der römisch-katholischen und den verschiedenen Pfingst- und Neupfingstkirchen zu unterscheiden, werden die Mitglieder der EKLBB als evangelisch-lutherisch bezeichnet. Hasenack, Johannes Friedrich; Bock, Carlos Gilberto (Hrsg.) Unidade: contexto e identidade da IECLB. Blumenau: Otto Kuhr, 2006, S. 170f. Zitiert nach Wachholz, Wilhelm. Luteranismo no Brasil: trajetórias e desafios. In: Estudos Teológicos, v. 49, Nr. 2: Jul./dez. 2009, São Leopoldo, S. 202. Diese Bezeichnung hat auch historische Hintergründe aufgrund der Entsendung von Geistlichen aus unterschiedlichen konfessionellen Orientierungen, worauf noch eingegangen werden soll.

1071 Diese magische Religiosität ist keine Besonderheit der Pommern, sondern war auch in anderen deutschen Staaten bekannt, wie Sachsen. Matthes, Christian. Magische Rituale als Volksmedizin: Der Glaube neben dem Glauben. Zu den frühneuzeitlichen Gefäßdeponierungen in Zeicha, Sachsen. In: Mitteilungen der Deutschen Gesellschaft für Arcbäologie des Mittelalters und der Neuzeit. Nr. 23, 2011, S. 237250, verfügbar in: http://journals.ub.uni-heidelberg.de/index.php/mitt-dgamn/article/view/17147/ 10963 Zugang am 24.3.2017.

1072 Calandro, Eduardo Antonio. Catequese com adultos: fé e resiliência. Goiânia: Pontifícia Universidade Católica de Goiás, 2013, S. 52f.

1073 Weingärtner, 150 Anos de Presença Luterana, S. 22; Weingärtner, Martin Luther e Santa Catarina, S. $97 \mathrm{f}$.

1074 Weingärtner, História da Comunidade Evangélica de Timbó, S. 253. 
Es ist anzunehmen, dass unter ihnen Altlutheraner ${ }^{1075}$ oder Mitglieder von Erweckungsgruppen zu finden waren, die sich durch eine Laienbewegung kennzeichneten. Diese trugen sicher zur Entwicklung von Laiengemeinden bei, denn aufgrund ihrer Glaubenserfahrungen setzten sie ihre Praktiken mit Bibelstunden, Lesegottesdiensten und Hausandachten pragmatisch um. Kirchliche Amtshandlungen spielten eine wichtige Rolle in ihrem Glaubensleben, nicht als bloße Tradition, sondern vor allem als Mittel zur Vergebung der Sünden. Es ist denkbar, dass sie Besprechung von Krankheiten und Himmelsbriefen ablehnten. Dieses ist jedoch nur eine Annahme, da sie in Zeiten von Not und Verzweiflung vermutlich auch nach allen möglichen Mitteln gegriffen haben. Viele „Gesundbeter“ zählten zudem zu den treusten Gemeindemitgliedern.

Die zweite Gruppe, sicher die große Mehrheit der Pommern in Brasilien, hatte keine Gegenwehr zur Einführung der Union ${ }^{1076}$ in der Heimat geboten. Das erklärt, warum sie sich mit anderen Einwanderern aus verschiedenen Konfessionen friedlich auf die Errichtung evangelischer Gemeinden einigen konnten. Auch sie brachten ihre Glaubenselemente mit, führten Andachten in der Regel nur bei besonderen Anlässen oder in Notsituationen durch, beteten aber täglich auswendig gelernte Gebete. Zudem zeigten sie keine große Initiative für die Gründung von Hausgemeinden. Wenn diese jedoch vorhanden waren, nahmen sie daran teil. Sie engagierten sich eher bei konkreten Arbeiten wie dem Errichten von Kirchen, Schulen und Pfarrhäusern. Über ihr Verhalten berichtet Wüstner: „Treue Gemeindemitglieder finden sich hier, aber man muß sie suchen. Sie kommen in der Gemeindeversammlung wie auch im öffentlichen Gemeindeleben nicht zu Wort. Sie handeln mehr, als sie reden ".1077 Für sie spielten kirchliche Amtshandlungen eine entscheidende Rolle, jedoch eher aufgrund ihrer religiösen und anthropologischen Bedeutung als Übergangsriten oder kirchliche Tradition, die sie mit magischen Praktiken verbanden. Sie wurden oft als abergläubische Christen ${ }^{1078}$ bezeichnet, obwohl sie sich selbst nicht als solche sahen.

Für eine dritte Gruppe wurden Kirche und Religion nur als eine Notwendigkeit betrachtet ${ }^{1079}$, weswegen sie auch nicht aktiv am Kirchenleben teilnahmen. Manche hatten schlechte Erfahrungen mit der Kirche in ihrer Heimat gemacht, die sich meist auf die Seite der Großgrundbesitzer gestellt hatte. Angesichts der Unabhängigkeit in Bezug zu kirchlichen Organisationen in den Siedlungsgebieten begannen einige Siedler die Bedeutung der Kirche als Institution abzuwerten. Sie ließen sich oft als Mitglieder einschreiben, nur um das Recht auf die Vollziehung von kirchlichen Amtshandlungen zu haben. Zudem begnügten sie sich mit einer

\footnotetext{
1075 Über die Altlutheraner und Erweckungsgruppen in Pommern siehe Kapitel II Abschnitt 2.2.

1076 Über die Einführung der kirchlichen Union in Preußen siehe Kapitel II Abschnitt 2.2.

1077 Brief von Pastor Wüstner, Palmeira de Santa Joanna, 4.11.1929, MLV 51/17 87.

1078 Brief von Pastor Georg Burger an den Missionsdirektor Dr. Fr. Eppelein, Neuendettelsau, 12.11.1942, MEW 4.166.

1079 Jahresbericht Pastors Friege an das Kirchliche Außenamt, 10.7.1937, EZA 5/2535.
} 
sporadischen pfarramtlichen Betreuung, was aber nicht bedeutet, dass der Glaube an sich keine Rolle in ihrem Leben spielte, denn besonders in der Not wandten auch sie sich ihm zu. Gegenüber magischen Praktiken war ihre Einstellung ambivalent. Trotz alledem blieben sie in der Regel ihrem evangelisch-lutherischen Glauben treu.

Es gab auch Interaktionen zwischen diesen Gruppen. Aus diesem Grund sollte diese Einordnung nicht statisch gesehen werden, sondern lediglich dazu dienen, einen groben Überblick über die Pommern zu bieten, um kritisch mit einseitigen oder idyllischen Darstellungen umgehen zu können.

Da es jedoch manchmal dauern konnte, bis Einwanderer und deren Nachkommen einen ordinierten Pastor entsandt bekamen, suchten manche spontan nach einer Lösung dieses Problems. Sie wählten aus ihrer Mitte einen kundigen Laien oder Familienvater, der gut lesen und schreiben konnte und ein gewisses Geschick besaß, und machten ihn zum Pfarrer. In der Regel übernahmen dies Lehrer ${ }^{1080}$, die oft ebenfalls von der Gemeinde gewählt wurden, um pfarramtliche Funktionen, besonders kirchliche Amtshandlungen, auszuführen. ${ }^{1081}$ Sie gründeten „Hausgemeinden" 1082 und mithilfe ihrer mitgebrachten Glaubensquellen lasen sie Bibeltexte und Predigten aus einem Predigtbuch, sangen Gesangbuchlieder und beteten vermutlich nach den liturgischen Anweisungen im Anhang jener Quellen. Ein pommerscher Siedler aus Rio Grande do Sul beschreibt diesen Prozess wie folgend:

„Ein Vierteljahr war ich im Land. Da besuchte ich eines Sonntagsnachmittags einen von unserer Kolonie, um ibn über etwas zu befragen. (...) „Es ist doch gar nichts, daß man wie ein Heide hier in der Wildnis lebt und in keine Kirche gehen kann", sagte ich. Er sah mich an und meinte: „Es ist ja schlimm, daß wir keine Kirche und keinen Pastor haben - für einen rechtschaffenen Christen wenigstens -, aber als Heiden brauchen wir uns deshalb nicht zu fühlen. Wir konnten doch selbst unter uns so etwas wie Gottesdienste halten. Wie wärs, wenn wir jeden Sonntag in einem Hause uns zusammenfänden, ein Lied aus dem Gesangbuche sängen und eine Predigt vorläsen? Ich habe ein schönes Predigtbuch. Wie mir scheint, seid Ihr gerne mit dabei, und es werden sich gewiß noch mehrere finden. Sprecht noch mit anderen und kommt nächsten Sonntag zu mir: da fangen wir an". Ich war von Herzen damit einverstanden, und meine Frau, der ich davon erzählte, erst recht. Im Laufe der Woche sprach ich mit einigen, die ich traf; zu anderen ging ich hin. Wir wohnten ziemlich zerstreut auseinander. Die einen waren willig, die an.. ${ }^{* 1083}$ wenn ein richtiger Pastor käme und predigte! Aber lesen könne er auch für sich in seinem Hause. Ein anderer spottete sogar: Er gehöre nicht zu den Frommen. Damals

1080 Bereits in Pommern musste der Lehrer teilweise den Pastor vertreten. Damitz, Hans. Die Schule als Spiegelbild der gesellschaftlichen Entwicklung in Pommern bis zum Ende des 19. Jabrbunderts. Mai 1991, S. 18. Manuskript im Privatarchiv von Pastor Nelso Weingärtner.

1081 Schröder, Brasilien und Wittenberg, S. 162.

1082 Weingärtner, 150 Anos de Presença Luterana no V ale do Itajaí, S. 22.

$1083 *$ Unlesbar. 
verdroß mich das. Am nächsten Sonntag fanden wir uns zu ungefähr zehn Personen zusammen. Keine Glocken rief, keine Orgel erklang, und doch war uns feierlich zu Mute. Wir sangen ein Lied, dann wurde eine Predigt und ein Gebet aus Starks Gebetbuch gelesen. Den Schluß machte wieder ein Gesang. Das war der erste Gottesdienst, den wir armen, verlassenen Leute im Urwalde von Brasilien feierten. Der liebe Gott hat gewiß sein Woblgefallen daran gehabt, und andächtig waren wir, in der schönsten Kirche hätten wir es nicht mehr sein können. Als wir wieder nach Hause gehen wollten, sagte einer: „So wollen wir es doch jeden Sonntag halten!" Wir haben es gethan. Mit der Zeit kamen noch mehrere. Einige bielten sich abseits. Mit dem Ort der Zusammenkunft wurde gewechselt, so daßjedes Haus an die Reihe kam. Sehr oft genügte der Raum nicht, und einzelne mußten draußen sitzen. Wir haben schöne Sonntage und schöne Feste gefeiert".1084

Nach Pastor Wüstner aus Joinville (SC):

„Der Einzelne hat sich als „religiöser“ Mensch mit seiner Privatreligion nicht einfach abgefunden, sein Lesen der Bibel, seine Morgen- und Abendandachten, sein Beten und Singen der Gesangbuchlieder drängte nach einem Zusammenschluß mit all denen, die denselben evangelischen Glauben besaßen, die in derselben Kirche getauft und konfirmiert wurden und die mit ihm auf demselben Wege zur ewigen Heimat sind. Sie wollten Gemeinde, ihr Ziel war Kirche, losgelöst von der Kirche ihrer Heimat, inmitten einer völlig fremden Umwelt". 1085

Joachim Holz berichtet aus einer Gemeinde in Espírito Santo:

„Nun hatten die Leute auch Verlangen nach Gottes Wort. Da haben die Leute eine Versammlung einberufen. Da haben sie beschlossen, alle 14 Tage einen Lesegottesdienst zu halten. Und haben so schön gesungen. Eine Melodie weiß ich heute noch: „Wachet auf, ruft uns die Stimme "“". 1086

Vor allem Siedler mit pietistischen Erfahrungen in Laiengemeinden, wie aus der Bezeichnung „Stundenleute“ zu entnehmen ist, übernahmen die Initiative zur Realisierung von Lesegottesdiensten in Brasilien. ${ }^{1087}$ Pastor Schlünzen berichtet, dass man bei den Pommern merkte, wie ihre Großeltern von der Tätigkeit der Erweckungsbewegungen beeinflusst worden waren und dieses Erbe ihren Nachkommen hinterlassen hatten. ${ }^{1088}$ Sie „brachten eine streng religiöse Erziehung mit und waren gewöhnt, jeden Sonntag in die Kirche zu gehen und sich Trost aus Gottes Wort für die Tage der

1084 Erinnerungen eines deutschen Ansiedlers in Brasilien. In: Sonntagsblatt für die evangelischen Gemeinden in Brasilien. Nr. 34, 12. Jahrgang, Februar 1899, S. 133, AHI.

1085 Wüstner, S. 10.

1086 Holz, Joachim. Die ersten sechs Jahren in Espírito Santo, Brasilien. In: Heimatbote für die Gemeinden der Deutschen Lutherischen Kirche in Espirito Santo. Nr. 4, April 1936, S. 3, MEW 4.194. Das Lied befindet sich im Heiligen Lippen- und Herzens-Opfer Lied 167; im Vermehrten Kirchen-und Haus-GesangBuch Lied 478; Deutscher Evangelischer Kirchenausschuß. Deutsches Evangelisches Gesangbuch Lied 311. 1087 Granzow, Pommeranos unter dem Kreuz des Südens, S. 139.

1088 Schlünzen, F. Deutsche in Brasilien. Neuendettelsau: Freimund, 1936, S. 27, MEW 3.16. 
barten Arbeit ₹u bolen "1089 Diese Gewohnheit wurde in den Siedlungsgebieten etabliert und so hielten einige Siedler Sonntags regelmäßig Lesegottesdienst. Viele Siedler nahmen mit Freude an diesen Hausgottesdiensten teil. Laut Josenhaus waren es „Stunden der Erquickung "1090 für sie, vor allem nach den ersten Monaten voller Sorgen in der Fremde, als sie nach vielen Enttäuschungen schon fast die Hoffnung verloren hatten. Sie empfanden die Gottesdienste als Notwendigkeit ${ }^{1091}$, denn "obne Glauben gebt's nicht" .1092 Der Kolonist Krüger aus Espírito Santo berichtet:

„So sehr Tag fuer Tag gearbeitet wurde: Am Sonntag rubte die Axt. Aus dem Blechkasten wurden Bibel und Gesangbuch ausgepackt, oft schon unansehnlich geworden. Man kam in Nachbarschaften zusammen und wurde still unter Gottes Wort. Welch Reichtum war es, wenn diese Menschen in der Verlassenheit und Wildnis des Urwaldes merkten: Auch wir sind, trotz. unserer Notlage, Gottes Kinder. Gewöbnlich wars so: Ein alter, bärtiger Familienvater übernahm gan₹ selbstverständlich das Amt des Vorlesers. Und dann sassen sie alle um ibre Gesangbücher herum, und die alten Glaubenslieder, gesungen aus rauben Keblen erklangen durch den Urwald und richteten die müden und verzagten Herzen auf: „Wer nur den lieben Gott lässt walten // und hoffet auf Ihn allerzeit // den wird er wunderbar erbalten // in allem Kreuz und Traurigkeit. // Wer Gott, dem Allerböchsten, traut, // der hat auf keinen Sand gebaut". Oder: „Befiel du deine Wege // und was dein Herze kränkt // der allertreusten Pflege // des, der den Himmel lenkt. // Der Wolken, Luft und Winde //gibt Wege, Lauf und Babn, // der wird auch Wege finden, // da dein Fuss gehen kann"“.1093

Solche Lieder gaben den Siedlern Trost und Halt mitten in ihrer Not, ihren Ängsten und ihrer Verlassenheit.

Die Organisation von kirchlichen Gemeinden in Urwaldgebieten umfasste aber auch eine soziale Funktion. Angesichts der Abgeschiedenheit in den Kolonien bildeten sie das wichtigste soziale Umfeld, das den mühsamen Arbeitsrhythmus der Woche unterbrach und den Siedlern die Möglichkeit gab, geistliches Leben zu entwickeln und neue Kräfte für die Bewältigung einer kommenden Woche zu schöpften. ${ }^{1094}$ Sie waren bei Krankheit und Tod auf sich allein gestellt und sehnten sich daher nach einem tröstenden Wort „aus dem Mund eines anderen Menschen" oder nach einer "Rede über etwas anderes als das, was die täglichen Verpflicbtungen"

\footnotetext{
${ }^{1089}$ Evangelische Synode von Santa Catarina und Paraná, S. 76.

1090 Josenhaus. Der Evangelische Heidenbote, Nr. 4, April 1864, S. 38.

1091 Stoer, S. 5.

1092 Arbeitsgemeinschaft 25. Juli in Rio Grande do Sul, S. 69.

1093 Soboll, S. 13f. Das Lied Wer nur den lieben Gott lässt walten befindet sich in: Heiliges Lippen- und Herzens-Opfer Lied 802; Vermehrtes Kirchen- und Haus-Gesang-Buch Lied 276; Deutscher Evangelischer Kirchenausschuß. Deutsches Evangelisches Gesangbuch, Lied 224. Das Lied Befiel du deine Wege in: Heiliges Lippen- und Herzens-Opfer Lied 632; Vermehrtes Kirchen- und Haus-Gesang-Buch Lied 373; Deutscher Evangelischer Kirchenausschuß. Deutsches Evangelisches Gesangbuch, Lied 218.

1094 Altmann, S. 160.
} 
oder Gefahren, die jederzeit auftraten, betraf.1095 Der Gottesdienst ermöglichte den Siedlern also eine Gemeinschaft mit anderen zu bilden, die ihre Sorgen und Nöte teilten. Neben und aus dieser Gemeinschaft wuchs auch die Nachbarschaftshilfe ${ }^{1096}$ und das Wohltätigkeits- und kulturelle Vereinsleben, worauf im späteren noch eingegangen wird. Im Rahmen eines Gottesdienstes erfuhren sie von Krankheitsfällen, Notsituationen und Unfällen und boten Hilfe an. Dort diskutierten sie auch über Probleme und suchten gemeinsam nach Lösungen.

Die Tätigkeit der Laien hatte eine große Bedeutung für die Erhaltung des evangelisch-lutherischen Glaubens im brasilianischen Urwald. Ihnen ist es zu verdanken, dass das kirchliche Leben nicht ausstarb und Menschen sich in Gottesdienste sammeln konnten:

„[Das treue] Festhalten an der Sonntagsandacht, dem Katechismusunterricht in der Schule, den Hausandachten: Morgen-, Abend- und Tischgebet und vor allem an dem regelmäßig eingeführten Laiengottesdienst an den Sonn- und Feiertagen mit Gebet, Gesang, Vorlesung der Erklärung der Sonntagsepistel und des Sonntagsevangeliums. In dieser Weise wurde die Religion praktisch geübt und in der Seele erhalten".1097

Viele Gemeinden verfügten zu dieser Zeit über keine historischen Register, was vermutlich auch der Grund für den Mangel an schriftlichen Belegen über die Tätigkeit der Laien sein kann. Jedoch blieben einige Namen durch mündliche Überlieferung erhalten und konnten später niedergeschrieben werden. In Blumenau (SC) hielt der Kolonisator Dr. Blumenau seit 1850 Gottesdienste im Einwandererschuppen. ${ }^{1098} 1852$ übernahm der Lehrer Ferdinand Ostermann diese Funktion. ${ }^{1099}$ In Santa Isabel (SC) vollzog ein Tischler namens Georg Lesegottesdienste ${ }^{1100}$, in Brusque (SC) war es der ,alte Bartz" "1101, in Timbó (SC) die Lehrer Julius Scheidemantel ${ }^{1102}$ und Alwin Lämmel. ${ }^{1103}$ In Jacú-Assú-Itoupava (SC) leitete Johannes Ignowski Lesegottesdienste ${ }^{1104}$, in Jequitibá (ES) wurden sie von dem Kolonisten Friedrich Schulz vollzogen. ${ }^{1105}$ Der Siedler Christian Christmann schrieb

1095 Dietschi, Johannes R. Gedanken bei einem Kirchweihfest im brasilianischen Urwald. In: Der Deutsche Ansiedler, Nr. 24, Mai 1886, S. 37. Zitiert nach Witt, S. 63.

1096 Weingärtner, 150 Anos de Presença Luterana no Vale do Itajaí, S. 22.

1097 Arbeitsgemeinschaft 25. Juli in Rio Grande do Sul, S. 68.

1098 Von Tschudi, Reisen nach Süd-Amerika, 3. Band, S. 392.

1099 Weingärtner, 150 Anos de Presença Luterana no Vale do Itajaí, S. 12.

${ }^{1100}$ Von Tschudi, Reisen nach Süd-Amerika, 3. Band, S. 408, vgl. Josenhaus, Der Evangelische Heidenbote, Nr. 4, April 1864, S. 45; Weingärtner, Martin Luther e Santa Catarina, S. $57 \mathrm{f}$.

1101 Seyferth, Giralda. Nacionalismo e identidade étnica. Florianópolis: Fundação Catarinense de Cultura, 1981, S. 132.

1102 Weingärtner, História da Comunidade Evangélica de Timbó, S. 50. Der Lehrer Scheidemantel wurde 1908 mit einer Ehrenurkunde ausgezeichnet als Anerkennung für seine 40jährige Tätigkeit in Kirche und Schule.

1103 Weingärtner, História da Comunidade Evangélica de Timbó, S. 55.

${ }^{1104}$ Lutherische Kirche in Brasilien, S. 91.

1105 Damitz, Entwicklungsaspekte zur Situation der Brasilianer, S. 17. 
einige Predigten in Santa Cruz do Sul (RS) ${ }^{1106}$, in Pelotas (RS) übte der Lehrer Eduardo Wilhelmy pfarramtliche Funktionen aus ${ }^{1107}$ und auch in Alliança (RS) waren Lehrer als Pastoren tätig. ${ }^{1108}$

Viele Reichsdeutsche und Geistliche schmälerten später den Wert der Tätigkeit dieser Laien, als hätten sie die pfarramtlichen und schulischen Funktionen nur übernommen, weil sie für die schwere Bauernarbeit aufgrund ihres Alters oder körperlicher Unfähigkeit nicht mehr in Frage kamen. ${ }^{1109}$ Auch wenn dies teilweise der Fall gewesen sein mag, hatte es trotzdem keinen Einfluss auf ihre Befähigung und den Zuspruch durch die Gemeinden. Im Existenzkampf der ersten Siedlungsjahre zählte jede Arbeitskraft und man konnte nicht auf arbeitsfähige Kolonisten verzichten. Den Personen, die nicht dieselbe Leistung erbringen konnten, wurde stattdessen die Entwicklung des geistigen Lebens anvertraut. Sie wurden nicht ausgeschlossen, sondern für ihre Erfahrungen, Fähigkeiten und Begabungen bewundert und in den geistlichen Dienst berufen. Das entspricht der lutherischen Lehre des Priestertums aller Gläubigen durch die äußerliche Berufung einer Gemeinde, nach welcher keine Gemeinde ohne Prediger und Lehrer bestehen sollte und jeder durch die Taufe und durch den Glauben zum Priester und zur öffentlichen Verkündigung des Wortes berufen ist. ${ }^{1110}$ Laut Prien begannen die Siedler dieser Praktik in der Regel mehr intuitiv als bewusst zu folgen ${ }^{1111}$, ohne eine direkte theologische Verbindung mit diesem lutherischen Erbe zu machen. Es existierte auch kein Ordinationsverfahren. Jedoch folgerten viele Eltern bereits aus der lutherischen Lehre die Verantwortung für die konfessionelle Erziehung ihrer Kinder - vor allem auf Grundlage des Kleinen Katechismus Luthers. Andere nahmen in der alten Heimat an Erweckungsgruppen teil, in denen einige Laien als Prediger wirkten. Diese Gruppen stützten sich unter anderem auf die lutherische Doktrin des Priestertums aller Gläubiger. In diesem Sinne können ehemalige Mitglieder von Erweckungsgruppen aus theologischen Gründen diese Doktrin und ihre Praxis in brasilianischen Siedlungsgebieten umgesetzt haben. Gemeindemitglieder in São Lourenço do Sul (RS) bezeichneten Kolonistenpastoren als "Wablpfarrer" ${ }^{\text {1112 }}$, was in gewisser Weise der Berufung durch die Gemeinde entsprechend der Doktrin des

\footnotetext{
1106 Schröder, Brasilien und Wittenberg, S. 133.

${ }^{1107}$ Fonseca, S. 82.

1108 Dedekind, 75 Jabre deutsch-evangelischer Diasporaarbeit, S. 67.

1109 Sudhaus, Paul. Vergessene dentsche Glaubensbrüder. Hamburg, 1903, S. 6, EZA 200/1/5807; Anhang. Brasilianische Correspondenz des Dr. Rotermund, S. 43f, EZA 200/1/2151.

1110 Luther, Martin. Das eyn Christliche versammlung odder gemeyne recht und macht habe, alle lere zu urteylen und lerer zu beruffen, eyn und abzusetzen, Grund und ursach aus der schrifft, 1523. In: D. Martin Luthers Werke, 11. Band. Weimar: Böhlaus, 1900, S. 411f; Luther, Martin. Ein Urtheil der Theologen zu Paris über die Lehre Doctor Luthers. Eine Gegen-Urtheil Doctor Luthers. Schutzrede Philipp Melanchtohns wider dasselbe Parische Urtheil für D. Luther, 1521. In: D. Martin Luthers Werke. 8. Band. Weimar: Böhlau, 1899, S. 273; Luther, Martin. De captivitate Babylonia ecclesiae praeludium, 1520. In: D. Martin Luthers Werke. 6. Band. Weimar: Böhlau, 1888, S. 566.

1111 Prien, S. 72.

1112 Sudhaus, Paul. Vergessene deutsche Glaubensbrïder. Hamburg, 1903, S. 7, EZA 200/1/5807.
} 
Priestertums aller Gläubigen zum Ausdruck brachte. Dass die praktische Umsetzung dieser Lehre nachhaltige Wirkungen auf das Gemeindeleben hatte, zeigt sich am Beispiel von Gemeindemitgliedern, die den gewählten Kolonistenpastor nicht durch einen ordinierten Pastor ersetzen wollten und sich zu Freigemeinden entwickelt haben. Diese praktizieren teilweise bis heute die äußerliche Berufung ihrer Pastoren durch die Gemeinde, obwohl sie keine theologische Ausbildung haben. ${ }^{1113}$ Bewusst oder unbewusst setzten die Einwanderer aber die lutherische Lehre praktisch um. ${ }^{1114}$

Jahrzehnte später erkannte die Kirche die Arbeit der Laien in Diasporagebieten an und ermutigte sie, diese Arbeit aufgrund des Pfarrmangels oder angesichts einer sehr sporadischen Betreuung durch diese fortzusetzen. Das Evangelische Hausbuch für Deutsche im Ausland schlug beispielsweise vor, den Gottesdienst durch eine Andacht in einem Haus oder geeigneten Raum zu ersetzten und im Rahmen der Liturgie für Hausandachten eine Predigt oder Betrachtung aus einem Andachtsbuch zu verlesen. ${ }^{1115}$

Hausgemeinden entstanden auch mit der Ausdehnung der Siedlungsgebiete oder durch Migrationsbewegungen im Laufe des 19. und 20. Jahrhunderts ${ }^{1116}$, denn die Kirche siedelte hierdurch von einem Ort zum anderen. ${ }^{1117}$ Weil der zuständige Pastor jedoch aufgrund der großen Distanzen nicht überall sein konnte ${ }^{1118}$, vollzogen Laien weiterhin Lesegottesdienste ${ }^{1119}$, vertraten ihn im Krank-

1113 Oswald, Tamara. As igrejas evangélicas luteranas livres e independentes em São Lourenço do Sul. In: XI Encontro estadual de História, 23-27.7.2012. Rio Grande: Universidade Federal do Rio Grande (FURG), 2012, S. 578.

1114 Dreher, História do povo luterano, S. 52.

1115 Deutscher Evangelischer Kirchenausschuß. Evangelisches Hausbuch, S. 4.

1116 Halle, G. Kurze Geschichte der deutsch-evangelisch-lutherischen Gemeinde zu Ijuhy, S. 10, AHI, SR 83/25; Lutherische Kirche in Brasilien, S. 90, 178, 206, 210; Witt, S. 101, 119; Belchior. In: Der Deutsche Ansiedler, November 1907, EZA 5/2488; Ulrich, Claudete Beise. História da Paróquia Evangélica Luterana Apóstolo Tiago. In: Klug, João; Ulrich, Claudete Beise (Org). Presença e atuação da Igreja Evangélica de Confissão Luterana de Jaraguá do Sul. Porto Alegre: Metrópole, 2008, S. 246f; Gaede, S. 65f, 145; Weingärtner. História da Comunidade Evangélica de Timbó, S. 272.

1117 Droste, Struktur und Mission der EKLBB, S. 211; Brief von Pastor Karl Mehler an den Missionsdirektor, Toledo (PR), 27.8.1955, MEW 4.214.

1118 Lutherische Kirche in Brasilien, S. 235. In Santa Catarina waren die meisten Gemeinden nach Schröder zu weit ausgedehnt und besaßen eine große Mitgliederanzahl, so dass sie trotz der Ankunft von Geistlichen schlecht versorgt werden konnten. Schröder, Brasilien und Wittenberg, S. 346. Die Gemeinde Badenfurt-Pomerode (SC) besaß 1907 etwa 9.000 Mitglieder, die nur von einem Pastor betreut wurde. Prien, S. 151. Der Pastor von Santa Leopoldina II-Jequitibá (ES) musste neun Stunden reiten, um bestimmte Gemeinden zu erreichen und der von Santa Leopoldina I (ES) zwölf. Wernicke, S. 94. Pastor Treptau musste achtzehn Stunden reiten, um die Gemeinde 25 de Julho (ES) zu besuchen, Gaede, S. 65. Bestimmte Pfarrbezirke umfassten mehr als 100 Kilometer. CampinhoDomingos Martins (ES) wählte deshalb einen Vorleser für Gottesdienste, um in Notfällen den Pastor aufgrund der Distanzen und des Arbeitsaufwandes zu unterstützen. Bericht der Evangelischen Gesellschaft für die protestantischen Deutschen in Amerika vom Jahre 1932, EZA 5/483.

1119 Wernicke, S. 118; Wilbert et. al., S. 85. 
heitsfall1120 und übernahmen den pfarramtlichen Dienst besonders in Vakanzzeiten. ${ }^{1121}$ „Jeder tat sein Möglichstes, um die pfarrlose Zeit schadlos für die Gemeinde zu überbrücken".1122

Das kirchliche Leben entwickelte sich aber auch aus der Notwendigkeit heraus, die nötigen kirchlichen Amtshandlungen zu vollziehen. Ein Pommer aus Rio Grande do Sul berichtet weiter:

„Hatten wir Gottes Wort am Sonntage, so feblte doch noch viel. Das heilige Abendmahl konnte nicht gefeiert werden. Es wurden Kinder geboren - auch uns eins -, die blieben obne Taufe. Nur die in Sterbensgefahr sich befanden, erhielten die Nottaufe. An Schulunterricht war kein Gedanke. Wenige Eltern nabmen sich ibrer Kleinen an und brachten ibnen etwas Lesen und Schreiben bei, andere hatten keine Lust oder kein Geschick dazu und ließen die Kinder aufwachsen wie die jungen Kälber. Auch hätten Kinder im Laufe der Zeit konfirmiert werden sollen, es mußte ebenfalls unterbleiben. Der erste Todesfall trat ein, indem ein kleines Kind starb. Ein Fleck im Walde wurde eingefriedigt und zum Gottesacker gemacht. Rechnete man so alles zusammen, was uns fehlte, so stellte sich doch heraus, daß wir übel darum waren. Was sollte aus uns und aus unseren Kindern werden, wenn es noch weiter so fortging?".1123

Aus diesem Grund vollzogen Laien oder Lehrer auch Bestattungen ${ }^{1124}$ und das Evangelische Hausbuch diente Laien als Muster zur Vollziehung von Bestattungen und Leichenfeiern im Hause und auf dem Friedhof. ${ }^{1125}$ In einem Heftchen des Gustav-Adolf-Vereins in Rio Grande do Sul wird die Vollziehung einer Beerdigung durch Laien wie folgend dargestellt:

„Ein Hausvater stimmte den Gesang an: „Mitten wir im Leben sind... “.1126 Die Trauergemeinde fiel mit ihren Stimmen ein. Ein kurzes Gebet wurde gesprochen, dann wurde der Sarg geschlossen. (...) Auf dem Friedhofe am offenen Grabe angelangt, entblößten sich die Häupter aller. Ein lautes Vaterunser wurde gesprochen, und dann senkte sich

1120 Evangelische Synode von Santa Catarina und Paraná, S. 78.

1121 Bühler, Fritz. Ein Beitrag zur Kirchenkunde Südamerikas, S. 12, MLV 51/17 108; Pastoren, Pastorin, Kirchenvorsteher und Gemeinden in der lutherischen Kirche Brasiliens (Auszüge von Briefen aus Brasilien). In: Gruß des Martin-Luther-Vereins in Bayern an seine Mitglieder und Freunde anläßlich seiner Jahrestagung in Ansbach, 1953, S. 5, MEW 3.19; Halle, G. Kurze Geschichte der deutsch-evangelisch-lutherischen Gemeinde zu Ijuby, S. 9, AHI, SR 83/25; Lutherische Kirche in Brasilien, S. 44, 212; Stoer, S. 13.

1122 Wüstner, S. 16.

1123 Erinnerungen eines deutschen Ansiedlers in Brasilien. In: Sonntagsblatt für die evangelischen Gemeinden in Brasilien. Nr. 34, 12. Jahrgang, Februar 1899, S. 133. AHI. Vgl. Dedekind, Brasilien, S. $42 \mathrm{f}$.

1124 Weingärtner, 150 Anos de Presença Luterana no Vale do Itajaí, S. 12; Giurus, Friedrich. Crônica da Paróquia Evangélica Luterana de Indaial 1889-1969. Blumenau: Tipografia e Livraria Blumenauense, 1969, S. 116; Altmann, S. 61f, 161; Weingärtner, História da Comunidade Evangélica de Timbó, S. 50, 55, 99, 162; Krenke, Alfonso. Diálogo Informal, 6.5.2007. Zitiert nach Wilbert et. al., S. 85.

1125 Deutscher Evangelischer Kirchenausschuß. Evangelisches Hausbuch, S. 79-81.

1126 Lied 987 im Heiligen Lippen- und Herzens-Opfer einer gläubigen Seele; Lied 459 im Vermebrten Kirchenund Haus-Gesang-Buch; Deutscher Evangelischer Kirchenausschuß.Deutsches Evangelisches Gesangbuch Lied 305. 
der Sarg in die Tiefe. So nahmen evangelische Kolonisten in der Zerstreunng, die keinen Seelsorger in der Nähe hatten, Abschied von ibrem Toten".1127

Sakramente und kirchliche Amtshandlungen spielten, wie später noch beschrieben werden wird, eine wichtige Rolle im religiösen Leben der Pommern. Sie wollten ihre Kinder taufen und, im Ernstfall, nicht ungetauft sterben lassen. So vollzogen Laien ${ }^{1128}$, manchmal Großeltern und Hebammen, aber auch Mitglieder des Kirchenvorstandes ${ }^{1129}$ und Lehrer ${ }^{1130}$ die Nottaufe, bevor das Kind starb oder wenn es sehr krank war. Sie übernahmen dabei auch eine wichtige seelsorgerische Funktion. Später enthielt auch das Hausbuch ein Muster für die Durchführung von Nottaufen. ${ }^{1131}$ Wenn das Kind überlebte, wurde es vom Pastor in einem Gottesdienst gesegnet. ${ }^{1132}$ Wenn jemand krank im Sterbebett lag und kein Geistlicher verfügbar war, wurden neben „Gesundbetern“ auch Gemeindemitglieder, die für ihre kirchlichen Dienste bekannt waren, hinzu gebeten. Sie beteten für die Sterbenden ${ }^{1133}$ und reichten ihnen das heilige Abendmahl dar. ${ }^{1134}$ Konfirmations- und Religionsunterricht wurde auch von Laien erteilt. Für Konfirmationen und Trauungen gingen die Kolonisten in der Regel zu einer Hauptgemeinde oder warteten auf einen ordinierten Pastor. Wenn der Geistliche diese abgelegenen Gemeinden besuchte, vollzog er in einem mehrstündigen Gottesdienst Taufen, Konfirmationen, Trauungen, Abendmahl und segnete zusätzlich die Verstorbenen auf dem Friedhof. Wo jedoch überhaupt keine Aussicht auf die Ankunft eines Geistlichen bestand, vollzogen ausnahmsweise auch Lehrer und Laien ${ }^{1135}$ diese Amtshandlungen.

Die Tätigkeit der Laien ist jedoch vom Phänomen des „Koloniepfarrertums“ zu unterscheiden, das im Grunde nur in den Gemeinden von Rio Grande do Sul präsent war. Die „Kolonistenpastoren“ oder „Freipastoren“136 wurden von den Gemeinden anerkannt oder berufen und waren ausgestattet mit Bibel, Gesangbuch, Kleinem Katechismus, Predigt- und Andachtsbüchern mit Amtshandlungenvorschriften. So befähigt übernahmen sie das Predigt- und Lehramt in kirchlichen Ge-

\footnotetext{
1127 Gustav-Adolf-Verein in Rio Grande do Sul (Hrsg.) Gesegnete Kindergabe, S. 15f, EZA 5/2222.

1128 Altmann, S. 161; Witt, S. 97.

1129 Bühler, Fritz. Ein Beitrag zur Kirchenkunde Südamerikas. [1917/1918], S. 13, MLV 51/17 108.

1130 Weingärtner, História da Comunidade Evangélica de Timbó, S. 35, 50, 53-55, 99, 162; Weingärtner, 150 Anos de Presença Luterana no Vale do Itajaí, S. 12; PRIEN, S. 69.

${ }^{1131}$ Deutscher Evangelischer Kirchenausschuß. Evangelisches Hausbuch, S. 65f.

1132 Witt, S. 97; Altmann, S. 161.

1133 Siehe Gebete für Kranke und Sterbende im Christlichen Gebet-Bücblein, S. 6-8, 41-45; Geist-reiches Gebet-Buch, S. 81-84; Deutscher Evangelischer Kirchenausschuß. Evangelisches Hausbuch, S. 71-78; Stark, Tägliches Handbuch, S. 187-318.

1134 Bühler, Fritz. Ein Beitrag zur Kirchenkunde Südamerikas, [1917/1918], S. 13, MLV 51/17 108.

1135 Wie Trauungen in Santo Ângelo (RS) um 1860. Comité für die protestantischen Deutschen in Südbrasilien. Die Arbeit unter den evangelischen Deutschen in Südbrasilien. Barmen: L. Langewiesche, 1869, S. 23, EZA 200/1/2151.

1136 Rieth, Ricardo Willy. Raízes históricas e identidade da Igreja Evangélica Luterana do Brasil (IELB). In: Estudos Teológicos v. 49, Nr. 2: Jul./Dez. 2009, São Leopoldo, S. 210.
} 
meinden und Schulen. ${ }^{1137}$ Reiseprediger Pastor Willich berichtet, dass er mehr als einen ehrenwerten Mann kennen lernte, „, bei dem die Leute hin und wieder zusammenkamen, um ein geistlich Lied zu singen und vermittelst eines Predigtbuchs sich zu erbauen ".1138 Praktisch handelt es sich hierbei um dieselbe pfarramtliche Funktion wie bei einer Notsituation, aber in Santa Catarina und Espírito Santo wurde die pfarramtlichen Tätigkeiten der Laien eingestellt, sobald ordinierte Pastoren verfügbar waren. Bei Bedarf oder mit deren Erlaubnis durften sie noch tätig sein und wurden teilweise von den Geistlichen ausgebildet oder mit liturgischen Materialien ausgerüstet. Im Falle der Kolonistenpastoren wurde dies nicht so gehandhabt, da sie als Konkurrenten zu ordinierten Pastoren gesehen wurden. Sie übten neben ihrem Amt auch weltliche Berufe aus ${ }^{1139}$, wobei die Mehrheit jedoch der bäuerlichen Schicht angehörte. In Santa Cruz do Sul (RS) werden namentlich ein gewisser Wolfram ${ }^{1140}$, Karl Wilhelm Weise und Hugo Alexander Klein ${ }^{1141}$ in dieser Funktion erwähnt. In Santo Ângelo (RS) war ein ehemaliger Waldhüter und Bahnwärter namens Stricker Kolonistenpastor, und als Pastor Tüsmann die Gemeinde verließ, übernahm ein gewisser Schäfer diese Gemeinde. ${ }^{1142}$ In São Lourenço do Sul (RS) waren ein Siedler namens Voß ${ }^{1143}$ und der Schneider Henrique Schmitt ${ }^{1144}$, in Mühlenpikade-São Lourenço do Sul (RS) ein Offizier, ein Forstbeamter, ein Schlosser und ein Dr. phil. als solche tätig. ${ }^{1145}$ Auf die Konflikte zwischen Kolonistenpastoren und ordinierten Geistlichen wird an späterer Stelle eingegangen.

${ }^{1137}$ Dedekind, Brasilien, S. 43; Schröder, Brasilien und Wittenberg, S. 79.

1138 Als ich Urwaldpfarrer war! Bericht Pastor Willich zu der Zeitung Unterm südlichen Kreuz, Nr. 20, 10. Jahrgang, São Leopoldo, 18.9.1908, EZA 200/1/5807.

1139 Unter ihnen gab es Offiziere, Unteroffiziere, Seemänner, Wald- und Bahnwächter, Forstgehilfen, Postbeamte, Weber, Schneider, Schlosser, Rechtsanwälte und Lehrer. Fischer, Joachim. A luta contra os pastores-colonos no Rio Grande do Sul no século XIX. In: Fischer, Joachim (Hrsg.) Ensaios Luteranos. São Leopoldo: Sinodal, 1986, S. 39; Dedekind, 75 Jahre deutsch-evangelischer Diasporaarbeit, S. 51.

1140 Als Avé-Lallemant die Kolonie besuchte, stellte sich Wolfram ihm als evangelischer Geistlicher vor und er befand ihn als freundlichen und gefälligen Mann, der ihn aber nach einem Gespräch davon überzeugt hatte, nicht Theologie studiert zu haben. Robert Avé-Lallemant hatte einen Bruder, Friedrich Avé-Lallemant, der zwischen 1843 und 1848 als Pastor in Rio de Janeiro (RJ) tätig war. Avé-Lallemant, Reise durch Süd-Brasilien im Jabre 1858. 1. Teil, S. 194, 213.

1141 Sínodo Riograndense. Comunidade Evangélica de Santa Cruz do Sul 1862 - 100 - 1962. Santa Cruz do Sul: Litografia da Cia. de Fumo Santa Cruz [ohne Angabe des Jahres], S. 7, AHI, SR 144/15; vgl. Schröder, Die deutsche Einwanderung nach Südbrasilien, S. 90.

1142 Dedekind, 75 Jahre deutsch-evangelischer Diasporaarbeit, S. 51.

1143 Dedekind bezeichnete Voß als treuen Pfarrer und er gab sogar eine Zeitung heraus. Dedekind, 75 Jabre deutsch-evangelischer Diasporaarbeit, S. 66.

1144 Bosenbecker, S. 52.

1145 Dedekind, 75 Jabre deutsch-evangelischer Diasporaarbeit, S. 68. 


\subsubsection{Die Bedeutung von kirchlichen Amtshandlungen, Gebeten und Liedern}

Nachdem die Laientätigkeit bei dem Vollzug von kirchlichen Amtshandlungen behandelt wurde, soll nun die religiöse, aber auch anthropologische Bedeutung kirchlicher Amtshandlungen für Migrantengruppen, das Zusammenspiel kirchlicher und magischer Praktiken und besonders den Trost und die Bewältigungskraft, die sie angesichts der widrigen Situationen spendeten, analysiert werden. Weil Einwanderer und Nachkommen wenige Berichte über die Bedeutung von kirchlichen Amtshandlungen hinterließen, ist auf kirchliche Lieder und Gebete, die sie gern bei solchen Anlässen sangen, zurückzugreifen, denn diese brachten ihre erlebte und gefüblte Spiritualität und Religiosität zum Ausdruck, wie sie es schriftlich oder mündlich nicht auszudrücken vermochten.

Aus anthropologischer Sicht erlangen religiöse Rituale und Zeremonien besondere Bedeutung in den wichtigen Lebensphasen (Geburt, Heirat und Tod) des Menschen. Laut Van Gennep besteht das Menschenleben aus einer Reihe von Etappen, deren End- und Anfangsphasen ähnlich sind. Zu jedem dieser Ereignisse gehören Zeremonien mit dem Ziel, das Individuum aus einer definierten Situation in eine andere zu überführen. ${ }^{1146}$ Besonders in diesen Momenten greifen Menschen auf ihren familiären Glauben zurück. Im Migrationskontext wird dieser besonders bewahrt und fungiert als kultureller Identitäts- und Einheitsfaktor, durch welchen Migranten untereinander ihre Traditionen, Bräuche und Sitten an einem Ort der Sicherheit kultivieren können. Lauser und Weißköppel weisen darauf hin, dass Religionen ähnlich wie Ethnizitäten essentialisiert werden. Sie erscheinen verdinglicht, jenseits von Geschichte und immun gegen Wandlungsprozesse. Hierdurch ist es möglich, sie auf andere Bereiche zu übertragen und sie können so den Menschen Halt in einer dynamischen und unsicheren Welt ermöglichen. Die nationale und ethnische, wie auch die religiöse Identität kann gezielt und strategisch gegen Ausgrenzung, Benachteiligung und diskriminierende Gewalt wirken. Religiöse Bindung in Wechselwirkung mit ethnischen/nationalen Zugehörigkeiten fungiert letztendlich als wichtige Ressource zur Bildung notwendiger Identitätsprozesse im Migrationskontext, wo sie eine dringende und alltägliche Bestrebung ausübt. ${ }^{1147}$

In diesem Sinne übernahmen Übergangsriten im Rahmen der kirchlichen Amtshandlungen in Verbindung mit Praktiken magischen Inhaltes eine Wider-

\footnotetext{
1146 Van Gennep unterteilt hier die Übergangsriten in folgenden Kategorien: Trennungsriten (wie beispielsweise Tod), Schwellen- oder Umwandlungsriten (Schwangerschaft, Adoption) und Angliederungsriten (Hochzeitszeremonien). In den Trennungsriten wird das Individuum von seiner sozialen Gruppe getrennt. Schwellenriten umfassen den Übergang zwischen Trennungsriten und die Vorbereitung für die Angliederung. Und Angliederungsriten beziehen sich auf die Integration eines Individuums in einer sozialen Gruppe. Van Gennep, Arnold. Übergangsriten. Frankfurt a. Main/New York: Campus Verlag, 1999, S. 15, 21.

1147 Lauser, Andrea; Weißköppel, Cordula. Einleitung. Die neue Aufmerksamkeit für Religion in der Migrations- und Transnationalismusforschung. In: Lauser, Andrea; Weißköppel, Cordula. Migration und religiöse Dynamik. Bielefeld: Transcript Verlag, 2008, S. 10f.
} 
standsfunktion für die Existenz der Einwanderer und deren Nachkommen in Brasilien. Nach Bahia und Maltzahn markierten sie die Entwicklung der Individuen und ihre Einführung in die Gemeinde und reproduzierten bäuerliche und familiäre Identitätswerte. ${ }^{1148}$ In allen Phasen der Übergangsriten verflochten sich profane und sakrale Ebenen, deren Wissensdomäne, mit Ausnahme der Besprechungsformeln, ein gemeinsames und durch Generationen vermitteltes Erbe der Gruppe umfasste. ${ }^{1149}$ Laut Durkheim ist jede Religion ein komplexes System von Riten, Mythen, Dogmen und Zeremonien, das heilig und profan in seine sozialen Praktiken und geistigen Einstellungen einschließt. ${ }^{1150}$ Während religiöse Riten von der Existenz einer heiligen Macht, die als solche angerufen wird, ausgehen, setzen magische Riten eine automatische Macht voraus, die durch ein Wort oder einen Gegenstand freigegeben wird. ${ }^{1151}$

Die Pommern sahen in allem, was sie taten, das Wirken Gottes oder göttlicher Mächte und ihr alltägliches Leben wurde durch religiöse Erfahrungen geprägt. Eine gute Ernte wurde als Segen Gottes angesehen, Landplagen, schlechtes Wetter und Missernten galten wiederum als Strafe. Sie beteten deswegen um Segen und Schutz für ihren $\mathrm{Hof}^{1152}$, für gutes Wetter, für unbeschadete Reisen, aber vor allem in Krankheits-, Krisen- und Verlustmomenten. Für diese Anliegen fanden sie Gebete in Gesang- und Andachtsbüchern, aber auch in Himmels- und Schutzbriefen. Sie suchten in religiösen Riten innerhalb der kirchlichen Gemeinde, in Verbindung mit magischen Handlungen, Hilfe zur Bewältigung ihrer Lebensübergänge und Schwierigkeiten und um das Ende ihres Leidens. Laut Rölke handelt es sich um eine Religiosität, die durch alltägliche Erfahrungen mit dem Heiligen elaboriert wurde. ${ }^{1153}$

Rituale sind besonders in Übergangsphasen des menschlichen Lebens, die sich durch Spannungen, Angst, Unsicherheit und Leiden kennzeichnen, wichtig. Sie helfen Menschen, diese Übergänge zu verstehen und zu bewältigen, geben ihnen

\footnotetext{
1148 Bahia, S. 82; Maltzahn, S. 13.

1149 Bahia, S. 136.

1150 Durkheim, Émile. As formas elementares de vida religiosa (o sistema totêmico na Austrália). São Paulo: Paulinas, 2008. Zitiert nach Maltzahn, S. 99.

1151 Riviere, Claude. Os ritos profanos. Petrópolis: Vozes, 1996, S. 31. Zitiert nach Silva, Ana Neri Nascimento da. Ritos Terapêuticos: uma abordagem do sofrimento à resiliência na terapia familiar. São Leopoldo: Escola Superior de Teologia, 2007, S. 11.

1152 Beim Erntedankfest brachten die Pommern Gaben zum Altar hin. Sie glaubten, dass diese Gaben vor dem Altar gesegnet wurden und somit ihre Kulturen besser gedeihen würden. Rölke, Raízes da Imigração alemã, S. 590. Um ihre Plantagen und Vieh zu schützen, machten sie Gebrauch von Praktiken magischen Inhaltes. Über Sympathien und magische Praktiken in Umgang mit Saatzeiten, Pflanzen und Getier siehe Magisch-sympathetischer Hausschatz, S. 136-138, 141f, 156f. Besprechungsformeln für den Schutz und gegen Krankheiten in Vieh, Stall und Hof. Ebd., S. 62, 68f, 71, 81-97. Himmelsbriefe wurden zum Beispiel unter dem Trog, aus dem die Tiere ihr Futter aßen, gelegt. Weingärtner, Mundo da Superstição, S. 35. Das Vieh und die Ländereien wurden auch oft besprochen. Granzow, Pommeranos unter dem Kreuz des Südens, S. 27.

1153 Rölke, Raizes da Imigração alemã, S. 567.
} 
die Idee einer Kontinuität mitten in den Veränderungen und Brüchen des Lebens und stellen die soziale Ordnung wieder her. ${ }^{1154}$ Bei der Bewältigung von normativen Krisen, die im Zusammenhang mit Lebensübergängen stehen, erwartbar und vorhersehbar sind, bilden Handlungs- und Orientierungsmuster älterer Generationen ein steuerndes Schema. Und die Muster der Bewältigung normativer Krisen können auch bei der Bewältigung nicht-normativer Krisen, die oft traumatisch sind, helfen. ${ }^{1155}$ Laut Walsh ziehen Menschen in widrigen Lebensumständen Trost, Kraft und Orientierung ,aus den Bindungen zu ibren kulturellen und religiösen Traditionen ".1156 Im Migrationskontext versuchen sie oft durch die religiöse Verortung eine kulturelle Rückbindung an die Herkunftsethnie, wo sie eine kollektive Kontinuität mit ihrer Herkunft herstellen und Ruhe, Annahme und Sicherheit finden, während ansonsten ihre kulturelle Identität auf die verschiedensten Weisen infragegestellt wird. ${ }^{1157}$ So beruhten die konservativen kirchlichen Gepflogenheiten der pommerschen Einwanderer und deren Nachkommen auf einer eingewurzelten und ernsthaften religiösen Überzeugung und auf einem traditionellen Beharren gewohnter Überlieferungen. ${ }^{1158}$ Sie bewahrten die alten Sitten und Eigenarten $^{1159}$ und wünschten sich vor allem, „daß die Kinder in der herkömmlichen Weise getauft, die Ehen nach der evangelischen Ordnung eingesegnet und die Toten mit einem Wort des Trostes und der Hoffnung bestattet würden, wie man es gewohnt war" "1160 Es handelte sich jedoch nicht nur um Glaubenstraditionen. Obwohl die Religion sie von der Geburt bis zum Tod prägte und ihre Handlungen sich durch religiöse Rituale kennzeichnen $^{1161}$, besaßen sie eine authentische Glaubensfrömmigkeit, denn ,der evangelische Glaube muß doch wobl in den Einwanderern tiefer verankert gewesen sein als in der bloß äußerlichen Anbänglichkeiten an das Ererbte ".1162

Kirchliche Amtshandlungen gehörten zur Glaubens- und Religionsgeschichte der Pommern. Wenn sie nach der Bedeutung ihres Glaubens oder ihrer Kirche gefragt wurden, erwähnten sie in der Regel ihre Beteiligung am kirchlichen Leben

\footnotetext{
1154 Maltzahn, S. 106f, 126.

1155 Hildenbrand, Bruno. Resilienz, Krise und Krisenbewältigung. In: Welter-Enderlin, Rosmarie; Hildenbrand, Bruno (Hrsg.) Resilienz - Gedeihen trotz widriger Umstände. Heidelberg: Carl-Auer, 2010, S. 210 .

1156 Walsh, Froma. Ein Modell familialer Resilienz und seine klinische Bedeutung. In: WelterEnderlin, Rosmarie; Hildenbrand, Bruno (Hrsg.) Resilienz - Gedeiben trotz widriger Umstände. Heidelberg: Carl-Auer, 2010, S. 67; vgl. Welter-Enderlin, Rosmarie. Resilienz und Krisenkompeten₹. Heidelberg: Carl-Auer, 2010, S. 60.

1157 Kustor-Hüttl, Beatrice. Weibliche Strategien der Resilien₹: Frankfurt a.M.: Brandes \& Apsel, 2011, S. $57,126 f, 129$.

1158 Damitz, Hans. Die Kirche im Land, S. 9. Manuskript im Privatarchiv von Pastor Nelso Weingärtner.

${ }^{1159}$ Sudhaus, Paul W. L. Aus S. Lourenço. In: Sonntagsblatt Nr. 48, 1902, S. 190. Zitiert nach Witt, S. 115 .

${ }^{1160}$ Fischer, Geschichte der Evangelischen Kirche, S. 94.

1161 Dreher, História do Povo Luterano, S. 9, 11.

1162 Fischer, Geschichte der Evangelischen Kirche, s. 94.
} 
und dass sie in dieser evangelisch-lutherischen Gemeinde getauft, konfirmiert und getraut wurden, so wie ihre Kinder, und auch dort bestattet werden wollten. Deswegen sind die Beurteilungen von Pastor Friege, die Pommern seien „christlich unbewegt" und kirchliche Amtshandlungen seien ihnen eine Art „Lebensversicherung fuer die Ewigkeit" "163, und von Pastor Kessel, die Kirche bedeutete für sie ein ,gewohnheitsmässig-äusserliches Mitmachen "1164, falsch. Diese Sichtweise betrachtet die Pommern aus einer rein institutionellen Perspektive, ohne ihre Religiosität in ihrer anthropologischen Bedeutung für ihr Dasein zu beachten, und misst die Qualität ihres Glaubens an dogmatischen Kategorien, ohne Berücksichtigung ihres Glaubensverständnisses und der erlebten Religiosität. Auch wenn sich nicht alle aktiv am Gemeindeleben beteiligten, umfasste ihre evangelisch-lutherische Religiosität einen sehr existentiellen Bereich ihres Lebens. Es mag aufgrund der mangelhaften Schulbildung am ,Verstaendnis für die tieferen Fragen des cbristlichen Lebens" "165 gefehlt haben und sie hatten Schwierigkeiten, subjektive Glaubensgrundlagen zu erfassen. Aber theoretische Glaubensansätze definieren nicht allein den Glauben und können auch die Frömmigkeit eines Menschen nicht vollständig erfassen. Außerdem konnten auch Geistliche die verstreuten Gemeindemitglieder zunächst fast ausschließlich mit sporadischen Amtshandlungsgottesdiensten bedienen, was zur Hervorhebung kirchlicher Amtshandlungen beitrug. Auch die Kultivierung der häuslichen Pietät wird in solcher dogmatischen Perspektive unterschätzt.

Kirchliche Amtshandlungen sicherten den Betroffenen und ihren Angehörigen in Notsituationen, besonders bei Nottaufen und Abendmahlsfeiern für Sterbende und Schwerkranke, den Beistand Gottes und die Hoffnung auf ewiges Lebens zu und erteilten ihnen den göttlichen Segen in angrenzenden Lebenssituationen. In diesem Sinne übernahmen sie eine Bewältigungsfunktion in allen Lebensphasen des Menschenlebens, unabhängig vom Grad der Partizipation in der kirchlichen Gemeinde. Laut Pastor Bühler herrschte angesichts der widrigen Lebensumstände ein Hunger nach Gottes Wort und Gaben. Aus diesem Verlangen traten die Siedler mit „Heilsbegier" an das Abendmahl, brachten ihre Kinder zur Taufe, setzten sich für die Unterrichtung der Jugendlichen ein, erbaten den Segen für Ehepaare und wollten ihre Verstorbenen christlich bestatten. ${ }^{1166}$

Nach Filipp \& Aymanns und Imber-Black können Rituale, die auch im Rahmen von kirchlichen Amtshandlungen und Praktiken magischen Inhaltes stattfinden, als Gefäß für Emotionen dienen und negative Gefühle oder erschütterte Überzeugungen zum Ausdruck bringen. Sie geben den Menschen Halt und Struktur in unbekannten Situationen und helfen ihnen dabei, den Umgang mit einem

\footnotetext{
1163 Jahresbericht Pastors Friege an das Kirchliche Außenamt, 10.7.1937, EZA 5/2535.

1164 Bericht Kessel an den Evangelischen Oberkirchenrat, Bedenfurt, 11.6.1921, EZA 5/2455.

1165 Jahresbericht Pastors Friege an das Kirchliche Außenamt, 10.7.1937, EZA 5/2535.

1166 Bühler, Fritz. Ein Beitrag zur Kirchenkunde Südamerikas. [1917/1918], S. 7, MLV 51/17 108.
} 
belastenden Ereignis in bestimmte äußere Bahnen zu lenken und zu regulieren ${ }^{1167}$, die Gegenwart zu strukturieren, den Weg in die Zukunft zu finden, sich aus einer Erstarrung zu lösen, zu größerer Offenheit zu führen, Abläufe hervorzuheben, Heimlichtuereien feierlich aufzulösen und Widerstandskraft zu entwickeln. ${ }^{1168}$ Ihre spirituelle Dimension oder Verankerung in alten Traditionen ermöglicht Gedanken und Gefühle, die mit einem fraglichen Ereignis einhergehen, neu zu ordnen. Außerdem schaffen sie zugleich einen sozialen Schauplatz für Betroffene, auf dem sie Zuwendung und Unterstützung durch eine soziale Gemeinschaft erfahren und das Ereignis mit anderen teilen können. ${ }^{1169}$ Sie führen letztlich auch zu der Erkenntnis, dass die tiefsten Verbindungen eines Menschen über den Tod hinaus fortbestehen. ${ }^{1170}$

Für pommersche Einwanderer und deren Nachkommen spielten Gebete und Gesangbuchlieder eine entscheidende Rolle in ihrem religiösen Leben. Gebete wurden bei besonderen Anlässen, in Bedarfs- oder Verzweiflungsmomenten, im Rahmen kirchlicher Amtshandlungen oder magischer Praktiken frei formuliert oder gelesen. Obwohl die Pommern gewöhnlich Gebrauch von fertig formulierten Gebeten machten, drückten sie durch die Wahl ihrer Gebete und Lieder ihre Gefühle, Glaubensvorstellungen und Anliegen aus. Und das gesprochene Wort war Bestandteil ihres religiösen Wirkens. Gebete wiesen auf eine enge spirituelle und religiöse Beziehung mit Gott hin, an den sie sich besonders in widrigen Situationen wandten. Bestimmte Gebete prägten seit der Kindheit ihr Leben und umfassten gleichzeitig ein religiöses, kulturelles und familiäres Ethos, denn sie gehörten zur Glaubenstradition einer Familie und wurden von Generation zu Generation, in der Regel von den Müttern, in der Muttersprache einer bestimmten ethnischen Gruppe, weitergegeben und gelernt. Sie waren im tiefsten Dasein der Menschen verankert und riefen immer wieder Emotionen hervor, besonders in Krisenmomenten, Krankheitsfällen oder beim Verlust von Angehörigen. Gleichzeitig bildeten sie die Grundlagen ihres Glaubens und umfassten eine sakrale Bedeutung. Ebenso war es mit Liedern, die dazu noch andere Emotionen aktivierten. Einige von ihnen galten als eine Art Glaubensbekenntnis. Sie wünschten sich, diese Lieder bei besonderen Anlässen zu singen, wählten sie im Sterbebett und als Bestattungslieder, und schöpften daraus die Kraft für die Bewältigung ihres Leidens. Angehörige bewahrten Lieblingslieder ihrer Verstorbenen in Erinnerung und

\footnotetext{
${ }^{1167}$ Filipp, Sigrun-Heide; Aymanns, Peter. Kritische Lebensereignisse und Lebenskrisen. Stuttgart: W. Kohlhammer, 2010, S. 124.

1168 Imber-Black, Evan. Wird es schlimmer, wenn man darüber spricht? Resilienz angesichts einer lebensbedrohlichen Krankheit. In: Welter-Enderlin, Rosmarie; Hildenbrand, Bruno. (Hrsg.) Resilienz - Gedeiben trotz widriger Umstände. Heidelberg: Carl-Auer, 2010, S. 94, $102 \mathrm{f}$.

1169 Filipp; Aymanns, S. 124.

1170 Imber-Black, S. 103.
} 
wenn sie wieder gesungen wurden, gedachten sie derer und fanden in den Worten Trost. ${ }^{1171}$

Laut Pastor Langholf waren die Pommern in ihren Äußerungen über das Innen- und Gebetsleben besonders zurückhaltend. Viele Geistliche waren deshalb der Meinung, das Gebet sei für die meisten von ihnen nur eine liturgische Form des Gottesdienstes, und gehöre nur dorthin, aber dem war nicht so. Obwohl sie selten frei beteten, verwendeten sie Stark's Handbuch regelmäßig, beispielsweise vor dem Abendmahlsgang und besonders in Krankheitsmomenten. Er berichtet weiter über eine Bibelstunde, in der er einen jungen Mann bat, das Schlussgebet zu sprechen. Dieser ging hinaus, holte Stark's Handbuch, suchte sich ein passendes Stück aus und las andächtig vor. ${ }^{1172}$ Auch Pastor Burger berichtet über die zurückhaltende und verschlossene Art der Pommern, die gewöhnlich Tischgebete und Abendsegen aus Stark's Handbuch lasen. Ihr Gebetsleben umfasste meist Gebetsbücher oder auswendig gelernte Liederverse, hinzu kamen Himmelsbriefe und Besprechungsgebete. ${ }^{1173}$ Diese Quellen waren jedoch Zeugnis ihres Glaubens und ihrer Religiosität und drückten ihre religiösen Emotionen und Anliegen, die sie nicht in eigenen Worten zu äußern wussten, aus.

Im Folgenden werden kurz die kirchlichen Amtshandlungen in Verbindung mit Praktiken magischen Inhaltes dargestellt. Dabei wird der Schwerpunkt besonders auf religiöse Elemente und Gegenstände und auf Lieder und Gebete gelegt, die den Pommern und deren Nachkommen in widrigen Lebensumständen Widerstandskraft gewährten.

\subsubsection{Geburt und Taufe}

Durch die Taufe wurde das Kind der gesamten Gemeinde vorgestellt und bekam damit seine erste Identität, und zwar als Mitglied einer evangelisch-lutherischen Gemeinde. ${ }^{1174}$ Nach dem Taufgottesdienst feierte die Familie das „Kindelbei“, „Kindöp“ oder, wie es in Hinterpommern bekannt war, „Kloatsch“"oder „Klotz“, wo das Kind seine soziale Existenz bestätigt bekam. ${ }^{1175}$ In diesem Sinne umfasste die Taufe die Integration des Kindes in die religiöse und soziale Gemeinschaft, wobei seine Existenz zuvor nur im familiären Kreis begründet war. ${ }^{1176}$ Bahia weist darauf

\footnotetext{
1171 Sedmak erwähnt in seinem Buch das Beispiel einer Mutter, die bei einem Autounfall ihren Ehemann und ihre beiden Kinder verloren hat. Sie brachte ein Lied, das sie am Tag des Unfalls gehört hat und am Krankenhausbett ihres Sohnes summte, in Verbindung mit ihm. Immer, wenn sie es hörte, erinnerte sie sich an ihn, was ihr zur Kraftquelle im Umgang mit ihrem Verlust wurde. Sedmak, Clemens. Innerlichkeit und Kraft. Freiburg im Breisgau, 2013 S. 269f. Diese Funktion übernahmen kirchliche Lieder auch für die Pommern.

1172 Schreiben Pastors Langholf über das Gebet, MEW 4.118.

1173 Brief von Pastor Georg Burger an den Missionsdirektor Dr. Fr. Eppelein, Neuendettelsau, 12.11.1942, MEW 4.166.

1174 Bahia, S. 154f.

1175 Rölke, Descobrindo Raízes, S. 48.

1176 Maltzahn, S. 58.
} 
hin, dass bei vielen Bestattungen der Tauftag des Verstorbenen zusammen mit seinen anderen Daten angegeben wurde. Nicht getauft worden zu sein bedeutete, dass die Person in einer Grenzsituation stehen geblieben war, im Vergleich mit dem Zustand des Todes, des in der Gebärmutter, der Unsichtbarkeit oder des Dunkels. ${ }^{1177}$ Die Taufe ermöglichte außerdem trotz eines unvermeidlichen Todes den Eintritt in einem neuen Zustand, das heißt eine Existenz als ein getauftes evangelisch-lutherisches Mitglied, das als Kind Gottes aufgenommen wurde und nun Hoffnung auf die Auferstehung nach dem Tode erhielt, was auch die Bedeutung von Nottaufen erklärt. In diesem Sinne war eine Existenz ohne Taufe beziehungsweise ohne den Segen, den Schutz und die Verheißung Gottes unvorstellbar. ${ }^{1178}$ Nach Angaben pommerscher Nachkommen in Pelotas (RS) wurde die Taufe als Vorbedingung für die Erlösung gesehen. ${ }^{1179}$

Jedoch noch vor der Taufe spielten religiöse-magische Rituale eine wichtige Rolle. Bei der Entbindung lasen manche Väter in Espírito Santo ihrem Kind die Geschichte von Christi Geburt aus einem Buch vor ${ }^{1180}$ und Hebammen oder andere Frauen legten einen Himmels- oder Schutzbrief auf den Bauch oder auf die rechte Seite der Frau. ${ }^{181}$ Der Grund dafür ist im Himmels- und im Schutzbrief selbst zu finden: „Eine Frau im Kindesnöten wird leicht entbunden, wenn der Mann des Neugeborene [sic!] der Mutter zur rechten Seite dieses Briefes legt, und es wird von Unglück befreit sein“.1182 Nach der Entbindung beteten die Mütter das „Vaterunser" dicht am Kindermund, damit es leichter lernen konnte ${ }^{1183}$, und ein weiteres Gebet aus Stark's Handbuch. ${ }^{1184}$ Dieses Andachtsbuch enthielt als Anhang ein Gebetsbüchlein für Schwangere, Gebärende, Wöchnerinnen und Unfruchtbare. ${ }^{1185}$ Hierzu ein Beispiel:

„Allmächtiger, großer und starker Gott! (...) Ich preise dich, daß du meine Geburtsschmeržen gelindert, mich fröhlich entbunden und in der Geburt deine Hand über mich gehalten hast. Herr, wie groß ist deine Allmacht, wie herrlich ist deine Stärke! du bieltest mich, da ich sinken wollte; erquicktest mich, wenn ich schwach und obnmächtig werden wollte, und stärkest mich, wenn alle Kräfte dahin waren. Ja, du hast Alles herrlich aus-

1177 Turner, V. O processo ritual: estrutura e anti-estrutura. Petrópolis: Vozes, 1974, S. 117, 130, 177. Zitiert nach Bahia, S. 155.

1178 Bahia, S. 154f; vgl. Brief von Pastor Georg Burger an den Missionsdirektor Dr. Fr. Eppelein, Neuendettelsau, 12.11.1942, MEW 4.166.

1179 Maltzahn, S. 57.

1180 Bahia, S. 145.

${ }^{1181}$ Maltzahn, S. 54.

1182 Himmelsbrief-Gredoria. In: Maltzahn, S. 142; vgl. Schutzbrief; Himmelsbrief-Gredoria.

1183 Borchers; Kaiser, S. 6; Rölke, Descobrindo Raizes, S. 48.

1184 Bahia, S. 145.

1185 Stark, Johann Friedrich. Tägliches Gebetbüchlein für Schwangere, Gebärende und Wöchnerinnen. Als den V. und VI. Theil des täglichen Handbuchs. Stuttgart: Steinkopf. Dieses Gebetsbüchlein entstand nach dem Wunsch von Frauen, die sich Gebete für ihren bestimmten Zustand wünschten. Der Autor fügte zu den Sprüchen und Gebeten auch manche, die ihm von einigen christlichen Frauen zur Hand gegeben worden waren, die ihnen erbaulich, schön und erquickend gewirkt haben. Ebd., S. 5. 
geführet, mein Kind mir geschenkt, mein Leben mir erhalten, alles Unglück abgewendet und mich nun nach Wunsch erfreuet (...) Beschütze, stärke und erhalte mich auch in diesem meinem Wochenbett. Ach! bewahre mich und mein Kind vor allem Unfall, vor Krankheiten und sonstigen gefährlichen Zufällen (...) mein Kind aber wollest du zu deinem Preis und deinem Rubm erhalten und mir Gnade verleihen, daß ich dereinst mit erneuerten Leibeskräften und guter Gesundheit meinen Kirchengang halten, in deinem Tempel erscheinen und vor deinem Angesicht mein freudiges Lob und Dankopfer abstatten möge ". 1186

Ungetaufte Kinder waren aus der Sicht der Pommern vielen Gefahren ausgesetzt. Diese hörten mit dem ersten Kirchenbesuch des Kindes sechs Wochen nach der Geburt, der nicht unbedingt mit der Taufe zusammenfallen musste, auf. ${ }^{1187}$ Trotzdem ließen viele ihre Kinder innerhalb dieser Zeit taufen. ${ }^{1188}$ Das Evangelische Hausbuch enthielt beispielsweise ein Gebet, das vor der Taufe zu sprechen war:

„O Herr Jesu Christe, unser einiger Heiland, du hast gesagt: lasset die Kindlein zu mir kommen: denn solcher ist das Reich Gottes. Auf dies dein Wort bringen wir dies Kind durch unser Gebet zu dir und bitten: nimm es an und laß es deiner Erlösung, die du uns am Kreuz durch dein bitteres Leiden und Sterben erworben hast, durch die heilige Taufe teilhaftig werden. Zeichne es in deine Hände und laß es dein sein und bleiben zu seiner Seelen Seligkeit um deines heiligen Namens willen. Amen. Mark. 10,13-16".1189

Nach Borschers und Kaiser wurde nach der Predigt am Taufgottesdienst ein besonderes Gebet für die Wöchnerin gesprochen und anschließend das Lied „Nun danket alle Gott"1190 gesungen.1191 Pommersche Nachkommen in Espírito Santo berichten, dass die Mutter bei der Taufe ihres Kindes einen Segen vor dem Altar erhielt und wieder in der Gemeinschaft angenommen wurde, denn zuvor durften sie und das Kind das Haus nicht verlassen ${ }^{1192}$, vermutlich, weil beide noch nicht gesegnet und auf diese Weise keinen Schutz enthalten hatten. Manche Kinder sollten nach Angaben pommerscher Nachkommen in Pelotas (RS) auch einen Tag vor der Taufe oder manchmal am Tauftag besprochen worden sein. ${ }^{1193}$

\footnotetext{
1186 Stark, Tägliches Gebetbüchlein für Schwangere, Gebärende und Wöchnerinnen, S. 56f. Dieses Gebet ist in einer zusammenfassenden Version im Evangelischen Hausbuch abgefasst. Deutscher Evangelischer Kirchenausschuß. Evangelisches Hausbuch, S. 64f.

1187 Borchers; Kaiser, S. 7.

1188 Bahia, S. 145.

1189 Deutscher Evangelischer Kirchenausschuß. Evangelisches Hausbuch, S. 64.

1190 Lied 869 im Heiligen Lippen- und Herzens-Opfer; Lied 421 im Vermehrten Kirchen- und Haus-GesangBuch; Lied 245 im Deutschen Evangelischen Kirchenausschuß. Deutsches Evangelisches Gesangbuch.

1191 Borchers; Kaiser, S. 7.

1192 Seibel, Imigrante no século do isolamento, S. 323f; Schlünzen, F. Deutsche in Brasilien. Neuendettelsau: Freimund, 1936, S. 14, MEW 3.16.

1193 Maltzahn, S. 56. In den 1970er Jahren war ein Pastor in Espírito Santo überzeugt, dass $90 \%$ der Täuflinge in der Gemeinde vorher schon besprochen wurden. Granzow, Pommeranos unter dem Kreuz des Südens, S. 27.
} 
Als Patinnen und Paten wählten die Eltern Personen, vor welchen sie Respekt hatten und die sie bewunderten, denn sie glaubten, das Kind erhielte deren Eigenschaften. ${ }^{1194}$ Aus diesem Grund hielten an manchen Orten alle Paten und Patinnen das Kind abwechselnd bei der Taufe. ${ }^{1195}$ Sie schenkten dem Kind einen Patenzetel oder Patenbrief, der mit Segenssprüchen beschrieben und reichlich ausgestaltet war und dessen Umschlag in Kreuzform umwickelt wurde. Patenbriefe konnten bis ins 17. Jahrhundert rückdatiert werden und entstanden möglicherweise mit anderen Gedenkblattformen zur Konfirmation oder zum Namenstag. ${ }^{1196}$ Sie konnten verschiedene Gegenstände enthalten, die den Wunsch für eine gute Zukunft, Wohlstand, Bequemlichkeit, Reichtum, Fruchtbarkeit, einen erfolgreichen Haushalt, Bewirtschaftung des Hofes oder Beruf symbolisierten ${ }^{1197}$, denn die Pommern glaubten, diese Symbole würden Einfluss auf die Zukunftsperspektiven der Kinder haben. ${ }^{1198}$ Für Mädchen wurde meistens eine Nähnadel mit Stickfaden, Zwirn, Gänsefeder, Leinsamen oder eine Haarsträhne, für Jungen Kaffee- oder Getreidekörner, Tierhaare oder Stahlfeder, Erde, Schwein- oder Kuhfell hinein gelegt. Unabhängig vom Geschlecht wurden auch einem Schriftstück mit Tintenfeder, ein Gebet, Geld, Münzen, Sparkassenbuch, Samen, Brotkrümel, ein silberner Löffel oder Schmuck beigelegt. ${ }^{1199}$ Es handelte sich nach Bahia um wichtige Symbole bäuerlichen Lebens, die teilweise die verschiedene Sozialisation von Frauen und Männern und das Gleichgewicht der wichtigsten Elemente für die Aufrechterhaltung der Kolonie kennzeichneten. ${ }^{1200}$

Die Analyse einiger Exemplare von Patenbriefen gibt wichtige Hinweise auf ihre religiöse Bedeutung. Sie enthalten verschiedene Bibelsprüche, wie aus Apg. 2,38: „,ut Buße und lasse sich ein jeglicher taufen auf den Namen Jesus zur Vergebung der Sünden; so werdet ibr empfangen die Gabe des Heiligen Geistes"; Joh. 10,14: „Ich bin der gute Hirte und kenne die Meinen und die Meinen kennen mich“; Mt. 19,14: „Lasset die Kinder zu mir kommen; denn solchen gebört das Himmelreich“; Mk. 16,16; „Wer glaubt und getauft wird, der wird gerettet werden; wer aber nicht glaubt, der wird verdammt werden" und Jes. 43,1b: „Fürchte dich nicht, denn ich habe dich erlöst; ich habe dich bei deinem Namen gerufen; du bist

\footnotetext{
${ }_{1194}$ Borchers; Kaiser, S. 8; Rölke, Descobrindo Raizes, S. 48.

1195 Borchers; Kaiser, S. 8; Maltzahn, S. 60.

1196 Beitl, K. Brief, Rel. Volkskunde. In: Höfer, Josef; Rahner, Karl. (Hrsg.) Lexikon für Theologie und Kirche. 2. Auflage, 2. Band, Freiburg: Herder, 1958, S. 687; Losse, Vera. Werde fromm und gut. Telgte: Museum Heimathaus Münsterland, 1999, S. 3, 6.

1197 Borchers; Kaiser, S. 8; Seibel, Imigrante no século do isolamento, S. 323f; Ulrich, S. 241.

1198 Maltzahn, S. 61.

1199 Thiel, Uwe; Neumann, Harry. Priebkow - ein Rittergut in Hinterpommern. Witten: DIP-Digital-Print, 2011, S. 378; Borchers; Kaiser, S. 8; Ulrich, S. 242; Bahia, S. 157f; Maltzahn, S. 60f; Seibel, Imigrante no século do isolamento, S. 324.

1200 Bahia, S. 157. Mehr über pommersche Sitten um Geburt und Taufe siehe Bahia, S. 140-160; Borchers; Kaiser, S. 5-8; Magisch-sympathetischer Hausschatz, S. 154, 157-160, 163f; Rölke, Descobrindo Raizes, S. 47-49.
} 
mein!"“1201 Vergebung der Sünden, Erlösung und Seligkeit, die nach dem Reformator Martin Luther (1483-1546) durch die Taufe gewirkt werden ${ }^{1202}$, so wie die Taufverheißung und die Zusicherung, Gottes Kinder zu sein, sind die Hauptthemen dieser biblischen Verse.

Das Exemplar in Abb. 7 aus dem Jahre 1943, enthält den verherrlichten Christus von Engeln umringt mit dem Spruch:

„Zum Andenken an die beilige Taufe:

Die Tauf', mein Kind, halt hoch und wert

Und danke für die Gaben,

Die dir dein Gott darin bescheert,

Und die uns alle laben,

Wenn nichts mehr sonst uns laben will.

Die laß, bis daß des Todes Ziel

Dich trifft, nicht ungepreiset.

Brauch alles wobl, und weil du bist

Nun rein in Christo worden,

So leb' und tu auch als ein Christ

Und halte Christi Orden.

Bis daß dort in der ew'gen Freud,

Er dir das Ehr- und Freudenkleid

An deine Seele lege".1203

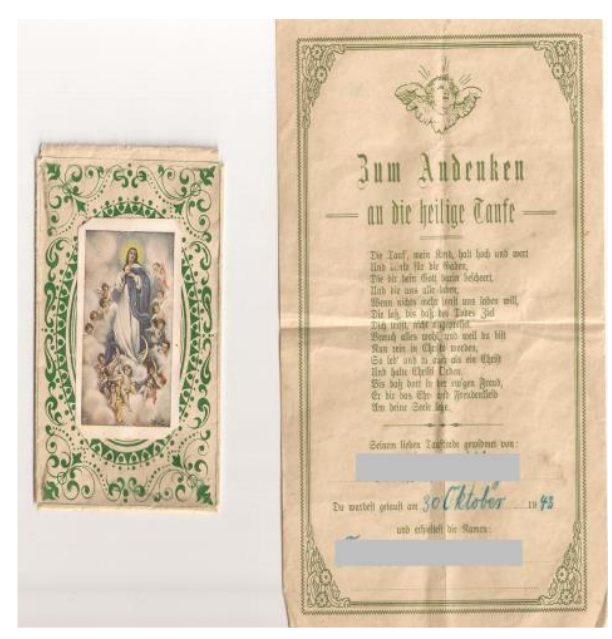

Abb. 7. Patenbrief aus Pelotas (RS), 30.10.1943. Quelle: Maltrahn, S. 145.

In Exemplaren aus dem Jahre 1984 (siehe S. 203) kann der bereits erwähnte Umschlag in Kreuzform erkannt werden. Aber nur das Exemplar in Abb. 8 erhielt eine Nadel mit Faden, das andere enthielt keinen symbolischen Gegenstand. Im Exemplar in Abb. 9 wurde folgender Spruch hinzugefügt:

\footnotetext{
1201 Siehe verschiedene Patenbriefe aus Pelotas (RS), Maltzahn, S. 145-148; Patenbrief aus dem Jahre 1984, Indaial (SC). Privatarchiv S. J. Die biblischen Zitate werden nach der Neuen Luther Bibel. Wollerau: La Buona Novella, 2010 zitiert.

1202 Siehe viertes Hauptstück im Kleinen Katechismus. In: Deutscher Evangelischer Kirchenausschuß. Evangelisches Hausbuch, S. 122f.

1203 Maltzahn, S. 145.
} 


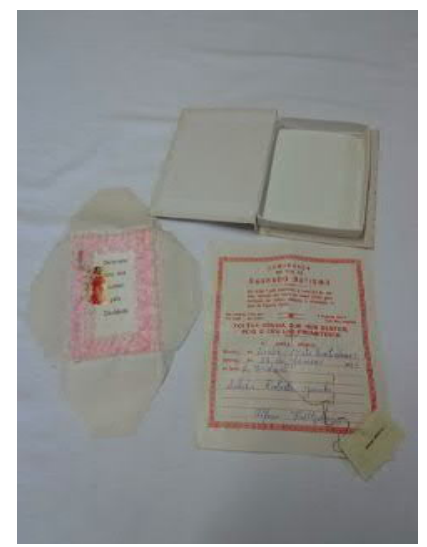

Abb. 8: Patenbrief aus Indaial (SC), 29.1.1984. Auf Portugiesisch. Quelle: Privatarchiv S.J.

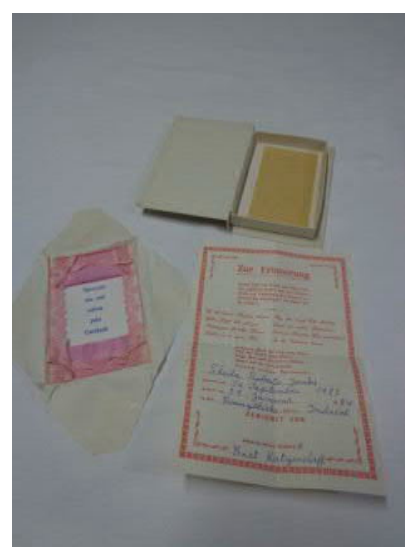

Abb. 9: Patenbrief aus Indaial (SC), 29.1.1984. Quelle: Privatarchiv S.J.

Andere Exemplare enthalten einen Segen:

„Der Herr sei mit Dir und bewahre Dich auf allen Deinen Wegen bis ins ewige Leben! Herr, sei meinem Patchen gnaedig

Mach es aller Suenden ledig

Schenke ihm die reine Seide

Der Gerechtigkeit zum Kleide;

Salbe es mit Deinem Geiste

Und ihm alle Hülfe leiste.

Dass der Segen deiner Haende

Auf ibn bleibe bis ans Ende".1205

1204 Patenbrief aus dem Jahre 1984, Indaial (SC). Auf Portugiesisch. Privatarchiv S. J. 1205 Maltzahn, S. 147. 
Die Sprüche in Gedichtform, wie auch die Segen weisen auf die Gaben Gottes, die durch die Taufe dem Täuflinge zugewiesen werden, auf seinen Schutz ${ }^{1206}$ und seine Hilfe, auf die Vergebung der Sünden, auf das geschenkte Gerechtigkeitskleid, auf die Bewahrung der Gebote und Aufforderung zum Gottesdienstbesuch und besonders auf das ewige Leben. Gewöhnlich waren Patenbriefe in Brasilien auch mit Taufliedern aus dem Gesangbuch versehen, wie das Tauflied „Liebster Jesu wir sind hier, deinem Worte nachzuleben", das häufig in Taufgottesdienste gesungen wurde:1207

„Liebster Jesu, wir sind hier, // deinem Worte nachzuleben. // Dieses Kindlein kommt zu dir, / / weil du den Befehl gegeben. / / Daß man sie zur dir binführe, // denn das Himmelreich ist ihre"208. (Benjamin Schmolck, 1672-1737).

In Abb. 8 ist dieses Lied in seiner portugiesischen Übersetzung zu sehen.

Dass Patenbriefe ursprünglich als Schutz nach dem Beispiel der Himmelsbriefe verwendet wurden, konnte nirgendwo belegt werden. Dies ist auch unwahrscheinlich, denn sie entstanden in einem anderen Kontext und zeitlich gesehen viel später als die Himmelsbriefe. Zudem wurden sie im Unterschied zu den Himmelsbriefen nicht bei sich getragen und wurden nach Losse zusammen mit den inhaltlichen Beigaben als Erinnerungsgeschenk der Paten und Patinnen angesehen. ${ }^{1209}$

Das Taufwasser war für die Pommern heilig, weswegen sie es gern nach der Taufe mit nach Hause nahmen, um es für die Heilung von Krankheiten zu verwenden. ${ }^{1210}$ Selbst die Taufe wurde von manchen als Heilmittel verstanden, weswegen kranke Kinder schnell getauft wurden, „denn bei dem oder jenes hats auch so gut geholfen "1211 Um diesen Brauch zu vermeiden, gossen Geistliche das Wasser nach der Taufe aus ${ }^{1212}$, was oft Protest auslöste. Auch das sogenannte Osterwasser, das am Ostermorgen vor dem Sonnenaufgang im Namen der Dreieinigkeit geholt werden musste, galt als heilig und heilsam gegen Krankheiten. ${ }^{1213}$ Die Mütter lernten von den älteren Frauen auch eine Reihe von Praktiken magischen Inhaltes für die Pflege ihrer Säuglinge. Jede Veränderung an ihrem Gesundheitszustand war Grund für die Suche nach „Gesundbetern“.1214

\footnotetext{
1206 Vgl. Losse, Abbildung 5, S. 13, 19.

1207 Rölke, Hermann. Beantwortung des "Fragebogens bezueglich des deutschen Kirchenliedes im Auslande", MEW 4.194.

1208 Deutscher Evangelischer Kirchenausschuß. Deutsches Evangelisches Gesangbuch, Lied 130.

1209 Losse, S. 7.

1210 Nach katholischem Brauch wurde das Wasser für die Taufe in der Osternacht geweiht und ihm eine heilende Wirkung zugeschrieben. Brückner, Annemarie. Taufe. In: Brednich, Rolf Wilhelm. Enzyklopädie des Märchens. Band 13. Berlin/New York: De Gruyter, 2010, S. 256.

1211 Brief von Pastor Grau an Weissman, Rio do Sul, 25.6.1928, BMA, PABV 1981.

1212 Bahia, S. 158; Maltzahn, S. 58.

1213 Altmann, S. 127f; Rölke, Raízes da Imigração alemã, S. 589; Bahia, S. 227 f; Maltzahn, S. 84.

1214 Bahia, S. 143f; Maltzahn, S. 54, 56.
} 


\subsubsection{Konfirmation und Trauung}

Das Schulsystem in den Kolonien vermischte sich manchmal mit dem Konfirmationsunterricht und mit der Konfirmation endete in der Regel auch der Schulbesuch der Kinder. Der Kleine Katechismus bildete die Unterrichtsbasis für den Konfirmandenunterricht ${ }^{1215}$, obwohl der Inhalt teilweise bereits auch in der Familie durch Rezitieren und Nachfragen einstudiert wurde. ${ }^{1216}$ Auf diese Weise kannten die Kinder ihn in der Regel auswendig, auch wenn sie nur wenig lesen und schreiben konnten. Oft beschränkte sich selbst der Konfirmandenunterricht auf das Auswendiglernen des Kleinen Katechismus. Die Funktion des Konfirmandenunterrichts bestand darin, die Kinder ins christliche Leben einzuführen. Vor dem Konfirmationsgottesdienst fand eine Konfirmationsprüfung im Rahmen eines Gottesdienstes statt, an der Konfirmanden vor der Gemeinde nach ihrer Glaubenskenntnis befragt wurden. Patinnen und Paten wurden dafür eingeladen und wer die Prüfung nicht bestand, musste den Konfirmationsunterricht ein weiteres Jahr besuchen.

Der Konfirmationstag galt als heiliger Tag ${ }^{1217}$, vor allem, weil die Konfirmanden hierbei zum ersten Mal am Heiligen Abendmahl teilnehmen durften. Im Konfirmationsgottesdienst bekannten sie der Gemeinde ihren Glauben und versprachen, Gott treu zu sein und an der kirchlichen Gemeinde aktiv teilzunehmen. Ab diesem Moment galten sie als tatkräftige Mitglieder der Gemeinde, durften als Vorstandsmitglieder und als Paten oder Patinnen gewählt werden, trugen finanziell zu der Gemeinde bei und wurden zum Abendmahl zugelassen. Der biblische Konfirmationsspruch prägte das Leben vieler pommerscher Einwanderer und deren Nachkommen, die ihn oft auswendig kannten. ${ }^{1218}$ Das Konfirmandenkind musste an diesem Tag auch das Tischgebet sprechen. Als Konfirmationsgeschenk bekamen sie häufig ihr erstes eigenes Gesangbuch, auch Uhren, Ringe und Geld. ${ }^{1219}$ Diese galten als Symbol für das Erwachsensein. Eine pommersche Frau in Pelotas (RS) berichtet, dass ihre Mutter ihr einen Himmelsbrief als Konfirmationsgeschenk gab, den sie aufbewahren und vor allem in Notsituationen lesen sollte. ${ }^{1220}$

Nach der Konfirmation konnten Jugendliche die Ehe eingehen, denn sie galt als Übergang zwischen Kindheit und Erwachsenenleben. ${ }^{1221}$ Das Brautpaar kannte sich im Wesentlichen aus dem Familien- oder Nachbarschaftskreis, was auch der Abgeschiedenheit der Siedlungsgebiete geschuldet war. Aber die religiöse Feindseligkeit zwischen Katholiken und Protestanten und die ethnische Absonderung

\footnotetext{
1215 Schröder, Brasilien und Wittenberg, S. 271.

1216 Maltzahn, S. 65.

1217 Siehe Aussage eines pommerschen Nachkommens in Pelotas (RS). Zitiert nach Maltzahn, S. 66.

1218 Bahia, S. 161f; Maltzahn, S. 64f.

1219 Thiel; Neumann, S. 378f; Borchers; Kaiser, S. 8, 14.

1220 Maltzahn, S. 85.

1221 Altmann, S. 99; Maltzahn, S. 65.
} 
trug wesentlich dazu bei, dass die deutschen Familien fast ausschließlich unter sich heirateten. Nach Seibel wurden einige Ehen von den Familien arrangiert. Im Hintergrund stand die Sorge um den Landerwerb, denn Töchter erbten kein Land. So diente die Ehe als Fortsetzung des sozialen Status einer Familie. ${ }^{1222}$ Mann und Frau mussten nach einem bäuerlichen Ethos auch bestimmte Eigenschaften besitzen: Er musste ein guter Kolonist und sie eine gute Hausfrau und gebärfähig sein und ihren Mann zusätzlich bei der Hofarbeiten unterstützen. ${ }^{1223}$ Willems weist darauf hin, dass Einwanderer und deren Nachkommen als Mitglieder einer mittleren Schicht in der brasilianischen Gesellschaft einerseits von einer landwirtschaftlichen und städtischen Elite von Lusobrasilianern verachtet wurden, andererseits verachteten sie wiederum Brasilianer, „Mulatos", „Caboclos" und Afrobrasilianer als Mitglieder der unteren Schichten. Diese soziale Konfiguration schloss „Ehen nach oben" und „Ehen nach unter" mit seltenen Ausnahmen aus. Mischehen fanden erst statt, als sich ein Teil dieser Schicht sozial nach oben oder nach unten bewegt hatte. ${ }^{1224}$ Nach Seyferth wurde eine Ehe zwischen deutschen Nachkommen und einem Mitglied anderer europäischer Gemeinschaften (Italiener beispielsweise) toleriert, mit einem Lusobrasilianer war sie nicht erwünscht und mit einem Mischling war sie inakzeptabel. ${ }^{1225}$

Im Bericht eines pommerschen Siedlers kommt die religiöse Auseinandersetzung im Bezug zu Mischehen sogar innerhalb derselben ethnischen Gruppe zum Ausdruck. Der Vater riet seinem Sohn ab, ein römisch-katholisches Mädchen, dessen Eltern aus Bayern stammten, zu heiraten. Es sei besser, ein Mädchen derselben Konfession zur Frau zu nehmen, um seinem Glauben nicht untreu zu werden. Der Braut machte er keine Vorwürfe, das Problem lag daran, dass sie katholisch war und nach brasilianischem Gesetz unterschreiben müsse, dass sie freiwillig der evangelischen Kirche beitreten würde, was aber wiederum ihr Vater nicht zulassen wollte. Für den Pommern konnte ein evangelischer Mann eine Konvertierung zum katholischen Glauben nicht mit seinem Gewissen vereinbaren und wenn der Sohn sich katholisch verheiratete, müsse er sich von seiner Familie trennen. Der Vater des Mädchens kam ihm entgegen und versuchte sich mit ihm zu einigen. Nichts konnte aber seine Meinung ändern und er versuchte mit allen Mitteln, seinen Sohn von dieser Ehe abzubringen:

„,,Ihr Pommern habt harte Köpfe" pflegte unser Pastor bisweilen im Scherze zu sagen. (...). Manchesmal nahm ich meinen Sohn vor. Meine Frau that desgleichen. Wir versuchten mit Güte und mit Strenge ihn von seinem Vorhaben abzubringen. Wir hielten ihm vor, was wir von Sprüchen und von Geschichten über Glaubenstreue wußten. Auch unser Pastor sprach ernste Worte mit ihm, es schien aber alles vergeblich zu sein. (...) Er

\footnotetext{
1222 Willems, S. 253.

1223 Bahia, S. 178-190; Seyferth, S. $148 f$.

1224 Willems, S. 326f, 331; vgl. Seyferth, S. 148; Bahia, S. 188.

1225 Seyferth, S. 164. Siehe ein Beispiel in Boehs.
} 
[der Vater des Mädchens] müsse nachgeben, sonst würden wir uns nie einigen. (...) „Werde nicht zum Verräter an deinem evangelischen Glauben und an deiner deutschen Sprache" so hatte mir mein alter Pastor in meinem Heimatsdorfe zugerufen. Das Wort hatte ich nicht vergessen. So oft ich mitarbeitete in Angelegenheiten der Gemeinde, klang es mir in den Obren und gab mir Trieb. Jetzt aber mußte ich ganz besonders daran denken (...) ".1226

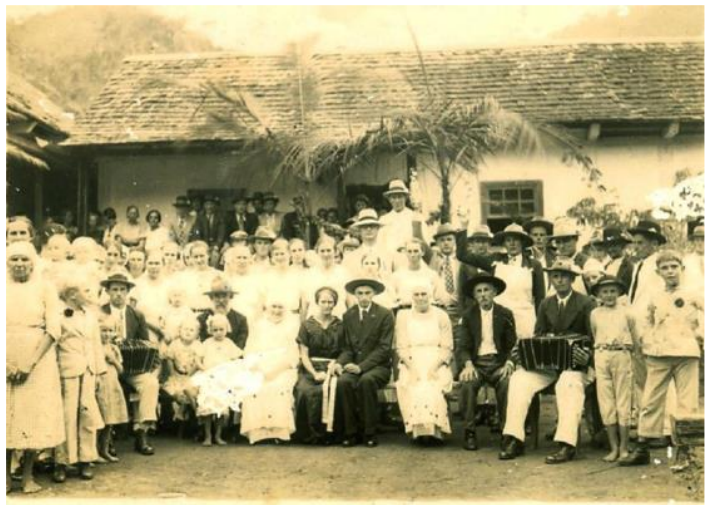

Abb. 10: Pommersche Hochzeit in einem Siedlungsgebiet in Espirito Santo. Quelle: Seibel, Imigrante no século do isolamento, S. 368 .
Letztendlich gab der katholische Bayer nach und ließ seine Tochter den evangelischen Pommern heiraten. ${ }^{1227}$ Wenn bereits Ehen zwischen Katholiken und Protestanten innerhalb derselben ethnischen Gruppe nicht erduldet wurden, repräsentierte die unterschiedliche Konfession ein weiteres Hindernis für interethnische Ehen. In diesem Sinne erschwerte die Religion eine Assimilation zwischen Einwanderern und deren Nachkommen und der einheimischen Bevölkerung. ${ }^{1228}$ Mischehen wurden oft mit einem moralischen Ausschluss aus der Gemeinde bestraft. Man gratulierte den Eheleuten am Hochzeitstag nicht, besuchte sie später nicht ${ }^{1229}$ und schloss diese von Erbe und Brautgabe aus ${ }^{1230}$, denn sie brachen mit den ethnischen Bindungen und Referenzen und mit der ethnischen Kultur und Religion der Gruppe und wurden so zur Gefährdung der sozialen und ethnischen Reproduktion. ${ }^{1231}$

Wenn ein Paar sich dazu entschloss zu heiraten, wurde die kirchliche Trauung in einem Gottesdienst bekannt gegeben und das Brautpaar nahm am Abendmahl teil. ${ }^{1232}$ Dann fand eine Reihe von Ritualen magischen und religiösen Inhaltes statt,

\footnotetext{
1226 Erinnerungen eines deutschen Ansiedlers in Brasilien. In: Sonntagsblatt für die evangelischen Gemeinden in Brasilien. Nr. 38, 12. Jahrgang, 1899, S. 150f. AHI.

${ }^{1227}$ Erinnerungen eines deutschen Ansiedlers in Brasilien. In: Sonntagsblatt für die evangelischen Gemeinden in Brasilien. Nr. 39, 12. Jahrgang, 1899, S. 154. AHI.

1228 Willems, S. 327. Ein ähnliches Phänomen kann unter türkischen Migrantenfamilien in Deutschland betrachtet werden. Die muslimische Gemeinschaft privilegiert bis heute eine muslimische ethnische Endogamie, denn eine Mischehe hätte den Ausschluss aus familiären und sozialen Netzwerken zur Folge und könne den Rückkehr in das jeweilige Herkunftsland verhindern. Kustor-Hüttl, S. 118f, $272 \mathrm{f}$.

1229 Altmann, S. 110, 113, 161.

1230 Bahia, S. 192-197, 203.

1231 Bahia, S. 191.

1232 Rölke, Descobrindo Raízes, S. 66.
} 
die hier nicht ausführlich behandelt werden können: der Hochæeitsbitter ${ }^{233}$, der alle zur Hochzeitsfeier einlud; der Polterabend; das Gedicht der Köchinnen; das Betreten der Kirche; das Hochzeitsmahl, an deren Vorbereitung sich die Nachbarschaft stark beteiligte, etc. ${ }^{1234}$, die zum Teil von Ort zu Ort variierten. Die kirchliche Zeremonie umfasste in ländlichen Gemeinden strenge moralische Regeln. ${ }^{1235}$ Pastor Rölke weist darauf hin, dass bei Hochzeiten in Espírito Santo das Loblied

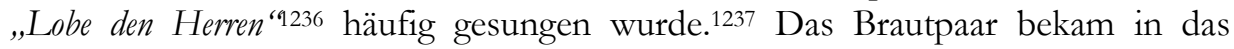
Hochzeitsgewand neben anderen symbolischen Gegenständen wie Getreide, Samenkörner, Flachs, Salz, Haare und Feder auch Brotstücke hineingesteckt, um Haus und Hof gut bewirtschaften und sich emporarbeiten zu können. ${ }^{1238}$ Sie ähnelten den Gegenständen, die dem Kind in den Patenbrief gelegt wurden. Das Hochzeitsbild mit allen geladenen Gästen (Abb. 10, Siehe S. 207) diente als Erinnerung an das Zugehörigkeitsgefühl zu einer religiösen und ethnischen Gemeinde. Es umfasste außerdem einen magischen und religiösen Charakter, denn durch die Hochzeit wurde die Reproduktion und der Fortbestand einer Gruppe gesichert. ${ }^{1239}$

\subsubsection{Die Feier des Heiligen Abendmahls}

Die Abendmahlsfeier, die unter den Pommern als Heiliges Abendmabl bezeichnet wurde, war ein wichtiger Bestandteil des Glaubenslebens. Viele von ihnen folgten den Anweisungen zur Selbstprüfung für den Abendmahlgang auf Grundlage des Dekalogs ${ }^{1240}$ und der Beicht- und Abendmahlgebete in Stark's Handbucb ${ }^{1241}$, im

1233 Nach Bahia war die Einladung des Hochzeitsbitters etymologisch gesehen auch ein Gebet, wie auch die der Frauen beim Polterabend. Bahia, S. 225.

1234 Dazu siehe Borchers; Kaiser, S. 17-23; die Arbeit von Da Cunha, Gladson Pereira. Noivo, noiva e louças quebradas: Simbologia, Teatralidade e Performance nas cerimônias mágicas no casamento pomerano sob a perspectiva antropológica de Van Gennep, Turner e Geertz. In: ANTROPOS, Revista de Antropologia, ano 4. v. 5, maio 2012. S. 153-181. Verfügbar in: http://revista.antropos.com.br/ downloads/maio2012/Artigo6-Noivo.pdf Zugang am 2.4.2014; Thiel; Neumann, S. 380-384; Bahia, S. 223-226, 236-263; Altmann, S. 106-108, 111; Maltzahn, S. 72-78; Soboll, S. 96-99; Rölke, Descobrindo Raízes, S. 66-75; Rölke, Raizeses da Imigração alemã, S. 576-582; vgl. Magisch-sympathetischer Hausschatz, S. 122, 134f, 161.

1235 Falls die Braut keine Jungfrau mehr war, durfte sie nicht mit Kranz und Schleier heiraten und der Bräutigam dürfte keinen grünen Schmuck tragen. Die Glocken wurden während der Hochzeit nicht geläutet. Falls sie gelogen hatten, wurden sie mit öffentlicher Kirchenbuße und Geldstrafe bestraft. Lutherische Kirche in Brasilien, S. 233; Seibel, Imigrante no século do isolamento, S. 373f; vgl. Soboll, S. $95 \mathrm{f}$.

1236 Deutscher Evangelischer Kirchenausschuß. Deutsches Evangelisches Gesangbuch, Lied 254.

1237 Rölke, Hermann. Beantwortung des „Fragebogens bezueglich des deutschen Kirchenliedes im Auslande", MEW 4.194.

1238 Magisch-sympathetischer Hausschatz, S. 163.

1239 Rölke, Raỉzes da Imigração alemã, S. 581.

1240 Vgl. Die Beichte und das Amt der Schlüssel im Luthers Kleinen Katechismus, Jaspis, S. $97 \mathrm{f}$.

1241 Stark, Tägliches Handbuch, S. 224-235, 384-386. 
Evangelischen Hausbuch1242 oder im Gebetsbüchlein im Anhang der Gesangbücher. ${ }^{1243}$ Für sie galt das Sakrament als heilig, und man sollte nicht ohne die entsprechende Selbstprüfung, Beichte und Versöhnung vor den Altar treten. Diese Regeln liegen begründet in biblischen Texten, wie 1. Kor. 11,28-29: „Der Mensch prüfe aber sich selbst, und dann esse er vom Brot und trinke aus dem Kelch. Denn wer unwürdig isst und trinkt, der isst und trinkt sich selber zum Gericht" und Mt. 5,24: „geh zuerst hin und versöhne dich mit deinem Bruder". Ein Gebet für den Vorabend des Abendmahlsgottesdienstes lautete:

„Himmlischer Vater! In dieser Abendstunde kommen wir zu dir, dich um deinen Segen für die heilige Feier am morgigen Tage zu bitten. Wir fühlen, wie sehr wir Vergebung, Frieden und neue Kraft zum Guten nötig haben. Im Glauben an deinen lieben Sohn, der auch für uns sein Leben zum Opfer gegeben hat, möchten wir an deinem Tische mit ibm aufs neue uns vereinigen, auf daß wir ein besseres Leben fübren in der Gerechtigkeit, die dir gefällig ist. So gib denn, Herr, dazu morgen uns und allen, die dich an deinem Tische suchen, beiligen Ernst und stille Sammlung, damit wir eine gesegnete und würdige Feier haben. O Herr hilf; o Herr, laß alles wohlgelingen. Amen. 1 Korinther 11,23-32 ".1244

In der Gemeinde Santa Maria de Jetibá (ES) bestimmte die Gemeindeordnung, dass Gemeindemitglieder sich für das Abendmahl anmelden und vor dem Abendmahlgottesdienst an der privaten Beichte teilnehmen sollten. ${ }^{1245}$ Droogers sieht in dieser Anmeldung eine Strategie der Geistlichen, die Versöhnung zwischen zerstrittenen Mitgliedern zu fördern. Zudem sollte es praktischen Gründen dienen, die genaue Menge von Brot und Wein für das Abendmahl zu besorgen, für die die angemeldeten Gemeindemitglieder auch einen Beitrag zahlten. ${ }^{1246}$ Diese Praxis beruht aber auch auf historischen Grundlagen. Laut Dörfler-Dierken mussten Kommunikanten dem Geistlichen seit der Reformationszeit einen gewissen Obulus entrichten, später wurde auch das freiwillige Beichtgeld oder Beichtpfennig eingesetzt. ${ }^{1247}$ Die Anmeldung zum Heiligen Abendmahl hat ihre Wurzel wiederum in der individuellen Beichte vor dem Abendmahl im Sinne eines Beichtverhörs vor dem Pastor, die beispielsweise Luther für empfehlenswert gehalten hatte und als Möglichkeit zur individuellen Erziehung und Bildung dienen sollte. Der Geistliche müsse sich vergewissern, dass kein Gemeindemitglied mit irrigen Auffassungen am Heiligen Mahl teilnehme und es als Gericht genieße. Auch nach Bugenhagen durften Geistliche niemanden zum Sakrament zulassen, der nicht

\footnotetext{
${ }^{1242}$ Deutscher Evangelischer Kirchenausschuß. Evangelisches Hausbuch, S. 57-63.

1243 Geist-reiches Gebet-Buch, S. 52-65; Christliches Gebet-Büchlein, S. 11-34.

1244 Deutscher Evangelischer Kirchenausschuß. Evangelisches Hausbuch, S. 61.

1245 Entwurf einer Gemeindeordnung der deutschen ev.luth. Kirchengemeinde Sta. Maria, Archiv der Parochie Santa Maria de Jetibá. Zitiert nach Gaede, S. 126.

1246 Droogers, A. Religiosidade popular luterana. São Leopoldo: Sinodal, 1984. Zitiert nach Bahia, S. 162, Anmerkung 13.

1247 Dörfler-Dierken, Angelika. Die Möllner Kommunikantentafeln. Neumünster: Wachholtz, 2003, S. 37, $103 f$.
} 
zuvor Rechenschaft und Bericht über seine Sünden und seinen Glauben abgelegt hatte. Wer am Heiligen Abendmahl teilnehmen wollte, sollte sich vorher beim Pfarrer anmelden, damit dieser feststellten könne, wer die Abendmahlslehre kannte. ${ }^{1248}$ Die Privatbeichte als Bedingung für die Abendmahlsteilnahme wurde dann in Kirchenordnungen der Orthodoxie beibehalten. Am Samstagsnachmittag sammelte sich die Gemeinde in der Kirche und versöhnte sich. ${ }^{1249}$ Im 17. und 18. Jahrhundert setzten orthodoxe, pietistische und aufgeklärte Kreise auf unterschiedliche Herangehensweisen für die Förderung der individuellen Selbstprüfung und in den 1830er Jahren ordnete das Königlich-Dänische Konsistorium die Einführung eines Kommunikantenbuches an, das den Namen jedes Beichtkindes verzeichnen sollte. Alle, die vorhatten, am Sonntag zur Beichte zu kommen, sollten sich einen Tag zuvor anmelden, um in dieses Buch eingetragen zu werden. ${ }^{1250}$ Aus dieser Entwicklung heraus wurde die Anmeldung zum Abendmahl auch in den Gemeinden Brasiliens eingeführt. Und wie bereits in den Kirchenordnungen des 16. Jahrhunderts als Vorbereitung für das Abendmahl bestimmt wurde, nahmen diejenigen, die mit anderen Gemeindegliedern Streit hatten oder Ehebruch begangen hatten, nicht am Abendmahl teil. Pastor Burger berichtet:

„Sie [die Sakramente] stehen bei meiner brasilianischen Gemeinde in hohem Ansehen, besonders bei den Pommern (...) Das Abendmabl [wird] sehr geschätzt. So ist der Abendmahlsgang allgemein üblich. Die Verantwortung in der Beichte ist den Leuten klar. Ich weiss von einigen, die jahrelang nicht zum Abendmahl gingen, weil irgendwie Streit nicht beizulegen war".1251

Als Analogie für die Anmeldungs- und Beichtpraxis unter den Pommern dient auch eine reformierte Tradition. Reformierte Gemeinden in Frankreich verwendeten seit ca. 1561 Marken aus Blei oder einem anderen unedlem Metall, genannt „Méreaux“"252, als Erkennungsmittel zur Zulassung zum Abendmahl. Nach der

\footnotetext{
1248 Dörfler-Dierken, S. 39f, 61f.

1249 Dörfler-Dierken, S. 87. Die Oldenburger Kirchenordnung von 1573 bestimmte zum Beispiel, wie Gemeindemitglieder sich auf das Abendmahl vorbereiten sollten. Sie betraf nicht nur das äußere Ritual, sondern auch die rechten Überzeugungen der Kommunikanten, die Versöhnung mit anderen Menschen, das Bekenntnis der Sünden in der Beichte am Samstag vor dem Abendmahlgottesdienst, die Vermeidung von vielen Essen und Trinken am Vorabend des Abendmahlsgangs, das sich nicht auffallend oder schmucklos anziehen und nicht viel Geld tragen, die biblische und andächtige Vorbereitung zum Sakrament und das Fasten am Sonntagmorgen. Ebd., S. 128f. Vgl. Form zu Beichten vnd Christliche Fragstücke für dieselbigen. So zum Abendmahl des Herrn gehen wollen: wie sie zum Stralsund in Pommern in den Kirchen den Kindern vnd Gesinde vor der Cantzel vorgelesen werden. Stralsund: Meder, 1640.

1250 Döfler-Dierken, S. 164f und Fußnote 21.

1251 Brief von Pastor Georg Burger an den Missionsdirektor Dr. Fr. Eppelein, Neuendettelsau, 12.11.1942, MEW 4.166.

1252 Die Bezeichnung geht nach Desel auf das lateinische Verb mereri, das verdienen oder würdig sein bedeutet, zurück. Desel, Jochen. Zugang zum Abendmabl. Bad Karlshafen: Verlag der Deutschen Hugenotten-Gesellschaft, 2013, S. 7.
} 
Auffassung des Reformators Calvin (1509-1564) war das Abendmahl Nahrung für die Seele und wurde für diejenigen, die unwürdig daran teilnahmen, zum Gift. Zudem sollte auf diese Weise jeder, der am Abendmahl teilnehmen wollte, zur Buße ermahnt werden. Bereits 1541 führte er in Genf die Kirchenzucht ein. Sie bestand aus einem Gespräch mit dem Pfarrer oder einem Kirchenältesten im Haus des Betroffenen, die für Unbußfertige zur Exkommunion führen konnte. Um zu verhindern, dass Fremde oder Unwürdige am Abendmahl teilnehmen, wurden Marken angefertigt, die alle Gemeindemitglieder, die unterrichtet wurden, und Fremde, die ihren Glauben bezeugt hatten, mitnahmen und wodurch bezeugt wurde, dass sie zum Abendmahl zugelassen waren. Außerdem zahlten Gemeindemitglieder bei der Abgabe der Marken einen Beitrag. Wallonisch-reformierte, aber auch lutherische Gemeinden der Niederlande verwendeten bereits im 16. Jahrhundert solche Marken. In Schottland wurden sie durch den Reformator John Knox (ca. 1510-1572) eingeführt und einige schottische Gemeindemitglieder lieBen sich die letzte Abendmahlsmarke, die sie erhalten hatten, als Eintrittskarte in den Himmel in den Sarg legen. Von dort verbreiteten sich die Abendmahlsmarken in den reformierten Kirchen weltweit. In deutschsprachigen Ländern wurden sie mit einigen Ausnahmen erst nach der Aufhebung des Edikts von Nantes 1685 eingeführt, beispielsweise in Stettin. ${ }^{1253}$ In manchen Gemeinden gab es auch kollektive Vorbereitungs- oder Beichtgottesdienste vor oder am Vorabend des Abendmahls. ${ }^{1254}$

Für Pommern in Brasilien umfasste die Abendmahlsfeier aber auch eine sehr wichtige seelsorgerische Funktion. Besonders Schwerkranke und Sterbende baten um die Darreichung des Heiligen Abendmahls. ${ }^{1255}$ Laut Rölke betrachteten manche es als Genesungsmittel, nachdem alle anderen Maßnahmen gescheitert waren. Das Abendmahl wurde auch als Vorbereitung auf den Tod angesehen, in wessen Rahmen die Person beichtete, Vergebung ihrer Sünden und Seligkeit zugesprochen bekam, sich rechtzeitig mit jemandem versöhnte und Abschied nahm. Es sollte auch den Weg zur Erlösung bereiten ${ }^{1256}$, damit sie friedlich und selig sterben konnten. ${ }^{1257}$ Laut Pastor Treptau aus California (ES) spendete das heilige Mahl Heimgehenden in Unruhe und Angst, Trost und Frieden. ${ }^{1258}$ Auf seinem Sterbe-

\footnotetext{
${ }^{1253}$ Desel, S. 7-19.

1254 Desel, S. 29. Die Abendmahlsmarken waren ein Instrument der Kirchenzucht, vereinfachten auch die Arbeit der Kirchenältesten mit dem Zählen der Kommunikanten, besserten die Gemeindefinanzen oder wurden für eine Armenkasse bestimmt. Ebd., S. 34-45.

1255 Abschrift eines Briefes an die Missionsleitung [Wüstner], ohne Angabe des Datums, MEW 4.185.

1256 Rölke, Raíres da Imigração alemã, S. 572.

1257 Riegel-Widderhausen, Aus der Arbeit des Lutherischen Gotteskasten in Brasilien. Verlag des Lutherischen Gotteskasten Bayern, 1926, S. 14f, MLV 51/17 108; Thiel; Neumann, S. 379; Rölke, Descobrindo Raizes, S. 78.

1258 Bericht von Pastor Gustav Treptau von 4.12.1893. Zitiert nach Schmidt, Die Anfänge der Diakonie, S. 26.
} 
bett ließ Herr Ramlow aus Pomerode (SC) beispielsweise den Pastor rufen, weil er sich auf den Weg, den er zu gehen hatte, vorbereiten wollte. ${ }^{1259}$ In einem Gebet aus Stark's Handbuch kommt die Bedeutung des Heiligen Abendmahls als Vorbereitung für den Tod deutlich zum Ausdruck:

„Mein Jesu! mich hat herzlich verlanget, das heilige Abendmahl zu empfangen, ehe ich sterbe. Nun dieses Verlangen ist mir nun jetzt erfüllt und gestillt worden; du hast mich gespeist und getränkt mit deinem beiligen Leib und Blut, dafür preise ich dich von Grund meiner Seele. Ich liege hier auf meinem Bette, wovon ich durch deine Allmacht wieder aufkommen, aber worauf ich auch sterben kann, wenn es dein heiliger Wille ist. Darum habe ich mich vorbereitet; meine Seele ist nun genesen, nachdem ich mit Jesu vereinigt bin; ja ich will nun gerne sterben, nachdem ich, o Jesu! zu der genauesten Gemeinschaft mit dir gelangt bin. (...) Willst du mich, o Gott! nun durch den Tod von diesem Leben absondern, so geschehe dein Wille. Ich weiß, meine Sünde ist mir vergeben, darum darf ich mich nicht fürchten, vor dich zu treten; denn wo Vergebung der Sünden ist, da ist auch Leben und Seligkeit. Ich weiß, Jesus hat mir seine Gerechtigkeit geschenkt; wenn ich in diesem Schmuck und Ehrenkleide vor dich, o Gott! komme, so wirst du mich um derselben willen von dem Gericht frei- und lossprechen. Nun, bin ich gerecht worden durch den Glauben, so habe ich Frieden mit Gott durch unsern Herrn Jesum Christum; durch ibn ist mir der Himmel und der Zugang zu dem Gnadenthron geöffnet. Ich weiß, Jesus ist mein Fürsprecher bei Gott; ich sterbe in der Gnade Gottes, in dem Frieden mit Gott; ich bin des Beistandes des heiligen Geistes versichert. So bin ich selig, so sterbe ich selig, so fahre ich selig aus der Welt, und werde auch ewig selig seyn. (...) diese himmlische Speise und dieser Trank stärke und erhalte mich in wabrem Glauben zum ewigen Leben. So ist denn auch mein Wunsch erfüllt, daß meine Speise vor dem Absterben auch das heilige Abendmahl seyn möge. Verleihe mir auch, daß mein letztes Wort, das ich auf der Welt rede, Jesus seyn möge, und meine letzten Gedanken, die ich habe, auf Jesu Blut, Tod, Leiden und Sterben und auf sein heiliges Verdienst gerichtet seyn mögen, so weiß ich, daß ich fröhlich und selig sterben werde. Ist Gott für uns, wer mag wider uns seyn? (...) Amen ".1260

Das Heilige Abendmahl stärkte den Glauben an das ewige Leben und half bei der Bewältigung der Todesnot. Das Gebet weist auf das Abendmahl als Genesung für die Seele, die den Sterbenden in Ruhe und Frieden zum Heiland fahren lässt, auf die Gemeinschaft mit Gott und auf die Vergebung der Sünden, die zum ewigen Leben und zur Seligkeit führen, entsprechend Luthers Auslegung zum Abendmahl im Kleinen Katechismus ${ }^{1261}$, hin. Jesus als Fürsprecher und gerechter Stellvertreter vor dem göttlichen Gericht taucht auch auf, wie auch der Wunsch, die letzten Gedanken vor dem Tod auf ihn gerichtet zu haben.

\footnotetext{
1259 Buzzarello, S. 37.

1260 Der Kranke betet nach dem Genusse des heiligen Abendmahls. Stark, Tägliches Handbuch, S. 234f. 1261 Viertes Hauptstück im Kleinen Katechismus von Martin Luther. In: Deutscher Evangelischer Kirchenausschuß. Evangelisches Hausbuch, S. $123 \mathrm{f}$.
} 
Pastor Langholf berichtet auch über einen Sterbenden, zu dem er gerufen wurde. Einen Kirchenvorsteher hatte er bereits gebeten, „Ein Stück aus dem Handbuch "1262 (hier ist Stark's Handbuch gemeint) vorzulesen und als der Pastor das Haus betrat, sagte der Sterbende zu ihm: „Der Jahn hat mir schon aus dem Handbuch vorgelesen, nun geben Sie mir noch das Nachtmahl und dann kann es abgehen" [zu Sterben gehen]. Nach dem Abendmahl sagte er: „Lesen Sie bitte mal das vom „Trost im Leid“ für meine Frau und Kinder. Den wird's gut tun". Nach dem Abendmahl fühlte er sich dann gerüstet für seinen Gang. ${ }^{1263}$ Ein Gebet oder Aufmunterung zum Gebet mit dem Titel „Trost im Leid“"konnte weder im Evangelischen Hausbuch noch in Stark's Handbuch gefunden werden. Es ist aber davon auszugehen, dass der Sterbende sich auf ein ähnliches Gebet, wie das Folgende, bezog:

„Ewiger, gütiger und großer Gott! ich weiß nicht, wie nahe meines Lebens Ende etwa seyn möchte, und wann du über mich gebieten und mich von der Welt abfordern werdest, darum will ich mich in Zeiten zu meinem Sterben anschicken, besonders aber auch mit Beten und Singen. Ich nehme hiemit Abschied von allen meinen Verwandten, Bekannten, Woblthätern und Freunden; ich befehle sie dir, o großer Gott! in deinen Schutz, deine Liebe und Gnade; thue ibnen Gutes für die mir erzeigte Liebe und Woblthaten, und da ich ibnen nicht Alles vergelten kann, so wollest du an meiner Statt hinfort ibr reicher $V$ ergelter seyn. Ich verlasse meine Freunde, Verwandte und Bekannte, aber du, o großer Gott! wollest sie nicht verlassen; erhalte sie in deiner Furcht, im Glauben und in Frömmigkeit, damit wir uns einander im ewigen Leben wieder sehen mögen. Ich gehe den Weg aller Welt, ich gehe voran, aber im Himmel werden die Gläubigen und Kinder Gottes wieder zusammen kommen. Diejenigen aber, o getreuer Gott! die ich hinterlasse, und welchen mein Abschied von der Welt betrübend und schmerzlich seyn wird, denen gib deinen reichen Segen. Der Herr segne euch, ibr meine geliebten Angehörigen, er segne euch an Leib und Seele; er sei hinfort euer V ater, Versorger und Pfleger; er nehme euch in seinen Schutz, er beschere euch nach seiner väterlichen Gnade ein gesegnetes Auskommen, und bewahre euch vor allem Uebel. Nur fürchtet hinfort Gott, und seid fromm, setztet ener $V$ ertrauen auf ihn, und wisset, er wird sich über euch erbarmen und euch gnädig seyn. Wendet euch nicht von ihm ab durch den Unglauben, durch Bosheit und unchristlichen Wandel; sondern seid ibm getreu bis in den Tod, so wird er euch die Krone des Lebens geben. Lasset nicht von Gott, so wird er euch auch nicht verlassen. Ehret, dienet, liebet und gehorchet ihm. Ja, der Gott aller Gnade und Barmberzigkeit segne euren Aus- und Eingang, daß ibr die Gesegneten des Herrn seyn und bleiben möget. O großer Gott! ich habe sie gesegnet, laß sie auch gesegnet bleiben. Und biemit lege ich mich in deine Arme, o dreieiniger Gott! nimm meine Seele hin, nimm sie auf in die ewige Freude. Ich begehre aufgelöset und bei Christo zu seyn.

1262 Gebete für Kranke und Sterbende, Sprüche, Seufzer und Gebete dem Sterbenden vorzusprechen, Seufzer und Gebete eines Sterbenden und Segensspruch oder Einsegnung eines Sterbenden. In: Stark, Tägliches Handbuch, S. 257-318; vgl. Deutscher Evangelischer Kirchenausschuß. Evangelisches Hausbuch, S. 71-79; Geist-reiches Gebet-Buch, S. 82-85; Christliches Gebet-Büchlein, S. 41-45.

1263 Schreiben Pastors Langholf über das Gebet, MEW 4.118. 


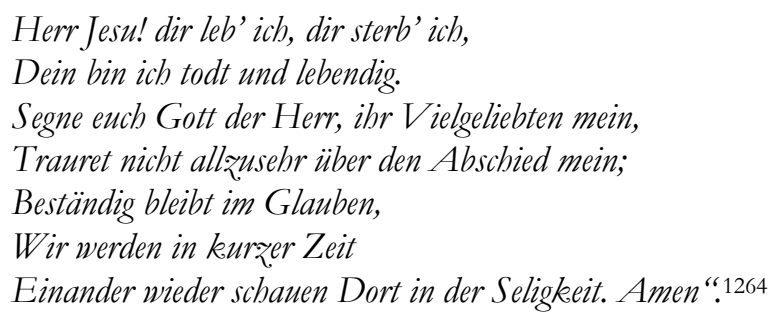

Je nach Anliegen konnten Kranke und Sterbende aus Stark's Handbuch, aus dem Gebetsbüchlein im Anhang ihrer Gesangbücher oder auch aus anderen Andachtsund Gebetsbücher Gebete zur Schmerzlinderung, um Geduld, Beistand im Leiden, Glaubensstärkung, Vergebung der Sünden, Trost, seliges Ende, Himmelsfreude nach einem mühsamen Leben etc. auswählen, wie es im Inhaltsverzeichnis dieser Quellen leicht zu finden war. Hieraus schöpften sie Widerstandskraft für die Bewältigung ihres Leidens, ihrer Ängste, Krankheiten und Todesnot.

Viele Kranke und Sterbende wünschten sich auch, das Lied „Ob Haupt voll Blut und Wunden" zu singen. Paul Gerhards Lieder waren anscheinend von pommerschen Einwanderer und ihren Nachkommen sowohl in Brasilien als auch in den Vereinigten Staaten beliebt. ${ }^{1265}$ Vor allem die letzten Strophen sind hierzu aussagekräftig:

„7. Es dient zu meinen Freuden und tut mir herzlich wobl, // wenn ich in deinem Leiden, mein Heil, mich finden soll. // Ach möcht ich, o mein Leben, an deinem Kreuze bier / / mein Leben von mir geben, wie wohl geschähe mir!

8. Ich danke dir von Herzen, o Jesu, liebster Freund / / für deine Todesschmerzen, da du's so gut gemeint // Ach gib, daß ich mich balte zu dir und deiner Treu, // und wenn ich nun erkalte in dir mein Ende sei.

9. Wenn ich einmal soll scheiden, so scheide nicht von mir; // wenn ich den Tod soll leiden, so tritt du dann bierfür; // wenn mir am allerbängsten wird um das Heræe sein, // so reiß mich aus den Ängsten, kraft deiner Angst und Pein.

10. Erscheine mir zum Schilde, zum Trost in meinem Tod // und laß mich sehn dein Bilde in deiner Krenzesnot // da will ich nach dir blicken, da will ich glaubensvoll // dich stets an mein Herz. drücken. Wer so stirbt, der stirbt wobl".1266 (Paul Gerbard, 1607-1676).

Dieses Passionslied stellt das Leiden Christi für die Erlösung der Menschen dar, mit dem er sich ihnen gleichmachte und auf diese Weise ihnen in Gnade und Liebe entgegenbrachte. Wie Jesus Christus die Qual des Todes fühlte, so identifizier-

1264 Der Sterbende nimmt Abschied und gibt den Seinigen den Segen. Stark, Tägliches Handbuch, S. 264-266.

1265 Von Thadden, Rudolf. Trieglaff. Göttingen: Wallstein, 2010, S. 103.

1266 Im Heiligen Lippen- und Herzens-Opfer Lied 289; im Vermehrten Kirchen- und Haus-Gesang-Buch Lied 92. Deutscher Evangelischer Kirchenausschuß. Deutsches Evangelisches Gesangbuch, Lied 45. Vgl. Der Sterbende will auf Jesum Christum sterben, Stark, Tägliches Handbuch, S. 282-284. 
ten sich Schwerkranke und Sterbende mit dem leidenden Christus und baten ihm um Hilfe für die Bewältigung ihrer Ängste und der Pein vor dem Tode. Ein angenehmes Sterben wäre ein Sterben mit Blick und im Vertrauen auf den Gekreuzigten, der durch seinen Tod die Todesmacht überwand, indem er das Erlösungswerk am Kreuz vollzog und von den Toten auferstand.

Pastor Zluhan berichtet über eine Frau aus Santa Isabel (SC), die nach der Geburt ihres fünften Kindes schwer krank im Bett lag. Fiebrig begann sie die dritte und vierte Strophe des Liedes „Nun laß uns gehn und treten“ zu singen. Obwohl ihr die Kräfte ausgingen und sie nicht mehr mitsingen konnte, folgte sie dem Lied, indem sie lächelte, winkte und mit dem Kopf schüttelte. ${ }^{1267}$ Einige Strophen, die sie zu singen begann, sollten hier Erwähnung finden:

„3. Durch so viel Angst und Plagen, durch Zittern und durch Zagen, durch Krieg und große Schrecken, die alle Welt bedecken.

4. Denn wie von treuen Müttern, in schweren Ungewittern, die Kindlein hier auf Erden mit Fleiß verwabret werden.

5. Also auch und nichts minder läßt Gott ihm seine Kinder, wenn Not und Trübsal blitzen, in seinem Schoße sitzen.

7. Gelobt sei deine Treue, die alle Morgen neue! Lob sei den starcken Händen, die alles Herzleid wenden.

8. Laß ferner dich erbitten, o Vater, und bleib mitten in unserm Kreuz und Leiden ein Brunnen unserer Freuden.

13. Hilf gnädig allen Kranken, gib fröbliche Gedanken den hochbetrübten Seelen, die sich mit Schwermut quälen.

14. Und endlich, was das meiste, füll uns mit deinem Geiste, der uns hier herrlich ziere, und dort zum Himmel führe".1268 (Paul Gerhard, 1607-1676).

Dieses Lied gedenkt dem Beistand Gottes in verschiedenen widrigen, kritischen, schrecklichen und beängstigenden Lebenssituationen. Gott nimmt seine Kinder im Schoße an, bewahrt sie vor Gefahren, wendet ihr Leid in Freude, tröstet die Schwermütigen und führt sie letztendlich zum Himmel, wo sie Frieden und Seligkeit finden werden.

Pastor Wüstner berichtet, dass während seiner Besuche bei älteren Menschen in den 1940er Jahren Volkslieder wie „Auf Adlers Flügel“269 und „Näher mein Gott zu dir" 270 diese besonders ansprachen.

${ }^{1267}$ Zluhan, Christian (Hrsg.) 29. Jahresbericht der Erziehungsanstalt in St Isabella, Estado St ${ }^{a}$ Katharina, Brasilien vom 1.3.1893 bis 1.3.1894. Basel: M. Werner-Riehm, 1895, S. 4-6, 9, 11f, BMA, PABV 708. ${ }_{1268}$ Im Heiligen Lippen- und Herzens-Opfer Lied 226; im Vermebrten Kirchen- und Haus-Gesang-Buch Lied 68; Deutscher Evangelischer Kirchenausschuß. Deutsches Evangelisches Gesangbuch, Lied 24.

${ }^{1269}$ Text von Annie von Wethern-Viebahn, 1931, Melodie von Emil Janssen und Johann Courad. In keinem der hier betrachteten Gesangbücher erhalten.

1270 Text Sarah Adams (1841) und Erhard Friedrich Wunderlich (1875), Melodie Lowell Mason (1859); vgl. Lied 159 in der Kleinen Missionsharfe mit einem anderen Text. Um welche Version es sich handelte, konnte aus der Quelle nicht festgestellt werden. 
Bei der Verwendung von Andachts- und Gesangbücher handelte es sich um einen Faktor der Kontingenz. Nicht alle pommerschen Einwanderer und deren Nachkommen machten Gebrauch von Gebeten und Liedern, sie waren ihnen aber zugänglich und sie konnten nach Bedarf oder Wunsch auf sie zurückgreifen. Die genannten Beispiele dienen als Muster für die Bedeutung von Gebeten und Liedern im Umgang mit Krankheit und Tod. Diese Quellen schenkten den Menschen, die sie lasen, hörten oder sangen, Glaubenskraft, Hoffnung und einen neuen Lebenssinn, der sich auf Gottes Heilszusagen und auf das ewige Leben im Himmelsreich richtete. Auf diese Weise ermöglichten sie den Kranken und Sterbenden, aber auch ihren Angehörigen einen zuversichtlichen Umgang mit Leid, Bedrängnis, Angst und Todesnot.

\subsubsection{Beerdigung}

Der Tod wurde wie andere Lebensereignisse von den Pommern als ein von Gott gegebenes Schicksal angesehen. Wenn jemand im Haus starb, führten sie eine Reihe von Bräuchen magischen Inhaltes durch ${ }^{1271}$, um dem Verstorbenen den Zugang zum Jenseits zu erleichtern und damit er, beziehungsweise seine Seele, nicht andere mit in den Tod reißen konnte. Diese Bräuche variierten von Ort zu Ort. In Espírito Santo beispielsweise durfte das Wasser, das bei der Reinigung des Leichnams verwendet worden war, an keinem Ort, wo Mensch darauf treten konnten, auch nicht in der Nähe von Ställen, ausgegossen werden. ${ }^{1272}$ In Rio Grande do Sul wurde es hingegen aufbewahrt und für Besprechungen verwendet. ${ }^{1273}$ Diese Varianten geben Hinweise auf die Vielfalt magischer Traditionen in verschiedenen Gebieten, aber auch auf eine mögliche Assimilierung von Elementen anderer Einwanderergruppen.

Laut Rölke war es normal, dass bald nach der Todesstunde jemand aus der Familie ein Gebet aus einem Andachtsbuch, meistens aus Stark's Handbuch, vorlas oder vorsprach. Danach sangen alle ein Lied aus ihrem Gesangbuch, möglichst das Lieblingslied des Verstorbenen. ${ }^{1274}$ Nach Aussage von Erich Boldt wurde die Wanduhr auf dem Todeszeitpunktes stehen gelassen, um die Abfahrtzeit des Verstorbenen zur Ewigkeit anzugeben. ${ }^{1275}$

Die Trauerfeier fand im Haus des Verstorbenen statt und anschließend ging der Trauerzug zum Friedhof. Manchmal legten Angehörige Gegenstände des Verstorbenen, die ihn während seines Lebens begleitet hatte, mit in den Sarg und entsprachen damit oft den Wünschen des Verstorbenen. Unter ihnen befanden

\footnotetext{
1271 Thiel; Neumann, S. 385; Magisch-sympathetischer Hausschatz, S. 123-125, 130, 152-154, 161; Rölke, Descobrindo Raizes, S. 78-84; Rölke, Raizes da Imigração alemã, S. 582-587; Borchers; Kaiser, S. 26-32; Maltzahn, S. 79-83; Bahia, S. 291-314.

1272 Rölke, Raizes da Imigração alemã, S. 583.

1273 Maltzahn, S. 79f.

1274 Rölke, Descobrindo Raízes, S. 78.

1275 Interview mit Erich Boldt, 1994. Zitiert nach Rölke, Raízes da Imigração alemã, S. 583.
} 
sich wichtige Glaubensquellen, wie Bibel, Gesangbuch, die nach dem Wunsch des Verstorbenen in seine Händen gelegt werden sollten, damit er Gott in Ewigkeit loben konnte ${ }^{1276}$, den Kleinen Katechismus, ein Gebetbuch, das Tauf- oder Konfirmationszeugnis und der Ehering. Daneben wurden Objekte des täglichen Lebens hinzugefügt, bei älteren Menschen Rasiermesser, Kamm, Seife, Bürste, Handtuch, Arbeitsinstrumente, etc., bei Kindern Spielzeuge. ${ }^{1277}$ Die Hände des Verstorbenen wurden in Gebetsform gekreuzt und die Trauergäste legten ihre Hände oben drauf und verabschiedeten sich mit einem „Wiedersehen " 2278 , einem Hinweis auf den Glauben an die Auferstehung und auf ein Wiedersehen im ewigen Leben.

Nach der Aussage eines pommerschen Nachkommen in Pelotas (RS) mussten ungetaufte Kinder, die im Haus des Verstorbenen wohnten, noch während der Trauerfeier neben seinem Sarg getauft werden. ${ }^{1279}$ Diese Vorgehensweise bekommt in Verbindung mit dem biblischen Text aus dem Röm. 6,3-5 eine tiefere Bedeutung für den christlichen Glauben:

„Oder wisst ibr nicht, dass alle, die wir in Christus Jesus getauft sind, in seinen Tod getauft sind? So sind wir mit ihm begraben durch die Taufe in den Tod, damit, genau wie Christus von den Toten auferweckt ist durch die Herrlichkeit des Vaters, auch wir ein neues Leben leben. Denn wenn wir mit ihm zur Gleichbeit seines Todes gepflanzt sind, so werden wir es auch zu der seiner Auferstebung sein".

Der „Grännisbitter“, „Begräbnisbitter“ oder die „Totenfrau“ ging von Haus zu Haus und lud zur Trauerfeier und zu dem nachfolgenden Leichenmahl ein. ${ }^{1280}$ Nachbarn halfen bei der Zubereitung von Mahlzeiten und unterstützten Angehörige schon vorher bei der Fertigung des Sargs, der Aushebung eines Platzes auf dem Friedhof und anderen Details der Beerdigung. Die Gemeinde beteiligte sich zahlreich an der Trauerfeier und stand den Angehörigen solidarisch bei. Laut Pastor Schlünzen fühlte sich die ganze Kolonie besonders bei Beerdigungen wie eine gemeinsame Familie an. Es war eine Ehre, das Grab einer nahestehenden Person zu zuschaufeln. Keiner scheute sich, dem Toten einen letzten Dienst zu erweisen und den Sarg, an dicke Bambusstange gebunden, zu tragen. ${ }^{1281}$ Wer nicht dabei sein konnte, begleitete die Trauerfeier durch das Glockenläuten ${ }^{1282}$, soweit Glocken vorhanden waren. Pasa weist in diesem Sinne auf die Bedeutung der gesamten Gemeinde bei der Bewältigung von Trauer hin. Der Tod eines Gemeindemitglieds war ein öffentliches Ereignis, das mehr oder weniger die gesamte soziale

\footnotetext{
1276 Bahia, S. 285.

1277 Borchers; Kaiser, S. 27; Rölke, Descobrindo Raízes, S. 79; Bahia, S. 295; Maltzahn, S. 80.

1278 Rölke, Raízes da Imigração alemã, S. $584 \mathrm{f}$.

1279 Maltzahn, S. 81.

1280 Borchers; Kaiser, S. 26; Maltzahn, S. 79.

1281 Schlünzen, F. Deutsche in Brasilien. Neuendettelsau: Freimund, 1936, S. 15f, MEW 3.16.

1282 Rölke, Descobrindo Raízes, S. 79 f.
} 
Gruppe, der er angehörte, betraf. Die Gemeinschaft verarbeitete den Verlust eines Mitgliedes gemeinsam. ${ }^{1283}$

Lieder, die in den beiden pommerschen Gesangbücher oder im Liederbuch Kleine Missionsharfe enthalten sind und zu der Frömmigkeitstradition der Pommern und deren Nachkommen gehörten und von ihnen in Beerdigungen gern gesungen wurden, waren: „Laßt mich gehen, lass mich gehen" "284, „Der Mond ist aufgegangen" "285, „Mitten wir im Leben sind" 286 , „Wer weiß, wie nahe mir mein Ende“.1287 Diese Lieder wurden später auch im Deutschen Evangelischen Gesangbuch aufgenommen. Eine empirisch-quantitative Forschung kann unter pommerschen Einwanderer und deren Nachkommen des hier betrachteten Zeitraums leider nicht mehr durchgeführt werden. Deswegen kann nur noch auf die mündliche Überlieferung und auf die Angaben einiger Pastoren ${ }^{1288}$, die Jahrzehnte in Gemeinden pommerscher Kolonisation gearbeitet haben, zurückgegriffen werden. Zwei dieser Lieder verdienen nähere Betrachtung. Einige Strophen des Liedes „Wer weiß, wie nahe mir mein Ende“ lauten:
„1. Wer weiß, wie nahe mir mein Ende! Hin geht die Zeit, her kommt der Tod. Ach wie geschwinde und behende kann kommen meine Todesnot!
:/Mein Gott! Mein Gott! Ich bitt durch Christi Blut: mach's nur mit meinem Ende gut:/
3. Herr, lehr mich stets mein End bedenken, und wenn ich einstens sterben muß, die Seel in Jesu Wunden senken und ja nicht sparen meine Buß.
5. Mach immer süßer mir den Himmel und immer bittrer diese Welt; gib, daß mir in dem Weltgetümmel die Ewigkeit sei vorgestellt.
6. Ach Vater, deck all meine Sünde mit dem Verdienste Christi zu, darein ich mich fest gläubig winde; das gibt mir recht erwünschte $\mathrm{R} u h$. 7. Nichts ist, das mich von Jesu scheide, nichts, es sei Leben oder Tod; ich leg die Hand in seine Seite und sage: Mein Herr und mein Gott! 8. Ich habe Jesum angezogen schon längst in meiner heilgen Tauf;

1283 Pasa, Fabiane Maria Lorandi. "Eles partiram cedo": Morte, luto e resiliência diante da fé cristã. Porto Alegre: Pontifícia Universidade Católica do Rio Grande do Sul, 2013, S. 17.

1284 Kleine Missionsharfe Lied 6; Deutscher Evangelischer Kirchenausschuß. Deutsches Evangelisches Gesangbuch, Lied 387.

1285 Kleine Missionsharfe Lied 46a; Deutscher Evangelischer Kirchenausschuß. Deutsches Evangelisches Gesangbuch, Lied 373.

1286 Im Heiligen Lippen- und Herzens-Opfer Lied 987; im Vermehrten Kirchen- und Haus-Gesang-Buch Lied 459; Deutscher Evangelischer Kirchenausschuß. Deutsches Evangelisches Gesangbuch, Lied 305

$1287 \mathrm{Im}$ Heiligen Lippen- und Herzens-Opfer Lied 1005; im Vermehrten Kirchen- und Haus-Gesang-Buch Lied 467; Deutscher Evangelischer Kirchenausschuß. Deutsches Evangelisches Gesangbuch, Lied 330.

1288 Rölke, Hermann. Beantwortung des "Fragebogens bezueglich des deutschen Kirchenliedes im Auslande", MEW 4.194; Weingärtner, Nelso. E-Mail von 5.10.2015; Beskow, Aldo. E-Mail von 10.10.2015; Rölke, Helmar Reinhard. Die Gotteskastenarbeit im Staat Espírito Santo als Voraussetzung für die Entwicklung einer Lutherischen Synode. In: Backhause, Martin; Zeller, Hans. (Hrsg.) Aufbruch in Grenzen. Neuendettelsau/Nürnberg/Erlangen: Verlag für Mission und Ökumene/mabaseVerlag/Martin-Luther-Verlag, 2016, S. 79. 
du bist mir auch daher gewogen, hast mich zum Kind genommen auf.

9. Ich habe Jesu Leib gegessen, ich hab sein Blut getrunken hier;

nun kannst du meiner nicht vergessen, ich bleib in ibm und er in mir.

11. Ich leb indes in Gott vergnüget und sterb obn alle Kümmernis;

mir genüget, wie mein Gott es füget, ich glaub und bin es gan₹ gewißs:

Mein Gott! Mein Gott! Ich bitt durch Christi Blut: mach's nur mit meinem Ende gut".

(Ämilie Juliane von Schwarzburg-Rudolsstadt 1637-1706).

Mit diesem Trostlied baten Sterbende oder Angehörige um ein gutes Ende für sich oder für die Ihrigen und gedachten auch dem plötzlichen, unerwarteten Tod, beziehungsweise der Vergänglichkeit des Lebens. Es weist auch auf die Vergebung der Sünden durch die Verdienste, die Wunder und das Blut Christi, auf die süße Ewigkeit im Vergleich zur bitteren und unruhigen Welt und auf die Verheißungen, die in beiden Sakramente zugesichert werden, nämlich Kind Gottes durch die Taufe zu sein und verbunden mit Christus durch das Abendmahl zu bleiben, hin. Dadurch muss derjenige, der auf Gott vertraut, nichts fürchten, denn ihm bereitet Gott ein seliges Ende.

Das Lied „Laßt mich gehen"lautet:

„1. Laßt mich gehn, laßt mich gehn, // daß ich Jesum möge sehn; / / meine Seel ist voll Verlangen, // ibn auf ewig zu empfangen // und vor seinem Thron zu stehn.

2. Süßes Licht, süßes Licht, // Sonne, die durch Wolken bricht // o wann werd ich dabin kommen, // daß ich dort mit allen Frommen // schau dein holdes Angesicht!

3. Ach wie schön, ach wie schön // ist der Engel Lobgetön! // Hätt ich Flügel, bätt ich Flügel / / flög ich über Tal und Hügel // heute noch nach Zions Höhn.

4. Wie wirds sein, wie wirds sein, // wenn ich rieh in Salem ein, // in die Stadt der goldnen Gassen! // Herr, mein Gott, ich kanns nicht fassen, // was das wird für Wonne sein.

5. Paradies, Paradies, // wie ist deine Frucht so süß! // Unter deinen Lebensbäumen // Wirds uns sein, als ob wir träumen; // bring uns, Herr, ins Paradies!" (Gustav Knak, 1806-1878).

Die Hoffnung auf das ewige Leben im Paradies und der Wunsch, Jesu Angesicht dort zusammen mit anderen Frommen, die im Tod vorangegangen waren, zu erblicken, gemeinsam mit den Engel ihn zu loben, die Wonne in der goldenen Stadt nach einem harten Leben zu genießen und für immer bei Jesus zu sein, kommen in diesem Trostlied zum Ausdruck. Dass dieses Lied bei den Pommern besonders beliebt war hat vermutlich auch historische Hintergründe, denn es wurde vom Erweckungsprediger Gustav Knak geschrieben, der im hinterpommerschen Wusterwitz als Pfarrer (1834-1850) tätig war und viele Pommern durch seine Missionierung beeinflusste.

Schließlich soll noch ein Gebet aus dem Evangelischen Hausbuch aufgeführt werden, an das sich Angehörige angesichts ihres Verlustes und ihrer Trauer wenden 
konnten, Trost in die Auferstehungszusagen und auf den Beistand Gottes gewährte:

„Herr unser Gott, deine Hand liegt schwer auf uns, und um Trost ist uns sehr bange. Wir verstehen deine Gedanken und Wege nicht. Wir sehen deine Liebe in dieser Züchtigung nicht. Aber wir wollen glauben, daß du über uns Gedanken des Friedens hast und nicht des Leides. Wir wollen auch unter Tränen sprechen: Der Herr hat's gegeben, der Herr hat's genommen. Hilf uns, daß wir auch im Glauben sprechen können: Der Name des Herrn sei gelobt! Mache uns stark, daß wir in stiller Ergebung beten: Dein Wille geschehe! Es ist der Herr, er tue, was ihm wohlgefällt! Ich will schweigen und meinen Mund nicht auftun; du wirst es wobl machen. Erbarme dich unser in unserer Trauer und tröste uns nun wieder, nachdem du uns so schwer heimgesucht hast. Bleibe bei uns, Herr, verlaß uns nicht; gib uns deinen Geist ins Herz, daß wir seines Todes und seiner Auferstebung uns getrösten und nicht trauern wie die andern, die keine Hoffnung haben. Allmächtiger Gott, erbarme dich unser und gib uns deinen Frieden. Amen. Luc. 12,3548 "1289

Die Pommern sahen den Tod als Willen Gottes ${ }^{1290}$, was ihnen dabei half, ihn besser zu akzeptieren. Jedoch für die Bewältigung der Trauer erwies sich die Hoffnung auf die Auferstehung und die Hinwendung zu Gott im Leiden als besonders tröstlich. Die Auferstehungshoffnung gab dem Tod einen neuen Sinn beziehungsweise die Sicherheit auf ein Leben in Ewigkeit mit Gott und anderen Geliebten, die im Tod vorangegangen waren. Der Beistand Gottes durch sein Wort, durch Gebete und Lieder stärkte ihren Glauben und gab ihnen Frieden, auch wenn es ihnen manchmal schwerfiel, den Willen Gottes beim Tod eines Angehörigen begreifen zu können.

Zusammenfassend lässt sich feststellen, dass mitgebrachte Glaubensquellen und gepflegte Traditionen eine entscheidende Hilfe für die Organisation von Hausgemeinden in Brasilien darstellten. Die Einwanderer und deren Nachkommen hatten Sehnsucht nach kirchlichem Leben und Gemeinschaft und wollten auf die nötigsten kirchlichen Amtshandlungen nicht verzichten. Auf diese Weise, mithilfe ihrer mitgebrachten Glaubensquellen und kirchlichen Erfahrungen in Verbindung mit Handlungen magischen Inhaltes, konnten sie ihren Glauben trotz aller widrigen Umstände der ersten Siedlungsjahre erhalten. Dieser Glaube war wiederum für die Bewältigung von Lebensübergängen, Krisen und Verlusten in brasilianischen Siedlungsgebieten überlebenswichtig.

\footnotetext{
1289 Deutscher Evangelischer Kirchenausschuß. Deutsches Evangelisches Hausbuch, S. 78.

1290 Rölke, Raizes da imigração alemã, S. 582.
} 


\section{Die Entwicklung der Pommern in Brasilien}

Die brasilianische Regierung wünschte sich fleißige und arbeitswillige Einwanderer, die das Land aus seiner ökonomischen Rückständigkeit herausholen sollten. Durch ihre Arbeitsethik trugen pommersche Einwanderer und deren Nachkommen zu diesem Projekt bei. In diesem Abschnitt soll auf die Organisation bäuerlicher Betriebe und ihre Herausforderungen in brasilianischen Siedlungsgebieten, wie auch auf die industrielle Entwicklung in manchen Gebieten, die den Siedlern einiger Kolonien bessere Aufstiegsmöglichkeiten bot, eingegangen werden. Der Industrialisierungsprozess erreichte jedoch nicht alle Kolonien und mit dem Zuzug neuer Einwanderer am Ende des 19. und Anfang des 20. Jahrhunderts lief der Prozess der Entstehung neuer Kolonien parallel zur Entwicklung der Alteingesessenen. Die Untersuchung der wirtschaftlichen Entwicklung der Pommern und deren Nachkommen ist hier wichtig, um die finanziellen Bedingungen, die die institutionelle Entwicklung kirchlicher Gemeinden und die Errichtung massiver Kirchen ermöglichten, zu verstehen.

\subsection{Die Organisation eines familiären Subsistenzbetriebes und ihre Herausforderungen}

Nach der Rodungsarbeit und Errichtung einer provisorischen Hütte im Urwald, begannen die Siedler die Anbauarbeit. Sie organisierten sich in familiären Kleinbetrieben, die die Produktion fast aller Produkte, die sie für ihren eigenen Konsum benötigten, ermöglichte. Der Überschuss wurde auf dem Markt abgesetzt. Allmählich setzten sie sich für die Verbesserung landwirtschaftlicher Methoden im Hinblick auf eine Kommerzialisierung ein. Diese Entwicklung und die Herausforderungen, die die Siedler dabei zu meistern hatten, sollen nun kurz analysiert werden.

Pommersche Einwanderer mussten sich in Brasilien an neue Hausbaumuster ${ }^{1291}$, Anbauverhältnisse und Kulturen anpassen, was sie jedoch relativ schnell meisterten. Bereits nach zwei oder drei Jahren hatten sie, je nach lokalen Verhält-

1291 In Gebieten, wo kontinuierlich neue Einwanderungswellen ankamen, konnten drei Stufen der Bauentwicklung beobachtet werden: ältere Kolonisten besaßen bereits Fachwerk-, Backstein- oder Lehmhäuser, jüngere hatten Holzhäuser erbaut und Neuankömmlinge errichteten zunächst Palmiten- oder Lehmhütten. Willems, S. 158-161. Die Bauart verriet oft die Herkunft der Siedler. Köbling, Fritz. Die Kolonie São Lourenço im Staate Rio Grande do Sul. In: Deutsche Post, São Leopoldo, 18.11.1908, Nr. 3355, EZA 121/19. In Pomerode (SC) beispielsweise bauten die Pommern Fachwerkhäuser, denn sie stammten aus dem pommerschen Gebiet Rega, wo im 12. und 13. Jahrhundert deutsche Siedler aus Niedersachsen, Westfalen, Friesland und Flandern gesiedelt hatten und das altsächsische Bauernhaus nach Pommern mitbrachten. Büge, Klaus. Das Gescblecht der Büges aus dem Kreis Greifenberg. Husum: Husum Druck und Verlagsgesellschaft, 2001, S. 107f, 110, 114. In Espírito Santo errichteten sie Häuser aus Lehm, die verputzt und gekalkt wurden, und strichen die Wände weiß und die Öffnungen blau, die Farben Pommerns. Wagemann, S. 69f; Grosselli, S. 397. Städtische Wohnhäuser wohlhabender Einwanderer wiesen wiederum Bauelemente lusobrasilianischer Häuser höherer Schichten auf. 
nissen, einen familiären Subsistenzbetrieb organisiert und nach etwa zehn Jahren erweiterten oder errichteten sie bessere Wohnungen, in der Regel mithilfe der Nachbarschaft ${ }^{1292}$, und kultivierten größere Anbauflächen. ${ }^{1293}$ In den familiären Landwirtschaftsbetrieben erledigte die Familie allein die gesamte Hofarbeit. Nur sporadisch oder bei Bedarf kam ein Nachbar zur Hilfe. Nach Wagemann hegten die Pommern keine kapitalistischen Interessen, wie beispielsweise an Großbetrieben. Der Grund dafür bestand in der Tatsache, dass aufgrund der schlechten StraBen- und Transportmöglichkeiten ihre Produkte nicht optimal auslieferbar und somit die nötige Warenversorgung eines solchen Betrieben nicht gewährleistet werden konnten. ${ }^{1294}$ Die geringe Produktion und die hohen Transportkosten kompensierten zudem nicht die Anwendung intensiverer landwirtschaftlichen Methoden. ${ }^{1295}$ Obwohl ihre Kleinbetriebe mit Hilfe einer differenzierten Mischkultur widerstandsfähig gegen ökonomischen Umwandlungen Brasiliens war ${ }^{1296}$, kritisiert von Tschudi das gemischte Produktionssystem, das seiner Sicht nach der Grund für den niedrigen Verkaufspreis kolonialer Produkte war. ${ }^{1297}$

Es wurde vielerorts nur mit der Hacke gearbeitet, mit Ausnahme von São Lourenço do Sul (RS), wo in den breiten Tälern teilweise den Pflug gebraucht wurde. ${ }^{2298}$ In Rio Grande do Sul und Santa Catarina konnte laut Seyferth ca. 30\% einiger Grundstücke nicht bebaut werden, weil sie sich in steinigen, schrägen, hügeligen Bereichen ${ }^{1299}$ oder in Sumpfgebieten ${ }^{1300}$ befanden. ${ }^{1301}$ Der Boden in Santa Leopoldina (ES) bestand wiederum aus Quarzsand, einer dünnen Humusschicht und dichtem, faserigem Wurzelgewebe, was sich für die meisten Kulturen als unbrauchbar erwies. ${ }^{1302}$ Dona Francisca (SC) und Blumenau (SC) waren auch

\footnotetext{
1292 Bericht von Egon Tiedt. Zitiert nach Altmann, S. 23.

1293 Bürger, Otto. Brasilien. Leipzig: Dieterich, 1926, S. 371; Dedekind, Brasilien, S. 33, 36; Kahle, S. $27 \mathrm{f}$.

1294 Wagemann, S. 75-77.

1295 Willems, S. 236-239.

1296 Willems, E. Einwanderungsprobleme Brasiliens. In: Kyklos IV, 1950, S. 60-68, S. 61. Zitiert nach Potthast-Hubold, Elke. Zum Mundartgebrauch in Siedlungen pommerscher Auswanderer des 19. Jabrbunderts in Espirito Santo. Neumünster: Karl Wachholtz, 1982, S. 10.

1297 Von Tschudi, Bericht über den Zustand der Kolonien der brasilianischen Provinzen Santa Catharina und San Pedro do Rio Grande do Sul, S. 220f, vgl. Von Tschudi, Reisen durch Süd-Amerika. 3. Band, S. 357.

${ }^{1298}$ Dedekind, Brasilien, S. 33.

1299 Wie zum Beispiel in den Kolonien Nova Petrópolis (RS) und Santa Cruz do Sul (RS). Von Tschudi, Reisen durch Südamerika, 4. Band, S. 39, 48.

1300 Wie in Dona Francisca-Joinville (SC). Von Tschudi, Bericht über den Zustand der Kolonien der brasilianischen Provinzen Santa Catharina und San Pedro do Rio Grande do Sul, S. 210, 231.

1301 Seyferth, G. A colonização alemã no vale do Itajaí-Mirim. Porto Alegre, 1974, S. 60. Zitiert nach Grosselli, S. 362.

1302 Von Tschudi, Bericht über die Kolonien Santa Isabel, Santa Leopoldina und Rio Novo usw., S. $266 f$.
} 
oft von Überschwemmungen betroffen. ${ }^{1303}$ Zudem waren die Siedler in allen Kolonien landwirtschaftlichen Verlusten ausgesetzt, die durch Plagen, Feldmäuse, Ameisen, Raupen, Insekten, Dürre, Frost und Unwetter verursacht wurden. ${ }^{1304}$ Das Vieh wurde oft von Zecken oder Schmeißfliegen geplagt, die ihre Larve in der Haut des Tieres hinterließ, was sich letztlich negativ auf das Leder auswirkte. ${ }^{1305}$ Dies alles schlug sich in Pessimismus wieder ${ }^{1306}$, denn viele von ihnen hatten sich den Anfang leichter vorgestellt. ${ }^{1307}$ Andere ließen sich trotz der vielen Probleme nicht entmutigen. ${ }^{308}$ "Trotz aller Schwierigkeiten, verwweifelten wir nie "sagte ein Kolonist, „denn es ist besser, klein anzufangen, als gleich groß sein zu wollen "1309 Dabei darf nicht vergessen werden, dass etliche Einwanderer Ländereien mit besseren Bodenbeschaffenheiten erhielten, wie beispielsweise in Blumenau (SC) ${ }^{1310}$, in einigen Gegenden von Santa Leopoldinas (ES) ${ }^{1311}$ und in Santa Cruz do Sul (RS). ${ }^{1312}$

Neben dem Anbau verschiedener Pflanz- und Saatkulturen, bauten die Siedler in Espírito Santo auch Kaffee an. Dieser erlangte eine erhebliche wirtschaftliche Bedeutung als Exportprodukt für Brasilien, so dass andere Kulturen in der Regel nur für den familiären Konsum angebaut wurden. In den 1870er Jahren bildete der Kaffee eine sehr gute Einnahmequelle, aber die daraufhin praktizierte Monokultur brachte auch Nachteile mit sich. Weil das Kommunikationsnetz mangelhaft war und die Kolonisten damit keinen Zugang zu aktuellen Preisen bekamen, kauften Geschäftsleute deren Kaffee zu geringeren Preisen als dem aktuellen Kurs. ${ }^{1313}$

1303 Überschwemmungen, die in Blumenau (SC) große Verheerungen verursacht haben, sind in den Jahren 1852, 1855, 1861, 1891, 1898 und besonders 1911 erwähnt. Der Urwaldsbote, Nr. 28/29, 19. Jahrgang, 7.10.1911, EZA 5/2489; Der Urwaldsbote, Nr. 30, 19. Jahrgang, 11.10.1911, EZA 5/2489; Von Tschudi, Reisen durch Süd-Amerika, 3. Band, S. 353, 384f, 401.

1304 Graetsch, Ergänzungsbericht der Gemeinde Brusque für das Jahr 1931, S. 4, EZA 5/2526; Granzow, Pommeranos unter dem Kreuz des Südens, S. 47; Evangelische Confirmanden in Brasilien, S. 38, EZA 200/1/2151; Josenhaus, Der Evangelische Heidenbote, Nr. 4, April 1864, S. 46; Von Tschudi, Reisen durch Süd-Amerika, 3. Band, S. 27, 384f; Von Tschudi. Bericht über die Kolonien Santa Isabel, Santa Leopoldina und Rio Novo usw., S. 261; Grube, S. 62-64; Kahle, S. 24; Rölke, Raízes da Imigração alemã, S. 455-461; Zluhan, Christian (Hrsg.) 29. Jahresbericht der Erriehungsanstalt in Sta Isabella. Basel: Werner-Riehm, 1895, S. 6, 9, 11f, BMA, PABV 708.

1305 Rölke, Raízes da imigração alemã, S. 447.

1306 Von Tschudi, Bericht über die Kolonien Santa Isabel, Santa Leopoldina und Rio Novo usw., S. $274 f$.

${ }^{1307}$ Briefe aus Südbrasilien (Rio Grande do Sul, Serragebiet). Beiblatt der christlichen Tageszeitung „Aufwärts“ (Bethel). Hüben und Drüben, Nr. 1, 3. Jahrgang, März 1927, EZA 5/355.

1308 Allgemeine Auswanderungszeitung, Rudolfstadt, 1852, S. 321. Zitiert nach Schröder, Brasilien und Wittenberg, S. 328.

${ }^{1309}$ Der Heimatbote, Nr. 4, Ano 2, April 1936. Zitiert nach Rölke, Raízes da Imigração alemã, S. 253.

${ }^{1310}$ Die Kolonie Blumenau in Brasilien. Der Weimarschen Zeitung, eingesandt von Herrn Justizrath Hering in Jena. In: Blumenau, Hermann. Jabresbericht über die Ereignisse und Fortscbritte der deutschen Kolonie Blumenau 1856. Hamburg: Robert Kittler, 1857, S. 5f; Von Tschudi, Reisen durch Süd-Amerika, 3. Band, S. 384.

1311 Von Tschudi, Reisen durch Süd-Amerika, 3. Band, S. 23, 26.

1312 Von Tschudi, Reisen durch Süd-Amerika, 4. Band, S. 48, 54.

1313 Wernicke, S. 73. 
Im Unterschied zu großen Kaffeebauern, die staatlich gefördert wurden und die ihre Produkte billig und regelmäßig liefern konnten, verfügten die Siedler über keine Produktionsmittel und mussten ihre Kaffeesäcke auf Maultieren transportieren. ${ }^{1314}$ Das geschah aber nicht nur in Bezug auf Kaffee, laut Salamoni konnten Siedler in Rio Grande do Sul auch nicht mit landwirtschaftlichen Großbetrieben Mittelbrasiliens konkurrieren, die ihre Produkte in dynamischen Märkten leichter kommerzialisierten. ${ }^{1315}$ Weil Siedler in Espírito Santo aber alle Investitionen in die Kaffeekultur setzten, verursachten dessen Preissturz ihren finanziellen Ruin und gefährdeten den wirtschaftlichen Bestand der Kolonien. ${ }^{1316}$

Besonders in Santa Catarina, aber auch in Rio Grande do Sul und Espírito Santo siedelten Mitglieder verschiedener Gewerbetätigkeiten und Repräsentanten intellektueller Schichten, unter ihnen auch manche Pommern. Ihre Anpassung in den Siedlungsgebieten war schwieriger, einige waren der Meinung, ,diejenigen, welche nicht von Hause aus Bauern und tüchtige Arbeitsleute sind und dem gebildeten Stande angehören, können niemals gute und glückliche Colonisten werden"1317, weil ihre Hoffnungen nicht in den brasilianischen Siedlungsgebieten erfüllt werden konnten. Demgegenüber entwickelten sich fleißige, aber auch bescheidene, unbemittelte und freie Kolonisten, die nichts als ihre Arbeitskraft mitbrachten, zu wohlhabenden Eigentümern. ${ }^{1318}$ Weil die Pommern aber verallgemeinert als Bauern und Tagelöhner bezeichnet wurden, standen sie in dem Ruf ,die besten Siedler" 1319 und das „passende Menschenmaterial für die Gründung einer neuen Kolonie "1320 $\mathrm{zu}$ sein, ohne Berücksichtigung weiterer Faktoren und lokaler Bedingungen. Ihre Anpassungsfähigkeit wurde ihrer Tüchtigkeit zugeschrieben ${ }^{1321}$, denn sie waren „gute Bauern aus Pommern “ und

\footnotetext{
1314 Auszug aus dem Reisebericht des Pastors Braunschweig, S. 2, EZA 5/2569.

1315 Salamoni, Giancarla. A imigração alemã no Rio Grande do Sul - o Caso da Comunidade Pomerana de Pelotas. In: História em Revista, Pelotas, V. 7, dezembro 2001, S. 37 f.

1316 Auszug aus dem Reisebericht Pastors Braunschweig, S. 2, EZA 5/2569; vgl. Unsre Reise nach Brasilien, von Frau Pfarrer Peter aus Santa Joana (ES), 6.2.1903. In: Evangelisch-lutherischer Friedensbote aus Elsaß-Lotbringen. Nr. 16, 19.4.1903, S. 159, MLV 51/17 77; Rölke, Raízes da Imigração alemã, S. 163. Mit dem Absturz der nordamerikanischen Börse 1929 verlor der Kaffee ca. 90\% Verkaufspreis in einem Jahr. Viele Kolonisten verschuldeten sich. Präsident Vargas versuchte eine größere Krise zu vermeiden und kaufte die gesamte Produktion. Weil Lagerungskosten sehr teuer waren, ordnete die Regierung die Verbrennung von etwa 78 bis 80 Millionen Kaffeesäcken zwischen 1931 und 1944 an. Roos; Eshuis, S. 84.

1317 Busch, G. (Hrsg.) Brasilia. Ein deutsches Blatt, der Belehrung, der Politik und der Colonisation gewidmet, Petrópolis, 6.2.1861, EZA 5/2571.

1318 Von Tschudi, Reisen durch Süd-Amerika, 3. Band, S. 371; vgl. Avé-Lallemant, Reise durch Südbrasilien im Jahre 1858. 2. Teil, S. 196, 226-228.

1319 Arquivo Público do Estado do Espírito Santo, GDG, Segunda Série (383L), Buch 71, doc. dd 03/11/1873. Zitiert nach Grosselli, S. 221.

${ }^{1320}$ H. Aus der Gründungszeit der Kolonie Santa Cruz. In: Deutsches Volksblatt, Nr. 268, Porto Alegre, 15.11.1926, S. 15. Zitiert nach Willems, S. 61.

1321 Auszug aus den Akten der Riograndenser Synode, 7.5.1866, EZA 5/2432.
} 
an Fleiß und Landwirtschaft gewöhnt. ${ }^{1322}$ Aus diesem Grund wurden sie von manchen Kolonisatoren bevorzugt ${ }^{1323}$ und negative Integrationsfähigkeit von Siedlern einer bestimmten Herkunft galt als Bestätigung für die Arbeitsüberlegenheit anderer. 1324

Arbeiter und Handwerker stammten in der Regel aus ländlichen oder halbländlichen Gebieten und arbeiteten in der Landwirtschaft neben ihren eigentlichen Berufen. Weil aber die Struktur der Gesellschaft in den Siedlungsgebieten nicht dem Spezialisierungsgrad in der Heimat entsprach, fanden sie in den Kolonien keine Anstellung. ${ }^{1325}$ Siedler konnten deren Dienste angesichts ihrer mangelnden Ressourcen nicht in Anspruch nehmen und fertigten alles im Haus und Hof, auch Möbel $^{1326}$, Arbeitsgeräte ${ }^{1327}$ und Zäune ${ }^{1328}$ selbst. Alle mussten mehr oder weniger handwerkliche Fähigkeiten entwickeln ${ }^{1329}$, da in den Siedlungsgebieten auch keine Werkstätten vorhanden waren. So verloren Handwerker und Arbeiter ihr Kapital, ihren Beruf und ihren sozialen Status. Bauern hingegen fanden in Brasilien optimale Lebensbedingungen. Sie erwarben große Ländereien zu billigen Preisen, was ihnen innerhalb einer wenig definierten sozialen Struktur einen gewissen Status gewährte, den sie in der alten Heimat nie erlangt hätten. ${ }^{1330}$ Sie waren trotz aller Schwierigkeiten zufriedener und litten nicht so viel an Heimweh nach der alten Heimat, wie die anderen Siedler. ${ }^{1331}$

1322 Bericht von Dr. Rotermund. Die Gemeinden der Kolonie São Lourenço, 8.8.1911, EZA 121/116; vgl. Auszug aus den Akten V. 114. I. E. O. 1931/1868: Brief Borchards an den Oberkirchenrat Berlin, Montevideo, 1.3.1868, EZA 5/2304; Comité für die protestantischen Deutschen in Südbrasilien. Die Arbeit unter den evangelischen Deutschen in Südbrasilien. Barmen: L. Langewiesche, 1869, S. 24, EZA 200/1/2151.

1323 Rheingantz, Karl Wilhelm. Die Gründung der Kolonie São Lourenço und ihr Gründer Jakob Rheingantz [1907?], S. 23f, EZA 5/2304; Schröder, Die deutsche Einwanderung nach Südbrasilien, S. 95.

1324 Seyferth, Nacionalismo e identidade étnica, S. 158. Von Tschudi bezeichnet die Schweizer als der „arbeitsscheueste Emigrant und wenig sparsam“, Fluck, S. 177 und die Sachsen waren in Brasilien als „Gesindel” bekannt, siehe Brief von Höhne, Rio de Janeiro, 4.10.1869. Zitiert nach Rölke, Raízes da Imigração alemã, S. 610; vgl. Schröder, Brasilien und Wittenberg, S. 270.

1325 Ferraz, S. 59.

1326 Über Hauseinrichtungen siehe Wagemann, S. 98-101; Rölke, Raízes da Imigração alemã, S. 331-338.

1327 Bald errichteten sie auch Mühlen und Maschinen für die Verarbeitung ihrer Produkte und Erhöhung der Produktion, wie Mais-, Reis-, Farin-, Maniokmühlen, Säge-, Wasser- und Mahlmühlen, Zuckerpressen und Manjolos, eine rudimentäre hydraulische Maschine zur Verarbeitung der Kaffeebohnen. Siehe Wernicke, S. 80-85; Soboll, S. 127f; Seibel, Imigrante no século do isolamento, S. 108, 195.

1328 Grimm, H. Deutsche Tätigkeit und Not in Espírito Santo. In: Traeger, P. (Hrsg.) Süd- u. MittelAmerika. Berlin: Verlag G.m.b.H., 30.9.1913, Nr. 18, 6. Jahrgang, S. 278, EZA 5/2563.

1329 Schreiben des Pfarrers Christian Zluhan in Sancta Izabel vom 29.11.1878. In: Blätter des GustavAdolf-Vereins für das Evangelische Württemberg, Nr. 1, 7. Jahrgang, 1879, S. 6f, EZA 200/1/2151; Grimm, H. Deutsche Tätigkeit und Not in Espírito Santo. In: Traeger, P. (Hrsg.) Süd- u. MittelAmerika, 30.9.1913, Nr. 18, 6. Jahrgang, S. 278f, EZA 5/2563; Ramlow; Resende, S. 12; Soboll, S. 15.

1330 Willems, S. 170.

1331 Aus der Gründungszeit der Kolonie Santa Cruz. In: Deutsches Volksblatt, Nr. 268, Porto Alegre, 15-XI-1926, S. 15. Zitiert nach Willems, S. 60f. 
Das brasilianische Rodungssystem verursachte wiederum die Erodierung des Bodens ${ }^{1332}$, der sich nach etwa zwei Jahren erschöpfte, zu Brache gemacht und erneut in Brand gesetzt wurde. ${ }^{1333}$ Ca. zehn Jahren konnte darauf keine gute Ernte mehr erbracht werden, sondern nur spärliche Weide. Weil Siedler in der Regel ihr Vieh frei weiden ließen, produzierten diese auch kein Düngemittel. ${ }^{1334}$ Nach zwanzig bis vierzig Jahren sahen sich viele gezwungen, entweder bestimmte Dünger anzuwenden ${ }^{1335}$ oder umzusiedeln ${ }^{1336}$, ebenso wie jüngere Generationen, die kein Land mehr in älteren Kolonien fanden. Das führte sie nach Wagemann zu einer primitiven Lebensführung und kultureller Rückständigkeit, denn mit der Abwanderung konnte sich die Hauptkolonien nicht weiter entwickeln und die Migranten mussten erneut die primitive Rodungsarbeit in neuen Kolonien durchführen. ${ }^{1337}$

Eine der größten Schwierigkeiten der Bauern war der konkurrenzfähige Absatz ihrer Produkte auf dem Markt. In den ersten Siedlungsjahren, als sie noch keine Maultiere, Pferde oder Ochsenkarren besaßen, mussten sie die Produktion auf ihren Rücken bis zum Stadtplatz tragen. Verbindungen zwischen Kolonien und Städten wurden zwar allmählich hergestellt, aber trotzdem waren die Distanzen

1332 Von Tschudi, Reisen durch Süd-Amerika. 3. Band, S. 25; Rocha, S. 132; Von Tschudi, Reisen durch Süd-Amerika, 4. Band, S. 38; Willems, S. 242; Grosselli, S. 351f. Die konservative Pflanzeraristokratie war für die Bevorzugung einer extensiven Landwirtschaft verantwortlich und investierte nicht in moderne Anbaumethoden. Durch ihren Einfluss prägte sie die landwirtschaftlichen Methoden in den Kolonisationsgebieten. Dieses Verhalten lag aber auch in Zusammenhang mit den großen Flächen in einem bis dahin wenig bewohnten Land und an Bildungsmangel.

1333 Seibel, Imigrante no século do isolamento, S. 225; Seibel, Imigrante a duras penas, S. 191.

1334 Avé-Lallemant, Reise durch Südbrasilien im Jahre 1858. 2. Teil, S. 236.

1335 Pottast-Hubold, S. 15.

1336 Über die Migrationsbewegung der Einwanderer in Rio Grande do Sul siehe Witt, S. 28-36, 85, 91; Grothe, S. 20, 28f, 35f; Von Tschudi, Reisen durch Süd-Amerika, 4. Band, S. 11, 33f; Maltzahn, S. 47; Granzow, Pommeranos unter dem Kreuz des Südens, S. 126; Aldinger, S. 28f; Damitz, Hans. Die deutsch-pommerschen Siedlungen in den drei Südstaaten Brasiliens und ibr kulturelles Leben. Vortrag am Seminar der Ostsee-Akademie vom 25-27. April 1997, S. 6. Manuskript im Privatarchiv von Pastor Nelso Weingärtner; Ruf. Auswanderung nach Brasilien, Neuendettelsau: Buchdruckerei der Diakonissenanstalt. Ohne Angabe von Datum, S. 2, MLV 51/17 60; Gaede, S. 138; Lutherische Kirche in Brasilien, S. 169f. In Espírito Santo siehe Wagemann, S. 37f; Rölke, Raízes da Imigração alemã, S. 245, 317; Roos; Eshuis, S. 87; Bahia, S. 74; Krause, Lutherische Synode in Brasilien, S. 105f; Martinuzzo, José Antonio. Germânicos nas Terras do Espirito Santo. Vitória: Governo do Estado do Espírito Santo, 2009, S. 68; Damitz, Hans. Die ausgewanderten Pommern und die Stellung von Scbule und Kirche im ländlichen Brasilien. Mai/Juni 1991, S. 17. Manuskript im Privatarchiv von Pastor Nelso Weingärtner; Gaede, S. 137f; Lutherische Kirche in Brasilien, S. 169f, 197f; Daemon, S. 332; Von Tschudi, Reise durch Süd-Amerika, 3. Band, S. 37. In Santa Catarina siehe Wilbert et. al., S. 80; Willems, S. 44; Aldinger, S. 29; Schröder, Brasilien und Wittenberg, S. 295; Krause, Lutherische Synode in Brasilien, S. 61f; Comité für die protestantischen Deutschen in Brasilien, S. 82f; Damitz, Die deutsch-pommerschen Siedlungen, S. 5; Weingärtner, História da Comunidade Evangélica de Timbó, S. 233f; Lutherische Kirche in Brasilien, S. 95; Grothe, S. 20, 35f; Ruf. Auswanderung nach Brasilien, Neuendettelsau: Buchdruckerei der Diakonissenanstalt, S. 2, MLV 51/17 60 .

1337 Wagemann, S. $73 f$. 
immer noch groß. ${ }^{1338}$ Zunächst organisierten sich die Siedler nicht in Kooperativen oder Wirtschaftsverbänden, die sich für die Verbesserung ihrer Produktionsmittel und einer gemeinsamen Produktion einsetzen oder Auskunft über eine bessere Nutzung ihres Kapitalüberschusses für die Vermehrung von Gewinnen geben konnten. ${ }^{1339}$ Alle kümmerten sich um die Bewirtschaftung ihres eigenen Grundstückes. Diejenigen, die einen Kredit aufgenommen hatten, bereuten es später, weil sie anscheinend von Banken oder Kreditinstituten übervorteilt worden waren. ${ }^{1340}$ Jedenfalls mangelte es in Brasilien an einer landwirtschaftlichen Politik, die den Siedlern für einen rationalen Anbau und für die Anlage landwirtschaftlicher Musterbetriebe hätte Orientierung geben können. Eine Ausnahme bildeten die staatlichen Kolonien in Rio Grande do Sul ${ }^{1341}$, wo der Staat Saatgut lieferte und Viehkrankheiten bekämpfte. In der privaten Kolonie Blumenau (SC) verschaffte sich der Kolonisator Samen von der kaiserlichen Regierung und verteilte diesen an die Bauern ${ }^{1342}$, während in der privaten Kolonie Dona FranciscaJoinville (SC) die Regierung den Kolonisten mit Zuschüssen von 50, 100 oder 200 Milréis zur Anschaffung von Vieh, Handmühlen oder Pfannen für die Verarbeitung des Maniokmehls und Zuckerpressen unterstützte, die nach einigen Jahren aber verzinst zurückgezahlt werden mussten. ${ }^{1343}$ In Espírito Santo förderte der Staat erst ab 1935 die Landwirtschaft in Koloniegebieten durch den Erwerb landwirtschaftlicher Maschinen und Geräte, Diversifikation des Kulturanbaus und die Einführung von Viehzucht. In Santa Teresa (ES) wurde eine Landwirtschaftsschule gegründet, um den Siedlern eine Alternative zur Kaffeemonokultur anzubieten. ${ }^{1344}$ Optimierte Anbaumethoden wurden allmählich auch durch neue Einwan-

1338 Pelotas (RS) lag 50 bis 80 Kilometer von den Kolonisten aus São Lourenço do Sul (RS) entfernt. 1891 mussten Siedler aus Blumenau (SC) ihre Produkte mit Ochsenkarren in einer zweitägigen Reise bis zur Stadtzentrum fahren. Von dort wurden sie in Kanus bis zum Hafen Itajaí (SC) transportiert und von dort in die Hauptstadt Desterro (SC), wo die Zollbeamten die Steuer einzogen. Die Transportkosten bis Rio de Janeiro (RJ) waren zwei bis dreimal teurer als eine Reise nach Europa. Ballod, Carl. Der Staat Santa Catharina. Stuttgart, 1892, S. 56, 60. Zitiert nach Willems, S. 114. Kolonisten aus Santa Leopoldina (ES) benötigten für Hin- und Rückreise bis zum Hafen, den Aufenthalt mitgerechnet, drei Reisetagen. Von Tschudi, Reisen durch Süd-Amerika, 3. Band, S. 15. Das war ein weiteres Motiv, weswegen sie sich der Kaffeekultur widmeten, denn der Absatz anderer Produkte und der Mangel eines internen Marktes machten diese unrentabel. Martinuzzo, S. 55.

1339 Willems, S. 61; Giemsa, G.; Nauck, E. G. Lebens- und Gesundheitsverhältnisse der deutschen Kolonisten in Espírito Santo (Brasilien). Hamburg: Institut für Schiffs- und Tropenkrankheiten, S. 21, MLV 51/17 108.

1340 Granzow, Pommeranos unter dem Kreuz des Südens, S. 37. Deutsche Pastoren überredeten Siedler in Espírito Santo, ihr Geld nicht in brasilianischen Banken einzuzahlen. Sie übernahmen somit nach Droogers die Funktion einer Sparkasse durch ihre Kontakte zu deutschen Banken. Droogers, S. 25.

1341 Arbeitsgemeinschaft 25. Juli in Rio Grande do Sul, S. 27.

1342 Von Tschudi, Reisen durch Süd-Amerika, 3. Band, S. 385; Ferraz, S. 15.

1343 Von Tschudi, Bericht über den Zustand der Kolonien der brasilianischen Provinzen Santa Catharina und San Pedro do Rio Grande do Sul, S. 215, 219.

1344 Rölke, Raízes da Imigração alemã, S. 178, 422; Damitz, Entwicklungsaspekte zur Situation der Brasilianer, S. 34 . 
derer eingeführt, sowie die Tierzucht und der Kooperativismus. Dieser rief zunächst großen Widerwillen seitens der älteren Siedlern hervor, die diesen aus der alten Heimat nicht kannten. ${ }^{1345}$ Auch neue Anbaumethoden und Kulturen konnten sich nur langsam durchsetzten. ${ }^{1346}$

Nach der Bewältigung der ersten großen Probleme genossen die Siedler ein angenehmeres Leben. Manche konnten nach der Tilgung ihrer Landschuld Geld sparen, womit sie dann mehr Land erwarben ${ }^{1347}$ und letztlich Wohlstand erlangten. ${ }^{1348}$ Einige, die sich nicht anpassten oder aufgrund der unterschiedlichen Verhältnisse nicht denselben Erfolg erzielten, was nicht an einem Mangel an Arbeitseifer gelegen hatte ${ }^{1349}$, kehrten enttäuscht zurück in die alte Heimat. ${ }^{1350}$ Entscheidend für die Bewältigung der Schwierigkeiten in den ersten Siedlungsjahren war aber die Überzeugung, eine bessere Zukunft für die eigenen Nachkommen zu schaffen. Diese optimistische Einstellung half den Einwanderern unter allen Umständen auszuhalten. Ein Kolonist aus Blumenau (SC) schrieb 1867 über das Zufriedenheitsgefühl, das Landgut und die Häuser, ,alles durch unsere eigenen Hände hergestellt" zu wissen. Er vermutete, dass sich in dreißig oder fünfzig Jahren Enkel und Urenkel sich nicht mehr vorstellen könnten, wie schwer dieser Anfang gewesen war. Er freute sich, ihnen durch seine Arbeit und Mühe ein Zuhause und eine Heimat gegeben zu haben, in der , sie fortschreiten und wirtschaftliche Unabhängigkeit und Handelsfreibeit erreichen" konnten. Das Opfer „zum Wobl unserer Kinder und für den Fortschritt dieses Landes "war es seiner Meinung nach wert gewesen. ${ }^{1351}$

\footnotetext{
1345 Willems, S. 162f, 167.

1346 Auszug aus dem Reisebericht Pastors Braunschweig, EZA 5/2569; Granzow, Pommeranos unter dem Kreuz des Südens, S. 159.

1347 Comité für die protestantischen Deutschen in Brasilien, S. 58; vgl. Bahia, S. 80-85; Willems, S. 307. In São Lourenço do Sul (RS) beispielsweise besaß nur selten eine Kolonistenfamilie wenig als 100 Morgen Land, die meisten verfügten über 200 oder 300 Morgen. Köbling, Fritz. Die Kolonie São Lourenço im Staate Rio Grande do Sul. In: Deutsche Post, Nr. 3355, São Leopoldo, 18.11.1908, EZA 121/19. Die Familie Rahn aus Testo Alto-Pomerode (SC) erhielt 1878 zunächst 80 Morgen Land und erwarb später zwei zusätzliche Kolonien. Granzow, Pommeranos unter dem Kreuz des Südens, S. 114 .

1348 Von Tschudi, Bericht über die Kolonien Santa Isabel, Santa Leopoldina und Rio Novo usw., S. 286; Avé-Lallemant, Reise durch Südbrasilien im Jabre 1858. 1. Teil, S. $253 \mathrm{f}$.

1349 Von Tschudi, Bericht über den Zustand der Kolonien der brasilianischen Provinzen Santa Catharina und San Pedro do Rio Grande do Sul, S. 256; vgl. Schlünzen, F. Deutsche in Brasilien. Neuendettelsau: Freimund, 1936, S. 7-9, MEW 3.16; Avé-Lallemant, Reise durch Südbrasilien im Jabre 1858. 2. Teil, S. 197.

1350 Briefe aus Südbrasilien (Rio Grande do Sul, Serragebiet) In: Hüben und Drüben, Nr. 1, 3. Jahrg., März 1927, EZA 5/355.

1351 Associação dos Amigos do Arquivo Histórico de Indaial, t. 1, n. 4, dez. 2015/fev. 2016, S. 16f; vgl. Wernicke, S. $120 f$.
} 


\subsection{Der Industrialisierungsprozess in den Siedlungsgebieten}

Im Zuge des Ausbaus des Straßennetzes, der Entwicklung der Kolonien und des Industrialisierungsprozesses gründeten einige Siedler handwerkliche Werkstätten, die sich allmählich zu industriellen Betrieben entwickelten. In diesen Unternehmen fanden viele eine Nebentätigkeit zu dem landwirtschaftlichen Betrieb und ein sicheres Einkommen. Diese Entwicklung soll im Folgenden betrachtet werden.

In der zweiten Hälfte des 19. Jahrhunderts bildete sich eine Unternehmerschicht in Brasilien, die nach Modernisierung und Fortschritt strebte. Auch die Bedeutung des Landes als Kaffeeexporteur führte schrittweise zu einem Urbanisierungs- und Industrialisierungsprozess. 1870 wurden mit Hilfe ausländischen Kapitals weitverzweigte Bahnstrecken ausgebaut, Häfen verbessert und die Industrie vorangetrieben. ${ }^{1352}$ Neue Regionen Brasiliens wurden erschlossen und damit Transportkosten für den Verkauf von Produkten reduziert. Besonders die südlichen Kolonien in Rio Grande do Sul und Santa Catarina profitierten davon. In Espírito Santo blieb die industrielle und unternehmerische Entwicklung aufgrund schlechterer Straßenverbindungen und einer auf der Kaffeemonokultur basierenden Ökonomie hinter dieser Entwicklung zurück, obwohl der Staat hier ab 1892 und verstärkt ab 1908 in Bahn- und Straßenbau und Industrialisierung investierte. ${ }^{1353}$ Besonders nach dem Preisverfall von Kautschuk, Zucker und Kaffee um 1913 sah sich Brasilien gezwungen, die eigene Landwirtschaft zu diversifizieren und in die heimische Industrie zu investieren. In der Hochkonjunktur des internationalen Kapitalismus erlebte das Land eine neue wirtschaftliche Dynamik mit technischen Fortschritten im Produktionsbereich, einer Produktionssteigerung, Ausbau des Verkehrsnetzes und Entwicklung des Kreditwesens.

In diesem Kontext begannen sich kleine Firmen und Unternehmen in Gebieten pommerscher Kolonisation, wie Santa Cruz do Sul (RS) und Blumenau (SC) ${ }^{1354}$, zu entwickeln. Einige ehemalige Handwerker und Arbeiter ließen sich Maschinen ${ }^{1355}$ und Fachkräfte ${ }^{1356}$ aus der Heimat kommen und stellten Kolonisten

\footnotetext{
1352 Bürger, Brasilien, S. 32, 345.

1353 Grosselli, S. 128-132; Rölke, Raíres da Imigração alemã, S. 164, 241, 508.

${ }^{1354}$ Eine Studie über Santa Cruz do Sul (RS) seit Beginn der Kolonisation bis zum Jahre 1930 zeigte, dass die Mehrheit der Unternehmen den deutschen Einwanderern und deren Nachkommen gehörten. Sie waren für die Herstellung des größten Teils der Produktion und für die Mehrheit der städtischen Steuereinnahme verantwortlich. Auch in Blumenau (SC) stammten die meisten Unternehmen aus ihrer Initiative und sie bildeten 1920 die Mehrheit der Geschäftsleute. Gertz, René. Os Luteranos no Brasil. In: Revista de História Regional 6(2), 2001, S. 23-27; vgl. Ammon, Wolfgang. Deutsche Leistung in Santa Catarina. In: Deutsche Arbeit, 36 (1936) 12, S. 559. Zitiert nach Gertz, O fascismo no sul do Brasil, S. 195. Der Pommer Emil Odebrecht war in Blumenau (SC) an der Entwicklung der Verkehrs- und Kommunikationsinfrastruktur beteiligt und engagierte sich als Distriktleiter für den Ausbau der Eisenbahnverbindung zwischen Rio de Janeiro (RJ) und Porto Alegre (RS) und für die Entwicklung des Telegraphensystems in den Staaten Santa Catarina und Paraná. Seine Söhne gründeten in den Ortschaften des Itajaitals wichtige Handelshäuser, LAST, S. 83.

1355 Ferraz, S. 58.

1356 Willems, S. 249-251.
} 
gegen Tag- und Monatslohn ein. Mit der Entwicklung der Kolonien und der Verbesserung der finanziellen Lage der Siedler konnten diese nun bestimmte Dienste und Produkte konsumieren, statt sie selbst herstellen zu müssen. Ohne hinderliche Gesellschaftsschichten in den Siedlungsgebieten konnte selbst ein geschickter Kolonist ein Unternehmen gründen und damit sozial aufsteigen. Zunächst gründeten die Eltern Werkstätten auf ihre Ländereien, die von ihren Nachkommen zu Grundstoffindustrien oder Unternehmen ausgebaut wurden. ${ }^{1357}$ Viele Siedler arbeiteten alsbald in derartigen Firmen, so dass der landwirtschaftliche Betrieb nicht mehr deren einzige Einnahmequelle darstellte. Unternehmerfamilien sandten ihre Kinder bald nach Deutschland, um sie dort technisch und administrativ ausbilden $\mathrm{zu}$ lassen. Kinder mittlerer Familien lernten hingegen einen Beruf, indem ihre Eltern sie in eine Lehre schickten ${ }^{1358}$, und gründeten später ihre teilweise eigenen Unternehmen. ${ }^{1359}$ Kinder unbemittelter Familien gingen wiederum in die Städte, um in Familien- und Geschäftshäusern, bei Verwandten oder Bekannten zu arbei$\operatorname{ten}^{1360}$, eine bessere Schule zu besuchen und mit ihrem Einkommen der Familie zu helfen.

Auf diese Weise trugen pommersche Einwanderer und deren Nachkommen zur industriellen Entwicklung in den Siedlungsgebieten bei ${ }^{1361}$, was ihnen folglich soziale Anerkennung, ökonomische und politische Bedeutung bescherte. Ihre Integration in das brasilianische Wirtschaftssystem, besonders in Stadtgebieten, ermöglichte ihnen einen sozialen Aufstieg durch sichere Einnahmenquellen und einen engeren Kontakt mit der Aufnahmegesellschaft.

1357 Von Tschudi, Reisen durch Süd-Amerika, 3. Band, S. 394, 401; Von Tschudi, Reisen durch SüdAmerika, 4. Band, S. 37; Bühler, Fritz. Ein Beitrag zur Kirchenkunde Südamerikas, [1917/1918], S. 84, MLV 51/17 108; Avé-Lallemant, Reise durch Südbrasilien im Jabre 1858. 2. Teil, S. 200, 236; Buzzarello, S. 33; Rölke, Raízes da Imigração alemã, S. 318-320; Bosenbecker, S. 65, 130.

1358 Evangelische Synode von Santa Catarina und Paraná, S. 70, 72; Volkmann; Volkmann, S. 17f; Altmann, S. 154f.

1359 Volkmann; Volkmann, S. 17f; Elia, Silvio Edmundo. Pomerode - um caso de bilingüismo. Prefeitura Municipal de Pomerode. Pomerode, sua história, sua cultura, suas tradições. V. 5. Pomerode: Prefeitura Municipal, 1991, S. 51.

1360 Seibel, Imigrante no século do isolamento, S. 187f; Port, Ido. "Ele" - uma história de sofrimento. In: $O$ Semeador, Nr. 93, Juni 2014; Costa, S. 233.

1361 Trotz der ökonomischen Beziehungen mit Deutschland entwickelte sich die deutschbrasilianische Industrie unabhängig von der finanziellen Unterstützung des Deutschen Reiches. Deutschbrasilianer konsumierten ihre eigenen Industrieprodukte, importierten aber Maschinen, die für die Entwicklung und Modernisierung ihrer Industrien notwendig waren. Bald stellten sie auch ihre eigenen Maschinen her. Willems, S. 260-263. 


\section{IV - Institutionelle Formierung und Konflikte}

Nach der Untersuchung der ökonomischen Entwicklung der Einwanderer und deren Nachkommen, soll in diesem Abschnitt die Institutionalisierungsphase kirchlicher Gemeinden bis zur Entstehung der Synoden betrachtet werden. Ältere sowie jüngere Gemeinden werden beiderseits berücksichtigt, denn ihre Entwicklung folgt demselben Muster. Zunächst wird auf die Ankunft von Geistlichen verschiedener Ausbildungsstätten und konfessioneller Orientierungen und auf die Festlegung der ersten Gemeinderegeln eingegangen. Im zweiten Teil ist die Bautätigkeit bei der Errichtung von Gotteshäusern in verschiedenen Phasen zu betrachten. Das Engagement der Gemeindemitglieder bei der Aufbauarbeit gibt Auskunft über die Bedeutung eines würdigen Gotteshauses und der aktiven Partizipation bei Bauprojekten innerhalb einer kirchlichen Gemeinde, was den Menschen die Bildung sozialer Netzwerke ermöglicht, einen Sinn im Leben gibt und somit bei der Bewältigung von Schwierigkeiten hilft. In Anschluss soll die Entwicklung der sozialen Umwelt der Siedler untersucht werden, die den Aufbau wichtiger Institutionen im Siedlungsgebiet beinhaltet. Der letzte Teil widmet sich der Entstehung der Synoden und dem Auftreten verschiedener Konflikte, die durch unterschiedliche Interessen, finanzielle Schwierigkeiten und konfessionelle Unterschiede motiviert wurden. Letztere entwickelten sich aus dem Wunsch heraus, sich dauernder und geordneter Pfarrdienste zu erfreuen und Unabhängigkeit von der Mutterge- 
meinde zu erlangen. Diese Forderungen zeigen, dass ein bestimmtes konfessionelles Bewusstsein unter den Siedlern vorhanden war.

\section{Die Ankunft der Geistlichen und die Strukturierungsphase der Gemeinden}

Geistliche verschiedener Herkunft, Bildung und konfessioneller Orientierungen kamen nach Brasilien, um Einwanderer und deren Nachkommen in der Diaspora kirchlich zu betreuen. Reiseprediger waren wiederum in zerstreuten Gebieten aufgrund der großen Distanzen von wesentlicher Bedeutung, denn sie betreuten die isolierten Siedlerfamilien während ihrer Rundreisen. Ihre Tätigkeit und die Organisation der ersten Gemeinden wird im Folgenden betrachtet.

Die brasilianische Regierung versprach den Einwanderern vertraglich die Anstellung und Besoldung von Pastoren. Dies geschah jedoch nur in Einzelfällen, wie zum Beispiel in São Leopoldo (RS) 1824, wo Pastor Johann Georg Ehlert durch den Agent des brasilianischen Kaiserreiches, Major von Schäffer, eingestellt wurde. ${ }^{1362}$ Die Regierung unterbrach jedoch die Besoldung des Pfarrers und übernahm sie erst nach erheblichen Protesten wieder. ${ }^{1363}$ Pastor Oswald Hesse kam 1857, sieben Jahren nach der Ankunft der ersten Einwanderer nach Blumenau (SC), nachdem der Kolonisator die Regierung 1855 schriftlich und persönlich dazu aufrief, einen Geistlichen aus Deutschland kommen zu lassen und dessen Kosten zu übernehmen. ${ }^{1364}$ Pastor Daniel Jacob Hoffmann übernahm 1851 das Pfarramt in Dona Francisca-Joinville (SC) und wurde zunächst vom Hamburger Kolonisationsverein besoldet, aber auf Betreiben des Vereins übernahm die kaiserliche Regierung einige Jahre später den Pfarrlohn. ${ }^{1365}$ Dieser wurde um 1866 wieder gestrichen. ${ }^{1366}$ Der Basler Missionar Carl Wagner wurde 1861 von der Regierung für Santa Isabel (SC) engagiert und besoldet, obwohl ihm die Gemeindemitglieder aufgrund der Unregelmäßigkeit seiner Besoldung einen Zuschuss zahlen mussten. ${ }^{1367}$ Nach Santa Leopoldina (ES) kam der erste von der Regierung bezahlte Pastor 1864, nachdem die Kolonie sieben Jahren von Santa Isabel (ES)

1362 Dreher, Kontexte und Kirche, S. 17. Er wurde zusammen mit Pastor Friedrich Sauerbronn für Nova Friburgo (RJ), Karl Leopold Voges für Três Forquilhas (RS) und Friedrich Christian Klingelhoeffer für Campo Bom (RS) engagiert. Fischer, Geschichte der Evangelischen Kirche, S. 95f.

${ }^{1363}$ Hennig, S. 89f.

${ }^{1364}$ Dr. Blumenau ließ 1858 auch ein Pfarrhaus für den Pastor bauen. Scheerer. Festschrift der Evangelischen Kirchengemeinde Blumenau, S. 3, EZA 5/2486; vgl. Schröder, Brasilien und Wittenberg, S. $270 \mathrm{f}$.

1365 Es handelte sich um 1:000\$000 (1 Conto de Réis). Der Vertrag zwischen der Hamburger Kolonisationsgesellschaft und Pastor Hoffmann wurde in Hamburg am 7.10.1851 angefertigt. Bühler, Fritz. Ein Beitrag zur Kirchenkunde Südamerikas. [1917/1918], S. 4-6, 11, MLV 51/17 108.

1366 So übernahm die Hamburger Kolonisationsgesellschaft die vollständige Besoldung. Als der Vertrag zwischen der Regierung und dem Kolonisationsverein 1882 abgelaufen war, musste die Gemeinde selbst die Gebühren und Pfarrbesoldung übernehmen. Wüstner, S. 21f.

1367 Stoer, S. 7. 
aus durch Pastor Neudörffer, auch von der Regierung besoldet ${ }^{1368}$, sporadisch betreut wurde. ${ }^{1369}$ Es ist davon auszugehen, dass mit der Anstellung von Geistlichen in älteren Kolonien in jeder Provinz die Regierung ihr Versprechen in Bezug auf die kirchliche Betreuung der Einwanderer als erfüllt ansah. Laut Hess wurde diese Hilfe für weitere Gemeinden in Zusammenhang mit der Kostenstreichung für Einwanderung 1830 oder weil die Besoldung vertraglich befristet war ${ }^{1370}$ eingestellt. Nach Schlatter erklärte sich die brasilianische Regierung bereit, nur für Gemeinden mit mehr als 600 Protestanten einen Geistlichen einzustellen. ${ }^{1371}$ Ende 1880 wurde die Pfarrbesoldung auch für die erwähnten Pfarrbezirke eingestellt ${ }^{1372}$, nachdem zuvor ihre Löhne bereits um die Hälfte gekürzt wurden. ${ }^{1373}$

In allen anderen Gemeinden waren die Gemeindemitglieder auf sich selbst gestellt. Sie baten flehend um einen Geistlichen und beklagten, die deutsche Kirche habe sie vergessen. ${ }^{1374}$ Aufgrund der enormen Distanzen zu bereits vorhandenen Pfarrsitzen, konnten Gemeindemitglieder von Zweiggemeinden auch nicht am Gottesdienst in den Kirchen der Hauptgemeinden teilnehmen. Es gab zunächst keine kirchliche Institution aus der alten Heimat, die sich um die Entsendung von Pastoren oder Missionaren nach Brasilien kümmerte, weswegen die Berufung und Anstellung von Geistlichen in unterschiedlicher Weise ablief. In der Regel wandten sich die Einwanderer an Geistliche ${ }^{1375}$, die bereits in der Muttergemeinde tätig

${ }^{1368}$ Der Pastor von Santa Isabel (ES) erhielt 800 Milréis von der Regierung und weitere 20 Milréis monatliche Gratifikation für den Schulunterricht. Außerdem gewährte die Regierung 400 Milréis für den Bau eines Pfarrhauses. Der katholische Priester bekam dagegen 360 Milréis. Brief von 5.10.1858 an das Ministerium für Reichsangelegenheiten - Generalbüro für Öffentliche Ländereien; Brief des Ministeriums für Reichsangelegenheiten an den Provinzpräsidenten von 23.10.1858, beide in APEES. Zitiert nach Rölke, Raǐes da Imigração alemã, S. 363f, 524; vgl. Von Tschudi, Bericht über die Kolonien Santa Isabel, Santa Leopoldina und Rio Novo, S. 262; Busch, G. F. (Hrsg.) Brasilia. Petrópolis, 6.2.1861, EZA 5/2571.

1369 Von Tschudi, Reisen durch Süd-Amerika. 3. Band, S. 35; Dedekind, 75 Jahre deutsch-evangelischer Diasporaarbeit, S. 83; Schröder, Brasilien und Wittenberg, S. 330.

1370 Hees, Ulrich. Pastorado e Pastores no Rio Grande do Sul. In: Fischer, Joachim (Hrsg.) Ensaios Luteranos. São Leopoldo: Sinodal, 1986, S. 21.

1371 Schlatter, Wilhelm. Gescbicbte der Basler Mission 1815-1915. Basler: Missionsbuchhandlung, 1916, S. 89f; Fluck, S. 192.

1372 Grimm, H. Deutsche Tätigkeit und Not in Espírito Santo. In: Traeger, P. (Hrsg.) Süd- u. MittelAmerika. Nr. 18, 6. Jahrgang, 30.9.1913. Berlin: G.m.b.H, S. 280, EZA 5/2563.

1373 Sandreczki, H. Siebenter Bericht über die Evangelische Schulanstalt in der Colonie ItajahyBrusque, Provinz St. Catharina, Brasilien und Rechenschaft über die hierfür eingegangenen Gaben, 1880, S. 11, BMA S VI A.1-T.I. 11, S C VI C 6. Nach Prien waren auch römisch-katholische Gemeinden in Siedlungsgebieten arm. Viele Kirchen, besonders im Binnenland, befanden sich in mangelhaftem Zustand. Wegen niedriger Besoldung verließen viele katholische Priester diese Gebiete. Prien, S. 83-90; vgl. Baviera, S. 76, 88.

1374 Bericht von Pastor Borchard über Santa Cruz do Sul (RS), 7.12.1864. Zitiert nach Schröder, Brasilien und Wittenberg, S. 134; vgl. Sudhaus, Paul. Vergessene deutsche Glaubensbrüder. Hamburg, September 1903, S. 2, EZA 200/1/5807.

1375 In Itoupava (SC) wandten sich die Gemeindemitglieder an den Nachbarpastor Conrad Roesel, der in Brüdertal (SC) tätig war. Dieser verließ seine Gemeinde und wurde 1902 in Itoupava (SC) angestellt. Lutherische Kirche in Brasilien, S. 87. In Hansa-Humbold (SC) baten sie den Pastor aus 
waren oder auch an Pastoren ${ }^{1376}$ oder Regierungsbeauftragte ${ }^{1377}$, die im Auftrag der Kirche oder des Staates die Siedlungsgebiete bereisten. Andere wandten sich direkt an Missionsanstalten (Barmen, Basel, Saint Chrischona) oder an den Oberkirchenrat ${ }^{1378}$, später auch an den Gotteskastenverein ${ }^{1379}$ und an kirchliche Synoden. ${ }^{1380}$ Die Ausbildung oder konfessionelle Orientierung dieser Geistlichen spielte angesichts der Not der Siedler zunächst keine Rolle.

Seit 1857 entsandte der Evangelische Oberkirchenrat der Preußischen Landeskirche in Berlin einige Geistliche, die aber nur für Gemeinden in Espírito Santo bestimmt waren. ${ }^{1381}$ Diese wurden in Barmen ausgebildet, gehörten der evangelischen Mission an und vertraten, aufgrund ihrer Überkonfessionalität, einen neu-

São Bento do Sul (SC) um Hilfe. Baade, Joel Haroldo. Os conflitos comunitários e sinodais e a formação e consolidação da IECLB. São Leopoldo: Escola Superior de Teologia, 2011, S. 61.

1376 Als Pastor Hermann Borchard im Auftrag des Evangelischen Oberkirchenrates 1864 die Siedlungsgebiete zu besuchen begann, baten ihn mehrere Gemeinden um Hilfe. Er sorgte dann für die Entsendung von Geistlichen, die besonders aus der Barmer Gesellschaft kamen. Nachdem der Koloniedirektor von Santo Ângelo (RS), Baron von Kahlden, ihm um Hilfe bat, besuchte er die Kolonie 1868 und sorgte für die Entsendung des Pastors Tüsmann 1874. Dedekind, 75 Jabre deutsch-evangelischer Diasporaarbeit, S. 51, 103. Auch der Koloniedirektor von São Lourenço do Sul (RS) wandte sich 1867 an Borchard. Auszug aus den Akten V. 114 I - E. O. 649/1868, Brief Borchards an den Oberkirchenrat Berlin, São Leopoldo, 10.12.1867, EZA 5/2304; Schröder, Brasilien und Wittenberg, S. 161.

1377 Durch die Vermittlung des schweizerischen Bevollmächtigten Johann Jakob von Tschudi erhielt Santa Leopoldina (ES) 1864 ihren ersten Geistlicher, Pfarrer Reuter. Von Tschudi, Reisen nach SüdAmerika, 3. Band, S. 35; Wagemann, S. 39. Auch die Siedler in Santa Isabel (SC) baten ihn flehend, er solle bei der brasilianischen Regierung für die Entsendung eines evangelischen Geistlichen und Schullehrer intervenieren. Von Tschudi, Reisen nach Süd-Amerika. 3. Band, S. 408. So kam Pastor Carl Wagner 1861 nach Santa Isabel (SC).

1378 Der Kirchenvorsteher August Keunecke in Indaial (SC) und der Lehrer Albert Fiebes in Badenfurt (SC) wandten sich an die Barmer Missionsgesellschaft. Giurus, Crônica da Paróquia Evangélica Luterana de Indaial, S. 114; Schröder, Brasilien und Wittenberg, S. 275. Gemeindemitglieder in Santa Maria de Jetibá (ES) sandten Briefe an mehrere kirchlichen Instanzen. Brief der Gemeinde Santa Maria de Jetibá von 3.10.1903 im Archiv der Parochie Santa Maria de Jetibá. Zitiert nach Gaede, S. 116f. Der Siedler Johann Meisters, dessen Bruder im Basler Missionshaus studierte, und der Kirchenvorstand Tobler in Inselstraße-Joinville (SC) wandten sich 1862 wiederum an Saint Chrischona und baten um die Entsendung eines Pastors. So wurden 1864 zwei Zöglinge und ein Lehrer nach Joinville (SC) gesandt. Comité für die protestantischen Deutschen in Brasilien, S. 63f; Lutherische Kirche in Brasilien, S. 28; Bühler, Fritz. Ein Beitrag zur Kirchenkunde Südamerikas. [1917/1918], S. 17, MLV 51/17 108; Fluck, S. 327, Anmerkung 503.

13791899 schrieb das Gemeindemitglied Benjamin Barlösius von Santa Joana (ES) mehrmals an den Oberkirchenrat in Berlin und an die Basler Mission und bat dringend um die Entsendung eines Geistlichen. Trotz des dramatischen Charakters seiner Briefe, erhielt er keine Antwort. Erst 1901 antwortete das Predigerseminar in Kropp. Krause, Lutherische Synode in Brasilien, S. 108. Barlösius schickte dem ernannten Geistlichen eine Garantieurkunde mit der Unterschrift von 27 Gemeindemitgliedern, durch welche sie sich für seine Besoldung und Unterkunft verantwortlich erklärten. Gaede, S. 73.

${ }^{1380}$ Gemeindemitglieder aus Ijuí (RS) wandten sich an die Riograndenser Synode. Halle, G. Kurze Geschichte der deutsch-evangelisch-lutherischen Gemeinde zu Ijuby, S. 4, AHI, SR 83/25.

${ }^{1381}$ Nach Dreher hatte nur die Gemeinde Rio de Janeiro (RJ) eine herausragende Stellung für PreuBen. Unter den Gründer der Gemeinde befand sich der preußische Konsul von Theremin. Dreher, Igreja e Germanidade, S. 77. Die Gemeinden Espírito Santos lagen ihr geographisch am nahestehen. 
tralen Standpunkt. ${ }^{1382}$ Bald grenzte aber der Oberkirchenrat die Entsendung weiterer Pastoren aufgrund der zurückhaltenden Position Preußens in Bezug zur Auswanderung nach Brasilien ein. ${ }^{1383}$ Erst im Kontext der Missionserweckungsbewegung kümmerte er sich ab 1864 wieder um die Diasporagemeinden. Im Auftrag des Oberkirchenrates bereiste Pastor Hermann Borchard in diesem Jahr die südlichen Kolonisationsgebiete, um sich über die Lage der deutschen Siedler in Bezug zu Kirche und Schule zu erkundigen. Im Süden von Rio Grande do Sul und in der Kolonie Santa Cruz do Sul (RS), wo sich viele Pommern niederließen, war die Situation besonders schlimm. Nach Mühlenpikade-São Lourenço do Sul (RS) kam 1870 Pastor Dr. Gruel, der 1872 die Gemeinde bereits wieder verließ. Zwischen 1875 und 1897 war kein Pfarrer in den Gemeinden des Südbezirks dieser Kolonie im Amt. ${ }^{1384}$ Der Geistliche aus São Leopoldo (RS) kam ab 1852 gelegentlich nach Santa Cruz do Sul (RS), aber der erste ansässige Pastor, Hermann Bergfried, kam erst 1866 durch die Barmer Gesellschaft dorthin. ${ }^{1385}$ Aus diesem Grund entwickelte sich hier das Phänomen des Kolonistenpfarrertums besonders stark. 1864 übernahm dann die Evangelische Gesellschaft für die protestantischen Deutschen in Nordameri$k a^{1386}$ von Barmen aus die Unterstützung evangelischer Gemeinden in Brasilien und Chile, so dass bald eine Evangelische Gesellschaft für die protestantischen Deutschen in Südamerika (Elberfeld) gegründet wurde. Ab 1865 sandte diese etwa 200 Pastoren und 40 Lehrer zu evangelischen Gemeinden in Brasilien, besonders in Rio Grande do Sul1387, wo viele Einwanderer und deren Nachkommen Jahrzehnte pfarrlos ausharren mussten.

Nach dem Besuch und auf Anregung des schweizerischen Bevollmächtigten von Tschudi, der zwischen 1858 bis 1861 verschiedene Siedlungsgebiete besuchte, auch die hier erwähnten Provinzen, kamen die ersten vier Basler Missionare nach Brasilien. ${ }^{1388}$ Die Basler Missionare standen unter dem Schutz der brasilianischen

\footnotetext{
1382 Rölke, Raízes da Imigração alemã, S. 554f.

${ }^{1383}$ Fischer, Geschichte der Evangelischen Kirche, S. 96. Siehe Kapitel II Abschnitt 4.2.

${ }^{1384}$ Fischer, A luta contra os pastores-colonos, S. 39; Schöder, Brasilien und Wittenberg, S. 162.

1385 Sínodo Riograndense. Comunidade Evangélica de Santa Cruz do Sul 1862 - 100 - 1962, S. 7, AHI, SR 144/15; Schröder, Die deutsche Einwanderung nach Südbrasilien, S. 90.

1386 Sie wurde vom Direktor der Rheinischen Mission, Dr. Friedrich Fabri gegründet. Er gehörte zu den Kreisen, die eine deutsch-kolonialexpansionistische Ideologie für Südbrasilien vertraten. Siehe Kapitel II, Abschnitt 4.3.

${ }^{1387}$ Dreher, Igreja e Germanidade, S. 82. Für eine Auflistung der Geistlicher, die von der Evangelischen Gesellschaft nach Brasilien gesendet wurden, siehe Dedekind, 75 Jahre deutsch-evangelischer Diasporaarbeit, S. 102-111.

1388 Brasilien kam bereits 1826 für die Basler Mission in Frage, nachdem schweizerische Immigranten dringend um einen Seelsorger gebeten hatten. Weil die Verhältnisse in Brasilien aber für die Anstellung eines Predigers unsicher waren, und die Missionsgesellschaft ihre Aufgabe als Mission unter den Heiden in Asien und Afrika verstand, unterblieb die Entsendung von Missionare in den ersten Jahren. Schlatter, S. 89; Josenhaus, Der Evangelische Heidenbote, Nr. 4, April 1864, S. 36. Die Aussendung von Geistlichen für Diasporagemeinden in Brasilien war ihrer Sicht eine Sache der dortigen Behörde oder der Heimatkirche. Fluck, S. 79, 81.
} 
Regierung, die ihnen die Reise gewährte und eine Besoldung in Aussicht stellte. ${ }^{1389}$ Zwischen 1861 und 1874 kamen insgesamt 23 Basler Missionare in die Gemeinden in Espírito Santo und Santa Catarina. ${ }^{1390} 1874$ kamen weitere drei, diesmal nach Rio Grande do Sul, die jedoch von der Evangelischen Gesellschaft in Barmen entsandt wurden. ${ }^{1391}$ Als aber der Inspektor Josenhans sein Amt 1879 aufgab, zog sich das Komitee der Basler Mission schrittweise aus Brasilien zurück. ${ }^{1392}$ Die Basler Missionare besaßen einen unierten Charakter auf pietistisch-biblischer Grundlage und vertraten eine interkonfessionelle Sichtweise im Rahmen ihrer Tätigkeit. ${ }^{1393}$

Bald begann sich der Gotteskastenverein ${ }^{1394}$ für Brasilien zu interessieren, weil viele lutherische Deutschrussen dorthin ausgewandert waren. Auch der Barmer Pastor Johannes Friedrich Brutschin nahm Ende der 1880er Jahren Kontakt mit ihm auf und informierte ihn über die Notlage pfarrloser Gemeinden, nachdem er zuvor seine Beziehungen mit der Riograndenser Synode abgebrochen hatte. ${ }^{1395} \mathrm{Nach}$ Rölke setzte sich der Gotteskastenverein aber für die Diasporaarbeit in Brasilien ein, nachdem er über die Entstehung der Riograndenser Synode, mit uniertem Charakter, erfuhr. ${ }^{1396}$ Gotteskastenmissionare vertraten eine strenge und einheitliche lutherische und konfessionelle Orthodoxie mit Schwerpunkt auf Moral und Pietät und verstanden ihren Dienst in der Diaspora als Erhaltung des Luthertums. Ihr strenges Luthertum stellte sich gegen die Entstehung einer unierten Kirche in Brasilien. Um die Entwicklung einer unierten Kirche unter Einwanderer lutherischen Glaubens in Brasilien einzudämmen soll der Präsident des Gotteskastenvereins seinen Neffen Otto Kuhr überzeugt haben, selbst nach Brasilien als Reiseprediger zu gehen. Zwischen 1897 bis 1939 wurden insgesamt 50 Missionare nach Brasilien entsandt. ${ }^{1397}$

Die Kolonien Hansa Hammonia, heute Ibirama (SC), und Brüdertal bildeten besondere Ausnahmen. Nach Hansa Hammonia kam Pastor Dr. Paul Aldinger ursprünglich als Kolonist, wurde jedoch aufgrund des Pfarrmangels 1902 von den

\footnotetext{
1389 Josenhaus, Der Evangelische Heidenbote, Nr. 4, April 1864, S. 37; Fluck, S. 352. Weil die Gehälter nicht regelmäßig ausgezahlt wurden, wandte sich das Basler Komitee an von Tschudi und an Raffard, die bei der Regierung intervenieren sollten. Brief von Josenhans an von Tschudi, Basel, 1.12.1874, BMA, FB, 2,1.

1390 Fluck, S. 191. Fischer, Geschichte der Evangelischen Kirche, S. 96 und Dreher, História do Povo Luterano, S. 53 erwähnen nur 17.

1391 Prien, S. 78.

1392 Fluck, S. 369

1393 Fluck, S. 359.

${ }^{1394}$ Die Bezeichnung Gotteskeasten weist auf zwei biblische Texte hin, 2. Kön. 12 und Mk. 12,41-42, die Referenz auf die Opferkasten für die Erhaltung des Tempels machen. Weingärtner, Martin Luther e Santa Catarina, S. 132.

1395 Baade, Os conflitos comunitários e sinodais, S. 119.

${ }^{1396}$ Rölke, Raízes da Imigração alemã, S. 541.

1397 Eppelein, Friedrich. 3 Jahre Dienst an lutherischen Glaubensgenossen im Inland und Ausland. Der Martin-Luther-Verein in Bayern 1860-1945. In: Gruß des Martin-Luther-Vereins in Bayern an seine Mitglieder und Freunde anläßlich seiner Jabrestagung in Ansbach (als Sendbrief Nr. 14 ausgeliefert) 1953, S. 2, MEW 3.19.
} 
Einwanderern zum Pastor gewählt. ${ }^{1398}$ Mit einigen Wolgadeutschen aus Chatura reiste Pastor Gottfried Wilhelm Lange vom Evangelischen Oberkirchenrat mit. Er erwarb ein Grundstück von ca. 5.000 Morgen in Brüdertal (SC) am Itapocu-Tal und gründete eine Brüdergemeinde, die von 1886 bis 1897 existierte. Sie wurde aufgelöst und die Gemeindemitglieder gingen in die evangelisch-lutherischen Gemeinden der Kolonie Dona Francisca-Joinville (SC) über, während Pastor Lange die Gemeinde Brusque (SC) übernahm. ${ }^{1399}$

Im Unterschied zu den Absolventen von Missionsseminaren in Barmen, Basel, Saint Chrischona, Neuendettelsau, Hermannsburg oder Kropp stammten die akademisch gebildeten Theologen vom Berliner Oberkirchenrat aus verschiedenen territorialen Kirchen und vertraten in der Regel eine liberale Theologie. Droogers spricht außerdem von einem sozialen Unterschied zwischen den beiden Gruppen. Während akademisch gebildete Pastoren aus der mittleren Schicht stammten und nur für eine begrenzte Zeit eine Pfarrtätigkeit in Brasilien übernahmen, waren Missionare von eher bescheidener Herkunft und arbeiteten auf unbestimmte Zeit ${ }^{1400}$, oft ihr Leben lang, und für geringere Löhne. ${ }^{1401}$ Aus diesem Grund wurden besonders Missionare „näher am Volk“ empfunden, während akademisch gebildete Pastoren Gehorsam und Respekt, entsprechend einer hierarchischen Kirchenstruktur, einforderten. ${ }^{1402} 1907$ gründete der Evangelische Oberkirchenrat in Soest/Westfalen ein Auslands- und Diasporaseminar zur Bildung einer Pfarrerschaft für Brasilien. Sie wurden auf Lebenszeit entsandt und konnten nicht in Deutschland angestellt werden. Das Seminar wurde später nach Stettin und danach nach Ilsenburg/Harz verlegt. ${ }^{1403}$

Angesichts des Pfarrmangels und der Ausdehnung von Siedlungsgebieten war die Tätigkeit der Reiseprediger von entscheidender Bedeutung. ${ }^{1404}$ Nach Fischer sollten sie in Rio Grande do Sul auch gegen die Tätigkeit der Kolonistenpastoren angehen, weswegen sie gezielt nach der Ankunft neuer Immigrationswellen angestellt wurden. ${ }^{1405}$ Sie bereisten von Zeit zu Zeit zerstreute und kirchlich unbetreute Gebiete und vollzogen Gottesdienste und kirchliche Amtshandlungen in mehrstündigen Gottesdiensten. Später sorgten auch kirchliche Synoden für die Anstellung von Reisepredigern. Zwischen 1875 und 1897 bereisten Reiseprediger die

\footnotetext{
1398 Weingärtner, Martin Luther e Santa Catarina, S. 104.

1399 Weingärtner, Martin Luther e Santa Catarina, S. 124-129; Hennig, S. 104.

1400 Bereits Pastor Borchard setzte sich für die Entsendung von Missionare aus Barmen, weil sie im Unterschied zu den akademisch gebildeten Pastoren länger im Land verblieben. Hennig, S. 94f.

1401 Droogers, S. 22.

1402 Rölke, Die Gotteskastenarbeit im Staat Espírito Santo, S. 86.

${ }^{1403}$ Dreher, Kontexte und Kirche, S. 22f.

1404 Über die Tätigkeit der Reiseprediger in Rio Grande do Sul siehe Witt, S. 49-136.

${ }^{1405}$ Fischer, A luta contra os pastores-colonos, S. 51. Fischer, Joachim. Os primórdios da pregação itinerante e do trabalho de diáspora no Sínodo Rio-Grandense. In: Fischer, Joachim (Hrsg.) Ensaios Luteranos. São Leopoldo: Sinodal, 1986, S. 56.
} 
pfarrlosen Gemeinden im Südbezirk von São Lourenço do Sul (RS). ${ }^{1406}$ Von 1891 bis 1893 war Pastor Haetinger als Reiseprediger im Staat Rio Grande do Sul eingesetzt. Aber die finanziellen Schwierigkeiten der Riograndenser Synode und die Föderalistische Revolution (1893-1895) machten diese Reisepredigertätigkeit für eine gewisse Zeit unmöglich. ${ }^{1407}$ Sie konnte erst 1899 wieder aufgenommen werden. ${ }^{1408}$ Anfang des 20. Jahrhunderts sandte die Riograndenser Synode den Reiseprediger Pastor Paul Sudhaus, um die Gebiete von São Lourenço do Sul (RS) zu bereisen und sporadisch zu versorgen. ${ }^{1409}$ In Arroio do Tigre (RS) wurden Siedler erst 1904 von den Reisepredigern Max Dedekind und Wilhelm Karl Ostercamp besucht. Auch andere Reiseprediger besuchten die Gemeinde, bis Pastor Friedrich Wilhelm Hasenack sie 1911 vollkommen übernahm. ${ }^{1410}$ In Santa Catarina übernahm der lutherische Missionar Otto Kuhr und bis 1910 der evangelische Pastor Radlach die Reisepredigertätigkeit ${ }^{1411}$, in Espírito Santo wurden Reiseprediger seit 1907 angestellt. ${ }^{1412}$

An diese Stelle soll kurz die Ankunft von Missourimissionaren erwähnt werden, denn auch sie waren in den hier analysierten Siedlungsgebieten tätig. 1899 hatte sich Pastor Friedrich Brutschin an einen ehemaligen Klassenkamerad der Basler Pilgermission Saint Chrischona gewandt, der in der Missourisynode ${ }^{1413}$ tätig war, und bat um Hilfe für die Besetzung zahlreicher Pfarrstellen in Rio Grande do Sul. 1900 kam der erste Missouripastor, Rev. J. C. Broders für eine Erkundungsreise nach Novo Hamburgo (RS). Nach Rieht entsetzte ihn die moralische Situation der Siedler und angesichts der Tätigkeit von Pastoren der Riograndenser Synode empfahl er Rio Grande do Sul nicht für eine Mission der Missourianer. Bevor er abreiste, besuchte er aber das Gebiet São Pedro do Sul (RS), wo er dann auch die erste Missourigemeinde gründete. ${ }^{1414}$ Laut Prien entstand die erste richtige Missourige-

\footnotetext{
1406 Fischer, A luta contra os pastores-colonos, S. 39; Schröder, Brasilien und Wittenberg, S. 162.

1407 Witt, S. 101, 104.

1408 Die Reiseprediger in Rio Grande do Sul bekamen finanzielle Unterstützung von der Evangelischen Gesellschaft für Protestanten in Amerika und älteren Gemeinden, später auch vom Gustav-Adolf-Werk. Prien, S. 128f, Fischer, Os primórdios da pregação itinerante S. 60f; Witt, S. 58, 73, 75.

1409 Prien, S. 80.

1410 Gelegentlich besuchte Rev. Schulz von Soledade (RS) die Gemeindemitglieder in Rincão EstrelaArroio do Tigre (RS) und 1900 vollzog der katholische Priester Guilherme Müller eine Messe in Arroio Bonito (RS), zwischen Arroio do Tigre (RS) und Sobradinho (RS). Há 75 anos Deus veio à floresta. In: Jornal Paladino Serrano, 25.6.1980, S. 7f; Os 70 anos da Paróquia Evangélica de Sobradinho - Arroio do Tigre. In: Jornal Paladino Serrano, 18.2.1975, S. 9: AHI, SR 83/69.

1411 Dedekind, 75 Jahre deutsch-evangelischer Diasporaarbeit, S. 73.

1412 Über die Tätigkeit der Reiseprediger in Espírito Santo siehe Soboll, S. 92-94. 1901 und 1902 wurden in Guandu (ES) neue Einwanderer und ältere Siedler, die dort umsiedelten, zunächst durch den katholischen Priester Carl Josef Ernst Le Due aus dem Kloster Vila Velha (ES) betreut. Schröder, Brasilien und Wittenberg, S. 337. Bald organisierten sich die Gläubigen aber in einer evangelischen Gemeinde.

${ }^{1413}$ Es handelt sich hierbei um die Lutheran Church - Missouri Synod, die 1847 von Einwanderern, unter ihnen Altlutheraner, die nach der Einführung der Union in Preußen in die Vereinigen Staaten ausgewandert waren, gegründet wurde.

1414 Rieth, S. $213 \mathrm{f}$.
} 
meinde jedoch 1900 im Gebiet der Freigemeinden pommerscher Kolonisation in Pelotas (RS) und São Lourenço do Sul (RS). ${ }^{1415}$ Jedenfalls erhielt Broders bald Unterstützung durch Rev. W. Mahler und angesichts der dringenden Bitten anderer pfarrerlosen Gemeinden kamen immer mehr Pastoren aus den USA nach Brasilien, zunächst in verschiedenen Kolonien von Rio Grande do Sul, später auch in die Gemeinden anderer Staaten, unter ihnen Santa Catarina (1921) und Espírito Santo (1929). Aus der Tätigkeit der Missourimissionare entstand 1904 die MissouriSynode, die sich zu der Evangelisch-Lutherischen Kirche Brasiliens entwickelte. ${ }^{1416}$ Die Missourianer vertraten ebenfalls eine strenge Auslegung des Luthertums und einige Gemeindemitglieder in Brasilien wechselten mal zur Evangelischen Kirche Lutherischen Bekenntnisses in Brasilien, mal zur Evangelisch-Lutherischen Kirche Brasiliens.

Nach Jahren, gar Jahrzehnten ohne geregelte kirchliche Betreuung waren die Siedler froh und dankbar, dass endlich ein Geistlicher zu ihnen kam. Das gab ihnen neue Hoffnung und das Gefühl, nicht von ihrer Kirche im Stich gelassen worden zu sein. Pastor Brutschin berichtet 1894, dass während eines Gottesdienstes bei einigen Gemeindemitgliedern in Barão do Triumpho-São Jerônimo (RS) feierliche Stille herrschte und „in den Augen mancher erglänzten Thränen “.1417 In Joinville (SC) freuten sich die Menschen ,über den neuen Nachschub, über den lebendigen Gruß in der Person des Pfarrers. Sie schöpften Mut".1418

Quellen über die Bildung kirchlicher Gemeinden vor der Ankunft der Geistlichen sind selten. Kolonisten hinterließen aufgrund ihrer geringen Schreibkompetenz nur in Ausnahmefällen schriftliche Berichte über ihren Glauben und die Entwicklung ihrer Gemeinden. ${ }^{1419}$ Besonders Geistliche setzten sich für eine ordentliche Erfassung von kirchlichen Amtshandlungen ein und hinterließen Berichte über die Gemeinden, in denen sie tätig waren. Man versuchte später, mündliche Überlieferungen zu protokollieren, aber bis dahin gingen viele Informationen verloren. Zudem wurden manche Gemeindearchive während der Kriegszeit geplündert und Dokumente beim Versuch, sie davor zu schützen, stark beschädigt. ${ }^{1420}$ So wird die Entstehung kirchlicher Gemeinden erst mit dem Besuch oder

\footnotetext{
1415 Prien, S. 524.

1416 Rieth, S. 213-215. Die Missourisynode gründete bereits 1907 ein Seminar für die Bildung brasilianischer Lehrer und Geistlicher und bekam dafür große Unterstützung von der nordamerikanischen Mutterkirche. Auf diese Weise wurde einen wichtigen Schritt zur Entwicklung einer in Brasilien verwurzelten Kirche gemacht. Prien, S. 525f.

1417 Schreiben Brutschins an den Gotteskastenverein, zitiert nach Krause, Lutherische Synode in Brasilien, S. $46 \mathrm{f}$.

1418 Wüstner, S. 13.

1419 Damitz, Pommerland in Brasilien, S. 4.

${ }^{1420}$ In Pomerode (SC) versteckte der Kirchenvorstand während des Zweiten Weltkriegs die kirchlichen Bücher im Dachboden seines Hauses. Aufgrund von Feuchtigkeit wurden diese teilweise unlesbar. Liesenberg, S. 5. In Timbó (SC) wurde ein Teil der Gemeinde- und Schulbücher konfisziert. Gemeindeprotokolle und -register vergrub Pastor Blümel rechtzeitig im Keller des ehemaligen Gemeindesekretärs, Heinrich Herweg, die später in Vergessenheit gerieten. Dreißig Jahre später, nach Anfrage von Pastor Weingärtner, der eine Chronik über die Gemeinde schreiben wollte, wur-
} 
Ankunft eines Pastors ${ }^{1421}$, mit der Anfertigung der ersten Gemeindestatuten ${ }^{1422}$ oder mit der Errichtung einer Kirche auf dem Marktplatz ${ }^{1423}$ dokumentiert. Die Tätigkeit vieler Laien verlor dabei an Bedeutung und wurde in vielen Fällen nicht in der Geschichte der Gemeinden mit aufgenommen.

In diesem Sinne gewinnt einer der wenigen erhaltenen Berichte eines pommerschen Siedlers aus einer Gemeinde in Rio Grande do Sul große Bedeutung, denn er gibt Auskunft über den Anfang vieler Gemeinden, deren Mitglieder sich aus eigener Initiative zusammenschlossen und sich auf die Berufung und Besoldung eines Pfarrers einigten. Seit etwa zwei Jahre wohnten er und seine Familie zusammen mit anderen Einwandererfamilien in der Kolonie, als sie eines Tages erfuhren, dass sich verschiedene Kolonien, mehrere Tagesreisen von ihnen entfernt, zu einer Gemeinde zusammengeschlossen und einen Geistlichen erhalten hatten. Dieser wollte auch sie besuchen, Kirche und Abendmahl halten und zusehen, wie ihnen geholfen werden konnte. Als er an einem bestimmten Sonntag ankam, freu-

den sie wieder gefunden, aber ein Teil davon war mittlerweile stark beschädigt. Weingärtner, História da Comunidade Evangélica de Timbó, S. $181 \mathrm{f}$.

${ }^{1421}$ In Picada Velha-Santa Cruz do Sul (RS) wird die Gründung der ersten evangelischen Gemeinde 1865 datiert, obwohl mehrere Kolonistenpastoren vorher dort tätig waren und die Gemeinde bereits 1858 eine Kapelle errichtete. Weil Vila Santa Cruz sich 1859 zum Stadtzentrum dieser Kolonie entwickelte und dort 1862 die Gemeinde Santa Cruz gegründet wurde, wurde Picada Velha 1866 zu Zweiggemeinde herabgesetzt. Sínodo Riograndense. Comunidade Evangélica de Santa Cruz do Sul 1862 100 - 1962, S. 7. In Blumenau (SC) wird die Entstehung der Gemeinde auf 9.8.1857 datiert, als Pastor Oswald Hesse dort seinen ersten Gottesdienst feierte, obwohl Gottesdienste und kirchliche Amtshandlungen seit 1850 vollzogen wurden. Weingärtner, 150 Anos de Presença Luterana no Vale do Itajaí, S. 29. Auch in Laranja da Terra (ES) galt der erste von einem ordinierten Pastor vollzogenen Gottesdienst am 10.10.1910 als Gemeindegründung. Lutherische Kirche in Brasilien, S. 178.

1422 In Timbó (SC) feierte Pastor Hesse seit 1873 Gottesdienste in einer Schule. Trotzdem wird die Gründung der Gemeinde erst am 24.9.1887 festgelegt, als Pastor Sandreczki die Gemeindestatuten aus Brusque (SC) als Modell vorstellte und die Gemeinde einen Vorstand wählte. Im Februar 1885 hatten aber bereits achtzehn Familienmitglieder durch Unterschrift erklärt, der Gemeinde beizutreten und einen Beitrag von 2 Milréis als erste Ratenzahlung entrichten zu wollen. Weingärtner, Nelso. Crônica da Comunidade Evangélica de Timbó. Blumenau: Gráfica 43, 1969, S. 12-28.

${ }^{1423}$ Laut Elia wurde die Gemeinde Pomerode (SC) 1862 gegründet. Elia, S. 51. Dies ist unter anderem aus einem Taufregister zu entnehmen. Pomerode wurde von Blumenau (SC) und später von Badenfurt (SC) aus betreut und im Taufregister Badenfurts wurde März 1863 die Taufe von Karl Koch in Rio do Testo-Pomerode (SC) eingetragen, Liesenberg, S. 6. Aber die Entstehung der Gemeinde Pomerode wird erst mit dem Bau der Marktkirche 1884 verbunden. Auch die Entstehungsgeschichte der Gemeinde Indaial (SC) blieb nicht erhalten und wird mit der Grundsteinlegung einer Kirche 1884 verbunden. Giurus, Crônica da Paróquia Evangélica Luterana de Indaial, S. 108f. Die Gründung der Gemeinde Califórnia-Santa Leopoldina (ES) wurde am 20.7.1873 mit der Abstimmung über die Errichtung eines Gottesdienstlokals im Landlos von August Boernke festgelegt. Gaede, S. 56. Obwohl in Jaraguá do Sul (SC) die Pastoren Kuhr (1904) und Schlünzen (1905 bis 1907) Gottesdienste im Haus von Heinrich Marquardt vollzogen, wurde die Gründung der Gemeinde am 1.4.1907 festgelegt, nach der Errichtung der Schule, die als Gottesdienstlokal diente. Claas, Armando Emílio. História da Paróquia Evangélica Luterana Apóstolo Pedro: Primórdios da Comunidade Evangélica de Jaraguá do Sul. In: Klug, João; Ulrich, Claudete Beise (Org.) Presença e atuação da Igreja Evangélica de Confissão Luterana de Jaraguá do Sul. Porto Alegre: Metrópole, 2008, S. 25. 
te sich der Siedler, dass die Gemeinde nach langer Zeit wieder ,einen richtigen Gottesdienst" - es heißt, einen Gottesdient mit einem Pastor, denn Laien vollzogen bereits Lesegottesdienste dort - und das heilige Abendmahl feiern konnte, die ungetauften Kinder wurden getauft und am Gottesacker hielt der Pastor eine kleine Andachtsfeier. „Es war ein schöner Tag“, berichtet er, „das Heræ wurde einem weich“. Weil der Pastor bei den Kolonisten übernachten musste, nutzten sie die Gelegenheit, mit ihm über die kirchliche Betreuung der Kolonie zu sprechen. Sie wurden sich einig, dass der Pastor sie dreimal im Jahre besuchen würde, denn öfters konnte er die fünftägige Reise nicht auf sich nehmen. Für diese Reise sollten die Familien ihm eine Entschädigung zahlen. Der Siedler berichtet weiter:

„Ein Anfang mit der Gemeindebildung war gemacht. (...) Dieser Sonntag war ein Freudentag für all gewesen, denen an ibrem Glauben noch etwas gelegen war. Zu ibnen gehörten doch die meisten. (...) Einige, die früher sich zurückgehalten hatten sagten jetrt: „Das hat uns gefallen; wir machen auch mit" ".1424

Weil der Pastor nur sporadisch kommen konnte, setzten die Siedler ihre eigenen Erbauungsstunden fort. Sie wünschen sich aber einen ansässigen Pfarrer, denn, nach Angaben eines Siedlers, griff es ,doch mehr das Gewissen an, wenn der Pastor ein ernstes Wort redete. Es hat jeder nötig, daß er einmal kräftig an seine Sünde erinnert wird". ${ }^{425}$ Nach dreieinhalb Jahren zog ihr eigener Pastor zu ihnen.

„W as war das für ein freudiger Tag", berichtete auch der Siedler Emil Manke aus Itoupava Central-Blumenau (SC), als die Kolonisten am 3. September 1883 eine Versammlung abhielten und stolz in das „neuangeschaffte Protokollbuch" schreiben konnten, dass sie einen „Evangelischen Kirchenverein“ gegründet und Statuten verfasst hatten. Jedes Gemeindemitglied hatte monatlich 80 Milréis beizutragen und diese halbjährlich zu entrichten. Auch ein Kirchenvorstand mit drei Mitglieder wurde gewählt. ${ }^{1426}$ Kirchliche Beiträge wurden teilweise auch in Naturalien bezahlt. In Dona Josepha (RS) trug beispielsweise jede Kolonistenfamilie mit 6 Milréis und einen halben Sack Mais zur Kirche bei ${ }^{1427}$, in einer Zweiggemeinde des Pfarrbezirkes Luxemburgo (ES) zahlte jedes Familienmitglied 100 Milréis und 20 Scheffel Mais. ${ }^{1428}$ Kirchliche Amtshandlungen wurden in der Regel einzeln vergütet. ${ }^{1429}$

Weil von Beginn der Einwanderung bis etwa 1900 der kirchliche Dienst in der Regel nur Gottesdienste, kirchliche Amtshandlungen und das Erziehungswesen

\footnotetext{
1424 Erinnerungen eines deutschen Ansiedlers in Brasilien. In: Sonntagsblatt für die evangelischen Gemeinden in Brasilien. Nr. 34, 12. Jahrgang, Februar 1899, S. 134. AHI.

1425 Erinnerungen eines deutschen Ansiedlers in Brasilien. In: Sonntagsblatt für die evangelischen Gemeinden in Brasilien. Nr. 34, 12. Jahrgang, Februar 1899, S. 134. AHI.

${ }^{1426}$ Evangelische Synode von Santa Catarina und Paraná, S. 70.

${ }^{1427}$ Schröder, Brasilien und Wittenberg, S. 136.

1428 Gaede, S. 57.

${ }^{1429}$ Das wurde in Gemeindestatuten von Blumenau (SC) 1888 geregelt. $1^{\circ}$ Centenário da Comunidade Evangélica de Blumenau 1857-1957. Blumenau, 1957. Zitiert nach Prien, S. 69.
} 
umfasste ${ }^{1430}$, wurden diejenigen, die zum Bau von Kirchen, Schulen und Friedhöfen, sowie zur Besoldung von Geistlichen und Lehrern und den Reisenkosten der Reiseprediger beitrugen, automatisch zu Gemeindemitgliedern und hatten somit das Recht auf kirchliche Betreuung. Das erweckte ein Gefühl von Vereinsgedanken, nach welchem Gemeindemitglieder sich als Besitzer kirchlichen Vermögens verstanden. Auch Gemeindestatuten wurden nach dem Muster eines Vereinsstatuts erarbeitet. ${ }^{1431}$ Zur Entwicklung von Vereinsgedanken trug auch die Verbindung zwischen Kirche, Friedhof und Schule und die Bildung von Friedhofs-1432 und Schulgemeinden bei. ${ }^{1433}$ Weil sie an keine kirchlichen Organisation gebunden waren, stellte jede Gemeinde ihre eigenen Regeln auf und bildete somit eine kleine unabhängige Kirche für sich. Das erschwerte später die Entwicklung der Synoden.

Dabei soll jedoch nicht vergessen werden, dass sich nicht alle Siedler automatisch den Gemeinden anschlossen, vor allem dort, wo sie keinen vom Staat besoldeten Pastor erhielten. Manche zahlten nur Beiträge oder Gebühren für die Vollziehung von kirchlichen Amtshandlungen, andere begnügten sich mit einer sporadischen Betreuung und wollten keine eigenständige Gemeinde bilden. Es gab auch zahlungsunwillige Gemeindemitglieder, die trotzdem Anteil an Kirche und Schule haben wollten. Auch wenn es zunächst keine sozialen Schichten innerhalb der Gemeinde gab, galten gleiche Beitragsquoten im Laufe der Zeit, als manche Siedler sich zu Industriellen oder Händlern entwickelten, als Ungerechtigkeit. Die Versuche, einen den Besitzverhältnissen proportionalen Beitrag einzuführen wurden aber oftmals abgelehnt. ${ }^{1434}$ Pastor Soboll aus Rio Ponte (ES) berichtet wiederum über die Resistenz einiger Kirchenmitglieder bei der Festlegung eines Gemeindebeitrags. Sie meinten, sie seien „evangelische Christen “ und wünschten die Vollziehung von kirchlichen Amtshandlungen für sich und ihre Kinder, wofür sie auch bezahlen würden. „Aber einen festen und geordneten Gemeinde-Beitrag zablen wir nicht, wir wünschen keinen Zwang, wir sind Demokraten!!" 1435

1430 Als die Gemeinde Pelotas (RS) am 20.10.1888 gegründet wurde, sah sie als ihre grundsätzlichen Aufgaben die Bewahrung lutherischen Glaubens und die schulische Erziehung der Jugend an. Fonseca, S. 82.

1431 Weingärtner, Crônica da Comunidade Evangélica de Timbó, S. 26.

1432 Aus dem Deutschen Evangelischen Friedhofsverein entwickelte sich beispielsweise die Gemeinde in Curitiba (PR) 1866. Fugmann, W. Die Deutschen in Paraná. S. 49. Zitiert nach Krause, Lutherische Synode in Brasilien, S. 96. Die Friedhofsgemeinde Misterioso (ES) bildete die Grundlagen für die Entstehung der Gemeinde Palmeira de Santa Joana (ES). Gaede, S. 70.

1433 Willems, S. $353 \mathrm{f}$.

${ }^{1434}$ Schmidt, Die Anfänge der Diakonie in Espirito Santo, S. 179.

1435 Soboll, S. 113. Wer sich außerhalb des Gemeindelebens hielt, wurde als Demokrat geächtet, Wagemann, S. 40. Laut Rölke waren industrielle Arbeiter aus Sachsen Liberale und stellten sich oft gegen die Kirche, welche Sympathie für die Monarchie pflegte. Sie wurden aus diesem Grund als „Kommunisten“ oder „Demokraten“ bezeichnet. Bald hielten die Siedler jeden, der nicht am kirchlichen Leben partizipierte, für Kommunisten oder Demokraten. Hierin wurden sie, so Rölke, von Geistlichen, die vom preußischen Oberkirchenrat entsandt wurden, beeinflusst. Rölke, Raízes da Imigração alemã, S. 372f, 475. In Pommern bezog sich das Wort „Demokrat“ zur Zeit der Emigration auf Men- 
Wegen der schwierigen Finanzlage der Gemeinden wurden auch unchristliche Maßnahmen getroffen, um zahlungsunwillige Mitglieder in ihren Rechten auf kirchliche Dienste einzuschränken, um so einen finanziellen Beitrag zu forcieren. Geistliche und/oder Vorstandsmitglieder schlossen diejenigen aus, die keinen geregelten Beitrag zahlten, und zwangen andere, ihr Mitgliedsrecht durch Eintrittsgelder zu erkaufen. ${ }^{1436}$ In Timbó (SC) beschloss der Kirchenvorstand 1890 und 1891, dass ausschließlich zahlende Gemeindemitglieder Gottesdienste besuchen durften. Nicht-Mitglieder mussten einen separaten Beitrag für die Teilnahme an Gottesdiensten zahlen, was auch kontrolliert wurde. 1893 wurde auch ein Beitrag für die Teilnahme am Abendmahl für Mitglieder (100 Réis) und NichtMitglieder (1.000 Réis) festgelegt. ${ }^{1437}$ In Santa Isabel (SC) wurden indifferente und finanziell rückständige Gemeindemitglieder von der Mitgliedsliste durch Anordnung von Pastor Zluhan gestrichen. ${ }^{1438}$ In Espírito Santo mussten NichtMitglieder auch höhere Gebühren für die Vollziehung von kirchlichen Amtshandlungen zahlen. ${ }^{1439}$ Wer in Arroio do Tigre (RS) mehr als drei Jahren in der Kolonie wohnte, ohne sich als Gemeindemitglied angemeldet zu haben, musste das Dreifache an Gebühren zahlen. Finanziell rückständige Gemeindemitglieder konnten ihre Mitgliedsrechte verlieren, mit Ausnahme ärmerer Familien. ${ }^{1440}$ Auch die Distanz zum Pfarrsitz bestimmte in manchen Orten die Beitragquote. In Ijuí (RS) trugen Mitglieder, die in der Nähe des Pfarrsitzes wohnten, mit 8 Milréis bei, die anderen 6 Milréis. Nicht-Mitglieder zahlten Gebühren für kirchliche Amtshandlungen und nur 2 Milréis an die Gemeinde ${ }^{1441}$, vermutlich, damit ihre Kinder die Schule besuchen konnten.

Eine Ausnahme bildete Joinville (SC). Als Pastor Johann Friedrich Stapel nach Empfehlungen aus Hamburg ${ }^{1442}$ Gebühren für kirchliche Amtshandlungen in der Gemeinde einführen wollte protestierte der Kirchenvorstand. Bis 1864 wurden alle Siedler automatisch als Gemeindemitglieder angesehen. Danach, vermutlich in Zusammenhang mit der Verselbständigung der Nachbargemeinde Inselstraße (SC), beschloss der Kirchenvorstand, dass sich alle Gemeindemitglieder eintragen mussten. Nicht eingetragene Personen wurden zwar nicht von der Gemeinde ausgeschlossen, besaßen aber auch keine beratende und beschließende Stimme in der Gemeindeversammlung. ${ }^{1443} 1883$ wurden letztendlich auch Gebühren für

\footnotetext{
schen, die die öffentliche Ordnung störten. In einigen Gemeinden mussten sie höheren Beträge für kirchliche Amtshandlungen zahlen. Willems, S. 180.

1436 Wirth, S. 58.

1437 Weingärtner, Crônica da Comunidade Evangélica de Timbó, S. 38, 40.

1438 Stoer, S. 12.

${ }^{1439}$ Soboll, S. 114.

${ }^{1440}$ Há 75 anos Deus veio à floresta. In: Jornal Paladino Serrano, 25.6.1980, S. 7f, AHI, SR 83/69.

${ }^{1441}$ Halle, G. Kurze Geschichte der deutsch-evangelisch-lutherischen Gemeinde zu Ijuhy, S. 10, AHI, SR 83/25.

1442 Diese Kolonie wurde vom Hamburger Kolonisationsverein gegründet.

1443 Wüstner, S. 18-20.
} 
kirchliche Amtshandlungen festgesetzt und Nicht-Mitglieder mussten das vierfache für jede dieser Amtshandlungen zahlen. ${ }^{1444}$

Laut Pastor Friege zahlten die Pommern, trotz einiger Proteste, ihre kirchlichen Beiträge im Wesentlichen regelmäßig. ${ }^{1445}$ Pastor Halle berichtet indes, dass auch in finanziell erträglichen Zeiten die Gemeindemitglieder ihren Beitrag nicht zahlen wollten, obwohl ein gewisser Wohlstand allmählich in den Kolonien zu spüren war. ${ }^{1446}$ Diese Bewertungen müssen aber je nach Kontext und nach der Beziehung zwischen Pastor und Gemeindemitgliedern gelesen werden. Jüngere Kolonien befanden sich im Vergleich zu älteren in einer schwierigeren Lage, weil einige Siedler in älteren Kolonien sich bereits kommerziell oder industriell etabliert hatten. Die gute oder schlechte Beziehung zum Pastor hatte wiederum Einfluss auf die Partizipation in der Gemeinde sowie auf die Gemeindebeiträge.

Die großen Distanzen, Gefahren im Urwald und teilweise unpassierbare Straßen verlangten großes Durchhaltevermögen, Mut und Beharrlichkeit, um an den Gottesdiensten teilzunehmen. Regengüsse machten Bäche und Flüsse unpassierbar, rissen Brücken fort, Erdrutsche und Bäume versperrten für Tage die Wege. ${ }^{1447}$ Aus diesem Grund konnte manchmal der Pastor oder etliche Gemeindemitglieder nicht bis zum Kirchenplatz gelangen und mussten unterwegs umkehren. Familien aus Itoupava Central (SC) brauchten beispielsweise fünf Wegstunden, um bis zum Kirchenplatz in Blumenau (SC) zu gelangen, ,und was für Wege waren das" 1448 , in Rio Novo (ES) waren es sechs. ${ }^{1449}$ In Santa Isabel (SC) konnten einige Gemeindemitglieder nicht an einem Tag hin und zurück zum Gottesdienst kommen. ${ }^{1450}$ In Santa Leopoldina II-Jequitibá (ES) mussten andere um 2 Uhr morgens auf-

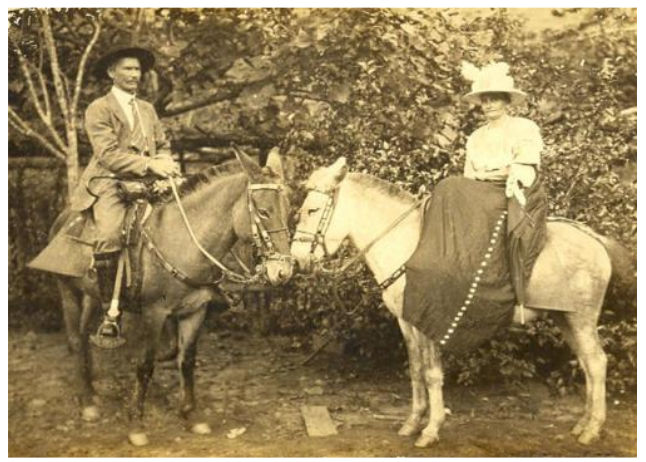

Abb. 11: Kolonisten in Espirito Santo unterwegs zur Kirche. Quelle: Seibel, Imigrante no século do isolamento, S. 136. brechen, um zur Kirche gehen zu

\footnotetext{
1444 Bühler, Fritz. Ein Beitrag zur Kirchenkunde Südamerikas, [1917/1918], S. 23f, MLV 51/17 108.

1445 Jahresbericht von Pastor Friege an das Kirchliche Außenamt, 10.7.1937, EZA 5/2535.

${ }_{1446}$ Halle, G. Kurze Geschichte der deutsch-evangelisch-lutherischen Gemeinde zu Ijuby, S. 11, AHI, SR 83/25.

1447 Riegel-Widdershausen, Aus der Arbeit des Lutherischen Gotteskasten in Brasilien. Verlag des Lutherischen Gotteskasten in Bayern, 1926, S. 12, MLV 51/17 108; Josenhaus, Der Evangelische Heidenbote, Nr. 4, April 1864, S. 45f; Laroche, Fritz (Hrsg.) Der Evangelische Heidenbote, Nr. 10, Oktober 1931. Basel: Missionsbuchhandlung, S. 161.

1448 Evangelische Synode von Santa Catarina und Paraná, S. 68, 70.

1449 Abschrift des Briefes von Pastor Reuther an Pfarrer Peter in Spöck, Santa Leopoldina, 30.6.1864, BMA, FB, 1,1.

1450 Josenhaus, Der Evangelische Heidenbote, Nr. 4, April 1864, S. $45 f$.
} 
können. ${ }^{1451}$ Durch die Binnenwanderung entstanden auch immer neue Gemeinden und Pfarrbezirke im Landesinneren, vor allem zwischen 1875 und 1914. ${ }^{1452}$ Die Gemeindemitglieder, die dorthin gesiedelt waren, blieben zunächst an ihre Muttergemeinden angeschlossen. Obwohl sich in Lagoa Serra Pellada (ES) beispielsweise deutsche Adventisten niedergelassen hatten und vermutlich dort eine Gemeinde gegründet hatten, ritten die Siedler zum Gottesdienst bis zur evangelischen Muttergemeinde. Ab und zu kam ein Pfarrer auf der Durchreise zu ihnen und vollzog Hausgottesdienste und kirchliche Amtshandlungen. ${ }^{1453}$ Das zeigt, dass die Bedeutung des Glaubens über derjenigen der Ethnie und Sprache steht. Wäre ihr evangelisch-lutherischer Glauben nur an die deutsche Sprache gebunden, hätten sich die Siedler dieser Adventistengemeinde im Angesicht ihrer Notlage anschließen können. Einwanderer aus der neuen Kolonie Jaraguá do Sul (SC) besuchten wiederum die Kirche in der etwa 50 Kilometer entfernten Gemeinde Timbó (SC). ${ }^{1454}$

Trotz aller Distanzen, der Unwetter und anderer Schwierigkeiten war der Gottesdienst überall gut besucht, teilweise gab es keine ausreichenden Sitzplätze für alle. ${ }^{1455}$ In verschiedenen Gemeinden von Espírito Santo, Santa Catarina und Rio Grande do Sul wird berichtet, dass die Pommern , sehr kircbliche Leute " waren. ${ }^{1456}$ Die Mehrheit wünschte sich ein religiös geprägtes Leben und ein christliches Be-

1451 Schröder, Brasilien und Wittenberg, S. 330.

1452 Wellnitz, Britta. Deutsche evangelische Gemeinden im Ausland. Tübingen: Mohr Siebeck, 2003, S. 285.

1453 Damitz, Entwicklungsaspekte zur Situation der Brasilianer, S. 24.

1454 Claas, S. 21.

1455 Bericht von Pastor Burger mit Frau, Limoeiro-Jatiboca, 6.1.1933, MEW 4.166; Brief von Pastor Langholf an den Missionsdirektor der Hermannsburger Mission Haccius, 25.10.1921. Zitiert nach Müller, Reinhart. Hermannsburger in Lateinamerika. Hermannsburg: Missionshandlung Hermannsburg, 2001, S. 36; Brief von Pastor Baptist Weber, Pontal 3.3.1933, MEW 4.206; Brief von Pastor Hohlfeld, Timbó, 29.11.1921, EZA 5/2455; Reisebericht von Pastor Otto Kuhr, In: Der Lutherische Gotteskasten, Nr. 3, 26. Jahrgang, 1905, S. 49-54, EZA 200/1/2152; Schreiben von Pastor Kuhr an Stirner vom 9.-11.3.1898, zitiert nach Krause, Lutherische Synode in Brasilien, S. 72; Brief von Pastor Otto Kuhr an seine Mutter, 28.1.1898. Zitiert nach Giurus, Friedrich. Otto Kuhr. In: Backhause, Martin; Zeller, Hans. (Hrsg.) Aufbruch in Grenzen. Neuendettelsau/Nürnberg/Erlangen: Verlag für Mission und Ökumene/mabase-Verlag/Martin-Luther-Verlag, 2016, S. 20; Schröder, Brasilien und Wittenberg, S. 338; Von Tschudi, Reisen durch Süd-Amerika. Leipzig, 3. Band, S. 392; Evangelische Synode von Santa Catarina und Paraná, S. 160; Jahresbericht über das Gemeindeleben in Brusque im Jahre 1928. Gemeindeblatt für die evangelischen Gemeinden Brusque und Itajaby, Nr. 12, 1. Jahrgang, März 1929, S. 3, EZA 5/2525; Laroche, Der Evangelische Heidenbote, Nr. 10, Oktober 1931, S. 161; Aus überseeischen Briefe. In: Der Deutsche Ansiedler, 1884, BMA, PABV 545; Comité für die protestantischen Deutschen in Südbrasilien. Die Arbeit unter den evangelischen Deutschen in Südbrasilien. Barmen: L. Langewiesche, 1869, S. 18, 22f, EZA 200/1/2151.

1456 Brief von Pastor Otto Kuhr an seine Mutter, 28.1.1898. Zitiert nach Giurus, Otto Kuhr, S. 20; Reisebericht Dr. Rahlwes über Mittelbrasilien, Santa Catharina und Paraná, 1928, S. 13, EZA 5/2175; Fortsetzung des Reiseberichtes des Kommissars der verbündeten luth. Gotteskasten Deutschlands über Sta. Catharina, Paraná und and. Staaten Brasilien, Dekan Wolhorst Volkert, MLV 51/17 108; Auszug aus den Reisebericht von Pastor Braunschweig über die deutschen evangelischen Gemeinden in Brasilien, 22.2.1909, EZA 5/2505; Reisebericht von Pastor Braunschweig vom Jahre 1907, EZA 5/2173; Schröder, Brasilien und Wittenberg, S. 139. 
wusstsein war in ihnen erweckt worden. ${ }^{1457}$ In Paraíso (RS) zeigten die Pommern einen starken „religiösen Sinn"1458 und in Alliança (RS) kennzeichneten sie sich durch ihre ,pommersche Kirchlichkeit" aus. ${ }^{1459}$ Die Hauptgemeinde des Pfarrbezirkes Barão do Triumpho (RS), die aus etwa dreißig pommerschen Familien bestand, war ,die größte und kirchlich wie religiös lebendigste“.1460 In Sinimbu (RS) war die Gemeinde als das ,heilige Viertel"bekannt. ${ }^{1461}$ Das berichten evangelische wie lutherische, akademisch wie seminaristisch gebildete Geistliche und auch der schweizerische Bevollmächtigte von Tschudi. Es sollen aber auch die verschiedenen anderen Gruppen, die, wie schon beschrieben, ihre Religiosität und ihren Glauben auf unterschiedliche Art auslebten, nicht vergessen werden. Es wird beispielsweise berichtet, dass einige Siedler sich vom Gottesdienst und dem Abendmahl fernhielten ${ }^{1462}$, auch wenn diese Tatsache von einigen nicht erwähnt wurde, sondern deutsche Siedler im allgemeinen als fleißige, ordentliche und kirchlich gesonnene Menschen dargestellt wurden. Es kann jedoch beobachtet werden, dass Not und Isolierung in den Kolonien das Interesse für kirchliches Leben, im religiösen sowie im sozialen Sinne, anregte, so dass auch diejenigen Siedler, die zunächst nicht regelmäßig teilnahmen, später ihre Meinung änderten ${ }^{1463}$ und den Kirchenbesuch nicht mehr versäumen wollten. ${ }^{1464}$ „Diese Menschen befanden sich in einer Lage, die ibre Herzen öffnete für das Trost- und Kraftwort der Bibel" "1465, schrieb Pastor Wüstner. Sie waren froh, wenn sie sich um Gottes Wort sammeln und daraus Trost und Kraft für ihre müde und verlangende Seele holen konnten. ${ }^{1466}$ „Ohne die Gemeinde wären wir arme Leute' 1467 , sagte ein Kolonist zu seinem Pfarrer. Ihre Bedeutung fand besonders in dem Engagement bei der Errichtung kirchlicher Gebäude ihren Ausdruck, dass nun im Folgenden beschrieben werden soll.

\footnotetext{
1457 Brief von Pastor Reuther über die evangelische Gemeinde von Sta. Leopoldina an die Konferenz der Basler Brüder in Brasilien (1867), BMA, FB, 1,1.

1458 Comité für die protestantischen Deutschen in Brasilien, S. 58; Schröder, Brasilien und Wittenberg, S. 153.

1459 Reisebericht von Pastor Braunschweig über die deutschen evangelischen Gemeinden in Brasilien vom Jahre 1907, S. 89, EZA 5/2173.

1460 Als ich Urwaldpfarrer war! Bericht von Pastor Willich zu der Zeitung Unterm südlichen Kren\%: Nr. 20, 10. Jahrgang, São Leopoldo, 18.9.1908, S. 1, EZA 200/1/5807.

1461 Schröder, Brasilien und Wittenberg, S. 139.

1462 Fortsetzung des Reiseberichtes des Kommissars der verbündeten luth. Gotteskasten Deutschlands über Sta. Catharina, Paraná und and. Staaten Brasilien Dekan Wolhorst Volkert, MLV 51/17 108.

1463 Riegel-Widdershausen, Aus der Arbeit des Lutherischen Gotteskasten in Brasilien. Verlag des Lutherischen Gotteskasten in Bayern, 1926, S. 10, MLV 51/17 108; vgl. Erinnerungen eines deutschen Ansiedlers in Brasilien. In: Sonntagsblatt für die evangelischen Gemeinden in Brasilien. Nr. 34, 12. Jahrgang, Februar 1899, S. 134. AHI.

${ }^{1464}$ Schlünzen, F. Deutsche in Brasilien. Neuendettelsau: Freimund, 1936, S. 16, MEW 3.16.

1465 Wüstner, S. 15.

1466 Schlünzen, F. Deutsche in Brasilien. Neuendettelsau: Freimund, 1936, S. 16, MEW 3.16.

1467 Grottke, G. Aus der Arbeit einer lutherischen Gemeinde in Nordbrasilien, 10.1.1938, S. 37, MLV 51/17 108.
} 


\section{Errichtung von Orten für den Gottesdienst}

Die ersten Einwandererfamilien trafen sich, um ihre Gottesdienste abzuhalten, zunächst in Privathäusern oder anderen improvisierten Stätten. Bald errichteten sie jedoch Gebäude, welche unter der Woche als Schule und Sonntags als Gotteshaus dienen konnten, bis sie in der Lage waren, eine Kirche zu bauen, die dann mit der Anschaffung von Glocken einen Turm erhielt. Dieser Abschnitt widmet sich der Analyse der Errichtung von Gottesdiensthäusern in verschiedenen Entwicklungsphasen. Chronologisch ist eine systematische Darstellung nicht möglich, denn jüngere wie ältere Gemeinden folgten in der Regel demselben Muster für die Errichtung kirchlicher Gebäude. Hinsichtlich der Thematik ist die Untersuchung der Beteiligung und Opferbereitschaft der Gemeindemitglieder bei der Aufbauarbeit von tragender Wichtigkeit. Dieses Engagement gab den Einwanderern und deren Nachkommen, in der Isolierung ihres Daseins in den Siedlungsgebieten und angesichts ihrer Verluste und Tristessen, einen wichtigen Sinn im Leben, stärkte die Gemeinschaft unter ihnen und wurde als ein Glaubensbekenntnis und -erbe für die Nachkommen angesehen. Auch die Bedeutung der Kirche als heiliger Ort für die göttliche Anbetung und Vollziehung von kirchlichen Amtshandlungen und als Ausdruck der Ansässigkeit der Einwanderer in der neuen Heimat soll im Folgenden erläutert werden.

2.1. Erste Phase: Hausgemeinden, provisorische Gottesdienstorte und Errichtung von Kirchen-Schulen, Bethäusern und Kapellen

In den ersten Siedlungsjahren trafen sich die Einwanderer, in Ermangelung kirchlicher Gebäude, zum Gottesdienst in Privathäusern. Auch provisorische Stätten, wie beispielsweise Einwandererbaracken ${ }^{1468}$, Ställe ${ }^{1469}$, Schuppen ${ }^{1470}$, Schmieden ${ }^{1471}$, in der Wohnung des Kolonieverwalters ${ }^{1472}$, Pfarr- und Lehrerhäuser ${ }^{1473}$,

1468 Zum 50jährigen Jubiläum der evangelischen Gemeinde in Blumenau. In: Der Dentsche Ansiedler, November 1907, EZA 5/2488; Scheerer. Festschrift der Evangelischen Kirchengemeinde Blumenau, S. 3, EZA 5/2486; Weingärtner, Martin Luther e Santa Catarina, S. 104; Weingärtner, História da Comunidade Evangélica de Timbó, S. $242 \mathrm{f}$.

${ }^{1469}$ Schröder, Brasilien und Wittenberg, S. 162; Lutherische Kirche in Brasilien, S. 91.

1470 Bühler, Fritz. Ein Beitrag zur Kirchenkunde Südamerikas. [1917/1918], S. 7, MLV 51/17 108; Gemeindeblatt für die evangelischen Gemeinden Brusque und Itajahy, Nr. 5, August 1928, S. 1, EZA 5/2525; Weingärtner, História da Comunidade Evangélica de Timbó, S. 235-237; Stoer, S. 4; Liesenberg, S. 6; Hornburg, Rudolf. Jahrhundertfeier der evangelischen Kirche von Testo Alto. In: Prefeitura Municipal de Pomerode. Pomerode, sua história, sua cultura, suas tradições. V. 3. Pomerode: Prefeitura Municipal, 1986, S. 32.

1471 Witt, S. 130.

1472 Josenhaus, Der Evangelische Heidenbote, Nr. 4, April 1864, S. 38.

${ }^{1473}$ Holz, Joachim. Die ersten sechs Jahren in Espírito Santo, Brasilien. In: Heimatbote für die Gemeinden der Deutschen Lutherischen Kirche in Espirito Santo. Nr. 4, April 1936, S. 4, MEW 4.194. 
eine Maniokmehl-Mühle1474 oder ein Saal dienten als Versammlungsort für den Gottesdienst. ${ }^{1475}$ Manchmal taten sich einige Siedler zusammen und zimmerten schnell ein Häuschen aus Brettern ${ }^{1476}$ oder Ziegeln, das weder über eine Decke, noch über Fenster und Putz an den Wänden verfügte. ${ }^{1477}$ In anderen Fällen musste der Gottesdienst im Freien abgehalten werden, unter ,glühender Sonnenhitze“ "oder wenn es regnete in Ställen. ${ }^{1478}$ Laut Germano Malikoski sammelten sich Familien in Palmeira de Santa Joana (ES) zunächst unter einem Mangobaum zum Gottesdienst. ${ }^{1479}$ In Gaspar (SC) diente ein kreatives Benachrichtigungssystem als Ersatz für Glocken. Gemeindemitglieder schmückten das Haus, in dem der Gottesdienst am nächsten Tag stattfinden sollte, mit Palmenblättern. Jeder, der an dem Haus vorbeiging wusste Bescheid und benachrichtigte die Nachbarn. ${ }^{1480}$ Auch wenn dies keine wirklich würdigen Orte waren, war nach Angaben eines unbekannten Pastors das Wichtigste dennoch vorhanden: „Gottes Wort und Herzen, die nach dem Trost desselben verlangend waren".1481

Die innere Ausstattung dieser Gottesdienststätten war schlicht und wirkte improvisiert. Menschen hockten sich auf den Boden oder standen an der Wand und hörten aufmerksam zu. ${ }^{1482}$ Bretter wurden auf Kisten ${ }^{1483}$ oder auf Pfähle, die in die Erde gerammt wurden ${ }^{1484}$, gelegt und ein einfacher Tisch diente als Altar und Kanzel. ${ }^{1485}$ Der Bericht eines anonymen Pastors weist auf diese mangelnden Ressourcen der Kolonisten in Bezug auf ihre Gottesdienste in den Anfangsjahren hin, die jedoch gerade deswegen eine große Bedeutung gewannen:

1474 Bericht von Pastor Mitkönig über die Gemeinde Santa Leopoldina (ES), EZA 5/2583; Stuhr, Rubens. História da Comunidade de Luxemburgo. In: O Semeador, Nr. 78, S. 11. Zitiert nach Gaede, S. 49f; Stoer, S. 5.

1475 In Timbó (SC), Weingärtner, História da Comunidade Evangélica de Timbó, S. 116 f.

1476 Erinnerungen eines deutschen Ansiedlers in Brasilien. In: Sonntagsblatt für die evangelischen Gemeinden in Brasilien. Nr. 35, 12. Jahrgang, 1899, S. 134. AHI; vgl. Brief eines Kolonisten aus Blumenau, 14.9.1868. Zitiert nach Weingärtner. 150 Anos de Presença Luterana no Vale do Itajaí, S. 18.

1477 Lutherische Kirche in Brasilien, S. 178.

1478 Abschrift des Briefes von Pastor Reuther an Pfarrer Peter in Spöck, Santa Leopoldina, 30.6.1864, BMA, FB, 1,1; Aus den Erinnerungen eines alten Pfarrers. Veröffentlicht in Der Christenbote Blumenau, in laufenden Vorsetzungen, Nr. 11 vom November 1921 bis Nr. 8 vom August 1922. In: Evangelische Synode von Santa Catarina und Paraná, S. 112, 114.

1479 Malikoski.

1480 Scheerer, Festschrift der Evangelischen Kirchengemeinde Blumenau, S. 6, EZA 5/2486.

1481 Aus den Erinnerungen eines alten Pfarrers. Veröffentlicht in Der Christenbote Blumenau, in laufenden Vorsetzungen, Nr. 11 vom November 1921 bis Nr. 8 vom August 1922. In: Evangelische Synode von Santa Catarina und Paraná, S. 114, 116.

1482 Riegel-Widdershausen, Aus der Arbeit des Lutherischen Gotteskasten in Brasilien. Verlag des Lutherischen Gotteskasten in Bayern, 1926, S. 10, MLV 51/17 108.

1483 Rölke, Raízes da Imigração alemã, S. 321.

1484 Aus den Erinnerungen eines alten Pfarrers. Veröffentlicht in Der Christenbote Blumenau, in laufenden Vorsetzungen, Nr. 11 vom November 1921 bis Nr. 8 vom August 1922. In: Evangelische Synode von Santa Catarina und Paraná, S. 112, 114.

1485 Lutherische Kirche in Brasilien, S. 178; Granzow, Pommeranos unter dem Kreuz des Südens, S. 116. 
„Einen Altar hatte er improvisiert, indem er über zwei Schnapsfässer ein Brett legte und über dieses ein Handtuch breitete. Ein drittes Schnapsfass diente mir als Sitz. in Ermangelung eines Stubls oder Schemels. So wenig würdig und stilvoll das war, wir feierten doch fröbliche Weibnachten, denn „die grosse Freude" ist an keinen Raum gebunden. Übrigens war auch der Stall in Bethlehem und die Krippe wenig „würdig und stilvoll“. Auch drei Kinder konnte ich taufen, wobei, wieder wenig stilvoll, eine grosse Bratpfanne als Taufbecken diente. Herzlich dankbar waren diese verlassenen Leute, dass sie, zum erstenmale seit drei Jabren, einen Gottesdienst gehabt hatten".1486

Provisorische Orte erschienen den Einwanderern und deren Nachkommen aber auf Dauer als unwürdig. So beschlossen einige von ihnen, je nach finanziellen Mitteln, eine Kapelle, ein Bethaus oder eine Schule, die unter der Woche als Schule und Sonntags als Kirche diente, zu errichten. Die für diese Funktionen gebauten Gebäude befriedigten gleich zwei für die Siedler wichtige Bedürfnisse, nämlich das einer Kirche und einer Schule. Gleichzeitig würden sie dadurch nicht gegen ein Gesetz der Bundesverfassung von 1824 verstoßen, dass Protestanten das Bauen von Gebäuden untersagte, die nach außen hin den Anschein eines Tempels erwecken könnten. Die Errichtung solcher Gebäude und die Wahl des Baubereichs gestalteten sich nicht konfliktlos. Hier und dort gab es Familienmitglieder, die zunächst nicht mit dem Bau einverstanden waren, weil sie sich nicht von der Hauptgemeinde trennen, die Entscheidungen der Baukommission nicht anneh-

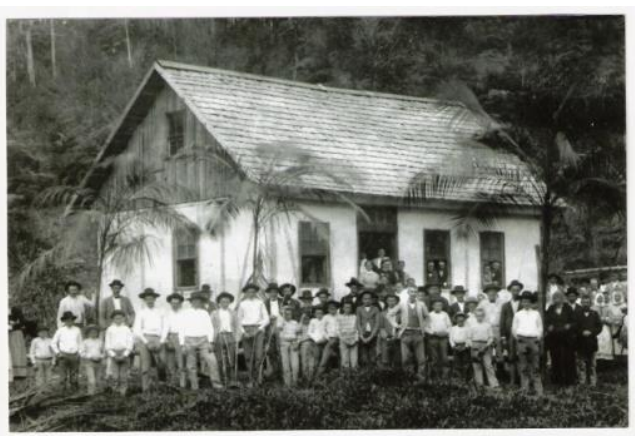

Abb. 12: Kirchen-Schule in Rio Claro (ES) im Jabr 1900. Foto von Anivaldo Kuhn. Quelle: Seibel, Imigrante no século do isolamento, S. 554. men oder keine zusätzlichen Anstrengungen auf sich nehmen wollten. Diejenigen jedoch, die an dem Bau teilnahmen, halfen mit Spenden von Baumaterial, freiwilliger Arbeitsleistung und finanziellen Zuschüssen. Sie arbeiteten in einer Art Interessensgemeinschaft und errichteten somit alle Gebäude gemeinsam. Grundstücke wurden oft von Gemeindemitgliedern gespendet. ${ }^{1487}$ Dies geschah oft in Not- und Entbehrungszeiten ${ }^{1488}$, als die Siedler noch um ihre eigene Existenz kämpften, sich nämlich um die Errichtung eines eigenen Hauses als Ersatz für die erste vorläufige Hütte oder um die Bewirtschaftung ihrer Höfe zu sorgen hatten.

1486 Aus den Erinnerungen eines alten Pfarrers. Veröffentlicht in Der Christenbote, Blumenau, in laufenden Vorsetzungen, Nr. 11 vom November 1921 bis Nr. 8 vom August 1922. In: Evangelische Synode von Santa Catarina und Paraná, S. 116.

1487 Gaede, S. 277; Wilbert et. al., S. 101; Lutherische Kirche in Brasilien, S. 28, $197 f$.

1488 Rundschreiben vom Gemeindevorstand aus São Leopoldo, 5.12.1906. In: Müller, Herança de geração em geração, S. 43. 
Ein Pastor berichtet, dass in einer Kolonie in Santa Catarina die Siedler zunächst ein Palmitenhaus, das als Schul- und Kirchenraum diente, bauten und erst dann eigene Häuser errichteten. ${ }^{1489}$

Bei einer großen Anzahl von Gemeinden, besonders in Zweiggemeinden, diente das Schulgebäude auch als Ort für den Gottesdienst, weswegen solche

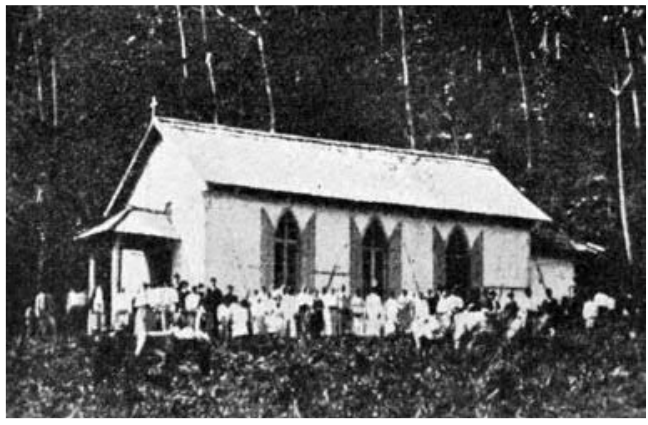

Abb. 13: Kapelle der Zweiggemeinde Suiça-Jequitibá (ES). Quelle: Wernicke, S. 163. Diese Gemeinde gehörte zunächst zur evangelischen Hauptgemeinde Santa Leopoldina (ES). Als sie sich 1946 wieder mit dem von ibr abgetrennten Teil - der die Zweiggemeinde Rio Bonito bildete - vereinigte, wurde sie von der lutherischen Hauptgemeinde Jequitibá (ES) aus bedient.
Gebäude als Kirchen-Schulen bekannt wurden (Abb. 12, siehe S. 249). ${ }^{1490}$ Für die Vollziehung von kirchlichen Amtshandlungen gingen die Siedler, je nach Verhältnis und Distanz noch zum Pfarrsitz. ${ }^{1491}$ Manchmal war dies auch von den Bestimmungen eines Pfarrbezirkes oder vom Geistlichen abhängig. Mancherorts fusionierten die Gemeinden in einem Gebäude die Kirchen-Schule und auch die Pfarrwohnung, bis die Gemeinde in der Lage war, eine separate Pfarrwohnung zu errichten. ${ }^{1492}$ Bei Pastor Willich finden sich wichtige Auskünfte über die Einrichtung und Vollziehung von Gottesdiensten in einer Kirchen-Schule, weswegen sein Bericht hier wiedergegeben werden soll:

„An das Lehrerizimmer schloß sich der große Raum, in welchem Schule gehalten und gepredigt wurde. Vorn eine Art Podium, auf dem ein Tisch sich befand, der Sonntags zum Altare bergerichtet wurde. Auf dem Altare standen beim Gottesdienst stets frische Blumenbuketts, denn Sommer und Winter blühen Blumen in Menge. Vom Altare aus

1489 Aus den Erinnerungen eines alten Pfarrers. Veröffentlicht in Der Christenbote Blumenau, in laufenden Vorsetzungen. Nr. 11 vom November 1921 bis Nr. 8 vom August 1922. In: Evangelische Synode von Santa Catarina und Paraná, S. 110.

1490 Beispiele von Kirchen-Schulen in Gemeinden von Santa Catarina: Scheerer. Festschrift der Evangelischen Kirchengemeinde Blumenau, S. 4, 12 EZA 5/2486; Lutherische Kirche in Brasilien, S. 28, 44; Schröder, Brasilien und Wittenberg, S. 271; Weingärtner, História da Comunidade Evangélica de Timbó, S. 48, 116f, 242f, 254; Weingärtner, 150 Anos de Presença Luterana no Vale do Itajaí, S. 15, 32; Evangelische Synode von Santa Catarina und Paraná, S. 78, 80; Liesenberg, S. 21f; Claas, S. 26, 28f; Wilbert et. al., S. 90f, 96; Ulrich, S. 190; Josenhaus, Der Evangelische Heidenbote, Nr. 4, April 1864, S. 46. Beispiele von Kirchen-Schulen in Espírito Santo: Gotteskastenwerk, In: Evangelisch-lutherischer Friedensbote aus ElsaßLothringen. Nr. 27, 3.7.1904, S. 238, MLV 51/17 77; Krause, Lutherische Synode in Brasilien, S. 105-108; Lutherische Kirche in Brasilien, S. 173, 222; Gaede, S. 110, 186. Kirchen-Schulen in Rio Grande do Sul: Rheingantz, Karl Wilhelm. Die Gründung der Kolonie São Lourenço und ibr Gründer Jakob Rheingantz [1907?], S. 27, EZA 5/2304.

1491 Liesenberg, S. 21.

1492 Der Heimatbote Nr. 4, Ano 2, April 1936. Zitiert nach Rölke, Raízes da Imigração alemã, S. 253. 
wurde die Predigt gehalten. Die Gemeinde saß zum Teil auf Schulbänken oder stand, wo diese nicht ausreichten, an den Wänden umber. Auch draußen am Fenster standen gern Leute, weil sie da zugleich bequem die angebundenen Pferde beobachten konnten. Häufig wurden Bänke hergestellt dadurch, daß lange Bretter auf irgendwelche Unterlagen aufgelegt wurden".1493

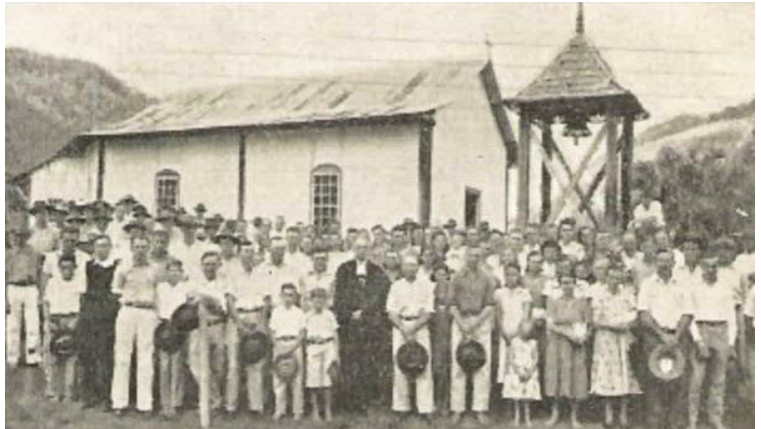

Abb. 14: Kapelle der Zweiggemeinde Rio Bonito-Jequitibá (ES). Sie wurde am 31.5.1931 eingeweibt. Rio Bonito war eine Abtrennung von der Zweiggemeinde Suiça und wurde ab 1933 von der lutherischen Hauptgemeinde Jequitibá (ES) aus bedient. 1946 vereinigte sie sich wieder mit der Zweiggemeinde Suiça. Quelle: Lutherische Kirche in Brasilien.
In anderen Orten bauten die Siedler zunächst eine meist schlichte Kapelle oder einen Betsaal (Abb. 13, siehe S. 250), die oder der unter der Woche als Schule diente. ${ }^{1494}$ Die Kapellen in Brusque (SC) und BadenfurtBlumenau (SC) waren aus Palmiten mit Dachblatt ${ }^{1495}$, der Betsaal in Ijuí (RS) wurde wiederum auf einen massiven Unterbau mit Fachwerk und Backstein gebaut. ${ }^{1496}$ In Itoupava-Central-Blumenau (SC) zahlte die neugebildete Gemeinde 600 Milréis für das Haus von Wilhelm Denker, das zur Kapelle umgebaut wurde. ${ }^{1497}$ Bei Bedarf wurden Kapellen und Bethäuser im Laufe der Zeit erweitert und zu kleinen Kirchen umgewandelt oder mit einem Glockenstuhl (Abb. 14) oder Turm versehen.

1493 Als ich Urwaldpfarrer war! Bericht Pastor Willich zu der Zeitung Unterm südlichen Kreu₹. Nr. 20, 10. Jahrgang, São Leopoldo, 18.9.1908, EZA 200/1/5807.

1494 Beispiele von Kapellen oder Bethäuser in Espírito Santo: Brief von Pastor Pflügel an Raffard, Rio Novo, 10.7.1862, BMA, FB, 1,1; Wernicke, S. 118; Damitz, Die ausgewanderten Pommern, S. 17; Damitz, Entwicklungsaspekte zur Situation der Brasilianer, S. 25f, 33; Lutherische Kirche in Brasilien, S. 203, 206, 221, 225-227; Gaede, S. 125, 131, 144, 146f, 156, 169; Josenhaus, Der Evangelische Heidenbote, Nr. 4, April 1864, S. 38. In Gemeinden von Rio Grande do Sul: Sínodo Riograndense. Comunidade Evangélica de Santa Cruz do Sul 1862 - 100 - 1962, S. 7, AHI, SR 144/15; Von Tschudi, Reisen durch Süd-Amerika, 4. Band, S. 23; Halle, G. Kurze Geschichte der deutsch-evangelisch-lutherischen Gemeinde zu Ijuby, S. 10, AHI, SR 83/25; Witt, S. 52; Dedekind, 75 Jahre deutsch-evangelischer Diasporaarbeit, S. 56. In Gemeinden von Santa Catarina: Von Tschudi, Reisen durch Süd-Amerika. 3. Band, S. 410; Lutherische Kirche in Brasilien, S. 82f, 92; Weingärtner, 150 Anos de Presença Luterana no Vale do Itajaí, S. 15; Giurus, Crônica da Paróquia Evangélica Luterana de Indaial, S. 149; Wilbert et. al., S. 98.

1495 Von Tschudi, Reisen durch Süd-Amerika, 3. Band, S. 400; Colonie Zeitung und Anzeiger für Dona Francisca und Blumenau, 2.7.1864, S. 108f. Zitiert nach Fluck, S. 150; Weingärtner, 150 Anos de Presença Luterana no Vale do Itajaí, S. 31.

1496 Halle, G. Kurze Geschichte der deutsch-evangelisch-lutherischen Gemeinde zu Ijuby, S. 4, AHI, SR 83/25.

1497 Evangelische Synode von Santa Catarina und Paraná, S. 70. 
In diesen provisorischen Stätten suchten und fanden die Siedler allsonntäglich und teilweise an Abenden unter der Woche „,Trost und Stärkung“.1498

\subsection{Zweite Phase: Errichtung von massiven Kirchen und Anschaffung von Glocken}

Allmählich vergrößerte sich die Mitgliederzahl in manchen Gemeinden durch die Ankunft neuer Einwanderer und Migranten oder aufgrund von Familienzuwachs. Auch die finanziellen Bedingungen besserten sich im Laufe der Zeit, sodass manche Gemeinden an die Errichtung einer massiven Kirche denken konnten. In anderen Fällen ersetzte eine kleine Kirche die baufällige Kapelle oder KirchenSchule. Ein Siedler gibt reichliche Details über die Bauart und Ausstattung der Kirche sowie über das Kreuz auf dem Dach, was das Gebäude in Ermangelung einer Glocke als Kirche kennzeichnen sollte. In seinem Bericht kommt außerdem der Stolz der Siedler, die Kirche mit den eigenen Händen gebaut zu haben, zum Ausdruck. Dieser Umstand war den Siedlern sehr wichtig und stärkte gleichzeitig ihr Selbstwertgefühl sowie ihre Selbstwirksamkeit und Motivation, da ihre Kenntnisse, Bauerfahrungen und ihre Kreativität bei der inneren Ausstattung der Kirche wertgeschätzt wurden:

„Das Haus, welches wir früher als Schule benutzt hatten, genügte jetzt nicht mehr. Daher wurde beschlossen, eine einfache Kirche zu bauen. An Holz fehlte es nicht, Steine wurden nicht dabei verwendet. Jeder mußte mit Hand anlegen. Einige verstanden etwas von Zimmerarbeit. So brachten wir ein einfaches Haus zustande, ganz aus rohem Holz. gefertigt, mit Schindeln gedeckt. Auf dem Dache stand ein Kreur. In dieses Innere setzten wir Bänke, einen Tisch als Altar und eine Art Kanzel. Schwarzes Tuch zum Schmucke des Altars- und der Kanzel war in dem brasilianischen Flecken zu baden. Die Fenster vertraten einfache hölzerne Laden. (...) Wir waren stolz auf unsere Kirche. Mit unserer Hände Arbeit und mit unserem Schweiß hatten wir sie gebaut. Der Tag der Einweihung war ein großer Festtag. Wie sie so dastand, mit Palmzweigen geschmück.t, glaubten wir, es gäbe keine schönere in der ganzen Welt".1499

Die ersten protestantischen Kirchen wurden zunächst ohne Turm gebaut oder erhielten einen separaten Glockenstuhl und andere Verzierungen, wie das erwähnte Kreuz auf dem Dach, welche sie als Kirche auswiesen. Die Rede von Glockenstühlen in Hinblick auf die frühen Kirchbauten zeigt, dass Gemeindemitglieder sich bereits Glocken angeschafft hatten, welche jedoch ihren Kirchen den vom Gesetz untersagten äußeren Anschein eines Tempels gab. Dieser Gesetzesverstoß

\footnotetext{
1498 Aus den Erinnerungen eines alten Pfarrers. Veröffentlicht in Der Christenbote Blumenau, in laufenden Vorsetzungen, Nr. 11 vom November 1921 bis Nr. 8 vom August 1922. In: Evangelische Synode von Santa Catarina und Paraná, S. 110.

1499 Erinnerungen eines deutschen Ansiedlers in Brasilien. In: Sonntagsblatt für die evangelischen Gemeinden in Brasilien. Nr. 35, 12. Jahrgang, 1889, S. 134. AHI.
} 
ist bereits ab den 1850er und 1860er Jahren dokumentiert ${ }^{1500}$, doch die lokalen Behörden verhielten sich den Gemeinden gegenüber flächendeckend tolerant. ${ }^{1501}$ Der Grund dafür umfasst unterschiedliche Faktoren: Die Isolierung und Abgelegenheit der Siedlungsgebiete und die große Zahl von Einwanderern im Vergleich zur ansässigen brasilianischen Bevölkerung in bestimmten Gebieten. Auch genossen manche Einwanderer bereits einen gewissen ökonomischen und politischen Einfluss und stellten eine Anzahl von Abgeordneten in den städtischen Kammern, wie in Joinville (SC) und Blumenau (SC). Es wurden auch römisch-katholische Einwanderer in den Kolonien angesiedelt, welche vermutlich aus ethnischen Gründen keinen Widerstand gegen die Errichtung protestantischer Kirchen leisteten. Schließlich sah selbst die brasilianische Bevölkerung kein Problem in dem tempelartigen Aussehen der Kirchen und beteiligte sich sogar bei Einweihungsfeiern protestantischer Gemeinden.

Es ist nicht möglich, die Errichtung und Einweihung aller Kirchen in den verschiedenen Gemeinden pommerscher Kolonisation zu beschreiben. Hier sollen nur einige Beispiele dargestellt werden, die einen Überblick über das Engagement und die Zusammenarbeit der Einwanderer und deren Nachkommen geben sollen. Stellenweise finanzierte die brasilianische Regierung den ganzen oder einen Teil des Baus einer protestantischen Kirche, vor allem auf Marktplätzen. 1857 gewährte sie 4.000 Milréis für den Bau einer Kirche in Santa Isabel-Campinho (ES). ${ }^{1502}$ 1865 dekretierte die kaiserliche Regierung die Errichtung zweier Kirchen in Blumenau (SC), einer römisch-katholischen und eine evangelischen. ${ }^{1503}$ Kaiser Pedro II. selbst entwarf den Bauplan einer achteckigen neugotischen Kirche für die Evangelischen Christen und unterstützte den Bau mit etwa 60.000 Mark $^{1504}$ (Abb. 15 siehe S. 254). Auch die Petition um staatliche Hilfe für die Erbauung der evangelischen Kirche in Joinville (SC) fand Gehör und die brasilianische Regie-

1500 Wachholz, Luteranismo no Brasil, S. 182; vgl. Prien, S. 124. Die Gemeinde Luxemburg-Santa Leopoldina (ES) besaß bereits in den 1860er Jahren einen Glockenstuhl für zwei Glocken. Wernicke, S. 62.

${ }^{1501}$ Die Behörden reagierten nur, wenn Katholiken Protest erhoben, wie in Petrópolis (RJ). Pastor Ströle wurde eingesperrt, weil eine aufgeschlagene Bibel und zwei Kelche an der Fassade der Kirche angebracht wurden. Der katholische Nuntius verklagte ihn bei der Regierung, so dass der Delegat die Entfernung der Verzierungen anordnete. Der Pastor erklärte jedoch, dass für Deutsche äußere Abzeichen nur aus Turm und Glocken bestehen würden. Die Verzierungen mussten letztendlich nicht entfernt werden. Josenhaus, Der Evangelische Heidenbote, Nr. 4, April 1864, S. 44.

1502 Von Tschudi, Reisen durch Süd-Amerika, 3. Band, S. 12; Busch, G. F. Brasilia. 3. Jahrgang, Petrópolis, 6.2.1861, EZA 5/2571; Schröder, Brasilien und Wittenberg, S. 329.

1503 Weingärtner. 150 Anos de Presença Luterana no Vale do Itajaí, S. 14.

${ }^{1504}$ Die Kirche konnte erst im Jahre 1877 eingeweiht werden, als die Gemeinde ihr 25-jähriges Jubiläum feierte. Scheerer. Festschrift der Evangelischen Kirchengemeinde Blumenau, S. 3, EZA 5/2486; Zum 50jährigen Jubiläum der evangelischen Gemeinde in Blumenau. In: Der Deutsche Ansiedler, November 1907, EZA 5/2488. 
rung stellte die bedeutende Summe von 10 Contos de Réis zur Verfügung ${ }^{1505}$, später bewilligte sie darüber hinaus 200 Milréis monatlich für deren Vollendung. Auch Kirchenmitglieder trugen freiwillig mit 700 Milréis zum Bau bei. ${ }^{1506}$ Für den Kirchbau in Santa Cruz do Sul (RS) sammelten die Gemeindemitglieder 3.693 Milréis und bekamen zudem 300 Thaler (etwa 423 Milréis) von der preußischen Regierung geschenkt. 1867 folgten weitere 590 Milréis. ${ }^{1507}$ In der Regel aber mussten die Siedler ihre Gotteshäuser auf eigenen Kosten errichten.

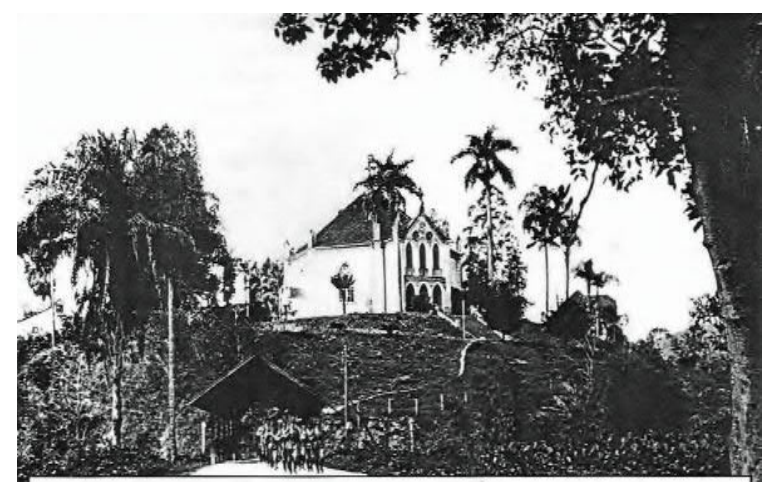

Abb. 15: Heiliggeistkirche in Blumenau (SC), eingeweibt am 23.9.1877. Foto von Edson Klemann. Quelle: Weege, Fotos Antigas Blumenau.

Vollziehung von Gottesdiensten und kirchlichen Amtshandlungen. Einige Gemeindemitglieder hatten, angesichts der schwierigen Zeiten und schwankender Wirtschaftssituation, Zweifel bezüglich der Errichtung kirchlicher Gebäude. Diese waren keinesfalls unbegründet, denn beispielsweise musste die Gemeinde Pontal (ES) den Plan für die Errichtung einer Kirche aufgrund einer Kaffeekrise, von welcher die Siedler stark betroffen waren, aufgeben. ${ }^{1509}$ „Die Kirche kostet uns die letate Kub auf der Weide, die Kirche frisst unseren ganzen Schweiss auf"1510 oder "Ich helfe nicht mit" "511 waren oft zu hörende Sätze. In einigen Fällen wurden die ersten Ent-

1505 Bühler, Fritz. Ein Beitrag zur Kirchenkunde Südamerikas. [1917/1918], S. 9, MLV 51/17 108; Wüstner, S. 15. Der Hamburger Kolonisationsverein hatte hier das Landstück für die Errichtung von Kirche, Schule und Pfarrhaus geschenkt. Die Kirche wurde am 7.8.1864 eingeweiht.

1506 Bühler, Fritz. Ein Beitrag zur Kirchenkunde Südamerikas. [1917/1918], S. 18, MLV 51/17 108.

1507 Sínodo Riograndense. Comunidade Evangélica de Santa Cruz do Sul. 1862 - 100 - 1962, S. 7f, AHI, SR 144/15; Hennig, S. 95.

1508 Brief von Pastor Jakob Sauer an die Missionsfreunde, Lomba Grande, 10.2.1928, BMA, PABV 1875 .

1509 Delegantensynode in Guandu am 21.6.1930, Protokoll Nr. 9. In: Protokollbücher des Synoden Nordkreises in Brasilien 1923, MEW 3.22

1510 Lutherische Kirche in Brasilien, S. 84.

1511 Giurus, Crônica da Paróquia Evangélica Luterana de Indaial, S. 164. 
würfe abgelehnt ${ }^{1512}$, in anderen weigerten sich einige Kirchenmitglieder ihren finanziellen Beitrag zu zahlen oder mitzuhelfen. ${ }^{1513}$ Aus dem Protokoll einer Gemeindesitzung in Timbó (SC) vom 15. Dezember 1889 geht hervor, dass die Kirchenbauarbeiten mehrmals unterbrochen werden mussten, weil nicht alle Gemeindemitglieder ihren monatlichen Beitrag rechtzeitig gezahlt hatten. ${ }^{1514}$

Grundstücke wurden in manchen Fällen von Gemeindemitgliedern gespendet. ${ }^{1515}$ Manchmal mussten sie zunächst geebnet ${ }^{1516}$ oder der Wald am Kirchenplatz gerodet werden. ${ }^{1517}$ Bruchsteine, Granitblöcke, Holzbalken, Kalk, Ziegel und Zement wurden teilweise auf den eigenen Schultern durch die schmalen Straßen bis zur Baustelle getragen ${ }^{1518}$ oder mit dem Esel transportiert. ${ }^{1519}$ Um nicht täglich zwei Stunden Zeit zu verlieren, kochten Gemeindemitglieder in Biriricas (ES) ihr Mahl auf dem Arbeitsplatz und übernachteten in einem Schuppen, während zwei weitere Familien die engagierten Handwerker fünf Monate in ihren Häuser beherbergten. Andere Familien ließen Bänke, Kanzel und Altar anfertigen, während ein Junggeselle, der bald in der neuen Kirche heiraten wollte, die bunten Glasfenster stiftete. Zusätzlich spendeten Familienmitglieder den doppelten Kirchenbeitrag sowie 60 freiwillige Arbeitstage für die Errichtung ihrer Kirche. ${ }^{1520}$ Freiwillige Arbeitstage, Geldspenden und Baumaterial ${ }^{1521}$ wurden von Kirchenmitgliedern verschiedener Gemeinden gespendet. Über den Kirchenbau in Timbó (SC) berichtet Carl Friedrich Butzke:

\footnotetext{
1512 Lutherische Kirche in Brasilien, S. 195.

1513 Wüstner, S. 31.

1514 Die Teilnehmer dieser Kirchensitzung verpflichteten sich dann zur Übernahme eines Schuldscheines, um mit einem Darlehen für die Fertigstellung des Kirchenbaus zu sorgen. Weingärtner, História da Comunidade Evangélica de Timbó, S. 88f.

1515 Evangelische Synode von Santa Catarina und Paraná, S. 72.

1516 Bericht über die Einweihung der neuerbauten Kapelle in Biriricas an das Kirchliche Außenamt Berlin durch Pfarrer Hoepffner, Rio de Janeiro, EZA 5/2583; Von Tschudi, Reisen nach Süd-Amerika, 3. Band, Fußnote S. 38.

${ }^{1517}$ Brief von Pastor Reuther an Von Tschudi, Santa Leopoldina, 25.10.1864, BMA, FB, 1,1.

1518 Stoer, S. 20.

${ }^{1519}$ Langholf, Johan. Dienst an den zerstreuten in Brasilien, S. 38, MEW 4.118.

1520 Bericht über die Einweihung der neuerbauten Kapelle in Biriricas an das Kirchliche Außenamt Berlin durch Pfarrer Hoepffner, Rio de Janeiro, EZA 5/2583. Die Kirche konnte am 5.12.1937 feierlich eingeweiht werden.

${ }^{1521}$ Halle, G. Kurze Geschichte der deutsch-evangelisch-lutherischen Gemeinde zu Ijuby, S. 5, 9, AHI, SR 83/25; Evangelische Synode von Santa Catarina und Paraná, S. 72; Weingärtner, Crônica da Comunidade Evangélica de Timbó, S. 28, 30, 36; Weingärtner, História da Comunidade Evangélica de Timbó, S. 88f; Interview von Anivaldo Kuhn in Melgaço, 2004. Zitiert nach Seibel, Imigrante no século do isolamento, S. 542f; Grimm, H. Deutsche Tätigkeit und Not in Espírito Santo. In: Traeger, P. (Hrsg.) Süd- u. MittelAmerika. Berlin: Verlag G.m.b.H., 30.9.1913, Nr. 18, 6. Jahrgang, S. 280, EZA 5/2563; Gaede, S. 187f; Brief von Pastor Jakob Sauer an die Missionsfreunde, Lomba Grande, 10.2.1928, BMA, PABV 1875; Schröder, Brasilien und Wittenberg, S. 137, 164; Dedekind, 75 Jahre deutsch-evangelischer Diasporaarbeit, S. 39; Wilbert et. al., S. 92.
} 
„Wieder wurde Versammlung, zum Kirchbau, gehalten. Da wurde ich als erster Vorstand gewählt. Die Kirche habe ich direkt gebaut mit August Klug und Friedrich Klug. Wir haben in unserem Walde Holz geschlagen. Zimmermann Gustman hat das Holz. verbunden und aufgerichtet. Die Maurerarbeit machte der Maurer Fröhlich. Die Kirche steht heute noch. Die Bänke in der Kirche machte Julius Vogel und Carl Bewiahn ".1522

In Jequitibá (ES) füllten die Siedler Holzrahmen mit Lehm und stampften diesen zusammen, denn Ziegeln waren in den abgeschiedenen Siedlungsgebieten noch nicht verfügbar und konnten durch die schmalen Schneisen auch nicht zum Bauplatz transportiert werden. ${ }^{1523}$ Ein Kolonist berichtet, ,die Alten haben an den Mauern so gestampft, dass die Bärte gewackelt haben“" weswegen alle großen „Respekt vor ihrem Kirchbau" hatten. ${ }^{1524}$ In vielen Gemeinden wurden die Ziegel von den Siedlern selbst hergestellt. ${ }^{1525}$ Das Dach wurde gewöhnlich mit harten, resistenten und dicken Holzlatten oder mit Schindeln und Zinkblech gedeckt. ${ }^{1526}$ Wenn die Gemeinden das Geld für den Kirchbau nicht allein aufbringen konnten, organisierten sie Sammelaktionen, wie in Ijuí (RS), wo die Herren Klever und Franz Berenhäuser sich anboten, Kollektenreisen in alten Kolonien durchzuführen, um zusätzliche Spenden zu sammeln. ${ }^{1527}$

Die innere Ausstattung der Kirchen war vor allem in den ersten Jahren sehr schlicht. Kirchenbänke, der Verschlag für die Kirchendecke, Altar und Kanzel wurden selbst angefertigt ${ }^{1528}$, Taufbecken, Abendmahlsutensilien, Altargewände und Harmonien erst allmählich angeschafft. In Indaial (SC) diente das Ziegeldach der ersten Kirche 1885 zugleich als Decke, die Bänke hatten keine Lehnen, es war kein Altarraum vorhanden und als Sakristei diente ein Bretterkasten. Nur die gotischen Fenster gaben dem Bau ein kirchliches Aussehen. ${ }^{1529} 1923$ bildete die Gemeinde eine „Verschönerungskasse“, um einen neuen Altar, ein Altarbild, einen Taufstein, zwei Nummernbretter, eine Kniebank, Altar-, Kanzel- und Taufsteinbekleidung und einen Vorhang zur Sakristei anzuschaffen. ${ }^{1530}$ In vielen Gemeinden schenkten oder fertigten Gemeindemitglieder selbst Kruzifixe ${ }^{1531}$, Leuchter ${ }^{1532}$,

1522 Butzke, Carl Friedrich Wilhelm. Mein Lebenslauf und Lebenskampf. Zitiert nach Evangelische Synode von Santa Catarina und Paraná, S. 98.

1523 Gaede, S. 61f; Granzow, Pommeranos unter dem Kreuz des Südens, S. 53.

1524 Soboll, S. 66.

1525 Hornburg, S. 32; Gaede, S. 187f; Damitz, Entwicklungsaspekte zur Situation der Brasilianer, S. 29; Lutherische Kirche in Brasilien, S. 218.

1526 Hornburg, S. 32.

${ }^{1527}$ Halle, G. Kurze Geschichte der deutsch-evangelisch-lutherischen Gemeinde zu Ijuby, S. 5, 9, AHI, SR 83/25.

1528 Weingärtner, Crônica da Comunidade Evangélica de Timbó, S. 30, 36; Weingärtner, História da Comunidade Evangélica de Timbó, S. 88f.

${ }_{1529}$ Reisebericht Pastors Otto Kuhr. In: Der Lutherische Gotteskasten, Nr. 3, 26. Jahrgang, 1905, S. 52, EZA 200/1/2152; Schröder, Brasilien und Wittenberg, S. 276; Giurus, Crônica da Paróquia Evangélica Luterana de Indaial, S. 110, 123.

1530 Giurus, Crônica da Paróquia Evangélica Luterana de Indaial, S. 136 f.

1531 Bericht Pastors Hösch über das Reisepredigtgebiet Rio Doce do Norte von Espírito Santo und Minas Gerais von Juli bis 31.12.1928, Santo Antonio, 4.1.1929, MLV 51/17 69; Langholf, Johan. 
Kirchenfenster ${ }^{1533}$, Taufsteine ${ }^{1534}$ und andere kirchliche Gegenstände ${ }^{1535}$ an. Das war kein leichtes Opfer für Gemeindeglieder aus ärmlichen Verhältnissen. Die Gemeinde Rio do Sul (SC) konnte sich beispielsweise die geplante Inneneinrichtung, die Bemalung der Kirche und die Anschaffung von Glocken zunächst nicht leisten. Aber darin sahen die Kirchenmitglieder eher etwas Positives: „Wir sind ja stets in Not, aber das erhält frisch und lässt das Geschaffene böher werten".1536 Zur Innenausstattung von Gotteshäusern trugen neben anderen deutschen Vereinen (wie das Gustav-Adolf-Werk), die 1910 gegründete Obra Gustavo Adolfo, der Gotteskastenverein, aber auch Frauenhilfegruppen bei, die in den ersten Jahren des 20. Jahrhunderts gegründet worden waren. Durch ihre Mithilfe konnten viele Gemeinden beim Kirchenbau ${ }^{1537}$, bei Renovierungen ${ }^{1538}$ oder anderen Bauarbeiten in Kirchen, bei Gemeindezentren ${ }^{1539}$, Pfarrhäusern, bei der Innenausstattung von Kirchen ${ }^{1540}$ und der Anschaffung von Kruzifixen, Abendmahlutensilien, Taufbecken ${ }^{1541}$, Glocken $^{1542}$, Harmonien, Ornat ${ }^{1543}$, Bibeln, Gesangbüchern, Musikinstrumenten und anderen Dingen unterstützt werden. ${ }^{1544}$

Dienst an den zerstrenten in Brasilien, S. 36, MEW 4.118. Die Familie Fißner spendete für die Kirche in Joinville (SC) das Altarkruzifix. Wüstner, S. 28f.

1532 Für die Kirche in Brusque (SC) spendete ein Kolonist zwei Kronleuchter für 600 Mark. Schröder, Brasilien und Wittenberg, S. 274.

1533 Die Familie Hering stiftete Kirchenfenster mit christlichen Motive für die Kirche in Blumenau (SC). Scheerer. Festschrift der Evangelischen Kirchengemeinde Blumenau, S. 7f, EZA 5/2486.

1534 Wüstner, S. 28f; Bühler, Fritz. Ein Beitrag zur Kirchenkunde Südamerikas. [1917/1918], S. 18, MLV $51 / 17108$.

1535 Müller, Herança de geração em geração, S. 68. In Brusque (SC) sorgten einige Frauen für die Anschaffung würdiger Abendmahlutensilien. Schröder, Brasilien und Wittenberg, S. 274. In Joinville spendete Hugo Delitsch das Taufbecken. Wüstner, S. 28f.

1536 Auszug aus der Zeitung Der Deutsche Ansiedler April/Juni 1932, BMA, PABV 1981.

1537 Claas, S. 33.

1538 Stoer, S. $21 \mathrm{f}$.

1539 Sínodo Riograndense. Comunidade Evangélica de Santa Cruz do Sul. 1862 - 100 - 1962, S. 10, AHI, SR 144/15.

1540 Stoer, S. 21f.

1541 Der Frauenverein spendete der Gemeinde Pomerode (SC) einen Taufstein. Jahresbericht Pastors Friege an das Kirchliche Außenamt, 10.7.1937, EZA 5/2535.

1542 Über das Engagement der Frauenhilfe in Novo Hamburgo (RS) für die Anschaffung von Glocken und für die Errichtung einer neuen Kirche in Novo Hamburgo (RS) siehe Wachholz, Wilhelm. Uma Igreja Diferente. Novo Hamburgo: Com-Texto Gráfica e Editora, 2001, S. 14, 41f. Im Jahre 1940 spendete die Frauenhilfe von Jaraguá do Sul (SC) eine kleine Glocke für die Kirche samt 6.000 Milréis für die Tilgung der Gemeindeschulden. Claas, S. 33.

1543 Stoer, S. 22.

1544 Droste, Rolf. Die Bedeutung der Obra Gustavo Adolfo für die Evangelische Kirche Lutherischen Bekenntnisses in Brasilien. In: Gustav-Adolf-Werk (Hrsg.) Evangelium - Markt - Kreu₹: evangelisch-lutherisch in Brasilien. Leipzig: Verlag des Gustav-Adolf-Vereins, 2011, S. 69; Weingärtner, Martin Luther e Santa Catarina, S. 132. 


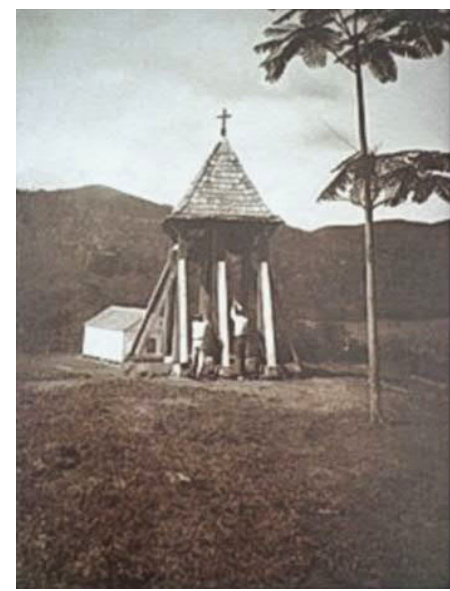

Abb. 16. Der Glockenstubl in Rio Ponte (ES). Die Quelle erwähnt kein Datum, aber wenn es sich um den ersten Glockenstubl dieser Gemeinde handelt, könnte er während der Amtszeit von Pastor Soboll, zwischen 1928 und 1932, errichtet worden sein. Foto von Herwig Soboll. Quelle: Soboll, S. 67.

Je nach finanziellen Ressourcen schafften sich die Gemeinden selbst Glocken an oder bekamen eine oder mehrere geschenkt. Sie wurden in der Regel zunächst in einem provisorischen hölzernen Glockenstuhl aufgehangen ${ }^{1545}$ (Abb. 16), bis die Gemeinden imstande waren, eine massive Turmkirche oder einen massiven Turm ihren bereits vorhandenen Kirchen anzugliedern. Für die Anschaffung von Glocken organisierten sich die Gemeindemitglieder ein weiteres Mal, um Spendengelder zu sammeln. Die Gemeindemitglieder in Santa Maria de Jetibá (ES) veranstalteten 1906 beispielsweise eine „Kaffeesammlungskampagne“.1546 In anderen Gemeinden spendeten Kirchenmitglieder zusätzliche Geldbeträge. ${ }^{1547}$ Schwierig wurde die Lage für die Gemeinde Novo Hamburgo (RS). Aufgrund der Geldentwertung nach dem Ersten Weltkrieg genügten die 1922 gesammelten 3:100\$000 (drei Contos und hunderttausend Réis) für die Anschaffung ihrer Glocken nicht mehr, sodass die Gemeindemitglieder weitere 2:000\$000 an die Bochumer Firma in Westfalen zahlen mussten. Erst zwei Jahren später, am 25. Juli 1924, konnten die Glocken endlich feierlich in einem Gottesdienst eingeweiht werden. Auch sie wurden zunächst in einem provisorischen Glockenstuhl aufgehängt. ${ }^{1548}$ Trotz aller Schwierigkeiten ließen sich die Kirchenmitglieder nicht von der Anschaffung von Glocken abbringen. Pastor Soboll schlug zum Beispiel der Gemeinde Rio Ponte (ES) mehrmals vor, sich zunächst ein Harmonium anzuschaffen, aber sie wünschten sich lieber Glocken. Als festgestellt wurde, dass sie noch nicht genügend Geld dafür gesammelt hatten, spendeten die Familien erneut höhere Summen, um die Glocken kaufen zu können. ${ }^{1549}$

\footnotetext{
1545 Schröder, Brasilien und Wittenberg, S. 276; Reisebericht Pastors Otto Kuhr, In: Der Lutherische Gotteskasten, Nr. 3, 26. Jahrgang, 1905, S. 52, EZA 200/1/2152; Giurus, Crônica da Paróquia Evangélica Luterana de Indaial, S. 110, 123; Lutherische Kirche in Brasilien, S. 194, 218, 223; Weingärtner, História da Comunidade Evangélica de Timbó, S. 245; Damitz, Entwicklungsaspekte zur Situation der Brasilianer, S. 22.

1546 Gaede, S. 195.

1547 Langholf, Johan. Dienst an den zerstreuten in Brasilien, S. 36f, MEW 4.118; Lutherische Kirche in Brasilien, S. 206.

1548 Wachholz, Uma Igreja Diferente, S. 11, 13.

${ }^{1549}$ Soboll, S. 61f.
} 
Besonders der Glockentransport durch schmale Schneisen stellte eine große Herausforderung dar, die die Siedler jedoch mit viel Kreativität, Zusammenarbeit und Ausdauer zu meistern wussten. Gemeindemitglieder von Santa Maria de Jetibá (ES) zogen ihre Glocken in sechs Reitstunden unter Ziehen und Schieben bis zum Pfarrsitz. ${ }^{150}$ In Pomerode (SC) wurden die Glocken mithilfe zweier Ochsenkarren von der Hafenstadt Itajaí (SC) etwa 70 Kilometer bis zum Kirchenplatz transportiert (Abb. 17), wo sie feierlich empfangen wur-

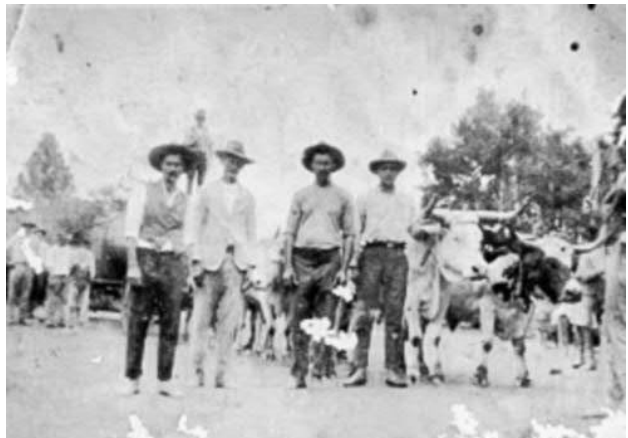

Abb. 17: Transport von Glocken von Itajai (SC) bis nach Pomerode (SC). Der Turm für die drei Glocken wurde 1900 errichtet. Quelle: Weege, Heike. Fotos antigas de Pomerode. 2013. den. ${ }^{151}$ Die Glocken der Gemeinde Jequitibá (ES) wurden vom Hafen in Vitória (ES) bis Porto do Cachoeiro (ES) in Kanus transportiert. Von dort trugen einige Mitglieder der Gemeinde sie mit Hilfe von Holzstämmen auf den Schultern fünf Stunden lang über 30 Kilometer auf ansteigenden Pfaden bis zum Kirchen-

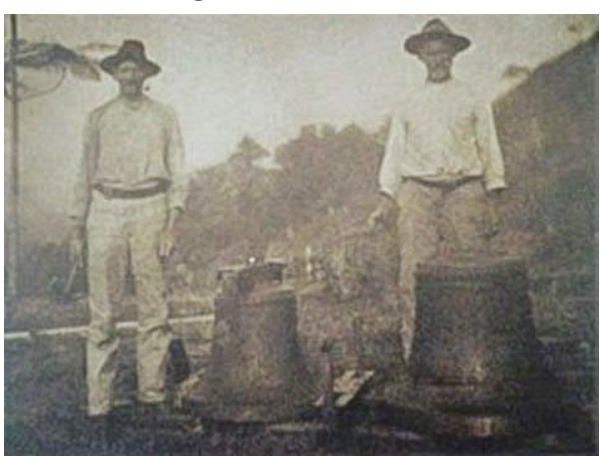

Abb. 18: Transport von zwei Glocken in Rio Ponte (ES). Die Gemeinde schuf ihre Glocken während der Amtszeit von Pastor Soboll an, zwischen 1928 und 1932. Foto von Herwig Soboll. Quelle: Soboll, S. 62. platz. ${ }^{1552}$ Die Glocken der Gemeinde Laranja da Terra (ES) wurden 1924 ein Stück durch gebirgiges Gelände getragen und dann mit eigens gefertigten zerlegbaren Karren abgeholt. ${ }^{1553}$ Schließlich soll der folgende Bericht aus Rio Ponte (ES) zitiert werden, der die Situation genauer beschreibt. Es handelt sich dabei um eine der wenigen erhaltenen zeitgenössischen Darstellungen über die Opferbereitschaft und die Zusammenarbeit der Kirchenmitglieder bei dem Glockentransport. Zugleich verdeutlicht er die Problemlösungsfähigkeit und Beharrlichkeit der Siedler (Abb. 18):

1550 Damitz, Entwicklungsaspekte zur Situation der Brasilianer, S. 21; vgl. Lutherische Kirche in Brasilien, S. 175 .

${ }^{1551}$ Liesenberg, S. 6; Altmann, S. $158 f$.

1552 Grimm, H. Deutsche Tätigkeit und Not in Espirito Santo. In: Traeger, P. (Hrg). Süd-u. Mittel-Amerika. Berlin: Verlag G.m.b.H., 30.9.1913, Nr. 18, 6. Jahrgang, S. 280, EZA 5/2563; Gaede, S. 62.

${ }^{1553}$ Langholf, Johan. Dienst an den zerstreuten in Brasilien, S. 36f, MEW 4.118. 
IV - Institutionelle Formierung und Konflikte

„Bis auf 2 Reitstunden Entfernung konnte auf weiten Umwegen von der Babnstation aus schon ein Caminhão (LKW) bei gutem Wetter heranfahren. Aber dann? Und so fragte ich sie: ,Wie stellt Ihr Euch das vor? Wer könnte so schwere Glocken tragen?' Sie sagten: ,Das ist nur dann möglich, wenn wir alle anfassen. Jetat haben wir die Glocken gakauft [sic!], jetzt holen wir sie auch her. Für Esel sind die viel so schwer, das geht nicht. Also müssen wir selbst zupacken!! So kamen die starken Männer zusammen, 56 an der Zabl, holten starke Bambusstangen, und zwar von der ganz dicken Sorte, so 12 bis $15 \mathrm{~cm}$ im Durchmesser. Die sollten wohl das Gewicht der Glocken aushalten. Aber die Stangen bogen sich doch ganz schön durch. Also wurden die Männer nach der Grösse aufgestellt: die kleinsten je vorn und binten nahe der Glocke und dann, je grösser sie waren, desto weiter von der Glocke entfernt. So wurde das Durchbiegen der Bambusstangen einigermassen ausgeglichen. Die stärksten Männer wurden zur grossen und die schwächeren zur kleinen Glocke beordert. Es wurde für jede Glocke eine doppelte Mannschaft ausgesucht, damit Unterwegs [sic!] immer wieder abgewechselt werden konnte. Dann gings los, ab durch den Urwald. Ein imponierendes Bild. Man merkte, dass jeder alle Kraft einsetzen musste. Damit die Last nicht zu lange drückte, liefen die Leute ser [sic!] schnell, aber nach fünf Minuten musste schon die andere Gruppe die Last übernehmen. So wurde gewechselt, obne die Schritte zu verlangsamen und obne die Glocke abzusetzen. Einer der nicht tragen konnte, versuchte da, wo gerade der Weg breiter war, neben der Glocke herzulaufen und schlug mit einem Stück Eisen an die Glocke im Takt seiner Schritte. So hörten die Leute auf den Kolonien, wie die Glocken angebaumelt kamen. Auf jeden Fall gab jeder sein Letztes an Kraft und Einsatr. (...) Sie hatten wirklich kein trockenes Fädchen am Leibe, einer wie der andere, und tropften nur so. Dergleichen babe ich nie vorher und nie nachher gesehen ".1554

Kurz vor der Proklamierung der Republik 1889 entschlossen sich manche Gemeinden, Türme an ihre Kirchen anzubringen. Geistliche und Gemeindemitglieder waren über die Annäherung der Republik, bezüglich religiöser Gleichberechtigung, informiert, weswegen sie sich mutig für den Turmbau einsetzten. In Timbó (SC) beispielsweise erfuhr das Gemeindemitglied Frederico Donner durch den Kongressabgeordneten Dr. Paulo Ramos, dass Religionsfreiheit bald per Gesetz durchgesetzt werden würde. So plante die Gemeinde 1888 die Errichtung einer Turmkirche, obwohl sie sicherheitshalber zunächst einmal einen Turm entworfen hatte, der zu einem Haupteingang umgestaltet werden konnte. ${ }^{1555}$ Zwar wurde die Kirche erst 1890 eingeweiht (Abb. 19 siehe S. 261), aber die Behörden konnten schon während des Baus erahnen, dass es sich um eine stattliche Turmkirche handelte, taten aber nichts, um den Bau zu stoppen. 1887 hatte die Gemeinde Santa Isabel (SC) eine Petition an das kaiserliche Ministerium gesandt mit der Bitte,

\footnotetext{
1554 Soboll, S. 63-65; vgl. mit Bericht über das Glockeneinweihungsfest zu Rio Ponto am 25.5.1930, EZA 5/2602. Hier werden 70 Männer für den Transport der Glocken erwähnt. Die Angabe Pastor Sobolls scheint jedoch genauer zu sein.

1555 Weingärtner, História da Comunidade Evangélica de Timbó, S. 87.
} 
einen Kirchturm errichten zu dürfen. Diese Petition fand aber kein Gehör ${ }^{1556}$, vermutlich weil die Regierung offiziell keine Erlaubnis herausgeben wollte, die gegen die Bundesverfassung verstieß. Es kann auch nicht sicher geklärt werden, ob die Gemeinde nur um eine Erlaubnis des Ministeriums ersuchte, oder ob sie auf finanzielle Unterstützung für den Bau hoffte, da sie nach 1889 theoretisch einen Turm bauen durfte, es aber erst 1916 tat. Doch auch andere Gemeinden begannen nun Kirchtürme zu bauen. Gemeindemitglieder von Santa IsabelCampinho (ES) (heute Domingos Martins) begannen 1886 einen Turm an ihre Kirche zu bauen. ${ }^{1557}$ Der Turm wurde 1887 eingeweiht und lokale Beamte sowie die ansässige Bevölkerung unternahmen nichts dagegen. 1558

Für die Gemeinde Santa Maria (RS) war das Unternehmen nicht gerade einfach. Die Gemeindemitglieder sammelten sich 1887 im Verborgenen und bauten zusammen einen Turm. Die Behörden beteiligten sich zwar an der Feier, doch der Polizeichef drohte der Gemeinde mit gesetzlichen Strafen und ordnete ein Verbot der Gottesdienste an. Mithilfe einflussreicher Politiker der republikanischen Partei, einer Unterschriftensammlung mit 7.893 Unterschriften, die vom Präsident der Riograndenser Synode, Pastor Dr. Rotermund zusammen mit einem Antrag auf Gleichberechtigung religiöser Rechte an die Kammer in Rio de Janeiro (RJ) gereicht wurde ${ }^{1559}$, und auch aufgrund eines Protests, bei dem

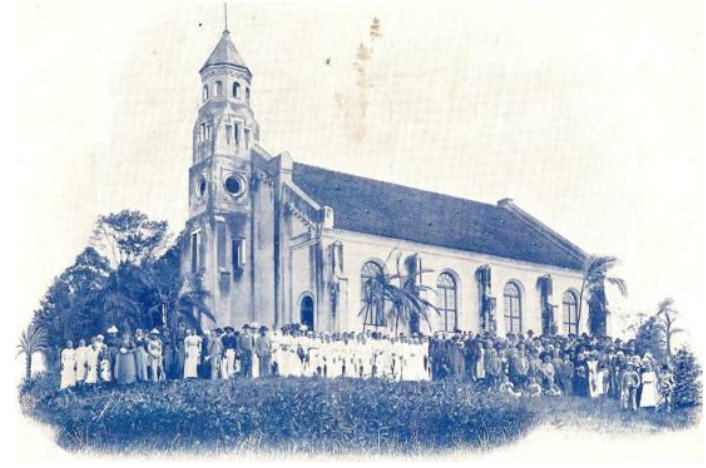

Abb. 19: Erste Stadtkirche in Timbó (SC), errichtet zwischen 1888 und 1890, eingeweibt am 28.9.1890. Foto vom Fotograf Schmidt aus Salto Weissbach (SC). Sie gehört zu einer Sammlung, die anlässlich des 50. Jahrestages der Gründung der Kolonie Blumenau (SC) 1900 veröffentlicht wurde. Quelle: Weingärtner, História da comunidade evangélica de Timbó, S. 89.

\footnotetext{
1556 Stoer, S. 12.

${ }^{1557}$ Laut Rölke, Raízes da Imigraşão alemã, S. 370 wurde der Turm 1866 errichtet. Es handelte sich um einen Tippfehler.

1558 Wernicke, S. 101; Damitz, Entwicklungsaspekte zur Situation der Brasilianer, S. 4.

${ }^{1559}$ Es handelt sich um die Bittschrift, die am 28.5.1887 an die Landesrepräsentanten gesendet wurde und die Änderung des 5. Artikels der Bundesverfassung und des Artikels Nr. 276 des Strafgesetzbuches beantragte, welche die Realisierung von Gottesdiensten in Gebäuden mit dem äußerlichen Anschein einer Kirche den Evangelischen Christen verboten. Unter den Unterzeichnenden befanden sich viele Katholiken. Brief des Synodalvorstandes an die „Augustos e Dignissimos Senhores Representantes da Nação“, 28.5.1887, AHI, SR 1/3 Beilage 076; SR 1/4 Beilage 003; SR 4/4 Beilage 001. Mit einer Aufhebung des Gesetzes versuchte die Synode die Gemeinde Santa Maria (RS) und ihren Vorstand davor zu beschützen, dass ihr Turm eingerissen wurde oder sich einen Prozess einzuhandeln. Nach Schröder sandte auch die Gemeinde Santa Maria (RS) einen Rundbrief an alle evangelischen Gemeinden Brasiliens mit der Bitte, die Aufhebung des Gesetzes einzufordern. Schröder, Brasilien und Wittenberg, S. 49.
} 
auch Katholiken teilnahmen, wurde die Wiedereröffnung der Kirche vom VizePräsident der Provinz angeordnet. ${ }^{1560}$ Floss erwähnt eine ähnliche Begebenheit in irgendeiner anderen Gemeinde in Rio Grande do Sul oder Santa Catarina, wobei er den Ort nicht nennt, der in den 1880er Jahren einen Turm an ihre Kirche bauen wollte. Er vermutet aber, dass die Gemeindemitglieder nur von einem lokalen Verbot für die Errichtung protestantischer Turmkirchen ausgingen und nahmen dieses nicht ernst. „Besonders tatendurstige Gemeindeglieder kamen zusammen und gingen ans Werk. Aber heimlich, nur heimlich". In einer geschlossenen Scheune schnitten sie Bauholz zurecht und zimmerten einen Kirchturm zusammen, der später nur noch aufgestellt werden musste. In einer Nacht sammelten sie sich dann, schleppten die schweren Bohlen und Balken aus der Scheune und stellten den Turm auf. Morgens war das Werk getan. Die Unbeteiligten schauten sich verdutzt an und konnten nicht glauben, ,gestern noch "Scheune" und heute ein ausgewachsener Kirchturm". Es kam zu vereinzelter Kritik, aber ,was einmal gebaut war, durfte obne Richterspruch nicht entfernt werden ". 1561

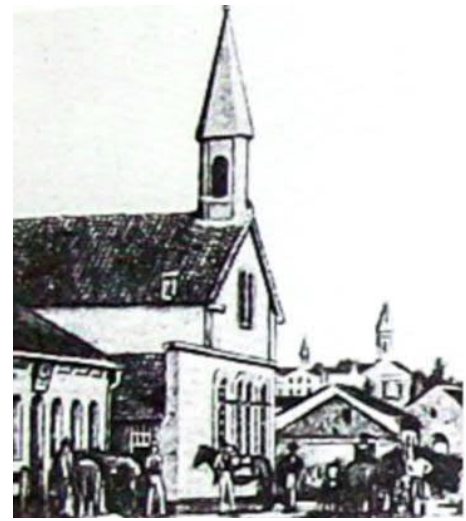

Abb. 20: Evangelische Kirche in Santa Cruz do Sul im Jabr 1872. Quelle: Sinodo Riograndense. Comunidade Evangélica de Santa Cruz do Sul 1862-100-1962, S. 8. AHI, SR 144/15.

In einem Artikel des Evangelischen Heidenbotens wird berichtet, dass bereits um die 1870er Jahre eine Gemeinde in Rio Grande do Sul einen Kirchturm baute und sich zwei Glocken anschaffte. Der genaue Ort und der Autor bleiben anonym. Die Gemeindemitglieder bereiteten alles im Verborgenen vor und von einem Tag auf den anderen wurde der Turm aufgestellt. Die römisch-katholische Bevölkerung drohte den evangelischen Mitgliedern mit der Zerstörung des Gebäudes; letztendlich geschah aber nichts dergleichen. Auf den ersten Blick scheint dieser Bericht mit dem von Santa Maria (RS) übereinzustimmen, aber das Jahr und die Drohungen der Katholiken weisen auf eine andere Gemeinde hin. ${ }^{1562}$ Es handelt sich in dem Bericht angeblich um die Gemeinde Santa Cruz do Sul (RS), deren Kirche bereits 1872 einen Turm zunächst auf dem Dach ihrer Kirche erhielt (Abb. 20). 1878 bauten die Siedler dann einen Turm an die Kirche (Abb. 21, siehe S. 263), trotz des existierenden Bauverbots und mehr als zehn Jahre vor der Ausrufung der Republik, als die religiöse Gleichberechtigung gesetzlich bestätigt wurde. Drei Glocken kamen 1879 hinzu. In der Gemeindechronik wird erwähnt, dass die Kirchenmitglieder der Meinung waren,

\footnotetext{
1560 Prien, S. 125; vgl. Römer, Ch. (Hrsg.) Der Evangelische Heidenbote, Nr. 1 Januar 1888. Basel: Verlag der Missionsbuchhandlung, S. 46.

${ }^{1561}$ Evangelische Synode von Santa Catarina und Paraná, S. 204.

1562 Römer, Der Evangelische Heidenbote, Nr. 1 Januar 1888, S. 46.
} 


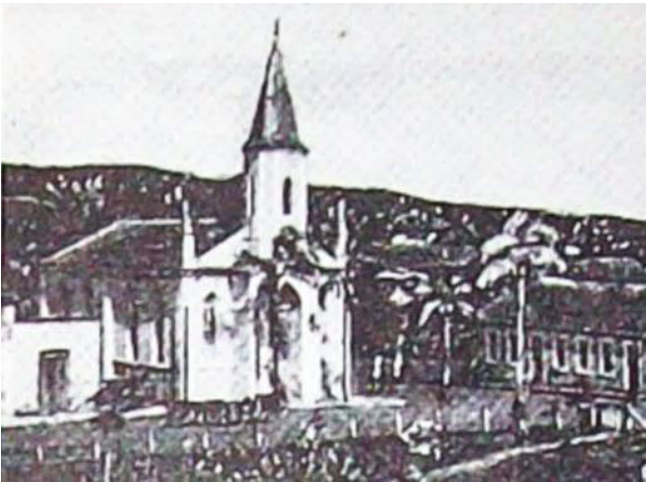

Abb. 21: Evangelische Kirche in Santa Cruz do Sul (RS) im Jahr 1878. Mit Hilfe der preußischen Regierung wurde das Dach und vermutlich auch die Fassade zwischen 1865 und 1867 erneut gebaut. Diese Kirche wurde 1924 abgerissen, weil die neue Kirche eingeweiht werden konnte. Quelle: Sinodo Riograndense. Comunidade Evangélica de Santa Cruz do Sul 1862100-1962, S. 9. AHI, SR 144/15. das Gesetz würde nicht gegen sie angewendet werden. ${ }^{1563}$ Keine Quelle berichtet von polizeilichen Maßnahmen oder Gottesdienstverboten, wie es in Santa Maria (RS) neun Jahre später der Fall war.

Dieser Vorfall muss sich herumgesprochen haben, denn eine Gemeinde nach der anderen begann in den 1880er Jahren einen Turm an ihre Kirche zu bauen, manche baten die Regierung sogar um Erlass des Einfuhrzolls für die Anschaffung von Glocken aus Deutschland. Die Gemeinde Santa Maria da Bocca do Monte (RS) lud schließlich die Spitzen der Behörde zur feierlichen Grundsteinlegung des Turmes ein und forderte sie auf, ein Dokument zu unterzeichnen, in welchem sie ihre Teilnahme bestätigten. Dies sollte späteren Quereleien vorbeugen. ${ }^{1564}$ Weitere Kirchentürme, von deren Errichtung keine schriftlichen Belege erhalten geblieben sind, sind in anderen Staaten gebaut worden. Pastor Liesenberg berichtet, dass die Gemeinde Testo Alto-Pomerode (SC) 1886 auch einen kleinen Turm auf das Dach der Kirche baute. ${ }^{1565}$ Eine Fotografie belegt aber, dass der Turm bereits 1871 existierte (Abb. 22). Später wurde die Kirche erweitert und erhielt einen massiven Turm (Abb. 23, siehe S. 264).

Es lässt sich feststellen, dass viele Gemeinden entgegen der verbreiteten Meinung eher aufgrund mangelnder Ressourcen keine Türme an ihren

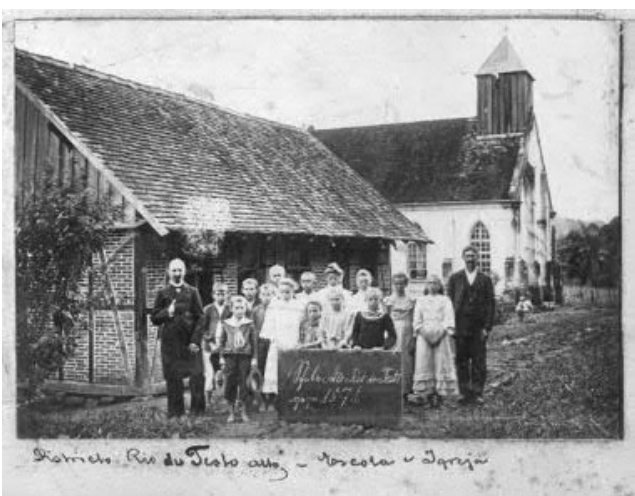

Abb. 22: Schule und im Hintergrund die Kirche in Testo Alto-Pomerode (SC) mit ibrem provisorischen Turm im Jahr 1871. Foto von Marcos Röck. Quelle: Wittmann, Igreja da Paz-Pomerode. Kirchen errichteten, als aufgrund des

1563 Sínodo Riograndense. Comunidade Evangélica de Santa Cruz do Sul. 1862 - 100 - 1962, S. 9, AHI, SR $144 / 15$.

1564 Römer, Der Evangelische Heidenbote, Nr. 1 Januar 1888, S. 46.

1565 Liesenberg, S. 19. 


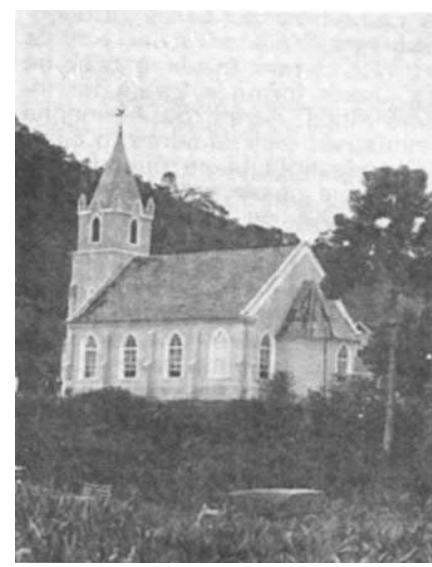

Abb. 23: Der Vergleich: Kirche in Testo Alto-Pomerode (SC) im Jabr 1927. Quelle: Weege, Fotos antigas de Pomerode. 2011. staatlichen Verbots. Weil sie in der Regel selbst für die Errichtung kirchlicher Gebäude zu sorgen hatten, bauten sie in Etappen je abhängig von ihren Ressourcen und entsprechend der hier dargestellten Bauentwicklung, die parallel zur Entwicklung der Siedlungsgebiete und ihrem ökonomischen Aufstieg verlief. Dies wird in einem Kolonistenbericht deutlich: „Glocken oder Orgel anzuschaffen, daran konnte vorläufig nicht gedacht werden. Den Evangelischen waren im Kaiserreich zwar Glocken und Turm verboten, aber im Unvalde kam es nicht so genau darauf an".1566 Und Pastor Zluhan berichtet, dass der Gottesdienst zunächst in einer Kolonieschule stattfand. Wenn der Raum zu eng wurde, schritten die Gemeindemitglieder zum Bau einer Kapelle. „Erst nach Jahren kommt es zu einem Kirchbau und zur Anschaffung von Altargeräten und etwa zu einer Glocke ".1567

In der kaiserlichen Zeit zeigte sich die brasilianische und katholische Bevölkerung tolerant und auch da, wo Protest erhoben oder Gottesdienste verboten wurden, entschied sich die Sache letztendlich zugunsten der Einwanderer und deren Nachkommen. Gegen das umstrittene Gesetz wurde in mehreren Gebieten bewusst oder unbewusst verstoßen. Letztlich hinderte es die Siedler nicht an der Errichtung ihrer kirchlichen Gebäude.

2.3. Dritte Phase: Der Aufbau einer „würdigen“ Kirche nach der Ausrufung der Republik

Mit der Ausrufung der Republik 1889 und dem Erlass einer neuen Bundesverfassung 1890, die die Gleichberechtigung aller Religionen und Konfessionen gewährte, konnten die Gemeinden ihre Kirchen ohne Einschränkungen mit Türmen und Verzierungen schmücken. Wieder versammelten sich Gemeindemitglieder zur Arbeit und errichteten oder erweiterten ihre Kirchen durch Türme. In diesem Sinne zeichneten sich protestantische Gemeinden in Brasilien über Jahrzehnte durch kirchliche Bautätigkeiten aus. Im Gegensatz zur Kaiserzeit fiel mit der Ausrufung der Republik aber die finanzielle Unterstützung seitens des Staates für den Kirchenbau gänzlich weg. Die Errichtung einer massiven Turmkirche gibt zudem Auskunft über den endgültigen Prozess der Niederlassung der Einwanderer und deren Nachkommen in ihrer neuen Heimat. Außerdem diente sie letztlich als ein konkretes Glaubensbekenntnis und -erbe auch für die folgenden Generationen.

\footnotetext{
1566 Erinnerungen eines deutschen Ansiedlers in Brasilien. In: Sonntagsblatt für die evangelischen Gemeinden in Brasilien. Nr. 35, 12. Jahrgang, 1889, S. 134. AHI.

1567 Zluhan, Christian. 40. Jahresbericht der Erziehungsanstalt in Sta. Isabella, Estado Sta. Katharina, Brasilien, vom 1.3.1904 bis 1.3.1905, Basel, 1907, S. 9f. Zitiert nach Wirth, S. 57f.
} 
Die neue Bundesverfassung, die religiöse Gleichberechtigung einschloss, gab den Einwanderern und deren Nachkommen neue Motivation für die Errichtung einer „würdigen Kirche" mit Turm und Glocken. Viele Gemeinden setzten sich opferbereit für den Turmbau und die Verschönerung ihrer Kirchen ein, denn sie wollten sich ihrer neu erworbenen Religionsfreiheit „würdig zeigen", wie aus Joinville (SC) zu hören war:

„Die Republik. hat uns die Glaubensfreibeit gegeben, und alle kleinlichen Bescbränkungen unserer Gottesverehrungen, alle erbärmlichen Gesetze, welche uns keine würdigen, ausgestatteten Gotteshäuser zuerkennen wollte, sind vom Hauch der Freibeit in alle Winde verwebt. Zeigen wir uns der Freiheit würdig! Verschönern wir unser Betthaus durch einen Turm, der mabnend gen Himmel weist, versehen wir diesen Turm mit Glocken, welche mit ibren harmonischen Tönen zum Menschenherz sprechen, welche mit ehernen Zungen verkünden, daß die Gemeinde Joinville sich ibres evangelischen Glaubens bewußt ist und denselben frei verkïndet. Auf zur Tat! Mit Gott und mit vereinten Kräften! ‘. 1568

Die Kirchenmitglieder sammelten sich und spendeten freiwillige Arbeitstage, Baumaterial und Geld für den Turmbau, für die Anschaffung von Glocken, sofern sie noch keine besaßen, für die Erweiterung der Kirchen oder für den Bau von massiven Kirchen als Ersatz für Kapellen, Bethäuser oder Kirchen-Scbulen.1569 Ziegel wurden in abgelegenen Gebieten noch selbst gefertigt und das Baumaterial an vielen Orten mit Hilfe von Lasteseln transportiert oder auf den Schultern getragen. ${ }^{1570}$ Für den Bau des Kirchturms in São Leopoldo (RS) arbeitete Siegfried Krohn beispielsweise bis zu zwölf Stunden am Tag. ${ }^{1571}$ In Jaraguá do Sul (SC) musste der Kirchenbau zwischen Ende der 1920er und Anfang der 1930er Jahre aufgrund finanzieller Schwierigkeiten mehrmals unterbrochen werden und die Gemeinde verschuldete sich dabei enorm. Aus diesem Grund schlug der Pastor vor, es zunächst bei einer Kirche ohne Turm zu belassen, doch die Mehrheit der Gemeindemitglieder war damit nicht einverstanden. Manche baten in anderen Orten um Spenden, andere liehen sich Geld, bis ihre Turmkirche letztlich 1935 eingeweiht werden konnte. ${ }^{1572}$ Wichtig ist weiterhin die Tatsache, dass manche Gemeinden ihre Kirchen und Turmkirchen während des Ersten und Zweiten

\footnotetext{
1568 Wüstner, S. 28.

${ }^{1569}$ Dedekind, 75 Jahre deutsch-evangelischer Diasporaarbeit, S. 39; Schröder, Brasilien und Wittenberg, S. 88, 170; Sínodo Riograndense. Comunidade Evangélica de Santa Cruz do Sul. 1862 - 100 - 1962, S. 10, AHI, SR 144/15; Giurus, Crônica da Paróquia Evangélica Luterana de Indaial, S. 128; Brief Pastor Schlünzen an den Direktor Dr. Eppelein, Jaraguá, 8.9.1933, MEW 4.199; Lutherische Kirche in Brasilien, S. 223.

1570 Bericht Pastors Walter Adler über den Kirchbau in Ponto 1934-1936, EZA 5/2602.

1571 Mitteilungen aus der Gemeinde São Leopoldo Nr. 4, 1971. Zitiert nach Müller, Herança de geração em geração, S. 57.

1572 Lutherische Kirche in Brasilien, S. 75, 80; Claas, S. 31.
} 
Weltkrieges und während der Nationalisierungszeit 1573 errichteten. 1915 bauten die Mitglieder der Gemeinde Laranja da Terra (ES) ihre Kirche in nur vier Monaten. 15741916 begann die Errichtung einer neuen Kirche in Santa Cruz do Sul (RS), die aber aufgrund des Krieges erst im November 1924 eingeweiht werden konnte. ${ }^{1575}$ Die Auswirkungen der Geldentwertung auf die Anschaffung von Glocken nach dem Ersten Weltkrieg in Novo Hamburgo (RS) wurde bereits erwähnt. Vor allem in Gemeinden, in denen die Schule zugleich für den Gottesdienst diente, wurde die Situation ab 1937 erheblich erschwert, da Schulen nun nicht mehr zu diesem Zweck verwendet werden durften. Aus diesem Grund baute die Gemeinde Itapocuzinho-Jaraguá do Sul (SC) unverzüglich ihre erste Kirche und weihte sie 1938 ein. ${ }^{1576}$ Die geplante Errichtung eines neuen Tempels in Novo Hamburgo (RS) konnte wiederum erst 1948 stattfinden.

Die massiven Turmkirchen sollten nach Ansicht der Gemeindemitglieder ein öffentliches Bekenntnis ihres Glaubens sein, für die brasilianische Gesellschaft und auch für zukünftige Generationen. Im Aufruf an die Mitglieder der evangelischen Gemeinde in Novo Hamburgo (RS), der zur Sammlung für Spenden für den Bau einer neuen Kirche diente, betonte der Kirchenvorstand:

„Die Gemeinde ist es sich selber schuldig, ein Gotteshaus zu besitzen, das dieses $\mathrm{Na}$ mens würdig ist, das zum Besuch des Gottesdienstes einlädt und mit allen seinen Einrichtungen Gott und der Gemeinde zur Ehre gereicht. Wer auf seinen Glauben etwas bält, wird gern eine Opfergabe darbringen, die dazu beitragen soll, das Ansehen der evangelischen Kirche zu mehren".1577

Aus dem Einweihungsdiskurs des Gemeindevorstandes Werno R. Korndörfer sind weitere Hinweise für die Bedeutung einer ,würdigen“ Kirche zu entnehmen. Die alte und schlichte Kirche entsprach seiner Sicht nach weder den räumlichen Bedürfnissen noch dem spirituellen Leben der Gemeinde. Eine neue Kirche in gotischem Stil mit Turm und Glocken sollte dazu mahnen, über den wirtschaftlichen Fortschritt nicht das kirchliche Leben zu vernachlässigen. ${ }^{1578}$ Seine Worte werden durch bürgerliche Ansichten geprägt und deuten an manchen Stellen auf den Wettbewerb zwischen einigen Gemeinden, immer größere und schönere Kirchen zu errichten, hin. Sie geben jedoch auch Auskunft über die Bedeutung des Glaubens als Mittelpunkt des sozialen Lebens, über den Wunsch, sozial und religiös von der brasilianischen Gesellschaft anerkannt zu werden und über die end-

\footnotetext{
1573 Als der Präsident Getúlio Vargas 1937 nach einem Putsch den Neuen Staat gründete und auf eine forcierte Integration der Einwanderer und deren Nachkommen abzielte, teilweise durch Einschränkung ihrer Institutionen, wie deutsche Schule, Presse und Kirche.

1574 Lutherische Kirche in Brasilien, S. 178.

1575 Sínodo Riograndense. Comunidade Evangélica de Santa Cruz do Sul. 1862 - 100 - 1962, S. 10, AHI, SR $144 / 15$.

1576 Ulrich, S. 207.

1577 Wachholz, Uma Igreja Diferente, S. 25.

1578 Wachholz, Uma Igreja Diferente, S. 58.
} 


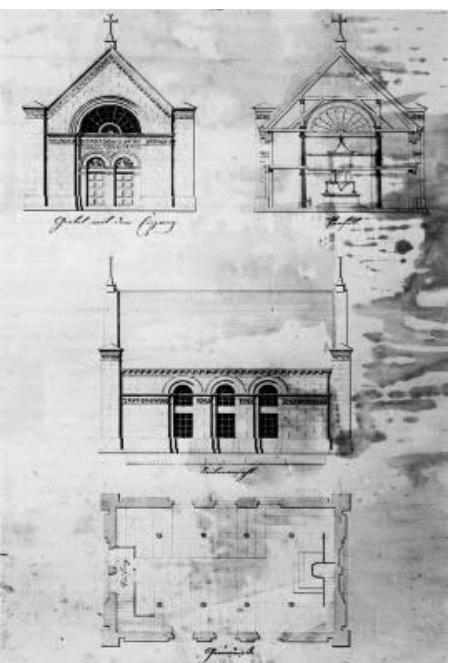

Abb. 24: Die Dorfkirche von Nakel nach dem Plan von 1819. Quelle:

Schubert, S. 66.

gültige Niederlassung der Einwanderer und deren Nachkommen in einer neuen Heimat.

Die Gemeindemitglieder besaßen bereits eine Vorstellung von würdigen Kirchen, die sie aus der alten Heimat mitgebracht hatten, und versuchten das ihnen bekannte Kirchenmodell je nach vorhandenen Ressourcen in den eigenen Siedlungsgebieten nachzuahmen. Weil aber an dieser Stelle von einem Kirchenmuster die Rede sein kann, muss hier auf das Modell der staatlichen Normkirche in Preußen eingegangen werden, das im frühen 19. Jahrhundert im Prozess der technischen Normierung und Modernisierung sowie der königlichen Religionspolitik geplant wurde. König Friedrich Wilhelm III. (1797-1840) suchte im Kontext des preußischen Agendenstreits (1822-1840) den Anschluss an vorkonfessionell-altkirchliche Traditionen. Nach den Vertragsverhandlungen zur Heiligen Allianz zwischen Preußen, Österreich und Russland im Jahre 1815 besuchte er die Kirche St. Philippe du Roule in Paris und nach seiner Rückkehr beauftragte er den Berliner Oberbaurat Schinkel im Oktober 1815 mit einem entsprechenden Umbau der baufälligen Dom- und Hofkirche. Diese Kirche wurde mit Rücksicht auf die neu einzuführende Liturgie entworfen, die der König zu entwickeln begonnen hatte. Auf eine Nachbildung der Kirche St. Philippe du Roule sollte auch die 1795 abgebrannte Postdamer Hauptkirche St. Nicolai 1826 auf Staatskosten wieder aufgebaut wer-

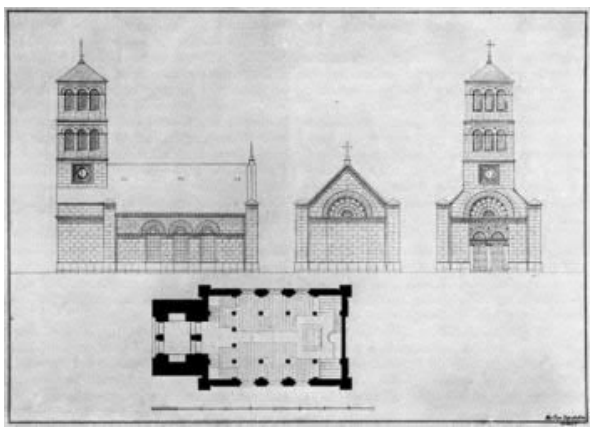

Abb. 25: Der Normalkirchenplan mit Turm von 1827. Quelle: Schubert, S. 67. den, wofür Schinkel auf seiner Studienreise nach Paris und England den Auftrag erhielt, die Pariser Kirche eingehend zu studieren. ${ }^{1579}$ Laut Schubert arbeitete Schinkel schließlich die Pläne für eine weitere Kirche, die Dorfkirche in Nakel in der Provinz Posen, während des Domumbaus in Berlin aus. Bei einem Besuch in den östlichen Provinzen des Königreiches musste der König im August 1826 in diesem Dorf übernachten. Am nächsten Tag besuchte er die kleine Dorfkirche, die im März 1824 fertig gestellt worden war und

1579 Schubert, Anselm. Religiöse Restauration und technische Rationalisierung. Die „preußische Normalkirche" als staatliche Einheitskirche. In: Historische Zeitschrift. Bd. 297, Nr. 1. München: de Gruyter Oldenbourg, 2013, S. 74-77. 


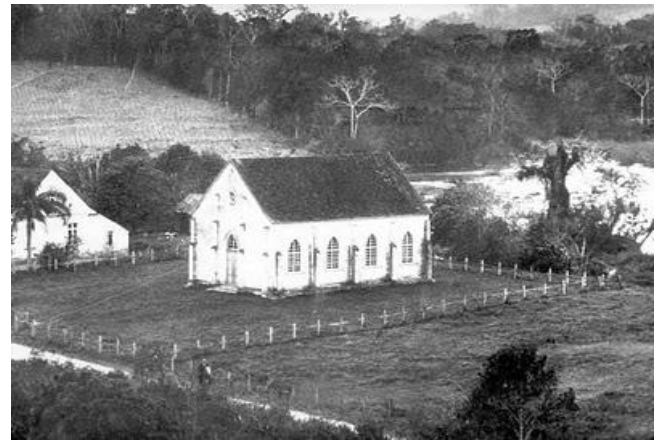

Abb. 26: Kirche in Badenfurt (SC) am Anfang des 20. Jahrbunderts, eingeweibt am 7.7.1872. Quelle: Wittmann, Grupo folclórico Badenfurt. deren große Ähnlichkeit mit dem umgebauten Dom ihm aufgefallen sein muss. Er erklärte ihren Bauplan (Abb. 24 siehe S. 267) am 11. Juli 1827 kurzerhand zum Muster für den Bau aller kleineren evangelischen Kirchen Preußens, die ganz oder zum Teil auf königliche Kosten erbaut werden sollten. ${ }^{1580}$ Auf diese Weise bildeten der Berliner Dom, die Potsdamer Stadtkirche und die Dorfkirche in Nakel nach dem Vorbild von St. Philippe du Roule das Muster für Groß- und Kleinkirchen. Schinkel wurde darüber hinaus im November 1827 beauftragt, ein Kirchenmodell mit einem Turm zu entwerfen, obwohl die Kosten des Turmbaus nicht von der königlichen Kasse übernommen werden sollten (Abb. 25 siehe S. 267). Für die Größe der Kirche gab es keine Norm, sie konnte den Bedürfnissen entsprechend proportional verändert werden. Weil im Innern die Empore aus Platzgründen bis an die Altarwand herangezogen wurde, mangelte es der Kirche an einer Apsis. Der Kanzelaltar bildete das Zentrum der Kirche, was aber mit dem Erlass vom 21. August 1882 in Preußen nicht mehr gestattet war. ${ }^{1581}$

Besonders in den Provinzen West- und Ostpreußen, Pommern und im Großherzogtum Posen wurden Kirchen entsprechend dieser Norm errichtet, weil die Gemeinden auf einen Zuschuss von der Krone angewie-

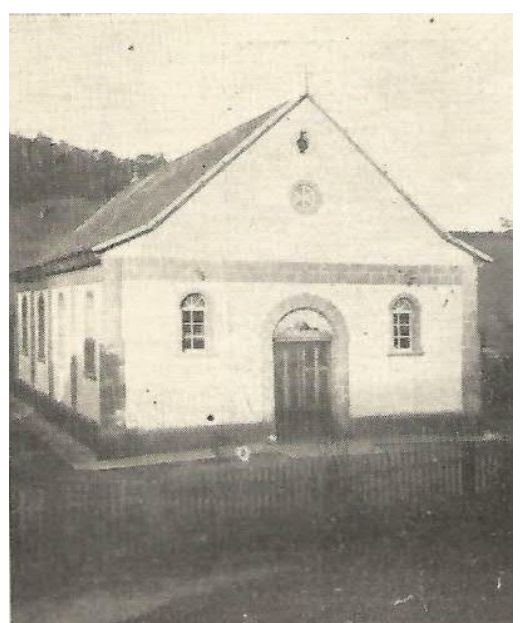

Abb. 27: Kirche von Santa Maria (ES), erbaut zwischen 1917 und 1918, eingeweibt am 14.7.1918. Quelle: Lutherische Kirche in Brasilien. sen waren. Obwohl der ursprüngliche Entwurf keinen Turm umfasste und der König die Kosten für diesen in der Regel nicht übernahm, errichteten doch fast alle Gemeinden den von Schinkel nachträglichen entworfenen Turm. Es darf abschließend nicht vergessen werden, dass sich die Normierung der preußischen

\footnotetext{
1580 Schubert, S. 65f.

1581 Schubert, S. 66f. Laut Schubert vereinigte das Modell einer staatlichen Normalkirche alle Merkmale, die als architektonische Insignien der Liturgiepolitik des Königs galten. Mithilfe dieser Musterkirche konnte der König die Vision einer ,"̈̈berkonfessionellen und staatlichen Einheitskirche wenigstens auf dem Gebiet des Kirchenbaus" durchsetzen, denn alle vom Staat bezahlten Kirchen wurden zu Nachahmungen der königlichen Hof- und Domkirche in Berlin und dienten damit der Verbreitung seiner Religionspolitik. Ebd., S. 78f.
} 


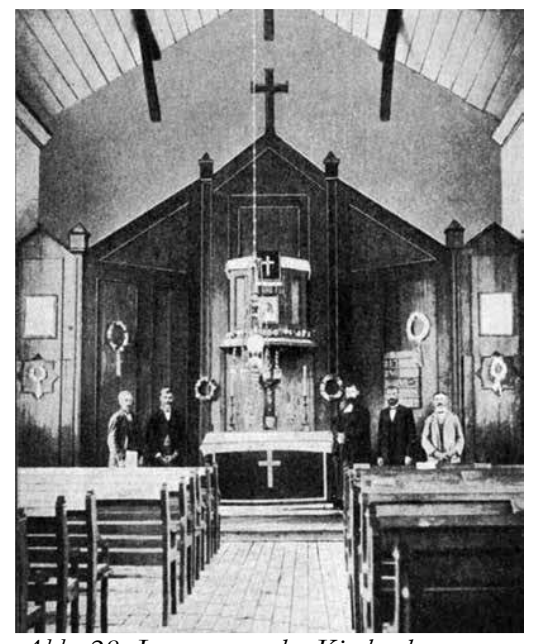

Abb. 28: Innenraum der Kirche der evangelischen Gemeinde Campinho (ES) mit ibrer Altarkanzel nach dem Modell der preußischen Normalkirche. Quelle: Wernicke, S. 105.

Kirchen auf Neubauten, die auf Staatskosten erbaut wurden, bezog ${ }^{1582}$ und dass der Thronfolger Friedrich Wilhelm IV. (1840-1861) den Normalkirchenerlass 1840 wieder aufhob. 1583 Aus diesem Grund wurde nur ein kleiner Teil der preußischen Kirchen nach dem Modell der Normalkirche errichtet.

Das Modell der Normalkirche kann an verschiedenen Kirchen evangelischer und lutherischer Gemeinden in Brasilien wieder gefunden werden. Die evangelische Kirche in Badenfurt-Blumenau (SC) ${ }^{1584}$ (Abb. 26 siehe S. 268), auch die lutherische Kirche in Santa Maria (ES) (Abb. 27 siehe S. 268), entsprechen beispielsweise dem Entwurf der Dorfkirche in Nakel aus dem Jahre 1819. Doch im Gegensatz zu den preußischen Kirchen wurde der am Ende des 19. Jahrhunderts in Preußen nicht mehr gebrauchte Kanzelaltar in brasilianischen evangelischen Gemeinden weiterhin gebaut, wie beispielsweise in den Kirchen der Gemeinden Santa IsabelCampinho (ES) (Abb. 28) und Santa Leopoldina I-Luxemburg (ES).1585 In lutherischen Gemeinden war dies nicht der Fall, wie die Beispiele der Gemeinden Joinville (SC), Jaraguá II (SC), Jaraguá Alto (SC) (Abb. 29) und Laranja da Terra (ES) ${ }^{1586}$ zeigen. Auch der Plan der Normalkirche mit Turm kann in vielen Gemeinden beider Konfessionen in Brasilien wieder gefunden werden, wie zum Beispiel in

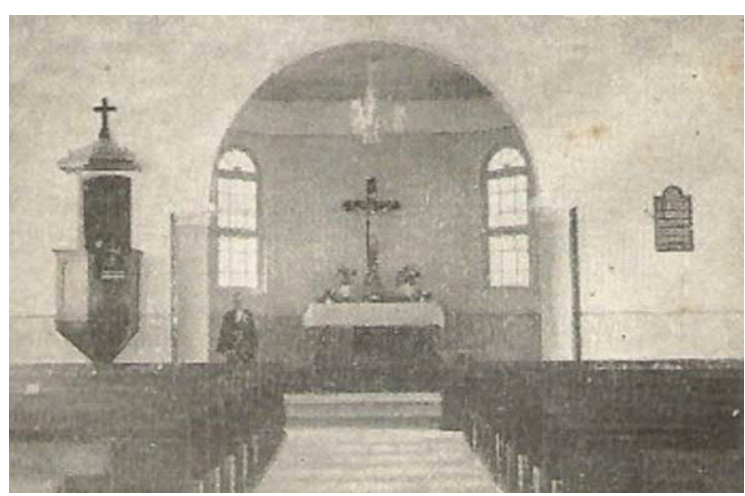

Abb. 29: Das Innere der Martin-Luther-Kirche der lutherischen Gemeinde Jaraguá Alto-Jaraguá do Sul (SC), eingeweiht im Jahr 1951, obne die Altarkanzel. Quelle: Lutherische Kirche in Brasilien.

\footnotetext{
1582 Schubert, S. 79 f.

1583 Schubert, S. 68.

1584 Evangelische Synode von Santa Catarina und Paraná, S. 52.

1585 Wernicke, S. 63.

1586 Lutherische Kirche in Brasilien.
} 


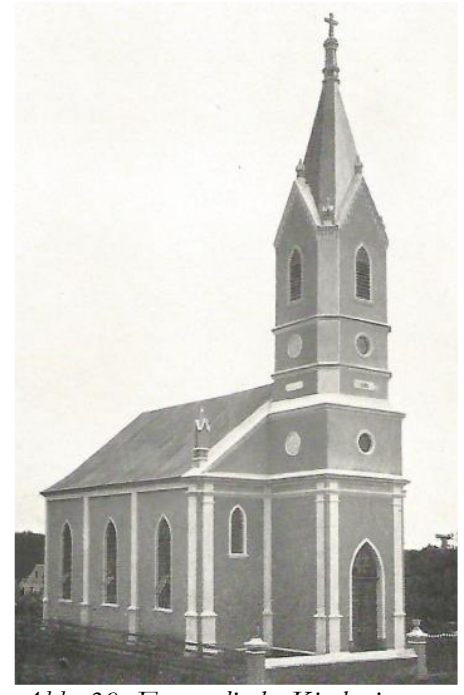

Abb. 30: Evangelische Kirche in Nova Petrópolis (RS), eingeweiht im Jahr 1905. 1908 schloss sich die Gemeinde an die preußische Landeskirche. Quelle: Dedekind. 75 Jahre deutsch-evangelischer Diasporaarbeit.

den evangelischen Kirchen in Pomerode (SC) ${ }^{1587}$, Badenfurt (SC) ${ }^{1588}$, Nova Petrópolis (RS) (Abb. 30) und Santa Cruz do Sul (RS) ${ }^{1589}$ und in den lutherischen Kirchen in Inselstraße (SC) (Abb. 31, siehe S. 271), Joinville (SC), Jaraguá do Sul (SC), Jequitibá (ES), Lagoa (ES) und Santa Maria (ES). 1590

Es ist schwierig festzustellen, ob die Gemeindemitglieder diesem Bauplan der Normalkirche bewusst umsetzten. Mit Blick auf das Eintreffen von Missionaren aus dem Gotteskastenverein und deren Ablehnung bezüglich der preußischen Kirchenunion traf dies für lutherische Gemeinden gewiss nicht zu. Aufgrund seiner Einfachheit eignete sich der Bauplan aber besonders für diejenigen Gemeinden in Brasilien, die in der Regel weder über einen Architekten noch über einen Ingenieur für die Anfertigung und Durchführung eines eigenen Bauplans verfügten. Meist entwarfen Gemeindemitglieder selbst den Bauplan für ihre Kirche und führten ihn entsprechend ihrer Baukenntnisse und der vorhandenen Ressourcen aus. Manchmal errichteten sie ihre Kirchen auch nach dem Muster ihrer ehemaligen Dorf- oder Stadtkirchen in der alten Heimat. Im südlichen Mittelpommern herrschten beispielsweise Dorfkirchen aus fein behauenen Granitquadern und Feldsteinkirchen aus unbearbeiteten Steinen vor. Entlang der Küste, wo vorwiegend nach niedersächsischer Art gebaut wurde, gab es viele Fachwerkkirchen sowie schlanke Backsteinkirchen in Backsteingotik. ${ }^{1591}$ Aspekte dieser Architektur wurden in Gemeinden Brasiliens teilweise nachgeahmt, wobei viele Exemplare aufgrund von Instandhaltungs- und Renovierungsmaßnahmen und Umbauten nicht erhalten geblieben sind. 1928 errichtete die Gemeinde Rio Ada-Timbó (SC) eine Fachwerkkirche ${ }^{1592}$, auch die erste Kirche in Laranja da Terra (ES) war eine

\footnotetext{
1587 Weege, Heike. Fotos antigas de Pomerode. Verfügbar in: http://fotosantigaspomerode.blogspot.de/ 2011_01_01_archive.html Zugang am 24.4.2017; Wittmann, Angelina. Igreja da Paz - Pomerode - 130 anos. Verfügbar in: https://angelinawittmann.blogspot.de/2015/11/igreja-da-paz-pomerode-130-anos.html Zugang am 24.4.2017.

1588 Wittmann, Angelina. Grupo folclórico Badenfurt. Verfügbar in: https://angelinawittmann.blogspot.de/ 2014/07/grupo-folclorico-badenfurt-tradicional.html Zugang am 21.4.2017.

1589 Sínodo Riograndense. Comunidade Evangélica de Santa Cruz do Sul. 1862 - 100 - 1962, S. 10, AHI, SR 144/15.

${ }^{1590}$ Lutherische Kirche in Brasilien.

1591 Büge, S. 115.

1592 Weingärtner, Crônica da Comunidade Evangélica de Timbó, S. 78.
} 
aus Lehmziegeln gemauerte Fachwerkkirche gewesen ${ }^{1593}$ und schließlich besaß auch Linha Araripe-Nova Petrópolis (RS) eine solche Fachwerkkirche. Ein erhaltenes Exemplar einer Fachwerk- und Backsteinkirche befindet sich in Ribeirão Liberdade-Benedito Novo (SC) (Abb. 32). Als Erinnerung an die Heimat wurden manche Kirchen blau und weiß, in den Farben Pommerns, gestrichen, wie bei-

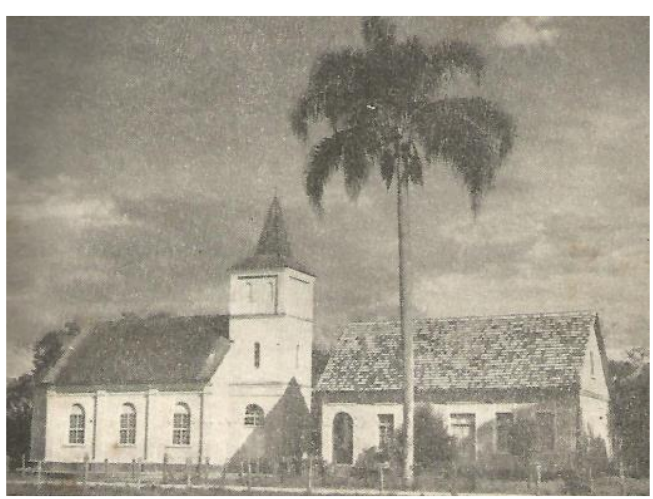

Abb. 31: Kirche und Pfarrbaus in Inselstraße (SC). Der Bau der Kirche begann 1897. Über die Einweibung gibt es keine Unterlagen. 1904 wurde der Turm für zwei Glocken errichtet.

Quelle: Lutherische Kirche in Brasilien. spielsweise in Regatal-Pomerode (SC). ${ }^{1594}$

Besonders bei dem Bau von Kirchen an Pfarrsitzen sorgten Pastoren oder einflussreiche Gemeindemitglieder für einen Bauplan oder für die Anstellung eines deutschen Architekten. Die Kirche in São Leopoldo (RS) wurde nach dem Plan des Leipziger Architekten Zeissig gebaut $^{1595}$, für die Turmkirche in Timbó (SC) entwarf der Architekt Krohnberger den Bauplan ${ }^{1596}$ und für die neue Kirche in Novo Hamburgo (RS) 1939 wandte sich die Gemeinde an den Architekten Wiederspahn. Aufgrund des Krieges konnte der Bau der Kirche in Novo Hamburgo (RS) aber erst 1948 beginnen. Dem Wunsch der Gemeindeglieder entsprechend folgte man jedoch nun nicht dem ersten, sondern einem anderen gotischen Bauplan, der von dem brasilianischen Architekten Siegfried Costa aus Ijuí (RS) entworfen worden war (Abb. 33 siehe S. 272). ${ }^{1597}$ Der lutherische Pastor Weber fertigte wiederum den Plan für die Errichtung der Kirche zu Pontal (ES) (Abb. 34) selbst an und die Errichtung der ersten Kirche in Indaial (SC) wurde vom Kaufmann Heinrich Schreep über-

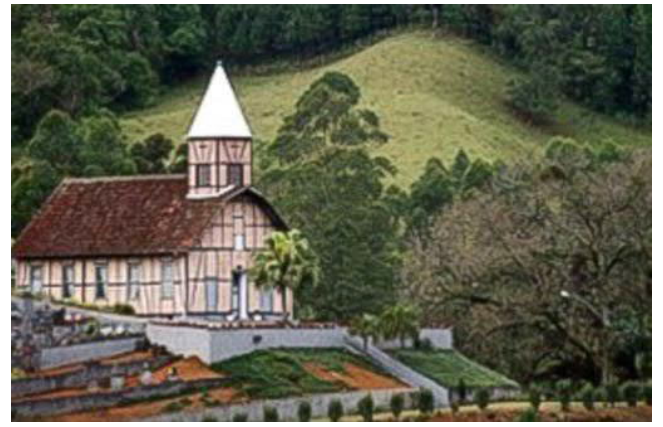

Abb. 32: Fachwerkkirche in Ribeirão LiberdadeBenedito Novo (SC), errichtet 1917 und eingeweibt im Jabr 1927. Foto von Ricardo Silva, 23.9.2010. Quelle: Silva. Igreja enxaimel de Benedito Novo.

\footnotetext{
1593 Langholf, Johan. Dienst an den zerstreuten in Brasilien, S. 38, MEW 4.118.

${ }^{1594}$ Granzow, Grün ist das Tal am Rio Itajai, S. $25 \mathrm{f}$.

1595 Müller, Herança de geração em geração, S. 25.

1596 Weingärtner, História da Comunidade Evangélica de Timbó, S. 92.

1597 Wachholz, Uma igreja diferente, S. 23, 27, $32 \mathrm{f}$.
} 


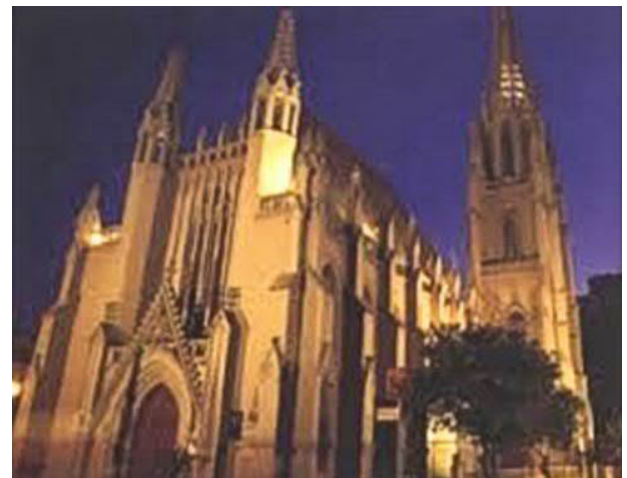

Abb. 33: Himmelfahrtskirche in Novo Hamburgo (RS). Sie wurde zwischen 1948 bis 1951 errichtet und am 7.10.1951 eingeweibt. 2.000 Menschen beteiligten sich bei der Feier. Quelle: Comunidade Evangélica de Confissão Luterana Ascensão. nommen. 1908 wurde sie nach Entwürfen, die der lutherische Pastor Karl Bergold zur Verfügung stellte, unter der Leitung von Gustav Gebhardt und Christian Böhme umgebaut. Der Entwurf für den Turm wurde von dem Bautechniker Grubitsch, nach Plänen von Pastor Bergold 1920, angefertigt. ${ }^{1598}$ Pastoren bemühten sich in einigen Fällen auch um eine finanzielle Unterstützung durch deutsche Vereine aus der Heimat, wie das Gustav-AdolfsWerk ${ }^{1599}$ oder den Gotteskastenverein. ${ }^{1600}$ All dies führte zu der Tatsache, dass bis zum Ersten Weltkrieg nur wenige brasilianische Architekturelemente übernommen wurden. Erst nach dem

Zweiten Weltkrieg begannen diese allmählich den Kirchenbaustil der deutschen Gemeinden zu beeinflussen. Die Gemeinden bevorzugten in der Regel den gotischen Stil, wie an den verschiedenen Beispielen zu erkennen ist.

Die Errichtung einer massiven Turmkirche als letzte Stufe der sozialen, wirtschaftlichen und religiösen Entwicklung der Einwanderer und deren Nachkommen in Brasilien wurde als ein konkretes Glaubensbekenntnis wahrgenommen. In seinem Gedicht beim Richtfest in Joinville (SC) am 19. November 1892 hob Ottokar Dörfell hervor, der Glockenturm sei nicht nur dem Gotteshaus und der Kirchengemeinde zur Zier gemacht. Er sollte ein Symbol sein, „dass jedes Mitglied glaubensvoll mit warmen Herzen und frommen Sinn stets aufwärts strebe zum Himmel bin", ein Kernpunkt, ,der im Kampfe der Welt in Lieb und Treu uns zusammenhält" und eine Mahnung zu innerem Frieden und zur Einigkeit. ${ }^{1601}$ Auch der Vorsitzende Parucker wies in seinem Diskurs bei der Turm- und Glockenweihe am 18. Dezember 1892

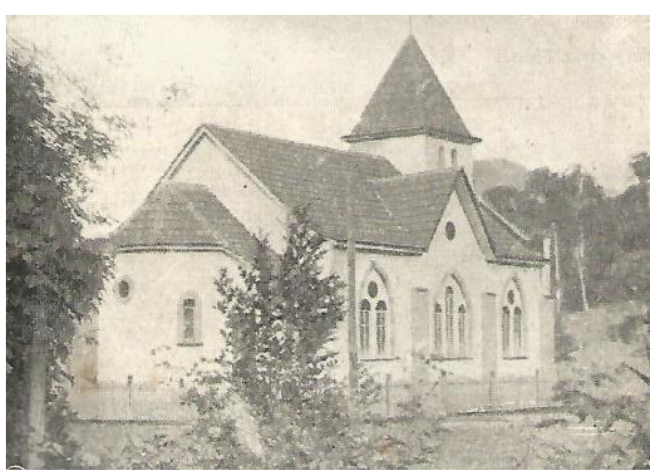

Abb. 34: Kirche in Pontal (ES), eingeweibt am 15.1.1933 und erbaut nach dem Plan von Pastor Weber. Quelle: Lutherische Kirche in Brasilien.

\footnotetext{
1598 Giurus, Crônica da Paróquia Evangélica Luterana de Indaial, S. 109, 126.

1599 Schröder, Brasilien und Wittenberg, S. 170.

1600 Weingärtner, Martin Luther e Santa Catarina, S. 132.

1601 Bühler, Fritz. Ein Beitrag zur Kirchenkunde Südamerikas. [1917/1918], S. 32f, MLV 51/17 108.
} 
auf die religiöse Bedeutung von Turm und Glocken hin. Für ihn handelt es sich dabei um ein Glaubenszeugnis und -erbe. Ein Teil dieses Diskurses soll hier wiedergegeben werden:

„Wie er [der Turm] nach oben strebt und zum Himmel weist, soll er uns mahnen, unseren Blick nach oben zu richten, unsere Gedanken aus dem Vergänglichen und Irdischen dem ewigen Unvergänglichen zuzuwenden, in allen Lagen des Lebens auf Gott zu vertrauen und echter Religiosität, wahrem Glauben eine Stätte in unseren Herzen zu bereiten. Die Glocken (...) sollen uns mahnen, wenn sie ibren Ruf zur Gottesverehrung erschallen lassen, diesem Ruf auch Folge zu leisten (...). Ihre Stimme soll uns aus unserer Gleichgültigkeit aufrütteln, unser evangelisches Gewissen schärfen, unser evangelisches Bewußtsein erwecken und kräftigen. Ihre Stimme soll uns immer wieder an das teure $V$ ermächtnis erinnern, welches wir durch die Reformation von unseren Voreltern empfangen haben, wofür dieselben geblutet haben und gestorben sind. (...) Wir sind in diesem Lande nur ein schwaches Häuflein evangelischer Christen. (...) Ein inniger Glaube, und vor allem das evangelische Bewußtsein, [ist, was] uns befähigt, nicht bloß schlauen Verfübrungen zum Abfall, sondern auch der Unduldsamkeit und etwaigen religiösen Verfolgungen mit Kraft und Festigkeit zu widerstehen. „Ein feste Burg ist unser Gott, ein gute Wehr und Waffen!" Dieser Turm mit seinen Glocken ist aber nicht bloß für uns, die jetzt Lebenden errichtet, er ist auch für unsere Kinder und Nachkommen. An uns ist es, den religiösen Gedanken, welchen Turm und Glocken in uns anregen, auf unsere Kinder zu übertragen, und in ibren Herzen wahre Frömmigkeit, echten Glauben und den festen protestantischen Geist zu pflanzen und aufzuziehen. Unsere Kinder werden dies dann auch ibren Kindern tun und so fort bis in die spätesten Geschlechter. Erfüllen wir darum diese ernste Pflicht treu und gewissenhaft an unseren Kindern, und der reichste Segen wird nicht ausbleiben. (...) Das walte Gott!".1602

Worte wie diese berührten viele Menschen während der entsprechenden Einweihungsfeiern, Quellen berichten über Tränen in den Augen ${ }^{1603}$ oder kindliche Freude. ${ }^{1604}$ Es handelte sich zweifellos um ein wichtiges Ereignis in der Glaubensgeschichte protestantischer Einwanderer und deren Nachkommen, die sich jahrelang nach einer Turmkirche gesehnt hatten.

Ein Gedicht, $W$ as die Glocken singen ${ }^{1605}$, das bei der Glockenweihe in Rio Ponte (ES) vorgelesen wurde, bringt die Bedeutung des Glockenklangs in frohen und traurigen Momenten des Menschenlebens zum Ausdruck. Weiterhin verweist es auch auf die Funktion der Glocken innerhalb des Wochenrhythmus, besonders in

1602 Bühler, Fritz. Ein Beitrag zur Kirchenkunde Südamerikas. [1917/1918], S. 34f, MLV 51/17 108; Wüstner, S. 33f.

1603 Bühler, Fritz. Ein Beitrag zur Kirchenkunde Südamerikas. [1917/1918], S. 36, MLV 51/17 108; Sínodo Riograndense. Comunidade Evangélica de Santa Cruz do Sul 1862 - 100 - 1962, S. 8, AHI, SR 144/15; Lutherische Kirche in Brasilien, S. 84; Römer, Ch. Der Evangelische Heidenbote, Nr. 6, Juni 1887. Basel: Verlag der Missionsbuchhandlung, S. 43.

1604 Soboll, S. 66.

1605 Soboll, S. 69. 
den bäuerlichen Gesellschaften. Die Glocken läuteten, „um Gott, den Herm, im Himmel (...) zu danken und loben". Am Samstag, als die Arbeitswoche vollbracht war, läuteten sie den Sonntag ein, damit die Menschen von der Arbeit ruhen, die Hände falten und die Woche mit Dank und Lob beschließen konnten. Am Sonntag riefen sie die Gemeindemitglieder zum Gotteshaus und für diejenigen, die nicht kommen konnten, läuteten sie während des Vaterunsers „dreimal (...) durch den Wald", was unter den Pommern in Brasilien als „Gebetsstunde" oder „Betglocke"1606 bekannt wurde. Wenn Mann und Frau Hochzeit feierten, läuteten sie mit „lautem, freudigen Ton, dann schallet die Freude ins Land binein“. Wenn sie aber bang tönten, „so singen sie einen Grabgesang und geleiten den Toten zur letzten $\mathrm{R} u b(. .$.$) ein Lied von der ewigen$ Seligkeit" ${ }^{1607}$ In diesem Sinne fungierten die Glocken auch als ein wichtiges Kommunikationsmittel in Siedlungsgebieten und machten die Siedler auf kirchliche Amtshandlungen und besondere Ereignisse aufmerksam, luden zum Gottesdienst ein und gaben wöchentlich die Zeiten für Anfang und Ende der Arbeitszeit an. Viele Glöckner widmeten ihr Leben ihrem Beruf. Alberto Vesper war beispielsweise über einen Zeitraum von sechzig Jahren als Glöckner in der Gemeinde Jequitibá (ES) tätig. . $^{1008}$

Zusammenfassend stellen wir fest, dass die Bedeutung des evangelischlutherischen Glaubens für pommersche Einwanderer und deren Nachkommen in Brasilien von ihrem Engagement und ihrer Opferbereitschaft bei der Errichtung kirchlicher Gebäude in ihren unterschiedlichen Phasen nicht zu trennen ist. Aus Sicht der Gemeindemitglieder war die Bauarbeit ein Ausdruck ihres Glaubens und ihrer Glaubens- und Lebensgeschichte. Zudem sollten sie als Erbe für ihre Nachkommen dienen. Wenn zwar einerseits die Errichtung kirchlicher Gebäude ihren opferwilligen Geist zuweilen über die Maße beanspruchte, fühlten sie sich doch andererseits durch die Bautätigkeiten an etwas Sinngebendem beteiligt. Gemeindebauarbeiten schenkten ihnen ein Projekt für ihr Leben und zuweilen auch einen Lebenssinn. Je mehr sich Gemeindemitglieder an diesen Bauarbeiten beteiligten, desto höher schätzten sie ihre kirchliche Gemeinde. Im Angesicht ihrer geleisteten Arbeit freuten sie sich und erinnerten sich nostalgisch an ihr vollbrachtes Werk. Siegfried Krohn aus São Leopoldo (RS) berichtet: „ich sehe, dass es nicht umsonst war".1609 Aus der aktiven Beteiligung an diesen Bautätigkeiten für einen höheren Zweck schöpften die Gemeindemitglieder auch Kraft für die Bewältigung ihrer Isolation, ihrer Schwierigkeiten und ihrer Verluste.

Die hier verwendeten Quellen weisen nicht explizit auf die Bedeutung kirchlicher Gebäude als heilige Orte für die Vollziehung von kirchlichen Amtshandlun-

\footnotetext{
1606 Gaede, S. 201. In anderen Gemeinden läutete sie neunmal: für die sieben Petitionen des Vaterunsers samt Einführung und Anschluss. Müller, Herança de geração em geração, S. 63.

1607 Soboll, S. 69.

1608 Gaede, S. 203.

1609 Mitteilungen der Gemeinde São Leopoldo Nr. 4, 1971. Zitiert nach Müller, Herança de geração em geração, S. 57.
} 
gen hin. Doch jede Religion organisiert oder errichtet heilige Stätten für die Feier von Gottesdiensten und dem Ausführen von Ritualen, in denen Menschen die Manifestation des Heiligen erfahren können. Wenn ein Raum heilig gesprochen wird, erhält er auch die Bedeutung eines heiligen Ortes zur Verehrung der Gottheit und unterscheidet sich dadurch von anderen, profaneren Orten. ${ }^{1610}$ Das galt auch für die Kirchen der Einwanderer und deren Nachkommen. Im Kirchenbuch der Gemeinde Picada Café (Kaffeeschneis) (RS) steht geschrieben, „Wie aus dem Herzen aller rief es: Laßt uns eine Kirche bauen, um den lieben Gott gemeinschaftlich zu loben, zu bitten und anzubeten ". 1611 Die Kirche war der Ort der Offenbarung Gottes durch Wort und Sakrament und nahm eine wichtige Rolle für die Vollziehung von kirchlichen Amtshandlungen und bei Lebensübergängen ein. Die Siedler wollten sich in einer würdigen Kirche trauen und ihre Kinder dort taufen und konfirmieren lassen und ihre Toten auf einem eingesegneten Friedhof, möglichst neben der Kirche unter dem Klang der Glocken bestatten. Das wird im Bericht einer Pfarrfrau über die Beerdigung eines kleinen Jungen hervorgehoben. Die betroffene Familie wohnte weit entfernt vom Pfarrsitz Joinville (SC), der Vater kam nach anderthalb Reisetagen zum Pfarrhaus geritten und bat den Pastor, die Bestattung seines vierjährigen Fritz zu vollziehen. Als der Pfarrer ihn zu seinem Haus begleiten wollte, drehte er verlegen an seinen Hut und sagte: „Nein, Herr Pfarrer, Sie brauchen Ihr Pferd nicht satteln. Ich habe meinen Fritz gleich mitgebracht in einer Kiste, auf dem Pferd draußen. Mein Junge soll mit Glockenklang und Gebet beerdigt werden ".1612

Die Lebensgeschichte mehrerer Generationen, die verschiedenen Übergänge und Krisen, die glücklichen und traurigen Momente waren mit dem Gotteshaus verbunden. Es war der Anbetungsort, an dem die Gemeindemitglieder in Notsituationen, Verzweiflung und Angst die Nähe, den Beistand und die Hilfe Gottes im gemeinsamen oder stillen Gebet suchten. Das kommt in den Worten des Kirchenvorstandes von São Leopoldo (RS) zum Ausdruck. Die dort erwähnte Kirche bot Raum zur Entwicklung eines „religiösen Geistes“ für mehrere Generationen. In ihr wurde das Evangelium gepredigt, durch das viele Menschen im Glauben und Gemüt gestärkt wurden und Trost, Hoffnung und Zuflucht für ihre Sorgen, Bedürfnisse und Versuchungen fanden. Dort wurden kirchliche Amtshandlungen vollzogen und festliche Gottesdienste gefeiert und die Gemeinde preiste Gott durch Singen und Gebet. Die Kirche bescherte viel Segen im Leben der Kirchenmitglieder. ${ }^{1613}$ In Gottes Wort und in sozialem Kontakt mit anderen suchten die Gemeindemitglieder nach Geborgenheit, Geselligkeit und Gemeinschaft, nach konkreter und gegenseitiger Unterstützung für ihre Probleme, nach geistiger Er-

\footnotetext{
1610 Amaro, Luana da Silva. Resiliência, religiosidade e sentido de vida em mulheres com câncer de mama. João Pessoa: Universidade Federal da Paraíba, 2014, S. 37f.

1611 Arbeitsgemeinschaft 25. Juli in Rio Grande do Sul, S. 67.

161231 Jahre Pfarrfrau in Brasilien. Bericht von Frau Pastor Zischler, Juni 1964, S. 6f, MEW 4.193.

1613 Rundschreiben vom Gemeindevorstand aus São Leopoldo, 5.12.1906. Zitiert nach Müller, Herança de geração em geração, S. 43.
} 
bauung und christlicher Unterweisung. Emil Manke aus Itoupava Central (SC) berichtet:
„Wie dankbar waren die Menschen damals, wenn sie sich alle paar Monate einmal in der primitiven Kapelle zum Gottesdienst versammeln konnten. Da gab es kaum einen, der nicht erschienen wäre. Die Kirche hat den ersten Kolonisten eine entscheidende Lebenshilfe gewährt, dass sie mit dem Urwald fertig wurden und nicht ihm unter- gingen" "1614

Die Errichtung kirchlicher Gebäude hatte außerdem eine besondere Bedeutung in Bezug auf die politische, soziale, kulturelle und religiöse Positionierung der Einwanderer und deren Nachkommen in Brasilien. Bis zur Ausrufung der Republik durften diese weder Ämter belegen noch wählen, sozial lebten sie meistens isoliert und kulturell wie religiös standen sie am Rande der Gesellschaft, weil sie eine andere Sprache, andere Sitten und Gebräuche und eine andere Religion pflegten. Ihre Kirchen gaben nun Zeugnis über ihren Anspruch auf Anerkennung. Dies war ein wichtiger Schritt auf dem Weg zur Anpassung, nach oder neben dem noch andere Schritte im politischen, sozialen und unternehmerischen Bereich folgten. Massive Kirchbauten deuten außerdem auf eine definitive Niederlassung beziehungsweise auf die Errichtung einer dauerhaften Heimat in der Fremde hin. Aus diesem Blickwinkel können die Worte von Emil Manke verstanden werden: „Nun hatten wir ein Gemeindezentrum. Ein entscheidender Schritt war getan, dass all die Neusiedler bier eine dauernde wirkliche Heimat finden konnten".1615 Menschen sind aufgrund ihrer Existenz, Abstammung und Zugehörigkeit „zu lokalen, kulturellen und natürlichen Orten und Geschichten an besondere Plätre, Gegenden und Landschaften " gebunden und werden auch von diesen geprägt. ${ }^{1616}$ Die Verbindung mit einem bestimmten Platz zur Gestaltung des religiösen, kulturellen und sozialen Lebens haben die Einwanderer und deren Nachkommen in den Siedlungsgebieten geschaffen, indem sie ein Gemeindezentrum, in diesem Fall die Kirche, errichtet haben. Dort fühlten sie sich Zuhause beziehungsweise beheimatet und konnten ihre einheimischen Traditionen weiter pflegen. Als Beheimatete beanspruchten sie das Recht zur Mitsprache über das Leben in diesem $\mathrm{Ort}^{1617}$ und bald auch über das Leben in dieser neuen Heimat. Bergmann erweitert auch die Auffassung der „gelebten Religion“ bezüglich ihrer Bedeutung in der Lebenswelt und versteht Religion als eine ,geistigräumliche Dimension des Sichbefindens-in-Umgebungen". Sie nimmt Einfluss auf die Wahrnehmung und auch auf die Gestaltung und das Handeln in, mit und durch Räume und lässt diese auf sich wirken. ${ }^{1618}$ In diesem Sinne ermöglichte das kirchli-

\footnotetext{
1614 Evangelische Synode von Santa Catarina und Paraná, S. 70.

1615 Evangelische Synode von Santa Catarina und Paraná, S. 70.

1616 Bergmann, Sigurd. Raum und Geist. Zur Erdung und Beheimatung der Religion - eine theologische Ästhetik des Raumes. Göttingen: Vandenhoeck \& Ruprecht, 2010, S. 49.

1617 Bergmann, S. 49.

1618 Bergmann, S. 140.
} 
che Gebäude den Einwanderern und deren Nachkommen bei oder mit anderen räumlich zu sein.

Für einige Pommern stand die Erbauung eines Gotteshauses im Mittelpunkt des Siedlungsbaus, aber auch im Mittelpunkt ihres Lebens. ${ }^{1619}$ Frau Helena Gumz aus Jaraguá do Sul (SC) berichtet: „Es ist immer eine Ehre, wenn im Ort eine Kirche ist". ${ }^{1620}$ Die Gemeinschaftsarbeit während der verschiedenen Bauperioden ermöglichte darüber hinaus die Entwicklung von sozialen Netzwerken, die das Gemeinschaftsgefühl unter den deutschen Einwanderern und deren Nachkommen stärkte. ${ }^{1621}$ Sie trafen sich, aßen, kochten und übernachteten teilweise zusammen am Arbeitsplatz. Ein Ehepaar aus Itapocuzinho Alto-Jaraguá do Sul (SC) berichtet: „Die Kirche verbindet die Menschen“.1622 Einweihungsfeiern, Gedenk- und Jubiläumsfeste bildeten unter anderem die Gelegenheit, das „Bedürfnis nach Geselligkeit und Lebensgenuß zи befriedigen ".1623 Verwandte, Freunde und Bekannte kamen auch aus einem weitem Umkreis zusammen, marschierten an der Seite einer Musikkapelle und feierten zusammen. Dies waren wichtige soziale Zusammenkünfte, vor allem dort, wo es noch nicht zur Gründung von Vereinen gekommen war.

Kirchbauten konnten Kirchenmitglieder auch nach einer Krise oder Gemeindespaltung zusammenbringen. Als Schröderstraße (SC) einige Gemeindemitglieder an die Missourigemeinde verlor, hielten die verbliebenen Familien umso fester zusammen, weil sie nun ein größeres Opfer für die Vollendung des Kirchenbaus leisten mussten. Diese Zusammenarbeit stärkte die Gemeinschaft unter ihnen. Dieser Entwicklungsprozess kommt bei der Benennung ihrer fertig gestellten Kirche im Jahre 1932 zum Ausdruck: Friedenskirche. ${ }^{1624}$ Einige Familienmitglieder der Gemeinde Rio Perdidos-Santa Isabel (SC), die jahrelang in Feindseligkeit und Spannungen gelebt hatten, versöhnten sich schließlich, nachdem 1934 die Glocke für die 1909 erbaute Kapelle gekauft wurde. ${ }^{1625}$ In manchen Fällen hingegen brachte die Beteiligung beim Kirchbau auch die Konkurrenz zwischen den gegenseitigen Parteien zum Ausdruck, wenn nämlich eine Gruppe ihre Kirche schneller als die andere fertig stellen wollte. ${ }^{1626}$ Die Nachbargemeinden Indaial (SC) und Carijós (SC) wetteiferten beispielsweise miteinander um eine schnellere Fertig-

\footnotetext{
1619 Soboll, S. 39.

1620 Interview mit Helena Gumz (D. Lilly) am 7.5.2007. Zitiert nach Ulrich, S. 249.

1621 Ergänzungsbericht zum tabellarischen Jahresbericht 1937 über die Gemeinde Santa Leopoldina von Pastor Friege, EZA 5/2588.

1622 Interview mit Ricardo und Hilda Maas am 17.5.2007. Zitiert nach Ulrich, S. 249.

1623 Grothe, S. 74.

1624 Lutherische Kirche in Brasilien, S. $61 \mathrm{f}$.

1625 Stoer, S. 23.

1626 Gaede, S. 91.
} 
stellung ihrer Kirchen. ${ }^{1627}$ Schließlich aber brachten auch diese Konflikte die Bedeutung der Kirche für die Siedler zum Ausdruck, wie noch zu sehen sein wird.

\section{Die Errichtung anderer Institutionen in den Siedlungsgebieten}

Einwanderer und deren Nachkommen setzten sich nicht nur für den Aufbau kirchlicher Gemeinden, sondern auch für die Errichtung anderer Institutionen ein, die in den Siedlungsgebieten nicht vorhanden waren, die sie aber für den Aufbau ihrer Existenz in Brasilien für wichtig hielten: Schulen, Bildungsstätten, Krankenund Entbindungshäuser, Alten- und Waisenheime und kulturelle Vereine. Sie entstanden und entwickelten sich neben oder in enger Verbindung mit kirchlichen Gemeinden und neben deren institutionellen Organisation seit der Ankunft von Geistlichen. Über die Bedeutung der Entwicklung einer eigenen sozialen Umwelt, der Bildung sozialer Netzwerke und der sozialen Unterstützung wird in diesem Abschnitt berichtet.

\subsection{Das Schul- und Bildungswesen}

In den Siedlungsgebieten Brasiliens mangelte es an staatlichen Schulen und es dauerte ziemlich lange, bis der Staat sie dort einrichtete. ${ }^{1628}$ Die Gesetzgebung garantierte 1824 die unentgeltliche Grundbildung, aber praktisch wurden nur wenige Schulen errichtet, die zudem Schwierigkeiten bei der Besoldung von Lehrkräften hatten und über eine beschränkte Methodologie verfügten. ${ }^{1629}$ In Städten standen staatliche und private Schulen teilweise unter römisch-katholischer Schulaufsicht. ${ }^{1630}$ Aus diesem Grund schickten viele Einwanderer ihre Kinder nicht dorthin, weil sie diese nicht römisch-katholisch erziehen lassen wollten. ${ }^{1631}$ In abgeschiedenen Gebieten aber, wie die Mehrheit der Kolonien, gab es keine Schulen.

\footnotetext{
1627 Indaial (SC) legte den Grundstein ihrer Kirche im August 1884 und weihte sie am 31.5.1885 ein, während Carijós den Grundstein im September 1884 legte und die Kirche am 19.7.1885 einweihte. Giurus, Crônica da Paróquia Evangélica Luterana de Indaial, S. 110.

1628 Nach 300 Jahren als portugiesische Ausbeutungskolonie war das junge Land noch nicht imstande, überall Schulen zu errichten. Dreher, Igreja e Germanidade, S. 59.

1629 Rocha, S. 93; Fonseca, S. 32f.

1630 Schröder, Brasilien und Wittenberg, S. 48, 206. Nach dem Schulgesetz von 1854 durften ausschließlich römisch-katholische Lehrer in staatlichen Schulen unterrichten. 1868 hob die Regierung dieses Schulgesetz auf. Ebd., S. 356f; Fischer, Geschichte der Evangelischen Kirche, S. 135.

1631 Wie beispielsweise in Santa Leopoldina (ES), Rocha, S. 131; Santa Isabel (ES), Grosselli, S. 159 und Pelotas (RS), Fonseca, S. 59. Laut Grosselli wollten sie ihre Kultur, Religion und Sprache nicht verlieren, Grosselli, S. 228. In den ersten Siedlungsjahren gab es noch keinen Zusammenhang zwischen Bildung und deutsch-expansionistischen Zielsetzungen, weswegen es nicht automatisch mit der Deutschtumspflege in Verbindung gebracht werden sollte.
} 
Laut Willems erwarteten die Einwanderer, dass der brasilianische Staat ihnen Schulen zur Verfügung stellte, wie sie es aus der alten Heimat gewohnt waren. ${ }^{1632}$ In Brasilien existierte aber keine allgemeine Schulpflicht. Die Siedler hätten sich damit abfinden und sich ausschließlich ihrem landwirtschaftlichen Betrieb widmen können. Aber angesichts der staatlichen Vernachlässigung und trotz ihrer mangelnden Ressourcen suchten sie aktiv nach einer Lösung für den Schulmangel und errichteten selbst unzählige Schulen an verschiedenen Orten. ${ }^{1633}$ Interessant ist, dass dieses Phänomen in den Kolonien verschiedener Provinzen zu beobachten war, ohne dass sie von irgendeiner Instanz dazu aufgefordert wurden und ohne dass sie untereinander in Kontakt standen. Dies weist auf einen allgemeinen Wunsch nach Grundbildung neben einer religiösen oder konfessionellen Erziehung hin, denn nach pommerschem Muster war das Schulwesen stark mit dem Konfirmationsunterricht verbunden. ${ }^{1634}$ Schule und Kirche waren in manchen Fällen für eine Zeit so miteinander vernetzt, dass die Entwicklung einer dieser Institutionen die andere beeinflusste. ${ }^{1635}$

Zusammenfassend existierten drei verschiedene Arten von Schulen in den Siedlungsgebieten, die in deutscher Sprache unterrichteten. ${ }^{1636}$ Sie entsprechen, wie auch die Kirchbauten, der ökonomischen Entwicklung in den Siedlungsgebieten und können in verschiedene Phasen unterteilt werden. Diese Unterteilung geht auf Kreutz zurück, der das Schulwesen im Staat Rio Grande do Sul bis in die

1632 Willems, S. 273f, 277. Bereits der Reformator Martin Luther betonte die Verantwortlichkeit der Städte bei der Errichtung von Schulen. Luther, Martin. „An die Ratherren aller Städte deutsches Lands, daß sie christliche Schulen aufrichten und halten sollen“, 1524. In: D. Martin Luthers Werke. 15. Band. Weimar: Böhlaus Nachfolger, 1899. S. 9-53. Jedoch, obwohl die Schulpflicht in der Mitte des 19. Jahrhunderts systematisch in den Dörfern Pommerns eingeführt wurde, erschienen erst am 15.10.1872 die Allgemeinen Bestimmungen, betreffend das Volksschulwesen für alle preußischen Staaten mit verbindlichen und einheitlichen Vorschriften. Thiel; Neumann, S. 80-82. Die meisten Kinder aus bäuerlichen, handwerklichen und mittleren Schichten, die als wichtige Arbeitskräfte galten, lernten aber kaum das Lesen und Schreiben und besaßen so nur eine rudimentäre Schulbildung. Tessner, Gerda. Verlorenes Land. Eine Lebensgeschicbte aus Hinterpommern. Kassel: Selbstverlag, 2007, S. 19. Sie umfasste besonders die biblische Unterweisung und Erlernen des Kleinen Katechismus. Damitz, Die Schule als Spiegelbild, S. 10.

$16331907 \mathrm{gab}$ es in der Kolonie Blumenau (SC) 112 Schulen: 4 staatliche und 108 Privatschulen. Bericht des Pastors Braunschweig über seine Reise durch die deutschen evangelischen Gemeinden in Brasilien im Jahre 1907, S. 23, EZA 5/2173.

1634 Später ließen es auch Pastoren nicht zu, dass Kinder ohne mindestens drei Schuljahre den Konfirmationsunterricht besuchten. Auszug aus dem Reisebericht des Pastors Braunschweig, S. 3, EZA 5/2569; Schröder, Brasilien und Wittenberg, S. 361. Sie vollzogen keine Konfirmation oder Trauung von Analphabeten. Aus der Geschichte der Gemeinde Brusque. In: Gemeindeblatt für die evangelischen Gemeinden Brusque und Itajaby, Nr. 5, 2. Jahrgang, August 1928, EZA 5/2525; Seibel, Imigrante a duras penas, S. 196.

1635 Klug, João; Ulrich, Claudete. Introdução. In: Klug, João; Ulrich, Claudete Beise (Org.) Presença e atuação da Igreja Evangélica de Confissão Luterana de Jaraguá do Sul. Porto Alegre: Metrópole, 2008, S. 18. 1636 Prien, S. 289; vgl. Fonseca, S. 46. 
1930er Jahre hinein untersuchte. ${ }^{1637}$ Seine Unterteilung gilt jedoch als Beispiel für die Untersuchung des Schulwesens in Kolonisationsgebieten anderer Provinzen: a) Kolonie- oder Gemeindeschulen in Gebieten mit niedriger Bevölkerungsdichte und wo fast keine staatlichen Schulen zur Verfügung standen, deren Lehrer meistens keine Ausbildung besaßen und für die Übernahme dieser Funktion gewählt wurden. Sie vermittelten schulische Grundlagen und standen in enger Verbindung zu kirchlichen Gemeinden. In der Provinz Rio Grande do Sul entstanden sie nach Kreutz zwischen 1825 bis 1850, aber auch im Laufe des 19. und 20. Jahrhunderts mit der Ausdehnung oder Gründung neuer Kolonien in den drei hier beschriebenen Provinzen; b) deutsche Schulen in industriellen Städten. Entstanden von 1850 bis 1875 verfügten sie über Lehrkräfte, die in Lehrerseminaren, besonders deutschen, ausgebildet wurden; c) deutsche Volks- und Mittelschulen, die im Vergleich zu deutschen Schulen konfessionell (katholisch oder evangelisch) oder interkonfessionell sein konnten. ${ }^{1638}$ Die konfessionellen Schulen wurden teilweise von kirchlichen Gemeinden, nichtkonfessionelle höhere Schulen meist von Schulvereinen finanziert. ${ }^{1639}$ Laut Kreutz entstanden sie zusammen mit Lehrervereinen, vor allem zwischen 1875 und 1900. Mittlere Schulen waren in größeren Städten und höhere in Großstädten anzutreffen. Der Zeitraum zwischen 1900 bis 1938 umfasste letztlich eine Phase der Strukturierung und Institutionalisierung kirchlicher Gemeinden und Synoden. Eine Reihe von Initiativen zur Bildung und Weiterbildung von Lehrkräften, Verbesserung der Infrastruktur in den Schulen und Herausgabe didaktischen Materials wurden durchgeführt. Auf die Entwicklung des Schulwesens wird im Folgenden eingegangen.

\subsubsection{Kolonie- und Gemeindeschulen}

Angesichts des Mangels an Schulen begannen manche Siedler, ihre Kinder, Enkelkinder und Nachbarn zuhause zu unterrichten. ${ }^{1640}$ Weil das aber nicht überall geschah und Eltern nicht zusehen wollten, wie ihre Kinder sich zu Analphabeten entwickelten oder wie „das Vieh, obne Religion" "641 aufwuchsen, setzten sie sich

\footnotetext{
1637 Kreutz, Lúcio. Material Didático e Currículo na Escola Teuto-Brasileira do Rio Grande do Sul. São Leopoldo: Unisinos, 1994, S. 26f. Zitiert nach Fonseca, S. 47.

1638 Bühler, Fritz. Ein Beitrag zur Kirchenkunde Südamerikas. [1917/1918], S. 85, MLV 51/17 108.

${ }^{1639}$ Schulze, S. $87 f$.

1640 Gustav Adolf-Verein in Rio Grande do Sul (Hrg). Gesegnete Kindergabe, S. 12-14, EZA 5/2222; Zluhan, Christian. 40. Jahresbericht der Erįiehungsanstalt in Sta. Isabella, Estado Sta. Katharina, Brasilien, vom 1.3.1904 bis 1.3.1905, Basel, 1907, S. 9f. Zitiert nach Wirth, S. 57f; Kahle, S. 35; Arbeitsgemeinschaft 25. Juli in Rio Grande do Sul, S. 39f; Seyferth, Nacionalismo e identidade étnica, S. 131.

1641 Grimm, H. Deutsche Tätigkeit und Not in Espírito Santo. In: Traeger, P. (Hrsg.) Süd- u. MittelAmerika. Berlin: Verlag G.m.b.H., 30.9.1913, Nr. 18, 6. Jahrgang, S. 280, EZA 5/2563. Es handelt sich um eine Nachahmung der Worte Luthers in der Vorrede zum Kleinen Katechismus. Luther stellt im Rahmen seiner Visitationen fest, dass viele Menschen, besonders in den Dörfern, weder das Vaterunser noch das Glaubensbekenntnis und die Zebn Gebote kannten und „leben dabin wie das liebe Vibe [Vieh] ". Luther, Martin. Enchiridion. Der kleine Catechismus für die gemeine Pfarherr und Prediger,
} 
selbst für die Gründung von Schulen ein und übernahmen somit eine Funktion des Staates, der eigentlich für die Errichtung von Schulen verantwortlich sein sollte. Weil der Staat aufgrund eines mangelnden Staatshaushalts nicht in der Lage war, überall Schulen in den Siedlungsgebieten zu errichten und Lehrkräfte anzustellen, und weil die Einwanderer nicht zu lange auf eine Lösung für dieses dringende Problem warten wollten, richteten sie, mit den ihnen zur Verfügung stehenden Ressourcen, ein eigenes Schulwesen ein. Sie wiesen also eine aktive Bewältigungsstrategie für die Lösung eines gemeinsamen Problems auf. Carl Friedrich Butzke aus Rio dos Cedros (SC) berichtet, wie die Siedler den Mangel an Schulen pragmatisch lösten, wie sie sich dafür organisierten und Aufgaben zu deren Errichtung verteilten:

„Es waren schulpflichtige Kinder da. Johann Lemke hielt Versammlung. Wir wurden einig. Ich, Ferdinand Zumach und Carl Jahnke wurden als Vorstand gewählt. Wir haben turmaweise gearbeitet. Wie das Holz fertig war, da hat der Zimmermann Lahsan das Holz verbunden. Da wurde die Schule aufgerichtet. Die Schulbänke machten Julius $V$ ogel und Carl Bewiahn. Der erste Lehrer war Julius Scheidemantel. Der hat in der Schule viele Jahre gelehrt. Er war ein gerechter und ebrlicher Lebrer. Er rubt in Timbó auf dem Friedhof. Unser lieber Gott habe ihn selig ".1642

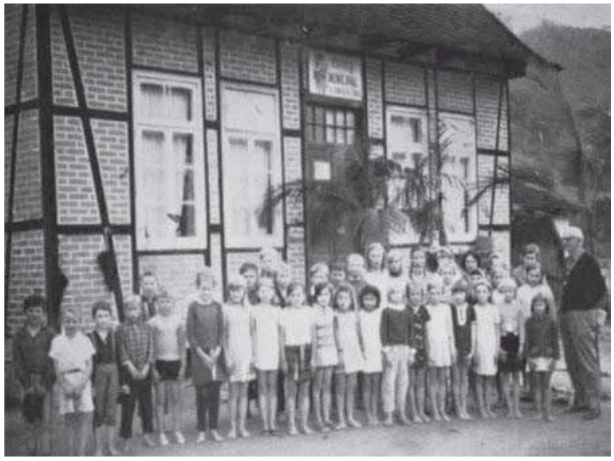

Abb. 35: Schule in Testo Alto-Pomerode (SC). Quelle: Granzow. Pommeranos unter dem Kreuz des Südens.
Ähnlich wie mit Laien und Kolonistenpfarrern wählten sie jemanden aus ihrer Mitte, der sich für den Schulunterricht eignete, und ernannten ihn zum Lehrer. Als Unterrichtsort dienten Schuppen ${ }^{1643}$, Kolonistenhäuser ${ }^{1644}$, ein Raum im Pfarrhaus ${ }^{1645}$ oder KirchenSchulen. ${ }^{1646}$ Die Schulgebäude wurden an Urwaldstraßen errichtet, an welchen sich Bauernhöfe in Entfernungen von etwa zwanzig bis dreißig Kilometer aneinander reihten, manchmal sogar weiter. ${ }^{1647}$ Aufgrund dieser Distanzen und weil Kinder auch als Arbeitskräfte

1529. In: Dr. Martin Luthers Werke. 30. Band, 1. Teil. Weimar: Böhlaus, 1910, S. 267. Diesen sollten die Pfarrer und Prediger den Katechismus beibringen.

1642 Butzke, Carl Friedrich Wilhelm. Mein Lebenslauf und Lebenskampf. Zitiert nach Evangelische Synode von Santa Catarina und Paraná, S. 98.

1643 Seibel, Imigrante a duras penas, S. 197.

1644 Damitz, Entwicklungsaspekte zur Situation der Brasilianer, S. 25.

1645 Weingärtner, 150 Anos de Presença Luterana no Vale do Itajaí, S. 26.

1646 Schröder, Brasilien und Wittenberg, S. $236 \mathrm{f}$.

1647 Bürger, Brasilien, S. 384f. 
dienten ${ }^{1648}$, konnten diese am Unterricht nur unregelmäßig teilnehmen. In vielen Orten besuchten sie nur drei-, zwei- oder sogar nur einmal pro Woche die Schule für ein bis vier Jahre. ${ }^{1649}$ In der Privatkolonie São Lourenço do Sul (RS) sollten nach Angaben von Karl Rheingantz, Sohn des Kolonisators Jakob Rheingantz, die Kinder etwa sieben Jahre, den ganzen Tag die Schule besucht haben ${ }^{1650}$, was aber angesichts der damaligen Verhältnisse übertrieben zu sein scheint. ${ }^{1651}$ In der Provinz Rio Grande do Sul sorgten die „Brummers"1652 für die Entwicklung eines ordentlichen Schulwesens in Santa Cruz do Sul (RS) ${ }^{1653}$, obwohl von Tschudi dieser Aussage widersprach und die Schulbedingungen in Santa Cruz do Sul (RS) eher als „traurig“bezeichnete. ${ }^{1654}$

Manchmal unterstützte der brasilianische Staat das Schulwesen der Siedler. In Espírito Santo verhandelte die Provinzregierung über die Eröffnung von Schulen und die Entsendung von Lehrern aus Europa und zahlte teilweise deren Besoldung. ${ }^{165}$ Die Provinzregierung von Santa Catarina spendete wiederum 846 Milréis für den Bau einer Erziehungsanstalt in Santa Isabel (SC). ${ }^{1656}$ Das Gesetz von 1864 gewährte den Privatschulen einen rechtlichen Status in der Provinz Rio Grande do Sul, auch wenn diese in deutscher Sprache unterrichteten. 1908 versprach die Regierung auch staatliche Hilfe für die bereits vorhandenen Privatschulen und für den Bau weiterer und zahlte zudem für die Lehrkräfte an Schulen in Siedlungsge-

1648 Bericht von Pastor Faulhaber, 21.4.1890, EZA 5/2482; Avé-Lallemant, Reise durch Südbrasilien im Jahre 1858. 1. Teil, S. 213.

1649 Grimm, H. Deutsche Tätigkeit und Not in Espírito Santo. In: Traeger, P. (Hrsg.) Süd- $u$. MittelAmerika. Berlin: Verlag G.m.b.H., 30.9.1913, Nr. 18, 6. Jahrgang, S. 277, EZA 5/2563; Wernicke, S. 91f; Granzow, Pommeranos unter dem Kreuz des Südens, S. 46f; Arbeitsgemeinschaft 25. Juli in Rio Grande do Sul, S. 61; Comité für die protestantischen Deutschen in Brasilien, S. 36. Mehrere Schultage konnten teilweise nicht eingeführt werden, weil manche Gemeindemitglieder mit Austritt drohten. Siehe Lutherische Kirche in Brasilien, S. 179, 234; Gaede, S. $134 f$.

1650 Rheingantz, Karl Wilhelm. Die Gründung der Kolonie São Lourenço und ibr Gründer Jakob Rheingantz [1907?], S. 28, EZA 5/2304.

1651 In Zweiggemeinden dieser Kolonie betrug den Schulbesuch nur drei Jahren. Fonseca, S. 63.

1652 Hierbei handelt es sich um deutsche Offiziere aus der ehemaligen schleswig-holsteinischen Armee, die aufgrund der Niederschlagung der Revolution von 1848 nach Brasilien emigrierten. Sie besaßen eine gute akademische Bildung und beeinflussten Einwanderer mit liberalen Ideen. Fonseca, S. 14f, vgl. Von Tschudi, Bericht über den Zustand der Kolonien der brasilianischen Provinzen Santa Catharina und San Pedro do Rio Grande do Sul, S. 250.

1653 Truda, F. de Leonardo. A colonização alemã no Rio Grande do Sul. In: Revista do Instituto Histórico-Geográfico do Rio Grande do Sul, II Trimestre, Ano X, Porto Alegre, 1930, S. 297f. Zitiert nach Willems, S. 275.

1654 In der ganzen Kolonie gab es nur zwei öffentliche Schulen. Eine der Schulen hatte keine Schüler, weil die Siedler ihre Kinder den Kolonistenpastor nicht anvertrauen wollten. In der anderen unterrichtete einen Lehrer ohne Ausbildung, der laut von Tschudi "dem Trunke ergeben "war. Weil er bald gestorben ist, blieb die Schule geschlossen. Von Tschudi, Reisen durch Süd-Amerika, 4. Band, S. $51 \mathrm{f}$.

1655 Von Tschudi, Reisen durch Süd-Amerika. 3. Band, S. 14; Brief des Ministeriums für Reichsangelegenheiten-Generalbüro für Öffentlichen Ländereien, 30.3.1860; Briefe des Ministeriums für Gelegenheiten der Landwirtschaft, des Handels und der öffentlichen Arbeiten an die Provinzialregierung von 30.10.1872 und 13.1.1873. Alles zitiert nach Rölke, Raízes da Imigração alemã, S. 527f.

1656 Brief von Wagner an Josenhans, Sta. Isabel, 20.3.1863, BMA, FB, 1,1. 
bieten, die allerdings die deutsche Sprache beherrschten mussten. ${ }^{1657}$ In der Regel zahlten aber die Siedlerfamilien selbst den Schulbeitrag für ihre Kinder. ${ }^{1658}$ Manchmal beherbergten sie Lehrer in ihren Häusern ${ }^{1659}$ und, angesichts der mangelnden Ressourcen, erhielten diese ihre Besoldung auch in Naturalien ${ }^{1660}$ oder durch Arbeitsleistung. ${ }^{1661}$ Aus demselben Grund wollten einige Eltern ihre Kinder nur zweimal in der Woche zur Schule schicken, da sie so ihrer Ansicht nach nur den halben Beitrag zahlen mussten. ${ }^{1662}$

Die Schulbedingungen waren eher mangelhaft. Lehrer besaßen selten eine fachliche Ausbildung und mussten verschiedene Klassen gleichzeitig unterrichten. Nur allmählich führten Schulen größerer Kolonien das zwei- oder mehrklassige System ein, je nach Anzahl der Kinder und Lehrkräfte und nach den finanziellen Ressourcen der Familien. Oft verfügten die Schulen nicht über geeignete Schulbücher, so dass die Bibel, das Gesangbuch und der Kleine Katechismus in vielen Fällen als didaktisches Material dienten. ${ }^{1663}$ Auf diese Weise nahm die Schule eine konfessionelle Orientierung an.

Ausnahmsweise übernahmen aber auch gebildete Lehrer den Unterricht, weswegen nicht generell von schlechter Schulbildung in Siedlungsgebieten die Rede sein kann. In Testo Central-Pomerode (SC) unterrichtete von 1887 bis 1926 der pommersche Lehrer Hermann Rahn, der in der Heimat zum Pädagogen ausgebildet war. ${ }^{1664}$ Die Schule in Testo Alto-Pomerode (SC) bekam auch einen ausgebildeten Lehrer, Friedrich Schürmann, der von der Schulleitung in Blumenau (SC) ernannt wurde. ${ }^{1665}$ Die bessere Versorgung durch ausgebildete Lehrer in der Kolonie Blumenau (SC) lag an der Verwaltung des Kolonisators Dr. Blumenau, der für die Anstellung von Lehrern sorgte ${ }^{1666}$ und bereits bei der Ansiedlung der Landlosen, Grundstücke für die Errichtung von Schulen bestimmte.

\footnotetext{
1657 Willems, S. 278-280; Gertz, O fascismo no sul do Brasil, S. 70.

1658 Wagemann, S. 122, 126; Rheingantz, Karl Wilhelm. Die Gründung der Kolonie São Lourenço und ibr Gründer Jakob Rheingantz [1907?], S. 27, EZA 5/2304; Willems, S. 282.

${ }^{1659}$ Houllou, Jean Raphael Zimmermann. História do Colégio Evangélico Jaraguá. In: Klug, João; Ulrich, Claudete Beise (Org.) Presença e atuação da Igreja Evangélica de Confissão Luterana de Jaraguá do Sul. Porto Alegre: Metrópole, 2008, S. 356.

1660 Guenther, Anita. Biografia do primeiro professor em Pomerode. In: Prefeitura Municipal de Pomerode. Pomerode, sua história, sua cultura, suas tradições. V. 1. Pomerode: Prefeitura Municipal, 1985, S. 5; Altmann, S. 88.

1661 Seibel, Imigrante no século do isolamento, S. $147 \mathrm{f}$.

1662 Weingärtner, História da Comunidade Evangélica de Timbó, S. 55.

1663 Krümpel, Erich. Bericht über die „Ev.-luth.- Gemeinde zu Limoeiro-Jatiboca“. Archiv der Parochie Santa Maria de Jetibá. Zitiert nach Gaede, S. 134f; Von Tschudi, Reisen durch Süd-Amerika, 3. Band, S. 392; Weingärtner, 150 Anos de Presença Luterana no Vale do Itajaí, S. 25; Rölke, Raízes da Imigração alemã, S. 380 .

${ }^{1664}$ Heyde, Franz von der. Fundação da Escola Alemã em Testo Central. In: Prefeitura Municipal de Pomerode. Pomerode, sua história, sua cultura, suas tradições. V. 4. Pomerode: Prefeitura Municipal, 1987, S. $20 \mathrm{f}$.

1665 Buzzarello, S. 34.

1666 Weingärtner, História da Comunidade Evangélica de Timbó, s. 45.
} 
Dr. Blumenau erarbeitete 1868 Statuten, die normativ für die ganze Kolonie waren ${ }^{1667}$, und sorgte dafür, dass der Provinzpräsident João José Coutinho den Lehrer Fernando Ostermann für Blumenau (SC) engagierte, um Unterricht in deutscher und portugiesischer Sprache zu erteilen. ${ }^{1668}$

Jedoch in fast allen Kolonien, selbst in einigen Gebieten der Kolonie Blumenau (SC), lernten die Kinder meistens das mechanische Lesen und Schreiben samt biblischer Geschichten. Aus diesem Grund konnte eine große Anzahl der Siedler zwar lesen, aber das Gelesene nicht genau verstehen oder interpretieren. Die Verständigungsschwierigkeit war dort umso größer, wo hauptsächlich das pommersche Plattdeutsch gesprochen wurde. ${ }^{1669}$ Laut Pastor Kessel sprachen die Siedler in Badenfurt-Blumenau (SC) teilweise ein ,barbarisches Deutsch“"1670 In Rio do Sul (SC) besaßen 90\% der Gemeindemitglieder einen geringen Wortschatz, der kein abstraktes Wort beinhaltete ${ }^{1671}$ und hatten Schwierigkeiten, sich richtig auszudrücken. ${ }^{1672}$

Die Siedler sorgten aber mit den ihnen vorhandenen Ressourcen für eine elementare Bildung ihrer Kinder. Geistliche setzten diese Arbeit fort. Basler Missionare waren die ersten, die sich besonders für Schulen engagierten. Sobald sie in eine Gemeinde entsandt wurden, setzten sie sich für die Errichtung schulischer Anstalten ein. ${ }^{1673}$ Seit 1864 engagierte sich auch der Evangelische Oberkirchenrat in Zusammenhang mit verschiedenen anderen Institutionen und religiösen Anstalten finanziell für das Schulwesen in Brasilien. Zudem förderten sie das Entsenden deutscher Lehrkräfte in die Kolonien. Im Allgemeinen setzten sich evangelische wie lutherische Geistliche besonders für die Verbesserung des Unterrichtsniveaus,

1667 Statutenmuster für Schulgemeinden in der Kolonie Blumenau von 15.5.1868. In: Weingärtner, História da Comunidade Evangélica de Timbó, S. 147-150. Hier wurde bestimmt, dass Eltern 8jähriger Kinder den Schulbeitrag zahlen mussten, auch wenn sie diese nicht zur Schulen schicken wollten. Schröder berichtet, dass 5\% des Einkommens des Kolonieverbandes zur Förderung der Geistesbildung, beispielsweise für Anschaffung von Büchern, 15\% für Kultur und 80\% für Gemeindezwecke verwendet werden sollte. Ein Ausschuss von fünf Personen sorgte für Kirchen- und Schulangelegenheiten. Schröder, Die deutsche Einwanderung nach Südbrasilien, S. 110.

1668 Associação dos Amigos do Arquivo Histórico de Indaial, t. 1, n. 2, jun./ago. 2015, S. 38.

1669 Grimm, H. Deutsche Tätigkeit und Not in Espírito Santo. In: Traeger, P. (Hrsg.) Süd- u. MittelAmerika. Berlin: Verlag G.m.b.H., 15.10.1913, Nr. 19, 6. Jahrgang, S. 294, EZA 5/2563; vgl. mit Auszug aus dem Reisebericht des Pastors Braunschweig, S. 3, EZA 5/2569.

1670 Bericht von Pastor Kessel an den Evangelischen Oberkirchenrat, 11.6.1921, S. 2, EZA 5/2455.

1671 Brief von Pastor Grau an Weissman, Rio do Sul, 25.6.1928, BMA, PABV 1981.

1672 Willems, S. 285.

1673 Wie die Konfirmationsanstalt (Internat) in Santa Isabel (SC), gegründet im Jahre 1863 durch Pastor Wagner. Brief von Werner Hagmann, 25.11.1986, BMA, PABV 613; vgl. Weingärtner, Martin Luther e Santa Catarina, S. 69, 71-74; und die Schule in Brusque (SC), Sandreczki, H. Berichte über die Ev. Schulanstalt in der Colonie Brusque/Itajaí-Brusque, Provinz St. Catarina, Brasilien. Basel/St. Chrischona: 1871, 1874, 1877, 1878, 1880. In: BMA S VI A.1-T.I.11, S VII C 1, C 2, C 3, C 4, C 5, C 6, C 7. Die Konferenz der Basler Missionare beschloss, als Hauptaufgabe Erziehungsanstalten zu gründen. Bericht des Präsidenten der Konferenz über seine Tätigkeit, Rio de Janeiro, August 1868, $\mathrm{BMA}, \mathrm{FB}, 1,2$. 
Verlängerung der Schulzeit1674, Einführung von Lehrplänen ${ }^{1675}$ und Anstellung deutscher Lehrer ein. Außerdem arbeiteten sie zusammen mit Lehrer- und Schulvereinen, vertraten die Interessen der Gemeindeschulen gegenüber dem Staat ${ }^{1676}$ und gaben angesichts des Mangels an didaktischen Material vor allem Lehrbücher, auch in der Landessprache, heraus. ${ }^{1677}$

Kolonie- und Gemeindeschulen blieben vom Einfluss großdeutscher Propaganda, besonders ab 1890, nicht verschont. In Zusammenhang mit der Tätigkeit deutscher Geistlicher und Lehrer erhielten sie didaktisches Material und finanzielle Unterstützung deutscher Vereine, die von deutsch-nationalistischer Ideologie geprägt waren. ${ }^{1678}$ Dieser Einfluss beschränkte sich nicht nur auf Südbrasilien, wo seit 1890 die Einwanderung nach expansionistischen und ideologischen Interessen gelenkt worden war und wo Kolonielehrer in Pomerode (SC) und Benedito Novo (SC) beispielsweise Literatur von deutschen „Lesepaten "1679 erhielten. Der deutsche Konsul in Rio de Janeiro (RJ) schenkte den Kolonieschulen im Staat Espírito Santo didaktisches Material ${ }^{1680}$ und Rölke berichtet über Schulen, die am Anfang des 20. Jahrhunderts Schulunterstützungsgesuche an die deutsche Regierung sandten. ${ }^{1681}$ In den 1930er Jahren stellte auch die deutsch-nationalsozialistische Partei deutsche Lehrer in verschiedenen Schulen an, weil diese an deutsche Schulvereine angegliedert waren. ${ }^{1682}$ Auf diese Weise fungierten die Sprache, der Lehrplan, die Inhalte, das didaktische Material und seine Perspektivität, die Lieder und das Verhalten der Lehrer als Übertragungsmittel des Deutschtums. Die deutschbrasilianische Bevölkerung trennte aber die Deutschtumsideologie vom deutschen Nationalismus, wie noch ausführlicher behandelt wird. In diesem Sinne förderten die meisten Lehrer das Deutschtum auch in den Kolonieschulen, aufgrund der ethnischen und kulturellen Werte dieser Einwanderergruppe, ohne notwendigerweise eine politische und nationale Identifikation mit dem deutschen Reich zu pflegen. Andererseits setzten sich aber Lehrkräfte, besonders nach dem Ersten Weltkrieg,

\footnotetext{
1674 Kießling, Bruno. Brasilienbericht. In: Schmidt, Die Anfänge der Diakonie in Espirito Santo, S. 156; Lutherische Kirche in Brasilien, S. 179, 181.

1675 Weingärtner, História da Comunidade Evangélica de Timbó, S. 138.

${ }^{1676}$ Fischer, Geschichte der Evangelischen Kirche, S. 138.

1677 Wie Pastor Dr. Wilhelm Rotermund in São Leopoldo (RS) und Pastor Hermann Faulhaber in Blumenau (SC). Fonseca, S. 71f; Müller, Herança de geração em geração, S. 15; Wernicke, S. 91; Weingärtner, 150 Anos de Presença Luterana no Vale do Itajaí, S. 25.

1678 Schulze, S. $89 f$.

1679 Altmann, S. 44.

1680 Wernicke, S. 93 f.

1681 Schulunterstützungsgesuche von den Schulen in Califórnia (ES), Melgaço I (ES) und II und Tijuco Preto (ES) von den Jahren 1908 und 1909, und in Califórnia (ES), Tijuco Preto (ES), Nolasco (ES) und Três Pontões (ES) im Jahr 1913. Rölke, Raižes da Imigração alemã, S. 382. 1682 Seyferth, Nacionalismo e identidade étnica, S. 132.
} 
auch für den Unterricht in der Landessprache ein ${ }^{1683}$, jedoch nur dort, wo sie diese beherrschten, und zwar als Zweitsprache. ${ }^{1684}$ Laut Willems unterrichtete keine Schule in Städten nach 1930 ausschließlich auf Deutsch, nur im Binnenland und in isolierten Gebieten gestaltete sich die Situation anders. ${ }^{1685}$

Manche Kolonie- und Gemeindeschulen vermittelten im Laufe ihrer Entwicklung eine gute Bildung oder gediehen zu qualifizierten Erziehungsanstalten. Davon zeugten etliche auch nach der Nationalisierung des Schulsystems gute Ergebnisse und einige Gebieten, an denen diese Einrichtungen standen, konnten noch bis vor ein paar Jahren die besten Alphabetisierungsquoten Brasiliens vorweisen. ${ }^{1686}$

\subsubsection{Deutsche Schulen}

Seit der Ankunft deutscher Geistlicher entstanden besonders in Städten oder Gebieten, die sich allmählich zu industriellen und kommerziellen Zentren entwickelten, deutsche Schulen. Sie verfügten von Anfang an über einen besseren Lehrplan und eine gute Infrastruktur. Die bereits 1866 gegründete deutsche Schule in Joinville (SC) vermittelte zum Beispiel eine gute Volksschulbildung und darüber hinaus Kenntnisse einer Realschule. ${ }^{1687}$

Aufgrund der politischen Interessen zur Bewahrung des Deutschtums in Südbrasilien entstanden deutsche Schulen besonders in den Staaten Rio Grande do Sul und Santa Catarina. Sie erhielten finanzielle Unterstützung, Lehrkräfte und didaktisches Material, bald auch Propagandamaterial, unter anderem vom Verein für das Deutschtum im Ausland und dem Auslandsinstitut 1688 aus Deutschland und standen durch ihre Angliederung an die Deutsche Schulvereine mit dem Allgemeinen Deutschen Schulverein in Deutschland in Verbindung. ${ }^{1689}$ Ein Internat wurde beispielsweise in Blumenau (SC) gegründet, um zu verhindern, dass die ,deutschen Jungen mit Fremdrassigen zusammenkommen und lusobrasilianischem Einfluß erliegen ".1690 Auch ein deutsches, vorwiegend evangelisches Gymnasium sollte in derselben Stadt gegründet werden, um den Schülern die Möglichkeit zu bieten ,in einer Schul-

1683 Schlünzen, F. Deutsche in Brasilien. Neuendettelsau: Freimund, 1936, S. 20, MEW 3.16; Aus Kirche und Schule, Santa Cruz. In: Sonntagsblatt für die evangelischen Gemeinden in Brasilien. Nr. 35. 12. Jahrgang, 1899, S. 135. AHI.

1684 Rölke, Raízes da Imigração alemã, S. 380; Seyferth, Nacionalismo e identidade étnica, S. 133.

1685 Willems, S. 287.

1686 Gertz, Os Luteranos no Brasil, S. 17.

1687 Schlünzen, F. Deutsche in Brasilien. Neuendettelsau: Freimund, 1936, S. 20f, MEW 3.16.

1688 Gertz, O fascismo no sul do Brasil, S. 70.

1689 Seyferth, Nacionalismo e identidade étnica, S. 133. Das 1898 gegründete Deutsche Gymnasium in Pelotas (RS) bekam finanzielle Unterstützung von der Brasilianischen Bank für Deutschland, die Knabenschule in Porto Alegre (RS) wurde wiederum vom Deutschen Hilfsverein gegründet und bekam Unterstützung aus dem Deutschen Reich, Fonseca, S. 14, 76, 83.

1690 Aufzeichnung eines Gesprächs des Gemeindeverbandsvorsitzenden Pastor Scheerer beim Oberkirchenrat in Berlin am 11.09.1933, EZA 5/2463. 
anstalt deutschen evangelischen Geistes zu verbleiben "1691 Das Projekt sollte vom deutschen Auswärtigen Amt und von führenden deutschen Firmen in Blumenau (SC) und Brusque (SC) finanziert werden. Unter der deutschbrasilianischen Bevölkerung herrschte wiederum die Meinung, deutsche Schulen wären besser als die staatlichen Schulen Brasiliens ${ }^{1692}$, vor allem, weil der Staat das Schulwesen in vielen Siedlungsgebieten vernachlässigt hatte. Auch die Siedler wünschen sich, dass ihre Kinder in der deutschen Kultur und in deutscher Sprache erzogen werden sollten, um ihr deutsches Erbe nicht zu verlieren. ${ }^{1693}$ Doch für viele Lehrer standen nicht die politischen Interessen, sondern eine ehrliche Sorge um gute Schulbildung angesichts eines mangelhaften Schulsystems im Vordergrund ihres Engagements. Deutsche Geistliche und Lehrer hatten in diesem Kontext oft keine bessere Alternative, als finanzielle Unterstützung von diesen Institutionen trotz deren ideologischer Einstellung (Bewahrung des Deutschtums unter Einwanderern und deren Nachkommen) zu akzeptieren. Zudem erhielten selbst einige deutsche Schulen staatliche Subventionen der brasilianischen Regierung ${ }^{1694}$, falls diese auch die Landessprache in ihrem Lehrplan einführten.

\subsubsection{Volks- und Mittelschulen und die Ausbildung von Lehrern}

Die auch durch Initiative der Geistlichen gegründeten mittleren und höheren Schulen besaßen einen festen Lehrplan und geordnete Verhältnisse mit zwei bis vier Lehrkräften und mehreren Klassen ${ }^{1695}$, und bekamen teilweise ausgebildete Lehrerkräfte aus Deutschland oder Lehrer, die aus einem deutschbrasilianischen Seminar stammten und so die Anforderungen der brasilianischen Behörden erfüllten. Ihre Anzahl war aber sehr gering angesichts der Bedürfnisse in den Siedlungsgebieten und sie litten vor allem in den ersten Jahren unter finanziellen Schwierigkeiten aufgrund geringer Schülerzahlen und weil Kolonisten aus dem Hinterland ihre Kinder nicht in die Stadt schickten.1 ${ }^{1696}$ Dies lag zum einen darin begründet, dass ihre Kinder in ersten Linie bei der landwirtschaftlichen Arbeit benötigt wurden und eine höhere Schule samt Unterkunft in der Stadt nicht bezahlbar war, und zum anderen, dass aus ihrer Sicht eine elementare Bildung, die das Lesen, Schreiben und Rechnen umfasste, für ihre Verhältnisse ausreichend waren.

Manche Eltern aber, die ihren Kindern eine bessere Bildung ermöglichen wollten und für eine Unterkunft in der Stadt bei Verwandten oder Bekannten sorgten oder es sich bereits leisten konnten, schickten diese in die dortigen deutschen

\footnotetext{
1691 Bericht von Propst Funke, 10.08.1931, EZA 5/2485.

1692 Seyferth, Nacionalismo e identidade étnica, S. 137.

1693 Festschrift zum 60. Jährigen Bestehen der Deutsch-Evangelischen Schule in Brusque, Brusque, 1933. Zitiert nach Seyferth, Nacionalismo e identidade étnica, S. 139.

${ }^{1694}$ Wie die deutsche Schule in Blumenau (SC). Willems, S. 289.

${ }^{1695}$ Liesenberg, S. 14f; Weingärtner, Crônica da Comunidade Evangélica de Timbó, S. 52.

1696 Fischer, Geschichte der Evangelischen Kirche, S. 138, 140; Schröder, Brasilien und Wittenberg, S. 222 f.
} 
Schulen oder in höhere katholische Schulen, in kostenlose Staatsschulen oder auf Internate in den Hauptstädten. ${ }^{1697}$ In letzteren Fällen wurden die Siedler oft von deutschen Geistlichen und Bildungskreisen wegen ihrer Gleichgültigkeit gegenüber ihrem deutschen Erbe und des Verlustes ihrer deutschen Sprache kritisiert, sowie dafür, dass sie so nicht dazu beitrugen, das deutsche Schulwesen aufrecht zu erhalten. ${ }^{1698}$ Hintergrund dafür war nicht nur die Deutschtumspflege, sondern auch der Plan zur Entwicklung einer konfessionellen Bildung und die Entstehung einer evangelischen Kirche in Brasilien. Tambara weist auch auf die Existenz eines ideologischen Wettbewerbs zwischen den Konfessionen im Staat Rio Grande do Sul hin. Dieser fand in Zusammenhang mit der Ankunft deutscher Jesuiten statt, als sich die Feindseligkeit zwischen Katholiken und Protestanten in manchen Gebieten potenzierte. So versuchten beide religiöse Ausrichtungen die erste Schule in einem bestimmten Gebiet zu gründen. Aufgrund der mangelnden Ressourcen großer Teile der Siedler würde die Entstehung einer anderen Schule am gleichen Ort nicht möglich sein. ${ }^{1699}$ Im Staat Santa Catarina entstanden wiederum Schulvereine, denen deutschen Protestanten und Katholiken angehörten und die keinen oder einen interkonfessionellen Religionsunterricht erteilten. ${ }^{1700}$ Hier förderte das gemeinsame Interesse für Schulbildung die Annäherung zwischen beiden Konfessionen.

Bereits Ende des 19. Jahrhunderts, Anfang des 20. Jahrhunderts und vor allem nach dem Ersten Weltkrieg setzten sich Geistliche mit Unterstützung kirchlicher Synoden auch für die Ausbildung von Lehrern ein. Sie veranstalteten selbst in Pfarrhäusern Lehrkurse und stellten Weiterbildungsangebote für Kolonielehrer ${ }^{1701}$ oder gründeten Lehrerseminare. ${ }^{1702}$ Manche dieser Fortbildungsstätten wurden

1697 Brief an die Missionsleitung [von Wüster?], ohne Angabe von Datum, MEW 4.185; Fischer, Geschichte der Evangelischen Kirche, S. 137f; Willems, S. 174.

1698 Der Kompass, Ano 1937, Nr. 25; Bund Deutscher Vereine (Hrsg.) Hundert Jabre Deutscbtum in Rio Grande do Sul, Porto Alegre, 1924, S. 59f. Zitiert nach Willems, S. 292f; Dreher, Igreja e Germanidade, S. 93.

1699 Tambara, Elomar. A Educacão no Rio Grande do Sul sob o Castilhismo. Porto Alegre: Universidade Federal do Rio Grande do Sul, 1991, S. 417. Zitiert nach Fonseca, S. 50. Die höhere Schule in São Leopoldo (RS) wurde beispielsweise 1867 gegründet. Weil Jesuiten 1869 und Franziskaner 1870 ihre Schulen in derselben Stadt errichteten, musste sie bereits 1872 schließen. 1888 gründete Pastor Dr. Rotermund der Collegio Independencia, der 1893 nach Novo Hamburgo (RS) verlegt wurde und 1897 auch einging. Dedekind, 75 Jahre deutsch-evangelischer Diasporaarbeit, S. 44.

1700 Schröder, Brasilien und Wittenberg, S. 237.

1701 Brief von Pastor Gustav Braun an den Präsidenten der Basel Mission P. J. Rossel, 21.11.1978, BMA, PABV 2198; Sandreczki, H. Bericht über die Evangelische Schulanstalt in der Colonie Itajahy-Brusque. [1881], S. 9, BMA, S VI A.1-T.I. 11, S VII C 7; Halle, G. Kurze Geschichte der dentsch-evangelischlutherischen Gemeinde zu Ijuby, S. 18, AHI, SR 83/25; Evangelische Synode von Santa Catarina und Paraná, S. 78; Lutherische Kirche in Brasilien, S. 217, 234; Schmidt, Die Anfänge der Diakonie in Espirito Santo, S. 119, 142; Arbeitsgemeinschaft 25. Juli in Rio Grande do Sul, S. 62.

1702 Wie die Neue Schule in Blumenau (SC) 1889. Auszug eines Hundertjahrbuches von Blumenau, 1950. In: Associação dos Amigos do Arquivo Histórico de Indaial. Indaial. Conbecendo sua história. Indaial: AMARHIN, t. 1, n. 3, set./nov. 2015, S. 36f; Altmann, S. 80; das Lehrerseminar im Asyl 
auch ideologisch beeinflusst und zielten nach einer Bildung im deutschen Geist ab. ${ }^{1703}$ Ihre Bedeutung aber für die Fortbildung vieler Siedler sollte dadurch nicht unterschätzt werden. Am Beispiel einiger Pastoren gaben die Lehrer Otto Büchler, der das Lehrerseminar in Santa Cruz do Sul (RS) besuchte, und Georg August Büchler, Lehrer in der Neuen Schule in Blumenau (SC), verschiedene didaktische Bücher für den Unterricht in Kolonieschulen heraus. ${ }^{1704}$ Zudem spielten Lehrkräfte, die in diesen Anstalten ausgebildet wurden, eine entscheidende Rolle in der Nationalisierungs- und Kriegszeit. Aufgrund ihrer Bildung, teilweise in der Landessprache, konnten sie staatliche Examina bestehen und wurden anstelle deutscher Lehrer und Geistlicher in verschiedenen Gemeinde- und Kolonieschulen und in deutschen Schulen eingesetzt. Sie übernahmen auch zusammen mit anderen Kirchenmitglieder den Pfarrdienst, als Pastoren inhaftiert wurden. ${ }^{1705}$

Der brasilianische Staat verhielt sich in dieser Situation meistens indifferent und behinderte die Arbeit in Gemeinde- oder Kolonieschulen und deutschen Schulen, Gymnasien und Lehreranstalten nicht. In manchen Fällen förderte und begünstigte die Regierung diese Entwicklung, wie im Staat Santa Catarina (SC). ${ }^{1706}$ Im Staat Rio Grande do Sul erlaubte das Gesetz von 17. Mai 1864 den Unterricht in deutscher Sprache in Schulen und 1877 war die deutsche Sprache sogar Voraussetzung für die Einstellung von Lehrkräften, die in Siedlungsgebieten unterrichten wollten, was 1881 auch in der Reform der Normalschule bestimmt wurde. ${ }^{1707}$ So entzog sich der Staat seiner Verantwortung gegenüber dem Schulwesen und nutzte das deutsche Engagement als Gelegenheit, den Staatshaushalt mit der

\footnotetext{
Pella in Taquari (RS) 1908, das 1910 nach Santa Cruz do Sul (RS) und 1926 nach São Leopoldo (RS) verlegt wurde, Fischer, Geschichte der Evangelischen Kirche, S. 138, 140; Schröder, Brasilien und Wittenberg, S. 222; die landwirtschaftliche Schule von Pastor Aldinger in Hansa Hammonia-Ibirama (SC), die auch Kolonielehrer bildete, Prien, S. 70; Weingärtner, Martin Luther e Santa Catarina, S. 104; das Evangelische Lehrseminar in São Leopoldo (RS) 1913, Schulze, S. 88; der Lehrpräparande in Timbó (SC) 1931, Allerlei. In: Das Schulbuch, Nr. 34, São Leopoldo, Mai 1931, S. 9, EZA 5/2453, Brief Pastors Blümel, Leiter der Ev. Lehrpräparande Timbó an Bischof Henkel von 5.4.1937, EZA 5/2508; der Lehrpräparande in Limoeiro-Jatiboca (ES) 1938, der aber aufgrund des Nationalisierungsprogramms nicht in Betrieb genommen werden konnte, Bericht von Pastor Paul Koch auf der Distriktsynode in Santa Maria am 4.-5.8.1928 über die synodalen Lehrerkonferenzen von 1927 in Laranja da Terra und Santa Maria sowie über die Arbeit zur Hebung unserer Schulen und ihres Lehrerstandes. In: Schmidt, Die Anfänge der Diakonie in Espirito Santo, S. 119.

${ }^{1703}$ Das Lehrerseminar in Santa Cruz do Sul (RS) wurde reichlich vom Deutschen Staat unterstützt und erhielt 1926 eine komplette Ausstattung an Unterrichtsmaterialien, darunter Bücher, Karten, Sportgeräte und Chemiepräparate. Schulze, S. 90.

1704 Auszug eines Hunderjahrbuches von Blumenau, 1950. In: Associação dos Amigos do Arquivo Histórico de Indaial. Indaial, t. 1, n. 3, set./nov. 2015, S. 36f. Eine mögliche Verwandtschaft zwischen beiden konnte aus den Quellen nicht festgestellt werden.

${ }^{1705}$ Schmidt, Die Anfänge der Diakonie in Espirito Santo, S. 140-146.

1706 Fischer, Geschichte der Evangelischen Kirche, S. 135; Seyferth, Nacionalismo e identidade étnica, S. 183.

1707 Willems, S. 278-280; Gertz, O fascismo no sul do Brasil, S. 70.
} 
Errichtung von Schulen nicht auch noch zu belasten. Währenddessen konnte sich das deutsche Schulwesen institutionalisieren und ausdehnen.

\subsection{Die Errichtung von Kranken- und Entbindungshäusern und sozialen Anstalten}

Sehr früh erkannten Einwanderer und deren Nachkommen die Bedeutung sozialer Netzwerke für die Bewältigung von Schwierigkeiten im brasilianischen Urwald. Ein Kolonist und Sattler aus Blumenau (SC) berichtet, dass ,einer auf des Andern bedarf". 1708 Es handelte sich hierbei um die sogenannte Nachbarschaftshilfe ${ }^{1709}$, auch Puscheru1710, Bittarbeit oder Juntament ${ }^{1711}$ genannt. Seit ihrer Ankunft unterstützten die Siedler sich gegenseitig bei Urwaldrodung, der Errichtung von Wohnungen, beim Straßenbau, Transporten von Produkten ${ }^{1712}$ oder von Kranken zum Arzt ${ }^{1713}$ und in allen anderen Bereichen ihres Lebens, wo sie Hilfe benötigten. Vor allem bei Krankheits-1714, Unfalls- und Todesfällen von Familienmitgliedern sammelte sich die Nachbarschaft, um einer betroffenen Familie bei ihren Problemen, die sie allein nicht mehr selbst bewältigen konnte, beizustehen. Diese Hilfe wurde ohne Entgelt geleistet, jedoch in stiller Vereinbarung, bei Bedarf die gleiche Unterstützung zu erhalten. ${ }^{1715}$

Nach diesem Prinzip unterstützten sich auch Frauen bei der Entbindung ihrer Kinder und der Erledigung der Hausarbeit nach deren Geburt. Groß war ihre Not, weil sie keine medizinische Hilfe eines Arztes oder einer Hebamme erhielten und ältere Frauen konnten trotz ihrer Erfahrung manchmal Mütter oder Kinder in schwierigen Fällen nicht retten. Aus diesem Grund, als Gemeinden bereits über einen Geistlichen verfügten und die Gemeindemitglieder die Errichtung von Kirchen, Schulen, Friedhöfen und Pfarr- und Lehrerwohnungen in Gemeinschaftsarbeit erledigt hatten, setzten sie sich mit ihren Pastoren zusammen, um für die Anstellung deutscher Krankenschwestern, Ärzte und Hebammen zu sorgen. Seit

\footnotetext{
1708 Bürger, Colonie Blumenau, S. 15; vgl. Briefe aus Südbrasilien (Rio Grande do Sul, Serragebiet). In: Hüben und Drüben, Nr. 1, März 1927, 3. Jahrgang, EZA 5/355; Altmann, S. 159; Weingärtner, História da Comunidade Evangélica de Timbó, S. $77 \mathrm{f}$.

1709 Grothe, S. 77.

1710 Granzow, Pommeranos unter dem Kreuz des Südens, S. 172.

1711 Es handelte sich hier um eine Germanisierung des portugiesischen Wortes ajuntamento und bedeutet Versammlung. Wernicke, S. 164; Willems, S. 246, 255.

1712 Kolonisten aus Timbó (SC) sammelten sich in Gruppen von acht bis zehn Personen und trugen Maissäcke auf die Schultern bis nach Encano-Indaial (SC), um sich gegenseitig vor wilden Tieren im Urwald zu schützen. Beim Rückweg brachten sie dann das verarbeitete Maismehl ihren Nachbarn, die fünfzehn Tagen zuvor den Mais dorthin getragen hatten. Weingärtner, História da Comunidade Evangélica de Timbó, S. 77.

1713 Weingärtner, História da Comunidade Evangélica de Timbó, S. 91; Kahle, S. 92.

1714 Bosenbecker, S. 117-120.

1715 Wagemann, S. 78; Schmidt, Die Anfänge der Diakonie in Espirito Santo, S. 177; Weingärtner, 150 Anos de Presença Luterana no Vale do Itajaí, S. 22; Wernicke, S. 164f; Granzow, Pommeranos unter dem Kreuz des Südens, S. 172.
} 
1909 waren zwei Krankenschwestern in Blumenau (SC) tätig, die Hebammeschwester Martha Linke und die Gemeindeschwester Auguste Küchler. ${ }^{1716} 1913$ wurde die erste wittenbergische Diakonisse vom Diakonissenhaus für das Ausland nach Blumenau (SC) ausgesandt. ${ }^{1717}$ Bald folgten noch andere, besonders nach Rio Grande do Sul. ${ }^{1718} 1914$ sandte auch das evangelisch-lutherische Diakonissenmutterhaus in Flensburg die erste Diakonisse, Ina Hochreuter, nach Joinville (SC). ${ }^{1719}$ In Santa Maria (ES) war die Krankenschwester und Hebamme Johanna Matzat stationiert. ${ }^{1720}$ Familie Piske beherbergte wiederum die Diakonisse Auguste Schlosser in Timbó (SC). ${ }^{1721}$ Der seit 1913 ersehnte Plan für die Errichtung eines Diakonissenmutterhauses in São Leopoldo (RS) konnte aber erst 1939 verwirklicht werden, nachdem 1938 eine Schwesternschaft in Brasilien gegründet wurde. ${ }^{1722}$

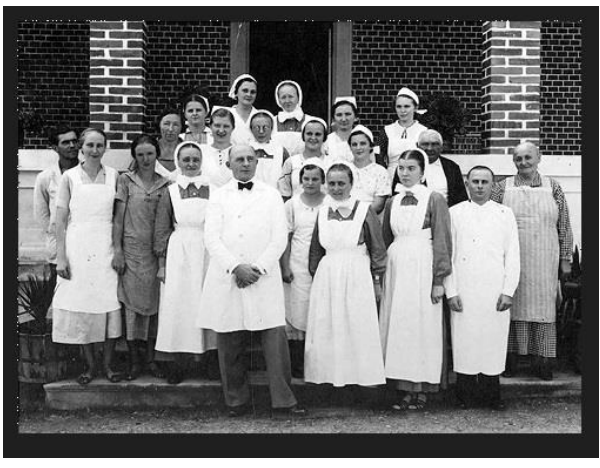

Abb. 36: Der Chefarzt, Dr. Christian Johnsen, und die Schwestern des Evangelischen Krankenhauses in Blumenau (SC). Quelle: Wittmann, Hospital Santa Catarina.
1914 wurde der Grundstein für die Errichtung eines Deutschen Krankenhauses in Porto Alegre (RS) gelegt. Aufgrund des Ersten Weltkrieges konnte mit dem Bau erst 1924 begonnen und 1927 seinem Dienst übergeben werden. 1937 erhielt es eine Entbindungsstation. ${ }^{1723} 1916$ begann mithilfe des Verein Evangelischer Gemeinden von Santa Catarina und Paraná der Bau eines evangelischen Krankenhauses in Blumenau (SC). Die Gemeinde spendete das Grundstück und engagierte sich im Sammeln von Spenden, aber der Bau musste aufgrund des Krieges unterbrochen werden und

\footnotetext{
1716 Bericht über die Tätigkeit des „Evang. Frauenvereins Blumenau“, 18.3.1911, EZA 5/2488.

1717 Die Arbeit der Diakonissen in Blumenau (SC) umfasste die Versorgung des Krankenhauses, des Wöchnerinnenheims Johannastift, der Frauenschule, der Gemeindepflege und Kindergartenarbeit. Bericht betr. Lage der Diakonissenarbeit in Blumenau, 22.2.1936, EZA 5/2487; Scheerer. Festschrift der Evangelischen Kirchengemeinde Blumenau. Blumenau: Artur Koehler, S. 16, EZA 5/2486.

17181933 arbeiteten 52 Diakonissen in Brasilien, 32 von ihnen innerhalb der Riograndenser Synode in Gemeinden, Kindergärten, Schulen und Krankenhäuser. Prien, S. 292; vgl. Bliedner, Aufgaben unserer Diakonissenarbeit in Gegenwart und Zukunft. In: Dohms, Hermann (Hrsg.) Deutsche Evangelische Frauenbilfe und Schwesternarbeit in Brasilien. Sonderdruck der Deutschen Evangelischen Blätter für Brasilien. São Leopoldo: Rotermund, S. 6, EZA 200/1/2149.

${ }^{1719}$ Fischer, Geschichte der Evangelischen Kirche, S. 149; Schröder, Brasilien und Wittenberg, S. 272.

1720 Krause, Lutherische Synode in Brasilien, S. 177.

${ }^{1721}$ Weingärtner, História da Comunidade Evangélica de Timbó, S. $223 \mathrm{f}$.

1722 Prien, S. 292; Fischer, Geschichte der Evangelischen Kirche, S. 149.

${ }^{1723}$ Hospital Moinhos de Vento. Nossa História. Verfügbar in: http://www.hospitalmoinhos.org.br/ historia/ Zugang am 4.5.2017.
} 
das Krankenhaus konnte erst 1920 eingeweiht werden.1724 Ärzte und Schwestern aus Deutschland wurden angestellt (Abb. 36 siehe S. 291), um die Krankenpflege zu übernehmen. ${ }^{1725} 1923$ wurde in Blumenau (SC) auch das Wöchnerinnenheim Johannastift in Betrieb genommen, das bereits 1931 erweitert wurde. ${ }^{1726}$ In Brusque (SC) stifteten 1938 der Unternehmer Carlos Renaux, einige Privatleute und die Frauenhilfe medizinische Instrumente und einen Entbindungs- und Operationstisch für ein Entbindungszentrum. ${ }^{1727}$

Auch andere soziale Bereiche wurden berücksichtigt. In den ersten Siedlungsjahren reagierten die Siedler pragmatisch auf die Situation von Waisen, die ihre Eltern während der Überseereise oder bald danach verloren hatten, oder auch auf kinderreiche Familien, die aus verschiedenen Gründen in Not gerieten. Sie erhielten Unterstützung von besser stehenden Verwandten oder Bekannten, die diese Kinder adoptierten. ${ }^{1728}$ Mit der Ankunft der Geistlichen und im Zuge eines Urbanisierungsprozesses in einigen Siedlungsgebieten begann die Institutionalisierung auch in diesem Bereich. Reiseprediger Haetinger gründete 1892 in Taquari (RS) das Asyl Pella. 1900 wurde dort ein Altersheim angegliedert. Beide Einrichtungen waren mit der Riograndenser Synode verbunden. 1907 wurde dem neugeschaffenen Evangelischen Wohltätigkeitsverein in Brusque (SC) ein Altersheim gegründet. ${ }^{1729}$ In Joinville (SC) engagierten sich 1916 etwa 80 Frauen für die Gründung eines Wohltätigkeitsvereins für Kranken- und Waisenpflege, das Helenenstift. Aufgrund des Krieges konnte es erst 1921 seinem Dienst aufnehmen. ${ }^{1730}$ In Pirabeiraba/Joinville (SC) wurde 1934 mithilfe der Evangelisch-Lutherischen Synode das Asyl Bethesda gegründet. ${ }^{1731}$

Besonders Frauen engagierten sich bei sozialen Arbeiten, vor allem nach der Gründung von Frauenvereinen. Deren Tätigkeit bezüglich sozialer Aktivitäten wurde von den kirchlichen Gemeinden gefördert, so dass sie von Anfang an eine führende Rolle in den Gemeinden übernahmen. ${ }^{1732} 1907$ wurde der Evangelische

\footnotetext{
1724 Scheerer. Festschrift der Evangelischen Kirchengemeinde Blumenau. Blumenau: Artur Koehler, S. 17, EZA 5/2486.

1725 Rendtorff, Franz (Hrsg.) Die evangelische Diaspora, insbesondere des Auslandsdeutschtums. Leipzig: J. C. Hinsrisch'sche Buchhandlung, 1920/1921, S. 141.

1726 Es erhielt diesen Namen nach Frau Johanna Hering, die das Grundstück für den Bau stiftete. Frau Elsbeth Holetz schenkte dazu ein weiteres Grundstück. Blumenauer Gedenktage. Ausschnitt einer Zeitung vom Jahre 1932, S. 52f, EZA 5/2486; Scheerer. Festschrift der Evangelischen Kirchengemeinde Blumenau. Blumenau: Artur Koehler, S. 18-20, EZA 5/2486.

1727 Ergänzungsbericht 1938 der Gemeinde Brusque (SC) vom Pastor Graetsch, S. 1, EZA 5/2526.

1728 Schmidt, Die Anfänge der Diakonie in Espirito Santo, S. 140; Granzow, Pommeranos unter dem Kreuz des Südens, S. 30; Weingärtner, História da Comunidade Evangélica de Timbó, S. 78.

1729 Schröder, Brasilien und Wittenberg, S. 274f; vgl. Dedekind, 75 Jahre deutsch-evangelischer Diasporaarbeit, S. 73.

1730 Kahle, S. 101.

1731 Lutherische Kirche in Brasilien, S. 246f; Fischer, Geschichte der Evangelischen Kirche, S. $126 f$.

1732 Rambo, Arthur Blasio. O Associativismo teuto-brasileiro e os primórdios do cooperativismo no Brasil. EDUNI-SUL, 1988, S. 73. Zitiert nach Baade, Os conflitos comunitários e sinodais, S. 89.
} 
Frauenverein in Blumenau (SC) gegründet, der sich bereits 1909 für die Einrichtung eines Schwesterheimes engagierte. ${ }^{1733}$ Er eröffnete 1929 auch ein Mädchenpensionat mit einer Frauen- und Haushaltsschule. ${ }^{1734}$ Der 1920 gegründete Frauenverein in Joinville (SC) setzte sich für Krankenpflege und Jugendarbeit ein und war für die Erhaltung eines Kindergartens, der 1917 eröffnet wurde ${ }^{1735}$, und des Helenenstifts, verantwortlich. ${ }^{1736}$ Weil viele Frauen bereits in den lokalen Industrien arbeiteten, wurde zwischen 1932 und 1933 zudem eine Kleinkinderschule und 1936 ein zweiter Kindergarten gegründet. ${ }^{1737}$ In Santa Cruz do Sul (RS) sammelte die Frauenhilfe Spenden für den Bau eines evangelischen Heims und gründete einen Kindergarten und ein Internat für Mädchen, die später die Synodalschule besuchen wollten. ${ }^{1738}$

\subsection{Errichtung kultureller und landwirtschaftlicher Vereine}

Einwanderer und deren Nachkommen ließen sich in Gebieten nieder, in denen es an kulturellen und geistigen Anregungen mangelte und sie besaßen zunächst weder die Bedingungen und Ressourcen noch den Zugang oder staatliche Unterstützung für die Beschaffung von Literatur, geistiger Bildung oder die Gründung von Vereinen. Ihre Priorität galt dem Bau von Kirche, Schule und Friedhof und erst danach widmeten sie sich geistigen und kulturellen Interessen. Dieses zeigte sich jedoch schon früh in der Suche nach erbaulicher Literatur, Anschaffung von Musikinstrumenten und der Bildung von kirchlichen Gemeinden. Die Entstehung und Entwicklung kulturellen Lebens schöpfte sich aus und in Verbindung mit der kirchlichen Gemeinde.

Die Entwicklung geistigen und kulturellen Lebens weist je nach Kontext Besonderheiten auf. In Städten wie Joinville (SC) und Porto Alegre (RS) war es abwechslungsreicher als im Binnenland, ebenso dort, wo sich Intellektuelle, Liberale und Repräsentanten verschiedener Berufe in größerer Anzahl niederließen. Die Vorliebe für Musik und Kirchenlied begünstigte jedoch überall die Entstehung kirchlicher Liedergruppen, Chöre ${ }^{1739}$ und Posaunenchöre. ${ }^{1740}$ In Joinville (SC)

\footnotetext{
1733 Bericht über die Tätigkeit des „Evang. Frauenvereins Blumenau“, 18.3.1911, EZA 5/2488.

1734 Scheerer. Festschrift der Evangelischen Kirchengemeinde Blumenau. Blumenau: Artur Koehler, S. 20f, EZA 5/2486; Schröder, Brasilien und Wittenberg, S. 272.

${ }^{1735}$ Lutherische Kirche in Brasilien, S. 34.

1736 Wüstner, S. 58.

1737 Wüstner, S. 66, 68f. Über das Engagement der Frauenhilfe von Jaraguá do Sul (SC), Timbó (SC) und Indaial (SC) bei der Berufung von deutschen Hebammen, Diakonissen und Krankenschwestern und die Errichtung von Entbindungshäusern und Kindergärten siehe Claas, S. 32f; Weingärtner, Crônica da Comunidade Evangélica de Timbó, S. 84; Giurus, Crônica da Paróquia Evangélica Luterana de Indaial, S. $145 f$.

1738 Sínodo Riograndense. Comunidade Evangélica de Santa Cruz do Sul 1862 - 100 - 1962, S. 10, AHI, SR $144 / 15$.

1739 Abschriften von Briefen Ausgewanderter. In: Hüben und Drüben, Nr. 4, August 1926, 2. Jahrgang, EZA 5/264.
} 
waren bereits 1861 ,zwei Gesangvereine "vorhanden. ${ }^{1741}$ Auch Blumenau (SC) besaß schon früh einen. ${ }^{1742} 1911$ gab es einen Posaunenchor in Santa Maria de Jetibá (ES) ${ }^{1743}$ und bald folgten andere Gemeinden, wie Laranja da Terra (ES) ${ }^{1744}$, ihrem Beispiel.

Besonders in Südbrasilien ${ }^{1745}$, aber auch im Staat Espírito Santo ${ }^{1746}$ gründeten Einwanderer und deren Nachkommen Schützen-, Turn-, Gymnastik-, Segel-, Kegel-, Reit-, Theater-, Lese-, Gesang-, Hilfs- und Volksvereine. ${ }^{1747}$ Diese Vereine unterstützten wiederum manchmal die Gründung von Krankenhäusern, Altenheimen und Genossenschaften. Laut Willems waren Genossenschaften den älteren Einwanderern unbekannt, so dass Bauernvereine ${ }^{1748}$, Zuchtviehstationen und bäuerliche Genossenschaftsbanken ${ }^{1749}$ erst mit der Ankunft neuer Einwanderer nach 1890 entstanden. ${ }^{1750}$ Einige Vereine, wie der Bund der Kolonievereine, der Riograndenser Bauernverein, der Deutsche Handwerkerverband und Hilfs- und Krankenvereine waren interkonfessionell und vertraten die Interessen von Siedler verschiedener Konfessionen. ${ }^{1751}$

Kultur- und Sportvereine wurden besonders durch ein kleines Bürgertum kultiviert und geben Auskunft über eine Elitenbildung in Siedlungsgebieten. Sie entsprachen dem Bedürfnis nach Geselligkeit ${ }^{1752}$ und der Bewahrung kultureller Iden-

1740 Scheerer. Festschrift der Evangelischen Kirchengemeinde Blumenau. Blumenau: Artur Koehler, S. 16, EZA 5/2486.

1741 Von Tschudi, Bericht über den Zustand der Kolonien der brasilianischen Provinzen Santa Catharina und San Pedro do Rio Grande do Sul, S. 219.

1742 Von Tschudi, Reisen durch Süd-Amerika, 3. Band, S. 393.

1743 Gemeindemitglieder spendeten 10 Milréis für die Anschaffung von Posaunen aus Deutschland. Gaede, S. 206 f.

1744 Langholf, Johan. Dienst an den zerstreuten in Brasilien, S. 17, MEW 4.118. Hier wurde 1923 das erste Chor- und Posaunenfest organisiert. Gaede, S. 213.

1745 Statistiken der deutschen Vereine in Brasilien aus den Jahren 1932 und 1933: Gemeinden Brusque, Itoupava, Badenfurt und Pomerode (SC), EZA 5/4220; Gemeinde Timbó-Benedito (SC), EZA 5/4224; Gemeinde Indaial (SC), EZA 5/4229; Gemeinde São Lourenço do Sul (RS), EZA $5 / 4219$.

1746 Statistiken der deutschen Vereine in Brasilien aus den Jahren 1932 und 1933: Gemeinden von Espírito Santo, EZA 5/4227, EZA 5/4222.

1747 Associação dos Amigos do Arquivo Histórico de Indaial. Indaial. Conhecendo sua história. Indaial: AMARHIN, t. 2, n. 2, jun./ago. 2016, S. 34f; Aldinger, S. 27; Von Tschudi, Reisen durch Süd-Amerika, 3. Band, S. 393; Von Tschudi, Reisen durch Süd-Amerika, 4. Band, S. 11; Willems, S. 403; Lutherische Kirche in Brasilien, S. 49; Halle, G. Kurze Geschichte der deutsch-evangelisch-lutherischen Gemeinde zu Ijuby, S. 14, AHI, SR 83/25; Associação dos Amigos do Arquivo Histórico de Indaial, t. 1, n. 4, S. 24.

1748 Von Tschudi, Bericht über den Zustand der Kolonien der brasilianischen Provinzen Santa Catharina und San Pedro do Rio Grande do Sul, S. 219f; Von Tschudi, Reisen durch Süd-Amerika, 3. Band, S. 366.

1749 Kahle, S. 102; Rheingantz, Karl Wilhelm. Die Gründung der Kolonie São Lourenço und ibr Gründer Jakob Rheingantz. [1907?], S. 21, EZA 5/2304.

1750 Willems, S. 256.

1751 Arbeitsgemeinschaft 25. Juli in Rio Grande do Sul, S. 41.

1752 Publicação em comemoração do Cinquentenário da Associação dos Atiradores, Brusque, 1916, S. 9. Zitiert nach Willems, S. 114. 
tität in der Fremde, weswegen sie letztendlich auch Raum für die Entwicklung des Deutschtums boten. In Espírito Santo, wo sich der Industrialisierungs- und Urbanisierungsprozess nicht so schnell wie im Süden vollzog und wo sich kein unternehmerisches Bürgertum bildete, waren diese Vereine nicht so stark repräsentiert, weshalb die Kirchengemeinde dort weiterhin als wichtigste Institution für die Entwicklung geistigen Lebens fungierte. ${ }^{1753}$

Die Zusammenarbeit bei der Gründung aller Institutionen, die zunächst nicht in den Siedlungsgebieten vorhanden waren, förderte die Gemeinschaft und die Entwicklung sozialer Netzwerke außerhalb der Familie, die wichtig für die Bewältigung von Schwierigkeiten und Herausforderungen in den Kolonien waren. Vor oder nach dem Gottesdienst, in kirchlichen Versammlungen, aber auch in Geschäftshäuser trafen sich Gemeindemitglieder, um sich auszutauschen und über ihre Probleme zu diskutieren. In diesen Gesprächen entschlossen sie sich für die Gründung ihrer Organisationen und Vereine. Darüber hinaus vertraten Geistliche und Kirchenvorstände die Interessen der Kolonisten bei Behörden. ${ }^{1754}$ Sie trugen also Verantwortung füreinander und für die Gemeinde. Nach Pastor Grottke war die Gemeinde eine „Kraftquelle für ihr inneres und äußeres Leben“. Die Kirche war die erste, die „ein Wort für die inneren und äußeren Nöte hatte und half, soviel es in ihrer Macht stand". 1755

Die rege Partizipation am sozialen Leben in der kirchlichen Gemeinde gewährte den Siedlern soziale Anerkennung. Bereits die Berufung für die Übernahme einer besonderen Funktion entsprechend der jeweiligen Fähigkeit (Lehrer, Kolonistenpastor, Waldarzt, „Gesundbeter“, Hebamme, Gemeindevorsteher, Sargtischler, Totengräber, Glöckner, Baumeister, Musiker) stärkte ihr Selbstbewusstsein, ihre Selbstwirksamkeit und Problemlösefähigkeit. Das Engagement bei der Gründung von Schulen, Kranken- und Entbindungshäusern, Organisationen und Vereinen schenkte ihnen wie am Beispiel des Kirchenbaus ein sinnvolles Lebensprojekt.

Die Bildung dieser Institutionen verlief jedoch nicht immer konfliktlos. Nicht alle Siedler nahmen an dieser sozialen Dynamik teil und entsprachen damit nicht der erarbeiteten Normen, die sich innerhalb familiärer, nachbarlicher und kirchlicher Netzwerke bei alltäglichen Umständen entwickelten und in unabhängigen und selbständigen Organisations- und Resistenzformen die Lösung ihrer Probleme bildeten. Wer sich den Normen nicht anpasste oder ihnen nicht folgte, wurde sozial ausgeschlossen und mit Sanktionen und Strafen belegt. In Santa Cruz do Sul (RS) wurden beispielsweise Siedler, die nicht bei dem Bau von Straßen geholfen hatten, mit dem Verlust ihres Viehs als eine Art Vergeltungsmaßnahme gedroht. ${ }^{1756}$ Und soziale Ausgrenzung hatte vor allem in abgeschiedenen Gebieten

\footnotetext{
1753 Wagemann, S. $119 f$.

1754 Willems, S. $353 \mathrm{f}$.

1755 Grottke, G. Aus der Arbeit einer lutherischen Gemeinde in Nordbrasilien, 10.1.1938. Zeitungsartikel, S. 37, MLV 51/17 108 .

1756 Willems, S. 179.
} 
harte Konsequenzen. Als der Holländer Frans Smoor in Holanda-Santa Leopoldina (ES) die Tochter eines ehemaligen Sklaven heiratete, wurde er von der Gemeinde und vom Pastor abgewiesen. Er durfte zwar noch Gemeindemitglied sein, aber an keiner kirchlichen Veranstaltung teilnehmen. Er vermisste die Gemeinschaft seiner ehemaligen Bekannten und Verwandten und begann aufgrund der sozialen Ausgrenzung zu trinken. Letztlich beging er Selbstmord. ${ }^{1757}$ Dieses Beispiel verdeutlicht einerseits, wie die kirchliche Gemeinde und die Gemeinschaft unter ihren Mitgliedern den Siedlern einen wichtigen Halt bot. Andererseits zeigt es aber, wie die religiöse Gemeinde auch für die Ausgrenzung derjenigen, die sich nicht an ihre ethnischen und kulturellen Normen anpassten, verantwortlich war. Die enge Verbindung zwischen Ethnie und evangelisch-lutherischen Glauben unter Einwanderern und ihren Nachkommen in Brasilien kommt hier zum Ausdruck.

Einwanderer und deren Nachkommen bildeten eine einzigartige und lebenswichtige soziale Umwelt in brasilianischen Siedlungsgebieten, in welcher sie sich gegenseitig unterstützten und für die Entwicklung von Institutionen sorgten, die in den Siedlungsgebieten noch nicht vorhanden waren und vom Staat vernachlässigt wurden. Durch diese Institutionen setzten sie sich für die Bekämpfung von schulischen, ärztlichen, kooperativen und geselligen Mängeln ein, für sie selbst, aber auch für die ansässige Gesellschaft. Zudem leisteten sie einen wichtigen erzieherischen, diakonischen und sozialen Dienst und trugen wesentlich zur kulturellen und geistigen Entwicklung der Kolonien bei.

\section{Die Entstehung kirchlicher Synoden in Brasilien und die Entwicklung von Konflikten aufgrund unterschiedlicher Interessen}

Wie bereits beschrieben, mussten die unabhängigen und selbstständigen Gemeinden selbst für die Berufung von Geistlichen und für den Bau und die Erhaltung von Kirchen und anderen Institutionen sorgen. Seit ihrer Ankunft setzten sich die Geistlichen für die Bildung einer kirchlichen Organisation ein, um die zerstreuten Gemeinden miteinander zu verbinden. Ihr Ziel war die Bildung einer institutionellen Kirche, die somit jedoch gegen das Prinzip einer Gemeindekirche, wie die Siedler ihre Gemeinden bis dahin geführt hatten, verstieß. Im Folgenden sollen die Bildung kirchlicher Synoden, der Konflikt zwischen Haupt- und Zweiggemeinden bezüglich ihrer Unabhängigkeitsbestrebungen, die konfessionellen Differenzen und die Streitigkeiten zwischen einzelnen Gemeinden, Pastoren, Missionaren und Kolonistenpastoren aufgrund unterschiedlicher Interessen betrachtet werden. Hierdurch soll vor allem Auskunft über das konfessionelle Bewusstsein der Siedler

1757 Roos; Eshuis, S. 78. 
und über ihren Wunsch nach einer besseren kirchlichen Betreuung dargestellt werden.

Die Einwanderer bildeten keine konfessionelle Einheit. Neben Pommern kamen auch Mitglieder anderer deutscher Staaten, aus der Schweiz, Österreich, Holland, Polen, Ungarn, Dänemark, England, Norwegen, Frankreich, Luxemburg, Finnland und Russland nach Brasilien. Obwohl die Mehrheit lutherischer Konfession war, die sich entsprechend der Tradition der Preußischen Union als evangelisch bezeichnete ${ }^{1758}$, fanden sich unter ihnen auch römisch Katholische, Reformierte, Waldenser, Anabaptisten, Mennoniten und freie Mitglieder. Mit Ausnahme der Katholiken, schlossen sie sich aus pragmatischen Motiven in evangelischen Gemeinden zusammen, da keine protestantischen Gemeinden in den Siedlungsgebieten vorhanden waren. Ihre internen Differenzen wurden in den ersten Jahrzehnten beigelegt ${ }^{1759}$, denn sie befanden sich in einer gemeinsamen religiösen, kulturellen und sprachlichen Diaspora, mussten gemeinsam den Pfarrmangel bewältigen und besaßen dasselbe Interesse an einem kirchlichen Leben. Ihre Gemeinden folgten in diesem Sinne in der Regel keiner konfessionellen Benennung und verfügten auch über keine Statuten, die diese bestimmten. Joinville (SC) bezeichnete sich 1864 beispielsweise schlicht als Evangelische protestantische Kirchengemeinschaft. ${ }^{1760}$ Konfessionelle Besonderheiten blieben jedoch erhalten. Diese konnten sich unter anderem in der Ausstattung der Kirche zeigen. ${ }^{1761}$

Die konfessionelle Einigkeit war in den ersten Jahrzehnten nur möglich, weil Geistliche, die in den jeweiligen Gemeinden tätig waren, zunächst aus unierten oder evangelischen Bildungsanstalten entsandt wurden. Hinzu kam, dass die Mehrheit lutherischer Pommern, die in der Heimat die Einführung der preußischen Union erlebt hatte, keinen Widerwillen gegen unierte Geistliche hegten. ${ }^{1762}$ Angesichts ihres Verlangens nach kirchlichem Leben spielte die konfessionelle Zugehörigkeit der Geistlichen zu dieser Zeit auch eine untergeordnete Rolle. Die „religiöse Harmonie" sollte möglichst erhalten bleiben, wie auch aus einem Dokument, das 1868 in

\footnotetext{
1758 Wachholz, Luteranismo no Brasil, S. 182f.

1759 Obwohl die Einwanderer verschiedener Herkunft den Lebensstil ihrer unterschiedlichen Heimatdörfer in einer regionalen Ethnizität zu reproduzieren versuchten, Droogers, S. 29, ermöglichte ihre Heterogenität nach Willems keine vollständige Transplantation einer lokalen oder regionalen Tradition in den Siedlungsgebieten, Willems, S. 32, 39f. Auch wenn die Pommern in einigen Gebieten, wie beispielsweise in Espírito Santo die größte Einwanderergruppe bildeten, Lutherische Kirche in Brasilien, S. 173, übernahmen sie bestimmte Eigenschaften anderer Gruppen in einem Assimilationsprozess, der unter den Immigranten stattfand. In keinem Gebiet gibt es ein kulturelles Element, das im Laufe der Zeit keine Veränderungen aufwies. Willems, S. 106f, 176f. Auch Ackermann weist darauf hin, dass die regionale Differenzierung zwischen Pommern und Deutschen ein junges Phänomen in Espírito Santo ist. Ackermann, S. 248f.

1760 Wüstner, S. 19.

${ }^{1761}$ Der Altarraum folgte gewöhnlich einer lutherischen Konfiguration, die Wände waren aber kahl und calvinistisch. Dreher, Kontexte und Kirche, S. 15.

1762 Dreher, Geschichte der EKLBB. In: Brakemeier, Gottfried (Hrsg.) Glaube im Teilen bewahrt. Erlangen: Verlag der Ev.-Luth. Mission, 1989, S. 175.
} 
den Grundstein der Kirche in Blumenau (SC) gelegt wurde, zu entnehmen ist. Dort wird ,ein in einem deutschen Pfaffenbrutneste aufgehetzte Geistlicher" erwähnt, der diese Harmonie ,vergeblich zu stören versuchte“.1763 Das Dokument enthält keine weitere Angaben, aber es kann angenommen werden, dass der ansässige Pfarrer, die Kolonieverwaltung und einflussreiche Mitglieder der Gemeinde den Zusammenhalt innerhalb der evangelischen Gemeinde förderten.

Geistliche versuchten von Anfang an Gemeinden in einer kirchlichen Organisation zu vereinigen und strebten nach der Bildung einer Kirche in Brasilien. Die Gründe dafür waren zum Teil persönlicher Natur: Ihr Lohn und Kranken- und Rentenpflege waren nicht gesichert, sie konnten jederzeit entlassen werden und waren der Willkür mancher Kirchenvorsteher ausgesetzt. In einer kirchlichen Organisation könnten sie sich untereinander bei Problemen unterstützen, ihre Arbeitsbedingungen wären gesichert und eine regelmäßige Entsendung von Geistlichen und Lehrern in die Gemeinden könnte gewährleistet werden. Die Gemeindemitglieder interessierten sich jedoch nicht für eine kirchliche Institutionalisierung, sie hatten sich in Kolonie- oder Freigemeinden ${ }^{1764}$ beziehungsweise in einer Gemeindekirche ${ }^{1765}$ organisiert. Laut Dedekind sahen sie in der Gründung von Synoden eine Strategie, Gemeinden zu einer höheren Pfarrbesoldung zu zwingen, und in Pfarrkonferenzen die Möglichkeit für Pastoren, sich zu vergnügen und sich über die Gemeinden zu beschweren. ${ }^{1766}$ Kirchliche Institutionen fungierten nach ihrer Sicht als ein

\section{„Verein von Pastoren, die sich (...) zur geistlichen Obrigkeit der Gemeinden aufwerfen, dieselben beherrschen und ibnen die Freibeit einschränken, ibnen Gesetze geben, Abga- ben auflegen, Prediger aufbringen, ja vielleicht gar das Eigentum der Gemeinden sich in die Hände spielen wollen". ${ }^{1767}$}

Die negative Erfahrung mit der Landeskirche in der alten Heimat, wo Gutsbesitzer zugleich Patronatsherren waren und Geistliche eher deren Interessen vertraten, als die des gewöhnlichen Volks ${ }^{1768}$, löste Unzufriedenheit und Abneigung

1763 Blumenau 1868. Denkschrift im Grundstein der Evangelischen Kirche vom Pastor Oswald Hesse. In: Evangelische Synode von Santa Catarina und Paraná, S. 34.

1764 Dedekind, Brasilien, S. 41.

1765 Fischer, Geschichte der Evangelischen Kirche, S. 103.

1766 Dedekind, Max. Deutsch-evangelische Kirche von Rio Grande do Sul (Riograndenser Synode). In: Sonntagsblatt Nr. 15, 1. Jahrgang, 1901, S. 2. Zitiert nach Witt, S. 68.

1767 Krause, Lutherische Synode in Brasilien, S. 127.

1768 In manchen Orten nutzen Einwanderer die Möglichkeit, Geistliche als Knechte zu behandelt, weil diese von ihnen bezahlt wurden. Schröder, Brasilien und Wittenberg, S. 332; Lutherische Kirche in Brasilien, S. 187. In Gemeinden von Rio Grande do Sul sollen einige Gemeindemitglieder den Pastor sogar verprügelt haben, denn ihrer Aussicht nach müsse er dasselbe erleiden, was sie erduldet haben, und das Abhängigkeitsverhältnis zur Gemeinde anerkennen. Dazu Hees, Pastorado e Pastores no Rio Grande do Sul, S. 24. „Tu Hus hett der Gautsbesitzer up uns peddt; nu wolln wie hie upn Paster un upn Köster peddn“ (,Zuhause, d.h. in Deutschland, hat der Grundbesitzer uns getreten; nun wollen wir bier auf den Pastor und auf den Küster treten“). Hennig, Fußnote 71, S. 106. 
gegen ein geplantes Staatskirchentum aus. ${ }^{1769}$ In Brasilien angekommen freuten sie sich, von staatlichen Kirchenorganen befreit zu sein ${ }^{1770}$ und wollten sich nicht erneut „kommandieren lassen“.1771 Dieser Meinung waren jedoch nicht alle Gemeinden und deren Mitglieder. Einige erkannten die Bedeutung von Synoden für die Entwicklung einer Kirche in Brasilien. Zudem erhofften sie sich dadurch eine bessere Betreuung und Hilfe bei dem Bau kirchlicher Gebäude, Schulen und Anstalten.

Als Vorstufe für die Gründung der Synoden dienten Pfarrkonferenzen. Bereits 1867 beriefen Basler Missionare eine ${ }^{1772}$ in Rio de Janeiro (RJ) ein. Ihr konnten sich auch Geistliche anderer evangelischer Konfessionen, die die Konferenz als kirchliche Obrigkeit anerkannten und einen Beitrag zahlten, angliedern. ${ }^{1773}$ Der Basler Missionar Wagner lud Pastor Borchard und seinen Kollegen aus Barmen, die in Rio Grande do Sul tätig waren, ein, sich den Basler Brüdern anzuschließen und eine Synode für das ganze Kaiserreich zu gründen. ${ }^{1774}$ Borchard erkundigte sich zunächst beim Evangelischen Oberkirchenrat ${ }^{775}$, der darauf negativ reagierte. ${ }^{1776}$ Die Basler Missionare verließen jedoch nach 1874 allmählich ihre Stellen und die Basler Mission gab Brasilien als Missionsgebiet auf.

In Rio Grande do Sul übernahm Pastor Borchard 1868 die Initiative zur Bildung einer evangelischen Synode und gründete die Deutsch-Evangelische Synode der Provinz São Pedro do Rio Grande do Sul. Nur wenige Pastoren schlossen sich ihr an, angeblich aufgrund der unterschiedlichen konfessionellen Bildung und Herkunft.

\footnotetext{
${ }^{1769}$ Fischer, Geschichte der Evangelischen Kirche, S. 102.

1770 Fischer, A luta contra os pastores-colonos no Rio Grande do Sul no século XIX, S. 44f.

${ }^{1771}$ Erinnerungen eines deutschen Ansiedlers in Brasilien. In: Sonntagsblatt für die evangelischen Gemeinden in Brasilien. Nr. 35, 12. Jahrgang, 1899, S. 135. AHI.

1772 Sie wurde aber unter den Basler Missionare und dem Komitee der Basler Mission als Synode benannt. Protokoll der 6. Sitzung der Zweiten Konferenz, Rio de Janeiro, 26.10.1868, BMA, FB, 1,2; Brief von Josenhans an Wagner, Basel, 23.10.1869, BMA, FB, 2,1; Brief von Josenhans an die Synode der brasilianischen Brüder, Basel, 31.3.1870, BMA, FB, 2,1.

1773 Geschaeftsordnung der Conferenz Evangelischer Pastoren zu Rio de Janeiro. Wie sie von den Unterzeichneten berathen und angenommen worden ist. Rio de Janeiro, 19.8.1867, BMA S. VI A.1T.I.11, S VI A 1-4; Schlatter, S. 90; Prien, S. 114.

${ }_{1774}$ Brief von Pastor Wagner an das Komitee der Basler Mission, Rio de Janeiro, 6.4.1866, BMA, FB, 1,1 .

1775 Borchard war der Meinung, der Zeitpunkt dafür sei noch nicht gekommen. Die großen Distanzen samt Reisekosten und Zeitaufwand machten die Teilnahme von Pastoren aus Rio Grande do Sul an einer Konferenz in Rio de Janeiro (RJ) auch unmöglich. Er wollte für Brasilien dem Muster von Preußen folgen und den Provinzen die Gründung eigener Synoden selbst überlassen und sie erst später in einer Generalsynode zusammenführen. Brief von Pastor Borchard an den Evangelischen Oberkirchenrat, São Leopoldo, 7.5.1866, EZA 5/2178.

1776 Er toleriere die Teilnahme seiner Pastoren an einer Konferenz der Basler Missionare nicht, es sei denn, dass Gemeinden, die früher zur Preußischen Landeskirche gehörten, wieder unter die Obrigkeit des Oberkirchenrates fallen und Pfarrstellen von ihm besetzt werden würden. Brief vom Evangelischen Oberkirchenrat an Pastor Borchard, Berlin, 27.7.1866, EZA 5/2178.
} 
So löste sich die Synode nach wenigen Jahren wieder auf. ${ }^{1777}$ Später gründete Pastor Dr. Wilhelm Rotermund angesichts der nahenden Ausrufung der Republik in Brasilien die Riograndenser Synode 1886.1778

Der lutherische Gotteskastenverein sah in dem Berliner Oberkirchenrat eine Institution, die sich auf ein Staatskirchentum stützte. Zudem war er strikt gegen eine Union zwischen Lutheranern und Reformierten. So bildeten lutherische Pastoren 1899 eine eigene Pfarrsynode ${ }^{1779}$, die dem Verband der lutherischen Gotteskastenvereine angeschlossen war und in welchem alle lutherischen Geistlichen in Brasilien automatisch Mitglieder wurden. 1905 wurde die Evangelisch-Lutherische Synode von Santa Catarina, Paraná und anderen Staaten von Brasilien gegründet. ${ }^{1780}$ Sie legte im Unterschied zu anderen Synoden von Anfang an eine klare konfessionelle Glaubensbasis in ihren Statuten fest und führte eine einheitliche Liturgie ein, was letztendlich zu einem guten Verständnis der Geistlichen und Gemeinden und zu einer positiven Einstellung gegenüber einer einheitlichen Kirche beitrug. ${ }^{1781}$

1888 trafen sich drei evangelischen Pastoren in Santa Catarina, um über die Planung einer Pfarrkonferenz in diesem Staat zu sprechen. Bald schlossen sich auch andere Geistliche an, die sich jedoch nicht über die Gründung einer Synode einigen konnten. Das lag an der Vielfältigkeit der einzelnen Entsendungshäuser, an der unterschiedlich gestalteten theologischen Bildung und an der Verbindung mit verschiedenen Landeskirchen in der Heimat. ${ }^{1782}$ Auch die Gründung einer Evangelischen Pastoralkonferenz 1896 konnte die Geistlichen nicht nachhaltig verbinden. Erst 1911 kam es zur Gründung des Vereins Evangelischer Gemeinden von Santa Catharina und Paraná, die mit der Pastoralkonferenz verbunden war. ${ }^{1783}$

Die Verhandlungen für die Bildung einer Synode in Mittelbrasilien begannen aus der Initiative des deutschen Repräsentanten des Oberkirchenrates in Brasilien, Pastor Martin Braunschweig. Er sammelte 1907 vier evangelische Pastoren aus Espírito Santo in Porto do Cachoeiro (ES) in einer Pfarrkonferenz zusammen. ${ }^{1784}$

\footnotetext{
1777 Dreher, Arno. Aufbruch in die Zukunft. In: Fischer, Joachim; Jahn, Christoph (Hrsg.) Es begann am Rio dos Sinos. Erlangen: Verlag der Ev. Lutherischen Mission, 1970, S. 12.

1778 Mehr darüber Prien, S. 118-131.

1779 Prien, S. 99, 169f. Weingärtner berichtet, dass bis 1899 die lutherischen Pastoren an der evangelischen Pastoralkonferenz teilnahmen. Als sie jedoch eine eigene Pastoralkonferenz gründeten, wurde der Dialog unterbrochen und ein feindseliges Verhalten begann zwischen beiden Synoden und ihren Geistlichen. Weingärtner, Martin Luther e Santa Catarina, S. $136 f$.

${ }_{1780}$ Mehr dazu Prien, S. 168-183.

${ }^{1781}$ Weingärtner, Martin Luther e Santa Catarina, S. 141.

${ }^{1782}$ Schröder, Brasilien und Wittenberg, S. 346.

1783 Mehr dazu Prien, S. 147-156.

${ }^{1784} \mathrm{Zu}$ diesem Anlass schlug Pastor Schüler vor, die lutherischen Kollegen miteinzubeziehen. Das wurde aber von der Konferenz als Hindernis bei der Entwicklung einer Synode abgelehnt, Prien, S. 159 f. $1913 \mathrm{kam}$ es doch zur Gründung eines Kircblichen Vereins der Gemeinden in Espirito Santo in Santa Leopoldina (ES) durch Vertreter der Gemeinden des Evangelischen Oberkirchenrates und des Lutherischen Gotteskastenvereins. Nach Schmidt wurden aber die Statuten für den Gemeindeverband der deutsch-evangelischen Gemeinden in Espirito Santo zugunsten der Statuten der Mittelbrasilianischen Synode 1915 verdrängt. Schmidt, Die Anfänge der Diakonie, S. 46.
} 
Eine erste Pfarrversammlung der evangelischen Pastoren, die in den Staaten Espírito Santo, Minas Gerais, São Paulo und Rio de Janeiro tätig waren, fand anlässlich der Kircheneinweihung in São Paulo (SP) 1908 statt und gilt als offizieller Gründungstag der Pfarrkonferenz in Mittelbrasilien. Anfang Dezember 1911 fand die dritte Konferenz in Petrópolis (RJ) statt, bei der über die Entstehung der Mittelbrasilianischen Synode für das Jahr 1912 verhandelt wurde. ${ }^{1785}$

Nach der Gründung der Synoden gab es Gemeinden, die offiziell der Synode beitraten und deren kirchliche Körperschaft anerkannten und andere, die sich nicht anschlossen, obwohl ihre Geistlichen einer Synode angehörten. ${ }^{1786}$ Die Mehrheit verhielt sich zögerlich und schloss sich erst im Laufe der Zeit einer Synode $a^{1787}$, andere Gemeinden im Staat Rio Grande do Sul bildeten Freigemeinden. ${ }^{1788}$ Grund dafür war die bereits erwähnte Abneigung gegen staatliche Kirchenorgane, die sie aus ihrer alten Heimat kannten, und die angebliche Beschränkung ihrer Autonomie. In diesem Sinne folgte der Anschluss von Pastoren unabhängig vom Anschluss und der konfessionellen Haltung der Gemeinden, obwohl diese in der Regel dem Bekenntnis ihrer Geistlichen folgten. Aber die Verbindung $\mathrm{zu}$ einer Synode war labil und in Vakanzzeiten oder Krisen leicht auflösbar. ${ }^{1789}$ Deutschsprachige Gemeinden konnten sich auch ab 1900 der Landeskirche Preußens anschließen, was immer mehr Gemeinden, einige teilweise mit Vorbehalt ${ }^{1790}$, taten.

\subsection{Konflikte zwischen Gemeinden, Geistlichen, Missionaren und} Kolonistenpastoren

Die unterschiedlichen Interessen zwischen Gemeindemitgliedern und ihren Pastoren, zwischen Geistlichen verschiedener Konfessionen und Ausbildungen, zwischen Gemeindemitgliedern untereinander und zwischen ordinierten Geistlichen und den Kolonistenpastoren und Missionaren der Gnadauer Mission und des Deutschen Gemeinschafts-Diakonieverbandes trugen zur Entwicklung von Konflikten und Gemeindespaltungen bei. Manchmal verbanden sich auch mehrere Motive, so dass es schwierig ist, die Entwicklung von Konflikten und Gemeindespaltungen in Ge-

\footnotetext{
1785 Mehr darüber Prien, S. 157-168.

1786 Krause, Lutherische Synode in Brasilien, S. 127.

1787 Joinville (SC) schloss sich erst 1940 der Evangelisch-Lutherischen Synode an. Krause, Lutherische Synode in Brasilien, S. 130. Ein Mitglied in Santa Cruz do Sul (RS) sprach sich 1887 gegen den Anschluss an die Riograndenser Synode in der ersten Versammlung der Synode aus. Die erste Ordentliche Versammlung der Riograndenser Synode in Santa Cruz am 4. und 5.5.1887, Leipzig 1887, S. 20, zitiert nach Prien, S. 121.

1788 Gertz, Os Luteranos no Brasil, S. 16.

1789 Krause, Henrique. Die Entwicklung der Synode ab 1930 bis zum Zweiten Weltkrieg und seine Folgen. In: Backhause, Martin; Zeller, Hans. (Hrsg.) Aufbruch in Grenzen. Neuendettelsau/Nürnberg/ Erlangen: Verlag für Mission und Ökumene/mabase-Verlag/Martin-Luther-Verlag, 2016, S. 103. 1790 Wie beispielsweise die Gemeinden Ferraz (RS), Santa Augusta (RS) und Aliança (RS). Prien, S. 140.
} 
meinden aus drei verschiedenen Staaten, in denen die Besetzung von Pfarrstellen sehr unterschiedlich und unregelmäßig verlief, systematisch zu beschreiben. In der folgenden Darstellung werden Beispiele in Betrachtung gezogen, die wiederkehrende Konfliktstrukturen beschreiben und besonders Auskunft geben über den Wunsch nach einer besseren kirchlichen Betreuung und über die Bedeutung der kirchlichen Gemeinden für die Gemeindemitglieder.

In erster Linie erschwerte besonders der häufige Pfarrwechsel den Aufbauprozess der Gemeinden. ${ }^{1791}$ Er bedeutete zunächst einmal vor allem finanzielle Schwierigkeiten für verarmte Gemeinden, die oft einen Teil oder die gesamten Reisekosten der Pfarrfamilie übernehmen mussten. ${ }^{1792}$ Die Gemeindemitglieder sehnten sich nach einem Pastor und nach einem geordneten Kirchenleben und fühlten sich verraten, wenn dieser nach einer langen Wartezeit die Gemeinde bald wieder verließ. Dies war meistens bei akademisch gebildeten Pastoren der Fall ${ }^{1793}$, denn ihnen fielen das primitive Leben und die schwierigen Verhältnisse in den Kolonien besonders schwer. Die Siedler waren bald der Meinung, dass „Berliner Pastoren" kurz nach ihrer Ankunft in Brasilien nach Deutschland zurückzukehren wollten, um für ihre Verdienste in der Diaspora gute Stellen zu bekommen oder Bücher über den brasilianischen Urwald zu veröffentlichen. ${ }^{1794}$ Sie wünschten sich aber keine Pastoren, die sich gleich nach der Übernahme einer Gemeinde ausrechneten, wann sie wieder zurückkehren konnten oder solche, ,die man drüben nicht gebrauchen kann"1795, sondern Geistliche, die mindestens zehn Jahren bei ihnen blieben. ${ }^{1796}$ Aus diesem Grund bevorzugten einige Gemeinden „Gotteskastenpastoren", weil diese aufgrund ihrer missionarischen Ausbildung länger in Brasilien blieben ${ }^{1797}$ und für eine niedrigere Besoldung arbeiteten. Hier kommt der Interessenkonflikt zwischen Gemeindemitglieder und Geistlichen zum Ausdruck. Dies beeinträchtigte nicht zuletzt das Vertrauensverhältnis zwischen ihnen: Manche Gemeindemitglieder fühlten sich von Pastoren, die die Gemeinde nach kurzer Zeit

\footnotetext{
${ }^{1791}$ Lutherische Kirche in Brasilien, S. 45; Brief der Gemeinde Santa Maria de Jetibá von 3.10.1903 im Archiv der Parochie Santa Maria de Jetibá. Zitiert nach Gaede, S. 116f.

1792 Das war eine Bedingung für die Entsendung von Pastoren seitens der Barmer Gesellschaft. Als Gegenleistung verlangte die Riograndenser Synode von der Barmer Gesellschaft die Entsendung ordentlicher Geistlicher für wenigstens fünf Jahren. Fischer, A luta contra os pastores-colonos, S. 50f. 1793 Sie blieben etwa sechs Jahren in Brasilien und innerhalb dieser Jahren wechselten sie ein- oder zweimal die Gemeinde. Die Gemeinde Santa Leopoldina II-Jequitibá (ES) verzeichnete in vierzehn Jahren nur acht Jahren ohne Pfarrwechsel. Dreher, Igreja e Germanidade, S. 73f und Fußnote 100. Jedoch auch unter lutherischen Missionaren des Gotteskastenvereins konnte ein großer Gemeindewechsel registriert werden, siehe Lutherische Kirche in Brasilien, S. 229-231.

1794 Geschichte der luth. Gemeinde Santa Joana (unveröffentlicht). Zitiert nach Krause, Lutherische Synode in Brasilien, S. 107.

1795 Auszug aus einem Reisebericht des Pastors Marczynski, ohne Datum. Zitiert nach Prien, S. 320.

1796 Auszug aus dem Reisebericht des Pastors Braunschweig, S. 5f, EZA 5/2569; vgl. Brief der Gemeinde Santa Maria de Jetibá von 3.10.1903 im Archiv der Parochie Santa Maria de Jetibá. Zitiert nach Gaede, S. $116 f$.

1797 Droogers, S. 22.
} 
verließen, vernachlässigt oder gar missachtet und Pastoren befanden sich oft in einer instabilen Situation in Gemeinden, die sich keiner Synode oder kirchlichen Organisation anschließen wollten und sie jederzeit entlassen konnten.

Evangelische Geistliche sahen wiederum in den lutherischen Gotteskastenpastoren Konkurrenten und Eindringlinge, die durch geringere Pfarrlöhne die Gemeinden gewinnen wollten, und bezeichneten sie als „,undeutsch“, „,ungebildet“, „,billige Sorte“, „unlautere Wettbewerb", „Halbbluttheologen"1798 und „eingerostete Konfessionalisten".1799 Sie warfen ihnen zudem vor, dass sie keine akademische Ausbildung genossen hatten. Von der Kanzel aus wurden Siedler sogar vor kirchlichen Amtshandlungen der Gotteskastenpastoren gewarnt, denn diese waren nicht von einer anerkannten Territorialkirche ausgesandt und besaßen kein theologisches Examen. ${ }^{1800}$ Die lutherischen Geistlichen wiederum nannten die evangelischen „Mischmaschprotestanten“, weil sie einer unierten Kirche angehörten, welche Reformierte und Lutheraner vereinigte. Sie widersprachen den Vorwürfen der evangelischen Pastoren, in dem sie erklärten, sie versorgten ausschließlich Gemeinden, die pfarrlos waren und sie dringend um Hilfe baten. Zudem vergewisserten sie sich, dass sie keiner kirchlichen Organisation angeschlossen waren und verlangten von ihnen eine schriftliche Bestätigung über ihren evangelisch-lutherischen Glauben. ${ }^{1801}$ Auch in den Gemeindezeitungen griffen evangelische und lutherische Geistliche sich gegenseitig an, brachten die Kirchenmitglieder damit durcheinander und regten zu Auseinandersetzungen an. Lutherische Siedler wurden beispielsweise von evangelischen Nachbarn und ehemaligen Glaubensbrüder beschimpft oder provoziert: „willst du zu einem lutherischen Himmel gehen? "1802 und sogar Familien zerstritten sich untereinander. ${ }^{1803}$ In diesem Sinne wurde der Konflikt zwischen Geistlichen unterschiedlicher Konfession und Ausbildung, die in denselben Gebieten tätig waren, den Gemeindemitgliedern übertragen. Die ,religiöse Harmonie" war gefährdet und Gemeinden begannen sich aus konfessionellen Gründen zu spalten.

Ein musterhaftes Beispiel für den Konflikt zwischen Geistlichen und Kirchenmitgliedern, zwischen Geistlichen untereinander und letztendlich zwischen evangelischen und lutherischen Gemeinden und Pastoren bietet die Gemeinde Indaial (SC). Der Berliner Pfarrer Hägeholz verließ die Gemeinde 1898 aufgrund eines Konflikts mit dem Kirchenvorstand ${ }^{1804}$ und zog nach Timbó (SC), die zum

\footnotetext{
1798 Bühler, Fritz. Ein Beitrag zur Kirchenkunde Südamerikas. [1917/1918], S. 59f, MLV 51/17 108.

1799 Weingärtner, Martin Luther e Santa Catarina, S. 136f.

1800 Rölke, Die Gotteskastenarbeit im Staat Espírito Santo, S. 84.

1801 Riegel-Widdershausen, Aus der Arbeit des Lutherischen Gotteskasten in Brasilien. Verlag des Lutherischen Gotteskasten in Bayern, 1926, S. 7, MLV 51/17 108. Bühler, Fritz. Ein Beitrag zur Kirchenkunde Südamerikas. [1917/1918], S. 52-54, MLV 51/17 108; Lutherische Kirche n Brasilien, S. 8.

1802 Brief von Pastor Wrede an Stirner 29.6.1910. Zitiert nach Droogers, S. 23.

1803 Weingärtner, 150 Anos de Presença Luterana no Vale do Itajaí, S. 42f.

1804 Beschwerden über groben Ansprachen des Pastors bei Taufen und Trauungen und aufgrund von Misshandlungen der Konfirmanden führten bereits zu Spannungen zwischen der Gemeinde und
} 
Pfarrbezirk Indaial (SC) angehörte. Dort gründete er eine eigenständige Gemeinde. Gemeindemitglieder aus Timbó (SC), die mit der Trennung von Indaial (SC) nicht einverstanden waren, bildeten wiederum eine eigene Zweiggemeinde, die sich der Hauptgemeinde Indaial (SC) anschloss. ${ }^{1805}$ Der Evangelische Oberkirchenrat sandte Pastor Max Ziegel als neuen Pastor für Indaial (SC), so dass der Pfarrbezirk nun über zwei evangelische Geistliche verfügte. Weil keine genaue territoriale Abgrenzung festgelegt wurde, verfügten beide Geistlichen über Mitglieder in Zweiggemeinden und Predigtplätze an denselben Orten, sogar im Pfarrsitz des anderen. Niemand wusste genau, welche Mitglieder welcher Gemeinde angehörten. Als Pfarrer Ziegel nach Deutschland zurückkehrte, wandte sich die Gemeinde Indaial (SC) wieder an den Oberkirchenrat. Dieser wollte als obere Kirchenleitung den Konflikt lösen und empfahl der Gemeinde, sich mit der Trennung von Timbó (SC) abzufinden und sich über territoriale Grenzen zu verständigen. Indaial (SC) akzeptierte dies nicht, löste sich vom Oberkirchenrat und wandte sich 1902 an den lutherischen Pastor Roesel in Itoupava (SC). ${ }^{1806}$ So bekam sie den lutherischen Pastor Bergold. Nun waren Kirchenmitglieder und Gemeinden auch konfessionell geteilt. ${ }^{1807}$

Die Freiheit in Bezug auf den Anschluss an eine Synode löste weitere Konflikte aus, besonders, wenn evangelische und lutherische Pastoren Gemeinden in Grenzgebieten betreuten, wie es der Fall in Gemeinden pommerscher Kolonisation in Santa Catarina und Espírito Santo war. In vielen Orten wurden zwei Gotteshäuser gebaut, ein evangelisches und ein lutherisches. Besonders wenn die Bitte einer vakanten oder getrennten Gemeinde um kirchliche Betreuung von der Nachbargemeinde verweigert wurde, wandte sich diese oder ein Teil von ihr an einen anderen Pastor, der auch der anderen Konfession angehören konnte, wie es im Fall in Cresciuma (ES) ${ }^{1808}$ und Pedreira (SC) war. In Pedreira (SC) wandte sich ein Teil des Gemeindevorstands an den evangelischen Nachbarpastor in São Bento do Sul (SC), die Mehrheit der Gemeinde blieb an die lutherische Landgemeinde Dona Francisca (SC) angeschlossen. Die „Abtrünnigen“wurden aus Pedreira (SC) ausgeschlossen und als Racheakt verschlossen sie die Kirche und verweigerten so dem lutherischen Pastor und dessen Gemeindemitgliedern das Betreten der Kirche. ${ }^{1809}$ An dieser Stelle darf nicht vergessen werden, dass Gemeindespaltungen gerade entstanden sind, weil

\footnotetext{
dem Pastor. Aber als Pastor Hägeholz den Parochialvorstand für sich beanspruchte, kam es zum Bruch mit demselben. Giurus, Crônica da Paróquia Evangélica Luterana de Indaial, S. 119f. Nach Weingärtner sollte der Pastor sich auch geweigert haben, eine Konfirmation zu vollziehen. Weingärtner, Crônica da Comunidade Evangélica de Timbó, S. 42.

1805 Weingärtner, História da Comunidade Evangélica de Timbó, S. $114 \mathrm{f}$.

1806 Giurus, Crônica da Paróquia Evangélica Luterana de Indaial, S. 122. Nach Prien sollte der evangelische Pastor Ziegel der Gemeinde empfohlen haben, sich an den Gotteskastenverein zu wenden, Prien, S. 177.

1807 Weingärtner, História da Comunidade Evangélica de Timbó, S. 236f, $255 f$.

${ }^{1808}$ Lutherische Kirche in Brasilien, S. 215.

${ }^{1809}$ Lutherische Kirche in Brasilien, S. 47f.
} 
die verschiedenen Gemeindemitglieder mal ein engeres, mal ein distanzierteres Verhältnis mit dem Pastor pflegten, regelmäßig oder eher selten von ihm besucht wurden, mehr oder weniger aktiv am Gemeindeleben teilnahmen und unterschiedliche Meinungen zu den Funktionen eines Pastors hatten. Geistliche konnten fast eine autokratische Stellung in vielen Gemeinden übernehmen. Sie waren nicht nur als Seelsorger, Prediger und Lehrer tätig, sondern wurden, wie bereits gesehen, in Notfällen auch als Arzt, Berater und Vermittler in Konfliktsituationen beansprucht. ${ }^{1810}$ Dementsprechend erhöhte sich ihre Machtstellung. Je nach ihren eigenen Vorstellungen und Erwartungen waren die Gemeindemitglieder entweder enttäuscht oder zufrieden. Wenn einige von ihnen aus persönlichen Gründen beispielsweise aufgrund eines Konflikts mit dem Pastor, der Verweigerung, eine Amtshandlung zu vollziehen, des Widerstands gegen ein angeblich autoritäres Verhalten usw. - sich von der ursprünglichen Gemeinde abwandten und einen anderen Geistlichen suchten, hielten wiederum andere, ebenfalls aus persönlichen Gründen - dem Freundschaftsverhältnis, der Dankbarkeit für eine geleistete Hilfe, dem Respekt gegenüber der Figur des Pastors - treu zu ihm. Auf diese Weise spielten die unterschiedlichen Wahrnehmungen und die Eigeninteressen eine groBe Rolle bei Gemeindespaltungen.

Auch der Loslösungsprozess von Zweiggemeinden, die sich durch die Ausdehnung der Kolonien und den Zuzug neuer Siedler teilweise deutlich vergrößerten, gestaltete sich schwierig. Hier kommt der Interessenkonflikt zwischen Gemeindemitgliedern untereinander und zwischen ihnen und ihrem Pastor zum Ausdruck. Als Grundlage diente der Wunsch nach regelmäßiger Betreuung. Inselstraße (SC) beispielsweise bat 1862 den Pastor von Joinville (SC) um die Vollziehung monatlicher Gottesdienste. Er weigerte sich und erklärte, nur zwei Gottesdienste im Jahre vollziehen zu können, denn sonst würden alle Straßen der Kolonie diese Begünstigung verlangen und die Kirche in Joinville (SC) bliebe leer. Sein Verhalten bildete die Grundlage dafür, dass Inselstraße (SC) sich von Joinville (SC) unabhängig erklärte und einen eigenen Pastor berief. ${ }^{1811}$ Gemeindemitglieder von Joinville (SC) waren darüber jahrelang gekränkt und als Pastor Heinrich Kötter 1895, ohne den Gemeindevorstand von Joinville (SC) zu fragen, die Vertretung in Inselstraße (SC) übernahm, protestierte der Kirchenvorstand dagegen, obwohl zu einem früheren Zeitpunkt der Pastor von Inselstraße (SC) in einer Notsituation auch die Vertretung von Joinville (SC) übernommen hatte. Das löste auch einen Konflikt zwischen Geistlichem und der Gemeinde aus, wonach der Pastor letztlich seine Stelle aufgab. ${ }^{1812}$ So wird deutlich, dass auch Gemeindemitglieder, besonders Kirchenvorsteher, sich dem Geistlichen gegenüber autoritär verhielten.

1810 Siehe Kapitel III, Abschnitte 2.2. und 3.1.

1811 Wüstner, S. 18; Lutherische Kirche in Brasilien, S. 28.

1812 Bühler, Fritz. Ein Beitrag zur Kirchenkunde Südamerikas. [1917/1918], S. 38-40, MLV 51/17 108; Wüstner, S 29f. 
Ein Teil einer Gemeinde erklärte sich manchmal mit der Loslösung nicht einverstanden oder wurde dadurch benachteiligt. Als Indaial (SC) sich 1889 von Blumenau (SC) trennte, schlossen sich die Bewohner von Carijós, heute ein Stadtviertel von Indaial (SC), aus geographischen Gründen - der Itajaí-Açu-Fluss - der Gemeinde Badenfurt (SC) an, die sich bereits 1884 von Blumenau (SC) losgesagt hatte. Beide Gemeinden (Indaial und Carijós) errichteten ihre eigenen Kirchen, die sozusagen nur durch den Fluss getrennt waren. Gemeindemitglieder von Palmeira Santa Joana (ES), die von Jequitibá (ES) betreut wurden, sollten sich der Gemeinde São João de Petrópolis (ES) anschließen, die bereits einen eigenen Berliner Pfarrer berufen hatte. Sie fühlten sich aber dadurch in ihren Interessen benachteiligt. Ihre Gegenvorschläge blieben unbeantwortet und sie lehnten den Anschluss letztlich ab. Weil der evangelische Pastor in Jequitibá (ES) diese Mitglieder auch nicht mehr betreute, blieben sie von Mitte 1899 bis Ende 1900 ohne geistliche Führung und erhielten auf ihre Bitten keine Antwort, weder vom Oberkirchenrat, noch aus Basel. Es ist zu vermuten, dass beide Instanzen auf eine Versöhnung hofften und keinen Geistlichen gesandt haben, weil die kleine Gemeinde angeblich noch nicht in der Lage war, ihn selbst zu besolden. Inzwischen trat auch die Gemeinde 25 de Julho (ES) in Konflikt mit evangelischen Pastoren, denn diese wollten ihnen auch den Anschluss an São João de Petrópolis (ES) aufzwingen. Palmeira de Santa Joana (ES) und 25 de Julho (ES) wandten sich an das Predigerseminar Kropp und erhielten 1901 dann den lutherischen Pastor Peter. ${ }^{1813}$ Geistliche der anderen Konfession nutzten auf diese Weise den Interessenkonflikt zwischen Gemeindemitgliedern, um sich in bestimmten Gebieten zu etablieren und bald mehrere Kollegen zu Zweiggemeinden zu berufen, die sich verselbstständigen wollten.

Ältere Gemeinden versuchten die Einheit eines Pfarrbezirkes so lang wie möglich zu erhalten, weswegen sie teilweise bewusst die Gründung von Zweiggemeinden und selbstständigen Pfarrbezirken verhinderten, denn die Autonomie einer Gemeinde bedeutete schließlich den Austritt von Kirchenmitgliedern, die bis dahin für die Erhaltung des Pfarrsitzes mitverantwortlich waren. Als Jequitibá (ES) sich von Santa Leopoldina (ES) trennen wollte, beriefen die Kirchenmitglieder Pastor Schäfer aus Santa Isabel-Campinho (ES) zum Geistlichen. Pastor Neudörffer aus Santa Leopoldina (ES) war damit nicht einverstanden und beschwerte sich bei den kirchlichen Instanzen in Basel, was zur Folge hatte, dass Pastor Schäffer nach vier Monate Aufenthalt in der Gemeinde wieder nach Deutschland zurückkehren musste. ${ }^{1814}$ Die Quellen geben keine weitere Auskunft über diese Maßnahme, aber vermutlich wollte die Basler Missionsgesellschaft einen Konflikt zwischen ihren Missionaren und Geistlichen des Oberkirchenrats vermeiden. Zudem begann sie sich zu dieser Zeit von Brasilien zurückzuziehen. ${ }^{1815}$ Die Situation verschlimmerte sich als Pastor Neudörffer eine neue Kapelle zwischen

\footnotetext{
1813 Krause, Lutherische Synode in Brasilien, S. 105-108; vgl. Lutherische Kirche in Brasilien, S. 174. 1814 Dedekind, 75 Jahre deutsch-evangelischer Diasporaarbeit, S. 84; Gaede, S. 60.

1815 Siehe Kapitel IV, Abschnitt 1.
} 
Santa Leopoldina (ES) und Jequitibá (ES) errichten ließ, was die neue Gemeinde Jequitibá (ES) in ihrem Aufbauprozess schwächte. Mithilfe eines Katholiken schrieben die Gemeindemitglieder von Jequitibá (ES) einen Brief an Pastor Dr. Rotermund aus der Riograndenser Synode und baten um die Entsendung eines Geistlichen aus Barmen. So kam Pastor Friedrich Mühlinghaus 1881 nach Jequitibá (ES). ${ }^{1816}$ Jequitibá (ES) erschwerte wiederum die Unabhängigkeitsbestrebungen von Santa Maria de Jetibá (ES). Die Konflikte zwischen Haupt- und Zweiggemeinde begannen bereits mit dem Kapellenbau in Santa Maria de Jetibá (ES). Die Hauptgemeinde Jequitibá (ES) wollte, dass Santa Maria de Jetibá (ES) nur eine Schul-, aber nicht Kapellengemeinde werden sollte. Letztlich beschloss die Hauptgemeinde, dass in Santa Maria de Jetibá (ES) zwei jährliche Gottesdienste abgehalten werden durften, unter der Bedingung, dass sie sich nicht von der Hauptgemeinde trennte. ${ }^{1817}$ Die Vollziehung von Trauungen in der Kapelle von Santa Maria de Jetibá (ES) und der Antrag auf Befreiung von Gebühren für Kirche und Schule wurde abgelehnt. ${ }^{1818}$ Als der evangelische Pastor sich weigerte, ein Brautpaar aus Santa Maria de Jetibá (ES) zu trauen, das zu diesem Anlass aus Jequitibá (ES) kommen musste ${ }^{1819}$, wandte sich die Gemeinde an den lutherischen Pastor Peter aus Palmeira de Santa Joana (ES). Er sorgte für die Entsendung des lutherischen Pastors Wrede nach Santa Maria de Jetibá (ES). ${ }^{1820}$ Anhand dieser beiden Beispiele kann sowohl der Interessenkonflikt zwischen Haupt- und Zweiggemeinden, die sich entweder für die finanzielle Absicherung des Pfarrsitzes oder für eine bessere kirchliche Betreuung einsetzten, als auch der Widerstand mancher Gemeindemitglieder und Zweiggemeinden gegen autoritäre Beschlüsse der Hauptgemeinde oder des Geistlichen beobachtet werden.

Der finanzielle Faktor spielte eine große Rolle bei der Spaltung von Gemeinden oder Übertritten zu einer anderen Synode. Oft schlossen sich Gemeindemitglieder derjenigen Gemeinde an, die den niedrigsten Beitrag für die Aufrechterhaltung der Kirchengemeinde verlangte. ${ }^{1821}$ Nach Rölke wurde diese Praxis von den Berliner Pastoren akzeptiert ${ }^{1822}$, obwohl sie in der Regel den lutherischen Pastoren vorgeworfen wurde. Als die Zweiggemeinde Itoupava-Massaranduba (SC) sich

\footnotetext{
1816 Gaede, S. 60f.

${ }^{1817}$ Lutherische Kirche in Brasilien, S. 174.

1818 Die Gemeindemitglieder in Santa Maria de Jetibá (ES) mussten denselben Beitrag wie in Jequitibá (ES) zahlen, obwohl sie nicht regelmäßig kirchlich betreut werden konnten, dazu 8 Milréis für jede Pfarrreise nach Santa Maria de Jetibá (ES); obwohl die dortigen Familien ihre beiden Kapellen selbst aufbauen mussten, sollten sie sich an den Kosten für die Errichtung kirchlicher Gebäude in Jequitibá (ES) beteiligen. Der Gegenvorschlag aus Santa Maria de Jetibá (ES), 600 Milréis für die Vollziehung monatlicher Gottesdienste in ihrer Gemeinde zu zahlen, wurde von Jequitibá (ES) abgelehnt. Gaede, S. 111. Burger berichtet aber, dass Jequitibá (ES) Santa Maria de Jetibá (ES) bei der Errichtung einer ihren Kapellen half. Lutherische Kirche in Brasilien, S. 224.

${ }^{1819}$ Droogers, S. 21.

${ }^{1820}$ Lutherische Kirche in Brasilien, S. 174f; Schröder, Brasilien und Wittenberg, S. 332.

1821 Giurus, Crônica da Paróquia Evangélica Luterana de Indaial, S. 116, $137 f$.

1822 Rölke, Die Gotteskastenarbeit im Staat Espírito Santo, S. 83.
} 
von Blumenau (SC) trennte, suchte sie sich beispielsweise einen lutherischen Pfarrer, weil ihr die Gehaltsforderungen eines evangelischen Geistlichen des Oberkirchenrates zu hoch waren. ${ }^{1823}$ Auch in Lagoa Serra Pellada (ES) konnten sich die Gemeindemitglieder nicht über die Kosten und Regularien für die Errichtung einer unabhängigen Gemeinde einigen. Ein Teil schloss sich der Gemeinde Laranja da Terra (ES) an, während der andere einen eigenen Predigtplatz errichtete. ${ }^{1824}$

Diejenigen, die sich von ihrer Hauptgemeinde trennten, beanspruchten, wie erwartet, weiterhin die Nutzungsrechte an den in Zusammenarbeit errichteten kirchlichen Gebäuden. Die Konflikte wurden immer massiver und einige landeten letztlich vor Gericht. Das geschah beispielsweise bei einem Teil der evangelischen Mitglieder aus Rio Claro (ES), der sich an den lutherischen Pastor Wrede gewandt und sich Santa Maria de Jetibá (ES) angeschlossen hatte. Daraufhin erklärte die evangelische Gemeinde Jequitibá (ES), dass der abtrünnige Teil nun nicht mehr in der Schule seine Gottesdienste feiern dürfe. Die Sache wurde vor den Richter in Porto do Cachoeiro (ES) gebracht. ${ }^{1825}$ In Itoupava (SC) untersagte der evangelische Teil dem lutherischen die Benutzung der Kirche, der daraufhin 1908 eine eigene Kirche einweihen musste. ${ }^{1826}$ Ausgetretene Gemeindemitglieder in Três Pontões (ES), die sich der Missourisynode zuwandten, bemächtigten sich der ortsansässigen Kirche ${ }^{1827}$ und in Santa Clara (RS) eskalierten die Konflikte zwischen Kirchenmitgliedern der Riograndenser Synode und der Missourisynode so sehr, dass Missourianer die Kirche besetzten. Sie wurde danach in Brand gesetzt. ${ }^{1828}$

Die Entscheidung über den Ort für den Bau von Pfarrhäusern, Schulen und Kirchen und der Disput über die Höhe der Beiträge zur Deckung der Baukosten lösten weitere Konflikte und Spaltungen aus. Hintergrund hierfür war der Wunsch, die Kirche und den Pfarrsitz möglichst in der eigenen Nähe zu haben, aber auch Zahlungsunwilligkeit. In Ijuí (RS) konnten sich die Bewohner der Linie 8 nicht über den Bau eines Pfarrsitzes auf dem Marktplatz einigen und engagierten deshalb einen eigenen Pastor. ${ }^{1829}$ Gemeindemitglieder aus Palmeira de Santa Joana

\footnotetext{
1823 Krause, Lutherische Synode in Brasilien, S. 84.

1824 Damitz, Entwicklungsaspekte zur Situation der Brasilianer, S. 25.

1825 Dieser beschloss, dass alle Gemeindemitglieder, die für den Erwerb des Grundstückes und Bau des Schulgebäudes beitrugen, dasselbe Nutzungsrecht hatten. Schreiben von Pastor Wrede an Stirner vom 21.11.1904 bzw. 15.11.1905. Zitiert nach Krause, Lutherische Synode in Brasilien, S. 115f; siehe auch das Beispiel von Cresciuma (ES) und ihrer abgerissenen Kapelle, die wieder aufgebaut werden musste, Lutherische Kirche in Brasilien, S. 216f.

1826 Evangelische Synode von Santa Catarina und Paraná, S. 72; Lutherische Kirche in Brasilien, S. 88f, 92. In Itoupava Rega (SC) nutzten beide Bevölkerungsteile zunächst zusammen die Schule, die auch als Gottesdienstort diente. Aber als sich der Konflikt zwischen den evangelischen und lutherischen Mitgliedern 1910 verschärfte, baute der lutherische Teil seine eigene Kirche.

${ }^{1827}$ Rölke, Die Gotteskastenarbeit im Staat Espírito Santo, S. 85.

1828 Evangelischer Gemeinde-Kalender, 1922, S. 73. Zitiert nach Willems, S. 340.

${ }^{1829}$ Halle, G. Kurze Geschichte der deutsch-evangelisch-lutherischen Gemeinde zu Ijuhy, S. 6f, AHI, SR 83/25. Ähnliches geschah in Jequitibá, Gaede, S. 59f, in Alto California (ES), Ebd., S. 57, in Katharinenstraße (SC), Lutherische Kirche in Brasilien, S. 53f und in Santa Isabel (SC), Stoer, S. $15 f$.
} 
(ES) stritten über die Auszahlung der vereinbarten Summe an den Baumeister für die Errichtung des Tempels, später auch wegen Renovierungsarbeiten. ${ }^{1830}$ In Jaraguá do Sul (SC) konnten sich die Zweiggemeinden Rio da Luz-Vitória (SC) und Rio da Luz II (SC) 1929 nicht über den Bau einer gemeinsamen Kirche einigen und errichtete letztlich jeder ein eigenes Gotteshaus. ${ }^{1831}$

Konflikte zwischen evangelischen und lutherischen Gemeinden kamen in Rio Grande do Sul nicht vor, weil hier keine Pastoren aus dem Gotteskastenverein tätig waren. Hier entstanden die Spaltungen aufgrund des Konflikts zwischen evangelischen Geistlichen und Kolonistenpastoren. Letztere vollzogen, wie schon beschrieben, dieselben Handlungen wie ordinierte Geistliche angesichts des Pfarrermangels und arbeiteten für geringere Löhne. In den vielen Jahren des Pfarrermangels begnügten sich die Gemeindemitglieder aber mit ihnen. Zudem kamen Kolonistenpastoren auch dem Wunsch einiger Gemeindemitglieder nach, sich keiner staatlichen und institutionellen Kirche anzuschließen, denn diese hatte ihnen bereits in der Heimat einen unierten Glauben aufzwingen wollen. ${ }^{1832}$ Hees sieht in dem Gesetz von 1863, das die Registrierung von protestantischen Geistlichen reglementierte, ohne einen Beleg für eine kirchliche Ordination und theologische Ausbildung zu fordern, die Grundlage für die Entwicklung des Kolonistenpfarrertums in Rio Grande do Sul. ${ }^{1833}$ Damit die von den Kolonistenpastoren eingesegneten Ehen vom Staate anerkannt werden konnten, wurden sie auf Antrag des Gemeindevorstandes als Pfarrer registriert $^{1834}$, wie es vor allem für die Kolonistenpastoren in Gemeinden der Kolonie São Lourenço do Sul (RS) belegt werden konnte. ${ }^{1835}$ Das Phänomen ist jedoch in erster Linie dem Pfarrermangel und der Entwicklung freier und selbstständiger Gemeinden zuzuordnen, weil nach Prien der Staat keinen Kolonistentfarrer als Geistlichen registrieren ließ, ohne die Gemeindeprotokolle, die die Wahl des Pastors durch die Gemeinde belegten, zu überprüfen. ${ }^{1836}$

Ordinierte Geistliche nannten die Kolonistenpfarrer in abwertender Form „Pseudopfarrer", „Privatgeistlicher“, „Berufsgeistlicher"1837 - beziehungsweise die keiner Landes-

\footnotetext{
${ }^{1830}$ Lutherische Kirche in Brasilien, S. 186f.

1831 Wilbert et. al., S. 101f. Das geschah auch in Cresciuma-Guandu (ES), Lutherische Kirche in Brasilien, S. 210-212.

1832 Nach Rieht steht die Entstehung von Freigemeinden in Zusammenhang mit der Unionskirche in Preußen, welche Altlutheraner und Mitglieder von Erweckungsgruppen verfolgte. Rieht, S. 209; vgl. Clemens, Lieselotte. Die Auswanderung der pommerschen Altlutheraner in die USA. Hamburg: Pommerscher Zentralverband, 1976, S. 16-32. Auch Kapitel II, Abschnitt 2.2.

1833 Hees, Pastorado e Pastores, S. 22. Über den Protest der Riograndenser Synode gegen die Registrierung von Kolonistenpastoren siehe Brief an den würdigen Vertretern der Nation, 30.5.1885, EZA 5/2157; Brief des Vorstandsrats der Riograndenser Synode an den Vertretern der Nation, São Leopoldo, 1.7.1886, AHI, SR 1/3, Beilage 072 .

1834 Anhang. Brasilianische Correspondenz des Dr. Rotermund, S. 43f, EZA 200/1/2151.

1835 Antrag an den Provinzpräsidenten von 26.5.1863. Zitiert nach Bosenbecker, S. 52; Oswald, S. 571 f.

1836 Prien, S. 74.

1837 Sudhaus, Paul. Vergessene dentsche Glaubensbrüder. Hamburg, 1903, S. 7, EZA 200/1/5807.
} 
kirche oder kirchlichen Synode angehörten, sondern privat und ohne irgendein kirchliches und theologisches Examen von den Gemeinden angestellt wurden „gemachte Pfarrers"1838 und „Schnapspfarrer".1839 Ihrer Ansicht nach wurden sie nicht mehr benötigt, da die „wahren Geistlicher"1840 angekommen waren. Sie wurden auch weitaus negativer dargestellt, als dubiose, gescheiterte, ,fahnenflïchtig gewordenen und kassierte Offiziere“" Ungebildete, den Süchten ergebene und „nichtswürdige Subjekte“, die mit der Übernahme von pfarramtlichen Pflichten nur ihren Lebensunterhalt sichern wollten. ${ }^{1841}$ Einige wurden aber als treue Männer angesehen, die als „Hauspriester" und „Nothelfer der Kirche“ das Wort verkündeten und die Sakramente darreichten. ${ }^{1842}$

Der Grund für die abwertende Bezeichnung und den Konflikt mit Kolonistenpastoren liegt darin, dass sie keine theologische Bildung und kirchliche Ordination besaßen und weil sie dieses Amt unabhängig ausübten, ohne einer kirchlichen Organisation unterstellt zu sein. Dadurch gefährdeten sie die Gründung und Existenz kirchlicher Synoden in Brasilien. ${ }^{1843}$ Im Grunde ging es hier auch um den Konflikt zwischen den verschiedenen Auffassungen über die kirchliche Betreuung und Organisation des Kirchenwesens. Allmählich erkannten die ordinierten Pfarrer aber, dass den Kolonistempastoren die Entstehung und der Fortbestand vieler evangelischer Gemeinden zu verdanken war. ${ }^{1844}$ Doch trotz des geistlichen Notstandes vieler „Seelen, die um ibr Heil besorgt sind und nach der Predigt des Wortes Gottes sehnsüchtig verlangen, die aber keine Möglichkeit haben, eine Predigt zu hören oder das Sacrament zu empfangen" "845, gab es kein Bestreben einer Zusammenarbeit oder der Ausbildung von Kolonistenpastoren für den Einsatz in entlegenen Gebieten. Als Pastor Borchard 1866 die erste Kirche auf dem Marktplatz von Nova Petrópolis (RS) einweihte, forderte er, die Kirche solle nur von einem ordinierten Pastor geöffnet werden. Weil dort ein Kolonistenpfarrer tätig war, sollte nun ein Pfarrer aus den benachbarten Kolonien alle zwei Monate die Gemeinde betreuen. Ob diese Forderung auch eingehalten wurde, kann nicht belegt werden, denn mit der Ankunft des ersten Geistlichen 1868, Pastor Hunsche, wurde sie nur viermal im Jahr besucht. ${ }^{1846}$

\footnotetext{
1838 Prien, S. 73.

1839 Anhang. Brasilianische Correspondenz Dr. Rotermund, S. 43f, EZA 200/1/2151; Dedekind, Brasilien, S. 43.

1840 Rieth, S. 210.

1841 Sudhaus, Paul. Vergessene deutsche Glaubensbrüder. Hamburg, 1903, S. 7, EZA 200/1/5807;

Dedekind, Brasilien, S. 44; Dedekind, 75 Jahre deutsch-evangelischer Diasporaarbeit, S. 21.

1842 Dedekind, 75 Jahre deutsch-evangelischer Diasporaarbeit, S. 21.

1843 Witt, S. 62.

1844 Anhang. Brasilianische Correspondenz des Dr. Rotermund, S. 45f, EZA 200/1/2151; vgl. Granzow, Pommeranos unter dem Kreuz des Südens, S. 154.

1845 7. Bericht des Comités für die protestantischen Deutschen in Südamerika, Pastor Borchard, 1878. Zitiert nach Schröder, Brasilien und Wittenberg, S. 87.

1846 Schröder, Brasilien und Wittenberg, S. 87.
} 
Eine Trennung fand statt, als einige Gemeindemitglieder dem ordinierten Pastor folgten, weil er gebildet war und von der deutschen Kirche anerkannt wurde, und der andere Gemeindeteil dem Kolonistenpfarrer treu blieb, weil er bis dahin loyal und zu einem geringen Lohn arbeitete. Falls der ordinierte Pastor sich aus irgendeinem Grund weigerte, eine kirchliche Amtshandlung zu vollziehen, gingen Gemeindemitglieder einfach zum Kolonistenpastor, der ihrem Anliegen ohne Rücksicht auf Gemeindestatuten oder kirchliche Vorschriften entgegen kam. ${ }^{1847}$ Daraus bildeten sich letztendlich Freigemeinden und die Evangelisch-lutherischen Freikirchen, die sich keiner Synode anschlossen und ihre Unabhängigkeit und Selbstständigkeit behielten, wie es der Fall 1863 in Mühlenpikade (RS), 1868 in Harmonia II (RS) und 1883 in Gusmão (RS) war, alles Zweiggemeinden der Kolonie São Lourenço do Sul (RS). Hier konnten Gemeindemitglieder ihre evangelisch-lutherische Religiosität, die auch magische Elemente enthielt, in der Regel ohne Missbilligung der Geistlichen praktizieren. ${ }^{1848}$

Es sollte nicht vergessen werden, dass ab 1927 Missionare der Gnadauer Mission und ab 1932 Marbuger Missionare nach Brasilien kamen. Ende 1926 schrieb Frau Johanna Michel-Lörcher aus Mato Preto-São Bento do Sul (SC) an Direktor Burkhardt vom Johanneum. Sie stellte die schlechte geistliche Situation der Einwanderer in Südbrasilien dar und bat um die Entsendung eines Missionars. Der Gnadauer Verband sandte darauf den Missionar Alfred Pfeiffer 1927 nach Brasilien, der seitdem Andachten, Kinder-, Gemeinschafts- und Bibelstunden in Blumenau (SC), Timbó (SC) ${ }^{1849}$, Benedito Novo (SC), Jaraguá do Sul (SC), Joinville (SC), Itajaí (SC), Hansa Hammonia (heute Ibirama) (SC), Taió (SC), Rio das Antas (SC), Südarm (heute Rio do Sul) (SC) und in Curitiba (PR) vollzog. 1956 reiste auch ein Missionar nach Ijuí (RS). Die Gnadauer Mission verstand sich aber nicht als Kirche, wollte weder einen kirchlichen Gemeinschaftsverband noch eine Kirche bilden, sondern erkannte die Synoden als kirchliche Organisationen im Sinne einer deutschen Landeskirche an. ${ }^{1850}$ Am 16. November 1936 gründete die Gnadauer Mission

\footnotetext{
1847 Laut Schulze verdeutlichte der Konflikt zwischen ihnen auch, wie gefährlich die Kolonistenpastoren für das kirchliche Deutschtumsprojekt waren. Schulze, S. 320.

1848 Oswald, S. 576. Erst später schlossen sich viele Mitglieder oder ganze Freigemeinden entweder der Evangelischen Kirche Lutherischen Bekenntnisses in Brasilien oder an die Missourianer beziehungsweise Evangelisch-Lutherische Kirche Brasiliens durch die sogenannte "Aktion Präsident Wischmann" an. Damit wollte die Evangelische Kirche Lutherischen Bekenntnisses in Brasilien die Kirchenmitglieder, die sie aufgrund des Pfarrermangels verloren hatte, wiedergewinnen. Diese Aktion bekam finanzielle Unterstützung vom Außenamt der Evangelischen Kirche Deutschlands. Hees, Ulrich. Metamorfoses de uma Igreja de Emigrantes. In: Fischer, Joachim (Hrsg.) Ensaios Luteranos, São Leopoldo: Sinodal, 1986, S. 84. Andere, besonders im Süden von Rio Grande do Sul, schlossen sich der Evangelischen Kongregationskirche Brasiliens an, Dreher, História do Povo Luterano, S. 54. Bis heute gibt es aber immer noch Freigemeinden.

1849 In Timbó (SC) schlossen sich Gemeindemitglieder 1941 an die Gnadauer Gemeinschaftsbewegung an. Weingärtner, Crônica da Comunidade Evangélica de Timbó, S. 88.

1850 Schmidt, Norbert. Von der Evangelisation zur Kirchengründung. Marburg an der Lahn: Francke, 1991, S. $244 f$.
} 
einen Verband, den Markusverein, der aber aufgrund der Nationalisierungsgesetze aufgelöst und durch die Sociedade União Cristã (Gesellschaft der christlichen Gemeinschaft) ersetzt wurde. ${ }^{1851}$

1932 kamen auch die Marburger Missionare Jesse und Melzer in die Kolonie Rio Avaí (PR). 1934 reiste Jesse im Auftrag der Leitung der Deutschen GemeinschaftsDiakonieverbandes nach General Osório (heute Ibirubá) (RS) und knüpfte Kontakte in Ijuí (RS), wo pommersche Familien wohnten und wohin er ab 1936 den Schwerpunkt seines Wirkens verlegte. Hier wurde auch 1956 die erste Station eines Gnadauer Missionars in Rio Grande do Sul eröffnet. Inzwischen kamen drei weitere Missionare nach Brasilien und 1936 reiste der erste Deutschbrasilianer, Alcides Jucksch, nach Marburg, um sich für den Missionsdienst in Brasilien ausbilden zu lassen. ${ }^{1852}$ Überall in den Häusern waren Missionare für Andachtsfeiern willkommen und bereits 1934 gründeten Marburger Missionare die Igreja de Cristianismo Decidido (Gemeinde/(Kirche) für entschiedenes Christentum). ${ }^{1853}$ Weil sie nicht als Pfarrer ordiniert waren, durften sie keine kirchlichen Amtshandlungen vollziehen, sondern mussten Gläubige bei solchen Anlässen an ordinierte Pastoren verweisen. ${ }^{1854}$ Das stellte für sie jedoch kein Problem dar, denn sie missbilligten die Vollziehung von kirchlichen Amtshandlungen ${ }^{1855}$, ein nicht unumstrittenes Thema innerhalb der Leitung des Deutschen Gemeinschafts-Diakonieverband. Dieser

1851 Schmidt, Von der Evangelisation zur Kirchengründung, S. 209-215. 1960 beschloss die Jahreshauptversammlung der Sociedade União Cristã eine einjährige Bibelschule für 14 und 15jährige Jugendliche zu errichten. Der erste Kandidat, Arthur Clebsch, kam aus Ijuí (RS). Wegen Mangel an geeigneten Mitarbeitern wurde sie 1977 geschlossen und im März 1986 als Bibelinstitut in Mato Preto-São Bento do Sul (SC) wieder eröffnet. Der Aufbau und Betrieb der Bibelschule sollte in Verbindung mit der Leitung der Evangelischen Kirche Lutherischen Bekenntnisses in Brasilien (EKLBB) erfolgen. Die Ausbildung sollte drei Jahre umfassen und zusammen mit dem Bibelinstitut das Theologische Zentrum Pbiladelphia der MEUC - Missão Evangélica União Cristã (Evangelische Mission für Christliche Gemeinschaft) bilden. 1988 wurde das Theologische Bildungszentrum gegründet. Heute bildet diese Institution (FLT-Faculdade Luterana de Teologia) eines der drei anerkannten Theologiezentren der EKLBB.

1852 Alcides Jucksch gestaltete den Missionsdienst in Brasilien nach dem Zweiten Weltkrieg. Seitdem gab der Deutsche Gemeinschafts-Diakonieverband den Marburger Missionaren freien Raum für ihre Arbeit, einschließlich des Vollzuges von kirchlichen Amtshandlungen. Schmidt, Von der Evangelisation zur Kirchengründung, S. 62, 111.

1853 Schmidt, Von der Evangelisation zur Kirchengründung, S. 57. Magalhães geht hier einer falschen Interpretation nach, als sie sagt, die Marburger Mission löste sich von der EKLBB ab. Magalhães, Pangermanismo e nazismo, S. 176.

${ }^{1854}$ Brief von Th. Krawielitzki an Th. Grischy am 31.10.1933. Zitiert nach Schmidt, Von der Evangelisation zur Kirchengründung, S. 68.

1855 Der erste Direktor der Marburger Mission riet den Missionaren in Brasilien von der Vollziehung von Amtshandlungen ab und missbilligte die Einführung des Abendmahls in den Gemeinden Curitiba (PR) und Ponta Grossa (PR). Seiner Meinung nach waren kirchliche Amtshandlungen, wie das Abendmahl und die Taufe, sinnlose und abhängig machende Rituale, die nichts mit dem wahren Glauben zu tun hatten. Wenn man den "lahmen Leuten" noch Abendmahlsfeiern einrichtete, machte man sie erst tot. Zudem habe Christus ihn nicht zu taufen, sondern um das Evangelium zu predigen gesandt. Brief Th. Krawielitzki an K. F. Hering, 2.6.1934 und 23.8.1934. Zitiert nach Schmidt, Von der Evangelisation zur Kirchengründung, S. 68f. 
wollte auch keine eigenständige Kirche gründen, sondern verstand sich als ein freies innerkirchliches Werk, unabhängig von der Jurisdiktion der offiziellen Kirche, der selbstständig in ihrem Wirkungskreis aber gleichzeitig mit ihr zusammenarbeiten wollte. ${ }^{1856}$ Am 1. August 1947 gründeten sie auch die Vereinigung der Kirchen für entschiedenes Christentum. ${ }^{1857}$

Obwohl beide Gruppen innerhalb der Synoden arbeiten wollten, ohne von ihnen eingegliedert zu werden, entstanden einige Konflikte zwischen ihnen und den ordinierten Pastoren. In den ersten Jahren arbeiteten Geistliche und Gnadauer Missionare harmonisch miteinander. Dem Missionar in São Bento do Sul (SC) boten Pastoren sogar die Übernahme einer Pfarrstelle oder eines halben Pfarramtes an, was er aber mehrmals ablehnte. ${ }^{1858}$ Aber in Blumenau (SC) fürchtete man, es könne sich eine Sekte um den Gnadauer Missionar Pfeiffer bilden. Die Auseinandersetzungen zwischen ihm und Pastor Schrerer in Blumenau (SC) führten 1930 letztendlich zur Entstehung einer freikirchlichen Versammlung beziehungsweise einer unabhängigen freien Gemeinde. ${ }^{1859}$ Das trieb den Kirchenvorstand Herr Müller-Hering dazu, einen Brief an den Evangelischen Oberkirchenrat zu schreiben. Auch Propst Funcke machte sich Sorgen, dass es zur Bildung freikirchlicher oder kirchenfeindlicher Gemeinden kommen könnte. ${ }^{1860}$ Ab 1937 entspannte sich aber die Beziehung zwischen dem Evangelischen Gemeindeverband von Santa Catarina und den Gnadauer Missionare. ${ }^{1861}$ Die Tätigkeit der Marbuger Missionare wurde von Geistlichen als Eindringen in ihre Arbeitsgebiete verstanden, obwohl noch viele Gemeinden über keinen ansässigen Pfarrer verfügten und unregelmäßig betreut wurden. Die Pfarrer wussten jedenfalls nicht, wie man mit ihnen umgehen sollte, wie das Beispiel des Pastors Burghardt aus Guarani (RS) zeigte, der sich bei dem Präsident der Riograndenser Synode, Pastor Dohms, hierzu erkundigte. 1862

Zusammenfassend lässt sich feststellen, dass das Eigeninteresse oft das Gemeinschaftsinteresse überwog und verschiedene Konzepte von Kirche und kirchlicher Betreuung aufeinanderprallten. Geistliche verschiedener Konfessionen und

1856 Schmidt, Von der Evangelisation zur Kirchengründung, S. 89f. Schwestern aus Marburg wurden auch nach Brasilien gesandt, zu einigen Gemeinden in den Staaten Paraná, Rio Grande do Sul und auch nach Brusque (SC). Sie arbeiteten aber unter der Führung der Frauenhilfe der Riograndenser Synode und der Frauenhilfe fürs Ausland. Ebd., S. 82-106.

1857 Schmidt, Von der Evangelisation zur Kirchengründung, S. 125-148.

1858 Schmidt, Von der Evangelisation zur Kirchengründung, S. 244.

${ }^{1859}$ Der Kreis, der an den Evangelisationen des Gnadauer Missionars Pfeiffer teilnahm, löste sich 1930 auf, weil dieser den Wunsch der Teilnehmer, eigene Abendmahlsfeier in der Gruppe zu vollziehen, einzuhalten versuchte. Schmidt, Von der Evangelisation zur Kirchengründung, S. 209, 257.

1860 Brief von Müller-Hering an den Evangelischen Oberkirchenrat von 29.11.1930 und Brief von Propst Funcke an den Evangelischen Oberkirchenrat von 18.12.1930, beides in EZA 5/2485.

1861 Schmidt, Von der Evangelisation zur Kirchengründung, S. 211, 247-252.

1862 Brief von Pastor Burghardt, Guarani, 28.8.1936 an Pastor Dohms und Abschrift des Briefes Nr. 2672 von Pastor Dohms an Pastor Burghardt, 28.10.1936. In: AHI SR 15/6, Beilagen 007 und 006. Vgl. mit Richtlinien der Evangelischen Kirche in Bayern bezüglich der Arbeit des Gemeinschafts-diakonieverbandes, 14.7.1924, AHI, SR 15/6, Beilage 005. 
Bildung und Kolonistenpastoren konkurrierten teilweise miteinander für die Erhaltung ihrer Pfarrstelle in Gemeinden, die noch mit vielen finanziellen Schwierigkeiten zu kämpfen hatten und deren Gemeindemitglieder bis dahin nach eigenen Alternativen für die Erhaltung ihres Gemeindewesens suchen mussten. Ihr Bestreben nach Unabhängigkeit duldete teilweise keinen Zwang einer institutionellen Kirche, von der sie sich in den ersten Siedlungsjahren im Stich gelassen gefühlt hatten. Sie strebten nach einer regelmäßigeren Pfarrbetreuung und wollten angesichts der großen Distanzen die Kirche in ihrer Nähe haben, was ihnen teilweise verweigert wurde. So suchten sie nach einer anderen Lösung, die oft zu Gemeindespaltungen und Konflikten führte. Diese erschwerten die Entwicklung von Gemeinden und Synoden, zeigen aber auch die große Bedeutung der Kirche für Einwanderer und deren Nachkommen, denn für die Unabhängigkeit von Gemeinden und die Besoldung eines eigenen Pastors mussten sie noch größere finanzielle Opfer bringen.

\subsection{Konfessionelle Streitigkeiten}

Nachdem die Untersuchung der Konflikte zwischen Mitgliedern, Gemeinden und Geistlichen verschiedener Konfession, Bildung und Herkunft abgeschlossen wurde, richtet sich der Blick nun auf Streitigkeiten mit einem konfessionellen Hintergrund. Obwohl viele Einwanderer und deren Nachkommen keine Auskunft über theologische Aspekte ihrer Konfession zu geben wussten, zeigten sich ihre unterschiedlichen konfessionellen Einstellungen spätestens mit der Kritik an Pastoren, die ihre Gottesdienste und kirchliche Amtshandlungen anders, als sie es gewöhnt waren, vollzogen. Manchmal weisen diese Konflikte auch auf die verschiedenen Formen hin, den evangelisch-unierten und evangelisch-lutherischen Glauben aufzufassen.

In den ersten Siedlungsjahren versuchten die Einwanderer, wie bereits beschrieben, sich über einen evangelischen Glauben angesichts ihres gemeinsamen Interesses für Kirche und Schule zu einigen. Die konfessionelle Orientierung der Einwanderer unterschiedlicher Herkunft würde besonders mit der Ankunft lutherischer Gotteskastenpastoren eine größere Rolle spielen. Pastor Scheerer behauptete, dass sie sich über den konfessionellen Unterschied zwischen reformierten und lutherischen Gemeinden nicht bewusst und Spaltungen innerhalb der Gemeinde ausschließlich finanzieller Natur waren. ${ }^{1863}$ Diese Ansicht sollte jedoch nicht auf diese Weise verallgemeinert werden, denn aus dem Verhalten der Gemeindemitglieder in verschiedenen Gemeinden kann auch auf andere Gründe geschlossen werden.

Gemeindemitglieder in Hansa-Hammonia (SC), die sich als Lutheraner bekannten, akzeptierten die durch Pastor Dr. Aldinger eingeführte Änderung im 5. Hauptstück des Kleinen Katechismus, „Das ist mein Leib, das für euch gegeben wird" für „Das bedeutet den Leib und Blut usw. " nicht. Dies zeigt, wie einige Gemeindemitglie-

1863 Tagebuch Nr. 157/33, Blumenau, 29.3.1933 an den Oberkirchenrat. Zitiert nach Prien, S. 244f. 
der die lutherische Lehre gut kannten und eine ihrer wichtigsten Glaubensquellen, den Kleinen Katechismus, besonders wertschätzten oder fast für heilig hielten. Immerhin handelte es sich um einen wichtigen Inhalt ihres Glaubens: die wahre Auffassung und dementsprechend den rechten Empfang des Heiligen Abendmabls. Sie lösten sich von der Gemeinde und bildeten die Evangelisch-lutherischen Kirchengemeinde Taquaras, die klare Bekenntnisgrundlagen aufwies, und erhielten einen lutherischen Pastor aus dem Gotteskastenverein. ${ }^{1864}$

In Santa Maria de Jetibá (ES) schrieben Gemeindeglieder einen Brief an die kirchlichen Instanzen und baten um die Entsendung eines Pastors mit Ausbildung in den konfessionellen Schriften der evangelisch-lutherischen Kirche. ${ }^{1865} \mathrm{Im}$ Hintergrund stand die Sorge um die Anstellung eines Geistlichen, der die Gemeinde in die evangelisch-lutherische Lehre einführen und sie dabei betreuen sollte. Bei der konstituierenden Versammlung der Evangelisch-Lutherischen Synode 1905 in Inselstraße (SC) wandte sich ein Gemeindemitglied wiederum gegen die Verwendung von lutherisch als konfessionelle Bezeichnung der Synode. Friedrich Papst, Repräsentant der Gemeinde Kilometer 21 (SC), erwiderte, dass der Beiname lutherisch angesichts der vielen "Sekten" in der Evangelischen Kirche, die den Kleinen Katechismus verwerfen, nötig sei. ${ }^{1866}$ Als Pastor Otto Kuhr sich 1898 für die Anstellung eines lutherischen Pastors für Joinville (SC) einsetzte, widersetzten sich manche Gemeindemitglieder. ${ }^{1867} 1903$ und 1904 organisierten sie sogar eine Bittschrift, um die ursprüngliche Version der Statuten wieder herzustellen, die sich gegen eine Anstellung eines Missionars aussprach, denn ihrer Ansicht widersprach ein Geistlicher ,mit der Einseitigkeit seines orthodoxen Luthertums" dem Profil der Gemeinde. Dieser Antrag wurde aber abgelehnt. ${ }^{1868}$ Auch in Indaial (SC) protestierte ein Reformierter gegen die Anstellung des lutherischen Pastors Bergold. ${ }^{1869}$ Pastor Scheerer scheint sich hingegen selbst zu widersprechen, denn später sagte er, dass sowohl die Reformierten als auch die Lutheraner in Santa Catarina ein "ausgeprägtes konfessionelles Bewußtsein“ besaßen. ${ }^{1870}$

Wie bei Hansa-Hammonia (SC), spalteten sich auch andere Gemeinden aufgrund konfessioneller Dispute. In der lutherischen Gemeinde Itoupava Rega (SC) wollten Gemeindemitglieder wie früher als evangelisch benannt werden, aber der Pastor bestand darauf, sie als lutherisch zu bezeichnen. Das stieß auf Widerstand und Pastor Roesel wurde gekündigt, akzeptierte dies jedoch nicht und wohnte weiterhin in diesem Gebiet. Als der evangelische Pastor Langbein 1906 ankam, bilde-

\footnotetext{
1864 Evangelisch-lutherisches Gemeindeblatt v. 2, Nr. 11, Mai 1907, S. 85. Zitiert nach Prien, S. 178.

${ }^{1865}$ Brief der Gemeinde Santa Maria de Jetibá von 3.10.1903 im Archiv der Parochie Santa Maria de Jetibá. Zitiert nach Gaede, S. 116.

1866 Krause, Lutherische Synode in Brasilien, S. 123.

1867 Wüstner, S. 42f.

1868 Krause, Lutherische Synode in Brasilien, S. 75f.

${ }^{1869}$ Krause, Lutherische Synode in Brasilien, S. 87.

${ }^{1870}$ Funcke. Verhandlungen mit Pastor Scheerer/Blumenau am 11.9.1933 und folgende Tage.

EZA 5/2463, zitiert nach Prien, S. 481.
} 
ten sich, mit Ausnahme von Luiz Alves (SC), Spaltungen in allen Zweiggemeinden, wobei ein Teil dem lutherischen Pastor Roesel treu blieb, während der andere den evangelischen Pastor Langbein annahm. ${ }^{1871}$ Das persönliche Verhältnis zwischen Gemeindemitgliedern und ihren Geistlichen, das im oberen Abschnitt beschrieben wurde, spielte hier vermutlich auch eine wichtige Rolle.

Der Umgang mit pommerschen Einwanderern und deren Nachkommen war bezüglich ererbter Traditionen und kirchlich-liturgischer Handlungen oft schwierig. ${ }^{1872}$ Sie hielten starr an ihren ,pommerschen Glauben “ fest ${ }^{1873}$, an „starren Formen des kirchlichen Lebens mit pietätvoll gewahrten Zeremonien" 1874 und an ,hergebrachten Überlieferungen " 1875 Sie mussten mit Geduld geführt werden, denn ,im Guten laesst sich vieles bei ihm [der Pommer] erreichen, im Boesen nichts. Zwang laesst er sich nicht gefallen. Dagegen protestiert er tatkraeftig “1876 Darin sah Pastor Schlünzen jedoch etwas Positives, denn sie prüften alles und wenn das Ergebnis der Prüfung nach ihrem Maßstab, den sie an Gotteswort maßen, positiv ausfiel, hielt ihre Treue allen Umständen stand. ${ }^{1877}$ Einige Beispiele sollen dies verdeutlichen.

In Barra do Cresciuma (ES) ärgerten sich pommersche Gemeindemitglieder, weil der Pastor in der Schlussliturgie das Gebet zum Altar hin sprach. Einer von ihnen redete mit dem Pastor und erklärte, dass er deswegen mit weiteren 42 Familienmitgliedern beziehungsweise der Hälfte der Gemeinde austreten würde. ${ }^{1878}$ Auch in Indaial (SC) nahmen einige Anstoß daran, dass der lutherische Pastor sich bei Gebeten zum Altar hin wandte, wo sonst alle evangelischen Geistlichen, gemäß ihrer Agenda, zur Gemeinde hin gewandt sprachen. Einige sahen darin eine Extravaganz oder etwas „Katholisches“, ein Reformierter protestierte, dieses Verhalten der lutherischen Pastoren spräche für eine Verehrung des Kruzifixes und ging nicht mehr zur Kirche. ${ }^{1879}$ In São Domingos-São Lourenço do Sul (RS) verwendete der Pastor die württembergische statt der ,pommerschen Liturgie" bei Taufen und Beerdigungen. Die Gemeindemitglieder waren der Meinung, „Der neue Pfarrer kann seine Sache nicht".1880 Laut Pastor Sudhaus aus São Lourenço do Sul (RS) hatte der Pastor, "der-abgesehen von anderen Amtshandlungen- noch nicht eine Beerdigung secundum ritum

1871 Schröder, Brasilien und Wittenberg, S. 278; Evangelische Synode von Santa Catarina und Paraná, S. $72,74$.

1872 Müller, Hermannsburger in Lateinamerika, S. 28.

1873 Dedekind, Brasilien, S. 49.

1874 Schröder, Brasilien und Wittenberg, S. $164 \mathrm{f}$.

1875 Brief von Pastor Schröder an Propst Hübbe, Blumenau 2.6.1926, EZA 5/2535.

1876 Jahresbericht von Pastor Friege an das Kirchliche Außenamt, 10.7.1937, EZA 5/2535.

1877 Schlünzen, F. Deutsche in Brasilien. Neuendettelsau: Freimund, 1936, S. 27, MEW 3.16.

1878 Brief von Pastor Erich Fischer, Barra do Crisciuma, 28.4.1931; Brief von Pastor Erich Fischer an das Missionshaus, Barra do Crisciuma 29.4.1931, MLV 51/17 67; auch MEW 4.178.

1879 Krause, Lutherische Synode in Brasilien, S. 88. Dieselbe Beschwerde taucht selbst nach der Fusion des Vereins Evangelischer Gemeinden von Santa Catarina und Paraná mit der Evangelisch-Lutherischen Synode 1962 auf. Baade, Os conflitos comunitários e sinodais, S. $295 \mathrm{f}$.

1880 Schröder, Brasilien und Wittenberg, S. 163. 
Pommeranum vollzogen hat", seine Prüfung durch die Gemeinde nicht bestanden. 1881 Deutschrussen in Linie 8-Ijuí (RS), unter ihnen auch Pommern, wünschten sich die Verwendung ihrer alten Gottesdienstordnung. Dabei stießen sie auf Widerstand von Siedlern älterer Kolonien, die wiederum nach der Ordnung, die sich dort eingebürgert hatte, Gottesdienst feiern wollten. ${ }^{1882}$ Der Basler Pastor Reuther berichtet demgegenüber über Konfessionsstreitigkeiten zwischen strengen Lutheranern und Calvinisten in Rio Novo (ES). Die Lutheraner verlangten die Einführung einer altlutherischen Gottesdienstordnung, bei welcher unter anderem bei der Taufe das Kreuzzeichen über den Kindern zu machen war. ${ }^{1883}$ Merkwürdig war das Verhalten des lutherischen Pastors Hugo Hedrich. Er empfahl Schweizer Familien, die dort bis 1909 von evangelischen Pastoren aus Basel oder Berlin betreut wurden, zu einem presbyterianischen Geistlichen zu gehen ${ }^{1884}$, vermutlich, weil die Streitigkeiten sonst kein Ende fanden. Hier widerspiegelt sich der konfessionelle Unterschied zwischen Evangelisch-Unierten und Altutheranern, der auch in Brasilien unter den Pommern vorhanden war: Die Mehrheit von ihnen nahm die evangelische beziehungsweise unierte Agenda an und tolerierte bestimmte Besonderheiten der lutherischen Liturgie nicht. Altlutheraner wiederum verlangten die Vollziehung von Amtshandlungen nach der altlutherischen Liturgie.

Pommersche Einwanderer und deren Nachkommen waren sich ihres lutherischen oder evangelischen Glaubens in anderem Maße als die Geistlichen bewusst. Einige protestierten gegen Abweichungen, die nicht ihrer konfessionellen Ansicht entsprachen oder gegen das autoritäre Verhalten mancher Geistlicher, die ihnen ihre eigene Konfession aufzwingen wollten. Zudem sollte die schon erwähnte Differenzierung zwischen den drei verschiedenen Frömmigkeitsformen unter den Pommern und deren Nachkommen nicht vergessen werden. Diejenigen, die in der Heimat zu Altlutheranern oder zu Erweckungsgruppen gehörten, identifizierten sich in der Regel mit den lutherischen Gotteskastenpastoren und setzten sich für die Bewahrung eines ,reinen Luthertums" ein. Die Mehrheit nahm die Union an und bezeichnete sich als „Evangelisch". Sie hatten, wie auch andere Reformierte, Schwierigkeiten mit dem liturgischen Verhalten lutherischer Pastoren, weil sie an eine evangelische Agenda gewöhnt waren. Andere begnügten sich mit vereinzelten Gottesdiensten und der Durchführung von kirchlichen Amtshandlungen und nahmen an konfessionellen Diskussionen gar nicht teil. Jedenfalls kann nicht von einer allgemeinen konfessionellen Unkenntnis oder einem Mangel an konfessionellem Bewusstsein die Rede sein. Die konfessionelle Orientierung der pommerschen Ein-

\footnotetext{
1881 Sudhaus, Paul. Vergessene deutsche Glaubensbrüder. Hamburg, September 1903, S. 5, EZA 200/1/5807. Hervorhebung P. S.

1882 Halle, G. Kurze Geschichte der deutsch-evangelisch-lutherischen Gemeinde zu Ijuby, S. 6f, AHI, SR 83/25.

1883 Brief von Pastor Reuther an Weitbrecht, Santa Leopoldina, 2.1.1865, BMA, FB, 1,1.

1884 Brief von Pastor Hugo Hedrich an den presbyterianischen Rev. Alvaro Reis, Domingos Martins, 4.8.1909, transkribiert durch Pastor Samuel Barbosa In: Traços Históricos. Quelle, die durch Idalto Scheidegger Stauffer 2003 zur Verfügung gestellt wurde. Zitiert nach Rölke, Raízes da Imigração alemã, S. 472, 559-561.
} 
wanderer und deren Nachkommen in Brasilien entsprach vielleicht nicht rein dogmatischen und doktrinären Aspekten, wurde aber besonders in liturgischen Angelegenheiten deutlich. 


\section{V - Im Zeichen des Nationalismus}

Die Einwanderer und deren Nachkommen hatten für die Bildung eines eigenen Umfelds gesorgt. Angesichts der Isolierung in den meisten Siedlungsgebieten, gefördert durch die Deutschtumspflege, die durch die deutsche Kirche, Schulen, Vereine und Presse vermittelt wurde, sonderten sie sich teilweise ethnisch, sprachlich und religiös von der brasilianischen Gesellschaft ab. Im ökonomischen, unternehmerischen, politischen und sozialen Bereich sehnten sie sich nach Integration, wollten aber gleichzeitig die Bindung an ihre kulturellen Wurzeln nicht verlieren. Weil Brasilien im Ersten sowie im Zweiten Weltkrieg Deutschland den Krieg erklärte, aber auch im Zuge einer nationalistischen Bewegung in Brasilien wurden sie in ihren Institutionen und auf dem ökonomischen Sektor eingeschränkt und aufgrund ihrer Sympathie für Deutschland, den Nationalsozialismus oder den brasilianischen Integralismus, aber auch aufgrund der Verwendung der deutschen Sprache, verfolgt und inhaftiert. Wie sie darauf reagierten, in ihrem Glauben wieder Durchhaltensvermögen und Bewältigungskraft fanden und das kirchliche Leben so weit wie ihnen möglich, erhielten, soll im folgenden Kapitel betrachtet werden. 


\section{Ethnische und Deutschtumsproblematik}

Bevor auf die Schwierigkeiten während der Kriegs- und Nationalisierungszeit eingegangen wird, soll zunächst die ethnische Problematik der Einwanderer und deren Nachkommen in Brasilien betrachtet werden. Dafür ist ein zeitlicher Sprung in die ersten Siedlungsjahre nötig, um das Phänomen in seiner Komplexität zu verstehen. Die Immigrationspolitik Brasiliens hatte wesentlich zur ethnischen und kulturellen Abgrenzung zwischen Einwanderern und einheimischer Bevölkerung beigetragen. Der stärkere Zuzug neuer Einwanderungswellen in Zusammenhang mit ihrer geographischen Isolierung, der Vernachlässigung durch den brasilianischen Staat bei der Errichtung eines Schulwesens, dem Aufbau einer eigenen Umwelt und der Ankunft deutscher Pfarrer, Lehrer, Ärzte, Unternehmer und Intellektueller, die nach der Vereinigung Deutschlands 1871 und besonders nach 1890 über stärkere nationalistische Denkensweisen verfügten, verringerte die Bedeutung einer Assimilation ${ }^{1885}$ mit den Brasilianern. Einwanderer und deren Nachkommen erlebten für mehrere Generationen einen Konflikt zwischen zwei Nationen, Kulturen und Identitäten.

Anders, als oft hervorgehoben wird, litten nicht alle Einwanderer unter Heimweh. ${ }^{1886}$ Die bedrückenden Lebensbedingungen, die sie in der alten Heimat erlebt hatten, waren ihnen oft noch präsent und obwohl die Bedingungen in den brasilianischen Kolonien sie häufig enttäuschten und ihnen Schwierigkeiten bereiteten, waren sie in der Regel zufrieden mit den sich ihnen bietenden Aufstiegsmöglichkeiten. Ihre Sehnsucht und ihr Heimatgefühl richteten sich vielmehr auf das ursprüngliche Heimatdorf, die hinterlassene Familie, Bekannte und Nachbarn und auf Sitten und Gebräuche, nicht jedoch auf ein nationales Territorium ${ }^{1887}$, wobei

\footnotetext{
1885 Assimilation bedeutet hier die allmähliche Veränderung der Gefühle und Attitüden eines Menschen aufgrund seiner Sesshaftigkeit und Partizipation in einer fremden Kultur. Der Mensch verliert allmählich die Erinnerungen, Traditionen und persönlichen Beziehungen zum Herkunftsort und übernimmt Normen, Ideale und Glauben einer neuen Kultur. Die allmähliche und in ihrem größten Teil unbewusste Traditionsveränderung und -loyalität umfasst die Essenz der persönlichen Assimilation. Reuter, Edward B. The American Race Problem, Study of the Negro. New York, 1937. Zitiert nach Willems, S. 25.

1886 Erdheim spricht von einem Verhältnis voller Widersprüche zur ursprünglichen Heimat und Kultur bei Migranten. Einerseits versuchen sie aufgrund schlechter wirtschaftlicher Bedingungen oder Bedrohungen, ein neues Leben in einem neuen Land zu beginnen. Andererseits sind sie in der ursprünglichen Kultur aufgewachsen. Der Kulturschock in der Fremde bringt diese Strukturen durcheinander und sie versuchen dieses Chaos zu überwinden, indem sie bewusst auf alte Grundmuster zurückgreifen und die kollektive Identität betonen. Erdheim, Mario. Parentifizierung und Trauma. In: Psychosozial, Nr. 103, 29. Jg., Heft 1, S. 23. Zitiert nach Kustor-Hüttl, S. 46. Wenn Migranten der ersten Generation sich oft besser als jüngeren Generationen anpassen können, wird von einem „Migrantenparadox" gesprochen. Masten, Ann S. Resilienæ: Modelle, Fakten \& Neurobiologie. Paderborn: Junfermann, 2016, S. 234.

1887 Willems, S. 31; vgl. Erinnerungen eines deutschen Ansiedlers in Brasilien. In: Sonntagsblatt für die evangelischen Gemeinden in Brasilien. Nr. 40, 12. Jahrgang, 1899, S. 158, AHI; Funke, Alfred, Brasilien im 20. Jahrbundert. Berlin, 1927, S. 342. Zitiert nach Willems, S. 151.
} 
diese Gefühle später für die Verbreitung deutschtümlicher Gedanken missbraucht werden würden. Deutschland umfasste einen geographischen Begriff, den viele von ihnen kaum mit Inhalt zu füllen wussten und der allmählich in Vergessenheit geriet. ${ }^{1888}$ Sie wussten, wo ihre Vorfahren drüben wohnten, aber selbst der Kontakt mit Verwandten und Bekannten brach bald ab. ${ }^{1889}$

Eine Assimilation zwischen Einwanderern und der brasilianischen Bevölkerung scheiterte, weil die brasilianische Regierung Immigranten als Mittel für den Rückzug von indigenen Völkern und gegen Afrobrasilianer in ihrer rassistischen Weißelungspolitik benutzte. ${ }^{1890}$ Außerdem wurden indigene Völker, Afrobrasilianer, „Caboclos" und „Mulatos" von Einwanderern sowie von Lusobrasilianern als minderwertig, faul und gefährlich angesehen und für „Wilde" (indigene Völker) und Sklaven (Afrobrasilianer) gehalten. Einwanderer wurden dagegen für ihre Arbeitseffizienz und ihre Tugenden hoch geschätzt. ${ }^{1891}$ In den südlichen Staaten kämpften Lusobrasilianer wiederum jahrelang um Ländereien, die jedoch den Einwanderern billig verkauft wurden. Nicht-Einwanderer erwarben selten ein Grundstück in diesen Gebieten und es war ihnen in Regierungskolonien sogar verboten. ${ }^{1892}$ So wurden Einwanderer von den Einheimischen als Eindringlinge wahrgenommen. Und weil Einwanderer als Bauern eingesetzt wurden, galten sie für die lusobrasilianische Elite materialistischen und positivistischen Charakters als Bürger zweiter Klasse, denn diese Arbeit leisteten vormals meistens Sklaven. ${ }^{1893}$ Auch die Einschränkung politischer Rechte für Einwanderer und ihr Misstrauen gegenüber brasilianischen Beamten erschwerten das Verhältnis zwischen beiden Seiten. Angesichts der kulturellen Spannung und Diskriminierung zwischen verschiedenen Ethnien wurde eine ethnische Mischung abgelehnt. ${ }^{1894}$

\footnotetext{
1888 Pottast-Hubold, S. 19.

1889 Grothe, S. 41.

1890 Rieth, S. 209. Dazu siehe Kapitel II, Abschnitt 5.2.

${ }^{1891}$ Ihnen wurden Fleiß, Ordnungsliebe, Treue, Gründlichkeit, Friedfertigkeit, Sparsamkeit, Sauberkeit, Ernst, Pflichtgefühl, Ehrlichkeit, Zuverlässigkeit, Beharrlichkeit, Zucht und Arbeitsamkeit zugesprochen. Den Brasilianern wurden Trägheit, Unreinlichkeit, Unpünktlichkeit, Selbstüberschätzung, Oberflächlichkeit, Gesetzlosigkeit, ausschweifendes Leben und Arbeitsscheue zugeschrieben. Schulze, S. 134-137, 162f; vgl. Seyferth, Nacionalismo e identidade étnica, S. 159-163.

1892 Bosenbecker, S. 131. Das Kolonisationsgesetz regelte 1907 die Konzession von höchstens 10\% der Ländereien in Kolonisationsgebiete für „Einheimische“. Dressel, Heinz. A Igreja Evangélica face ao desafio brasileiro. In: Fischer, Joachim (Hrsg.) Ensaios Luteranos. São Leopoldo: Sinodal, 1986, S. $114 f$.

1893 Koseritz, Carl von. Das deutsche Element in der Provinz Rio Grande do Sul. In: Koseritz deutscher Volkskalender, 1879. Zitiert nach Willems, S. 140f.

1894 Seyferth, Nacionalismo e identidade étnica, S. 148. Laut Erdheim grenzen sich Einwanderer generell von der einheimischen Bevölkerung ab, weil ihre Erfahrungen über Erlebnisse und Erinnerungen von denjenigen, die kein ähnliches Schicksal erlebt haben, nicht verstanden werden können. Erdheim, Mario. Parentifizierung und Trauma. In: Psychosozial, Nr. 103, 29. Jg., Heft 1, S. 23. Zitiert nach Kustor-Hüttl, S. 43. In Anlehnung an Kustor-Hüttl (Kustor-Hüttl, S. 39), die über die Übertragung von emotional unbewältigten Lebensthemen und traumatischen Ereignisse von den Eltern an
} 
An dieser Stelle ist zu betonen, dass Deutschtum in dieser Arbeit, in Anlehnung an Seyferth, die ethnische Ideologie der deutschbrasilianischen Gemeinschaft in Brasilien umfasst. Sie basiert auf einer gemeinsamen Herkunft und Abstammung und auf einem gemeinsamen kulturellen Erbe, übernimmt aber meist unbewusst auch Kriterien des deutschen Nationalismus. In diesem Sinne handelt es sich um eine nationalistische Ideologie, die aber in der neuen Heimat auf differenzierte Weise aufgenommen und somit schlicht als ethnische Ideologie verstanden wurde. ${ }^{1895}$

Obwohl besonders die ländliche Bevölkerung ihre Sitten, Bräuche, Kultur, Sprache und Religion pflegte, engagierte sie sich nicht für ihre systematische und bewusste Bewahrung im Sinne einer Deutschtumskultur. ${ }^{1896}$ Deutsch und Pommerisch galten als ländliche Sprachen und Deutsch war die verständlichste und am häufigste repräsentierte Kommunikationssprache unter Einwanderern verschiedener Herkunft. ${ }^{1897}$ Außerdem übernahmen Einwanderer von Anfang an Vokabeln, Bräuche, Sitten, Verhaltensweisen, Methoden, Techniken und Werte von der Aufnahmegesellschaft und verloren bestimmte Kenntnisse aus der alten Heimat, die nun nicht mehr umgesetzt werden konnten. ${ }^{1898}$ Die Gleichstellung der deutschen Sprache mit der Deutschtumspflege in den ersten Siedlungsjahren ist laut Prien ein Irrtum. ${ }^{1899}$ Der deutschen Sprache wurde von Einwanderern und deren Nachkommen vielmehr ein symbolischer Charakter zugesprochen und umfasste ethnische wie religiöse Werte. Die Bibel, der Kleine Katechismus, Andachts-, Gebets-, und Gesangbücher, Himmelsbriefe, Haussprüche und Besprechungsformeln ${ }^{1900}$ waren auf Deutsch geschrieben. Deutsch war auch die Sprache des Reformators Martin

die nächste Generation spricht, kann festgestellt werden, dass ethnische Diskriminierungen von der ersten auf die nächsten pommerschen Generationen in Brasilien übertragen wurden.

1895 Seyferth, Nacionalismo e identidade étnica, S. 3f.

1896 Gertz, O fascismo no sul do Brasil, S. 101, 109.

${ }^{1897}$ Lutherische Kirche in Brasilien, S. 20.

1898 Willems, S. 107, 156-167. Boss spricht über ,dialektisches Denken“", wenn Menschen in der Fremde mehrere Identitäten annehmen müssen. „Die Entwurzelten“ "halten an einigen Lebensweisen aus ihrer ursprünglichen Heimat fest und übernehmen zugleich neue Lebensweisen der neuen Umwelt. Kontinuität und Wechsel fügen sich zusammen. Boss, Pauline. Verlust, Trauma und Resilienz. Stuttgart: Klett-Cotta, 2008, S. 174.

1899 Prien, S. 28.

1900 Besprechungsformeln wurden in der Regel auf Hochdeutsch geschrieben und kopiert, so besprachen die Pommern hauptsächlich auf Hochdeutsch. Einige aber, die die Formeln auswendig gelernt hatten, besprachen auf Pommerisch. Siehe Interviews mit pommerschen Nachkommen in Seibel, Imigrante no século do isolamento, S. 347, 349. Pommerisch ist eine niedersächsische Sprache, die in den Tieflandgebieten des Baltischen Meeres gesprochen wurde. Im 12. Jahrhundert wurde sie mit deutschen Bauern nach Pommern gebracht und um 1400 bildete sie die Hauptsprache im Land. Ab der Reformation wurde das Hochdeutsch in Schule, Kirche und öffentlichen Bereich eingeführt, obwohl das Pommerisch weiterhin in informellen Kreisen in Gebrauch stand. Der Status einer internationalen Handelssprache verlor das Pommerisch im 16. und 17. Jahrhundert, als die Macht des hanseatischen Bundes sank. Seitdem wurde es als Dialekt behandelt. Tressmann, Ismael. O Pomerano: uma língua baixo-saxônica. In: Revista da Farese, V. 1, Nr. 1, jul./nov. 2008. Santa Maria de Jetibá: Faculdade da Região Serrana, S. 10-21. 
Luther, was ihr den Charakter einer heiligen Sprache verlieh, als „Sprache des religiösen Lebens".1901 Luther übersetzte die Bibel auf Deutsch und setzte somit die Grundlage des Neuhochdeutschen. Die Entstehung des „neuen Glaubens“ in Zusammenhang mit einer „neuen Sprache“ bekam für orthodoxe Protestanten eine religiöse Bedeutung, denn sie wurde sozusagen heilig geboren und repräsentierte die Vermittlung heiliger Worte. ${ }^{1902}$ Zudem lernten Pommern Pommerisch und Deutsch gewöhnlich durch Auswendiglernen von Gebeten und aus Gesangbuchliedern. Nach Schlünzen formulierten sie ihre Gedanken durch die Worte der Bibel, des Kleinen Katechismus und des Gesangbuches, die ihnen einfach, klar, stark und populär sowie in unerreichbarem Maße gemütstief waren. ${ }^{1903}$ Als der ,persönlichste Umgang des Menschen mit Gott" 1904 sprachen sie ihr Gebet in ihrer Muttersprache, denn Menschen beten entsprechend ihrer kulturellen und religiösen Identität. ${ }^{1905}$

Die Bedeutung der deutschen Sprache als heilige Sprache kann auch am Beispiel der Freigemeinden betrachtet werden. Dort wurden nach Aussagen pommerscher Nachkommen Pastoren nach zwei Kriterien ausgewählt: Aufgrund ihres moralischen Verhaltens und der Beherrschung der heiligen beziehungsweise der deutschen Sprache. ${ }^{1906}$ Sie galt als „Kirchensprache“ oder „Gottesdienstsprache“, auch wenn sie nicht mehr vollkommen verstanden wurde. Das pommersche Platt schien den Pommern und deren Nachkommen laut Granzow einen niedrigeren Rang zu besitzen, denn es galt als ,gewöhnlich und hinterwäldlerisch“. Deswegen musste der Pastor auf Deutsch predigen. ${ }^{1907}$ Auch wenn die Hervorhebung des Hochdeutschen als Kirchensprache in Verbindung mit der Kirchenpolitik der Synoden stand ${ }^{1908}$, wurde dies von den Gemeindemitgliedern aufgrund der sakralen Bedeutung innerhalb ihrer Kultur und Religion ebenso gesehen. ${ }^{1909}$

\footnotetext{
1901 Schlünzen, F. Deutsche in Brasilien. Neuendettelsau: Freimund, 1936, S. 26, MEW 3.16.

1902 Willems, S. 350f; Bahia, S. 42.

${ }^{1903}$ Schlünzen, F. Deutsche in Brasilien. Neuendettelsau: Freimund, 1936, S. 26, MEW 3.16.

1904 Bölitz. Zitiert nach Schlünzen, F. Deutsche in Brasilien. Neuendettelsau: Freimund, 1936, S. 24,

MEW 3.16.

1905 Boss, S. 192.

1906 Maltzahn, S. 87.

1907 Granzow, Pommeranos unter dem Kreuz des Südens, S. 129.

1908 Potthast-Hubold, S. 22f.

${ }^{1909}$ Es muss an dieser Stelle ein Unterschied zwischen geschriebener und gesprochener Sprache gemacht werden. Das gesprochene und mündlich überlieferte Pommerisch war die alltägliche Kommunikationssprache im Familien- und Nachbarschaftskreis. Hochdeutsch und Portugiesisch genossen ein höheres Ansehen und galten vor allem als Schriftsprachen. Die schlechten Schulbedingungen lösten aber allmählich einen Verlust des Hochdeutschen unter Einwanderern und deren Nachkommen aus, wobei es für mittelschichtige und wohlhabende Familien zum differenzierten Merkmal wurde. Das war besonders im Staat Espírito Santo der Fall, denn während in pommersche Siedlungsgebiete in den Staaten Rio Grande do Sul und Santa Catarina mehr oder weniger ununterbrochen neue Einwanderer siedelten, die unter anderem zur Bewahrung der deutschen Sprache beitrugen, stagnierte die Einwanderung in Espírito Santo nach 1875 fast gänzlich, so dass jüngere Generationen fast ausschließlich in der pommerschen Mundart kommunizierten. Das gesprochene Deutsch der unteren
} 
Auch wenn die Einwanderer zunächst praktisches Interesse an der Erlernung der Landessprache hatten, um beispielsweise Produkte auf dem Markt zu verkaufen ${ }^{1910}$ oder um sich sozial höher zu stellen ${ }^{1911}$, verlor die Verwendung der Landessprache mit dem Zuzug neuer Einwanderer ab der Hälfte des 19. Jahrhunderts und der konsequenten Vermehrung der Anzahl deutschsprachiger Gebiete zunehmend an Bedeutung. Es kam zur Gründung deutscher Geschäftshäuser in den Kolonien, so dass die Unkenntnis der Landessprache kein Problem mehr für ökonomische Beziehungen darstellte. Mit dem stärkeren Einwanderungszuzug in den letzten Dekaden des 19. Jahrhunderts, in Verbindung mit der Entstehung des Deutschen Reichs 1871, was zum Wachstum deutsch-nationalistischer Gefühle führte, und mit der Tätigkeit kirchlicher Missionsvereine, die im nationalen Sinne Kirchen und Schulen in Brasilien finanziell unterstützte, verbreitete sich auch unter den alten Einwanderern und deren Nachkommen die Ideologie einer nationalen Identität, des Deutschtums und der ethnischen Vortrefflichkeit der Deutschen. ${ }^{1912}$ Vor allem die nach 1848 ausgewanderten Liberalen begrüßten diese Unifikation $^{1913}$, viele freuten sich über den deutschen Sieg im deutschfranzösischen Krieg (1870-1871) und versuchten, an Informationen über hinterbliebene Verwandte heranzukommen. ${ }^{1914}$ Das Deutsche Reich gewährte den Einwanderern in Brasilien zwischen 1893 bis 1913 zudem das Recht, die deutsche

Schichten übernahm aber überall verschiedene Laut- und grammatische Merkmale der Landessprache sowie Begriffe anderer ethnischen Gruppen. So entwickelten die Einwanderer und deren Nachkommen eine deutschbrasilianische Sprache, die ein Deutscher sowie ein Brasilianer zunächst schwierig verstehen konnten. Dressel, S. 115; Willems, S. 197, 121-123; Seyferth, Nacionalismo e identidade étnica, S. 128f. Selbst die Aufnahmegesellschaft assimilierte die Sprache der Einwanderer und integrierte sie in deren Erbe. Dies traf besonders für Ehegatten (Willems, S. 196f, 215), aber auch Sklaven von Einwanderern (Von Tschudi, Reisen durch Süd-Amerika, 4. Band, S. 27; Willems, S. 215, 248), indigene Völker, Afrobrasilianer oder „Mestiços" zu, die mit Einwanderer und deren Nachkommen sozialisiert oder von ihnen adoptiert wurden (Gertz, O fascismo no sul do Brasil, S. 69; Kuehne, João. Colonização alemã no Brasil. In: Delegacia de ordem política e social de Santa Catarina. O punhal nažista no coração do Brasil. Florianópolis: Imprensa Oficial do Estado, 1944, S. 116; Schlünzen, F. Deutsche in Brasilien. Neuendettelsau: Freimund, 1936, S. 14, MEW 3.16; Granzow, Pommeranos unter dem Kreuz des Südens, S. 103). Sobald sie ihre Sprache, Kultur und Religion assimilierten, wurden sie in der ethnischen Gruppe integriert.

1910 Alle Kolonisten in Santa Isabel (SC) sollen die Landessprache mehr oder weniger beherrscht haben. Von Tschudi, Reisen durch Süd-Amerika, 3. Band, S. 407. In São Leopoldo (RS) konnte auch die Mehrheit der Siedler Portugiesisch sprechen, aber sie taten dies nur, wenn sie mit Brasilianern verhandeln mussten. Von Tschudi, Reisen durch Süd-Amerika, 4. Band, S. 32.

1911 Willems, S. 106.

1912 Perazzo, Priscila Ferreira. O Perigo Alemão e a Repressão Policial no Estado Novo. São Paulo: Divisão de Arquivo do Estado, 1999, S. 57.

1913 In Porto Alegre (RS) wurde sie groß gefeiert. Schulze, S. 145.

1914 Wüstner, S. 21f; in manchen Gemeinden wurden Feier für den deutschen Sieg veranstaltet. Dreher, Igreja e Germanidade, S. 63, 75. 
Staatsangehörigkeit zu behalten ${ }^{1915}$, was das Gefühl einer deutsch-ethnischen Zusammenzugehörigkeit unter ihnen stärkte. ${ }^{1916}$

Die Evangelische Kirche in Deutschland folgte zu dieser Zeit den Interessen des Deutschen Reiches. Deutsche Geistliche in der Diaspora förderten das Deutschtum und sahen sich als Träger des deutschen Christentums und der deutschen Zivilisation. ${ }^{1917}$ Besonders Geistliche mit akademischer Bildung ${ }^{1918}$, aber auch die Evangelische Gesellschaft für die Protestanten in Amerika, vor allem als Dedekind 1908 die Leitung dort übernahm, brachten den evangelischen Glauben mit der Deutschtumspflege in Verbindung. „Deutschtum und Evangelium sind auf Leben und Tod miteinander verbunden" "1919, schrieb Pastor Dr. Rotermund. So wurden ethnische Einwanderergruppe mit der religiösen Gemeinschaft gleichgestellt, manchmal übertrafen nationale und ethnische Aspekte sogar die Bedeutung des kirchlichen Dienstes und es bestand die Gefahr, dass der Diasporadienst als ,ethnische Assistenz."verstanden werden konnte. ${ }^{1920}$ Missionare des Gotteskastenvereins wiesen dagegen zunächst keinen bewussten Nationalismus auf. ${ }^{1921}$ Nach Pastor Fugmann stellte die lutherische Kirche das „Bekenntnis über Nationalität und Sprache“ und wenn Nachkommen kein Deutsch mehr beherrschten, solle man in der ihnen gewohnten Sprache predigen. ${ }^{1922}$ Im Grunde jedoch herrschten differenzierte Meinungen zu diesem Thema. Es gab Pastoren mit akademischer Bildung, die sich gegen die gezielte Bewahrung des Deutschtums in brasilianischen Gemeinden aussprachen und für den kirchlichen Dienst bei anderen Ethnien kritisiert wurden, während

\footnotetext{
1915 Magalhães, Pangermanismo e nazismo, S. 111f.

1916 Bürger, Brasilien, S. 378, 380. Bilder des deutschen Kaisers erschienen in der deutschbrasilianischen Presse und deutsch-nationale Jahrestage dienten zur Stärkung des Gruppengefühls einer bürgerlichen Elite, die sich in Vereinen traf und feierte. Schulze, S. 145. Auch Geistliche fügten die Feiern von Geburtstagen oder Sterbensgedenktage der deutschen Kaiser in die Liturgie mit ein. So wurden die deutschen Kaiser verehrt. Prien, S. 353; Dreher, Igreja e Germanidade, S. 75; Stoer, S. 12.

1917 Droogers, S. 24, 29.

1918 Dreher, Igreja e Germanidade, S. 20.

1919 Krause, Lutherische Synode in Brasilien, S. 296.

1920 Dreher, Igreja e Germanidade, S. 101-104, 108. Obwohl Brasilianer manche Reiseprediger beherbergten, an protestantischen Gottesdiensten teilnahmen und sogar ihre Kinder evangelisch taufen ließen, Witt, S. 120-129, verstanden die deutschen Geistlichen ihre Aufgabe in der Regel als Mission unter Deutschen oder Deutschstämmigen. Ihre Zurückhaltung muss aber in Zusammenhang mit dem Konflikt zwischen Protestanten und Jesuiten, den religiösen Einschränkungen für Protestanten vor der Ausrufung der Republik 1889, dem ausgedehnten Arbeitsfeld und dem Mangel an finanziellen Ressourcen betrachtet werden. Nach 1889 änderte sich die Situation aber auch nicht gravierend. 1937 schlugen einige synodale Vorstandsmitglieder vor, Kirchenmitglieder, die kein Deutsch mehr beherrschten, in andere brasilianischen Kirchen, die unter anderem durch die Aktivität nordamerikanischer Missionare entstanden, zu schicken. Protokoll der 9. Ordentlichen Versammlung der Mittelbrasilianischen Synode in Rio de Janeiro vom 19.-22.1.1937. Zitiert nach Butzke, Paulo Afonso. Ernesto T. Schlieper: Teologia e Edificação de Comunidade na IECLB do Pós-Guerra. In: Estudos Teológicos, v. 49, Nr. 2-Jul./dez. 2009, São Leopoldo, S. 258.

1921 Prien, S. 154.

1922 Schreiben Fugmanns an das Hilfewerk des Lutherischen Gotteskasten, 15.4.1931. Zitiert nach Krause, Lutherische Synode in Brasilien, S. 225.
} 
einige Pfarrer des Gotteskastenvereins wiederum die Deutschtumsideologie vertraten. Laut Pastor Bestmann zum Beispiel konnten die Ausgewanderten nicht vor dem Ansässigwerden in Brasilien bewahrt werden, aber sie blieben weiterhin „Glieder des deutschen Volkes" und das "nur durch Festhaltung des lutherischen Glaubens, der deutschen Treue, deutscher Sprache und Sitte".1923

Ab 1924 war ein Anschluss der evangelischen Kirchen im Ausland an den 1922 gegründeten Deutschen Evangelischen Kirchenbund möglich. Zunächst schloss sich ihm die Riograndenser Synode 1929 an, 1933 die Evangelisch-Lutherischen Synode. ${ }^{1924}$ Der Verein Evangelischer Gemeinden von Santa Catarina und Paraná und die Mittelbrasilianische Synode wollten ebenfalls dem Bund beitreten, aber die langen Verhandlungen und die Ereignisse um 1933 unterbrachen diesen Prozess. Sie blieben an den Evangelischen Oberkirchenrat gebunden und wurden ab 1936 vom Außenamt der Deutschen Evangelischen Kirche übernommen. Weil 1933 der Kirchenbund die Deutsche Evangelische Kirche integrierte, wurden die ihm angeschlossenen Synoden 1934 dem Außenamt unterworfen. So waren die vier Synoden in Brasilien der Deutschen Evangelische Kirche angegliedert. ${ }^{1925}$ Ebenso wie der Evangelische Oberkirchenrat und der Deutsche Evangelische Kirchenbund übte auch das Außenamt einen ideologischen Einfluss auf die Kirchenarbeit in Brasilien aus. Die Deutschtumsfrage erhielt immer mehr Bedeutung unter evangelischen sowie lutherischen Geistlichen und Gemeinden und das konfessionelle Bewusstsein rückte an zweite Stelle. Die Assoziation des Deutschtums mit dem Protestantismus, selbst seitens der Brasilianer ${ }^{1926}$, trug letztendlich dazu bei, eine Assimilation der deutschsprachigen Siedler zu verhindern. ${ }^{1927}$

Inwieweit Kirchenmitglieder sich aber von der ideologischen Indoktrination beeinflussen ließen ist schwer zu sagen. Nach Dreher zogen sie keine bewusste Verbindung zwischen Deutschtum und Kirche. Die Gemeinden zeichneten sich durch ihre Unabhängigkeit aus, konnten Geistliche jederzeit entlassen und der

1923 Bestmann, H. J. Die kirchliche Not der deutschen Lutheraner in Südamerika. S. 16 Zitiert nach Krause, Lutherische Synode in Brasilien, S. 48.

1924 Der Anschluss der Evangelisch-Lutherischen Synode an den Deutschen Evangelischen Kirchenbund geschah erst nach vielen Spannungen zwischen dem Deutsch-Evangelischen Kirchenbund und den MartinLuther Bund, internen Spannungen in der Evangelisch-Lutherischen Synode selbst und zwischen dem Martin-Luther-Bund und der Evangelisch-Lutherischen Synode. Dazu Prien, S. 245-258; Krause, Lutherische Synode in Brasilien, S. 206-242; Dreher, Igreja e Germanidade, S. 177-207.

1925 Dreher, Igreja e Germanidade, S. 218-221.

1926 Dreher, Igreja e Germanidade, S. 19; Prien, S. 27. Bahia weist darauf hin, dass Vorstellungen einer gemeinsamen Herkunft und Abstammung wichtige Elemente darstellen, auf die Menschen erneut zurückgreifen, um eine bestimmte ethnische Identität oder kollektive Religion zu formulieren. Wenn ein Glaube als Besonderheit bestimmter sozialen Gruppen verstanden wird, wird er als einen zugeordneten und angemessenen Glauben für oder von einer ethnischen Gemeinde definiert. Der Eintritt in diese Religion wird dann von den vorhandenen sozialen Beziehungen, die auf Blut, Verwandtschaft, Herkunft und Geburt basieren, abhängig gemacht, was die Besonderheit der religiösen Gemeinde erhöht. Ethnische und religiöse Identität waren unter Einwanderern und deren Nachkommen gegenseitig konsolidiert und voneinander abhängig. Bahia, S. 374-376.

1927 Willems, S. 122. 
Anschluss an die preußische Kirche löste Kritik gegen Deutschland aus. Die Gemeinden fürchteten den Verlust ihrer Autonomie für den „preußischen Helm " und wollten ihre Verbindung mit der neuen Heimat demonstrieren. ${ }^{1928}$ Zudem spielte die Entsendung von Pastoren und die finanzielle Unterstützung seitens kirchlicher Organisationen bei der Bewahrung des Deutschtums eine sekundäre Rolle. Ab 1900 konnte sogar ein bewussterer Brasilianismus in manchen Gemeinden festgestellt werden, besonders in städtischen Gebieten. Nach einer Reise durch die deutschen evangelischen Gemeinden in Brasilien berichtete Probst Martin Braunschweig, dass einige Gemeinden Pastoren bevorzugten, die auch die Landessprache beherrschten. ${ }^{1929}$ In manchen Gebieten, wie in Santo Ângelo (RS) um $1903^{1930}$ und in Três Forquilhas (RS) um 19011931, wurden bereits portugiesische Gottesdienste vollzogen. Ein deutscher Schuldirektor bedauerte, dass der ,deutsche Nationalstolz. " in São Lourenço do Sul (RS) verginge und klagte über die „Entdeutschung"1932 unter den Siedlern. Viele Geistliche, wie Probst Funcke1933 und Pastor Max Dedekind ${ }^{1934}$, beschwerten sich über den Verlust des Deutschtums und den Einfluss der Brasilianer beziehungsweise über die „,Verbrasilianisierung "1935 der Kirchenmitglieder, trotz ihrer Arbeit zur Bewahrung des Deutschtums. Sie beklagten, dass viele Familien aus „Nachlässigkeit, Stumpfsinn und Bequemlichkeit"1936 kein Deutsch mehr sprachen und ihre Kinder in staatliche statt in deutsche Schulen schickten, worauf einige Eltern erwiderten, „Wir sind in Brasilien“ oder „Wir sind Brasilianer".1937 Wer sich ethnisch vermischte, sich seines Deutschtums schämte oder sich am brasilianischen Staatsleben beteiligte wurde in einigen Fällen aus der kirchlichen Gemeinschaft ausgeschlossen und als „Renegate "1938 und „Deutsch-

\footnotetext{
1928 Dreher, Igreja e Germanidade, S. 100f.

1929 Bericht von Probst Braunschweig in Leipzig über seine Reise durch die deutschen evangelischen Gemeinden in Brasilien im Jahre 1907, S. 49. Zitiert nach Dreher, Igreja e Germanidade, S. 100.

1930 Witt, S. 116.

1931 Dreher, Igreja e Germanidade, S. 61.

1932 Köbling, Fritz. Die Kolonie São Lourenço im Staate Rio Grande do Sul. In: Deutsche Post Nr. 3355, São Leopoldo, 18.11.1908, EZA 121/19; vgl. mit dem Bericht von Lacmann, Wilhelm. Ritte und Rasttage in Südbrasilien. Berlin, 1906, S. 156. Zitiert nach Willems, S. 143; vgl. Gertz, O fascismo no sul do Brasil, S. 101f.

1933 Brief von Funcke an den Deutschen Evangelischen Kirchenausschusses, Porto Alegre, 13.5.1932. Anlage: Kirche und Deutschtum. Vortrag, gehalten auf die Synodaltagung der Deutschen Ev. Kirche von Rio Grande do Sul, S. 16. Zitiert nach Schulze, S. 276.

1934 Dedekind, Max. Deutsch-evangelische Sorgen in Brasilien. In: Der Deutsche Ansiedler, N. 67, 5/6, S. 6. Zitiert nach Schulze, S. 278.

1935 Schulze, S. 275.

1936 Ammon, Wolfgang. Weltwert der deutschen Sprache. In: Deutsche Post, 25.2.1925, S. 1. Zitiert nach Schulze, S. 277.

1937 Schulze, S. 275-279; Der Kompass, Ano 1937, Nr. 25; Bund der Deutschen Vereine (Hrsg.) Hundert Jahre Deutschtum in Rio Grande do Sul, Porto Alegre, 1924, S. 59f. Zitiert nach Willems, S. $292 \mathrm{f}$.

1938 Sonntagsblatt für die evangelischen Gemeinden in Brasilien, Nr. 26, 1891, S. 8. Zitiert nach Dreher, Igreja e Germanidade, S. 99f; Gertz, O fascismo no sul do Brasil, S. 109.
} 
tumsverächter"'1939 bezeichnet. Die Deutschtumsakteure waren der Ansicht, dass durch Mischehen und durch eine katholische Erziehung der Kinder der „deutsche Charakter der Familie" unfehlbar verloren ginge. Die entschiedene Beteiligung am brasilianischen Staatswesen wiederum führe ihrer Meinung nach dazu, dass die Deutschbrasilianer sich nicht mehr mit dem Deutschtum identifizieren. ${ }^{1940}$ Nur wenige Geistliche, wie Ernst August Kunert und Friedrich Wüstner, erkannten die Notwendigkeit des Erlernens der Landessprache für die kirchliche Mission und kritisierten die starke Betonung der nationalen Identität vonseiten der Deutschen. Der kirchliche Dienst sollte keine nationalistische Gestalt haben. ${ }^{1941}$

Laut Oberacker überwogen bei der Mehrheit der Einwanderer und deren Nachkommen ökonomische Interessen über die der Ethnie und der Zugehörigkeit zu einer deutschen Gemeinschaft. ${ }^{1942}$ Die Versuche, sie für das Deutschtum zu gewinnen ${ }^{1943}$, hatten zwar manchmal Erfolg, scheiterten jedoch bald an dem Desinteresse, „Deutsch zu sein“ oder „Deutsch zu bleiben“. Die liberale und intellektuelle deutschbrasilianische Elite, sowie neue Einwanderer, die nach 1890 emigrierten, bezeichneten sie aus diesem Grund als ungebildete und kulturlose Menschen, beklagten sich über ihr „schlechtes Deutsch“ und ihre Dialekte ${ }^{1944}$ und kämpften gegen die ,sprachliche Korruption“ an. ${ }^{1945}$ In diesem Sinne trifft die Vermutung, es gäbe Einwanderer und deren Nachkommen, die ausschließlich Deutsch oder Pommerisch sprachen, nicht zu. In sehr abgeschiedenen und rein ländlichen Gebieten konnte deren portugiesisches Vokabular zwar deutlich beschränkt sein, aber ein bedeutender Teil besaß aus praktischen Gründen und Interessen eine Grundkenntnis der Landessprache. ${ }^{1946}$ Sie befanden sich in Transition zwischen der „deutschbrasilianischen " und der Landessprache und entwickelten so einen Bilinguismus. ${ }^{1947}$ Trotzdem kann eine gewisse Resistenz bei der Einführung der Landes-

1939 Schulze, S. 281.

1940 Schulze, S. 279, 281.

1941 Dreher, Igreja e Germanidade, S. 103; vgl. Abschrift eines Briefes [Wüstner] an die Missionsleitung, ohne Angabe von Datum, MEW 4.185; Lutherische Kirche in Brasilien, S. 191.

1942 Oberacker, K. Die volkspolitische Lage des Deutschtums in Rio Grande do Sul. Jena, 1936, S. 49. Zitiert nach Willems, S. 259.

1943 Laut Magalhães zeigt es die Diskrepanz zwischen den Repräsentanten des Deutschtums und dem Wunsch deutscher Nachkommen nach Integration und sozialen Aufstieg. Magalhães, Pangermanismo e nazismo, S. 151.

1944 Schulze, S. 256f, $270 f$.

1945 Willems, S. 227.

1946 Gertz, O fascismo no sul do Brasil, S. 70.

1947 Deutsch und Pommersch wurden weiterhin durch Familie, deutsche Schule und Kirche vermittelt, während Portugiesisch durch Kontakt mit Brasilianern auf der Straße, bei der Arbeit, im Geschäft und in öffentlichen Schulen oder Gymnasien in Hauptstädten verwendet wurde. Willems, S. 227f. Während ein gewisser Bilinguismus allmählich in Schule und Kirche akzeptiert wurde, lehnte der familiäre Kreis diesen jedoch ab. Portugiesisch durfte als zweite Sprache gelernt werden, aber nicht die gebräuchliche Sprache im familiären Kreis sein. Seyferth, Nacionalismo e identidade étnica, S. 148 . 
sprache seitens der Einwanderer und deren Nachkommen nicht geleugnet werden. ${ }^{1948}$

Die Deutschtumsideologie breitete sich allmählich vor allem unter unternehmerischen und intellektuellen Schichten in städtischen Gebieten aus. ${ }^{1949}$ Doch auch andere gesellschaftliche Schichten der Kolonisten identifizierten sich mit dem Deutschtum. Sie fanden durch diese Ideologie, durch die Ankunft neuer Einwanderer und durch Institutionen, wie Kirche, Schule, Presse ${ }^{1950}$ und Vereine ${ }^{1951}$ eine neue Verbindung zu der Kultur ihrer Vorfahren. Die Reaktionen auf diese Verbindung konnten nach Willems Akzeptanz, Indifferenz oder Ablehnung, oder eine Kombination all dieser Faktoren sein. Die Siedler konnten beispielsweise den Mahnungen der Deutschtumsakteure folgen und Hochdeutsch als Ersatz für ihre bis dahin verwendeten Dialekte annehmen, sie konnten diese Mahnungen ignorieren und den Entwicklungsprozess zu einer deutschbrasilianischen Sprache weiterhin fortsetzen oder einfach bewusst entgegen den Mahnungen der Deutschtumsakteure die Landessprache verwenden. So konnte sich eine hybride Kultur, die die Elemente zweier Hauptkulturen übernahm, unter ihnen entwickeln. Solange diese sogenannte doppelte Loyalität der Einwanderer und deren Nachkommen zu beiden Kulturen von der brasilianischen Gesellschaft und ihrer Führung toleriert wurde, waren die Kolonisten keinem Identitätskonflikt ausgesetzt. Sobald sie sich aber zwischen ihnen entscheiden mussten, trat ihr kultureller und sozialer Marginalisierungszustand und ihr persönlicher Konflikt damit hervor. ${ }^{1952}$ Dann betonten sie ihre deutsche Herkunft und fühlten sich als Deutscher oder als Pommern, jedenfalls nicht als Brasilianer, auch nicht die in Brasilien geborenen Generationen. ${ }^{1953}$ Sie verstanden sich auch nicht als Reichsdeutsche ${ }^{1954}$, welchen gegenüber

1948 In der Schulgemeinde Rio do Testo-Pomerode (SC) schlug ein Mitglied 1911 die Einführung einiger Stunden Portugiesisch im Lehrplan vor. Dies stieß auf großen Widerstand, zwei Gemeindemitglieder waren der Meinung, ihre Kinder müssen nie die Landsprache lernen, weil alle dort nur Deutsch sprachen. Buzzarello, S. 36.

1949 Gertz, René. O perigo alemão. Porto Alegre: UFRGS, 1991, S. 17. Zitiert nach Fáveri, Marlene. Memórias de uma (outra) guerra. Florianópolis: Universidade Federal de Santa Catarina, 2002, S. 33; Perazzo, S. 61.

1950 Die deutschsprachige Presse informierte Einwanderer und deren Nachkommen über Entwicklungen im Deutschen Reich, vertraten das Deutschtum und berichteten über Aktivitäten im Reich. Sie vertraten jedoch unterschiedliche politische Meinungen, was manchmal zu Konflikten untereinander führen konnten. Schulze, S. 92. Die deutsche Presse in Brasilien engagierte sich besonders zwischen 1890 bis 1940 für die Verbreitung einer Volkstumsideologie. Seyferth, Nacionalismo e identidade étnica, S. 15.

1951 Über die Verbindung deutscher Vereine in Brasilien zum Deutschtum siehe Schulze, S. 97-103. Obwohl im Staat Espírito Santo keine kulturellen Vereine oder Zeitungen für die Förderung des Deutschtums gegründet wurden, verbreitete es sich hier durch die Tätigkeit der Geistlichen und Lehrer und teilweise durch deutsche Zeitungen und didaktisches Material aus dem Süden. Ackermann, S. 116.

1952 Willems, S. 149, 298.

1953 Boss spricht in ihrem Buch über Migranten und Immigranten der älteren Generation, die vielleicht der Annahme sind, ihre Heimat sei woanders. Die jüngere Generation kann wiederum das 
sie ihren Brasilismus hervorhoben, weil diese ihr Deutschtum streng verteidigten und alles, was brasilianisch war, negativ belegten und damit auch sie beleidigten. ${ }^{1955}$ Besonders mit Neudeutschen ${ }^{1956}$, die eine aggressive Form des Deutschtums pflegten, traten sie in Konflikt.

Angesichts dieser Problematik, wurde der Begriff „Deutschbrasilianertum“ übernommen, um die doppelte Zugehörigkeit von Einwanderern und deren Nachkommen als Individuen deutscher Abstammung und gleichzeitig brasilianischer Staatsangehörigkeit zu bezeichnen. ${ }^{1957}$ Die Kategorien von „Nationalität" und „Staatsbürgerschaft" wurden aber vom deutschen Nationalismus und vom brasilianischen Staat unterschiedlich interpretiert, was durch das Verständnis des doppelten Zugehörigkeitsgefühls der Deutschbrasilianer erläutert werden muss. Der deutsche Nationalismus differenzierte zwischen beiden, indem er Staatsbürgerschaft für das Verhältnis zwischen Menschen mit einem Staat und Nationalität für das Verhältnis zwischen Menschen zu einer Nation oder einem Volk oder beides verwendete. Nach der Sicht der Brasilianer umfasste Nationalität aber beide Begriffe, nämlich Nationalität und Staatsbürgerschaft, weswegen sich der brasilianische Nativismus gegen die Bewahrung des Deutschtums stellte.

Nach Seyferth kann die Nationalität durch Vererbung (jus sanguinis), durch den Geburtsort (jus solis) oder durch die Kombination von beiden beschrieben wer-

Land, in dem sie leben, oft schon als Heimat bezeichnen. Aber die Generation dazwischen fühlt sich zwischen Herkunftsland und neuer Heimat hin- und hergerissen. Boss, S. 213f. Dieser Konflikt zwischen „zwei Heimatländer" konnte bei mehreren Generationen pommerscher Nachkommen in Brasilien nicht überwunden werden.

1954 Der Begriff wurde in Brasilien verwendet, um deutsche Einwanderer, die nach 1871 emigrierten, zu bezeichnen.

1955 Bericht des Generalsuperintendenten Dr. Zoellner in Münster über seine Reise durch die deutschen evangelischen Gemeinden im Jahre 1910, S. 45f. Zitiert nach Dreher, Igreja e Germanidade, S. 100.

1956 So wurden Deutsche bezeichnet, die nach dem Ersten Weltkrieg nach Brasilien ausgewandert waren.

1957 Der Begriff stammte nach Schulze aus den 1860er Jahren und wurde aus dem USamerikanischen Konzept des Deutschamerikanertums inspiriert. In den 1870er Jahren begann er von einer deutsch bürgerlichen und intellektuellen Elite in Zusammenhang mit der Verbreitung des deutschen Nationalismus in Kolonisationsgebieten verwendet zu werden. Die Kategorien von Reichs-, Neu- und Auslandsdeutschen entstanden wiederum um 1890, als die deutschbrasilianische Presse eine größere Reichweite entwickelte und von deutschen Nationalismus beeinflusst wurde. Schulze, S. 233f; Seyferth, Nacionalismo e identidade étnica, S. 216f. „Teutobrasileiro "war die brasilianische Bezeichnung für das Deutschbrasilianertum, die sich zur Abgrenzung gegenüber Lusobrasilianern eignete, aber gleichzeitig die Tatsache bekräftigte, in Brasilien gäbe es keine ,reine"Brasilianer und Teutobrasileiros seien das gleiche wie Lusobrasilianer, Schulze, S. 234. Als eine Republik verschiedener Ethnien, so die Sicht der deutschbrasilianischen Presse, solle die brasilianische Regierung keine Nationalität beanspruchen, denn eine solche gab es nicht, und keine Ethnie dürfe ihre nationale oder ethnischkulturelle Merkmale anderen aufzwingen. Wenn Lusobrasilianer das Recht hatten, ihre Sprache in Schule, Handel, Justiz und Politik zu verwenden, musste es auch den anderen Immigranten erlaubt sein. Seyferth, Nacionalismo e identidade étnica, S. 58f, 65, 69. 
den. ${ }^{1958}$ Aufgrund des Verständnisses über Nationalität als eine Mischung zwischen jus sanguinis und jus solis vermischten Einwanderer und deren Nachkommen Konzepte wie Heimat, Staatsbürgerschaft und Nationalität miteinander. Das passierte aufgrund der unter ihnen verbreiteten volkstümlichen Ideologie, dass ein „Deutscher immer ein Deutscher sein“ würde, unabhängig von seinem Geburtsort. Auf diese Weise konnte jeder deutsche Nachkomme die deutsche Nationalität für sich beanspruchen, während die deutsche Staatsangehörigkeit ein exklusives Recht der Reichsdeutschen war. Er bildete aufgrund seiner Kultur, Sprache und Herkunft eine ethnische Einheit mit anderen Deutschen (Volkstum), ohne dabei Verräter des Staates, der ihm seine Staatsangehörigkeit verliehen hat, zu werden. Sie verbanden also Nationalität an das jus sanguinis und Staatsangehörigkeit an das jus solis. ${ }^{1959}$

Der Konflikt zwischen Aufnahmegesellschaft und neuen Einwanderern sowie Deutschbrasilianern im Ersten Weltkrieg, worauf noch einzugehen ist, führte zu einem Rückzug im Akkulturationsprozess. Die Erinnerung an die Heimat der Vorfahren wurde teilweise idealisiert und romantisiert, nostalgische Erinnerungen an eine Heimat, die es so, wie sie zur Zeit der Auswanderung gewesen war, gar nicht mehr gab, wurden den Deutschbrasilianern durch Propaganda vermittelt und es schien, als lebten sie noch dort. ${ }^{1960}$ So gewann die Bindung durch das Blut und die Kategorie „Volksgenosse“ eine größere Bedeutung und diese volkstümliche Ideologie wurde stärker als zuvor verbreitet und aufgenommen. ${ }^{1961}$ In Zusammenhang mit dem 100. Jubiläum deutscher Einwanderung 19241962 und mit der Entstehung eines, trotz der Kriegsfolgen, modernen Deutschlands, entwickelten die Einwanderer und deren Nachkommen einen Stolz auf ihre ethnische Herkunft. ${ }^{1963}$ Gleichzeitig verhielten sie sich aber misstrauisch gegenüber Neudeutschen, manchmal sogar fremdenfeindlich, aggressiv und ablehnend, weil sie die deutschen Sozialisten für den verlorenen Krieg verantwortlich machten und weil sie ihre Ersparnisse bei Spekulationen mit deutschen Marken verloren hatten. ${ }^{1964}$ Ein weiteres Motiv hierfür bildete der Arbeitsmarkt in manchen Siedlungsgebieten, wo deutschbrasilianische Unternehmer gebildete Arbeitskräfte aus der alten Heimat rekrutierten und dadurch einen Konflikt mit deutschbrasilianischen Arbeitern auslösten, die sich dadurch benachteiligt fühlten. ${ }^{1965}$ Zuletzt spielten ihre verschiedenen Weltansichten, Ideologien, Kultur, Bildung, Erfahrungen und Sprache

\footnotetext{
1958 Seyferth, Nacionalismo e identidade étnica, S. 8f, 65.

1959 Seyferth, Nacionalismo e identidade étnica, S. 36, 42.

1960 Magalhães, Marionilde Brepohl de. Racismo no sul do Brasil: heranças de um mito. In: Revista História. São Paulo, Nr. 129-131, ago-dez 1993, ago-dez 1994, S. 171-173.

1961 Seyferth, Nacionalismo e identidade étnica, S. 76.

1962 Diese Feier trug zur Erhöhung des ethnischen Bewusstseins unter Deutschen und Deutschbrasilianern und zur Beförderung der deutschen Kultur bei. Dreher, Igreja e Germanidade, S. 48.

1963 Perazzo, S. 60.

1964 Willems, S. 56f, 185-187.

1965 Seyferth, Nacionalismo e identidade étnica, S. 14, $167 \mathrm{f}$.
} 
eine Rolle bei den Konflikten. ${ }^{1966}$ Der Antagonismus zwischen Deutschbrasilianern und Reichs- und Neudeutschen fand seinen Höhenpunkt in den 1930er Jahren, als die nationalsozialistische Ideologie den Deutschbrasilianern einen Vormundschaftzustand auferlegen wollte, den diese nicht akzeptierten. Auch wenn die Deutschbrasilianer ihre ehemalige Herkunftsheimat idealisierten, identifizierten sie sich jedoch weder mit dem Deutschen Reich noch mit einem nationalen deutschen Staat. ${ }^{1967}$ Ihre Kultur und ihr ethnisches Gefühl waren mit der alten Heimat verbunden, aber ihre Arbeitskraft und Loyalität gehörten Brasilien. ${ }^{1968}$ Deutsch war ihr Volkstum und brasilianisch ihre Staatsangehörigkeit, darin sahen sie keinen Widerspruch. ${ }^{1969}$ Laut Prien wird die Deutschtumsproblematik oft ohne die angemessene Differenzierung zwischen „deutsch-nationalem " und „deutsch-ethnischem" Denken behandelt. ${ }^{1970}$

Den Neudeutschen gegenüber hoben Deutschbrasilianer ihre brasilianische Staatsbürgerschaft hervor und behandelten diese wie Ausländer. Das beschränkte sich jedoch nur auf den Arbeitsmarkt und das gesellschaftliche Leben, denn innerhalb der Familie und der religiösen Gemeinde betonten sie Deutschbrasilianer zu sein, im Unterschied zu den Brasilianern. Diesen gegenüber hoben sie ihre deutsche Ethniæität hervor. ${ }^{1971}$ Brasilianer wiederum sahen Deutschbrasilianer als Ausländer, selbst diejenigen, die in Brasilien geboren waren. An das Konzept der „ausländischen Bevölkerung"1972 wurden Begriffe, wie „ethnische Zyste“, „Pangermanismus", „Deutschtum " und später „Nazismus" als rassische Merkmale geknüpft, welche die Gefahr solcher Gruppen für die Nationalität andeuteten und als Schimpfworte

1966 Willems, S. 111, 125f, 185; Seyferth, Nacionalismo e identidade étnica, S. 168. Das betraf teilweise auch die Beziehung zwischen reichsdeutschen Geistlichen und deutschbrasilianischen Gemeindemitgliedern. Magalhães, Pangermanismo e nazismo, S. 32; Dreher, Igreja e Germanidade, S. 100, 212.

1967 Seyferth, Nacionalismo e identidade étnica, S. 169f.

1968 Über die Hervorhebung ökonomischer Interessen seitens der Deutschbrasilianer, die sich in Bezug zu einer angeblichen politischen Loyalität zu Deutschland antagonistisch herausstellten und Vorteile für Brasilien brachten, siehe Willems, S. 263-265. Vgl. Gertz, O fascismo no sul do Brasil, S. 6365, 105-107; Perazzo, S. 39. Nach der Sicht einer industriellen, liberalen und intellektuellen deutschbrasilianischen Elite waren wirtschaftliche, soziale und politische Fortschritte in Brasilien den deutschen Einwanderern zu verdanken. In diesem Sinne entsprachen sie aber eher der deutschtümlichen Ideologie, die besagte, Deutsche und Deutschbrasilianer können nur zur Entwicklung der brasilianischen Gesellschaft beitragen und loyale Staatsbürger sein, indem sie ihre deutsche Identität bewahrten. Eine Rassenmischung bedeutete den Untergang all dessen und führe zur "Zersetzung des Staates". Schlünzen, F. Deutsche in Brasilien. Neuendettelsau: Freimund, 1936, S. 5, MEW 3.16; vgl. Der Deutsche Ansiedler, 77. Jahrgang, Juni 1939. Zitiert nach Py, S. 218-220; Grube, S. 88; Dedekind, Brasilien, S. 9; Droogers, S. 28.

1969 Seyferth, Nacionalismo e identidade étnica, S. 98f. Die Trennung zwischen Staatsbürger und Volksgenosse war in der Weimarer Republik üblich und Hindenburg forderte die Auslandsdeutschen auf: „Liebe zum neuen Vaterland - Treue dem alten Mutterland“. So wurde das Bekenntnis bekräftigt, das Brasilianertum sei Heimat und Vaterland, aber das Deutschtum Stammesheimat und Stammesvolk. Schulze, S. 237.

1970 Prien, S. 361.

1971 Seyferth, Nacionalismo e identidade étnica, S. 171-173.

1972 Seyferth, Nacionalismo e identidade étnica, S. 88. 
galten. ${ }^{1973}$ Indem Brasilianer sie als Deutsche bezeichneten, hoben sie nicht nur deren ethnische Herkunft hervor, sondern stellten sie auch als ,fremd" dar. Sie bildeten den „anderen "Teil der brasilianischen Kultur. ${ }^{1974}$ Gleichzeitig wurden Deutschbrasilianer durch die volkstümliche Propaganda immer wieder daran erinnert: "vergiss nicht, dass du ein Deutscher bist". Dieser Slogan sollte unter ihnen die Idee einer sozialen Kohäsion prägen und die deutsche und deutschbrasilianische Bevölkerung unterschiedlicher Gebiete ethnisch und völkisch verbinden. Und je mehr sie sich an die Heimat ihrer Vorfahren banden, umso mehr distanzierten sie sich von der brasilianischen Gesellschaft, wobei Sprache und Kultur bald Resistenzfunktionen gegenüber den Homogenisierungsversuchen des brasilianischen Nationalismus übernahmen. ${ }^{1975}$

Die Nationalisierungsmaßnahmen Brasiliens ab 1937 erschütterten die Grundlagen der deutschbrasilianischen Kultur und führten zur Spaltung in Assimilationsverteidiger und -gegner und zu teilweise heftigen Diskussionen über Assimilation in Presse, Kirche und Vereinen. Für Deutschbrasilianer galt die deutsche Sprache als heilig, der deutsche Nationalismus sah sie als Mittel zur Bewahrung deutscher Volkskultur und Volksgemeinschaft und der brasilianische Nationalismus sah in ihr eine Straftat. So standen die Deutschbrasilianer zwischen zwei Nationalisierungswellen, die ihren Identitätskonflikt noch verschlimmerten. Die mittlere Generation hatte meistens den Anschluss an die brasilianische Kultur nicht vollzogen, verlor jedoch den Anschluss zur Herkunftskultur. ${ }^{1976}$ Aber die Nationalisierungsmaßnahmen wirkten anders als erwartet auch als Mittel zur Festigung volkstümlicher Prinzipien. Um ausländische Einflüsse zu beseitigen und das brasilianisch-nationale Gefühl unter der Bevölkerung deutscher Abstammung zu verbreiten, griff der Staat die Institutionen der Deutschbrasilianer an, womit sich diese eine soziale Umwelt geschafft hatten, als der brasilianische Staat ihre Bedürfnisse ignorierte. Der Vorwurf, alle Deutschen und Deutschbrasilianer seien „Nazis", ordnete sie trotz Differenzen derselben Kategorie zu und stärkte die ethnische Solidarität unter ihnen. ${ }^{1977}$ Zudem wurden sie wieder an den Rand der brasilianischen Gesellschaft gedrängt. ${ }^{1978}$ Manche isolierten sich wieder und äußerten sich einfach nicht mehr öffentlich über ihre Sympathie für Deutschland und für die deutsche Kultur. ${ }^{1979}$ Mit Ausnahme einer deutschbrasilianischen Elite zeigten viele kein Interesse mehr für das politische Leben Brasiliens und schlossen sich in ihren Institutionen ein, indem sie die Notwendigkeit eines inneren Zusammenhalts her-

\footnotetext{
1973 Willems, S. $126 f$.

1974 Magalhães, Pangermanismo e nazismo, S. 76.

1975 Magalhães, Pangermanismo e nazismo, S. 118-120.

1976 Giurus, Crônica da Paróquia Evangélica Luterana de Indaial, S. 152.

1977 Seyferth, Nacionalismo e identidade étnica, S. 194.

1978 Perazzo, S. 48.

1979 Die verbotenen Erinnerungen, die durch Schuld-, Scham- oder Ressentimentsgefühle verschwiegen wurden, kamen in informellen Kreisen, wie innerhalb der Familie, in der Nachbarschaft und bei festlichen Angelegenheiten zum Ausdruck. Magalhães, Racismo no sul do Brasil, S. 176.
} 
vorhoben. ${ }^{1980}$ Ein weiterer Teil ließ sich willig oder unwillig assimilieren. Besonders jüngere Generationen, die in den Schulen und im städtischen Arbeitsmarkt stärker Spott, Gewalt und Unterdrückung ausgesetzt waren, zeigten eine Antipathie gegenüber deutscher und pommerscher Kultur auf. Ihre kulturelle Identität wandelte sich in ein Scham-, Erniedrigungs- und Verlegenheitsgefühl. ${ }^{1981}$ Diejenigen jedoch, die die deutsche Volkstumsideologie vertraten, radikalisierten sich in ihrer Meinung und verhielten sich so, als wären sie eine ethnische Minderheit, die vom Staat unterdrückt wurde.

Nach dem Zweiten Weltkrieg führte vor allem das Zusammenarbeiten von Brasilianern und Deutschbrasilianern in Fabriken und die graduelle Nivellierung beider Gruppen in derselben sozialen Schicht zu interethnischen Ehen und zum stufenweisen Verzicht auf die Verwendung der deutschen Sprache, je nach industrieller Entwicklung und Urbanisierungsprozess in den verschiedenen Gebieten. Ethnische Kriterien verloren immer mehr an Bedeutung, obwohl weder Industrialisierung, Urbanisierung noch Nationalisierung die ethnische Besonderheit vollständig beseitigen konnten. ${ }^{1982}$ In den 1950er und 1960er Jahren existierte sie noch und in den 1970er Jahren begann ein „Re-Ethnisierungsprozess" $" 1983$, indem die Kultur verschiedener Einwanderergruppen als Kulturerbe betrachtet und gefördert wurde. ${ }^{1984}$ So gelten Deutschbrasilianer teilweise bis heute als „brasilianische Staatsbürger deutscher Abstammung". 1985

\section{Der Erste Weltkrieg und die Reaktion der brasilianischen Bevölkerung}

Der Ausbruch des Ersten Weltkriegs löste zunächst keine bedeutende Reaktion in Brasilien aus. Die Situation änderte sich aber als Brasilien 1917 Deutschland den Krieg erklärte. Besonders die brasilianische Bevölkerung wurde gegen Deutsche und Deutschbrasilianer aufgehetzt, deutsche und deutschbrasilianische Geschäfte und Industrien, Schulen und Kirchen wurden geplündert und geschlossen, Geistliche und Siedler inhaftiert und die deutsche Sprache verboten. Nun sollen diese Ereignisse und die Reaktion der Einwanderer und deren Nachkommen auf die

\footnotetext{
1980 Magalhães, Racismo no sul do Brasil, S. 175.

1981 Alves, Liane C. Últimos pomerânios. In: Revista Terra, São Paulo, v. 7, S. 72-77, jul. 1998, S. 77. Zitiert nach Siller, S. 114; vgl. Seibel, Imigrante no século do isolamento, S. 296.

1982 Seyferth, Nacionalismo e identidade étnica, S. 218.

1983 Gertz, René. Os „súditos alemães“ no Brasil e a „pátria-mãe” Alemanha. In: Espaço Plural. Ano IX, Nr. 19, 2008, S. 67-73. Zitiert nach Maltzahn, S. 44.

1984 Beispiele für diese Entwicklung ist in der Architektur, Gastronomie und Sprache, die teilweise wieder in den Schulen eingeführt wurde, wie auch die jährlichen Feste, wie beispielsweise das Oktoberfest in Blumenau (SC) und Santa Cruz do Sul (RS), das Immigrantenfest in Timbó (SC), das Pommernfest in Pomerode (SC) und Santa Maria de Jetibá (ES), das Sommerfest in Domingos Martins (ES) zu sehen.

1985 Seyferth, Nacionalismo e identidade étnica, S. 218.
} 
neue Situation dargestellt werden. Dies geschieht mit besonderem Augenmerk auf die Auswirkungen ihres Glaubens während dieser Zeit.

Der Ausbruch des Ersten Weltkriegs 1914 sorgte bei vielen Reichsdeutschen und Deutschbrasilianern für patriotische Begeisterung. ${ }^{1986}$ Sie feierten deutsche Siege, einige stellten sich dem Wehrdienst im Generalkonsulat zur Verfügung und kirchliche Gemeinden und Vereine sammelten Geld für das Rote Kreuz. ${ }^{1987} \mathrm{Zu}$ diesen deutsch-nationalistischen Aktion wurden sie mehr oder weniger von vielen Geistlichen beeinflusst. In Gottesdiensten wurde beispielsweise für den deutschen Kaiser, für Soldaten und für einen deutschen Sieg gebetet ${ }^{1988}$, Geistliche predigten über die Bedeutung dieser Zeiten für das deutsche Volk und begründeten die Notwendigkeit eines Kriegs mit der Hilfe biblischer Texte. ${ }^{1989}$ Nach ihren Predigten und Gottesdiensten gaben sie Auskunft über die Kriegslage in Europa, Gemeinden in Espírito Santo feierten Missionskriegsfeste ${ }^{1990}$ und einige Pastoren veranstalteten Missionskriegsreisen. ${ }^{1991}$ Ein Bericht über das Missionsfest in Califórnia (ES) 1914 gibt Auskunft über die deutsch-nationalistische Kriegspropaganda, die von Pastoren ausgeübt wurde, und wie diese für positive Stimmung sorgte. Diese idyllische Darstellung der Ereignisse stimmte nicht unbedingt mit der Reaktion der Siedler überein. Eine genaue Analyse der realen Reaktionen ist aufgrund fehlender Quellen jedoch nicht möglich:

„Das Missionsfest wurde zu einem Kriegsfest. Die eingeübten Missionsquartette wurden
aus dem Stegreif mit Kriegsquartetten vertauscht. Die Missionsvorträge wandelten sich
während des Redens zu vaterländischen Ansprachen um. Die glühende Liebe zum Va-
terlande, durch die ungeheure Wucht der Ereignisse zu lodernden Flammen angefacht,
legte den Rednern die Worte auf die Lippen. Ihrer heiligen Begeisterung gelang es auch,
die trägen Herzen der Hörer aufzurütteln. Mit tränenden Augen erzählten die Kolonis-
ten, solch schönes, erhebendes Fest hätten sie noch nie erlebt. Eine rechte Vorstellung hat-
ten die Kolonisten vom Kriege nicht... Was an Verleumdungen des Kaisers und der deut-
schen Kriegsführung durch die Brasilianer ihnen zu Obren kam, wurde nicht geglaubt
oder beeinträchtigte doch ihre Gefühle für das Vaterland nicht. In dieser Hinsicht hatten
wir Pastoren nicht viel aufklärende Arbeit zu tun. Schwerer war es, die Zuversicht auf

1986 Dreher, Igreja e Germanindade, S. 105; Perazzo, S. 50. Das war laut Dreher eine Folge ihrer Randposition in der brasilianischen Gesellschaft in den ersten Republikjahren, Dreher, Igreja e Germanidade, S. 47, hat aber auch sicherlich mit der Verbreitung deutsch-nationalistischer Ideologie zu tun.

1987 Bühler, Fritz. Ein Beitrag zur Kirchenkunde Südamerikas. [1917/1918], S. 69, MLV 51/17 108; Dreher, Igreja e Germanidade, S. 105; Schulze, S. 100; Prien, S. 355.

1988 Magalhães, Pangermanismo e nazismo, S. 142.

1989 Bericht Keitels über die Gemeinde Laranja da Terra vom Februar 1913. Zitiert nach Krause, Lutherische Synode in Brasilien, S. 179f; Dreher, Igreja e Germanidade, S. $105 f$.

${ }^{1990}$ Wie am 1.8.1915 in Califórnia (ES), Schmidt, Die Anfänge der Diakonie, S. 39; am 7.9.1915 in Santa Leopoldina (ES), am 25.10.1915 in Jequitibá (ES) und am 24.1.1915 in Campinho (ES). Ein Gruß aus dem brasilianischen Urwald. In: Tägliche Rundschau Nr. 528, 17.10.1915, EZA 5/2563.

${ }^{1991}$ Fischer, Erich. Espirito Santo und der Weltkrieg. In: DEv 14, 1917, S. 189-201. Zitiert nach Dreher, Igreja e Germanidade, Fußnote 37, S. 47. 


\section{Deutschlands Sieg bei den Kolonisten zu erhalten. Zwar ersehnten sie ibn alle nicht nur des Vaterlandes wegen, sondern auch um ibrer selbst wegen. Denn sie waren überzengt und sind es noch, daß im Falle einer Niederlage die in der Kolonie ansässigen Brasilianer auf die vielgehaßten und beneideten Deutschen losschlagen würden".1992}

Dieser Bericht belegt auch, dass die späteren Angaben, Kolonisten in Espírito Santo hätten keine Information über den Kriegsverlauf erhalten ${ }^{1993}$, nicht stimmen, auch wenn für Espírito Santo nicht der Belagerungszustand erklärt wurde. ${ }^{1994}$ Obwohl das Gemeindeleben und das Schulwesen in den hier behandelten Staaten zunächst nicht besonders davon betroffen war ${ }^{1995}$, konnten manche Pastoren nicht mehr aus ihrem Heimaturlaub zurückkehren ${ }^{1996}$ und die finanzielle Unterstützung aus Deutschland wurde eingestellt. Die Situation verschlimmerte sich mit dem Abbruch der diplomatischen Beziehungen zwischen Brasilien und Deutschland im April 1917 und vor allem mit der Kriegserklärung Brasiliens im Oktober 1917. In mehreren Orten, besonders in den Städten von den Staaten Rio Grande do Sul und Santa Catarina, wie Porto Alegre (RS), Pelotas (RS), Florianópolis (SC) und Itajaí (SC), stieg die Wut der brasilianischen Bevölkerung gegen Deutsche und Deutschbrasilianer gefährlich an. ${ }^{1997}$ Bereits im Februar 1917 berichteten Zeitungen über Überfälle auf deutsche Geschäfte als eine Art vorauseilende Verteidigungsmaßnahme im Fall eines deutschen Angriffs auf Brasilien. Das Hotel Schmidt und die Firma Bromberg in Porto Alegre (RS) wurden in Brand gesetzt, weil sie unter dem Verdacht standen, Kriegswaffen und -munition zu lagern. Die Zeitung O Combate von São Paulo (SP) berichtet am 2. Mai 1917 über eine angeblich von Deutschen als Genozidtaktik verübte Wasservergiftung in Porto Alegre (RS). ${ }^{1998}$ Der englische Konsul in Porto Alegre (RS) soll wiederum Männern befohlen haben, Häuser von Deutschen anzuzünden. ${ }^{1999}$ In der Nacht vom 30. zum 31. Oktober 1917 wurde in Pelotas (RS) die Schriftdruckerei der Zeitung Deutsche Wacht gestürmt, Maschinen, Möbel, Satzkästen und andere Gegenstände auf der Straße verbrannt und das Deutsche Schützenhaus in Brand gesetzt. In Rio Grande (RS) wurde zwei Tage später eine Reihe deutscher Firmen und Privathäuser beschädigt, der Klub Germania in Brand gesetzt und eine Schule

\footnotetext{
1992 Ein Gruß aus dem brasilianischem Urwald. In: Tägliche Rundschau Nr. 528, 17.10.1915, EZA $5 / 2563$.

1993 Seibel, Imigrante no século do isolamento, S. 211f.

${ }^{1994}$ Dreher, Igreja e Germanidade, S. 47.

1995 Brief des Ständigen Vertreters des Evangelischen Oberkirchenrates, 15.11.1917, S. 1, EZA $5 / 2158$.

${ }^{1996}$ Evangelische Synode von Santa Catarina und Paraná, S. 80.

1997 Brief des Ständigen Vertreters des Evangelischen Oberkirchenrates, 15.11.1917, S. 1, 3, EZA 5/2158; Radlach. Die Einwirkungen des Weltkrieges auf die deutsch-evangelischen Gemeinden in Santa Catharina. In: Geißler, Bruno (Hrsg.) Die Kulturbedeutung der deutschen evangelischen Kirche in Brasilien, S. 24, EZA 5/2158; Schulze, S. 198.

1998 Magalhães, Pangermanismo e nazismo, S. 114.

1999 Dedekind, Brasilien, S. 12.
} 
durch Steinwürfe ebenfalls beschädigt. In Santa Maria da Bocca do Monte (RS) wurde die Schule von einer Volksmenge angegriffen und musste auf das Kirchengrundstück verlegt werden. ${ }^{2000}$ In Florianópolis (SC) wurde in der Nacht vom 28. zum 29. Oktober 1917 der Klub Germania verwüstet, das deutsche Schützenhaus verbrannt, die deutsche Schule und das Pfarrhaus wurden angegriffen und Geschäftshäuser mit Steinen beworfen. Einige deutsche Vereine änderten schnell ihre Statuten, um eine Identifikation mit dem Deutschen Reich zu vermeiden. ${ }^{2001}$ Jedoch im Gegensatz zu Rio Grande do Sul kam es in Santa Catarina zunächst kaum zu Unruhen, da Behörden, unter anderem der Gouverneur Felipe Schmidt, Deutschbrasilianer waren. Aufgrund der hohen Konzentration von Deutschen und Deutschbrasilianern in einigen Gebieten beschränkten sich die Tumulte auf kleinere Demonstrationen in der Hauptstadt Florianópolis (SC) und schüchterne Paraden im Binnenland. In der Zentralregierung wurde Außenminister Lauro Müller nur aufgrund des starken Drucks seitens der Presse und des Parlaments seines Amtes enthoben. ${ }^{2002}$ In Espírito Santo sollen nach Angaben pommerscher Nachkommen einige Häuser durchsucht und Waffen beschlagnahmt worden sein. ${ }^{2003}$ Doch so schnell, wie die Bevölkerung sich gegen Deutsche und Deutschbrasilianer aufhetzen ließ, so rasch verging ihre Wut auch wieder. ${ }^{2004}$

Deutsche Banken in Brasilien standen unter der Leitung eines Fiskals und durften weder neue Geschäfte eingehen noch Zahlungen an nicht-alliierte Länder oder neutrale Brasilianer tätigen. Guthaben von Deutschen wurden eingefroren, deutsche Versicherungsgesellschaften geschlossen ${ }^{2005}$, kommerzielle Verträge mit bestimmten deutschen Firmen verboten, wie auch öffentliche Bekundungen für das Deutsche Reich, die Verbreitung deutscher Zeitungen und deutsche Feierlichkeiten, unter ihnen das 400. Reformationsjubiläum 1917.2006 In Porto Alegre (RS) wurde 1918 der Nationale Verteidigungsbund (Liga de Defesa Nacional) gegrün$\operatorname{det}^{2007}$, um die nationalen Gefühle gegen die deutsche Kultur und das „preußische

${ }^{2000}$ Brief des Ständigen Vertreters des Evangelischen Oberkirchenrates, 15.11.1917, S. 2, 7-9, EZA $5 / 2158$.

2001 Prien, S. 192.

2002 Magalhães, Pangermanismo e nazismo, S. 116.

2003 Aussage von Ida Ramlow Berger, Santa Maria de Jetibá, 2001. Zitiert nach Rölke, Raízes da Imigração alemã, S. 165.

${ }^{2004}$ Radlach. Die Einwirkungen des Weltkrieges auf die deutsch-evangelischen Gemeinden in Santa Catharina. In: Geißler, Bruno (Hrsg.) Die Kulturbedeutung der deutschen evangelischen Kirche in Brasilien, S. 25, EZA 5/2158.

2005 Brief des Ständigen Vertreters des Evangelischen Oberkirchenrates, 15.11.1917, S. 7f, EZA $5 / 2158$.

2006 Magalhães, Pangermanismo e nazismo, S. 116.

2007 Siehe die Statuten des Nationalen Verteidigungsbundes. In: A Federação, Porto Alegre, 23.11.1917, Nr. 270, anno 34, EZA 5/2158. Es handelte sich hierbei um einen Verein zur Förderung nationalistischer Maßnahmen gegen Ausländer und Einheimische, die diese unterstützten. Sein Ziel lag in der Verbreitung der Nationalisierungspropaganda, die Nationalisierung religiöser, sportlicher oder kultureller Vereine (unter Androhung von Auflösung) deutschen Charakters, eine Überwachung nationalistischer Anordnungen in Schulen, die Propagierung der Landessprache in öffentli- 
Krebsgeschwür" in Rio Grande do Sul anzutreiben. Durch die Veröffentlichung von „schwarzen Listen" zielte er unter anderem auf den Boykott deutscher Geschäftshäuser ab. ${ }^{2008}$

Die deutsche Sprache und alle anderen Dialekte, die in ihrer Mundart noch in Gebrauch waren, wurden überall mit Ausnahme von Espírito Santo öffentlich verboten. Wer sich nicht streng daran hielt, erregte die Wut der brasilianischen Bevölkerung und es kam nicht selten zur Verhaftung von Deutschen und Deutschbrasilianern. In Blumenau (SC) und Joinville (SC) bereitete das Verbot deutscher Sprache besondere Schwierigkeiten, denn sie wurde sogar in der Stadtverwaltung und in staatlichen Protokollen verwendet. ${ }^{2009}$

Das Schulwesen war am stärksten von gesetzlichen Maßnahmen betroffen. Drei Tage nach der Kriegserklärung wurden 267 deutsche Schulen allein in Santa Catarina durch Polizeiverfügung geschlossen. Etwa 15.000 Kinder blieben dadurch vom Schulunterricht ausgeschlossen ${ }^{2010}$, auch wenn einige Pastoren sich bereit erklärten, Portugiesisch zu unterrichten. Laut Pastor Schlünzen blieben sie nur für ein halbes Jahr geschlossen, mussten dafür aber nationalisiert und in Bundesschulen umgeformt werden. ${ }^{2011}$ Die Wiedereröffnung von Privatschulen in diesem Staat im Jahr 1918 ist nach Wirth dem Einfluss deutschsprachiger Führungskreise zu verdanken. Die Evangelische Pastoralkonferenz von Santa Catarina und Paraná verhandelte mit dem Munizipal-Schulinspektor über die Verwendung deutscher Sprache als Sprache im Religionsunterricht, die täglich eine Stunde an Privatschulen vermitteln werden sollte. ${ }^{2012}$ In Rio Grande do Sul dekretierte der Staatssekretär Protásio Alves die Schließung aller Schulen, in denen Portugiesisch keine Unterrichtssprache bildete. Deutsch durfte nur als Fremdsprache gelehrt werden. ${ }^{2013}$ In Espírito Santo jedoch wurden Gemeindeschulen nur vorübergehend geschlossen. Gemeinden, die ihre Einrichtungen staatlichen Schulen zur Verfügung stellten, sollten in der Regel dafür eine Vergütung bekommen. Ob es tatsächlich dazu kam, kann nicht nachgewiesen werden. 2014

chen Bereichen, die Aufforderung zum Ersatz von Geistlichen, die zur Entnationalisierung brasilianischer Bürger beitrugen, die Indoktrination von Jugendlichen in Bezug zum Nationalismus, die Auszeichnung von patriotisch, nationalistischen Taten Jugendlicher, die Anzeige von Handlungen gegen die nationale Souveränität Brasiliens und die Berücksichtigung nationaler Feiertage.

2008 Schröder, Brasilien und Wittenberg, S. 223; Prien, S. 197.

2009 Prien, S. 184, 197.

2010 Schröder, Brasilien und Wittenberg, S. 356f; Fischer, Geschichte der Evangelischen Kirche, S. 150.

2011 Bericht Pastor Schlünzen, Jaraguá 9.1.1920, MLV 51/17 81. Nach dem Bericht des Leiters der Neuen Deutschen Schule in Blumenau (SC), Dr. Herbert Koch, waren die Schulen, die wieder eröffnet werden durften, keine deutschen Schulen mehr. Bericht des Ständigen Vertreters des Evangelischen Oberkirchenrates in Brasilien, 14.5.1918, S. 3f, EZA 5/2158.

2012 Wirth, S. 116.

2013 Der Erlass soll aber nicht so überall streng wie in Santa Catarina durchgesetzt worden sein. Brief des Ständigen Vertreters des Evangelischen Oberkirchenrates, 14.5.1918, S. 4, EZA 5/2158.

2014 Krause, Lutherische Synode in Brasilien, S. 154. 
Gesetze und Erlasse wurden aber nicht überall in demselben Maß umgesetzt und brachten auch nicht immer den zunächst erwarteten Erfolg. Niemand wusste wirklich, in welcher Form die Gesetze umgesetzt werden sollten, da sie Interpretationsspielraum ließen. Die Reaktion hing mehr oder weniger vom Verhalten der lokalen polizeilichen Organe und von der Art und Weise, wie sie die Anordnungen interpretierten ab, auf welche Art sie diese durchsetzten und bei Ermittlungen und Anzeigen umgingen. In einer Stadt konnte beispielsweise eine Gemeindeschule noch funktionieren, in einem naheliegenden Ort wurde sie wiederum geschlossen. ${ }^{2015}$ Wo die Bevölkerung keine Beschwerde gegen das deutsche Schulwesen einreichte und der Nationale Verteidigungsbund nicht präsent war, konnten Schulen weiterhin in einige Fächern auf Deutsch unterrichten, wie in Teutônia (RS) und Santa Cruz do Sul (RS). Aber solche Begünstigungen konnten jederzeit aufgehoben werden ${ }^{2016}$, denn es wurden ständig neue Anordnungen und Gesetze erlassen. In Badenfurt (SC) konnte als Ersatz für die Regelschule eine Sonntagsschule in der Kirche eingerichtet werden ${ }^{2017}$, in anderen Orten wurde der Unterricht in Lehrer- oder Pfarrhäusern geheim abgehalten. ${ }^{2018}$ In der Regel waren deutsche Schulen in Städten stärker getroffen, Kolonieschulen blieben meistens verschont.

Auch das kirchliche Leben in evangelischen sowie lutherischen Gemeinden wurde eingeschränkt. ${ }^{2019}$ Bereits am 24. Dezember 1917 wurden Gottesdienste in Joinville (SC) und Jaraguá do Sul (SC) verboten, obwohl für Joinville (SC) erst am 12. Januar 1918 ein offizielles Verbot der deutschen Sprache erlassen wurde. Jaraguá do Sul (SC) erhielt von März bis Dezember 1918 eine Genehmigung für die Vollziehung von liturgischen Feiern und Konfirmandenunterricht. Für die Tätigkeit als Reiseprediger musste Pastor Kuhr eine Reisegenehmigung beantragen, durfte aber seine Arbeit überall in deutscher Sprache fortführen. ${ }^{2020}$ Offiziell waren nach dem Erlass des Staatssekretärs Fulvio Aducci von Februar 1918 deutsche Predigten in Santa Catarina verboten. Der Konfirmandenunterricht wurde

\footnotetext{
2015 In Inselstraße (SC) konnte die Schule bald wieder eröffnet werden, in der Nachbargemeinde Brüdertal (SC) wurde ein brasilianischer Lehrer eingesetzt, die Vereinsschule in Joinville (SC) blieb geschlossen. In Jaraguá do Sul (SC) blieb die Schule ebenfalls geschlossen, bis Pastor Schlünzen ein brasilianisches Staatsexamen absolvierte. Krause, Lutherische Synode in Brasilien, S. 150.

2016 Brief des Ständigen Vertreters des Evangelischen Oberkirchenrates in Brasilien, 14.5.1918, S. 4, EZA 5/2158.

${ }^{2017}$ Radlach. Die Einwirkungen des Weltkrieges auf die deutsch-evangelischen Gemeinden in Santa Catharina. In: Geißler, Bruno (Hrsg.) Die Kulturbedeutung der deutschen evangelischen Kirche in Brasilien, S. 25, EZA 5/2158.

2018 Seyferth, Nacionalismo e identidade étnica, S. 134.

2019 Auch römisch-katholische Gemeinden deutscher Sprache wurden angegriffen und Missourigemeinden mussten ihre deutschen Gottesdienste einstellen. Weil jedoch die Katholische Kirche sich als Kirche der Brasilianer und Verteidiger des Patriotismus präsentierte, die Missourisynode ihren deutschen Namen und Charakter während des Ersten Weltkrieges aufgab und noch andere Kirchen sich als nationale Kirche propagierten oder sich neutral verhielten (Prien, S. 198f), waren die hier behandelten evangelischen und lutherischen Gemeinden von den nationalistischen Maßnahmen am stärksten betroffen.

2020 Krause, Lutherische Synode in Brasilien, S. 150-152.
} 
zunächst bis Ostern erlaubt, ab April 1918 wieder verboten, so dass in mehreren Gemeinden keine Konfirmation stattfinden konnte. ${ }^{2021}$ Manche Geistlichen erteilten Konfirmandenunterricht in entlegenen Häusern. Weil die Predigt, nicht aber das Gebet in deutscher Sprache verboten war, fügten Pastoren nach dem Sonntagstext oder zwischen Hymnen ein längeres Gebet oder die Lesung eines erbaulichen Textes aus den Luthersschriften ${ }^{2022}$, aus dem Kleinen Katechismus oder aus der Väterliteratur ${ }^{2023}$ an. In vielen Landgemeinden wurden jedoch zeitweise deutsche Predigtgottesdienste vollzogen, allerdings nur dort, wo die brasilianische Nachbarbevölkerung nichts dagegen hatte. Im Staat Rio Grande do Sul wurde, nachdem am 17. November 1917 bereits die Verwendung der deutschen Sprache bei Predigten und öffentlichen Anlässe verboten worden war, nach der Anordnung des Belagerungszustands auch die Liturgie in deutscher Sprache verboten. Die Autoritäten befahlen der Riograndenser Synode, Gottesdienste für eine gewisse Zeit auszulassen, um das entzürnte Volk nicht zu provozieren. Kirchliche Amtshandlungen durften allerdings in der Kirche stattfinden unter der Bedingung, den Seiteneingang zu verwenden.2024 Im April 1918 gab der Polizeichef Annibal Loureiro Richtlinien für den liturgischen Dienst in protestantischen Gottesdiensten heraus, nach welchen unter anderem die Predigten und Auslegungen in der Landessprache vollzogen ${ }^{2025}$ oder durch eine sonntägliche Lesung ersetzt werden mussten, die jedoch nicht von der Kanzel gelesen werden durfte. Kirchliche Amtshandlungen in Kirchen und Privathäusern sowie der Konfirmationsunterricht konnten wieder stattfinden. Obwohl die Gottesdienste in Gemeinden vom Staat Espírito Santo nicht davon betroffen waren, wurde in Campinho (ES) die deutsche Predigt auch verboten. ${ }^{2026}$ Nur die Mittelbrasilianische Synode hatte bereits 1915 eine liturgische Agenda in portugiesischer Sprache herausgegeben, weil mit Ausnahme pommerscher Gemeinden in Espírito Santo alle evangelischen Gemeinden in den Staaten São Paulo, Rio de Janeiro und Minas Gerais mehr oder weniger sprachlich und kulturell assimiliert waren. ${ }^{2027}$

2021 Brief des Ständiger Vertreters des Evangelischen Oberkirchenrates, 14.5.1918, S. 1, EZA $5 / 2158$.

2022 Radlach. Die Einwirkungen des Weltkrieges auf die deutsch-evangelischen Gemeinden in Santa Catharina. In: Geißler, Bruno (Hrsg.) Die Kulturbedeutung der deutschen evangelischen Kirche in Brasilien, S. 25, EZA 5/2158; Krause, Lutherische Synode in Brasilien, S. 151.

2023 Rundschreiben von Pastor Gabler, 17.2.1918. Zitiert nach Weingärtner, Crônica da Comunidade Evangélica de Timbó, S. 50.

2024 Prien, S. 194f.

2025 Zeitung A Pátria, São Leopoldo, 13.4.1918, AHI, SR 6/5 Beilage 046; Zeitung Correio do Povo. Porto Alegre, Ano XXIV Nr. 147, 23.6.1918, AHI, SR 13/5 Beilage 020; Zeitung A Federação. Porto Alegre, Ano XXXV Nr. 92, 19.4.1918, AHI, SR 13/5 Beilage 022.

2026 Brief des Ständiger Vertreter des Evangelischen Oberkirchenrates, 14.5.1918, S. 1f, EZA $5 / 2158$.

2027 Prien, S. 167. 
Die brasilianische Regierung sah in deutschen Pastoren „Agenten des Kaisers", die die Kanzel für Kriegs- und Kaiserreden verwendeten. ${ }^{2028}$ Aus diesem Grund wurden sie besonders ins Visier genommen. In Pelotas (RS) und Rio Grande (RS), wo die deutsche Presse sehr aktiv war und sich ein Kern des brasilianischen Nativismus entwickelte, konnten Gemeinden nicht mit neuen Pastoren aus Deutschland besetzt werden. ${ }^{2029}$ In Santa Maria (RS) wurde das Pfarrhaus am 14. April 1917 überfallen und der Pastor musste fliehen. Zwei weitere Geistliche wurden 1918 in Rio Grande do Sul verhaftet, einer musste die Stadt verlassen, der andere wurde bald wieder entlassen. ${ }^{2030}$ Pastor Oberacker aus Arroio do Padre (RS) wurde ohne einen triftigen Grund verhaftet und mit dem Vorwurf als rebellischer Deutscher der Stadt verwiesen. ${ }^{2031}$ In Jaraguá do Sul (SC) wurde das Pfarrhaus Weihnachten 1917 mit Holz und Steinen beworfen ${ }^{2032}$, in Joinville (SC) wurde das Pfarrhaus März 1918 von Soldaten besetzt ${ }^{2033}$ und die Pfarrfamilie in dem Rohbau des Helenenheims untergebracht. ${ }^{2034}$ In Indaial (SC) wurde für Pastor Bergold ein Haftbefehl erlassen, weil er einer polizeilichen Verordnung bezüglich eines Unterrichtsverbots nicht rechtzeitig folgte, wobei ihm diese erst verspätet zugestellt worden war. Nach Klärung der Tatsachen wurde er jedoch nicht verhaftet. ${ }^{2035}$ Beamte aus Campinho-Santa Isabel (ES) rieten Pastor Walter Schmitt 1917, die Stadt zu verlassen. ${ }^{2036}$ In Santa Maria de Jetibá (ES) wurde Pastor Wrede mit zwei Gemeindemitgliedern, Friedrich Grulke und Erwin Kerckhoff, vor der Kircheinweihung inhaftiert, nachdem sie von einem Lehrer, angeblich aufgrund der Verwendung der deutschen Sprache, denunziert worden waren. ${ }^{2037}$ Mehrere Pastoren wurden in Zeitungen persönlich angegriffen. ${ }^{2038} \mathrm{Zu}$ Übergriffen kam es jedoch nur vereinzelt. Pastor Sudhaus aus Santa Cruz do Sul (RS) wurde im November 1917 von Beamten in einer Buchhandlung geschubst, verhöhnt, als Staatsfeind beschimpft und ins Gesicht geschlagen. Er beklagte sich schriftlich beim Staats-

\footnotetext{
2028 Krause, Lutherische Synode in Brasilien, S. 147.

2029 Brief des Ständigen Vertreters des Evangelischen Oberkirchenrates, 14.5.1918, S. 6, EZA $5 / 2158$.

${ }^{2030}$ Dreher, Igreja e Germanidade, S. 108.

2031 Prien, S. 197.

2032 Krause, Lutherische Synode in Brasilien, S. 150.

2033 Wüstner, S. 55, 61.

${ }^{2034}$ Krause, Lutherische Synode in Brasilien, S. 152. Aber die Gemeinde bekam dafür 100 Réis monatlich als Entschädigung. Abschrift eines Briefes von Pastor Bühler, Joinville, 8.8.1918, MLV 51/17 66.

2035 Krause, Lutherische Synode in Brasilien, S. 151.

2036 Abschrift eines Briefes von Pastor Schmitt, 23.11.1917, EZA 5/2576; Brief des Ständigen Vertreters des Evangelischen Oberkirchenrates, 14.5.1918, S. 6f, EZA 5/2158.

${ }^{2037}$ Bericht von Dorothea Hoffmann Wrede im Archiv der Parochie Santa Maria de Jetibá. Zitiert nach Gaede, S. 139 f.

${ }^{2038}$ Radlach. Die Einwirkungen des Weltkrieges auf die deutsch-evangelischen Gemeinden in Santa Catharina. In: Geißler, Bruno (Hrsg.) Die Kulturbedeutung der deutschen evangelischen Kirche in Brasilien, S. 24f, EZA 5/2158.
} 
anwalt im Distrikt Rio Pardo (RS), weil die Polizei nichts dagegen unternahm ${ }^{2039}$, aber sein Protest blieb ohne Konsequenzen für die Angreifer. Pfarrer Schwab in Braço do Norte (SC) erlitt wiederum einen Streifschuss am Kopf und Pastor Radlach aus Badenfurt-Blumenau (SC) wurde als „feindlicher Ausländer" angezeigt, aber er berichtete, die brasilianische Polizei behandelte ihn mit größter Höflichkeit. ${ }^{2040}$

Evangelische wie lutherische kirchliche Gebäude wurden vereinzelt geschlossen oder gar geplündert. Am 24. Dezember 1917 belagerte ein Mob die Kirche in Joinville (SC) während des Gottesdienstes und wartete auf Pastor Müller. Dieser konnte unerkannt entkommen. Die nächsten Gottesdienste mussten auf behördlichen Rat gekürzt werden oder fielen ganz aus. ${ }^{2041}$ Viele Kirchenmitglieder fürchteten sich, angesichts der angespannten Situation, ihre Kirchen zu betreten. Eine detaillierte Beschreibung über eine Kirchenplünderung stammt aus Rio Negro (PR) 1918. Sie dient als Muster für die Beschreibung von möglichen Plünderungen in den hier behandelten pommerschen Gebieten, die aber wegen des Kriegszustandes nicht aufgezeichnet werden konnten:

„Ein wilder Pöbelhaufen drang gegen Abend im Dezember 1918 in die Kirche vor, um sie zu zerstören. Große Pflastersteine wurden in dieselbe geschleudert, die Fenster zertrümmert, der Taufstein beschädigt, desgleichen die Bänke, Leuchter und Verzierungen von Altar und Kanzel herabgerissen. Unter dem Harmonium war Fener angelegt worden "2042

Einerseits unterwarfen sich die Mitglieder der evangelischen und lutherischen Gemeinden den behördlichen Anordnungen und leisteten keinen Widerstand. ${ }^{2043}$ Geistliche versuchten durch Besuche, Hausandachten oder Familienabende die Gemeinde zusammenzuhalten und geistliche Veranstaltungen fanden teilweise an anderen Orten, wie in Privat- und Pfarrhäusern, statt. In Joinville (SC) waren sie aber laut Pastor Wüstner selbst in Privathäusern zeitweilig verboten. ${ }^{2044}$ Wenn eine Gefahr drohte, benachrichtigten sich die Gemeindemitglieder untereinander oder den Pastor. ${ }^{2045}$ Bei vakanten Gemeinden vollzogen Pfarrer aus benachbarten Ge-

2039 Brief von Pastor Sudhaus an den Staatsanwalt des Bezirks Rio Pardo, Dr. João Pompilio de Almeida Filho, vom 30.9.1918, AHI, SR 13/5, Beilage 008.

2040 Radlach. Die Einwirkungen des Weltkrieges auf die deutsch-evangelischen Gemeinden in Santa Catharina. In: Geißler, Bruno (Hrsg.) Die Kulturbedeutung der deutschen evangelischen Kirche in Brasilien, S. 24, 27, EZA 5/2158.

2041 Krause, Lutherische Synode in Brasilien, S. $150 f$.

2042 Krause, Lutherische Synode in Brasilien, S. 149.

2043 Brief des Ständigen Vertreters des Evangelischen Oberkirchenrates, 14.5.1918, S. 6, EZA $5 / 2158$.

2044 Wüstner, S. 51.

2045 Ein Vorstandsmitglied in Badenfurt (SC) kam einmal eilig und aufgeregt zu Pastor Radlach gelaufen, der gerade an einem Nationalfeiertag des Landes Konfirmationsunterricht gab, und bat, dass er schnell die Kinder nach Hause schicken sollte, denn Brasilianer waren in Umzüge organisiert und gegen alles Deutsche erregt. Radlach. Die Einwirkungen des Weltkrieges auf die deutsch- 
meinden Gottesdienste und kirchliche Amtshandlungen. 2046 Andererseits gab es auch Initiativen für die Wiederherstellung des kirchlichen Lebens. Evangelische Gemeinden in Blumenau (SC) und Brusque (SC) und Frauen aus der lutherischen Gemeinde Joinville (SC) wandten sich an den Innenminister in Rio de Janeiro (RJ) und an die Staatsregierung und baten um Aufhebung des Sprachverbots bei kirchlichen Aktivitäten, mit der Begründung, die Bundesverfassung erlaube allen Religionen ihren Kultus frei auszuüben. Weil die Gemeindemitglieder aber kein Portugiesisch verstehen konnten, wurde diese Religionsfreiheit durch das Verbot beschränkt. So erlaubten die Behörden des Staates Santa Catarina die Verwendung der deutschen Sprache in der Liturgie. ${ }^{2047}$ In Joinville (SC) durften ab März 1918 auch der Konfirmandenunterricht und die Chorübung auf Deutsch fortgesetzt werden. ${ }^{2048}$

Liturgische Gottesdienste, die aufgrund der neuen gesetzlichen Maßnahmen während des Kriegs neu gestaltet werden mussten, waren teilweise besser besucht als zuvor. ${ }^{2049}$ Hieraus wird die Bedeutung des Glaubens in widrigen Situationen deutlich. Nachdem die Herausforderungen der ersten Siedlungsjahre überwunden waren, die pommerschen Nachkommen sich emporgearbeitet und einen gewissen Wohlstand erreicht hatten, berichteten einige Quellen über einen Interessensverlust am kirchlichen Leben, wie in Brusque (SC) Anfang der 1880en Jahren ${ }^{2050}$ und in Espírito Santo in den 1880er und 1890er Jahren. ${ }^{2051}$ Als sich jedoch aufgrund des Krieges die ethnische Gemeinschaft in ihrer kulturellen Identität bedroht fühlte, teilweise verfolgt wurde und Gewalt erdulden musste, aber auch aufgrund der Einschränkungen ihres kirchlichen, schulischen und gesellschaftlichen Lebens, gewann ihre Religion und das Gemeindeleben erneut eine große Bedeutung. Sie fanden in Gottes Wort Trost und einen sicheren Halt für die Bewältigung ihrer Ängste und Stärke gegen ethnische Diskrimination und Widrigkeiten.

Mit dem Kriegsende und der Aufhebung des Belagerungszustandes 1919 durfte die deutsche Sprache wieder in Kirche und Schule verwendet werden und gottesdienstliche Handlungen kehrten in ihrer alten Form zurück. ${ }^{2052}$ Alle Synoden engagierten sich bei Wohltätigkeitsaktionen für die Kriegsopfer in Europa, sammelten Lebensmittel- und Kleiderspenden ${ }^{2053}$ und organisierten Kaffeesammlun-

\footnotetext{
evangelischen Gemeinden in Santa Catharina. In: Geißler, Bruno (Hrsg.) Die Kulturbedeutung der deutschen evangelischen Kirche in Brasilien, S. 25, EZA 5/2158.

2046 Brief des Ständigen Vertreters des Evangelischen Oberkirchenrates, 14.5.1918, S. 6f, EZA $5 / 2158$.

2047 Zeitung Jornal da Tarde Nr. 101, 11.3.1918, AHI, SR 13/5 Beilage 034.

2048 Krause, Lutherische Synode in Brasilien, S. $150 \mathrm{f}$.

2049 Schreiben an den Oberkirchenrat in Berlin, 28.3.1919, EZA 5/2483.

2050 Aus der Geschichte der Gemeinde Brusque. In: Gemeindeblatt für die evangelischen Gemeinden Brusque und Itajaby, Nr. 5, 1. Jahrgang, August 1928, S. 3, EZA 5/2525.

2051 Gaede, S. $90 \mathrm{f}$.

2052 Brief des Ständiger Vertreter des Evangelischen Oberkirchenrates, 14.5.1918, EZA 5/2158.

2053 Prien, S. 185, 218; Schulze, S. 149.
} 
gen2054 für Deutschland. Das zeigt, dass die ethnische Verbindung mit der alten Heimat noch eng war, obwohl die Bedeutung des sozialen Engagements als sinnvolles Projekt für Menschen, die nach schwierigen Erfahrungen anderen helfen wollen, nicht geleugnet werden kann.

Der Erste Weltkrieg und die Maßnahmen gegen deutschsprachige Gemeinden führten auf eine positive Weise zu einem Transformations- und Erlernungsprozess. Gemeinden und Pastoren evangelischer und lutherischer Konfession, die gemeinsam von den Repressalien betroffen gewesen waren, erkannten die Notwendigkeit einer friedlichen Zusammenarbeit. 1919 begannen die Verhandlungen zwischen der Mittelbrasilianischen Synode und der Evangelisch-Lutherischen Synode für eine gemeinsame Arbeit in Espírito Santo. Geistliche des Evangelischen Oberkirchenrates erklärten sich bereit, große Gemeinden an lutherische Pastoren abzugeben und dafür kleinere zu übernehmen. Nicht alle Gemeindemitglieder und Gemeinden unterwarfen sich aber den Beschlüssen, die von den oberen Kircheninstanzen oder Geistlichen getroffen wurden. ${ }^{2055}$ Die lutherischen Pastoren Wrede und Petersen hielten sich beispielsweise nicht an die Vereinbarungen und gründeten kleinere Kapellengemeinden mitten in größeren evangelischen Gemeinden und versprachen den Gemeindemitgliedern eine günstigere Pfarrbetreuung als die bisherige. Um dagegen anzugehen schlossen evangelische und lutherische Gemeinden in Espírito Santo im November 1925 das Santa Maria Abkommen ab. Es beinhaltete Zuständigkeitsgrenzen, gegenseitige Vertretung bei kirchlichen Amtshandlungen, gegenseitige Besuche bei festlichen Aktivitäten und eine Gleichschaltung der Pfarrgehälter, um der gegenseitigen Konkurrenz ein Ende zu machen. ${ }^{2056}$ Das Problem der Konkurrenz in Bezug auf geringere Pfarrbesoldungen konnte allmählich auch in Santa Catarina durch intersynodale Konferenzen überwunden werden. Im Februar 1921 einigten sich alle Gemeinden, die jemals zur Kolonie Blumenau (SC) gehört hatten, über gleiche Grenz- und Beitragsregelungen während einer Kirchenversammlung in Indaial (SC).2057 Im August 1926 fand ein erstes Zusammentreffen zwischen evangelischen und lutherischen Geistlichen in Jaraguá do Sul (SC) statt. Der Dialog trug zur Entstehung einer besseren Atmosphäre zwischen beiden Seiten bei, obwohl Grenzstreitigkeiten und Übertreten von Gemeindemitgliedern aufgrund billigerer Kirchenbeiträge immer wieder geschahen. ${ }^{2058}$ Erst in der intersynodalen Konferenz in Jaraguá do Sul (SC) 1934 einigten sich der Gemeindeverband Evangelischer Gemeinden von Santa Catarina und Paraná und die Evangelisch-Lutherische Synode über den Anschluss der lutherischen Gemeinde

\footnotetext{
2054 Abschrift des Briefes des Schulrates in Rio Bonito, Santa Leopoldina, 18.10.1926. Zitiert nach Rölke, Raízes da Imigraşão alemã, S. $119 \mathrm{f}$.

2055 Das geschah in den Gemeinden Crisciúma (ES), Guandu (ES), Prien, S. 242 und mit Gemeindemitglieder des Pfarrbezirks São Bento (ES), Lutherische Kirche in Brasilien, S. 202.

${ }^{2056}$ Damitz, Entwicklungsaspekte zur Situation der Brasilianer, S. 29.

2057 Giurus, Crônica da Paróquia Evangélica Luterana de Indaial, S. 131-133.

2058 Wie zwischen der lutherischen Gemeinde Indaial (SC) und der evangelischen Gemeinde Timbó (SC). Brief Pastors Bergold von 8.2.1921, AHI, SL 1/1, Beilage 075.
} 
Curitiba (PR) an den Evangelischen Gemeindeverband, die im Gegensatz etwa 1.340 Familienmitglieder der Pfarrbezirke Indaial (SC) und Massaranduba (SC) abgeben sollte. ${ }^{2059}$ Nach einem Jahr beschwerte sich jedoch Propst Funcke über Implementierungsfehler und gegenseitiges Misstrauen. ${ }^{2060}$ Immerhin setzte sich der Dialog fort. Diese Entwicklung weist jedenfalls auf einen kontinuierlichen Wachstumsprozess unter Geistlichen, Mitgliedern, Gemeinden und Synoden, trotz Rückschlägen, hin.

\section{Die Position der Deutschen und Deutschbrasilianer im Verhältnis zum brasilianischen Integralismus und zum Nationalsozialismus}

Bevor auf die strengen Nationalisierungsmaßnahmen mit der Entstehung des Neuen Staates eingegangen wird, soll der Schauplatz zweier nationalistischer Wellen, dem brasilianischen Integralismus und dem deutschen Nationalsozialismus, analysiert werden. Zudem soll die Position der Deutschen und Deutschbrasilianer beiden Ideologien gegenüber betrachtet werden, um die Folgen im Nationalisierungsprozess und im Zweiten Weltkrieg gegen sie verstehen zu können.

\subsection{Der brasilianische Integralismus}

Viele Einwanderer und deren Nachkommen traten der Integralistischen Bewegung in Brasilien bei oder sympathisierten mit ihr, obwohl es sich hierbei um eine brasilianisch-nationalistische Bewegung handelte. Warum es dazu kam und welches Interesse dahinter stand, soll nun kurz betrachtet werden.

Im Zuge des brasilianischen Nationalismus wurde 1932, wie bereits im zweiten Kapitel dargestellt, die Integralistische Bewegung gegründet. Diese fand große Akzeptanz innerhalb der deutschen Siedlungsgebiete ${ }^{2061}$, vor allem bei einflussreichen Persönlichkeiten ${ }^{2062}$, in Santa Catarina auch unter Mitgliedern der mittleren und

\footnotetext{
2059 Prien, S. 329 f.

2060 Bericht Funckes von 16.11.1935, S. 3ff. Zitiert nach Prien, S. 318f.

${ }^{2061}$ In Espírito Santo bildeten sich integralistische Kreise in Gebieten deutscher und italienischer Kolonisation, wie Vitória, Domingos Martins, Pau-Gigante, Cachoeiro do Itapemirim, Colatina, möglicherweise auch in Santa Teresa und Castelo. Pommersche Siedler standen sogar unter der Führung der integralistischen Partei in Domingos Martins (ES). Ackermann, S. 7, 36-38. In Santa Catarina gab es integralistische Ortsgruppen in Blumenau, Itajaí und Joinville, Kahle, S. 113f, die aber Anhänger und eine bedeutende Wahlquote in benachbarten Städten, wie Jaraguá do Sul, São Bento do Sul, Brusque, Timbó und Rio do Sul erzielten. In Rio Grande do Sul waren sie in Novo Hamburgo, Campo Bom, São Leopoldo und Santa Cruz do Sul vertreten. Gertz, O fascismo no sul do Brasil, S. 158-172.

${ }^{2062}$ Hunsche, Karl-Heinrich. Der Brasilianische Integralismus. Geschichte und Wesen der faschistischen Bewegung Brasiliens. Stuttgart, 1938, S. 118-123. Zitiert nach Wirth, S. 26.
} 
Arbeiterschicht ${ }^{2063}$ und in Espírito Santo hauptsächlich unter der ländlichen Bevölkerung. ${ }^{2064}$ In der Hauptstadt dieses Staates, Vitória (ES), fand die erste Versammlung der Bewegung 1934 statt, wobei Plínio Salgado zum Führer gewählt wurde. Hier sollen viele Bewohner der Bewegung aus Angst, ihre Ländereien mit einem Erstarken der kommunistischen Partei zu verlieren, beigetreten sein. ${ }^{2065} \mathrm{Im}$ Südbrasilien hatte der wachsende Industrialisierungsprozess den unteren Schichten einen sozialen Aufstieg ermöglicht und diese Gruppe nutzte den Integralismus als Instrument zum Erwerb politischen Ansehens. In Santa Catarina entstand der Integralismus auch als Alternative zur nativistischen Oberschicht, die den Einwanderern und deren Nachkommen feindlich gegenüber standen. ${ }^{2066}$

Deutschbrasilianer sehnten sich nach einer politischen Veränderung, an welcher sie aktiv partizipieren konnten. Sie hofften, dass sich im Zuge des nationalistischen Integralismus ihre ökonomische und politische Situation im Land bessern würde, ebenso wie Hitler in Deutschland für Fortschritt, Modernität und für die Beschaffung neuer Arbeitsstellen durch den Nationalsozialismus gesorgt hatte. ${ }^{2067}$ Der Integralismus versprach ihnen eine politische Partizipation ${ }^{2068}$, stellte sie erstmalig allen Brasilianern gleich und wusste die Betonung ihrer brasilianischen Staatsbürgerschaft, trotz ihrer kulturellen und ethnischen Besonderheit, zu ihren Gunsten zu nutzen. ${ }^{2069}$ Er sicherte ihnen auch den Schulunterricht in deutscher Sprache selbst in staatlichen Schulen, falls dort die Hauptsprache Portugiesisch wäre ${ }^{2070}$, und selbst Brasilianer sollten Deutsch lernen. ${ }^{2071}$ Integralisten organisierten Abendkurse zur Erlernung der Landessprache ${ }^{2072}$, eine Initiative, die von vielen Deutschbrasilianer gelobt wurde, und predigten die Akzeptanz ethnischer Pluralität ebenso wie die Bewahrung deutscher Kultur und Institutionen, obwohl dies in Gegensatz zur Parteiideologie stand.

Deutschbrasilianer, die aufgrund ihrer brasilianischen Staatsbürgerschaft von einer Mitgliederschaft an der deutsch-nationalsozialistischen Partei ausgeschlossen

2063 Ulrich, S. 199-201; Altmann, S. 46.

2064 Ackermann, S. 59. Laut Ackermann ist fragwürdig, ob die Anhängerschaft zum Integralismus in Verbindung mit dem Industrialisierungs- und Urbanisierungsprozess zu sehen ist. Ebd., S. 92. Auch Pastor Müller berichtet, dass der Integralismus in Joinville (SC) 1935 Mitglieder aus allen Ständen umfasste. Brief von Pastor Müller an Dr. Eppelein, Joinville, 16.2.1935, MEW 4.209.

2065 Ackermann, S. 28f, 33.

2066 Gertz, O fascismo no sul do Brasil, S. 169, 195-197, $201 \mathrm{f}$.

2067 Ackermann, S. 93, 294; vgl. Bericht von Herbert und Dorothea Kuhn. Zitiert nach Rölke, Raízes da Imigração alemã, S. 416; Altmann, S. 46.

${ }^{2068}$ Gertz, O fascismo no sul do Brasil, S. 114f.

${ }^{2069}$ Seyferth, Nacionalismo e identidade étnica, S. 105; vgl. Ackermann, S. 62.

2070 Zeitung O Integralista von 15.11.1934, Porto Alegre. Zitiert nach Kahle, S. 116; Kuehne, João. O Integralismo nazi-fascista em Santa Catarina. In: Delegacia de ordem política e social de Santa Catarina. O punbal narista no coração do Brasil. Florianópolis: Imprensa Oficial do Estado, 1944, S. 169; Seyferth, Nacionalismo e identidade étnica, S. $103 f$.

2071 Reale, Miguel. Diretrizes do Integralismo, Blumenauer Zeitung 24.12.1935. Zitiert nach Kuehne, O Integralismo nazi-fascista em Santa Catarina, S. 163.

2072 Gertz, O fascismo no sul do Brasil, S. 187. 
waren, fanden Übereinstimmungen zwischen beiden Regimen und traten dem brasilianischen Integralismus bei. ${ }^{2073}$ Sie wurden teilweise als dasselbe Regime in unterschiedlichen Ländern verstanden ${ }^{2074}$ und der Integralismus als ,brasilianischer Nationalsozialismus" vorgestellt ${ }^{2075}$, während Nicht-Integralisten als Kommunisten galten. ${ }^{2076}$ Der entscheidende Unterschied zwischen beiden Nationalismen fiel ihnen nicht auf: Während der Integralismus für die Integration aller Rassen in einem brasilianischen Volk im Sinne eines Staates plädierte, setzte sich der Nationalsozialismus für die Bewahrung einer reinen Rasse im Sinne einer Volksgemeinschaft ein. ${ }^{2077}$ Prien spricht aber über eine enge Kooperation zwischen Nationalsozialisten und Integralisten ${ }^{2078}$ und es gibt Indizien über Kontakte zwischen Mitgliedern beider Parteien. ${ }^{2079}$ Integralisten machten gleichzeitig Propaganda für beide Nationalismen, obwohl Gertz eine politische Allianz zwischen beiden Parteien ausschließt. ${ }^{2080}$ Die NSDAP erlaubte nur „notmäßig“ eine Anhängerschaft ihrer Mitglieder an die integralistische Bewegung ${ }^{2081}$ und betrachtete mit Sorge die Entwicklung des Integralismus in Siedlungsgebieten, denn dieser stimmte nicht mit ihren eigenen Interessen in Brasilien überein, auch wenn sie den Integralismus für sein Anliegen, Kommunisten zu verfolgen und die Liberaldemokratie zu bekämpfen, lobten. ${ }^{2082}$ Nach Seyferth ist es auch schwierig zu behaupten, dass Hunderte von Menschen, die sich mit dem deutschen Nationalismus und seiner extremen anti-brasilianischen Politik identifizierten, gleichzeitig Mitglieder einer

2073 Ackermann, S. 65; Gertz, O fascismo no sul do Brasil, S. 114; Kuehne, O Integralismo nazi-fascista, S. 125. Ackermann vermutet, dass Siedler in Domingos Martins (ES) sich mit dem Integralismus identifizierten, weil in Espírito Santo fast keine nationalsozialistischen Parteikerne vorhanden waren. Sie sieht eine Verbindung zwischen Ethnie und Integralismus unter Deutschbrasilianer in dieser Stadt. Ackermann, S. 303.

2074 Ackermann, S. 277; Briefe von Baericke an den Major Hansotto Vorberg, 30.5.1933 und 15.6.1933. In einem Brief von 25.2.1934 schreibt er, dass die Organisation der integralistischen Bewegung identisch mit dem Nationalsozialismus ist. Wenn das „gründe Hemd" (Integralisten) seine Funktion erfüllt habe, könne man wieder die „braune Farbe“ (Nationalsozialismus) anziehen. Beide Briefe zitiert nach Kuehne, O Integralismo nazi-fascista em Santa Catarina, S. 122f.

2075 Kolonie-Zeitung, Nr. 85, 25.10.1933. Zitiert nach Seyferth, Nacionalismo e identidade étnica, S. 103.

2076 Ackermann, S. 295.

2077 Kahle, S. 115-117.

2078 Prien, S. 285 f.

2079 Integralisten beteiligten sich beispielsweise an die Feier des Aufstiegs Hitlers in Rio de Janeiro (RJ). Ackermann, S. 65. Die Tochter des ehemaligen deutschen Konsuls in Blumenau (SC) und Beauftragter des Wirtschaftsdepartments der Nationalsozialisten in Santa Catarina, Sigrid Rohkohl, besaß eine integralistische Mitgliedskarte vom Jahre 1934 und drei Integralisten aus Brusque (SC) gründeten einen NSDAP-Kreis in der Stadt. Kuehne, O Integralismo nazi-fascista em Santa Catarina, S. $127,135$.

2080 Blumenauer Zeitung von 9.6.1934 und 24.7.1934. Zitiert nach Gertz, O fascismo no sul do Brasil, S. $192 \mathrm{f}$.

2081 Brief des Ortsgruppenleiters in Blumenau an den Stuetzpunktwalter der DA in Hansa-Humboldt (SC) von 9.1.1936. Zitiert nach Kuehne, O Integralismo nazi-fascista em Santa Catarina, S. 134. 2082 Kahle, S. $114 \mathrm{ff}$. 
brasilianisch-nationalistischen Partei sein konnten. ${ }^{2083}$ Jedenfalls wurde der Integralismus ideologisch durch den Nationalsozialismus beeinflusst und wollte ihn teilweise nachahmen. Präsident Vargas wiederum gehörte früher zum Integralismus, distanzierte sich jedoch 1937 von ihm und unterhielt zwischenzeitlich gute Beziehungen zum Dritten Reich. ${ }^{2084}$

\subsection{Der Nationalsozialismus}

Einwanderer und Deutschbrasilianer wurden im Zweiten Weltkrieg als „Nazis" beschimpft, angegriffen und inhaftiert, obwohl viele eine offene Opposition zu den Nationalsozialisten verfolgten. In welchen Kreisen Sympathisanten und Parteimitglieder in den hier betrachtenden Siedlungsgebieten zu finden waren, welche Interessen oder unter welchen Bedingungen Deutsche und Deutschbrasilianer als Mitglieder akzeptiert wurden und wie Menschen verschiedener Schichten auf die Aktivität der NSDAP in Städten, Vereinen, Schulen und Kirche reagierten, soll im Folgenden betrachten werden.

Die Entstehung des ersten Kreises der NSDAP (Nationalsozialistische Deutsche Arbeitspartei) 1931 in der Hauptstadt des Staates Rio Grande do Sul, Porto Alegre (RS), soll zunächst mit Wohlwollen unter der deutschbrasilianischen Bevölkerung betrachtet worden sein. ${ }^{2085}$ In Santa Catarina entfaltete der Nationalsozialismus seine Aktivitäten besonders zwischen 1933 und 1938 in Verbindung mit einem neuen Zustrom deutscher Einwanderer. Ortsgruppen bildeten sich in Blumenau (SC), Itajaí (SC) und Joinville (SC). ${ }^{2086}$ In Espírito Santo wiederum engagierte sich der Nationalsozialismus nicht so stark wie im Süden bei der Anwerbung von Mitgliedern ${ }^{2087}$, weil hier seit 1875 nicht so viele Reichs- und Neudeutsche eingewandert waren. Aber auch hier gab es Mitglieder und Mittel für die Verbreitung der Volkstumsideologie, unter anderem durch deutsche Pastoren und deutsche Zeitungen aus dem Süden.

Nationalsozialisten in Brasilien organisierten mit Hilfe des deutschen Konsulats Hitlers Geburtstagsfeiern ${ }^{2088}$ und andere nationalsozialistische Feiertage ${ }^{2089}$, wie beispielsweise in São Leopoldo (RS), Porto Alegre (RS), Blumenau (SC), Brusque (SC) und Florianópolis (SC), tätigten Sammlungen für das Winterhilfswerk $^{2090}$ und Eintopfsonntage. Prien weist aber darauf hin, dass kirchliche Ge-

\footnotetext{
2083 Seyferth, Nacionalismo e identidade étnica, S. 103.

${ }^{2084}$ Gertz, O fascismo no sul do Brasil, S. 116f, 132.

2085 Vortrag von Dr. Frick in Gleiwitz, In: Deutsche Allgemeine Zeitung, 28.11.1937. Zitiert nach Py, S. 147.

2086 Kahle, S. $113 \mathrm{f}$.

2087 Ackermann, S. 135.

2088 Prien, S. 386.

2089 Siehe Fotos verschiedener nationalsozialistischen Feiern und Versammlungen im Anhang bei Py. Über beschlagnahmtes Material in Santa Catarina Fáveri, S. 236-243.

2090 Seyferth, Nacionalismo e identidade étnica, S. 93f. Nach Angaben von Seyferth finanzierte er nicht Kriegsbetroffene, sondern die NSDAP.
} 
meinden und Anstalten sich in gewisser Weise gezwungen sahen, an Sammlungen für das Winterhilfswerk mitzuwirken, um die finanzielle Unterstützung des Kirchlichen Außenamtes oder der Deutschen Evangelischen Kirche für die Synoden nicht zu verlieren. ${ }^{2091}$ Im Anschluss an diese Veranstaltungen oder auch unabhängig davon wurden Aufmärsche mit Uniformierten und mit der Hakenkreuzflagge veranstaltet ${ }^{2092}$, die die brasilianische Bevölkerung und die Polizei provozierten. ${ }^{2093} \mathrm{Zu}$ diesen Anlässen, aber auch in der Synodalversammlung der Riograndenser Synode 1934 wurden neben der brasilianischen die deutschen Reichs- und Hakenkreuzflaggen begrüßt. ${ }^{2094}$ Bilder von Hitler und Nazisymbole wurden ausgestellt und die brasilianische und deutsche Hymne gesungen. ${ }^{2095}$

Der Nationalsozialismus gewann vor allem deshalb die Sympathien der Deutschbrasilianer, weil diese sich eng mit der Kultur ihrer Vorfahren verbunden fühlten und in einer Beteiligung an der NSDAP im Ausland eine Möglichkeit fanden, mehr über die deutsche Politik zu erfahren. Zudem wollten sie auch Widerstand gegen eine zwangsmäßige Assimilation durch den brasilianischen Nationalismus leisten und somit aus ihrer politischen Isolierung seit dem Ersten Weltkrieg heraustreten. Einige glaubten an eine Angliederung ihrer deutschen Herkunftsgebiete an Deutschland und somit an eine mögliche und definitive Rückkehr zur Heimat. ${ }^{2096}$ Nach Gertz war es aber schwierig zu unterscheiden zwischen dem, was als Deutschtumsideologie, bewusste Anhängerschaft zum Nationalsozialismus oder Treuedemonstration zur brasilianischen Regierung galt ${ }^{2097}$, die bis dahin eine gute Beziehung zu Deutschland pflegte, an deutschen Feierlichkeiten in den Siedlungsgebieten teilnahm und diese sogar förderte. Letztere Vermutung wirkt jedoch ein wenig übertrieben, denn Deutschbrasilianer sahen in den Beteiligungen staatlicher Autoritäten an ihren Feiern höchstens die Anerkennung ihrer Beiträge als Staatsbürger deutscher Abstammung. Oft verstanden sie aber nationalsozialistische Symbole als rein ethnisch-kulturelle Elemente, deren Inhalte ihnen kaum bekannt war, aber dennoch verehrt wurden. Nach Perazzo bedeutete beispielsweise der Besitz eines Nazisymbols nicht immer eine bewusste politisch-ideologische

\footnotetext{
${ }^{2091}$ Deutsche Evangelische Kirche A. 320, Berlin, 21.1.1936 an die Vorsitzenden vom Evangelischen Gemeindeverband, der Mittelbrasilianischen Synode und den Ständigen Vertreter. Zitiert nach Prien, S. 326 .

2092 Schulze, S. 102; Ribas, Antônio de Lara. O Nazismo em Santa Catarina. In: Delegacia de ordem política e social de Santa Catarina, O punbal naz̧ista no coração do Brasil. Florianópolis: Imprensa Oficial do Estado, 1944, S. 20, 22 f.

2093 Py, S. 42, 147; Ludwig, S. 87f.

2094 Flaggeordnung der DEK von RS - Synodalberichte 1914-1936, 41. Synodalversammlung, S. 74f. Zitiert nach Prien, S. 309.

2095 Perazzo, S. 61.

2096 Magalhães, Pangermanismo e nazismo, S. 43f. Ein Lehrer in Pomerode (SC) glaubte, Hitler könnte deutsche Nachkommen repatriieren. Altmann, S. 46.

2097 Gertz, O fascismo no sul do Brasil, S. 90.
} 
Identifikation mit dem Regime, denn Siedler zeigten oft Zuneigung für jede Erinnerung an die Heimat ihrer Vorfahren. ${ }^{2098}$

Die Anzahl der NSDAP-Mitglieder in Brasilien war gering2099 und unter ihnen waren besonders reichsdeutsche Geschäftsleute als Sympathisanten oder Parteianhänger vertreten. ${ }^{2100}$ Das ist unter anderem der nationalsozialistischen Propaganda in Brasilien zu entnehmen, die besonders eine deutsche und deutschbrasilianische städtische Elite erreichte. ${ }^{2101}$ Die urbane deutschsprachige Gemeinde stand auch in engem Kontakt mit Konsulaten, Firmen und deutschen Banken ${ }^{2102}$, in denen Mitglieder der Nazipartei einen immer größeren Einfluss ausübten. Diplomaten, Export- und Importangestellte, Mitarbeiter der Telegrafenunternehmen, Unternehmer, Angestellte deutscher Firmen und deutsche Beamte waren von der Partei abhängig 2103 und standen, gewollt oder ungewollt, mit dem Nationalsozialismus in Verbindung. Wer sich nicht freiwillig der Partei anschloss, sich neutral verhielt oder eine anti-nationalsozialistische Position vertrat wurde als „Verräter" bezeichnet ${ }^{2104}$, verfolgt, gedemütigt, kontrolliert ${ }^{2105}$ und boykottiert. ${ }^{2106}$

2098 Perazzo, S. 163.

2099 Nach Gertz waren es höchstens 5.000 Parteimitglieder. In Rio Grande do Sul und in Santa Catarina waren es etwa 400 bis 500 Parteimitglieder bei mehr als 25.000 Reichsdeutschen. Gertz, O fascismo no sul do Brasil, S. 86. Herbert Guss, ehemaliger Nazileiter in Brasilien berichtet, dass 1936 800.000 Menschen deutscher Abstammung in Brasilien lebten, davon waren höchstens 30.000 in Deutschland geboren. Von diesen sollten etwa 2.000 NSDAP-Parteimitglieder gewesen sein. Brief von Hermann Guss, Rio de Janeiro, 9.8.1936. Zitiert nach Py, S. 38. In Espírito Santo gab es 41 Nazi-Mitglieder unter 623 Reichsdeutschen. Ackermann, S. 65, 135.

${ }^{2100}$ Nach dem polizeilichen Bericht waren NSDAP-Mitglieder Bankiers, Geschäftspersonen, Unternehmer und deren Mitarbeiter, Industrielle, Lehrer, Schuldirektoren, Ingenieure, Journalisten, Versicherungsvertreter, Verleger, Elektrotechniker, Transportmitarbeiter, Buchhalter, Pastoren, Metzger, Mechaniker, Fahrer und Ärzte. Investigationsbericht über die Nazipartei, von Octávio Ramos Jr., São Paulo, 16.9.1942. Strafregister Nr. 5.405 "Nazismo". DEOPS-SP, DAESP und Schreiben (Anschrift) von Antonio Lara Ribas, Polizeikommissar von Florianópolis, an Antonio Mourão Ratton, Sicherheitssekretär von Santa Catarina. Delegacia de Ordem Política e Social, Florianópolis, 3.12.1943. Ministerium der Justiz und Inneren Angelegenheiten, Nationale Sicherheitsabteilung, IJ1 1382, ANRJ, (B113, PFP). Zitiert nach Perazzo, S. 64f, 236-244.

${ }^{2101}$ Seyferth, Nacionalismo e identidade étnica, S. 176.

${ }^{2102}$ Deutsche Konsulate pflegten enge Korrespondenz mit Parteimitgliedern in Deutschland und bekamen Propagandamaterial, das in deutschen Siedlungsgebieten verteilt wurde. Der deutsche Konsul in Porto Alegre (RS) kontrollierte die Parteifinanzen, die direkt von Berlin an die Auslandsorganisationen gesandt und von der deutsch transatlantischen Bank für bestimmte Personen gutgeschrieben wurden. Außerdem sollte er junge Deutsche in Brasilien für die nationalsozialistische Armee registriert haben. Py, S. 82-94, vgl. Neue Deutsche Zeitung Nr. 159, 8.7.1939. Die „Freiwilligen“ mussten sich dem deutschen Konsulat vorstellen. Wer sich bis 31.7 .1939 nicht registrieren ließ, musste eine Strafe zahlen oder konnte verhaftet werden.

2103 Gertz, O fascismo no sul do Brasil, S. 64; Perazzo, S. 62.

${ }^{2104}$ Py, S. 58, 297.

2105 Mitglieder, die aus der Partei austraten, wurden Opfer der Rache ehemaliger Parteigenossen. Py, S. 334-341, 360-367.

2106 Beispielsweise Geschäftsleute, Zeitungsdirektoren, Firmen und Industrien. Py, S. 44, 49, 112, 143, 148, 158, 166; Dreher, Igreja e Germanidade, S. 51. 
Aber auch etliche Geistliche und Lehrer ${ }^{2107}$ waren Mitglieder oder verbreiteten die nationalsozialistische Ideologie, was als Grund für ihre spätere Verfolgung und Inhaftierung galt. Die Riograndenser Synode wurde sogar als Abteilung der NSDAP angesehen. ${ }^{2108}$ Der Bischof der Deutschen Evangelischen Kirche, Theodor Heckel, versuchte jedoch die Fortführung der Diskussionen um den Kirchenkampf in Brasilien zu vermeiden. ${ }^{2109}$ Alle vier brasilianischen Synoden verhielten sich als kirchliche Organisationen neutral, obwohl jeder Geistliche individuelle Sympathien für die eine oder andere Richtung aufweisen konnte, wie es auch bei den Gemeinden der Fall war. In der Regel sprachen aber Geistliche ihre Treue gegenüber der deutschen Kirchenleitung aus. In Santa Catarina berief sich der Evangelische Gemeindeverband von Santa Catarina und Paraná nach Wirth auf Hitler oder auf die nationalsozialistische Lehre, kritisierte aber nationalsozialistische Tätigkeiten und Äußerungen, die die vom Deutschtum gesetzten Grenzen überschritten. Eine klare inhaltliche Unterscheidung zwischen Nationalsozialismus und Deutschtumspflege nahm der Evangelische Gemeindeverband aber auch nicht vor. ${ }^{2110}$ Geistliche der Lutherischen Synode stellten Luther und Hitler als Führer zur Errettung des deutschen Volkes dar und nahmen die rassistische Ideologie kritiklos auf.2111 Pastor Fischer gründete in Guandu (ES), Laranja da Terra (ES) und Cresciuma (ES) Kampfgemeinschaften oder Mädchenfreizeiten ${ }^{2112}$, die sich gegen Mischehen und für die Bewahrung einer reinen Rasse unter den Einwanderern und deren Nachkommen einsetzten. ${ }^{2113}$ Auch in São Leopoldo (RS) nahm die Arbeit mit Jugendlichen nach 1933 immer mehr

${ }^{2107}$ Der Lehrer des evangelischen Lehrerseminars, Hermann Wrede, war Ortsleiter in São Leopoldo (RS), Gertz, O fascismo no sul do Brasil, S. 166. Eine polizeiliche Durchsuchung im Evangelischen Proseminar in São Leopoldo (RS) fand 1938 eine Korrespondenz zwischen Pastor Knäpper und verschiedenen Abteilungen der NSDAP in Deutschland. Bei Pastor Hugo Kammer in Santa Cruz do Sul (RS) fand die brasilianische Polizei Briefmarken, die nach ihrer Sicht als Ersatz für Beitragsquittungen verwendet wurden. Sie ging davon aus, dass er die Finanzen der Partei kontrollierte, obwohl sie keine Beweise für diese Vermutung vorlegte. Bericht des Inspektorchefs Armin Walter Bernhard an den Polizeichef Aurélio da Silva Py. Zitiert nach Py, S. 192-194, 229. Auch in Serra Pellada (ES) beschlagnahmte die Polizei nationalsozialistisches Propagandamaterial unter Geistlichen, Ackermann, S. 140. Bücher mit nationalsozialistischen Inhalt wurden durch die Bücherei des Evangelischen Gemeindeverbandes von Espirito Santo verbreitet, unter ihnen Werke, wie Mein Kampf und Wir Deutsche in der Welt, Rölke, Raízes da Imigração alemã, S. 406. Später traten manche Pastoren aus der NSDAP aus, weil sie nicht mehr mit deren Ideologie übereinstimmten. Dreher, Igreja e Germanidade, S. 172.

2108 Py, S. 212; Vida Policial. Porto Alegre, September 1942, S. 37; Januar 1943, S. 46; September 1943, S. 53. Zitiert nach Dreher, Igreja e Germanidade, S. $170 f$.

${ }^{2109}$ Über die Diskussion um den Kirchenkampf innerhalb der Synoden Dreher, Igreja e Germanidade, S. 125-164; Prien, S. 397-421; Wirth, S. 149-152.

${ }^{2110}$ Wirth, S. 149.

2111 Evangelisch-lutherisches Gemeindeblatt, v. 28, Nr. 2, Februar 1934 und Nr. 3, März 1934. Zitiert nach Prien, S. $418 f$.

2112 Synodalversammlung in Pontal am 21.5.1934 und Kreisversammlung in Laranja da Terra am 17.6.1936. In: Protokollbücher des Synoden Nordkreises in Brasilien, MEW 3.22; Schmidt, Die Anfänge der Diakonie, S. 171-174; Dreher, Igreja e Germanidade, S. 208f.

${ }^{2113}$ Rölke, Raízes da Imigração alemã, S. 410. 
nationalsozialistische Formen an ${ }^{2114}$ und in Timbó (SC) organisierte der Lehrer Nils eine Pfadfinderschaft nach dem Muster der Hitlerjugend. ${ }^{2115}$

NSDAP-Mitglieder übten einen großen Druck auf Deutsche und Deutschbrasilianer aus. Aus ihrer Sicht verloren diejenigen, die mit dem Nationalsozialismus nicht einverstanden waren, ihr Deutschtum und stellten keine wahren Deutschen mehr dar. Jedoch besonders in städtischen Gemeinden ${ }^{2116}$, wo eine große Anzahl von NSDAP-Anhängern zu finden war, bildete sich eine offene und bewusste Opposition zum Nationalsozialismus. Diese stellte sich gegen die Tätigkeit der NSDAP in Brasilien und kritisierte das Vorgehen der Auslandsorganisation, ihr öffentliches und provozierendes Verhalten, mit dem sie die Wut der Nativisten in Brasilien auf sich zogen. ${ }^{2117}$ Die Erinnerung an das Anti-Deutsche-Verhalten der brasilianischen Gesellschaft gegenüber Deutschen und Deutschbrasilianern im Ersten Weltkrieg trug wesentlich zu dieser kritischen Haltung bei. Das Eindringen der Nationalsozialisten und ihrer Ideologie könnte ihrer Ansicht nach eine Gefahr für eine gemäßigtere Deutschtumspflege darstellen. In Deutschland wiederum berichtete man enttäuscht über den Mangel an nationalsozialistischer Begeisterung bei den Deutschbrasilianern. ${ }^{2118}$ In Rio Grande do Sul kam es bald zu Protesten gegen die Aktivitäten der NSDAP und der größte Teil der Deutschbrasilianer weigerte sich, der reichsdeutschen Führung zu folgen. Andere waren der Meinung, deutsche Wirtschaftsinteressen in Brasilien dienten einem Missbrauch des Deutschtums, wie die Deutschbrasilianer es verstanden. In Santa Catarina wurden fast alle NSDAP-Ortsgruppen sowohl von Deutschen als auch Deutschbrasilianern abgelehnt. In Joinville (SC) missbilligten Deutschbrasilianer die Besuche von Parteigenossen in Schulen, um Spenden für das Winterhilfswerk zu sammeln. Sie waren auch gegen Angriffe und den Boykott von Firmen und Unternehmensmitarbeitern, gegen die Einmischung in kirchliche Angelegenheiten ${ }^{2119}$ und gegen eine vermutliche Annexion der südlichen Staaten Brasiliens an das Deutsche Reich. ${ }^{2120}$

Die ländliche Bevölkerung zeigte meistens kein Interesse am Nationalsozialismus oder leistete ihm keine bewusste Gefolgschaft ${ }^{2121}$, obwohl damit nicht gesagt

\footnotetext{
2114 Dreher, Igreja e Germanidade, S. 142-148.

2115 Weingärtner, História da Comunidade Evangélica de Timbó, S. 141. Über die Jugendarbeit in den brasilianischen Synoden und ihre Beziehung zu der Hitlerjugend siehe Prien, S. 387-397. Über die Arbeit des Jugendrings in Rio Grande do Sul siehe Py, S. 239-283. Andere Zellen der nationalsozialistischen Partei in Brasilien waren die Deutsche Arbeitsfront, die Arbeitsgemeinschaft der deutschen Frauen im Ausland, der Bund deutscher Mädchen im Ausland, der Verein der nationalsozialistischen Lebrer und der Deutsche Kriegsverein. Py, S. 68f; Ribas, O Nazismo em Santa Catarina, S. $24 \mathrm{f}$.

2116 Dreher, Igreja e Germanidade, S. 175.

2117 Brief des Lehrers Robert Soechting, 2.1.1934, BA R5 7/1193. Zitiert nach Gertz, O fascismo no sul do Brasil, S. $84 f$.

2118 Schulze, S. 102f, 248-250; Gertz, O fascismo no sul do Brasil, S. 82; Py, S. 52f.

2119 Bericht des Konsuls Gerken, 8.10.1933, BA, ZSg 133/63 Bd. 8. Zitiert nach Gertz, O fascismo no sul do Brasil, S. 84.

2120 Seyferth, Nacionalismo e identidade étnica, S. 68f.

2121 Seyferth, Nacionalismo e identidade étnica, S. 176; Perazzo, S. 61.
} 
war, dass sie vom Nationalsozialismus keine Kenntnis hatten. Sie waren gegen die Organisation einer fremden Partei in Brasilien und lehnten diese sogar teilweise $\mathrm{ab}^{2122}$, was oft auch kommerzielle und persönliche Verfolgung auslöste. ${ }^{2123}$ Sie missbilligten auch die Einbeziehung von Themen der reichsdeutschen Politik in den Predigten. ${ }^{2124}$ Nationalsozialistische Geistliche und intellektuelle Kreise kritisierten sie wiederum als „unsoziale“ und „schweigsame“ Leute. Ihrer Ansicht nach habe das eintönige Leben im Urwald, das tropische Klima und die körperliche Arbeit den Siedlern eine breitere Perspektive genommen und zu einer „Monotonie der Seele" geführt. ${ }^{2125}$ Aber die Nationalsozialisten interessierten sich auch nicht besonders für diese Menschen, weil sie kein „reingermanisches Blut" besaßen, sondern ,vorwiegend wendisch-germanische Pommern der halbhörigen, ländlichen Arbeiterschicht und alpinisch-keltisch-germanische Hunsrücker aus kulturarmen Hochland" waren. „Die wertvollsten Eigenschaften echten ,Deutschtums" "lagen nicht in ihrem Blut. ${ }^{2126}$

Auch das Eindringen nationalsozialistischer Parteigenossen in deutsche Vereine ${ }^{2127}$ löste Protest aus und führte zu einer Opposition. ${ }^{2128}$ Die Nationalsozialisten versuchten eine Mehrheit unter den Vereinsmitgliedern zu bilden oder Führungspositionen zu besetzen und zudem den Anschluss des Vereins an nationalsozialistische Dachverbände durchzuführen. Das geschah beispielsweise mit kulturellen, sportlichen, kirchlichen und Wohltätigkeitsvereinen in Porto Alegre (RS), Santa Cruz do Sul (RS) ${ }^{2129}$ und mit unzähligen Vereinen in Rio Grande do Sul2130 und Santa Catarina. ${ }^{2131}$ Der Verband 25 de Julho in Rio Grande do Sul soll gegründet worden sein, um Deutschbrasilianer unter der Leitung der Nazis zu versammeln. ${ }^{2132}$ Einige Vereinsmitglieder wurden vertrieben, weil sie sich gegen die nationalsozialistische Politik aussprachen ${ }^{2133}$ und andere traten aus traditionellen Ver-

\footnotetext{
2122 Memorandum von Dr. Franz Metzler, ehemalige Besitzer und Direktor der Zeitung Deutsches Volksblatt an den Innenminister von Rio Grande do Sul, Dr. Miguel Tostes. Zitiert nach Py, S. 144. 2123 Py, S. 55, 232.

2124 Wirth, S. 152 und Fußnote 61, S. 169.

2125 Wüstner, Fr. Evangelische Gemeindeblatt - Volkstumsarbeit. In: Freimund 32, 1934, S. 332. Zitiert nach Krause, Lutherische Synode in Brasilien, S. 269.

2126 Brief von Probst Funcke Nr. 1416/32 von 23.5.1932, S. 19. Zitiert nach Prien, S. 370. In Joinville (SC) wurde eine Einteilung in fünf Gruppen durchgeführt: Die NSDAP-Parteigenossen, der Klub Germania, die Stahlhelmgruppe, die abseitsstehenden Reichsdeutschen und die „Masse der Deutschbrasilianer". Schreiben von Müller an Gottfried Werner von 9.1.1934. Zitiert nach Krause, Lutherische Synode in Brasilien, S. 276.

${ }^{2127}$ Laut Perazzo konnten auch Wohltätigkeits- und kulturelle Vereine, Schulen, Klubs und Firmen hinter den Kulissen Spionage und nationalsozialistische Propaganda üben. Perazzo, S. $28 f$.

2128 Schulze, S. 248-250.

${ }^{2129}$ Schulze, S. 103.

${ }^{2130}$ Py, S. 58f, siehe auch Brief von Luiz Beck da Silva an den Polizeichef Paulo Acosta Rodrigues, Santa Cruz, 25.2.1938. Zitiert nach Py, S. 113.

2131 Ribas, O Nazismo em Santa Catarina, S. 55f.

2132 Prien, S. 285.

2133 Ribas, O Nazismo em Santa Catarina, S. 68.
} 
einen wegen der Beteiligung von Nationalsozialisten aus. ${ }^{2134}$ In Pelotas (RS) entfernte ein Mitglied des Vereins Germania die Hakenkreuzflagge und wurde von Parteimitgliedern dazu vernommen. ${ }^{2135}$ Der Riograndenser Turnerbund hob eine von den NSDAP-Mitgliedern durchgeführte Angliederung an den Verband Deutscher Vereine wieder auf. ${ }^{2136}$ Auch in Porto Alegre (RS) versuchten die Nationalsozialisten erfolglos die Direktion des Verbandes Deutscher Vereine zu übernehmen. ${ }^{2137}$ Aber nur wenige Vereine leisteten öffentlichen Widerstand und traten dem Dachverband nicht bei. Das geschah laut Silva, weil sie sich machtlos gegenüber den Nationalsozialisten fühlten und zudem keinen Rückhalt von der brasilianischen Regierung in ihrem oppositionellen Verhalten erhielten. ${ }^{2138}$ Oft machte sowohl die brasilianische Regierung als auch die brasilianische Bevölkerung keinen Unterschied zwischen Deutschen und Deutschbrasilianern. Dies könnte ein Grund dafür sein, dass viele Vereine nicht ihre politische Unterstützung für eine offene Resistenz suchten. Nicht zu leugnen ist aber, dass einige von ihnen womöglich nichts gegen eine Angliederung hatten.

Laut Gertz ist zwischen den Reaktionen auf die Machtübernahme der Nationalsozialisten und ihrer Parteiaktivität in Brasilien zu unterscheiden. Die Opposition der Deutschen und Deutschbrasilianer richtete sich in diesem Sinne gegen die NSDAP-Ortsleitung, nicht gegen das Dritte Reich oder den Nationalsozialismus. ${ }^{2139}$ Ethnische und politische Prinzipien wurden getrennt, denn Deutsche und Deutschbrasilianer in Brasilien ermöglichten dem deutschen Nationalsozialismus überhaupt erst einen Verbreitungsraum, wenn nur der ethnische Aspekt seiner Doktrin betont wurde. ${ }^{2140}$ Letztendlich erwies sich die Tätigkeit der NSDAP in Brasilien als selektiv. ${ }^{214}$ Obwohl sie ihre Ideologie gezielt auch unter Deutschbrasilianern verbreitete, um sie für das „Neue Deutschland“ zu gewinnen oder vom

\footnotetext{
2134 Brief von Herbert Werner Haase an die Familie Korsukewitz, 4.6.1934, BA, NS 26/663 und Bericht von Kurt Prayon Untergang oder Aufstieg des Deutschtums in Brasilien, 10.4.1936, BA R57/474/45. Zitiert nach Gertz, O fascismo no sul do Brasil, S. 85.

2135 Brief von Hugo Müller an Friedrich Ruge, Pelotas, 24.1.1938. Zitiert nach Py, S. 63 und Beilage 4.

2136 Py, S. 234f.

2137 Gertz, O fascismo no sul do Brasil, S. 82f.

2138 Brief von Luiz Beck da Silva an den Polizeichef Paulo Acosta Rodrigues, Santa Cruz, 25.2.1938. Zitiert nach Py, S. 115-117.

${ }^{2139}$ Gertz, O fascismo no sul do Brasil, S. 80, 87; Py, S. 52f.

2140 Gertz, O fascismo no sul do Brasil, S. 102-104.

2141 Mitglieder der NSDAP bekamen die Orientierung, sich weder an die Politik der Gastländer zu beteiligen noch die Parteiideologie unter Nicht-Deutschen zu verbreiten, eine Empfehlung, die nicht gefolgt wurde. Magalhães, Pangermanismo e Nazismo, S. 136f. Weil die NSDAP Reichs- und Neudeutsche privilegierte, verschärfte sie unbewusst den Konflikt zwischen ihnen und Deutschbrasilianern, Seyferth, Nacionalismo e identidade étnica, S. 93, 176f. So ist dem Nationalsozialismus nicht gelungen, wie dem Deutschtum Jahren zuvor, eine kollektive Identität zu bilden, Magalhães, Pangermanismo e narismo, S. 158.
} 
„Großen Deutschland“2142 zu überzeugen, stellte sie als Bedingung für eine Anhängerschaft die Tatsache, deutsches Blut zu haben und Deutsch zu sprechen. ${ }^{2143}$ Die so durchgeführte Selektion schloss Deutschbrasilianer, die kein Hochdeutsch beherrschten und interethnische Ehen eingegangen waren, von vornherein aus. Deutschbrasilianer, die trotzdem Mitglieder wurden, leugneten dies später. Sie bekannten höchstens Sympathie für den Nationalsozialismus gehabt oder gewissen Prinzipien zugestimmt zu haben. ${ }^{2144}$

Als der Integralismus 1937 und die NSDAP 1938 in Brasilien verboten wurden, sorgte dies bei der deutschen und deutschbrasilianischen Bevölkerung für Verwirrung, denn Präsident Vargas gehörte zuvor auch dem Integralismus an ${ }^{2145}$ und der deutsche Nationalismus konnte sich in Brasilien nur aufgrund seiner Sympathien und guten Beziehungen zu Deutschland entfalten. ${ }^{2146}$ Obwohl das Deutsche Reich als Muster für den brasilianischen Neuen Staat diente und die Deutschen die erwünschten ethnischen Eigenschaften für die Einrichtung eines modernen Staates besaßen, wurden sie nur akzeptiert, wenn sie sich „verbrasilianisieren "ließen. ${ }^{2147}$ Ihr Deutschtum jedoch wurde als Staatsideologie angesehen und dem Nationalsozialismus gleichgestellt und galt daher als Gefahr für die nationale Sicherheit. ${ }^{2148}$

\section{Das Nationalisierungsprogramm und seine Auswirkungen auf kirchliche Gemeinden}

Noch grundlegender als im Ersten Weltkrieg beschränkten die Nationalisierungsmaßnahmen in den 1930er Jahren das kirchliche Leben, das Vereinsleben und insbesondere das deutsche Schulwesen. Deutsche und Deutschbrasilianer sahen in ihrer umfangreichen Tätigkeit bei der Errichtung von Kirchen, Schulen, Vereinen, Anstalten und des Pressewesens einen Beweis ihrer Treue zum brasilianischen Staat und dessen Entwicklung. Der brasilianische Nationalismus hingegen sah genau in diesen Institutionen sowie in dem Bestreben der Bewahrung der deutschen Kultur und Sprache eine Gefahr für die brasilianische Nation und begann jene Einrichtungen zu nationalisieren.

Bereits im Jahre 1931 dekretierte ein Schulgesetz, dass Lehrkräfte an Privatschulen in Zukunft fachlich und sprachlich durch ein Staatsexamen geprüft wer-

\footnotetext{
2142 Diskurs des deutschen Ministers Dr. Frick in der Deutschen Allgemeinen Zeitung, 28.11.1937. Zitiert nach Py, S. 146.

${ }^{2143}$ Schulze, S. 102.

${ }^{2144}$ Seyferth, Nacionalismo e identidade étnica, S. $177 \mathrm{f}$.

2145 Wirth, S. 156.

2146 Gertz, O fascismo no sul do Brasil, S. 87.

2147 Perazzo, S. 44.

2148 Seyferth, Nacionalismo e identidade étnica, S. 178f.
} 
den mussten und einem festen Lehrplan verpflichtet waren. ${ }^{2149}$ Privatschulen, die sich diesen Regeln nicht anpassten, sollten geschlossen und theoretisch durch staatliche Schulen ersetzt werden. Doch diese entsprachen wiederum nicht den schulischen Bedürfnissen der Siedlungsgebiete. Der Verband Evangelischer Gemeinden von Santa Catarina und Paraná wandte sich in dieser Angelegenheit an den Staatsinterventor mit einer Eingabe, in der man sich darüber beklagte, dass die Schließung der Schulen ein Verstoß gegen die Religionsfreiheit sei. ${ }^{2150}$ Die Gemeinden Blumenau (SC), Brusque (SC), São Bento do Sul (SC) und Joinville (SC) sandten Schreiben an die Regierung mit der Bitte, sie solle den Lehrern die Möglichkeit gewähren, rechtzeitig die portugiesische Sprache zu erlernen und Sonderkurse zur Vorbereitung auf das staatliche Examen anbieten. ${ }^{2151}$ Die Riograndenser Synode beteiligte sich wiederum an einem überkonfessionellen Manifest der Protestanten, die mit einer Unterschriftensammlung für das Recht eintraten, dass ihnen, analog zu den Katholiken, die Erteilung des Religionsunterrichts an staatlichen Schulen zugestanden werde. ${ }^{2152}$

Als im Jahre 1937 der Neue Staat ausgerufen wurde, erfasste eine tiefgreifende Nationalisierungswelle das Land. Der amtierende Präsident Getúlio Vargas erklärte die „Brasilianisierung der Eingewanderten“2153 zu seinem wesentlichen Ziel und strebte dessen Umsetzung durch eine Nationalisierung des Schulwesens, die Einführung von geregelten Schulplänen und durch die Zwangsassimilierung ethnischer, sprachlicher und kultureller Minderheiten. ${ }^{2154}$ Bis 1939 trat eine Reihe von Gesetzen in Kraft, welche je nach lokalen Verhältnissen teilweise strenger, teilweise milder durchgesetzt wurden. Durfte bis dahin der Unterricht an Privatschulen von staatlich geprüften Lehrern übernommen werden, so bestimmte 1938 ein neues Gesetz, dass ausnahmslos staatliche Lehrkräfte die Hauptfächer an Privatschulen zu unterrichten hätten. Darüber hinaus mussten staatlich geprüfte Lehrer entsprechend einer staatlichen Gehälterskala bezahlt werden, womit für viele Ge-

\footnotetext{
2149 Das neue Schulgesetz für Santa Catharina. In: Schulbuch, Organ zum Ausbau der Schulbuchliteratur in Brasilien, Nr. 34, São Leopoldo, Mai 1931, EZA 5/2453. Beim ersten Staatsexamen von Privatschullehrern in Blumenau (SC) haben nur 8 von 84 Lehrern die Prüfung bestanden. HarmsBaltzer. Die Nationalisierung der deutschen Einwanderer und ibrer Nachkommen in Brasilien als Problem der deutsch-brasilianischen Beziehungen 1930-1938. Berlin, 1970, S. 26. Zitiert nach Wirth, S. 153.

2150 Bericht von Pastor Funke, 22.5.1931, EZA 5/2462; Protokoll des Gemeindeverbandsvorstandes 1931, EZA 5/2462. Der Grundgedanke war, dass eine gründliche Schulung Voraussetzung für das religiöse Leben sei, obwohl der Religionsunterricht und die Grundfächer nach der Meinung vieler Einwanderer und deren Nachkommen nur in der Muttersprache erlernt werden konnten. Bei der Eingabe bezeichneten Gemeinden die Erlernung der Landessprache für Kinder, die in Brasilien geboren waren, als notwendig und versprachen, alles ihnen Mögliche zu unternehmen, um Lehrer auszubilden, die den Anforderungen entsprachen, wenn sie nur ausreichend Zeit und staatliche Geldmittel zur Verfügung gestellt bekämen. Wirth, S. 154.

${ }^{2151}$ Schreiben des Lehrers W. Sächting, 7.5.1931, EZA 5/2453.

2152 Brief Funcke von 19.9.1933 mit Beilagen an den Oberkirchenrat. Zitiert nach Prien, Fußnote 17, S. 282 .

2153 Schulze, S. 204f.

2154 Ackermann, S. $97 \mathrm{f}$.
} 
meinde- und Kolonieschulen die Finanzierung der Lehrkräfte unmöglich wurde. ${ }^{2155}$ Weiterhin verbat das Gesetz den Schulen jedwede Abhängigkeit von nichtschulischen und ausländischen Organisationen. In bestimmten Gebieten richtete der Staat sogar systematisch neue Schulen ein, um das deutsche Schulwesen zu schwächen. ${ }^{2156}$

In Rio Grande do Sul war die Situation bis zum April 1939 zunächst nicht übermäßig angespannt. Die Synodalschulen in Santa Cruz do Sul (RS) und Candelária (RS), das Evangelische Gymnasium in São Leopoldo (RS) und das Evangelische Stift in Novo Hamburgo (RS) durften zunächst weiterhin Deutsch ab dem 6. Schuljahr unterrichten. Weil die Schulen in Santa Cruz do Sul (RS) und São Leopoldo (RS) unter Bundesaufsicht standen, durfte bei ihnen noch Religionsunterricht erteilt werden. Reichsdeutsche durften ihre Lehrstellen behalten, soweit sie die erforderlichen Kenntnisse der Landessprache aufwiesen. ${ }^{2157}$ In Santa Catarina hingegen durfte keine private Schule ohne vorherige Genehmigung des Binnen- und Justizsekretariats ihren Lehrbetrieb fortsetzten. Weil die Mehrheit der Gemeinde- und deutschen Schulen nicht imstande war, die Vorschriften entsprechend umzusetzen, erhielten sie keine staatliche Genehmigung und mussten schließen. ${ }^{2158}$ Nach Weingärtner wurden 589 von 661 Schulen in diesem Staat willkürlich von der Regierung geschlossen. Ihre Unterrichtsmaterialien wurden beschlagnahmt und nach Florianópolis (SC) gebracht, wo sie verschwanden. ${ }^{2159}$ Auch in Espírito Santo wurden Privatschulen geschlossen, obwohl erst einen Monat später verbindliche Regelungen für das private Schulwesen festgelegt wurden, die dennoch keine Gemeindeschule erfüllen konnte.

Das Dekret vom 25. August 1939 verbat endgültig eine Fremdsprache als Unterrichtssprache in Schulen. ${ }^{2160}$ Der Religionsunterricht konnte zwar teilweise noch außerhalb der Schule in deutscher Sprache stattfinden ${ }^{2161}$, doch auch diese mögliche Umgehung der Regelung variierte in ihrem Erfolg je nach Strenge, mit der die Nationalisierungsmaßnahmen durchgesetzt wurden. In Espírito Santo wurde beispielsweise auch jede kirchliche Unterweisung für Kinder und Jugendli-

\footnotetext{
2155 Dreher, Igreja e Germanidade, S. 165.

2156 Dedekind, Brasilien, S. 45.

${ }^{2157}$ Prien, S. 448.

2158 Über die Bedingungen für den Erhalt einer solchen Genehmigung siehe Bericht des Bildungsministeriums - 1938. In: E-Mail von Valdim Utech an Pastor Nelso Weingärtner, 29.9.2003. Privatarchiv von Pastor Nelso Weingärtner. Allein im Jahre 1938 wurden 48 Schulenanträge in Santa Catarina abgelehnt. Andere Schulen beantragten kein Gesuch, weil sie im Voraus wussten, dass sie die Anforderungen nicht erfüllen konnten.

${ }^{2159}$ Weingärtner, História da Comunidade Evangélica de Timbó, S. 158.

2160 Zeitungsabschnitt über die Nationalisierung der Schulen, EZA 5/2455, ohne Angabe von Autor und Zeitung; Fischer, Geschichte der Evangelischen Kirche, S. 163f.

2161 Rundschreiben Nr. 1058 des Erziehungssekretärs J. P. Coelho de Souza an den RegionalPolizeikommissar, Porto Alegre, 6.8.1941, AHI, SR 17/6 Beilage 007, auch SR 15/7 Beilage 007.
} 
che verboten. 2162 In Brusque (SC) und Blumenau (SC) nahmen Kinder zwei Jahre am Religionsunterricht außerhalb der regulären Schulzeit vor dem Konfirmandenunterricht teil. ${ }^{2163} \mathrm{Im}$ außerschulischen Religionsunterricht in Rio Grande do Sul waren sogar mehr Kinder als zuvor in den Schulen anwesend ${ }^{2164}$, in Herval Seco (RS) hingegen untersagte der Polizeistellvertreter die doktrinäre Vorbereitung der Jugendlichen zum Konfirmationsgottesdienst und erklärte die Erlaubnis des zuständigen Lehrers Zank für ungültig. ${ }^{2165}$ Geistliche ermahnten die Eltern, ihren Kindern den Katechismus, Bibelsprüche und Lieder auf Deutsch selbst beizubringen $^{2166}$, unter anderem damit sie trotz der Verbote konfirmiert werden konnten. ${ }^{2167}$ Aus diesem Grund etablierte sich die häusliche Unterweisung in vielen Orten. ${ }^{2168}$ Pommersche Nachkommen berichten außerdem, dass sie teilweise den Konfirmandenunterricht auch geheim besuchten. In Serra Pellada (ES) machten die Kinder Umwege durch den Wald, um das Pfarrhaus zu erreichen, obwohl ihre Eltern dabei das Risiko einer Verhaftung eingingen. ${ }^{2169}$ In Pomerode (SC) übernahmen Laien und Lehrer den Konfirmationsunterricht ${ }^{2170}$ und in Laranja da Terra (ES) wurde der Religionsunterricht nach dem Gottesdienst ${ }^{2171}$ oder abends geheim abgehalten. ${ }^{2172}$ Seyferth berichtet, dass in Blumenau (SC) und Brusque (SC) geheimer abendlicher Schulunterricht in privaten Häusern zur Regel wurde..$^{2173}$

Weil staatliche Schulen in Brasilien säkularisiert waren und dort kein Religionsunterricht erteilt wurde, protestierten Geistliche und Gemeindemitglieder entschlossen gegen die Schließung ihrer Schulen, unter anderem, um ihren Kindern eine konfessionelle Erziehung zu gewährleisten. Einige Schulen konnten sich den Verordnungen anpassen und ihre Arbeit fortsetzen, doch oft war die einzige Mög-

\footnotetext{
2162 Brief von Karl Hünemörder an das Kirchliche Aussenamt, 25.2.1939, EZA 5/2164; Bericht von Pastor Rölke im Archiv der Parochie Santa Maria de Jetibá. Zitiert nach Gaede, S. 178f; Seibel, Imigrante no século do isolamento, S. 259; Prien, S. 430.

2163 Ergänzungsbericht von Pastor Graetsch für das Jahr 1938, Brusque (SC), S. 1, EZA 5/2526; Scheerer. Festschrift der Evangelischen Kirchengemeinde Blumenau. Blumenau: Druck von G. Artur Koehler, S. 13f, EZA 5/2486. Der Evangelische Gemeindeverband sorgte auch dafür, dass Gemeinden die Konfirmation vom Besuch eines erweiterten Konfirmandenunterrichts abhängig machten. Brief von Pastor Blümel an Bischof Henkel, 5.4.1937, EZA 5/2508. So wurde die Aufnahme im Konfirmationsunterricht in Brusque (SC) sogar mittels einer Prüfung durch den Kirchenvorstand kontrolliert. Ergänzungsbericht 1938 der Gemeinde Brusque (SC) vom Pastor Graetsch, S. 1, EZA 5/2526.

2164 Prien, S. 452f.

2165 Entwurf eines Briefes von Pastor Dohms an den Polizeichef in Porto Alegre Herr Darcí Vignoli, [1942?] AHI, SR 15/7 Beilage 016.

2166 Krause, Lutherische Synode in Brasilien, S. 288.

2167 Seibel, Imigrante no século do isolamento, S. 258.

2168 Bericht von Pastor G. Grottke aus Laranja da Terra, Februar 1938, MEW 4.188.

2169 Seibel, Imigrante no século do isolamento, S. 260, 262.

${ }^{2170}$ Liesenberg, S. 15f; Evangelische Synode von Santa Catarina und Paraná, S. 82.

${ }^{2171}$ Damitz, Entwicklungsaspekte zur Situation der Brasilianer, S. 24.

2172 Ackermann, S. 271.

${ }^{2173}$ Seyferth, Nacionalismo e identidade étnica, S. 182.
} 
lichkeit für die Erhaltung des Schulwesens in vielen Siedlungsgebieten zwischen 1939 und 1945 die Fusion deutscher Privatschulen mit staatlichen Schulen. ${ }^{2174}$ Vielen staatlichen Schulen mangelte es aber an geeigneten Lehrkräften, die sich mit den deutsch- und pommerschsprachigen Kindern verständigen konnten. Aufgrund der Isolierung in manchen Siedlungsgebieten gaben diese ihre Bemühungen diesbezüglich schon bald auf. Aus diesem Grund war es vielen Kindern trotz der Schulpflicht und des Unterrichts in der Landessprache nicht möglich, systematisch Portugiesisch zu lernen. ${ }^{2175}$ Etliche Schüler wurden von brasilianischen Lehrkräften aufgrund ihrer Abstammung beschimpft und wegen der Verwendung ihrer Muttersprache bestraft oder verspottet. ${ }^{2176}$ Auf diese Weise wurde die staatliche Schule zum „Ort des Versagens und der Beschämung, des Zwangs und der Demütigung, der Ausgrenzung und der Entmutigung'2177, also zu einer immensen Belastung für deutsche und deutschbrasilianische Kinder. Nationalisierungsmaßnahmen riefen somit nicht zuletzt Wut in den Kindern hervor, die daraufhin beispielsweise während der Zivildemonstrationen Steine auf die brasilianische Flagge warfen oder das Mitsingen der brasilianischen Hymne verweigerten. ${ }^{2178}$

Manche Pastoren brachen bewusst die Verbote und erteilten weiterhin Religionsunterricht in deutscher Sprache. Sie nutzten teilweise die Kirche als Schule ${ }^{2179}$ und ermutigten auch andere Lehrer, ihren Unterricht auf Deutsch fortzusetzen. ${ }^{2180}$ Aus diesem Grund galten die Pastoren bald als ,fremde Saboteure", die die Religion missbrauchten, um feindliche Propaganda gegen Brasilien zu betreiben und das Gastland zu verspotten. ${ }^{2181}$ Dort, wo Pastoren noch unterrichten durften, wurden sie von staatlichen Lehrkräften inspiziert und mussten Bußgelder zahlen, falls sie die Bestimmungen nicht einhielten. ${ }^{2182}$ Im Laufe der Zeit begann der Staat die Schulgebäude in einigen Orten zu enteignen. ${ }^{2183}$ Die Gemeinde Jaraguá do Sul

\footnotetext{
2174 Nach Angaben der Zeitung Der Deutsche Ansiedler wurden bis August 1939 nur 5 der 450 privaten Schulen in Santa Catarina registriert, während in Rio Grande do Sul 1.113 registriert waren. Der Deutsche Ansiedler, Januar/März 1939. Zitiert nach Py, S. 218.

2175 Granzow, Pommeranos unter dem Kreuz des Südens, S. 55f; Seibel, Imigrante no século do isolamento, S. 147.

2176 Seibel, Imigrante no século do isolamento, S. 255f; Altmann, S. 42f, 93; Fáveri, S. 99-104; Prien, S. 447.

2177 Göppel, Rolf. Bildung als Chance. In: Opp, Günther, Fingerle, Michael. Was Kinder stärkt. München: Ernst Reinhardt, 2008, S. 255.

2178 Fáveri, S. 68.

2179 Rundschreiben Nr. 1058 des Erziehungssekretärs J. P. Coelho de Souza an den RegionalPolizeikommissar, Porto Alegre, 6.8.1941, AHI, SR 17/6 Beilage 007, auch SR 15/7 Beilage 007.

${ }^{2180}$ Dreher, Igreja e Germanidade, S. 172.

${ }^{2181}$ Brief von Karl Hünemörder an das Kirchliche Aussenamt, 25.2.1939, EZA 5/2164; vgl. Brief von Pastor Fr. Wüstner an Dr. Eppelein, Palmeira 25.2.1939, MEW 4.185.

2182 Schlünzens Tätigkeitsbericht vom 1.12.1938. Zitiert nach Krause, Lutherische Synode in Brasilien, S. 288; vgl. Rundschreiben Nr. 1058 des Erziehungssekretärs J. P. Coelho de Souza an den RegionalPolizeikommissar, Porto Alegre, 6.8.1941, AHI, SR 17/6 Beilage 007, auch SR 15/7 Beilage 007.

2183 Rölke, Hermann. Gemeindebericht 1938, Arquivo Histórico da Paróquia de Santa Maria de Jetibá. Zitiert nach Gaede, S. 174; Seibel, Imigrante no século do isolamento, S. 273f; Granzow, Pommeranos unter dem Kreuz des Südens, S. 115.
} 
(SC) versuchte einer solchen Enteignung zu entgehen, indem sie zu Beginn des Jahres 1937 neue Statuten für den Schulverein verfasste, entsprechend derer die Schule fortan als exklusives Eigentum der Evangelisch-Lutherischen Gemeinde galt und für keinen anderen Zweck als für den Schulunterricht verwendet werden durfte. Dennoch übernahm der Staat das Gebäude, die Schule wurde geschlossen und in einen Klub umfunktioniert. ${ }^{2184}$ Deutsche Pastoren, Diakone und Lehrer mussten in verschiedenen Orten den Schuldienst aufgeben oder wurden zwangsweise entlassen.

Einwanderer und deren Nachkommen protestierten, mit vereinzelten Ausnahmen, nicht gegen die Nationalisierung des Schulwesens. Zwar bedauerte vor allem die ältere Generation die Schließung oder Enteignung ihrer Schulen, unter anderem, weil sie sie selbst errichtet hatten. Doch nach Pastor Wüstner wurden die Nationalisierungsmaßnahmen besonders von den jüngeren Gemeindemitgliedern positiv wahrgenommen, während die restlichen Mitglieder diese meist gleichgültig hinnahmen und sich ihnen nicht zur Wehr setzten. Wüstner fragte sich, ob diese Gleichgültigkeit der Angst vor den Autoritäten geschuldet war oder vielmehr dem Wunsch entsprach, sich endlich aus dem Zwischenzustand eines DeutschBrasilianers zu emanzipieren. ${ }^{2185}$ In Garcia-Blumenau (SC) beantragten die Gemeindemitglieder hingegen in mehreren Briefen an den Staatsinterventor Nereu Ramos die Wiedereröffnung der Schulen ${ }^{2186}$ und in Brusque (SC) wurde beklagt, dass die Regierung über sechzig Jahre die Existenz deutscher Schulen toleriert habe und nun im Zuge der Nationalisierung ihnen die Landessprache als Unterrichtssprache aufzwingen wolle, wozu aber die Kapazitäten fehlten. ${ }^{2187}$ Eine Stellungnahme, die die Erlernung der Landessprache ablehnte, gab es jedoch nicht.

Obwohl die brasilianische Regierung die Einführung der Landsprache an den Schulen verpflichtend anordnete, stellte sie weder genügend Ressourcen zur Verfügung, noch schaffte sie angemessene Übergangsbedingungen zur Umsetzung dieser Maßnahme. Nach Pastor Kessel fiel es vielen Kindern bereits schwer, die elementarsten Schulkenntnisse in einer Fremdsprache wie Portugiesisch zu erfassen. In den besten Fällen führte die zwangsmäßige Aneignung zu einem „papageienhaften Nachplappern der fremden Worte' 2188 , was den gesamten Lernprozess, auch in den Hauptfächern, beeinträchtigte. Pastor Radlach berichtet: „Es werden jetət in den Gemeindeschulen Analphabeten in zwei Sprachen groß erzogen".2189

${ }^{2184}$ Houllou, S. 373-375. Die Schule wurde erst 1953 wieder eröffnet.

${ }^{2185}$ Wüstner, Friedrich. Unsere Lage, 27.10.1938. Zitiert nach Dreher, Igreja e Germanidade, S. 212.

2186 Unterzeichnungsschrift der Bewohner vom Stadtbezirk Garcia, Blumenau, an den Interventor Nereu Ramos, 4.12.1940. Ofícios Recebidos de Diversos, Jan/Dez 1940, Palácio do Governo APESC. Zitiert nach Fáveri, S. 79.

2187 Seyferth, Nacionalismo e identidade étnica, S. 182.

${ }^{2188}$ Bericht von Pastor Kessel an den Evangelischen Oberkirchenrat, 11.6.1921, EZA 5/2455.

${ }^{2189}$ Radlach. Die Einwirkungen des Weltkrieges auf die deutsch-evangelischen Gemeinden in Santa Catharina. In: Geißler, Bruno (Hrsg.) Die Kulturbedeutung der deutschen evangelischen Kirche in Brasilien, S. 26, EZA 5/2158. 


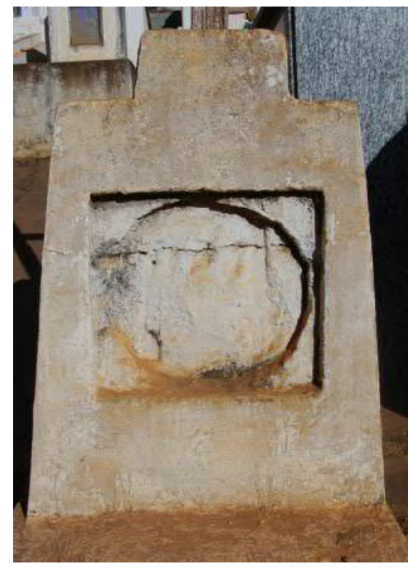

Abb. 37: Beschädigtes Grab in der Nationalisierungszeit. Quelle: Seibel, Imigrante no século do isolamento, S. 270.

In der letzten Vorkriegsversammlung der Riograndenser Synode in Santa Cruz do Sul (RS) 1937 gab Pastor Dohms Auskunft über eine Gemeinde, die ihren Friedhof am Allerheiligentag wegen Gewaltdrohungen nicht einweihen konnte. In einer anderen wurde der Gemeindeschatzmeister überfallen und in einer dritten Gemeinde auf das Pfarrhaus geschossen. ${ }^{2190}$ Seit Mai 1938 wurden Friedhöfe verstaatlicht und kirchliche Friedhöfe, die nicht mit öffentlichen Friedhöfen verbunden waren, geschlossen. Dies geschah beispielsweise mit den Friedhöfen der Gemeinden Brusque (SC), Indaial (SC) und Jaraguá do Sul (SC). ${ }^{2191}$ Lediglich Orte, die Sitz der lokalen Verwaltung waren und mehr als 300 Einwohner hatten, und Orte, die mehr als zwölf Kilometer vom nächsten Friedhof entfernt waren, sollen eine Ausnahme gebildet haben. ${ }^{2192}$ Die Gemeindemitglieder sollten fortan ihre Verstorbenen in katholischen Gebieten beerdigen, wobei sich aber die Katholiken teilweise vehement dagegen wehrten, dass Protestanten auf ihrem Gottesacker begraben werden sollten. ${ }^{2193}$ Aus diesem Grund mussten die protestantischen Gläubigen ihre Verstorbenen in manchen Orten auf entfernten Friedhöfen bestatten. Fremdsprachige Inschriften mussten innerhalb von dreißig Tagen entfernt oder durch portugiesische ersetzt werden. Sollte sich jemand nicht an diese Anordnungen halten, wurde die Arbeit durch die Präfektur ausgeführt und eine Geldstrafe von 100 Milréis eingefordert ${ }^{2194}$ oder den Familien mit Folter und Verhaftung gedroht. ${ }^{2195}$

Tafeln, Kreuze oder Bildwerke an Gräbern, Grüften und Mausoleen wurden abgerissen oder entfernt, viele Grabsteine zerstört und ihre fremdsprachigen Inschriften entweder mit dem Meißel entfernt, verbrannt ${ }^{2196}$ (Abb. 37) oder mit Zement bedeckt. ${ }^{2197}$ Aus Furcht vor diesen angedrohten Maßnahmen versteckten oder vergruben einige Siedler in Laranja da Terra (ES) die Steine mit den Grabin-

\footnotetext{
2190 Prien, S. $315 f$.

${ }^{2191}$ Ergänzungsbericht 1938 der Gemeinde Brusque (SC) vom Pastor Graetsch, S. 1, EZA 5/2526; Wilbert et. al., S. 111.

${ }^{2192}$ Bericht von Pastor Schliemann, 31.10.1938, EZA 5/2465; Harms-Baltzer. Die Nationalisierung der deutschen Einwanderer und ibrer Nachkommen in Brasilien als Problem der deutsch-brasilianischen Beziebungen 1930-1938. Berlin, 1970, S. 124. Zitiert nach Wirth, S. 156.

2193 Ergänzungsbericht von Pastor Graetsch über die Gemeinde Brusque (SC), 1938, S. 1, EZA $5 / 2526$.

2194 Brief von Pastor Schlünzen an das Kirchliche Außenamt Berlin, Joinville, 27.3.1939 EZA

5/2164; vgl. Seibel, Imigrante no século do isolamento, S. 271.

${ }^{2195}$ Bericht von Frau Lilli Sacht Tribess am 6.8.2007. Zitiert nach Ulrich, S. 208.

2196 Ackermann, S. 270; Seibel, Imigrante no século do isolamento, S. 269.

${ }^{2197}$ Bericht von Frau Lilli Sacht Tribess am 6.8.2007, zitiert nach Ulrich, S. 208.
} 
schriften und stellten sie zu einem späteren Zeitpunkt wieder zurück. ${ }^{2198}$ Auffällig ist es, dass in Jaraguá do Sul (SC) einige kühne Deutsche oder Deutschbrasilianer ${ }^{2199}$ den Bürgermeister von Jaraguá do Sul (SC), Leônidas Cabral Herbstes, verklagten, weil er die Entfernung von Grabinschriften verordnete. ${ }^{2200}$ Bald aber mussten in Joinville (SC) die Inschriften nicht mehr per Gesetz entfernt oder ausgewechselt werden 2201 und in Santa Leopoldina (ES) erklärte der Oberste Bonjardin, dass die Inschriften sich nicht auf Hitler bezogen, woraufhin die Siedler die Gräber wieder errichten konnten. ${ }^{2202}$

\section{Der Zweite Weltkrieg: Verbote, Verfolgung, Folter und Inhaftierungen}

Während des Zweiten Weltkrieges erreichte das Nationalisierungsprogramm seine bisher größten Ausmaße. Besonders nach der Kriegserklärung Brasiliens 1942 wurden Deutsche und Deutschbrasilianer bezüglich ihrer Sympathie oder Anhängerschaft zum brasilianischen Integralismus oder zum Nationalsozialismus, oder auch wegen der Verwendung der deutschen Sprache und Dialekte befragt, denunziert, von der Arbeit entlassen, geschäftlich boykottiert, letztendlich misshandelt, gefoltert oder inhaftiert. Gemeindemitglieder übernahmen wieder pfarramtliche Funktionen und versuchten ihren Glauben und dessen Praktizierung trotz aller Restriktionen zu erhalten. Wieder fungierte die kirchliche Gemeinde als sicherer Ort und als Kraftquelle für die Bewältigung widriger Umstände.

Der Ausbruch des Zweiten Weltkriegs 1939 löste nicht dieselbe Begeisterung unter den Einwanderern und deren Nachkommen aus wie der des Ersten Weltkrieges. Deutsche in Brasilien wurden teilweise gegen ihren Willen aufgefordert, sich zum Militärdienst in deutschen Konsulaten registrieren zu lassen ${ }^{2203}$, in Brusque (SC) weigerten sich die meisten Einwanderer, nach Deutschland zurückzukehren.2204 In anderen Orten aber meldeten sich Jugendliche freiwillig als

\footnotetext{
2198 Seibel, Imigrante no século do isolamento, S. 271.

2199 Die Autorin macht es nicht klar in ihrem Text, es waren aber eher Deutschbrasilianer.

2200 Zeitung A Gazeta von 21.5.1939 und Bericht des Generals Manoel Rebelo an den Staatsinterventor Nereu Ramos, 6.6.1939. Ofícios recebidos do Ministério da Guerra, 1939/194, Palácio do Governo. APESC. Zitiert nach Fáveri, S. $313 \mathrm{f}$.

2201 Brief von Pastor Schlünzen an das Kirchliche Außenamt Berlin, Joinville, 27.3.1939, EZA $5 / 2164$.

2202 Seibel, Imigrante no século do isolamento, S. 269.

2203 Polizeiliche Ermittlungen und Aussagen von Bernardo Guilherme Maahs und Wolfgang Neise; Brief von Polizeikommissar Plínio Brasil Milano an den Polizeichef Aurélio da Silva Py, 18.11.1939; Bekanntmachung des deutschen Konsuls in Porto Alegre. In: Neue Deutsche Zeitung Nr. 159, 8.7.1939. Alles zitiert nach Py, S. 285-287; 83-87; 91f. Falls sie keine Wehrpflicht leisteten, wurde ihnen mit dem Verlust ihrer deutschen Staatsangehörigkeit gedroht. Py, S. 298.

2204 Seyferth, Nacionalismo e identidade étnica, S. 192.
} 
Kriegssoldaten. ${ }^{2205}$ Obwohl seit 1940 Kriegsnachrichten in Rundfunktransmissionen und seit 1941 fremdsprachige Veröffentlichungen verboten waren, versuchten Deutsche und Deutschbrasilianer ständig Informationen über den Krieg zu erlangen, unter anderem wegen ihrer Bekannten oder Angehörigen, die vom deutschen Konsulat rekrutiert worden waren.2206 Viele von ihnen wurden nach und nach verhaftet, da die Radiotelegrafie auch ein bekanntes Instrument deutscher Spione war. Die Polizei überwachte die deutschen Einwanderer und Deutschbrasilianer, durchsuchte ihre Häuser nach ausländischen Empfangsstationen, versiegelte ihre Radioapparate, die dann nur noch staatlich kontrollierte Nachrichten empfangen konnten, und benachrichtigte außerdem den Geheimdienst über das Vorhandensein von Radiogeräten. ${ }^{2207}$ Als repressive Maßnahme musste beispielsweise eine Gruppe in Itajaí (SC) unter polizeilicher Aufsicht beschlagnahmte Radios bis zur Hauptstraße tragen, wo diese dann verbrannt wurden. ${ }^{2208}$

Gerüchte und Pressemitteilungen hetzten außerdem die brasilianische Bevölkerung gegen Ausländer auf. In den Städten gab es Demonstrationen und Proteste gegen Deutschland, Fabriken, Firmen, Zweig- und Privatgeschäfte von Deutschen und Deutschbrasilianern, deutsches Eigentum wurde zerstört und geplündert ${ }^{2209}$ und Straßenschilder mit deutschen Namen zerbrochen. Geschäfte und Häuser wurden mit Hakenkreuzen und Schimpfwörtern, wie „Verräter" oder „FünfteKolonne", bemalt oder mit Mist beschmiert ${ }^{2210}$, mit Steinen beworfen oder überfallen und die Besitztümer auf die Straße geworfen ${ }^{2211}$, wo sie manchmal noch in Brand gesteckt wurden.2212 Deutsche und Deutschbrasilianer wurden dagegen gezwungen, den brasilianischen Staat, den Präsidenten und die Staatsinterventoren $\mathrm{zu}$ bejubeln. In Joinville (SC) fanden sich bei einer marschierenden Menge mit Plakaten Aufschriften wie „Morram os ingratos" (es sterben die Undankbaren) oder „Descendentes! Contra o teu pai, contra o teu irmão, mas pelo Brasil“ (Nachkommen! Gegen deinen Vater, gegen deinen Bruder, aber für Brasilien). ${ }^{2213}$ Proteste, Demons-

\footnotetext{
2205 Schinke, Werner H. E. Erich Schulv, 1898-1974. Lageado: UNIVATES, 2013, S. 79f, 84. In Santa Catarina sollen nach Angaben des Polizeichefs Antônio de Lara Ribas 744 Jugendliche 1939 das Land verlassen haben. Ribas, O Nazismo em Santa Catarina, S. 30.

2206 Ein Mann in Timbó (SC) versteckte sein Radio in einem Brunnen und hörte die Nachrichten durch das Echo, Fáveri, S. 266-269. In Pomerode (SC), Altmann, S. 49f, sowie im Binnenland von Rio Grande do Sul, Cancelli, Elizabeht. O mundo da violência. Campinas: Universidade Estadual de Campinas, 1991, S. 320, versammelten sich Pommern im Geheimen, um Radio zu hören.

2207 Perazzo, S. 139, 159; Ackermann, S. 271.

${ }^{2208}$ Foto im Historischen Archiv von Itajaí (SC) und Aussage von Didymea Lázzares Oliveira, 72 Jahre, am 18.10.2001 in Itajaí (SC) für José Isaías Venera. Zitiert nach Fáveri, S. 263-265.

2209 Merkblatt über die Lage der Deutschen in Brasilien. Zusammengestellt auf Grund der bis Juli 1943 vorliegenden amtlichen und privaten Nachrichten, 31.7.1943, S. 5, MEW 3.20; Fonseca, S. 140; Ackermann, S. 128.

${ }^{2210}$ Fáveri, S. 100, 294; Junges, Leandro S. Perseguição começava na escola. In: A Notícia. Privatarchiv von Pastor Nelso Weingärtner.

2211 Ackermann, S. 291.

2212 Ackermann, S. 126f; Rölke, Raízes da Imigração alemã, S. 175.

2213 Fáveri, S. 35.
} 
trationen, Plünderungen und Verwüstungen sollen in Espírito Santo teilweise von der Zentralregierung unterstützt worden sein, die in diesem Kontext einige Deutschstämmige festnahm. ${ }^{2214}$ Auch Vereine, Schulen und Krankenhäuser wurden großflächig geschlossen oder enteignet ${ }^{2215}$, weil sich Jahre vor dem Krieg NSDAP-Parteimitglieder und Sympathisanten dort trafen und im dortigen Vorstand waren.2216 Bücher, Waffen ${ }^{2217}$, Gegenstände und Instrumente aus Schulbibliotheken, Vereinen und Krankenhäusern wurden beschlagnahmt. ${ }^{2218}$ Krankenschwestern und Diakonissen wurden mehrheitlich entlassen ${ }^{2219}$ und durch katholische Schwestern ersetzt ${ }^{2220}$, während erstere in Austauschtransporten 1944 nach Deutschland zurückgeschickt wurden. 2221

Deutsche Geschäftsleute oder Firmen kamen auf eine „Schwarže Liste“, weil sie unter dem Verdacht standen, mit den Nationalsozialisten zu kooperieren oder Handel zu betreiben. Sie litten unter anderem unter dem Boykott von Importprodukten seitens der nordamerikanischen Regierung 2222 , außerdem wurden ihre deutschen Angestellten durch Brasilianer ersetzt, da ein Gesetz es den Arbeitgebern nahelegte, die Arbeitsverträge mit Ausländern aus den Achsenländern aufzukündigen. 2223 Auch Deutschbrasilianer wurden aus Firmen entlassen und ihren öffentlichen Ämtern enthoben. ${ }^{2224}$ In Rio do Testo-Pomerode (SC) wurde die

2214 Almeida, Amylton de. Incêndio nas mentes. Produktion von Luiz Claudio Gobbi, Rede Gazeta, 1990 Videoaufnahme, 45min. Zitiert nach Ackermann, S. 130.

2215 Merkblatt über die Lage der Deutschen in Brasilien, 31.7.1943, S. 3, MEW 3.20; Brief von Bischof Dr. Heckel an die deutschen evang. Pfarramt aus Südamerika, Berlin, 11.9.1944, S. 5, MEW 3.20; Fáveri, S. 256 f.

2216 Perazzo, S. 87; Seyferth, Nacionalismo e identidade étnica, S. 189.

2217 Die Beschlagnahmung von Waffen in Schützenvereinen und Privathäusern zielte einerseits auf die Entwaffnung der Ausländer ab, andererseits auf die Lieferung dieser Waffen zu Überwachungszwecken in strategisch wichtigen Gebieten, vor allem in Küstennähe. Nach Angaben von Jamundá wurden die Waffen aber auch deshalb beschlagnahmt, weil sie nicht legal waren. Jamundá, Theobaldo Costa. Indaial: Município do Vale do Itajaí-Açú, 1943. In: Associação dos Amigos do Arquivo Histórico de Indaial, t. 2, n. 2, jun./ago. 2016, S. 34.

2218 Evangelische Synode von Santa Catarina und Paraná, S. 186.

2219 Merkblatt über die Lage der Deutschen in Brasilien, 31.7.1943, S. 3, MEW 3.20; Krause, Lutherische Synode in Brasilien, S. 303.

2220 Fáveri, S. $256 f$.

2221 Kurze Zusammenfassung aus Berichten Zurückgekehrter über die Internierungslager in Brasilien, 3.7.1944, EZA 5/2168.

2222 Merkblatt über die Lage der Deutschen in Brasilien, 31.7.1943, S. 3, MEW 3.20; Fáveri, S. 191.

2223 Ludwig, S. 88; Fáveri, S. 223-225. Paradoxerweise wurden diese Maßnahmen gerade zwischen 1938 und 1945 angeordnet, als die Regierung unter Vargas eine Reihe von Arbeitsgesetzen und sozial-politischen Verordnungen für die Verbesserung der Arbeitsbedingungen einführte.

2224 Merkblatt über die Lage der Deutschen in Brasilien, 31.7.1943, S. 2, MEW 3.20; Associação dos Amigos do Arquivo Histórico de Indaial, t. 1, n. 2 jun./ago. 2015, S. 32; Auszug von Jamundá, Theobaldo Costa. Indaial: Município do Vale do Itajai-Açu, 1943. In: Associação dos Amigos do Arquivo Histórico de Indaial, Indaial. Conbecendo sua história. Indaial: AMARHIN, t. 2, n. 1, mar./maio 2016, S. 36. Entlassene Angestellte und Arbeiter hatten das Recht auf eine Abfindung von je einem Monatsgehalt für jedes Dienstjahr. Diese durfte aber zehn Monatsgehälter nicht übersteigen. Merk- 
Firma Passold zwischen 1939 und 1945 von der Armee besetzt und die Arbeiter inhaftiert, weil diese Deutsch sprachen ${ }^{2225}$, die Firma Garoto in Vitória (ES) wurde während der Inhaftierung ihres Besitzers von staatlichen Interventoren verwaltet.2226 In Hinblick auf diese Ereignisse spielte das soziale Netzwerk in kirchlichen Gemeinden eine tragende Rolle, da dieses einigen Betroffenen bei der Suche nach einer neuen Anstellung half. ${ }^{2227}$ Außerdem wurde nach und nach die Mehrheit der Arbeiter doch wieder eingestellt. ${ }^{2228}$

In Espírito Santo war die Anhängerschaft oder frühe Sympathien für den Integralismus das Hauptmotiv für die Verfolgung und Inhaftierung von Deutschen und Deutschbrasilianern. ${ }^{2229}$ Prozesse von 1942 erwähnen als Anklagemotive die Anhängerschaft zum Integralismus, Extremismus, Sympathien für die Achsenländer und Deutschfreundlichkeit ${ }^{2230}$, obwohl die Siedler sich nach dem Verbot aller Parteien 1937 bereits vom Integralismus abgewandt hatten.2231 Inoffiziell wurden viele Einwanderer und Deutschbrasilianer wegen der Verwendung der deutschen oder pommerschen Sprache inhaftiert. In Santa Leopoldina (ES) unterstützte der Landkreisrichter öffentlich die Verhaftung pommerscher Einwanderer, die kein Portugiesisch beherrschten ${ }^{2232}$ und ein Polizeikommissar in Campinho-Santa Isabel (ES) ordnete Gewaltanwendung bei denjenigen an, die öffentlich Pommerisch oder Deutsch sprachen. ${ }^{2233}$ Auch in Santa Catarina wurden ehemalige Mitglieder oder Sympathisanten des Integralismus automatisch als Bedrohung der nationalen Sicherheit oder als Mitarbeiter der Achsenländer angesehen ${ }^{2234}$ und die Verwendung fremder Sprachen galt häufig als Motiv für Inhaftierungen. ${ }^{2235}$ In Pomerode (SC) wurden Menschen bei Hochzeitsfeiern, Gemeindefesten und beim Einkaufen festgenommen, weil sie sich auf Deutsch oder Pommerisch unterhielten. 2236

blatt über die Lage der Deutschen in Brasilien, 31.7.1943, S. 2-4, MEW 3.20. Über Arbeitsentlassungs- und Amtsaufhebungsprozesse siehe Fáveri, S. 218-230.

2225 Fáveri, S. 97.

2226 Rölke, Raizes da Imigração alemã, S. 425.

2227 Fáveri, S. 250.

2228 Merkblatt über die Lage der Deutschen in Brasilien, 31.7.1943, S. 4, MEW 3.20.

2229 Ackermann, S. 122-124.

2230 Ackermann, S. 15, 19 f.

2231 Ackermann, S. 293. Viele brannten oder warfen ihre integralistische Uniformen weg, damit ihre Anhängerschaft nicht bewiesen werden konnte. Berichte von Herbert und Dorothea Kuhn und von Bertoldo Discher. Zitiert nach Rölke, Raízes da Imigração alemã, S. 416f.

2232 Siller, S. 114.

2233 Ackermann, S. 272.

2234 Cancelli, S. 295; Seyferth, Nacionalismo e identidade étnica, S. 189; Fáveri, S. 179-184; vgl. Kuehne, O Integralismo nazi-fascista, S. 125.

2235 Über Prozesse des Nationalen Sicherheitsgerichts aufgrund der Verwendung deutscher Sprache siehe Fáveri, S. 69-89.

2236 Altmann, S. 47. Weitere Beispiele in Brusque (SC) und Joinville (SC) siehe Fáveri, S. 92; Junges, Leandro S. Histórias de torturas e humilhações. In: A Notícia. Privatarchiv von Pastor Nelso Weingärtner. 
Zeitungsartikel und Polizeidossiers2237 berichteten über die „Naziinfiltration", denunzierten eine „Narifizierung “ deutscher Siedlungsgebiete und deuteten jede Art von Deutschtumspflege als „Verrat an Brasilien“" was Unruhen auslöste. 2238 Die Regierung nutzte die Ideologie der „Deutschen Gefabr“, um ihre Unterdrückungsmaßnahmen frei und legitim durchzuführen. ${ }^{2239}$ Alle deutschen Einwanderer und Nachkommen standen automatisch unter Generalverdacht und waren der Willkür der Polizeiabteilung für politische und soziale Ordnung (DOPS- Departamento de Ordem Política e Social) ausgesetzt. Viertelinspektoren, Polizei und Armee waren überall, um Deutsche und Deutschbrasilianer zu überwachen. In Rio Grande do Sul organisierte die Polizei sogar Exkursionen ins Binnenland, um Kolonisten zu inhaftieren $^{2240}$ und in Santa Catarina wurde ein brutales Verhaftungssystem eingeführt. Die Polizeiagenten jagten regelrecht „Nazis" und „Faschisten" und scheuten nicht vor öffentlicher Folter, Beschlagnahmungen, Plünderungen, Hausüberfällen, Raub $^{2241}$ und persönlicher Rache. Nach Blumenau (SC) wurden zwei Jägerbataillone entsandt, um die Deutsche Gefabr zu kontrollieren. ${ }^{2242}$ In Espírito Santo wurden Vandalengruppen eingestellt, um „Naris" zu verfolgen. Sie verprügelten viele Siedler, belästigten Frauen und raubten Lebensmittel, Hausgeräte, Waffen und Tiere von den Familien. ${ }^{2243}$

Weil die Regierung die brasilianische Bevölkerung zum Verraten ermutigte, denunzierten viele, selbst Deutsche und Deutschbrasilianer ehemalige Freunde, Nachbarn und Bekannte für ihre Sympathien für oder Partizipation am Integralismus oder Nationalsozialismus und aufgrund der Verwendung einer fremden Sprache. Eine österreichische Lehrerin, die mit dem Erziehungssekretär verwandt war, wurde im Pfarrhaus in Santa Maria de Jetibá (ES) beherbergt und sandte den Behörden Informationen über Pastor Rölke. Selbst einige Mitglieder der Gemeinde verbreiteten unzutreffende Gerüchte über ihn, die später zu seiner Inhaftierung führten. ${ }^{2244}$ In Pomerode (SC) wurde ein Lehrer von einem Deutschen ange-

2237 Ein Polizeidossier wurde vom Polizeichef des Staates Rio Grande do Sul veröffentlicht: Py, Aurélio da Silva. A $5^{a}$ Coluna no Brasil. A conspiração Nazi no Rio Grande do Sul. Porto Alegre: Globo, 1942. Ein anderes wurde von der Polizeiabteilung für politische und soziale Ordnung in Santa Catarina herausgegeben: Delegacia de ordem política e social de Santa Catarina. O Perigo nazista no coração do Brasil. Florianópolis: Imprensa Oficial do Estado, 1944.

2238 Schulze, s. 199f; Fáveri, S. 35.

2239 Perazzo, S. 48.

${ }^{2240}$ Cancelli, S. 305f; Fáveri, S. 209.

${ }^{2241}$ Fáveri, S. 320.

2242 Perazzo, S. 55.

2243 Seibel, Imigrante no século do isolamento, S. 271-273; Rölke, Raízes da Imigração alemã, S. 171, 176; Ackermann, S. 291. In Vila Pavão (ES) wurden Häuser von solchen Banden bis nach dem Zweiten Weltkrieg überfallen. Sie wussten, dass Siedler wichtige Gegenstände in ihren Gärten versteckt oder vergraben hatten und forderten sie auf, diese auszugraben. Sie zwangen auch Frauen, sich mit Zuckersirup zu beschmieren, woraufhin sie sie mit Federn aus ihren Decken und Kissen bewarfen und sie zwangen, nackt zu tanzen. Jacob, Jorge Kuster. Bate-Paus. Produktion von Ylênia Silva, Vitória: Galpão Produções, 2005, DVD, 15min. Zitiert nach Ackermann, S. 140.

2244 Gaede, S. 178, 181. 
zeigt. $^{2245}$ In Campinho (ES) wurde Antonio Ricardo Kautsky mit Pastor Carl Bielefeld verhaftet, weil sich beide miteinander auf Deutsch unterhalten hatten. Er soll von seinem Stiefbruder Cleto Neves angezeigt worden sein. ${ }^{2246}$

Einflussreiche Einwanderer und Nachkommen, die über einen politischen Freundes- und Bekanntenkreis verfügten oder Freundschaften mit bestimmten Rechtsanwälten, Polizisten und Beamten pflegten, konnten trotz ihrer Inhaftierung bald freigelassen werden, wie der Unternehmer Renaux aus Brusque (SC) 2247 , aber auch Pastor Stoer. ${ }^{2248}$ Andere Familien wandten sich schriftlich an die örtlichen Autoritäten oder gar direkt an Präsident Vargas und baten um die Freilassung ihrer Angehörigen. ${ }^{2249}$ In kleineren Siedlungsgebieten pflegten Soldaten und Deutschbrasilianer eher ein freundschaftliches Verhältnis. Nach der Zahlung eines Lösegeldes wurden beispielsweise viele Inhaftierte in Pomerode (SC) wieder freigelassen. ${ }^{2250}$ Einige Unteroffiziere nahmen hier jedoch Menschen nur aus diesem Grund fest. In diesem Sinne fand die polizeiliche Unterdrückung ihre Grenzen in einem Nepotismus- und Privilegiensystem. Menschen wurden freigelassen, auch wenn eine Beteiligung an Spionagedienst oder NSDAP nachgewiesen wurde, andere wiederum, die von einem Gericht freigesprochen worden waren, blieben bis nach dem Kriegsende inhaftiert. ${ }^{2251}$

Nach den ersten Nachrichten über Inhaftierungen und Folterungen versteckten sich viele Einwanderer und Nachkommen in ihren Häusern, wann immer sie fremde Menschen in ihre Siedlung kommen sahen. ${ }^{2252}$ Sie fürchteten sich davor, sich in der Öffentlichkeit zu zeigen und zu sprechen, vor allem abends und an Orten, wo die Polizei stärker kontrollierte. Andere verließen ihre Häuser und suchten bei Freunden und Verwandten in anderen Orten Unterschlupf. Nach polizeilichem Befehl mussten vor allem Bewohner von Küstengebieten, wie in

\footnotetext{
2245 Altmann, S. 41, 46.

2246 Kautsky, Roberto Anselmo. Biografia de Roberto Carlos Kautsky. 14.12.1895/13.6.1953. Zitiert nach Ackermann, S. 138.

2247 Er hatte eine freundliche Beziehung mit der Familie Konder, die vor 1930 die Politik in Santa Catarina dominierte, und wurde nach siebzehn Tagen freigelassen. Aussage von C.W.L. für Maria Luiza Renaux, Blumenau, 2.12.1988 und Aussage von Antonio Carlos Konder Reis für Cristiane Manique Barreto, Itajaí am 25.4.1996. Zitiert nach Fáveri, S. 176f, 251.

2248 Einer seiner Freunde aus Florianópolis (SC) besuchte das Polizeioberhaupt Lara Ribas und bat um seine Freilassung. Er wurde zwei Tage später entlassen. Fáveri, S. 179. Roberto Carlos Kautsky wurde mithilfe brasilianischer Freunde in Espírito Santo freigelassen. Kautski, Roberto Anselmo. Biografia de Roberto Carlos Kautsky. 14.12.1895/13.6.1953. Zitiert nach Ackermann, S. 138.

2249 Brief von Fridolino Schwarz an den Interventor Nereu Ramos, 8.6.1943; Brief von Herta Hassler an den Staatsinterventor Nereu Ramos, Florianópolis, 4.10.1943; Brief von Gertrudes Niemeyer, Itajaí, an den Präsidenten der Republik, Getúlio Vargas, Rio de Janeiro, 7.10.1943. Zitiert nach Fáveri, S. 71, 153-156.

2250 Altmann, S. 41f, 47.

2251 Perazzo, S. 82; Fáveri, S. 249.

2252 Seibel, Imigrante no século do isolamento, S. 274.
} 
Itajaí (SC) 2253, São Francisco do Sul (SC) und Vitória (ES) 2254 ihre Häuser verlassen und ins Binnenland umziehen. ${ }^{2255}$ Andere Familien versteckten sich in Wäldern, in Kellern und anderen Verstecken, um sich vor gewaltsamen Übergriffen zu schützen. ${ }^{2256}$ In Ibirama (SC) gab es ein Versteck im Krankenhaus. ${ }^{2257}$ Weil im Zuge der Hausdurchsuchungen neben integralistischem und nationalsozialistischem Material auch Bücher, Bibeln, Gesangbücher, Wandsprüche und Schriften in deutscher Sprache und Fotos 2258 öffentlich in Brand gesteckt wurden ${ }^{2259}$, verbargen oder vergruben viele Familien diese Habseligkeiten im Wald, im Stall, auf dem Dachboden, auf Plantagen 2260 oder in den Häusern ihrer Bekannten. ${ }^{2261}$ Beschlagnahmte Gegenstände dienten der brasilianischen Polizei als Beweis für die konkrete Existenz einer Deutschen Gefahr und legitimierten so das Unterdrückungssystem. Die Polizei organisierte sogar eine öffentliche Zurschaustellung der beschlagnahmten Gegenstände. ${ }^{2262}$

Inhaftierungen waren manchmal mit Folter verbunden. Angeklagte mussten vor Gericht eine Erklärung abgeben und viele, besonders in Internierungslagern, wurden während ihres Verhörs gefoltert. ${ }^{2263}$ Doch dies wurde in der Regel nicht protokolliert. $^{2264}$ Aus diesem Grund und weil viele Beweisstücke vernichtet worden sind und Folteropfer sich nicht trauten, über ihre Erfahrungen zu sprechen, sind wenige, teilweise nur vage Informationen erhalten geblieben. ${ }^{2265}$ Als Paul Gebhard aus Brusque (SC) verhaftet und ins Internierungslager Trindade in Florianópolis (SC) gebracht wurde, erfuhr niemand aus seiner Familie, wo er war und es war ungewiss, ob man ihn je wieder sehen würde. Als er nach einem Jahr zurückkehrte sprach er kein Wort über die Zeit seiner Inhaftierung und damit

2253 Aussage von Dagoberto Blease, 78 Jahre für Juliana Maes de Carvalho, Itajaí, 18.9.2000. Zitiert nach Fáveri, S. 207.

2254 Interview mit Helmut Meyerfreund, 70 Jahre, Vitória, 14.4.2006. Zitiert nach Ackermann, S. 141.

2255 Cancelli, S. 313f; Merkblatt über die Lage der Deutschen in Brasilien, 31.7.1943, S. 2, 5, MEW

3.20. In Espírito Santo wurden etwa 40 Deutschen, 255 Italiener und 5 Japaner umgesiedelt.

2256 Ackermann, S. 140; Seibel, Imigrante no século do isolamento, S. 272.

${ }^{2257}$ Fáveri, Fußnote 710, S. 212.

2258 Einige besaßen Fotos aus ihrer militärischen Dienstzeit vor der Einwanderung, die von der brasilianischen Polizei als Treuesymbol zum Dritten Reich interpretiert wurden. Perazzo, S. 160-163.

2259 Zeitung Correio de São Leopoldo von 31.1.1942. Zitiert nach Dreher, Igreja e Germanidade, S. 169; Seibel, Imigrante no século do isolamento, S. 272; Ackermann, S. 140.

2260 Altmann, S. 47f; Fáveri, S. 302f; Liesenberg, S. 5; Seibel, Imigrante no século do isolamento, S. 262.

2261 Seibel, Imigrante no século do isolamento, S. 270.

2262 Junges, Histórias de torturas e humilhações. Beilagen mit Fotos von Plakaten, Abzeichen, Broschüren, Zeitungen, Uniformen und Materialpropaganda, die von der brasilianischen Polizei bei Deutschen und Deutschbrasilianern gefunden wurde siehe Py; Delegacia de ordem política e social de Santa Catarina.

2263 Die Folter wurde 1821 als Untersuchungs- und Bestrafungsmethode in Brasilien aufgehoben, wurde aber, besonders zwischen 1935 und 1945, noch angewandt. Die Unterlagen wurden jedoch größtenteils vernichtet. Über Foltermethoden in Gefängnissen siehe Cancelli, S. 391-395.

2264 Junges, Histórias de torturas e humilhações.

2265 Fáveri, S. 215. 
auch über eine mögliche Folter während dieser Zeit.2266 In Pomerode (SC) wurden einige pommersche Kolonisten verhaftet, einer von ihnen musste wegen Mitgliedschaft im Jugendbund, Besitz deutscher Bücher und Korrespondenz mit Mitgliedern des Jugendbundes in Deutschland einen Brief hinunterschlucken und Rizinusöl trinken. ${ }^{2267}$ In verschiedenen Regionen von Santa Catarina wurden Nachkommen von Einwanderern mit Schlagstöcken verprügelt oder wurden gezwungen Öl zu trinken. ${ }^{2268}$ Nach Fáveri wurde dieses Ritual seitens der Behörden als eine Art „Taufe" gesehen, durch welche die Einwanderer und deren Nachkommen mittels physischer und psychischer Gewalt ihre ursprüngliche Kultur verleugnen sollten. ${ }^{2269}$ Paulo Bauer berichtet über die Inhaftierung seines Vaters und anderer Männer in einer Bar und darüber, wie ein gewisser Herr namens Spezer verletzt wurde, als Polizisten seinen Bart mit Glasscherben rasierten.2270 In Santa Leopoldina (ES) wiederum steckten Polizisten Nägel unter die Fingernägel mancher Kolonisten. ${ }^{2271}$ Aus Barra do Tigre-Agrolândia (SC) gibt ein Bericht detaillierte Hinweise über die dortigen Foltermethoden. Leopoldo Will wurde 1942 auf seinem Heimweg von der Polizei angehalten, festgenommen und gezwungen, in der Öffentlichkeit Rizinusöl mit Diesel und Benzin zu trinken und auf einem öffentlichen Platz zu defäkieren. ${ }^{2272}$ Die Polizisten beschimpften ihn und als er auf Deutsch antwortete, schlugen sie ihn mit der Waffe auf den Kopf und steckten das Karabinerrohr in seinen Mund, nachdem sie es mit Öl befüllt hatten. Die Polizisten misshandelten Leopoldo Will so schwer, dass sie ihm dabei die Zähne brachen und seine Zehen zerquetschten. Kein Arzt war bereit ihn zu behandeln, weil er „Deutscher" war. Die Polizei drohte ihm nach dem Vorfall damit, ihm die Zunge durchzuschneiden, sollte er je darüber berichten. ${ }^{2273}$

Angesichts der Notlage vieler Familien, die denunziert, verfolgt und inhaftiert wurden, war es vor allem der Glaube, der den Menschen half eine positive Seite in ihren Leiden zu sehen und ihrer Situation eine sinnvolle Bedeutung zu geben. Er ermöglichte den Menschen, ihr Leid bis zu einem gewissen Maße zu ertragen und es in einem größeren Zusammenhang zu sehen. Dies geht beispielsweise aus dem Bericht eines pommerschen Siedlers, der in Vitória (ES) inhaftiert wurde, hervor:

„Denen, die Gott lieben, muß alles rum Besten dienen (...) 40 Jabre lang bin ich im Land und war immer zu arm, um eine Reise in die Hauptstadt zu machen. Nun

\footnotetext{
2266 Junges, Histórias de torturas e humilhações.

2267 Altmann, S. 44f.

2268 Weingärtner, Martin Luther e Santa Catarina, S. 116; Fáveri, S. 251.

${ }^{2269}$ Fáveri, S. 210.

2270 Aussage von Paulo Bauer, 86 Jahre, in Itajaí am 13.5.1995. Zitiert nach Fáveri, S. 216.

2271 Seibel, Imigrante no século do isolamento, S. 265.

2272 Junges, Histórias de torturas e humilhações.

2273 Junges, Histórias de torturas e humilhações; vgl. mit Aussage von Eduardo Will, 78 Jahre, und Max Will, 70 Jahre im März 2000 in Agrolândia für Olga Grimm. Zitiert nach Fáveri, S. 209-214.
} 
schickt er [Gott] die bösen Menschen, daß sie mich ganz umsonst hier herbringen! Ist das nicht wunderbar?"2274

Hans Gotthardt Miertschink wiederum berichtet, wie seine Familie sich im Haus des Großvaters versteckte, als sie hörten, dass alle Deutschen und Deutschstämmigen inhaftiert und in ein Internierungslager gebracht werden sollten. Auch in den Wäldern wurden Verstecke gebaut und die Männer bewaffneten sich mit Sicheln, Äxten, Buschmessern und Pfählen. Die Kinder trugen als Brandschutzmaßnahme Gefäße voll Wasser auf den Dachboden, für den Fall, dass ihr Haus von Banden attackiert werden sollte. Die Aufregung war groß. Abends sah Miertschink durch einen Riss in der Tür seinen Vater in einem geschlossenen Zimmer, „kniend, betend und singend". Eine Gruppe sammelte sich in einem anderen Zimmer und betete zusammen.2275 Der Bericht verdeutlicht, wie die Verfolgten sich zur Überwindung ihrer Ängste ihrem Glauben zuwandten und sich bereitwillig unter den Schutz Gottes stellten. In Gebeten, Liedern und biblischen Texten fanden sie Halt und Bestärkung in der Hoffnung, dass Gott ihnen beistehen werde.

Auch kirchliche Gemeinden litten wieder unter den polizeilichen Maßnahmen aufgrund ihrer Beziehungen zu deutschen Kirchen und Organisationen, der finanziellen Unterstützung aus Deutschland und der Verwendung der deutschen Sprache. In Santa Catarina wurde der Gebrauch einer Fremdsprache ab April 1939 ausschließlich bei privaten Gesprächen in Häusern, Vereinen oder auf geschlossenen Feiern geduldet. Die deutsche Sprache war damit auch im kirchlichen Bereich verboten und Offiziere ließen bekannt geben, dass jeglicher Verstoß mit schweren Strafen geahndet würde.2276 Der evangelische Pastor Methner in Blumenau (SC) schloss aus diesem Grund die Kirche. ${ }^{2277}$ In den verschiedenen deutschsprachigen Gemeinden wurde das Gesetz aber unterschiedlich gehandhabt: In einigen wurde die deutsche Sprache gänzlich untersagt und Gottesdienste bis auf weiteres verboten ${ }^{2278}$, in anderen, wie Joinville (SC), durfte 1940 die in der Landessprache gesprochene Predigt auf Deutsch wiederholt werden und in Jaraguá do Sul (SC) konnten Gottesdienste mit behördlicher Genehmigung wie gewohnt in der Kirche oder in Privathäusern auf Deutsch gehalten werden.2279 In Rio Grande do Sul verordnete das Dekret Nr. 1.545 vom August 1939, dass abgesehen von der Litur-

\footnotetext{
${ }^{2274}$ Grotke, G. Das Brasilienwerk. In: Martin-Luther-Verein in Bayern, Diasporawerk in zwei Erdteilen, S. 35. Zitiert nach Krause, Lutherische Synode in Brasilien, S. 303.

2275 Miertschink, Hans Gotthard. Familia Miertschink. (Bericht), S. 7f. Zitiert nach Gaede, S. 211.

2276 Edital des Kommandanten von Blumenau, 19.4.1939; Dekret von 18.4.1939. Beide zitiert nach Prien, S. 446.

2277 Pastor Schliemann, Tagebuch Nr. 871 an das Kirchliche Außenamt von Bord der "Monte Rosa", 9.5.1939. Zitiert nach Prien, S. 447.

2278 Altmann, S. 160.

2279 Krause, Lutherische Synode in Brasilien, S. 299.
} 
gie, Predigten ausschließlich in der Landessprache ${ }^{2280} \mathrm{zu}$ halten waren. Hiervon ausgenommen waren abgelegene Orte, in denen die Predigt in einer fremden Sprache wiederholt werden durfte, falls es die Anzahl der Mitglieder, die nicht der Landessprache mächtig waren, erfordern sollte.2281 Anstelle einer Predigt führten einige Pastoren in ihrem Gottesdienst kleinere Auslegungen biblischer Passagen oder längere Gebete in deutscher Sprache ein, die nicht von der Kanzel, sondern vor dem Altar gesprochen wurden. In Espírito Santo durften Kinder und Jugendliche zwischen 7 und 21 Jahren keine deutschen Gottesdienste besuchen. ${ }^{2282}$ Aus diesem Grund gaben die Pastoren religiöse Unterweisung als „Liedstunde ${ }^{\curvearrowleft 2283}$ aus. In Lagoa (ES), Laranja da Terra (ES), Palmeira (ES) und Pontal (ES) war die deutsche Predigt ab Februar 1939 verboten ${ }^{2284}$ und Behörden in Vitória (ES) untersagten sogar den Gemeindegesang in deutscher Sprache. ${ }^{2285}$ Aber in Santa Leopoldi-

2280 Wichtig ist zu erwähnen, dass etliche Geistliche die Landessprache in Gottesdiensten und kirchlichen Amtshandlungen bereits eingeführt hatten. In der Versammlung der Mittelbrasilianischen Synode 1933 war beschlossen worden, Portugiesisch als Gottesdienstsprache einzuführen, obwohl die portugiesische Sprache zunächst nur als Zusatzangebot verwendet werden sollte. Protokoll vom 2. Sitzungstage der 7. Versammlung der Mittelbrasilianischen Synode - W. Adler. Zitiert nach Prien, S. 337. Der Verband Evangelischer Gemeinden von Santa Catarina und Paraná entschied sich wiederum 1937 für die Feier kurzer Gottesdienste in portugiesischer Sprache, nach denen der normale Gottesdienst in deutscher Sprache stattfand. Briefe von Pastor Schliemann, Florianópolis, von 27.7.1938 und 22.6.1938. Zitiert nach Prien, S. 428. In Limoeiro-Jaticoca (ES) wurden zweisprachige Gottesdienste seit 1938 gehalten und Diakon Richard Olberg in Cresciuma (ES) verwendete weitgehend die Landessprache. Keißling, Bruno. Brasilienbericht. In: Schmidt, Die Anfänge der Diakonie, S. 158, 162. In Joinville (SC) fanden portugiesische Gottesdienste angesichts der wachsenden Anzahl von Mischehen seit 1931 statt, Pastor Hans Müller hatte dafür Liturgie und Lieder ins Portugiesische übersetzt. Wüstner, S. 64. Nach Angaben seines Kollegen Pastor Karl Müller konnten aber etwa 95\% der Gemeindemitglieder den Inhalt nicht richtig verstehen. Brief von Pastor Karl Müller an Adam, Joinville, 20.12.1938; Brief von Pastor Müller, Joinville, 14.2.1939, MEW 4.207. Laut Pastor Grottke lag dies daran, dass Deutschbrasilianer mit dem geringen Wortschatz, über den sie verfügten, portugiesische Predigten nicht angemessen erfassen konnten. Bericht von Pastor G. Grottke aus Laranja da Terra, Februar 1938, MEW 4.188. In manchen Orten setzte sich dieser Versuch deshalb nicht durch. Noch 1941 lehnte Palmeira de Santa Joana (ES) den Vorschlag einer allmählichen Einführung des Portugiesischen in kirchlichen Veranstaltungen ab, weil die Mehrheit der Gemeindeglieder damit vom kirchlichen Leben ausgeschlossen werden würde, Lutherische Kirche in Brasilien, S. 191.

2281 Py, S. 198f.

2282 Die Lage der Deutschen und der Gemeinden in Brasilien, EZA 5/2164; Prien, S. 430.

2283 Prien, S. 434.

${ }^{2284}$ Brief von Pastor Karl Hünemörder an das Kirchliche Aussenamt von 25.2.1939, EZA 5/2164; Brief von Pastor Fr. Wüstner an Dr. Eppelein, Palmeira 25.2.1939, MEW 4.185.

2285 Brief von Pastor Schlünzen an das Kirchliche Außenamt Berlin, Joinville, 27.3.1939, EZA 5/2164. Geistliche der Evangelisch-Lutherischen Synode waren die ersten, die neben Einzelinitiativen der evangelischen Pastoren Joseph Hohl 1932 und Hans Wiemer 1945 in Petrópolis (RJ) liturgisches Material und Lieder in die Landessprache übersetzten und herausgaben. Pastor Fugmann gab bereits 1933 das Liederheft „Cantate, Liturgia e Hymnos “ heraus, das vor allem aus presbyterianischen Liedern bestand, 1938 veröffentlichte er „Cantate, Himnos e Oraçoes Evangélicas“. Pastor Hans Müller übersetzte 1938/1939 Lieder aus den Missionsharfenliedern und dem „Deutschen Evangelischen Gesangbuch für Brasilien", das das Kirchliche Außenamt herausgegeben hatte. Diese Gesangbücher wurden auch von dem Verband Evangelischer Gemeinden von Santa Catarina und Paraná genutzt. Abschrift des Briefes von 
na (ES) konnte der kirchliche Dienst und selbst der Konfirmandenunterricht in deutscher Sprache trotz aller Verbote ohne Behinderung fortgesetzt werden. ${ }^{2286}$

Die Ausübung nationalistischer Maßnahmen waren zum einen vom Eifer der lokalen Behörden ${ }^{2287}$ und zum anderen vom Verhalten der kirchlichen Gemeinden oder Pastoren abhängig. ${ }^{2288}$ Sehr abgelegene Gemeinden blieben meistens verschont, weil die Polizei nur sehr begrenzten Zugang zu ihnen hatte und sie deshalb nur schwer kontrollieren konnte. ${ }^{2289}$ In einigen Fällen löste das Verhalten einiger Geistlicher die Anordnung strengerer Maßnahmen aus. Etliche Pastoren in Blumenau (SC) brachen beispielsweise die Vereinbarung mit Kapitän Adato de Melo, deutschsprachige Gottesdienste lediglich als Wiederholung portugiesischer Gottesdienste zu vollziehen. ${ }^{2290}$ Am 24. Dezember 1938 wurde Vikar Roland Mielke in Blumenau (SC) verhaftet, weil er trotz aller Ermahnungen und Warnungen eine Jugendgruppe leitete. Selbst der Kirchenvorsteher Müller-Hering hatte ihn dreimal erfolglos gebeten, die Jugendarbeit angesichts der Polizeimaßnahmen einzustellen. ${ }^{2291}$ Pastor H. Wiemer aus Itoupava (SC) wurde zusammen mit Lehrer Rahn verhaftet, weil er bilingualen Konfirmandenunterricht durchführte. ${ }^{2292}$ Pastor Ernesto Balbach in Serra Pellada (ES) widersetzte sich der polizeilichen An-

Pastor Schliemann an Pastor Dauner, 27.4.1943, AHI, SE 13/2, Beilage 286. Dem Gesangbuch, das von der Evangelisch-Lutherischen Synode herausgegeben worden war, wurde eine evangelische Liturgie auf Portugiesisch beigefügt. Der Verband Evangelischer Gemeinden bat um Erlaubnis, den Titel des Liederheftes in „Hinos da Igreja Evangélica“ zu ändern. Abschrift des Briefes von Pastor Schliemann an die Lutherische Synode, Nr. 141, 24.2.1942; Abschrift des Briefes von Pastor Schliemann an die Lutherische Synode, 22.12.1941, beides In: AHI, SE 13/2, Beilagen 291, 319, vgl. Brief von Pastor Schlünzen an die Evangelische Synode, 24.12.1941, AHI, SE 13/2, Beilage 321. 1939 stellte Pastor Fugmann ein „Manual de Culto Luterano" als Hilfsbuch für portugiesische Gottesdienste zur Verfügung. Schreiben von Pastor Fugmann an das Kirchliche Außenamt, 1.11.1939, EZA 5/2208; vgl. Krause, Lutherische Synode in Brasilien, S. 295. Die Evangelisch-Lutherische Synode veröffentlichte auch die portugiesische Übersetzung des Kleinen Katechismus (Schneider, Albert. Bericbt über die Jabre 1941-1944. Zitiert nach Wilbert et. al., S. 110), und gab 1943 eine dritte Ausgabe des Liederbuches auf Portugiesisch, mit neuen Volksliedern und Liedern der „Kleinen Missionsharfe" heraus. Rundschreiben der Lutherischen Synode Nr. 98 von 12.6.1943, AHI, SL 4/2, Beilage 147.

2286 Brief von 24.4.1939 an das Kirchliche Außenamt durch die Mittelbrasilianische Synode. Zitiert nach Prien, S. 442.

2287 Die obersten Polizeibehörden in Rio Grande do Sul waren sehr tolerant. Bericht über die kirchliche Lage in der Riograndenser Synode. Buenos Aires, 4.4.1941, EZA 5/2165.

2288 Pastor Arthur Hahn in Santa Leopoldina (ES) fürchtete die Behörden nicht, denn die Familie des Bürgermeisters besuchte die Gottesdienste in seiner Gemeinde. Brief an das Kirchliche Außenamt durch die Mittelbrasilianische Synode, 24.4.1939. Zitiert nach Prien, S. 442. Der Staatsinterventor von Santa Catarina antwortete Pastor Weger in Canoinhas (SC) auf die Frage, wie es mit dem deutschen Gottesdienst weitergehen sollte, wie folgt: „Sie können rubig fortfahren, deutsch zu predigen. Hätten Ibre Amtsbrüder sich ebenso wenig politisch betätigt wie Sie, dann wäre auch ibnen nichts in den Weg gelegt worden". Brief von Pastor Schlünzen an das Kirchliche Außenamt, Joinville, 27.3.1939 EZA 5/2164.

2289 Malikoski.

2290 Prien, S. 442.

2291 Zeitung $A$ Notícia, von 10.6.1939, und A Comarca de Indaial, von 21.5.1939, AHI, SE 8/6, Beilage 040; Prien, S. 442 f.

2292 Prien, S. 443. 
ordnung, die Nationalhymne zu singen und „es lebe Brasilien“ zu rufen und schlug einen Polizisten mit einer Lampe. ${ }^{2293}$ Pastor Hahn in Santa Leopoldina (ES) weigerte sich wiederum, das Verbot der deutschen Sprache für Predigten und Ansprachen einzuhalten. ${ }^{2294}$

Mit der Kriegserklärung 1942 wurde die deutsche Sprache selbst in privaten Gesprächen nach dem Gottesdienst und bei häuslichen Versammlungen verboten. In Espírito Santo wurden manche Pastoren während der Gottesdienste ausspioniert oder offen kontrolliert ${ }^{2295}$, Gottesdienste wurden in einigen Gemeinden auch von der brasilianischen Polizei unterbrochen ${ }^{2296}$ und Soldaten betraten die Kirchen, um Menschen und Gebäude zu durchsuchen. ${ }^{2297}$ Im Angesicht der Verschärfung nationalistischer Maßnahmen verließ Pastor Karl Müller die Gemeinde Joinville (SC). ${ }^{2298}$ Zweiggemeinden konnten teilweise aufgrund eines Gesetzes, dass es untersagte, ohne Geleitbriefe von einer Stadt in die andere zu fahren, nicht mehr durch Pastoren betreut werden. Die Situation verschlimmerte sich noch als Pastoren inhaftiert wurden. ${ }^{2299}$ Sie wurden beschuldigt, „Nazis“, „Anti-

\footnotetext{
2293 Ackermann, S. 139.

${ }^{2294}$ Brief von Karl Hünemörder an das Kirchliche Aussenamt, 25.2.1939, EZA 5/2164.

${ }^{2295}$ Bericht Pastors Rölke im Archiv der Parochie Santa Maria de Jetibá. Zitiert nach Gaede, S. 179.

2296 Dreher, Igreja e Germanidade, S. 172.

${ }^{2297}$ Kuhn, Anivaldo. Interview. Zitiert nach Seibel, Imigrante no século do isolamento, S. $514 \mathrm{f}$.

2298 Wüstner, S. 73.
}

22991942 waren 34 Geistliche in der landwirtschaftlichen Strafkolonie Daltro Filho (RS), auf der Blumeninsel in Rio de Janeiro (RJ), in Belo Horizonte (MG) und in Vitória (ES) inhaftiert, siehe Prien, S. 459; vgl. Die Lage der Deutschen in Brasilien bis Oktober 1942, Berlin, Auswärtiges Amt, 15.1.1943, MEW 3.20. Über eine Liste mit inhaftierten Pastoren in Daltro Filho (RS), im Gefängnis Trindade in Florianópolis (SC) und im Internierungslager in der Kolonie Candido Mendes (RJ) siehe den Brief von Henkel an die Geistlichen aus Südamerika auf Deutschlandurlaub von 16.9.1943, EZA 5/2165; Merkblatt über die Lage der Deutschen in Brasilien, 31.7.1943, S. 6-16, MEW 3.20. Für eine andere Auflistung inhaftierter Pastoren siehe den Brief von Bischof Dr. Heckel an die deutschen evang. Pfarrämter aus Südamerika, Berlin, 11.9.1944, S. 2f, MEW 3.20. Über Inhaftierte in Florianópolis (SC) und Joinville (SC) siehe Junges, Os presos em Santa Catarina. In: A Notícia. Privatarchiv von Pastor Weingärtner. Über die Situation der Pastoren in den Lagern Santa Catarinas siehe Abschrift des Briefes von Major Hansotto Vorberg, 22.5.1944, EZA 5/2168. Während seiner Inhaftierung bekam Pastor Rölke Lebensmittel von seiner Familie geliefert. Brief von Gerda Rölke an den Vater, 8.10.1942. Zitiert nach Rölke, Raízes da Imigraşão alemã, S. 172f. In Ilha Grande (RJ) brachten Frauen aus der kirchlichen Gemeinde Obst, Gemüse und Kartoffeln zu Internierten. Inhaftierte, die keine Angehörigen in der Nähe hatten, weil sie nicht immer in die Konzentrationslager im Staat ihres Wohnsitzes gebracht wurden, bekamen eine Patin zugeteilt, die ihnen alle zwei Wochen ein Proviantpaket brachte. Bericht des Studienrats Dr. Kloster über das Lager Candido Mendes auf der Ilha Grande bei seinem Besuch am 27.7.1944, EZA 5/2168. Im Oktober 1942 wurden viele Pastoren in Vitória (ES) unter ,freiwilliger Verzichtleistung "ihrer Amtstätigkeit enthoben. Protokoll der Pastoralkonferenz des Nordkreises der Luth. Kirche in Brasilien zu S. Maria am 26.6.1946, Protokollbuch des Nordkreises II, MEW 3.22. Nach Pastor Grottke wurden sie in der Regel zehn Wochen in den Hauptstädten der Bundesstaaten in Schutzhaft genommen und nur unter ausdrücklicher Verpflichtung, nicht mehr zu amtieren, freigelassen, Grottke, G. Laranja da Terra, S. 56. Zitiert nach Krause, Lutherische Synode in Brasilien, S. 302; Lutherische Kirche in Brasilien, S. 181f. 1944 waren nur 
Nationalisten“, „Propagandisten" und "Agenten Hitlers in Brasilien“ zu sein ${ }^{2300}$, die Deutsche und Deutschbrasilianer durch religiöse Predigten politisch indoktrinieren wollten. Ziel der Polizei war die Eingrenzung und Schwächung der intellektuellen Führung der Deutschen in Brasilien.2301 Vakante Gemeinden, für die kein deutscher Pastor mehr zur Verfügung stand oder deren Pastoren inhaftiert waren, wurden zunächst von benachbarten Kollegen und manchmal sogar von einem Pastor einer anderen Synode übernommen. ${ }^{2302}$ Diese Situation führte in mancher Hinsicht zur vorläufigen Entspannung der Konflikte zwischen evangelischunierten und evangelisch-lutherischen Gemeinden, die jahrelang getrennt gewesen waren und sich nun in der Not gegenseitig unterstützten. Jequitibá (ES) beispielsweise übernahm die Vertretung von Santa Maria de Jetibá (ES), Rio Bonito (ES) und Suíça (ES), Cresciuma (ES) und Guandu (ES) reunierten sich nach dem Zweiten Weltkrieg. ${ }^{2303}$ Für weitere Gemeinden berief Pastor Dohms Theologiestudenten der obersten Klassen des Proseminars in São Leopoldo (RS) ${ }^{2304}$ und bereitete sie mit einem Intensivkurs auf die pfarramtliche Gemeindearbeit vor. ${ }^{2305}$ Geistliche in Espírito Santo erhielten erst gegen Ende des Jahres 1943 die Erlaubnis, ihren Dienst eingeschränkt fortzusetzen ${ }^{2306}$, nachdem jede Gemeinde zunächst Gebühren an Rechtsanwälte hatte zahlen müssen.2307

Auch kirchliches Vermögen wurde geplündert, beschlagnahmt, geraubt oder zerstört. Kruzifixe, Gefäße, Dokumente, Registerbücher, Agenden und Bücher wurden beschlagnahmt oder verbrannt. Biblische Texte auf deutscher Sprache mussten abgedeckt oder entfernt werden. ${ }^{2308}$ Motorräder, die dem Pfarrdienst als Ersatz für Pferde und Maultiere dienten, wurden beschlagnahmt. ${ }^{2309}$ Das Pfarrhaus in Rio Grande (RS) wurde von der Polizei besetzt, in Pelotas (ES) wurde das dortige Pfarrhaus im August 1942 in Brand gesteckt, ebenso wie der Innenraum

noch wenige Pastoren interniert. Kurze Zusammenfassung aus Berichten Zurückgekehrter über die Internierungslager in Brasilien, 3.7.1944, EZA 5/2168.

2300 Prien, S. 461-465; Junges, Histórias de torturas e humilhações.

2301 Py, S. 209.

2302 Evangelische Synode von Santa Catarina und Paraná, S. 82; Claas, S. 24.

2303 Lutherische Kirche in Brasilien, S. 210-212, 224f, 227.

23041921 gründete Pastor Hermann Dohms in seinem Haus in Cachoeira do Sul (RS) das theologische Proseminar. Dort besuchten zukünftige Theologen eine erste höhere Bildungsstufe, mussten aber ihre theologische Ausbildung dann in Deutschland fortsetzen. Das Proseminar wurde 1927 nach São Leopoldo (RS) verlegt und wurde 1946 zur Theologischen Fakultät der Evangelischen Kirche Lutherischen Bekenntnisses in Brasilien. Fischer, Geschichte der Evangelischen Kirche, S. 164f.

2305 Der Theologiestudent Edgar Liesenberg übernahm beispielsweise den pfarramtlichen Dienst in Blumenau (SC) und Pomerode (SC). Liesenberg, S. 15.

${ }^{2306}$ Lutherische Kirche in Brasilien, S. 182.

2307 Protokoll der Pastoralkonferenz des Nordkreises der Luth. Kirche in Brasilien zu S. Maria am 26.6.1946. In: Protokollbuch des Nordkreises II, MEW 3.22.

2308 Weingärtner, Martin Luther e Santa Catarina, S. 116.

${ }^{2309}$ Entwurf eines Briefes von Pastor Dohms an den Polizeichef in Porto Alegre, Darcí Vignoli, AHI, SR 15/7 Beilage 016; Abschrift des Briefes von Pastor Dohms an den Polizeichef Darcy Vignoli, 3.11.1943, AHI, SR 18/1, Beilage 002. 
der Kirche. Obwohl nach der Inhaftierung des Pastors keine kirchliche Aktivität mehr stattgefunden hatte, wurden in Santa Maria (RS) Kirche und Pfarrhaus mit Steinen beworfen und aus der Kirche das heilige Gefäß, die Orgel, das Mobiliar und mehrere Gegenstände beschlagnahmt und auf dem öffentlichen Platz verbrannt oder an einen unbekannten Ort gebracht. In zwei Gemeinden des Pfarrbezirks Santo Ângelo (RS) wurden die Kapellen in staatliche Schulen umfunktioniert, so dass dort kein Gottesdienstraum mehr zur Verfügung stand. ${ }^{2310}$ Zweiggemeinden in Brüdertal (SC) verblieben aufgrund des Verbots, Schulen als Kirche zu nutzen, ohne geistliche Versammlungsorte. Das Gotteshaus in São Francisco do Sul (SC) wiederum wurde verwüstet und kirchliche Gegenstände vernichtet oder ins Meer geworfen..$^{2311}$ In Palmeira de Santa Joana (ES) ${ }^{2312}$ und Santa Maria de Jetibá (ES) wurde das Gemeindehaus von der Regierung annektiert, um fortan für brasilianischen Unterricht genutzt zu werden, jedoch versammelten sich hier die Vorstands- und Gemeindemitglieder und fuhren nach Vitória (ES), um gegen den Beschluss zu protestieren. ${ }^{2313}$ Auch Pastor Dohms beschwerte sich in verschiedenen Briefen über Beschlagnahmungen und Plünderungen in den Gemeinden und forderte die Autoritäten dazu auf, dies zukünftig zu unterlassen und zu verhindern. 2314

Um die Inhaftierung von Pastoren zu verhindern, versteckten einige Gemeindemitglieder sie auf den Dachböden ihrer Häuser, wie zum Beispiel in Domingos Martins (ES), oder bauten ihnen ein Versteck, wie in Laranja da Terra (ES) ${ }^{2315}$ (Abb. 38, siehe S. 376). Als der Polizeikommissar zusammen mit seinen Soldaten Pastor Grottke festnehmen wollte, sammelten sich die Mitglieder in der Kirche, um ihn vor den Soldaten zu schützen. Eine weitere Gruppe versteckte sich in der Nähe einer Brücke und lauerte den Soldaten mit Hacken, Sicheln, Äxten, Revolvern und Karabinern auf. Als der Polizeikommissar davon erfuhr, ließ er von seinem Vorhaben ab. ${ }^{2316}$ Für Pastor Hermann Stoer aus Rio do Sul (SC), der mehrmals verhaftet wurde, übernahm die Gemeinde die Geldstrafe.2317

${ }^{2310}$ Merkblatt über die Lage der Deutschen in Brasilien, 31.7.1943, S. 5, MEW 3.20; Entwurf eines Briefes von Pastor Dohms an den Polizeichef in Porto Alegre, Darcí Vignoli, AHI, SR 15/7 Beilage 016; Abschrift des Briefes von Pastor Dohms an den Polizeichef Darci Vignoli, 19.10.1943, AHI, Beilage 009 und SR 18/1 Beilage 010.

${ }^{2311}$ Lutherische Kirche in Brasilien, S. 56.

${ }^{2312}$ Lutherische Kirche in Brasilien, S. 189.

2313 Rölke, Hermann. Auszug aus dem Protokoll der Jabresversammlung am Santa Maria, 10.1.1940. Archiv der Parochie Santa Maria de Jetibá. Zitiert nach Gaede, S. 181.

2314 Abschrift des Briefes Nr. 1507 von Pastor Dohms an den Polizeichef A. da Silva Py, 2.12.1942, SR 18/1, Beilage 022; Abschrift des Briefes von Pastor Dohms an den Polizeichef Darci Vignoli, 19.10.1943, AHI, SR 17/8, Beilage 009; Abschrift des Briefes von Pastor Dohms an den Polizeichef Darci Vignoli, 3.11.1943, AHI, SR 18/1, Beilage 002.

2315 Seibel, Imigrante no século do isolamento, S. 265-267.

2316 Seibel, Imigrante no século do isolamento, S. 267f, $293 \mathrm{f}$.

2317 Abschrift Majors Hansotto Vorberg Briefes von 22.5.1944, EZA 5/2168. Im Internierungslager Trindade in Florianópolis (SC) äußerte sich der Major Vorberg über die Möglichkeit eines Habeas 


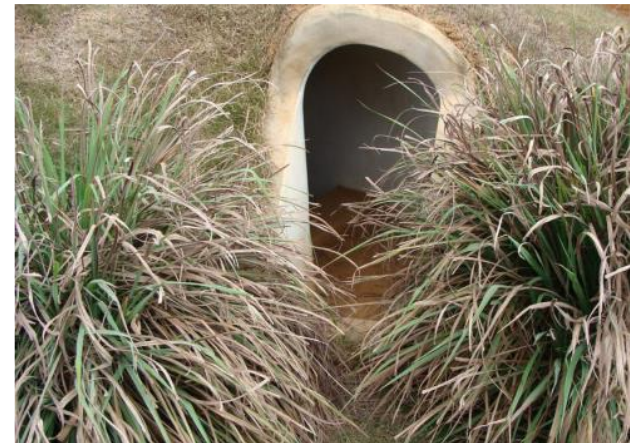

Abb. 38: Restauriertes Versteck von Pastor Grottke in Laranja da Terra (ES). Quelle: Seibel, Imigrante no século do isolamento, S. 268.
Angesichts der Inhaftierung der Pastoren und der zunehmenden $\mathrm{Va}$ kanz in den Gemeinden übernahmen Gemeindemitglieder wieder vermehrt selbst pfarramtliche Funktionen und vollzogen Lesegottesdienste sowie notwendige kirchliche Amtshandlungen, vor allem Beerdigungen und Nottaufen. ${ }^{2318}$ In Espírito Santo werden namentlich Emil Jahn in Cresciuma (ES), Wilhelm Raasch und August Eggert in Santo Antônio (ES), Richard Berger in Palmeira de Santa Joana (ES) ${ }^{2319}$, Franz Boldt ${ }^{2320}$, Alberto Schwarz und Miertsching in Santa Maria de Jetibá (ES), Teodoro Schwambach in Domingos Martins (ES) und Karl Reblin in Laranja da Terra (ES) ${ }^{2321}$ und in Guandu (ES) ${ }^{2322}$ erwähnt. Einige Familien versammelten sich auch in ihren Häusern, um zusammen zu beten, biblische Andachten zu feiern und Lieder aus dem Gesangsbuch zu singen. ${ }^{2323}$

Die Kirchenarbeit konnte damit zwar begrenzt fortgeführt werden, doch Geistliche befürchteten, die „Kirche des Wortes“könne zu einer „Kirche der äußerlichen, toten Zeremonien" werden. ${ }^{2324}$ Dabei unterschätzten sie jedoch die Bedeutung von Gesten, Gebeten und Liedern, der Liturgie und vor allem der kirchlichen Amtshandlungen und nicht zuletzt die religiöse und sakrale Bedeutung kirchlicher Gebäude. Diese Elemente hatten schon die Grundlage für die Entstehung von Gemeinden in brasilianischen Siedlungsgebieten gebildet, bevor dort überhaupt Pastoren eingetroffen waren. Eine auf Hochdeutsch gehaltenen Predigt war bereits vor dem Krieg und den Nationalisierungsmaßnahmen angesichts der mangelhaf-

Corpus für die Freilassung von Geistlichen zu erlangen. Brief des Bischofs Dr. Heckel an die Pastoren Blümel, Stoer, Neumann, Schuttkus, Andresen und Masskus (?), 9.6.1944, EZA 5/2168. Dr. Kloster berichtet aber, dass Habeas Corpus nur von Familien mit brasilianischen Kinder beantragt werden konnte, denn nach der Entlastung blieben die Inhaftierten noch unter Zwangsaufsicht gestellt. Bericht des Studienrats Dr. Kloster über das Lager Candido Mendes auf der Ilha Grande bei seinem Besuch am 27.7.1944, EZA 5/2168.

2318 Protokoll der Pastoralkonferenz des Nordkreises der Luth. Kirche in Brasilien zu S. Maria am 26.6.1946. In: Protokollbuch des Nordkreises II, MEW 3.22; Ackermann, S. 291.

2319 Lutherische Kirche in Brasilien, S. 191, 200f, 220.

2320 Gaede, S. 181.

2321 Seibel, Imigrante no século do isolamento, S. 264, 276.

2322 Lutherische Kirche in Brasilien, S. 213.

2323 Protokollbuch der Gemeinde Timbó (SC), 24.1.1940. Zitiert nach Weingärtner, Crônica da Comunidade Evangélica de Timbó, S. 58; Seibel, Imigrante no século do isolamento, S. 276.

2324 Protokoll der Pastoralkonferenz zu Santa Maria am 11.6.1941. In: Protokollbuch des Nordkreises II, MEW 3.22; vgl. Wüstner, S. 80. 
ten Bildungsverhältnisse und der Verwendung von Dialekten sowie der sprachlichen Assimilation portugiesischer Vokabeln von vielen Pommern und deren Nachkommen in manchen Gebieten ohnehin nicht genau verstanden worden, dennoch waren sie weiterhin fleißige Kirchgänger geblieben. Pastoren berichten, dass Gottesdienste, besonders mit Darreichung des Abendmahls, selten so gut besucht waren, wie in den Zeiten des Krieges ${ }^{2325}$, auch wenn einige Gemeindemitglieder dem Gottesdienst fernblieben, weil sie sich nicht in der Lage sahen, die nun portugiesische Predigt zu verstehen ${ }^{2326}$ und darüber traurig wie auch wütend waren:

„Zur Kirche gehe ich regelmäßig, aber wie anders sind jetzt die Gottesdienste. Die Predigt, die Gebete, ja, das Wort kann ich nicht verstehen. Wie oft sitze ich im Gotteshause und weine vor Zorn und Schmery, daß man uns das Evangelium vergattert hat, so daß wir es nicht verstehen können. Gott erbarme sich unserer armen Gemeinden".2327

Andere Gemeindemitglieder aber ließen sich nicht durch das Sprachverbot entmutigen. ${ }^{2328}$ Sie kannten die Liturgie und die Lieder, die sie teilweise auswendig gelernt hatten. Kirchenmitglieder berichten, dass die Gesten des Pastors in der Regel darauf schließen ließen, wann Glaubensbekenntnis oder das Vaterunser gebetet wurden und sie sprachen diese in Gedanken mit. Besonders tröstlich war deshalb der Segen am Ende des Gottesdienstes, denn wie die Pastoren die Hände hoben und den Segen auf Portugiesisch sprachen, erkannten die Gemeindemitglieder die Segenshandlung anhand der Gestik. ${ }^{2329}$

Die Kirche diente zudem als Zufluchtsort und die kirchliche Gemeinschaft gab vielen einen Halt bei der Bewältigung ihrer Ängste und ihrer gefährlichen Lage. In der Kirche trafen sich die Menschen, um Trost in biblischen Lesungen, Gebeten oder Liedern zu finden, um Informationen auszutauschen und sich gegenseitig zu unterstützen oder gar zu schützen, wie das Beispiel der Verstecken für die Pastoren zeigt. Die Kirche war weiterhin der Ort, an dem über Lösungen bezüglich der vielen Probleme beraten wurde, unter anderem über die Erhaltung des kirchlichen Lebens durch Lesegottesdienste, über häusliche Unterrichtung der

\footnotetext{
2325 Bericht von Pastor G. Grottke aus Laranja da Terra, Februar 1938, MEW 4.188; Krause, Lutherische Synode in Brasilien, S. 300; Liesenberg, S. 15; Wüstner, S. 80.

2326 Schneider, Albert. Bericht der Gemeinde Jaraguá II über das Jahr 1939. Zitiert nach Wilbert et. al., S. 110; Wüstner, S. 80.

2327 Bericht von Pastor Langholf [um 1941], S. 2, MLV 51/17 108. In Espírito Santo sollen etwa 95\% der Gemeindemitglieder eine Predigt in der Landessprache nicht verstanden haben können. Protokoll der Pastoralkonferenz des Nordkreises der Luth. Kirche in Brasilien zu S. Maria am 26.6.1946. In: Protokollbuch des Nordkreises II, MEW 3.22. In Rio Ada-Timbó (SC) sagte ein älteres Mitglied, dass die Gemeindemitglieder weinen würden, wenn sie nur noch einmal „ricbtige Gottesdienste" feiern und die Predigt verstehen könnten. Weingärtner, História da Comunidade Evangélica de Timbó, S. 246.

${ }^{2328}$ Lutherische Kirche in Brasilien, S. 103.

${ }^{2329}$ Weingärtner, História da Comunidade Evangélica de Timbó, S. 245.
} 
Jugendlichen und über die Frage nach der Vollziehung von kirchlichen Amtshandlungen angesichts der Inhaftierung von Pastoren. Laut Krause:

„Viele Gemeindeglieder kamen unter sich zu Hausgottesdiensten oder auch in den Kirchen zusammen, um sich gegenseitig zu stärken sowie ibren Willen zum Ausharren, auch obne den inhaftierten Pastor - oder bis zu seiner Freilassung zum Ausdruck zu bringen. Taufen und Beerdigungen wurden durch ein von der Gemeinde dazu beauftragtes Gemeindeglied vollzogen. Im großen und ganzen beschloß man aber zu warten, bis der Pfarrer wieder sein Amt ausüben könnte ".2330

Pastor Schlünzen hatte den Eindruck, dass das Interesse der Gemeindemitglieder an Kirche und Gemeinde durch die Not noch lebendiger geworden war. ${ }^{2331}$ Laut Pastor Langholf war die Treue zur Gemeinde größer als die Bedrängnis der Kriegs- und Nationalisierungszeiten und dies ermutigte die Gläubigen die widrigen Umstände auszuhalten. Sie stärkten sich in Hausgottesdiensten, kamen in der Kirche mit oder ohne Pastor zusammen und als die Geistlichen wieder freigelassen wurden, hielten sie der kirchlichen Gemeinde erst recht die Treue, ganz gleich ob sie Predigt und Liturgie verstanden oder nicht. ${ }^{232}$ Diese Entwicklung steht in scharfem Kontrast zu den Vorjahren des Krieges, in denen über eine mangelnde Anwesenheit bei den Gottesdiensten ${ }^{2333}$, über Unwilligkeit vieler Kirchenmitglieder bezüglich der Gemeindearbeit ${ }^{2334}$, über das Verschwinden einer „deutschevangelischen Frömmigkeit" und über ein zunehmendes Vertrauen auf Geld und Gut sowie Vermehrung des Besitztums und des Lebensgenusses ${ }^{2335}$ berichtet worden war. Im Angesicht der widrigen Umständen lernten die Gemeindemitglieder wieder die tiefgreifende Bedeutung kirchlichen Lebens zu schätzen. Gemeinde und Gemeindemitglieder wuchsen mit ihren Herausforderungen und weil die öffentliche Erhaltung von Schul- und Vereinswesen sowie jedwede Bautätigkeit verboten oder zumindest eingeschränkt worden waren, begann ,ein neues inneres $W$ achstum in den Gemeinden sich zu entfalten "2336

\footnotetext{
2330 Krause, Lutherische Synode in Brasilien, S. 302.

2331 Bericht von Pastor Schlünzen, 1.12.1941. Zitiert nach Krause, Lutherische Synode in Brasilien, S. 301.

2332 Bericht von Pastor Langholf [um 1941], S. 2, MLV 51/17 108.

2333 In Lomba Grande-Novo Hamburgo (RS) umfasste der Gottesdienstbesuch um 192880 bis 130 von 600 Familienglieder. Brief von Pastor Jakob Sauer an die Missionsfreunde, Lomba Grande, 10.2.1928, BMA, PABV 1875.

${ }^{2334}$ Der Christenbote, Nr. 2, Februar 1920 et. passim. Zitiert nach Prien, S. 218.

2335 Nachrichten: Die Gnadauer Mission in Brasilien. Ernst Modersohn, der den Artikel auf Grund der Korrespondenz mit Pfeiffer geschrieben hat. In: ,Licht und Leben' Nr. 35, 27.8.1933. Zitiert nach Prien, S. 239.

2336 Giurus, Crônica da Paróquia Evangélica Luterana de Indaial, S. 151.
} 
Mit Ausnahme einiger Gemeindemitglieder, die im Übertritt zur Missourikirche oder zum Katholizismus einen Ausweg fanden ${ }^{2337}$, wurden keine bedeutenden Verluste hinsichtlich der Mitgliederanzahl registriert. Während die Anzahl der Gemeinden und Predigtstellen vielerorts aufgrund der Inhaftierung von Geistlichen und den damit einhergehenden zunehmenden Vakanzen zurückgegangen war, stieg die Zahl der Kirchenmitglieder dagegen an. ${ }^{2338}$ Die zweisprachige Arbeit wurde im Zuge dieser Entwicklung in fast allen Gemeinden zur Notwendigkeit, was aber deren Fortsetzung nicht beeinträchtigen sollte.

Bezüglich der Frage nach der Hinwendung zu magischen Praktiken während der Nationalisierungs- und Kriegszeiten schweigen fast alle Quellen. Nur der Gnadauer Missionar Pfeiffer berichtete 1933 über ein Sich verlassen auf „Besprechen von Krankheiten" und Himmelsbriefe $e^{2339}$ in Santa Catarina. ${ }^{2340}$ Diese Praktiken wurden aber sicherlich fortgesetzt, besonders Himmels-, Schutz- und Hausbriefe erhielten vermutlich in Zeiten der Unsicherheit wieder eine wichtige Bedeutung als Schutzmaßnahme gegen alle Arten von Gefahren, denen die Menschen ausgesetzt waren. Etliche deutschbrasilianische Soldaten, die in den Krieg gezogen waren $^{2341}$, mochten solche Briefe bei sich getragen haben, wie dies auch deutsche Soldaten zu tun pflegten.

Nach Kriegsende wurden deutsche Gottesdienste allmählich wieder durchgeführt $^{2342}$ und viele Gemeindemitglieder waren zutiefst erfreut, wieder eine deutsche Predigt zu hören und die ihnen bekannten Lieder zu singen, „es ist dabei manche Freudenträne geflossen".2343 Die Wiedereinführung der deutschen Sprache wurde von allen Seiten sehr begrüßt, besonders ältere Generationen hatten sich nicht auf die portugiesische Sprache umstellen können und besaßen auch nicht die Möglichkeit, Schriftportugiesisch zu lernen. Meistens sprachen sie nur in der portugie-

\footnotetext{
${ }^{2337}$ Lutherische Kirche in Brasilien, S. 191, 220; Protokoll der Pastoralkonferenz des Nordkreises der Luth. Kirche in Brasilien zu S. Maria am 26.6.1946. In: Protokollbuch des Nordkreises II, MEW 3.22.

2338 Krause, Die Entwicklung der Synode, S. 115; Prien, S. 466.

2339 Siehe Kapitel IX - Exkurs über Himmelsbriefe.

2340 Nachrichten: Die Gnadauer Mission in Brasilien. Ernst Modersohn. In: ,Licht und Leben ' Nr. 35, 27.8.1933. Zitiert nach Prien, S. 239.

${ }^{2341}$ Deutschbrasilianer mussten als brasilianische Staatsbürger Militärdienst leisten. Diejenigen, die die Landessprache beherrschten, mussten für ein Jahr dienen, wer die Sprache nicht beherrschte, hatte eineinhalb bis zwei Jahre zu dienen. Cancelli, S. 275. Als Brasilien in den Krieg eintrat, gingen einige dieser Soldaten bis nach Rio de Janeiro (RJ). Wer noch in Deutschland geboren worden war, wurde an dem Kasernen-Liebesstrand in Rio de Janeiro (RJ) festgenommen, siehe Granzow, Grün ist das Tal am Rio Itajai, S. 14f. Andere kämpften in Monte Castelo, Italien vom 24.11.1944 bis zum 21.2.1945 und trafen auf dem Schlachtfeld deutsche Soldaten, mit denen sie Pommerisch sprachen. Dazu siehe Seibel, Imigrante no século do isolamento, S. 287; vgl. Rölke, Raíres da Imigração alemã, S. 399f; Seyferth, Nacionalismo e identidade étnica, S. 192.

2342 Weingärtner, História da Comunidade Evangélica de Timbó, S. 246; Krause, Lutherische Synode in Brasilien, S. 304.

${ }^{2343}$ Schneider, Albert. Bericht der Evangelische Lhutherische Gemeinde „Jaraguá II" über das Jahr 1946. Zitiert nach Wilbert et. al., S. 111; vgl. Weingärtner, História da Comunidade Evangélica de Timbó, S. 246.
} 
sischen Mundart, die sie von ihren brasilianischen Nachbarn gelernt hatten. Städtische Gemeinden kamen nun leichter mit der neuen Realität zurecht. Mancherorts mussten Geistliche Gottesdienste, kirchliche Amtshandlungen und Konfirmandenunterricht in zwei oder gar drei Sprachen abhalten (Portugiesisch, Deutsch und Pommerisch), da einige pommersche Nachkommen weder Hochdeutsch noch Portugiesisch beherrschten. ${ }^{2344}$ Die Gemeinden blieben für eine Zeit lang zweioder dreisprachig 2345 , doch anders als vor dem Krieg war Deutsch nun nicht mehr Kirchensprache. Gemeindemitgliedern wurde nach dem Krieg mehr und mehr bewusst, dass Portugiesisch durchaus auch im Gottesdienst verwendet werden konnte und dass eine protestantische Kirche portugiesischer Sprache ebenso im Bereich des Möglichen lag. ${ }^{2346}$ So wurde Portugiesisch allmählich zur Gottesdienstsprache. ${ }^{2347}$ Damit zeigte sich, dass der evangelisch-lutherische Glaube keineswegs an die deutsche Sprache gebunden war, wie in den Jahren zuvor so stark betont worden war.

Nach dem Krieg waren die Friedensbemühungen deutlich zu spüren und diese trugen zu einer nachhaltigen Annäherung zwischen Deutschen, Deutschbrasilianern und Brasilianern bei. Obwohl Geistliche ratlos und enttäuscht auf die Kapitulation Deutschlands reagierten, stimmte Pastor Wüstner dem Vorschlag eines brasilianischen Offiziers zu, neben deutscher auch brasilianische gefallene Soldaten in einem Gottesdienst zu gedenken. So feierte die Gemeinde Joinville (SC) einen Gedenkgottesdienst sowohl für deutsche, als auch für brasilianische Gefallene. ${ }^{2348}$ Evangelisch-unierte, lutherische und auch katholische Gemeinden sammelten Spenden für Hilfsaktionen, die Hungernden und Kriegsbetroffenen in Deutschland zu Gute kommen sollten. Hierfür autorisierte sogar die brasilianische Regierung die Einrichtung von Sammelstellen in größeren wie kleineren Städten. ${ }^{2349}$

Zusammenfassend zeigt sich, dass Einwanderer und deren Nachkommen trotz aller Einschränkungen und Herausforderungen im Ersten wie im Zweiten Weltkrieg und während der Nationalisierungszeit ihrem Glauben treu blieben. Auf die Inhaftierung und Rückkehr von Pastoren nach Deutschland reagierten sie wie in den ersten Siedlungsjahren mit der Beauftragung eines Kirchenmitgliedes aus ihrer

2344 Sendbrief 12, Neuendettelsau 1952, S. 10. Zitiert nach Krause, Lutherische Synode in Brasilien, S. 308; Seibel, Imigrante no século do isolamento, S. 298.

2345 Schlieper, Ernesto Th. Evangelische Gemeinden Lutherischen Bekenntnisses in Brasilien. In: Brunotte, Heinz; Ruppel, Erich (Hrsg.) Gott ist am Werk. Hamburg, 1959, S. 139f. In Jaraguá do Sul (SC) wurden in den 1950er Jahren deutsche Gottesdienste gehalten mit einer kurzen portugiesischen Ergänzung. Erst 1955 wurden portugiesische Gottesdienste eingeführt. Interview mit Pastor Karl Gehring. Zitiert nach Claas, S. 42.

2346 Prien, S. 438.

2347 Piske, Meinrad. Die Kirchwerdung von 1949 bis 1997. In: Backhause, Martin; Zeller, Hans. (Hrsg.) Aufbruch in Gren₹en. Neuendettelsau/Nürnberg/Erlangen: Verlag für Mission und Ökumene/ mabase-Verlag/Martin-Luther-Verlag, 2016, S. 137.

2348 Krause, Lutherische Synode in Brasilien, S. 304.

2349 Wüstner, S. 82. 
Mitte für die Vollziehung von Gottesdiensten und kirchlichen Amtshandlungen, um das kirchliche Leben so weit wie möglich aufrecht zu erhalten. Doch passten sie sich nicht nur der Situation an, sondern protestierten auch gegen nationalistische Maßnahmen, die übereilt oder auf ungerechte Weise durchgeführt wurden. Dass Kirchenmitglieder Gottesdienste mit Predigten in portugiesischer Sprache besuchten, obwohl sie deren Inhalt nur unzureichend verstehen konnten, und dass später die Landessprache als Gottesdienstsprache von ihnen akzeptiert wurde, gibt einen Hinweis auf die Bedeutung des evangelisch-lutherischen Glaubens, der jenseits von ethnischen Aspekten Gültigkeit beanspruchen konnte. Letztendlich erinnerten diese schwierigen Zeiten viele Gemeindemitglieder wieder an die Bedeutung ihrer kirchlichen Gemeinden und an die Notwendigkeit, in der Not Differenzen zu überwinden und innerhalb der Gemeinschaft zusammenzuhalten. Sie setzten sich nun vor allem für die Erhaltung des kirchlichen Lebens und für das innere Wachstum der Gemeinden ein. 



\section{VI - Beheimatung}

Die Nationalisierungs- und Kriegszeiten waren für die Gemeinden, aber auch für die Synoden in Brasilien eine harte Bewährungszeit. Dennoch trugen sie wesentlich zur Reflexion über die Notwendigkeit einer in Brasilien verwurzelten Kirche in Brasilien bei. Über die Entstehung der Evangelischen Kirche Lutherischen Bekenntnisses in Brasilien soll nun kurz berichtet werden.

Die kirchlichen Synoden in Brasilien waren bis zur Kriegserklärung 1942 maßgeblich von der Mutterkirche in Deutschland abhängig und auf deren Hilfe angewiesen. Als die finanzielle Unterstützung ausblieb, mussten sich die Synoden deshalb um alternative Formen der Existenzsicherung bemühen. Evangelisch-unierte wie evangelisch-lutherische Gemeinden waren in der Kriegs- und Nationalisierungszeit mit denselben Schwierigkeiten konfrontiert und hatten sich gegenseitig, nach der Inhaftierung oder der Rückkehr von Pastoren nach Deutschland unterstützt. Weil Pastoren beider Konfessionen zusammen inhaftiert worden waren, entstand trotz der früheren konfessionellen und theologischen Differenzen und der lokalen Streitigkeiten Raum für eine friedliche Zusammenarbeit und für das ehrgeizige Projekt des Aufbaus einer Kirche in Brasilien, die alle Synoden unter einem Dach zusammenfassen sollte. Die schwierigen Erfahrungen der gemeinsam durchlebten Zeit bildeten damit einen wichtigen Wendepunkt, denn durch den Reflexionsprozess, der mit der Bildung einer nachhaltig in Brasilien verwurzelten 
Kirche einherging, wurden die letzten Nachwirkungen der Vorstellung einer „Deutschen Kirche im Ausland“ überwunden. ${ }^{2350}$

Die ersten Verhandlungen über eine Zusammenarbeit zwischen Berliner Oberkirchenrat und Gotteskastenverein fanden bereits 1908 in Nürnberg statt. Dort wurde noch über eine mögliche räumliche Trennung des Arbeitsgebietes diskutiert. Dieser Plan hätte jedoch einen großen Verlust für den Gotteskastenverein in Bezug auf dessen geographisches Arbeitsgebiet und in der Bekenntnisfrage bedeutet.2351 Aus diesem Grund wurde der in Deutschland ausgearbeitete Vorschlag in Brasilien nicht akzeptiert. Beide Seiten versprachen jedoch einander friedlich zu begegnen, da die Bildung einer evangelisch-lutherischen Kirche in Brasilien in Aussicht stand. ${ }^{2352}$ Kurz nach der Entstehung des Neuen Staates 1937 schrieb Pastor Knäpper aus der Riograndenser Synode im August 1938 an alle anderen Synodalpräsidenten (Hoepffner: Mittelbrasilianische Synode; Schliemann: Verein Evangelischer Gemeinden von Santa Catarina und Paraná; Schlünzen: Evangelisch-Lutherische Synode) und schlug vor, nun eine deutsch-evangelische Kirche in Brasilien ins Leben zu rufen. Die Präsidenten trafen sich zwar zu einer Konferenz, waren aber zu dieser Zeit noch sehr vom „protestantischen Ekeklesianismus" geprägt und damit auch anfällig für einen deutschen Ethnizismus, womit sie die Existenz einer protestantischen Kirche in Brasilien eher gefährdeten. ${ }^{2353}$ Danach mussten die Verhandlungen aufgrund der Nationalisierungs- und Kriegszeit unterbrochen werden.

Bald nach Kriegsende nahmen die vier Synoden 1946 die Verhandlungen wieder auf. Sie konnten sich auf eine gemeinsame konfessionelle Basis einigen, erkannten dieselben konfessionellen Schriften an (die Bibel, die altkirchlichen Bekenntnisse, die Augsburgische Konfession und den Kleinen Katechismus) und strebten nach der Gründung einer evangelisch-lutherischen Kirche, da das Bewusstsein für Konfessionalität als Reaktion auf die frühere volkstümliche Betonung in der Kirchenarbeit einen Bedeutungszuwachs erfuhr. Außerdem machte die Arbeit mit der lutherischen Synode die Hervorhebung des lutherischen Elements erforderlich.2354 Die Grundsatzordnung des Synodalverbandes, die die Pastoren Hermann Dohms und Ernesto Schlieper, Präsident und Vizepräsident der Riograndenser Synode, vorbereiteten, wurde am 22. Juli 1948 angenommen und 1949 ratifiziert. Die Glaubensgrundlage war nach Krause eine ,konziliatorische, das Evangelisch-unierte und Lutherische verbindende Formulierung "2355 Prien hingegen bestreitet das unierte Element, da seiner Sicht nach keine unierten Synoden in Brasilien existierten, ebensowenig

\footnotetext{
2350 Dreher, Igreja e Germanidade, S. 246.

2351 Die lutherischen Pastoren konnten Gemeinden nicht zu einer evangelischen Kirche unierten Charakters zuweisen, auch wenn diese sich verpflichtete, ausschließlich lutherische Pastoren, die aber einer unierten Kirche angehörten, dorthin zu senden. Prien, S. 180-183.

${ }^{2352}$ Lutherische Kirche in Brasilien, S. 11.

2353 Prien, S. 485-488.

2354 Prien, S. 489.

2355 Krause, Lutherische Synode in Brasilien, S. 314.
} 
reformierte Gemeinden, die sich auf den Heidelberger Katechismus beriefen. ${ }^{2356}$ Dieser Standpunkt kann aber angesichts der Vielfalt von liturgischem Material, der unterschiedlichen konfessionellen Orientierung evangelischer Geistlicher und der Anzahl ursprünglich reformierter Kirchenmitglieder nicht in derart einschränkender Form bestätigt werden. Eine zweite Auflage des Hausbuchs für die Deutschen im Ausland beispielsweise enthielt sogar den Heidelberger Katechismus ${ }^{2357}$ und verschiedene reformierte Elemente wurden schon von Beginn an in der kirchlichen Architektur, teilweise auch in der Liturgie und der Gemeinderegel übernommen. Zudem verloren die Synoden durch den Synodalbund keineswegs ihre Selbstständigkeit und es entstand ebensowenig eine einheitliche Kirche, denn weder in der Theorie, noch in der Praxis war ein einheitliches Bekenntnis vorhanden. Eine gewisse Kontinuität der theologischen und kirchlichen Traditionen existierte parallel in der Gesamtkirche, doch über diese hinaus entstanden auch neue und andere konfessionelle und theologische Anschauungen. Die evangelisch-lutherische Kirche behielt in ihrer Form und ihrer praktischen Gestalt einen unionistischen Charakter, auch wenn sie das lutherische Bekenntnis klar in ihre Verfassung aufnahm. ${ }^{2358}$

Zur Fusion der evangelischen (Gemeindeverband Evangelischer Gemeinden von Santa Catarina und Paranâ) und der lutherischen Synode (Evangelisch-Lutherische Synode von Santa Catarina und Paraná und andere Staaten) 1962 trugen letztlich wiederum die Erfahrungen der Geistlichen beider Synoden in den Internierungslagern bei, sowie die Arbeit mit Jugendlichen und die gemeinsame theologische Ausbildung evangelischer und lutherischer Studenten in der Theologischen Fakultät in São Leopoldo (RS), die im Jahre 1946 gegründet worden war. ${ }^{2359}$ Die neugegründete Synode bezeichnete sich als Evangelisch-Lutherische Synode von Santa Catarina und Paraná. ${ }^{2360}$ Ihre Entstehung war aber keineswegs von der Beilegung aller Konflikte und konfessionellen Streitigkeiten zwischen ihren Gemeinden und Geistlichen begleitet, die teilweise bis in die 1990er Jahre in bestimmten Gebieten auszumachen waren. ${ }^{2361}$

Nach der Vereinigung dieser beiden Synoden übernahm der Synodalbund 1962 den Namen Evangelische Kirche Lutherischen Bekenntnisses in Brasilien. Am 25. Oktober 1968 gliederten alle Synoden (die Riograndenser Synode, die EvangelischLutherische Synode von Santa Catarina und Paraná, der Verein Evangelischer Gemeinden von Santa Catarina und Paraná und die Mittelbrasilianische Synode) sich in die Gesamtkir-

\footnotetext{
2356 Prien, S. 507.

2357 Brief des Deutschen Evangelischen Kirchenausschußes an den Vorstand der Riograndenser Synode, Berlin, 16.8.1910, AHI, SR 10/1 Beilage 008.

2358 Krause, Lutherische Synode in Brasilien, S. 323.

2359 Weingärtner, 150 Anos de Presença Luterana no V ale do Itajaí, S. 43.

2360 Weingärtner, Martin Luther e Santa Catarina, S. $142 \mathrm{f}$.

2361 Baade, Os conflitos comunitários e sinodais, S. 288-297.
} 
che ein. ${ }^{2362}$ Bei der Namensgebung fällt einerseits der Kompromiss mit der evangelisch-lutherischen Konfessionalität, andererseits auch die Herausforderung der Verkörperung einer brasilianischen Kirche auf. Die Kirche verschrieb sich der Aufgabe, ihre Glaubensbotschaft im brasilianischen Kontext zu verkündigen und Antworten im Angesicht dieser neuen Realität zu geben ${ }^{2363}$, obgleich sie nahezu immer vor der Gefahr stand, ein Denk- und Arbeitsmodell aus Deutschland nach Brasilien zu importieren. ${ }^{2364}$

Die Entstehung der Evangelischen Kirche Lutherischen Bekenntnisses in Brasilien war das Resultat eines wachsenden Entwicklungsprozesses, der seinen Anfang zu Beginn des 19. Jahrhunderts mit der Bildung der ersten Hausgemeinden nahm. Dieser Prozess war zu jeder Zeit von Schwierigkeiten, Herausforderungen, Interessenskonflikten, Spaltungen, Streitigkeiten und Rückschlägen geprägt. Diese Geschichte sowie die widrigen Umstände der Nationalisierungs- und Kriegszeit stärkten die Gemeinden und motivierten sie in dem Vorhaben, aus einer Überlebenssituation in eine neue Realität der Konvivenz und des Zusammenlebens hineinzuwachsen. 2365

2362 Dreher, Aufbruch in die Zukunft, S. 12; Krause, Lutherische Synode in Brasilien, S. 313, 324. Mehr dazu Prien, S. 465-536.

2363 Schlieper, Ernesto T. Unsere Kirche vor der Entscheidung. AHI. Ohne Jahresangabe. Zitiert nach Butzke, S. 254.

${ }^{2364}$ Müller, Reinhart. Entwicklungstendenzen und ihre Folgen. In: Fischer, Joachim; Jahn, Christoph (Hrg). Es begann am Rio dos Sinos. Erlangen: Verlag der Ev. Lutherischen Mission, 1970, S. 74.

2365 Droste, Struktur und Mission der EKLBB, S. 206f. 


\section{VII - Fazit}

„Wenn das Wort Gottes nicht mein Trost gewesen wäre, wäre ich in meinem Elend qusammengebrochen".2366

Pommersche Einwanderer und deren Nachkommen brachten neben ihren Hoffnungen auf ein besseres Leben und auf eine bessere Zukunft für ihre Kinder auch ihre evangelisch-lutherische Religiosität mit nach Brasilien. Sie half ihnen bei der Bewältigung ihrer Ängste, Tristessen, Verluste, Krisen und Schwierigkeiten bereits auf der Überfahrt, aber insbesondere während des Aufbaus einer neuen Existenz in Brasilien. Angesichts des Mangels an Ärzten und Krankenhäusern in den Siedlungsgebieten beriefen die Einwanderer und deren Nachkommen Personen aus ihren Reihen, die aufgrund ihrer Erfahrung, ihres Kenntnisstandes oder ihres Besitzes von medizinischer und homöopathischer Literatur, von Heilkunderezepten und magischen Formeln Menschen in einer Notsituation helfen konnten. Die Religiosität der Pommern war hier von entscheidender Bedeutung. Sie glaubten daran, dass „Gesundbeter“, die in Besitz magischer Quellen waren, Menschen kurieren konnten. „Gesundbeter" übernahmen damit nicht nur eine medizinische und heilkundige Funktion, sondern übten darüber hinaus auch eine seelsorgerliche

2366 Worte eines Siedlers, die Pastor Hunsche in einer Ansprache auf einer Synodalversammlung in São Leopoldo wiedergegeben hat. In: Sonntagsblatt Nr. 26 (1), 1912, S. 3. Zitiert nach Witt, Osmar Luiz. Igreja na Migração e Colonizaçãa. São Leopoldo: Sinodal/IEPG, 1996, S. 44. Übersetzung auf Deutsch S. J. 
Funktion aus, indem sie mit kranken und sterbenden Menschen beteten, ihre Hoffnung auf Heilung stärkten und ihnen mit allen verfügbaren Ressourcen zu helfen versuchten.

Angesichts der verschiedensten Gefahren, denen die Einwanderer und deren Nachkommen in den Siedlungsgebieten ausgesetzt waren, vertrauten viele von ihnen auf Himmels- und Schutzbriefe. Dabei handelte es sich um Quellen magischen Inhaltes, von denen sich die Besitzer Schutz gegen allerlei Gefahren an Leib, Haus und Hof, vor allem aber gegen Krankheiten und bei Entbindungen versprachen. Weil diese Briefe aber magische Formeln mit biblischen Texten, kirchlicher Symbolik (Bekreuzigung, Engelsbilder) und Gebeten, die inhaltlich stark den Gebeten aus ihren Andachtsbüchern ähnelten, verknüpften, sahen die Einwanderer und deren Nachkommen in ihnen keinen Widerspruch zu ihrem evangelischlutherischen Glauben. Die darin enthaltenen Texte wurden in schwierigen und kritischen Situationen gebetet und entsprachen dem Bedürfnis der Menschen, einen greifbaren Schutz zu besitzen, der ihnen den Beistand und die Hilfe Gottes, seines Engels Michael oder des Kreuzes Christi im Umgang mit Ängsten und Gefahren zusicherte.

Angesichts des Pfarrermangels pflegten viele Einwanderer und deren Nachkommen ihren Glauben mithilfe ihrer mitgebrachten Glaubensquellen - Bibel, Gesangbuch, Andachts- und Predigtbücher und der Kleine Katechismus. Aus diesen Quellen konnten sie Kraft und Hoffnung für die Bewältigung ihrer Nöte, Tristessen, Ängste, Verluste, Krankheiten, Schwierigkeiten und Probleme schöpfen, denn der Glaube gab ihnen Ausdauer und Mut im Kampf um ihr Dasein und auf Gott vertrauten sie in aller Bedrängnis und Verlassenheit. In dem Verlangen nach Gottes Wort beschlossen mehrere Familien, selbst Hausgottesdienste mithilfe der obengenannten Quellen in ihren Häuser zu vollziehen. Sie wählten jemanden aus ihrer Mitte, der sich für die Aufgabe eines Pfarrers eignete, und erklärten ihn zum Pastor. Dieser vollzog auch die nötigen Amtshandlungen, besonders Bestattungen, Nottaufen und die Darreichung des Abendmahls. Kirchliche Amtshandlungen waren darüber hinaus auch von kultureller und anthropologischer Bedeutung. Sie vermittelten den Einwanderern und deren Nachkommen inmitten einer fremden Umwelt das Gefühl von kultureller Identität und Zugehörigkeit zu einer Gemeinschaft, die bestimmte kulturelle Werte, Traditionen, Rituale, Symbole und Gesten verkörperte und gebrauchte. Der innerethnische Vollzug von über Generationen gepflegten Übergangsriten war für die Einwanderer und deren Nachkommen ein ordnendes Element innerhalb ihres Lebens und half ihnen im Umgang mit kritischen Lebenssituationen, die sie mit der Unterstützung einer Glaubensgemeinschaft vollziehen konnten.

Das religiöse und spirituelle Leben der Pommern und deren Nachkommen war keineswegs homogen. Einige von ihnen gehörten den in der Heimat verankerten sogenannten Altlutheranern oder den Erweckungsbewegungen an, die Mehrheit jedoch schloss sich mit der Einführung der Union der evangelischen Kirche der- 
selben an. Andere wiederum hielten sich aufgrund ihrer negativen Erfahrungen mit der Kirche in der Heimat von einer aktiven Partizipation am Kirchenleben fern. Viele pommersche Einwanderer und deren Nachkommen legten großen Wert auf die Anwendung von Praktiken magischen Inhaltes, ohne darin einen Widerspruch zu ihrem kirchlichen Glauben zu sehen. Solche Praktiken waren jedoch nicht unumstritten: Einerseits wurden sie von (vermutlich) strengen Lutheranern als Aberglauben abgetan, andererseits entwickelten einige Einwanderer und deren Nachkommen eine breite allgemeine Skepsis gegen sie. Diese unterschiedlichen Formen des Glaubens und der Religiosität hatten Einfluss auf die Gestalt und Entwicklung der Gemeinden in Brasilien. Einige Gemeindemitglieder pflegten ihren Glauben anhand regelmäßiger häuslicher Andachten und beteiligten sich sehr aktiv an Laiengottesdiensten und am kirchlichen Leben. Die Mehrheit hingegen ergriff zwar nicht die Initiative in Bezug auf die Gründung von Gemeinden, beteiligte sich aber sehr wohl bei Bautätigkeiten und konkreten Aufgaben. Für sie nahmen magische Formeln für die Behandlung von Krankheiten sowie Himmels- und Schutzbriefe eine wichtige Rolle ein. Wieder andere Pommern waren zwar offiziell Gemeindemitglieder, nahmen aber nur selten am Gemeindeleben teil und begnügten sich mit der Inanspruchnahme von kirchlichen Amtshandlungen, was zunächst nicht darauf schließen lässt, dass sie sich in kritischen Lebenssituationen ihrem Glauben und ihrer Kirche nicht besonders zuwandten. Andererseits übernahmen der Glaube und die Religiosität, unabhängig von der Regelmäßigkeit des Kirchenbesuches, der Pflege häuslicher Andachten und der Partizipation an kirchlichen Handlungen, gerade durch den Vollzug von kirchlichen Amtshandlungen, die Besprechung von Krankheiten, den Besitz von Himmels- und Schutzbriefen und die Bedeutung von kirchlichen Liedern, Gebeten und biblischen Texten sowie durch das kirchliche Gemeinschaftsleben eine Bewältigungsfunktion im Umgang mit Schwierigkeiten und begünstigten die Bildung sozialer und hilfreicher Netzwerke.

In den ersten Siedlungsjahren organisierten sich die Einwanderer hauptsächlich in landwirtschaftlichen Familienbetrieben. Im Laufe der Zeit gründeten sie dann Handwerkstätten, die von ihren Nachkommen im Zuge des Industrialisierungs- und Urbanisierungsprozesses in Brasilien allmählich zu kleinen Industrien ausgebaut wurden. Parallel zu dieser Entwicklung begann der Institutionalisierungsprozess kirchlicher Gemeinden. Die Einwanderer und deren Nachkommen erhielten oder beriefen deutsche Geistliche, die sie in der Regel selbst mit eigenen Ressourcen besolden mussten. Die Geistlichen kamen aus unterschiedlichen Bildungsstätten und vertraten verschiedene konfessionelle Positionen. Für die Siedler spielte die Konfession der Geistlichen jedoch angesichts ihrer kirchlichen Not zunächst keine Rolle, sie sehnten sich hauptsächlich nach einem ordentlichen und regelmäßigeren Kirchenleben. So begannen die Hausgemeinden sich in Pfarrbezirke zu strukturieren. Trotz der Distanzen und des Zustandes der Urwaldsstraßen kamen viele von ihnen zur Kirche, da diese besonders in den ersten Siedlungsjah- 
ren einem religiösen, aber auch sozialen Bedürfnis der Siedler entsprach: Sie sehnten sich nach Gottes Wort, das ihnen Trost für die Bewältigung ihrer täglichen Herausforderungen spendete, aber angesichts ihrer Isolierung auch nach Gemeinschaft und Gesellschaft mit anderen Menschen.

Zunächst trafen sich die Einwanderer und deren Nachkommen an provisorischen Orten zum Gottesdienst. Diese wurden allmählich durch Kirchen-Schulen, ein Gebäude, das unter der Woche als Schule und sonntags als Kirche fungierte, sowie durch Kapellen und Bethäuser ersetzt. Doch auch diese Einrichtungen erwiesen sich bald für die wachsende Anzahl der Gemeindemitglieder als zu klein, sodass jene sich dazu entschlossen, eine massive, größere Kirche, zunächst ohne Turm, zu bauen. Die Annahme, dass das staatliche Verbot, protestantische Gotteshäuser mit einem äußeren Tempelmerkmal zu versehen, dazu geführt habe, zunächst turmlose Kirchen zu errichten, wird sowohl von Aussagen seitens der Siedler, als auch von anderen Quellen relativiert. Viele Gemeinden erwarben bereits in den 1850er und 1860er Jahren Glocken, die in einen Glockenstuhl gehängt wurden, was den Kirchen bereits den deutlichen Anschein eines Tempels gab. Darüber hinaus errichteten andere Gemeinden bereits in den 1870er Jahren Türme, obgleich der Staat erst mit der republikanischen Verfassung 1890 die religiöse Gleichberechtigung erließ, die solche Baumaßnahmen überhaupt erlaubte. Die Errichtung von Turmkirchen war damit weniger durch die staatliche Regulierung bedingt als durch die ökonomische Entwicklung der Einwanderer und deren Nachkommen in Brasilien, die bis zu einem gewissen Zeitpunkt finanziell schlicht noch nicht in der Lage waren, massive „würdige "Turmkirchen zu errichten.

Die Gemeindemitglieder erbrachten große Opfer für die Errichtung ihrer Gotteshäuser. Sie spendeten freiwillige Arbeitszeit, Baumaterial und Geld und mussten die schweren Glocken über schmale Straßen teilweise über kilometerweit tragen. Der Bau einer Kirche gab den Siedlern ein sinnvolles Ziel und verkörperte konkret die Bedeutung des Glaubens und der Kirche in ihrem Leben. Beim Kirchbau handelte es sich deshalb einerseits um ein öffentliches Glaubensbekenntnis und ein Erbgut für die Nachkommen, andererseits symbolisierte dieser aber gleichermaßen den Anspruch auf religiöse, politische und soziale Anerkennung, weil die Einwanderer mit dem Bau der Kirche zugleich ihre Heimat im Aufnahmeland aufbauten.

Aus der Nachbarschaftshilfe entwickelte sich unter anderem auch das soziale Leben innerhalb der kirchlichen Gemeinde. Einwanderer und deren Nachkommen, die sich bereits in einer besseren ökonomischen Lage befanden, investierten dementsprechend in das Schulwesen und errichteten Krankenhäuser, Entbindungsstationen, Heime und verschiedene Vereine. Für das Lehramt in den ersten Kolonieschulen wählten sie nach dem Beispiel der anfänglichen Pastorenauswahl einen kundigen Laien. Mit der Ankunft der Geistlichen entstanden die deutschen und die Volks- und Mittelschulen, die über einen umfangreicheren und durchdachteren Lehrplan verfügten. Die Geistlichen setzten sich bald nach ihrem Ein- 
treffen für die Fortbildung einiger Kolonisten ein und ließen deutsche Diakone und Lehrer für die Tätigkeit in Schulen und Gemeinden aus Deutschland kommen. Angesichts des Mangels an ausgebildeten Ärzten ließen sich die Gemeindemitglieder auch Krankenschwestern, Diakonissen und Ärzte aus der alten Heimat kommen.

Auch Konflikte zwischen Gemeindemitgliedern, Gemeinden, Geistlichen, Missionaren und Kolonistenpastoren können Auskunft über die Bedeutung des Glaubens geben. Sie entstanden aufgrund der Spannung zwischen dem Wunsch der Geistlichen nach der Gründung einer institutionalisierten Kirche und dem Wunsch vieler Gemeindemitglieder, weiterhin autonom und unabhängig von kirchlichen Institutionen als Gemeindekirche zu existieren, aufgrund des Verlangens nach regelmäßigerer kirchlicher Betreuung oder mehr Selbständigkeit von einer Muttergemeinde, gelegentlich aufgrund finanzieller Schwierigkeiten, manchmal wegen entgegen gesetzter Interessen und Konfessionsstreitigkeiten zwischen evangelisch-unierten und evangelisch-lutherischen Gemeindemitgliedern, Geistlichen und Synoden. Letztere brachten nicht nur in Konfliktsituationen die konfessionellen Unterschiede sowie ein konfessionelles Bewusstsein unter den Einwanderern und deren Nachkommen zum Ausdruck.

Die ethnische Abgrenzung der Einwanderer und deren Nachkommen nach außen als eine Art psychologischer Schutz in der Fremde stärkte die innere Kohäsion. Doch entstand mit dem Gedanken einer Bewahrung des Deutschtums und im Zuge der Verbreitung deutscher Volkstumsideologie gleichermaßen ein Identitätskonflikt. Die Einwanderer und deren Nachkommen betrachteten sich zwar als brasilianische Staatsbürger, verstanden sich aber gleichzeitig als Mitglieder einer deutschen Volksgemeinschaft und wollten ihre sprachlichen und kulturellen Besonderheiten bewahren. Diese grundlegende Einstellung wurde von einem Großteil der brasilianischen Bevölkerung im Rahmen der wachsenden nationalistischen Bewegung als Undankbarkeit, gar als Verrat gegen das Aufnahmeland betrachtet. Als Brasilien 1917 Deutschland den Krieg erklärte, wurde die brasilianische Bevölkerung endgültig systematisch gegen Deutsche und Deutschbrasilianer aufgehetzt. Neben Plünderungen und Protesten wurde sogar die deutsche Predigt in manchen Gemeinden verboten. Mit der Gründung des Neuen Staates 1937 verfolgte die brasilianische Führungsschicht unter anderem auch die erzwungene Nationalisierung der fremdsprachigen Bevölkerung. Schulen, an denen in deutscher Sprache unterrichtet wurde und die nicht den nationalistischen Vorgaben entsprachen, wurden einfach geschlossen. Die Situation verschlimmerte sich als Brasilien 1942 Deutschland erneut den Krieg erklärte. Eine Reihe von Gesetzen beschränkte das alltägliche Leben, die Geschäftsfähigkeit, die Mobilität und schließlich die von den Einwanderern und deren Nachkommen gegründeten Institutionen, nämlich die Kirche, das Schulwesen, Vereine, Anstalten und Krankenhäuser. Viele dieser Einrichtungen wurden geschlossen oder enteignet, die deutschen Gottesdienste wurden eingeschränkt oder zeitweise ganz eingestellt. Geistli- 
che und Gemeindemitglieder wurden wegen Verwendung der deutschen oder pommerschen Sprache in der Öffentlichkeit oder wegen Sympathie oder Beteiligung am brasilianischen Integralismus oder am Nationalsozialismus - Strömungen, die inzwischen von der Regierung verboten worden waren - gefoltert und inhaftiert.

Gerade in den widrigen Nationalisierungs- und Kriegszeiten keimte erneut ein größeres Interesse für das kirchliche Leben auf, womit sich die Annahme zu bewahrheiten scheint, dass Menschen sich besonders in schwierigen Situationen ihrem Glauben zuwenden. Gleichzeitig protestierten die Gemeindemitglieder in manchen Orten gegen die übereilten nationalistischen Maßnahmen und kämpften um die Erhaltung ihrer Institutionen. Die kirchliche Gemeinde fungierte zu dieser Zeit als Zufluchtsort, der den in dieser Zeit erneut an den Rand der Gesellschaft getriebenen Einwanderern und deren Nachkommen eine Heimstatt bieten konnte. Sie fanden in der Kirche und in ihrem Glauben und in ihrer Religiosität Halt und Stärkung für die Bewältigung ihrer Ängste, ihrer Unsicherheit und der sie konfrontierenden Bedrohungen sowie gegenseitige Unterstützung durch andere Gemeindemitglieder. Die Predigt, die nun auf Portugiesisch gehalten werden musste, wurde von vielen Gemeindemitgliedern nicht verstanden, was diese jedoch nicht vom Gottesdienstbesuch abzuhalten vermochte. Mithilfe von Liturgie, Gesten, Gebeten, Liedern und bekannten Melodien folgten sie den Gottesdiensten in Gedanken und Gefühlen. Wo Gemeinden ohne Pfarrer waren, da dieser entweder sein Amt zeitweise nicht ausüben durfte oder inhaftiert war, übernahmen Laien wieder pfarramtliche Funktionen. Zugleich hatten die schwierigen Erfahrungen auch einen positiven Effekt, führten sie doch zur Überwindung der internen Konflikte und zur Bildung einer in Brasilien verwurzelten Kirche.

Dass evangelisch-unierte sowie evangelisch-lutherische Gemeinden in Brasilien das Verbot der deutschen Sprache kompensieren konnten und trotzdem institutionell überlebten, zeigt, dass die Sprache als solche keine hinreichende Bedingung für das kirchliche Leben darstellte. Nach dem Zweiten Weltkrieg wurde die brasilianische Sprache allmählich als Kirchensprache eingeführt, obwohl für eine gewisse Zeit noch deutsche Gottesdienste für die Generation, die keinen Zugang zur Erlernung der Landessprache hatte, abgehalten wurden. Die Bedeutung des Glaubens überwog über die der Ethnie und die evangelisch-lutherische Kirche in Brasilien löste sich, entgegen vorheriger Prophezeiung, trotz der Abschaffung der deutschen Sprache als Kirchensprache keineswegs auf.

Die Einwanderer und ihre Nachkommen bewältigten und überwanden ihre Schwierigkeiten, Krankheiten, Krisen, Verluste und Bedrohungen im Laufe ihrer Geschichte in Brasilien mithilfe ihres Glaubens und ihrer Religiosität. Diese gaben ihnen neue Kräfte, Hoffnung, Zuflucht, Geborgenheit, Halt und Trost. Innerhalb der Glaubensgemeinschaft fanden die Einwanderer und deren Nachkommen konkrete und nachhaltige Unterstützung, festigten wichtige soziale Bindungen und beteiligten sich an kirchlichen Aktivitäten, Bauarbeiten und sozialen Projekten, in 
deren Verwirklichung sie Wertschätzung erfuhren und sich ein Gefühl von Lebenssinn einstellen konnte. Im Wirkkreis der Gemeinden errichteten sie eine eigene soziale Umwelt mit Institutionen, die in den Siedlungsgebieten noch nicht vorhanden, aber sehr wichtig für ihr alltägliches Leben und für die Entwicklung ihrer Kolonien waren. Sie selbst übernahmen die Verantwortung und ergriffen die Initiative für die Lösung ihrer Probleme, stärkten damit ihr Selbstbewusstsein und ihre Selbstwirksamkeit, lernten aus den widrigen Situationen und entwickelten wichtige Widerstands- und Bewältigungskompetenzen. Ausschlaggebend für die Bewältigung verschiedenster Schwierigkeiten war schlussendlich das Vertrauen: „W as Gott tut, das ist wohlgetan, es bleibt gerecht sein Wille. Wer Gott vertraut, hat wobl gebaut. Amen!" 2367

${ }^{2367}$ Butzke, Carl Friedrich Wilhelm. Mein Lebenslauf und Lebenskampf. Zitiert nach Evangelische Synode von Santa Catarina und Paraná, Unsere Väter. São Leopoldo: Rotermund, 1961, S. 100. Vers von Samuel Rodigart (1675). 



\section{VIII - Ausblick}

Religionen verkörpern seit Jahrtausenden für verschiedenste Völker und Gruppen eine Bewältigungskraft im Umgang mit Schwierigkeiten, Krankheiten, Verlusten, Kriegen und Rückschlägen. Noch heute suchen und finden Menschen mithilfe ihres Glaubens eine Erklärung oder sinnvolle Deutung für ihr Dasein, für das Leiden und den Tod, und sie erkennen den Beistand Gottes oder eines göttlichen Wesens inmitten der Schwierigkeiten ihres Lebens. Religionen vermitteln Halt, Geborgenheit, Beständigkeit und Sicherheit, indem sie mithilfe von Ritualen Menschen bei ihren Lebensübergängen und -krisen begleiten. Religiöse Gemeinden ermöglichen wiederum die Bildung sozialer Netzwerke und die aktive Beteiligung an Gemeindeprojekten, worin auch nach einer Krise ein neuer Lebenssinn gesehen werden kann.

Die Fähigkeit, mit Belastungen und Spannungen des Lebens umzugehen 2368 , Krisen und Schwierigkeiten zu bewältigen ${ }^{2369}$, psychisch widerstandsfähig zu sein $^{2370}$, aus belastenden Erfahrungen zu lernen ${ }^{2371}$, daraus gestärkt hervorzugehen

\footnotetext{
2368 Boss, Pauline. Verlust, Trauma und Resilien₹: Stuttgart: Klett-Cotta, 2008, S. 71.

${ }^{2369}$ Zander bezeichnet Resilienz als Fähigkeit, „starke seelische Belastungen, ungewöhnliche Entwicklungsrisiken, auch erlebte Traumata ,unbeschadeter" $z$ bewältigen als zu erwarten stïnde", Zander, Margherita. Einleitung. In: Zander, Margherita; Roemer, Martin (Hrsg.) Handbuch Resilienæförderung. Wiesbaden: Verlag für Sozialwissenschaften/Springer, 2011, S. 9.

2370 Wustmann, Corina. Resilien₹. Widerstandsfäbigkeit von Kindern in Tageseinricbtungen fördern. Berlin: Cornelsen, 2011, S. 18.
} 
und Krisensituationen als Ressource für die weitere Entwicklung und für die Bewältigung künftiger Belastungen einzusetzen ${ }^{2372}$, wird heute als Resilien $2^{2373}$ bezeichnet. Dabei handelt es sich um eine Kapazität, die in gewisser Hinsicht als eine anthropologische Grundkonstante beschrieben werden kann. Bis heute gibt es keinen Forschungszweig, der sich mit der Widerstandsfähigkeit von Einwanderern und deren Nachkommen im 19. und frühen 20. Jahrhundert auseinandersetzt. Die historische Darstellung der Geschichte der pommerschen Einwanderer und deren Nachkommen in Brasilien zeigt aber auf, dass sie verschiedenen widrigen, schwierigen, belastenden und gar traumatischen Situationen ausgesetzt waren, die auch im Themenfeld der Resilienzforschung angesiedelt sind und oft erwiesen sie sich in diesen Situationen als entsprechend widerstandsfähig. Die Resilienzforschung und die Ergebnisse einzelner Resilienzstudien könnten auf diese Weise mit der religiösen Erfahrung pommerscher Einwanderer und deren Nachkommen in Verbindung gebracht werden.

Migrantengruppen, wie die in dieser Studie untersuchten Pommern und deren Nachkommen, sind verschiedenen Risiken ausgesetzt: Litten sie bereits in ihren Herkunftsländern unter traumatischen Erlebnissen, Gewalt, Krieg oder sozialen Problemen, sind sie in der Fremde darüber hinaus psychosozialen Belastungen ausgesetzt, die sich aus ihrer sozialen Stellung am Rande der Gesellschaft und zugleich aus einer fehlerhaften Integrationspraxis ergeben. Vor allem in den ersten Jahren leben sie unter mangelhaften Wohnbedingungen, verfügen über einen begrenzten oder gar keinen Zugang zu Gesundheits- und Bildungssystemen, gelegentlich besitzen sie keinen legalen Aufenthaltstitel und verfügen somit über keinerlei bürgerliche Rechte, finden keine Arbeit oder erhalten nur einen unzureichenden Lohn und können sich aufgrund dieser Einschränkungen nur mangelhaft weiterentwickeln. Sie stehen darüber hinaus vor der Herausforderung, die kulturelle Distanz zwischen gänzlich verschiedenen Welten zu überbrücken und geraten oft in einen Kulturkonflikt oder in eine Identitätsdiffusion. ${ }^{2374}$ In der neuen Umgebung stellt sich ein Gefühl von Einsamkeit ein, die Trennungserfahrun-

\footnotetext{
2371 Sedmak, Clemens. Innerlichkeit und Kraft. Freiburg im Breisgau, 2013, S. 177f, 213.

2372 Fingerle, Michael. Der „riskante“ Begriff der Resilienz - Überlegungen zur Resilienzförderung im Sinne der Organisation von Passungsverhältnissen. In: Opp, Günther; Fingerle, Michael. Was Kinder stärkt. München: Ernst Reinhardt, 2008, S. 301.

2373 Der Begriff „Resilien₹“" stammt aus dem Lateinischen „resilire“, „resiliens" und bezeichnet das Zurückspringen oder Zurückkehren in einen ursprünglichen Stand. Blum, Wilhelm. Resilienz nach den Schriften der ersten Christen. In: Sedmak, Clemens; Bogaczyk-Vormayr, Małgorzata (Hrsg.) Patristik und Resilien₹. Berlin: Akademie Verlag, 2012, S. 11. In der modernen Forschung ist der Begriff jedoch aus dem angloamerikanischen Kontext übernommen worden und leitet sich aus dem englischen Wort „resilience“ ab, das Unverwüstlichkeit, Widerstandsfähigkeit, Spannkraft, Belastbarkeit, Elastizität oder Strapazierfähigkeit bedeutet. Fröhlich-Gildhoff, Klaus; Rönnau-Böse, Maike. Resilien₹: München: Ernst Reinhardt, 2015, S. 9.

2374 Lanfranchi, Andrea. Resilienzförderung von Kindern bei Migration und Flucht. In: WelterEnderlin, Rosmarie; Hildenbrand, Bruno (Hrsg.) Resilienz - Gedeiben trotz widriger Umstände. Heidelberg: Carl-Auer, 2010, S. 124f.
} 
gen können Trauergefühle auslösen und in der neuen Umwelt angekommen, können sich Migrantinnen und Migranten teilweise mit den neuen Verhältnissen, den Werten, der Sprache und der Kultur überfordert fühlen. ${ }^{2375}$

Demgegenüber darf jedoch nicht außer Acht bleiben, dass Migration ebenso als ein aktiver Schritt der Problembewältigung verstanden werden kann. Der im Herkunftsland gelernte „Habitus der Überlebenskunst“2376 wird in einem neuen Kontext umgesetzt und verfestigt. Migrantinnen und Migranten streben nach besseren Lebensbedingungen und -möglichkeiten, sei es in ökonomischer, bildungstechnischer, beruflicher oder familiärer Hinsicht und sie müssen viel Mut und Ausdauer aufbringen, um in einem neuen Land ein neues Leben für sich selbst und ihre Nachkommen aufzubauen. Sie stehen vor Herausforderungen, die sich in Umfang und Art radikal von denen innerhalb ihrer Herkunftsländer unterscheiden und trotzen diesen mithilfe der ihnen verfügbaren Ressourcen. In diesem Sinne kann Migration gleichzeitig risiko- wie auch resilienzfördernd sein. ${ }^{2377}$

In der Fremde kommt der Bewahrung kultureller Werte und der eigenen Sprache eine besondere Rolle zu, denn diese Elemente bilden eine Art „Defensivkultur".2378 Kinder aus Migrantenfamilien lernen gewöhnlich zunächst die Muttersprache ihrer Eltern, womit diese zur Basis des Gefühlsausdrucks seitens des Kindes wird und deshalb zu einem elementaren Identitätsteil seines Daseins gehört. Die Muttersprache bewusst abzulehnen oder zu leugnen würde der Eltern-KindBeziehung tiefgreifenden Schaden zufügen, nicht zuletzt, weil damit eine massive Einschränkung der sprachlichen Interaktion mit der Familie und mit der Gemeinde im mikrosozialen Umfeld einherginge. Psychologisch würde außerdem die Ablehnung eines wesentlichen Identitätsaspekts negativ auf das Selbstwertgefühl des Kindes wirken. ${ }^{2379}$

Auch der Komplex Religion wird in der kulturellen Muttersprache vermittelt und erlebt, weshalb religiöse Inhalte und Praktiken zusammen mit der Sprache ein wichtiges inneres Element der kulturellen Identität darstellt, die vor allem in der Fremde hervorgehoben und wahrgenommen wird. Gebete und Lieder, die in der Kindheit erlernt wurden, sind eingebettet in eine kulturelle und familiäre Glaubenstradition. Werden sie in der Muttersprache gebetet und gesungen, dann helfen

\footnotetext{
${ }^{2375}$ Kustor-Hüttl, Beatrice. Weibliche Strategien der Resilien₹: Bildungserfolg in der Migration. Frankfurt a.M: Brandes \& Apsel, 2011, S. 39f.

${ }^{2376}$ Seukwa, L. H. Der Habitus der Überlebenskunst. Zum Verbältnis von Kompetenz und Migration im Spiegel von Flücbtlingsbiographien. Münster/New York/München/Berlin, 2006. Zitiert nach Busche, Gesa Anne. Über-Leben nach Folter und Flucht. Resilienz kurdischer Frauen in Deutschland. Bielefeld: Transcript, 2013 S. 83.

2377 Busche, S. 42f, 208; Kustor-Hüttl, S. 35.

2378 Uslucan, Haci-Halil. Resilienzpotenziale bei Jugendlichen mit Migrationshintergrund. In: Zander, Margherita; Roemer, Martin. Handbuch Resilienzförderung. Wiesbaden: Verlag für Sozialwissenschaften/ Springer, 2011, S. 559.

2379 Uslucan, S. 564.
} 
sie dabei, den Weg zu Gott und zueinander zu finden. ${ }^{2380}$ Rituale sind auch ein wichtiger Bestandteil der persönlichen, sozialen und kulturellen Identitätsbildung und stärken die Gemeinschaft einer religiösen oder kulturellen Gruppe. Deswegen wird dem religiösen Glauben oder familiärer Religiosität besonders im Migrationskontext Bedeutung zugesprochen. Religion ist in der Regel an ein kulturelles System gebunden. Ihre Überzeugungen, Werte, Vorstellungen, Praktiken, Riten und Symbole werden von einer kulturellen Gruppe bejaht und angenommen, gehören zu deren Erbe und wirken zusammen mit der familiären Kohäsion aus traditionellen Gesellschaften als ein Schutzfaktor. ${ }^{2381}$ Sie haben Einfluss auf die Wahrnehmung und Sinngebung bestimmter Situationen und sorgen für die Festschreibung und Tradierung adaptiver Strategien, die im Umgang mit belastenden Lebenssituationen Resilienz fördern, traumatische Erlebnisse abwehren und gleichzeitig von Generation zu Generation weitergegeben werden. ${ }^{2382}$ Religion ermöglicht in der Migration auch eine Rückbindung an eine bestimmte Kollektivität sowie die Kontinuität mit der kulturellen Herkunft und sichert zugleich die Zugehörigkeit zu ihr. Das religiöse Gemeinschaftsleben bindet die Menschen aneinander und nimmt deswegen eine weitere protektive Funktion ein. Der religiöse Raum gewährt wiederum Sicherheit und umfasst einen Ort, wo Migrantinnen und Migranten Ruhe in einer Umgebung finden, in der ihre kulturelle Identität auf verschiedene Art und Weise infrage gestellt wird. Religion bietet letztlich Schutz vor Isolierung, Einsamkeit und Aussichtslosigkeit ${ }^{2383}$ und verfügt darüber hinaus über das Potenzial, negative Effekte der Diskriminierung zu mildern. ${ }^{2384}$

In diesem Sinne stuft die Resilienzforschung unter anderen personalen, familiären, kulturellen und umweltbezogenen Faktoren auch den Glauben, die Religiosität und die Spiritualität sowie eine religiöse Gemeinschaft als fördernde Faktoren für die Entwicklung von Resilienz ein. ${ }^{2385}$ Sie werden auch in verschiedenen empi-

2380 Borowski, Christiane. Rechnen, Lieben und Beten. In: Evangelische Kirche in Deutschland (Hrsg.) Das Magazin zum Themenjahr 2016. Reformation und die Eine Welt. Greven: Druckhaus Cramer, 2016, S. 81.

2381 Bengel, J., Meinders-Lücking, F.; Rottmann, N. Schut:faktoren bei Kindern und Jugendlichen. Stand der Forschung zu psychosozialen Schut_faktoren für Gesundheit (Forschung und Praxis der Gesundheitsförderung 35). Köln: BzgA, 2009, S. 115. Zitiert nach Fröhlich-Gildhoff, Klaus. Gemeinde: Das Quartier als Risiko- und Schutzfaktor. In: Steinebach, Christoph; Gharabagui, Kiaras (Hrsg.) Resilienzförderung im Jugendalter. Praxis und Perspektiven. Berlin/Heidelberg: Springer, 2013 S. 170; Masten, Ann S. Resilien₹: Modelle, Fakten \& Neurobiologie. Paderborn: Junfermann, 2016, S. 238.

2382 Masten, S. 227, 244; Boss, S. 106; Kustor-Hüttl, S. 127.

2383 Kustor-Hüttl, S. $126 f$.

2384 Masten, S. 241.

2385 Dazu siehe Werner, Emmy E. Risiko und Resilienz im Leben von Kindern aus multiethnischen Familien. In: Zander, Margherita; Roemer, Martin (Hrsg.) Handbuch Resilien̊förderung. Wiesbaden: Verlag für Sozialwissenschaften/Springer, 2011, S. 32-50; Wernder, Emmy E. Wenn Menschen trotz widriger Umstände gedeihen - und was man daraus lernen kann. In: Welter-Enderlin, Rosmarie; Hildenbrand, Bruno (Hrsg.) Resilienz - Gedeiben trotz widriger Umstände. Heidelberg: Carl-Auer, 2010. S. 28-42; Werner, Emmy. Entwicklung zwischen Risiko und Resilienz. In: Opp, Günther; Fingerle, Michael. Was Kinder stärkt. München: Ernst Reinhard, 2008. S. 20-31; Wustmann; Masten, S. 148; 
rischen Studien als wirksame Ressourcen zur Bewältigung widriger Umstände, belastender Erlebnisse und schwieriger Ereignisse betrachtet. Das Verhältnis zwischen Resilienz und Glauben/Spiritualität unter römisch-katholischen Gläubigen wurde beispielsweise von Stangl2386, Calandro ${ }^{2387}$ und Larrosa ${ }^{2388}$ untersucht. Um den Zusammenhang zwischen Religiosität, Bindung, Hoffnung und Wohlbefinden und den Moderationseffekt auf Stressoren zu untersuchen, führte Zink ${ }^{2389}$ eine Querschnittstudie und eine qualitative Befragung unter Erwachsenen und Jugendlichen aus bildungsfernen und bildungsnahen Schichten in Berlin durch. Die Befragten gehörten verschiedenen religiösen Gemeinden an, ein Teil war konfessionslos. Pasa ${ }^{2390}$ untersuchte ihrerseits die Bedeutung des christlichen Glaubens an die Auferstehung als Resilienzfaktor bei der Bewältigung von Verlusten und Trauer unter brasilianischen Frauen christlichen Glaubens, die ihre Kinder durch Gewalt (Unfall, Mord oder Selbstmord) verloren hatten und keinen Zugang zu psychologischer oder psychiatrischer Hilfe hatten. Studien mit albanischen Flüchtlingsfamilien ${ }^{2391}$ und afroamerikanischen Familien mit Migrationshintergrund 2392 wurden durchgeführt, um den Glauben und die Zugehörigkeit zu einer Kirchengemeinde bei der Bewältigung von Traumata, Armutsverhältnissen, Rassismus und anderen kritischen Ereignissen und Belastungen zu untersuchen. In einer Studie von Kustor-Hüttl ${ }^{2393}$ mit ausländischen Frauen in Deutschland stellte sich heraus, dass der Glaube ihnen Halt, Unterstützung, Orientierung, Kraft, Arbeitsfähigkeit, Zuversicht und Identität in der Fremde vermittelte. Andere Studien konnten wiederum feststellen, dass dem Glauben, einer Gemeinschaft oder einer Kameradschaft eine signifikante Bedeutung bei der Bewältigung von widrigen Umständen, Belastungen und Gewalt in Diktatur-Regimen ${ }^{2394}$, in Krieg- und

Fooken, I. Resilienz und posttraumatische Reifung. In: Maercker, Andreas (Hrsg.) Posttraumatische Belastungsstörungen. Berlin/Heidelberg: Springer, 2013, S. 79; vgl. Wustmann, S. 117; FröhlichGildhoff; Rönnau-Böse, S. 30f.

2386 Stangl, Elias D. Resilienz durch Glauben? Ostfildern: Matthias Grünewald, 2017.

2387 Calandro, Eduardo Antonio. Catequese com adultos: fé e resiliência. Goiânia: Pontifícia Universidade Católica de Goiás, 2013.

2388 Larrosa, Susana María Rocca. As contribuições da espiritualidade e da pastoral católicas no desenvolvimento da resiliência em jovens de 18 a 29 anos. São Leopoldo: Escola Superior de Teologia, 2011.

2389 Zink, Susanne Katja. Der Zusammenhang zwischen Religiosität, Bindung, Hoffnung und Woblbefinden unter Berïcksichtigung von Stress. Hamburg: Disserta Verlag, 2011.

${ }^{2390}$ Pasa, Fabiane Maria Lorandi. "Eles partiram cedo": Morte, luto e resiliência diante da fé cristã. Porto Alegre: PUC/RS, 2013, S. 10.

${ }^{2391}$ Becker, C.; Sargent; J.; Rolland, J. S. Kosovar Family Professional Educacion Collaborative (AFTA Newsletter 80). Washington DC: American Family Therapy Akademy, S. 26-30. Zitiert nach Walsh, Froma. Ein Modell familialer Resilienz und seine klinische Bedeutung. In: Welter-Enderlin, Rosmarie; Hildenbrand, Bruno (Hrsg.) Resilienz - Gedeiben trotz widriger Umstände. Heidelberg: CarlAuer, 2010, S. 59.

2392 Walsh, S. 67f; vgl. Masten, S. 237.

${ }^{2393}$ Kustor-Hüttl, S. 174, 191, 223.

${ }^{2394}$ McCubbin, M.; Maccubbin, H. I. Resiliency in families: A conceptual model of family adjustment and adaptation to stress and crisis. In: Maccubbin, H.; Thompson, A.; McCubbin, M. (Hrsg.) Family 
Nachkriegszeiten ${ }^{2395}$ und bei Inhaftierungen 2396 zukommt. Die Bedeutung des Glaubens und der Unterstützung einer Glaubensgemeinschaft für Menschen in sozial benachteiligen Situationen wurde wiederum von Masten ${ }^{2397}$ bei Eltern in Notunterkünften und von Braga ${ }^{2398}$ bei Frauen, die an einer IntegrativSystemischen Gemeindetherapie in João Pessoa, Staat Paraíba (PB) Brasilien, teilnahmen, untersucht. Die soziale Bindung der Mitglieder einer Glaubensgemeinschaft war letztlich auch sehr wichtig für die Bewältigung der Folgen des Hurricanes Katrina in New Orleans, USA im Jahre 2005. 2399

Einige Studien zeigen sogar eine positive Verbindung zwischen Glauben und Gesundheit auf, besonders in Bezug auf den positiven Umgang mit Diagnose und Behandlung. ${ }^{2400}$ Andere konnten wiederum eine schnellere Erholung von Verlustereignissen mit einer starken Bindung an einen spirituellen und religiösen Glauben verknüpfen, denn Religiosität und Spiritualität ermöglichen die Integration negativer Ereignisse und eine positive Einstellung zu ihnen. ${ }^{2401}$ Laut Stangl ermöglicht

assessment: resiliency, coping and adaptation - inventories for research and practice. Madison/WI: University of Wisconsin System, 1996, S. 1-64. Zitiert nach Reis, Olaf. Rostocker Längsschnittstudie (ROLS): Familienresilienz und intrafamiliäre Individuation in ostdeutschen Familien. In: Fooken, Insa; Zinnecker, Jürgen (Hrsg.) Trauma und Resilien₹: Weinheim/München: Juventa, 2009, S. 89.

2395 Klasen, F.; Oettingen, G.; Daniels, J.; Post, M.; Hoyer, C; Adam, H. Posttraumatic resilience in former Ugandan child soldiers. In: Child Development 81 (4), 2010, S. 1114-1128. Zitiert nach Masten, S. 137; Schörken, Rolf. Resilienz bei Kriegsverwundeten. Ein lebensgeschichtlicher Diskussionsbeitrag. In: Fooken, Insa; Zinnecker, Jürgen (Hrsg.) Trauma und Resilienz. Weinheim/München: Juventa, 2009, S. 43; Zinnecker, Jürgen. Schlusswort: Ein Kommentar aus historisch-gesellschaftlicher Perspektive. In: Fooken, Insa; Zinnecker, Jürgen (Hrsg.) Trauma und Resilien₹: Weinheim/München: Juventa, 2009, S. 206.

2396 Werner, Emmy E. Resilienz und Protektivfaktoren im Lebenslauf von Kriegskindern. Ausgewählte empirische Studien. In: Fooken, Insa; Zinnecker, Jürgen (Hrsg.) Trauma und Resilien\%: Weinheim/München: Juventa, 2009, S. 52-54; Sedmak, S. 1-12, 47-54, 271-273, 290.

2397 Masten, S. 237.

2398 Braga, Lucineide Alves Vieira. Terapia Comunitária e Resiliência: história de mulberes. João Pessoa: Universidade Federal da Paraíba, 2009, S. 62, 65, 69.

2399 Chamlee-Wright, Emily; Storr, Virgil Henry. Club Goods and Post-Disaster Community Return. In: Rationality and Society, Nr. 21 (4), 2009. Zitiert nach Wunsch, Albert. Mit mebr Selbst zum stabilen ICH! Resilienz als Basis der Persönlichkeitsbildung. Berlin/Heidelberg: Springer, 2013, S. $96 f$.

2400 Klein, Constantin; Albani, Cornelia. Die Bedeutung von Religion für die psychische Befindlichkeit: Mögliche Erklärungsansätze und allgemeines Wirkmodell. In: Zeitscbrift für Nachwuchswissenschaftler - German Journal for Young Researchs, Nr. 3, 2011, S. 15-36. Zitiert nach Stangl, S. 220-222. Boss, S. 103, 130; Pents, M. Older Adults with Cancer - Resilience and its Connection. In: The Gerontologist, Academic Research Library, Nr. 42, October 2002. Zitiert nach Bartolomei, Mônica. A fé como fator de resiliência no tratamento do câncer. São Paulo: Pontifícia Universidade Católica de São Paulo, 2008, S. 50; Welter-Enderlin, Rosmarie. Resilienz und Krisenkompeten;. Heidelberg: Carl-Auer, 2010, S. 82-85; Amaro, Luana da Silva. Resiliência, religiosidade e sentido de vida em mulheres com câncer de mama. João Pessoa: Universidade Federal da Paraíba, 2014, S. 6, 95f, 99-102; Stangl, S. 165, 256; Zink, S. 20, 99.

${ }^{2401}$ Filipp, Sigrun-Heide; Aymanns, Peter. Kritische Lebensereignisse und Lebenskrisen. Vom Umgang mit den Schattenseiten des Lebens. Stuttgart: W. Kohlhammer, 2010, S. 107f; Anonym, Über die persönliche Gottesberiehung und religiöse Selbsterfahrung zu psychischer Gesundheit. Norderstedt: Grin, 2016, S. 18; Pargament, K. I. The psychology of religion and coping: Theory, research, practice. New York: Guilford, 1997 und Pargament, K. I. The bitter and the sweet: An evaluation of the cost and benefits of religious- 
der christliche Glaube die Einbeziehung der Perspektive des Scheiterns im menschlichen Leben, unter anderem durch die Zentralität, die dem Kreuz als Erlösungssymbol in der christlichen Religion zugesprochen wird. Scheitern wird in der Resilienzforschung oft als Gegenteil von Resilienz gesehen. Aus theologischer Sichtweise kann Scheitern jedoch ein positives Potenzial enthalten und Möglichkeiten entstehen lassen, wenn ein Tiefpunkt erreicht wurde, nämlich dass „Stärke erst im Scheitern mobilisiert wird" "2402 Resilienz kann sich laut Larrosa auch an der Hermeneutik der Auferstehung orientieren. Weil sie einen kontinuierlichen Schöpfungs- und Transformationsprozess umfasst, in dem Menschen aus widrigen, kritischen, schmerzlichen und ungerechten Erfahrungen gestärkt hervorgehen und einen neuen Lebenssinn erfahren, können sich Parallelen zwischen Resilienz und dem Osterereignis, bei welchem neues Leben nach Leid und Tod entsteht, finden lassen. ${ }^{2403}$

Spirituelle und religiöse Überzeugungen ${ }^{2404}$, eine aufrichtige Frömmigkeit und praktizierte Spiritualität durch die Lektüre heiliger Texte und Bibelverse ${ }^{2405}$, kirchlicher Gesang, regelmäßiges Beten, Meditieren und Segen, religiöse Rituale ${ }^{2406}$, Zeremonien und Praktiken, vor allem die Bedeutung des Abendmahls zur Glaubensstärkung ${ }^{2407}$, können als besonders resilienzfördernd und heilsam in widrigen Situationen eingestuft werden. ${ }^{2408}$ Alle Religionen verfügen über Zeremonien und Rituale für wichtige, aber auch schwierige Ereignisse des menschlichen Lebens (Geburt, Pubertät, Erwachsenenalter, Heirat und Tod) und über Musik, Gebete, Weisheitsprüche, Symbole und Objekte, die der emotionalen Beruhigung und Unterstützung dienen. ${ }^{2409}$ Laut Stähli übernehmen Rituale und religiöse Praktiken eine „Überbrückungsfunktion“, indem sie in Grenzsituationen, in denen Menschen sich angesichts eines traumatischen Erlebnisses überhaupt nicht ausdrücken können, eine Distanz zum Belastungszustand schaffen und eine Kanalisierung der Gefühle ermöglichen. Das hilft den Menschen, neue Kräfte zu entfalten. ${ }^{2410}$

ness. In: Psychological Inquiry 13(3), 168-181, 2002. Zitiert nach Filipp; Aymanns, S. 271f; Boss, S. 103, 193; Utsch, Michael. Religionspsychologie. Voraussetzungen, Grundlagen, Forschungsüberblick. Stuttgart, 1998, S. 51. Zitiert nach Stangl, S. 214; Amaro, S. 39, 41; Zink, S. 25, 34; Sedmak, S. 282, 289.

2402 Stangl, S. $226 f$.

${ }^{2403}$ Larrosa, S. 83.

${ }^{2404}$ Stangl, S. 256; Masten, S. 199; Walsh, S. 67.

${ }^{2405}$ Pechmann, Burkhard. Resilienz gegen Ende des Lebenslaufs oder Woher kam die Kraft? In: Sedmak, Clemens; Bogaczyk-Vormayr, Małgorzata (Hrsg.) Patristik und Resilien:. Frühchristliche Einsichten in die Seelenkraft. Berlin: Akademie Verlag, 2012, S. 125, 134; Stangl, S. 252.

2406 Stangl, S. 256; Masten, S. 199, 228; Walsh, S. 61, 64.

2407 Verdichtungsprotokoll 5 und 9. In: Stangl, S. 316f, 327; Sedmak, S. 332.

2408 Stangl, S. 252.

${ }^{2409}$ Masten, S. 242.

2410 Stähli, Andreas. Rituale: Schutzfaktor der Mitarbeiter. In: Müller, Monika; Pfister, David (Hrsg.) Wie viel Tod verträgt das Team? Göttingen: Vandenhoeck \& Ruprecht, 2013, S. 201. 
Letztlich können die Einbindung und das Engagement in religiösen Gemeinden Resilienz fördern. ${ }^{2411}$ Das Prestige, das durch das Zugehörigkeitsgefühl zu einer Glaubensgemeinschaft empfunden wird, hat einen positiven Einfluss auf das Selbstbewusstsein der Menschen und die Teilnahme an einer Gemeinde kann als Ersatz oder Ausgleich für eine fehlende soziale Bestätigung dienen. ${ }^{2412}$ Hinzu bieten die Gemeinschaft und der soziale Kontakt mit Mitgliedern einer religiösen Gemeinde Halt, Orientierung und Unterstützung im Umgang mit Schwierigkeiten, Notsituationen, Problemen und Krisen ${ }^{2413}$ und können Menschen von deren schädlichen Auswirkungen schützen. Das aktive Engagement in konkreten Handlungen, die als sinnvoll und lohnenswert erachtet werden, gibt den Mitgliedern einer religiösen Gemeinschaft einen wichtigen Lebenssinn, wirkt als Quelle für Lebenszufriedenheit und inneres Wachstum und erweitert die Umsetzungsmöglichkeiten von Gemeindeprojekten. Zudem hat die Feier gemeinsamer Erfolge eine bedeutungsvollere Wirkung..2414 Wer sich für bestimmte Dienste in einer Gemeinde engagiert, erhält im Gegensatz dafür wiederum Wertschätzung und Anerkennung, die identitätsfördernd wirken und die Basis gegenseitiger Hilfeleistung bilden. ${ }^{2415}$

Dass Glaube, Religiosität und Spiritualität bei der Bewältigung von Krisen und schwierigen Umständen eine wichtige Rolle spielen, bedeutet aber nicht im Umkehrschluss, dass Misserfolge auf einen Mangel an Glauben zurückzuführen sind. ${ }^{2416}$ Nach Stangl ist der Glaube nicht in exklusiver Weise als Resilienz förderndes Existenzial anzusehen und wirkt nicht prinzipiell resilienzfördernd.2417 Zudem kann Resilienz auch ohne Bewertung oder Einbeziehung religiöser Komponenten festgestellt werden. ${ }^{2418}$ Larrosa weist auch darauf hin, dass weder Glaube, Religiosität noch Spiritualität Resilienz fördern können, wenn sie mit Fanatismen, Dogmatismus, Sektentum und Fundamentalismus verbunden sind und somit Gewalt, Unterdrückung, Diskriminierung und weitere Widrigkeiten erzeugen. ${ }^{2419}$ Religiöse Überzeugungen haben auch negative Aspekte, wenn sie dazu führen, dass Menschen auf ärztliche Hilfe verzichten (wie auf Bluttransfusionen, Impfun-

\footnotetext{
2411 Grotberg, Edith H. Anleitung zur Förderung der Resilienz von Kindern. Stärkung des Charakters. In: Zander, Margherita; Roemer, Martin (Hrsg.) Handbuch Resilienæförderung. Wiesbaden: Verlag für Sozialwissenschaften/Springer, 2011, S. 51, Walsh, S. 60-62, 71; Klasse, Eloisa; Menoni, Teresa. Construyendo alternativas al dolor. Reflexiones sobre la Resiliencia en Casabó, Cerro de Montevideo. In: Bauer, María; González, Elena; Sassón, Emilia; Perkal, Alicia Weigensberg de; Corti, Analía; Litvan, Marina Altmann de (Hrsg.) Resiliencia y vida cotidiana. Montevideo: Psicolibros Waslala, 2007, S. 183; Masten, S. 158, 161.

2412 Anonym, S. 14; vgl. Fröhlich-Gildhoff, S. 167.

2413 Larrosa, S. 53; Walsh, S. 60-62; Zink, S. 26.

2414 Wunsch, S. 98.

2415 Anonym, S. 14; Wunsch, S. 98.

2416 Walsh, S. 68.

2417 Stangl, S. 264.

2418 Stangl, S. 259.

${ }^{2419}$ Larrosa, S. 82f; Masten, S. 242; vgl. Kustor-Hüttl, S. 128.
} 
gen), wenn sie aufgrund überhöhter moralischer Werte den Menschen Schuld für bestimmtes Verhalten zuweisen (bei HIV-Patienten) ${ }^{2420}$, bestimmte Ereignisse als Gottes Strafe sehen, spirituellen Zweifel oder Gefühle des Verlassenseins und Unzufriedenheit mit Gott auslösen, Konsum von Drogen und Alkohol in ihren Praktiken fördern oder die Entwicklung von Selbstverantwortlichkeit und Autonomie durch Übertragung der gesamten Verantwortung auf Gott behindern. ${ }^{2421}$ Entscheidend ist, wie religiöse Überzeugungen das Bewältigungsverhalten ausrichten. Nicht zu vergessen ist, dass manche Individuen nach einer Krise den Glauben verlieren, in existentielle Verzweiflung verfallen und die Erfahrung machen können, dass Bezugspersonen ihnen nicht zur Seite gestanden, sie im Stich gelassen, verraten oder gar missbraucht haben. ${ }^{2422}$ Jedoch Studien, die diese Behauptungen empirisch belegen könnten, wurden bis jetzt noch nicht durchgeführt.

2420 Amaro, S. 47.

2421 Zink, S. 23, 25; Anonym, S. 17.

2422 Filipp; Aymanns, S. 115f; Masten, S. 162, 231. 



\section{IX - Exkurs: Himmelsbriefe}

Weil das Leben in den brasilianischen Urwaldgebieten unzähligen Gefahren ausgesetzt war, trugen viele Pommern "Himmelsbriefe" oder "Schutzbriefe" bei sich, hängten sie an die Wände ihrer Häuser oder legten sie auf den Dachboden, um sich vor möglichen Gefahren zu schützen. In diesem Exkurs werden (5) Exemplare der Himmelsbriefen untersucht, die sich unter pommerschen Einwanderer und deren Nachkommen in Brasilien erhalten haben.

Die brasilianische Anthropologin Bahia vermutet, in den Himmelsbriefen gestalte sich ein Dialog zwischen einem Bauern und Gott. ${ }^{2423}$ Eine Analyse ihrer Entstehungsgeschichte belegt aber, dass sie seit dem 6. Jahrhundert n. Ch. bekannt waren und einen Sitz im Leben im kirchlichen Bereich haben. Der Legende nach sollen sie in der Nähe heiliger Städte (Jerusalem, Konstantinopel oder Rom) vom Himmel herabgefallen oder an bestimmten Orten oder Kirchen plötzlich aufgetaucht sein. ${ }^{2424}$ Der ursprüngliche Brief (auf Marmor oder Eis mit goldenen Buch-

\footnotetext{
${ }^{2423}$ Bahia, Joana. O tiro da bruxa. Rio de Janeiro: Garamond, 2011, S. 357.

${ }^{2424}$ Wie beispielsweise im Mont Saint Michel in der Normandie, ein Heiligtum des Erzengels Michael, siehe Becker; Hans Günther; Nail, Norbert. Der alte Gasthof zum Scbützenpfubl in Marburg. Marburg: Magistrat der Stadt Marburg, 2008, S. 122; in der Kirche „zu Mechelburg“ [Mecklenburg oder Michelburg], in der Michaeliskirche zu St. Germain, in der St. Michel Abtei in der Normandie, über einen Altar des „Paulus und Petrus", „über der Taufe“, „über der Taufe Magdalenens". Dieterich, Albrecht. Himmelsbrief. In: Blätter für Hessische Volkskeunde, Nr. 3, III. Jahrgang, 1901, S. 10; Magischsympathetischer Hausschatz oder Die offenbarten Geheimnisse der natürlichen Magie. In: 6./ 7.
} 
staben geschrieben und durch einen Engel, zumeist Michael2425, zur Erde gebracht) "ließ sich nicht ergreifen".2426 Inhaltlich geben sich Himmelsbriefe als magische Schutzmittel aus gegen alle Sorten von Gefahren, die Menschen durch Krieg, Naturgewalten und Krankheiten begegnen können, sowie gegen Schäden im Jenseits, wie dem Tod oder der ewigen Verdammnis. ${ }^{2427}$

Die älteste Form eines christlichen Himmelsbriefes ist die göttliche Offenbarung für die Forderung der Sonntagsheiligung, der sogenannte Sonntagsbrief. Er soll von Christus selbst geschrieben worden sein und fiel vom Himmel auf den Altar des Petersdoms in Rom herab. Erste Erwähnung fand er angeblich 584 oder 585 n.Ch auf der spanischen Insel Ibiza, als Bischof Vincentius ihn in einem Gottesdienst verlas. Vincentius sandte Bischof Licinianus von Karthago eine Kopie davon und dieser sah in dem Brief einen Versuch, den jüdischen Sabbat in der Kirche einzuführen. Aus diesem Grund wurde der Brief als Ketzerei verworfen. ${ }^{2428}$ Dies verhinderte jedoch seine Verbreitung nicht.

Der Sonntagsbrief forderte die strenge Heiligung des christlichen Sonntags, entsprechend der von Konstantin gesetzlichen eingeführten Sonntagsruhe, die zudem strenge kirchliche Dispositionen einiger Bischöfe enthielt. Bald setzte sich die Sonntagsruhe in Gallien durch und wurde in die fränkische Gesetzgebung mit aufgenommen. Diese Tatsache lässt die Vermutung zu, dass der Brief aus dem fränkischen Reich stammen könnte. Zudem fiel er dort, angesichts der volkstümlichen Erzählungen eines schrecklichen Schicksals für Sonntagsschänder, auf fruchtbaren Boden. ${ }^{2429}$ Eine kirchliche Synode in Rom unter Papst Zacharias (741-752) verurteilte den Sonntagsbrief im Jahre $745^{2430}$ und verbat erfolglos seine Verbreitung. In Frankreich war er trotz der staatlichen Intervention von Karl dem Großen im Jahre 789 noch bekannt und hatte seine Anhänger sogar unter dem

Buch Moses. Einleitung und Bildkommentare von Bauer, Wolfgang. Berlin: Karin Kramer, 1979, S. 204; Stübe, R. Der Himmelsbrief. Tübingen: Mohr (Paul Siebeck), 1918, S. 2.

2425 Der Erzengel Michael wird als Überbringer der Himmelsbriefe dargestellt, weil er als Beschützer der Kirche gesehen wird und nach biblischem Zeugnis im Kampf gegen den Teufel siegte (Offb. 12,7-9; Jud. 1,9; Dan. 12,1). Magisch-sympathetischer Hausschatz, S. 204.

2426 Das entspricht der Tradition des Altertums, nach welcher nur Begnadeten die Götterbilder berühren dürften (vgl. 2 Sam. 6,7; Jes. 6,5). Stübe, Der Himmelsbrief, S. $43 f$.

${ }^{2427}$ Beckert; Nail, S. 130; Stübe, Der Himmelsbrief, S. 5.

2428 Stübe, Der Himmelsbrief, S. 12f; Stübe, Sonntagsbrief. In: Hoffman-Krayer, E.; Bächtold-Stäubli, Hanns (Hrsg.) Handwörterbuch des Deutschen Aberglaubens. Band VIII. Berlin/Leipzig: Walter de Gruyter, 1936/1937, S. 99f; Beitl, K. Brief, Rel. Volkskunde. In: Höfer, Josef; Rahner, Karl. (Hrsg.) Lexikon für Theologie und Kirche. 2. Auflage, 2. Band, Freiburg: Herder, 1958, S. 687; Röhrich, L. Himmelsbriefe. In: Galling, Kurt (Hrsg.) Die Religion in Gescbichte und Gegenwart. 3. Auflage, 3. Band. Tübingen: Mohr (Paul Siebeck), 1959, S. 339.

${ }^{2429}$ Stübe, Sonntagsbrief, S. 100f; Stübe, Der Himmelsbrief, S. 15.

${ }^{2430}$ In der dritten Redaktion des Sonntagsbriefes wird behauptet, dass er im Jahre 746 in Rom niedergefallen sein soll, ein Jahr nach der kirchlichen Synode, die einen Franken namens Adalbert wegen Besitz eines Himmelsbriefes verurteilte. Das beweist, dass der Brief in dieser Gestalt in Rom bekannt war. Stübe, Der Himmelsbrief, S. 17, 21. 
Klerus. ${ }^{2431}$ Mittels kirchlicher Beziehungen der iroschottischen und angelsächsischen Kirche kam der Brief Ende des 8. oder Anfang des 9. Jahrhunderts durch Mönche nach England und ca. im 10. Jahrhundert nach Island.2432 Aufgrund der Völkerwanderung in westeuropäische Länder erfuhr er eine zweite veränderte Redaktion in England oder Irland um 850 und zwischen den 9. und 15. Jahrhundert verbreitete er sich in Italien, Spanien, Frankreich, Deutschland, Österreich und Böhmen. Mit einer dritten Redaktion aus Osteuropa entstanden andere Variationen des Himmelsbriefes, die ihm eine bleibende und universale Wirkung gewährleisteten. Diese dritte Version erreichte die slawischen Völker, die Rumänen und Griechen ${ }^{2433}$ und verbreitete sich in zahlreichen handschriftlichen und gedruckten Kopien. ${ }^{2434}$

Im 13. Jahrhundert war der Sonntagsbrief auf deutschem Boden sehr verbreitet und ein Exemplar wurde im Kloster Weihenstephan-Freising auf Deutsch als Bußrede umgearbeitet. Um 1260 fand der Himmelsbrief besondere Aufmerksamkeit aufgrund der apokalyptischen und eschatologischen Panik in Italien und Deutschland. Joachim von Fiore (1135-1202) verkündete für dieses Jahr das Erscheinen des Antichristen, den Kampf gegen ihn und den Anfang des „Heiligen GeistReiches". Europa litt unter der Pest und der Kampf zwischen Kaiser und Papst verursachte eine Endzeitstimmung in der Bevölkerung. Flagellanten zogen durch die Städte und schlugen sich mit Geißeln in Bußfahrten unter Bußliedern, wobei eines dieser Lieder aus der dritten Redaktion des Himmelsbriefes bestand. ${ }^{2435}$ Nachdem der Himmelsbrief seit 1260 weitgehend aus der Öffentlichkeit verschwand, tauchte er um die Mitte des 14. Jahrhunderts wieder auf. Die schwedische Prophetin Brigitta (1303-1373) sandte einen Himmelsbrief an Papst Clemens VI. (13421352) im Kontext reformatorischer Bewegungen gegen die Verweltlichung der Kirche. Im Liber de reformatione monasteriorum vom Augustinerprobst Johannes Busch (1399-1479/1480) wird wiederum ein Schutzbrief genannt, der auf Papst Leo

2431 Der Abt Einhard von Fulda bot Kaiser Ludwig dem Frommen einen vom Erzengel Gabriel verfassten Brief an. Der Wallfahrtsort St. Michael in Bretagne-Frankreich war im Mittelalter ein wichtiger Verbreitungsort des Sonntagsbriefes und zahlreiche Abschriften bezeugen seine Verwendung. Stübe, Sonntagsbrief, S. 101.

2432 Stübe, Sonntagsbrief, S. 101; Stübe, Der Himmelsbrief, S. 15-18.

2433 Orientalische Exemplare des Himmelsbriefes sind in allen Rezensionen auf ein griechisches, vielleicht koptisches Original zurückzuführen, das nicht mehr erhalten ist. Aus dem Original entstanden auch die syrische und armenische Übersetzung. Alle anderen orientalischen Texte sind weitere Varianten des syrischen Exemplars. Stübe, Der Himmelsbrief, S. 25f. Nach Dieterich gab es griechische Exemplare von Himmelsbriefen aus byzantinischer Zeit, die in Konstantinopel und Jerusalem aufgetaucht sein sollen, Dieterich, S. 11. Außerdem fand der orientalische Philologe Dr. Bittner einen Himmelsbrief in einem armenischen Text aus dem Ende des 1. Jahrhunderts n.Ch., der von koptischen Christen stammen soll. Er befand sich unter den Kirchenbüchern neusyrischer Christen. Magischsympathetischer Hausschatz, S. 207.

2434 Stübe, Sonntagsbrief, S. 102; Stübe, Der Himmelsbrief, S. $19 f$.

2435 Stübe, Der Himmelsbrief, S. 21f. 
III. (795-816) zurückgeführt wurde. Er wurde 1451 in Halle gefunden, wo eine Soldatenfrau ihn in einem Beutel trug. ${ }^{2436}$

Nach Röhrich lieferte der Himmelsbrief in der Reformationszeit auch die literarische Form für theologische Streitschriften, beispielsweise Himmelsbriefe gegen den Ablass. ${ }^{2437} 1524$ gab Nikolaus Hermann (um 1500-1561) eine Bußpredigt heraus, die angeblich von Christus selbst verfasst wurde und als „Mandat Jesu Christi an alle seine getreuen Christen" galt. Gegen den Ablasshandel soll 1523 Urbanus Rhegius (1489-1541) einen Himmelsbrief gerichtet haben und in der Schweiz trat 1526 der Himmelsbrief in einer anonymen Schrift auf (Anklag und ernstliches Ermahnen Gottes des Allmächtigen zu einer gemeinsamen Eidgenossenschaft), die Heinrich Bullinger (15041575) zugeschrieben wurde. 1526 erwähnte Martin Luther (1483-1546) in seiner Schrift „Ob Kriegsknechte auch im seligen Stande sein können“, dass Soldaten sich im Kampf auf Aberglauben verließen. Er bemängelte darin, dass sie Ross und Reiter segnen ließen, Eisen und Büchsenstein beschwörten und neben St. Georgen, St. Christoffel und das Johannes Evangelium auch „sonst noch etwas bei sich, darauf sie sich verlassen“, trügen. ${ }^{2438}$ Als „sonst noch etwas" interpretiert Stübe den sogenannten Waffensegen. Sollte er mit dieser Vermutung richtig liegen, erhielten die Himmelsbriefe von Luther denselben negativen und abwertenden „Aberglaube“- Charakter wie sie auch von kirchlichen Instanzen zugeschrieben bekommen hatten. Dies verhinderte jedoch ihre Verwendung und Verbreitung unter Protestanten nicht, weder in der Reformationszeit noch in den brasilianischen Siedlungsgebieten nach der Ankunft der Geistlichen und entwertete auch nicht ihre Bedeutung als Glaubensquelle und Schutzmittel gegen Gefahren und Krankheiten.

Schutabriefe entwickelten sich wiederum im Kriegskontext. Schon früh erteilten Priester als Stellvertreter Gottes, diverser Götter oder himmlischer Mächte den Segen für Soldaten, die in den Krieg gingen. Im Mittelalter schrieben Mönche Segen auf Pergamentstreifen und gaben diese den Soldaten als Amulett mit in den Kampf.2439 Im 15. Jahrhundert, mit dem Fortschritt der Kriegstechnik und der Erfindung des Schießpulvers, wurden ursprüngliche Segensformeln, wie der sogenannte Schwertsegen, zu Kugel- und Waffensegen oder zu den Schutz- und Himmelsbriefe angepasst. Trotz aller Verbote verbreiteten sie sich besonders zur Zeit des Drei-

\footnotetext{
${ }^{2436}$ Es handelt sich um den Kaiser Karl Brief, der nach Stübe Papst Leo III. mit dem Hinweis gegeben wurde, er solle ihn Kaiser Karl dem Großen (768-814) geben, bevor er in die Schlacht bei Ronceval ziehe. Stübe, Sonntagsbrief, S. 102f; Stübe, Der Himmelsbrief, S. 22f.

2437 Röhrich, S. 339.

2438 Luther, Martin. Ob kriegsleutte auch ynn seligem stande seyn künden, 1526. In: D. Martin Luthers Werke. 19. Band. Weimar: Böhlau, 1897, S. 660.

${ }^{2439}$ In verschiedenen Kriegen wurden den Truppen kleine Heiligenbilder als Amulett mit ins Feld gegeben. Bauer, Wolfgang. Was hat man von dem Volksglauben und der Volksmedizin zu halten? In: 6./ 7. Buch Moses. Berlin: Karin Kramer, 1979, S. 21. Kirchenvertreter erteilten auch in späteren Zeiten den Segen vor Schlachten, auf Panzer, Maschinengewehren und Giftwaffen. Magischsympathetischer Hausschatz, S. 202.
} 
Bigjährigen Krieges (1618-1648) und der französischen Revolutionskriege (17921802).

Himmels- und Schutabriefe wurden nie offiziell als kirchliche Quelle anerkannt, obwohl ihre Herkunft nur aus der innerkirchlichen Entwicklung stammen kann. Sie wurden von der Kirche teilweise geduldet, manchmal sogar verbreitet, aber auch verboten oder bekämpft. Während sie im 15. Jahrhundert als Zaubermittel verboten wurden und derjenige, der sie bei sich trug, nicht am Heiligen Abendmahl teilnehmen durfte ${ }^{2440}$, erlaubte Papst Pius IX. (1846-1878) den Druck von Himmelsbriefen und erklärte sie 1870 in Glaubens- und Sittenfragen für unfehlbar. ${ }^{2441}$ In den 1860er Jahren erschien der Himmelsbrief bei dem Drucker Gustav Kühn in Neuruppin und bald auch in einer Ausgabe des 6. und 7. Buch Mosis. ${ }^{2442}$ Aufgrund der vielen Übersetzungen, Abschriften und Umarbeitungen bekamen Himmelsbriefe neue Gestalten, wobei markante Merkmale der ursprünglichen Typen erhalten blieben und noch zu erkennen sind. Sie waren im 19. Jahrhundert unter Katholiken wie Protestanten sehr beliebt ${ }^{2443}$ und mit der Auswanderung wurden verschiedene Exemplare mit nach Brasilien gebracht. Diejenigen, die sich bei pommerschen Nachkommen erhalten haben, sollen nun analysiert werden.

\section{(1-A) Exemplar des Himmelsbriefes genannt Gredoria aus Espírito Santo}

Eine Version des Himmelsbriefes genannt Gredoria wurde in Rio de Janeiro (RJ) gedruckt und befindet sich heute im Synodalsitz der Synode Espírito Santo a Belém in Vitória (ES). ${ }^{244}$ Es handelt sich hierbei angeblich um eine Kopie eines gedruckten Exemplars, das Einwanderer mit nach Brasilien brachten. Dasselbe Exemplar von ca. 1720, nur mit einem anderen Bild, befindet sich im Historischen Gebäude der Niedersächsischen Staats- und Universitätsbibliothek Göttingen. ${ }^{2445}$ Eine auf Portugiesisch übersetzte Version des Himmelsbriefes aus Espírito Santo befindet

\footnotetext{
${ }^{2440}$ Magisch-sympathetischer Hausschatz, S. 202.

2441 Beckert; Nail, S. 123.

2442 Magisch-sympathetischer Hausschatz, S. 207.

2443 Stübe, Sonntagsbrief, S. 103.

2444 Himmelsbrief Gredoria. Gedruckt in der Papelaria Alexandre Ribeiro, Rio de Janeiro. Ohne Jahresangabe. Din A4, 1 Blatt, 1 Seite. Quelle, die Dr. Claudete Beise Ulrich freundlicherweise zur Verfügung stellte.

2445 Himmels-Brief, welcher mit güldenen Bucbstaben geschrieben und ist zu sehen in der Michaelis Kirche zu St. German, wird genannt Gredoria, allwo der Brief über der Taufe schwebt. Blattmaße $41 \mathrm{~cm}$ x $341 / 2 \mathrm{~cm}, 1$ Blatt, 1 Seite. Rro 65. Niedersächsische Staats- und Universitätsbibliothek Göttingen, Inventarnummer DD97 D 1. Der Himmelsbrief-Typus Gredoria war als Neu-Ruppiner Bilderbogen Nr. 202 in Norddeutschland sehr verbreitet. Stübe, Gredoria. In: Hoffman-Krayer, E.; Bächtold-Stäubli, Hanns (Hrg). Handwörterbuch des Deutschen Aberglaubens. Band III. Berlin/Leipzig: Walter de Gruyter, 1930/1931, S. 1126f.
} 
sich auch im Synodalsitz der Synode Espírito Santo a Belém. ${ }^{2446}$ Der Inhalt des Briefes lautet:

„Jesus Christus zu haben ist

Im Wort, da man von Jesu liest

Jesu giebt Heil und Seligkeit

Dem, der Jesu dient allerzeit

Wer sich des Namens Jesu tröst't

Der wird durch Jesum Christ erlös't

Jesu, dem lieben Kindelein,

Dem herzlichlieben Jesulein.

Sey Lob und Preis! O Jesu mild,

Schütr. uns stets durch deinen Schild

Gieb uns, Herr Jesu, deine Gnad,

Daß uns Welt, Teufel, Tod nicht schad.

Gewiß ist der Tod, ungewiß ist der Tag,

Die Stund' auch niemand wissen mag,

Denn trau auf Gott und denk dabei:

Daßjede Stund' die letate sei

Im Leiden habt guten Muth,

Und liebe den, der Leid dir thut.

Freu' dich vom Herzen in Schwachbeit

Daß ist die ganze Vollkommenheit

So geht es zu in aller Zeit,

Thu' mir die Lieb' ich thu' dir Leid,

Hilf mir auf, ich sto $\beta^{\prime}$ dich nieder,

Ehr' mich groß, ich schand' dich wieder.

Sagt nicht alles, was du weißt,

Glaubt nicht alles was du hör'st,

Richte nicht alles, was du sehest.

Ach Gott, dies ganze Haus bewabr'

Für Feuer, Schaden und Gefahr.

Mit Gnad und Segen über uns walt.

Und uns dein reines Wort erhalt.

Herr Jesu durch den Namen dein

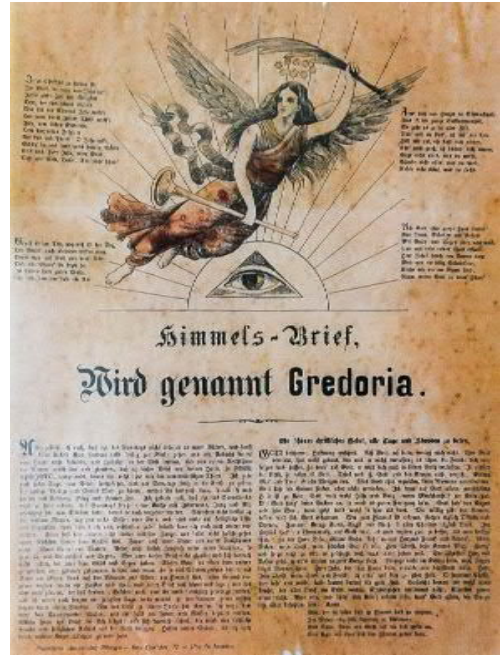

Abb. 39: Himmelsbrief Gredoria.

Gedruckt in der Papelaria Alexandre

Ribeiro, Rio de Janeiro (RJ). Quelle:

Synodalsitz der Synode Espirito Santo a

Belém.

Gieb mir ein seliges Stündlein,

Stehe mir bei am letzten End'

Nimm meine Seel', in deine Hand'.

2446 Carta do céu, também conhecida como Gredoria. Ohne Angabe des Druckers. DIN A4, 1 Blatt, 1 Seite. Quelle, die Dr. Claudete Beise Ulrich freundlicherweise zur Verfügung stellte. 


\section{Himmels-Brief, wird genannt Gredoria.}

Also gebiete ich euch, daß ibr des Sonntags nicht arbeitet an euren Gütern, und sonst keine Arbeit thut, sondern sollt fleißig zur Kirche gehen und mit Andacht beten, eure Haare nicht kräuseln, noch Hoffarth in der Welt treiben, und von eurem Reichthum den Armen mittheilen und glauben, daß ich diesen Brief von meiner Hand, in JESU CHRISTO, ausgesandt, damit ihr nicht thut, wie die unvernünftigen Thiere. Ich gebe euch sechs Tage, eure Arbeit fortzusetzen, und am Sonntage früh in die Kirche zu gehen, die heilige Predigt und Gottes Wort zu bören: werdet ibr das nicht thun, so will ich euch strafen mit Pestilenz, Krieg und theurer Zeit. Ich gebiete euch, daß ibr des Sonnabends nicht zu spät arbeitet, des Sonntags früh in der Kirche mit Jedermann, Jung und Alt, andächtig für eure Sünden betet, damit sie euch vergeben werden. Schwöret nicht bosaftig bei meinem Namen, begehret nicht Silber oder Gold, und sehet nicht, auf fleischliche Lüste und Begierden: denn sobald ich euch erschaffen habe, sobald kann ich euch wieder vernichten. Einer soll den andern nicht tödten mit der Zunge, und sollet nicht falsch gegen euren Nächsten binter den Rücken seyn. Freuet euch eurer Güter und eures Reichthum nicht. Ehret Vater und Mutter. Redet nicht falsch Zeugnis wider euren Nächsten, so gebe ich euch Gesundheit und Segen. Wer aber diesen Brief nicht glaubet, und sich darnach nicht richtet, der wird kein Glück. und Segen haben. Diesen Brief soll einer dem andern geschrieben oder gedruckt zukommen lassen: und wenn ibr so viel Sünden gethan hättet, als Sand am Meere, Laub auf den Bäumen und Sterne am Himmel sind, sollen sie euch vergeben werden, wenn ihr glaubet und thut, was dieser Brief euch lehret und saget; wer das aber nicht glaubet, der soll sterben. Bekehret euch, oder ibr werdet ewiglich gepeinigt werden, und ich werde euch fragen am jüngsten Tage, dann werdet ihr mir Antwort geben müssen wegen eurer vielen Sünden. Wer den Brief in seinem Hause hat oder bei sich trägt, dem wird kein Donnerwetter schaden, und ibr sollt vor Feuer und Wasser bebütet werden. Welche Frau den Brief bei sich träget, und sich darnach richtet, die wird eine liebliche Frucht und fröblichen Anblick auf die Welt bringen. Haltet meine Gebote, die ich euch durch meinen Engel Michael gesandt habe.

Ein schönes christliches Gebet, alle Tage und Stunden zu beten,

Gott bescheret, Hoffnung ernähret. Ach Gott ich bitte, verlaß mich nicht. Wer Gott vertraut hat wobl gebaut, den will er nicht verlassen; ob schon die Feinde dich verfolgen und hassen so trau' auf Gott, er wird dich auch in keiner Noth verlassen. Je größer die Noth, je näher ist Gott. Trink und iß, Gott und die Armen nicht vergiß; Gottes Güt' und Treu' ist alle Morgen neu. Was Gott thut erquicken, kann Niemand unterdrücken; Gott läßt die Seinen sinken aber nicht ertrinken. Ich trau' auf Gott allein, menschliche Hilfe ist zu klein; Gott weiß wohl Hilfe und Rath, wenn Menschenhilf ein Ende hat. Mit Gott fang' deine Sache an, so wird es guten Fortgang ha'n. Gott hab' vor Augen und sein Wort, so geht dir's wohl so hier als dort. Wer willig gibt den Armen, dessen wird sich Gott erbarmen. Wer zum Himmel ist erkoren, stechen täglich Disteln und Dornen. Jammer, Kreuz, Elend, Angst und Noth, ist aller Christen täglich Brod. Im Unglück hab' einen Löwenmuth, auf Gott trau', es wird werden gut, ja besser, als man boffen thut. Zu dir Herr Jesu, Gottes Sohn, steht meines Herzens Freud' und Wonn'. 
Mein Rubm, mein Trost, mein höchstes Gut ist mir, Herr Christ, dein theures Blut. Sorg' und sorge nicht zu viel, es geschieht doch, was Gott haben will. Der Christen Herz. auf Rosen geht, wenn's mitten unterm Kreuze steht. Verzage nicht im Kreuze dein, nach Regen folget Sonnenschein. Herr Jesu, der süße Name dein, erquicke mir die Seele mein. Herr Jesu Christ, mein Trost und Freud', ich trau' auf dich zu jeder Zeit. O frommer Christ, hier leid' und meid', bald kommt darauf die gute Zeit. Vielleicht kommt der wohl über Nacht, der aller Noth ein Ende macht. Kirchgehen versäumet nicht, Almosen geben, armet nicht. Bete rein, und schätr' dich klein, arbeite fein, trau' Gott allein, die Sorge laß Gott befohlen sein, Amen.

Gott, der du deine Lust im Himmel hast zu wohnen

Im Wesen einig bist, dreieinig in Personen:

Gott V ater, Sohn und Geist, all' die dich rufen an

Kein Gott mir obne dich den Himmel geben kann".2447

Bei einem Vergleich zwischen dem Exemplar aus Espírito Santo (H-ES) und dem der Staats- und Universitätsbibliothek Göttingen (H-SUBGö), fallen folgende Unterschiede auf: a) im E-ES trägt der Erzengel Michael eine schwebende Sternenkrone (mit acht Sternen) auf dem Kopf, hält in der rechten Hand eine Posaune (vgl. 1 Thes. 4, 16; Offb. 8, 6-13; 9; 11), die aber nicht gespielt wird, und in der linken einen grünen Zweig. Im Hintergrund steht das Auge der Vorsehung2448 (Abb. 39, siehe S. 410). Der Engel im SUBGö wandert, indem er mit der linken Hand eine Trompete am Mund hält und sie blasen möchte und in der rechten einen grünen Zweig trägt. Hinter ihm befindet sich ein Baumstumpf (Jes. 6,13; 11,1) und ein Busch. Die Abbildungen waren sehr wichtig, denn sie stellten die heilige Figur des Erzengels Michael visuell dar, so dass der Brief bereits damit eine schützende Funktion zugesprochen bekam, wie es beispielsweise bei anderen heiligen Ikonen in der römisch-katholischen Kirche der Fall ist. Ein pommerscher Nachkomme nannte diesen Brief deswegen „Engelsbrief“. Er sollte gerade wegen der Figur eines Engels ,besser" beziehungsweise mächtiger sein. ${ }^{2449}$ Außerdem stellen Abbildungen die Präsenz Gottes, der alles, was der Mensch macht, sehen kann und die Wiederkunft Christi aus dem Himmel nach dem Ruf des Erzengels und dem Schall der Posaune dar; b) im H-SUBGö wird nach dem Titel Himmelsbrief, genannt Gredoria, folgende Erklärung hinzugefügt, die im H-ES fehlt:

„Welcher mit güldenen Buchstaben geschrieben und ist zu sehen in der Michaelis Kirche zu St. German, wird genannt Gredoria, allwo der Brief über der Taufe schwebt. Wer

\footnotetext{
2447 Himmelsbrief Gredoria. Gedruckt in der Papelaria Alexandre Ribeiro, Rio de Janeiro.

2448 Das Auge der Vorsehung, auch allsehendes Auge oder Gottesauge genannt, wird von einem Strahlenkranz umgeben und einem Dreieck umschlossen, das auf die Dreieinigkeit verweist. In der Bibel erscheint dies als Symbol der Allgegenwart Gottes (Spr. 15,3: „Die Augen des Herrn sehen an allen Orten beide, die Bösen und die Aufrichtigen").

2449 Interview mit einem pommerschen Nachkommen. Zitiert nach Seibel, Imigrante no século do isolamento, S. 332.
} 
ihn angreifen will, vor dem weichet er, wer ibn aber abschreiben will, zu dem neiget er sich, und thut sich selbst auf" 2450

Sie weist auf die Legende über die Erscheinung des Briefes und auf seinen literarischen Typus, die schriftliche Offenbarung Gottes ${ }^{2451}$, hin. Deswegen wurden Himmelsbriefe auch als christliche Pseudoepigraphen oder Apokryphen angesehen ${ }^{2452}$; c) das H-ES enthält nach dem ,schönen christlichen Gebet" eine trinitarische und dogmatische Doxologie, die darauf hinweist, dass Gott allein den Menschen den Himmel und somit ewiges Leben schenken kann. Anstelle dieser Doxologie taucht beim H-SUBGö ein Schlusssatz auf, der auf den Schutz Jesu allein hinweist: „Nicht Teufel, Welt und Tod, soll mich von Jesu wenden, denn Jesus ist mein Schutr, ich bin in seinen Händen".

Der Name Gredoria, Credoria oder Grodoria kann eine volkstümliche Umbildung des „Deo gloria“ oder des Wortes „Credo“ sein, wie er angeblich unter den Pommern in Brasilien gebraucht wurde und in der portugiesischen Übersetzung einer anderen Version des Gredoriatypus vorkommt. ${ }^{2453}$ Weil er kaum Segen enthält, ist er wohl der älteste Typus von Himmelsbriefen. Die Gebote leiten sich zum Teil vom alttestamentlichen Dekalog ab, wie zum Beispiel „Schwöret nicht bosaftig bei meinem Namen" nach der Auffassung des zweiten Gebots von Luther im Kleinen Katechismus ${ }^{2454}$, ,einer soll den andern nicht tödten mit der Zunge (vgl. Jak. 3, 5-6), und sollet nicht falsch gegen euren Nächsten binter den Rücken seyn. (...) Redet nicht falsch Zeugnis wider euren Nächsten“vom achten Gebot, „ehret Vater und Mutter"vom vierten Gebot und „also gebiete ich euch, daß ihr des Sonntags nicht arbeitet" vom dritten Gebot. Die Forderung zur Heiligung des Sonntags wurde auch durch das Postulat, fleißig zur Kirche zu

${ }^{2450}$ Himmels-Brief, welcher mit güldenen Buchstaben geschrieben und zu sehen ist in der Michaelis Kirche zu St. German. Niedersächsische Staats- und Universitätsbibliothek Göttingen, Inventarnummer DD97 D 1.

${ }^{2451}$ Die anthropomorphe Vorstellung schreibender Götter ist nur bei Völkern mit früheren Schriftsysteme zu finden, was darauf hinweist, dass diese Tradition ursprünglich aus Ägypten, Babylon oder China stammt. Alles deutet jedoch darauf hin, dass Ägypten der Ursprungsort des Himmelsbriefes ist. Aus Ägypten übernahm der Hellenismus diese Tradition. Stübe, Der Himmelsbrief, S. 30; Stübe, Himmelsbrief. In: Hoffman-Krayer, E.; Bächtold-Stäubli, Hanns (Hrg). Handwörterbuch des Deutschen Aberglaubens. Band IV. Berlin/Leipzig: Walter de Gruyter, 1931/1932, S. 22f. Die Tradition des Himmelsbriefes ist weiterhin im jüdischen Talmud, in der mittelalterlichen Kabbala, in der judenchristlichen Sekte der Elkesaiten (2. Jahrhundert v. Ch.), in den Oden Salomos, in den gnostischen Thomasakten, im Hirten Hermas (um 130 n. Ch.), in einem altchristlichen Apokryphen aus dem 3. Jahrhundert (die Abgarsage), in der Antike, in der Philosophie, in der Mystik, im Islam, im Buch Mormon, in der christlichen Heiligenlegende und auch in der biblischen Überlieferung bekannt. Stübe. Himmelsbrief, S. 23-25; Stübe, Der Himmelsbrief, S. 31f, 33-42.

2452 Beckert; Nail, S. 131; Stübe, Himmelsbrief, S. 22.

${ }^{2453}$ In der übersetzten Version des Gredoria-Briefes aus Pelotas (RS) wird der Brief als „Mensagem (Carta) Celeste - (chamada Credo)" bezeichnet. Ohne Angabe des Druckers, 1 Blatt, 2 Seiten. Fotografie. In: Maltzahn, Gislaine Maria. Familia, ritual e ciclos de vida. Estudo Etnográfico sobre narrativas pomeranas em Pelotas (RS). Pelotas: Universidade Federal de Pelotas, 2011, S. $143 \mathrm{f}$.

2454 Deutscher Evangelischer Kirchenausschuß (Hrsg.) Evangelisches Hausbuch für die Deutschen im Ausland. Berlin: Mittler und Sohn, 1912, S. 116. 
gehen, ergänzt. Wer diese Gebote und andere moralische Forderungen, die an christliche Segenssprüche erinnern, erfüllte, sollte mit Segen und Glück gesegnet, gegen Donnerwetter, Feuer und Wasser geschützt und den Frauen bei der Geburt gesunder Kinder geholfen werden. Aus diesem Grund besaß dieser Himmelsbrief eine konkrete Bedeutung für die Siedler in Brasilien, die sich entsprechend ihrer Volksfrömmigkeit einen dauerhaften Schutz gegen Unwetter und Plagen, die ihre Plantagen zerstören und somit den Ruin ihres Betriebes verursachen konnten, aber auch den Schutz für Haus und Hof zusichern wollten. ${ }^{2455}$ Die Geburt gesunder Kinder spielte wiederum angesichts des Mangels an ausgebildeten Ärzten und Hebammen und der Notwendigkeit, gesunde Nachkommen für die Bewirtschaftung des landwirtschaftlichen Betriebes zu haben, eine entscheidende Rolle. Der Brief enthält letztlich die Forderung, ihn für andere abzuschreiben oder anderen gedruckt zukommen lassen. Dieser Forderung kamen viele Pommern in Brasilien für ihre Nachkommen, Verwandten und Bekannten gern nach. Das sollte ihnen, neben dem Glauben an seinen Zusagen und dem Bei-sich-tragen oder Aufbewahren im Haus, Vergebung der Sünden zusichern. Den Ungläubigen und Unbußfertigen wurde dagegen mit ewigen Strafen, Verdammnis und Tod gedroht. Die Gebete, die den Brief einleiten und abschließen, sind nach Stübe gereimte Variationen des Vaterunsers und Sprüche christlicher und allgemeiner moralischer Inhalte. 2456 Sie ermöglichten durch ihre Reime, ähnlich wie bei Gebeten und Liedern in Andachts- und Gesangbüchern, ein leichtes Auswendiglernen und weisen auf Themen, die auch in diesen kirchlichen Quellen auftauchten hin: Auf das Heil und die Erlösung durch Jesus Christus, auf den Schutz gegen Welt, Teufel und Tod, aber auch gegen Feuer, Gefahr und Schaden, auf die Vergänglichkeit des Lebens, auf den Beistand Gottes und auf ein seliges Ende.

\section{(1-B) Exemplar des Himmelsbriefes Gredoria aus Rio Grande do Sul}

Eine weitere Version des Himmelsbriefes, auch als Gredoria bezeichnet, befand sich unter pommerschen Nachkommen in Pelotas (RS) 2457 (H-RS). Der Inhalt des Briefes lautet:

(Gebete wie 1-A, aber in geänderter Reihenfolge)

\footnotetext{
2455 Schlegel, Birgit. Glaube und Magie gegen die Gefahren des Krieges in Schutzbriefen. In: Zeitschrift für Regionale Forschung und Heimatpflege - Südniedersachsen, 34. Jahrgang, 3/September 2006, S. 65. 2456 Stübe, Der Himmelsbrief, S. 7.

2457 Himmels-Brief, wird genannt Credoria. Ohne Angabe des Druckers. 1 Blatt, 2 Seiten. In: Maltzahn, S. 141f. Da es sich um eine Fotografie handelt, sind die Blattmaße nicht genau festzustellen.
} 

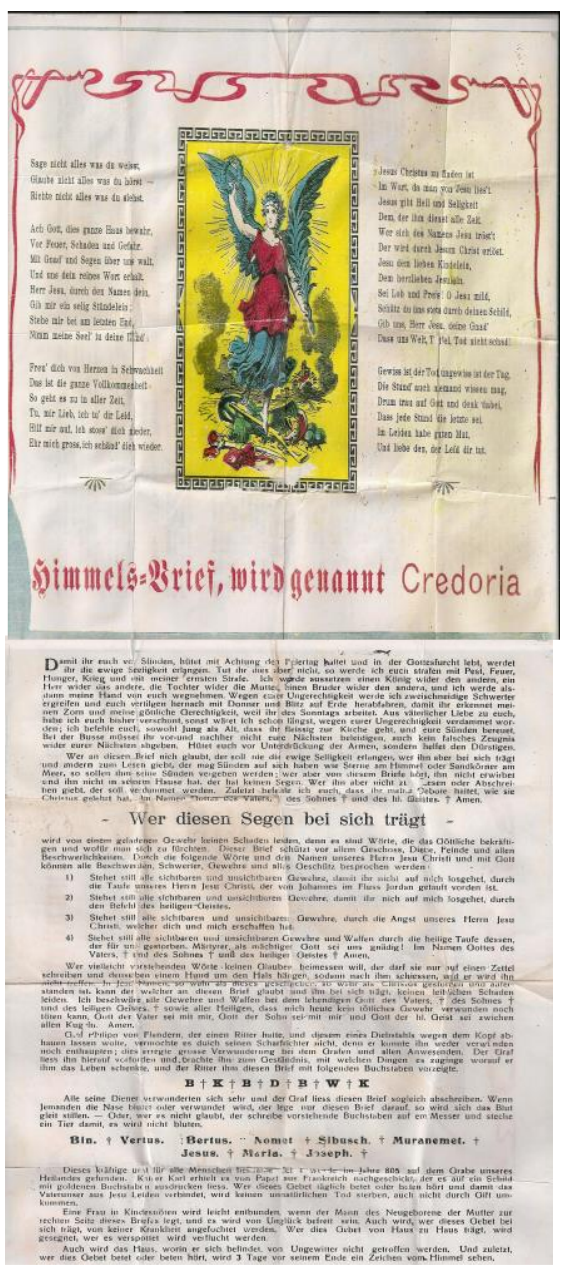

Abb. 40 und 41: Himmels-Brief Credoria, Exemplar pommerscher Nachkommen in Pelotas (RS). Quelle: Maltzahn, S. $141 f$.
„Damit ibr euch vor Sünden bütet mit Achtung den Feiertag haltet und in der Gottesfurcht lebt, werdet ihr die ewige Seeligkeit*2458 erlangen. Tut ibr dies aber nicht, so werde ich euch strafen mit Pest, Feuer, Hunger, Krieg und mit meiner ernsten Strafe. Ich werde aussetzen einen König wider den andern, ein Herr wider das andere, die Tochter wider die Mutter, einen Bruder wider den andern, und ich werde alsdann meine Hand von euch wegnehmen. Wegen euer Ungerechtigkeit werde ich zweischneidige Schwerter ergreifen und euch vertilgen bernach mit Donner und Blitz auf Erde* herabfabren, damit ihr erkennet meinen Zorn und meine göttliche Gerechtigkeit, weil ibr des Sonntags arbeitet. Aus väterlicher Liebe zu euch, habe ich euch bisher verschont, sonst wäret ich schon längst, wegen eurer Ungerechtigkeit verdammet worden; ich befehle euch, sowobl Jung als Alt, dass ibr fleissig zur Kirche geht, und eure Sünden bereuet. Bei der Busse müsset ihr vor- und nachber nicht eure Nächsten beleidigen, auch kein falsches Zeugnis wider eurer Nächsten abgeben. Hütet euch vor Unterdrückung der Armen, sondern helfet den Dürstigen.

Wer an diesen Brief nicht glaubt, der soll nie die ewige Selligkeit* erlangen, wer ibn aber bei sich trägt und andern zum Lesen gebt*, der mag Sünden auf sich haben wie Sterne am Himmel oder Sandkörner am Meer, so sollen ihm seine Sünden vergeben werden; wer aber von diesem Briefe hört, ihn nicht erwirbet und

ibn nicht in seinem Hause hat, der hat keinen Segen. Wer ibn aber nicht zu Lesen oder Abschreiben giebt, der soll verdammet werden. Zuletzt befeble ich euch, dass ihr meine Gebote haltet, wie sie Christus gelehrt hat. Im Namen Gottes des Vaters †, des Sohnes + und des hl. Geistes † Amen.

Wer diesen Segen bei sich trägt -

wird von einem geladenen Gewehr keinen Schaden leiden, denn es sind Wörte*, die das Göttliche bekräftigen und wofür man sich zu fürchten. Dieser Brief schützt vor allem 
Geschoss, Diebe, Feinde und allen Beschwerlichkeiten. Durch die folgende Wörte* und den Namen unseres Herrn Jesu Christi und mit Gott können alle Beschwerden, Schwerter, Gewehre und alles Geschütz besprochen werden;

1) Stehet still alle sichtbaren und unsichtbaren Gewehre, damit ibr nicht auf mich losgeht, durch die Taufe unseres Herrn Jesu Christi, der vom Johannes im Fluss Jordan getauft worden ist.

2) Stehet still alle sichtbaren und unsichtbaren Gewehre, damit ibr nicht auf mich losgeht, durch den Befehl des heiligen Geistes.

3) Stehet still alle sichtbaren und unsichtbaren Gewehre, durch die Angst unseres Herrn Jesu Christi, welcher dich und mich erschaffen hat.

4) Stehet still alle sichtbaren und unsichtbaren Gewebre und Waffen durch die heilige Taufe dessen, der für uns gestorben. Märtyrer, als mächtiger Gott sei uns gnädig! Im Namen Gottes des Vaters, † und des Sohnes † und des heiligen Geistes † Amen.

Wer vielleicht vorstehenden Wörte* keinen Glauben beimessen will, der darf sie nur auf einen Zettel schreiben und denselben einem Hund um den Hals hängen, sodann nach ihm schiessen, und er wird ihn nicht treffen. In Jesu Namen, so wahr als dieses geschrieber* so wahr als Christus gestorben und auferstanden ist, kann der welcher an diesen Brief glaubt und ihn bei sich trägt, keinen leiblichen Schaden leiden. Ich beschwöre alle Gewehre und Waffen bei dem lebendigen Gott des Vaters, † des Sohnes † und des heiligen Geistes † sowie aller Heiligen, dass mich heute kein tödliches Gewehr verwunden noch töten kann. Gott der Vater sei mit mir, Gott der Sohn sei mit mir und Gott der bl. Geist sei zwischen allen Kugeln. Amen.

Graf Philipp von Flandern, der einen Ritter hatte, und diesem eines Diebstahls wegen dem Kopf abhauen lassen wollte, vermochte es durch seinen Scharfrichter nicht, denn er konnte ihn weder verwunden noch enthaupten; dies erregte grosse Verwunderung bei dem Grafen und allen Anwesenden. Der Graf liess ibn hierauf vorforden ${ }^{2459}$ und brachte ibn zum Geständnis, mit welchen Dingen es zuginge worauf er ihm das Leben schenkte, und der Ritter ihm diesen Brief mit folgenden Buchstaben vorzeigte

\section{$B+K+B+D+B+W+K$}

Alle seine Diener verwunderten sich sehr und der Graf liess diesen Brief sogleich abschreiben. Wenn Jemanden die Nase blutet oder verwundet wird, der lege nur diesen Brief darauf, so wird sich das Blut gleit 2460 stillen. - Oder, wer es nicht glaubt, der schreibe vorstehende Buchstaben auf em ${ }^{2461}$ Messer und steche ein Tier, es wird nicht bluten.

Bin. † Vertus. † Bertus. † Nomet † Sibusch. † Muranemet. $f$ Jesus. † Maria. † Joseph. +

Dieses* kräftige und für alle Menschen beilsame Brief wurde im Jabre 805 auf dem Grabe unseres Heilandes gefunden. Kaiser Karl erbielt es von Papst aus Frankreich nachgeschickt, der es auf ein Schild mit goldenen Buchstaben ausdrucken liess. Wer die-

\footnotetext{
${ }^{2459}$ Es konnte nicht festgestellt werden, was hier gemeint ist.

2460 "gleich".

2461 "einem".
} 
ses Gebet täglich betet oder beten hört und damit das Vaterunser aus Jesu Leiden verbindet, wird keinen unnatürlichen Tod sterben, auch nicht durch Gift umkommen. Eine Frau in Kindesnöten wird leicht entbunden, wenn der Mann des Neugeborene* der Mutter zur rechten Seite dieses Briefes legt, und es wird von Unglück befreit sein. Auch wird, wer dieses Gebet bei sich trägt, von keiner Krankheit angefochtet werden. Wer dies Gebet von Haus zu Haus trägt, wird gesegnet, wer es verspottet wird verflucht werden. Auch wird das Haus, worin er sich befindet, von Ungewitter nicht getroffen werden. Und zuletzt, wer dies Gebet betet oder beten hört, wird 3 Tage vor seinem Ende ein Zeichen vom Himmel sehen".

Auf dem Bild dieses Exemplars trägt der Engel eine Lorbeerkrone auf dem Kopf, hält in der linken Hand einen grünen Zweig, in der rechten einen grünen Kranz und steht auf einen Haufen Waffen (ein Schwert, eine Flinte, einen Helm, ein Kriegswagenrad, eine Kanone und Kanonenkugeln und eine Tasche für Waffenausrüstung). Im Hintergrund stehen Häuser. In den Abb. 40 und 41 (siehe S. 415) können Zeichen erkannt werden, die darauf hindeuten, dass der Brief dreimal gefaltet wurde. Er befand sich im Besitz pommerscher Nachkommen in Pelotas (RS) und wurde von Maltzahn fotografiert. Auch von dieser Version gibt es eine portugiesische Übersetzung. ${ }^{2462}$

Der erste Teil des H-RS enthält ähnliche Elemente wie das H-ES. Die NichtErfüllung von Geboten und moralischen Forderungen zogen Pest, Feuer, Hunger, Krieg und ernsthafte Strafen nach sich. Hinzu fügt H-RS die Entzweiungen um Jesu willen nach dem biblischen Text von Mt. 10,35 (,ich werde aussetzen einen König wider den andern, ein Herr wider das andere, die Tochter wider die Mutter, einen Bruder wider den andern") und den trinitarischen Schluss ,im Namen des Vaters, des Sobnes und des Heiligen Geistes" mit der entsprechenden Bekreuzigung, wie das Symbol des Kreuzes $(\dagger)$ es in mehreren Teilen des Briefes darstellt. Möglicherweise bekreuzigten sich die Menschen, wenn sie diesen Brief lasen oder beteten, wie im Fall von Besprechungsformeln. Zum Schluss kommt die Forderung, den Brief täglich zusammen mit dem Vaterunser zu beten oder anzuhören, um an keinem unnatürlichen Tod oder durch Gift zu sterben. Außerdem bietet der Brief Schutz gegen Unwetter, der schnellen Stillung von Nasenbluten, eine leichte Entbindung und ein Zeichen des Himmels, drei Tage vor dem Tod. Wer ihn bei sich trug, anderen zum Lesen gab und „von Haus zu Haus" trug, dem sollte seine Sünden vergeben und er selbst gesegnet werden. Der Himmelsbrief besaß nur Wirksamkeit, wenn Menschen an seine Wirkung glaubten, wer nicht daran glaubte, ihn nicht erwarb, las oder zum Abschreiben weiter gab wurde mit Verdammnis und Fluch bedroht. Das löste Angst aus und sorgte gleichzeitig für seine Verbreitung. Der Schutz gegen Waffen spielte besonders in den ersten Siedlungsjahren eine Rolle, angesichts der Angriffe indigener Völker, bei Aufständen (Muckerbewegung in Rio

2462 Mensagen (carta) celeste, chamada Credo. Ohne Angabe des Druckers. Fotografie. 1 Blatt, 2 Seiten. In: Maltzahn, S. $143 \mathrm{f}$. 
Grande do Sul: 1868-1874), Revolutionen (Farrapenkrieg: 1835-1845 und Föderalistische Revolution: 1893-1895, beide auch in Rio Grande do Sul) und Kriegen (gegen die Argentinischen Provinzen: 1825-1828, Uruguay: 1864-1865 und Paraguay: 1864-1870), wo einige Einwanderer als Soldaten mitkämpfen oder Truppen den Siedlern Schaden zufügten. Womöglich dienten Himmelsbriefe auch während des Ersten und Zweiten Weltkrieges als Schutz gegen Angriffe der aufgehetzten Bevölkerung gegen Deutsche und Deutschbrasilianer und wurden angeblich auch von Soldaten bei sich getragen.

Im H-RS können zwei religionsgeschichtliche Entwicklungen, die die Wirkungskraft von Himmelsbriefen kennzeichneten, erkannt werden: Der Glaube an die Zauberkraft eines Textes oder Wortes und die magische Verwendung sinnloser erscheinender Buchstaben, Silben oder Worte, denen Wirksamkeit zugesprochen wurde und die angeblich der Seele einen Schlüssel zum Himmelstor gewähren sollten. ${ }^{2463}$ Dies verband sich mit dem Seelen- und Jenseitsglauben und den Heilshoffnungen der Menschen, was besonders in ihrem von Krankheiten, Gefahren und Ängste geprägten Dasein Bedeutung gewann. Zudem vermischt der Brief biblische Aussagen und die trinitarische Formel mit magisch-heidnischen Texten, wie Amulette, Bann- und Beschwörungsformeln, Blut- und Tiersegen, kryptische Buchstaben, Tierprobe und Zaubersprüchen. ${ }^{2464}$ Es handelt sich hierbei um eine Zusammensetzung ursprünglich unabhängiger Textstücke, die mit einer Einleitung, die eine Beschwörungsformel oder eine Erzählung enthält, versehen sind. Hier wird die erste Anwendung (beziehungsweise der Ursprung des Spruches) und ihre Wirkungsart (Formel) erklärt. Hinzu kommt ein historischer Teil mit einem Bericht über die Herkunft, den Fundort und die Fundzeit der unabhängigen Stücke. ${ }^{2465}$ Die verschiedenen Segen und Beschwörungsformeln umfassen Elemente der antiken Volksreligionen, die in der Zauberliteratur des Altertums auftreten, mittelalterliche und altgermanische Zauberformeln und christliche Traditionen, die zu Beginn der Neuzeit hinzugekommen sind.2466 Diese Elemente bringen das H-RS mit dem Holsteintypus in Verbindung. Daher sollte er eher als ein solches behandelt werden, obwohl er als Gredoriatypus überliefert wurde.

Der Holstein-Himmelsbrief trat um 1724 als Waffensegen ${ }^{2467}$ auf. Seine erste Abschrift stammt aus dem Jahre 1791 und er erwähnt Ortsnamen aus Holstein und

\footnotetext{
2463 Stübe, Der Himmelsbrief, S. 28f, 45-47.

2464 Zaubersprüche auf Papyrusblätter mit magischen Zeichen und Sprüchen wurden schon früh als Amulette gegen alle Art Gefahren getragen oder angebracht. Auch das Christentum sprach den Briefen von Heiligen eine gewisse Zauberkraft zu. Dieterich, S. 11. Segenssprüchen, Bann- und Zauberformel im Himmelsbrief finden nach Becker und Nail Parallel zum 10., 11. und 12. Buch Moses. Beckert; Nail, S. 129.

${ }^{2465}$ Stübe, Der Himmelsbrief, S. 6f.

2466 Magisch-sympathetischer Hausschatz, S. 174.

2467 Vgl. Waffensegen. In: Magisch-sympathetischer Hausschatz, S. 176-178; Kugel Abweichung und Eine Versicherung vor Schießen, Hauen und Stechen im Romanus-Büchlein oder Gott der Herr bewabre meine Seele,
} 
Nordwestdeutschland, daher seine Bezeichnung. Er wurde besonders in Kriegen verwendet und als „Himmelsbrief des Ersten Weltkrieges" bezeichnet. 2468 Weil er Schutz- und Segenssprüche, Verheißungen des Gredoriatypus mit einigen Variationen mit älteren und teilweise autarken Zauberformeln mit unabhängigen Sprüchen und biblischen Texten verbindet, kann es leicht zu einer Verwechslung mit dem Gredoriatypus kommen. Die unabhängigen Teile sollen kurz untersucht werden:

a) Das Grafamulett oder der Graf Philipp-Segen ist ursprünglich ein Waffensegen mit einem Buchstaben-Amulett zum Schutz vor Wunden, der von reisenden Handwerkern als Schutzmittel auf Wanderungen getragen wurde. Seine Herkunft lässt sich bis ins 15. Jahrhundert zurückverfolgen. Er trat erstmals 1523 und 1546 in Zusammenhang mit dem Himmelsbrief und in einem Flugblatt aus Köln 1604 auf. Der Legende nach ordnete Graf Philipp (oder Heinrich) ${ }^{2469}$ von Flandern die Enthauptung eines seiner Knechten an, diese scheiterte jedoch, weil er einen einzigartigen Schutz besaß. Der Graf versprach sein Leben zu schonen, wenn er ihm dieses Geheimnis offenbaren würde. So zeigte der Knecht ihn einen Zettel mit sinnlosen Zahlen und Buchstaben, wie sie im H-RS zusammen mit der Legende deutlich erkennbar ist, der eine magische Wirkung besitzen haben sollte und den Besitzern Unverwundbarkeit, Blutstillung, Schutz vor Naturgewalten und übler Nachrede und eine leichte Entbindung für Frauen zusicherte. Hierbei handelte es sich um spätere Zusätze zum ursprünglichen Schutz gegen Waffen ${ }^{2470}$;

b) Der Ölbergspruch ist ein weiterer Waffensegen oder Schutzspruch gegen Schwerter und Schusswaffen nach der Formel: „So wie Christus im Ölgarten stille stand, so sollen alle Geschütze stille stehen "2471 Zum alten Spruch gehörten Anweisungen, wie die Kraft des Briefes erproben werden könnte: Man sollte ihn an einem Hund anbinden und auf diesen schießen oder die Formel auf einen Degen oder Gewehr schreiben und ein Tier damit stechen. Hinzu werden Namen aus Zauberbücher (Bertus, Nomet, Sibusch, Muranemet) und die heilige Familie (Jesus, Maria,

\footnotetext{
meinen Aus- und Eingang. Leipzig: Hülsemann, [um 1880], S. 28, 34f. Das Romanus-Büchlein gehört zur magischen Literatur und enthält Bann-, Segen-, Beschwörungs- und Bittformeln.

2468 Stübe, Holsteiner-Typus. In: Hoffman-Krayer, E.; Bächtold-Stäubli, Hanns (Hrsg.) Handwörterbuch des Deutschen Aberglaubens. Band IV. Berlin/Leipzig: Walter de Gruyter, 1931/1932, S. 261; Stübe, Himmelsbrief, S. 21f; Stübe, Der Himmelsbrief, S. 7f, 10.

${ }^{2469}$ Stübe, Schutzbrief. In: Hoffman-Krayer, E.; Bächtold-Stäubli, Hanns (Hrsg.) Handwörterbuch des Deutschen Aberglaubens. Band VIII. Berlin/Leipzig: Walter de Gruyter, 1935/1936, S. 1385. In einem pommerschen Himmelsbrief trat der Namen Philipp Plometrin auf. Dieterich, S. 11.

2470 Stübe, Der Himmelsbrief, S. 8f; Stübe, Grafenamullet. In: Hoffman-Krayer, E.; Bächtold-Stäubli, Hanns (Hrsg.) Handwörterbuch des Deutschen Aberglaubens. Band III. Berlin/Leipzig: Walter de Gruyter, 1930/1931, S. 1111f.

${ }^{2471}$ Der Volksglaube besagte, dass die von Mönchen mitgebrachten Kräuter vom Ölberg und vom Kalvarienberg Zauberkräfte besaßen, zum Beispiel gegen Gicht. Stübe, Oelbergspruch In: HoffmanKrayer, E.; Bächtold-Stäubli, Hanns (Hrsg.) Handwörterbuch des Deutschen Aberglaubens. Band VI. Berlin/Leipzig: Walter de Gruyter, 1934/1935, S. 1246f; Stübe, Der Himmelsbrief, S. 8.
} 
Joseph) zitiert. ${ }^{2472}$ Einige Versionen, wie es bei H-RS der Fall ist, enthalten das Beispiel der Taufe Jesu in Zusammenhang mit dem Stillstand der Waffen und des Wassers;

c) Ein unabhängiger Teil, der in mittelalterlichen Zauberbüchern, beispielsweise im Colomanus-Büchlein erscheint, sollte „von Gott dem Abt Colomanus für seinen Vater, den König von Iberia, gesandt ${ }^{` 2473}$ worden sein. Der König glaubte zunächst nicht an die Schutzkraft des Briefes, weswegen er dessen Macht erstmal an einem Verbrecher erprobte, dem daraufhin weder Schwert noch Feuer und Gift schaden konnten. Als er dies sah, ordnete er die Vervielfältigung des Briefes an. Papst Leo III. schickte eine dieser Kopien an Kaiser Karl den Großen (768-814), der den Inhalt des Briefes auf einen Schild mit goldenen Buchstaben malen ließ. So entstand das Gebet Kaiser Karls des Großen. Nach einer anderen Fassung aus dem 15. oder 16. Jahrhundert aus Brieg (heute Brzeg, Polen) wurde der Kaiser-Karl-Segen vom Himmel durch Papst Leo III. an Kaiser Karl gesandt. Er sollte gegen Teufel, Feinde, Feuer, Wasser, Fieber, Diebe, Räuber, Gespenster, falsche Anklagen, das Hegen böser Gesinnung und böse Geister schützen. Papst Leo sandte seinem Bruder Carolo ein ähnliches Gebet in einem katholischen Erbauungsbuch. ${ }^{2474}$

Die Untersuchung der selbstständigen Stücke führt zu einem Vergleich des H-RS mit einem Exemplar des Himmelsbriefes aus Engelrod (H-Eng) ${ }^{2475}$, das Dieterich in den Blätter für Hessische Volkskunde 1901 veröffentlichte. Folgende Unterschiede fallen auf: a) H-Eng beginnt mit dem Grafamulett. Die magischen Buchstaben sind jedoch verschieden (B. J. H. K. h. h. R. St. K.) und der Graf selbst ordnete das Bei-sich-tragen des Briefes an. Der H-Eng knüpft die Blutstillung, die Heilung von Wunden und den Schutz im Krieg an die fünf Wunden Christi: K. h. s. G. K. ${ }^{2476}$, die die Namen der heiligen Familie und der Zauberbücher im H-RS ersetzten. Diese Wunden sicherten zu, dass kein falsches Urteil über die Person fällt. Der Satz endet mit den Buchstaben h.h.s.s. Danach folgt der Ölbergspruch in abgekürzter Form, den Schutz gegen Waffen und den Bericht über die Erscheinung des Briefes 1724 in Holstein, wo er ,über der Taufe in Rädergau“"schwebte und sich 1791 abschreiben ließ. Erst dann kommen die Forderung der Sonntagsheilung, die im Vergleich zu H-RS erweitert wurden, biblische und moralische

2472 Vgl. mit einem Himmelsbrief, der aus einem flandrischen Lazarett nach dem Ersten Weltkrieg ins Marburger Wirtshaus an der Lahn gelangte. Hier werden die Namen aus Zauberbücher anders angegeben: Bartus, Siebersch, Miroment. Nomet fehlt. Beckert; Nail, S. 116-120.

2473 Stübe, Karl-Segen (Kaiser) In: Hoffman-Krayer, E.; Bächtold-Stäubli, Hanns (Hrsg.) Handwörterbuch des Deutschen Aberglaubens. Band IV. Berlin/Leipzig: Walter de Gruyter, 1931/1932, S. $1006 f$.

2474 Stübe, Der Himmelsbrief, S. 9; Stübe, Karl-Segen (Kaiser), S. $1006 f$.

2475 Himmelsbrief. In: Dieterich, S. 9f.

${ }^{2476}$ Es konnte nicht festgestellt werden, um welche Wunden es sich genau handelt. Jedoch als Wunder Christi werden in den heiligen sieben Himmelsriegel die Fesselung Jesu mit Stricken, die Geißelung, die Dornenkrone, welche ihn auf den Kopf drückte, die Wunden an den Schultern aufgrund des Kreuztragens und die drei stündige Kreuzigung erwähnt. Die heiligen sieben Himmelsriegel welche ein frommer Einsiedler von seinem Schutzengel bekommen hat. Mit Bewilligung einer hohen Geistlichkeit aufs Neue zum Druck befördert zu Cöln am Rhein. In: Magisch-sympathetischer Hausschatz, S. 199-201. 
Gebote und die Aussprache von Drohungen gegen diejenigen, die dem Brief widersprechen und ihn nicht offenbaren. Das Kaiser Karl Gebet fällt aus. Im H-RS beginnt der Brief mit den moralischen Forderungen und Drohungen, die vom Ölbergspruch, vom Grafamulett und vom Kaiser Karl Gebet in dieser Reihenfolge gefolgt werden. Der Bericht über den Erscheinungsort entfällt, dafür wurde er auf dem Grab Jesu im Jahre 805 gefunden; b) H-Eng bietet einen besseren Schutz an als „Geld, Haus und Schutzbrief" und erwähnt, dass Jesus Christus selbst den Brief geschrieben hat, was seine Glaubwürdigkeit und Heiligkeit stärkte. Das kommt im H-RS nicht vor; c) im H-RS sollen die Menschen, die den Brief beten oder hören drei Tage vor ihrem Tod ein Zeichen vom Himmel bekommen. Sie sollen auch keinen unnatürlichen Tod sterben. Das wird im H-Eng nicht erwähnt; d) im H-RS sollen diejenigen, die nicht an den Brief glauben, ihn nicht lesen oder nicht zum Abschreiben weiter geben nie die ewige Seligkeit erlangen, im H-Eng sollen sie sterben und ihre Kinder einen bösen Tod erfahren, zudem sollen sie von der christlichen Kirche verflucht werden; e) im H-RS taucht die Forderung auf, den Brief zusammen mit dem Vaterunser zu beten, was die Bedeutung des Briefes als Gebet stärkt und ihn nach der Ansicht der Menschen nicht im Widerspruch mit ihrem kirchlichen Glauben sehen ließ. Das ist im H-Eng nicht der Fall; f) H-Eng erwähnt, dass die Gebote durch den Engel Gottes gesandt wurden. Obwohl H-RS die Abbildung des Erzengels Michael darstellt, wird er im Text nicht explizit erwähnt.

\section{(2) Exemplar des Himmelsbriefes aus Santa Catarina}

Unter pommerschen Nachkommen in Santa Catarina wurde ein weiteres Exemplar des Himmelsbriefes gefunden, der Pastor Nelso Weingärtner gegeben wurde. ${ }^{2477}$ Es lautet:

2477 Himmelsbrief. Ohne Angabe des Druckers. DIN A4, 2 Blätter, 3 Seiten. Privatarchiv von Pastor Nelso Weingärtner. 


$\dagger$
$Z$
$\dagger$
$D$
$I$
$A$
$B+Z+H G+F+B F R S$
$B$
$J$
$Z$
$\dagger$
$S$
$A$

„Kraft und Wirkung dieser Buchstaben

Es soll kein Haus sein, in welchem diese Buchstaben nicht gefunden werden. Wenn ibr diese Zeilen öfter zur Hand nehmet und die Segnungen und Gebeten [... ${ }^{* 2478}$ zeitlichen und ewigen Heiles willen und mit grösster Andacht betet, so werdet ibr nicht durch Krankheit heimgesucht, und werdet von eurer Krankheit befreit.

+ Das Kreuz Christi heile mich

$Z$ Der Eifer Deines Hauses, o Herr! befreit ${ }^{479}$ mich von allen Uebeln.

+ Das Kreuz Christi überwindet, das Kreuz herrschet, das Kreuz gebietet; durch das Zeichen des Kreuzes befreie mich, o Herr! von aller Krankheit.

$\boldsymbol{D}$ Gott, o mein Gott, vertreibe jede Krankheit von mir und von diesem Orte und befreie mich.

I In deine Hände, o Herr! empfeble ich meinen Geist, mein Herz und meinen Leib.

$\boldsymbol{A}$ Bevor Himmel und Erde war, war schon Gott, und Gott ist mächtig und stark, mich zu befreien von aller Krankheit.

+ Das Kreuz. Christi ist mächtig und stark, zu vertreiben alle Krankheiten von diesem Orte und von meinem Leibe.

$\boldsymbol{B}$ Die Hilfe Gottes ist gütigst bereit, jede Krankheit zu vertreiben von mir.

$\boldsymbol{J}$ Mein Herz beugt sich vor Deinem gerechten Angesichte, o Herr! auf dass ich nicht zu Schanden werde, während ich zu Dir rufe.

$Z \quad I c h$ habe gesehen den unbeständigen Frieden der Sünder, und habe dagegen geeifert und auf den Herrn gehofft.

+ Vor dem Kreuze Christi fliehen die Teufel, die Luft wird gereinigt und die Krankbeit vertrieben.

$\boldsymbol{S} \quad$ Ich bin Dein Heil spricht der Herr, rufe zu mir, und ich erhöre und befreie Dich von aller Krankheit.

$\boldsymbol{A}$ Die Tiefe hat zu dem Abgrunde gerufen, und Deine Stimme, o Herr! hat die Teufel vertrieben, befreie mich auch von allem Uebel und von jeder Krankheit.

2478 *unlesbar / vielleicht „euers“, wie in Romanus-Bücblein, S. 44.

2479 Im Romanus-Bücblein steht "befreiet". 
$\boldsymbol{B}$ Selig ist, der auf den Herrn hofft und nicht zurück blickt auf die Eitelkeiten und verderblichen Falschbeiten ${ }^{2480}$ der Welt.

+ Das Kreuz Christi, welches vorher in Schmach und Verachtung war, das jetzt2481 in Ruhm und Ansehen ist, gereicht2482 mir zum Heile, vertreibe den Teufel von diesem Orte und die verpestete Luft und jede Krankheit von meinem Leibe.

$\boldsymbol{Z}$ Der Eifer der Ehre Gottes bekehre mich bevor ich sterbe und in Deinem Namen heile mich, o Herr! von jeder Krankheit.

+ Das Zeichen des Kreuzes befreit das Volk Gottes und diejenigen von der Krankbeit, die auf den Herrn ihr Vertrauen setzen.

$\boldsymbol{H} V$ ertilgst2483 du, o törichtes ${ }^{2484}$ Volk, die Güte des Herrn mit Undank ${ }^{2485}$, bezable dein ${ }^{2486}$ Gelübde und biete dar das Opfer des Rubmes ${ }^{2487}$ und der Treue, denn der Herr ist mächtig und stark diesen Ort und mich zu befreien von aller Krankheit, denn ich weiss, dass diejenigen die auf den Herrn hoffen nicht zu Schanden werden.

$\boldsymbol{G}$ Wenn ich Dich, o Herr? ${ }^{488}$ nicht benedeien werde, so beftet sich meine Rede an meinem Halse und Schlunde an. Befreie auch mich von aller Krankheit und jeden Ort2489 von allem Uebel, in welchem Dein Namen angerufen wird.

$\boldsymbol{F} \quad$ Zur Stunde Deines Todes, o Herr mein Gott? ${ }^{490}$ ist über den ganzen Erdkreis eine Finsternis geworden, es wurde aber dadurch verfinstert und hinweggenommen die Macht des Teufels, weil der Sohn des lebendigen Gottes dazu gekommen ist, das er auflöse die Werke des Satans und vertreibe die Macht von allen Orten und von mir und jede Krankheit.

+ Das Kreuz Christi verteidige 2491 uns und vertreibe jede Krankheit, es befreie diesen Ort und alle Deine Diener, o Gott2492 von allem Uebel, weil Du, o Herr! überaus gütigst und barmherig bist und wahrhaftig sind Deine grossen Erbarmungen.

$\boldsymbol{B}$ Selig ist, der nicht zurück blickt auf die Eitelkeiten und verderbliche Falschbeiten ${ }^{2493}$ der Welt, denn von ${ }^{2494}$ bösen Tagen wird ihn der Herr befreien. O Herr! ${ }^{2495}$ habe ich von jeher gehofft, befreie mich von jeder Krankheit.

\footnotetext{
2480 Im Romanus-Büchlein steht: ,verderbliche Falschbeit“.

${ }^{2481}$ Im Romanus-Büchlein wird hier ,aber"hinzugefügt.

2482 Im Romanus-Büchlein steht: ,gereiche“.

2483 Im Romanus-Büchlein steht: „V ergiltst“.

2484 Im Romanus-Büchlein steht: „thörichtes“.

2485 Im Romanus-Büchlein steht hier ein ,?"“

2486 Im Romanus-Büchlein steht: ,deine“.

2487 Im Romanus-Büchlein steht: „Rubms“.

2488 Im Romanus-Büchlein steht kein ,,!“ sondern ,„;“.

${ }^{2489}$ Im Romanus-Büchlein steht ein Komma vor und nach „in jeden Ort".

2490 Im Romanus-Büchlein steht: „o Herr und mein Gott;“

${ }^{2491}$ Im Romanus-Büchlein steht: ,vertheidigt“"

${ }^{2492}$ Im Romanus-Büchlein steht: ,,!“.

2493 Im Romanus-Büchlein steht: „Falschbeit“.

2494 Im Romanus-Büchlein steht: ,am“.

2495 Im Romanus-Büchlein steht hier: ,auf dich“.
} 


\begin{abstract}
F Der Herr ist meine Zuflucht geworden, weil ich auf ihn gehofft habe, befreie mich, o Gott! von aller Krankheit.

$\boldsymbol{R}$ Blicke zurück auf mich, o Herr und mein Gott Adonay! von dem heiligen Throne Deiner Majestät und erbarme Dich meiner. ${ }^{2496}$ Befreie mich durch Deine Barmberzigkeit von aller Krankheit.

$\boldsymbol{S}$ Du o Herr! bist mein Heil, beile mich, und ich werde geheilt werden; mache mich gesund, und ich werde gesund sein. Es geschehe.

Wer diesen Himmelsbrief abschreibt, der soll drei Tage vorher fasten und drei mal den Himmelssegen beten, damit ihn Gott im Himmel erhört, damit auch das Glück und der Segen ins Haus und zu dem Kranken kommt, und derselbe geheilt wird. Also schreibe ibn keiner ab, der dies nicht tut".
\end{abstract}

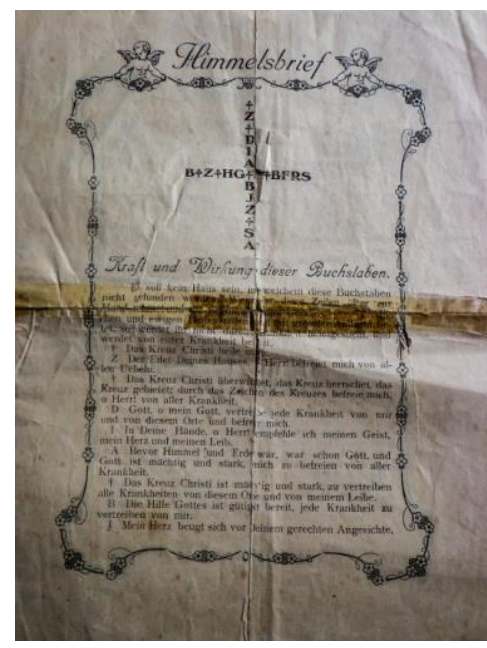

Abb. 42: Himmelsbrief. Quelle: Privatarchiv von Pastor Nelso Weingärtner.

Falten und andere Zeichen häufiger Verwendung sind in Abb. 42 deutlich zu erkennen. Im Romanus-Büchlein ${ }^{2497}$ taucht dieser Himmelsbrief als Segen neben anderen Gebeten und Segen zum Schutz gegen Feuer, Hexerei, Diebe, Feinde, Waffen usw. auf. Folgende Unterschiede können bei einem Vergleich dieses Exemplars aus Santa Catarina (H-SC) mit dem Segen im Romanus-Büchlein (S-RB) erkannt werden: a) im H-SC sowie im S-RB steht eine Form aus heiligen beziehungsweise magischen Buchstaben in Kreuzformat. Jeder Buchstabe und jedes Kreuz hat eine Bedeutung, die im Text erklärt wird. Nur für ein $\dagger$ zwischen den Buchstaben , $G$ “ und „F“, wie es in der Form innerhalb der horizontalen Linie des Kreuzes steht, fehlt im Text beider Exemplare die entsprechende Erklärung. Im H-SC ist der Brief aber von Blumen und auf der ersten Seite von zwei Engelchen umrahmt, was im S-RB nicht der Fall ist. Während die Darstellung des Erzengels Michael in den ersten Exemplaren (H-ES und H-RS) eine große Rolle spielte, verliert der Engel im H-SC und im S-RB an Bedeutung. Hier steht das Kreuz in Vordergrund; b) im H-SC fehlt die Erklärung über die Erscheinung des Briefes, die jedoch im S-RB vorkommt. Der Legende nach herrschte im Jahre 1546 die Pest und den Priestern, die im Konzil in Trient (1545-1563) versammelt waren, wurde auf anhaltendes und eifriges Gebet diese mysteriösen Buchstaben offenbart. Wer sie bei sich trug oder sie in Kreuzform an der Türschwelle seines Hauses schrieb, sollte von jeder Krankheit befreit werden. Sofort wurden die Menschen von der Pest befreit. Nach der Forderung, - es soll

\footnotetext{
2496 Im Romanus-Büchlein steht: ,,; befreie“.

2497 Romanus-Büchlein, S. 44-47.
} 
kein Haus sein, in dem „diese Buchstaben nicht gefunden werden “- wird berichtet, dass ein unbekannter Autor sie ins Deutsche übersetzte und erklärte, dass Menschen in Notzeiten oder sonst noch sie andächtig beten sollten. ${ }^{2498}$ Bei H-SC knüpft aber das Beten solcher Buchstaben an Heilung von und Schutz vor Krankheiten an; c) im S-RB fehlt der Schluss mit der Forderung, den Brief erst nach drei Tagen Fasten und dreimal Beten des Himmelssegens abzuschreiben, beziehungsweise erst nach einem Heiligungs- und Reinigungsritual. Das entsprach teilweise denselben Bedingungen, wie sie an Besprechungspersonen gestellt wurden, die bestimmte moralische Eigenschaften aufweisen mussten und als geweihte Menschen galten. ${ }^{2499}$ Anstatt dieses Schlusses kommt im S-RB ein Gebet vor, das auf die Vergebung nach aufrichtigem Beichten der Sünden und auf die Barmherzigkeit Gottes hinweist. ${ }^{2500}$

Auffällig ist im H-SC das Fehlen der Forderung der Sonntagsheiligung und anderer gesetzlich-moralischer Gebote, auch fehlen die Drohungen gegen die Ungehorsamen, Unbußfertigen und Ungläubigen sowie eine Erzählung über die Herkunft und die Erscheinung des Briefes, typische Merkmale der Himmelsbriefen. Aber in Brasilien wurde er als ein solcher überliefert und als Schutz gegen Gefahren und Krankheiten wie alle andere Himmelsbriefe verwendet. Der Schwerpunkt liegt hier auf der Heilung von allen Krankheiten und Befreiung von Übel und Pest durch die Macht des Kreuzes Christi. Auch die Todesstunde Jesu wird hervorgehoben, durch welche die Macht des Teufels, die Werke Satans und alle Krankheiten hinweg genommen werden sollten. Die ihm zugesprochenen Macht zur Heilung und zum Schutz gegen Krankheiten spielte für die Einwanderer und deren Nachkommen im brasilianischen Urwald, wo sie in der Regel keinen Zugang zu medizinischer Versorgung hatten, eine wesentliche Rolle. Sie glaubten, allein der Besitz dieses Briefes schütze sie vor Krankheiten. Einige Sätze erinnern oder leiten sich von biblischen Texte ab, unter anderem „Bevor Himmel und Erde war, war schon Gott" (Joh. 1,1), „rufe zu mir und ich erhöre und befreie dich" (Ps. 50,15), „bezable den Gelübte und biete dar das Opfer des Rubmes und der Treue" (5 Mos. 12,11), „Zur Stunde Deines Todes (...) ist über den ganzen Erdkreis eine Finsternis geworden" (Mt. 27,45),

\footnotetext{
2498 „Es soll kein Haus seyn, in welchem diese Buchstaben nicht gefunden werden. Damit ibr aber die Kraft und Bedeutung dieser Buchstaben desto mehr kennen lernet, so babe ich sie nach der Ordnung bier erklärt und in's Deutsche gesetzt, wie folgt, wo ich auch sicher hoffe, daß ibr nicht nur zur Zeit der Noth, sondern auch öfters dieses Buch zur Hand nehmet, um die Segnungen und Gebete um euers zeitlichen und ewrigen Heiles willen mit größter Andacht betet". Romanus-Büchlein, S. 44f.

2499 Bahia, S. 271.

2500 "O Herr, allmächtige Gott! nimmt auf mein Gebet, und verschone mich und Alle, die ibre Sünden aufrichtig bekennen, daß wir die Verzeibung und den ewigen Frieden durch deine Barmberzigkeit erlangen mögen. O Gott der Güte und der Barmbervigkeit der du die Sünde beleidiget, aber durch die Buße versöhnet wirst, stehe gnädig an mein demüthiges Gebet, und wende ab die Geißel deines Zornes, welche ich wegen meine Sünden wobl verdient habe, und laß mächtig werden in mir deine Erbarmungen, daß ich selbe groß machen kann vor allen Völkern, und deinen Namen lobpreisen in Ewigkeit". Romanus-Bücblein, S. 47.
} 
„Der Herr ist meine Zuflucht geworden“ (Jer. 16,19) und „,heile mich, und ich werde geheilt werden" (Jer. 17,14 und Ps. 6,3).

\section{(3) Haus- und Schutzbrief aus Espírito Santo}

Neben Himmelsbriefen besaßen die Pommern und deren Nachkommen in Brasilien auch Haus- und Schutzbriefe. Ein Exemplar, das unter pommerschen Nachkommen in Espírito Santo erhalten blieb ${ }^{2501}$ (HS-ES), enthält folgenden Inhalt:

„Haus- und Schutgbrief

Vom Jahre 1724

Befehl dem Herrn deine Wege, und hoffe auf ihn, er wird es wohl machen (Psalm 37,5)

Im Namen des Vaters, des Sohnes und des Heiligen Geistes. Amen.

Wer sich schützen will, damit er nicht umkomme, werfe seine Angst und Sorge auf Gott, befeble seine Seele Jesu, denn der gütige Vater im Himmel, durch dessen unendliche Gnade und Liebe er beschützet und beschirmet wird, wird sich seiner erbarmen.

Herr Jesus Christus, Du ewiges Wort des Vaters, nimm von mir weg, was mir schändlich ist. Laß mich wohnen im Schatten Deiner Gnade, damit ich Trost finde in allen Anfechtungen des bösen Feindes, und in der gottlosen Welt unversehet bleiben möge an Seele und Leib. Und sollten mich des Feindes Waffen tödten, so verleibe Du mir den Schutz, daß Du mich aufnimmst in Dein Himmelreich. Amen.

Du Friedensfürst, Herr Jesu Christ, sprich zu allen Königen und Fürsten: Friede sei mit euch! und laß Deinen Frieden über iher \#2502 Lande ruben, und laß uns Kinder des Friedens sein. Du hast uns ja in Frieden berufen, so laß uns auch in Frieden leben. Sollte aber der Krieg und seinen Schaden über uns kommen, so wollen wir nicht weichen und nicht wanken, sondern in todcämpfiger\# Treue in unserm Gott und an unserm [... $]^{* 2503}$ Herrscher [... $]^{*}$ ja wir wollen Gut und Blut unserm geliebten Landes $[\ldots]^{*}$ damit $[\ldots]^{*}$ den Feind besiegen und wir wieder durch den Frieden gewinnen $[. . .]^{*}$ Vater im Himmel uns durch Jesum Christum, Deinen [... $]^{*}$.

\section{Kräftiges Stoßseufzerlein um ein seliges Ende.}

$O$ barmberziger Gott und liebster Vater, weil uns Menschen das Ziel, Zeit und Stunde zu sterben unwissend und verborgen ist, so bitte ich Dich von Herzen, Du wollest mich in meiner Noth nicht verlassen, sondern, wenn ich sterben und meinen Geist aufgeben [... $]^{*}$ wollest Du bei mir stehen, denn auf Dich setze ich alle Hoffnung, Vertrauen und Zuversicht. Denn wenn ich Dich habe, so habe ich alles, was mich hier zeitlich und dort ewiglich erfreuen mag. Ergänze mich in meinem Erkenntniß und starken festen Glauben auf Deiner Gnade und Barmhervigkeit. Ach Herr Gott! laß das Wort Deines Sohnes,

\footnotetext{
${ }^{2501}$ Hausbrief. Version aus Neu Ruppin, gedruckt bei Gustav Kuhn. 1 Blatt, 1 Seite, Fotografie, die genaue Blattmaßnahmen können nicht bestimmt werden. In: Seibel, Imigrante no século do isolamento, S. 332 .

2502 \# weist auf grammatische Fehler in diesem Text.

2503 Unlesbar.
} 
welches Er am [... $]^{*}$ des heiligen Kreuzes gesprochen, auch mein letrtes Wort auf meinem Tod-[...]*, daß ich mit starkem Glauben und Vertrauen sagen kann [...]* lieber Vater, in Deiner Hände befehle ich meinem Geist, Du hast mich erlöset. Du [...]* Gott. Und wenn ich ja mit meinem Munde diese Worte nicht aussagen kann, so laß sie doch in mein Herz eingezeichnet sein, um deines allerliebsten Sobnes, meines Herrn Jesu Christi Willen. Amen“.

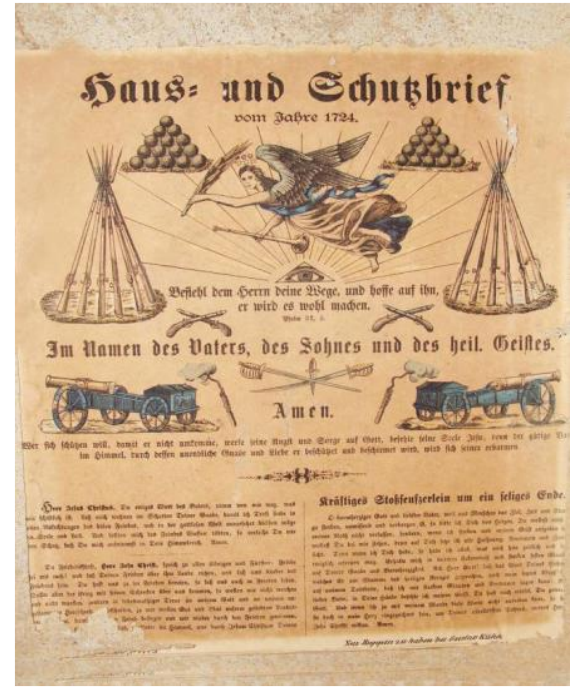

Abb. 43: Haus- und Schutzbrief aus dem Jahre 1724. Quelle: Seibel, Imigrante no século do isolamento, S. 332.

Das HS-ES enthält die Darstellung von Waffen (Kanonen, Kanonenkugeln, Schwerte, Flinten, Pulverpistolen und Sprengstoff), in deren Mitte der Erzengel Michael, wieder mit einer Posaune in einer und einem grünen Zweig in der anderen Hand abgebildet ist. Er trägt ebenfalls eine Sternenkrone auf dem Kopf und im Hintergrund steht das Auge der Vorsebung (Abb. 43). Zwischen den Abbildungen von Waffen steht der Ps. 37,5 und die trinitarische Formel „Im Namen des Vaters, des Sobnes und des heil. Geistes", darunter der Satz, der sich von den biblischen Texten -1 . Petr. 5,7 (werfe seine Angst und Sorge auf Gott), 1 Petr. 4,19 und Ps. 31,6 (befehle seine Seele Jesu) - ableitet. Andere Hausbriefe besaßen Abbildungen mit der Kreuzigung Jesu, eingerahmt von religiösen Familienszenen und darunter Gesangbuchsverse und den Spruch „Wo dies Blatt klebt an der Thür, da ist Segen für und für" oder Stücke aus Kinderliedern wie ,unter deinen Schirmen bin ich vor den Stürmen aller Feinde frei".2504 Auffällig ist, dass dieser Haus- und Schutzbrief auch im Jahre 1724, wie der Holsteinerstypus, entstanden sein soll. ${ }^{2505}$ In diesem Sinne können manche Versionen der Himmelsbriefen auch neben Haus- und Schutzbriefe als Haussegen entstanden sein. Die Gebete weisen auf den Schutz gegen Feinde und ihre Waffen und gegen den Krieg und seinen Schaden sowie auf den Wunsch nach Trost in allen Anfechtungen, nach Frieden und nach dem Beistand Gottes in der Todesnot hin. Sehr interessant ist

\footnotetext{
${ }^{2504}$ Lied 'Tesu, meine Freude, meine Herzens Weide". Im Heiliges Lippen- und Herzens-Opfer einer gläubigen Seele oder Vollständiges Gesangbuch. Stettin: Johann Samuel Leich, 1809: Lied 828; im Vermehrtes Kirchenund Haus-Gesang-Buch für das Königl. Schwedische Herzogthum Pommern und Fürstenthum Rügen. Greifswald: Hieronymus Johann Struck, 1750: Lied 381; im Deutscher Evangelischer Kirchenausschuß (Hrsg.) Deutsches Evangelisches Gesangbuch. Berlin: Mittler \& Sohn, 1926: Lied 131.

${ }^{2505}$ Ein handschriftliches Exemplar von einem Soldaten aus Fritzlar, vermittelt durch den Kunstmaler Otto Ubbelohde, enthielt den Ölbergspruch. Sein Inhalt entspricht, mit einigen Abweichungen, dem Schutžbrief, der noch zu untersuchen ist. Dieterich, S. 10.
} 
die Tatsache, dass der Schluss des letzten Gebetes mit wenigen Unterschieden mit einem Gebet im Evangelischen Hausbuch übereinstimmt. ${ }^{2506}$ Haus- und Schutzbriefe wurden zum Schutz gegen Unwetter, Diebstahl, Schaden und Gefahr für Haus und Bewohner verwendet. Sie wurden im Gebälk angebracht oder an die Wand geklebt oder gehängt ${ }^{2507}$, auch unter das Haupt eines Sterbendes, den Kindern ins Bett gegen Gicht und den Frauen auf oder unter den Körper bei Entbindungen gelegt. 2508

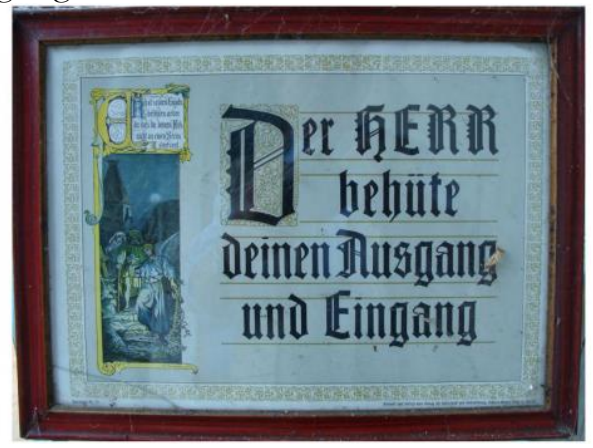

Abb. 44: Hausspruch. Quelle: Seibel, Imigrante no século do isolamento, S. 361.

besaßen sozusagen die Funktion, das Haus gegen alle Art Gefahren zu schützen und Segen für Haus und Hof zu bringen. ${ }^{2509}$ Letztendlich wurden Birkenzweige 2510 oder der sogenannte Pfingstkran $z^{2511}$ aus grünen Heilblätter nach dem Pfingstfest auf den Dachboden der Häuser oder Scheune gelegt, um diese gegen Brand zu schützen. ${ }^{2512}$ Der Pfingstkranz sollte nach Rölke das Haus auch mit der Präsenz des Heiligen Geistes erfüllen. ${ }^{2513}$

2506 Gebete in Todesnöten 1. Deutscher Evangelischer Kirchenausschuß, Evangelisches Hausbuch, S. 76.

2507 Magisch-sympathetischer Hausschatz, S. 108.

2508 Jacoby, Haussegen. In: Hoffman-Krayer, E.; Bächtold-Stäubli, Hanns (Hrsg.) Handwörterbuch des Deutschen Aberglaubens. Band III. Berlin/Leipzig: Walter de Gruyter, 1930/1931, S. 1575f.

${ }_{2509}$ Bahia, S. 348; Rölke, Helmar. Raizes da Imigração alemã. Vitória: Arquivo Público do Estado do Espírito Santo, 2016, S. 334f, 570.

2510 Thiel, Uwe; Neumann, Harry. Priebkow - ein Rittergut in Hinterpommern. Witten: DIP-Digital-Print, 2011, S. 387.

2511 Stuhr, Rubens. Ponto de Pregração Córrego Grande celebra Pentecostes. In: Igreja Evangélica de Confissão Luterana no Brasil. Portal Luteranos. 17.5.2013. Verfügbar in: http://luteranos.com.br/ conteudo/ponto-de-pregacao-corrego-grande-celebra-pentecostes Zugang am 22.10.2015.

2512 Rölke, Helmar Reinhard. Descobrindo Raízes. Vitória: UFES, 1996, S. 62f.

2513 Rölke, Raízes da Imigração alemã, S. 589. 


\section{(4) Exemplar des Schutzbriefes aus Santa Catarina}

Eine gedruckte 2514 (S-Weing) und eine handschriftliche Ausgabe des Schutzbrie$f e s^{2515}$ (S-SC) blieben unter pommerschen Nachkommen in Santa Catarina erhalten. Beide weisen Falten und Zeichen häufiger Verwendung auf, wie in Abb. 45 zu erkennen ist. Sie ähnelten sehr dem Haus- Schutz- und Himmelsbrief einer Leipziger Familie $^{2516}$ (S-Leip). Weil in der Regel die Mehrheit der Himmels- und Schutabriefe abgeschrieben wurden, kommt der handschriftlichen Version größere Aufmerksamkeit zu. Sie lautet:

\author{
„Gottes hilfreiche \\ vor jeder Gefahr, Streit \\ allerlei Krankheiten
}

\author{
Hand volle ${ }^{* 2517}$ uns \\ Unglück, Trübsal und \\ gnädig allseit* beschüzten.
}

\section{SCHUTZBRIEF!}

Ein Graf hatte einen Diener, dem wollte er das B. G. H. Haupt abschlagen lassen, vie* nun solches geschah, so hat es der Scharfrichter nicht abschlagen können. Wie es nun der Graf sah, so hat er den Diener gefragt, vie* solches zuginge, daß ihm das Schwert keinen

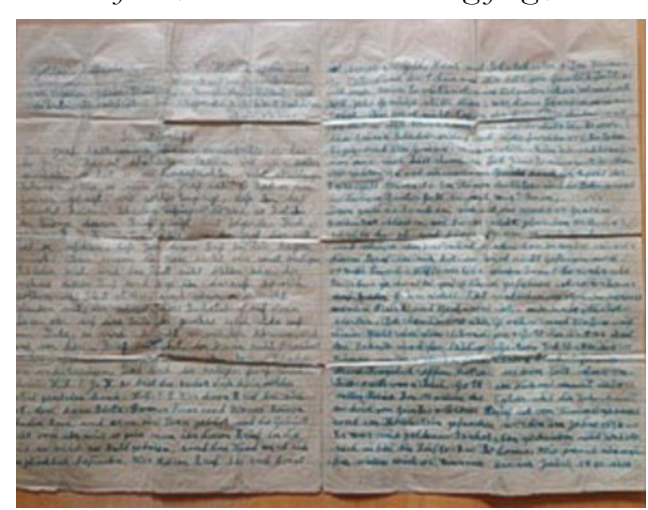

Abb. 45: Handabschrift eines Schutabriefes aus

Indaial (SC). Quelle: Privatarchiv S.J. Schaden zufügen könne, so hat ihm der Diener diesen Brief gezeigt mit folgenden Buschstaben: B. J. K. H. N. K. Als nun der Graf dies sah, hat er befoblen, daß Jeder disen* Brief bei sich tragen müste. * Wenn einem die Nase blutet, oder sonst blutigen Schaden hat, und das Blut nicht stillen kan,* der nebme diesen Brief und lege ibn darauf, so wird solhen* das Blut stillen, und wenn er es nicht glauben will, der schreibe diese Buchstaben auf einen Degen oder auf eine Seite des gewehrs* und stehe auf einem Platze, so wird er sib* nicht vervunden* können, und ver* diesen Brief bei sich trägt, der kann nicht bezaubert verden* und seine Feinde können ibn* keinen Schaden tun und zufügen. Das sind die heiligen fünf Wunden Christi: K. H. T. G. K. so bist du sicher, daß kein solches Urteil ge-

\footnotetext{
2514 Scbutzbrief. Ohne Angabe des Druckers. DIN A4, 1 Blatt, 2 Seiten. Privatarchiv von Pastor Nelso Weingärtner; vgl. Weingärtner, Nelso. Mundo da Superstição. São Leopoldo: Sinodal, 2014, S. 28-31. 2515 Schutzbrief. DIN A4, liniertes Schreibpapier. 2 Blätter, 4 Seiten. Privatarchiv S. J.

2516 Haus-, Schutz- und Himmelsbrief. In: Magisch-sympathetischer Hausschatz, S. 181-183. Ein anderer Schutzbrief, der von einem Soldaten des Landwehr-Infanterie-Regiments Nr. 133 in beiden Weltkriege getragen wurde, befindet sich in Ebd., S. 194-197. Nach Angaben des Soldaten wurde er dadurch von allen Schäden geschützt. Im Brief kann der Name des Inhabers angegeben werden. Er verfügt über einen anderen Inhalt, der Schwerpunkt liegt hierbei auf dem Schutz durch das Blut Christi. $2517 *$ weist auf Abschreibfehler hin, die im S-Weing korrekt angegeben werden.
} 
schehen kann. H. G. S. S.2518 Wer diesen Brief bei sich hat, dem kann Blity, Donner, Feuer und Wasser keinen Schaden tun, und wenn eine Frau gebärt, und die Geburt nicht von ibr will, so gebe man ibr diesen Brief in die Hand so wird sie bald gebären, und das Kind wird sich sebr glücklich befinden. Wer diesen Brief bei sich trägt, ist besser als Geld, Haus und Schatzkasten: † Im Namen des Vaters und des Sohnes und des heiligen Geistes † Gott sei mit mir, Amen. So wie Christus im Oelgarten still stand so soll jedes Geschäft2519 stille stehen, wer dieses Schreiben bei sich trägt, ihm wird nicht treffen des Feindes Geschütze und vor Dieben und Mörder wird er ihn beschützen, es soll ihm keiner Schaden, er darf sich nicht fürchten vor Pistolen, Degen und alle Gewehre, müssen stille stehn als sichtbar, so man auch nicht hält durch den Tod Jesu. ${ }^{2520}$ Es müssen stille stehen alle sichtbaren und unsichtbaren Gewehre 2521 durch den Befehl des Erzengels Michael. † Im Namen des Vaters und des Sohnes und des Heiligen Geistest Gott sei mit mir! Amen!2522 Segen2523 gegen die Feinde bei sich hat, der wird vor Gewehre* geschützt bleiben, wer dieses nicht glauben will, der schreibe dies ab und hänge es einem Hunde an den Hals und schieße ihn, so wird er sehen, das* es wahr sei, wer diesen Brief bei sich hat, der wird nicht gefangen noch von des Feindes $W$ affe verletzt werden. Amen!2524 So wahr als Christus gestorben gen Himmel gefahren ist so wahr er auf Erden gewandelt hat gestochen, gestohsen*, verletat worden Fleisch und Gedärme sollen mir unbeschädigt bleiben. ${ }^{2525}$ Ich beschwöre alle Gewehre und Waffen auf dieser Welt bei dem lebendigen + Gott des Vaters und des Sohnes und des Heiligen Geistes $\%$. Ich bitte im Namen unseres Herrn Jesu Christi Blut, dass mir keine Kugel treffen tut, sie sei von Gold oder von Silber oder von Blei, Gott im Himmel macht mir alles frei † Im Namen des Vaters und des Sobnes und des heiligen Geistes $† .2526$ Dieser Brief ist vom Himmel gesand und im Höllenstein gefunden worden im Jahre 1724. Er war mit goldenen Buchstaben geschrieben und erhob sich über die Lüfte zu Bodoma. Wie man ibn ergreifen

2518 Vgl. mit den Buchstaben des Himmelsbriefes aus Engelrod (H-Eng). In: Dieterich, S. 9f. Auch Abschnitt 1-B dieses Exkurses.

${ }^{2519}$ Im S-Leip steht: „, alles Geschütz“.

${ }^{2520}$ Im S-Leip steht: „Wer diesen Brief bei sich hat, den wird nicht treffen des Feindes Gescbütr. und Waffen, denselben wird Gott bekräftigen, daß er sich nicht fürchtet vor Dieben und Mördern. Es sollen ibn nicht treffen Geschütze, Degen, Pistolen und alle Gewehre müssen stehen, auch unsichtbar, so man sie auf ihn los bält, durch den Befehl und Tod Jesu".

${ }^{2521}$ Im S-Leip steht: , sicbtbaren und unsichtbaren (W affen)".

2522 Im S-Leip steht: „Im Namen Gottes des Vaters †, des Sobnes † und des beiligen Geistes †. Amen. Gott sei mit dir".

${ }^{2523}$ Im S-Weing steht: ,Wer diesen Segen".

${ }^{2524}$ Im S-Leip steht: „Wer diesen Brief bei sich hat, der wird von Gefabr geschützt bleiben. Wer diesem Briefe nicht glauben will, der scbreibe ibn ab, bänge ihn einem Hunde an den Hals und scbieß nach ibn, so wird er erfabren, daß es wabr sei".

${ }^{2525}$ Im S-Leip steht: „Wer diesen Brief bei sich trägt, dem wird nicht Gefabr drohn, noch wird er durch des Feindes Geschütz verletzt werden. So wabr das ist, daß Christus gestorben und gen Himmel gefahren, so kann ich gestochen, geschossen, auch an meinem Leibe verlet:t werden, und Fleisch und Gedärme, Alles soll mir unbeschädigt bleiben".

2526 Im S-Leip steht: „Ich bitte in dem Namen unseres Heilandes, Jesu Christi Blut, daß mich keine Kugel treffe, sie sei von Gold, Silber, Eisen oder Blei, Gott im Himmel mache mich von allen frei, im Namen Gottes des Vaters $\dagger$, des Sobnes † und des beiligen Geistes † Amen. 
wollte wich er zurück bis im Jahre 1790 sich Jemand fand und den Gedanken fasste, dass er den Brief abschreiben wollte. Zu diesem zeigte sich der Brief. ${ }^{2527}$ Ferner stand darin:2528 Wer am Sonntag arbeitet, der ist von mir verdammt. Ihr sollt des Sonntags ${ }^{2529}$ nicht arbeiten, sondern zur Kirche gehen und mit Andacht beten, von Eurem Reichthum sollt ihr den Armen geben ${ }^{2530}$, ihr sollt nicht sein wie unvernünftige Tiere, ich gebiete sechs Tage zur Arbeit, und den siebenten sollt ibr Gottes Wort hören ${ }^{2531}$, werdet ihr das nicht tun, so werde ich euch strafen bei teuren Zeiten, Pestilenz und Krieg. ${ }^{2532}$ Ich gebiete, dass ibr des Sonnabends nicht spät arbeitet jedermann sei er alt oder*,2533 soll für seine Sünden bitten, dass sie ihm sollen vergeben werden, schwört nicht bei meinem Namen begehrt nicht Gold oder Silber schwärmt nicht nach Menschen pracht*2534 so geschwind ich euch erhoben habe so geschwind kann ich Euch erschüttern ${ }^{2535}$ ehret Vater und Mutter redet nicht falsch Zengnis wider euren Nächsten, dann gebe ich euch Gesundheit und Frieden2536, wer dieses nicht glaubt und danach tut der ist von mir verdammt 2537 und wird weder Glück noch Segen haben. Ich sage Euch dass Jesus Christus diesen Brief geschrieben hat wer dieses verflucht der ist von mir verlassen und soll keine Hilfe haben wer diesen Brief hat und nicht geoffenbart 2538 , der ist verflucht von der christlichen Kirche, diesen Brief soll einer dem Anderen abschreiben ${ }^{2539}$ und wenn ibr soviel Sünden getan habt wie Sand am Meer und Laub auf den Bäumen so sollen sie vergeben werden ${ }^{2540}$ glaubt gewiss, dass ich den ehren werde wer nicht glaubt soll des Todes sterben, bekehret Euch, sonst werdet Ihr ernstlich bestraft werden ich werde Euch am jüngsten Tage bestrafen so Ihr mir nicht Antwort geben könnt einem jeglichen über seine Sünde ${ }^{2541}$, wer diesen Brief im Hause hat ${ }^{542}$, dem soll kein Donnerwetter treffen, welche Frau diesen

${ }^{2527}$ Im S-Leip steht: „Mit diesem Brief ist der Engel Michael vom Himmel gesandt und im Holsteinischen gefunden worden anno 1724. Er war mit goldenen Buchstaben geschrieben, betitelt Bondogne. Er schwebte über der Taufe; wer ibn angreifen wollte, dem wich er zurück bis Anno 1791, da sich jemand mit dem Gedanken näherte, ihn abzuschreiben und der Welt mitzuteilen. Zu diesem näherte sich der Brief". Ein Exemplar zitiert 1729 als Erscheinungsjahr. Dieterich, S. 10. Laut einem weiteren Exemplar aus Gillersheim ließ er sich 1771 abschreiben. Kreitz, Gerhard; Rode, Peter (Hrsg.) Chronik der Ortschaft Gillersheim. Berlin, 2005, S. 79f. Zitiert nach Schlegel, S. 68.

2528 Im S-Weing steht: ,darauf".

${ }^{2529}$ Im S-Weing steht: ,an dem Tage“.

${ }^{2530}$ Im S-Weing steht: ,in die Kirche gehen, mit Andacht beten und von eurem Reichtum den Armen geben“.

${ }^{2531}$ Im S-Leip steht: „ich gebiete 6 Tage zu arbeiten, den 7. sollt Ibr Gott bören“.

2532 Im S-Leip steht: „Werdet Ibr das nicht thun, so gebiete ich dann theure Zeit, Pestilenz, und Krieg“.

2533 Im S-Weing steht: ,alt oder jung"; im S-Leip: ,Jedermann er sei, jung oder alt".

${ }^{2534}$ Im S-Leip steht: ,„schämt Euch vor Menschenlust und Begier. Seid mit der Zunge nicht falsch... “

${ }^{2535}$ Dieser Teil fehlt in S-Leip.

${ }^{2536}$ Im S-Leip steht: „Dann gebe ich Gesundheit und Frieden, der darnach thut".

${ }^{2537}$ Im S-Leip steht: „Wer diesem Briefe nicht glaubt oder nicht darnach thut der ist von mir verlassen... ".

${ }^{2538}$ Im S-Leip steht: „(...) wer dem widerspricht, der ist verlassen und wird keine Hülfe baben“.

${ }^{2539}$ Im S-Leip steht: „einer den andern abschreiben lassen“.

2540 Im S-Leip steht hinzu: ,und Sterne am Himmel sind, so sollen sie Euch vergeben werden".

${ }^{2541}$ Im S-Leip steht: „Glaubt gewiß, das ist die Ehre, und wer das nicht glaubt, der soll sterben, und seine Kinder sollen eines bösen Todes sterben. Ich werde Euch am jüngsten Tage bestrafen, wo ibr nicht Antwort geben könnt von Euren Sünden".

2542 S-Leip fügt hinzu: „,oder bei sich hat". 
Brief bei sich trägt wird liebliche Frucht zur Welt bringen haltet die Gebote welch* ich Euch durch einem* Engel gesandt habe. Im Namen Jesu Christi Amen. Gott schütre "2543

S-SC enthält oben die Bleistiftzeichnung eines Kreuzes, die von einer Schutzformel umrahmt ist, sonst keine weiteren Verzierungen ebenso wie S-Weing. Aus der Kalligraphie lässt sich feststellen, dass die Person, die den Brief abgeschrieben hat, keine Schreibgewohnheit besaß. Das lässt sich aus den verschiedenen Abschreibfehler erkennen, die möglicherweise auch von einer anderen Kopie stammen konnten. S-SC und S-Weing stimmen inhaltlich komplett überein. Bei einem Vergleich von S-SC mit S-Leip fallen aber folgende Unterschiede auf: a) S-Leip beginnt erst ab dem Ölbergspruch; b) in S-Leip wird Gott denjenigen, der den Brief bei sich trägt, ,bekräftigen, daß er sich nicht fürchtet vor Dieben und Mördern “. Im S-SC wird Gott ihn lediglich vor ihnen ,bescbützen“. In S-Leip werden durch den Tod aber auch durch den Befehl Jesu alle sichtbaren und unsichtbaren Waffen ,still stehen", S-SC erwähnt dies im Zusammenhang mit dem Tod Jesu; c) durch dreimalige Aufzeichnung des Kreuzes bei der trinitarischen Formel ( $\dagger$ ) in S-Leip ist eine mögliche Praxis der Bekreuzigung deutlicher erkennbar als in S-SC, wo es nur zweimal, am Anfang und am Ende, vorkommt; d) die Formulierung des Satzes ,so wahr als Christus gestorben, gen Himmel gefahren ist, so wahr er auf Erden gewandelt hat, gestochen, gestoßen, verletzt worden, Fleisch und Gedärme sollen mir unbeschädigt bleiben" in S-SC deutet auf einen Schutz hin, der in Anlehnung an das Leiden Christi gewährt wird. Bei S-Leip bezieht sich das, gestochen, geschossen, auch an meinem Leibe verletzt werden "zusammen mit ,und Fleisch und Gedärme, Alles soll mir unbeschädigt bleiben" auf die Person, dem der Schutz zugesprochen wird; e) Der Erscheinungsort und das Abschreibungsjahr sind unterschiedlich: S-SC zitiert Höllenstein als Erscheinungsort, wo er sich über die Lüfte zu Bodoma erhob und sich 1790 abschreiben ließ. S-Leip erwähnt dagegen Holsteinischen, der Brief schwebte „über der Taufe", hieß Bondogne und ließ sich 1791 abschreiben; f) im S-SC kommt das Gebot vor, nicht für die Menschenpracht zu schwärmen, ergänzt durch die Drohung ,so geschwind ich euch erboben habe, so geschwind kann ich euch erschüttern". Diese Drohung entfällt bei S-Leip. Hier ist von „schämt Euch vor Menschenlust und Begier" die Rede; g) im S-SC soll derjenige, der den Brief bei sich hat und ihn abschreibt, geehrt werden. Laut S-Leip ist der Besitz und Abschreiben des Briefes ,die Ehre"; h) in S-Leip werden die Drohungen für diejenigen, die nicht an den Brief glauben, auf die Kinder erweitert, die einen „bösen Tod" sterben sollen; i) in S-Leip wird Michael namentlich als der Engel, durch den die Gebote durch den Brief übermittelt wurde, erwähnt. S-SC erwähnt ihn nicht.

Die analysierten Exemplare des Schutzbriefes enthalten Elemente des Gredoriaund des Holsteintypus. Hervorzuheben ist nur, dass sie namentlich verschiedene

2543 Im S-Leip steht: ,... Haltet meine Gebote, die ich Euch durch meinen Engel Michael gesendet habe, im Namen Jesu! Amen". 
Sorten von Waffen erwähnen (Degen, Gewehre, Waffen, Pistolen, Kugeln, Geschütze), ein Hinweis auf ein späteres Erscheinen, als die Waffentechnik schon fortgeschritten war. In diesem Sinne spielten sie wieder eine besondere Rolle als Schutzmaßnahme angesichts von Angriffen, Revolutionen und Kriege, die die Einwanderer und deren Nachkommen im Laufe der Geschichte ausgesetzt waren, aber auch als Schutz gegen Krankheiten und bei der Entbindung, denn Schutzbriefe wurden häufig von Frauen getragen. Auffällig ist, dass S-SC sowie H-Eng ${ }^{2544}$ diejenigen, die den Schutzbrief verfluchen, nicht an ihn glauben, ihn nicht abschreiben oder ihn nicht offenbaren mit Pest, Hunger, Feuer, Krieg und Tod bedroht werden. Zudem sollen sie auch von Gott verlassen (,,der ist von mir verlassen und soll keine Hilfe haben) und von der Kirche verflucht (,der ist verflucht von der christlichen Kirche") werden. Dadurch erlangte er mehr Autorität, denn der Beistand Gottes und die Mitgliederschaft in der kirchlichen Gemeinde waren für die Pommern sehr wichtig.

Schut̨briefe bestehen aus vier zunächst unabhängigen Teilen: a) eine Bannformel beziehungsweise Oelbergspruch; b) das Graf Philipp Amulett; c) der eigentliche Himmelsbrief; d) die Legende von Kaiser Karl. ${ }^{2545}$ Sie werden auch als "Moses letzte Briefe" bezeichnet. ${ }^{2546} \mathrm{Im}$ 16. Jahrhundert wurden einige Schutabriefe auch Papst Leo X. (1513-1521) oder Kaiser Karl V. (1520-1556) zugeschrieben. Sie waren in unterschiedlichen Formen in allen Stämmen bekannt und verbreiteten sich in Deutschland vor allem während Kriegszeiten, wie im Koalitionskrieg (1793), den Freiheitskriegen (1813-1815), im Krieg gegen Dänemark (1864), im PreußischDeutschen Krieg (1866) und im Deutsch-Französischen Krieg (1870-1871), als Soldaten sie bei sich in Brustbeuteln trugen, aber auch im Ersten Weltkrieg (19141918). Manche bewahrten ihn in versiegelten Glasröhren, um seine Kraft besser zu erhalten. ${ }^{2547}$

Laut Olbrich traten Himmels- und Schutzbriefe ursprünglich als Haussegen auf und wandelten sich erst später zu Kriegs- und Waffensegen. Sie konnten eine Art „,hristlicher Haustafel" gebildet haben, die als Haussegen im Haus aufgehängt, fleißig gelesen und von „Haus zu Haus“ getragen wurden. ${ }^{2548}$ Nach Bauer wurden sie aber für Kriegssoldaten entwickelt und sobald der Kampf zu Ende ging, bewahrten sie diese sorgfältig auf. Weil sie dann für lange Zeit nutzlos blieben und ihre Beziehung zum Krieg in Vergessenheit geriet, wurden sie allmählich zu einem allgemei-

\footnotetext{
${ }^{2544}$ Himmelsbrief aus Engelrod. In: Dieterich, S. 9f; vgl. Abschnitt 1-B dieses Exkurses.

2545 Magisch-sympathetischer Hausschatz, S. 207.

2546 Jacoby, Mosis, das sechste und siebente Buch. In: Hoffman-Krayer, E.; Bächtold-Stäubli, Hanns (Hrsg.) Handwörterbuch des Deutschen Aberglaubens. Band VI Berlin/Leipzig: Walter de Gruyter, 1934/1935, S. 583; vgl. Die Praktika des täglichen Lebens. In: 6./ 7. Bucb Moses. Einleitung und Bildkommentare von Bauer, Wolfgang. Berlin: Karin Kramer, 1979, S. 347-350.

2547 Stübe, Schutzbrief, S. 1384-1836; Magisch-sympathetischer Hausschatz, S. 174.

2548 Olbrich, Karl. Zehn Schutzbriefe unserer Soldaten. In: Band X der Mitteilungen der Scblesischen Gesellschaft für Volkskeunde, S. 45ff. Zitiert nach Magisch-sympathetischer Hausschatz, S. 207.
} 
nen Schutz gegen alle möglichen Gefahren verwendet. ${ }^{2549}$ Himmels- und Schutzbriefe wurden auch als Gebet verwendet. 2550 Weil sie unter anderem auch Vergebung der Sünden und Erlösung versprachen, wurden Exemplare auf den Sarg verstorbenen Menschen gelegt, wie es unter Pommern in Brasilien der Fall war, weswegen nur wenige Exemplare erhalten blieben. Wo immer Gefahr drohte, wurden sie als Zufluchtsmittel in Zusammenhang mit einem magischen Verständnis verwendet: Dem Kranken auf die Brust gelegt, um ihn zu heilen; der Frau unter das Kissen oder auf den Bauch, um ihr die Entbindung zu erleichtern oder als Abwehrmittel gegen Dämonen und Schwierigkeiten bei der Entbindung; den jungen Soldaten mit in dem Krieg oder Militärdienst; im Haus unter Dachbalken als Schutzmittel gegen Blitzschlag, Feuergefahr, Wassernot und Hochwasser; in Abschriften verbreitet und auf dem Körper getragen, um sich vor Krankheiten und Gefahren aller Art zu schützen. 2551

Himmels-, Haus- und Schutzbriefe boten auch vielen Einwanderern und Nachkommen in Brasilien eine wichtige Hilfe bei der Bewältigung von Ängsten, Gefahren und Bedrohungen. Sie sicherten ihnen einen greifbaren und dauerhaften Schutz in Notsituationen sowie den Segen und Beistand Gottes in ihrem alltäglichen Leben. Weil sie Gebete, biblische Gebote und Sprüche, die ähnlich wie Gesangbuchlieder und Gebete leicht auswendig zu lernen waren, und moralische Gesetze, die ihrer Volksfrömmigkeit entsprachen, enthielten, sahen sie in ihnen keinen Widerspruch zu ihrem evangelisch-lutherischen Glauben. Sie erkannten viele Ähnlichkeiten zwischen ihnen und ihren kirchlichen Glaubensquellen, auch wenn Himmels-, Haus- und Schutz̧briefe von den Geistlichen verboten und als Aberglaube bezeichnet wurden. ${ }^{2552}$ Einige Siedler verwendeten sie aus diesem Grund nicht, orthodoxe Lutheraner oder frühere Mitglieder von Erweckungsbewegungen haben sie teilweise bekämpft und andere standen ihnen gleichgültig gegenüber oder verspotteten sie gar. Aber für diejenigen, die sie verwendeten, bedeuteten sie eine wichtige Glaubensquelle, die ihnen Trost, Glaubensstärkung und Hoffnung in widrigen Situationen gab und bei der Bewältigung ihrer Ängste half.

\footnotetext{
2549 Magisch-sympathetischer Hausschatz, S. 205.

2550 Schlegel, S. $67 \mathrm{f}$.

2551 Stübe, Himmelsbrief, S. 26f; Magisch-sympathetischer Hausschatz, S. 205; Stübe, Der Himmelsbrief, S. 3.

2552 Brief von Pastor Georg Burger an den Missionsdirektor Dr. Fr. Eppelein, Neuendettelsau, 12.11.1942, MEW 4.166.
} 


\section{Abbildungsverzeichnis}

Abb. 1: Einschiffung im Hamburger Hafen. 106

Abb. 2: Haus und Landlos in Santa Isabel (ES). 121

Abb. 3: Mathias Nickel beim Herausziehen des Schlangengiftes in Melgacinho-Califórnia, Domingos Martins (ES). 124

Abb. 4: Erweiterung der Straße zwischen Pomerode und Blumenau (SC). 138

Abb. 5: Sator-Quadrat in einer handschriftlichen Besprechungsformel. 161

Abb. 6: Exemplar einer Bibel in pommerscher Sprache aus Espírito Santo.

Abb. 7: Patenbrief aus Pelotas (RS), 30.10.1943. 202

Abb. 8: Patenbrief aus Indaial (SC), 29.1.1984. 203

Abb. 9: Patenbrief aus Indaial (SC), 29.1.1984. 203

Abb. 10: Pommersche Hochzeit in einem Siedlungsgebiet in Espírito Santo. $\quad 207$

Abb. 11: Kolonisten in Espírito Santo unterwegs zur Kirche. 244

Abb. 12: Kirchen-Schule in Rio Claro (ES) im Jahr 1900.

Abb. 13: Kapelle der Zweiggemeinde Suíça-Jequitibá (ES). $\quad 250$

Abb. 14: Kapelle der Zweiggemeinde Rio Bonito-Jequitibá (ES). 251

Abb. 15: Heiliggeistkirche in Blumenau (SC), eingeweiht am 23.9.1877. 254

Abb. 16: Der Glockenstuhl in Rio Ponte (ES). 258 
Abb. 17: Transport von Glocken von Itajaí (SC) bis nach Pomerode (SC).

Abb. 18: Transport von zwei Glocken in Rio Ponte (ES).

Abb. 19: Erste Stadtkirche in Timbó (SC), errichtet zwischen 1888 und 1890.

Abb. 20: Evangelische Kirche in Santa Cruz do Sul im Jahr 1872.

Abb. 21: Evangelische Kirche in Santa Cruz do Sul (RS) im Jahr 1878

Abb. 22: Schule und im Hintergrund die Kirche in Testo AltoPomerode (SC).

Abb. 23: Der Vergleich: Kirche in Testo Alto-Pomerode (SC) im Jahr 1927.

Abb. 24: Die Dorfkirche von Nakel nach dem Plan von 1819.

Abb. 25: Der Normalkirchenplan mit Turm von 1827.

Abb. 26: Kirche in Badenfurt (SC).

Abb. 27: Kirche von Santa Maria (ES).

Abb. 28: Innenraum der Kirche der evangelischen Gemeinde Campinho (ES).

Abb. 29: Innenraum der Martin-Luther-Kirche der lutherischen Gemeinde Jaraguá Alto-Jaraguá do Sul (SC).

Abb. 30: Evangelische Kirche in Nova Petrópolis (RS).

Abb. 31: Kirche und Pfarrhaus in Inselstraße (SC).

Abb. 32: Fachwerkkirche in Ribeirão Liberdade-Benedito Novo (SC).

Abb. 33: Himmelfahrtskirche in Novo Hamburgo (RS).

Abb. 34: Kirche in Pontal (ES).

Abb. 35: Schule in Testo Alto-Pomerode (SC).

Abb. 36: Der Chefarzt und die Schwestern des Evangelischen Krankenhauses in Blumenau (SC).

Abb. 37: Beschädigtes Grab in der Nationalisierungszeit.

Abb. 38: Restauriertes Versteck von Pastor Grottke in Laranja da Terra (ES).

Abb. 39: Himmelsbrief Gredoria. Exemplar aus Espírito Santo. 


\section{Literaturverzeichnis}

\section{Primäre Quellen}

1.1. Pommersches Landesarchiv Greifswald (PLAG):

Rep 65c Nr. 154;

Rep 65c Nr. 162;

Rep 65c Nr. 167;

Rep 65c Nr. 158;

Rep 65c Nr. 163;

Rep 65c Nr. 169.

Rep 65c Nr. 159;

Rep 65c Nr. 166;

1.2. Quellen aus dem Evangelischen Zentralarchiv Berlin (EZA):

5/264;

$5 / 355$

5/428;

5/483;

$5 / 2157$

$5 / 2158$

$5 / 2164$

$5 / 2165$

$5 / 2168$
5/2173;

5/2175;

5/2178;

5/2185;

5/2201;

5/2208;

5/2222;

5/2304;

5/2352;
5/2425;

5/2432;

5/2453;

5/2455;

5/2462;

5/2463;

5/2465;

5/2476;

5/2482; 
5/2483;

5/2535;

5/4227;

5/2484;

$5 / 2563$;

$5 / 4229$

5/2485;

$5 / 2569$;

121/19;

5/2486;

5/2571;

121/116;

5/2487;

5/2576;

200/1/2149;

5/2488;

5/2583;

200/1/2151;

5/2489;

5/2588;

200/1/2152;

5/2505;

5/2602;

200/1/5807;

5/2508;

5/4219;

200/1/5818;

5/2510;

5/4220;

200/1/6070.

$5 / 2525$

5/4222;

5/2526;

5/4224;

1.3. Quellen aus dem Landesarchiv der Evangelisch-Lutherischen Kirche Bayerns in Nürnberg:

1.3.1. Akten Mission Eine Welt (MEW):

$\begin{array}{llll}3.16 ; & 4.118 ; & 4.193 ; & 4.209 ; \\ 3.17 ; & 4.166 ; & 4.194 ; & 4.214 . \\ 3.19 ; & 4.178 ; & 4.199 ; & \\ 3.20 ; & 4.185 ; & 4.206 ; & \\ 3.22 ; & 4.188 ; & 4.207 ; & \end{array}$

1.3.2. Akten Martin Luther Verein (MLV):
$51 / 1760$
$51 / 1769$;
$51 / 1766$
51/17 77;
$51 / 1787$
$51 / 1767$;
51/17 81;
51/17 108;
$51 / 17119$.

1.4. Quellen aus dem Basler Missionsarchiv (BMA):

\subsubsection{Personalakten:}

PABV 545 - Johann Leonhard Hollerbach;

PABV 613 - Christian Tischhauser;

PABV 703 - Johann Jakob Zink;

PABV 708 - Christian Zluhan;

PABV 1875 - Jakob Sauer;

PABV 1981 - Leonhard Grau;

PABV 2198 - Gustav Braun.

\subsubsection{Akten von Brasilien und Südamerika}

FB, 1,1;

FB, 2,1;

FB, 1,2;

S VI A.1-T.I. 11, S VI A 1-4; 
S VI A.1-T.I. 11, S VI F 2;

S VI A.1-T.I. 11, S VI C 5;

S VI A.1-T.I. 11, S VI C 1;

S VI A.1-T.I. 11, S VI C 6;

S VI A.1-T.I. 11, S VI C 2;

S VI A.1-T.I. 11, S VI C 7;

S VI A.1-T.I. 11, S VI C 3;

Q-3-1, 22.

S VI A.1-T.I. 11, S VI C 4;

1.5. Quellen aus dem Historischen Archiv der Evangelischen Kirche Lutherischen Bekenntnisses in Brasilien (Arquivo Histórico da IECLB) in São Leopoldo (AHI)

1.5.1. Sinodo Riograndense (SR)

SR 1/3;

SR 10/1;

SR 18/1;

SR $1 / 4$;

SR 13/1;

SR $18 / 3$

SR 2/3;

SR $13 / 5$;

SR 83/25;

SR 4/4;

SR 15/6;

SR 83/69;

SR 6/5;

SR $15 / 7$;

SR 144/15.

SR 8/4;

SR $17 / 6$;

SR 9/1;

SR 17/8;

1.5.2. Sinodo Evangélico de Santa Catarina e Paraná (SE)

SE 8/6;

SE $13 / 1$;

SE 38/6.

SE $11 / 1$;

SE $13 / 2$;

1.5.3. Sinodo Luterano de Santa Catarina, Paraná e outros Estados (SL):

SL $1 / 1$;

SL 4/2. 
1.5.4. Erinnerungen eines deutschen Ansiedlers in Brasilien. In: (1899) Sonntagsblatt für die evangelischen Gemeinden in Brasilien. 12. Jahrgang, Nr. 34, S. 133-134; Nr. 35, S. 134-135; Nr. 36, S. 142; Nr. 37, S. 146-147; Nr. 38, S. 150-151; Nr. 39, S. 154-155; Nr. 40, S. 157-158.

1.6. Predigt-, Andachts- und Gesangbücher und Quellen magischen Inhaltes:

(1979): 6./ 7. Buch Moses. Einleitung und Bildkommentare von Wolfgang Bauer Berlin: Karin Kramer.

Brastberger, Immanuel Gottlob (1857): Evangelische Zeugnisse der Wahrheit zur Aufmunterung im wahren Christenthum: theils über die gewöhnlichen Sonn-, Fest- und Feiertags-Evangelien, theils über die Passions-Geschichte unsers Erlösers; in einem vollständigen Predigt-Jahrgang zusammen getragen, und nebst dem Anhang einiger Casual-Predigten auf Verlangen dem Druck überlassen. Reutlingen: Enßlich \& Laiblin.

(ohne Jahresangabe): Carta do céu, também conhecida como Gredoria. Ohne Angabe des Druckers. DIN A4, 1 Blatt, 1 Seite. Quelle, die Dr. Claudete Beise Ulrich freundlicherweise zur Verfügung stellte.

(1750): Christliches Gebet-Büchlein. Anhang In: Vermebrten Kirchen- und HausGesang-Buch für das Königl. Schwedische Herzogthum Pommern und Fürstenthum Rügen. Greifswald: Hieronymus Johann Struck. 48 Seiten.

(1950): Das sechste und siebente Buch Moses. Das ist Moses magische Geisterkunst, das Geheimnisse aller Geheimnisse. Wortgetreu nach einer alten Handschrift, mit alten Holzschnitten. Braunschweig: Planet.

(1979): Das sechste und siebente Buch Mosis. Sein wahrer Wert und was das Volk darin sucht. Magisch-sympathetischer Hausschatz. Nach alten Ueberlieferungen aus Geheimschriften und Zauberbüchern für die heutige Zeit erklärt. Dresden: Gutenberg. In: 6./ 7. Buch Moses. Sein wahrer Wert und was das Volk darin sucht. Einleitung und Bildkommentare von Wolfgang Bauer. Berlin: Karin Kramer. S. XVII-LXIV.

[um 1880]: Das siebenmal versiegelte Buch der größten Geheimnisse oder magischsympathetischer Hausschatz in bewährter Mitteln wider viele Krankheiten und Gebrechen des Leibes; nebst wundersamen Geheimnisse zu Erreichung der verschiedenartigsten Zwecke. Leipzig: Hülsemann.

(1809): Der Kleine Catechismus mit der Auslegung D. Martin Luthers. Anhang In: Heiligen Lippen- und Herzens-Opfer einer gläubigen Seele oder Vollständiges Gesangbuch. Alten Stettin: Johann Samuel Leich. 16 Seiten.

Deutscher Evangelischer Kirchenausschuß. (Hrsg.) (1926): Deutsches Evangelisches Gesangbuch. Vom Deutschen Evangelischen Kirchenausschuß den deutschen evangelischen Gemeinden des Auslandes dargeboten. Berlin: Mittler \& Sohn. 
— (1912): Evangelisches Hausbuch für die Deutschen im Ausland. Berlin: Mittler und Sohn.

— (1909): Evangelisches Liederbuch für Deutsche im Ausland. Berlin: Mittler \& Sohn.

(1979): Die Praktika des täglichen Lebens, wie solche von klugen und erfahrenen Leuten als sonderlich nützlich und dienlich erachtet worden sind. In: 6./ 7. Buch Moses. Einleitung und Bildkommentare von Wolfgang Bauer. Berlin: Karin Kramer. S. 226-350.

[um 1880]: Die heiligen sieben Himmels-Riegel, welche ein frommer Ansiedler von seinem Schutz-Engel bekommen hat. Mit Bewilligung einer hohen Geistlichkeit aufs Neue zum Druck befördert zu Cöln am Rhein.

(1809): Evangelia und Episteln auf alle Sonn- und Fest-Tage durchs ganze Jahr wobey auch die in Pommern gebräuchliche Besondere Vesper-Texte befindlich, Nebst dem Symbolo Athanasii und der Geschichte vom Leiden, Sterben, Auferstehung und Himmelfahrt unseres Herrn und Heilandes Jesu Christi aus den vier Evangelisten zusammen gezogen. Wie auch die Zerstörung der Stadt Jerusalem mit allem Fleiß nach der Pommerschen Kirchen-Agenda eingerichtet. Anhang. In: Heiligen Lippen- und Herzens-Opfer einer gläubigen Seele oder Vollständiges Gesangbuch. Alten Stettin: Johann Samuel Leich. 112 Seiten.

(1809): Geist-reiches Gebet-Buch, darinnen Morgen- und Abend-Segen auf alle Tage in der Wochen, wie auch Sonn- und Fest-Tags, Buß-, Beicht-, Communion-, Dancksagungs-, Berufs-, Standes-, Creutr-, Anfechtungs-, Krieges-, Hungers-, Pestilen₹-, Wetter-, Reise-, Kranckbeits- und Sterbens-Gebete enthalten aus Arnds, Gerhards und anderer Evangelischen Lehrer geistreichen Büchern mit allem Fleiß zusammen getragen und in richtiger Ordnung verfasset. Mit Königl. Preuß. Allergnädigstem Privilegio. Alten Stettin: Johann Samuel Leich. Anhang. In Heiligen Lippen- und Herzens-Opfer einer gläubigen Seele oder Vollständiges Gesangbuch. Alten Stettin: Johann Samuel Leich, 1809. 84 Seiten.

Harms, Louis (1865): Predigten über die Episteln des Kirchenjahrs. Hermannsburg: Verlag des Missionshauses.

(1868): Predigten über die Evangelien des Kirchenjahrs. Hermannsburg: Verlag des Missionshauses.

(1851): Sechs Predigten und Dr. Luther's Anweisung zum Gebet. Celle: Schweiger \& Pick.

(ohne Jahresangabe): Haus- und Schutagrief. Neu Ruppin: Gustav Kuhn. 1 Blatt, 1 Seite, Fotografie. In: Seibel, Ivan (2010): Imigrante no século do isolamento/1870-1970. São Leopoldo: Traço. S. 332.

(ohne Jahresangabe): Haus-, Schutz- und Himmelsbrief. In: (1979): Magischsympathetischer Hausschatz oder Die offenbarten Geheimnisse der natürlichen Magie nebst Zauberformeln, Heil-Sprüchen und Schutzsegen wider 
allerlei Anfechtungen. In: 6./ 7. Buch Moses. Einleitung und Bildkommentare von Wolfgang Bauer. Berlin: Karin Kramer. S. 181-183.

(1956): Hausbuch. São Leopoldo: Sinodal.

(1959): Hausbuch. São Leopoldo: Sinodal.

(1809): Heiliges Lippen- und Herzens-Opfer einer gläubigen Seele oder Vollständiges Gesangbuch, enthält in sich die neuesten und alten Lieder des seeligen D. Lutheri und anderer erleuchteten Lehrer unserer Zeit zur Beförderung der Gottseligkeit bey öffentlichen Gottes-Dienst in Pommern und andern Orten zu gebrauchen, eingerichtet auch mit bekannten Melodeyen versehen; nebst Einem Geist-reichen Gebets-Buch von den Herrn General-Superintendenten Laurent David Bollhagen, mit vermehrtem Sonnund Festtags-Register versehen. Alten Stettin, gedruckt und verlegt von dem Königl. Preuß. Privilegierten Buchdrucker Johann Samuel Leich.

(1862): Heiliges Lippen- und Herzens-Opfer oder Vollständiges Gesang-Buch enthaltend alte und neue Lieder aus Dr. M. Luthers und anderen christlichen Gesangbüchern zur Beförderung der Gottseligkeit beim öffentlichen und bäuslichen Gottesdienst in Pommern und an anderen Orten zuerst eingerichtet von Dr. Laurentius David Bollhagen, Weiland General-Superintendenten des Herzogthums Pommern. Neue auf Anordnung des K. Consistorii der Provinz Pommern veranstaltete Ausgabe. Stettin: F. Hessenland. Privatarchiv von Pastor Nelso Weingärtner.

(ohne Jahresangabe): Himmelsbrief. In: Dieterich, Albrecht (1901): Himmelsbrief. In: Blätter für Hessische Volkskunde. Hrsg. im Auftrag der Vereinigung für Hessische Volkskunde, Nr. 3, III. Jahrgang. S. 9-10.

(ohne Jahresangabe): Himmelsbrief. Ohne Angabe des Druckers. DIN A4, 2 Blätter, 3 Seiten. Privatarchiv von Pastor Nelso Weingärtner.

(ohne Jahresangabe): Himmelsbrief Gredoria. Gedruckt in der Papelaria Alexandre Ribeiro, Rio de Janeiro. Din A4, 1 Blatt, 1 Seite. Quelle, die Dr. Claudete Beise Ulrich freundlicherweise zur Verfügung stellte.

(ca. 1720): Himmels-Brief welcher mit güldenen Buchstaben geschrieben und ist zu sehen in der Michaelis Kirche zu St. German, wird genannt Gredoria. Blattmaße $41 \mathrm{~cm} \mathrm{x}$ $34 \frac{1}{2} \mathrm{~cm}, 1$ Blatt, 1 Seite. Rro 65. Niedersächsische Staats- und Universitätsbibliothek Göttingen. Inventarnummer DD97 D 1.

(ohne Jahresangabe): Himmels-Brief wird genannt Credoria. Ohne Angabe des Druckers. 1 Blatt, 2 Seiten. Fotografie. In: Maltzahn, Gislaine Maria (2011): Familia, ritual e ciclos de vida. Estudo Etnográfico sobre narrativas pomeranas em Pelotas (RS). Pelotas: Universidade Federal de Pelotas. S. 141-142.

Jaspis, Albert Sigismund (1851): Der kleine Catechismus Luthers aus sich selbst erklärt, wie aus der heiligen Schrift, namentlich ibren Geschichten erläutert. Zugleich ein Hülfsbüchlein, durch den Unterricht in der biblischen Geschichte die Unterweisung in der evangelischen Heilslehre vorzubereiten. Elbersfeld/Leipzig: Wilhelm Hassel/ Barth \& Schulze. 
[1926?]: Kleine Missionsharfe im Kirchen-und Volkston für festliche und außenfestliche Kreise. 83. Auflage. Gütersloh: C. Bertelsmann. Quelle, die Cláudio Böhning freundlicherweise zur Verfügung stellte.

(1979): Magisch-sympathetischer Hausschatz oder Die offenbarten Geheimnisse der natürlichen Magie nebst Zauberformeln, Heil-Sprüchen und Schutzsegen wider allerlei Anfechtungen. In: 6./ 7. Buch Moses. Einleitung und Bildkommentare von Wolfgang Bauer. Berlin: Karin Kramer. S. 31225.

(ohne Jahresangabe): Mensagem (Carta) celeste (chamada Credo). Ohne Angabe des Druckers. 1 Blatt, 2 Seiten. Fotografie. In: Maltzahn, Gislaine Maria (2011): Família, ritual e ciclos de vida. Estudo Etnográfico sobre narrativas pomeranas em Pelotas (RS). Pelotas: Universidade Federal de Pelotas. S. 143-144.

(2010): Neue Luther Bibel. Nach der Übersetzung Martin Luthers. Wollerau: La Buona Novella. Zweite Aufgabe.

[um 1880]: Neunzig Geheimnisse, die ein frommer Einsiedler vom seinem Schutzengel bekommen hat, mit Bewilligung einer hohen Geistlichkeit auf's Neue zum Druck befördert für landwirtschaftliche und bäusliche Verhältnisse. Gedruckt zu Cöln am Rhein.

(1984): Patenbrief aus dem Jahre 1984, Indaial (SC). Privatarchiv Scheila Janke.

(1984): Patenbrief aus dem Jahre 1984, Indaial (SC). Auf Portugiesisch. Privatarchiv Scheila Janke.

[um 1880]: Romanus-Büchlein oder Gott der Herr bewahre meine Seele, meinen Aus- und Eingang; von nun an bis in alle Ewigkeit, Amen. Halleluja. Leipzig: Hülsemann.

(ohne Jahresangabe): Schutzbrief. Handschrift. DIN A4, liniertes Schreibpapier. 2 Blätter, 4 Seiten. Privatarchiv Scheila Janke.

(ohne Jahresangabe): Schutzbrief. Ohne Angabe des Druckers. DIN A4. 1 Blatt, 2 Seiten. Privatarchiv von Pastor Nelso Weingärtner.

[1980]: Sechstes u. siebentes Buch Mosis oder der magisch-sympathetische Hausschatz, das ist Mosis magische Geisterkunst, das Geheimniß aller Geheimnisse. Wortgetreu nach einer alten Handschrift mit staunenerregenden Abbildungen. Nachdruck der Ausgabe] Philadelphia. Leipzig: Hülsemann.

Stark, Johann Friedrich (19. Jahrhundert): Tägliches Gebetbüchlein für Schwangere, Gebärende und Wöchnerinnen; enthaltend Morgen- und Abend-Gebete, Aufmunterungen, Trost- und Erquickungs-Andachten und Gesänge, sowie auch Sprüche, Seufzer und Gebete, welche in Nöthen zu sprechen und vorzusprechen sind, und Erinnerungsund Trost-Gebete und Gesänge für Unfruchtbare. Als den V. und VI. Theil des täglichen Handbuchs. Stuttgart: Steinkopf.

(19. Jahrhundert): Tägliches Handbuch in guten und bösen Tagen: enthaltend Aufmunterungen, Gebete und Gesänge für Gesunde, Betrübte, Kranke und Sterbende, ferner Sprüche, Seufzer und Gebete, den Sterbenden vorzusprechen, mehrere Festan- 
dachten, Buß-, Beicht-, Communion- und Wetter-Gebete, Trost- und ErquickungsGebete und Gesänge, wie auch Kriegs-, Theurungs-, Pest- und Friedens-Gebete, nebst einem Gebetbüchlein für Schwangere, Gebärende, Wöchnerinnen und für Unfruchtbare. Stuttgart: Steinkopf.

- (1720): Tägliches Hand-Buch in guten und bösen Tagen. Aufmunterung, Gebete und Gesänge für Gesunde, Betrübte, Kranke und Sterbende. Sprüche, Seufzer und Gebete den Sterbenden vorzusprechen nebst Andachten für die Festzeiten und bei besonderen Gelegenheiten. Reutlingen: Enßlin \& Laiblin. Privatarchiv von Pastor Nelso Weingärtner.

(1750): Vermehrtes Kirchen- und Haus-Gesang-Buch für das Königl. Schwedische Herrogthum Pommern und Fürstenthum Rügen. Auf Verordnung der Königl. Hochpreisl. Regierung zum allgemeinen Gebrauch ausgefertiget. Nebst einem erbaulichen GebetBuche. Greifswald: Hieronymus Johann Struck.

\section{Sekundäre Quellen}

Ackermann, Silvia Regina (2009): Quando preferir um samba ao bino nacional é crime: integralismo, etnicidade e os crimes contra o Estado e a Ordem Social (Espírito Santo - 1934-1945). São Carlos: Universidade Federal de São Carlos.

Aldinger, Paul (um 1922): Kirchlich-kolonisatorisches Merkblatt für Brasilien. Witzenhausen: Chr. Trautvetter.

Altmann, Luciana (2002): 500 Anos de Pomerode. Histórias de vida de sete personagens. Santa Maria: Pallotti.

Amaro, Luana da Silva (2014): Resiliencia, religiosidade e sentido de vida em mulheres com câncer de mama. João Pessoa: Universidade Federal da Paraíba.

Anonym (2016): Über die persönliche Gottesbeziehung und religiöse Selbsterfahrung zu psychischer Gesundheit. Kann christliche Religiosität ein fördernder Faktor für Resilienz und Salutogenese sein? Norderstedt: Grin.

Arbeitsgemeinschaft 25. Juli in Rio Grande do Sul (Hrsg.) (1936): Kurze Geschichte der deutschen Einwanderung in Rio Grande do Sul. São Leopoldo: Rotermund.

Arquivo histórico de Joinville. Listagem informatizada dos imigrantes 1851-1891, 1897-1902. http://www.arquivohistoricojoinville.com.br/ListaImigrantes/lista/tudo. htm Zugang am 14.3.2016.

Associação dos Amigos do Arquivo Histórico de Indaial (2015): Indaial. Conhecendo sua bistória. Indaial: AMARHIN, t. 1, n. 2, jun./ago. 2015.

__ (2015): Indaial. Conbecendo sua história. Indaial: AMARHIN, t. 1, n. 3, set./nov. 2015. 
— (2015): Indaial. Conhecendo sua história. Indaial: AMARHIN, t. 1, n. 4, dez. 2015/fev. 2016.

- (2016): Indaial. Conhecendo sua história. Indaial: AMARHIN, t. 2, n. 1, mar./maio 2016.

- (2016): Indaial. Conhecendo sua história. Indaial: AMARHIN, t. 2, n. 2, jun./ago. 2016.

Auswandererlisten des Staatsarchiv Hamburg mit Hamburger Passagierlisten von 1850 bis 1934. Verfügbar In: http://www.hamburgerpassagierlisten.de/ Zugang am 22.3.2017.

Avé-Lallemant, Robert (1859): Reise durch Südbrasilien im Jabre 1858. 1. Teil. Leipzig: F. A. Brockhaus.

— (1859): Reise durch Südbrasilien im Jahre 1858. 2. Teil. Leipzig: F. A. Brockhaus.

Baade, Joel Haroldo (2007): Da guerra à união: uma abordagem histórica da caminhada da Associação Evangélica de Comunidades e do Sínodo Evangélico-Luterano até a sua fusão e formação do Sínodo EvangélicoLuterano Unido. São Leopoldo: Escola Superior de Teologia.

- (2011): Os conflitos comunitários e sinodais e a formação e consolidação da IECLB: as trajetórias da Associação Evangélica de Comunidades e do Sínodo Evangélico-Luterano até a sua fusão e constituição do Sínodo EvangélicoLuterano Unido em 1962. São Leopoldo: Escola Superior de Teologia.

Bahia, Joana (2011): O tiro da bruxa. Identidade, magia e religião na imigração alemã. Rio de Janeiro: Garamond.

Bartolomei, Mônica (2008): A fé como fator de resiliência no tratamento do câncer. Uma análise do que pensam os profissionais da saúde sobre o papel da espiritualidade na recuperação dos pacientes. São Paulo: Pontifícia Universidade Católica de São Paulo.

Bauer, Wolfgang (1979): Einleitung. In: 6./ 7. Buch Moses. Sein wahrer Wert und was das Volk darin sucht. Einleitung und Bildkommentare von Wolfgang Bauer. Berlin: Karin Kramer. S. 4-23.

- (1979): Vom sechsten und siebenten sowie vom achten und zehnten Buch Mosis. In: 6./ 7. Buch Moses. Sein wahrer Wert und was das Volk darin sucht. Einleitung und Bildkommentare von Wolfgang Bauer. Berlin: Karin Kramer. S. X-XVI.

(1979): Was hat man von dem Volksglauben und der Volksmedizin zu halten? In: 6./ 7. Buch Moses. Sein wahrer Wert und was das Volk darin sucht. Einleitung und Bildkommentare von Wolfgang Bauer. Berlin: Karin Kramer. S. 1-30.

Baviera, Princesa Teresa da (2013): Viagem ao Espirito Santo 1888 - Viagem pelos Trópicos Brasileiros. Vitória: Arquivo Público do Estado do Espírito Santo. 
Beckert, Hans Günther; Nail, Norbert (2008): Der alte Gasthof zum Scbützenpfubl in Marburg. Mit einem Beitrag über „Himmelsbrief“. Marburg: Magistrat der Stadt Marburg.

Beitl, K. (1958): Briefe, Rel. Volkskunde. In: Rahner, Karl. (Hrsg.) Lexikon für Theologie und Kirche. 2. Auflage, 2. Band, Freiburg: Herder. S. 687-688.

Bergmann, Sigurd (2010): Raum und Geist. Zur Erdung und Beheimatung der Religion - eine theologische Ästhetik des Raumes. Göttingen: Vandenhoeck \& Ruprecht.

(1859): Bericht des General-Landamtes für 1859. In: Hörmeyer, J. (Hrsg.) Actenstücke Brasilianischer Seite, betreffend die Kolonisation des Kaiserreiches. 1. Jahrgang, Heft 6, Rudolfstadt/Berlin: Verlag des F. priv. Hofbuchdruckerei/Franz Wagner. S. 22-48.

Beskow, Aldo. E-Mail von 10.10.2015.

Biehl, João Guilherme (1999): A guerra dos imigrantes: o espírito alemão e o estranho Mucker no sul do Brasil. In: Psicanálise e colonização: leituras do sintoma social no Brasil. Porto Alegre: Artes e Ofícios. S. 148-168.

Bitterli, Urs (2004): Die ,Wilden' und die ,Zivilisierten' Grundzüge einer Geistesund Kulturgeschichte der europäisch-überseeischen Begegnung. München: C. H. Beck.

Blum, Wilhelm (2012): Resilienz nach den Schriften der ersten Christen. In: Sedmak, Clemens; Bogaczyk-Vormayr, Małgorzata (Hrsg.) (2012): Patristik und Resilien₹. Frühchristliche Einsichten in die Seelenkraft. Berlin: Akademie Verlag. S. 11-30.

Boehs, Astrid (2008): Uma Familia, tempos, movimentos e espacos. Família de Johann Heinrich Eggert e Dorothea Louise nascida Tessmann. Verfügbar in: http://astrideboehs.blogspot.de/2008/11/uma-familia-temposmovimentos-e-espaos.html Zugang am 29.3.2016.

Borchers, Walter; Kaiser, Karl (1936): Leben und Sterben im pommerschen Volksbrauch. Stettin: Landesbauernschaftsverlag Pommern.

Borowski, Christiane (2016): Rechnen, Lieben und Beten. In: Evangelische Kirche in Deutschland (Hrsg.) Das Magazin zum Themenjahr 2016. Reformation und die Eine Welt. Greven: Druckhaus Cramer. S. 81.

Bosenbecker, Patricia (2011): Uma colônia cercada de estâncias: imigrantes em São Lourenço/RS (1857-1877). Porto Alegre: Universidade Federal do Rio Grande do Sul.

Boss, Pauline (2008): Verlust, Trauma und Resilienæ: Die therapeutische Arbeit mit dem "uneindeutigen Verlust". Stuttgart: Klett-Cotta.

Braga, Lucineide Alves Vieira (2009): Terapia Comunitária e Resiliência: história de mulheres. João Pessoa: Universidade Federal da Paraíba. 
Breitenbach, Wilhelm (1885): Die Provinz Rio Grande do Sul, Brasilien und die deutsche Auswanderung dabin. Heidelberg: Carl Winter's Universitätsbuchhandlung.

Brückner, Annemarie (2010): Taufe. In: Brednich, Rolf Wilhelm. Enzylklopädie des Märchens. Handwörterbuch zur historischen und vergleichenden Erzählforschung. Band 13. Berlin/New York: De Gruyter.

(ohne Jahresangabe): Büchlein mit Familiengenealogie, Família Johann Neuschrank e Helena Neuschrank. Colônia Arroio do Padre I, $10^{\circ}$ Distrito de Pelotas.

Büge, Klaus (2001): Das Geschlecht der Büges aus dem Kreis Greifenberg. Elf Generationen eines Bauerngeschlechts, das damalige Leben in Pommern und ein neuer Anfang nach Flucht und Vertreibung. Husum: Husum Druck und Verlagsgesellschaft.

Bürger, Otto (1926): Brasilien. Eines Landes- und Wirtschaftskunde für Handel, Industrie und Einwanderung. Leipzig: Dieterich.

Bürger, Alexander (1857): Colonie Blumenau, 19.1.1857. In: Blumenau, Hermann. Jahresbericht über die Ereignisse und Fortschritte der deutschen Kolonie Blumenau 1856. Erhaltend Aufsätze, Zeitungscorrespondenzen und Briefe von Ansiedler in Blumenau und deren Verwandten in Deutschland, so wie eine Karte des Itajahyflußgebietes. Hamburg: Robert Kittler. S. 13-16.

Busche, Gesa Anne (2013): Über-Leben nach Folter und Flucht. Resilienz kurdischer Frauen in Deutschland. Bielefeld: Transcript.

Butzke, Paulo Afonso (2009): Ernesto T. Schlieper: Teologia e Edificação de Comunidade na IECLB do Pós-Guerra. In: Estudos Teológicos, v. 49, n. 2 Jul./dez. 2009, São Leopoldo. S. 253-267.

Buzzarello, Silvinha (1996): O menino emigrante: Albert Paul Ramlow. In: Prefeitura Municipal de Pomerode. Pomerode, sua história, sua cultura, suas tradições. V. 6. Pomerode: Prefeitura Municipal. S. 30-37.

Calandro, Eduardo Antonio (2013): Catequese com adultos: fé e resiliência. Goiânia: Pontifícia Universidade Católica de Goiás.

Camões Filho, Ribeiro do Couto (2003): O Canto do Vento: a história dos prisioneiros alemães nos campos de concentração brasileiros. São Paulo.

Cancelli, Elizabeht (1991): O mundo da violência: repressão e estado policial na era Vargas (1930-1945). Campinas: Universidade Estadual de Campinas.

Carvalho, Augusto de (1876): O Brą̣il. Colonisação e Emigração. Esboço histórico baseado no estudo histórico dos systemas e vantagens que oferecem os Estados Unidos. Porto: Imprensa Portuguesa.

Christillino, Cristiano Luis (2006): A Colonização e a grilagen no Rio Grande do Sul no século XIX. In: MNEME Revista de Humanidades, v. 08. Nr. 22, jun./jul. de 2006, S. 101-126. Verfügbar in: http://periodicos.ufrn.br/ mneme/article/view/367/340 Zugriff am 1.4.2014. 
Claas, Armando Emílio (2008): História da Paróquia Evangélica Luterana Apóstolo Pedro: Primórdios da Comunidade Evangélica de Jaraguá do Sul. In: Klug, João; Ulrich, Claudete Beise (Org). Presença e atuação da Igreja Evangélica de Confissão Luterana de Jaraguá do Sul. Porto Alegre: Metrópole. S. 21-77.

Clemens, Lieselotte (1976): Die Auswanderung der pommerschen Altlutheraner in die US A. Ablauf und Motivation 1839-1853. Hamburg: Pommerscher Zentralverband e.V.

Comité für die protestantischen Deutschen in Brasilien (1878): Die Arbeit unter den Evangelischen Deutschen in Brasilien. Barmen: Wiemann.

Comunidade Evangélica de Confissão Luterana Ascensão (2011): $2^{\circ}$ Templo 1951-2011. Verfügbar in: http://www.ascensao.org.br/site/historia-dacomunidade-2/2-templo-1951-2011-2/ Zugang am 22.9.2016.

Correia, Wilson (1987): Eng. Carl August Wunderwald. O bandeirante alemão no sertão catarinense. In: Prefeitura Municipal de Pomerode. Pomerode, sua história, sua cultura, suas tradições. V. 4. Pomerode: Tipografia Mayer Ltda. S. 9-17.

Costa, Jairo Scholl (2007): O Pescador de Arenques. Pelotas: EDUCAT.

Creutzberg, Leonhard (2001): Estou pronto para cantar: subsídios para a hinariologia da IECLB. São Leopoldo: Sinodal.

Csallner, Heinz (2002): Bilder aus Hinterpommern. Über 360 Fotos vom Leben wie es damals war. Dörfler.

Da Cunha, Gladson Pereira (2012): Noivo, noiva e louças quebradas: Simbologia, Teatralidade e Performance nas cerimônias mágicas no casamento pomerano sob a perspectiva antropológica de Van Gennep, Turner e Geertz. In: ANTROPOS, Revista de Antropologia, ano 4. v. 5, maio 2012. S. 153-181. Verfügbar in: http://revista.antropos.com.br/downloads/ maio2012/Artigo6-Noivo.pdf Zugang am 2.4.2014.

Daemon, Basílio Carvalho (2010): Provincia do Espirito Santo. Sua descoberta, história cronológica, sinopse e estatística. Vitória: Secretaria do Estado da Cultura/Arquivo Público do Estado do Espírito Santo.

Damitz, Hans (1994): Das alte Pommern (bis Anfang 19. Jahrhundert), 24.9.1994. Manuskript im Privatarchiv von Pastor Nelso Weingärtner.

- (1991): Die ausgewanderten Pommern und die Stellung von Schule und Kirche im ländlichen Brasilien. Mai/Juni 1991. Manuskript im Privatarchiv von Pastor Nelso Weingärtner.

__ (1997): Die deutsch-pommerschen Siedlungen in den drei Südstaaten Brasiliens und ibr kulturelles Leben. Vortrag am Seminar der Ostsee-Akademie, 25-27. April 1997. Manuskript im Privatarchiv von Pastor Nelso Weingärtner.

__ (ohne Jahresangabe): Die Kirche im Land. Manuskript im Privatarchiv von Pastor Nelso Weingärtner. 
- (1987): Die wirtschaftliche und gesellschaftliche Entwicklung Pommerns zwischen 1800 und 1860. In: Greifenberg-Treptower Geschichtsverein e.V. (Hrsg.) Beiträge zur Greifenberg-Treptower Geschichte. Eichstätt: FranzSales-Verlag. S. 43-79.

— (ohne Jahresangabe): Entwicklungsaspekte zur Situation der Brasilianer deutscher Abstammung im Staat Espirito Santo. Manuskript im Privatarchiv von Pastor Nelso Weingärtner.

- (ohne Jahresangabe): Pommerland in Brasilien. Die Einwanderung nach Brasilien bis in die jüngste Zeit. Manuskript im Privatarchiv von Pastor Nelso Weingärtner.

(1991): Pommern im 19. Jahrbundert. 10.3.1991. Manuskript im Privatarchiv von Pastor Nelso Weingärtner.

(1994): Pommern im 19. Jahrbundert und die Auswanderung der Pommern. 29.9.1994. Manuskript im Privatarchiv von Pastor Nelso Weingärtner.

- (1989): Stellenwert der Christianisierung Pommerns und die Bedeutung für die pommersche Kirche. Januar 1989. Manuskript im Privatarchiv von Pastor Nelso Weingärtner.

(1863): Das Gesetz über die Ehen zwischen Nichtkatholiken und das Reglement zur Ausführung desselben. In: Hörmeyer, J. (Hrsg.) Actenstücke Brasilianischer Seite, 4. Band, Rudolfstadt/Berlin: Verlag des F. priv. Hofbuchdruckerei/Franz Wagner. S. 122-137.

Dedekind, Max (1912): 75 Jahre deutsch-evangelischer Diasporaarbeit in Nord- und Südbrasilien. Festschrift zum 75jährigen Jubiläum der „Evangelischen Gesellschaft für die protestantischen Deutschen in Amerika“. Barmen: Wiemann.

(1924): Brasilien, das Ziel deutscher Auswanderer und die Deutsche Evangelische Kirche in Brasilien. Zur Jahrhundertfeier deutscher Einwanderung in Brasilien. Elberfeld: Evangelischen Gesellschaft für die protestantischen Deutschen in Südamerika.

(1861): Dekret Nr. 1.141 von 11.9.1861 welches die bürgerlichen Rechtswirkungen der den Reichsgesetzen gemäß geschlossenen Ehen auf die Personen ausdehnt, welche eine von der Staats-Religion abweichende Lehre bekennen, und anordnet, daß die Heiraths-, Geburts- und Todtenregister der gedachten Personen sowie die nothwendigen Bedingungen geregelt werden, damit die Pastoren der tolerierten Religionen Handlungen vornehmen können, die bürgerliche Rechtswirkungen erzeugen. In: Hörmeyer, J. Actenstücke Brasilianischer Seite, 3. Jahrgang, Heft 3, Rudolfstadt/Berlin: Verlag des F. priv. Hofbuchdruckerei/Franz Wagner. S. 343-344.

Delegacia de ordem política e social de Santa Catarina (Hrsg.) (1944): O punhal nazista no coração do Brasil. Florianópolis: Imprensa Oficial do Estado. 
(1860): Der Gesetzentwurf in Bezug auf protestantischen Ehen. Zweite Lesung. In: Hörmeyer, J. (Hrsg.) Actenstücke Brasilianischer Seite, betreffend die Kolonisation des Kaiserreiches. 2. Jahrgang, Heft 4, Rudolfstadt/Berlin: Verlag des F. priv. Hofbuchdruckerei/Franz Wagner. S. 165-226.

Desel, Jochen (2013): Zugang zum Abendmahl. Méreaux im deutschen Refuge und in anderen deutschsprachigen Gemeinden. Bad Karlshafen: Verlag der Deutschen Hugenotten-Gesellschaft.

(1857): Die Kolonie Blumenau in Brasilien. Der Weimarschen Zeitung, eingesandt von Herrn Justizrath Hering in Jena. In: Blumenau, Hermann. Jahresbericht über die Ereignisse und Fortschritte der deutschen Kolonie Blumenau 1856. Hamburg: Robert Kittler. S. 5-6.

Dieterich, Albrecht (1901): Himmelsbrief. In: Blätter für Hessische Volkskunde. Hrsg. im Auftrag der Vereinigung für Hessische Volkskunde, Nr. 3, III. Jahrgang. S. 9-12.

Dörfler-Dierken, Angelika (2003): Die Möllner Kommunikantentafeln. Lutherische Abendmahlspraxis im Wandel der Zeit. Neumünster: Wachholtz.

Dreher, Arno (1970): Aufbruch in die Zukunft. In: Fischer, Joachim; Jahn, Christoph (Hrsg.) Es begann am Rio dos Sinos. Geschichte und Gegenwart der Ev. Kirche Lutherischen Bekenntnisses in Brasilien. Erlangen: Verlag der Ev. Lutherischen Mission. S. 9-13.

Dreher, Martin N. (1989): Geschichte der EKLBB. In: Brakemeier, Gottfried (Hrsg.) Glaube im Teilen bewahrt. Lutherische Existenz in Brasilien. Erlangen: Verlag der Ev.-Luth. Mission. S. 174-188.

—_ (2005): História do Povo Luterano. São Leopoldo: Sinodal.

—_ (1984): Igreja e Germanidade. Estudo crítico da história da Igreja Evangélica de Confissão Luterana no Brasil. São Leopoldo/Porto Alegre/Caxias do Sul: Sinodal/Escola Superior de Teologia São Lourenço de Brindes/Universidade de Caxias do Sul.

_ (2011): Kontexte und Kirche, Werden und Gegenwart der IECLB. In: Gustav-Adolf-Werk (Hrsg.) Evangelium - Markt - Kreuz: evangelischlutherisch in Brasilien. Festschrift anlässlich des 70. Geburtstages von Dr. Dr. h.c. Wilhelm Hüffmeier. Leipzig: Verlag des Gustav-Adolf-Werks. S. 12-29.

_- (2010): Sträflinge aus Mecklenburg-Schwerin und die Anfänge deutscher Einwanderung in Brasilien. São Leopoldo: Oikos. Zweisprachige Auflage.

Dressel, Heinz (1986): A Igreja Evangélica face ao desafio brasileiro. In: Fischer, Joachim. Ensaios Luteranos. Dos primórdios aos tempos atuais do luteranismo no Brasil. São Leopoldo: Sinodal. S. 112-124.

Droogers, André (2008): Religião, Identidade e Segurança entre Imigrantes Luteranos da Pomerânia no Espírito Santo (1880-2005). In: Religião e Sociedade, Rio de Janeiro, 28 (1). S. 13-41. 
Droste, Rolf (2011): Die Bedeutung der Obra Gustavo Adolfo für die Evangelische Kirche Lutherischen Bekenntnisses in Brasilien. In: GustavAdolf-Werk (Hrsg.) Evangelium - Markt - Kreuz: evangelisch-lutherisch in Brasilien. Leipzig: Verlag des Gustav-Adolf-Vereins. S. 66-71.

(1989): Struktur und Mission der EKLBB. In: Brakemeier, Gottfried (Hrsg.) Glaube im Teilen bewahrt. Lutherische Existenz in Brasilien. Erlangen: Verlag der Ev.-Luth. Mission. S. 205-218.

Elia, Silvio Edmundo (1991): Pomerode - um caso de bilingüismo. Prefeitura Municipal de Pomerode. Pomerode, sua história, sua cultura, suas tradições. V. 5. Pomerode: Prefeitura Municipal. S. 50-57.

Evangelische Gesellschaft für die protestantischen Deutschen in Amerika (1886): Der Deutsche Ansiedler, Nr. 5.

Evangelische Synode von Santa Catarina und Paraná (1961): Unsere Väter. Ein Heimatbuch, in dem wir aus unserer hundertjährigen Geschichte hören. Bearbeitet von Max-Heinrich Floss. São Leopoldo: Rotermund.

Familienforschungsportal. Verfügbar in: https://www.ancestry.de/ Zugang am 22.3.2017.

Fáveri, Marlene (2002): Memórias de uma (outra) guerra. Cotidiano e medo durante a Segunda Guerra em Santa Catarina. Florianópolis: Universidade Federal de Santa Catarina.

Ferraz, Luiz Pedreira do Coutto (1859): Die deutschen Ackerbau-Colonien in Santa Catharina (Brasilien). Ihre Lage und ihre Zukunft, dargestellt in den Berichten des kaiserlich Brasilianischen Staatsrathes. Hamburg: G. W. Niemeyer.

Filipp, Sigrun-Heide; Aymanns, Peter (2010): Kritische Lebensereignisse und Lebenskrisen. Vom Umgang mit den Schattenseiten des Lebens. Stuttgart: W. Kohlhammer.

Fingerle, Michael (2008): Der „riskante“ Begriff der Resilienz - Überlegungen zur Resilienzförderung im Sinne der Organisation von Passungsverhältnissen. In: Opp, Günther; Fingerle, Michael. Was Kinder stärkt. Erziehung zwischen Risiko und Resilienz. München: Ernst Reinhardt. S. 299-310.

Fischer, Joachim (1986): A luta contra os pastores-colonos no Rio Grande do Sul no século XIX. In: Fischer, Joachim (Hrsg.) Ensaios Luteranos. Dos Primórdios aos tempos atuais do luteranismo no Brasil. São Leopoldo: Sinodal. S. 33-52.

(1970): Geschichte der Evangelischen Kirche Lutherischen Bekenntnisses in Brasilien. In: Fischer, Joachim; Jahn, Christoph (Hrsg.) Es begann am Rio dos Sinos. Geschichte und Gegenwart der Ev. Kirche Lutherischen Bekenntnisses in Brasilien. Erlangen: Verlag der Ev. Lutherischen Mission. S. 83-204.

- (1986): Os primórdios da pregação itinerante e do trabalho de diáspora no Sínodo Rio-Grandense. In: Fischer, Joachim (Hrsg.) Ensaios Luteranos. 
Dos Primórdios aos tempos atuais do luteranismo no Brasil. São Leopoldo: Sinodal. S. 53-72.

Fluck, Marlon Ronald (2004): Basler Missionare in Brasilien. Auswanderung, Erweckung und Kirchenwerdung im 19. Jahrhundert. Bern: Peter Lang.

Fonseca, Maria Angela Peter da (2007): Estratégias para a Preservação do Germanismo (Deutschtum): Gênese e Trajetória de um Collegio Teuto-Brasileiro urbano em Pelotas (1898-1942). Pelotas: Universidade Federal de Pelotas.

Fooken, I. (2013): Resilienz und posttraumatische Reifung. In: Maercker, Andreas (Hrsg.) Posttraumatische Belastungsstörungen. Berlin/Heidelberg: Springer. S. 71-94.

(1640): Form zu Beichten vnd Christliche Fragstücke für dieselbigen. So zum Abendmahl des Herrn gehen wollen: wie sie zum Stralsund in Pommern in den Kirchen den Kindern vnd Gesinde vor der Cantzel vorgelesen werden. Stralsund: Meder.

Franceschetto, Cilmar (2014): Imigrantes Espirito Santo. Base de dados da imigração estrangeira no Espírito Santo nos séculos XIX e XX. Vitória: Arquivo Público do Estado do Espírito Santo.

_- (2004): Victor Frond: o pioneiro da fotografia no Espírito Santo - Dados sociológicos da imigração suíça no Espírito Santo. In: von Tschudi, Johann Jakob. Viagem à província do Espirito Santo. Vitória: Arquivo Público do Estado do Espírito Santo. S. 123-152.

Freeden, Hermann von; Smolka, Georg. (Hrsg.) (1937): Auswanderer. Bilder und Skizzen aus der Geschichte der deutschen Auswanderung. Leipzig.

Fröhlich-Gildhoff, Klaus (2013): Gemeinde: Das Quartier als Risiko- und Schutzfaktor. In: Steinebach, Christoph; Gharabaghi, Kiaras (Hrsg.) Resilienzförderung im Jugendalter. Praxis und Perspektiven. Berlin/Heidelberg: Springer. S. 165-181.

Fröhlich-Gildhoff, Klaus, Rönnau-Böse, Maike (2015): Resilienz: München: Ernst Reinhardt.

Gaede, Valdemar (2012): Presença Luterana no Espírito Santo. Os primórdios da presença luterana no estado do Espírito Santo e a história da Paróquia de Santa Maria de Jetibá. São Leopoldo: Oikos.

Gertz, René (1987): O fascismo no sul do Brasil. Germanismo, nazismo, integralismo. Porto Alegre: Mercado Aberto.

__ (2001): Os Luteranos no Brasil. In: Revista de História Regional 6 (2). S. 9-33.

Giurus, Friedrich (1969): Crônica da Paróquia Evangélica Luterana de Indaial 18891969. Blumenau: Tipografia e Livraria Blumenauense. Zweisprachige Auflage. 
_ (1998): Meinrad Piske - Flashes de uma vida dedicada à Igreja. Blumenau: Otto Kuhr.

- (2016): Otto Kuhr. In: Backhause, Martin; Zeller, Hans. (Hrsg.) Aufbruch in Grenzen. Von der Migrationskirche zur lutherischen Kirche in Brasilien. Neuendettelsau/Nürnberg/Erlangen: Verlag für Mission und Ökumene/mabase-Verlag/Martin-Luther-Verlag. S. 13-46.

Goehrtz, Emil (1931): Das Bauernhaus im Regierungsbezirk Köslin. In: Metz, Friedrich (Hrsg.) Forschungen zur deutschen Landes- und Volkskunde im Auftrage der Zentralkommission für wissenschaftliche Landeskunde von Deutschland. 28. Band, Heft 3. Stuttgart: J. Engelhorns Nachf. S. 244-269.

Goeters, J. F. Gerhard (1992): Der Anschluß der neuen Provinzen von 1815 (Sachsen, Vorpommern, Posen, Westpreußen, Westfalen, beide Rheinprovinzen) und ihre kirchliche Ordnung. In: Goeters, J. F. Gerhard; Mau, Rudolf (Hrsg.) Die Geschichte der Evangelischen Kirche der Union. Band I. Die Anfänge der Union unter landesherrlichem Kirchenregiment (1817-1850). Leipzig: Evangelische Verlagsanstalt. S. 77-87.

Goeze, Johann Melchior (1775): Versuch einer Historie der gedrucktenniedersächsischen Bibeln vom Jahr 1470 bis 1621. Halle: Gebauer.

Goldschmidt, Hans (1910): Die Grundbesitzverteilung in der Mark Brandenburg und in Hinterpommern vom Beginn des dreißigjährigen Krieges bis zur Gegenwart. Berlin: Carl Heymanns.

Göppel, Rolf (2008): Bildung als Chance. In: Opp, Günther, Fingerle, Michael. Was Kinder stärkt. Erziehung zwischen Risiko und Resilienz. München: Ernst Reinhardt. S. 245-264.

Grando, Marinês Z. (1984): A colonização Européia não portuguesa no Município de Pelotas. In: Ensaios FEE. Porto Alegre 5(2). S. 47-55.

Granzow, Klaus (1972): Grün ist das Tal am Rio Itajai. Pommeranos in Brasilien. Hamburg: Pommerscher Buchversand.

- (2000): Pommeranos unter dem Kreuz des Südens. Deutsche Siedler in Brasilien. Słupsk: Grawipol.

Grosselli, Renzo M. (2008): Colônias Imperiais na Terra do Café - Camponeses trentinos (vênetos e lombardos) nas florestas brasileiras, Espirito Santo 1874-1900. Vitória: Arquivo Público do Estado do Espírito Santo.

Grotberg, Edith H. (2011): Anleitung zur Förderung der Resilienz von Kindern. Stärkung des Charakters. In: Zander, Margherita; Roemer, Martin (Hrsg.) Handbuch Resilienzförderung. Wiesbaden: Verlag für Sozialwissenschaften/Springer. S. 51-101.

Grothe, Hugo (1936): Im Kamp und Urwald Südbrasiliens. Berlin/Halle: Buchhandlung des Waisenhauses.

Grube, Karl (1916): Bei deutschen Brüdern im Urwald Brasiliens. Eine Rundfahrt. Leipzig: Dieterich. 
Guenther, Anita (1985): Biografia do primeiro professor em Pomerode. In: Prefeitura Municipal de Pomerode. Pomerode, sua história, sua cultura, suas tradições. V. 1. Pomerode: Prefeitura Municipal. S. 5-8.

_- (1986): Histórias que a vida conta. In: Prefeitura Municipal de Pomerode. Pomerode: sua história, sua cultura, suas tradições. V. 1. Pomerode: Prefeitura Municipal. S. 5-8.

Heck, Uwe; Heitz, Gerhard (1995): Die Union der Stände von 1523. Ereignis und Folgen. In: Karge, Wolf; Rakow, Peter-Joachim; Wendt, Ralf. (Hrsg.) Ein Jahrtausend Mecklenburg und Vorpommern. Biographie einer Norddeutschen Region in Einzeldarstellungen. Rostock: Hinstorff. S. 134-142.

Hees, Ulrich (1986): Metamorfoses de uma Igreja de Emigrantes. In: Fischer, Joachim (Hrsg.) Ensaios Luteranos. Dos Primórdios aos tempos atuais do luteranismo no Brasil. São Leopoldo: Sinodal. S. 73-84.

_ (1986): Pastorado e Pastores no Rio Grande do Sul. In: Fischer, Joachim (Hrsg.) Ensaios Luteranos. Dos Primórdios aos tempos atuais do luteranismo no Brasil. São Leopoldo: Sinodal. S. 21-32.

Hennig, Martin (1986): Os auxílios de entidades evangélicas na Alemanha em prol dos evangélicos no Brasil, dos seus primórdios até o ano de 1900. In: Fischer, Joachim (Hrsg.). Ensaios Luteranos. Dos Primórdios aos tempos atuais do luteranismo no Brasil. São Leopoldo: Sinodal. S. 85-111.

Heyde, Franz von der (1987): Fundação da Escola Alemã em Testo Central. In: Prefeitura Municipal de Pomerode. Pomerode, sua história, sua cultura, suas tradiçoes. V. 4. Pomerode: Prefeitura Municipal. S. 18-22.

Heyden, Hellmuth (1960): Zur Geschichte der Kämpfe um Union und Agende in Pommern. In: Büttner, Heinrich; von Campenhausen, Hans Frhr; Fink, Karl August; Schneemelcher, Wilhelm; Wolf, Ernst. Zeitschrift für Kirchengeschichte. 4. Folge IX, LXXI. Band. Stuttgart/Berlin/Köln/Mainz: Kohlhammer Verlag. S. 287-323.

Hildenbrand, Bruno (2010): Resilienz, Krise und Krisenbewältigung. In: Welter-Enderlin, Rosmarie; Hildenbrand, Bruno. (Hrsg.). Resilienz-Gedeihen trotz widriger Umstände. Heidelberg: Carl-Auer. S. 205-229.

Hornburg, Rudolf (1986): Jahrhundertfeier der evangelischen Kirche von Testo Alto. In: Prefeitura Municipal de Pomerode. Pomerode, sua história, sua cultura, suas tradições. V. 3. Pomerode: Tipografia Mayer Ltda. S. 31-32.

Hospital Moinhos de Vento. Nossa História. Verfügbar in: http://www.hospitalmoinhos.org.br/historia/ Zugang am 4.5.2017.

Houllou, Jean Raphael Zimmermann (2008): História do Colégio Evangélico Jaraguá. In: Klug, João; Ulrich, Claudete Beise (Org). Presença e atuação da Igreja Evangélica de Confissão Luterana de Jaraguá do Sul. Porto Alegre: Metrópole. S. 353-414. 
Igreja Evangélica de Confissão Luterana no Brasil (2004): Hinos do Povo de Deus. V. 1. Hinário da Igreja Evangélica de Confissão Luterana no Brasil. 20. Auflage. São Leopoldo: Sinodal.

Imber-Black, Evan (2010): Wird es schlimmer, wenn man darüber spricht? Resilienz angesichts einer lebensbedrohlichen Krankheit. In: WelterEnderlin, Rosmarie; Hildenbrand, Bruno. (Hrsg.) Resilienz-Gedeiben trotz. widriger Umstände. Heidelberg: Carl-Auer. S. 94-103.

Jacoby (1930/1931): Haussegen In: Hoffman-Krayer, E.; Bächtold-Stäubli, Hanns (Hrsg.) Handwörterbuch des Deutschen Aberglaubens. Band III. Berlin/Leipzig: Walter de Gruyter. S. 1575-1576.

- (1934/1935): Mosis, das sechste und siebente Buch. In: Hoffman-Krayer, E.; Bächtold-Stäubli, Hanns (Hrsg.) Handwörterbuch des Deutschen Aberglaubens. Band VI. Berlin/Leipzig: Walter de Gruyter. S. 584-593.

Jahn, Adalbert (1868): Die Landvermessung und der Landbesitz in Brasilien. In: Sturz, J. J. Die deutsche Auswanderung und die Verschleppung deutscher Auswanderer. Mit speciellen Documenten über die Auswanderung nach Brasilien zur Widerlegung falscher Angaben. Berlin: Fr. Kortkampf. S. XLVIII.

Josenhaus (Hrsg.) (1864): Der Evangelische Heidenbote, Nr. 4, April 1864. Basel: Felix Schneider.

Junges, Leandro S. (ohne Jahresangabe): Campos de Concentração em Santa Catarina. In: A Notícia. E-Mail von Valdim Utech an Pastor Nelso Weingärtner, 29.9.2003. Privatarchiv von Pastor Nelso Weingärtner.

- (ohne Jahresangabe): Histórias de torturas e humilhações. Tratados como "quinta-coluna", descendentes de europeus eram obrigados a beber óleo no Alto Vale. In: A Notícia. E-Mail von Valdim Utech an Pastor Nelso Weingärtner, 29.9.2003. Privatarchiv von Pastor Nelso Weingärtner.

- (ohne Jahresangabe): Os presos em Santa Catarina. Em nome da segurança nacional suspeitos de apoiarem os países do Eixo eram detidos no Estado. In: A Notícia. E-Mail von Valdim Utech an Pastor Nelso Weingärtner, 29.9.2003: Personalarchiv von Pastor Nelso Weingärtner.

- (ohne Jahresangabe): Perseguição começava na escola. Engenheiro alemão teve bens confiscados e foi um dos primeiros a serem presos em Florianópolis. In: A Notícia. E-Mail von Valdim Utech an Pastor Nelso Weingärtner, 29.9.2003. Privatarchiv von Pastor Nelso Weingärtner.

Kahle, Maria (1937): Deutsche Heimat in Brasilien. Berlin: Grenze und Ausland.

Kaufmann, Thomas (2016): Erlöste und Verdammte. Eine Geschichte der Reformation. München: Beck.

- (2016): Geschichte der Reformation in Deutschland. Berlin: Suhrkamp.

— (1998): Reformatoren. Göttingen: Vandenhoeck \& Ruprecht. 
Kemper, Hans-Georg (1987): Deutsche Lyrik der frühen Neuzeit. Band 2: Konfessionalismus. Tübingen: Max Niemeyer.

Kessel, Oscar von (1868): Administration der Colonisations-Directoren. Mißbräuche. In: Sturz, J. J. Die deutsche Auswanderung und die Verschleppung deutscher Auswanderer. Mit speciellen Documenten über die Auswanderung nach Brasilien zur Widerlegung falscher Angaben. Berlin: Fr. Kortkampf. S. XLVI-XLVIII.

Klasse, Eloisa; Menoni, Teresa (2007): Construyendo alternativas al dolor. Reflexiones sobre la Resiliencia en Casabó, Cerro de Montevideo. In: Bauer, María; González, Elena; Sassón, Emilia; Perkal, Alicia Weigensberg de; Corti, Analía; Litvan, Marina Altmann de (Hrsg.) Resiliencia y vida cotidiana. Montevideo: Psicolibros Waslala. S. 159-194.

Klug, João; Ulrich, Claudete (2008): Introdução. In: Klug, João; Ulrich, Claudete Beise (Org.) Presença e atuação da Igreja Evangélica de Confissão Luterana de Jaraguá do Sul. Porto Alegre: Metrópole. S. 15-19.

Krause, Henrique (2016): Die Entwicklung der Synode ab 1930 bis zum Zweiten Weltkrieg und seine Folgen. In: Backhause, Martin; Zeller, Hans. (Hrsg.) Aufbruch in Grenzen. Von der Migrationskirche zur lutherischen Kirche in Brasilien. Neuendettelsau/Nürnberg/Erlangen: Verlag für Mission und Ökumene/mabase-Verlag/Martin-Luther-Verlag. S. 97-119.

- (1993): Lutherische Synode in Brasilien. Geschichte und Bekenntnis der Evangelisch-Lutherischen Synode von Santa Catarina, Paraná und anderen Staaten Brasiliens. Erlangen: Verlag der Ev- Luth. Mission.

Krockow, Christian Graf von (1985): Die Reise nach Pommern. Bericht aus einem verschwiegenen Land. Deutsche Verlags-Anstalt.

Kuehne, João (1944): Colonização alemã no Brasil. In: Delegacia de orden política e social de Santa Catarina. O punbal nazista no coração do Brasil. Florianópolis: Imprensa Oficial do Estado. S. 95-116.

- (1944): O Integralismo nazi-fascista em Santa Catarina. In: Delegacia de ordem política e social de Santa Catarina. O punbal nazista no coração do Brasil. Florianópolis: Imprensa Oficial do Estado. S. 117-183.

(1861): Kurze Übersicht der Maßregeln der Kaiserl. brasilianischen Regierung zu Gunsten der Kolonisation. In: Hörmeyer, J. (Hrsg.) Actenstücke Brasilianischer Seite, betreffend die Kolonisation des Kaiserreiches. 3. Jahrgang, Heft 1, Rudolfstadt/Berlin: Verlag des F. priv. Hofbuchdruckerei/Franz Wagner. S. 26-32.

Kustor-Hüttl, Beatrice (2011): Weibliche Strategien der Resilienz. Bildungserfolg in der Migration. Frankfurt a.M: Brandes \& Apsel.

Lanfranchi, Andrea (2010): Resilienzförderung von Kindern bei Migration und Flucht. In: Welter-Enderlin, Rosmarie; Hildenbrand, Bruno (Hrsg.) 
Resilienz-Gedeihen trotz, widriger Umstände. Heidelberg: Carl-Auer. S. 119138.

Laroche, Fritz (Hrsg.) (1931): Der Evangelische Heidenbote, Nr. 10, Oktober 1931. Basel: Verlag der Missionsbuchhandlung.

Larrosa, Susana María Rocca (2011): As contribuições da espiritualidade e da pastoral católicas no desenvolvimento da resiliência em jovens de 18 a 29 anos. São Leopoldo: Escola Superior de Teologia.

Last, Arne (2011): Die Auswanderung von Pommern nach Brasilien im 19. Jahrhundert. Greifswald: Ernst-Moritz-Arndt-Universität.

Lau, Franz (1958): Evangelische Diáspora. In: Galling, Curt (Hrsg.) Die Religion in Geschichte und Gegenwart, 3. Auf., 2. Band. Tübingen: Mohr (Paul Siebeck). S. 177-180.

Lauser, Andrea; Weißköppel, Cordula (2008): Einleitung. Die neue Aufmerksamkeit für Religion in der Migrations- und Transnationalismusforschung. Ein Plädoyer für die ethnologische Mikro- und Kontextanalyse. In: Lauser, Andrea; Weißköppel, Cordula. Migration und religiöse Dynamik. Ethnologische Religionsforschung im transnationalen Kontext. Bielefeld: Transcript. S. 7-32.

Lebender, Eberhard (2013): Ein Dorf und Rittergut in Hinterpommern. Prillwitz im Krs. Pyritz und seine 650jährige Geschichte. Wentdorf: Selbstverlag des Verfassers.

Leidig (1982): Die preußische Auswanderungspolitik. In: Philippovich, E. von (Hrsg.) Auswanderung und Auswanderungspolitike in Deutschland. Berichte über die Entwicklung und den gegenwärtigen Zustand des Auswanderungswesens in den Einzelstaaten und im Reich. Leipzig: Duncker \& Humboldt. S. 433-479.

Lienau, J. F. v. (Hrsg.) (1826): Darstellung meines Schicksals in Brasilien und der von mir gemachten Erfahrungen über die Behandlung der durch Major Schäffer dahin beförderten europäischen Auswanderer im Allgemeinen, besonders in militärischer Hinsicht. Nebst mehreren merkwürdigen Actenstücken. Schleswig: Taubstummen-Institut.

Liesenberg, Edgar (1983): Chronik des Evangelischen Pfarrbezirkes Rio do Testo Pomerode. Pomerode. Zweisprachige Auflage.

Losse, Vera (1999): Werde fromm und gut. Patenbriefe vom 18. bis zum frühen 20. Jahrhundert. Telgte: Museum Heimathaus Münsterland.

Lubinski, Axel (1997): Entlassen aus dem Untertanenverband. Die AmerikaAuswanderung aus Mecklenburg-Strelitz im 19. Jahrhundert. Osnabrück: Universitätsverlag Rasch.

Ludwig, Sabine (1997): In Blumenau und Pomerode. Bei Deutschen im Süden Brasiliens. Würzburg: Bergstadtverlag Korn. 
Luther, Martin (1524): „An die Ratherren aller Städte deutsches Lands, daß sie christliche Schulen aufrichten und halten sollen“. In: D. Martin Luthers Werke. 15. Band. Weimar: Böhlaus, 1899. S. 9-53.

- (1523): Das eyn Christliche versammlung odder gemeyne recht und macht habe, alle lere zu urteylen und lerer zu beruffen, eyn und abzusetzen, Grund und ursach aus der schrifft. In: D. Martin Luthers Werke. 11. Band. Weimar: Böhlaus, 1900. S. 408-416.

(1520): De captivitate Babylonia ecclesiae praeludium. In: D. Martin Luthers Werke. 6. Band. Weimar: Böhlau, 1888. S. 484-573.

_- (1521): Ein Urtheil der Theologen zu Paris über die Lehre Doctor Luthers. Eine Gegen-Urtheil Doctor Luthers. Schutzrede Philipp Melanchtohns wider dasselbe Parische Urtheil für D. Luther. In: D. Martin Luthers Werke. 8. Band. Weimar: Böhlau, 1899. S. 255-312.

_- (1529): Enchiridion. Der kleine Catechismus für die gemeine Pfarherr und Prediger. In: Dr. Martin Luthers Werke. 30. Band, 1. Teil. Weimar: Böhlaus, 1910. S. 239-425.

_- (1526): Ob kriegsleutte auch ynn seligem stande seyn künden. In: D. Martin Luthers Werke. 19. Band. Weimar: Böhlau, 1897. S. 623-662.

Lutherische Kirche in Brasilien (Hrsg.) (1955): Lutherische Kirche in Brasilien. Festschrift zum 50-jährigen Bestehen der lutherischen Synode am 9. Oktober 1955. São Leopoldo: Rotermund.

Lutterbeck, Jorge Alfredo (1977): Jesuitas no sul do Brasil. Capitulos de História da Missão e Provincia Sul-Brasileira da Companbia de Jesus. São Leopoldo: Instituto Anchietano de Pesquisas.

Magalhães, Marionilde Brepohl de (1998): Pangermanismo e nazismo. A trajetória alemã no Brasil. Campinas: UNICAP/FAPESP.

__ (1993/1994): Racismo no sul do Brasil: heranças de um mito. In: Revista História. São Paulo, Nr. 129-131, ago-dez 1993, ago-dez 1994. S. 165-178. Verfügbar in: http://www.revistas.usp.br/revhistoria/article/view/18727/20790 Zugang 30.5.2016.

Malikoski, Germano (2014): Interview am 24.12.2014. Quelle, die die Diakonin Angela Lemke freundlicherweise zur Verfügung stellte.

Maltzahn, Gislaine Maria (2011): Família, ritual e ciclos de vida. Estudo Etnográfico sobre narrativas pomeranas em Pelotas (RS). Pelotas: Universidade Federal de Pelotas.

Manke, Matthias (2007): "Denn es waren zum Theil nur Halbmenschen". Mecklenburg-Schwerin und die deutsche Brasilienauswanderung in den 1820er Jahren. In: Röpke, Andreas (Hrsg.) Mecklenburgische Jabrbücher. 122. Jahrgang. S. 159-222. 
Martínez, Elda González (2003): La Immigración esperada: la Política Migratoria Brasileña desde João VI hasta Getulio Vargas. Madrid: Consejo Superior de Investigaciones Científicas.

Martinuzzo, José Antonio (2009): Germânicos nas Terras do Espírito Santo Deutschsprachige im Bundesstaat Espirito-Santo. Vitória: Governo do Estado do Espírito Santo. Zweisprachige Ausgabe.

Marzahn, Wolfgang (1971): Erinnerungen an Hinterpommern. Hrsg. in Zusammenarbeit mit dem Ostkirchenausschuß Hannover. Leer (Ostfriesland): Gerhard Rautenberg.

Masten, Ann S. (2016): Resilienæ: Modelle, Fakten \& Neurobiologie. Das ganz normale Wunder entschlüsselt. Paderborn: Junfermann.

Matthes, Christian (2011): Magische Rituale als Volksmedizin: Der Glaube neben dem Glauben. Zu den frühneuzeitlichen Gefäßdeponierungen in Zeicha, Sachsen. In: Mitteilungen der Deutschen Gesellschaft für Archäologie des Mittelalters und der Neuzeit. Nr. 23. S. 237-250, verfügbar in: http://journals.ub.uni-heidelberg.de/index.php/mittdgamn/article/view/17147/10963 Zugang am 24.3.2017.

Meißner-Zuckers (1929): Die Landwirtschaft. In: Cronau, Curt (Hrsg.) Hinterpommern. Wirtschafts- und Kulturaufgaben eines Grenzbezirks. Stettin: M. Bauchwitz. S. 24-80.

Moeller, Walter O. (1973): The Mithraic origin and meanings of the Rotas-Sator square. Leiden: E. L. Brill.

Motsch, Christoph (2001): Grenzgesellschaft und frühmoderner Staat. Die Starostei Draheim zwischen Hinterpommern, der Neumark und Großpolen (15751805). Göttingen: Vandenhoeck \& Ruprecht.

Mühle, Rainer (1995): Zur Geschichte der Auswanderung aus Pommern im 19. Jahrhundert. In: Karge, Wolf; Rakow, Peter-Joachim; Wendt, Ralf. (Hrsg.) Ein Jahrtausend Mecklenburg und Vorpommern. Biographie einer Norddeutschen Region in Einzeldarstellungen. Rostock: Hinstorff. S. 263271.

Müller, Reinhart (1970): Entwicklungstendenzen und ihre Folgen. In: Fischer, Joachim; Jahn, Christoph (Hrsg.) Es begann am Rio dos Sinos. Geschichte und Gegenwart der Ev. Kirche Lutherischen Bekenntnisses in Brasilien. Verlag der Ev. Lutherischen Mission Erlangen. S. 68-74.

- (2001): Hermannsburger in Lateinamerika. Vom Dienst Hermannsburger Missionare und ihrer Frauen in Gemeinden und Kirchen Südamerikas 1898-1998. Hermannsburg: Missionshandlung Hermannsburg.

Müller, Telmo Lauro (1988): Herança de geração em geração. São Leopoldo: Rotermund.

Münch, Ernst (1995): Bauer und Herrschaft. Zu den Anfängen und zur Entwicklung der Grundherrschaft in Mecklenburg und Vorpommern. In: 
Karge, Wolf; Rakow, Peter-Joachim; Wendt, Ralf. (Hrsg.) Ein Jahrtausend Mecklenburg und Vorpommern. Biographie einer Norddeutschen Region in Einzeldarstellungen. Rostock: Hinstorff. S. 121-128.

Nagar, Carlo (1895): O Estado do Espírito Santo e a Imigração Italiana (fevereiro de 1895). Vitória: Arquivo Público do Estado do Espírito Santo.

Nüssel, Friederike (2005): Unionen, kirchliche. In: Betz, Hans Dieter; Browning, Don S.; Janowski, Bernd; Jüngel, Ebenhard (Hrsg.) Religion in Geschichte und Gegenwart. 4. Auf. Bd. 8. Mohr Siebeck. S. 750-752.

Oswald, Tamara (2012): As igrejas evangélicas luteranas livres e independentes em São Lourenço do Sul. In: XI Encontro estadual de História, 23-27.7.2012. Rio Grande: Universidade Federal do Rio Grande. S. 571-582

Pasa, Fabiane Maria Lorandi (2013): "Eles partiram cedo": Morte, luto e resiliência diante da fé cristã. Porto Alegre: Pontifícia Universidade Católica do Rio Grande do Sul.

Pechmann, Burkhard (2012): Resilienz gegen Ende des Lebenslaufs oder Woher kam die Kraft? In: Sedmak, Clemens; Bogaczyk-Vormayr, Małgorzata (Hrsg.) Patristike und Resilienz. Frühchristliche Einsichten in die Seelenkraft. Berlin: Akademie Verlag. S. 121-137.

Perazzo, Priscila Ferreira (1999): O Perigo Alemão e a Repressão Policial no Estado Novo. São Paulo: Divisão de Arquivo do Estado.

Petry, Leopoldo (1957): Episódio do Ferrabraz - Os Muckers. São Leopoldo: Rotermund.

Piske, Meinrad (2016): Die Kirchwerdung von 1949 bis 1997. In: Backhause, Martin; Zeller, Hans. (Hrsg.) Aufbruch in Grenzen. Von der Migrationskirche zur lutherischen Kirche in Brasilien. Neuendettelsau/Nürnberg/Erlangen: Verlag für Mission und Ökumene/mabaseVerlag/Martin-Luther-Verlag. S. 121-149.

Pommersche Landmannschaft (1985): Pommern, gestern, beute und morgen. Lübeck: Pommerscher Zentralverband.

Port, Ido (2014): "Ele" - uma história de sofrimento. In: O Semeador, Nr. 93, Juni 2014.

Potthast-Hubold, Elke (1982): Zum Mundartgebrauch in Siedlungen pommerscher Auswanderer des 19. Jahrhunderts in Espirito Santo (Brasilien). Eine Pilotstudie. Neumünster: Karl Wachholtz.

Prien, Hans-Jürgen (2001): Formação da Igreja Evangélica no Brasil. Das comunidades teuto-evangélicas de imigrantes até a Igreja Evangélica de Confissão Luterana no Brasil. São Leopoldo/Petrópolis: Sinodal/Vozes.

Py, Aurélio da Silva (1942): A $5^{a}$ Coluna no Brasil. A conspiração Nazi no Rio Grande do Sul. Porto Alegre: Globo. 
Rabuske, Arthur (1994/1996): Antigas paróquias dos jesuítas no Brasil meridional. São João do Montenegro, Santo Antonio de Estrela, Santa Teresinha de Campo Bom. In: Instituto anchietano de pesquisas. Pesquisas, São Leopoldo, $\mathrm{N}^{\circ} 29$.

Ramlow, Udo (1987): Bugres. In: Prefeitura Municipal de Pomerode, Pomerode, sua história, sua cultura, suas tradições. V. 4. Pomerode: Prefeitura Municipal. S. 49-50.

(1986): Desavenças entre Índios e Colonos. In: Prefeitura Municipal de Pomerode. Pomerode, sua história, sua cultura, suas tradições. V. 3. Pomerode: Prefeitura Municipal. S. 7-10.

Ramlow, Udo; Resende, João M. O. (1985): A colonização de Pomerode. In: Prefeitura Municipal de Pomerode. Pomerode, sua história, sua cultura, suas tradições. V. 2. Pomerode: Mayer. S. 11-16.

Reinicke, Christian (1993): Pacht. In: Lexikon des Mittelalters. Band 6. München/Zürich: Artemis \& Winkler.

Reis, Olaf (2009): Rostocker Längsschnittstudie (ROLS): Familienresilienz und intrafamiliäre Individuation in ostdeutschen Familien. In: Fooken, Insa; Zinnecker, Jürgen (Hrsg.) Trauma und Resilienæ. Chancen und Risiken lebensgeschichtlicher Bewältigung von belasteten Kindheiten. Weinheim/München: Juventa. S. 75-94.

(1938): Relatório do Departamento de Educação. In: E-mail von Valdim Utech an Pastor Nelso Weingärtner, 29.9.2003. Privatarchiv von Pastor Nelso Weingärtner.

Rendtorff, Franz (Hrg). (1920/1921): Die evangelische Diaspora, insbesondere des Auslandsdeutschtums. Monatshefte des Gustav-Adolf-Vereins namens des Centralvorstandes. Leipzig: J. C. Hinsrisch'sche Buchhandlung.

Ribas, Antônio de Lara (1944): O Nazismo em Santa Catarina. In: Delegacia de ordem política e social de Santa Catarina. O punhal nazista no coração do Brasil. Florianópolis: Imprensa Oficial do Estado. S. 15-92.

— (1944): Que é a „quinta-coluna“? In: Delegacia de ordem política e social de Santa Catarina. O punhal naz̧ista no coração do Brasil. Florianópolis: Imprensa Oficial do Estado. S. 187-205.

Ribeyrolles, Carlos (1860): Estudo sobre a colonisação brasileira extrabido do $3^{\circ}$ volume do Brasil Pittoresco. Rio de Janeiro: Typografhia Nacional.

Rieth, Ricardo Willy (2009): Raízes históricas e identidade da Igreja Evangélica Luterana do Brasil (IELB). In: Estudos Teológicos v. 49, n. 2: Jul./Dez. 2009, São Leopoldo. S. 207-221.

Rocha, Levy (2008): Viagem de Pedro II ao Espírito Santo. Vitória: Arquivo Público do Estado do Espírito.

Röhrich, L. (1959): Himmelsbriefe. In: Galling, Kurt; von Campenhausen, Hans Frhr; Dinkler, Erich; Gloege, Gerhard; Løgstrup, Knud E. (Hrsg.) 
Die Religion in Geschichte und Gegenwart. Handwörterbuch für Theologie und Religionswissenschaft. 3. Auflage, 3. Band. Tübingen: Mohr (Paul Siebeck). S. 338-339.

Rölke, Helmar Reinhard (1996): Descobrindo Raízes. Aspectos geográficos, históricos e culturais da Pomerânia. Vitória: UFES.

__ (2016): Die Gotteskastenarbeit im Staat Espírito Santo als Voraussetzung für die Entwicklung einer Lutherischen Synode. In: Backhause, Martin; Zeller, Hans. (Hrsg.) Aufbruch in Grenzen. Von der Migrationskirche zur lutherischen Kirche in Brasilien. Neuendettelsau/Nürnberg/Erlangen: Verlag für Mission und Ökumene/mabase-Verlag/Martin-Luther-Verlag. S. 77-96.

_- (2016): Raízes da Imigração alemã: história e cultura alemã no estado do Espírito Santo. Vitória: Arquivo Público do Estado do Espírito Santo.

Römer, Ch. (Hrsg.) (1888): Der Evangelische Heidenbote, Nr. 1, Januar 1888. Basel: Missionsbuchhandlung.

__ (1887): Der Evangelische Heidenbote, Nr. 6, Juni 1887. Basel: Missionsbuchhandlung.

Roos, Ton; Eshuis, Margje (2008): Os Capixabas Holandeses. Uma história holandesa no Brasil. Vitória: Arquivo Público do Estado do Espírito Santo.

Salamoni, Giancarla (2001): A imigração alemã no Rio Grande do Sul - o Caso da Comunidade Pomerana de Pelotas. In: História em Revista, Pelotas, V. 7, dezembro 2001. S. 25-42.

Schatz, Klaus (2013): Geschichte der deutschen Jesuiten (1814-1983). Band 1. (18141872). Münster: Aschendorff.

__ (2013): Geschichte der deutschen Jesuiten (1814-1983). Band 2. (1872-1917). Münster: Aschendorff.

Schinke, Werner H. E. (2013): Erich Schul\%, 1898-1974. Vida e obra de um imigrante alemão. Lageado: UNIVATES.

Schlatter, Wilhelm (1916): Geschichte der Basler Mission 1815-1915. Mit besonderer Berücksichtigung der ungedruckten Quellen. Basler: Basler Missionsbuchhandlung.

Schlegel, Birgit (2006): Glaube und Magie gegen die Gefahren des Krieges in Schutzbriefen. In: Zeitschrift für Regionale Forschung und Heimatpflege - Südniedersachsen, 34. Jahrgang, 3/September 2006, S. 65-70.

Schleinert, Dirk; Wartenberg, Heiko (2010): Das alte Pommern. Leben und Arbeiten auf dem platten Land. Rostock: Hinstorff.

Schlieper, Ernesto Th. (1959): Evangelische Gemeinden Lutherischen Bekenntnisses in Brasilien. In: Brunotte, Heinz; Ruppel, Erich (Hrsg.) Gott ist am Werk. Festschrift für Landesbischof Dr. Hanns Lilje zum 60. Geburtstag. Hamburg. S. 135-141. 
Schmidt, Artur (1984): Die Anfänge der Diakonie in Espirito Santo. Ein Beitrag zur evangelischen Diakoniegeschichte Brasiliens. Augsburg: FDL Verlag.

Schmidt, Norbert (1991): Von der Evangelisation zur Kirchengründung. Die Geschichte der Marburger Brasilienmission. Marburg an der Lahn: Francke.

Schmidt, Roderich (2009): Das historische Pommern. Personen, Orten, Ereignisse. Köln/Weimar/Wien: Böhlau.

Schörken, Rolf (2009): Resilienz bei Kriegsverwundeten. Ein lebensgeschichtlicher Diskussionsbeitrag. In: Fooken, Insa; Zinnecker, Jürgen (Hrsg.) Trauma und Resilienæ. Chancen und Risiken lebensgeschichtlicher Bewältigung von belasteten Kindheiten. Weinheim/München: Juventa. S. 39-46.

Schröder, Ferdinand (1936): Brasilien und Wittenberg. Ursprung und Gestaltung deutschen evangelischen Kirchentums in Brasilien. Berlin/Leipzig: De Gruyter.

- (1930): Die deutsche Einwanderung nach Südbrasilien bis zum Jahre 1859. Berlin: Ev. Hauptverein für Deutsche Ansiedler und Auswanderer E.V.

Schubert, Anselm (2013): Religiöse Restauration und technische Rationalisierung. Die „preußische Normalkirche“ als staatliche Einheitskirche. In: Historische Zeitschrift. Bd. 297, Nr. 1. München: de Gruyter Oldenbourg. S. 64-83.

Schulz, Petra Karin Ursula (2010): Tribsow. Ein Dorf in Hinterpommern. Geschichte und Geschichten. Husum: Husum Druck- und Verlagsgesellschaft.

Schulze, Frederik (2016): Auswanderung als nationalistisches Projekt. ,Deutschtum“ und Kolonialdiskurse im südlichen Brasilien (1824-1941). Köln/Weimar/Wien: Böhlau.

Sedmak, Clemens (2013): Innerlichkeit und Kraft. Studie über epistemische Resilienz. Freiburg im Breisgau: Herder.

Seibel, Ivan (2007): Imigrante a duras penas. Nova Petrópolis: Amstad.

— (2010): Imigrante no século do isolamento/1870-1970. São Leopoldo: Traço.

Seidler, Carl (1835): Zehn Jahre in Brasilien während der Regierung Dom Pedro's und nach dessen Entthronung mit besonderer Hinsicht auf das Schicksal der ausländischen Truppen und der deutschen Colonisten. Quedlinburg/Leipzig: Gottfr. Basse.

Seyferth, Giralda (1999): Colonização e conflito: estudo sobre "motins" e "desordens" numa região colonial de Santa Catarina no século XIX. In: Santos, José Vicente Tavares dos (Org.). Violências no tempo da globalização. São Paulo: Hucitec. S. 285-330.

- (1981): Nacionalismo e identidade étnica. A ideologia germanista e o grupo étnico teuto-brasileiro numa comunidade do Vale do Itajaí. Florianópolis: Fundação Catarinense de Cultura. 
Sievers (1929): Handel und Industrie mit besonderer Berücksichtigung des Verkehrswesens in: Cronau, Curt (Hrsg.) Hinterpommern. Wirtschafts- und Kulturaufgaben eines Grenzbezirks. Stettin: M. Bauchwitz. S. 81-119.

Siller, Rosali Rauta (2011): Infância, Educação Infantil, Migraçoes. Campinas: Universidade Estadual de Campinas.

Silva, Ana Neri Nascimento da (2007): Ritos Terapêuticos: uma abordagem do sofrimento à resiliência na terapia familiar. São Leopoldo: Escola Superior de Teologia.

Silva, Ricardo. Photo: Igreja enxaimel de Benedito Novo. Verfügbar in: https://www.flickr.com/photos/ricardosilva/5955208165 Zugang am 22.9.2016.

Soboll, Heinz Friedrich (2011): Esel und Pastoren im Land des Heiligen Geistes. São Paulo: Artebr.

Stähli, Andreas (2013): Rituale: Schutzfaktor der Mitarbeiter. In: Müller, Monika; Pfister, David (Hrsg.) Wie viel Tod verträgt das Team? Belastungs- und Schutzfaktoren in Hospizarbeit und Palliativmedizin. Göttingen: Vandenhoeck \& Ruprecht. S. 198-205.

Stangl, Elias D. (2017): Resilienz durch Glauben? Die Entwicklung psychischer Widerstandskraft bei Erwachsenen. Ostfildern: Matthias Grünewald.

Stoer, Hermann (ohne Jahresangabe): Crônica da Paróquia de Santa Isabel, a mais antiga colônia alemã-evangélica em Santa Catarina [Übersetzung von Felícia Emma Hatzk Schütz aus dem Original Chronik der Pfarrgemeinde Santa Isabel, der ältesten deutsch-evangelischen Siedlung in Santa Catharina, 1939]. Verfügbar in: http://www.aguasmornas.sc.gov.br/noticias3/santa\%20isabel.pdf Zugang 30.5.2016.

Stübe, R. (1918): Der Himmelsbrief. Ein Beitrag zur allgemeinen Religionsgeschichte. Tübingen: Mohr (Paul Siebeck).

_ (1030/1931): Grafenamullet. In: Hoffman-Krayer, E.; Bächtold-Stäubli, Hanns (Hrsg.) Handwörterbuch des Deutschen Aberglaubens. Band III. Berlin/Leipzig: Walter de Gruyter. S. 1111-1112.

— (1930/1931): Gredoria. In: Hoffman-Krayer, E.; Bächtold-Stäubli, Hanns (Hrsg.) Handwörterbuch des Deutschen Aberglaubens. Band III. Berlin/Leipzig: Walter de Gruyter. S. 1126-1127.

_- (1931/1932): Himmelsbrief In: Hoffman-Krayer, E.; Bächtold-Stäubli, Hanns (Hrsg.) Handwörterbuch des Deutschen Aberglaubens. Band IV. Berlin/Leipzig: Walter de Gruyter. S. 21-27.

(1931/1932): Holsteiner-Typus. In: Hoffman-Krayer, E.; BächtoldStäubli, Hanns (Hrsg.) Handwörterbuch des Deutschen Aberglaubens. Band IV. Berlin/Leipzig: Walter de Gruyter. S. 261. 
(1931/1932): Karl-Segen (Kaiser) In: Hoffman-Krayer, E.; BächtoldStäubli, Hanns (Hrsg.) Handwörterbuch des Deutschen Aberglaubens. Band IV. Berlin/Leipzig: Walter de Gruyter. S. 1006-1007.

(1934/1935): Oelbergspruch In: Hoffman-Krayer, E.; Bächtold-Stäubli, Hanns (Hrsg.) Handwörterbuch des Deutschen Aberglaubens. Band VI. Berlin/Leipzig: Walter de Gruyter. S. 1246-1247.

(1935/1936): Schutzbrief. In: Hoffman-Krayer, E.; Bächtold-Stäubli, Hanns (Hrsg.) Handwörterbuch des Deutschen Aberglaubens. Band VII. Berlin/Leipzig: Walter de Gruyter. S. 1384-1386.

— (1936/1937): Sonntagsbrief. In: Hoffman-Krayer, E.; Bächtold-Stäubli, Hanns (Hrsg.) Handwörterbuch des Deutschen Aberglaubens. Band VIII. Berlin/Leipzig: Walter de Gruyter. S. 99-104.

Stuhr, Rubens (2013): Ponto de Pregação Córrego Grande celebra Pentecostes. In: Igreja Evangélica de Confissão Luterana no Brasil. Portal Luteranos. 17.5.2013. Verfügbar in: http://luteranos.com.br/conteudo/ponto-depregacao-corrego-grande-celebra-pentecostes Zugang am 22.10.2015.

Sturz, J. J. (1868): Die deutsche Auswanderung und die Verschleppung deutscher Auswanderer. Mit speciellen Documenten über die Auswanderung nach Brasilien zur Widerlegung falscher Angaben. Berlin: Fr. Kortkampf.

Stutzer, G. (1886): Blumenau in Süd-Brasilien als Ziel der deutschen Auswanderung. Goslar: Ludwig Koch.

Sudhaus, Fritz (1940): Deutschland und die Auswanderung nach Brasilien im 19. Jabrhundert. Hamburg: Hans Christians.

Tessner, Gerda (2007): Verlorenes Land. Eine Lebensgeschichte aus Hinterpommern. Kassel: Selbstverlag.

Thiel, Uwe; Neumann, Harry (2011): Priebkow - ein Rittergut in Hinterpommern. Aus der Geschichte der Bauern- und Gutsdörfer Alt und Neu Priebkow sowie der dazu gehörigen Hassel- und Jungfermühle im Kreis Neustettin. Witten: DIP-Digital-Print.

Tressmann, Ismael (2008): O Pomerano: uma língua baixo-saxônica. In: Revista da Farese, V. 1, Nr. 1, jul./nov. 2008. Santa Maria de Jetibá: Faculdade da Região Serrana (Farese). S. 10-21. Verfügbar in: http://www.farese.edu.br/pages/biblioteca/pdf/revistafaresev1n1.pdf Zugriff am 16.6.2015.

Ullmann, Ingo (2007): Die rechtliche Behandlung holsteinischer Leibeigener um die Mitte des 18. Jahrbunderts. Dargestellt unter besonderer Berücksichtigung der Schmoeler Leibeigenschaftsprozesse von 1738 bis 1743 sowie von 1767 bis 1777 . Frankfurt a. M.: Peter Lang.

Ulrich, Claudete Beise (2008): História da Paróquia Evangélica Luterana Apóstolo Tiago. In: Klug, João; Ulrich, Claudete Beise (Org.) Presença e 
atuação da Igreja Evangélica de Confissão Luterana de Jaraguá do Sul. Porto Alegre: Metrópole. S. 179-293.

Uslucan, Haci-Halil (2011): Resilienzpotenziale bei Jugendlichen mit Migrationshintergrund. In: Zander, Margherita; Roemer, Martin. Handbuch Resilien̊förderung. Wiesbaden: Verlag für Sozialwissenschaften/Springer. S. 555-574.

Van Gennep, Arnold (1999): Übergangsriten. Frankfurt a. Main/New York: Campus Verlag.

Volkmann, Waldemar; Volkmann Elke (1985): Personalidade do nosso passado. In: Prefeitura Municipal de Pomerode. Pomerode, sua história, sua cultura, suas tradicões. V. 2. Pomerode: Prefeitura Municipal. S. 17-23.

Von Thadden, Rudolf (2010): Trieglaff. Eine pommersche Lebenswelt zwischen Kirche und Politik 1807-1948. Göttingen: Wallstein.

Von Tschudi, Johann Jakob (1988): As colônias de Santa Catarina. Apresentação e anotações de Walter F. Piazza Blumenau: CNPq/Fundação Casa Dr. Blumenau.

- (1861): Bericht des Herrn von Tschudi, außerordentlichen Gesandten in Brasilien über die Kolonien Santa Isabel, Santa Leopoldina und Rio Novo usw. vom 20. December 1860. In: Hörmeyer, J. (Hrsg.) Actenstücke Brasilianischer Seite, betreffend die Kolonisation des Kaiserreiches. 3. Jahrgang, Heft 3, Rudolfstadt/Berlin: Verlag des F. priv. Hofbuchdruckerei/Franz Wagner. S. 260-286.

- (1861): Bericht des Herrn von Tschudi, außerordentlichen schweizerischen Gesandten in Brasilien an den Bundesrath über den Zustand der Kolonien der brasilianischen Provinzen Santa Catharina und San Pedro do Rio Grande do Sul vom 18. Juni 1861. In: Hörmeyer, J. (Hrsg.) Actenstücke Brasilianischer Seite betreffend die Kolonisation des Kaiserreiches. 3. Jahrgang, Heft 3, Rudolfstadt/Berlin: Verlag des F. priv. Hofbuchdruckerei/Franz Wagner. S. 209-259.

- (1861): Bericht des schweizerischen außerordentlichen Gesandten in Brasilien, Hrn. v. Tschudi an den Bundesrath über die dortigen Verhältnisse der Kolonisten von 6. October 1860. In: Hörmeyer, J. (Hrsg.) Actenstücke Brasilianischer Seite, betreffend die Kolonisation des Kaiserreiches. 3. Jahrgang, Heft 1, Rudolfstadt/Berlin: Verlag des F. priv. Hofbuchdruckerei/Franz Wagner. S. 33-74.

_- (1867): Reise durch Süd-Amerika. 3. Band. Leipzig: F. A. Brockhaus.

- (1868): Reisen durch Süd-Amerika. 4. Band. Leipzig: F. A. Brockhaus.

- (2004): Viagem à provincia do Espirito Santo - imigraşão e colonizaçãa suiça, 1860. Übersetzung aus dem Französischen und aus dem Deutschen von Nara Saletto und Erlon José Paschoal. Vitória: Arquivo Público do Estado do Espírito Santo. 
Wachholz, Wilhelm (2009): Luteranismo no Brasil: trajetórias e desafios. In: Estudos Teológicos v. 49, n. 2: Jul./dez. 2009, São Leopoldo. S. 180-206.

- (2004): Luterano? Reformado? Unido? Evangélico! Aspectos históricos e teológicos da União Prussiana. In: Evangelho, Bíblia e Escritos Confessionais. Anais do II Simpósio sobre Identidade Evangélico-Luterana. São Leopoldo: Escola Superior de Teologia. S. 87-109.

- (2001): Uma Igreja Diferente. Novo Hamburgo: Com-Texto Gráfica e Editora.

Wagemann, Ernst Friedrich (1915): Die Deutschen Kolonisten im brasilianischen Staate Espirito Santo. München/Leipzig: Duncker \& Humbolt.

Walsh, Froma (2010): Ein Modell familialer Resilienz und seine klinische Bedeutung. In: Welter-Enderlin, Rosmarie; Hildenbrand, Bruno (Hrsg.) Resilienz-Gedeihen trotz widriger Umstände. Heidelberg: Carl-Auer. S. 43-79.

Weege, Heike (ohne Jahresangabe): Fotos Antigas Blumenau. Verfügbar in: http:// fotosantigasblumenau.blogspot.de/ Zugang am 18.4.2017.

- (2011): Fotos antigas de Pomerode. Verfügbar in: http://fotosantigas pomerode.blogspot.de/2011_01_01_archive.html Zugang am 14.2.2017.

_ (2013): Fotos antigas de Pomerode. Verfügbar in: http://fotosantigas pomerode.blogspot.de/2013_01_01_archive.html Zugang am 24.4.2017.

- (2011): Fotos antigas de Pomerode. Verfügbar in: http://fotosantigas pomerode.blogspot.de/2011/04/testo-alto.html Zugang am 24.4.2017.

Weimar, Günter (2005): Arquitetura Popular da Imigração Alemã. Porto Alegre: UFRGS.

Weingärtner, Nelso (2000): 150 Anos de Presença Luterana no Vale do Itajaí 18502000. Blumenau: Otto Kuhr.

- (1969): Crônica da Comunidade Evangélica de Timbó. Blumenau: Gráfica 43. Zweisprachige Auflage.

— E-Mail von 5.10.2015.

— (2008): História da Comunidade Evangélica de Timbó. Blumenau: Otto Kuhr.

- (2012): Martin Luther e Santa Catarina. Timbó: Tipotil.

— (2014): Mundo da Superstição. Orientação para a vida de fé. São Leopoldo: Sinodal.

Wellnitz, Britta (2003): Deutsche evangelische Gemeinden im Ausland. Ihre Entstehungsgeschichte und die Entwicklung ihrer Rechtsbeziehungen zur Evangelischen Kirche in Deutschland. Tübingen: Mohr Siebeck.

Welter-Enderlin, Rosmarie (2010): Resilienz und Krisenkompetenz. Heidelberg: Carl-Auer. 
Werner, Emmy (2008): Entwicklung zwischen Risiko und Resilienz. In: Opp, Günther; Fingerle, Michael. $W$ as Kinder stärkt. Erziehung zwischen Risiko und Resilienz. München: Ernst Reinhard. S. 20-31.

_- (2009): Resilienz und Protektivfaktoren im Lebenslauf von Kriegskindern. Ausgewählte empirische Studien. In: Fooken, Insa; Zinnecker, Jürgen (Hrsg.) Trauma und Resilienz: Chancen und Risiken lebensgeschichtlicher Bewältigung von belasteten Kindheiten. Weinheim/München: Juventa. S. 47-55.

_- (2011): Risiko und Resilienz im Leben von Kindern aus multiethnischen Familien. In: Zander, Margherita; Roemer, Martin (Hrsg.) Handbuch Resilienzförderung. Wiesbaden: Verlag für Sozialwissenschaften/Springer. S. 3250 .

__ (2010): Wenn Menschen trotz widriger Umstände gedeihen - und was man daraus lernen kann. In: Welter-Enderlin, Rosmarie; Hildenbrand, Bruno (Hrsg.). Resilienz - Gedeihen trotz widriger Umstände. Heidelberg: CarlAuer. S. 28-42.

Wernicke, Hugo (2013): Viagem pelas colônias alemãs do Espirito Santo. A população evangélico-alemã no Espírito Santo: uma viagem até os cafeicultores alemães em um estado tropical do Brasil. Vitória: Arquivo Público do Estado do Espírito Santo. Aus dem Original Deutsch-evangelisches Volkstum in Espirito Santo: Reise zu deutschen Kaffeebauern in einem tropischen Staate Brasiliens. Potsdam: Stiftungsverlag, 1910.

Wilbert, Loni Driemeyer; Sell, Simone Falk; Wilbert, Anildo; Jansch, Rolf Karl (2008): História da Paróquia Evangélica Luterana da Barra do Rio Cerro. In: Klug, João; Ulrich, Claudete Beise (Org.) Presença e atuação da Igreja Evangélica de Confissão Luterana de Jaraguá do Sul. Porto Alegre: Metrópole. S. 79-145.

Willems, Emílio (1980): A Aculturação dos alemães no Brasil. Estudo antropológico dos imigrantes alemães e seus descendentes no Brasil. São Paulo: Companhia Editora Nacional.

Wirth, Lauri Emilio (1992): Protestantismus und Kolonisation in Brasilien. Der evangelische Gemeindeverband in Brasilien: Kontextualität, Ekklesiologie und Institutionalisierung einer deutschen Einwandererkirche in Santa Catarina. Erlangen: Verlag der Ev- Luth. Mission.

Witt, Osmar Luiz (1996): Igreja na Migração e Colonização. A pregação itinerante no Sínodo Rio-Grandense. São Leopoldo: Sinodal/IEPG, 1996.

Wittmann, Angelina (2014): Grupo folclórico Badenfurt. Verfügbar in: https:/ / angelinawittmann.blogspot.de/2014/07/grupo-folclorico-

badenfurt-tradicional.html Zugang am 21.4.2017. 
- (2017): Hospital Santa Catarina. Inauguração 1920. Verfügbar in: https://angelinawittmann.blogspot.de/2017/05/hospital-santa-catarinainauguracao.html Zugang am 27.6.2017.

- (2015): Igreja da Paz - Pomerode - 130 anos. Verfügbar in: https://angelinawittmann.blogspot.de/2015/11/igreja-da-paz-pomerode130-anos.html Zugang am 24.4.2017.

Woortmann, Ellen Fensterseifer (2000): Identidades e Memória entre teutobrasileiros: os dois lados do Atlântico. In: Horizontes Antropológicos, Porto Alegre, Ano 6, Nr. 14, S. 205-238.

Wunsch, Albert (2013): Mit mehr Selbst zum stabilen ICH! Resilienz als Basis der Persönlichkeitsbildung. Berlin/Heidelberg: Springer.

Wustmann, Corina (2011): Resilienz. Widerstandsfähigkeit von Kindern in Tageseinrichtungen fördern. Berlin: Cornelsen.

Wüstner, Fr. (Hrsg.) (1951): Kirchengemeinde Joinville. Evangelisches Bekennen in Schwachheit und Kraft. 1851-1951. São Leopoldo: Rotermund \& Co.

Zaddach, Carl (1913): Lothar Bucher und die Verhältnisse in Hinterpommern von 1843-1848. Heidelberg: Carl Winters Universitätsbuchhandlung.

Zander, Margherita (2011): Einleitung. In: Zander, Margherita; Roemer, Martin (Hrg). Handbuch Resilienzförderung. Wiesbaden: Verlag für Sozialwissenschaften/Springer. S. 8-30.

Zink, Susanne Katja (2001): Der Zusammenhang zwischen Religiosität, Bindung, Hoffnung und Woblbefinden unter Berücksichtigung von Stress. Hamburg: Disserta Verlag.

Zinnecker, Jürgen (2009): Schlusswort: Ein Kommentar aus historischgesellschaftlicher Perspektive. In: Fooken, Insa; Zinnecker, Jürgen (Hrsg.) Trauma und Resilienz. Chancen und Risiken lebensgeschichtlicher Bewältigung von belasteten Kindheiten. Weinheim/München: Juventa. 
Die Religiosität der Pommern und deren Nachkommen ist gekennzeichnet durch eine Mischung aus religiösen Praktiken magischen Inhaltes und evangelisch-lutherischem Glauben. Als Hunderte von ihnen ab dem 19. Jahrhundert nach Brasilien auswanderten, brachten sie ihre Religiosität mit sich und haben sie auch in den Siedlungsgebieten weiter tradiert. So gelang es ihnen mithilfe unterschiedlicher kirchlicher und magischer Quellen ihre Verluste, Krisen, Krankheiten, Nöte und Schwierigkeiten zu meistern und ein einzigartiges Umfeld für sich und ihre Nachkommen in den brasilianischen Siedlungsgebieten zu schaffen. 